United States National Museum

Bulletin 216, Part 2

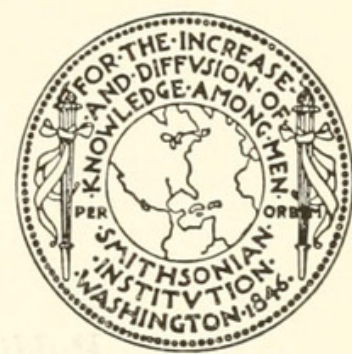

\title{
Ichneumon-Flies of
}

America North of Mexico:

2. Subfamilies Ephialtinae

Xoridinae

Acaenitinae

By HENRY and MARJORIE TOWNES

and Collaborators: G. Stuart Walley,

Luella Walkley, Dale Habeck, and

George Townes 


\section{Publications of the United States National Museum}

The scientific publications of the United States National Museum include two series, Proceedings of the United States National Museum and United States National Museum Bulletin.

In these series are published original articles and monographs dealing with the collections and work of the Museum and setting forth newly acquired facts in the fields of Anthropology, Biology, Geology, History, and Technology. Copies of each publication are distributed to libraries and scientific organizations and to specialists and others interested in the different subjects.

The Proceedings, begun in 1878, are intended for the publication, in separate form, of shorter papers. These are gathered in volumes, octavo in size, with the publication date of each paper recorded in the table of contents of the volume.

In the Bulletin series, the first of which was issued in 1875, appear longer, separate publications consisting of monographs (occasionally in several parts) and volumes in which are collected works on related subjects. Bulletins are either octavo or quarto in size, depending on the needs of the presentation. Since 1902 papers relating to the botanical collections of the Museum have been published in the Bulletin series under the heading Contributions from the United States National Herbarium.

Remington Kelloga

Director, United States National Museum

United States Government Printing Office, Washington, 1960

For sale by the Superintendent of Documents, U.S. Government Printing Office Washington 25, D.C. - Price $\$ 2.50$ (paper) 


\section{Contents}

Introduction . . . . . . . . . . . . . . . . . . . . . . . $\mathrm{v}$

Definition of subfamilies . . . . . . . . . . . . . . . . . . . 3

Subfamily Ephialtinae. . . . . . . . . . . . . . . . . . . . 4

Key to the tribes of Ephialtinae . . . . . . . . . . . . . . . . 5

1. Tribe Pimplini . . . . . . . . . . . . . . . . . . . . . 6

Key to the Nearctic genera of Pimplini . . . . . . . . . . 8

1. Genus Exeristes . . . . . . . . . . . . . . . . . . . 10

2. Genus Scambus . . . . . . . . . . . . . . . . . 15

Keys to the subgenera of Scambus. . . . . . . . . . . 16

Subgenus Endromopoda. . . . . . . . . . . . . . . . 18

Subgenus Lissoscambus . . . . . . . . . . . . . . . . 25

Subgenus Ateleophadnus . . . . . . . . . . . . . . . . . 27

Subgenus Scambus . . . . . . . . . . . . . . . . . . 36

Subgenus Erythroscambus . . . . . . . . . . . . . . 76

3. Genus Calliephialtes . . . . . . . . . . . . . . . . . . 80

4. Genus Apistephialtes. . . . . . . . . . . . . . . . . . 87

5. Genus Pimpla. . . . . . . . . . . . . . . . . . . . . 100

6. Genus Anastelgis . . . . . . . . . . . . . . . . . . . 109

7. Genus Dolichomitus . . . . . . . . . . . . . . . . . . 111

8. Genus Acropimpla. . . . . . . . . . . . . . . . . . . 159

9. Genus Iseropus . . . . . . . . . . . . . . . . . . . . 165

10. Genus Tromatobia . . . . . . . . . . . . . . . . . . 174

11. Genus Zaglyptus. . . . . . . . . . . . . . . . . . . . 188

12. Genus Clistopyga . . . . . . . . . . . . . . . . . . 195

13. Genus Alophosternum . . . . . . . . . . . . . . . . . 206

14. Genus Perithous. . . . . . . . . . . . . . . . . . . . 209

2. Tribe Polysphinctini . . . . . . . . . . . . . . . . . 216

Key to the Nearctic genera of Polysphinctini. . . . . . . . . 219

1. Genus Laufeia . . . . . . . . . . . . . . . . . . . . 220

2. Genus Schizopyga . . . . . . . . . . . . . . . . 224

3. Genus Zabrachypus . . . . . . . . . . . . . . . . . . 228

4. Genus Acrodactyla. . . . . . . . . . . . . . . . . . . 230

5. Genus Eruga . . . . . . . . . . . . . . . . . . . . . 238

6. Genus Piogaster. . . . . . . . . . . . . . . . . . . . 241

7. Genus Oxyrrhexis . . . . . . . . . . . . . . . . . . . 242

8. Genus Polysphincta . . . . . . . . . . . . . . . . 245

9. Genus Acrotaphus . . . . . . . . . . . . . . . . . . . 256

10. Genus Sinarachna. . . . . . . . . . . . . . 258

11. Genus Zatypota . . . . . . . . . . . . . . . . . . . . 262

3. Tribe Ephialtini . . . . . . . . . . . . . . . . . . . . 280

Key to the Nearctic genera of Ephialtini . . . . . . . . . . 281

1. Genus Itoplectis . . . . . . . . . . . . . . . . . . . . 281

2. Genus Ephialtes . . . . . . . . . . . . . . . . . . . . 302

3. Genus Coccygomimus . . . . . . . . . . . . . . . . . . 311 
Subfamily Ephialtinae-Continued Page

4. Tribe Theroniini . . . . . . . . . . . . . . . . . . 350

Key to the Nearctic genera of Theroniini. . . . . . . . . . . 351

1. Genus Theronia . . . . . . . . . . . . . . . . . . . . 351

2. Genus Delomerista . . . . . . . . . . . . . . . . . 362

3. Genus Pseudorhyssa. . . . . . . . . . . . . . . . . . 373

5. Tribe Poemeniini. . . . . . . . . . . . . . . . . 375

Key to the Nearctic genera of Poemeniini . . . . . . . . . . 376

1. Genus Poemenia . . . . . . . . . . . . . . . . . . . 376

2. Genus Podoschistus . . . . . . . . . . . . . . . 387

3. Genus Neoxorides . . . . . . . . . . . . . . . . . . . 389

6. Tribe Rhyssini. . . . . . . . . . . . . . . . . . . . 395

Key to the Nearctic genera of Rhyssini . . . . . . . . 395

1. Genus Rhyssa . . . . . . . . . . . . . . . . . . . . . 396

2. Genus Rhyssella . . . . . . . . . . . . . . . . . . 409

3. Genus Epirhyssa . . . . . . . . . . . . . . . . . . . . 413

4. Genus Megarhyssa . . . . . . . . . . . . . . . . . 415

Subfamily Xoridinae . . . . . . . . . . . . . . . . 436

Key to the tribes of Xoridinae . . . . . . . . . . . . . 437

1. Tribe Xoridini . . . . . . . . . . . . . . . . . . . . 437

Key to the genera of Xoridini . . . . . . . . . . . 438

1. Genus Ischnoceros . . . . . . . . . . . . . . . . . . . 438

2. Genus Aplomerus. . . . . . . . . . . . . . . . . . . . 439

3. Genus Odontocolon . . . . . . . . . . . . . . . . . . . 448

4. Genus Xorides. . . . . . . . . . . . . . . . . . . . . 489

Key to the subgenera of Xorides . . . . . . . . . . . 491

Key to the Nearctic subgenera, species groups, and species of

Xorides. . . . . . . . . . . . . . . . 492

1. Subgenus Gonophonus . . . . . . . . . . . . . . . . 494

2. Subgenus Cyanoxorides. . . . . . . . . . . . . . . 494

3. Subgenus Epixorides. . . . . . . . . . . . . . . . . 494

4. Subgenus Gonioprymnus . . . . . . . . . . . . . . . 495

5. Subgenus Moansa. . . . . . . . . . . . . . . . . . 495

6. Subgenus Moerophora . . . . . . . . . . . . . . . . 495

7. Subgenus Exomus. . . . . . . . . . . . . . . . . . 496

8. Subgenus Periceros . . . . . . . . . . . . . . . 501

9. Subgenus Xorides. . . . . . . . . . . . . . . . 501

10. Subgenus Pyramirhyssa . . . . . . . . . . . . 530

2. Tribe Labenini. . . . . . . . . . . . . . . . . . . . 530

1. Genus Labena . . . . . . . . . . . . . . . . . . . . . 531

3. Tribe Labiini . . . . . . . . . . . . . . . . . . . . . . . 537

1. Genus Grotea . . . . . . . . . . . . . . . . . . . 538

4. Tribe Poecilocryptini . . . . . . . . . . . . . . . 541

5. Tribe Brachycyrtini . . . . . . . . . . . . . . . . . . 541

1. Genus Brachycyrtus. . . . . . . . . . . . . . . . 542

Subfamily Acaenitinae. . . . . . . . . . . . . . . . . . 544

Key to the Nearctic genera of Acaenitinae . . . . . . . . . . . . 545

1. Genus Coleocentrus . . . . . . . . . . . . . . . . . . . . . 546

2. Genus Mesoclistus . . . . . . . . . . . . . . . . . . . . 560

3. Genus Arotes . . . . . . . . . . . . . . . . . . . . . . . 561

4. Genus Spilopteron . . . . . . . . . . . . . . 568

5. Genus Yezoceryx .. . . . . . . . . . . . . . . 578

Figures . . . . . . . . . . . . . . . . . . 580

Indices . . . . . . . . . . . . . . . . . 635 


\title{
Ichneumon-Flies of America North of Mexico
}

\author{
Henry and Marjorie Townes
}

\section{Introduction}

This Is PART 2 of a series of monographs on the ichneumon flies of America north of Mexico, prepared under a project supported by the Dow Chemical Company, the University of Michigan, and the National Science Foundation. The first paper, on the subfamily Metopiinae, was issued March 6, 1959, as U. S. National Museum Bulletin 216, part 1 .

The statements in part 1 about bibliography, material studied, and terminology apply also to this paper. References to original descriptions concerning Nearctic material are all given, and references to original descriptions based on exotic material are given where they seem necessary to explain the nomenclature. Papers on biology and morphology are cited, but those which record only hosts or localities, or which are secondary taxonomic references, are omitted. These can be located in a recent catalog, if they are of interest (Townes, 1944, Mem. Amer. Ent. Soc., No. 11, pp. 23-120). Most of the material in the larger North American collections, plus a few smaller lots of specimens, has been studied. The list of collections is the same as for part 1, except that very little of the material in the Corvallis and Edmonton collections was used for this paper.

As in part 1, the locality and host records we cite are only from specimens seen by ourselves. Unconfirmed records in literature are omitted. Some of these published records are valuable, but a large percentage are based on incorrect or questionable determinations. In most cases, the specimens on which the determinations were based have been studied again, and we hope they are now being recorded correctly. If a locality or host record in literature is not repeated, it is unconfirmed by our work. For names of the hosts, we have had to accept the statements on the pin labels, which in some cases are 
probably incorrect. We take responsibility for the determination of the parasites, but not of the hosts. The nomenclature of the hosts has been brought into conformity with recent usage, with the assistance of specialists in the U. S. National Museum and the U. S. Department of Agriculture.

In discussing the seasonal distribution of a species we have usually disregarded the dates on the pin labels of reared specimens because many of these emerged in an indoors climate, out of their natural season.

The morphology of the ovipositor tip is often useful in the taxonomy if these insects, so we have provided a figure $(329, \mathrm{i})$ explaining its terminology.

Other students of ichneumon flies have been helpful in supplying certain bits of information or assistance, comparing specimens with types, or discussing some of the taxonomic problems with us. Miss Luella Walkley of the U. S. Department of Agriculture, Mr. J. F. Perkins of the British Museum (Natural History), Mr. G. Stuart Walley of the Canadian Department of Agriculture, Prof. Toichi Uchida of Hokkaido University, Mr. Gerd Heinrich of Dryden, Maine, and Mr. R. R. Dreisbach of Dow Chemical Company are among these. Mr. Perkins' special knowledge of the family has made his help valuable. Mr. Walley has placed at our disposal the extensive locality and host information assembled by the Canadian Department of Agriculture. Mr. Dreisbach has been particularly helpful in collecting specimens for this study and being always ready with friendly encouragement. The thorough representation of the State of Michigan in the distributional data is the result of his efforts.

In a work that attempts to bring together and use all available information, it is essential to have the cooperation of the scientists and institutions which have been responsible for the gathering of the information and its conservation in accessible form. In the case of this paper the assistance from all sources has been unfailing. Curators of North American collections have lent the specimens under their care, and individuals and institutions the world over have given access to type specimens, or in some cases have sent them through the mails for study. In connection with this paper we have seen or reexamined types in the museums in Philadelphia, Washington, Ottawa, Quebec, Urbana, New Haven, Cambridge, Ithaca, London, Oxford, Brussels, Tervuren, Leiden, Amsterdam, Copenhagen, Lund, Stockhold, Helsinki, Leningrad, Warsaw, Wroclaw, Berlin, BerlinFriedrichshagen, Halle an der Salle, Munich, Vienna, Budapest, Turin, Genoa, Paris, Sapporo, and Taipeh. To the curators of all of these we wish to express our appreciation. Their cooperation has permitted the use of first-hand information for most of the nomenclatural decisions. 
The drawings of generic characters were made by Mr. Kakuzo Yamazaki of Tokyo, through the cooperation of Captain Wallace P. Murdock. The drawings of specific characters are mostly by Miss Y. Morimoto, who worked under the direction of Dr. M. Tokunaga of Kyoto, Japan. Figure 284 is from drawings by Miss M. McKay of the Canadian Department of Agriculture, lent for inclusion in this paper. Photomicrographs of genitalia are by Mr. John Alley of the University of Michigan Photographic Services. The Scambus drawings in figures $310-312$ were supplied by G. S. Walley and those of Delomerista in figures 313 and 316 by Luella Walkley. Mrs. Rosemary Frey and Miss Sharon Carey assisted with making the maps showing distribution. Typing was mostly by Mrs. Frey and Miss Ellen Linna.

When this paper was begun, four other students of the Ichneumonidae had already started on revisions of the genera Scambus, Delomerista, Poemenia, and Aplomerus; they have all agreed to include their work as parts of the entire revision, for the convenience of future students who would pref $\mathrm{r}$ a complete treatment, all under one cover. Although included in this revision and conforming with its style to some extent, these papers are independent contributions.

Other parts of this publication are by Henry and Marjorie Townes, as joint authors, but those portions that validate new generic, specific, and subspecific names are the work of the senior author alone. Thus their authorship should be "Townes" rather than "Townes and Townes." We make this statement to provide a shorter form for the citation of the author of the names. The same citation, "Townes," is correct for all names in our previous papers, for the same reason. 
and

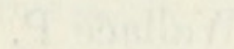


2. Subfamilies Ephialtinae Xoridinae Acaenitinae 


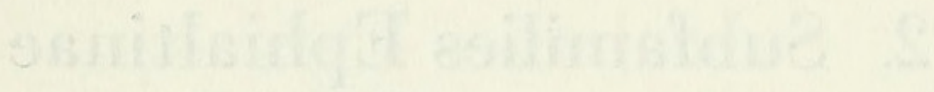

osmin

osmitionsont 


\section{Subfamilies Ephialtinae, Xoridinae, and Acaenitinae Defined}

The three subfamilies included in this bulletin were formerly all in one subfamily (Pimplinae) which was defined as having a rather elongate, cylindric body shape; areolet triangular or absent; sternaulus absent or weak and short; tarsal claws not visibly pectinate but often with an accessory tooth (especially in the female); first abdominal segment usually short and broad, with its spiracle at or in front of the midlength, and not strongly curved at the spiracle; and ovipositor almost always more than half as long as abdomen, without a subapical dorsal notch. The above definition will distinguish most of this group of species from the majority of other ichneumonids, but is not entirely adequate. No completely workable definition has yet been devised, and the student will need to rely on the habitus figures of the various genera for deciding doubtful cases of whether or not the specimen at hand belongs in the group treated here.

Studies in the last 20 years have shown the desirability of subdividing the subfamily Pimplinae of authors, to arrive at more natural and more easily defined groups of genera. There has been a progressive narrowing of the limits of the "Pimplinae" by taking unrelated groups away from it, and in this paper we divide the remainder to make three subfamilies. Two of the resulting subfamilies (Ephialtinae and Acaenitinae) are probably natural; the third (Xoridinae) may not stand as defined after further critical studies, but represents a plausible synthesis of present knowledge. It is close to the Gelinae.

Conclusions on relationships which have led to the splitting of the Pimplinae are based on all information available, some of which cannot easily be conveyed in terms of definite characters. Some very important data are in larval morphology. Our information on larvae stems mostly from Beirne's paper on ichneumonid larvae (Trans. Soc. Brit. Ent., vol. 7, pp. 123-190, 1941) and from a larger paper by Dr. J. R. T. Short (Proc. U. S. Nat. Mus., vol. 110, No. 3419, pp. 391-511, 64 figs., October 23, 1959). Dr. Short was kind enough to send us a manuscript copy of his paper, which has been extremely helpful in decisions on generic relationships. Such adult characters as can be stated definitely are given in the keys to the three subfamilies and in their descriptions. 
The subfamilies (formerly Pimplinae of authors) here included are separated by the following key:

1. Female subgenital plate very large, triangular, folded on the midline, its apex reaching or surpassing the apex of abdomen (figs. 308-310,a); apical third of abdomen of male compressed (deeper than wide) . 3. Acaenitinae (p. 544)

Female subgenital plate not enlarged, or if rarely enlarged (as in Clistopyga) not triangular and folded on midline (figs. 285-307); apical third of abdomen of male cylindric or depressed (wider than deep) . . . . . . . . . . . . 2

2. First abdominal sternite more or less free from its tergite (and the first tergite with a glymma), and/or the propodeum not areolated; epipleura often narrow or vestigial, but sometimes wide . . . 1. Ephialtinae (p. 4)

First abdominal sternite completely fused with its tergite (and the first tergite without a glymma); propodeum areolated; epipleura moderately wide to very wide . . . . . . . . . . 2. Xoridinae (p. 436)

\section{Subfamily Ephialtinae}

Figures 284-304,a

Front wing 2.5 to $30 \mathrm{~mm}$. long; apical margin of clypeus typically thin and with a median notch that makes it bilobed, but often (as in Polysphinctini, Poemeniini, and Rhyssini) of other shapes; labrum hidden beneath clypeus and mandibles; propodeum with few or no areas bounded by carinae except in Xanthopimpla, some Polysphinctini, and the Theroniini; costula present only in some Xanthopimpla and Theronia; tarsal claws often with an accessory tooth or basal lobe, especially in female; first sternite usually free from its tergite, the tergite with a glymma when its sternite is free; epipleura moderately wide to very narrow or vestigial; apical third of abdomen usually depressed or cylindric but in some females (especially Rhyssini) somewhat compressed; female subgenital plate usually transversely rectangular and weakly sclerotized, often with a median membranous area, never with a long median point.

The larva of the Ephialtinae differs from that of all other ichneumonids in having the sclerotic spur of the hypostoma and the stipital sclerome both well developed and reaching each other at their apices rather than the sclerotic spur reaching the stipital sclerome before its apex. The antenna is usually well developed and the mandible with teeth, but in the Ephialtini the antenna is vestigial and the mandible without teeth.

This is the largest group of the subfamily "Pimplinae" of recent authors and contains many common, well known species. Though it appears to be a very primitive group the species and genera are still rapidly subdividing, which results in some taxonomically difficult situations.

The subfamily contains the genus Pimpla and might be called 
"Pimplinae" rather than "Ephialtinae." We have chosen the latter name because it is based on the oldest genus of the subfamily. With the adoption of the name Ephialtinae all the supergeneric group names in the Ichneumonidae will be based uniformly on the oldest included genus, or when there is more than one of the same age, on the one selected by the first revisor. Although the subfamily name Pimplinae is well known, which would make it desirable to continue using the name, in previous applications it has included a different group of insects than our subfamily Ephialtinae.

The six tribes of the Ephialtinae are keyed out below. They are difficult to define and the beginner will have to use the key with care. The habitus figures of the Nearctic genera (figs. 284-304,a) should help in making correct tribal identifications.

\section{Key to the tribes of Ephialtinae}

1. Mesoscutum covered with sharp transverse wrinkles (figs. 300,b, and 302,b304,a) . . . . . . . . . . . . . . . . . . . . . . 2

Mesoscutum without transverse wrinkles, or sometimes with transverse wrinkles on only a small portion of its surface. . . . . . . . . . . . 3

2. First tergite with a sharp lateral longitudinal carina from its spiracle to its apex (fig. 300,b); last tergite of female elongate but without a horny rim or truncate horn at apex (fig. 300,b) (Genus Pseudorhyssa)

4. Theroniini (in part, p. 350)

First tergite without a distinct lateral longitudinal carina from its spiracle to the apex (figs. 302,b-304,a); last tergite of female elongate and ending in a heavy polished rim or a truncate horn (figs. 302,a-304,a)

6. Rhyssini (p. 395)

3. Prepectal carina absent (figs. 301 and 302 ,a); first tergite without a lateral longitudinal carina (at level of spiracle) except sometimes in Deuteroxorides; upper part of temple with a scabrous area except in Poemenia (figs. 301,b and 302,a) . . . . . . . . . . . 5. Poemeniini (p. 375)

Prepectal carina present except in Alophosternum, in Dolichomitus cuspidatus, and in a few extra-limital genera; first tergite usually with a lateral longitudinal carina; upper part of temple without a scabrous area . . . . . . 4

4. Mesopleural suture without a distinct angulation near the middle (figs. 298 and 299 ,a), or if there is an angulation (in the exotic genus Xanthopimpla) the tarsal claws each with an enlarged hair with a flattened tip and the apex of mandible twisted so that its lower tooth is toward the mouth; when hind tibia is banded there are apical and basal dark bands and a median pale band, the extreme base thus being dark . . 3. Ephialtini (p. 280)

Mesopleural suture with a weak angulation near the middle (figs. 285-297; 299 ,b and 300$)$; never with both an enlarged hair on the tarsal claws and the apex of the mandible twisted; when hind tibia is banded there are usually apical and subbasal dark bands and median and basal pale bands, the extreme base thus being pale. . . . . . . . . . . . . . . . . . 5

5. Tarsal claws of female without a basal tooth (figs. 299,b and 300,a); tergites 2 through 4 with fine indistinct punctures, polished or strongly mat; areolet present; male subgenital plate often longer than wide.

4. Theroniini (in part, p. 350) 
Tarsal claws of female, or at least the front claws of female, with a basal tooth except in Perithous and in the European genus Eremochila (figs. 285, a$297, \mathrm{~b})$; tergites 2 through 4 usually with rather coarse, distinct punctures; areolet present or absent; male subgenital plate usually wider than long . . 6

6. Last segment of tarsus not enlarged, a little narrower than the basal segment of the tarsus (figs. 285,a-292,a); areolet present except in Zaglyptus, Clistopyga, and some Tromatobia and Acropimpla; ovipositor of approximately uniform size between its middle and its apical point (figs. 285,a-292,a), except in Clistopyga (fig. 291,a) . . . . . . . 1. Pimplini (p. 6)

Last segment of tarsus enlarged, a little wider than the basal segment of the tarsus (figs. 292,b-297,b); areolet absent except in Laufeia; ovipositor tapered from near middle to its apical point (figs. 292,b-297,b).

2. Polysphinctini (p. 216)

\section{Tribe Pimplini}

Figures 285-292,a

Front wing 2.5 to $22 \mathrm{~mm}$. long; clypeus usually a little convex basally and a little impressed or concave apically, with a median notch in its apical margin which gives it a bilobed apex, sometimes the clypeus more uniformly convex, truncate apically, or with a median apical tubercle; mesoscutum without transverse wrinkles, its notauli moderately strong, weak, or vestigial; prepectal carina present except in Alophosternum, in Dolichomitus cuspidatus, and in an unnamed Neotropic genus; mesopleural suture with an angulation just above the middle; propodeum usually with its pleural carina complete, sometimes with apical part of lateral longitudinal carina preserved, and often with basal $0.4 \pm$ of median longitudinal carinae present, otherwise without carinae except that in Perithous the petiolar area may appear to be completely bounded by a carina; last segment of tarsus not enlarged, a little narrower than basitarsal segment; tarsal claws of male simple; tarsal claws of female with a large, basal, lobelike tooth (except in Perithous, on the hind claws of a Japanese species of Alophosternum, on the middle and hind claws of an unnamed Oriental genus, and in the European Eremochila ruficollis); tarsal claws without an enlarged hair with a flattened tip; areolet present except in Zaglyptus, Clistopyga, and in some species of Tromatobia and Acropimpla; nervellus broken above, near, or below the middle, or sometimes not broken; first tergite free from its sternite except in an unnamed genus from the Orient, its lateral carina usually strong; subgenital plate of male transverse, its apex usually truncate or retuse, but in Perithous longer than wide and tapered to a blunt point; last tergite of female without an apical horn or boss; ovipositor usually moderately long to very long, rather slender, and of uniform diameter, but in Clistopyga short, upcurved, and tapered.

The Pimplini are parasitic on hosts hidden within plant tissues or cocoons. Their long ovipositors are used in reaching such hosts. 
The larvae feed externally on the hosts and in correlation with this habit have rather large mandibles with serrate edges.

The tribe is difficult to divide into satisfactory genera. It is one of those situations in which the careful taxonomist would prefer to withhold judgment until much more information is available. The position of indecision, however, should not be maintained too long and we have written down our best judgment for the present. We hope that it proves to be useful and to have resulted in progress in the right direction. The keys were devised for maximum ease of use and accuracy, but are not foolproof. Interpretation of some of the characters needs experience, and the question of where the nervellus is broken (couplet 7) will, in borderline or questionable cases, require a trial run through both halves of the couplet. Some exotic species will not conform to all key characters. The genera may be grouped into assemblages which to a large degree seem to correspond to their real relationships. These are discussed below.

Pimpla group: Occipital carina complete, or rarely obsolete medially; tarsal claws of female with a lobelike tooth (except in Eremochila); male subgenital plate not elongate. There are two subgroups: A. The Pimpla subgroup tends to have a prominent dip on the midline above the occipital carina, temples tend to be broad, clypeus flatter, subgenital plate of female usually with a large, median membranous area, upper valve of ovipositor usually not attenuate at apex, and ridges of basal teeth of lower valve of ovipositor moderately oblique to vertical. The genera are Exeristes, Eremochila, Scambus, Flavopimpla, Calliephialtes, Holcopimpla, Delaulax, Xanthephialtes, Xanthophenax, Pimpla, Apistephialtes, Anastelgis, Dolichomitus, Afrephialtes, Mesoephialtes, Pimplaetus, and two undescribed genera. These genera are parasitic on larvae in plant tissues (buds, leaf rolls, stems, wood, etc.) and oviposition is through plant tissue to reach the host. B. The Tromatobia subgroup tends to lack the median dip in the occipital carina or to have only a weak dip, the temples usually narrower, clypeus more convex, subgenital plate of female usually completely sclerotized, upper valve of ovipositor usually with an attenuate point, and ridges of basal teeth of lower valve of ovipositor very oblique. The genera are Acropimpla, Sericopimpla, Cnemopimpla, Iseropus, Tromatobia, Zaglyptus, and Clistopyga. These genera are parasitic on cocoons of various kinds, including spider egg cocoons, and oviposition is through silk to reach the host.

Alophosternum group: Occipital carina absent medially above; mesoscutum covered with moderately dense hairs; tarsal claws of female with a basal tooth on the front claws, with or without a basal tooth on the middle and hind claws; male subgenital plate not elongate; basal half of ovipositor weakly decurved. Alophosternum 
and an undescribed genus from the Orient belong to this group. Alophosternum has been reared from leaf-mining larvae.

Brachycentropsis group: Occipital carina absent above; mesoscutum covered with dense hairs; tarsal claws of female each with a basal tooth; propodeum behind with a large smooth area bordered by a carina; first tergite with strong, complete lateral longitudinal carina, its dorsal longitudinal carinae very short and weak; female subgenital plate heavily sclerotized; ovipositor relatively short, compressed, the apex of its lower valve with a dorsal lobe that encloses apex of upper valve. Brachycentropsis of the Mediterranean region is the only genus.

Camptotypus group: Occipital carina absent above, often entirely absent; mesoscutum with few hairs or none, polished; tarsal claws of female with a large basal tooth; male subgenital plate not elongate; ovipositor straight. The genera of this group are tropical, Camptotypus in the Old World tropics and Zonopimpla, Odontopimpla, and four unnamed genera in the New World tropics. The host relations are not well known.

Perithous group: Occipital carina complete, without a median dip; tarsal claws of female without a basal tooth; propodeum with its petiolar area bounded by a more or less distinct carina (bounded in a similar way in the Brachycentropsis group but in none of the others); male subgenital plate elongate, ending in a median point. Perithous is the only genus. It parasitizes the nests of aculeate Hymenoptera living in stems.

\section{Key to the Nearctic genera of Pimplini}

1. Tarsal claws of female without a basal lobe (fig. 292,a); subgenital plate of male longer than wide, prolonged medially into a rounded point; abdomen of the Nearctic species black with a narrow white apical band on each tergite ................. 14. Perithous (p. 209)

Tarsal claws of female with a large basal lobe (at least in the Nearctic species); subgenital plate of male wider than long, usually without a median point; abdomen usually entirely black, rarely colored as above . . . . . . . . 2

2. Prepectal carina absent (fig. 291,b); occipital carina absent above; basal half of ovipositor down-curved (fig. 291,b) . . . . . 13. Alophosternum (p. 206)

Prepectal carina present except in Dolichomitus cuspidatus (figs. 285-291,a); occipital carina nearly always present above; basal half of ovipositor straight (figs. 285-291, a) . . . . . . . . . . . . . 3

3. Occipital carina not dipped downward at the midline, always strong medially; areolet often absent; frontal orbits often marked with white. (Parasites of spider eggs.) .................... . . . . .

Occipital carina dipped downward at the midline, sometimes weak or rarely obsolete medially; areolet present; frontal orbits never marked with

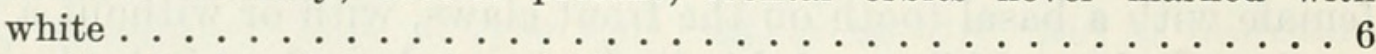

4. Nervellus broken below the middle or not broken; ovipositor tapered, its apical half more or less upcurved (fig. 291,a); female subgenital plate large and projecting (fig. 291,a) ........... 12. Clistopyga (p. 195) 
Nervellus broken above the middle (except in some extra-limital species of Zaglyptus); ovipositor of uniform diameter, straight (fig. 290); female subgenital plate not enlarged nor projecting . . . . . . . . . 5 5

5. Areolet usually present; propodeum without a distinct lateral subapical tubercle (fig. 290,a); basal tooth of ovipositor not enlarged] or free at the tip (fig. 331,c); ventral valve of ovipositor with a finely wrinkled surface.

10. Tromatobia (p. 174)

Areolet always absent; propodeum with a lateral subapical tubercle, the tubercle strong in the female (fig. 290,b), weak in the male; basal tooth of ovipositor large and with a long free tip (fig. 331,d); ventral valve of ovipositor with a smooth surface . . . . . . . . 11. Zaglyptus (p. 188)

6. Mesoscutum, or at least its lateral lobes, almost or quite bare of hairs; median dorsal carina of first tergite ascending from its beginning point at the basolateral corner of the tergite at $70^{\circ}$ to $90^{\circ}$ from the horizontal, then curved backward (fig. 286,b), in male extending some distance horizontally, in female short and ending abruptly; ovipositor not distinctly compressed.

3. Calliephialtes (p. 80)

Mesoscutum with dense or moderately dense hairs all over except (in the Nearctic fauna) in Anastelgis (Californian) and in a few species of Scambus from the western and southwestern parts of the Nearctic region; median dorsal carinae of first tergite, when present, ascending at $20^{\circ}$ to $65^{\circ}$ from the horizontal and apically extended horizontally in both sexes (figs. 285-

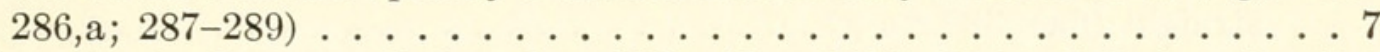

7. Nervellus broken at or below the middle (figs. 285 ,b; 286 ,a; 289 ,a); ovipositor more or less compressed . . . . . . . . . . . . . 8

Nervellus broken near or above the middle (figs. 285a; 287 ; 288); ovipositor

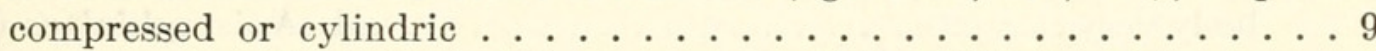

8. Second tergite with distinct oblique grooves cutting off its basolateral corners (fig. 289,a); clypeus of male white (or yellow in some exotic species); areolet receiving second recurrent vein usually at its outer corner (fig. 289 ,a), rarely the areolet absent; tip of dorsal valve of ovipositor, in profile, a little concave beyond the nodus; ridge of basal tooth of lower valve of ovipositor at about $15^{\circ}$ from the horizontal . . . 8. Acropimpla (p. 159)

Second tergite without oblique grooves cutting off its basolateral corners (fig. 286,a); clypeus of male black, blackish, or dark ferruginous; areolet always receiving second recurrent vein distinctly basad of its outer corner (fig. 286,a); tip of dorsal valve of ovipositor, in profile, convex or straight beyond the nodus, or occasionally a little concave; ridge of basal tooth of lower valve of ovipositor $20^{\circ}$ to $90^{\circ}$ from the horizontal. . 2. Scambus (p. 15)

9. Basal half or more of clypeus rather strongly convex; clypeus of male white or pale yellow; ovipositor somewhat compressed, its sheath about 0.3 to 0.7 as long as front wing, the ridges of the basal teeth on its lower valve about $30^{\circ}$ from the horizontal; hind tibia usually with conspicuous black and white banding .............. 9. Iseropus (p. 165)

Basal half of clypeus nearly flat; clypeus of male not white nor pale yellow except in Pimpla, black, blackish, ferruginous, or concolorous with the head; ovipositor subcylindric, its sheath about as long as or longer than front wing, the ridges of basal teeth of its lower valve mostly $40^{\circ}$ to $90^{\circ}$ from the horizontal; hind tibia without conspicuous black and white banding. . . . . . . . . . . . . . . . 10 
10. Second tergite with long, strong, basolateral grooves that cut off its basolateral corners (figs. 288 ,a,b) ; first tergite rather long, usually about as long as second tergite (figs. $288, a, b) \ldots \ldots \ldots \ldots \ldots$

Second tergite without oblique basolateral grooves or with relatively short and weak grooves (figs. 285,a; 287); first tergite rather short, usually much shorter than second tergite (figs. 285 ,a; 287) . . . . . . . . . 12

11. Lower valve of ovipositor without a subapical dorsal lobe (fig. 330,b); tip of upper valve of ovipositor with a dorsolateral, finely notched ridge; thorax of the Nearctic species largely ferruginous . . . . 6. Anastelgis (p. 109)

Lower valve of ovipositor with a subapical dorsal lobe (figs. $330, \mathrm{c}-\mathrm{h}$ ); tip of upper valve of ovipositor rounded above, without a dorsolateral ridge; thorax of the Nearctic species black, the mesosternum and lower part of mesopleurum sometimes tan or stramineous . . . 7. Dolichomitus (p. 111)

12. Clypeus about 2.5 as wide as long, rather flat (fig. 287 ,b), in the male always white or whitish; lower tooth of mandible distinctly longer than upper tooth; ovipositor sheath 1.8 to 5.0 as long as front wing; apex of ovipositor a little depressed, the ridges of its basal teeth turned strongly forward dorsally (figs. $329, \mathrm{~h} ; 330, \mathrm{a}) \ldots \ldots$. . . . . . . Pimpla (p. 100)

Clypeus about 1.8 as wide as long (figs. 285 ,a; 287 ,a), ferruginous to black, never white; lower tooth of mandible the same length as upper tooth; ovipositor sheath 1.0 to 6.0 as long as front wing; apex of ovipositor a little compressed, the ridges of its basal tooth straight or moderately

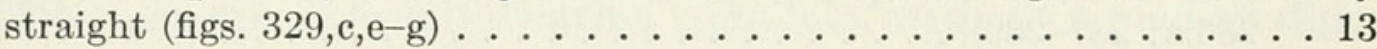

13. Median longitudinal carinae of propodeum distinct on the basal 0.25 or more of propodeum (fig. 285, a) ; body moderately elongate . 1. Exeristes (p. 10)

Median longitudinal carinae of propodeum absent or indistinct (fig. 287,a); body very elongate............ 4. Apistephialtes (p. 87)

\section{Genus Exeristes}

\section{FIgURE 285, a}

Exeristes Foerster, 1868, Verh. Naturh. Ver. Rheinlande, vol 25, p. 164. Type: (Pimpla roborator Gravenhorst) $=$ roborator $\quad$ (Fabricius); included by Schmiedeknecht, 1888.

?Liogaster Kriechbaumer, 1890, Ent. Nachr., vol. 16, p. 297. New synonymy. Name preoccupied. Type: (Liogaster longulus Kriechbaumer) $=$ ? arundinis (Kriechbaumer). New synonymy.

? Liotryphon Ashmead, 1900, Canadian Ent., vol. 30, p. 368 . New name for Liogaster Kriechbaumer.

Front wing 3.2 to $9 \mathrm{~mm}$. long; body moderately elongate; face and clypeus black or blackish or the clypeus tinged with ferruginous; clypeus moderately narrow, weakly convex with its apex impressed and made bilobed by a median apical notch, in the male of E. roborator with a median apical tubercle; occipital carina strongly dipped on the midline; mesoscutum with moderately dense, evenly distributed hairs; submetapleural carina complete; propodeum short or moderately short, its median longitudinal carinae sharp on its basal $0.3 \pm$; areolet subtriangular, longer than high, receiving second recurrent vein before its apex; nervellus broken near or above the middle; first tergite short, broad, its lateral longitudinal carina vestigial, its median 
longitudinal carinae extending about half its length; basal grooves on second tergite weak, almost transverse; third and fourth tergites with weak but definite tubercles, their apical impunctate margin occupying about 0.2 their length; female subgenital plate with a large median basal membranous area; ovipositor sheath about 1.4 as long as front wing; ovipositor straight, cylindric, its apex as in figure 329 , c.

According to our definition, this genus includes a single Nearctic species, as treated below, and the European Ichneumon roborator Fabricius 1793, Ephialtes longiseta Ratzeburg 1844, and Ephialtes arundinis Kriechbaumer 1887. The latter two species have not previously been referred to Exeristes.

\section{Exeristes comstockii (Cresson), new combination}

Figures 320 ,a; 329,c

Ephialtes comstockii Cresson, 1880, Ann. Rep. U. S. Dep. Agr. for 1879, p. 235, ㅇ . Lectotype: ๆ, Ithaca, N. Y. (Washington).

Biology: Cushman, 1927, Journ. Agr. Res., vol. 34, p. 616.-Miller, 1953, Ohio Journ. Sci., vol. 53, p. 60.

Front wing of male 5.5 to $6.8 \mathrm{~mm}$. long, of female 6.0 to $11.5 \mathrm{~mm}$ long; face with moderately coarse punctures that are separated by about 1.3 their diameter; temple moderately to strongly convex; punctures on mesopleurum and metapleurum moderately coarse to moderately fine, separated by about 1.2 to 3.0 their diameter; median carinae on propodeum extending about 0.55 the length of propodeum; tarsal claws of female each with a large basal lobe; nervellus broken near its upper 0.40 ; second tergite with coarse punctures; apical tergites of male progressively smoother and with finer punctures; ovipositor sheath about 1.45 as long as front wing. Specimens from the western half of North America have the face more coarsely

Figure 1.-Localities for Exeristes comstockii.

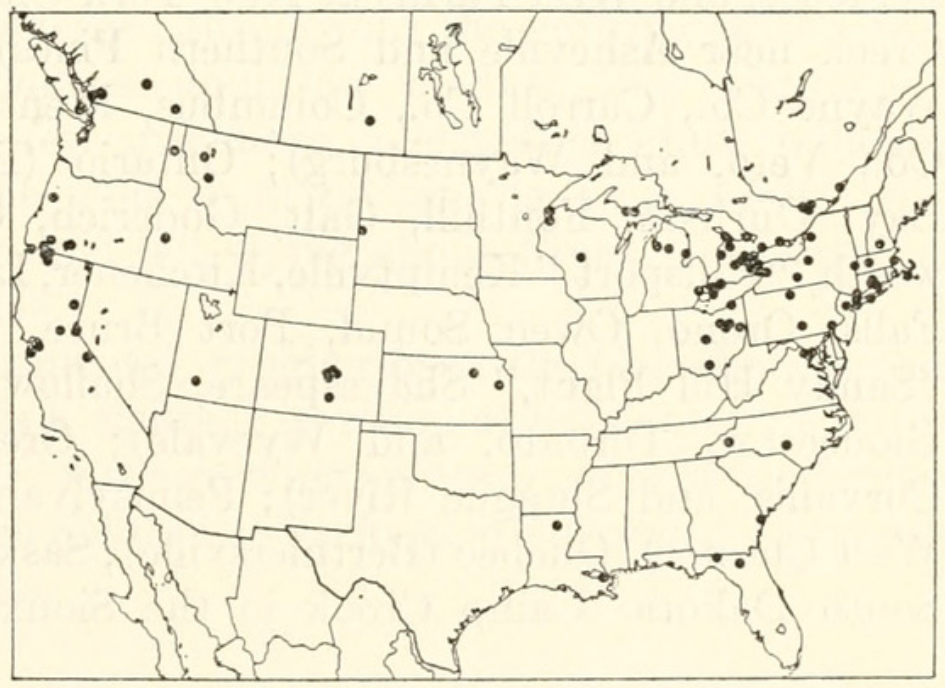


punctate and the temples more convex, on the average, than do specimens from the East.

Black. Clypeus and mandible reddish brown; palpi of male white; maxillary palpus of female whitish, brown basally; labial palpus of female brown; scape of male often tinged with stramineous or whitish in front; tegula and hind corner of pronotum white, the white on corner of pronotum extended forward along upper edge of pronotum; legs except hind tibia and tarsus fulvous, the front coxa of male and front and middle trochanters of male whitish, the hind femur infuscate apically; hind tibia and tarsus fulvous brown to fuscous, the hind tibia with its basal $0.2 \pm$ whitish or stramineous and the basal segments of hind tarsus paler basally.

The closest relative of this species seems to be Exeristes longiseta (Ratzeburg) of Europe.

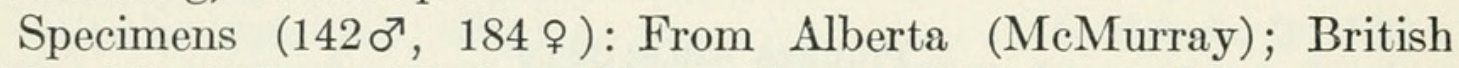
Columbia ("Green Timbers Forest Station," Kokanee Mt. at 9,000 ft., Steelhead, Vancouver, Vernon, and Victoria); California (American River, Ash Creek Basin, Fallen Leaf Lake in El Dorado Co., "Huckleberry Meadow," "Kyrowz Station," Leevining, Mount Diablo, Patricks Creek, Siskiyou Co., Stanford University, "Summerdale," Susanville, and Yreka); Colorado (Beulah, Cheyenne Mts., "Mt. Manitou," North Cheyenne Canyon, Ute Pass, and Williams Canyon in El Paso Co.); Connecticut (Hamden, Meriden, and New Haven); Florida (Lake City and Monticello); Georgia (Camp Stewart); Idaho (Centerville and Coeur d'Alene); Illinois (northern Illinois); Kansas (Douglas Co. and Riley Co.); Louisiana (Monroe and New Orleans); Maryland (Takoma Park); Massachusetts (Amherst, Martha's Vineyard, and Sharon Heights); Michigan (Detroit, East Tawas, Fife Lake, Higgins Lake, Munising, and Onota Township); Montana (Camas and Missoula); Newfoundland (West Bay); New Hampshire (Penacook); New Jersey (National Park); New York (Buffalo, Canaan, Ithaca, Long Island, Lowville, Port Chester, Syracuse, and West Farms at New York City); North Carolina (Bent Creek near Asheville and Southern Pines); Ohio (Apple Creek in Wayne Co., Carroll Co., Columbus, Mentor, New Pittsburg, Pike Co., Veto, and Waynesburg); Ontario (Bells Corners, Constance Bay, Durham, Fonthill, Galt, Goderich, Guelph, Hamilton, Hepworth, "Hillsport," Kemptville, Kitchener, London, Lorraine, Niagara Falls, Orono, Owen Sound, Port Bruce, Port Colborne, Rodney, "Sandy Hill Plant," Shakespeare, Shallow Lake, Stittsville, South Gloucester, Toronto, and Wyevale); Oregon (Ashland, Colestin, Corvallis, and Sprague River); Pennsylvania (Austin, Carlisle, and West Chester); Quebec (Berthiersville); Saskatchewan (Indian Head); South Dakota (Camp Crook in the Sioux National Forest); Utah 
(Panguitch); Virginia (East Falls Church and Vienna); and Wisconsin (Gordan, Minong, and Wood Co.).

This is a very common parasite of Lepidoptera (and sometimes of Pissodes) boring in the growing tips or cones of conifers. In the Austroriparian fauna it has been reared as a parasite of Laspeyresia caryana, feeding in the shucks of pecan. Specimens from the Southeast are somewhat more slender and with narrower temples than normal for the species, and the association with hosts in Carya rather than Coniferae suggests that they might be a different species or subspecies. We have not, however, found a way to distinguish them as a discrete taxon.

Rearing records are as follows: 1 from Choristoneura fumiferana, 2 from Barbara colfaxiana taxifoliella, 4 from B. colfaxiana siskiyouana, 1 from Dioryctria amatella, 1 from $D$. auranticella, 2 from $D$. zimmermani, 1 from Laspeyresia caryana, 1 from L. cupressana?, 3 from L. toreuta, 4 from L. youngana, 1 from Laspeyresia sp., 3 from Petrova albicapitana, 1 from P. comstockiana, 2 from Petrova sp., 1 from Pissodes strobi, 2 from material containing Pissodes strobi, 1 from material containing Pissodes sp., 1 from Razoumotskya cryptopoda, 50 from Rhyacionia buoliana, 3 from $R$. frustrana, 1 from $R$. rigidana, 3 from Rhyacionia sp., 1 from "tortricid in black knot," 1 from cones of Abies amabilis, 7 from $A$. concolor, 1 from cones of $A$. concolor, 2 from A. grandis, 1 from cones of Abies sp., 5 from cones of Picea glauca albertinana, 3 from Picea sitchensis, 2 from cones of Picea sp., 1 from Pinus contorta, 2 from $P$. edulis, 1 from $P$. jeffreyi, 2 from $P$. murrayana, 3 from $P$. ponderosa, 1 from cones of $P$. ponderosa, 1 from $P$. scopulorum, 2 from $P$. strobus, 1 from cones of $P$. strobus, 1 from $P$. sylvestris, 1 from $P$. virginiana, 1 from cones of Pinus sp., 2 from Pseudotsuga taxifolia, and 1 from Tsuga heterophylla. Out of the 326 specimens we have seen, all but about 21 specimens were certainly or probably reared, which indicates the importance of the species in the biological control of economic pests.

The reared specimens emerged throughout the growing season and some during the cold months, doubtless because they were in a laboratory climate. The few specimens collected as adults indicate that the species is on the wing from mid-spring to mid-fall. We ourselves have taken it in mid-fall, flying about Pinus virginiana, in abandoned overgrown fields.

This species is transcontinental, ranging from the Canadian to the Lower Austral zone. It is a common parasite of lepidopterous hosts (and sometimes of Pissodes) in the growing points or cones of coniferous trees. In the southeastern States it attacks also Laspeyresia caryana in the shucks of Carya nuts. 


\section{The Nearctic species of Scambus Hartig ${ }^{1}$}

By G. Stuart Wallex

In 1944, Townes published his reclassification of Nearctic Ichneumonidae; in it he listed the Nearctic species of Scambus with their synonymy. As previous taxonomic work on the genus consists largely of the descriptions of new species, which were included by authors in several genera, the Townes arrangement marked an important advance in the classification of the group and it has provided a basis for the present comparative study. That a better knowledge of the taxonomy of the Nearctic species is desirable has long been recognized, and it is primarily to satisfy this need that the present work was undertaken. It is hoped the following account will contribute toward a better understanding of the composition of the genus and will provide a more satisfactory means for the identification of the Nearctic species.

The greater part of the material studied is in the Canadian National Collection and the Townes collection, but a large number of specimens have also been studied from various other collections. I have also studied the types in the collections at Cambridge, New Haven, Quebec, Urbana, and Washington. Where I have not personally examined types I have relied mainly on material in the Townes collection compared with types, and on additional information provided by Dr. Townes and others as noted below.

To all who have aided in this study by the loan of material or the provision of information I am very grateful. I am especially indebted to Dr. Townes for information on certain genotype material and other types in several European museums, and for his aid in the solution of some taxonomic problems that have arisen in the course of this work. Miss L. M. Walkley has supplied information on several types at Washington; comparisons with notes on types at Philadelphia and Washington were made for me by my associate Dr. W. R. M. Mason; and Mr. J. F. Perkins of the British Museum (Natural History) has been most helpful in comparing Nearctic and Palearctic specimens and in supplying the Canadian National Collection with a valuable reference collection of Palearctic species. The aid of these persons is gratefully acknowledged.

The genus Scambus is widely distributed in the Northern Hemisphere. It is best represented in the Holarctic region but is also found in the Neotropic and Oriental regions. In the Nearctic region species and individuals are most abundant in cooler areas, especially in Canada and Alaska (except in the Arctic zone) and in the northern portion of

1 G. Stuart Walley, Senior Entomologist, Insect Systematics and Biological Control Unit, Entomology Division, Ottawa, Canada. Contribution No. 3861, Entomology Division, Science Service, Department of Agriculture, Ottawa, Canada. 
the United States. There is a marked reduction in abundance in the region of the southern limits of the Upper Austral zone, especially in eastern North America, and there are very few records from the Austroriparian faunal area. A few species are found in the Lower Sonoran faunal area. In the Neotropics the genus is represented by several species that form a distinctive subgenus confined to that region, except for a single species found in the western portion of the Nearctic region from California to southern British Columbia.

In this account 26 species plus 4 subspecies are recognized. Excluding alboricta (Cresson), which elsewhere in this publication (p. 162) Townes places in Acropimpla, all the species listed by Townes in 1944 are retained in Scambus. One species, lithocolletidis (Ashmead), has not been identified beyond verifying its generic position from the rather poorly preserved type specimen. It seems to belong in the nominate subgenus. Changes in the Townes arrangement include the removal of nigrifrons (Viereck) from synonymy with hispae (Harris) and its recognition as a valid species, the transfer of innominatus (Viereck) from the synonymy of hispae to that of transgressus (Holmgren), the synonymizing of bicoloripes (Ashmead) with brevicornis (Gravenhorst), and the subordination of eurae (Ashmead) to the rank of a subspecies of vesicarius (Ratzeburg). Additions include the recognition of nucum (Ratzeburg) and the nominate subspecies of vesicarius (Ratzeburg) from North America, the descriptions of 13 new species and 2 new subspecies from the Nearctic region, and the division of the genus into 5 subgenera.

\section{Genus Scambus}

Figures 285,b; 286, a

Small to medium-sized, slender to rather stout species, the Nearctic species with front wing 2.0 to $8.0 \mathrm{~mm}$. long; head usually moderately thin, but occasionally rather strongly thickened; occipital carina complete, but often very weak, dipped on the midline above; eye indistinctly to very weakly emarginate opposite antennal socket; cheek at most not more than 0.5 times breadth of base of mandible; antenna about 0.66 times as long as front wing; prepectal carina present; mesoscutum usually with distinct hairs but occasionally almost bare; areolet present, receiving second recurrent distinctly before outer corner; nervellus inclivous to perpendicular, broken definitely below middle or rarely at middle; legs slender to rather stout; front femur of male simple or excised beneath; front tibia of male varying from almost straight to rather strongly bent; all tarsal claws of female with a large basal lobe; propodeum convex and usually with short, rather weak, dorsomedial carinae at base, but sometimes with dorsomedial carinae rather strong and extending almost to apex; dorsal carinae of 
first tergite ascending from base of tergite at an angle of $20^{\circ}$ to $65^{\circ}$; second tergite without an oblique groove on either side at base; hind margin of subgenital plate of male truncate or biemarginate and with edge not upturned; ninth tergite (concealed in dried specimens) of male without a distinct process (appendiculum) at base; subgenital plate of female with a small to very large membranous excision at base; sheath rather densely clothed with rather long, suberect, basally compressed hairs; ovipositor weakly to strongly compressed, the upper valve usually with a preapical crest or "nodus," the lower valve usually with several, distinct, oblique or transverse ridges before apex.

In most members of the genus the body is black and the legs are mostly reddish to yellowish, the hind tibia whitish with distinct subbasal and apical fuscous annuli. Less frequently the thorax and abdomen are more or less red and the hind tibia may lack distinct markings.

Scambus seems most closely related to Exeristes, its resemblance being especially evident in such species as E. comstockii (Cresson). It appears less closely allied to Acropimpla, Iseropus, Tromatobia, and Alophosternum, but because of certain similarities it has often been confused with them in collections.

As here recognized the genus is rather broadly defined. It is divided into five subgenera. Three of these, Ateleophadnus, Endromopoda and Scambus, are Holarctic, and they include the majority of the members of the genus. The other two, Lissoscambus and Erythroscambus, are known only from a few North American species, the former from the Sonoran faunal area of the Nearctic and the latter largely from the Neotropic region.

The subgenera are distinguished principally by the differences given in the keys below. In using the keys, wherever possible it is desirable to have both sexes represented. Special care is required in distinguishing between the males of Endromopoda and Scambus.

\section{Keys to the subgenera of Scambus}

\section{MALES}

1. Submetapleural carina usually absent; mesoscutum mostly bare or with only very sparse hairs, occasionally with moderately dense hairs; propodeum without distinct dorsomedial carinae, sometimes with a shallow, median, longitudinal sulcus; first tergite with dorsal carinae absent or indistinct beyond apex of basal declivity; thorax red, with a few conspicuous black markings; front and middle legs, and hind tibia and tarsus, mostly whitish or creamy-white, the hind tibia sometimes with a few fuscous streaks or spots but without distinct fuscous annuli . . . . . . . . . . . 2

Submetapleural carina present; mesoscutum with rather evenly distributed, moderately dense hairs; propodeum usually with distinct (sometimes rather short) dorsomedial carinae; first tergite with dorsal carinae usually distinct 
for some distance beyond apex of basal declivity; thorax usually black, or black with a few reddish markings; front and middle legs varying from pale yellowish to mostly reddish; hind tibia usually more or less reddish, or whitish with distinct fuscous annuli . . . . . . . . . . . . . 3

2. Face densely clothed with rather coarse, whitish hairs; front femur with a conspicuous, preapical lamina beneath; hind femur with rather dense, long hairs on upper surface . . . . . . . . Erythroscambus (p. 76)

Face with sparse, inconspicuous, yellowish hairs; front femur excised beneath and without a preapical lamina; hind femur with only inconspicuous, short hairs on upper surface . . . . . . . . . Lissoscambus (p. 25)

3. Front femur with a single, broad, distinctly coriaceous excision beneath; front tibia rather strongly angularly bent near middle, and rather strongly swollen in apical 0.6 ; scape mostly, or entirely brownish or blackish beneath.

Ateleophadnus (p. 27)

Front femur entire or with a single or double excision beneath, the excision (except in $S$. nucum in which the excision is double) without distinct, coriaceous sculpture; front tibia moderately to very weakly, rather evenly bent, and not strongly swollen in apical 0.6 ; scape variable, frequently conspicuously whitish beneath . . . . . . . . . . . . . . . . 4

4. Propodeum long, with distinct, long, rather narrowly separated, dorsomedial carinae; first tergite of abdomen slender (1.5 to 2.0 times as long as wide); scape rarely mostly whitish beneath . . . . . . Endromopoda (p. 18)

Propodeum usually rather short, with shorter, more widely separated, dorsomedial carinae; first tergite of abdomen moderately stout (usually not more than 1.5 times as long as wide); scape often whitish beneath.

Scambus (p. 36)

\section{FEMALES}

1. Submetapleural carina usually absent; mesoscutum mostly bare or with only very sparse hairs, occasionally with moderately dense hairs; propodeum without distinct dorsomedial carinae, sometimes with a shallow, median, longitudinal sulcus; thorax red with a few conspicuous, black markings; hind tibia usually without distinct fuscous annuli . . . . . . . . . . 2

Submetapleural carina present; mesoscutum with rather evenly distributed, moderately dense hairs; thorax usually black or black with a few reddish markings, or if largely red then the propodeum with distinct, dorsomedial carinae; hind tibia usually with distinct fuscous annuli . . . . . . . . 3

2. Ovipositor rather short and stout, and strongly compressed, with the basalmost ridges on apex of lower valve forming an angle of about $45^{\circ}$ with its longitudinal axis; sheath about 0.5 times as long as abdomen.

Lissoscambus (p. 25)

Ovipositor long and slender, and only moderately compressed, with the basalmost ridges on apex of lower valve forming an angle of about $30^{\circ}$ with its longitudinal axis; sheath at least 0.75 times as long as abdomen.

Erythroscambus (p. 76)

3. Ovipositor very strongly compressed, with ridges on apex of lower valve at right angles to its longitudinal axis and dorsally not developed into forward directed teeth (fig. 310, c); subgenital plate with a rather small, median, basal, membranous excision; apical segment of tarsi strongly swollen; claws large and stout; propodeum long, with long, rather narrowly separated, dorsomedial carinae . . . . . . . . . Endromopoda (p. 18) 
Ovipositor rather strongly to rather weakly compressed, with at least the basalmost ridges on apex of lower valve distinctly oblique, and with most ridges more or less developed dorsally into forward directed teeth; subgenital plate with a large or moderately large, median, basal, membranous excision; apical segment of tarsi not strongly swollen; claws not especially large or stout; propodeum moderately long to rather short, with median carinae, when present, short to moderately long . . . . . . . . . . . . . . . 4

4. Ovipositor rather strongly compressed, with basalmost ridges on apex of lower valve forming an angle of about $40^{\circ}$ with its longitudinal axis; propodeum rather long, with distinct, long, dorsomedial carinae; subgenital plate with a moderately large, median, basal, membranous excision; sheath 0.4 to 0.7 times as long as abdomen . . . . . . . Ateleophadnus (p. 27)

Ovipositor rather weakly compressed, with basalmost ridges on apex of lower valve (except in S. protentus) forming an angle of about $30^{\circ}$ with its longitudinal axis; propodeum rather short, usually with rather short dorsomedial carinae; subgenital plate with a large, median basal, membranous excision; sheath (except in $S$. imparis) at least 0.66 times as long as abdomen.

Scambus (p. 36)

\section{Subgenus Endromopoda}

Figure 285,b

Scambus (Endromopoda) Hellén, 1939, Not. Ent., vol. 19, p. 56. Type: Scambus (Endromopoda) melanopyga (Gravenhorst); original designation.

Submetapleural carina present; propodeum long, with long, rather narrowly separated, parallel or subparallel, dorsomedial carinae; abdomi 1 al sternites in female unusually large and broad, with the basal and apical pairs larger than the others, and all except the basal pair with large, aciculate punctures; subgenital plate in female with basal membranous excision small, and often very shallow; sheath about 0.4 times as long as abdomen; ovipositor very strongly compressed, with ridges on apex of lower valve at right angles to its longitudinal axis and dorsally not developed into forward directed teeth (fig. 310,c); apical segment of tarsus unusually long (in mid tarsus of male subequal to segment one), and in female strongly swollen and with claws very large and stout; first abdominal tergite in male at least 1.5 times (and usually 2.0 times) as long as wide.

Most members of this subgenus parasitize insects living within the stems of reeds and grasses. The short, rigid, strongly compressed ovipositor, characteristic of the group, appears well suited to penetration between the fibrovascular bundles of monocotyledonous stems.

The subgenus is represented in both the Palearctic and Nearctic regions and includes one species (detritus) that is Holarctic.

\section{Key to the Nearctic species of the subgenus Endromopoda}

1. Metapleurum entirely reddish, or with a large reddish spot; abdomen more or less rufopiceous, or with distinct reddish markings; male front femur without an excision beneath; female front trochanter yellowish.

1. rubescens, new species 
Metapleurum and abdomen black; male front femur with a broad, shallow excision beneath; female front trochanter mostly reddish. . . . . . . . 2

2. Male without distinct white marking on scape beneath; female hind tibia rather indistinctly banded, broadly dull yellowish to pale reddish above on middle, and with reddish to reddish brown subbasal and apical annuii; female subgenital plate with a small, very shallow, median, basal, membranous excision . . . . . . . . . . . . . 2. detritus (Holmgren)

Male with scape broadly whitish at apex, or entirely whitish beneath; female hind tibia with a broad, white annulus (more or less interrupted beneath) at middle, between brownish to blackish subbasal and apical annuli; female subgenital plate with a narrow, rather deep, median basal, membranous excision . . . . . . . . . . . . . . . 3. productus, new species

\section{Scambus (Endromopoda) rubescens Walley, new species}

Figures $311, \mathrm{a} ; 320, \mathrm{~b}$

Male: Front wing 6.0 to $7.5 \mathrm{~mm}$. long; antenna with 24 to $26 \mathrm{seg}$ ments; cheek about 0.25 times breadth of mandible at base; mandible weakly coriaceous near base; thorax moderately long; propodeum about as long as deep, with strong, parallel, dorsomedial carinae extending from base to apical 0.2 ; interval between propodeal carinae sulcate and more or less rugose; propodeum on sides coarsely, and dorsally in region of apices of dorsal carinae more finely, rugose; legs stout; front femur simple; front tibia almost straight; segment 5 of tarsus distinctly swollen, but much less strongly so than in female; abdomen moderately stout; tergite 1 a little longer than wide, rather coarsely punctate, and rugose, except at base of median area; tergites 2 and 3 rather densely, deeply punctate, except on apices; tergite 4 with weaker, shallower punctures than tergite 3 ; tergites $5-7$ with very shallow, often indistinct punctures.

Black, often varying to more or less rufopiceous or reddish. Clypeus rufopiceous; more or less of scape beneath and pedicel entirely beneatb, yellowish varying to pale reddish; flagellum yellowish to

Figure 2.-Localities for Scambus (Endromopoda) rubescens.

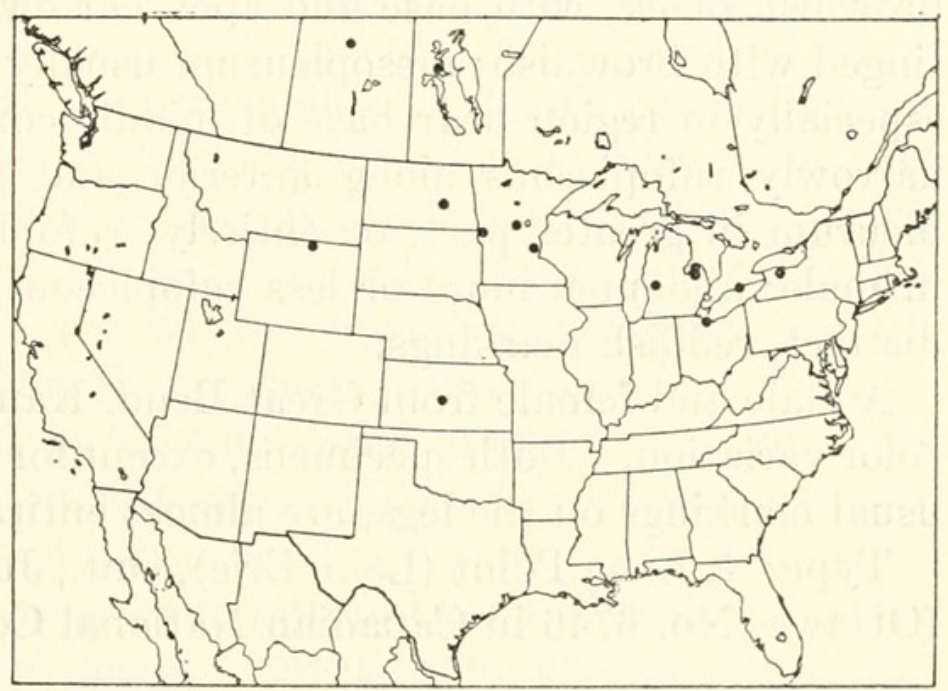


pale reddish beneath, and sometimes entirely reddish at apex; palpi pale yellowish; hind angle of pronotum yellowish; tegula pale yellowish; metapleurum varying from black to mostly dark reddish; abdominal tergites usually with bases and apices more or less rufopiceous; legs mostly reddish; apex of front coxa and all trochanters often pale yellowish; hind tibia with a broad, median, whitish annulus, and with narrow subbasal and broader apical fuscous annuli, the latter reddish beneath; hind tarsus reddish brown to dark brown, with segments 1-3 broadly yellowish at bases.

Female: Front wing 6.0 to $8.0 \mathrm{~mm}$. long; antenna with 25 to 28 segments; cheek about 0.33 breadth of mandible at base; mandible weakly coriaceous on basal 0.5 ; temple, as seen from above, weakly rounded on anterior 0.5 and strongly rounded behind; thorax moderately stout; propodeum as in male; legs stout; hind femur 3.5 times as long as deep; segment 5 of tarsus very strongly swollen; claws very large and stout; abdomen rather stout; tergite 1 about as long as wide, with sides and central region beyond basal declivity more or less granular and with scattered punctures; tergite 2 distinctly wider than long, and deeply, rather densely punctate except on apex; tergite 3 shorter and broader, but otherwise as in tergite 2 ; tergites 4 and 5 with punctures indistinct except in basal region; tergites 6 and 7 with very shallow, indistinct punctures; sternites large and broad, with coarse, aciculate punctures; subgenital plate with a rather small, basal, membranous excision; sheath about 0.4 times as long as abdomen.

Black, often varying to rufopiceous or reddish, especially on face, lower part of head, side of thorax, propodeum, and abdomen. Scape reddish to reddish brown beneath; pedicel more or less yellowish beneath; flagellum yellowish brown to reddish brown beneath, becoming entirely reddish at apex; clypeus, more or less of mandible, and sometimes cheek, rufopiceous varying to dark reddish; palpi brownish; tegula and hind angle of pronotum pale yellowish; stigma brownish black, with base and apex narrowly sordid yellowish; wing tinged with brownish; mesopleurum usually more or less rufopiceous, especially in region near base of middle coxa, a id sometimes rather narrowly rufopiceous along anterior and posterior margins; metapleurum in greater part, or entirely, rufopiceous or reddish; legs as in male; abdomen more or less rufopiceous, tergites sometimes with distinct, reddish markings.

A male and female from Great Bend, Kansas, represent an extreme color variation. Both specimens, except for the blackish head and the usual markings on the legs, are almost entirely red.

Type: + , Long Point (Lake Erie), Ont., June 21, 1939, G. S. Walley (Ottawa, No. 6746 in Canadian National Collection.) 
Paratypes: $\sigma^{x}, 2 \odot$, same data as type (Ottawa); $\sigma^{x}, ~ \circ$, Great Bend, Kans., June 5, 1939, R. H. Beamer (Lawrence). $\sigma^{7}$, ㅇ, Cedar Lake, Man., July 1936, Brues (Cambridge). $3 \sigma^{\top}$, Huron Co., Mich., June 9, 1951, R. R. Dreisbach (Dreisbach). +, Kent Co., Mich., June 9, 1949 (Dreisbach). 3오, Sand Point, Huron Co., Mich., June 25, 1922, R. F. Hussey (Dreisbach). 5o, Tuscola Co., Mich., June 9, 1951 (3 specimens), June 22, 1952, and July 9, 1950, R. R. Dreisbach (Dreisbach). $\sigma^{\pi}$, Cushing, Minn., June 24, 1940, H. Pratt and C. Pedersen (St. Paul). , Lake Calhoun, Hennepin Co., Minn., June 12, 1921, W. E. Hoffman (St. Paul). o, Traverse Co., Minn., O. W. Oestlund (St. Paul). + , Bergen Swamp, Genesee Co., N. Y., June 28, 1952, L. L. Pechuman (Townes). 2o, Tokio, N. Dak., July 28, 1937, H. T. Peters (Lawrence). , Sandusky, Ohio, Sept. 1, 1929, A. L. Melander (Cambridge). ㅇ, Prince Albert National Park, Sask., July 20, 1951, J. G. Rempel (Townes). क, mountains near Sheridan, Wyo., Metz (New York).

Host: Unknown.

\section{Scambus (Endromopoda) detritus (Holmgren)}

Figures $310, \mathrm{c} ; 311, \mathrm{~b} ; 320, \mathrm{c}$

Pimpla detrita Holmgren, 1860, Svenska Vetensk.-Akad. Handl., ser. 4, vol. 3, pt. 2, No. 10, p. 23. Types: $\sigma^{\top}$, $\uparrow$, Sweden (Stockholm).

Pimpla detrita Holmgren, Salt, 1931, Bull. Ent. Res., vol. 22, pt. 4, p. 519.

Brology: Holmes, 1953, Canadian Ent., vol. 85, p. 339.

Male: Front wing 4.0 to $6.0 \mathrm{~mm}$. long; antenna with 20 to 25 segments; cheek about 0.3 times breadth of mandible at base; mandible coriaceous on basal 0.5 ; thorax moderately elongate; propodeum about as long as deep, with rather strong, narrowly separated, subparallel, dorsomedial carinae that extend from base to apical 0.20 of propodeum; front femur with a broad, rather shallow excision beneath; abdomen slender; tergite 1 much longer than wide.

Black. Pedicel yellowish beneath; flagellum brownish to blackish above and yellowish to pale brownish beneath; palpi pale yellowish; hind angle of pronotum very narrowly yellowish; tegula pale yellowish; stigma dark brown, with a sordid yellowish spot at base; wing distinctly tinged with brownish; legs largely reddish, with coxae varying from reddish with fuscous bases to entirely blackish; trochanters yellowish to pale reddish; and hind tibia broadly yellowish to reddish yellow at middle, with subbasal and apical fuscous annuli.

Female: Front wing 4.3 to $8.0 \mathrm{~mm}$. long; antenna with 20 to 24 segments; cheek about 0.33 breadth of mandible at base; temple rather broad; thorax moderately stout; propodeum moderately long, with distinct, dorsomedial carinae extending from base to apical 0.33 ; sides of propodeum punctate and rugose, dorsal region smooth except for 


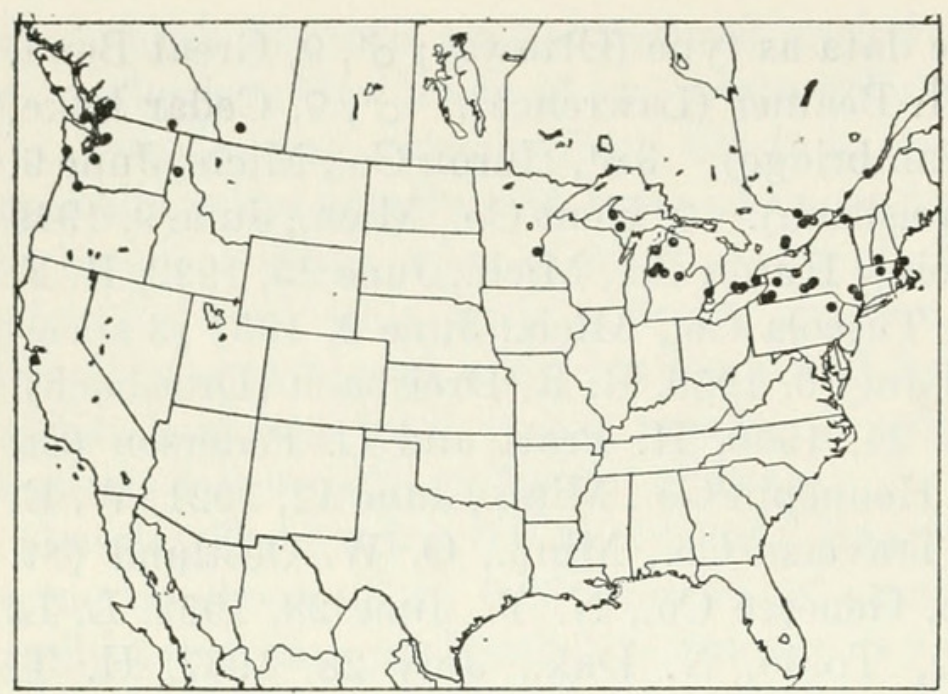

Figure 3.-Localities for Scambus (Endromopoda) detritus.

sparse, fine punctures; legs stout; abdomen stout, with tergite 1 as wide as or a little wider than long, and with its sides punctate and more or less rugose, and the apex of the central area finely, rather densely punctate; tergites 2-4 with numerous, rather unevenly distributed, distinct punctures, except on apices; tergite 5 with punctures rather shallow and indistinct except at base; tergites 6 and 7 with very shallow, indistinct punctures; sternites large and broad, with coarse, aciculate punctures; subgenital plate with a small, shallow, basal, membranous excision; sheath about 0.4 times as long as abdomen.

Black. Pedicel yellowish to reddish beneath; flagellum pale reddish beneath, with apex sometimes entirely reddish; clypeus piceous; palpi yellowish brown to fuscous; tegula pale yellowish; hind angle of pronotum narrowly pale testaceous; stigma brownish black, with base and apex narrowly sordid yellowish; wing tinged with brownish; legs mostly reddish, with front coxa often more or less fuscous at base; hind tibia without contrasting markings, sometimes almost uniformly reddish, but more often with indistinct, brownish to fuscous subbasal and apical bands, and with the central region broadly dull reddish yellow above, becoming pale reddish beneath; hind tarsus reddish, with basal two or three segments broadly yellowish at bases.

Specimens (32 $\sigma^{7}, 74$ ): From Alberta (Lethbridge); British Columbia (Agassiz, Cultus Lake, Milner, Robson, and Royal Oak); California (San Mateo); Idaho (Chatcolet Lake); Massachusetts (Beach Bluff, Gloucester, Holliston, Petersham, "Westhome," and Woods Hole); Michigan (Baraga Co., Cheboygan Co., Dickinson Co., Leelanau Co., Macomb Co., Manistee Co., Midland Co., Osceola Co., and Wexford Co.); Minnesota (Brooklyn Center in Anoka Co.); New Brunswick (Moncton); New Hampshire (Jaffrey); New York (Bemus Point, Darien, Ithaca, Joy, Labrador Lake in Cortland Co., McLean Bogs in Tompkins Co., Poughkeepsie, Randolph, and 
Shokan); Nova Scotia (Grand Pré); Ontario (Carp, Chatterton, Ingersoll, Marmora, Ottawa, Simcoe, South March, and Vineland Station); Oregon (Portland); Pennsylvania (Spring Brook); Quebec (Cap Rouge, Hemmingford, and Norway Bay); Washington (Ashford, Bellingham, Bothell, Index, San Juan Island, Seattle, Wiser Lake in Whatcom Co., and Westport).

The species has been taken in numbers from May until August, the largest number of captures being in July. Especially early and late records include April 17 and 20 at Bellingham and Seattle, Wash., respectively, and October 2 and 3, at Lethbridge, Alta., and San Mateo, Calif., respectively.

Hosts: Salt (1931) gives a comprehensive account of the species as a parasite of Cephus pygmaeus (Linnaeus) in England, and Holmes (1953) records it from Cephus cinctus Norton, from Lethbridge, Alta. Reared material at hand includes two females reared from Cephus pygmaeus, at Joy, N. Y., Aug. 28, 1924, and Darien, N. Y., Aug. 29, 1924; a male and female reared from wheat stems at Chatterton, Ont., July 30, 1953, by C. C. Loan; and a female reared from an oat stem at Grand Pré, N. S., July 26, 1957.

The species, which is also Palearetic, has a transcontinental distribution in the Transition zone in North America.

\section{Scambus (Endromopoda) productus Walley, new species}

Figures $311, \mathrm{c} ; 320, \mathrm{~d}$

Male: Front wing about $3.5 \mathrm{~mm}$. long; antenna with 22 segments; cheek about 0.25 times breadth of mandible at base; thorax elongate, the mesoscutum broadly flattened; propodeum a little longer than deep, with strong dorsomedial carinae that extend from base to apical 0.2 ; front femur with a broad, very shallow excision beneath; abdomen very slender; tergite 1 twice as long as wide.

Black. Scape and pedicel pale yellowish beneath; flagellum brownish to blackish above and yellowish to pale brownish beneath; palpi, tegula, and hind angle of pronotum, pale yellowish; stigma blackish, with small yellowish spot at base; legs reddish, with front coxa, middle coxa except at base, trochanters, and sometimes middle femur beneath, pale yellowish; front and middle tibiae and tarsi pale reddish to mostly yellowish; hind tibia broadly whitish at middle, with fuscous subbasal and apical annuli; hind tarsus with base of segment 1 broadly pale yellowish, the apex and remaining segments mostly rather pale brownish.

Female: Front wing 4.5 to $6.0 \mathrm{~mm}$. long; antenna with 21 to 23 segments; cheek about 0.30 breadth of mandible at base; temple rather broad, and only slightly receding for some distance behind 
eye; thorax and propodeum elongate, subcylindrical, the mesocutum rather broadly flattened; propodeum with dorsomedial carinae distinct, and extending from base to apical 0.25 ; dorsal surface of propodeum very finely rugulose in region of apices of dorsal carinae, and elsewhere with widely separated, large, shallow or suberased punctures; sides of propodeum with numerous, shallow, elongate punctures; legs stout, hind femur about 3.53 times as long as deep; abdomen slender; tergite 1 slightly longer than wide, with sides finely granular and with only a few, shallow punctures, the apex of central area more densely punctate; remaining tergites, except on apices, with numerous, unevenly distributed, rather large, distinct punctures; subgenital plate with a rather deep, narrow, membranous excision; sheath about 0.4 times as long as abdomen.

Black. Pedicel more or less brownish to yellowish brown beneath; flagellum yellowish to pale brownish beneath, especially at base, and often more or less brown at apex; palpi fuscous; tegula and small spot in hind angle of pronotum pale yellowish; legs reddish, with front coxa usually more or less fuscous at base; hind tibia with distinct, fuscous subbasal and apical annuli, and with a broad, median, whitish annulus that is interrupted beneath by a reddish stripe extending between the fuscous annuli; hind tarsus with apices of basal two segments, and the remaining segments largely or entirely, reddish brown.

Type: ㅇ, Norman Wells, N. W. T., July 23, 1949, W. R. M. Mason (Ottawa, No. 6747 in Canadian National Collection).

Paratypes $\left(18 \sigma^{x}, 46 \circ\right.$, including $9 \sigma^{\top}, 6$ 우 from type locality): From Alaska (Big Delta, Birch Lake near Fairbanks, Fairbanks, King Salmon on Naknek River, Nome, and Shaw Creek at Mile 289 on Richardson Highway); Alberta (Banff); British Columbia (Jesmond and Saanich); California (Hat Creek in Shasta Co., Mammoth Lake, near Sonora Pass at 8,000 ft., and Willits); Colorado (Estes Park, Glen Haven, and Steamboat Springs); Idaho (Bear Pass Creek in Butte Co.); Massachusetts (Holliston); Michigan (Clare Co., Delta Co., Huron Co., and Livingston Co.) ; Northwest Territories (Norman Wells); Nova Scotia (Queens Co.); Ontario (Blackburn and Jockvale); Oregon (Cannon Beach and Meacham); Quebec (Lac Mercier, Nominingue, and Parke Reserve in Kamouraska Co.); Rhode Island (Westerly); Saskatchewan (Prince Albert National Park); Utah (Logan Canyon); and Yukon Territory (Canyon Creek and Snag). Paratypes are deposited in the following collections: Berkeley, Cambridge, Davis, Dreisbach, Lawrence, Ottawa, St. Paul, and Townes.

Collection dates are from May 15 at Jockvale, Ont., to August 26 at Parke Reserve in Kamouraska Co., Que.

Host: Unknown. 

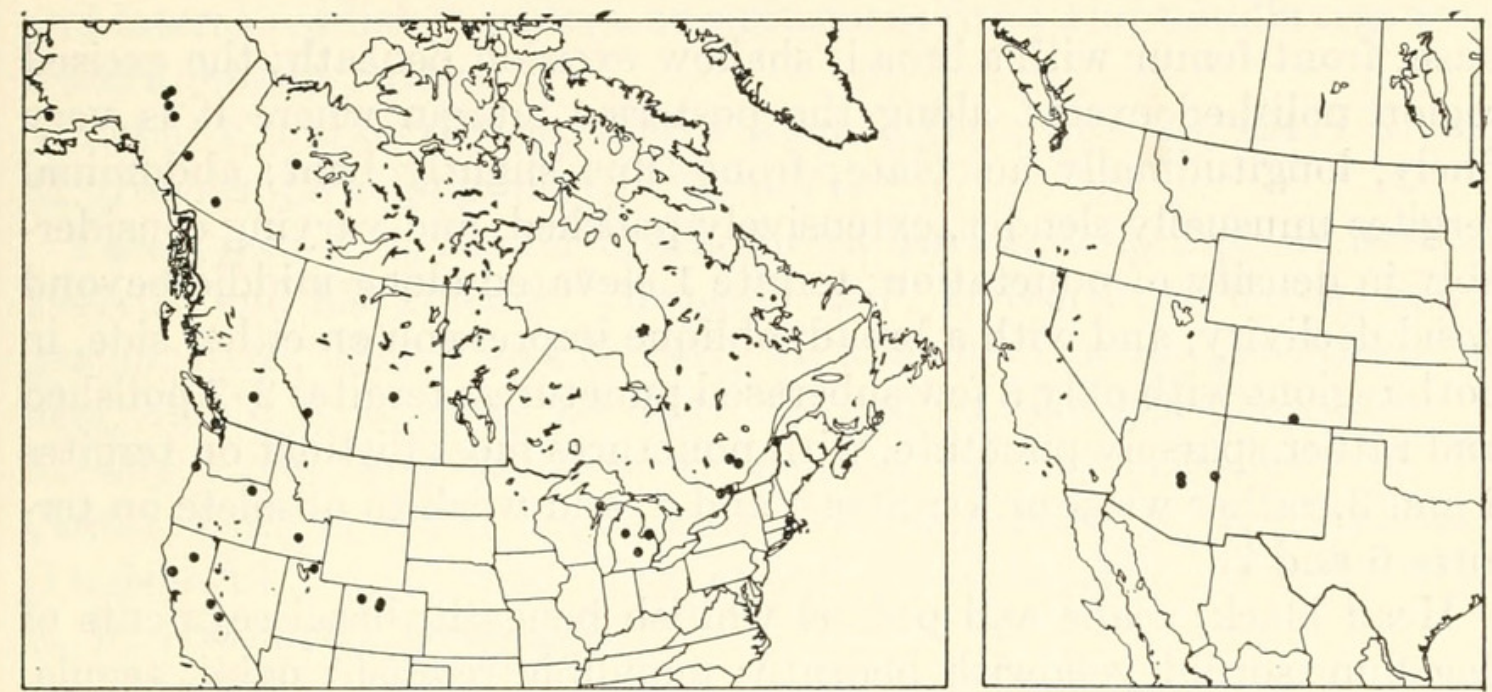

Figures 4, 5.-Localities: 4 (left), Scambus (Endromopoda) productus; 5 (right), S. (Lissoscambus) arizonensis.

\section{Lissoscambus Walley, new subgenus}

Type: Scambus (Lissoscambus) arizonensis, new species.

Submetapleural carina absent; propodeum rather long, unusually smooth and evenly convex, and without dorsomedial carinae; first tergite with median carinae not extending beyond apex of basal declivity (the latter opposite spiracle); tergites 2-6 unusually uneven, especially in female, and with coarse, very unevenly distributed punctures (crowded along subbasal impression, mostly lacking on median callosities, and elsewhere sparse and usually separated by intervals equal to two or three times the diameter of a puncture), except on the polished apical margins; subgenital plate of female with a very large, median, basal, membranous excision; ovipositor as in subgenus Ateleophadnus; male genitalia unusually small. Thorax red with blackish markings; propodeum and abdomen often more or less red.

This subgenus is known only from southwestern United States and Mexico. In addition to the type species described below, it contains Pimpla crassicauda Cresson 1874, and two undescribed Mexican species.

\section{Scambus (Lissoscambus) arizonensis Walley, new species}

Figure $311, \mathrm{~d}$

Male: Front wing 5.0 to $7.0 \mathrm{~mm}$. long; antenna with 26 to $28 \mathrm{seg}-$ ments; cheek about 0.24 times breadth of mandible at base; temple rather narrow and strongly receding; head, thorax, and propodeum with only weak traces of shallow punctures; propodeum moderately long, sometimes with a short, shallow, median, longitudinal sulcus at 
base; front femur with a broad, shallow excision beneath; the excised region polished except along the posterior margin where it is very finely, longitudinally aciculate; front tibia slightly bent; abdominal tergites unusually slender, extensively polished, and varying considerably in density of punctation; tergite 1 elevated along middle beyond basal declivity, and with a broad, oblique impression on either side, in both regions with only a few suberased punctures; tergites 2-7 polished and rather sparsely punctate, with punctures most distinct on tergites 2 and 3 , rather weak on tergites 4 and 5 , and weak to obsolete on tergites 6 and 7 .

Head black; scape and pedicel whitish beneath; basal segments of flagellum sordid yellowish beneath; mandible reddish; palpi, tegula, stripe on upper margin of pronotum extending from hind corner to a point opposite origin of notaulus, and a narrow line on mesepimeron, whitish; thorax red with conspicuous black markings, the latter principally as follows-prothorax except narrow submarginal stripe above, spot at middle of mesoscutum, small spot immediately in front of scutellum, postnotum except at middle, large spot in upper posterior corner of mesepisternum, most of prepectus, metapleurum in region above level of propodeal spiracle, metasternum, broad median longitudinal stripe on propodeum, and propodeum narrowly at base and apex; front and middle legs with coxae and trochanters very pale yellowish, femora pale reddish above varying to more or less pale yellowish on sides and beneath, and tibiae and tarsi pale yellowish more or less stained with pale reddish; hind coxa and femur except at apex, reddish; hind trochanters, tibia, and tarsus pale yellowish; apices of all tarsi fuscous; abdomen black to somewhat piceous.

Female: Front wing 8.0 to $8.5 \mathrm{~mm}$. long; antenna with 26 to 28 segments; cheek about 0.33 times breadth of mandible at base; thorax and propodeum closely resembling male; abdomen moderately stout; tergite 1 weakly convex, smooth and impunctate except for a very few, shallow or suberased punctures; tergites $2-5$ each with a pair of rather prominent, impunctate callosities and a broad, impunctate, apical margin; bases of tergites $2-6$ each with a distinct, densely punctate, transverse impression; tergite 7 rather indistinctly punctate; sheath about 0.55 times as long as abdomen.

Color as in male except as follows - scape pale yellowish at apex beneath; pedicel yellowish to yellowish brown beneath; flagellum pale brown beneath; black on prepectus extending behind prepectal carina as a small spot on mesepisternum; black on metasternum extending to include lower portions of metapleurum; propodeum black with a reddish stripe on either side along the rounded margin of the dorsal surface; abdomen with tergites varying from mostly black to mostly dull reddish, frequently several tergites black with subapical 
and lateral reddish markings or suffusions; front and middle legs with femora mostly reddish.

Type: ㅇ, Parker Creek, Sierra Ancha, Ariz., Apr. 20, 1947, H. and M. Townes (Washington, USNM 63743).

Paratypes: $0^{7}$, $\odot$, Parker Creek, Sierra Ancha, Ariz., Apr. 19 and 29, 1947, H. and M. Townes (Townes). $2 \sigma^{\top}$, o, Workman Creek, Sierra Ancha, Ariz., May 1 and 3, 1947, H. and M. Townes (Townes). ㅇ, near Alpine, Ariz., May 26, 1947, H. and M. Townes (Townes). क, Morley, Colo., Aug. 26, 1940, H. and M. Townes (Townes). ㅇ, W. Cortez Pass at 8,500 ft., Mexico, July 13, 1954, R. R. Dreisbach (Dreisbach). $\%$, Mexico City at 8,000 ft., Mexico, July 16, 1954, R. R. Dreisbach (Dreisbach).

Host: Unknown.

\section{Subgenus Ateleophadnus Cameron}

Ateleophadnus Cameron, 1905, Invert. Pacifica, vol. 1, p. 127.

Type: (Ateleophadnus bicarinata Cameron)=pterophori (Ashmead); monobasic.

Pseudopoemenia Kiss, 1924, Verh. Mitt. Siebenb. Ver. Naturw., vols. 72-74, p. 91.

Type: Pseudopoemenia annulata Kiss; monobasic.

Submetapleural carina present; propodeum rather long, with distinct, dorsomedial carinae on basal 0.66 ; first tergite with median carinae extending beyond apex of basal declivity (in male extending to apex of tergite); subgenital plate of female with a moderately large, median, basal, membranous excision; ovipositor (as in Lissoscambus) rather strongly compressed, with basalmost ridges on apex of lower valve forming an angle of about $40^{\circ}$ with its longitudinal axis and with most ridges developed dorsally into forward directed teeth; front femur of male with a distinct, broad, coriaceous excision beneath; front tibia of male distinctly (often strongly) bent near middle, and rather abruptly and sometimes strongly swollen beyond; male genitalia moderately large. Body black.

This subgenus is Holarctic. It contains three Nearctic species and the Palearctic annulata (Kiss), cincticarpus (Kriechbaumer), nigricans (Thomson), similis (Bridgman), and several undescribed species from the eastern Palearctic.

Keys to the Nearctic species of the subgenus Ateleophadnus

\section{MALES}

(Reliable characters have not been found for the separation of males of granulosus and deceptor.)

1. Front femur with a broad, deep excision beneath; front tibia strongly and angularly bent near middle, and abruptly and strongly swollen beyond the point of angulation; hind tibia rather indistinctly banded, the brownish subbasal and apical bands not sharply delimited by the intervening yellowish band.

1. pterophori (Ashmead) 
Front femur with a broad, rather shallow excision beneath; front tibia less strongly and more evenly bent at middle, and only moderately swollen beyond the middle; hind tibia with sharply defined blackish subbasal and apical bands separated by a broad, median, white band.

2. granulosus, new species 3. deceptor, new species

\section{FEMALES}

1. Hind tibia varying from uniformly reddish to reddish with very indistinct subbasal and apical fuscous bands . . . . . . 1. pterophori (Ashmead) Hind tibia with distinct black (or brownish-black) and white bands . . . 2

2. Upper valve of ovipositor in region beyond nodus slightly convex in lateral aspect (fig. 310,d); metapleurum usually smooth except for scattered punctures . . . . . . . . . . 2. granulosus, new species Upper valve of ovipositor in region beyond nodus flattened or slightly concave in lateral aspect (fig. 310,e); metapleurum usually more or less finely rugulose or somewhat granular on lower 0.5 . 3. deceptor, new species

\section{Scambus (Ateleophadnus) pterophori (Ashmead)}

Figures 311 ,e; 320,e

Pimpla pterelas of authors, not of Say.

Pimpla pterophori Ashmead, 1890, Proc. U. S. Nat. Mus., vol. 12, p. 445; .

Type: + , Los Angeles, Calif. (Washington).

Colpomeria litoralis Davis, 1898, Trans. Amer. Ent. Soc., vol. 24, p. 367; ð’.

Lectotype: $\sigma^{7}$, Michigan (Philadelphia); designated by Cresson, 1928.

Ateleophadnus bicarinata Cameron, 1903, Invert. Pacifica, vol. 1, p. 128; .

Type: $\uparrow$ (only tips of tarsi remaining), Ormsby County, Nev. (London).

Male: Front wing 3.0 to $6.5 \mathrm{~mm}$. long; antenna with 20 to 24 segments; cheek about 0.25 times breadth of mandible at base; thorax slightly elongate; propodeum moderately long, with dorsomedial carinae distinctly divergent posteriorly and extending to apical 0.2 of propodeum; front femur with a broad, deep, coriaceous excision beneath; front tibia strongly, angularly bent a little before middle, slender at base and strongly swollen beyond angulation; abdomen slender; claspers rather long and narrow.

Black. Pedicel and flagellum yellowish brown to pale brownish beneath; maxillary palpus pale yellowish; labial palpus fuscous; hind angle of pronotum sometimes with an inconspicuous yellowish brown spot; legs reddish, with front coxa often brownish to blackish except at apex; trochanters mostly yellowish; hind tibia indistinctly banded (broadly dull yellowish at middle, with fuscous or brownish subbasal and apical annuli); and hind tarsus brownish with segments paler at bases.

Female: Front wing 5.0 to $8.5 \mathrm{~mm}$. long; antenna with 20 to 25 segments; cheek about 0.38 times breadth of mandible at base; temple strongly rounded to occiput; thorax moderately stout; propodeum with dorsomedial carinae distinct and diverging posteriorly; sides and dorsal surface of propodeum with numerous, rather shallow punctures, 
Figure 6.-Localities for Scambus (Ateleophadnus) pterophori.

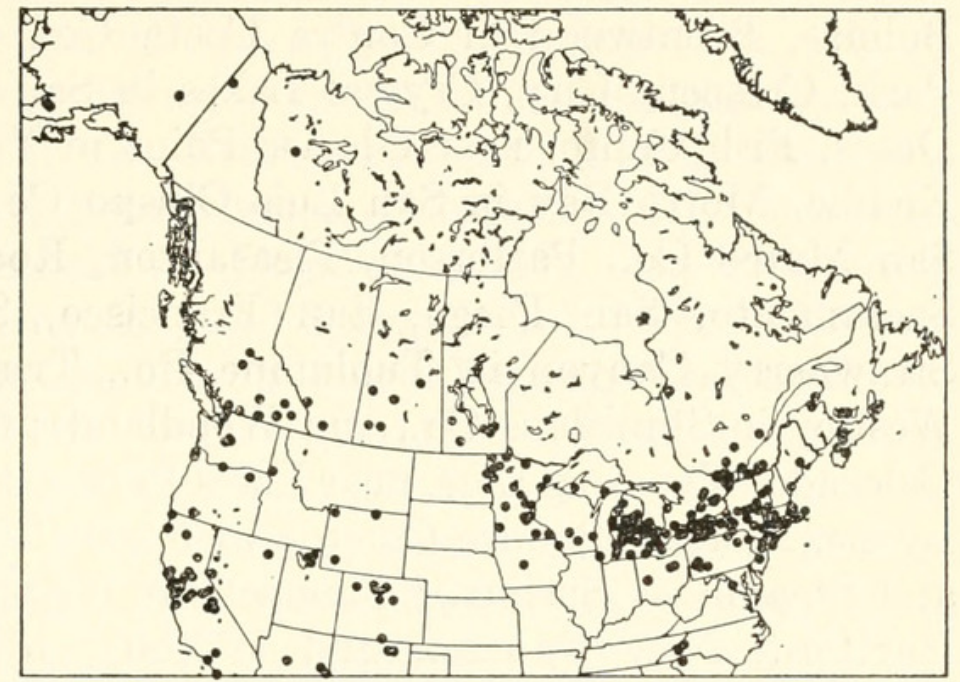

except between and beyond the median carinae; hind femur about 4.0 times as long as deep; abdomen rather stout; tergite 1 about as wide as long, with sides sparsely, and median area beyond the basal declivity rather densely, punctate; tergites $2-6$, except on apices, with numerous distinct punctures; tergite 7 rather smooth except for a few indistinct punctures; subgenital plate with a rather small, median basal, membranous excision; sheath about 0.7 times as long as abdomen.

Black, occasionally with abdominal tergites more or less piceous. Flagellum brownish beneath; clypeus piceous; palpi strongly fuscous; tegula pale yellowish; hind corner of pronotum narrowly pale yellowish brown; stigma blackish, with an obscure pale spot at base; legs rather uniformly reddish, with front coxa usually brownish or blackish basally, and hind tibia sometimes with obscure subbasal and apical infuscations.

This species is unusually variable in body proportions, specimens ranging from moderately slender to rather stout. There is some indication from reared material that the body shape may vary according to the host and its environment, slender specimens being associated with rather slender hosts living in slender stems, and stouter specimens with more stocky hosts living in fleshy structures such as seed pods. Careful breeding studies are greatly to be desired to obtain a better understanding of the nature of such variation.

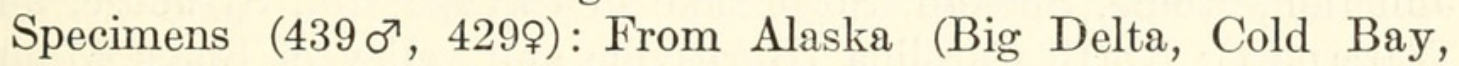
Haines, King Salmon on Naknek River, Makushin Bay on Unalaska Island, and Naknek); Alberta (Banff and Lethbridge); Arizona (near Alpine, Oak Creek Canyon, and White Mountain Reserve east of McNary); British Columbia (Agassiz, Downie Creek in Selkirk Mountains, Hatzic Lake, Kelowna, Likely, Manning Park, Oliver, Revelstoke in Selkirk Mountains, Robson, and Williams Lake); California (Alameda, Albany, Antioch, Barton Flat, Benecia, Berkeley, 
Bolinas, Brentwood in Contra Costa Co., Crane Flat in Yosemite Park, Crescent City, Crystal Lakes in San Mateo Co., Dardanelle, Davis, Fish Camp, near Glacier Point in Yosemite Park, Inverness, Keddie, Morro Bay in San Luis Obispo Co., Oakland, Palo Alto in San Mateo Co., Patterson, Pleasanton, Rock Creek in Shasta Co., Sacramento, San Diego, San Francisco, San Mateo, Sebastopol, Strawberry Canyon in Tuolumne Co., Trinidad in Humboldt Co., Westley in Stanislaus Co., and Woodland); Colorado (Cameron Pass, Colorado-Wyoming Line, near Estes Park, Glen Haven, Idaho Springs, Lyons, Morley, Poudre Canyon at 5,200 ft. in Larimer Co., Roggen, and Steamboat Springs); Connecticut (Canterbury, Colebrook, East Hartford, New Canaan, and Wilton); Idaho (Lewiston); Illinois (Chicago); Iowa (Ames); Maine (Kennebunkport, and Orono); Manitoba (Awemo, Riding Mountain National Park, Shoal Lake, Victoria Beach, and Winnipeg); Massachusetts (Boston, Cummington, Forest Hill, Holliston, Horseneck Beach at Westport, Melrose, South Hadley, South Yarmouth, Truro, Tyngsboro, and Woods Hole); Michigan (Alto, Bay City, Benton Harbor, Branch Co., Charlevoix Co., Clare Co., Delta Co., East Lansing, Genesee Co., Gladwin Co., Gogebic Co., Grand Rapids, Grand Traverse Co., Gratiot Co., Huron Co., Isabella Co., Lapeer Co., Macomb Co., Manistee Co., Marquette Co., Mason Co., Mecosta Co., Midland Co., Montcalm Co., Monroe Co., Muskegon Co., Ogemaw Co., Saginaw Co., St. Clair Co., Tuscola Co., Van Buren Co., and Wayne Co.); Minnesota (Badger, Big Stone Co., Cass Co., Crookston, Duluth, Fillmore Co., Garrison, Gray Cloud Islands, Houston Co., Kanabec Co., Koochiching Co., Lancaster in Kittson Co., Lincoln Co., Mille Lacs Co., Minneapolis, Norman Co., Plummer, Preston in Fillmore Co., St. Anthony Park, St. Paul, Sedan, Two Harbors, Viking, and "Washington Co."); Nevada (Deeth); New Brunswick (Jacquet River); New Jersey (Bergen Co., Moorestown, and Morristown); New Mexico (Cimarron and Cimarron Canyon in Colfax Co.); New York (Bemus Point, Buffalo, Canajoharie, Chafee, Clifton Springs, Elmira, Farmingdale, Fredonia, Greene Co., Hamlin, Honeoye Falls, Ithaca, Johnsonville, Lancaster, Lockport, Long Island, Ludlowville, McLean Reserve in Tompkins Co., Niskayuna, Oneonta, Pelham, Perry, Poughkeepsie, Randolph, Rochester Junction, Rome, Shokan, Springlake in Cayuga Co., Syracuse, and Waterport); North Carolina (Burnsville and valley of Black Mountains); North Dakota (Fargo and Trail Co.); Northwest Territories (Norman Wells); Nova Scotia (Baddeck, Kings Co., Parrsboro, Petite Rivière, and Round Hill); Ohio (Akron, Barberton, and Logan Co.); Ontario (Beamsville, Belleville, Bells Corners, Blackburn, Bowmanville, Britannia, Constance Bay, Eldorado in Hastings Co., Grimsby, Ingersoll, Jordan, Leamington, Marmora, Merivale, Niagara 
Glen, Niagara-on-the-Lake, Normandale, Ottawa, Point Pelee, Rockcliffe, St. Davids, Simcoe, Southampton, South Gloucester, Strathroy, Toronto, Trenton, Turkey Point, Ventnor, Vineland Station, and Waubamik); Oregon (Cannon Beach, Klamath Falls, Meacham, Seaside, and The Dalles); Pennsylvania (Allegheny Co., Coraopolis, Ingram, Jeannette, Mansfield in Tioga Co., Pike Co., Pittsburgh, Sample Station in Allegheny Co., and Spring Brook); Prince Edward Island (Brackley Beach in Canadian National Park and Dalvay House in Canadian National Park); Quebec (Aylmer, Brome, Cascapedia, Gracefield, Hemmingford, Ile de Montreal, Knowlton, Lac Mercier, New Richmond, Norway Bay, Rupert House, Stoneham, Sutton, and Wakefield); Rhode Island (Westerly); Saskatchewan (Great Sand Hills west of Swift Current, Rutland, Saskatoon, Swift Current, and White Fox); South Carolina (near Tigerville); Utah (Newton, Ogden, and Wellsville); Vermont (Laurel Lake near Jacksonville and Woodstock); Virginia (Falls Church); Washington (Ashford, Bellingham, Elbe, Marietta, and Mount Rainier at 4,200 and 5,000 ft.); Wisconsin (Gays Mills, Madison, Milwaukee, and Sauk Co.); Wyoming (Bitter Creek in Sweetwater Co., Firehole River in Yellowstone Park, and Sheridan); and Yukon Territory (Rampart House).

Hosts: This species is a common parasite of lepidopterous borers in the stems of herbaceous plants. Material at hand includes rearings from Epiblema strenuana (Walker), E. otiosana (Clemens) and Mompha eloisella (Clemens) in southern Ontario, and from a lepidopterous borer and the weevil Mononychus vulpeculus (Fabricius) in Iris seeds, in the vicinity of Ottawa, Ontario.

This is one of the commonest species in the genus. It has a transcontinental range in the Canadian and Transition zones. In the west it extends northward in the Hudsonian zone and southward in the Sonoran faunal area. Adults are on the wing from early spring to late autumn.

\section{Scambus (Ateleophadnus) granulosus Walley, new species}

Figures $310, \mathrm{~d} ; 311, \mathrm{f} ; 320, \mathrm{f}$

Male: Front femur with a broad, rather shallow, coriaceous excision beneath; front tibia moderately bent at middle and only moderately swollen beyond middle; clasper rather stout; structures in other respects as in pterophori.

Color as in pterophori, except as follows: labial palpus and hind angle of pronotum usually pale yellowish; hind tibia with sharply contrasting blackish (or brownish black) and white annuli.

Female: Structure as in pterophori; color as in pterophori, except as noted in key. 
Type: ㅇ, Leamington, Ont., May 31, 1937, G. S. Walley (Ottawa, No. 6748 in Canadian National Collection).

Paratypes: (In Canadian National Collection): $\sigma^{\top}$, McMurray, Alta., Aug. 8, 1953, G. E. Ball. ㅇ, Cultus Lake, B. C., July 1, 1948, H. R. Foxlee. \&, Lake Errock near Deroche, B. C., July 3, 1953, W. R. M. Mason. 2o, Robson, B. C., July 8 and Sept. 29, 1947, H. R. Foxlee. ㅇ, Robson, B. C., May 31, 1950, H. R. Foxlee. \%, Ruskin, B. C., June 26, 1953, W. R. M. Mason. 2o, Cummington, Mass., Aug. 22-27, 1947, Howard E. Evans. \&, Chamcook, N. B., June 24, 1938, T. N. Freeman. \&, Fredericton, N. B. \&, Jacquet River, N. B., July 7, 1940, G. S. Walley. ㅇ, Ithaca, N. Y., May 28, 1941, Howard E. Evans. $\sigma^{7}$, 2o, Ithaca, N. Y., June 3, 5, and 11, 1947, W. Mason. $6 \sigma^{\top}, 2$, Ithaca, N. Y., July 2 and Aug. 17, 1947, May 26, 1948, and May 8, 1949. $2 \sigma^{x}$, o, Norman Wells, N. W. T., June 27, July 9 and 10, 1949, W. R. M. Mason. ㅇ, Bridgewater, N. S., Aug. 25, 1936, T. N. Freeman. ত', Petite Rivière, N. S., Aug. 13, 1936, T. N. Freeman. क्, White Point Beach, Queens Co., N. S., Aug. 25, 1936, J. McDunnough. $\sigma^{7}$, Gananoque, Ont., July 9, 1941, G. S. Walley. $\odot$, Mer Bleue, near Ottawa, Ont., July 18, 1933, G. S. Walley. $\sigma^{7}$, Miners Bay, Ont., May 24, 1931, G. S. Walley. ণ,

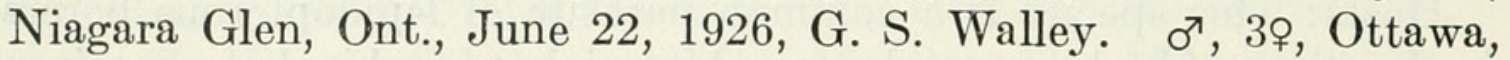
Ont., June 10, 1942, May 29, June 19, and July 17, 1946, G. S. Wolley. , St. Davids, Ont., May 26, 1933, G. C. Dustan. \&, South Gloucester, Ont., May 17, 1933, C. H. Young. \&, Beechgrove, Que., July 22, 1952, F. E. Bowes. $\sigma^{x}$, Fairy Lake, Que., June 1, 1927, G. S. Walley. \&, Georgeville, Que., June 24, 1936, G. S. Walley. ఠ’, Lac Mercier, Que., Aug. 17, 1937, G. S. Walley. ๆ, Wright, Que., June 11, 1926, G. S. Walley.

(In Townes collection): ণ, Edmonton, Alta., Aug. 29, 1948, E. H. Strickland. \&, Camino, Calif., June 27, 1948, Townes family. \&, Crescent City, Calif., Aug 4, 1940, H. and M. Townes. o, near

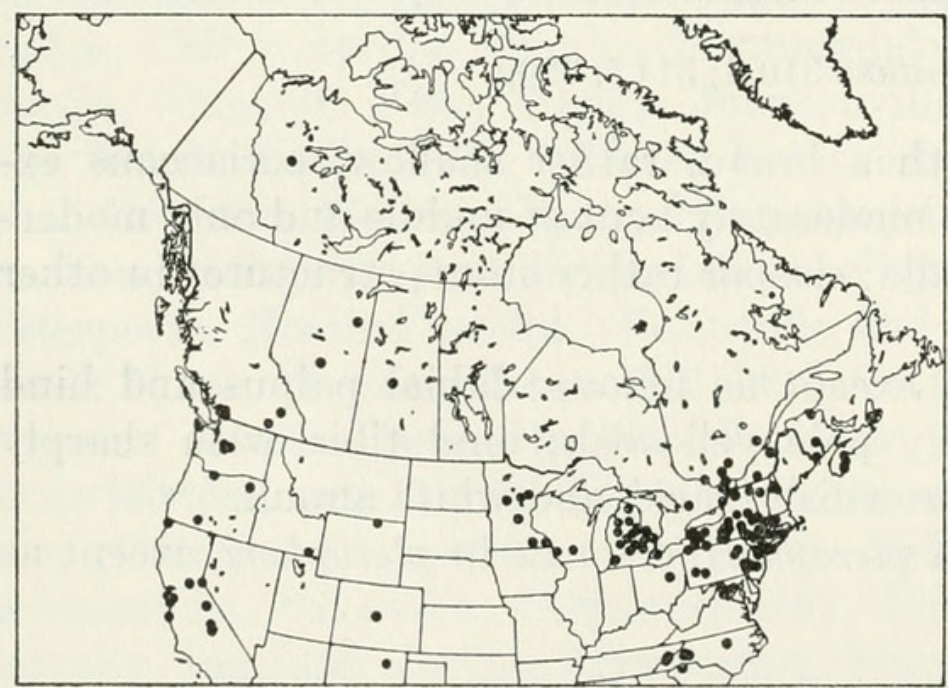

Figure 7.-Localities for Scambus (Ateleophadnus) granulosus. 
Glacier Point, Yosemite Park, Calif., July 18, 1948, Townes family. \%, Takoma Park, Md., June 22, 1944, H. and M. Townes. $\sigma^{7}$, ㅇ, Takoma Park, Md., May 24, 1942, and July 16, 1943, H. and M. Townes. $80^{x}$, So. Hadley, Mass., May 16-29, 1937, M. Chapman. 2\%, Mount Madison, N. H., June 23 and 24, 1938, H. and M. Townes. $2 \sigma^{\top}, 4$ 옹 Pinkham Notch, N. H., June 25, 1938, H. and M. Townes. $\sigma^{7}$, Randolph, N. H., Aug. 22, 1951, H., M., and D. Townes. $2 \sigma^{7}$, 2ᄋ, Moorestown, N. J., June 24 and Aug. 7, 1939, H. and M. Townes. $\sigma^{7}, 2$, , Bemus Point, N. Y., June 13 and Aug. 29, 1937, H. K. Townes. $\sigma^{7}$, Canajoharie, N. Y., Aug. 4, 1934, H. K. Townes. \&, Corning, N. Y., Aug. 3, 1937, H. K. Townes. क, Downsville, N. Y., Aug. 5, 1935, H. K. Townes. क, Elmira, N. Y., Aug. 4, 1937, H. K. Townes. $4 \sigma^{7}$, Farmingdale, N. Y., July 2 and 3, 1938, H. and M. Townes. $30^{7}, 3$, Ithaca, N. Y., May 20, 29, and 31, 1934, May 22 and July 24, 1936. $\sigma^{\top}$, ㅇ, Ithaca, N. Y., May 17 and July 12, 1936, P. P. Babiy. ᄋ, Ithaca, N. Y., Aug. 24, 1937, J. G. Franclemont. $\odot$, Ithaca, N. Y., May 27, 1936, W. Middlekauff. $17 \sigma^{7}$, 7\%, Ithaca, N. Y., June 1 and 6, and Sept. 7, 1935, May 17-31 and June 2, 1936, May 25, 1939, H. K. Townes. $\sigma^{7}$, Lake Mohonk, Ulster Co., N. Y., Aug. 1, 1936, H. K. Townes. $2 \sigma^{7}$, McLean Reserve, Tompkins Co., N. Y., May 29, 1937, H. K. Townes. , North Hoosick, N. Y., Sept. 4, 1934, H. K. Townes. $\sigma^{7}$, Oneonta, N. Y., Aug. 31, 1935, H. K. Townes. $4 \sigma^{x}$, 7ᄋ, Poughkeepsie, N. Y., June 29, and Sept. 1, 1936, H. K. Townes. $\sigma^{7}$, Rome, N. Y., June 24, 1934, H. K. Townes. $\sigma^{\Upsilon 7}$, 2ᄋ, Shokan, N. Y., July 9-11, 1936, H. K. Townes. $\sigma^{7}$, Slaterville, N. Y., July 11, 1936. $6 \sigma^{\top}, 5$, Syracuse, N. Y., May 8 and June 3, 1938, H. and M.

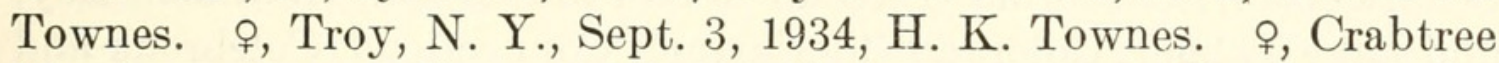
Meadows, Yancey Co., 3,600 ft., N. C., Aug. 22, 1950, Townes family. $\sigma^{\top}$, Hamrick, N. C., Aug. 19, 1950, H., M., and D. Townes. Co., N. C., June 10, 1951, H. and M. Townes. $130^{7}$, 3ㅇ, Akron, Ohio, May 18, 1941, H. K. Townes. $\sigma^{7}$, Meacham, Oregon, Aug. 20, 1940, H. and M. Townes. $7 \sigma^{x}$,, , Philadelphia, Pa., May 11 and June 29, 1941, H. and M. Townes. $9 \sigma^{\top}, 10 \%$, Spring Brook, Pa., Aug. 13, 1944, and May 17, July 16, and Aug. 25, 1945, H. K. Townes. ๑, Valley Forge, Pa., Aug. 9, 1939, H. and M. Townes. \%, Stoneham, Que., June 21, 1938, H. and M. Townes. क, Valley Junction, Que., June 22, 1938, H. and M. Townes. $2 \sigma^{\top}$, Westerly, R. I., July 27 and

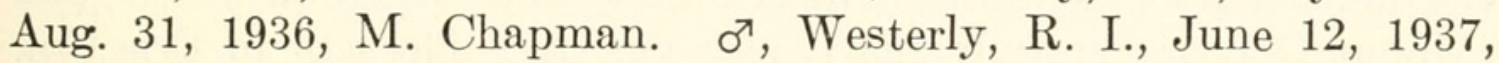
H. K. Townes and M. Chapman. क, Waskesiu, Sask., June 24, 1938, J. G. Rempel. $\sigma^{7}$, near Tigerville, S. C., May 8, 1944, H. and M. Townes. $7 \sigma^{7}, 3$, Ashford, Wash., Aug. 18, 1940, H. and M. Townes. $\sigma^{\top}$, ㅇ, Elbe, Wash., July 13, 1940, H. and M. Townes. $\sigma^{\top}$, Mount Rainier at 4,200 ft., Wash., Aug. 11, 1940. $3 \sigma^{7}, 2$, , Mount Rainier at 2,900, 4,700, 5,300, and 5,500 ft., Wash., July 11 and 23, and Aug. 
13, 14, and 16, 1940, H. and M. Townes. 29, Bolivar, W. Va., Sept. 22 and $24,1942, \mathrm{H}$. K. Townes.

(In other collections as noted below): 3\%, Carmel in Monterey Co., Calif., Mar. 23, 1919, E. P. Van Duzee (San Francisco). ㅇ, Giant Forest in Tulare Co., Calif., July 12, 1923, C. L. Fox (San Francisco). ᄋ, Mineralking in Tulare Co., Calif., July 12, 1935, G. E. Bohart (San Francisco). ㅇ, Sand dunes near San Francisco, Calif., June 25, 1922, C. L. Fox (San Francisco). \&, San Francisco, Calif., Mar. 25, 1926, M. C. Van Duzee (San Francisco). ㅇ, East Lansing, Mich., June 2, 1937, C. Sabrosky (East Lansing). , Grand Rapids, Minn., July 3, 1935, D. G. Denning (St. Paul). ণ , Hennepin Co., Minn., May 20 , 1922, A. A. Nichol (St. Paul). \&, Virginia, Minn., July 7, 1935, H. S. Telford (St. Paul). ค, Ramsey, N. J., Aug. 15, 1917, F. E. Lutz (New York). ㅇ, Flatbush, N. Y.. June 11, 1897, J. L. Zabriskie (New York). ᄋ, Lancaster, N. Y., Aug. 15, 1909, M. C. Van Duzee (San Francisco). ㅇ, North Fairhaven, N. Y., Sept. 3, 1918, S. H. Emerson (St. Paul). \%, Rock City, Cattaraugus Co., N. Y., June 9, 1915 (Ithaca). ㅇ, Baddeck, Cape Breton Island, N. S., July 6, 1928, G. Fairchild (Cambridge). ㅇ, Eagle Ridge, Klamath Lake, Oreg., June 16, 1924, C. L. Fox (San Francisco). क, Fairview, Luzerne Co., Pa., Aug. 1902, J. C. Bradley (Ithaca). o, Great Falls, Va., Sept. 24, N. Banks (Cambridge). $\quad$, Forks, Clallam Co., Wash., July 4, 1920, E. P. Van Duzee (San Francisco). , Madison, Wis., Oct. 2, 1953, L. K. Smith (Madison).

Additional specimens from: British Columbia (Downie Creek in Selkirk Mts.); California (Edgmar in San Mateo Co., Halfmoon Bay, and Lake Tahoe); Colorado (Florissant); Connecticut (Colebrook and Hartford); Idaho (Franklin); Massachusetts (Greenfield); Michigan (Arenac Co., Bay Co., Cheboygan Co., Genesee Co., Huron Co., Midland Co., Missaukee Co., Montcalm Co., Ogemaw Co., Osceola Co., Sanilac Co., Shiawassee Co., Tuscola Co., and Van Buren Co.); Minnesota (Fillmore Co., Houston Co., and Itasca Park); New Jersey (Morristown and Ramsey); New Mexico (Cimarron Canyon in Colfax Co.); North Carolina (Black Mts.); New York (Buffalo, Copake Falls, Ellis, Greene Co., New Russia in Essex Co., New Rochelle, Potsdam, Sea Cliff, Tonawanda Indian Reservation in Genesee Co., and Van Cortland Park); Ontario (Gravenhurst and Ridgeway); Oregon (Mount Hood); Pennsylvania (Gladwyn, Lake Pleasant in Erie Co., Pittsburgh, and Westmoreland Co.); Tennessee (Chimneys and Ramsey Cascades Trail, both in Great Smoky Mountains National Park); Vermont (Stowe); Virginia (Falls Church and Glencarlyn); Wisconsin (Gays Mills); and Wyoming (mountains near Sheridan).

Reliable characters have not been found for distinguishing between males of this species and deceptor. The majority of the males of 
granulosus have the lower side of the flagellum more distinctly yellowish than in deceptor, and in the latter the dorsomedial propodeal carinae tend to be more strongly and evenly divergent posteriorly, but there is sufficient variation in both characters as to leave the placing of a number of specimens in doubt.

Host: The species has been reared from Mompha eloisella (Clemens) at St. Davids and at South Gloucester, Ontario.

This species has a transcontinental distribution in the Canadian and Transition zones. The period of flight extends from May to October.

\section{Scambus (Ateleophadnus) deceptor Walley, new species}

Figures $310, \mathrm{e} ; 320, \mathrm{~g}$

Male: Agreeing with granulosus except as noted in the discussion under that species.

Female: Agreeing with granulosus except as noted in the key.

Differing from pterophori in the conspicuously annulate hind tibia, and in the shape of the apex of the upper valve of the ovipositor.

Type: ㅇ, Tweed, Ont., July 17, 1944, G. S. Walley (Ottawa, No. 6749 in Canadian National Collection).

FiguRe 8.--Localities for Scambus (Ateleophadnus) deceptor.

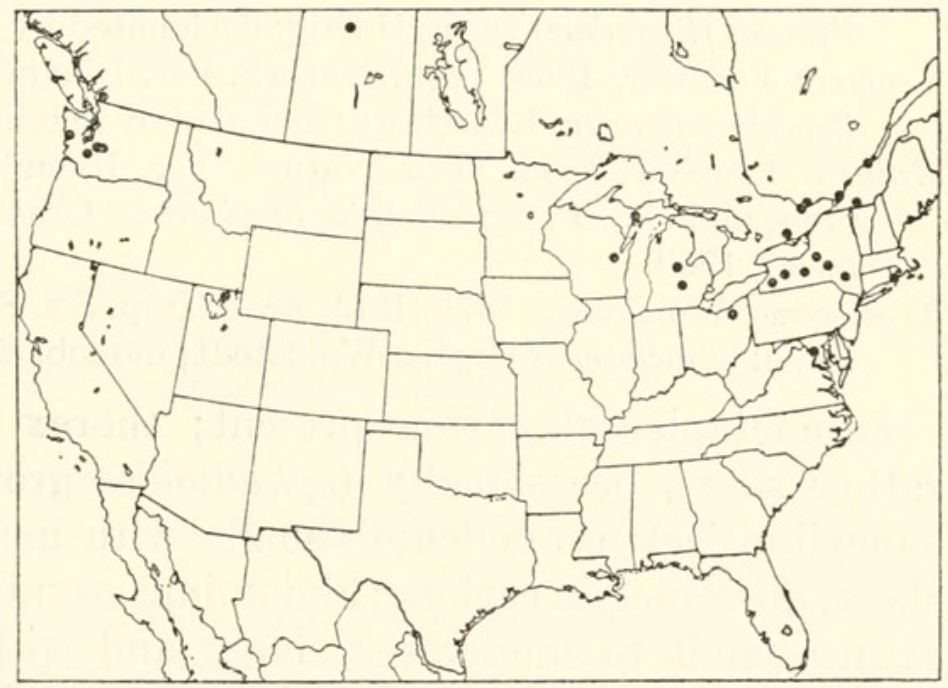

Paratypes: $\sigma^{7}$, Abbotsford, B. C., June 16, 1923, W. R. M. Mason (Ottawa). ' "Schnialls Ranch at 9,000 ft.," Colo., July 3, 1922 (New York). \&, Takoma Park, Md., June 17, 1942, H. and M. Townes (Townes). + , Delta Co., Mich., July 4, 1947, R. R. Dreisbach (Dreisbach). \&, George Reserve, Livingston Co., Mich., July 1, 1956, H. K. Townes (Townes). \&, Midland Co., Mich., June 17, 1939, R. R. Dreisbach (Dreisbach). $\sigma^{7}$, Midland Co., Mich., June 10 to 14, 1951,

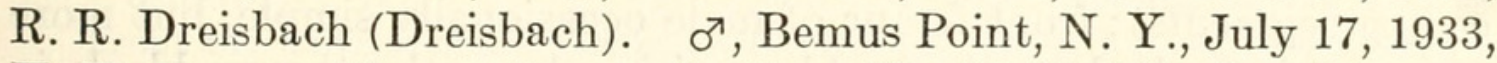

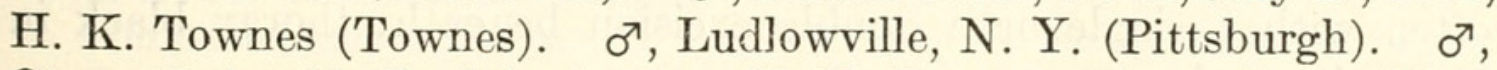
Otsego Lake, N. Y., July 1, 1935, H. K. Townes (Townes). , Pike, N. Y., 1900 (Lawrence). , Rome, N. Y., June 24, 1934, H. K. Townes 
(Townes). ণ , Shokan, N. Y., July 11, 1936, H. K. Townes (Townes). $\sigma^{7}$, Summit Co., Ohio, Sept. 1, 1937, Louis J. Lipovsky (Lawrence). \%, Galetta, Ont., July 22, 1942, G. S. Walley (Ottawa). 2\%, Tweed, Ont., July 15 to 17, 1944, G. S. Walley (Ottawa). $2 \sigma^{7}$, 4으, Cap Rouge, Que., July 8, 1953, R. Lambert (Ottawa). ๙ $\sigma^{7}$, Hull, Que., June 20, 1903 (Ottawa). 2o, Knowlton, Que., July 20, 1936, G. S. Walley (Ottawa). ㅇ, Montreal, Que., May 25, 1902 (Ithaca). $\sigma^{7}$, Westerly, R. I., June 16, 1936, M. Chapman (Townes). क, Waskesiu, Sask., June 24, 1938, J. G. Rempel (Townes). क, Wellsville, Utah, May 7, 1954, G. E. Bohart (Lawrence). ㅇ, Adna, Wash.. July 10, 1917, A. L. Melander (Cambridge). \&, Ashford, Wash., July 10, 1940, H. and M. Townes (Townes). o, Copalis, Wash., July 25, 1931, J. Nottingham (Lawrence). $\sigma^{7}$, ㅇ, Mount Rainier at 2,700 ft., Wash., July 8, 1940, H. and M. Townes (Townes). 2o, Sawyer Co., Wis., Aug. 1 to 8, 1937, D. Murray (St. Paul).

Host: Unknown.

\section{Subgenus Scambus}

Figure 286,a

Scambus Hartig, 1838, Jahresber. Fortschr. Forstw., vol. 1, p. 267. Type: Pimpla (Scambus) sagax Hartig; designated by Viereck, 1914.

Tromera Foerster, 1868, Verh. Naturh. Ver. Rheinlande, vol. 25, p. 164. Type: Pimpla pomorum Ratzeburg; included by Schmiedeknecht, 1888.

Epiurus Foerster, 1868, Verh. Naturh. Ver. Rheinlande, vol. 25, p. 164 . Name preoccupied. Type: Pimpla brevicornis Gravenhorst; designated by Ashmead, 1900.

Troctocerus Woldstedt, 1876, Bull. Acad. Imp. Sci. St. Petersbourg, vol. 22, p. 296. Type: Troctocerus elegans Woldstedt; monobasic.

Submetapleural carina present; thorax and propodeum usually rather short, occasionally (ephialtoides group) moderately long and subcylindrical; propodeum usually with more or less distinct, rather short, dorsomedial carinae; abdominal sternites in female varying from rather small to moderately large and with the basal pair usually larger than the others; subgenital plate in female with a large, basal, membranous excision; sheath varying from about 0.75 to 1.5 times as long as abdomen, or in imparis about 0.4 as long as abdomen; ovipositor moderately to weakly compressed, with basalmost ridges on apex of lower valve rather strongly (except in S. protentus) oblique, forming an angle of about $30^{\circ}$ with its longitudinal axis, and developed dorsally into forward directed teeth; apical segment of tarsus rather short (in female about equal to combined length of two preceding segments); front femur of male occasionally simple, but more often with a single or a double excision beneath; thorax black in Nearctic species. 
This subgenus is found in the Holarctic and Oriental regions and is represented by numerous species both in North America and in Eurasia. Among the Nearctic species there are five species groups as indicated in the key to females and the group descriptions.

\section{Keys to the Nearctic species of the subgenus Scambus}

\section{MALES}

1. Head very thick (not more than 1.65 times as broad as long); thorax elongate, subcylindrical; hind coxa unusually slender (not more than 0.66 times as deep as long). Ephialtoides Group (p. 40) . . . . . . . . . . . 2

Head not especially thick (at least 1.75 times as broad as long); thorax moderately stout; hind coxa not especially slender (at least 0.66 times as deep as long), various groups . . . . . . . . . . . . . . 4

2. Front femur with a broad, rather deep excision beneath.

2. ephialtoides Cushman

Front femur without an excision beneath . . . . . . . . . . . . . 3

3. Hind tibia whitish, with a narrow subbasal and a broad apical fuscous annulus; middle coxa pale yellowish except on inner side at base.

1. protentus, new species

Hind tibia rather indistinctly banded, the pale median annulus usually suffused with brownish and broadly interrupted beneath; middle coxa brownish or blackish except at apex. . . . . . . 3. longicorpus, new species

4. Scape whitish beneath, except sometimes at the base . . . . . . . . 5

Scape blackish beneath, except sometimes narrowly at the apex . . . . 12

5. Front femur slender and without an excision beneath.

5. vesicarius (Ratzeburg)

Front femur moderately stout and with a single or a double excision beneath . . . . . . . . . . . . . . . . . 6

6. Front femur with a single excision beneath . . . . . . . . . . . . 7

Front femur with a double excision beneath . . . . . . . . . . . . . 10

7. Front femur with a very broad, median excision beneath.

18. decorus, new species

Front femur with a narrow, preapical excision beneath . . . . . . . . . 8

8. Front femur with a very shallow, preapical excision beneath; front and middie femora pale yellowish . . . . . . . . . . 16. hispae (Harris)

Front femur with a moderately deep, preapical excision beneath; front and middle femora usually mostly reddish . . . . . . . . . . . . . 9

9. Clasper narrowly rounded at apex; middle coxa reddish.

17. nigrifrons (Viereck)

Clasper broadly rounded at apex; middle coxa pale yellowish.

6. imparis, new species

10. Excised region of front femur distinctly coriaceous; hind coxa usually black.

15. nucum (Ratzeburg)

Excised region of front femur without distinct, coriaceous sculpture; hind coxa usually reddish . . . . . . . . . . . . . . . . . . . . 11

11. Front and middle femora reddish; front femur with a distinct, double excision beneath. . . . . . . . . . . . . 14. tecumseh Viereck

Front and middle femora pale yellowish; front femur with a very weak, double excision beneath. . . . . . . . 13. transgressus (Holmgren)

12. Front femur without an excision beneath . . . . . . . . . . . . 13

Front femur with an excision beneath . . . . . . . . . . . . . . 14 
13. Propodeum with rather strongly elevated, dorsomedial carinae; first abdominal tergite moderately elevated; front coxa usually blackish.

8. brevicornis (Gravenhorst)

Propodeum without distinct, dorsomedial carinae; first tergite of abdomen only slightly elevated; front coxa whitish . . 10. tenebrosus, new species

14. Hind tibia with a broad, yellowish brown to reddish yellow median annulus that is not sharply delimited from the brownish or fuscous subbasal and apical annuli; hind corner of pronotum without a distinct, pale spot.

9. canadensis, new species

Hind tibia with a broad white median stripe or annulus that is sharply delimited from the reddish brown or black subbasal and apical annuli; hind corner of pronotum with a distinct pale spot. . . . . . . . . . . . 15

15. Front femur with a broad, deep, oblique excision beneath; clasper rather narrowly rounded at apex; hind tibia with median, pale annulus extending close to apex on outer side . . . . . . 12. aplopappi (Ashmead)

Front femur with a moderately broad and rather shallow, transverse excision beneath; clasper very broadly rounded at apex; hind tibia with median, pale annulus not extending close to apex on outer side.

11. dioryctriae, new species

\section{FEMALES}

1. Sheath about 0.4 times as long as abdomen (fig. 310 ,b); abdominal sternites 2.5 to 3.0 times as long as wide. IMPARIS GROUP (p. 38)

6. imparis, new species

Sheath at least 0.6 times as long as abdomen; abdominal sternites 1.5 to 2.0 times as long as wide. . . . . . . . . . . . . . . . . . . . 2

2. Head very thick (not more than 1.65 times as broad as long); thorax elongate, subcylindrical; hind coxa unusually slender (not more than 0.66 times as deep as long); ovipositor slender and weakly compressed, with nodus very weak or absent; sheath finely, rather inconspicuously hairy. EPHialtoides GROUP (p. 40). . . . . . . . . . . . . . . . . 3

Head not especially thick (at least 1.75 times as broad as long); thorax moderately stout; hind coxa not unusually slender (at least 0.66 times as deep as long); ovipositor not especially slender and usually moderately compressed, with nodus usually distinct (absent in atrocoxalis); sheath (except in subtilis) with rather coarse, conspicuous hairs . . . . . . . . . . 5

3. Basalmost ridge on apex of lower valve of ovipositor only slightly oblique (forming an angle of about $60^{\circ}$ with longitudinal axis of valve); upper valve of ovipositor without a nodus . . . . 1. protentus, new species

Basalmost ridge on apex of lower valve of ovipositor strongly oblique (forming an angle of about $30^{\circ}$ with longitudinal axis of valve); upper valve of ovipositor with a very weak nodus . . . . . . . . . . . . . . . 4

4. Sheath as long as body; abdominal tergites $2-5$ with strong, dense punctures (intervals between punctures usually less than diameter of puncture).

2. ephialtoides Cushman

Sheath a little shorter than body, at most as long as thorax and abdomen; abdominal tergites 2-5 with rather shallow, sparser punctures (intervals between punctures usually equal to or exceeding diameter of puncture).

3. longicorpus, new species

5. Upper valve of ovipositor with nodus rather strongly developed and with region beyond nodus distinctly, transversely flattened; apex of lower valve with oblique ridges strongly elevated and distinctly arcuate (fig. 310,f). Vesicarius GROUP (p. 46) 
Upper valve of ovipositor with nodus rather weak (rarely absent) or only moderately developed and with region beyond nodus transversely convex; apex of lower valve with oblique ridges moderately to weakly elevated and not distinctly arcuate . . . . . . . . . . . . . . . . . 7

6. Cheek about 0.5 as long as breadth of mandible at base; abdominal tergites with unusually large, distinct punctures; sheath with fine, rather short hairs; base of stigma with a short, pale stripe . . 4. subtilis, new species

Cheek about 0.33 as long as breadth of mandible at base; abdominal tergites with punctures smaller and often suberased or obscured by other sculpture; sheath with coarse, rather long hairs; base of stigma uniformly fuscous or with only a small, pale spot . . . . . . . . 5. vesicarius (Ratzeburg)

7. Upper valve of ovipositor without a nodus (fig. $310, \mathrm{~g}$ ); apex of lower valve smooth, except for a few, very minute ridges at the tip. Atrocoxalis GROUP (p. 53) . . . . . . . . . . . . 7. atrocoxalis (Ashmead)

Upper valve of ovipositor with a more or less distinct nodus; apex of lower valve with numerous, distinct ridges. Hispae Group (p. 54) . . . . . 8

8. Stigma brownish with a narrow, pale yellowish or whitish border on all three sides; propodeum unusually short, and rather abruptly and strongly declivous beyond middle; middle and hind coxae often more or less black.

8. brevicornis (Gravenhorst)

Stigma uniformly colored, without a narrow, pale yellowish or whitish border on all three sides; propodeum more elongate, with portion beyond middle more evenly and less strongly declivous; middle and hind coxae reddish, except in tenebrosus . . . . . . . . . . . . . . . . . . . . . . . . 9

9. All coxae dark reddish brown or blackish; head rather thick; temple not receding for some distance behind eye; propodeum without dorsomedial carinae. . . . . . . . . . . . 10. tenebrosus, new species

Middle and hind coxae reddish; head not especially thick; temple usually receding behind eye; propodeum usually with short, dorsomedial carinae.

10. Hind tibia dull reddish more or less suffused with fuscous, with indistinct, darker fuscous, subbasal and apical suffusions; humeral angle of pronotum black or very narrowly piceous . . . . . 9. canadensis, new species Hind tibia with a broad, median, whitish annulus and distinct brownish or fuscous, subbasal and apical annuli; humeral angle of pronotum usually with a distinct pale spot . . . . . . . . . . . . . . . . . . . . 11

11. Front and middle tibiae with a conspicuous, pale stripe on upper side extending to apex; hind tibia with pale annulus extending close to apex on upper side and beneath interrupted by a broad, fuscous stripe that joins the subbasal and apical annuli; tergites usually more or less reddish; hind angle of pronotum with a pale spot that usually extends forward as a short stripe along upper margin of pronotum . . . . 12. aplopappi (Ashmead)

Front and middle tibiae with stripe on upper side usually less conspicuous and not extending to apex; hind tibia with pale annulus not extending close to apex on upper side and usually only narrowly or indistinctly interrupted beneath; tergites without reddish markings, except in transgressus; pale spot in hind angle of pronotum usually not produced as a short stripe along upper margin of pronotum . . . . . . . . . . . . . . 12

12. Stigma translucent yellowish brown . . . 15. nucum (Ratzeburg) Stigma opaque brownish or blackish . . . . . . . . . . . . . . 13 
13. Abdominal tergites more or less reddish; subbasal fuscous annulus on hind tibia interrupted above; front trochanter whitish.

13. transgressus (Holmgren)

Abdominal tergites black; subbasal fuscous annulus on hind tibia complete.

14. Upper valve of ovipositor with a minute, median, longitudinal sulcus in region beyond nodus; sheath distinctly longer than abdomen; parasites of larvae feeding in cones of Picea . . . . . . . 11. dioryctriae, new species Upper valve of ovipositor without a minute, median, longitudinal sulcus in region beyond nodus; sheath not distinctly longer than abdomen; not associated with cones of Picea . . . . . . . . . . . . . . . . . . . . 15

15. Front trochanter reddish; palpi often more or less fuscous . . . . . . . 16 Front trochanter whitish; palpi usually entirely whitish . . . . . . . . 17

16. Upper valve of ovipositor with a distinct nodus. . . 14. tecumseh Viereck Upper valve of ovipositor without a distinct nodus. 17. nigrifrons (Viereck)

17. Front coxa reddish . . . . . . . . . . 16. hispae (Harris) Front coxa mostly fuscous . . . . . . 18. decorus, new species

\section{EPHIALTOIDES GROUP}

Head very thick; temple weakly rounded and not or only very slightly receding for a considerable distance behind eye; thorax elongate, subcylindrical; abdomen slender; first abdominal tergite small and narrow in comparison with other tergites; sheath slender, with short, fine, rather inconspicuous vestiture; ovipositor weakly compressed and very slender, with nodus very weak or absent; hind coxa unusually slender (not more than 0.66 times as long as deep).

Records indicate that species of this group may be confined to an association with conifers, the known rearings being exclusively from the cones of Abies and Picea.

The group contains three Nearctic species; ephialtoides, protentus, and longicorpus, the last mentioned represented by two subspecies. Relatively little material of any species has been available and the poor condition of most of the specimens emphasizes the need for more and better material to obtain a better understanding of the variation, distribution, and habits. The most productive method of obtaining specimens should be by rearing from collections of cones of various conifers.

\section{Scambus (Scambus) protentus Walley, new species}

\section{Figure $311, \mathrm{~g}$}

Male: Front wing $6.0 \mathrm{~mm}$. long; antenna with 24 segments; cheek almost 0.0 ; mandible coriaceous at base; temple, as seen from above, very broadly rounded except in region close to occiput; propodeum rather long, with dorsomedial carinae very weak and not extending beyond middle; front femur moderately stout, slightly flattened be- 
neath; front tibia slightly bent; abdomen slender; tergite 1 twice as long as wide, with dorsomedial carinae extending almost to apex, sides and apex with coriaceous to rugose sculpture; remaining tergites with crowded, irregular, shallow punctures, except on apices, the punctures shallower and more indistinct on successive tergites.

Black. Palpi, tegula, front and middle coxae, trochanters, broad annulus on hind tibia, and first segment of hind tarsus broadly at base, pale yellowish; femora reddish; front and middle tibiae pale reddish varying to yellowish; hind coxa reddish brown; hind tibia with a narrow, incomplete, subbasal, and a broad, complete, apical, fuscous annulus; hind tarsus brownish.

Female: Front wing $5.5 \mathrm{~mm}$. long; antenna with 22 segments; head very thick; temple about as wide as eye; thorax slender, subcylindrical; propodeum with dorsal carinae very weak and not extending beyond basal 0.25 ; sides of propodeum and dorsal surface near base with a few, suberased punctures; abdomen slender; tergite 1 rather small, with sides and apex of central area with coarse, shallow punctures; tergites $2-7$, except on apices, with numerous, large distinct punctures, the sculpture strongest on tergite 2, becoming weaker on successive tergites; sheath about equal to length of abdomen beyond tergite 1; hairs on sheath fine and rather inconspicuous; ovipositor weakly compressed, upper valve very slender at apex and without nodus, basalmost ridge on lower valve only slightly oblique.

Black. Antenna dark brown, with pedicel and flagellum paler brownish beneath; palpi and tegula pale yellowish; legs reddish, with markings as follows: front and middle trochanters above, apex of hind trochanter, stripe on upper surface of front and middle tibiae, broad annulus at middle of hind tibia, and front tarsus, pale yellowish; middle tarsus pale reddish brown; hind tarsus dark brownish, with first segment yellowish at base; apex of hind femur slightly fuscous; hind tibia with a narrow, pale brownish, subbasal annulus, and a broad, brownish, apical annulus. Abdomen black, sometimes rufopiceous beyond tergite 1 .

Type: ㅇ, Manitou, Colo., May 19, 1914, W. D. Edmonston (Washington, USNM 63744). The type bears the following additional data: "Hopk. U. S. No. 12408b, Par. Laspeyresia?, Picea engelmanni."

Paratypes: $\sigma^{\top}$, coastal region of southern British Columbia (reared at Vancouver, B. C., May 6, 1938, from cone of Picea sitchensis) W. Mathers (Ottawa). \&, Bear Lake at 9,000 ft., Estes Park, Colo., A. L. Melander (Cambridge). \&, White River, Mount Rainier, [Wash.] July 23, 1924, A. L. Melander (Cambridge).

Host: Laspeyresia? 

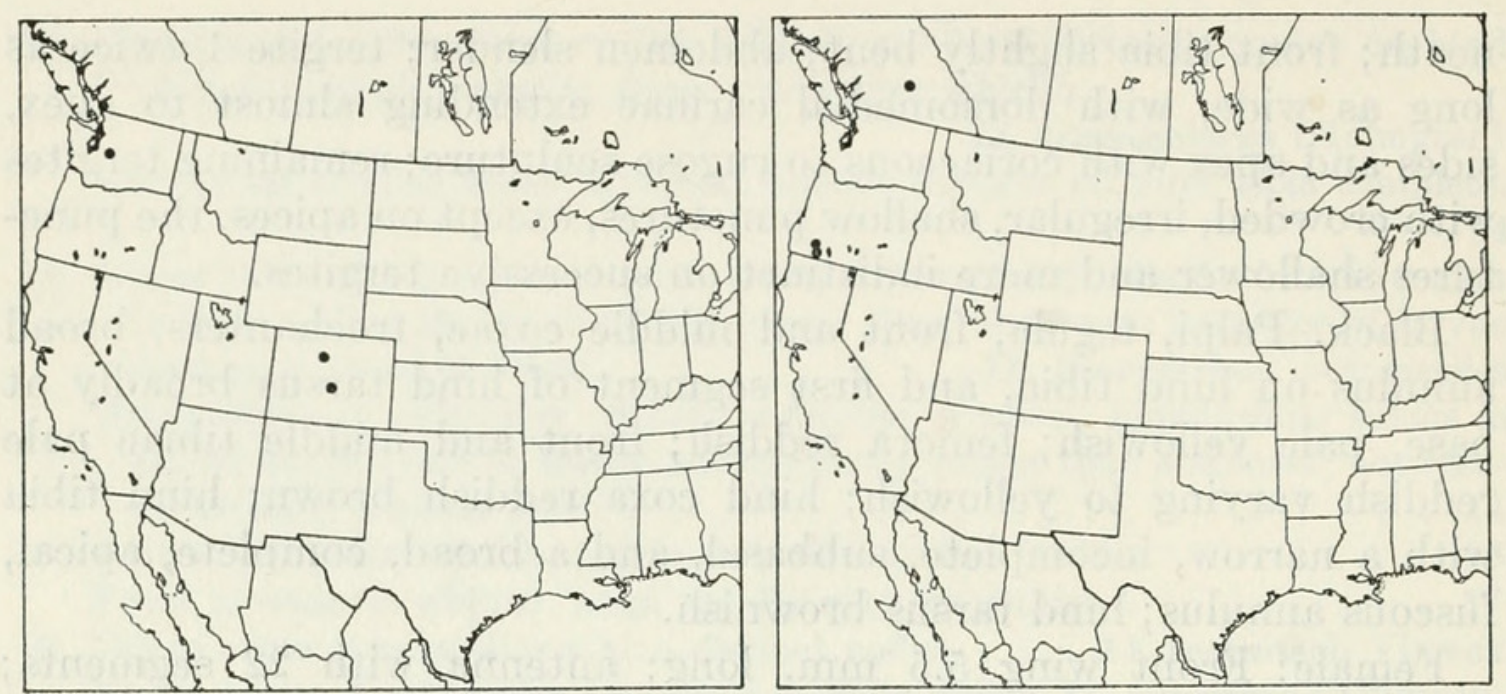

Figures 9, 10.-Localities: 9 (left), Scambus (Scambus) protentus; 10 (right), S. (S.) ephialtoides.

\section{Scambus (Scambus) ephialtoides Cushman}

Figure $311, \mathrm{~h}$

Scambus ephialtoides Cushman, 1917, Proc. U. S. Nat. Mus., vol. 53, p. 466; $\sigma^{x}$, $\uparrow$. Part. Type: $q$, Colestin, Oreg. (Washington).

Male: Front wing $4.5 \mathrm{~mm}$. long; antenna with 24 segments; head very thick; temple about 0.66 times as broad as eye; thorax rather slender; propodeum with dorsomedial carinae distinct, gradually diverging from base and extending to apical 0.25 of propodeum; hind coxa about 0.66 times as deep as long; front femur with a broad, rather deep excision beneath; front tibia flattened beneath, and evenly, rather strongly bent; abdomen slender; tergite 1 twice as long as wide, with median carinae strong and extending to apex; tergite 2 as long as tergite 1, except at apex with dense, irregular, shallow punctures; remaining tergites with progressively weaker sculpture.

Black. Palpi, pedicel beneath, and tegula, pale yellowish; stigma brown; front leg with coxa blackish at base, remainder of coxa, trochanter, apex of femur, and basal 0.5 of tibia, pale yellowish, remainder of femur, and tibia in apical 0.5 , pale reddish; middle leg pale yellowish, except coxa, which is mostly blackish, and femur, which is reddish except at base and apex; hind leg with coxa black, trochanter mostly pale yellowish, femur brownish black with base and apex narrowly yellowish, tibia broadly yellowish at middle, with a fuscous mark near base and a broad, fuscous annulus at apex, tarsus fuscous with segment 1 broadly, and the following segments narrowly pale at base.

Female: Length $9 \mathrm{~mm}$; head very thick, with temple as broad as eye and strongly rounded behind to the weak occipital carina; cheek very short; thorax slender, subcylindrical; propodeum moderately 
long, with sparse, suberased punctures, and with dorsomedial carinae extending nearly to apex; nervellus rather strongly inclivous; legs slender, the hind coxa in greatest depth barely 0.66 times as deep as long; abdomen slender, more than 1.5 times as long as head and thorax together; tergite 1 very small, at apex scarcely 0.5 times as wide as apex of tergite 2 ; tergites $2-5$ with large, very dense punctures except on polished apices; sheath as long as body; ovipositor slender, with a weak nodus and with basalmost ridge on apex of lower valve very strongly oblique.

Black. Clypeus entirely and mandible toward apex, piceous; antenna black, with scape at apex and pedicel beneath, piceous; palpi pale fuscous; tegula very pale yellowish; hind corner of pronotum without a pale spot; coxae rufopiceous to black; hind leg with trochanter piceous at base and whitish beyond, femur reddish, tibia fuscous with a paler basal annulus and an elongate paler spot above at middle, tarsus fuscous with an obscure paler annulus at base of first segment; front and middle legs with same color pattern but with colors paler and less contrasting, especially on front legs.

Specimens: Redescribed from the holotype and allotype from Colestin, Oreg., both of which were reared from Barbara colfaxiana siskiyouana Kearfott in cones of Abies concolor. One male paratype (Cushman's paratype $b$ ) from Siskiyou, Oreg., reared from cones of Abies concolor belongs to this species, as does also a male from Aberdeen Mt., B. C., reared from an anthomyid larva, Sept. 9, 1955, under Forest Insect Survey No. B. C. 2337-01 (Ottawa).

Host: Barbara colfaxiana siskiyouana Kearfott.

\section{Scambus (Scambus) longicorpus Walley, new species}

This is a rather variable species that closely resembles ephialtoides. It differs from ephialtoides, in the male, in lacking the excision of the front femur, and in the female in the slightly shorter ovipositor sheath and the much less densely punctate abdomen. It agrees with ephialtoides and differs from protentus in details of structure of the apex of the ovipositor.

The species is divided into two subspecies which differ as indicated in the key:

1. Male with scape mostly or entirely yellowish beneath; female with maxillary palpus yellowish and middle and hind femora pale reddish to reddish brown; food plant of host: Picea canadensis; range: Ontario, Saskatchewan, Alberta, and Alaska, east of the Continental Divide.

3a. longicorpus longicorpus, new subspecies

Male with scape dark brownish or blackish beneath; female with maxillary palpus fuscous and middle and hind femora rufopiceous to black; food plants of host: Picea sitkensis and P. engelmanni; range: Wyoming, Montana, California, Oregon, and British Columbia, west of the Continental Divide.

3b. longicorpus occidentalis, new subspecies 


\section{3a. Scambus longicorpus longicorpus Walley, new subspecies}

Figures $310, \mathrm{j} ; 311, \mathrm{i}$

Male: Front wing $3.0 \mathrm{~mm}$. long; antenna with 21 segments; head very thick anteroposteriorly, as wide through temples as through eyes; temple about 0.77 as broad as eye and strongly rounded to the weak occipital carina; thorax slender, subcylindrical; propodeum with rather weak, dorsomedial carinae extending from base to apical 0.25 of propodeum; hind coxa rather slender, about 0.66 as deep as long; front femur somewhat flattened beneath, but without a distinct excision; front tibia almost straight; abdomen slender; tergite 1 twice as long as wide at apex and equal in length to tergite 2, with median carinae distinct to apex; apex of central area, and lateral areas of tergite 1 , weakly sculptured; tergite 2 with dense, shallow, irregular punctures; remaining tergites with similar but weaker and successively diminishing sculpture.

Black. Palpi, scape and pedicel beneath, and tegula, pale yellowish; stigma blackish; front leg with coxa narrowly blackish at base, remainder of coxa, and trochanter pale yellowish, femur, tibia and tarsus pale reddish; middle leg with coxa mostly brownish, except at apex, the apex, also trochanter and basal 0.6 of tibia, pale yellowish, remainder of leg pale reddish; hind leg with coxa black varying to dark brown, base of trochanter brownish, remainder of trochanter and narrow base of tibia pale yellowish, femur dull reddish to brownish with paler extremities, tibia mostly rather dark brownish with the central portion somewhat paler but without a distinct pale stripe or annulus, tarsus brown with the segments slightly paler at base.

Female: Front wing $3.75 \mathrm{~mm}$. long; antenna with 21 segments; shape of head and thorax much as in male; temple almost as broad as eye; mandible with coriaceous sculpture near base; cheek very short, about 0.2 breadth of mandible at base; propodeum smooth, with a few, suberased punctures mostly on sides, and with only indistinct, dorsomedial carinae extending a little beyond middle; abdomen slender; tergite 1 rather small, with a few shallow punctures in lateral areas and at apex of central area; tergite 2 with large, shallow punctures which are mostly separated by intervals equal to or exceeding the diameter of a puncture; tergites $3-5$ similar to 2 but with punctures somewhat shallower, especially before the apical area; tergites 6 and 7 with punctures very shallow and indistinct; ovipositor very slender and rather weakly compressed, lower valve with basalmost ridge very oblique, upper valve with a weak nodus; sheath as long as portion of body posterior to origin of hind wing; valves with fine, rather inconspicuous hairs.

Black. Maxillary palpus yellowish, with apical segment fuscous; labial palpus fuscous; antenna varying from dark brownish to black; 
scape, pedicel and basal flagellar segments paler brownish beneath; tegula brownish, somewhat paler at base; coxae varying from dark brownish to almost black; front trochanter above, and middle and hind trochanters except at apices, brownish; remainder of front leg rather pale reddish, the tibia slightly paler at base; middle leg with femur reddish and tibia and tarsus somewhat brownish; hind leg with femur rather dark reddish and tibia and tarsus dark brownish.

Type: , Indian Head, Sask., reared in laboratory (Feb. 24, 1953) from cone of Picea glauca (Ottawa, No. 6751 in Canadian National Collection).

Paratypes ( $14 \sigma^{\top}, 8$, including $3 \sigma^{\top}$, ㅇ from type locality): From Alaska (Shaw Creek at Mile 289 on Richardson Highway); Alberta (Cold Lake, Coleman, Kananaskis, Lake Edna in Jasper National Park, Lake Louise at 6,500 ft., Porcupine Ranger Station, and West Porcupine Ranger Station); New Hampshire (base of Mount Washington); Ontario (Stittsville); Quebec (Berthierville, Indian House Lake, and Quyon); and Saskatchewan (Indian Head).

All material except single specimens from Shaw Creek, Mount Washington and Indian House Lake was reared by officers of the Division of Forest Biology, Canada Department of Agriculture, from cones of Picea canadensis.
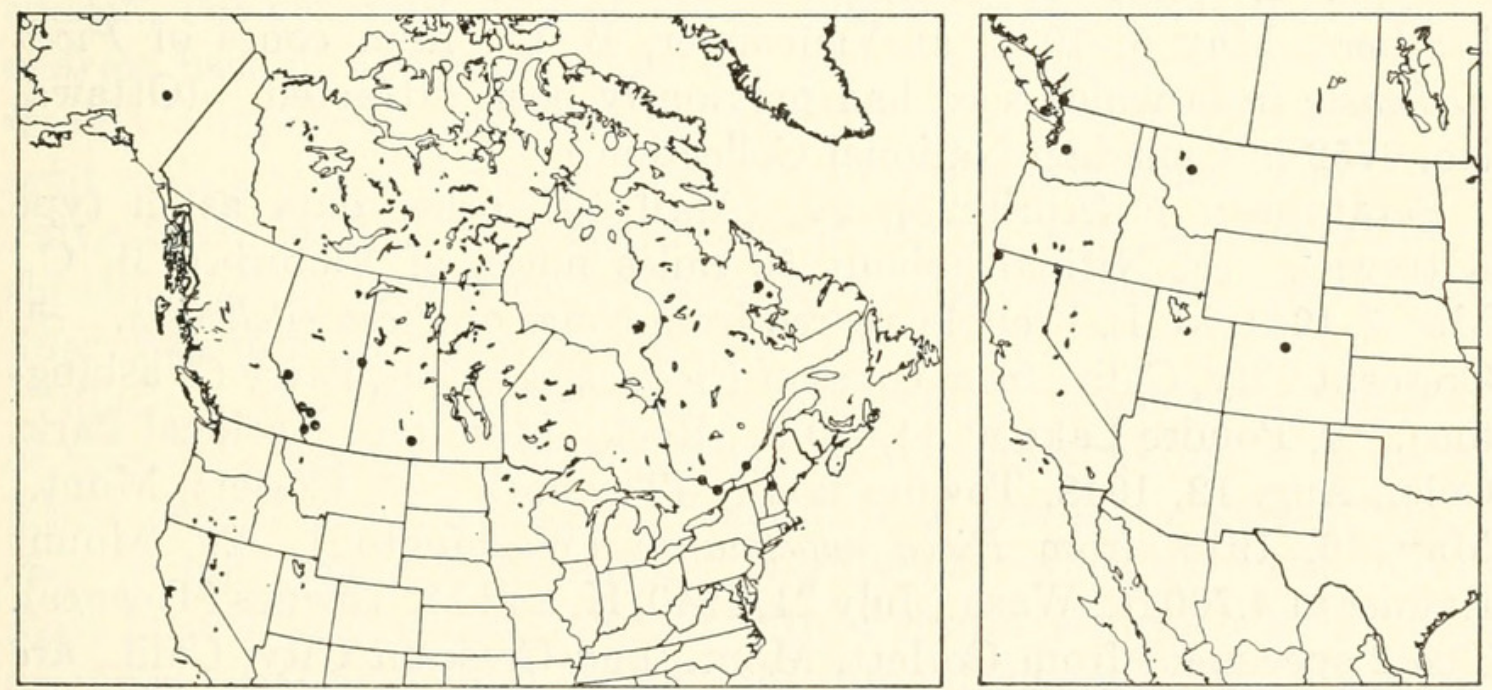

Figures 11, 12.-Localities: 11 (left), Scambus (Scambus) longicorpus longicorpus; 12 (right), S. (S.) l. occidentalis.

Hosts: At Indian Head, Sask., rearings from Picea canadensis cones yielded the lepidopteron Laspeyresia youngana (Kearfott), which is presumed to be a host for this species. A single female parasite was reared by L. Daviault at Berthierville, Que., from Dioryctria reniculella (Grote), and rearings by H. A. Tripp of collections from Stittsville, Ont. and Quyon, Que., from cones infested by the White spruce cone maggot, Peghylemyia anthracina (Czerny), yielded three female parasites. 


\section{3b. Scambus longicorpus occidentalis Walley, new subspecies}

Scambus ephialtoides Cushman, 1917, Proc. U. S. Nat. Mus., vol. 53, p. 466 . Part.

Differs from the typical subspecies principally as follows:

Male: Front wing $2.5 \mathrm{~mm}$. long.

Scape and pedicel brownish beneath; tegula brown; coxae, base of middle trochanter, and hind trochanter except at apex, dark brown to blackish; remainder of trochanters sordid yellowish; front femur dull reddish, suffused with brownish above; front tibia dull reddish; front tarsus paler reddish at base, becoming brownish toward apex; middle and hind legs with femora and segments beyond, dark brownish; wings tinged with brownish.

Female: Front wing $3.5 \mathrm{~mm}$. long.

Maxillary palpus fuscous; antenna almost uniformly dark brown or blackish; tegula brownish black; coxae and trochanters, except apices of latter, brownish black to black; apices of trochanters, and middle and hind femora very narrowly at bases, dull yellowish to pale brownish; remainder of front legs rather pale reddish brown; middle and hind femora beyond bases rufopiceous to black; remainder of middle and hind legs dark brown to blackish; wings tinged with brownish.

Type: + , coast of southern British Columbia; reared by W. Mathers, May 6, 1938, at Vancouver, B. C., from cones of Picea sitchensis from which seed had previously been extracted. (Ottawa, No. 6752 in Canadian National Collection.)

Paratypes: $\sigma^{\top}$ (April 23), 2ᄋ, (April 19), other data as in type (Ottawa). $\sigma^{7}$, Nitinat (about 50 miles north of Victoria), B. C., May 7, 1941, M. L. Prebble, reared from cones of Picea sitchensis. $\sigma^{7}$, Crescent City, Calif., from cones of Picea engelmanni, Parry (Washington). \&, Poudre Lake at 11,000 ft., Rocky Mountain National Park, Colo., Aug. 12, 1948, Townes family (Townes). $\sigma^{7}$, Corlett, Mont., May 16, 1914, from Picea engelmanni (Washington). 2ㅇ, Mount Rainier at 4,700 ft., Wash., July 21, 1940, H. and M. Townes (Townes). The 2 specimens from Corlett, Mont., and Crescent City, Calif., are paratypes $e$ and $f$, respectively, in Cushman's type series of ephialtoides.

Host: Unknown.

\section{VESICARIUS GROUP}

Rather small species (front wing in female usually from 3.0 to 5.0 $\mathrm{mm}$. long); head transverse; temple strongly rounded; cheek in female 0.33 to 0.5 times breadth of mandible at base; ocelli small; sheath slightly longer than abdomen; ovipositor slender, sagittate at apex; upper valve of ovipositor with a conspicuous nodus and with region beyond nodus more or less distinctly transversely flattened; lower 
valve of ovipositor with basalmost 2 or 3 ridges strongly elevated and distinctly curved; male front femur (male of subtilis unknown) slender and without an excision beneath.

One of the two included species has been reared on numerous occasions from sawfly galls in leaves of Salix.

The group contains the Nearctic subtilis, and the Holarctic polytypic vesicarius.

\section{Scambus (Scambus) subtilis Walley, new species}

\section{Male: Unknown.}

Female: Front wing about $5.0 \mathrm{~mm}$. long; antenna with 21 segments; ocelli unusually small, greatest diameter of a lateral ocellus equal to 0.6 times distance from ocellus to eye; cheek rather long, about 0.5 times breadth of mandible at base; temple, as seen from above, strongly rounded, and about 0.57 as long as eye; thorax and propodeum moderately stout; propodeum rather evenly convex, with weak, dorsomedial carinae extending from base to a little beyond middle; hind femur 4.2 times as long as deep; abdomen with tergite 1 only slightly elevated, and about as long as breadth at apex, its sides and central area at apex with numerous, coarse, rather shallow punctures; remaining tergites with numerous, unusually large, rather unevenly spaced, but generally well separated punctures; sternites, except pair nearest base of abdomen, unusually small; ovipositor slender, rather weakly compressed, sagittate at apex, its upper valve with a prominent nodus, and with region beyond nodus somewhat flattened; lower valve with basal 2 or 3 ridges rather strong and slightly arcuate; sheath slightly longer than abdomen; hairs on sheath shorter and finer than in most other species.

Black. Antenna blackish, becoming dark brownish on apical 0.35 of flagellum beneath; basal segment of maxillary palpus and entire labial palpus brownish black; remainder of maxillary palpus, small spot in hind angle of pronotum, and tegula, pale yellowish; stigma dark brown to blackish, marked with a sordid yellowish stripe that occupies basal angle and extends for some distance outwardly along costal margin; legs mostly reddish; front coxa and trochanter brownish to blackish; hind tibia dark brownish above, shading to reddish brown beneath, and marked above with a fairly distinct yellowish, longitudinal stripe on middle, and a small, yellowish spot at base; middle tibia with same pattern more faintly repeated; middle and hind tarsi brownish, narrowly paler at bases.

This species closely resembles vesicarius in the form of the ovipositor. In subtilis, however, the upper valve is a little less distinctly flattened beyond the nodus and the basal ridges of the lower valves are a little less strongly elevated. Other features of special value for the recog- 
nition of subtilis include the rather finely and inconspicuously hairy sheath, the unusually coarsely punctate abdomen, the unusually small abdominal sternites, the blackish labial palpus, and the yellowish mark on the base of the stigma.

Type: o, Leevining, Calif., June 24, 1948, H., M., G., and D. Townes (Washington, USNM 63745).

Paratypes: $ᄋ$, same data as type (Townes). Calif., June 28, 1954, R. M. Bohart (Davis). \&, Holbrook, Douglas Co., Nev., May 25, 1952, E. I. Schlinger (Davis). ㅇ, Eagle Ridge, Klamath Lake, Oreg., May 15, 1924, C. L. Fox (San Francisco).

Host: Unknown.

\section{Scambus vesicarius (Ratzeburg)}

Male: Front wing 3.25 to $4.50 \mathrm{~mm}$. long; antenna with 19 to 21 segments; cheek very short, about 0.15 times breadth of mandible at base; temple, as seen from above, strongly rounded and about 0.66 times as long as eye; thorax moderately stout; propodeum with rather strong, dorsomedial carinae extending from base to apical 0.25 ; front femur rather slender, very slightly flattened but without an excision beneath; front tibia very slightly bent; abdomen slender; tergite 1 about 1.5 times as long as wide, more or less rugulose, without distinct punctures; tergite 2 granular to rugulose, and indistinctly punctate, except at apex; remainder of tergites with rather similar but progressively weaker sculpture.

Female: Front wing 2.75 to $6.25 \mathrm{~mm}$. long; antenna 20 to $22 \mathrm{seg}-$ mented; cheek rather short, about 0.33 times the breadth of mandible at base; temple, as seen from above, rather strongly rounded and about 0.60 as long as eye; thorax and propodeum moderately stout; dorsomedial carinae of propodeum distinct and extending a little beyond middle; hind femur 4.85 times as long as deep; abdomen with tergite 1 moderately elevated and about as long as wide, with sides, and central area at apex, finely, irregularly rugulose and without distinct punctures; remaining tergites with numerous, rather unevenly distributed, moderately large, shallow or indistinct punctures that are often more or less confused with other sculpture; sheath a little longer than abdomen, with rather coarse, conspicuous hairs.

There are two subspecies, differentiated mainly by leg color. The nominate subspecies is widely distributed in the Palearctic region but in North America is known only from the Alaskan peninsula. There it replaces the subspecies euurae, which is otherwise transcontinentally distributed, chiefly in the Canadian and Hudsonian zones.

Hind tibia of male indistinctly brownish to fuscous subbasally and at apex, with intermediate region somewhat paler but not distinctly annulate; hind tibia in female uniformly dull reddish or pale brownish, with only traces of fuscous subbasal and apical annuli ... 5a. vesicarius vesicarius (Ratzeburg) 
Hind tibia in both sexes with distinct fuscous subbasal and apical annuli separated by a broad, median, whitish annulus which is usually complete in male and broadly interrupted beneath in female . . . . 5b. vesicarius euurae (Ashmead)

\section{5a. Scambus (Scambus) vesicarius vesicarius (Ratzeburg)}

Figure 320, h

Pimpla vesicaria Ratzeburg, 1844, Die Ichneumonen der Forstinsecten . . . .,

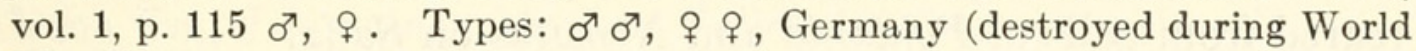
War II).

Male: Color as in vesicarius eurrae except as follows: tegula often fuscous posteriorly; front and middle coxae often narrowly fuscous at bases, occasionally blackish with yellowish apices; hind coxa usually black, rarely black with reddish apex; front and middle femora and tibiae almost uniformly pale reddish; hind femur dark reddish, sometimes suffused with fuscous; hind tibia brownish to fuscous subbasally and at apex, with intermediate region somewhat paler but not distinctly annulate; tarsi varying from pale to dark brownish with lighter bases.

Female: Color mostly as in vesicarius euurae except as follows: palpi usually more or less fuscous; tegula usually fuscous posteriorly; front and middle tibiae without fuscous annuli; hind tibia pale brownish to dull reddish, or occasionally with indistinct subbasal and apical fuscous annuli, but if so then without the intermediate region in form of a broad whitish annulus.

Mr. J. F. Perkins (British Museum) kindly supplied specimens of this species, from England, and has subsequently confirmed my identification. Other Palearctic material examined by me includes specimens from England, in the Townes collection, and a male taken in Lappland $\left(67^{\circ} 58^{\prime} \mathrm{N}\right.$. and $3^{\circ} 34^{\prime}$ E.), Sweden, July 25,1951 , by J. R. Vockeroth, and now in the Canadian National Collection.
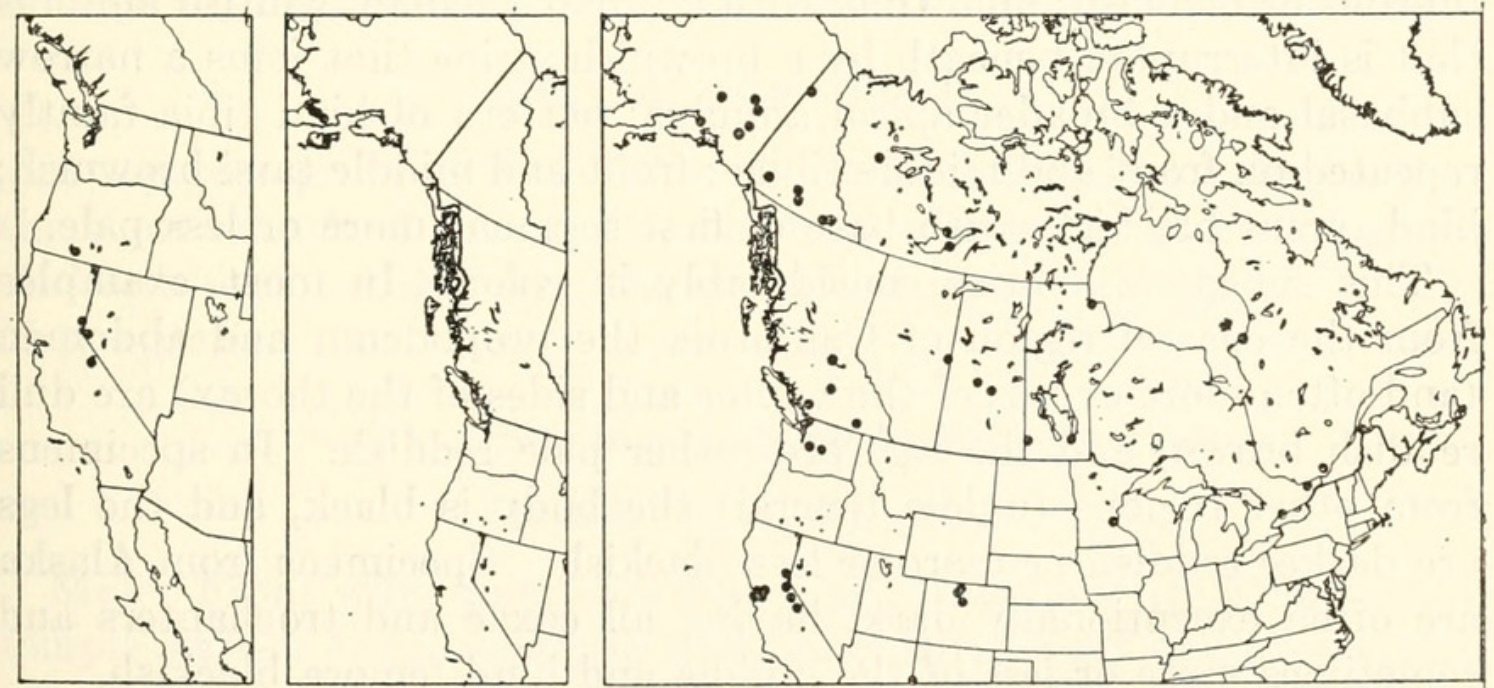

Figures 13-15.-Localities: 13 (left), Scambus (Scambus) subtilis; 14 (center), $S$. (S.) vesicarius vesicarius; 15 (right), $S$. (S.) v. euurae 
Specimens $\left(23 \sigma^{\top}, 22\right.$ ) : From Alaska (Cold Bay at $55^{\circ}$ N. and $163^{\circ}$ W., King Salmon on Naknek River, Kodiak, Naknek, Savonoski on Naknek Lake, and Soluka Creek at $58^{\circ} 4^{\prime}$ N. and $154^{\circ} 54^{\prime}$ W.).

Dates of capture range from July 10 to August 23, except for $50^{7}$, 1 , taken at Kodiak on an unspecified date in September.

Hosts: This subspecies has not been reared in North America but in the Palearctic region it has been reported on numerous occasions reared from galls of Pontania and Nematus on Salix.

\section{5b. Scambus (Scambus) vesicarius euurae (Ashmead), new status}

Figures 310,f; 311,j; 320,i

Pimpla euurae Ashmead, 1890, Proc. U. S. Nat. Mus., vol. 12, p. 447; $\$$, Lectotype (by present designation): $q$, Calif., bearing white label with data, “3747 \%, Sept. 9, '85.” Type: No. 2111, USNM (Washington).

Male: Black. Flagellum dark brown to black above, paler beneath, especially on basal 3 or 4 segments; scape and pedicel beneath, palpi, hind angle of pronotum, tegula, front and middle coxae, all trochanters, narrow basal band on hind tibia, a broader band at middle, and base of first segment of hind tarsus, pale yellowish; front and middle femora and tibiae mostly pale reddish above and pale yellowish beneath; hind coxa and femur usually reddish, occasionally with femur more or less fuscous, and coxa in part or entirely black; hind tibia with a narrow subbasal and a broader apical fuscous annulus; tarsi varying from brown to reddish brown.

Female: Black. Antenna blackish, flagellum paler beneath, especially toward base; pedicel beneath and occasionally apical rim of scape, sordid yellowish; palpi whitish, rarely somewhat fuscous; tegula and small spot in hind angle of pronotum yellowish white; stigma rather pale fuscous to light brownish, with darker margins; legs mostly reddish, with front coxa and trochanter sometimes castaneous or blackish; hind tibia with a broad, median, whitish annulus that is interrupted beneath by a brownish stripe that joins a narrow subbasal and a broader apical annulus; pattern of hind tibia faintly repeated on front and middle tibiae; front and middle tarsi brownish; hind tarsus blackish, with base of first segment more or less pale.

This subspecies varies considerably in color. In most examples from the coastal region of California the propodeum and abdomen (and often more or less of the venter and sides of the thorax) are dull reddish brown, and the legs are rather pale reddish. In specimens from other regions (unless teneral) the body is black, and the legs are darker reddish or more or less blackish. Specimens from Alaska are often exceptionally dark, having all coxae and trochanters and sometimes more or less of the middle and hind femora blackish.

Specimens (52 $\left.\sigma^{7}, 88 \%\right)$ : From Alaska (Anchorage, Big Delta, Mile 
213 on Richardson Highway, Mount McKinley at 1,600 and 1,700 ft., Nome, St. Paul Island, Shaw Creek at Mile 289 on Richardson Highway, and Summit Lake in Isabella Pass); Alberta (Blackfoot Hills); Arizona (near Alpine); British Columbia (Clinton, Diamond Head Trail at 3,200 ft. in Garibaldi Park, "Hatchery Arm," Likely, and Robson); California (Berkeley, Dardanelle, Donner Pass, Hope Valley in Alpine Co., Leevining, Moraga Valley in Contra Costa County, Oakland, and San Francisco); Colorado (Cameron Pass, Pingree Park in Larimer Co., and Walden); Manitoba (Birtle, Churchill, and Winnipeg); Minnesota (St. Paul); Northwest Territories (Cameron Bay on Great Bear Lake, Chesterfield, Norman Wells, "Sawmill Bay," and Yellowknife); Ontario (Bowmanville and Ottawa); Quebec (Great Whale River, Joliette, and Parke Reserve in Kamouraska Co.); Saskatchewan (Snowden and Waskesiu Lake); Washington (Bellingham, Blewitt, Mount Rainier at 4,700 and 5,000 ft., and Wiser Lake in Whatcom Co.); Yukon Territory (Haines Junction, Marsh Lake, Rampart House, Rancheria-Swift River, and Whitehorse).

Hosts: The subspecies has frequently been associated with Salix and with sawfly galls thereon. The type was reared from Eura sp. on Salix californica. Records at hand include rearings from Salix lasiolepis leaves at San Francisco and Moraga Valley, Contra Costa Co., Calif.; and from Salix petiolaris at Winnipeg, Man. Sawfly records include rearings from Euura sp. at Churchill, Man.; Nematus sp. at Snowden, Man.; Pontania californica Marlatt, and Pontania sp. at Berkeley, Calif.; Pontania sp. at Bellingham and Wiser Lake, Wash.; and Pontania? desmodioides Walsh at Ottawa, Ont.

This subspecies has a transcontinental distribution in the Hudsonian, Transition, and Canadian zones. A single female from Chesterfield, Northwest Territories (the only arctic record for the genus in North America) establishes its occurrence in the Arctic zone.

\section{IMPARIS GROUP}

A separate group is established for imparis largely on the basis of the short sheath of the female, which is reminiscent of the subgenus Ateleophadnus. Otherwise the species might be included in the hispae group.

\section{Scambus (Scambus) imparis Walley, new species}

Figures 310,b; 310,h; 311,k

Male: Front wing about $3.5 \mathrm{~mm}$. long; antenna with 20 segments; temple, as seen from above, strongly rounded; thorax and propodeum moderately stout; dorsomedial carinae of propodeum weak and not extending beyond its basal 0.5 ; front femur with a narrow, rather shallow, preapical excision beneath; front tibia distinctly bent; hind 
femur about 4.1 times as long as deep; tergite 1 of abdomen about 1.5 times as long as wide; clasper broadly rounded at apex.

Black. Scape and pedicel beneath, palpi, tegula, hind angle of pronotum, front and middle legs (except for slight reddish suffusions on femora and tibiae) and hind trochanter, whitish; hind tibia whitish, with narrow, subbasal and broad, apical fuscous annuli; apices of front and middle tarsi, and hind tarsus except bases of first two segments, fuscous.

Female: Front wing about $6.0 \mathrm{~mm}$. long; antenna with 23 segments; temple and thorax as in male; propodeum with dorsomedial carinae on basal 0.66 ; sides of propodeum rather densely, and dorsal surface more sparsely, punctate; hind femur about 3.6 times as long as deep; tergite 1 of abdomen slightly longer than wide; tergites 2-7 rather densely punctate except on apices; sheath 0.4 times as long as abdomen; ovipositor rather strongly compressed and with a distinct nodus.

Differs in color from male principally in the more uniformly reddish front and middle legs, which lack paler markings, except the tibiae, on which the pattern of the hind tibia is faintly repeated; also differs in having the palpi more or less dusky, the scape and pedicel blackish beneath, and the stigma brownish with darker margins.

Type: ㅇ, Robson, B. C., June 17, 1950, H. R. Foxlee (Ottawa, No. 6753, in Canadian National Collection).

Paratypes: ㅇ, Banff, Alta, July 2, 1949, E. H. Strickland (Townes). 2ᄋ, Edmonton, Alta., July 16 and Aug. 29, 1948, E. H. Strickland (Townes). ơ', Lillooet, B. C., Oct. 2, 1932, A. W. A. Phair (Ottawa). ㅇ, Nanaimo Biological Station, B. C., June 25, 1920, E. C. Van Dyke (San Francisco). $\quad \sigma^{\top}$, reared from Zelleria haimbachi Busck on Pinus contorta, Richmond, B. C., Aug. 26, 1954, J. H. McLeod (Ottawa). $3 \sigma^{7}, 4$ 웅 Robson, B. C., Apr. 23, Aug. 8 to 24 and 26 to 31, 1949, May
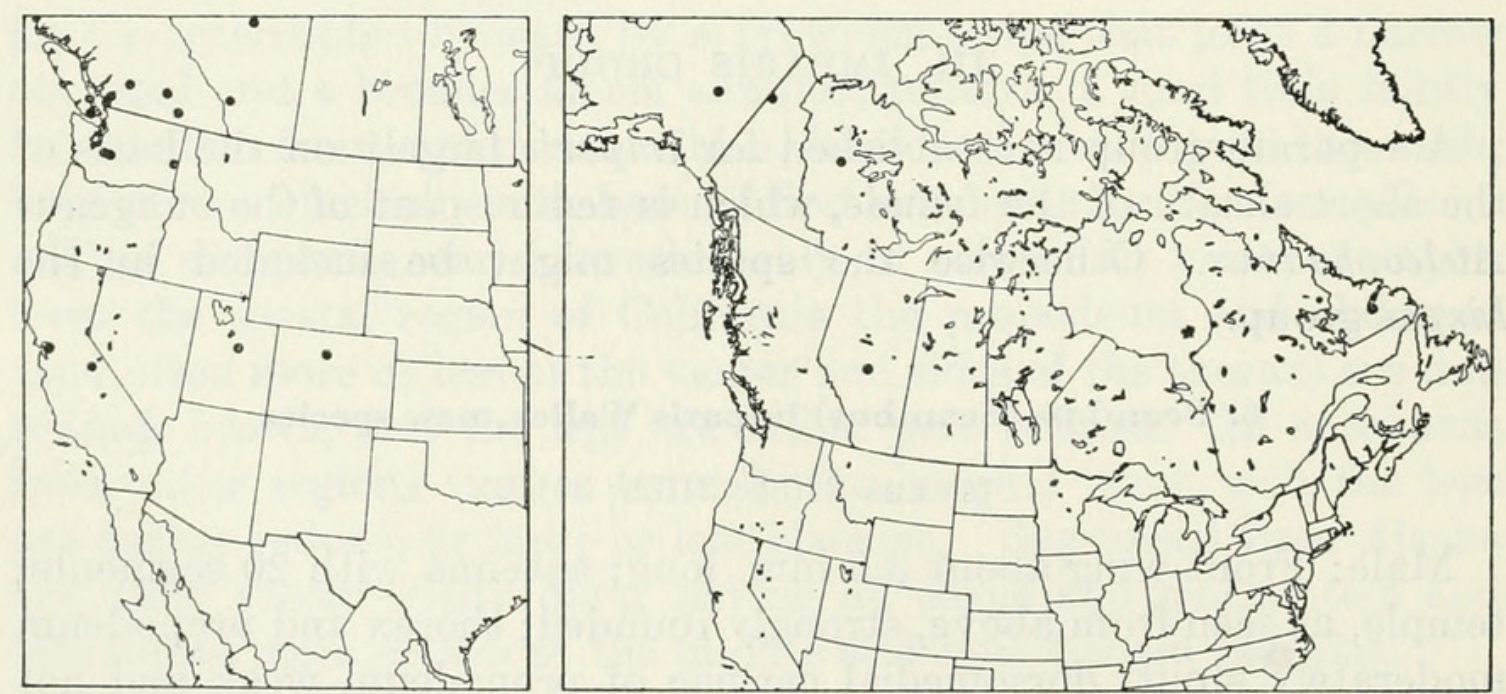

Figures 16, 17.-Localities: 16 (left), Scambus (Scambus) imparis; 17 (right), S. (S.) atrocoxalis. 
18, 1947, June 3, 1 to 17, and 17, 1950, H. R. Foxlee (Ottawa). +, Salmon Arm, B. C., June 23, 1925, A. A. Dennys (Ottawa). $\sigma^{7}$, Squamish, on Diamond Head trail at 4,600 ft., B. C., Aug. 29, 1953, W. R. M. Mason (Ottawa). o, Victoria, B. C., May 20, 1919, W. Downes (Ottawa). $\sigma^{\top}$, mass reared from Recurvaria milleri Busck, Lake Tenaya, Yosemite Park, Calif., Aug. 1, 1951 (Ottawa). ㅇ, Redwood Park, Contra Costa Co., Calif., May 16, 1954, Don Burdick (Berkeley). ㅇ, near Estes Park, Colo., June 13, 1948, H., M., G., and D. Townes (Townes). , Kigalie Ranger Station, La Sal National Forest, Utah, July 5, 1935, Brues (Cambridge). ㅇ, Elbe, Wash., July 25, 1940, H. and M. Townes (Townes). $\sigma^{7}$, Mica, Wash., July 14, 1918, A. L. Melander (Cambridge). ఠד, White River, Mount Rainier, Wash., July 23, 1924, A. L. Melander (Cambridge).

This species occurs in the Canadian and Transition zones from Alberta and northern British Columbia south to Colorado, Utah and central California.

Host: Zelleria haimbachi Busck.

\section{ATROCOXALIS GROUP}

A separate group is established for atrocoxalis because of the unique ovipositor structure as described in the key. Apart from this character the species might be included in the hispae group.

\section{Scambus (Scambus) atrocoxalis (Ashmead)}

Figure 310,g

Epiurus atrocoxalis Ashmead, 1902, Proc. Wash. Acad. Sci., vol. 4, p. 201; $\sigma^{7}$, . Part. Lectotype (by present designation): + , Muir Inlet, Alaska (Washington).

Male: Unknown.

Female: Front wing about $4.3 \mathrm{~mm}$. long; antenna with 21 segments; ocelli rather small, lateral ocellus with diameter 0.63 times distance from ocellus to eye; cheek about 0.27 breadth of mandible at base; temple, as seen from above, strongly rounded and about 0.7 times as long as eye; thorax and propodeum moderately stout; propodeum rather evenly convex, with dorsomedial carina distinct on basal 0.66 ; sides of propodeum and region between and on either side of carinae more or less finely rugulose; hind femur 4.4 times as long as deep; tergite 1 of abdomen about as long as wide, with sides finely irregularly rugulose and apex of central area with shallow irregular punctures; tergites 2-7 rather densely punctate except on the broad somewhat transstriate apices; sheath as long as abdomen; ovipositor slender (especially near apex) and weakly compressed, without nodus, and with only a few minute ridges very close to apex on lower valve. 
Black. Antenna brownish black, with pedicel pale yellowish beneath and flagellum yellowish (at base) to pale brownish beneath; palpi pale yellowish with traces of fuscous; tegula pale yellowish; hind angle of pronotum with a very small yellowish spot; stigma blackish; legs mostly reddish except as follows: front coxa brownish black, front and middle trochanters castaneous, middle coxa reddish to castaneous; hind tibia with narrow subbasal and broad apical fuscous annuli joined beneath by a reddish stripe that interrupts the broad median whitish annulus; hind tarsus brownish, with first segment broadly and the following segments narrowly paler at bases; pattern of hind tibia and tarsus more faintly repeated on middle leg.

Specimens (10\%): From Alaska (Fairbanks, June 25, 1952, W. R. Mason); Alberta (Edmonton, June 8, 1946, W. R. Mason); Newfoundland (Goose Bay, July 3, 1948, W. E. Beckel); Northwest Territories (Norman Wells, Aug. 2, 1944, W. R. Mason); Yukon Territory (Rampart House, July 11, 12, 1951, C. C. Loan and J. H. H. Martin), Sweden (Abisko in Lappland, July 31, 1951, J. R. Vockeroth).

This marks the first record of this species from the Palearctic region. Mr. J. F. Perkins has kindly compared the Abisko specimen with an example from Rampart House and is in agreement that they are conspecific.

Host: Unknown.

\section{HISPAE GROUP}

Moderate sized to large species (front wing in female 3.5 to 9.0 $\mathrm{mm}$. long); head usually rather thin but occasionally (tenebrosus) somewhat thickened; temple rather weakly to strongly rounded and usually rather strongly receding, occasionally (as in dioryctriae and tenebrosus) weakly receding; cheek in female 0.25 to 0.35 times breadth of mandible at base; thorax and propodeum usually moderately stout, occasionally ( $\sigma^{7}$ of aplopappi) rather slender; abdomen moderately stout; tergite 1 in male short to moderately long; sheath about as long as abdomen; ovipositor moderately compressed, with nodus distinct except in nigrifrons.

Black, sometimes with tergites more or less reddish; hind tibia usually with distinct fuscous and whitish annuli.

This group contains the Nearctic aplopappi, canadensis, decorus, dioryctriae, hispae, tecumseh, nigrifrons, tenebrosus and transgressus, the Holarctic brevicornis and nucum, and a number of Palearctic species. The taxonomy of the species is difficult, and wherever possible, in making identifications, it is desirable to have associated males and females. Also, it is important to have mature specimens in which the colors are fully developed, because the keys employ a number of color characters that are impossible to evaluate in immature or improperly preserved specimens. 


\section{Scambus (Scambus) brevicornis (Gravenhorst)}

Figures 311,1; 320,j

Pimpla brevicornis Gravenhorst, 1829, Ichneumonologia europaea, vol. 3, p. 211;

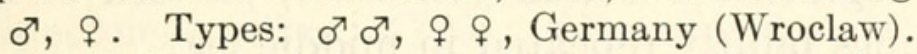

Epiurus bicoloripes Ashmead, 1902, Proc. Wash. Acad. Sci., vol. 4, p. 201; .

New synonymy. Type: + , Berg Bay, Alaska (Washington).

Male: Front wing 2.75 to $4.75 \mathrm{~mm}$. long; antenna with 18 to 22 segments; cheek very short, about 0.21 breadth of base of mandible; temple, as seen from above, moderately rounded and about 0.68 times as long as eye; thorax moderately stout; propodeum rather short, with dorsomedial carinae strong and extending from base to apical 0.25 , dorsal area with large, sballow, sparse punctures, sides more densely punctate and more or less rugose; legs stout, front femur very broad without excision beneath, front tibia slightly bent; abdomen rather stout; tergite 1 almost as broad as long, with median carinae strong and extending to apex, sides and central area beyond middle with irregular sculpture and scattered punctures; tergite 2 with coarse, dense punctures, except on apex; tergites 3-7 punctate, except on apices, with punctures progressively weaker on successive tergites; body with rather long, conspicuous vestiture.

Black. Pedicel yellowish beneath; flagellum blackish above at base, becoming brownish above toward apex, beneath pale brown to yellowish brown; maxillary palpus pale yellowish; labial palpus pale brown to fuscous; tegula and hind angle of pronotum yellowish; stigma brownish to blackish, narrowly paler at base and apex or with narrow pale margins; legs very variable, but usually with all femora and front and middle tibiae reddish (rarely with hind femur, and to a lesser degree middle femur, suffused with fuscous); coxae varying from entirely red to entirely black; trochanters usually yellowish to reddish, but occasionally middle and hind trochanters black; hind tibia with a narrow subbasal and a broader apical fuscous annulus

Figure 18.-Localities for Scambus (Scambus) brevicornis.

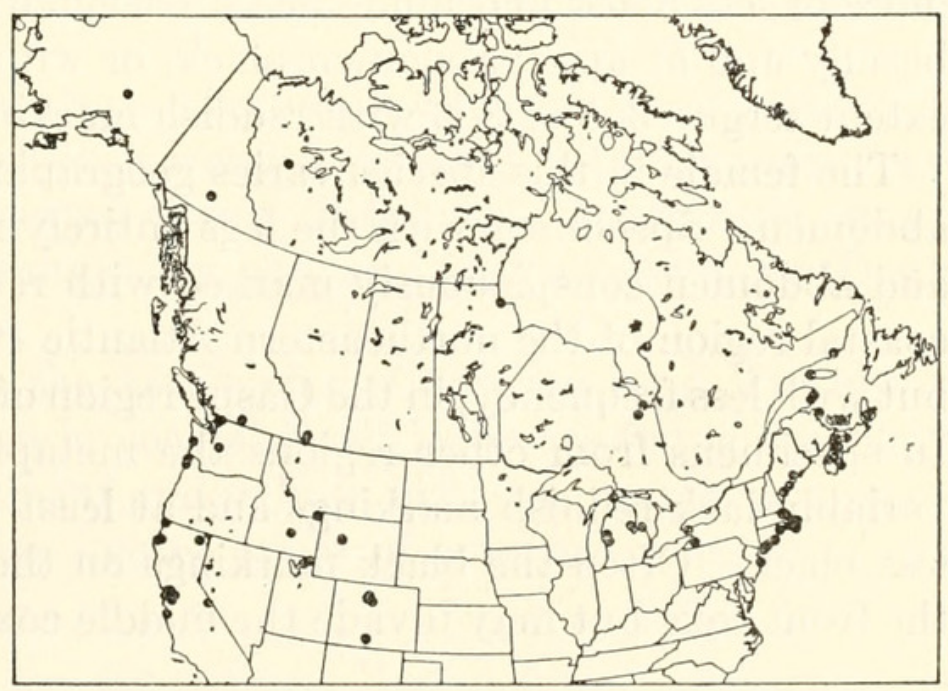


separated by a broad pale reddish to ochreous median annulus that is sometimes interrupted by a fuscous line beneath (the annuli usually distinct but not sharply delimited); hind tarsus brownish to fuscous, with bases of segments 1-3 dull yellowish; pattern of hind tibia and tarsus sometimes faintly repeated in middle leg.

Female: Front wing 3.5 to $8.0 \mathrm{~mm}$. long; antenna with 20 to 24 segments; ocelli small, lateral ocellus with diameter 0.66 times distance from ocellus to eye; cheek about 0.33 breadth of mandible at base; temple, as seen from above, with anterior 0.5 weakly rounded and posterior 0.5 strongly rounded to occiput; thorax moderately stout; propodeum unusually short, subhorizontal on about basal 0.4 and beyond rather abruptly and strongly declivous; dorsomedial carinae of propodeum moderately to rather strongly elevated, subparallel on subhorizontal portion of propodeum (at apex of which they are sometimes united by a more or less distinct, transverse carina) and often rather abruptly and strongly divergent beyond; sides and dorsal region of basal 0.4 of propodeum with numerous, large, shallow punctures, base of declivous portion more or less transversally, finely, irregularly rugulose; hind femur 3.6 to 4.0 times as long as deep; abdomen stout; tergite 1 usually distinctly broader than long, with sides and apex of central area moderately to densely punctate; tergites $2-7$, except on apices, with numerous, fairly evenly distributed punctures that are most distinct on tergites 2 and 3 and progressively shallower and less distinct on successive tergites; sheath as long as abdomen; ovipositor moderately compressed and with a distinct nodus.

Black, occasionally with reddish marking on metapleurum and abdomen. Flagellum as in male; maxillary palpus yellowish to fuscous; labial palpus fuscous; tegula and hind angle of pronotum yellowish; stigma blackish, usually with margins narrowly but rather conspicuously pale yellowish; metapleurum sometimes (in specimens having abdomen more or less red) with a reddish spot; legs varying from entirely reddish to reddish with coxae and sometimes trochanters more or less black and hind tibia occasionally somewhat fuscous subbasally and at apex; abdomen black, or with tergite 2 and to a lesser extent tergite $3-5$ or 3-6 with reddish markings.

The female in this species varies geographically in color of legs and abdomen. Specimens with the legs entirely red and the metapleurum and abdomen conspicuously marked with reddish predominate in the coastal region of the northeastern Atlantic states, and are also found, but with less frequency, in the Gaspé region of Quebec and in Michigan. In specimens from other regions the metapleurum and abdomen invariably lack reddish markings and at least the front coxa is more or less black. Often the black markings on the legs are not confined to the front coxa but may invade the middle coxa (beginning at the base) 
and extend to include more or less of the hind coxa and the trocbanters. The species varies clinally in coxal color, the frequency of specimens exhibiting the maximum black increasing in the direction of the northern extensions of its range.

Specimens $\left(59 \sigma^{7}, 177\right.$ ) : From Alaska (King Salmon on Naknek River, Kodiak, Mount McKinley at 1,700 and 2,500 ft., and Nome); Alberta (Waterton and Waterton Lakes) ; British Columbia (Osoyoos); California (Antioch in Contra Costa Co., Berkeley, Bishop, Bixby Creek in Monterey Co., Canby in Modoc Co., Crescent City, Eureka, La Jolla, "Miles," Palo Alto in San Mateo Co., Samao Beach in Humboldt Co., and San Francisco); Colorado (near Estes Park, Grand Lake, Great Sand Dunes National Monument in Alamosa Co., and Pbantom Valley in Rocky Mountain National Park at 9,400 ft.); Idaho (Bear Pass Creek in Butte Co., and Targhee Pass); Maine (Boothbay, Kennebunkport, and Orrs Island); Manitoba (Churcl ill); Massachusetts (Barnstable, Beach Bluff, Chelsea, Gloucester, Hyannis Port, Lynn Beach, Manomet, Provincetown, Tisbury, Truro, and Woods Hole); Michigan (Alabaster, "Big Stone Bay," Huron Co., Mackinac Co., Manistee Co., and Mason Co.); Newfoundland (Harmon Field); New Brunswick (Tabusintac); New Jersey (Seaside Park); New York (Bayville, Chautauqua Co., Long Beach on Long Island, and Orient); Northwest Territories (Norman Wells); Nova Scotia (Annapolis Royal in Kings Co., Baddeck, Berwick, Habitant, Kings Co., Ottawa House in Parrsboro, Petite Rivière, Port William, Starr's Point, Truro, and White Point Beach in Queen's Co.); Ontario (Moose Factory, Moosonee, and St. David's); Oregon (Cannon Beach and Warrenton); Prince Edward Island (Brackley Beach and Dalvay House in Canadian National Park); Quebec (Chandler, Ellis Bay on Anticosti Island, Great Whale River, Natashquan, and New Carlisle); Rhode Island (Westerly); Utab (Newton and Smithfield Canyon at 5,000 ft.); Washington (Bellingham, Birch Bay in Whatcom Co., Fort Casey on Whidby Island, Mount Rainier at 5,000 and 5,300 ft., and Westport); Wyoming (Lander); and Yukon Territory (Marsh Lake).

Hosts: The specimens studied include rearings from the following microlepidoptera: Anthophila pariana (Clemens), Choristoneura rosaceana (Harris), Laspeyresia nigricana (Stephens), Laspeyresia sp. on beach pea, Polychrosis viteana (Clemens), and Spilonota ocellana (Denis and Schiffermüller).

This species occurs in the Hudsonian, Canadian, and Transition zones. It is most common in coastal localities but is found sparingly in the interior of the continent and in both instances seems to prefer a habitat in which sandy or lighter types of soils are prevalent. At 
several stations in the Maritime Provinces of Eastern Canada it has been associated with wild legumes growing on sandy beaches.

\section{Scambus (Scambus) canadensis Walley, new species}

\section{Figures $310, \mathrm{~m} ; 312, \mathrm{a} ; 320, \mathrm{k}$}

Male: Front wing 3.5 to $5.0 \mathrm{~mm}$. long; antenna with 20 to 22 segments; cheek short, about 0.24 breadth of base of mandible; temple, as seen from above, moderately rounded and about 0.6 times as long as eye; propodeum moderately long, with dorsomedial carinae strong and extending from base to apical 0.25 , sides with irregular sculpture and dorsal area near middle more or less transversely rugulose; front femur with a very broad, rather shallow, polished excision beneath; front tibia rather stout and distinctly bent; abdomen rather stout; tergite 1 almost as broad as long with median carinae strong and extending to apex, sides and central area beyond middle rugulose; tergites 2-7 densely (in part confluently) punctate except on apices, with punctures progressively weaker on successive tergites.

Black. Pedicel and first segment of flagellum more or less pale beneath; palpi and tegula whitish to pale yellowish; stigma brownish black, with a small pale spot at base and apex; legs largely reddish; front coxa usually fuscous at base, or occasionally blackish except at apex; trochanters mostly pale yellowish; hind tibia rather indistinctly banded, narrowly yellowish at base and broadly pale yellowish brown to reddish yellow at middle, indistinctly narrowly annulate with fuscous subbasally, and broadly brownish to reddish brown at apex above; hind tarsus brownish, with base of first segment broadly, and the following segments narrowly, pale yellowish.

Female: Front wing 4.0 to $7.5 \mathrm{~mm}$. long; antenna with 21 to 23 segments; ocelli of moderate size, lateral ocellus with diameter 0.7 times distance from ocellus to eye; cheek about 0.33 breadth of

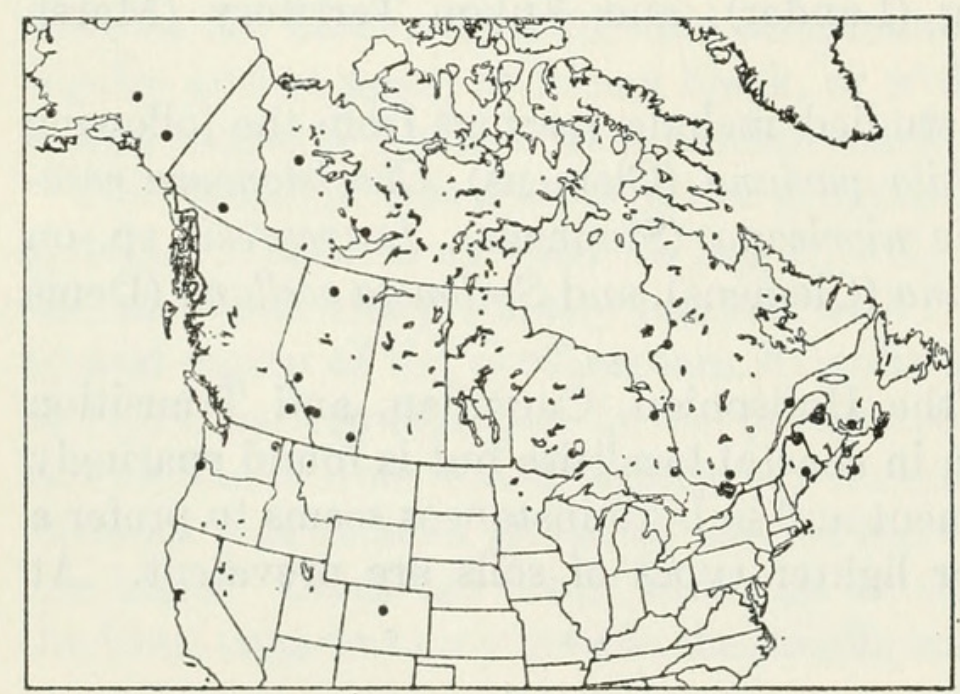

Figure 19.-Localities for Scambus (Scambus) canadensis. 
mandible at base; temple, as seen from above, rather strongly rounded; thorax and propodeum moderately stout; dorsomedial carinae of propodeum strongly elevated, slightly divergent, extending from base to apical 0.3 ; propodeum on sides with numerous, shallow, irregular punctures, and above with similar but sparser punctures near base and often more or less rugulose in region of apices of dorsal carinae; hind femur slender, 5.0 times as long as deep; abdomen moderately stout; tergite 1 as broad as long, with few distinct punctures except at apex of central area, sculpture on sides rather variable, usually very weak or absent anteriorly and elsewhere weakly to rather strongly and very irregularly rugulose; tergites 2-6 with crowded punctures except on the very broad somewhat transstriate apices; sheath as long as abdomen; ovipositor rather weakly compressed and with a distinct nodus.

Black. Clypeus, mandibles, and base of flagellum beneath, more or less piceous; apical segments of flagellum usually brownish; maxillary palpus sordid yellowish; labial palpus fuscous; hind angle of pronotum sometimes very narrowly piceous; tegula pale yellowish; wings somewhat tinged with brown; stigma blackish with a yellowish spot at base and apex; legs largely reddish; front coxa reddish brown to blackish, at least at base; hind tibia dull reddish, more or less suffused with fuscous, subbasally and at apex with indistinct fuscous annuli that are interrupted beneath; hind tarsus reddish brown to blackish, with first two segments paler at bases.

Type: $\odot$, Blackburn (near Ottawa), Ont., Sept. 16, 1946, G. S. Walley (Ottawa, No. 6754 in Canadian National Collection).

Paratypes (at Ottawa unless otherwise indicated): $3 \sigma^{\top}, 4 \%$, King Salmon on Naknek River, Alaska, Aug. 3 to 23, 1952, J. H. Hartley and W. R. Mason. 4ㅇ, Mount McKinley at 1,600, 2,000, and 2,500 ft., Alaska, Aug. 6 to 15, 1954, David Townes (Townes). ð', Summit Lake at Isabella Pass, Alaska, July 9, 1951, W. R. Mason. ㅇ, Banff, Alta., May 7, 1948, E. H. Strickland (Townes). ㅇ, Canmore, Alta., Aug. 28, 195?, A. R. Brooks. $11 \sigma^{\top}$, 4우, Elkwater Park Alta., July 7 to 30,1952, A. R. Brooks and L. A. Konotopetz. $\sigma^{7}$,, , Fort Vermillion, Alta., July 14 and 25, 1955. \&, Jasper at 6,670 ft., Alta., July 26, 1949, C. P. Alexander (Townes). 2o, Mount Revelstoke at 5,400 and 5,800 ft., B. C., Aug. 10 and 12, 1952, G. J. Spencer. $\sigma^{x}$, ᄋ, Pando, Colo., Aug. 7, 1950, R. R. Dreisbach and R. K. Schwab (Dreisbach). ๑, Fort Kent, Maine, Aug. 19, 1910 (Cambridge). \&, Orono, Maine, Sept. 15, 1913, H. M. Parshley (Cambridge). 4우, Campbellton, N. B., Sept. 20 and 24, 1947, D. F. Hardwick, o", Charlo, N. B., Aug. 24, 1954, D. R. Macdonald. б, ㅇ, Norman Wells, N. W. T., June 27 and 31,1949, W. R. Mason. $\sigma^{7}$, o, Reindeer Depot in Mackenzie Delta, N. W. T., June 28, 1948, J. R. Vockeroth. \&, Yellowknife, 
N. W. T., Aug. 16, 1949, R. R. Hall. $\sigma^{\top}$, ㅇ, Berwick, N. S., July 20 and 25, 1927, F. C. Gilliatt. $\sigma^{\nwarrow}$, King's County, N. S., Aug. 27, 1932. , St. Peters, N. S., Aug. 29, 1930, Prebble. $\sigma^{7}$, Starr's Point, N. S., July 22, 1950, D. D. Sutton. \&, Tory Creek at Guysboro, N. S., Aug. 3, 1936, T. N. Freeman. $\sigma^{7}$, ㅇ, White Point Beach, Queens Co., N. S. Aug. 3 and 17, 1935, J. McDunnough. \&, Barry's Bay, Ont., Sept. 1, 1942, G. S. Walley. ơ $^{7}$ 6\%, Blackburn, Ont., Sept. 16, 1946, G. S. Walley. $9 \sigma^{\top}$,, , Black Sturgeon Lake, Nipigon Provincial Park, Ont., July 17 to 27, 1944, N. R. Brown. o , Constance Bay, Ont., Sept. 19, 1936, O. Peck. $\sigma^{7}$, Mer Bleue, near Ottawa, Ont., May 10, 1933, G. S. Walley. $\sigma^{\top}$, + , Moose Factory, Ont., June 10 and 11, 1949, D. F. Hardwick and D. P. Gray. \&, Ottawa, Ont., May 29, 1925, C. H. Curran. ㅇ, Temagami, Ont., July 19, 1947, G. S. Walley. $20^{x}$, Cannon Beach, Oregon, Aug. 9, 1940, H. and M. Townes (Townes). + , Dalvay House in Canadian National Park, P. E. I., Aug. 8, 1940, G. S. Walley. क, Queen's Park, Aylmer, Que., Sept. 8, 1926, C. B. Hutchings. क, Cascapedia, Que., Aug. 5, 1954, W. J. Brown. 3ㅇ, Forestville, Que., August 8 and 11, 1950, J. R. McGillis and R. de Ruette. ' , Gatineau Park, Que., Sept. 2, 1956, W. R. M. Mason. 39, Great Whale River, Que., June 29, and July 7 and 18, 1949, J. R. Vockeroth. \&, Kazubazua, Que., July 18, 1935, F. A. Urquhart. $\sigma^{7}$, New Richmond on Gaspé Peninsula, Que., Aug. 6, 1954, J. E. H. Martin. \&, Colville, Wash., July 25, 1882 (Cambridge). $\sigma^{7}$, Canyon Creek, Y. T., Aug. 4, 1948, Mason and Hughes.

Host: The only host data for the species is afforded by a male and a female reared from Choristoneura conflictana (Walker) at Fort Vermillion, Alta., July 14 and 25, 1955, and a series of 9 males and 1 female reared by N. R. Brown, from Glypta fumiferanae (Viereck) which was a primary parasite of Choristoneura fumiferana (Clemens), at Black Sturgeon Lake, Ont., July 17 to 27, 1944.

This species has a transcontinental distribution in the Canadian and Hudsonian zones.

\section{Scambus (Scambus) tenebrosus Walley, new species}

Figure 312,b

Male: Front wing 3.0 to $3.25 \mathrm{~mm}$. long; antenna with 19 to 20 segments; mandible coriaceous except at apex; temple rather weakly rounded and not distinctly receding for some distance behind eye; occipital carina uniting with hypostomal carina at a distance from base of mandible equal to 0.5 times breadth of base of mandible; thorax moderately stout; propodeum rather short with dorsomedial carinae short and very weak or indistinct; legs stout; front femur simple; front tibia almost straight; abdomen moderately slender; 
tergite 1 about 1.5 times as long as broad; punctures on tergites shallow and indistinct, and often confused with other sculpture.

Black. Palpi, tegula, front and middle coxae, and trochanters, pale yellowish; front and middle femora reddish with paler apices; front and middle tibia pale reddish varying to yellowish; hind coxa blackish; hind femur brownish to brownish black; hind tibia pale yellowish with a weak, subbasal, fuscous annulus; hind tarsus brownish with a broad, pale annulus on base of segment 1 .

Female: Front wing 3.5 to $4.0 \mathrm{~mm}$. long; antenna with 19 to 20 segments; mandible, temple, and occipital carina as in male; cheek about 0.3 times breadth of base of mandible; thorax stout; propodeum short, evenly convex, without sculpture, and without dorsomedial carinae; legs rather stout; abdomen stout, with tergite 1 weakly elevated; punctures on tergites large and distinct, but rather shallow; sheath about as long as abdomen; ovipositor rather weakly compressed, with a very weak nodus.

Black. Palpi pale yellowish suffused with fuscous; tegula pale yellowish; coxae reddish brown varying to blackish; trochanters mostly brownish, the front trochanter yellowish in front; front and middle femora dull reddish, becoming paler beneath; hind femur brownish; hind tibia with narrow subbasal and broad apical fuscous annuli joined beneath by a brownish streak; pattern of hind tibia faintly repeated on front and middle tibiae; hind tarsus brownish, with first segment pale at base.

Type: \&, Poudre Lake at 11,000 ft., Rocky Mountain National Park, Colo., Aug. 12, 1948, Townes family (Washington, USNM 63746).

Paratypes: $2 \sigma^{\top}$, Workman Creek, Sierra Ancha, Ariz., Apr. 30, 1947, H. and M. Townes (Townes). \&, Mount Rainier at 4,200 ft., Wash., Aug. 11, 1940 (Townes).

Host: Unknown.

\section{Scambus (Scambus) dioryetriae Walley, new species}

FIGURE 312,c

Male: Front wing 3.5 to $5.5 \mathrm{~mm}$. long; antenna with 24 to 27 segments; temple rather broad, moderately rounded, and weakly receding; thorax and propodeum slightly elongate, the latter with distinct, dorsomedial carinae on basal 0.6 ; front femur with a very broad, shallow, somewhat oblique excision beneath; front tibia moderately and rather evenly bent; tergite 1 a little longer than broad, rugulose and punctate on sides and punctate at middle at apex; remaining tergites densely, rather coarsely punctate except on apices; clasper large and very broad. 
Black. Apical margin of scape and more or less of pedicel pale yellowish beneath; palpi, tegula, short stripe in hind angle of pronotum, front and middle coxae, and all trochanters, whitish; hind coxa and all femora reddish; front and middle tibiae reddish on apical 0.5 , becoming whitish toward base; hind tibia broadly whitish with narrow subbasal and broad apical fuscous annuli; basal segment of hind tarsus broadly, and the two following segments narrowly whitish at base.
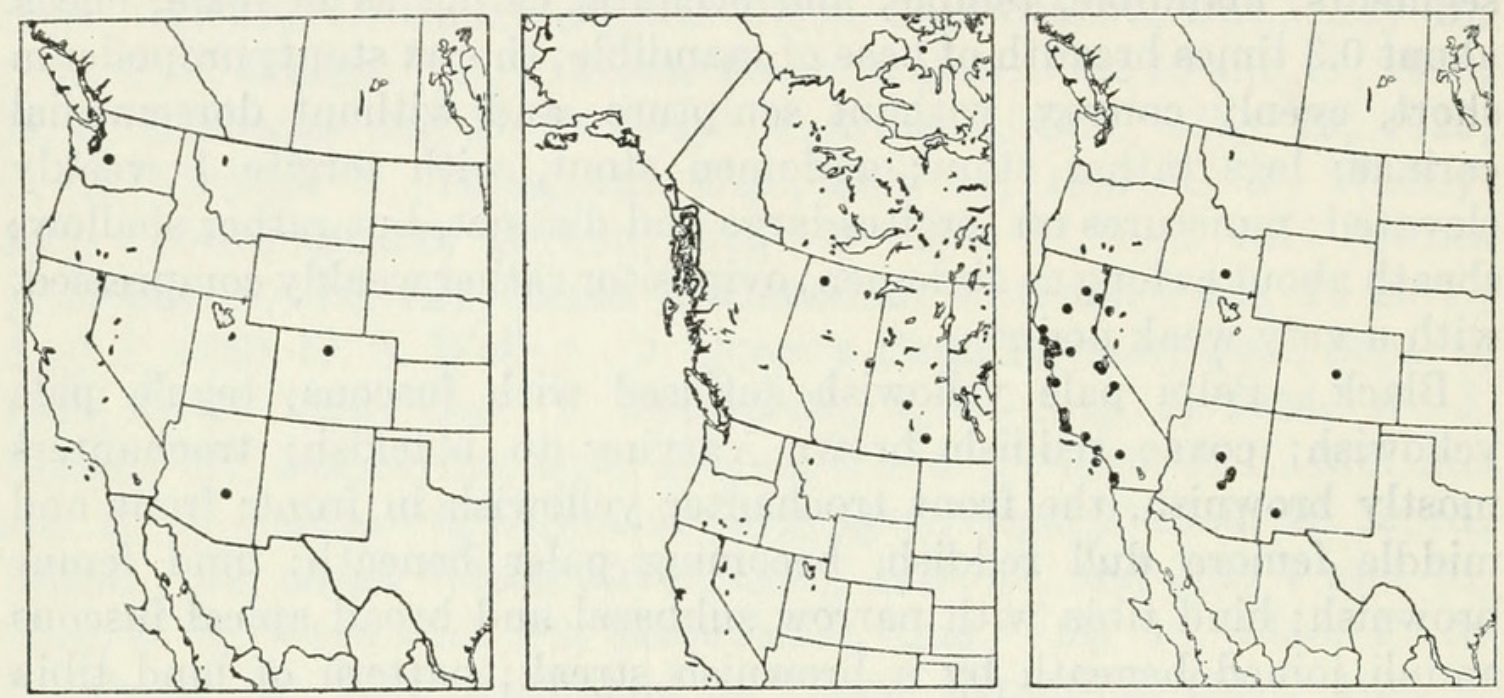

Figures 20-22.-Localities: 20 (left), Scambus (Scambus) tenebrosus; 21 (center), S. (S.) dioryctriae; 22 (right) $S$. (S.) aplopappi.

Female: Front wing 7.5 to $9.0 \mathrm{~mm}$. long; antenna with 26 to 28 segments; cheek about 0.28 times breadth of base of mandible; temple broad, rather strongly rounded, and rather weakly receding; thorax and propodeum slightly elongate, the latter with distinct, dorsomedial carinae on basal 0.6 ; tergite 1 punctate and rugulose except on basal declivity; remaining tergites with dense, distinct punctures except on apices; sheath as long as distance from tegula to apex of abdomen; ovipositor moderately compressed, and with a distinct nodus, the region beyond nodus with a minute, shallow, median, longitudinal sulcus.

Black. Clypeus brown; palpi pale yellowish more or less suffused with fuscous; tegula and short stripe in hind corner of pronotum whitish; stigma brownish black; legs mostly reddish; trochanters yellowish at apices; hind tibia with a narrow, subbasal, and a broad, apical, fuscous annulus; hind tarsus with base of first segment narrowly pale yellowish.

Type: , Indian Head, Sask., Apr. 13, 1948, reared in incubator from cone of Picea pungens, Forest Insect Survey No. 1157c (Ottawa, No. 6755, in Canadian National Collection). 
Paratypes (all in Ottawa): $2 \sigma^{\top}$,, , Indian Head, Sask., Apr. 1 to 28, 1948, reared in incubator from Picea pungens cones, Forest Insect Survey No. 1157. $\sigma^{\top}$, Indian Head, Sask., Feb. 21, 1954, emerged in laboratory from cone of Picea canadensis, Forest Insect Survey No. E30-561. क , reared from Dioryctria reniculella (Grote), Sutherland, Sask., July 25, 1939, Forest Insect Survey No. S-8-Y. ơ', emerged in laboratory from cone of Picea mariana, Grand Centre, Alta., Jan. 12, 1952. \&, emerged in laboratory from cone of Picea glauca, Upper Hay River, Alta., Feb. 5, 1952, Forest Insect Survey No. A.3948.

Host: Dioryctria reniculella (Grote).

\section{Scambus (Scambus) aplopappi (Ashmead)}

Figures 312 ,d 320,1

Pimpla aplopappi Ashmead, 1890, Proc. U. S. Nat. Mus., vol. 12, p. 446; هో. Type: $\sigma^{\top}$, Los Angeles, Calif. (Washington).

Scambus evetrivorus Rohwer, 1915, Proc. U. S. Nat. Mus., vol. 49, p. 225 ;.

Type: , Fort Bayard, N. Mex. (Washington).

Male: Front wing 3.2 to $4.8 \mathrm{~mm}$. long; antenna with 21 to 23 segments; head moderately thick; prescutum slightly gibbous; propodeum moderately long, sparsely coarsely punctate at base, and usually with a narrow sulcus between rather weak dorsal carinae that extend to about middle of dorsal surface; front femur with a broad, deep oblique excision beneath; front tibia moderately bent; abdomen slender; tergite 1 about 1.5 times as long as broad; tergite 2 a little longer than broad; sides and apex of tergite 1 rather coarsely irregularly rugose; tergites 2-7 except at apices, with numerous, coarse, shallow punctures; tergites 9 and 10 not separated by a distinct suture; subgenital plate broadly, shallowly, emarginate at apex; clasper short and rather broad at apex.

Black. Scape and pedicel brownish beneath; palpi, tegula, and a narrow, short stripe extending forward from hind angle of pronotum, whitish; front and middle legs pale reddish with coxae (except sometimes at bases), trochanters, a stripe on femora, and tibiae, whitish; hind legs reddish with trochanter beneath, a broad annulus on hind tibia (extending nearly to apex above), and three basal segments of tarsus except at apices, whitish; subbasal fuscous annulus on bind tibia vestigial, and apical annulus narrowed above; abdomen often more or less brownish.

Female: Front wing 5.0 to $8.0 \mathrm{~mm}$. long; antenna with 23 to 26 segments; ocelli of moderate size, lateral ocellus with diameter 0.85 times distance from ocellus to eye; cheek about 0.30 breadth of mandible at base; temple, as seen from above, moderately rounded; thorax and propodeum moderately stout; metapleurum finely, rather evenly punctate; dorsal carinae of propodeum short and indistinct, 
or absent; sides of propodeum densely, and dorsal region sparsely, punctate; hind femur about 4.5 times as long as deep; abdomen moderately broad; tergite 1 about as broad as long, with numerous punctures on sides and at apex of central area; tergites $2-7$, except on the weakly transstriate apices, rather densely punctate, with punctures progressively shallower and more indistinct on successive tergites; all except the first pair of sternites unusually small; sheath as long as abdomen; ovipositor rather weakly compressed and with a distinct nodus.

Black, usually with reddish suffusion or markings on abdomen, especially on sides of apical tergites; palpi pale yellowish, more or less stained with pale reddish; hind corner of pronotum with a short whitish mark; legs reddish, with trochanters more or less pale yellowish beneath; tibiae and tarsi mostly as in male, but usually with fuscous markings more distinct on hind tibia.

Specimens $\left(360^{7}, 42\right.$ \%): $\odot$, Oak Creek Canyon, Ariz., July 9, 1941, R. H. Beamer (Lawrence). ๆ, Oak Creek Canyon, Ariz., May 19, $1947, H$. and M. Townes (Townes). $\sigma^{\top}, \circ$, Parker Creek, Sierra Ancha, Ariz., Apr. 20 and 29, 1947, H. and M. Townes ('Townes). $4 \sigma^{7}$, near Roosevelt Lake, Ariz., Apr. 23 and 27, 1947, H. and M. Townes (Townes). $7 \%$, Workman Creek, Sierra Ancha, Ariz., Apr. 30, and and May 1 and 3, 1947, H. and M. Townes (Townes). \&, Berkeley, Calif., May 1, 1952, R. Schuster (Berkeley). \&, Bixby Creek, Monterey Co., Calif., Aug. 5, 1949, M. Wasbauer (Berkeley). \&, Bridge Creek Camp, Lassen Co., Calif., July 9, 1949, H. A. Hunt (Davis). ค, Corral Hollow, San Joaquin Co., Calif., Oct. 21, 1946, G. E. Bohart (Berkeley). ণ $\sigma^{7}$, Crane Flat, Yosemite Park, Calif., July 22, 1948, Townes family (Townes). \&, Grover City, San Luis Obispo Co., Calif., July 4, 1956, P. D. Hurd (Berkeley). ' o, Inverness, Marin Co., Calif., March 31, 1949, P. D. Hurd (Berkeley). \&, La Jolla, Calif., July 13, 1941, R. H. Beamer (Lawrence). ㅇ, La Jolla, Calif., July 13, 1941, E. L. Todd (Lawrence). $12 \sigma^{\top}$, 3\%, Lake Tenaya, Yosemite Park, Calif., July 29, 1949, reared in laboratory, Jan. 24, 1950, July 27 and Aug. 1 and 17, 1951 (Ottawa). $\sigma^{x}$, o, Lake Tenaya, Yosemite Park, Calif., July 10, 1953, J. H. McLeod (Ottawa). क् Lompoc, Calif., Aug. 9, 1938, R. H. Beamer (Lawrence). 2 \%, Lone Pine, Calif., July 28, 1940, D. E. Hardy (Lawrence). Aug. 10, 1938, L. W. Hepner (Lawrence). o, Mount Lassen at 8,000 ft., Calif., Aug. 31, 1936, T. D. A. Cockerell (San Francisco). \%, Oakland, Calif., May 1936, E. S. Ross (Townes). ㅇ, Occidental, Sonoma Co., Calif., Sept. 16, 1938, R. H. Beamer (Lawrence). $40^{\top}$, Pentz in Butte Co., Calif., June 11, 14, 16, and 17, 1928, H. H. Keifer (San Francisco). $\quad$ \&, Pescadero, San Mateo Co., Calif., May 9, 1954, M. Wasbauer (Berkeley). क, Pismo Beach, San Luis Obispo Co., Calif., 
Aug. 5, 1951, W. D. Murray (Berkeley). क, San Diego, Calif., Aug. 26, 1891, F. E. Blaisdell (San Francisco). $40^{\pi}$, San Francisco, Calif., Mar. 23, 25, and 29, 1926, H. H. Keifer (San Francisco). \&, Santa Catalina Island, Calif., Aug. 31, 1936, T. D. A. Cockerell (San Francisco). क, Tamarack Flat, Yosemite Park, Calif., July 24, 1948, Townes family (Townes). क् Tesla, Alameda Co., Calif., Sept. 19, 1950, F. Morishita (Berkeley). \&, Upper Santa Ana River, San Bernardino Co., Calif., Sept. 23, 1946, G. H. and J. L. Sperry (Lawrence). $3 \sigma^{7}, 5$ o, Ventura Calif., Aug. 5 and 6, and Sept. 1, 1932 (Berkeley). क, Florissant, Colo., July 18, 1907, S. A. Rohwer (Cambridge). $60^{x}$, Minidoka Forest, Idaho, July 27 and Aug. 10, 1949, and July 29 and Aug. 30, 1950 (Ottawa).

Hosts: Reared from Recurvaria milleri Busck at Lake Tenaya, Calif.; Recurvaria sp. at Minidoka Forest, Idaho; Stomopteryx nigrella (Chambers) at San Francisco, Calif.; and Rhyacionia frustrana bushnelli at Fort Bayard, N. Mex., this reared specimen being the type of aplopappi.

This species occurs in Arizona, California, Colorado, Idaho, and New Mexico.

\section{Scambus (Scambus) transgressus (Holmgren)}

Figure 312 ,e

Pimpla transgressa Holmgren, 1868, Kongliga Svenska fregatten Eugenies resa . . . 1851-53, vol. 2 (Zoologi), pt. 12, Hymenoptera p. 405; ㅇ․ Type q , California (Stockholm).

Epiurus innominatus Viereck, 1912, Proc. U. S. Nat. Mus., vol. 42, p. 149; . New synonymy. Type: , Esquimalt, B. C. (Washington).

Male: Front wing 3.5 to $4.5 \mathrm{~mm}$. long; antenna with 21 to 22 segments; temple strongly rounded and rather strongly receding; thorax and propodeum moderately stout, the latter with dorsomedial carinae usually rather weak and extending a little beyond middle; legs moderately stout; front femur with a weak, double excision beneath; front tibia very weakly, evenly bent; abdomen moderately slender.

Black, with abdomen usually more or less rufopiceous. Front and middle legs entirely, or almost entirely, pale yellowish to whitish; hind coxa reddish; hind trochanter whitish; hind tibia with narrow, subbasal, fuscous annulus interrupted above.

Female: Front wing 4.5 to $7.0 \mathrm{~mm}$. long; antenna with 21 to 24 segments; cheek about 0.33 times breadth of mandible at base; temple strongly rounded and moderately receding; thorax moderately stout; propodeum rather short, with dorsomedial carinae weak to indistinct except at base and not extending beyond middle; abdomen moderately stout; segments $2-5$ with unusually large sternites; sheath about as long as abdomen; upper valve of ovipositor with a distinct nodus. 
Black, usually with abdomen, and frequently sides of thorax and of propodeum, more or less reddish. Pedicel and base of first segment of flagellum pale yellowish beneath; clypeus, mandible, and adjoining region of gena often reddish brown; palpi, tegula, and a rather large spot in hind corner of pronotum yellowish white; tergite 1 entirely, and other tergites at apices, black to brownish black; remainder of tergites varying from almost entirely black to entirely dull reddish; legs reddish, with front and middle trochanters pale yellowish; hind tibia and bases of first three segments of hind tarsus with broad whitish annuli; subbasal fuscous annulus of hind tibia interrupted above.

Females of this species having the abdomen more or less reddish are liable to be confused with the female of aplopappi but may be distinguished by the much larger abdominal sternites and the differences in the markings on the legs noted in the key.

Specimens $\left(14 \sigma^{7}, 67 \%\right): 4 \sigma^{7}$, , Colwood, B. C., July 5 and 23, 1929, W. H. A. Preece (Ottawa). 3ㅇ, Courtenay, B. C., Mar. 21 and Apr. 21, 1931 (Ottawa). 2ᄋ, Cultus Lake, B. C., Oct. 21 and 22, 1938, J. K. Jacob (Ottawa). \&, Cultus Lake, B. C., July 13, 1948, H. R. Foxlee (Ottawa). 2\%, Duncan, B. C., July 10, 1910, and July 4, 1911 (Ottawa). 29, Duncan, B. C., July 12 and December 1928, W. G. Mathers (Ottawa). $\sigma^{\top}, 2$, Esquimalt, B. C., July 10, 1911 (Ottawa). \&, Forbidden Plateau, Vancouver Island, B. C., July 13, 1935, J. D. Gregson (Ottawa). ף, Langford, B. C., June 8, 1941, K. Graham (Ottawa). 7\%, Malahat, B. C., Sept. 21, 1928, W. Downes (Ottawa). 2\%, Robson, B. C., June 1 and 23, 1948, H. R. Foxlee (Ottawa). $\quad$, Saanich, B. C., May 1929, W. H. A. Preece (Ottawa). 4ㅇ, Vancouver, B. C., July 8, 1915, R. N. Crystal (Ottawa). $20^{7}$, 5\%, Vancouver, B. C., July 8 and 24 and Aug. 1, 4, 5, 9, and 11, 1930, H. B. Leech (Ottawa). 2\%, Vancouver, B. C., 1925, K. E. Schedl (Ottawa). क, Victoria, B. C., June 1, 1900, G. W. Taylor (Ottawa). ๑, Victoria, B. C., Apr. 15, 1917, A. E. Cameron (Ottawa). o', Victoria, B. C., July 11, 1941, K. Graham (Ottawa). $2 \sigma^{\top}, 4$, Alameda Co., Calif., Jan. 27, 1917, J. C. Bridwell (Berkeley). 4\%, Crescent City, Calif., Aug. 1 and 2, 1940, H. and M. Townes (Townes). 9ㅇ, Muir Woods, Marin Co., Calif., Aug. 20, 1908, J. Ch. Bradley (Ithaca). + , Muir Woods, Marin Co., Calif., Apr. 23, 1911, E. C. Van Dyke (San Francisco). $\sigma^{\top}$, University of California Campus, Berkeley, Calif., Feb. 22, 1956, W. W. Middlekaufi (Berkeley). \&, Lake Waha, Idaho, June 9, 1918, A. L. Melander (Cambridge). ð', 2\%, Cannon Beach, Oreg., Aug. 6, 9, and 11, 1940, H. and M. Townes (Townes). 2\%, Ashford, Wash., July 10, 1940, H. and M. Townes (Townes). 3\%, Bellingham, Wash., June 3 and 19, 1944, R. D. Shenefelt (Madison). $\sigma^{7}$, Carters Point on San Juan Island, Wash., 
July 23, 1944, W. W. Baker (Madison). 3\%, Mount Rainier at $2,900,3,500$, and $3,800 \mathrm{ft}$., Wash., July 7,12 , and $15,1940, \mathrm{H}$. and M. Townes (Townes). $\sigma^{7}$, Valleyford, Wash., June 25, 1924, A. L. Melander (Cambridge).

Hosts: This species has been reared on a number of occasions in the Vancouver region of British Columbia from Acleris variana (Fernald) and Choristoneura fumiferana (Clemens). Other records include rearings from Archips rosanus (Linnaeus) and Grapholitha packardi (Zeller) at Vancouver, B. C., Anthophila pariana (Clemens) at Bellingham, Wash., and a nematine stem gall on Salix at Valleyford, Wash.

This species occurs in the western part of the Transition zone, at low elevations and especially in coastal regions, from southwestern British Columbia to central California.

\section{Scambus (Scambus) tecumseh Viereck}

FIGURE $310, \mathrm{i}, 1 ; 312, \mathrm{f} ; 321$, a

Scambus (Scambus) tecumseh Viereck, 1917, Bull. Connecticut Geol. Nat. Hist. Surv., No. 22, p. 320; + . Type: $q$, West Haven, Conn. (Connecticut Agr. Exp. Sta., New Haven).

Male: Front wing 2.0 to $5.5 \mathrm{~mm}$. long; antenna with 20 to $22 \mathrm{seg}$ ments; temple moderately rounded and rather strongly receding; thorax and propodeum rather stout, the latter usually with distinct dorsomedial carinae extending a little beyond middle; front femur rather stout, with a moderately distinct double excision beneath; front tibia distinctly, evenly bent; abdomen moderately stout; tergite 1 about 1.3 times as long as broad.

Black. Front and middle coxae, and all trochanters, whitish; hind coxa reddish, occasionally varying to more or less fuscous; front femur
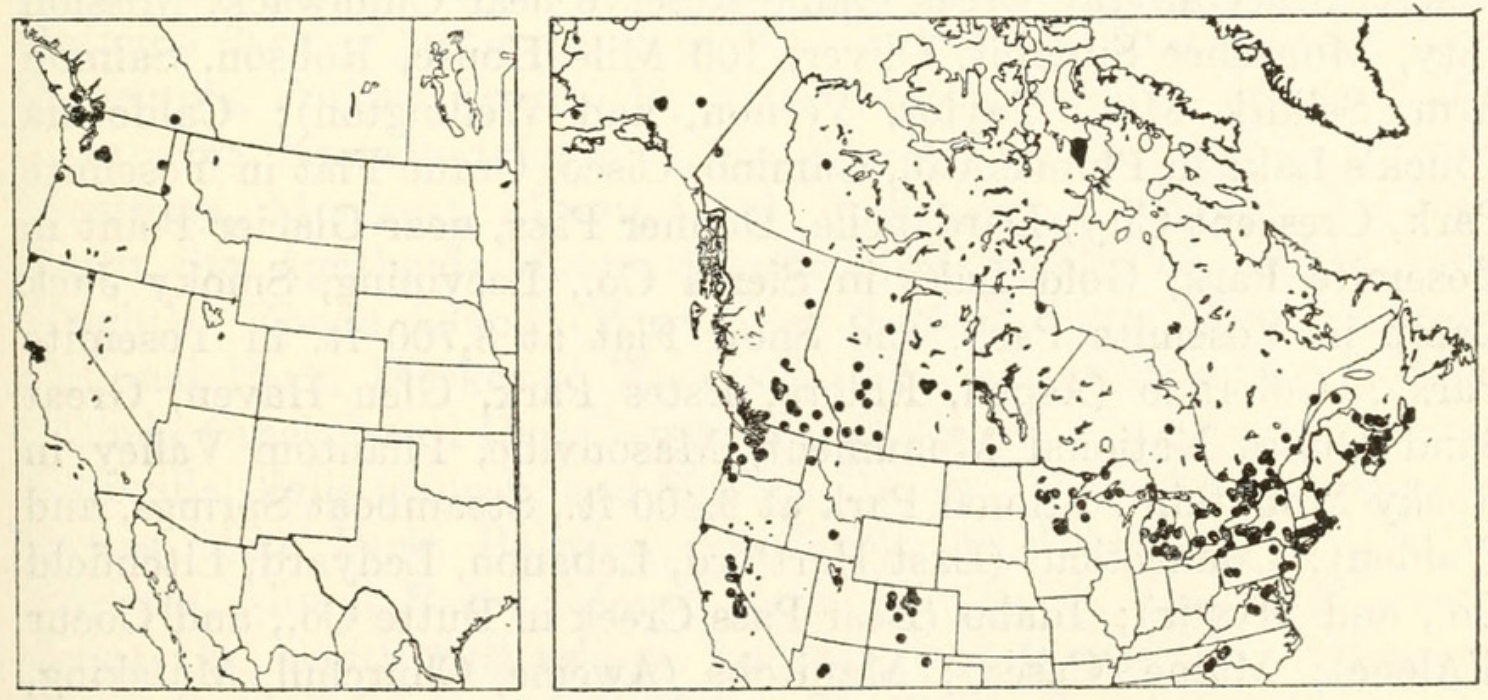

Figures 23, 24.--Localities: 23 (left), Scambus (Scambus) transgressus; 24 (right), S. (S.) tecumseh. 
and tibia reddish; middle femur and tibia reddish above, varying to whitish beneath; hind tibia with subbasal fuscous annulus complete.

Female: Front wing 4.5 to $8.5 \mathrm{~mm}$. long; antenna with 21 to 24 segments; cheek about 0.35 times breadth of base of mandible; temple strongly rounded and rather weakly receding; thorax moderately stout; propodeum rather short and usually with short, rather weak, dorsomedial carinae; sheath about as long as or a little longer than abdomen; ovipositor with a distinct nodus.

Black. Palpi usually tinged with fuscous; tegula and spot in hind corner of pronotum whitish; stigma blackish; legs mostly red; hind tibia and basal two or three segments of hind tarsus whitish with fuscous annuli, the subbasal fuscous annulus on hind tibia complete and often joined with the apical annulus by a narrow fuscous streak beneath; pattern of hind tibia faintly repeated on front and middle tibiae.

This species may not prove to be distinct from buolianae (Ratzeburg) of Europe. I have been unable to distinguish females, and males appear to differ only in slight details in the structure of the front femur. In the male of tecumseh the median swelling on the underside of the femur that gives rise to the double emargination is usually distinct only on the anterior margin of the femur, whereas in buolianae it usually extends across the femur almost to the posterior margin.

Specimens $\left(85 \sigma^{x}, 551\right.$ ) $)$ : From Alaska (Anchorage, King Salmon on Naknek River, Mount McKinley at 1,600, 1,700, 2,000, and 2,500 ft., and Shaw Creek at Mile 289 on the Richardson Highway); Alberta (Camrose, Cowley, Edmonton, Elkwater Park, Lake Louise, Lethbridge, McMurray, Red Deer, and Rockyford); Arizona (Chiricahua Mts., Flagstaff, and Oak Creek Canyon); British Columbia (Bowser, Chilcotin, Clinton, Cultus Lake, Delta, Fernie, Fort Nelson, Jesmond, Likely, MacGillivray Creek Game Reserve near Chilliwack, Mission City, Monashee Summit, Oliver, 100 Mile House, Robson, Salmon Arm, Selkirk Mts., Taylor, Vernon, and Wellington); California (Buck's Lake in Plumas Co., Camino, Cisco, Crane Flat in Yosemite Park, Crescent City, Dardanelle, Donner Pass, near Glacier Point in Yosemite Park, Gold Lake in Sierra Co., Leevining, Smoky Jack Camp in Yosemite Park, and Snow Flat at 8,700 ft. in Yosemite Park); Colorado (Aspen, Eldora, Estes Park, Glen Haven, Great Sand Dunes National Monument, Masonville, Phantom Valley in Rocky Mountain National Park at 9,400 ft., Steamboat Springs, and Walden); Connecticut (East Hartford, Lebanon, Ledyard, Litchfield Co., and Mystic); Idaho (Bear Pass Creek in Butte Co., and Coeur d'Alene); Maine (Casco); Manitoba (Aweme, Churchill, Mafeking, and Red Deer River); Maryland (Takoma Park); Massachusetts 
(Holliston, Jamaica Plain, Lexington, Milton, Needham, and Revere); Michigan (Alger Co., Ann Arbor, Bath, Bay Co., East Lansing, Houghton Co., Ingham Co., Isabella Co., Isle Royale, Kent Co., Livingston Co., Luce Co., Mackinac Co., Marquette Co., Mason Co., Midland Co., Newaygo Co., Roscommon Co., and Tuscola Co.); Minnesota (Cass Co., Cook Co., Fort Snelling, Hennepin Co., Itasca Park, Lake Co., Laporte, St. Anthony Park, St. Louis Co., and St. Paul); New Brunswick (Greys Mills, Tabusintac, and Waweig); New Hampshire (Lake of the Clouds at 5,000 ft. on Mount Washington); New Jersey (Moorestown); New Mexico (Cimarron); New York (Bemus Point, Canajoharie, Farmingdale, Gasport, Hunter in Greene Co., Ithaca, Lake Mohonk in Ulster Co., Lake Sebago in Bear Mountain Park, McLean Reserve in Tompkins Co., Mount Marcy, Newark in Wayne Co., Oak Orchard Swamp in Genesee Co., Oneonta, Poughkeepsie, Ringwood in Tompkins Co., Slaterville, and Spring Lake in Cayuga Co.); North Carolina (Black Mts., Cedar Mt., Crabtree Meadows in Yancey Co. at 3,600 ft., Mount Mitchell, and Mount Pisgah at 5,000 to 5,749 ft.); Northwest Territories (Cameron Bay on Great Bear Lake, and Norman Wells); Nova Scotia (Aldershot, Berwick, Blomidon, Canard, Habitant, Kings Co., Kingston, Medford, Parrsboro, Petite Rivière, St. Peters, Smiths Cove, Starr's Point, Truro, and Waterville); Ontario (Belleville, Bells Corners, Blackburn, Bobcaygeon, Brighton, Cainsville, Constance Bay, Eldorado in Hastings Co., Galetta, Greely, Ingersoll, Kingston, London, Manotick, Mansfield, Marmora, Mer Bleue near Ottawa, Merivale, Merrickville, Niagara Falls, Orillia, Ottawa, Paris, St. Davids, Smoky Falls on Mattagami River, Southampton, Thornbury, Timagami, Uxbridge, Vernon, Vittoria, and Winchester); Oregon (Cannon Beach, McMinnville, and Seaside); Pennsylvania (Ingram, Lake Pleasant in Erie Co., Philadelphia, Pittsburgh, and Spring Brook); Prince Edward Island (Alberton, Charlottetown, and Dalvay House in Canadian National Park); Quebec (Aylmer, Beechgrove, Cap Rouge, Deschenes, Forestville, Fulford, Gracefield, Hemmingford, Hull, Ile de Montreal, Kazabazua, Knowlton, Lachine, Lac Mercier, Lacoste, Laniel, Marks, Montigny, Montreal, Mount Lyall, Nominingue, Norway Bay, St. Esprit, Ste. Agathe de Monts, Stoneham, Wakefield, Westmount, and Wright); Rhode Island (Westerly); Saskatchewan (Prince Albert National Park, Waskesiu, Waskesiu Lake, and White Fox); Utah ("Chalk Creek," and Dry Canyon in Salt Lake Co.); Virginia (Charlottesville, Falls Church, and Skyline Drive); Washington (Ashford, Barnes State Park, Bayview, Birch Bay in Whatcom Co., Elbe, Marietta, Mount Baker, Mount Rainier, Quilcene, San Juan Island, Skagit Co., South Bellingham, Tacoma, and Westport); Wisconsin (Clark Co. and Sawyer Co.); Yukon Territory (Snag). 
Hosts: Specimens examined include rearings from Acleris sp. on Cornus, Choristoneura conflictana (Walker), C. fumiferana (Clemens), Endothenia hebesana (Hübner), Exotelia dodecella (Linnaeus), Lymnaecia phragmitella (Stainton), Malacosoma pluviale (Dyar), Phalonia rutilana (Hübner), Recurvaria sp., Sparganothis sulphureana Clemens, Spilonota ocellana (Denis and Schiffermüller), Trichotaphe levisella (Fyles) and Rhyacionia buoliana (Schiffermüller).

This is one of the commonest Nearctic species. It has a transcontinental distribution and is especially abundant in the Transition and Canadian zones.

\section{Scambus (Scambus) nucum (Ratzeburg)}

Figure $312, \mathrm{~g}$

Pimpla nucum Ratzeburg, 1844, Die Ichneumonen der Forstinsecten

vol. 1, p. 115. Type: $\%$, Germany (destroyed in World War II).

Male: Front femur with a distinct double excision beneath, the excised regions with distinct coriaceous sculpture; structure otherwise as in males of tecumseh.

Hind coxa usually fuscous; hind femur usually more or less suffused with blackish color; otherwise as in tecumseh.

Female: Structure as in tecumseh.

Hind angle of pronotum with a very small or indistinct yellowish spot; stigma translucent yellowish brown; color otherwise as in tecumseh.

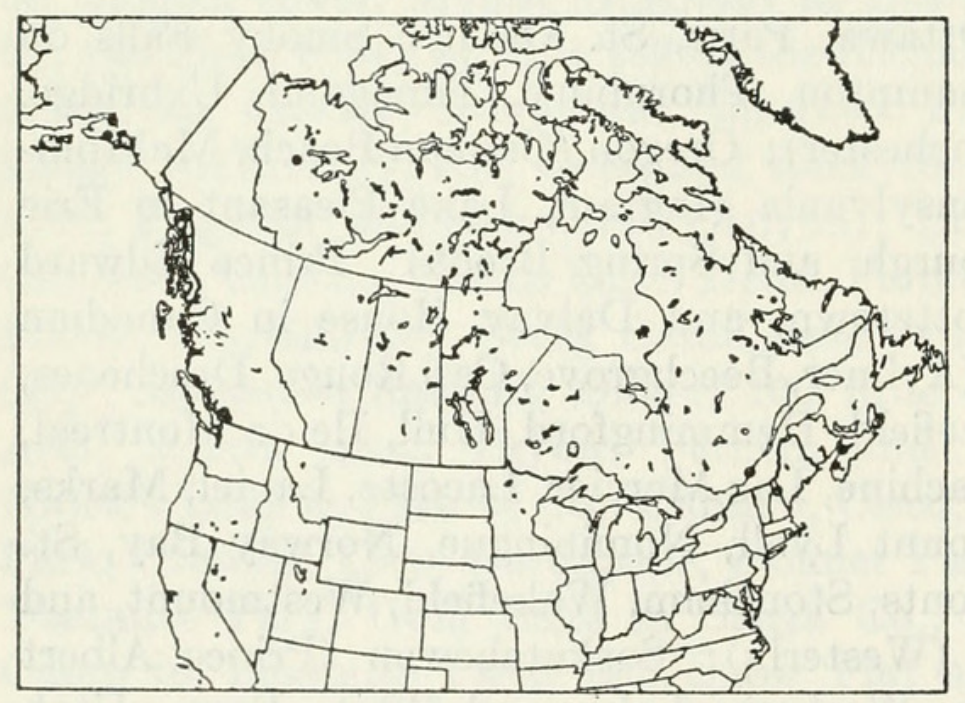

Figure 25.-Localities for Scambus (Scambus) nucum.

Specimens $\left(8 \sigma^{\pi}, 15 \%\right)$ : From Alaska (Hope on Kenai Peninsula, Seward, and Taku Glacier near Juneau); British Columbia (Mission City and Diamond Head trail at 3,200 ft., near Squamish); New Hampshire (Lake of the Clouds at 5,000 ft. on Mount Washington); Northwest Territories (Norman Wells); Nova Scotia (Blomidon and Annapolis); Quebec (Berthierville). 
This species has not previously been recorded from North America. Nearctic specimens have been compared with European examples of nucum (the latter supplied through the kindness of Mr. J. F. Perkins) and no significant differences have been found. The Nearctic material shows a small amount of variation, especially in color, and the specimens from Alaska agree a little more closely with the European specimens of nucum than do the specimens from eastern Canada. The two species that nucum most closely resembles are the Nearctic tecumseh and the Palearctic buolianae. It is distinguished from both species in the male by the coriaceous excision of the front femur and in the female by the translucent, pale brownish stigma.

Host: Specimens from Blomidon, N. S., were reared from Spilonota ocellana (Denis and Schiffermüller).

\section{Scambus (Scambus) hispae (Harris)}

Figures $310, \mathrm{k} ; 312$, h; 321,b

Ichneumon hispae Harris, 1835, Boston Journ. Nat. Hist., vol. 1, p. 149; . Type: ${ }^{2}$ Massachusetts (Cambridge).

Pimpla indagatrix Cresson, 1870, Trans. Amer. Ent. Soc., vol. 3, p. 146; ơ Type: $\sigma^{7}$, Illinois (Philadelphia).

Pimpla minuta Weed, 1887, Bull. Illinois State Lab. Nat. Hist., No. 3, p. 41; $\sigma^{\top}$. Type: $\sigma^{7}$, Urbana, Illinois (Urbana).

Pimpla gossypii Ashmead, 1890, Proc. U. S. Nat. Mus., vol. 12, p. 445; ㅇ. Type: ○, Selma, Alabama (Washington).

Male: Front wing 3.5 to $5.5 \mathrm{~mm}$. long; antenna with 21 to 23 segments; temple moderately rounded and rather strongly receding; thorax and propodeum rather stout, the latter usually with distinct, dorsomedial carinae extending a little beyond middle; front femur rather stout and entire except for a very weak preapical excision beneath; front tibia very weakly, rather evenly bent; abdomen moderately stout; tergite 1 slightly longer than broad, rugose on sides and at apex; following tergites except on apices finely and densely punctate, the punctures often confused with fine, rugose sculpture.

Black. Scape and pedicel beneath, palpi, tegula, and hind angle of pronotum pale yellowish to whitish; front and middle legs and hind trochanters pale yellowish white; hind coxa and femur reddish, the latter narrowly fuscous at apex; hind tibia with a narrow, weak, often incomplete fuscous annulus near base, and a broader, complete, fuscous annulus at apex; basal 3 segments of hind tarsus whitish with fuscous apices.

Female: Front wing 4.0 to $7.5 \mathrm{~mm}$. long; antenna with 20 to 24 segments; cheek about 0.25 times breadth of base of mandible; temple moderately rounded and rather strongly receding; thorax moderately stout; propodeum rather short and usually with short and weak to indistinct dorsomedial carinae; basal segment of hind tarsus distinctly 
longer than the 3 following segments combined; sheath as long as or a little longer than abdomen; ovipositor moderately compressed and with a distinct nodus.

Black. Palpi, tegula, and spot in hind corner of pronotum, whitish; stigma blackish, legs mostly reddish, front trochanter and often apices of middle and hind trochanters, whitish; hind tibia with narrow subbasal and a broader apical fuscous annulus; hind tarsi with basal 3 segments whitish with fuscous apices.

Specimens (179 $\left.\sigma^{7}, 397 \%\right)$ : From Alabama (Selma); Alaska (Haines); Alberta (Jasper National Park, McMurray, and Waterton Lakes); Arizona (Parker Creek in Sierra Ancha, Pocket Creek in Sierra Ancha, and Workman Creek in Sierra Ancha); British Columbia (Cultus Lake, Lyon, Pemberton, and Robson); California (Camino, Donner Pass, Inverness, Leevining, Palmdale, Smoky Jack Camp in Yosemite Park, and near Sonora Pass); Colorado (near Estes Park and Phantom Valley at 9,400 ft. in Rocky Mountain National Park); Connecticut (Canterbury and Woodstock); Delaware (Newark); Idaho (Moscow Mountain and Wallace); Illinois (Rantoul and Urbana); Kansas (Doniphan Co. and Lawrence) ; Maine (Mount Desert, Orono, Pittston and Strong); Maryland (Hughesville, Ringgold, near Rockville, and Takoma Park); Massachusetts (Barnstable, Boston, Holliston, Humarock, Petersham, Sharon, South Hadley, and Wellfleet); Michigan (Ann Arbor, Bay City, Douglas Lake, East Lansing, George Reserve in Livingston Co., Kalkaska Co., Keweenaw Co., Marquette Co., Midland Co., Missaukee Co., Monroe Co., Newaygo Co., Old Mission, Roscommon Co., and Traverse City); Minnesota (Cass Co., Chisago Co., Duluth, Kawishiwi River, Mississippi bluff in Houston Co., Ottertail Co., St. Anthony Park, and St. Paul); Montana ("Columbia," Glacier National Park, and Jefferson Island); New Brunswick (Campbellton and Fredericton); Newfoundland (Goose Bay); New Hampshire (Franconia, Lake of the Clouds on Mount Washington at 5,000 ft., summit of Mount Washington, and Randolph); New Jersey (Chesilhurst and Moorestown); New York (Bemus Point, Bethany, Elmira, Farmingdale, Fredonia, Hilton, Ithaca, Lake Sebago in Bear Mountain State Park, Lexington in Greene Co., Poughkeepsie, Shokan, and Yonkers) ; North Carolina (Burnsville, Crabtree Meadows in Yancey Co. at 3,600 ft., Mount Pisgah at 4,800 to 5,300 ft., and Wake Co.); Northwest Territories (Norman Wells); Nova Scotia (Aldershot, Annapolis, Baddeck, Berwick, Blomidon, Canard, Coldbrook, Kings Co., Northville, Parrsboro, Rockland, South Milford, South Waterville, Sydney, Tory Creek in Guysboro Co., Welsford, and White Point Beach in Queens Co.); Ohio (Barberton in Summit Co.); Ontario (Algonquin Park, Ailsa Craig, Arnprior, Bells Corners, Brantford, Brighton, Brule Lake, Carleton Co., Chalk River, Con- 
stance Bay, Dundas, Dunrobin, Eels Lake, Forest, Golden Lake, Grenfell, Hastings Co., Hawk Lake, Hillsdale, Hudson, Kapuskasing, Jordan, Mansfield, Mattawa, Meldrum Bay, Mer Bleue near Ottawa, Merivale, Mildmay, Milnet, Moose River Crossing, Niagara Falls, Nicholson, Normandale, Ottawa, Oxford Station, "Peffer," Port Colbourne, Queenston, Rockcliffe, Rutter, St. Charles, St. Davids, Searchmont, Sheguiandah, Simcoe, Skead, Spencerville, Sudbury, Toronto, Tweed, Uxbridge, Vermilion Bay, Vineland Station, Williamston, and Wyevale); Pennsylvania (Crisp in Westmoreland Co., Pittsburgh, and Spring Brook); Prince Edward Island (Brackley Beach in Canadian National Park and Dalvay House in Canadian National Park); Quebec (Berthierville, Cap Rouge, Cascapedia River, Cross Point, Gracefield, Hull, Kazabazua, Lachine, Lac Mondor at Ste. Flore, Montreal, Mount Albert at 3,000 to 3,200 ft., Nominingue, Wakefield, and Wright); Rhode Island (Ashaway, and Westerly); South Carolina (Clemson, Greenville, and Venus in Greenville Co.); Vermont (Rutland); Virginia (Charlottesville, Falls Church, and Skyline Drive); Washington (Olympia at 5,000 ft., Port Angeles, and Whatcom Co.); West Virginia (Philippi in Barbour Co.); Wisconsin (Door Co., Madison, Pierce Co., Rib Mountain State Park, Sawyer Co., and Trempealeau Co.); and Yukon Territory (Marsh Lake).
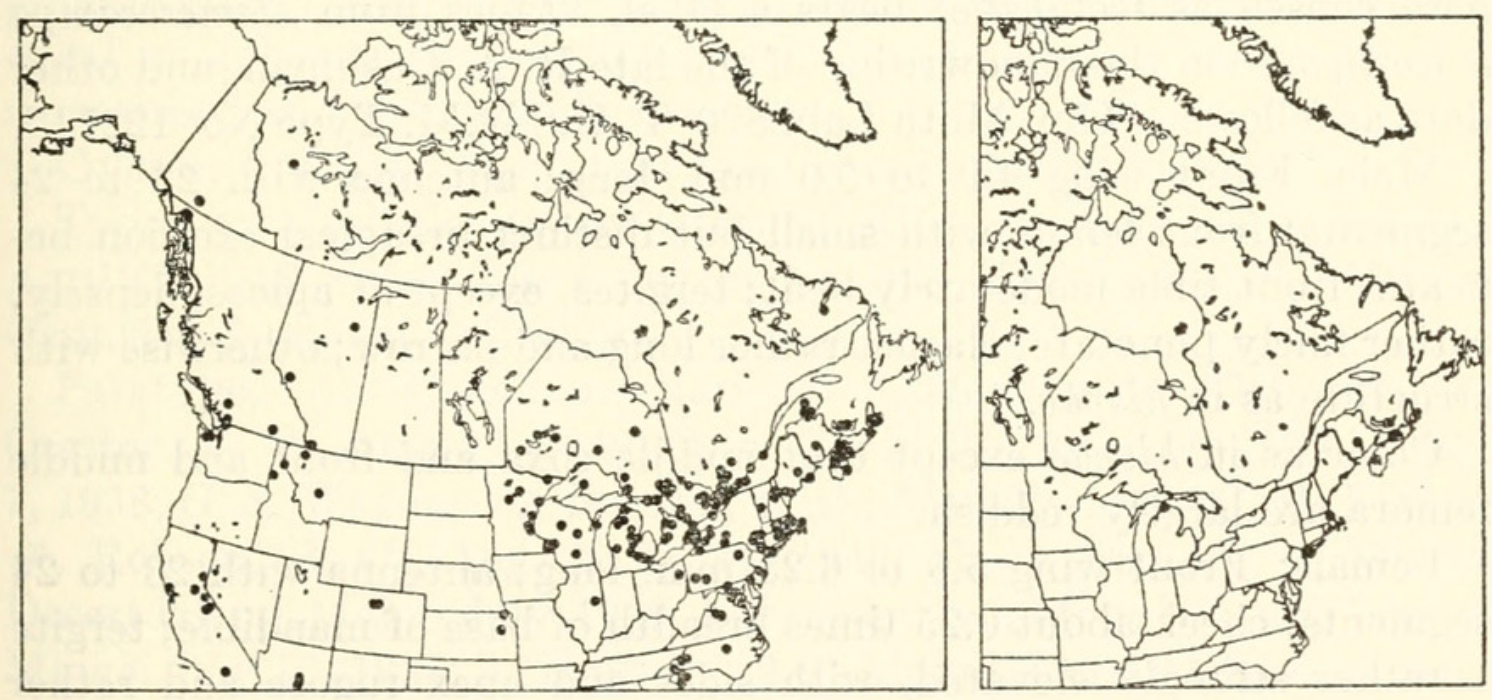

Frgures 26, 27.-Localities: 26 (left), Scambus, (Scambus) hispae; 27 (right), S. (S.) nigrifrons.

Hosts: Specimens examined include rearings from Acrobasis betulella Hulst, A. comptoniella Hulst, A. rubrifasciella Packard, Anacampsis innocuella (Zeller), Anisota rubicunda (Fabricius), Anthophila pariana (Clerck), Archips rosanus (Linnaeus), Arthrochlamys bebbianae Brown, Choristoneura fumiferana (Clemens), C. pinus 
Freeman, Coleophora pruniella Clemens, Episimus argutanus (Clemens), Exartema connectum McDunnough, Hedia variegana (Hübner), Heterarthrus nemoratus (Fallén), Laspeyresia molesta Busck, Lexis bicolor (Grote), Malacosoma disstria (Hübner), Metallus rohweri MacGillivray, Psilocorsis sp., Spilonota ocellana (Denis and Schiffermüller), Tischeria sp., and Rhyacionia buoliana (Schiffermüller).

This is a common species with a transcontinental range, mainly in the Canadian and Transition zones.

\section{Scambus (Scambus) nigrifrons (Viereck)}

Figure $312, \mathrm{i}$

Pimpla (Epiurus) nigrifrons Viereck, 1909, Proc. Ent. Soc. Washington, vol. 11, p. $211 ; \sigma^{\top}$, + . Lectotype (by present designation): $\sigma^{\top}$, ? Massachusetts (Washington).

This species was described from six males and two females without locality or host data. Information recently kindly provided by Miss L. M. Walkley, from records at the U.S. National Museum, has established that the above specimens were sent to the former "Bureau of Entomology" by W. F. Fiske. This, I believe, indicates that the specimens probably originated in New England, as at the time in question Fiske was stationed at the Gipsy Moth Laboratory near Boston, Mass. In addition, one male in the type series (the specimen here chosen as lectotype) bears a label, "types from Hemerocampa leucostigma" in the handwriting of the late R. A. Cushman, and other data as follows: "Gip. Moth Lab. 820-T, U.S.N.M. Type No. 12274".

Male: Front wing 4.0 to $5.0 \mathrm{~mm}$. long; antenna with 23 to 24 segments; front femur with small but distinct preapical excision beneath; front tibia moderately bent; tergites, except at apices, densely, rather finely punctate; clasper rather long and narrow; otherwise with structure as in hispae.

Color as in hispae except that middle coxa and front and middle femora are largely reddish.

Female: Front wing 5.0 to $6.25 \mathrm{~mm}$. long; antenna with 23 to 24 segments; cheek about 0.25 times breadth of base of mandible; tergite 1 rather strongly elevated, with sides and apex rugose and rather densely punctate; upper valve of ovipositor witbout a distinct nodus.

Color as in tecumseh.

Specimens $\left(22 \sigma^{\top}, 28 \%\right)$ : From Massacbusetts (Boston); Michigan (Cheboygan Co.); New Brunswick (Devon); New York (Brooklyn and Flatbush on Long Island); Nova Scotia (Kemptown, Round Hill, and Truro); Prince Edward Island (Charlottetown).

The species was reared (probably in laboratory) at Charlottetown, P. E. I., and Round Hill, N. S., during April, and at other stations on various dates during July and August. 
Hosts: Reared from Hemerocampa leucostigma (Abbott and Smith) at Kemptown, N. S., tussock moth at Devon, N. B., and at Charlottetown, P. E. I., and "Orgyia" sp. at Flatbush, Long Island, N. Y.

\section{Scambus (Scambus) decorus Walley, new species}

Figure 312,j

Male: Front wing 2.5 to $4.2 \mathrm{~mm}$. long; antenna with 20 to 21 segments; front femur rather stout, and with a single, broad, median excision beneath; abdomen a little more slender than in tecumseh; structure otherwise as in tecumseh and nucum.

Black. Front and middle legs whitish, with front femur and tibia more or less tinged with reddish; hind coxa reddish or occasionally somewhat fuscous; hind trochanter whitish; hind femur reddish with apex more or less fuscous; hind tibia with subbasal fuscous annulus complete; color otherwise as in tecumseh.

Female: Front wing 4.5 to $5.5 \mathrm{~mm}$. long; antenna with 21 to 22 segments; cheek about 0.25 times breadth of base of mandible; temple strongly rounded and rather weakly receding; thorax moderately stout; propodeum with short, very weak, dorsomedial carinae; hind tarsus with basal segment very slightly longer than following three segments combined; abdomen moderately stout; tergite 1 rather small and with few punctures; tergites $2-6$ with large, usually distinctly separated punctures and with broad, more or less transstriate apices; sheath equal or subequal to length of abdomen; ovipositor rather weakly compressed and with a distinct nodus.

Color as in hispae except that front coxa is mostly fuscous.

Type: \%, Merivale (near Ottawa), Ont., reared in laboratory April 17, 1948, Forest Insect Survey No. 048-6D (Ottawa, No. 6756 in Canadian National Collection).

Paratypes (in Canadian National Collection at Ottawa): $\sigma^{7}$, Creston, B. C., June 27, 1949, D. B. Waddell. \&, Likely, B. C., July 7, 1938, G. S. Walley. ๆ, Robson, B. C., May 20, 1949, H. R. Foxlee. $\sigma^{7}$, Robson, B. C., Aug. 26 to 31, 1949, H. R. Foxlee. Desert Island, Maine, July, 1929, A. Brower. $\sigma^{7}$, Mount Desert Island, Maine, July 10, 1931, A. Brower. $2 \sigma^{x}$, Mount Desert Island, Maine, July 4 and 5, 1932, A. Brower. $4 \sigma^{\top}$, Aweme, Man., June 25, 1924, R. M. White. $\sigma^{7}$, Fredericton, N. B., June 21, 1957, No. 57-0064-01-2. $\sigma^{7}$, Annapolis, N. S., May 25, 1927, F. C. Gilliatt. $\sigma^{7}$, Annapolis, N. S., Aug. 17, 1929, F. C. Gilliatt. ऽð, ㅇ, Berwick, N. S., July 17, 1928, F. C. Gilliatt. $\sigma^{x}$. Blomidon, N. S., July 24, $1950 . \sigma^{7}$, Kings Co., N. S., July 1955, H. Stultz. $2 \sigma^{\top}$, Mattock, Hants Co., N. S., July 1957, J. McDunnough. $\sigma^{\top}$, 우, Parrsboro, N. S., July 11 and Aug. 5, 1944, J. McDunnough. $2 \sigma^{x}$, Pleasant Point, N. S., Apr. 3 and 5, 1954, J. McDunnough. $\sigma^{7}$, Welsford, N. S., June 17, 1955, C. 
McConnell. $\quad \sigma^{\top}$, Armstrong, Ont., July 11, 1947, Forest Insect Survey No. S47-10966. ㅇ, Blackburn, Ont., May 22, 1941, G. S. Walley. $\sigma^{\top}$, Carleton Co., Ont., May 14, $1949 . \quad \sigma^{\top}$, Carp, Ont., Apr. 29, 1948, Forest Insect Survey No. 48-13C. $\sigma^{7}$, Jock River in Carleton Co., Ont., May 21, 1927, G. S. Walley. क, Merivale, Ont., May 5, 1930, J. J. de Gryse. $\sigma^{x}$, Merivale, Ont., reared in laboratory, Feb. 26, 1945, Forest Insect Survey No. O44-1866. $23 \sigma^{\top}$, \&, Ottawa region, Ont., 1930, J. J. de Gryse. $\sigma^{\top}$, Ottawa, Ont., reared in laboratory, Jan. 1949, O. Peck. $2 \sigma^{7}$, Ottawa, Ont., reared in laboratory, Mar. 28 and 31, 1952, J. F. McAlpine. $\sigma^{\top}$, Vineland, Ont., June 28, 1932, D. F. Patterson. $\sigma^{7}$, Windsor, Ont., May 21, 1941, Forest Insect Survey No. 3399. ๆ, Abbotsford, Que., Sept. 8, 1937, G. E. Shewell. ㅇ, Cascapedia River, Que., July 13, 1933, M. L. Prebble. $5 \sigma^{\pi}, 14 \%$, Parke Reserve in Kamouraska Co. at $950 \mathrm{ft}$., Que., Aug. 8 to 26, 1957, W. R. M. Mason. \&, Door Co., Wis., July 16, 1932, M. H. Doner.

Paratypes (in Townes Collection): $3 \sigma^{x}, 3$, Mount McKinley at 1,600 and 2,000 ft., Alaska, Aug. 6 to 15, 1954, David Townes. \&, Edmonton, Alta., Aug. 29, 1948, E. H. Strickland. ơ, Randolph, N. H., July 3, 1946, J. Peck and M. Townes. $4 \sigma^{7}$, Ashford, Wash., Aug. 6 and 18, 1940, H. and M. Townes. $\sigma^{x}, \%$, Mount Rainier at 2,900 ft., Wash., July 7, 1940, H. and M. Townes.

Hosts: This species is a parasite of microlepidopterous larvae that live in concealed or protected situations. The type and a number of paratypes were reared in the Ottawa region from Paraclemensia acerifoliella (Clemens). Other records include rearings from Amorbia humerosana (Clemens), Choristoneura fumiferana (Clemens), Coleophora pruniella Clemens, C. salmani Heinrich, Chrysopora stipella var. naeviferella (Duponchel), Gracillaria sp., holster case on Vaccinium, larva in hawthorn fruit, Phalonia rutilana (Hübner), pistol case on apple, and Spilonota ocellana (Denis and Schiffermüller).

This species has a transcontinental distribution and is found mostly in the Canadian and Transition zones.

\section{Erythroscambus Walley, new subgenus}

\section{Type: Pimpla hirticauda Provancher.}

Submetapleural carina usually absent (rarely a very weak carina is present in hirticauda); mesoscutum in most regions usually bare or with only very sparse hairs, occasionally with moderately dense hairs; propodeum with dorsomedial carinae absent or represented only by weak longitudinal elevations separated by a shallow median sulcus; subgenital plate in female with a large, basal, membranous excision; ovipositor rather weakly compressed, with ridges on apex of lower 
valve as in the subgenus Scambus. Thorax red with a few conspicuous black markings.

The subgenus shows a remarkable convergence with Lissoscambus in several structural features and in color.

This is a Neotropic subgenus, except for hirticauda, which is found in the western Nearctic. The described Neotropic species that belong in this subgenus are (according to information supplied by $\mathrm{H}$. K. Townes, who has recently studied their types): Pimpla albipes Cresson, 1874; Pimpla coxata Smith, 1879; Epiurus albitibia Morley, 1914; Epiurus flavipes Cameron, 1904; and Ephialtes nigriceps Brullé, 1846. These are all new combinations with the generic and subgeneric names, except that albipes has already been referred to the genus Scambus.
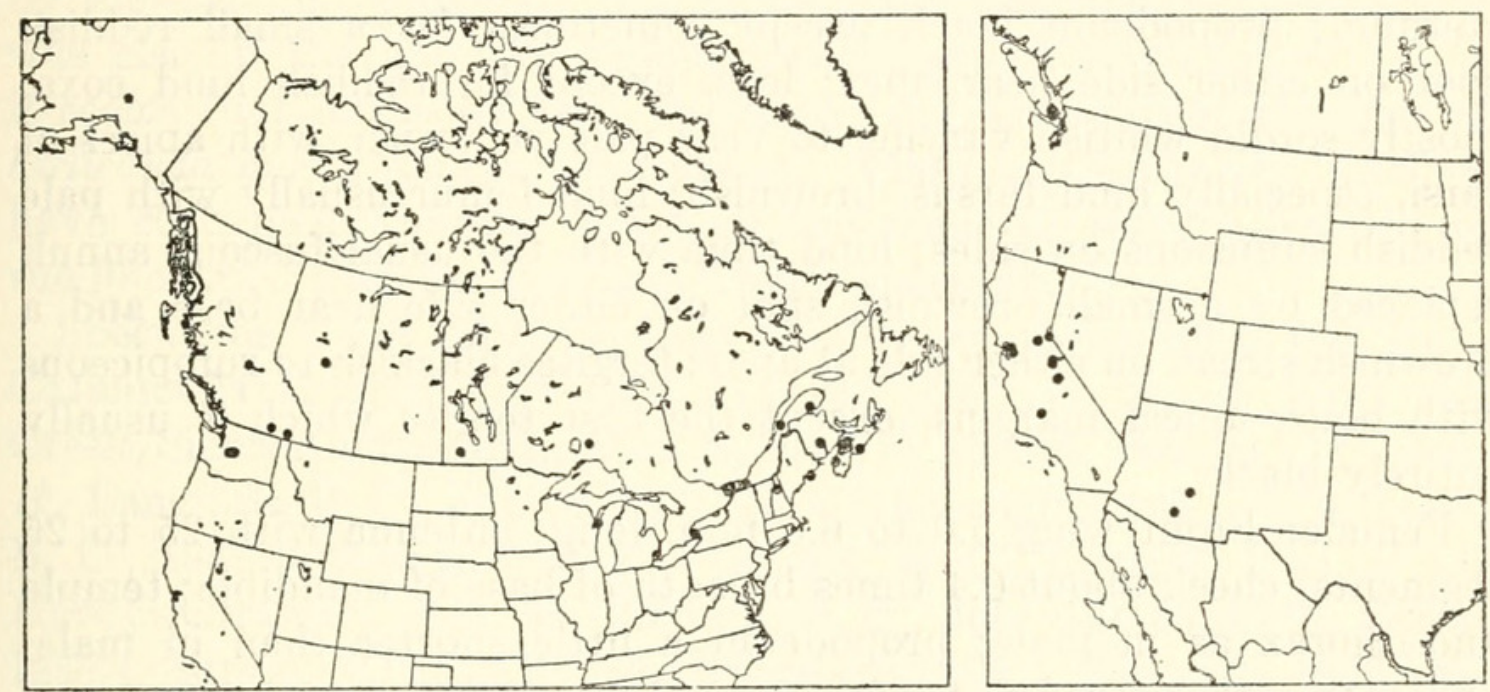

Figures 28, 29.-Localities: 28 (left), Scambus (Scambus) decorus; 29 (right), S. (Erythroscambus) hirticauda.

\section{Scambus (Erythroscambus) hirticauda (Provancher), new combination}

Figures $312, \mathrm{k} ; 321, \mathrm{c}$

Pimpla hirticauda Provancher, 1886, Additions et corrections au volume II de la faune entomologique du Canada traitent des hyménoptères, p. 116; . Type: $९$, [probably from Victoria, B. C.] (Quebec).

Scambus hirticauda (Provancher), Townes, 1944, Mem. Amer. Ent. Soc., No. 11, p. 25.

Scambus hirticauda (Provancher), Townes, 1951, U. S. Dep. Agr., Agr. Monog., No. 2, p. 186.

Male: Front wing 4.0 to $5.0 \mathrm{~mm}$. long; antenna with 25 to 26 segments; cheek about 0.28 times breadth of base of mandible; temple rather strongly rounded and strongly receding; face with rather dense, coarse pubescence; thorax, especially above, polished and with only traces of a few weak punctures; propodeum with a 
shallow, median, longitudinal sulcus; front femur with a short, weakly bisinuate, preapical lamina beneath; front tibia almost straight; hind femur above with rather dense, long, fine pubescence; abdomen slender, with median carinae of tergite 1 short and extending only slightly beyond spiracle; tergite 1 and apices of following tergites impunctate, remainder of tergites with sparse, shallow punctures which are often indistinct and more or less confused with finer sculpture; clasper small and rather short.

Head black; scape and pedicel beneath, tegula, hind corner of pronotum and a short line extending forward along upper margin, whitish; thorax red with conspicuous black markings that include prothorax except a narrow submarginal reddish stripe above, region of bases of wings and a large spot in upper posterior corner of mesepisternum; propodeum black except sometimes for a small reddish spot on either side near apex; legs, except for reddish hind coxa, mostly sordid whitish varying to very pale yellowish, with apices of tarsi, especially hind tarsus, brownish; hind femur usually with pale reddish suffusions on sides; hind tibia with the usual fuscous annuli replaced by a small brownish spot on either side near base and a brownish streak on either side at apex; tergites blackish to rufopiceous with black apical margins, except the first tergite which is usually entirely black.

Female: Front wing 5.0 to $6.5 \mathrm{~mm}$. long; antenna with 25 to 26 segments; cheek about 0.4 times breadth of base of mandible; temple and thorax as in male; propodeum a little shorter than in male; abdomen rather slender; tergite 1 mostly smooth except for traces of coriaceous sculpture and a few indistinct punctures; tergites 2-6 with numerous, large, usually distinct punctures except on apices; sheath slightly shorter than abdomen; ovipositor moderately compressed and with a distinct nodus, portion of upper valve beyond nodus flattened or slightly concave in lateral aspect, basalmost ridges on lower valve very strongly oblique.

Color as in male except as follows: scape brownish beneath except on narrow apical margin, prepectus mostly black, hind femur reddish except on upper margin, abdomen beyond tergite 1 frequently with tergites largely or entirely reddish except on apices.

In his recent catalogs of the Ichneumonidae Townes $(1944,1951)$ questioned Provancher's record of this species from Ottawa, Ont., and suggested the type locality to be more probably southern California. Recently, the writer found in the Canadian National Collection a recognizable but badly damaged specimen of hirticauda bearing the data "Pimpla hirticauda \%, Victoria, 1885" in script (hand of James Fletcher), and a printed number label "126." Circumstantial 
evidence indicates that this specimen originated from the Rev. G. W. Taylor, at Victoria, B. C., and it seems possible that a "duplicate" may have been sent to Provancher, the latter being the type of hirticauda now in the Quebec Museum. This view is supported by the fact that Provancher is known to have described other species of Ichneumonidae collected by Taylor in the Victoria region and sent to him by other workers (one such lot sent by William Brodie of Toronto was the source of some confusion as to locality and collector), and also by the fact that James Fletcher, honorary curator of entomology in the Department of Agriculture, at Ottawa, was at the time in question engaged in a correspondence and traffic in specimens with both Taylor and Provancher. That Provancher attributed the specimen to J. A. Guignard of Ottawa, Ont., may be accounted for by the fact that Guignard, who at that time was Fletcher's assistant, was also in the habit of sending specimens to Provancher. Thus it seems that confusion as to the source and collector of the type of hirticauda might readily have arisen. The fact that recent rearings have corfirmed Victoria as within the range of the species add to the likelihood that the type is a Taylor specimen.

Specimens $\left(14 \sigma^{\top}, 21\right.$ \%): + , Bear Wallow at about 8,000 ft., Santa Catalina Mts., Ariz., July 12 to 17, 1916 (New York). ㅇ, Workman Creek, Sierra Ancha, Ariz., Apr. 28, 1947, H. and M. Townes (Townes). $\sigma^{7}$, Langford, B. C., June 8, 1941, K. Graham (Ottawa). ' Victoria, B. C., 1885 (Ottawa). ơ 2 2 , Victoria, B. C., Apr. 23, 1941, G. A. Hardy (Ottawa). $5 \sigma^{7}, 9$ \%, Victoria, B. C., July 5 to 13,1956 , Forest Insect Survey (Ottawa). ఠ', Berkeley, Calif., Feb. 22, 1956, W. Middlekauff (Berkeley). $2 \sigma^{7}$, Camino, Calif., June 28 and 29, 1948, Townes family (Townes). $4 \sigma^{7}$, , Crane Flat, Yosemite Park, Calif., July 22, 1948, Townes family (Townes). \&, Glenville, Kern Co., Calif., Apr. 24, 1949, Linsley, MacSwain, and Smith (Berkeley). ๑, Huntington Lake, Calif., July 7, 19-, Blaisdel (San Francisco). \&, Lake Tahoe, Calif., Aug. 28, 1948, R. M. Bohart (Townes). †, hills back of Oakland, Calif., May 11, 1930, E. C. Zimmerman (San Francisco). , Snow Flat at 8,700 ft., Yosemite Park, Calif., July 26, 1948, Townes family (Townes). \&, "Trinity," Sonoma Co., Calif., Dec. 20, 1932, N. W. Frazier (Berkeley).

Hosts: Records include rearings from Gracillaria sp. on Quercus garryana at Langford and at Victoria, B. C., in 1941, and from Malacosoma pluviale (Dyar), at Victoria, B. C., in 1956. According to information provided by Mr. D. Evans of the Forest Biology Laboratory, at Victoria, the rearings from Malacosoma are the only records of recovery of this species from many thousands of Malacosoma larvae reared at Victoria since 1949. 


\section{Genus Calliephialtes}

Figure 286,b

Calliephialtes Ashmead, 1900, Proc. U. S. Nat. Mus., vol. 23, p. 54. Type: (Pimpla xanthothorax Ashmead)=grapholithae (Cresson); original designation.

Front wing 4.0 to $12.5 \mathrm{~mm}$. long; body elongate; face and clypeus blackish to fulvous, ordinarily concolorous with the rest of head or the clypeus somewhat paler; clypeus of moderate width, almost flat, its apex impressed and with a deep median notch which makes it bilobed; occipital carina complete, with a dip on the midline; mesoscutum mostly or entirely polished, almost or quite bare or with hairs anteriorly and marginally and the rest bare; submetapleural carina varying from complete to present only as a compressed tubercle anteriorly; propodeum rather short, its median longitudinal carinae entirely absent or indicated by low rounded ridges; areolet subtriangular, receiving second recurrent vein in front of its hind corner; nervellus broken near, somewhat below, or somewhat above the middle; first tergite short, with moderately strong lateral longitudinal ridges, its median longitudinal carinae ascending from the beginning point at basolateral corner at $70^{\circ}$ to $90^{\circ}$ from the horizontal, then curved backward, in male extending some distance horizontally, in female short and ending abruptly; basal grooves on second tergite weak, almost transverse; third and fourth tergites with well formed tubercles, their apical impunctate area extending about 0.2 their length; female subgenital plate sclerotized only laterally and apically; ovipositor sheath about 1.2 to 1.4 as long as front wing; ovipositor straight, cylindric, its tip as in figure 329 ,d.

In the past, the genus Calliephialtes has had broad, indefinite limits and included an unnatural assemblage of species. We are restricting it to a rather closely related group of species centered in the Neotropic region, but with four species entering the Nearctic region. The remaining Nearctic species that were formerly in Calliephialtes are placed in Exeristes, Apistephialtes, and Dolichomitus.

Rearing records for the genus show that the species characteristically attack caterpillars or other larvae in galls, nuts, nutlike fruits, or cases.

\section{Key to the Nearctic species of Calliephialtes}

1. Mesoscutum anteriorly with numerous hairs; nervellus broken near middle; femora unitormly fulvous (figs. 321,d,e). Notandus group (p. 8). . . 2

Mesoscutum anteriorly practically hairless; nervellus broken below middle; femora white, dark brown behind, the hind femur dark brown also at base and apex (figs. $321, \mathrm{f}, \mathrm{g}$ ). Grapholithae Group (p. 84) . . . . . . . . 3

2. Groove between propodeum and metapleurum containing a carina between the spiracle and apex of propodeum; white of upper edge of pronotum not 
reaching forward to notaulus; scape of male entirely black; front coxa of female pale fulvous . . . . . . . . . 1. notandus (Cresson) Groove between propodeum and metapleurum not containing a carina; white of upper edge of pronotum reaching forward beyond notaulus; scape of male white in front; front coxa of female whitish . . 2. thurberiae Cushman 3. Metapleurum, propodeum, and abdomen black. . 3. grapholithae (Cresson) Metapleurum and propodeum ferruginous; abdomen mostly ferruginous.

4. ferrugineus Cushman

\section{NOTANDUS GROUP}

Front part of median lobe of mesoscutum with rather dense hairs; anterolateral part of lateral lobe of mesoscutum with sparse hairs; upper 0.4 of pleural suture weak; nervellus broken almost exactly at middle; femora uniformly fulvous.

This species group includes the two Nearctic species below.

\section{Calliephialtes notandus (Cresson)}

Figure 321 , d

Pimpla notanda Cresson, 1870, Trans. Amer. Ent. Soc., vol. 3, p. 148; $\sigma^{7}$, Lectotype: $\uparrow$, Pennsylvania (Philadelphia).

Bıology: Riley, 1877, Ann. Rep. Ins. Missouri, vol. 9, p. 98.-Leiby, 1922, Journ. New York Ent. Soc., vol. 33, p. 93.

Front wing of male 4.2 to $6.5 \mathrm{~mm}$. long, of female 5.5 to $10.8 \mathrm{~mm}$. long; anterolateral part of lateral lobe of mesoscutum with sparse hairs; groove between propodeum and metapleurum containing a carina between spiracle and apex of propodeum; propodeal punctures rather coarse, separated by about 0.7 their diameter; ovipositor sheath about 1.25 as long as front wing.

Black. Palpi, tegula, and stripe on upper margin of pronotum reaching from hind corner almost to notaulus, white; mesosternum, mesopleurum except above, lateral lobe of mesoscutum except marginally, scutellum, postscutellum, more or less of metapleurum, coxae, trochanters, and femora, fulvoferruginous; tibiae brownish fulvous, whitish above, the whitish with a faint narrow subbasal brownish interruption and not quite reaching apex of tibiae; tarsi brownish fulvous, whitish above toward the base; flagellum tinged with reddish brown. The male trochanters and front coxae are whitish, more or less tinged with fulvous. In specimens from west of the hundredth meridian the abdomen is often more or less ferruginous with its first tergite, apical band on second to fourth tergites, apicolateral stripe on fifth and sixth tergites, and seventh and following tergites, blackish.

Specimens (113 $\sigma^{7}, 189$ \%): From British Columbia (Wellington); California (Artois, Bolinas, Colusa, Davis, Folsom, Lone Pine, Los Cerritos in Los Angeles Co., Onyx, Oxnard, Redlands, Roseda in 
Los Angeles Co., San Francisco, San Luis Obispo Co., Stanford University, Visalia, Wood Lake in Tulare Co., and Woodland); Colorado (Boulder Co., Fort Collins, and Valmont in Boulder Co.); Connecticut (East Hartford and East River); District of Columbia (Washington); Florida (Gainesville, Orlando, and Tarpon Springs); Georgia (Thomasville); Idaho (Bliss); Illinois (Decatur); Indiana (Bloomington, Lafayette, and Spencer); Iowa (Ames, Anamosa, Dickinson Co., Luther, Lyon Co., Mitchell Co., and Ruthven); Kentucky (Lexington); Louisiana (Opelousas); Maryland (Beltsville, Cabin John, Hagerstown, Riverdale, and Takoma Park); Massachusetts (Amherst, Cohasset, and Readville); Michigan (Delta Co., East Lansing, Grand Rapids, Mecosta Co., Midland Co., Three Oaks, Tuscola Co., and Wayne); Minnesota (Fort Snelling, Hennepin Co., Luverne, Mille Lacs Lake near Vineland, Mississippi Bluff in Houston Co., North St. Paul, Polk Co., Sedan, and Yellow Medicine Co.); New Jersey (Clifton, Clementon, Moorestown, Ocean Grove, Riverton and Seaside Park); New York (Babylon, Brooklyn, Flatbush, Hamburg, Ithaca, Lancaster, Montauk Point on Long Island, Orient, Riverhead, Rockaway, Shokan, Staten Island, and Van Cortland Park in New York City); North Carolina (Greensboro, Jacksonville, Lake Mattamuskeet in Hyde Co., and Morehead); Ohio (Barberton, Bellefontaine, Cleveland, Columbus, Delaware Co., Hocking Co., Kelleys Island, Middle Bass Island, Montgomery Co., Ottawa Co., Summit Co., and Wooster); Oklahoma (Ardmore and Kenton); Ontario (Black Rapids on the Rideau River, Hamilton, Jordan, and Pelee Island); Oregon (Powder River in Baker Co. at 3,000 ft.); Pennsylvania (Arendtsville, Crisp in Westmoreland Co., Enola, Highspire, New Cumberland, North East, Oak Station in Allegheny Co., Philadelphia, Pittsburgh, and Spring Brook); Quebec (southern Quebec province); Rhode Island (Providence and Westerly); South Carolina (Clemson, Greenville, McClellanville, and Venus in Greenville Co.); Texas (Alpine, Brazos Co., Denton, and Jacksonville); Utah (Black Rock Beach in Wasatch Co., and Salt Lake City); Virginia (Arlington, Charlottesville, East Falls Church, Falls Church, Meadows of Dan in Patrick Co., Mountain Lake Biological Station in Giles Co., Paeonian Springs, Richmond, Rosslyn, Vienna, and Warrenton); Washington (Clarkston, Pullman, and Wawawai); West Virginia (Bolivar); and Wisconsin (Boscobel, Madison, Milwaukee, and Sturgeon Bay).

Adults occur throughout the growing season. They are particularly common in spring and fall. Unusually early and late seasonal records are: February 18 at Orlando, Fla.; February 19 at Oxnard, Calif.; March 14 at Los Cerritos, Calif.; March 15 at Denton, Tex.; March 21 at Tarpon Springs, Fla.; April 10 at Lake Mattamuskeet, N. C. 

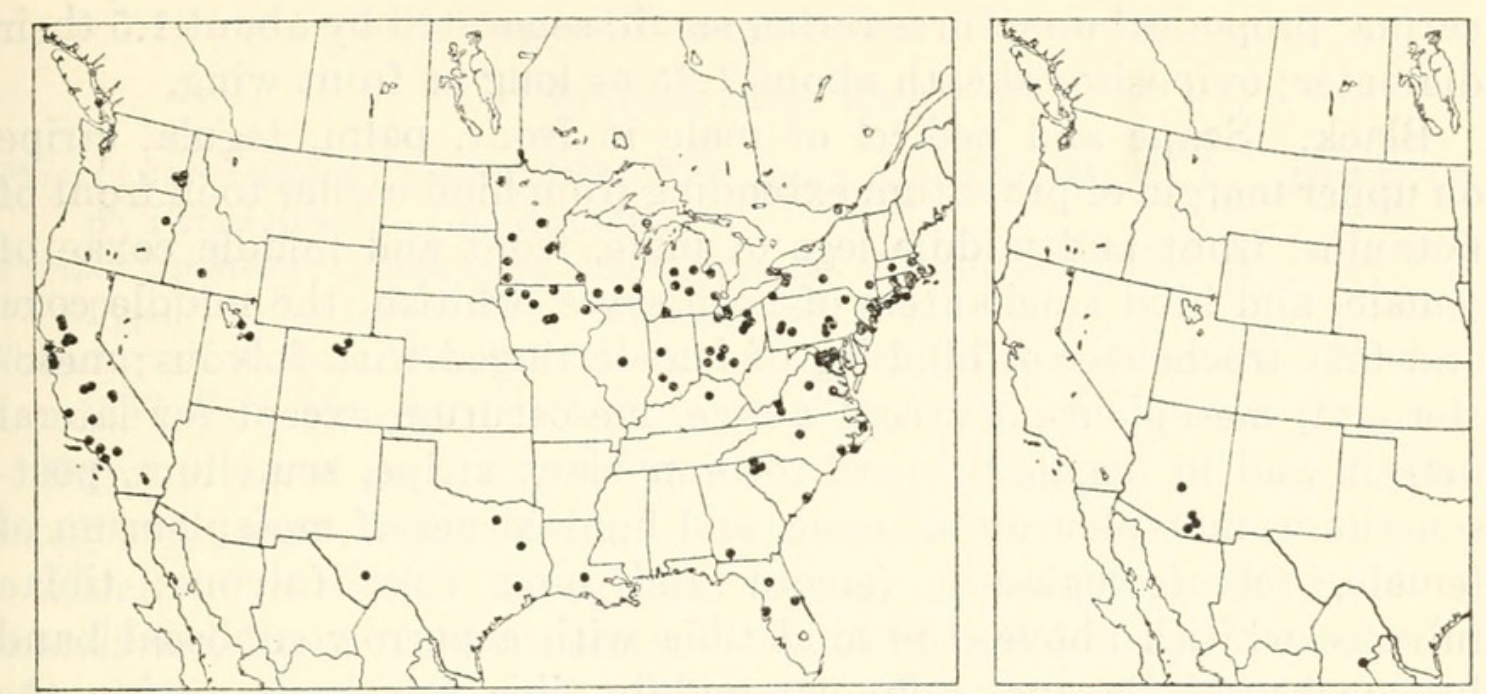

Figures 30, 31.-Localities: 30 (left), Calliephialtes notandus; 31 (right), C. thurberiae.

and at Jacksonville, N. C.; April 23 at Hagerstown, Md.; April 30 at Ithaca, N. Y.; October 18 at Takoma Park, Md.; October 19 at Charlottesville, Va.; October 29 at Bellefontaine, Ohio; October 30 at Davis, Calif.; and November 15 at Takoma Park, Md.

Rearing records are as follows: 1 rearing from Epiblema desertana, 2 from E. strenuana, 1 from "Gelechia" sp., 1 from Gnorimoschema baccharisella, 2 from G. gallae-asteriella, 13 from G. gallaesolidaginis, 1 from Walshia "amorphella," 1 from a bruchid in Lotus, one from a moth larva, 9 from stems of Ambrosia, 1 from larva in gall on Quercus, 1 from stem of Yucca?, and 2 from a gall. There is a female in Washington from western Kansas, from L. C. Brons, labeled preying on [Melanopus] spretus. This may be the origin of the old record of Lissonota brunnea being a parasite of Melanopus spretus (1891, Insect Life, vol. 3, p. 464), based on a mistaken biological observation and a mistaken identification of the parasite.

This species occurs in most of the United States and southern Canada. Adults occur from early spring to late fall. The habitat is always in the open, in fields with coarse weeds, where the usual hosts are lepidopterous larvae boring or making galls in the stems of weeds of the family Compositae.

\section{Calliephialtes thurberiae Cushman}

FigURE 321,e

Calliephialtes thurberiae Cushman, 1915, Proc. Ent. Soc. Washington, vol. 17, p. $132 ; \sigma^{7}$,. Type: , Santa Rita Mts., Ariz. (Washington).

Front wing of male about $6 \mathrm{~mm}$. long, of female about $7.5 \mathrm{~mm}$. long; anterolateral part of lateral lobe of mesoscutum with very sparse hairs; groove between propodeum and metapleurum not containing a 
carina; propodeal punctures rather small, separated by about 1.5 their diameter; ovipositor sheath about 1.25 as long as front wing.

Black. Scape and pedicel of male in front, palpi, tegula, stripe on upper margin of pronotum extending from hind corner to in front of notaulus, front and middle legs of male, front and middle coxae of female, and hind trochanters of both sexes, whitish, the middle coxa and first trochanter of hind leg of female tinged with fulvous; mesosternum, mesopleurum except above, mesoscutum except for lateral margin and in female a broad median black stripe, scutellum, postscutellum, metapleurum of male, and hind corner of metapleurum of female, fulvoferruginous; femora and hind coxa fulvous; tibiae fulvous, whitish above, the hind tibia with a narrow subbasal band brownish and its apex fulvous; middle tibia faintly repeating the brownish subbasal band of the hind tibia; tarsi light fulvous, the basal segments whitish above except at the apex.

Specimens: $\sigma^{\top}$, reared from gall, Camp Creek, Cavecreek, Ariz., L. H. Weld (Washington). $\sigma^{\top}, 8$ (including type and paratype), reared from Anthonomus grandis thurberiae Stone Cabin Canyon (two of the nine specimens labeled also McCleary's Ranch), Santa Rita Mts., Ariz., Dec. 3, 4, 5, and 6, 1913 (not April 12 and March 12 as reported erroneously in original description), E. A. Schwarz (Washington and Townes). \&, reared from Anthonomus grandis thurberiae, Sawmill Canyon at 4,600 ft., Santa Rita Mts., Ariz., Dec. 5, 1913, Barber and Schwarz (Washington). ㅇ, from bolls of Gossypium thurberi, Rincon Mts., Ariz., "3-11-46," W. Kauffman (Washington). 9, from gall of Disholcaspis on Quercus oblongifolia, "Sycamore Flat," Ariz., Dec. 2, 1918, G. Hofer (Washington). ㅇ, San Jose, Costa Rica, July 21, 1926, H. Y. Gouldman (Washington). \&, 10 miles south of Linares, Nuevo Leon, Mexico, Dec. 24, 1940, G. E. Bohart (San Francisco). क, Tlahualilo, Mexico, July 29, 1905, A. W. Morrill (Washington). $2 \sigma^{\top}, 2 \circ$, intercepted in plant quarantine on avacado, red haw, and wild apple from Mexico, May 7, 1939; July 16, 1942; Oct. 12, 1926; and Nov. 27, 1940 (Washington).

This species has been taken in southern Arizona, Mexico, and Costa Rica. It has been reared from cynipid galls and from Anthonomus grandis thurberiae.

\section{GRAPHOLITHAE GROUP}

Mesoscutum practically without hairs; upper 0.4 of pleural suture obsolete; nervellus broken near its lower 0.4 ; legs ivory white, with dark brown markings more or less as described for $C$. grapholithae.

This species group includes the Nearctic $C$. grapholithae, an undetermined species from Brazil, and three Antillean species, one of which (C. ferrugineus) reaches southern Florida. 


\section{Calliephialtes grapholithae (Cresson)}

Figures $321, f ; 329$,d

Pimpla grapholithae Cresson, 1890, Ent. News, vol. 1, p. 50; ه⿱一 $\sigma^{\top}$, Pennsylvania (Philadelphia).

Pimpla xanthothorax Ashmead, 1890, Proc. U. S. Nat. Mus., vol. 12, p. 446;. Type: $\uparrow$, Kirkwood, Mo. (Washington).

Brology: Hamilton, 1890, Ent. News, vol. 1, p. 49.--Nickels, Pierce, and Pinkney, 1950, U. S. Dep. Agr. Tech. Bull. No. 1011, pp. 12-14.

Front wing of male 4.0 to $6.5 \mathrm{~mm}$. long, of female 5.5 to $8.5 \mathrm{~mm}$. long; ovipositor sheath about 1.2 as long as front wing.

Black. Head with ferruginous tinges; clypeus brownish fulvous; mandible largely fulvous, blackish apically; palpi, scape and pedicel of male in front, apical margin of scape of female in front, and tegula, white; thorax fulvous, its metapleurum and metasternum black; legs white, with dark brown or black marks as follows: hind coxa basoventrally in front and on most of its hind face, triangular area on middle and hind trochanters behind, broad stripe on femora behind, narrow base and apex of hind femur, base of hind tibia, apex of middle and hind tibiae, apical half of last segment of tarsi, and narrow apex of first four segments of middle and hind tarsi. In the male the dark markings on the legs are fainter and less extensive than in the female.

Specimens $\left(66 \sigma^{7}, 176 \%\right)$ : From Connecticut (East River and Lyme); Delaware (Wilmington); District of Columbia (Twining); Florida (Coconut Grove, Monticello, Royal Palm Park, and St. Augustine); Georgia (Albany, Dewitt in Mitchell Co., Fort Valley, and Thomasville); Louisiana (Tallulah); Maryland (Hyattsville and Takoma Park); Massachusetts (Brookline and Humarock); Michigan (Ann Arbor and Midland Co.); Mississippi (Lucedale); New Jersey (Burlington and Moorestown); New York (Brooklyn, Ithaca, Lancaster, Millwood, New Baltimore, Nyack, Otsego Lake, and Poughkeepsie); North Carolina (Elizabethtown); Ohio (Columbus, Eagleville in Ashtabula Co., Hinckley in Medina Co., Nicholsville, and New Richmond); Ontario (Alsea, Bothwell, Craig, Chatham, Ottawa, St. Davids, and Toronto); Pennsylvania (Harrisburg and North East); South Carolina (Clemson, Columbia, Greenville, and McClellanville); Texas (Brownsville, Brownwood, Cuero, Dallas, Denton, Lake Charlotte east of Houston, and Webb Co.); Virginia (Falls Church and Vienna); and West Virginia (French Creek and Kanawha Station in Wood Co.).

Adults occur from early spring to late fall. Unusually early and late dates of capture are: February 18 at Lake Charlotte, Tex.; February 22 at St. Augustine, Fla.; February 23 at Albany, Ga.; March 5 at Greenville, S. C.; October 17 at Ithaca, N. Y.; October 18 at New Richmond, Ohio; October 31 at Albany, Ga.; November 11 at Nicholsville, Ohio; and November 14 at Hyattsville, Md. 

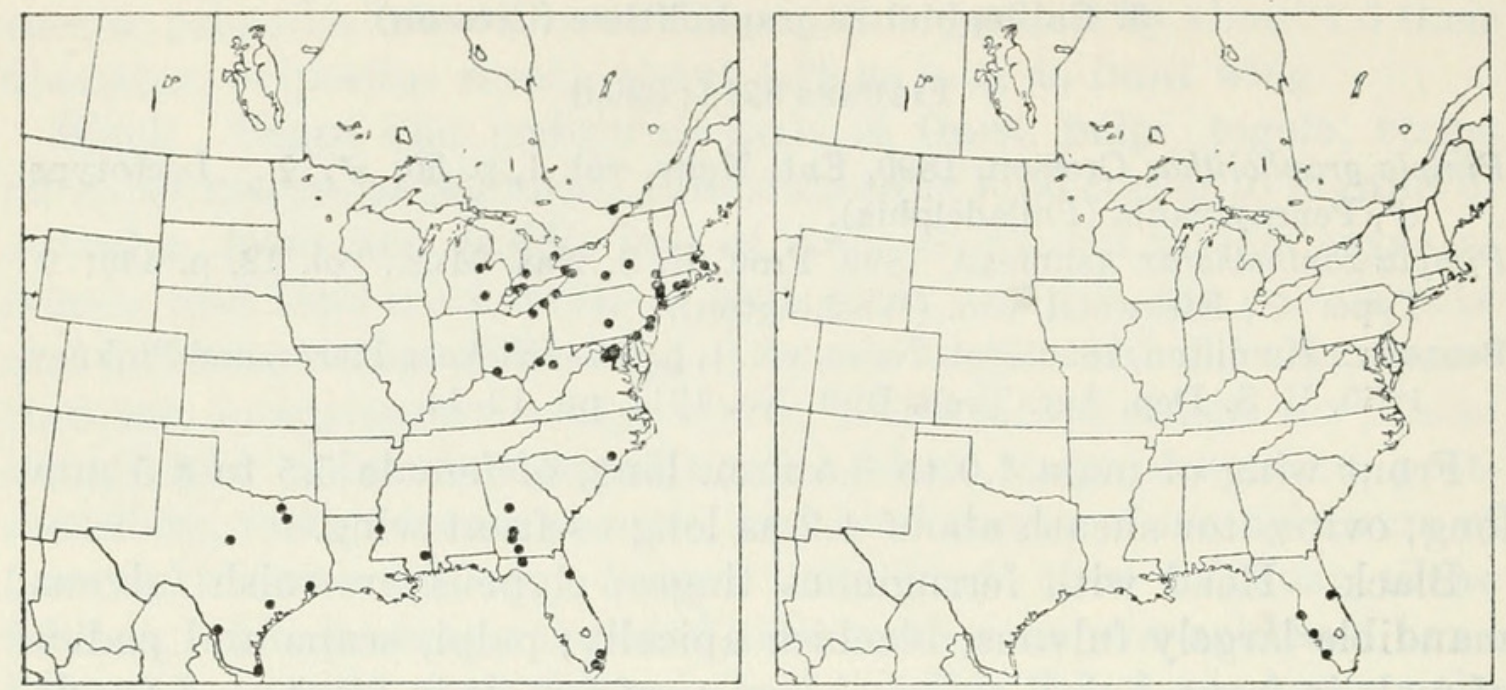

Figures 32, 33.-Localities: 32 (left), Calliephialtes grapholithae; 33 (right), C. ferrugineus.

Rearing records are as follows: 1 from Acrobasis hebescella, 4 from A. juglandis, 1 from A. rubrifasciella, 1 from Carmenta texana?, 1 from Conotrachelus nenuphar, 4 from Grapholitha molesta, 17 from Laspeyresia caryana, 1 from Meskea dyspteraria, 1 from Phylloxera gall, 1 from Stagmatophora ceanothiella, 2 from Thyridopteryx ephemeraeformis, 1 from bagworm, 1 from moth attacking Fagus nuts, 2 from Ambrosia stems, 2 from Baptisia, 4 from shucks of Carya nuts, and 1 from Salix. Though commonly reared, the species is not frequently collected. In our experience it frequents overgrown fields and the edges of woods but is not in dense woods.

This species is in the eastern and Gulf States and in Ontario. It is adult throughout the growing season. A large variety of caterpillars in galls, nuts, burrows, and cases serve as hosts.

\section{Calliephialtes ferrugineus Cushman}

\section{Figure $321, \mathrm{~g}$}

Calliephialtes ferrugineus Cushman, 1940, Proc. U. S. Nat. Mus., vol. 88, p. 362; ․ Type: $\uparrow$, Boqueron, Puerto Rico (Washington).

Front wing of male about $6.7 \mathrm{~mm}$. long, of female 6.0 to $8.8 \mathrm{~mm}$. long; ovipositor sheath about 1.4 as long as front wing.

Ferruginous. Palpi, front of scape of male, apical margin of scape in front of female, tinge on front of pedicel of male, tegula, and legs, ivory white, the legs with dark brown markings as described for $C$. grapholithae except that sometimes there is also a dark brown mark on hind side of first trochanter of front leg; antenna blackish brown except as described otherwise; male abdomen with black apical bands on second to fifth tergites and beyond fourth tergite increasingly darkened toward the tip; female abdomen with blackish apical band on 
second to fourth tergites, blackish apicolateral mark on fifth tergite, and whitish marks on ventral edge of apical tergites; ovipositor sheath black.

Specimens: $\sigma^{x}$, Crystal Beach, Fla., May 18, 1952, J. R. Vockeroth (Ottawa). ㅇ, Englewood, Fla., Apr. 12, 1952, G. S. Walley (Ottawa). \&, Marco Beach, Collier Co., Fla., Apr. 26, 1955, H. E. and M. A. Evans (Ithaca). $\%$, in McPhail trap, Orange Co., Fla., Oct. 1936, O. D. Link (Townes). \&, Delicias Oriente, Cuba, Feb. 24, 1915 (New York). $\sigma^{7}$, Buenos Aires, Trinidad Mts., Cuba, May 8 to 14, 1936, P. J. Darlington (Cambridge). \& (type), Boqueron, Puerto Rico, May 20, 1938, K. A. Bartlett (Washington).

Wolcott records rearings in Puerto Rico from Hypsipyla grandella and Pectinophora gossypiella (1941 and 1948, Journ. Agr. Univ. Puerto Rico, vol. 25, p. 141, and vol. 32, p. 765).

This species is known from Florida, Cuba, and Puerto Rico.

\section{Genus Apistephialtes}

FigURE 287,a

Apistes Seyrig, 1927, Eos, vol. 3, p. 221. Name preoccupied. Type: (Apistes perversus Seyrig) =ascaniae (Rudow); monobasic.

A pistephialtes Seyrig, 1928, Eos, vol. 4, p. 380. New name for Apistes Seyrig.

Front wing 4 to $12 \mathrm{~mm}$. long; body very long and slender; face and clypeus black or the clypeus brownish or ferruginous; clypeus rather narrow, weakly convex, its apical part impressed and with a median notch which makes it bilobed, rarely also with a median subapical tubercle; occipital carina complete, dipped on the midline; mesoscutum with moderately dense, evenly distributed hairs except in a Neotropic species which has the mesoscutum almost bare; submetapleural carina complete; propodeum rather long, without median longitudinal carinae but usually with a broad weak median groove on its basal $0.4 \pm$; first tergite of moderate length, usually about 1.65 as long as wide in male and 1.4 as long as wide in female, with a distinct lateral carina or ridge, its median longitudinal carinae extending about half its length; oblique basal grooves on second tergite short, weak, and indistinct; third and fourth tergites with distinct tubercles, their apical impunctate area occupying about 0.25 their length; female subgenital plate sclerotized only laterally and apically; ovipositor sheath about 1.6 to 3.0 as long as front wing; ovipositor slender, straight, cylindric, its tip as in figures 329 ,e-g.

This genus includes the Holarctic Ephialtes tenuiventris Holmgren 1860 and Ephialtes arcticus Roman 1914; the six Nearctic species treated below; the European Pimpla punctulata Ratzeburg 1848, Pimpla caudata Ratzeburg 1848, Ephialtes crassiseta Thomson 1877, Ephialtes ascaniae Rudow 1883, and Ephialtes cydiae Perkins 1942; 
the Japanese Ephialtes laspeyresiae Uchida 1932; an undescribed species from Japan; and the Neotropic Ephialtes atriceps Cresson 1873. These names are all new combinations in Apistephialtes.

All but Ascaniae of the five species listed as European, and the Japanese laspeyresiae, and the American variatipes and nucicola have all been reared from the codlin moth (Carpocapsa pomonella) which indicates that the genus commonly attacks Lepidoptera pupating under loose bark, or in similar situations.

\section{Keys to the Nearctic species of Apistephialtes}

\section{MAIES}

(Males of A. masoni and arcticus are unknown.)

1. Hairs on combined costa and subcosta long, erect, and with curled-over tips; first tergite about 2.4 as long as wide apically, wider basally than apically; nervellus usually a little in front of basal vein but sometimes opposite basal vein . . . . . . . . . . 1. tenuiventris (Holmgren)

Hairs on combined costa and subcosta normal (short and decumbent); first tergite about 1.65 as long as wide apically, narrower basally than apically; nervellus opposite basal vein .

2. Clypeus with a median transverse tooth . . . . 7. dentatus, new species Clypeus without a median tooth . . . . . . . . . . . . . . . . 3

3. Scutellum fulvous; propodeum with crowded punctures and with low median parallel ridges in place of the median longitudinal carinae . . . . . . . 4

Scutellum black; propodeum with sparse punctures and without median ridges. . . . . . . . . . . . . . . . . 5

4. Scape in front blackish near base, the apical part white; middle coxa and femur more or less fulvous; apex of clasper elongate.

2. variatipes (Provancher)

Scape in front entirely white; middle coxa and femur white; apex of clasper short . . . . . . . . . . . 6. petulcus (Cresson)

5. Scape mostly white in front; white on upper margin of pronotum extending from hind corner about two-thirds the distance to notaulus; hind tibia white above except at apex . . . . . . . 5. nucicola (Cushman)

Scape black; white on upper margin of pronotum extending from hind corner to in front of notaulus; hind tibia dusky white to fuscous above, its basal $0.2 \pm$ paler .

8. coracinus, new species

\section{FEMALES}

1. Lateral sternites of second to fifth abdominal segments about 5 times as long as wide; nervellus usually in front of basal vein, but sometimes opposite it; first tergite about 2.1 as long as wide . . . . 1. tenuiventris (Holmgren)

Lateral sternites of second to fifth abdominal segments about 2 to 4 times as long as wide; nervellus opposite basal vein; first tergite about 1.4 as long as wide . . . . . . . . . . . . . . . . 2

2. Apical half of clypeus sharply separated from basal half by a transverse declivity . . . . . . . . . . . 7. dentatus, new species

Apical half of clypeus not distinctly separated from basal half, the clypeus without a transverse declivity . . . . . . . . . . . . . . . . . 3 
3. Palpi and most of tegula brown; tip of ovipositor rather blunt (fig. $329, \mathrm{~g}$ ).

4. arcticus (Roman)

Palpi and tegula white; tip of ovipositor more acute . . . . . . . . . . 4

4. Scutellum partly or entirely fulvous; most of punctures on propodeum separated by their diameter or less . . . . . . . . . . . . . . . . . 5

Scutellum entirely black; punctures on propodeum sometimes separated by more than their diameter . . . . . . . . . . . . . . . . . . 6

5. Middle coxa fulvous; tip of ovipositor not unusually slender (fig. $329, \mathrm{f}$ ).

2. variatipes (Provancher)

Middle coxa white, tinged with fulvous basally; tip of ovipositor exceptionally slender . . . . . . . . . . . . . 6. petulcus (Cresson)

6. Trochanters of front leg and second trochanter of hind leg not whitish, fulvous like their femora; punctures on central part of propodeum separated by less than their diameter . . . . . . . . 3. masoni, new species

Trochanters of front leg and second trochanter of hind leg whitish, much paler than their fulvous femora; punctures on central part of propodeum separated by more than their diameter . . . . . . . . . . . . . . . . . 7

7. White on upper margin of pronotum extending from hind corner about twothirds the distance to notaulus; front coxa fulvous, its apex more or less whitish; upper edge of hind tibia whitish, with a brown band apically and subbasally . . . . . . . . . . . 5. nucicola (Cushman)

White on upper margin of pronotum extending from the hind corner to in front of notaulus; front coxa mostly white; upper edge of hind tibia light brown, darker apically and subbasally . . . 8. coracinus, new species

\section{Apistephialtes tenuiventris (Holmgren), new combination}

Figures $329, \mathrm{e} ; 330, \mathrm{j} ; 334$

Ephialtes tenuiventris Holmgren, 1860, Svenska Vetensk.-Akad. Handl., ser. 4, vol. 3, No. 10, p. 14; $\sigma^{7}$, $\subsetneq$. Types: $\sigma^{7}$, $\subsetneq$, Sweden (Stockholm).

Ephialtes pacificus Harrington, 1894, Canadian Ent., vol. 26, p. 248; ๙ో, ․ Types: $\sigma^{7}$, + , Victoria, B. C. (Ottawa).

Ephialtes pusio Walsh, 1873, Trans. Acad. Sci. St. Louis, vol. 3, p. 111; ㅇ․ New synonymy. Type: $\uparrow$, ? Illinois (destroyed in Chicago fire of 1871).

Front wing of male 7.0 to $8.0 \mathrm{~mm}$. long, of female 9.7 to $12 \mathrm{~mm}$. long; propodeum a little rugulose near its midline and with indistinct parallel longitudinal ridges at position of the median longitudinal carinae, its punctures separated by about 0.6 their diameter; first tergite of male about 2.4 as long as wide; male subgenital plate and the preceding sternite as in figure $330, \mathrm{j}$; male eighth and ninth tergites not fused; male clasper moderately elongate (fig. 334); ovipositor sheath about 2.5 as long as front wing; tip of ovipositor as in figure 329 ,e.

There are some additional structural characters by which this species differs from all the others in its genus, and which might be sufficient basis for placing it in a separate genus. These are as follows: hair on face of male very dense (moderately dense in the other species of the genus); hairs on combined costa and subcosta of male long, erect, with curled-over tips (moderately short and inclined in the other species of the genus); nervellus usually in front of basal vein by about 
1.5 its width, but sometimes opposite basal vein (always opposite basal vein in the other species); first tergite exceptionally long, in the male widened basally, about 2.4 as long as its apical width, in female faintly widened apically, about 2.1 as long as wide (in the other species of the genus widened apically in both sexes, about 1.65 as long as wide in male, about 1.4 as long as wide in female); socond tergite with rather long and strong oblique basolateral grooves (these grooves shorter and weaker in the other species); lateral sternites of second to fifth abdominal segments about 8 times as long as wide in male, about 5 times as long as wide in female (in the other species 4 to 5 times as long as wide in male, about 2 to 4 times as long as wide in female).

Male: Black. Scape in front except at its base, pedicel in front, palpi, tegula, narrow wedge-shaped mark on upper margin of pronotum reaching from hind corner about 0.65 the distance to notaulus, front and middle coxae, trochanters except for fuscous upper side of hind first trochanter, front and apex of front and middle femora, and front and middle tibiae except for fulvous tinges, white; clypeus ferruginous; front tarsus pale stramineous basally, darker apically: middle tarsus brown, darker apically; hind femur fulvous, with a subapical infuscate band and its extreme apex white; hind tibia infuscate, its basal 0.12 and the basal 0.6 of its lower part whitish; hind tarsus fuscous.

Female: Black. Clypeus dusky ferruginous; maxillary palpus stramineous, its base fuscous; labial palpus light brown; tegula and wedge-shaped mark on upper margin of pronotum white, the wedgeshaped mark reaching from the hind corner 0.6 the distance to notaulus; front and middle coxae, trochanters, and femora fulvous, the apex of femora paler; front and middle tibiae dusky fulvous, a little paler at base, below, and on apex of middle tibia in front; front tarsus dusky fulvous; middle tarsus infuscate; hind tarsus fuscous; hind coxa, trochanters, and femur fulvous, the femur infuscate near apex, its extreme apex stramineous; hind tibia fuscous, paler on its basal 0.12 and below.

Specimens $\left(120^{7}, 100 \%\right)$ : From British Columbia (Departure Bay, Kaslo, Robson, Vancouver, Victoria, and Wellington); California (Big Sur, Boulder Creek, Camino, Carmel, Fish Camp, Giant Forest in Tulare Co., Mesa Grande in Sonoma Co., Monterey Co., mountains near Claremont, Pacific Grove, Paradise Valley in Fresno Co., Santa Clara Co., San Jacinto Mts., Santa Cruz, and Yosemite Valley); Colorado (near Estes Park and Steamboat Springs); Maryland (Takoma Park); Michigan (Coopersville, East Lansing, Midland Co., and Seney); Montana (Madison River in Gallatin National Forest and Lake McDonald); New York (Bemus Point, Ithaca, and New Russia); Ohio (Summit Co.); Ontario (Ottawa); Oregon (Corvallis); Pennsyl- 
vania (Crisp in Westmoreland Co. and Overbrook); Quebec (Cascapedia, Hemmingford, Knowlton, Lac Mondor, Montreal, Otter Lake, Sweetsburg, and Wright); Texas; Vermont (Laurel Lake near Jacksonville); Washington (Ashford and Keyport) Wisconsin (Door Co.); Sweden; and Germany.

Most dates of capture are from late June to early August, but the total spread of dates is from late spring to late summer. Particularly early and late records are: April 5 in Monterey Co., Calif.; May 12 at Carmel, Calif.; May 29 at Boulder Creek, Calif.; May 31 at Ithaca, N. Y.; June 10 at Wright, Que.; August 22 at Ithaca, N. Y.; August 24 at Robson, B. C.; August 27 at Cummington, Mass.; August 28 at Lac Mondor, Que.; and September 3 at Cascapedia, Que. This seasonal distribution indicates that there is a single generation per year.

Reared specimens are as follows: ㅇ, from Melanophila consputa in Pinus radiata, Boulder Creek, Calif., May 29, 1919, R. D. Hartman. , from sawfly in bark, Santa Clara Co., Calif., July 22, 1904, Coleman. $\sigma^{x}$, o , from gallery of sawfly in bark of Pinus radiata, Monterey Co., Calif., April 5, 1904, Coleman. o $\sigma^{7}$, from Xiphydria sp., Seney, Mich., W. F. Floke.

This species is transcontinental in southern Canada and northern United States. It is common and widespread also in Europe. Adults occur mostly from late June to early August.
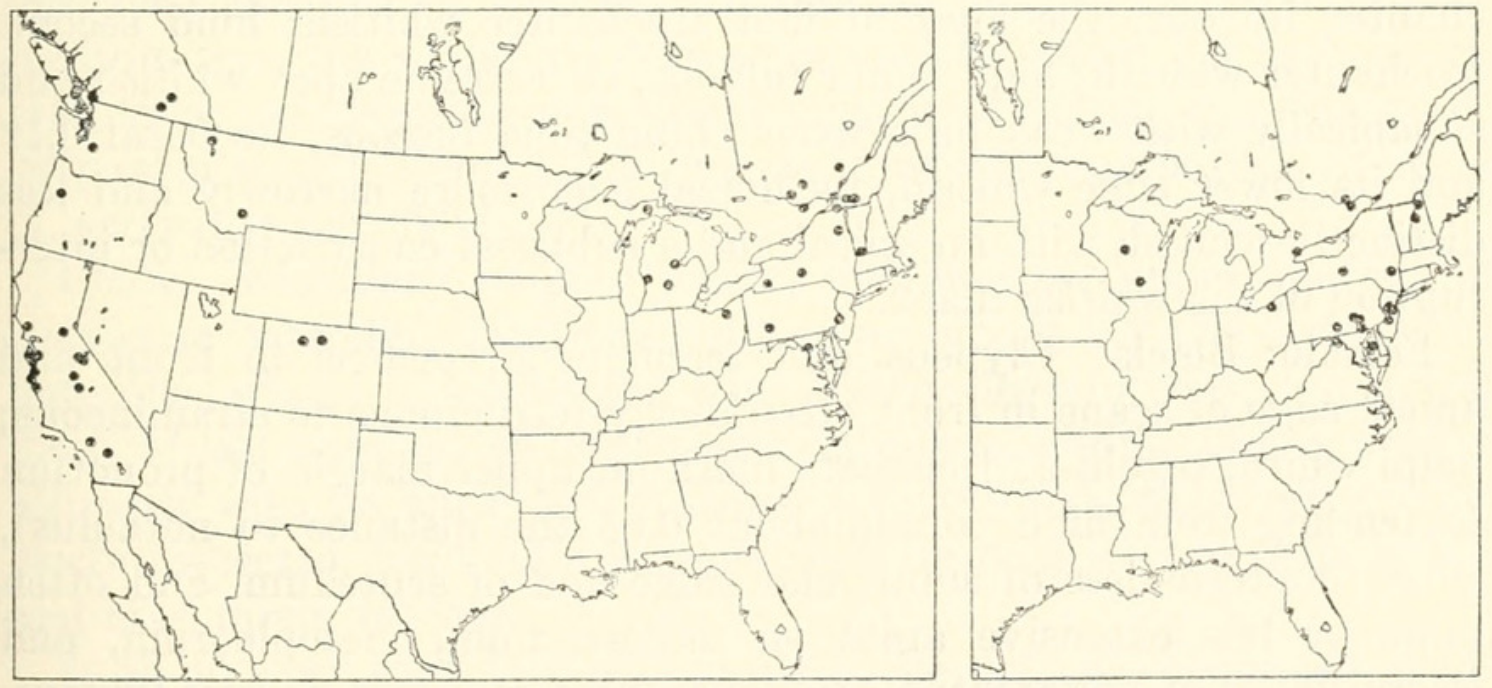

Figures 34, 35.-Localities: 34 (left), Apistephialtes tenuiventris; 35 (right), A. variatipes.

\section{Apistephialtes variatipes (Provancher), new combination}

Figures $329, \mathrm{f} ; 330, \mathrm{k} ; 335$

Ephialtes variatipes Provancher, 1886, Additions et corrections au volume II de la faune entomologique du Canada traitent des hyménoptères, p. 114; $\sigma^{7}$. Type: $\sigma^{7}$, Ottawa, Ont. (Ottawa). 
Pimpla stultor Davis, 1898, Trans. Amer. Ent. Soc., vol. 24, p. 367; ఠ’. New synonymy. Type: $\sigma^{7}$, Toronto, Ont. (Philadelphia).

Calliephialtes benefactor Cushman, 1931, Proc. U. S. Nat. Mus., vol. 79, art. 14, p. $6 ; \sigma^{\top}, \uparrow$. Type: $q$, Burlington, N. J. (Washington).

Front wing of male 4.5 to $9.0 \mathrm{~mm}$. long, of female 7.0 to $11.5 \mathrm{~mm}$. long; propodeum a little rugulose near its midline and with indistinct parallel longitudinal ridges at position of the median longitudinal carinae, its punctures separated by about 0.8 their diameter; male subgenital plate and the preceding sternite as in figure 330 , k; apex of male clasper elongate (fig. 335 ); male eighth and ninth tergites not fused; ovipositor sheath about 2.5 as long as front wing; tip of ovipositor as in figure 329 ,f.

Male: Black. Upper half of scape in front, pedicel in front, palpi, tegula, and narrow wedge-shaped mark on upper margin of pronotum extending from hind corner about 0.7 the distance to notaulus, white; clypeus ferruginous; often more or less of mesoscutum except for a broad median stripe, often more or less of mesosternum and mesopleurum, and always the subtegular ridge and scutellum, fulvous; front coxa whitish with a fulvous tinge; front trochanters white; front and middle femora fulvous, whitish in front and on apex; front and middle tibiae whitish with fulvous tinges; front tarsus whitish, tinged with fulvous apically; middle coxa fulvous and whitish; middle trochanters white, the first trochanter fulvous basally above; middle tarsus stramineous, its last segment fuscous; hind coxa and first trochanter fulvous, the apex of first trochanter whitish; hind second trochanter whitish; hind femur fulvous, its extreme apex whitish and subapically with weak infuscation; hind tibia fuscous, its basal 0.12 and its lower edge whitish, its dorsal edge more narrowly and less distinctly whitish with an apical and a subbasal constriction or interruption of the whitish mark.

Female: Black. Clypeus dull ferruginous; pedicel in front and apical edge of scape in front often dusky ferruginous to stramineous; palpi white; tegula and cuneate mark on upper margin of pronotum (extending from hind corner about 0.65 the distance to notaulus), white; more or less of subtegular ridge and of scutellum, and often more or less extensive areas on mesosternum, mesopleurum, and lateral lobes of mesoscutum, fulvous; front and middle legs fulvous, the apex of their first trochanters, all of second trochanters, apex of femora, and basal $0.15 \pm$ of tibiae whitish, the middle tarsus somewhat infuscate; hind coxa and first trochanter fulvous; hind second trochanter whitish with fulvous tinges; hind femur fulvous, its apical $0.15 \pm$ infuscate and its extreme apex stramineous; hind tibia infuscate, its lower and upper edges a little paler and its basal $0.15 \pm$ stramineous; hind tarsus fuscous.

Specimens (35 $\left.0^{7}, 51 \%\right)$ : From Maryland (Easton); Minnesota 
("Crystal Lake"); New Hampshire (Franconia and Randolph); New Jersey (Burlington, Glen Moore, New Brunswick, and South River); New York (Greene Co. and Ithaca); Ohio (Puritas Springs in Cuyahoga Co.); Ontario (Ottawa and Toronto); Quebec (Aylmer); Pennsylvania (Chambersburg, Harrisburg, Manchester, and Stewartstown); West Virginia (Kearneysville); and Wisconsin (Madison and Rib Mountain State Park).

All but 1 male and 10 females were reared, probably indoors, thus giving little information about the natural season of the adults. The collected specimens include a male taken August 3 and females on May 12, June 7 and 14, "June," "July," August 10, 21, and 27, September 5 , and "Sept."

Rearing records are: 1 from Canarsia ulmiarrosorella, 4 from overwintering cocoons of Carpocapsa pomonella, 1 from C. pomonella, 13 from overwintering cocoons of Grapholitha molesta, 1 from G. molesta, and 1 from "bleeding Pinus."

This species is in Ontario, Quebec, and the northeastern United States. It parasitizes lepidopterous cocoons under scales of bark of deciduous trees.

\section{Apistephialtes masoni, new species}

Male: Unknown.

Female: Front wing 6.0 to $7.7 \mathrm{~mm}$. long; propodeum a little rugulose near position of median longitudinal carinae, its punctures of medium size, the sublateral ones separated by about 1.0 their diameter, those near position of median longitudinal carinae more crowded; ovipositor sheath about 1.7 as long as front wing; ovipositor tip as in A. variatipes (fig. $329, \mathrm{f}$ ).

Black. Maxillary palpus, tegula, and line on upper margin of pronotum extending from the hind corner about 0.6 the distance to notaulus, white; labial palpus pale brown; legs fulvous, the apical $0.6 \pm$ of last segment of front tarsus infuscate, middle tarsus weakly infuscate with its apex dark fuscous, apex of hind femur rather narrowly infuscate, hind tibia fuscous with its base a very little paler, and hind tarsus fuscous.

It is possible that this will prove to be only a subspecies of $A$. variatipes.

Type: ㅇ, Haines Junction, Yukon Territory, Aug. 2, 1948, Mason and Hughes (Ottawa).

Paratypes: $\odot$, Mile 149 on the Richardson Highway, Alaska, July 4, 1951, W. R. M. Mason (Ottawa). o, Black Foot Hills, Alta., Aug. 7, 1940, A. R. Brooks (Ottawa). \&, Drumheller, Alta., July 30, 1950, E. H. Strickland (Townes). क, Transcona, Man., June 17, 1924, G. S. Brooks (Ottawa). \&, Norman Wells, N. W. T., July 4, 1949, 
W. R. M. Mason (Ottawa). \&, Bells Corners, Ont., Aug. 11, 1936, G. S. Walley (Ottawa). †, locality illegible, May 5, 1885 (Ottawa). This is a species of Canada and Alaska.
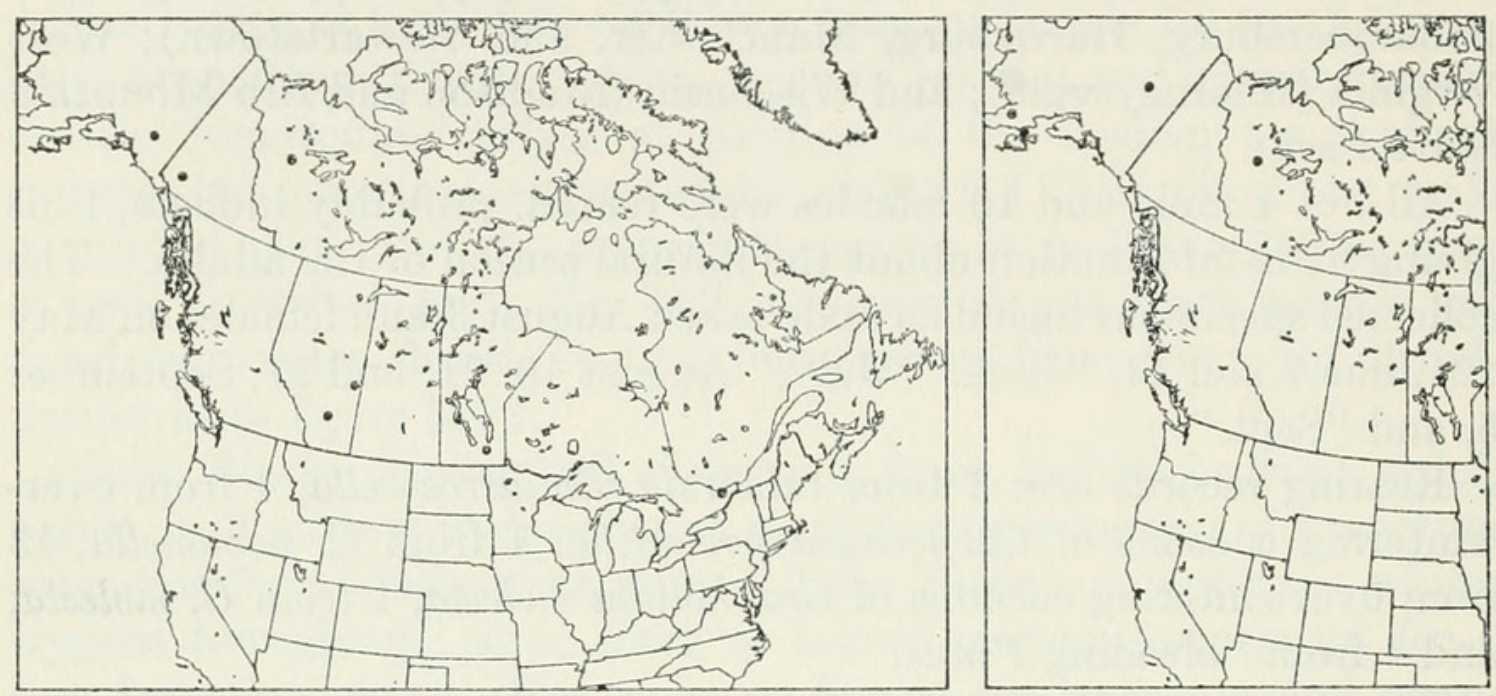

Figures 36, 37.-Localities: 36 (left), Apistephialtes masoni; 37 (right), A. arcticus.

\section{Apistephialtes arcticus (Roman), new combination}

Figure $329, \mathrm{~g}$

Ephialtes arcticus Roman, 1914, Mém. Acad. Imp. Sci. St. Petersbourg, ser. 8, cl. Phys.-Math., vol. 29, No. 7, p. 6;. . Type: $q$, Cape Chara-Ullach, mouth of Lena River, aretic Siberia (Leningrad).

Female: Front wing 7.7 to $9.5 \mathrm{~mm}$. long; propodeum a little rugulose near its midline and with indistinct parallel longitudinal ridges at position of median longitudinal carinae, its punctures separated by about 0.7 their diameter; ovipositor sheath about 2.2 as long as front wing; tip of ovipositor unusually blunt (fig. $329, \mathrm{~g}$ ).

Black. Palpi light brown; tegula brown, its base whitish; hind corner of pronotum white, the white prolonged forward along upper edge of pronotum to about 0.55 the distance to notaulus; front leg fulvous, its tarsus a little brownish; middle leg fulvous, its tibia a little brownish and its tarsus brown with the apical segment dark brown; hind coxa and trochanters fulvous; hind femur fulvous with a subapical fuscous band, its extreme apex stramineous; hind tibia fuscous brown, its basal 0.12 pale brown; hind tarsus fuscous.

The type was seen in Leningrad, and though it was not compared directly with Nearctic material, it seemed to agree with Nearctic specimens in all respects, including the dark brown tegula and the heavy ovipositor tip.

Specimens: $\odot$, Katzebue, Alaska, May 29, 1951, Mona McKinnon (Washington). ㅇ, Naknek Lake, Savonoski, Alaska, July 23, 1919, James S. Hine (Columbus). ㅇ, Mile 103, Steese Highway, Alaska, 
June 20, 1951, Mason and McGillis (Ottawa). o , Norman Wells, N. W. T., July 10, 1949, W. R. M. Mason (Ottawa).

This is a species of Siberia, Alaska, and northwestern Canada.

\section{A pistephialtes nucicola (Cushman), new combination}

\section{Figure 330,$1 ; 336$}

Calliephialtes nucicola Cushman, 1931, Proc. U. S. Nat. Mus., vol. 79, art. 14, p. $5 ; \sigma^{\top}$, $\uparrow$. Type: $\uparrow$, Saticoy, Calif. (Washington).

Biologr: Barrett, 1932, Journ. Econ. Ent., vol. 25, p. 1111.

Front wing of male 4.0 to $5.0 \mathrm{~mm}$. long, of female 4.6 to $7.5 \mathrm{~mm}$. long; propodeum entirely smooth and polished, its punctures separated by about 1.5 their diameter; male subgenital plate and the preceding sternite as in figure 330,1 ; apex of male clasper elongate (fig. 336); male eighth and ninth tergites not fused; ovipositor sheath about 1.9 as long as front wing; tip of ovipositor as in A. variatipes (fig. 329 ,f).

Male: Black. Clypeus and mandible dusky ferruginous; scape in front except at extreme base, pedicel in front, palpi, tegula, cuneate mark on upper margin of pronotum extending from hind corner about 0.7 the distance to notaulus, front coxa, and front and middle trochanters, white; middle coxa white, tinged with fulvous basally; front and middle tibiae white, more or less tinged with fulvous; front tarsus white, its apex tinged with fulvous; middle tarsus whitish, brownish apically; front and middle femora fulvous, their apex and more or less of front face white; hind coxa and femur fulvous, the apex of the femur white; hind first trochanter fulvous basally, white apically: hind second trochanter white; hind tibia mostly whitish, its apex fuscous, the fuscous restricted to the apex dorsally but laterally extending basad for about 0.4 the length of the tibia; hind tarsus stramineous, each segment brownish apically, the last segment entirely brown.

Female: Black. Clypeus and mandible dull ferruginous; pedicel in front and apical margin of scape in front, brownish; maxillary palpus white; labial palpus stramineous; tegula and cuneate mark on upper margin of pronotum white, the white mark extending from hind corner about 0.65 the distance to notaulus; front and middle legs fulvous, their trochanters and upper edge of their tibiae whitish; hind coxa, first trochanter, and femur fulvous, the femur with a faintly infuscate subapical band and its extreme apex stramineous; hind tibia infuscate below, whitish above, its apex infuscate and its whitish area with a subbasal constriction; hind tarsus brown, fuscous apically.

Specimens $\left(760^{\top}, 150 \%\right)$ : From Arizona (Parker Creek and Pocket Creek, both in the Sierra Ancha); British Columbia (Nanaimo and Robson); California (Alameda Co., Black Point in Marin Co., Carmel, Catalina Island, Fairfax, Fish Camp, Gasquet, Giant Forest, Glen 
Ellen, Menlo Park, Mountain Home in San Bernardino Co., Ojai, San Diego Co., San Francisco, Santa Ana Mts., Santa Barbara, Santa Margarita, Saticoy, Stanford, Strawberry, Ventura, and Walnut Creek); Colorado (North Cheyenne Canyon); New Mexico (Manzano and Las Vegas); Oregon (Ashland, Aurora, Corvallis, Dilley, Dundee, Elmira, Eugene, Goshen, Gresham, Hillsboro, Independence, Junction City, "Lane Park," Marion Co., Monitor, Oakridge, Pedee in Polk Co., Scappoose, Stayton, Washington Co., and Woodburn); and Washington ("Minnehaha" and Tacoma).
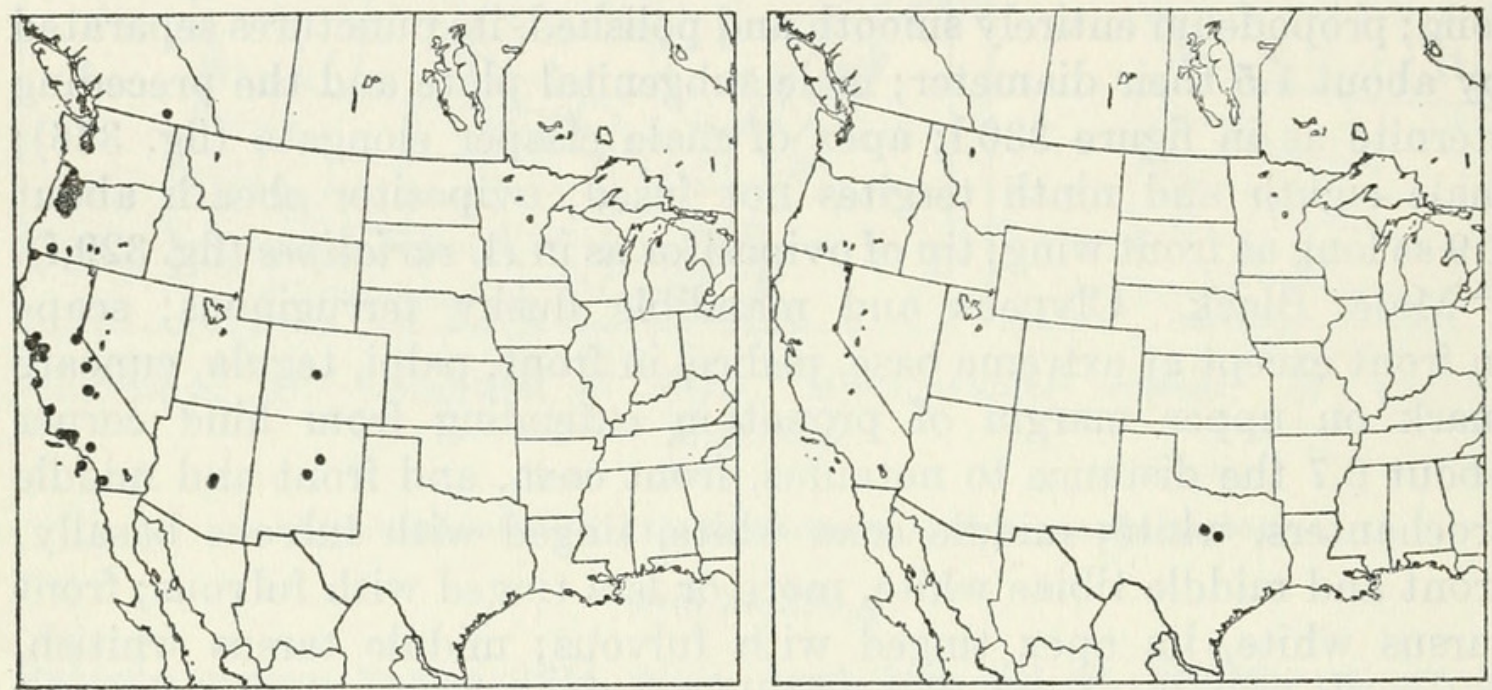

Figures 38, 39.-Localities: 38 (left), Apistephialtes nucicola; 39 (right), A. petulcus.

Field collected specimens have been taken throughout the growing season. Unusually early and late records are: March 23 at Carmel, Calif.; April 14 at Black Point, Marin Co., Calif.; May 1 at Robson, B. C.; October 19 in San Diego Co., Calif.; and November 11 at San Francisco, Calif. Reared adults have about the same range of dates.

Rearing records are as follows: 1 rearing from Andricus gells, 2 in Oregon from "Cynips maculipennis," 1 from galls of Disholcaspis eldoradensis, 9 from galls on Quercus, 15 from "oak apple" (a cynipid gall on Quercus), 1 from Quercus undulata, 2 from acorns, 1 from acorns of Quercus lobata, 1 from Quercus, 2 from nuts of wild Corylus, 3 from nuts of cultivated Corylus, 3 from Carpocapsa pomonella attacking nuts of Juglans, 1 from a Pontania gall on Salix, and 1 from Gnorimoschema bacharisella.

This species is widely distributed in western United States and in British Columbia. Adults occur throughout the growing season. The hosts are varieties of larvae in many kinds of galls and nuts, particularly on Fagaceae. 


\section{Apistephialtes petulcus (Cresson), new combination}

Figures $331, \mathrm{k} ; 337$

Pimpla petulca Cresson, 1872, Trans. Amer. Ent. Soc., vol. 4, p. 165; †. Type:

\% , Bosque County, Tex. (Washington).

Front wing of male about $4.8 \mathrm{~mm}$. long, of female about $6 \mathrm{~mm}$. long; propodeum a little rugulose centrally and with a faint indication of parallel longitudinal ridges at the position of the median longitudinal carinae, its punctures separated by about 0.8 their diameter; male subgenital plate and the preceding sternite as in figure $331, \mathrm{k}$; apex of male clasper short (fig. 337); male eighth and ninth tergites not fused; ovipositor sheath 1.7 as long as front wing; ovipositor tip a little more slender than in $A$. variatipes.

Male: Black. Clypeus and mandible dusky ferruginous, the mandible whitish basally; scape and pedicel in front, palpi, tegula, cuneate mark on upper margin of pronotum extending from hind corner 0.7 the distance to notaulus, and front and middle legs white, the apical $0.6 \pm$ of the last segment of front aLd middle tarsi brown; flagellum stramineous beneath; mesoscutum except for a broad median stripe, scutellum, postscutellum, mesosternum, and most of mesepisternum, fulvous; hind coxa fulvous, its apex white; hind trochanters white; hind femur fulvous, its apex and sometimes its front face white; hind tibia whitish, with a narrow subbasal and a broad apical brown band, the apical and subbasal brown areas faintly connected on front face by a narrow stripe; hind tarsus brown, darkest apically, the first segment broadly and the second segment narrowly stramineous basally.

Female: Colored rather similar to females of $A$. dentatus with extensive pale markings, but with the middle coxa white.

Specimens: o (type), Bosque Co., Tex. (Washington). $\sigma^{7}$, Eastland Co., Tex., Apr. 4, 1921, Grace O. Wiley (St. Paul). $\sigma^{7}$, Texas, Belfrage (Washington). ๆ, Texas, Belfrage (London). ๆ, Tuxpan, Michoacan, Mexico, July 17, 1956, R. and K. Dreisbach (Dreisbach). This is a rare species, known only from Texas and Mexico.

\section{Apistephialtes dentatus, new species}

Figures 331,$1 ; 338$

Front wing of male 4.0 to $6.7 \mathrm{~mm}$. long, of female 6.2 to $11.0 \mathrm{~mm}$. long; clypeus of male with a moderate-sized median transverse tooth; clypeus of female with its apical half separated from basal half by a sharp transverse declivity (in other species of the genus these clypeal specializations are absent in both sexes); propodeum a little rugulose centrally and with two weak parallel longitudinal ridges at the position of the median longitudinal carinae, its punctures separated by about 0.6 their diameter; male subgenital plate and the preceding sternite 
as in figure 331,1 ; apex of male clasper rather elongate (fig. 338); male eighth and ninth tergites not fused; ovipositor sheath about 1.65 as long as front wing; tip of ovipositor as in A. variatipes (fig. $329, \mathrm{f}$ ).

Male: Black. Clypeus and mandible largely dark ferruginous; pedicel in front, scape in front except at base, palpi, tegula, cuneate mark on upper margin of pronotum extending from hind corner 0.7 the distance to notaulus; front coxa, middle coxa except behind, front and middle trochanters, and hind trochanters except for the first trochanter above, white; mesoscutum except for median stripe, scutellum, mesosternum and mesepisternum except for prepectus and some of upper part of mesepisternum, and metapleurum centrally, fulvous; front and middle femora white, fulvous above and behind; front tibia light brown, whitish above and anteroventrally; front tarsus whitish, its apex brown; middle tibia light brownish, whitish in front and below, with a faint subbasal brown mark; middle tarsus brown, darker apically; hind coxa and femur fulvous, the femur with a light infuscation apically, its extreme apex whitish; hind tibia infuscate, its basal 0.15 and its under side except near apex, whitish; hind tarsus fuscous.

Female: Black. Clypeus and mandible dull ferruginous; front of pedicel and of upper margin of scape, brownish; palpi, tegula, and cuneate mark on upper margin of pronotum reaching from hind corner about 0.8 the distance to notaulus, white; thorax with a variable amount of fulvous, sometimes with extensive fulvous markings as described for the male, sometimes the fulvous markings reduced, and sometimes without fulvous markings; scutellum fulvous or black, often black; front coxa white, tinged with fulvous basally; front and middle trochanters whitish, the first trochanters fulvous above; front femur fulvous, white in front and with a white spot apically behind; front tibia light reddish brown, with a white stripe in front and above; front tarsus brownish fulvous; middle femur white in front near apex and with a white apical spot behind; middle tibia light brown, stramineous below and subbasally; middle tarsus brown; hind coxa fulvous; hind first trocha.ster fulvous, pale apically; hind second trochanter whitish, fulvous above; hind femur fulvous, subapically infuscate, its extreme apex stramineous; hind tibia dark brown, with a subbasal stramineous streak above and its under side stramineous except near apex; hind tarsus fuscous.

Type: 9 , reared from larva of Enoclerus sphegeus in Pinus lambertiana, Yosemite, Calif., Jan. 30, 1938, G. R. Struble (Washington, USNM 63683).

Paratypes: + , Bilby, Alta., July 1, 1925, Owen Bryant (Washington). ㅇ, Aspen Grove, B. C., June 15, 1933, K. Graham (Ottawa). ð’, Biological Station, Nanaimo, B. C., June 27, 1920, E. P. Van Duzee 


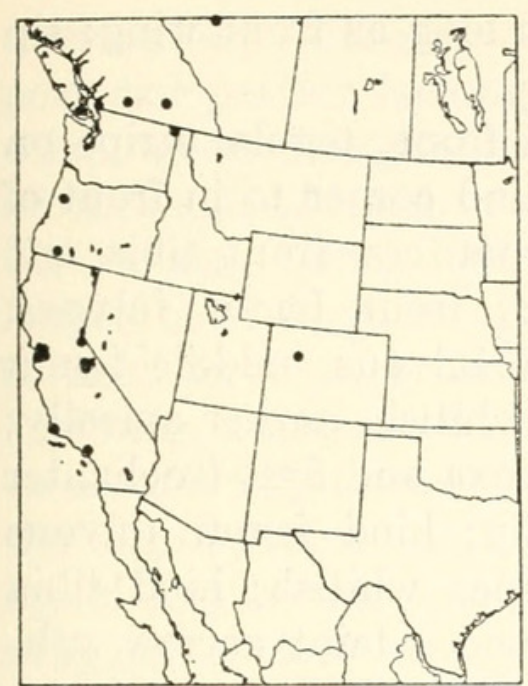

Figures 40, 41.-Localities: 40

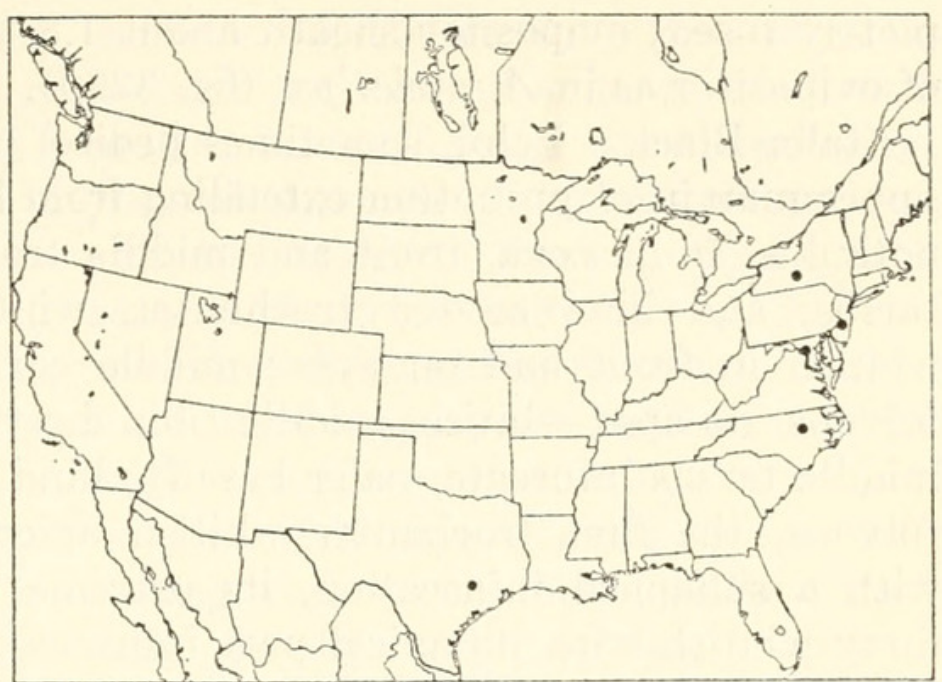

(left), Apistephialtes dentatus; 41 (right), A. coracinus.

(Townes). क, reared from Enoclerus sphegeus in Pseudotsuga, Cowichan Lake, B. C., May 25, 1941, K. Graham (Ottawa). \&, Sugar Lake, B. C., Sept. 1, 1924, E. R. Buckell (Ottawa). क, Vancouver, B. C. (Washington). $\sigma^{7}$, Berkeley, Calif., May 17, 1937, R. M. and G. E. Bohart (San Francisco). ค, Echo Lake, 7,400 ft., Calif., July 20, 1933, E. O. Essig (Berkeley). 3ㅇ, near Glacier Point, Yosemite Park, Calif., July 16 and 17, 1948, H., M., G., D., and J. Townes (Townes). $\sigma^{7}$, Glendale, Calif., July 21, 1941, E. I. Schlinger (Davis). †, Lompoc, Calif., Aug. 6, 1938, L. W. Hepner (Lawrence). ㅇ, Menlo Park, Calif., Jan. 1905, F. Hornung (Washington). $\sigma^{7}$, o , reared from Thanasimus nigriventris, North Fork, Calif., May 5, 1927, H. L. Person (Washington). क, Oakland, Calif., Apr. 1, 1950, R. Schuster (Townes). क , reared from Enoclerus sphegeus, Yosemite, Calif., Jan. 27, 1938, G. R. Struble (Townes). 2o, reared from Picea engelmanni, New Castle, Colo. (Washington). \&, reared from Libocedrus decurrens, Ashland, Oreg., Feb. 3, 1919, W. E. Glendinning (Washington). †, Corvallis, Oreg., Aug. 24, 1935, G. Ferguson (Washington). \&, Metaline Falls, Wash., June 10, 1931, W. D. Bedard (Washington).

This is a species of the Canadian and Transition zones of the West. It is parasitic on clerids in Coniferae.

\section{Apistephialtes coracinus, new species}

Figures $331, \mathrm{~m} ; 339$

Front wing of male 4.1 to $5.4 \mathrm{~mm}$. long, of female 5.8 to $8.7 \mathrm{~mm}$. long; propodeum smooth, without rugulosity or longitudinal ridges, its punctures separated by about 1.5 their diameter; male subgenital plate and the preceding sternite as in figure $331, \mathrm{~m}$; apex of male clasper rather short (fig. 339); male eighth and ninth tergites com- 
pletely fused; ovipositor sheath about 1.8 as long as front wing; tip of ovipositor as in A. variatipes (fig. $329, \mathrm{f}$ ).

Male: Black. Palpi, sometimes pedicel in front, tegula, stripe on upper margin of pronotum extending from hind corner to in front of notaulus, front coxa, front and middle trochanters, front tibia and tarsus, and hind second trochanter, white; front femur fulvous, whitish in front and on apex; middle coxa fulvous; middle femur fulvous, its apex whitish; middle tibia dirty whitish, darker apically; middle tarsus infuscate, paler basally; hind coxa and first trochanter fulvous, the first trochanter whitish apically; hind femur fulvous with a subapical infuscation, its extreme apex whitish; hind tibia dirty whitish with its apical part infuscate and a faint narrow subbasal infuscate band; hind tarsus fuscous.

Female: Black. Palpi, tegula, and stripe on upper margin of pronotum extending from hind corner to in front of notaulus, white; front coxa and trochanters white, the coxa fulvous basally; middle and hind coxae fulvous; middle and hind first trochanters fulvous, whitish apically; middle and hind second trochanters whitish; front leg beyond trochanters fulvous, its tarsus brownish apically; middle femur and tibia fulvous; middle tarsus infuscate; bind femur fulvous with a weak subapical infuscation; hind tibia brown, a little paler basally above and its apex darker; hind tarsus fuscous.

Type: $\sigma^{7}$, Plummers Island, Md., April 1924, H. S. Barber (Washington, USNM 63684).

Paratypes: + , Moorestown, N. J., June 25, 1939, H. and M. Townes (Townes). व7, Varna, Tompkins Co., N. Y., July 19, 1946, A. Stone (Washington). क , Wake Co., N. C., Apr. 20, 1952, H. and M. Townes (Townes). \%, Brazos Co., Tex., Apr. 10, 1941, R. W. Strandtmann (Townes). $\%$, no data (Cambridge).

There is a scarce, but widely distributed species in eastern United States.

\section{Genus Pimpla}

\section{FigURe 287,b}

Pimpla Fabricius, 1804, Systema piezatorum, p. 112. Type: Ichneumon manifestator Linnaeus; designated by Curtis, 1828.

Front wing 3.7 to $14 \mathrm{~mm}$. long; body very long and slender; face black; clypeus of male white or whitish, of female ferruginous or brown; clypeus very wide (about 2.5 as wide as long), weakly convex, its apical part somewhat impressed and with a deep median emargination; lower tooth of mandible a little longer and wider than upper tooth (in most other Pimplini the lower tooth of mandible is the same size as upper tooth or a little smaller); occipital carina complete, dipped on the midline; hair on mesoscutum moderately dense, evenly 
distributed; submetapleural carina complete or more or less of its posterior portion lacking; propodeum moderately long, with a broad, weak, median longitudinal groove on its basal $0.4 \pm$ and a weak ridge on each side of the groove in place of the median longitudinal carinae, the carinae themselves not present; areolet subtriangular, a little longer than high, receiving second recurrent vein before its outer corner; nervellus broken at or above the middle; first tergite short and wide, much shorter than the second tergite; basal oblique grooves on second tergite broad and weak, extending about 0.3 the length of the tergite; third and fourth tergites with large weak tubercles, their apical impunctate bands occupying about 0.35 their length; female subgenital plate sclerotized only basally and laterally; ovipositor sheath 1.8 to 5.0 as long as front wing; ovipositor straight, slender, cylindric, its apex as in figures 329 ,h and 330 ,a, the apex a little depressed with the ventral valves somewhat enclosing the dorsal valve, the ridges of their basal teeth curved forward near the dorsal end.

The generic name Pimpla, in its long history, has had a variety of applications. Traditionally, it has been and still is used for nearly all of the shorter bodied Pimplini like Scambus, Tromatobia, Exeristes, Iseropus, etc., and for members of the tribes Ephialtini and Theroniini. From a nomenclatural standpoint its proper application was decided when Curtis designated Ichneumon manifestator as the genotype, in 1828. We limit the name to the species closely related to this genotype. Certain recent authors limit the name to Coccygomimus (in the Ephialtini), basing their action on what they regard as the "usage" of the name and on an Opinion (No. 159), published in 1945, of the International Commission on Zoological Nomenclature, rather than on Curtis' genotype selection in 1828 . (Opinion No. 159, incidentally, is a spurious one. It has the same history and status as Opinion No. 166, on Psammochares; see Townes, 1958, Syst. Zool., vol. 6, p. 151-156.)

Pimpla, as defined here, contains a small number of elongate species and is confined to the Holarctic region (including the mountains of Formosa). There are four species in North America, of which two (spatulata and brevis) occur also in Europe. In Europe, we know of four species (including the two Holarctic ones) but their nomenclature is rather confused. By far the commonest European species, which may be manifestator (Linnaeus), is near the Holarctic P. spatulata but differs in having the male clasper tapered to a point and in both sexes a little less infuscation on the apex of the hind femur. Ephialtes polytauma Heinrich 1949, described from southern Germany, is a rare species of which we have seen only the type (Townes Collection) and a specimen in the Munich museum. Ephialtes duplicauda 
Heinrich 1949, described also from southern Germany, is close to $P$. brevis, and may be the same species. The type is a female, and is difficult to determine with certainty. The species from the eastern Palaearctic are Ephialtes hokkaidonis Uchida 1928 (Japan), Ephialtes tenchozanus Sonan 1936 (Formosa), and Ephialtes arisanus Sonan 1936 (Formosa). The above are hereby referred to the genus Pimpla where all except manifestator and brevis make new combinations.

\section{Keys to the Nearctic species of Pimpla}

\section{MALES}

1. Hairs on combined costa and subcosta decumbent, most of them about 0.3 as long as the stigma is wide; apex of clasper a long finger-like lobe (fig. 340).

1. decumbens, new species

Hairs on combined costa and subcosta mostly erect, most of them about 0.8 as long as the stigma is wide; apex of clasper various . . . . . . . . 2

2. Apex of clasper rather broadly spatulate (fig. 343) . 4. spatulata, new species Apex of clasper a short point, or elongate and fingerlike (figs, 341, 342) . . . 3

3. Apex of clasper a short point (fig. 341); many of the hairs on lower half of temple suberect and about as long as labial palpus; temple in profile about 0.45 as long as eye . . . . . . . . . . 2. macra (Cresson) Apex of clasper elongate, fingerlike (fig. 342); hairs on lower half of temple inclined, about 0.35 as long as labial palpus; temple in profile about 0.62 as long as eye . . . . . . . . . . . . 3. brevis (Morley)

\section{PEMALES}

1. Dorsal part of basal three teeth of ovipositor tip turned only a little forward (fig. 329,h); second trochanter of hind leg ivory white. . . . . . . . . 2

Dorsal part of basal three teeth of ovipositor tip turned forward almost horizontally (fig. 330,a); second hind trochanter fulvous above. . . . . . . 3

2. Hairs on lower half of temple a little denser, shorter, and less erect; nervellus broken near its upper 0.35 ; clypeus about 2.25 as wide as long; ovipositor sheath about 2.6 as long as front wing. (These female characters are all variable and seldom permit a certain determination.)

1. decumbens, new species

Hairs on lower half of temple a little sparser, longer, and more erect; nervellus broken near its upper 0.45 ; clypeus about 2.2 as wide as long; ovipositor sheath about 3.0 as long as front wing. (These female characters are all variable and seldom permit a certain determination.). . 2. macra (Cresson)

3. Temple rather strongly convex, in pronile about 0.7 as long as eye; first tergite about 1.05 as long as wide; ovipositor sheath about 4.5 as long as front wing; face unusually wide and flat . . . . . . . . 3. brevis (Morley)

Temple moderately convex, in profile about 0.57 as long as eye; first tergite about 1.25 as long as wide; ovipositor sheath 1.8 to 3.0 as long as front wing; face moderately wide and flat. . . . . . . 4. spatulata new species

\section{Pimpla decumbens, new species}

Figure 340

Male: Front wing 5.4 to $7.8 \mathrm{~mm}$. long; hairs on lower half of temple inclined, about 0.6 as long as labial palpus; hairs on combined costa 
and subcosta decumbent, most of them about 0.3 as long as the stigma is wide; nervellus broken near its upper 0.35 ; submetapleural carina present on the front 0.15 to 0.8 of metasternum; first tergite about 1.8 as long as wide; clasper apically in the shape of a long fingerlike lobe.

Black. Clypeus, scape and pedicel except above, palpi, elongate hind corner of pronotum, tegula, front and middle coxae, trochanters and front and middle tibiae and tarsi, white; front andmiddlefemora fulvous, white at base and apex and in front; hind coxa and femur fulvous, both white on extreme apex, the femur with a narrow subapical fuscous band; hind tibia white, its apical $0.3 \pm$ and a dorsal stripe beyond its basal $0.3 \pm$ fuscous; hind tarsus fuscous, the basal $0.25 \pm$ of its basitarsus whitish.

Figure 42.-Localities for Pimpla decumbens.

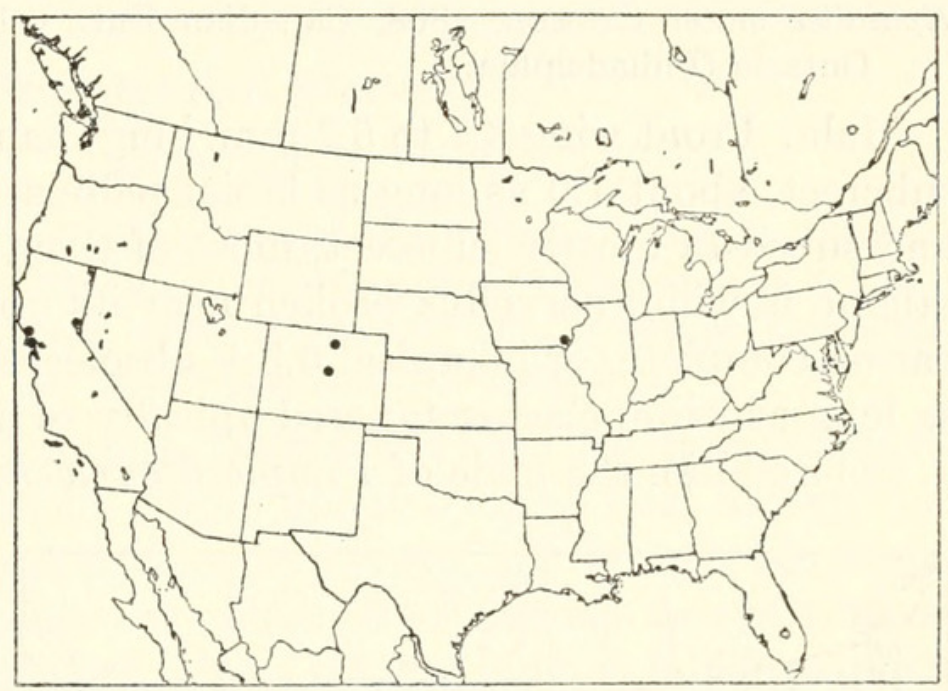

Female: Front wing 6.0 to $7.7 \mathrm{~mm}$. long; clypeus about 2.25 as wide as long; nervellus broken near its upper 0.35 ; first tergite about 1.45 as long as wide; ovipositor sheath about 2.6 as long as front wing; dorsal part of basal three teeth of ovipositor tip turned a little forward.

Black. Clypeus light reddish brown; palpi white; elongate hind corner of pronotum, tegula, and second trochanters white; coxae fulvous, the front coxa whitish apically; first trochanter of front leg white, tinged with fulvous behind; femora fulvous, their extreme apex white, the hind femur infuscate subapically; front and middle tibiae obscurely varied with pale fulvous, whitish, and pale fuscous; front tarsus light brownish; middle tarsus infuscate; hind tibia infuscate, darker apically and subbasally and its basal $0.2 \pm$ whitish; hind tarsus fuscous, its basitarsus whitish basally.

Type: $\sigma^{\top}$, near Estes Park, Colo., June 13, 1948, H., M., G., and D. Townes (Washington, USNM 63685).

Paratypes: $2 \sigma^{7}$, Victoria, B. C., May 5 and 11, 1926, W. Downes (Ottawa). $\sigma^{7}$, Cazadero, Calif., Mar. 4, 1934, R. M. and G. E. Bohart (Townes). $\quad \sigma^{7}$, Donner Pass, Calif., Aug. 1, 1948, H., M., G., and D. 
Townes (Townes). $\sigma^{\top}$, Marin Co., Calif., Aug. 3, 1929, P. W. Oman (Lawrence). $3 \sigma^{7}$, near Estes Park, Colo., June 12 and 13, 1948, H., M., G., D., and J. Townes (Townes). $\sigma^{7}$, Manitou, 6,629 ft., Colo., July, E. S. Tucker (Washington). $\sigma^{\top}$, Henry Co., Iowa, May 10, 1945, Holmes Foster (Ottawa).

In addition to the male types we have a number of females that probably belong to this species, but these cannot be determined with certainty.

This species ranges from British Columbia and California eastward to Iowa.

\section{Pimpla macra (Cresson)}

Figures $329, \mathrm{~h} ; 341$

Ephialtes macer Cresson, 1868, Canadian Ent., vol. 1, p. 35;. Lectotype:, Ontario (Philadelphia).

Male: Front wing 3.7 to $5.7 \mathrm{~mm}$. long; hairs on lower half of temple suberect, about 1.0 as long as labial palpus; hairs on combined costa and subcosta mostly suberect, most of them about 0.8 as long as the stigma is wide; nervellus broken near its upper 0.45 ; submetapleural carina complete, or its apical $0.3 \pm$ obsolescent; first tergite about 1.9 as long as wide; clasper tapered apically to a rounded point.

Colored like the male of Pimpla decumbens.

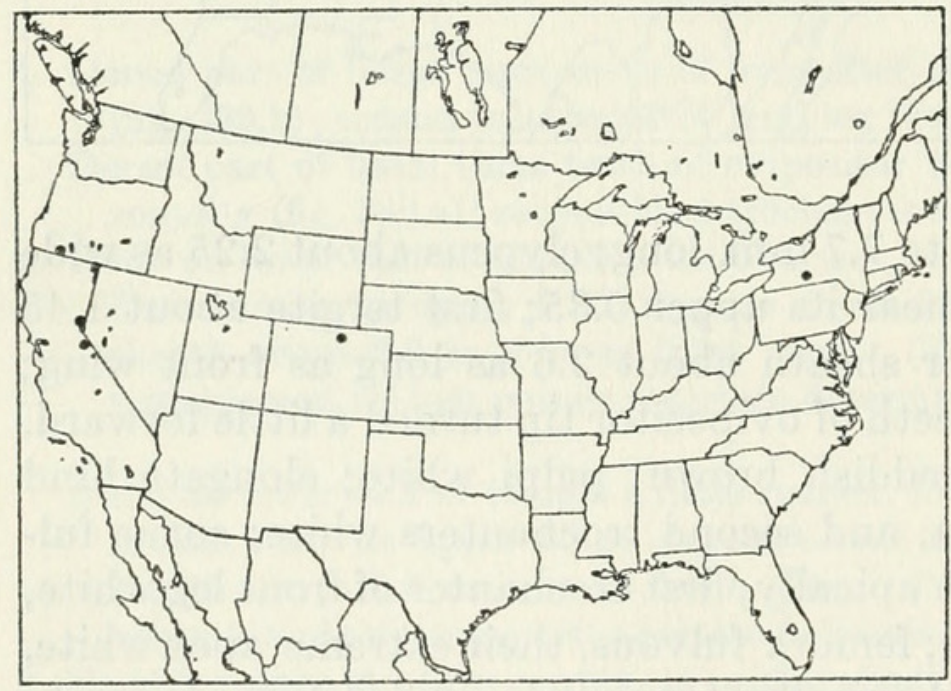

Figure 43.-Localities for Pimpla macra.

Female: Front wing 6.0 to $8.0 \mathrm{~mm}$. long; clypeus about 2.2 as wide as long; nervellus broken near its upper 0.45 ; first tergite about 1.3 as long as wide; ovipositor sheath about 3.0 as long as front wing; dorsal part of basal three teeth of ovipositor tip turned a little forward. These characters are not constant enough for reliably distinguishing females of this species from those of $P$. decumbens.

Colored like the female of Pimpla decumbens.

The type of Ephialtes macer is a female, and though it probably belongs to the species described above it may turn out to be a female 
of $P$. decumbens. It is not possible, at present, to be certain of its identity.

Specimens: $\sigma^{\top}$, Donner Pass, Calif., Aug. 1, 1948, H., M., G., and D. Townes (Townes). $2 \sigma^{x}$, near Sonora Pass, 8,000 ft., Calif., July 6, 1948, H., M., G., and D. Townes (Townes). $2 \sigma^{7}$, northern California (Washington). $\sigma^{7}$, Estes Park, 7,800 ft., Colo., June 7, 1956, R. and K. Dreisbach (Dreisbach). ๙ ${ }^{7}$, Ithaca, N. Y., June 2, 1936, H. Townes (Townes). $\sigma^{\top}$, reared from "N. brevicornis" in Pinus ponderosa, Ashland, Oreg., Apr. 14, 1916, F. P. Keen (Washington).

We have also a number of females which are probably this species, but since females cannot be separated with certainty from those of $P$. decumbens, they are not reported here.

This species is transcontinental in the Transition and Canadian zones.

\section{Pimpla brevis (Morley)}

Figure 342

Ephialtes brevis Morley, 1914, Revision of the Ichneumonidae . . . in the British Museum ...., vol. 3, p. 23; . Lectotype, hereby designated: , St. Martin's Falls, Albany River, Ont. (London). The lectotype has been labeled and segregated in the British Museum type collection.

Male: Front wing 7.8 to $8.8 \mathrm{~mm}$. long; face unusually wide and flat; temple moderately convex, in profile about 0.62 as long as eye (in males of the other Nearctic species of Pimpla the temple is rather weakly convex, and in profile only about 0.45 as long as eye); hairs on lower half of temple inclined, about 0.35 as long as labial palpus; hairs on combined costa and subcosta mostly suberect, most of them about as long as the stigma is wide; nervellus broken at or a little above the middle; submetapleural carina present on the front $0.5 \pm$ of metasternum; first tergite about 1.4 as long as wide; clasper elongate, its apical part fingerlike.

FIgURe 44.--Localities for Pimpla brevis.

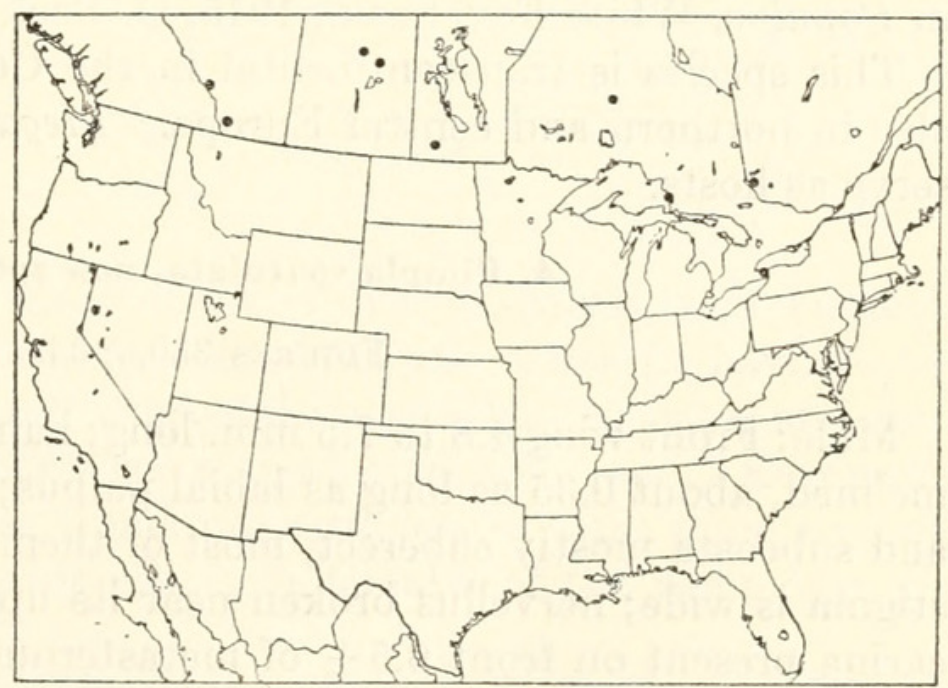


Colored like the male of $P$. decumbens except that the mandible has a large, subbasal, triangular, ochreous area.

Female: Front wing 9.5 to $11.5 \mathrm{~mm}$. long; face unusually wide and flat; clypeus about 2.6 as wide as long; temple rather strongly convex, in profile about 0.7 as long as eye (in females of the other Nearctic species the temple is only moderately convex and in profile only about 0.57 as long as eye); thorax unusually short and densely punctate; first tergite about 1.05 as long as wide; punctures on second to fourth tergites unusually dense; ovipositor sheath about 4.5 as long as front wing; dorsal part of basal three teeth of ovipositor tip turned forward almost horizontally; upper valve of ovipositor with two blunt ridges near level of basal teeth on the lower valve, these teeth more distinct than in $P$. spatulata.

Colored like the female of $P$. spatulata.

This species occurs also in Europe. We have seen two males from Finland (Helsinki museum) which are indistinguishable from Nearctic males, and some of the paratype females of Ephialtes duplicauda Heinrich, from southern Germany, seem to be typical P. brevis. The type of $E$. duplicauda, however, is a little different from these paratypes, and may not be the same species.

Specimens: + , Banff, Alta., Aug. 10, 1938, G. S. Walley (Ottawa). ๑, Cowley, Alta., 191-, R. N. Chrystal (Washington). ণ, Aweme, Man., June 30, 1925, R. D. Bird (Ottawa). ᄋ, Frater, Ont., Aug. 5, 1925, C. E. Youch (Ottawa). ९, Niagara Glen, Ont., June 23, 1926, G. S. Walley (Ottawa). \& (lectotype), St. Martin's Falls, Albany River, Ont. (London). ๆ, Laniel, Que., July 12, 1931, M. B. Dunn (Ottawa). 7\%, collected near logs containing nests of Megachile, Torch River, Sask., September 1944, Clark (Ottawa and Townes). $2 \sigma^{\top}$, reared from Megachile nivalis, White Fox, Sask., May 1945, O. Peck (Ottawa and Townes). 2\%, reared from Megachile inermis, White Fox, Sask., May 1945, O. Peck (Ottawa). $\sigma^{7}$, taken from Megachile cell in Populus, White Fox, Sask., 1945, O. Peck (Ottawa).

This species is transcontinental in the Canadian zone and occurs also in northern and central Europe. Megachile spp. nesting in logs serve as hosts.

\section{Pimpla spatulata, new species}

Figures $330, a ; 343$

Male: Front wing 4.8 to $7.5 \mathrm{~mm}$. long; hairs on lower half of temple inclined, about 0.35 as long as labial palpus; hairs on combined costa and subcosta mostly suberect, most of them about 0.8 as long as the stigma is wide; nervellus broken near its upper 0.32 ; submetapleural carina present on front $0.5 \pm$ of metasternum; first tergite about 1.5 
as long as wide; clasper elongate, its apical part rather broadly spatulate.

Colored like the male of $P$. decumbens except that the subapical fuscous mark on the hind femur is a little more extensive, occupying about 0.14 the length of the femur.

Female: Front wing 7.7 to $13.8 \mathrm{~mm}$. long; clypeus about 2.35 as wide as long; nervellus broken near its upper 0.32 ; first tergite about 1.25 as long as wide; ovipositor sheath 1.8 to 3.0 as long as front wing; dorsal part of basal three teeth of ovipositor tip turned forward almost horizontally.

Black. Clypeus light reddish brown; palpi stramineous; hind corner of pronotum (with a short forward extension along upper margin of pronotum), and tegula, white; coxae fulvous; second trochanters whitish, the second trochanter of hind leg fulvous above; first trochanter of front leg whitish in front; femora fulvous, the extreme apex of femora whitish, the hind femur narrowly brownish at base and with a subapical fuscous area that occupies about 0.15 its length; front and middle tibiae fulvous, obscurely varied with whitish and pale fuscous; hind tibia infuscate, a little paler below and its basal $0.2 \pm$ stramineous; front and middle tarsi pale brownish, infuscate apically (especially the middle tarsus); hind tarsus fuscous, pale at extreme base.

Figure 45.-Localities for Pimpla spatulata.

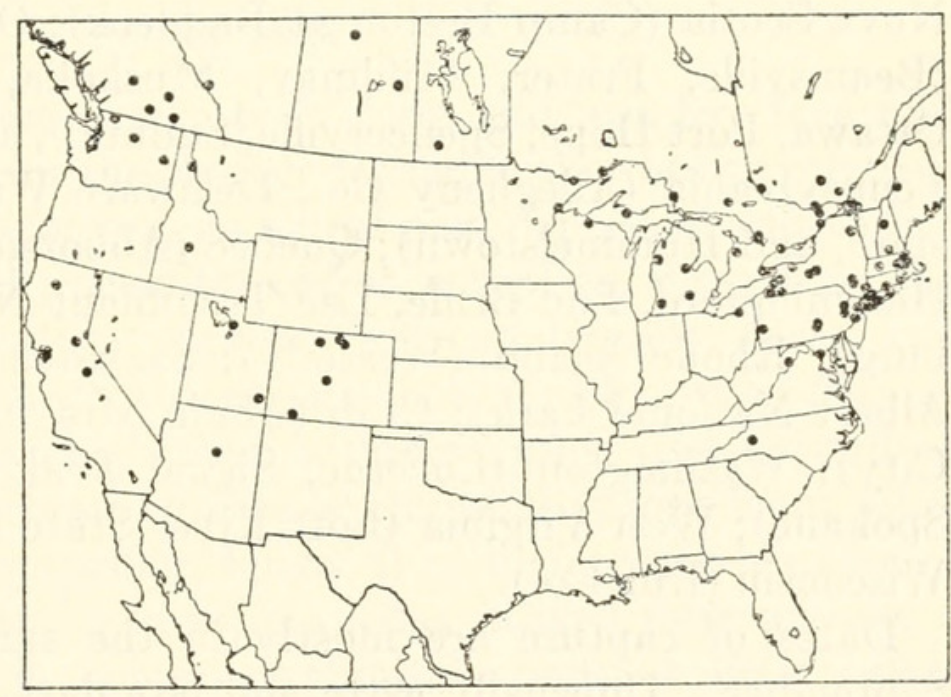

We have seen a short series of males of this species from Finland (Helsinki museum), which differ from Nearctic males in having the long hairs on the costal and subcostal veins a little shorter and less erect. They seem to represent a distinguishable race. European museums doubtless possess females of spatulata in some numbers but these are not easy to distinguish from females of the commoner $P$. "manifestator."

Type: $\sigma^{7}$, Bar Harbor, Maine, June 15, 1938, A. E. Brower (Washington, USNM 63685). 
Paratypes $\left(12 \sigma^{7}, 165\right.$ ) : From Alberta (Banff); Arizona (Oak Creek Canyon); British Columbia (Midday Valley at Merritt, Penticton, Robson, and Trinity Valley); California (Camino, Carrville, Fish Camp, and Oakland); Colorado (near Estes Park, Gothic at 9,000 ft., Granite Peaks Camp at 9,000 ft. near Bayfield, Pingree Park in Larimer Co., Steamboat Springs, and Waldo Canyon); Connecticut (Branford, New Canaan, and New Haven); Idaho (Sagehen Res. in Boise National Forest and Wallace); Maine (Jackman); Manitoba (Aweme); Maryland (Plummers Island and Town Hill); Massachusetts (Blue Hills, Brookline, Cambridge, Holliston, Natick, North Saugus, and South Hadley); Michigan (Ann Arbor, Manistee Co., Marquette Co., Midland Co., and Warren Woods in Berrien Co.); Minnesota (Basswood Lake in Lake Co. and Duluth); New Brunswick (St. John); New Hampshire (Franconia and Peterborough); New Jersey ("Berwick," Englewood, Madison, and Trenton); New York (Allegheny State Park, Belmont State Park on Long Island, Bemus Point, Big Indian Valley in the Catskill Mts., Chafee, Derby, Freeville, Frontenac Point on Cayuga Lake, Greene Co., Heart Lake in Essex Co., Ithaca, McLean Bogs Reserve in Tompkins Co., Millwood, Mount Sinai on Long Island, Onteora Mt. in Greene Co., Orient, Poughkeepsie, Rochester, and West Farms at New York City); North Carolina (Crabtree Meadows in Yancey Co. at 3,600 ft.); Nova Scotia (Camp Breton at Baddeck); Ohio (Cleveland); Ontario (Beamsville, Frater, Mildmay, Muskoka, Niagara Glen, Orillia, Ottawa, Port Hope, Spencerville, Sudbury, and Thunder Bay Beach); Pennsylvania (Allegheny Co., Delaware Water Gap, Easton, Highspire, and Hummelstown); Quebec (Abbotsford, Aylmer, Cascapedia, Hemmingford, Lac Brule, Lac Tremblant Nord, Laniel, and Sweetsburg); Rhode Island (Westerly); Saskatchewan (Leslie and Prince Albert National Park); Utah (Abajo Mts. in San Juan Co. and Park City); Washington (Lucerne, Signal Peak on Mount Adams, and Spokane); West Virginia (Lost River State Park in Hardy Co.); and Wisconsin (Iron Co.).

Dates of capture are mostly in the summer months and early September. Unusually early and late dates are May 24, 29, and 30 at Ithaca, N.Y.; May 27 at Carrville, Trinity Co., Calif.; May 30 at Ottawa, Ont.; September 27 at Wallace, Idaho; October 4 and 20 at Holliston, Mass.; October 8 at Peterborough, N.H.; October 21 at New Canaan, Conn.; and November 1 at Highspire, Pa. Dates of collection of the 13 males are May 24 and 29; June 2, 8, 13, 15, 19, 20, and 25; July 1 and 23; and one reared on May 2. Males begin to appear a little ahead of the females and disappear about the middle of the season of flight, which indicates a single generation a year with a life span of two to three months for the females. 
Biological data associated with the specimens are meager. One female was collected while ovipositing in a conifer, a male was reared from a log of Picea canadensis infested with Tetropium cinnamopterum, another male reared from Ptosima gibbicollis in Cercis canadensis, a female reared from Pinus ponderosa, and another female reared from Pseudotsuga taxifolia. It has been assumed that the species is parasitic on wood boring Coleoptera, and it has been an easy step for someone rearing both the parasite and a coleopterous borer from a piece of wood to conclude that the borer was the host. More careful work, however, has shown that this and related species are parasites in the cells of bees and wasps nesting in wood, so the above records from Coleoptera seem incorrect or very doubtful. The only indisputable host record is a female reared from a prepupa of Rygchium sp. in a tube bored in a stick of wood (a "trap nest"), the nest collected at Derby, N.Y., by L. H. Krombein and the rearing completed by K. V. Krombein, Aug. 17, 1958.

This species is transcontinental in the Canadian and Transition zones, and a form only slightly different is in northern Europe. It is adult from about June 1 to October. It has been reared from a vespid nest in wood.

\section{Anastelgis, new genus}

Figure 288,a

Front wing 6 to $16 \mathrm{~mm}$. long; body long and slender; face and clypeus black or blackish, or the clypeus ferruginous or brown; clypeus moderately wide, weakly convex, its apical part depressed and with a deep median apical notch; occipital carina complete, dipped on the midline; hair on mesoscutum varying from moderately dense and evenly distributed to almost absent; median part of outer face of mandible with punctures which tend to run together as longitudinal striae; submetapleural carina complete or almost so; propodeum without carinae; areolet subtriangular, longer than high, receiving second recurrent vein well before its apex; nervellus broken near middle, a little above middle, or in some extralimital species a little below middle; first tergite moderately long, its lateral carina present or represented by a strong ridge, its median dorsal carinae extending about half its length; basolateral grooves on second tergite sharp, extending about 0.55 the length of the tergite; third and fourth tergites with prominent tubercles, their apical impunctate area occupying about 0.2 their length; female subgenital plate with a large median basal membranous area; ovipositor sheath about 1.35 as long as front wing; ovipositor straight, cylindric, its apex as in figure 330 ,b.

Genotype: Anastelgis terminalis, new species. 
We place one Nearctic species, the Neotropic (Calliephialtes) Anastelgis brasiliensis (Enderlein) 1919 (new combination), and three undescribed Neotropic species in this genus. The European Ephialtes gnathaulax Thomson 1877, the Japanese Ephialtes chui Uchida 1934, and some undescribed species from Japan and China correspond in most characters to the American species placed definitely in Anastelgis, but have the outer face of mandible more strongly and completely punctatostriate, and because of this and a different geographic distribution it seems probable that they represent a different evolutionary line, and are not congeneric with the American species placed in Anastelgis.

\section{Anastelgis terminalis, new species}

Figure $330, \mathrm{~b}$

Front wing of male $6 \mathrm{~mm}$. long, of female 7.6 to $10.5 \mathrm{~mm}$. long; mesoscutum with dense hairs all over; metapleurum with fine, rather sparse punctures; propodeum polished, with sharp punctures laterally and basolaterally; third and fourth tergites with sharp, rather small, well-separated punctures; ovipositor sheath about 1.3 as long as front wing.

Male: Head black. Clypeus and mandible dull ferruginous; scape and pedicel ivory, blackish brown above; flagellum blackish brown; palpi stramineous; thorax ferruginous, the tegula, hind corner of pronotum, and vertical mark on prepectus ivory; upper part of propleurum, scrobe of pronotum, propodeum, and metanotum fuscous, the propodeum with ferruginous stains; front and middle legs ivory, the femora behind and apex of tarsal segments pale fulvous; hind leg fulvous, the extreme apex of coxa, trochanters, apex of femur, and tibia except for base, apex, and under side, ivory or white; hind tarsus light brown, the segments a little darker apically and paler basally; abdomen blackish brown, the apical impunctate bands on the tergites black,

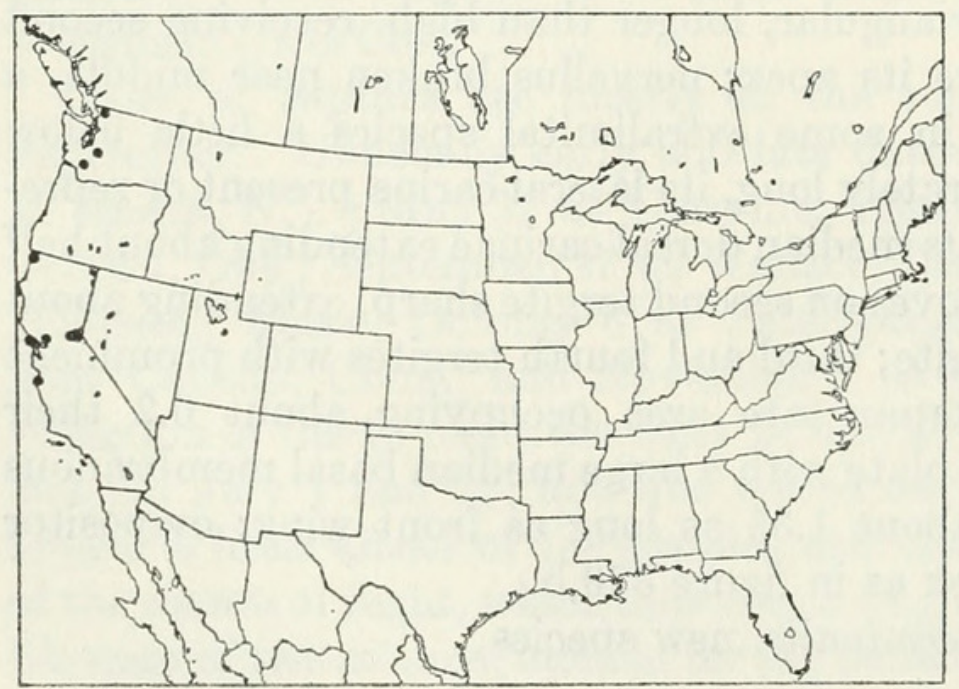

Figure 46.-Localities for Anastelgis terminalis. 
and second and third tergites with an obscure, transverse, preapical fulvous spot on each side.

Female: Head blackish, sometimes with ferruginous stains near clypeus. Clypeus, mandible, scape, and pedicel ferruginous, the scape and pedicel blackish above. Flagellum black. Palpi whitish. Thorax black with more or less ferruginous and ferruginous stains, the following always ferruginous: lower part of propleurum, mesoscutum, scutellum, postscutellum, mesosternum, mesopleurum except above, and much or all of metapleurum; tegula and hind corner of pronotum ivory. Legs fulvous, the front coxa, middle coxa except behind, front and middle first trochanters except behind, and all second trochanters ivory; hind tibia paler fulvous above; hind tarsus brownish, darker apically. Abdomen dark brown, the apical impunctate margins of the tergites darker, especially toward the sides. Ovipositor sheath black, its apical 0.18 white.

This is the only Nearctic species of Ephialtinae with the ovipositor sheath white at the apex.

Type: ค, Inverness, Calif., Oct. 6, 1946, H. K. Townes (Washington, USNM 63686).

Paratypes: $\odot$, Carmel, Calif., July 14, 1929, L. S. Slevin (San Francisco). क, Crescent City, Calif., Aug. 4, 1940, H. and M. Townes (Townes). ㅇ, Echo Lake, El Dorado Co., Calif., July 19, 1955, W. W. Middlekauff (Berkeley). क, Fallen Leaf Lake, El Dorado Co., Calif., July 1931, O. H. Swezey (San Francisco). ㅇ, Green Valley, Solano Co., Calif., Apr. 8, 1947, R. M. Bohart (Davis). o $\sigma^{7}$, same data as type (Townes). 2o, Mill Valley, Calif., July 30, 1948, H. and D. Townes (Townes). \&, Riverton, El Dorado Co., Calif., July 18, 1931, E. C. Van Dyke (Townes). \&, Ashford, Wash., July 18, 1940, H. and M. Townes (Townes). o, Barnes State Park, Wash., Aug. 12, 1940, H. and M. Townes (Townes). क, Nooksack River, Mount Baker, Wash., Aug. 13, 1925, A. L. Melander (Cambridge).

This species is known from Washington and California. It is adult throughout the growing season.

\section{Genus Dolichomitus}

Figure 288,b

Closterocerus Hartig, 1847, Ber. Naturw. Ver. Hartz, for 1846, p. 18. Name preoccupied. Type: Closterocerus sericeus Hartig; monobasic.

Dolichomitus Smith, 1877, Proc. Zool. Soc. London, for 1877, p. 411. Type: Dolichomitus longicauda Smith; monobasic.

Diclosterocerus Viereck, 1914, U. S. Nat. Mus. Bull. 83, p. 45 . New name for Closterocerus Hartig.

Exeristoidea Viereck, 1924, Canadian Ent., vol. 56, p. 202. Type: (Ichneumon (Exeristoidea) watsoni Viereck) $=$ cephalotes (Holmgren). 
Front wing 5 to $22 \mathrm{~mm}$. long; body long and slender with the ovipositor long; face black or concolorus with the rest of head; clypeus black to fulvous, moderately wide, weakly convex to flat, its apical part impressed and with a deep median notch, rarely also with a median apical tubercle; teeth of mandible of equal length; occipital carina complete, with a strong dip on the midline; hairs on mesoscutum moderately dense, evenly distributed, or in some Neotropic species the mesoscutum bare or almost so; prepectal carina usually present, absent only in the Nearctic D. cuspidatus; submetapleural carina complete; propodeum moderately long, usually with median longitudinal carinae on more or less of its basal half; areolet rather elongate, the first intercubitus tending to be longer and more oblique than in other genera of Pimplini; second recurrent received basad of apical corner of areolet; nervellus broken near or above the middle, usually distinctly above the middle; first tergite long, about as long as second tergite, its lateral and median longitudinal carinae usually long and strong; basal oblique grooves of second tergite long and strong, extending about 0.55 the length of the tergite; third and fourth tergites with strong or moderately strong tubercles, their apical impunctate bands occupying about 0.1 their length; female subgenital plate narrowly sclerotized apicolaterally and usually very narrowly across the apex, the rest membranous; ovipositor cylindric, straight or its apex often curved in dead specimens, its apex as in figures 330 ,c to $330, \mathrm{~h}$; ovipositor sheath 1.2 to 8.0 as long as front wing. The lower valve of the ovipositor has a subapical lobe that somewhat encloses the sides of the upper valve near its tip. This is the most distinctive feature of the genus. The long first tergite and the long, deep, basolateral oblique grooves on the second tergite are additional strong characters.

The species of Dolichomitus are slender, with a long ovipositor, and mostly large in size. The Nearctic species are black with fulvous legs, except that one very common species has the abdomen red and the hind coxa black. They are the largest of our Pimplini and with their long ovipositors are spectacular insects. The species have formerly been placed under the generic names Ephialtes, Ichneumon, or Pimpla, usually under Ephialtes, but refinements in zoological and nomenclatural information make it necessary to classify them under Dolichomitus. The genus Dolichomitus itself contains a heterogeneous lot of species and a searching study of the world fauna may show the need for redefining it. This is for the future, however, and the classification presented here seems to be the best possible with the information available today. 


\section{Keys to the Nearctic species of Dolichomitus}

\section{MALES}

(Males of cephalotes, buccatus, flexilis, and foxleei are unknown.)

1. Hind coxa black; middle coxa with three strong tubercles (basal, median, and apical) on its outer side; abdomen usually mostly red, but sometimes black. Irritator group (p. 128), in part . . 9. irritator (Fabricius)

Hind coxa fulvous, or sometimes more or less black in D. terebrans; middle coxa without three tubercles on its outer side; abdomen entirely black . 2

2. Median segments of flagellum enlarged, about twice as wide as the basal segments; lower half of mesepimeron densely hairy. Sericeus group (p. 157).

19. sericeus (Hartig)

Median segments of flagellum not enlarged, of approximately the same width as the basal segments; lower half of mesepimeron without hairs or with a few hairs near its hind margin . . . . . . . . . . . . . . 3

3. Pronotum with a white stripe on its upper margin, extending forward from its hind corner. Taeniatus group (p. 116) . . . . . . . . . . . 4

Pronotum without a white stripe on its upper margin, but its extreme hind corner often white or fulvous . . . . . . . . . . . . . . . . 6

4. Clypeus with a strong median apical tooth; prepectal carina absent; tubercles of third tergite flattened so that the tergite is rather smooth.

3. cuspidatus, new species

Clypeus without a median tooth; prepectal carina present below; tubercles of third tergite rounded and prominent . . . . . . . . . . . 5

5. Front coxa entirely white; punctures on third tergite separated by about 0.6 their diameter . . . . . . . . . 1. dolichosoma (Viereck)

Front coxa white in front, the rest fulvous; punctures on third tergite separated by about 1.5 their diameter . . . . . 2. taeniatus, new species

6. Clasper with a strong notch near the middle of its upper margin (figs. 344 and $348)$; nervellus broken near or a little above its middle. Tuberculatus GROUP (p. 121) . . . . . . . . . . . . . . . . . . . . . 7

Clasper without a strong notch near the middle of its upper margin (figs. $349,350,352-357)$; nervellus broken distinctly above its middle. IrRITATOR GROUP (p. 128), in part, and IMPERATOR GBOUP (p. 152) . . . . 8

7. Genitalia as in figure 348; first trochanter of hind leg fuscous above; front wing 5.0 to $7.2 \mathrm{~mm}$. long . . . . . . . . 4. terebrans (Ratzeburg)

Genitalia as in figure 344; first trochanter of hind leg entirely fulvous; front wing 8.0 to $12.5 \mathrm{~mm}$. long . . . . . . 5. tuberculatus (Fourcroy)

8. Apex of clasper truncate or somewhat concave (figs. 349 and 350); prepectal carina ending near lower 0.12 of hind margin of pronotum . . . . . . 9

Apex of clasper rounded or somewhat pointed (figs. 352-357); prepectal carina often extending above lower 0.2 of hind margin of pronotum $\quad 10$

9. Apex of clasper somewhat concave (fig. 349); apex of penis with a dorsal lobe (fig. 349) . . . . . . . . . . . 7. populneus (Ratzeburg)

Apex of clasper truncate (fig. 350); apex of penis without a dorsal lobe (fig. $350)$

8. messor (Gravenhorst)

10. Clasper rather broad apically (fig. 353) . . . 14. californicus, new species

Clasper narrow apically (figs. 352, 354-357) . . . . . . . . . . . . 11

11. Apex of clasper weakly pointed (fig. 355); hind femur blackish brown; front wing 5.4 to $6.4 \mathrm{~mm}$. long . . . . . . . 16. pygmaeus (Walsh)

Apex of clasper evenly rounded; hind femur fulvous, usually infuscate at apex; front wing 6.0 to $13 \mathrm{~mm}$. long . . . . . . . . . . . 12 
12. Pedicel white, its upper outer side brownish; scape white in front; punctures of third tergite distinct, moderately coarse . . . . . . . . . . . . 13

Pedicel black; scape black or with a white spot in front; punctures of third tergite rather indistinct and small . . . . . . . . . . . . . . . . 14

13. Apical part of clasper wider (fig. 354); median longitudinal carinae of propodeum distinct . . . . . . . . . . . 15. vitticrus, new species

Apical part of clasper narrower (fig. 356); median longitudinal carinae of propodeum not distinct . . . . . . . . . . . 17. pterelas (Say)

14. First tergite about 1.85 as long as wide; third tergite with weak fine punctures and rather distinct transverse aciculation; scape with a small white spot in front. . . . . . . . . . . . . 12. aciculatus (Hellén)

First tergite about 2.5 as long as wide; third tergite with moderately weak fine punctures and indistinct transverse aciculation; scape entirely black

18. imperator (Kriechbaumer)

\section{FEMALES}

1. Abdomen mostly red; coxae black. Irritator group (p. 128), in part.

9. irritator (Fabricius)

Abdomen entirely black; coxae mostly or entirely fulvous, the front coxa sometimes white . . . . . . . . . . . . . . . . . . 2

2. Dorsally projecting flange of lower valve of ovipositor with two widely spaced ridges (fig. $330, \mathrm{~g}$ ). IMPerator Group (p. 152) . . . . . . . . . . . 3

Dorsally projecting flange of lower valve of ovipositor with four or more closely spaced ridges (figs. $330, \mathrm{c}-\mathrm{f} ; 330, \mathrm{~h}$ ) . . . . . . . . . . . . . 4

3. Punctures on second to fourth tergites moderately coarse and distinct; second tergite strongly narrowed toward its base, about 0.7 as wide at base as at apex; propodeal carinae obsolescent, distinct only on the basal 0.15 to 0.4 of the propodeum ............ . 17. pterelas (Say)

Punctures on second to fourth tergites very small, close, and somewhat obscured by aciculation; second tergite weakly narrowed toward its base, about 0.85 as wide at base as at apex; propodeal carinae strong, distinct on the basal 0.4 or more of the propodeum . 18. imperator (Kriechbaumer)

4. Pronotum with a white stripe on its upper margin extending forward from its hind corner; basal three ridges on ovipositor tip slanted forward and downward (fig. 330,c). Taeniatus grodp (p. 116) . . . . . . . . . . . 5

Pronotum without a white stripe on its upper margin, its hind corner black, white, fulvous, or reddish brown; basal three ridges on ovipositor tip usually approximately vertical (figs. $330, \mathrm{~d}, \mathrm{e}, \mathrm{f}, \mathrm{h}$ ) . . . . . . . . . . . 7

5. Clypeus with a small median apical tooth; prepectal carina absent; punctures on mesopleurum moderately coarse and close, their interspaces about 0.7 their diameter . . . . . . . . . . 3. cuspidatus, new species

Clypeus without a median tooth; prepectal carina present below; punctures on mesopleurum rather fine and distant, their interspaces more than 2.0 their diameter. . . . . . . . . . . . . . . . . . . . . . . . . 6

6. Front coxa white; temple moderately convex; abdomen a little narrower and more coarsely punctate, the second tergite about 1.16 as long as wide.

1. dolichosoma (Viereck)

Front coxa fulvous; temple rather strongly convex; abdomen a little wider and more finely punctate, the second tergite about 1.13 as long as wide.

2. taeniatus, new species

7. Lower half of mesepimeron with rather dense hairs; clypeus with a narrow, weakly raised and delimited basal area. SERICEUs Group (p. 157).

19. sericeus (Hartig) 
Lower half of mesepimeron bare or with a few hairs along its hind edge; clypeus usually without a distinctly delimited basal area . . . . . . . 8

8. Ovipositor sheath 4 to 6 times as long as head and body; body short and stout; temples slightly bulging. Cephalotes group (p. 127).

6. cephalotes (Holmgren)

Ovipositor sheath 1 to 3 times as long as head and body . . . . . . . . 9

9. Dorsal lobe of tip of lower valve of ovipositor tapered off at hind end (fig. 330 ,d); nervellus broken between its middle and its upper 0.40 ; prepectal carina complete above, reaching the swelling along front margin of mesopleurum. Tuberculatus group (p. 121). . . . . . . . . . . . 10

Dorsal lobe of tip of lower valve of ovipositor ending abruptly at hind end (figs. 330,e,f); nervellus broken near or above its upper 0.40 ; prepectal carina complete or incomplete above. IrRITATOR GROUP (p. 128) except for D. irritator (see couplet 1) . . . . . . . . . . . . . . . . . . . . 11

10. Nervellus broken near its middle; front wing 5.3 to $11.7 \mathrm{~mm}$. long; face almost flat, its punctures fine . . . . . . . . 4. terebrans (Ratzeburg)

Nervellus broken near its upper 0.40 ; front wing 10.8 to $17 \mathrm{~mm}$. long; face convex medially, its punctures rather coarse . 5. tuberculatus (Fourcroy)

11. Temple bulging laterally a little beyond outside tangent of eye; flagellum rather short, the fifth segment from apex about 1.1 as long as wide.

10. buccatus, new species

Temple not bulging beyond outside tangent of eye . . . . . . . . . . 12

12. Prepectal carina ending dorsally usually near level of lower 0.3 of hind edge of pronotum (but sometimes extending faintly farther dorsad); hind femur entirely fulvous, without an apical fuscous mark; spinelike hairs on middle tibia rather dense; punctures on outer face of hind femur rather sparse, separated by about 3 to 6 times their diameter . . . . . . . . . . . 13

Prepectal carina ending dorsally near level of middle of hind edge of pronotum; hind femur fulvous with its apex more or less infuscate, sometimes entirely infuscate; spinelike hairs on middle tibia rather sparse; punctures on outer face of hind femur rather dense, separated by about 2 to 3 times their diameter . . . . . . . . . . . . . . . . . . . . 14

13. Ovipositor teeth just behind dorsal lobe very oblique, not separated from last tooth on dorsal lobe by a gap (fig. 330,e); ovipositor sheath about 1.25 as long as front wing; first tergite about 1.3 as long as wide.

7. populneus (Ratzeburg)

Ovipositor teeth just behind dorsal lobe subvertical, separated from last tooth on dorsal lobe by a gap (fig. 330,f); ovipositor sheath about 1.65 as long as front wing; first tergite about 1.9 as long as wide. 8. messor (Gravenhorst)

14. Ovipositor sbeath about 2.7 as long as front wing . . . . . . . . . . 15 Ovipositor sheath 1.4 to 1.7 as long as front wing. . . . . . . . . . . 16

15. Shaft of lower valve of ovipositor approximately smooth; tergites 2 to 4 transversely punctatoaciculate behind the tubercles; hind femur fuscous; clypeus not unusually flattened . . . . . . . 11. flexilis, new species

Shaft of lower valve of ovipositor minutely roughened and with irregularly spaced small tubercles; hind femur fulvous, its apex fuscous; olypeus unusually flattened . . . . . . . . . 12. aciculatus (Hellén)

16. Front wing 7.0 to $12.5 \mathrm{~mm}$. long; temple rather strongly swollen; propodeum rather elongate, with rather sparse punctures; hind tibia whitish on basal $0.15 \pm$; hind corner of pronotum black or narrowly and obscurely ferruginous; last four segments of maxillary palpus white. 16. pygmaeus (Walsh) 
Front wing 8.7 to $22 \mathrm{~mm}$. long; temple not unusually swollen; propodeum of moderate length, with moderately dense punctures; combination of color characters not as above . . . . . . . . . . . . . . . . . . 17

17. Last four segments of maxillary palpus medium brown; hind corner of pronotum entirely black or its apex narrowly dusky ferruginous; median longitudinal carinae of propodeum strongly divergent . 13. foxleei, new species

Last four segments of maxillary palpus white or whitish; hind corner of pronotum white or pale fulvous; median longitudinal carinae of propodeum moderately divergent . . . . . . . . . . . . . . . . 18

18. Upper face of front and middle tibiae fulvous, the basal $0.15 \pm$ whitish; temple moderately convex; range: west of Rocky Mts.

14. californicus, new species

Upper face of front and middle tibiae white from base to apex; temple rather strongly convex; range: Atlantic to $100^{\circ}$ west longitude.

15. vitticrus, new species

\section{TAENIATUS GROUP}

Median segments of male flagellum not widened; pronotum with a white stripe on its upper margin, extending forward from its hind corner; prepectal carina present below, its dorsal end near lower 0.15 of hind margin of pronotum, or in $D$. cuspidatus the prepectal carina entirely lacking; lower half of mesepimeron almost bare, with a few hairs along its hind margin above; propodeum without distinct median longitudinal carinae; front and middle coxae and trochanters of male not specialized, the middle coxa not even with the area of dense fine hairs present in most of the rest of the genus; nervellus broken near its upper 0.45 ; ovipositor sheath about 1.5 to 2.1 as long as front wing; dorsal lobe at tip of lower valve of ovipositor rather weak, apically tapered, with three ridges that slant forward and downward, followed by more nearly vertical ridges (fig. 330,c).

This group includes the three Nearctic species described below and the Cuban (Ephialtes) Dolichomitus rufescens (Cresson) 1865 (new combination).

\section{Dolichomitus dolichosoma (Viereck), new combination}

\section{Figures 333 ,a; 345}

Ephialtes dolichosoma Viereck, 1912, Proc. U. S. Nat. Mus., vol. 42, p. 637 ; $\subsetneq$.

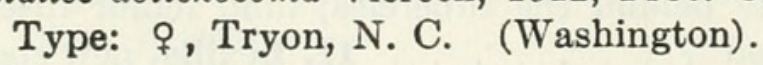

Male: Front wing 5.7 to $7.0 \mathrm{~mm}$. long; clypeus without a median tooth; prepectal carina moderately strong; first tergite about 1.55 as long as wide; second tergite about 1.20 as long as wide; tubercles on third tergite rather convex, covered with moderately coarse punctures whose interspaces are about 0.6 their diameter; subgenital plate as in figure 333 , a ; genitalia as in figure 345 .

Black. Clypeus and mandible tinged with ferruginous; scape and pedicel in front, palpi, tegula, rather broad stripe on upper edge of 
pronotum extending from hind corner to in front of notaulus, and front coxa, white; most of mesosternum, of lower half and sometimes anterodorsal area on mesopleurum, more or less of lobe of mesoscutum, and usually scutellum, fulvoferruginous; trochanters white, the upper side of first trochanter of middle and hind legs fulvous; femora fulvous, white at apex, the hind femur with a subapical infuscate band; front tibia and tarsus whitish, with pale fulvous tinges; basal half of middle tibia whitish with a faint subbasal infuscate band; apical half of middle tibia whitish above and below, the sides whitish basally and brownish apically; basal $0.7 \pm$ of hind tibia whitish above and below, somewhat infuscate, more strongly infuscate at an incomplete subbasal band; apical $0.3 \pm$ of hind tibia infuscate, a little paler above and below; middle and hind tarsi fuscous, the middle tarsus paler, their basitarsi whitish at base.

Female: Front wing 8.0 to $11.5 \mathrm{~mm}$. long; clypeus without a median apical tooth; prepectal carina moderately strong; first tergite about 1.30 as long as wide; second tergite about 1.16 as long as wide; tubercles of third tergite rather convex, covered with rather coarse punctures whose interspaces are about equal to their diameter; ovipositor sheath about 1.50 as long as front wing.

Black. Palpi, tegula, rather broad stripe on upper margin of pronotum extending from hind corner to in front of notaulus, and front coxa, white; mandible, clypeus, mesosternum, lower half of mesopleurum, subtegular ridge, lateral lobe of mesoscutum, and scutellum, often more or less tinged with ferruginous; middle and hind coxae fulvous, the base of middle coxa whitish; front trochanters white, tinged with fulvous behind; middle trochanters fulvous, the second trochanter and apex of the first trochanter whitish in front and below; hind trochanters fulvous, the second trochanter paler below; femora fulvous, very pale at apex, the hind femur with a weak subapical infuscation; front tibia fulvous, whitish in front; middle tibia fulvous, brownish apically and in a subbasal ring; hind tibia brown, a little darker apically and in a subbasal ring; front tarsus fulvous, brownish apically; middle tarsus brown; hind tarsus dark brown.

Specimens: 2ᄋ, "Cerocarpus parvifolius," North Cheyenne Canyon, Colo., June 7, 1915, George Hofer (Washington). ㅇ, "hickory post," Barnesville, Ga., Apr. 10, 1934, T. L. Bissel (Washington). 2\%, "pecan post," Milner, Ga., Mar. 22, 1934, T. L. Bissel (Washington). ๑, Douglas Co., Kans., October, E. S. Tucker (Washington). $\sigma^{x}$, Mayo, Md., Oct. 27, 1945, H. and M. Townes (Townes). ㅇ, Mayo Beach, Md., Oct. 19, 1946, H. and M. Townes (Townes). o, on Prunus americana, Oxford, Miss., Mar. 24, 1949, H. V. Weems, Jr. (Washington). 2 (one of them the type), "Castanea dentata," Tryon, N. C., W. F. Fiske (Washington). o, Linglestown, Pa., July 24, 1913, 
W. S. Fisher (Washington). ๆ, Wetzel's Swamp, Harrisburg, Pa., May 7, 1910, W. S. Fisher (Washington). o , Greenville, S. C., July 12, 1931, H. Townes (Townes). $5 \sigma^{7}, 9$ 우, reared from Quercus, Pregnall, S. C., Feb. 18, 1905, and Mar. 3 and 25, 1905, W. F. Fiske (Washington and Ottawa). \&. U. S., June 18, 1913 (Washington). ๆ, C. V. Riley (Washington). $\sigma^{\top}$, June 17, 1913 (Washington).

This species occurs in the Alleghanian and Carolinian faunas. It is adult throughout the growing season. Larvae in hardwoods serve as hosts.
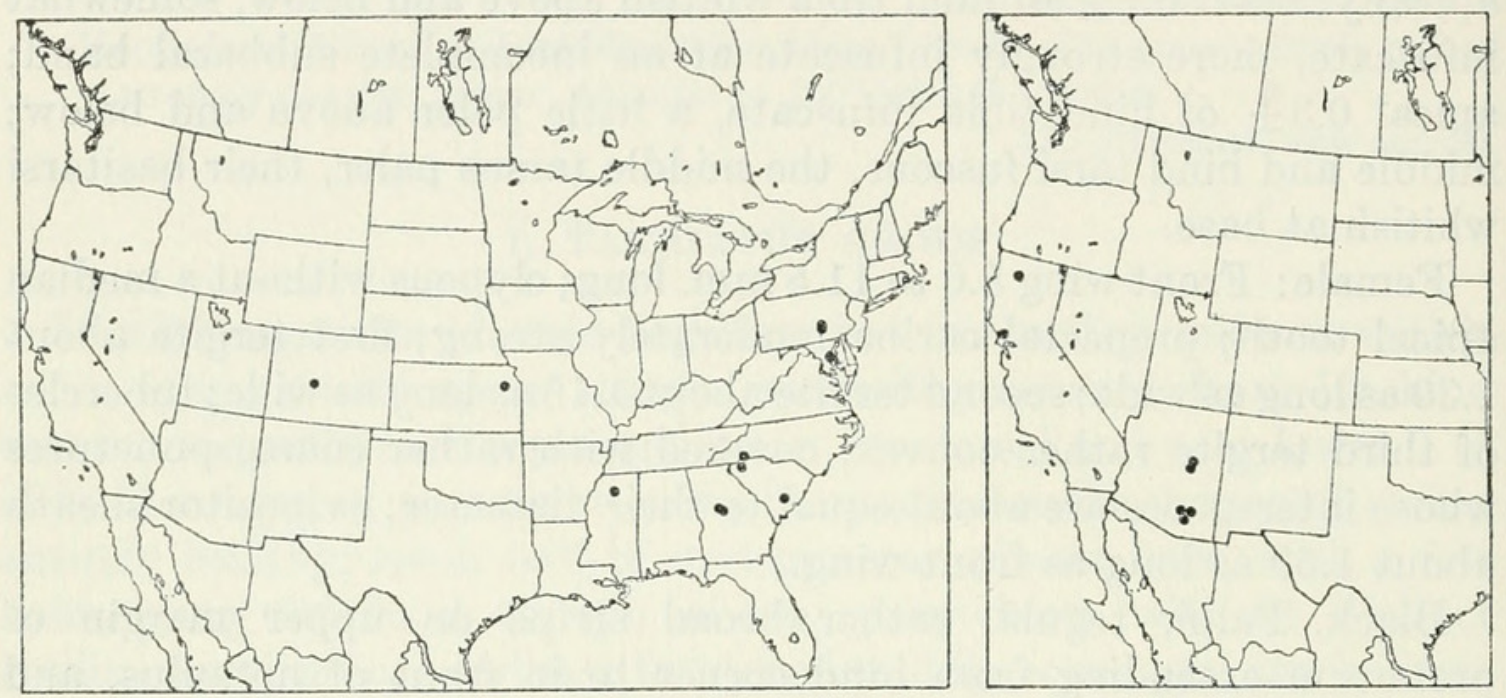

Figures 47, 48.-Localities: 47 (left), Dolichomitus dolichosoma; 48 (right), D. taeniatus.

\section{Dolichomitus taeniatus, new species}

Figures 330,c; 333,b; 346

Male: Front wing 5.6 to $8.0 \mathrm{~mm}$. long; clypous without a median tooth; prepectal carina moderately strong; first tergite about 1.30 as long as wide; second tergite about 1.18 as long as wide; tubercles on third tergite very prominent, covered with rather small punctures whose interspaces are about 2.5 their diameter; abdomen strongly narrowed posteriorly and the apical segments shortened; subgenital plate as in figure $333, \mathrm{~b}$; genitalia as in figure 346.

Black. Mandible and clypeus faintly tinged with ferruginous; maxillary palpus, usually a spot on front of scape, tegula, and stripe on upper margin of pronotum extending from hind corner to notaulus, white; labial palpus brown; coxae fulvous, the front coxa in front and the middle coxa basally in front, ivory; trochanters fulvous, the first trochanters of front and middle legs in front and below, the second trochanter of front leg except behind, and the second trochanter of middle leg below, ivory; front and middle femora fulvous, partly ivory in front; hind femur fulvous, a little infuscate apically, its 
extreme apex pale; front and middle tibiae light brown, whitish in front and below and with a whitish dorsal stripe; hind tibia fuscous, with a dusky whitish dorsal stripe; front and middle tarsi brownish fulvous; hind tarsus fuscous.

Female: Front wing 6.3 to $12.5 \mathrm{~mm}$. long; clypeus without a median apical tooth; prepectal carina moderately strong; first tergite about 1.28 as long as wide; second tergite about 1.0 as long as wide; tubercles of third tergite very prominent, covered with small punctures whose interspaces are about 2.5 their diameter; ovipositor sheath about 1.65 as long as front wing, its apex as in figure 330 ,c.

Black. Clypeus and mandible tinged with ferruginous; maxillary palpus blackish at base, the rest white but brownish apically; labial palpus dark brown; tegula and stripe on upper margin of pronotum extending from hind corner to notaulus, white; coxae fulvous; trochanters fulvous, the second trochanters and apex of first trochanters of front and middle legs whitish below and in front; front and middle femora fulvous, whitish apically in front; hind femur fulvous, a little infuscate toward apex, its extreme apex paler; tibiae colored as in male but with the dark markings a little more extensive and pronounced; front tarsus brownish fulvous; middle and hind tarsi fuscous, the middle tarsus paler.

Type: $\sigma^{7}$, Parker Creek, Sierra Ancha, Ariz., Apr. 29, 1947, H. and M. Townes (Washington, USNM 63687).

Paratypes: $2 \sigma^{\nearrow}, 2$, , Parker Creek, Sierra Ancha, Ariz., Apr. 19 and 29, 1947 and May 2 and 4, 1947, H. and M. Townes (Townes). ๑, "Palmerlee," Ariz., N. Banks (Cambridge). $\sigma^{7}$, reared from Cercidium, Redington, Ariz., May 22, 1915, Chrisman (Berkeley). 39, reared from Prosopis, Sabino Canyon, Ariz., Mar. 3, 1920, W. D. Edmonston (Washington). $\sigma^{7}$, $\%$, reared from Prosopis, Sabino Canyon, Ariz., Mar. 2 and 13, 1917, G. Hofer (Washington). $0^{x}$, + , reared from Chrysobothris edwardsii in Fouquiera, Sabino Canyon,

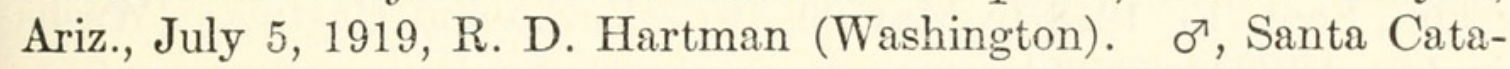
lina Mts., Ariz., May 21, 1914, M. Chrisman (Washington). o $\sigma^{7}$, , reared from Salix, Santa Catalina Mts., Ariz., Chrisman (Washington). б', Workman Creek, Sierra Ancha, Ariz., Apr. 30, 1947, H. and M. Townes (Townes). $\quad 0^{x}$, Carrville, Calif., June 11, 1934, G. E. Bohart

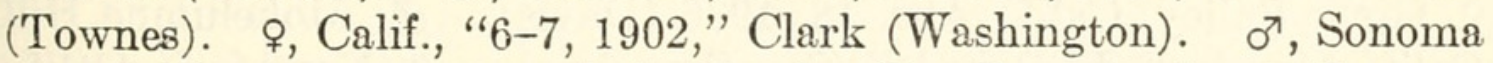
Co., Calif., Apr. 16, 1911, J. A. Kusche (San Francisco). †, Sonoma Co., Calif., May 19, 1910, J. A. Kusche (San Francisco). \&, U. S., Mar. 7, 1913 (Washington).

This species occurs in the Upper Sonoran and Lower Sonoran faunas of southern California and Arizona, where it parasitizes beetles boring in desert trees and shrubs. Adults occur mostly in the spring. 


\section{Dolichomitus cuspidatus, new species}

Figures $333, \mathrm{c} ; 347$

Male: Front wing 7.5 to $10.5 \mathrm{~mm}$. long; clypeus with a median apical knoblike tooth; prepectal carina absent; first tergite about 1.55 as long as wide; second tergite about 1.35 as long as wide; tubercles of third tergite exceptionally flat, covered with moderately coarse punctures whose interspaces are about 1.3 their diameter; abdomen exceptionally smooth and tapered apically, its seventh tergite long, a little narrowed apically, its apex rounded off; subgenital plate as in figure $333, \mathrm{c}$; genitalia as in figure 347 .

Black. Clypeus and mandible a little tinged with ferruginous; base of maxillary palpus blackish, the rest whitish but brownish apically; labial palpus dark brown; tegula and a narrow stripe on upper margin of pronotum extending from hind corner about 0.65 the distance to notaulus, white; coxae fulvous, infuscate at base, the front coxa ivory in front; trochanters fulvous, the front trochanters ivory in front and below; femora fulvous, the front and middle femora pale at apex in front and the hind femur infuscate apically; front and middle tibiae infuscate, pale below and in front and with a pale stripe on their basal $0.18 \pm$ above; hind tibia dark brown, a little paler below; front and middle tarsi fulvous brown; hind tarsus dark brown.

Female: Front wing 9.0 to $11.5 \mathrm{~mm}$. long; clypeus with a small median apical tooth; prepectal carina absent; first tergite about 1.28 as long as wide; second tergite about 1.0 as long as wide; tubercles of third tergite exceptionally flat, covered with moderately coarse punctures whose interspaces are about 0.7 their diameter; ovipositor sheath about 2.1 as long as front wing.

Black. Colored as in the male except that there are no ivory marks on the front coxa nor on the front and middle trochanters.

Type: $\sigma^{x}$, reared from Monochamus maculosus, Boulder Creek, Calif., Sept. 13, 1918 to May 29, 1919, Burke and Hartman (Washington, USNM 63688).

Paratypes: $0^{7}, 2$, Berkeley, Calif., Apr. 8 and 10, 1932, E. O. Essig (Berkeley and Townes). $4 \sigma^{\top}, 4$ 으, reared from Monochamus maculosus, Sept. 13, 1918 to May 29, 1919, Burke and Hartman (Washington). \%, Grass Valley, Calif., Apr. 18, 1936 (Davis). ণ ণ Mokelumne Hill Calif., March, F. E. Blaisdell (San Francisco). $\sigma^{7}$, Northfork, Calif., Apr. 30, 1926, H. E. Burke (Berkeley). $\sigma^{\top}$, Solano County, Calif., Mar. 4, 1936 (Townes).

This species occurs only in California. It is adult in March and April. 


\section{TUBERCULATUS GROUP}

Median segments of male flagellum not widened; pronotum entirely black; prepectal carina complete, its dorsal end moderately strong, curved forward to near front margin of mesopleurum; lower half of mesepimeron almost bare, with a few hairs along its hind margin above; front and middle coxa and trochanters of male not specialized, except that in $D$. terebrans terebrans the outer side of the middle coxa has rather dense hairs; nervellus broken near or a little above the middle; hind femur about 0.52 as long as deep, rather densely punctate; propodeum rather short, its basal half with rather prominent median longitudinal ridges; ovipositor sheath about 1.2 to 1.7 as long as front wing; dorsal lobe of tip of lower valve of ovipositor tapered posteriorly, with about seven ridges most of which slant a little forward and downward (fig. 330,d).

This group includes the two Holarctic species described below and (Ephialtes) Dolichomitus crassus (Morley) 1913 (new combination) from India.

\section{Dolichomitus terebrans (Ratzeburg)}

Figures 333 , d; 348

Male: Front wing 5.0 to $7.2 \mathrm{~mm}$. long; face rather wide, with fine subadjacent punctures; nervellus broken near its middle; first tergite about 1.7 as long as wide; second tergite about 1.2 as long as wide; subgenital plate as in figure 333,d; genitalia as in figure 348 .

Female: Front wing 5.3 to $11.8 \mathrm{~mm}$. long; face very wide, almost flat, centrally with fine rather sparse punctures; nervellus broken near its middle; first tergite about 1.25 as long as wide; ovipositor sheath about 1.2 as long as front wing.
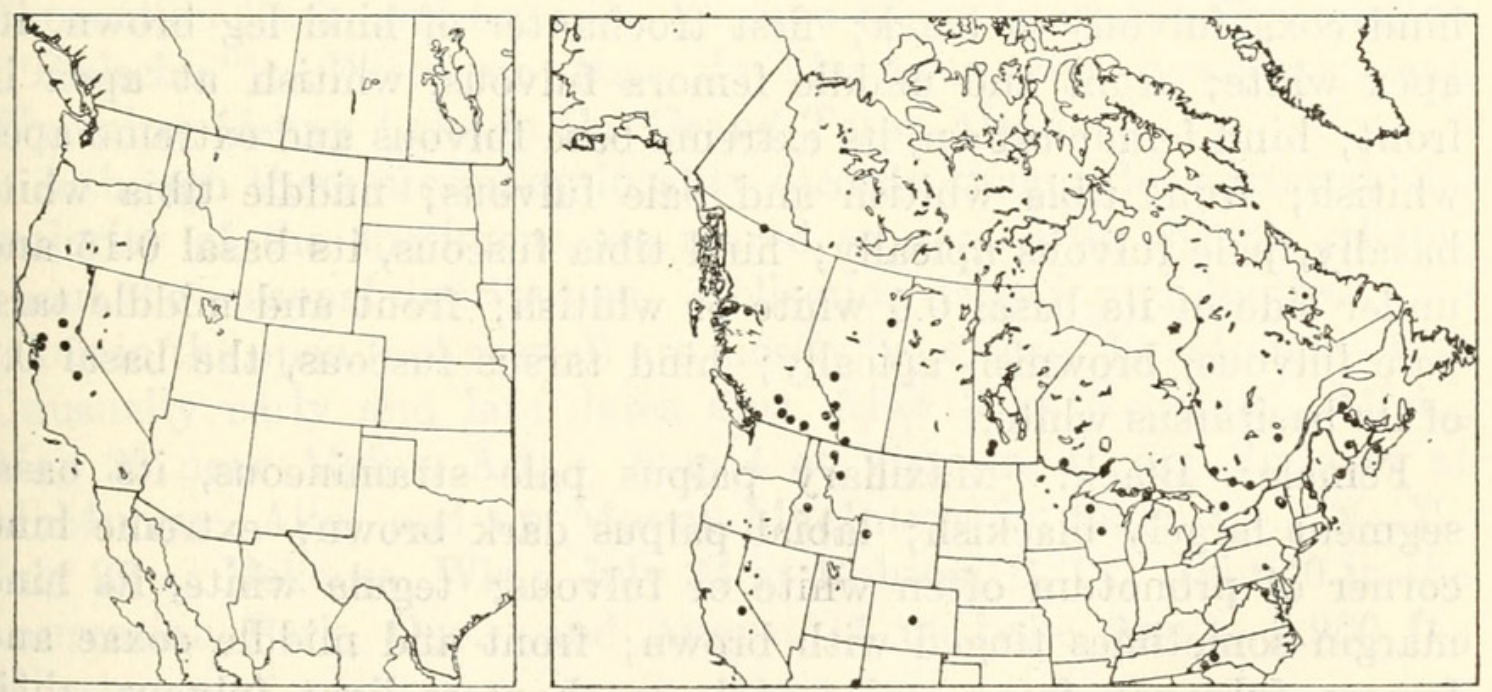

Frgures 49, 50.-Localities: 49 (left), Dolichomitus cuspidatus; 50 (right), D. terebrans nubilipennis. 
The small size, short tergites, flat face of female, and nervellus broken near the middle, together with the species group character of the ovipositor tip, make this species easy to distinguish.

This is a Holaretic species parasitic on curculionoid larvae under the bark of northern conifers. There is a European and a North American subspecies as keyed and described below:

1. Abdomen less densely punctate, the punctures on tubercles of second to fourth tergites of female separated by about 0.7 their diameter, the middle field of first tergite with only a few punctures apically; hair on outer side of middle coxa of male not unusually dense; hind coxa of male fulvous to black; tegula entirely white or its apical margin faintly brownish. Range: Canadian zone of North America. . 4a. terebrans nubilipennis (Viereck)

Abdomen more densely punctate, the punctures on tubercles of second to fourth tergites of female separated by about 0.3 their diameter; hair on outer side of middle coxa of male rather dense; hind coxa of male entirely black; tegula ivory, its apex conspicuously brownish. Range: northern Europe . . . . . . . . . . 4b. terebrans terebrans (Ratzeburg)

4a. Dolichomitus terebrans nubilipennis (Viereck), new status and new combination

Exeristes nubilipennis Viereck, 1912, Proc. U. S. Nat. Mus., vol. 42, p. 638; .

Type: $\uparrow$, Columbia Falls, Mont. (Washington).

Exeristes hyalinipennis Viereck, 1912, Proc. U. S. Nat. Mus., vol. 42, p. 638; .

Type: $\uparrow$, Columbia Falls, Mont. (Washington).

This subspecies is a little more slender than D. terebrans terebrans (the European subspecies), with sparser and coarser punctures, and some color differences as noted in the key. There are some additional minor differences in coloration, as described below.

Male: Black. Palpi, tegula, sometimes extreme hind corner of pronotum, front and middle trochanters, and second trochanter of hind leg, white; front and middle coxae white, more or less fulvous basally; hind coxa fulvous to black; first trochanter of hind leg brown, its apex white; front and middle femora fulvous, whitish at apex in front; hind femur brown, its extreme base fulvous and extreme apex whitish; front tibia whitish and pale fulvous; middle tibia white basally, pale fulvous apically; hind tibia fuscous, its basal 0.15 and under side of its basal 0.6 white or whitish; front and middle tarsi pale fulvous, brownish apically; hind tarsus fuscous, the basal 0.2 of its basitarsus white.

Female: Black. Maxillary palpus pale stramineous, its basal segment largely blackish; labial palpus dark brown; extreme hind corner of pronotum often white or fulvous; tegula white, its hind margin sometimes tinged with brown; front and middle coxae and femora fulvous; front and middle trochanters light fulvous, their second trochanters paler; front tibia brownish fulvous, its basal 0.15 paler; front tarsus light brown; middle tibia brown, its basal 0.15 pale; 
middle tarsus dark brown; hind coxa fulvous, its apex faintly infuscate; first hind trochanter brownish fulvous; second hind trochanter yellowish fulvous; hind femur brown, often fulvous basally; hind tibia fuscous, its basal 0.15 stramineous; hind tarsus blackish, the base of its basitarsus paler.

The above description of female coloration applies particularly to specimens from eastern North America. In some specimens from western North America the legs are more uniformly colored, the coxae, trochanters, and femora being fulvous with the apex of the hind femur fuscous, and the pale marking at the bases of the tibiae and hind tarsus lacking or obscured. This coloration is rather like that of the European subspecies.

Specimens (51 $\sigma^{\top}, 83$ ㅇ): From Alberta (Brazeau Reserve on the Cardinal River, Lake Agnes at 6,900 ft., McMurray, and Waterton); Arizona (near Alpine); British Columbia (Cedarvale, Kootenay Crossing in Kootenay National Park, Lorna, Lower Post, Mount Apex near Hedley, Mount Revelstoke, Robson, Round Lake near Smithers, Skeena, Trinity Valley, Vancouver, and Victoria); California (Yosemite Valley); Colorado (North Cheyenne Canyon); Idaho (Smiths Ferry); Maine (Bar Harbor); Manitoba (Aweme and Onah); Michigan (Grand Isle, Seney, and Negaunee); Montana (Columbia Falls and Corlett); New Brunswick (Bathurst, Chatham, and Fredericton); Newfoundland (St. Johns); New Hampshire (Mount Washington at 2,000 to 4,000 ft., Rye, and Tamworth); New York (top of Mount MacIntyre in Essex Co. and top of Mount Whiteface at 4,872 ft. in the Adirondacks); North Carolina (Mount Mitchell at 6,600 ft., Pisgah Ridge, and "Silver Mt."); Nova Scotia (Kentville); Ontario (Chalk River, Fort Francis, Sand Lake, and Victoria County Forest); Quebec (Aylmer, Cascapedia River, Lac J.-Cartier at 2,600 ft. in Laurentian Park, and Laniel); Virginia (Falls Church); Washington ("Pialschie"); Wisconsin (Lac de Flambeau and Nekoosa); and Wyoming (Jenny Lake in the Grand Teton Mts.).

Although there are many locality records among this material, the majority of the specimens are reared so give little that is reliable about the seasonal distribution. Collection dates for adults that were taken in the open (not reared) are mostly from early June to mid-July. Unusually early and late dates are: May 3 at Negaunee, Mich.; May 23 near Alpine, Ariz.; June 4 at Victoria, B. C.; June 11 at McMurray, Alta. and on Mount MacIntyre in Essex Co., N. Y.; July 22 at Nekoosa, Wis.; July 24 at Robson, B. C.; July 30 in the Laurentian Park, Que.; and August 15 at Lake Agnes, 6,900 ft., Alberta.

Rearing records are as follows: 3 from Pissodes dubius, 4 from $P$. engelmanni, 1 from $P$. fasciatus, 1 from $P$. rotundatus, 15 from 
P. strobi, 1 from Pissodes sp. in Pinus contorta, 1 from Pissodes sp. in red fir, 12 from Pissodes sp., 1 from Scolytus sp. in Pseudotsuga taxifolia, 2 from Abies lasiocarpa, 4 from Picea engelmanni, 2 from Picea sp., 1 from Pinus virginiana, 6 from Pseudotsuga taxifolia, and 1 from trunk of Larix.

This subspecies is transcontinental in the Canadian zone. Adults occur mostly in June and the first half of July. The usual hosts are weevils of the genus Pissodes, which feed under the bark of conifers.

\section{4b. Dolichomitus terebrans terebrans (Ratzeburg), new combination}

Pimpla terebrans Ratzeburg, 1844, Die Ichneumonen der Forstinsecten . . . , vol. 1, p. 114, $\subsetneq$. Type: $\uparrow$, ?Germany (destroyed during World War II).

This is the subspecies of Europe, differing as noted in the key and in a few additional characters of color.

Male: Black. Palpi white; tegula white but its apex brown; front coxa white in front; middle coxa white, blackish basally behind; trochanters white, the hind first trochanter brown, at least above; front and middle femora fulvous, whitish in front; front and middle tibiae pale fulvous, paler basally; front and middle tarsi pale fulvous, the apex brownish; hind femur fulvous, its apex fuscous; hind tibia fuscous, its basal 0.15 whitish and a stripe beneath on its basal $0.6 \pm$, also whitish; hind tarsus fuscous, the basal 0.12 of its basitarsus pale brown.

Female: Black. Maxillary palpus pale brown, dark brown basally; labial palpus dark brown; tegula yellowish white, its apex brown; front and middle legs fulvous; hind coxa, trochanters, and femur fulvous, the apex of femur rather narrowly and weakly infuscate; hind tibia dark brown, paler basally; hind tarsus blackish brown, the extreme base of its basitarsus brown.

Described from $1 \sigma^{7}$ from England, 1 fo from Sweden, and $3 \sigma^{\top}, 5$ 우 from Germany.

\section{Dolichomitus tuberculatus (Fourcroy)}

Figures 330,d; 333,e; 344

Male: Front wing 8.0 to $12.5 \mathrm{~mm}$. long; face of medium width, with sharp, moderately small punctures that are separated by about 0.5 their diameter; nervellus broken near its upper 0.40 ; first tergite about 2.0 as long as wide; second tergite about 1.45 as long as wide; subgenital plate as in figure 333 ,e; genitalia as in figure 344 .

Female: Front wing 10.8 to $17 \mathrm{~mm}$. long; face of moderate width, with sharp, moderately coarse punctures that are separated by about their diameter; nervellus broken near its upper 0.40 ; first tergite about 1.8 as long as wide; second tergite about 1.32 as long as wide; 
ovipositor sheath about 1.7 as long as front wing; tip of lower valve of ovipositor as in figure 330 ,d.

The prepectal carina strong and complete above, hind femur rather short and with unusually dense punctures, rather large size and stout build, distinctive male genitalia, and especially the species group character in the ovipositor tip make this species easy to distinguish.

The range is Holarctic, with a distinct subspecies in Japan as keyed and described below:

1. Middle and hind coxae fuivous; hind femur fulvous, its apex narrowly fuscous; range: Holarctic except Japan . 5a. tuberculatus tuberculatus (Fourcroy) Middle and hind coxae blackish brown; hind femur usually brown; range: Japan . . . . . . . . . . 5b. tuberculatus jezoensis (Uchida)

\section{5a. Dolichomitus tuberculatus tuberculatus (Fourcroy), new combination}

Ichneumon tuberculatus Fourcroy, 1785, Entomologia parisiensis, p. 395; . Type: $\uparrow$, France (lost).

Male: Black. Clypeus ferruginous; sometimes apical part of scape in front and sometimes pedicel in front, fulvous; maxillary palpus white; labial palpus brown; tegula white or stramineous, its apex brownish; front and middle coxae and femora fulvous, the apex of femora pale fulvous; front and middle trochanters, tibiae, and tarsi pale fulvous, the basal $0.15 \pm$ of the tibiae yellowish fulvous; hind coxa, trochanters, and femur fulvous, the apex of femur narrowly infuscate; hind tibia and tarsus fuscous, the tibia paler and its basal 0.12 stramineous; extreme base of hind basitarsus light brown.

FigURE 51.-Localities for Dolichomitus iuberculatus tuberculatus.

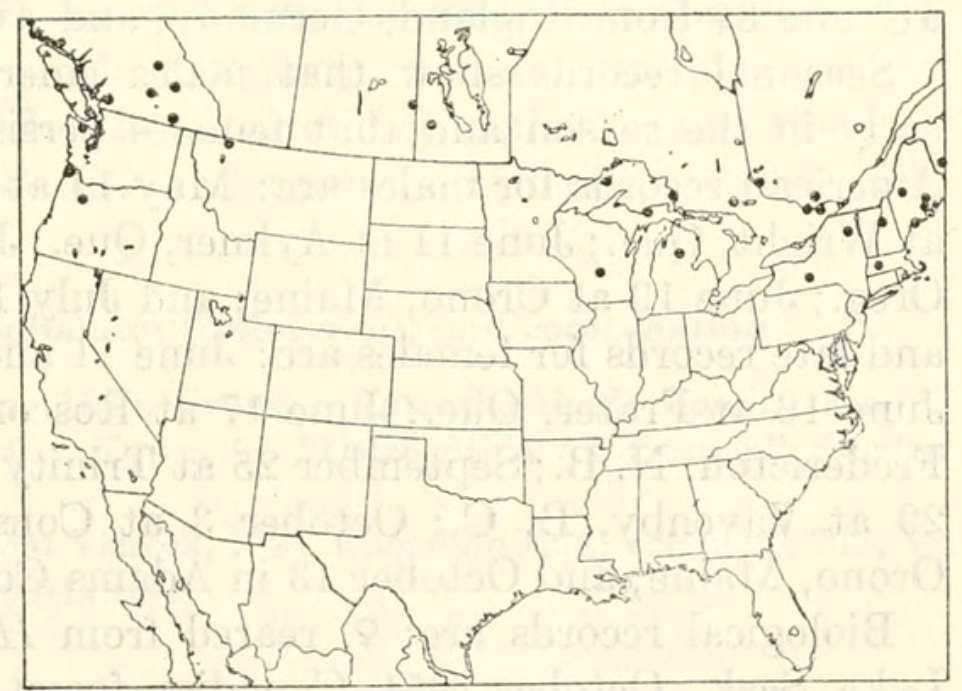

Female: Black. Clypeus largely ferruginous; maxillary palpus stramineous, blackish at base; labial palpus dark brown; tegula stramineous or fulvous, paler basally and darker apically; front leg fulvous; middle leg fulvous, the apex of its femur, base of its tibia, and apex of its tibia in front, pale fulvous; hind coxa, trochanters, 
and femur fulvous (the femur more of a yellowish fulvous than in most species of Dolichomitus), the apex of femur narrowly fuscous; hind tibia and tarsus dark reddish brown, its basal 0.15 fulvous; hind tarsus fuscous.

European and American specimens are rather different, the American specimens averaging a little more slender, with the ovipositor a little longer, and with the punctures a little less dense. In color, the apex of the hind femur of American specimens averages more extensively and intensively infuscate. These differences, though noteworthy, do not seem constant enough for a subspecific distinction.

The type of the name tuberculatus is lost and the original description is unsatisfactory, but a rather consistent tradition has developed that the present species is Fourcroy's tuberculatus, so the name is applied here.

Specimens $\left(6 \sigma^{7}, 45 \%\right)$ : From Alaska; British Columbia (Diamond Head Trail at Garibaldi near Squamish at 3,200 ft., Robson, Sugar, Trinity Valley, and Vavenby); Maine (Belfast, Orono, Southport and The Forks); Manitoba (Riding Mountain National Park); Massachusetts (Amherst); Michigan (Isle Royale, Onata Township in Alger Co., and Roscommon); Montana (Glenn Lake in Glacier National Park at 4,200 ft.); New Brunswick (Fredericton); New Hampshire (Franconia); New York (Ithaca and Mount Whiteface at 2,000 to 4,000 ft.); Ontario (Constance Bay, Frater, Ottawa, and Sudbury); Oregon (Breitenbush and Cannon Beach); Quebec (Cascapedia River, Laniel, and Wright); Saskatchewan (Madge Lake); Washington (Olympic Hot Spring); and Wisconsin (Adams Co.). We have also $9 \sigma^{7}$ and 8 ㅇ from England, Germany, and Austria.

Seasonal records show that males emerge and disappear rather early in the season and that females persist into the fall. The six American records for males are: May 14 at Amherst, Mass.; May 29 at Wright, Que.; June 11 at Aylmer, Que.; June 17 at Cannon Beach, Oreg.; June 19 at Orono, Maine; and July 19 at Laniel, Que. Early and late records for females are: June 11 and July 13 at Laniel, Que.; June 16 at Frater, Que.; June 17 at Roscommon, Mich.; July 15 at Fredericton, N. B.; September 25 at Trinity Valley, B. C.; September 29 at Vavenby, B. C.; October 3 at Constance Bay, Ont. and at Orono, Maine; and October 13 in Adams Co., Wis.

Biological records are: ㅇ, reared from Hylobius pinicolus, Madge Lake, Sask., October 1954, Canadian forest insect survey. \&, reared from Hylobius pinicolus, Riding Mountain National Park, Man., Mar. 5, 1953, Canadian forest insect survey. $\quad$, reared from Monochamus scutellatus, June 4, 1948, Canadian forest insect survey. †, reared from Monochamus, A. D. Hopkins. 4우, flying about a pile of new lumber, Ottawa, Ont., Sept. 18, 1950, D. F. Hardwick. 
This subspecies is Holarctic. In America it is transcontinental in the Canadian zone. Adult males occur mostly from mid-May to mid-July; females occur from mid-June to early October. It parasitizes Coleoptera boring under the bark of Pinus.

\section{5b. Dolichomitus tuberculatus jezoensis (Uchida), new combination}

Ephialtes tuberculatus var. jezoensis Uchida, 1928, Journ. Fac. Agr. Hokkaido Univ., vol. 25, p. 89; . Type: $\uparrow$, Hokkaido (Sapporo).

Male: Unknown.

Female: Colored like the female of $D$. tuberculatus tuberculatus except that the coxae are dark brown or blackish (with the front coxa often more or less fulvous), the fulvous of the hind trochanters somewhat tinged with brown, the hind femur brownish fulvous or brown, and the hind tibia only indistinctly paler at the base.

We have four females from Japan (Hokkaido and Honshu).

\section{CEPHALOTES GROUP}

Male unknown to us.

Body unusually stout; temple unusually wide and bulging a little. Pronotum black, its extreme hind corner paler; prepectal carina complete, but weak above, dorsally with a rather even slant toward front margin of mesopleurum; lower half of mesepimeron with a few hairs, these mostly near its hind edge; nervellus broken above the middle; hind femur about 4.3 as long as deep; first tergite of female about 1.36 as long as wide; second tergite of female about 1.0 as long as wide; ovipositor sheath about 4.4 to 5.7 as long as front wing; dorsal lobe of tip of lower valve of ovipositor tapered apically, with about six ridges, most of which slant forward and downward.

This species group includes the Holarctic D. cephalotes and the Japanese (Ephialtes) Dolichomitus elongatus (Uchida), 1928 (new combination).

\section{Dolichomitus cephalotes (Holmgren), new combination}

Ephialtes cephalotes Holmgren, 1860, Svenska Vetensk.-Akad. Handl., ser. 4,

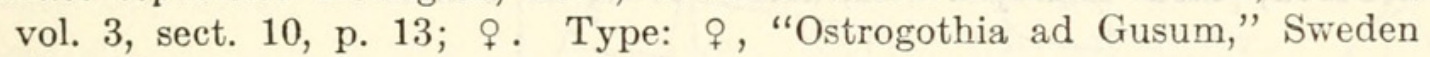
(Stockholm).

Ichneumon (Exeristoidea) watsoni Viereck, 1924, Canadian Ent., vol. 56, p. 202; 9 . Type: $\uparrow$, Aylmer, Que. (Ottawa).

Male: Unknown.

Female: Front wing 15 to $18 \mathrm{~mm}$. long; third tergite with moderately convex tubercles, the tubercles with fine, rather distant punctures and close fine aciculation; ovipositor sheath about 5.5 as long as front wing.

Black. Clypeus and mandible tinged with ferruginous; palpi stramineous to brown, the labial palpus a little darker than the maxil- 
lary palpus; extreme hind corner of pronotum fulvous; tegula stramineous; front and middle legs fulvous; hind coxa and trochanters fulvous, the second hind trochanter a little paler; hind femur fulvous, its extreme apex faintly infuscate; hind tibia and tarsus brown, the tibia paler basally.

The Japanese D. elongaius (Uchida) is very similar to this species but has the ovipositor only about 4.5 as long as the front wing and the abdomen mostly polished, with very little fine aciculation.

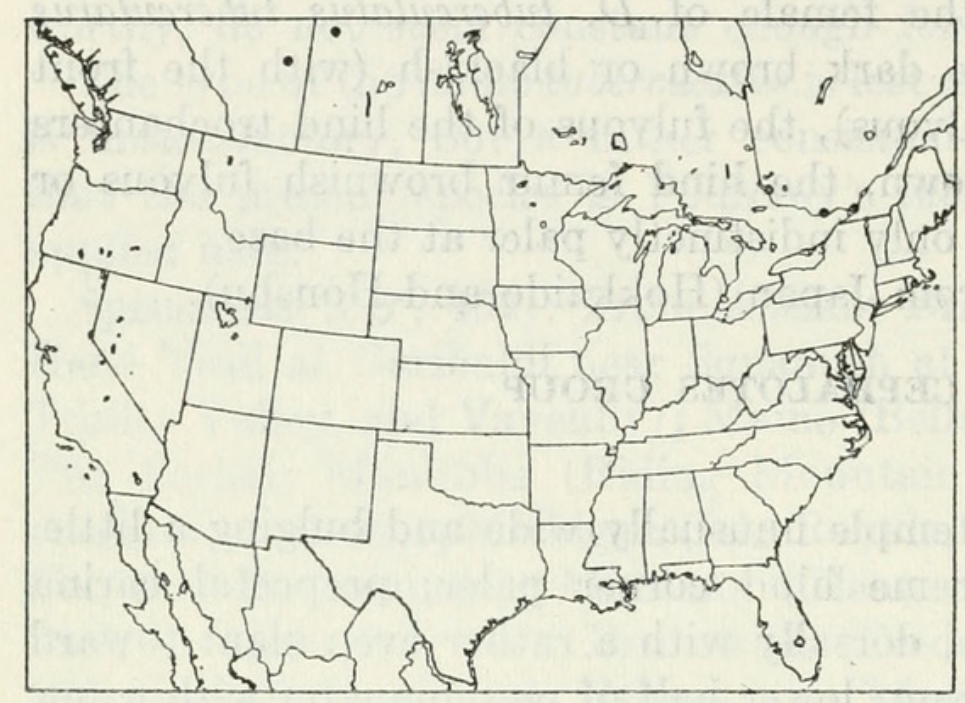

Figure 52.-Localities for Dolichomitus cephalotes.

We have seen the type of $E$. cephalotes but have not compared Nearctic specimens with it directly.

Specimens: ㅇ, Hardisty, Alta., June 1, 1937, E. H. Strickland (Townes). 5 ㅇ (one of them the type of 1 . watsoni), Aylmer, Que., June 15, 20, 22, and 23, 1924 and June 4, 1925, C. B. Hutchings and H. L. Viereck (Ottawa). ค, Aylmer, Que., June 8, 1925, H. L. Viereck (Townes). ㅇ, Laniel, Que., June 26, 1944, A. R. Brooks (Ottawa). ণ, Montreal, Que., June 4, C. J. Ouellet (Ithaca). ㅇ, Vawn, Sask., June 10, 1942, M. Perillot (Ottawa).

This is a rare species. It is known from Quebec, Saskatchewan, Alberta, and Europe. Adults occur in June.

\section{IRRITATOR GROUP}

Median segments of male flagellum not widened; pronotum without a white stripe along its upper margin, but its hind corner often white or pale; prepectal carina ending above ventral 0.15 of hind margin of pronotum, often reaching dorsad to middle of hind margin of pronotum where it curves forward toward front margin of mesopleurum; lower half of mesepimeron almost bare, with a few hairs along hind margin above; nervellus broken above the middle; ovipositor sheath 1.2 to 2.8 as long as front wing; dorsal lobe of tip of lower valve of 
ovipositor strong, abruptly declivous posteriorly, with usually four subvertical ridges (figs. $330, e, f)$.

This group contains about half of the genus, including the nine Nearctic or Holarctic species described below; the European Ephialtes agnoscendus Roman 1939, Ephialtes curticornis Perkins 1943, Ephialtes dux Tschek 1868, Ephialtes mesocentrus Gravenhorst 1829; Ephialtes tschitscherini Kokujev 1904, from the Urals; the Japanese Ephialtes macropunctatus Uchida 1928 and Ephialtes nakamurai Uchida 1928; the Oriental Ephialtes feralis Tosquinet 1903, Ephialtes iridipennis Morley 1913, Ephialtes melanomerus Vollenhoven 1878, and Ephialtes tinctipennis Cameron 1899; and Ephialtes nigricans Cameron 1886, from Guatemala. These all are hereby referred to Dolichomitus and are new combinations with the generic name. We have some additional Oriental and Palaearctic species which are undescribed.

\section{Dolichomitus populneus (Ratzeburg), new combination}

Figures 330 ,e; 333,f; 349

Ephialtes populneus Ratzeburg, 1848, Die Ichneumonen der Forstinsecten . . . vol. 2 , p. $100 ; \sigma^{7}$, + . Type: $\sigma^{7}$, ? Germany (destroyed during World War II)

Male: Front wing 6.7 to $7.0 \mathrm{~mm}$. long; face with fine, sharp punctures whose interspaces are about 0.6 their diameter; prepectal carina ending just above lower corner of pronotum; propodeum partly weakly rugulose, with large, weak, scattered punctures; median longitudinal carinae of propodeum moderately strong, ridgelike, extending about 0.7 the length of propodeum; front trochanters somewhat flattened below and with very short, fine, dense hairs; hairs on outer side of middle coxa a little finer and denser than elsewhere on the coxa; front and middle coxae and trochanters not specialized except as described; first tergite about 2.1 as long as wide; second tergite about 1.7 as long as wide; subgenital plate as in figure

Figure 53.-Localities for Dolichomitus populneus.

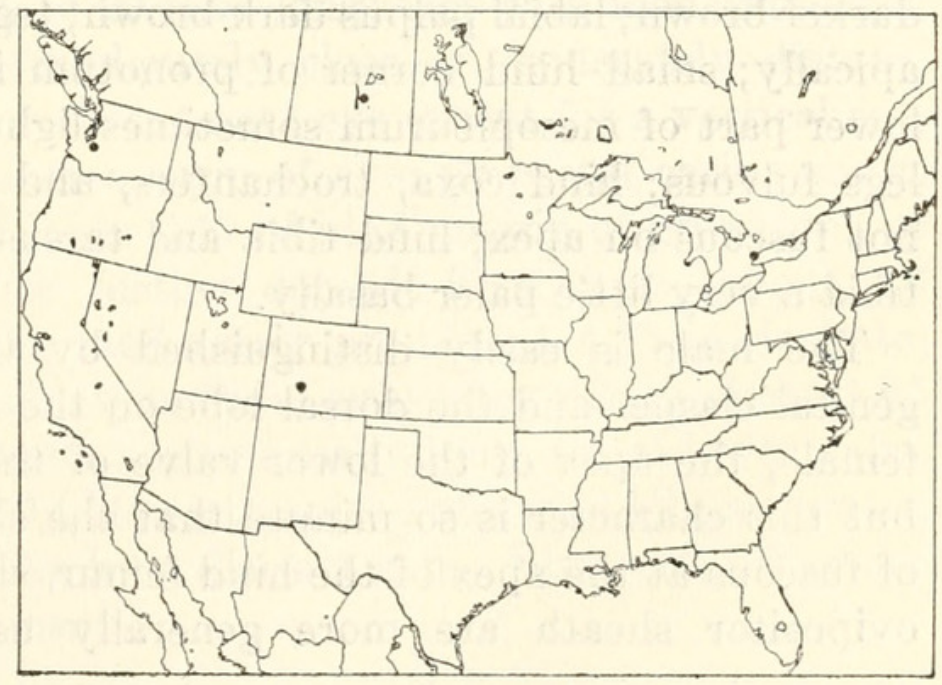


333 ,f; genitalia as in figure 349 , the apex of clasper broadly, weakly emarginate and the penis with a dorsal lobe that in side view makes it appear briefly bifurcate.

Black. Clypeus ferruginous; scape with a light brown area in front; palpi whitish, brown at base; tegula white; hind corner of pronotum pale fulvous; mesosternum and lower part of mesopleurum sometimes light brown; front and middle coxae and femora fulvous, the femora yellowish, fulvous apically and in front toward apex; front and middle trochanters yellowish fulvous; front and middle tibiae and tarsi pale fulvous, the front of front tibia yellowish fulvous; hind coxa, trochanters, and femur fulvous, the femur with an apical infuscate band, the apical margin stramineous; hind tibia and tarsus infuscate, the base of tibia and of basitarsus and under side of tibia except near apex stramineous.

Female: Front wing 8.5 to $10.3 \mathrm{~mm}$. long; face rather short, with moderate sized, sharp, close punctures, but near eye relatively impunctate except for vertical row of smaller punctures paralleling inner margin of eye; prepectal carina exceptionally short, its dorsal end at level of lower 0.15 of hind margin of pronotum; hind femur about 4.5 as long as deep, the hairs on its front face moderately sparse; spinelike bristles on hind tibia very strong and numerous; punctures on propodeum moderately sharp and dense, the interspaces of the sublateral ones about 0.5 their diameter; median longitudinal carinae of propodeum rather weak, extending about half the length of propodeum; first tergite about 1.3 as long as wide; second tergite about 0.95 as long as wide; third tergite polished, its tubercles rounded, subcircular, rather prominent, polished, and covered with moderately sharp punctures whose interspaces are about 0.6 their diameter; ovipositor sheath about 1.25 as long as front wing, its hairs unusually long; tip of lower valve of ovipositor as in figure 330 ,e, the teeth apicad of its dorsal lobe unusually oblique and closely spaced.

Black. Clypeus ferruginous; maxillary palpus brown, its base darker brown; labial palpus dark brown; tegula pale yellowish, fulvous apically; small hind corner of pronotum fulvous; mesosternum and lower part of mesopleurum sometimes light brown; front and middle legs fulvous; hind coxa, trochanters, and femur fulvous, the femur not fuscous on apex; hind tibia and tarsus dark reddish fuscous, the tibia a very little paler basally.

The male is easily distinguished by the emarginately truncate genital clasper and the dorsal lobe on the apex of the penis. In the female, the apex of the lower valve of the ovipositor is distinctive, but this character is so minute that the short prepectal carina, lack of fuscous at the apex of the hind femur, short first tergite, and short ovipositor sheath are more generally useful characters, and the 
ovipositor tip is ordinarily used only as a final confirmation of the determination. The female is very similar to that of $D$. messor.

Our European specimens have the stigma light brown, while our American specimens have it dark brown or blackish. The material is too scanty, however, to decide whether the American representatives should be considered a distinct subspecies.

Specimens: + , Hinsdale Co., Colo., June 28, 1937, C. L. Johnston (Lawrence). o, parasite on wood borer in aspen (Populus sp.), Oct. 5, 1909 (Ottawa). $2 \sigma^{7}, 1$, Toronto, Ont., October 1898, Wm. Brodie (Washington and Townes). \%, Earl Grey, Sask., June 28, 1925, J. D. Ritcher (Ottawa). 2o, Ashford, Wash., Aug. 18, 1940, H. and M. Townes (Townes). o, near Hamburg, Germany, G. Heinricb (Townes). $\%$, reared from Saperda populnea, Hanover, Germany, G. Heinrich (Townes).

This species is transcontinental in the Transition zone and occurs also in Europe. It is rare in America. Its usual host is Saperda boring in Populus and Salix.

\section{Dolichomitus messor (Gravenhorst), new combination}

\section{Figures $330, f ; 333, \mathrm{~g} ; 350$}

Male: Front wing 5.5 to $11.5 \mathrm{~mm}$. long; face with moderately small, sharp, dense punctures and dense hairs; prepectal carina and propodeum approximately as in $D$. populneus; front trochanters and base of front femur more or less flattened below, with more or less dense fine hairs; apex of front coxa in front with dense fine hairs; outer side of middle coxa often with a weak median swelling on which the hairs are a little denser than elsewhere on the coxa; first and second tergites about 1.9 as long as wide; subgenital plate as in figure 333,g; genitalia as in figure 350 .

Colored more or less as described under the subspecies $D$. messor perlongus,

Female: Front wing 10.5 to $22 \mathrm{~mm}$. long; face with moderate-sized sharp punctures that are moderately close or moderately distant, rather evenly distributed or absent near eye except for a vertical row of punctures paralleling inner margin of eye; prepectal carina short, its dorsal end near level of lower 0.17 of hind margin of pronotum, or sometimes faintly continued further dorsad; first tergite about 1.6 as long as wide, its tubercles moderately prominent, a little elongate; second tergite about 1.4 as long as wide; ovipositor sheath about 1.65 as long as front wing, its hairs not unusually long; tip of lower valve of ovipositor as in figure 330 ,f, its teeth apicad of dorsal lobe separated from hind edge of dorsal lobe by a distinct gap. Structure otherwise as described for D. populneus. 
Color more or less as described under the subspecies $D$. messor perlongus.

The male is distinguished by the clasper, which has its apex squarely truncate but with the corners rounded. The female is very similar to that of $D$. populneus. It is distinguished from populneus as noted in the key.

This species is Holarctic. It is divisible into one European and two Nearctic subspecies as keyed and described below. The two Nearctic subspecies are distinguishable over most of their range, but in the Canadian zone of Canada there is a broad zone of overlap and intergrades, where the assignment of many of the specimens to an individual subspecies is difficult and somewhat arbitrary. We have seen $30^{\pi}$ and 5 ㅇ which are so exactly intermediate that a subspecific assignment has not been possible. These are from Boulder, Colo.; Aweme, Man.; Sudbury, Ont.; Covey Hill, Que.; and Indian Head, Sask.

\section{MALES}

1. Outer side of middle coxa with a faint median swelling; punctures on outer side of middle coxa a little denser than elsewhere on the coxa; stigma light brown, the edges dark brown; hind legs less contrastingly marked; range: Europe . . . . . . . . . . . 8c. messor messor (Gravenhorst) Outer side of middle coxa with a distinct median swelling; punctures on outer side of middle coxa about twice as dense as elsewhere on the coxa; stigma blackish brown, somewhat paler centrally; hind legs more contrastingly marked . . . . . . . . . . . . . . . . . . . . . . 2

2. Face with moderately coarse punctures and moderately dense hairs; under side of front trochanters moderately flattened and with moderately fine and dense punctures, the punctures no finer and only a little denser than on the apical part of the femur above; punctures on basal third of front femur below only a little denser than normal; range: Rocky Mts. to Pacific and eastward in the Canadian zone . . . 8a. messor sparsus, new subspecies

Face with rather fine, very dense punctures and very dense hairs; under side of front trochanters and of basal third of front femur strongly flattened and with very fine and dense punctures; range: Atlantic to Rocky Mts.

8b. messor perlongus (Cresson)

\section{FEMALES}

1. Stigma light or medium brown, the edges darker; range: Europe.

8c. messor messor (Gravenhorst)

Stigma dark brown or blackish.

2. Punctures on lateral 0.1 of face irregularly arranged, not leaving an impunctate strip next to eye; subdorsal hair sockets on front face of hind femur separated by about 1.2 the length of the hairs; range: Rocky Mts. to Pacific and eastward in the Canadian zone . . . 8a. messor sparsus, new subspecies

Punctures on lateral 0.1 of face usually in a single vertical row paralleling the eye margin and leaving the rest of this area impunctate; subdorsal hair sockets on front face of hind femur separated by about 0.9 the length of the hairs; range: Atlantic to Rocky Mts. . . . 8b. messor perlongus (Cresson) 


\section{8a. Dolichomitus messor sparsus, new subspecies}

Male: Differs structurally from the male of $D$. messor perlongus as described in the key.

Colored like the male of $D$. messor perlongus except that the scape often lacks the pale spot in front, labial palpus usually has the first two segments brown rather than only the first segment, the fulvous markings are a little more reddish, and the fuscous markings on the hind leg average a little paler.

Female: Differs structurally from the female of $D$. messor perlongus as described in the key. In color it differs in having the fulvous coloration a little darker and the fuscous on the hind leg averaging a little less distinct. The wings average a little darker than in the subspecies perlongus and in most specimens from the Great Basin they are heavily infuscate.

Type: $\sigma^{7}$, near Alpine, Ariz., May 29, 1947, H. and M. Townes (Washington, USNM 63689).

Paratypes $\left(24 \sigma^{7}, 46 \%\right)$ : From Alberta (Beaverlodge); Arizona (near Alpine, Bear Wallow on Mount Lemmon, and Parker Creek in the Sierra Ancha); British Columbia (MacGillivray Creek Game Reserve near Chilliwack, 100 Mile House, Robson, and Vancouver); California (Antioch, Buck's Lake in Plumas Co., Clarksburg, Convict Lake, Dardanelle, Fish Camp, Hope Valley in Alpine Co., Leevining, Mammoth, Meadow Valley, San Francisco, Saticoy, Truckee, Vade, and Yosemite); Colorado (Cheyenne Canyon, Mount Harris, and North Cheyenne Canyon); Idaho (Coeur d'Alene and Riggins); New Mexico (Jemez Springs); Oregon (Alkali Lake, Hood River, Portland, and Seaside); Utah (Logan, Provo, Stansbury Island in Tooele Co., and Uinta Co.); Washington (Buckley, Easton, Ellensburg, Loon Lake, Mount Rainier at 4,700 ft., and Puyallup); Wyoming (Yellowstone National Park); and Yukon (Whitehorse).

Collection dates are mostly in spring, early summer, and fall, with a few records in late summer. The only records between July 19 and September 11 are: August 10 at Seaside, Oreg.; August 11 at Whitehorse, Yukon; and August 18 at Logan, Utah. Of the 24 males 20 were taken on various dates between April 24 (at Ellensburg, Wash.) and May 26 (at Vancouver, B. C.). The other four were taken June 15 at Truckee, Calif.; July 3 at Dardanelle, Calif.; July 15 at Fish Camp, Calif.; and July 19 at 4,700 ft. on Mount Rainier, Wash. It may be that the early males represent a first generation and the later males a second generation but the seasonal records for females are not consistent with this possibility. Unusually early and late records for females are: March 31 at Antioch, Calif.; May 13 at Bear Wallow, Mount Lemmon, Ariz.; May 16 at Loon Lake, Wash.; May 24 near Alpine, Ariz.; May 26 at Vancouver, B. C.; October at Provo, Utah; 
October 9 and 10 at Robson, B. C.; and November 29 at Jemez Springs, N. Mex.

Rearing records are: $\circ$, from Buprestis confluens in Populus tremuloides, Vade, Calif., Feb. 4, 1916, H. E. Burke. 3ㅇ, from Saperda moesta in Populus trichocarpa, Riggins, Idaho, Apr. 6 to 8, 1914, Josef Brunner. ' †, from Saperda tulari, Clarksburg, Calif., "11-4-35." \%, from Saperda sp. in Populus tremuloides, North Cheyenne Canyon, Colo., Geo. Hofer. $0^{7}$, from Xylocrius agassizi in Ribes, Buckley, Wash., Apr. 29, 1938, W. W. Baker. 2o, from Xylocrius agassizi in Ribes, Puyallup, Wash., May 1939, W. W. Baker.

This subspecies occurs in the Canadian and Transition zones of western North America. Adults occur from early spring to fall but are scarce in the last half of summer. It has been reared from coleopterous borers in Populus and Ribes.

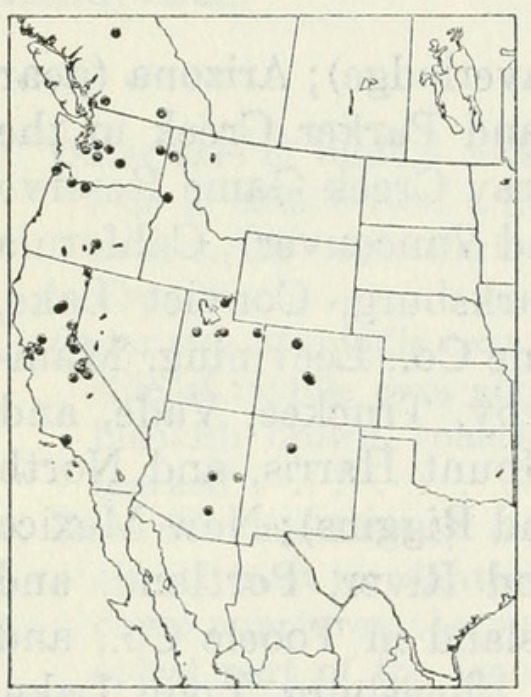

Figures 54, 55.-Localities: 54 (left), Dolichomitus messor sparsus; 55 (right), D. m. perlongus.

8b. Dolichomitus messor perlongus (Cresson), new status, new combination

Ephialtes perlongus Cresson, 1870, Trans. Amer. Ent. Soc., vol. 3, p. 143; $\sigma^{7}$. Type: $\sigma^{\top}$, Massachusetts (Philadelphia).

Ephialtes gigas Walsh, 1873, Trans. Acad. Sci. St. Louis, vol. 3, p. 110; 9 . New synonymy. Type: + , Illinois? (destroyed in Chicago fire of 1871).

Male: Face with rather small, dense punctures and dense hairs; the first trochanter of front leg flat or a little concave; second trochanter of front leg almost flat below; under side of front trochanters and of basal third of front femur with very fine dense punctures from which arise fine short hairs; outer side of middle coxa with a distinct median swelling which is covered with fine punctures that are about twice as dense as elsewhere on the coxa.

Black. Clypeus mostly ferruginous; scape with a large pale yellowish spot in front; palpi whitish, their basal segment brown; meso- 
sternum and lower part of mesopleurum sometimes light brown; tegula and hind corner of pronotum yellowish white, the tegula fulvous apically; front and middle legs fulvous, their tarsi, tibiae in front, and apex of femora in front, pale yellowish fulvous; apical half of last segment of front tarsus tinged with brown; apical 0.6 of last segment of middle tarsus brown; hind coxa, trochanters, and femur fulvous, the femur with a subapical infuscation, its extreme apex pale; hind tibia fuscous, its basal 0.15 whitish and a light brown stripe beneath on its basal half; hind tarsus fuscous, the base of its basitarsus stramineous; stigma blackish brown.

Female: Punctures on lateral 0.1 of face usually in a single vertical row paralleling eye margin and leaving the rest of this area impunctate; subdorsal hair sockets on front face of hind femur separated by about 0.9 the length of the hairs.

Black. Clypeus ferruginous; mandible often stained with ferruginous; labial palpus and base of maxillary palpus dark brown, the rest of maxillary palpus brown; mesosternum and lower part of mesopleurum sometimes light brown; tegula pale yellowish, its apex fulvous; narrow hind corner of pronotum fulvous; legs fulvous, the hind femur often with a very faint subapical infuscation, the apex of hind tibia infuscate, and the hind tarsus brownish, darker apically; stigma blackish or blackish brown, usually a little paler medially; wing membrane usually tinged with light brown.

The type of Ephialtes gigas Walsh is destroyed, but the description leaves little doubt as to its identity. Walsh describes particularly the rather elongate tubercles on the tergites, the "smoky yellow" tinge of the wings, and the legs as entirely pale rufous except for infuscation on the tarsi and on the tip of the hind tibia.

Specimens $\left(28 \sigma^{x}, 40\right.$ o $)$ : From Colorado (Denver); Connecticut (West Rock); Idaho (Lewiston and Riggins); Maine (Rangeley); Manitoba (Aweme and Riding Mountain Park); Massachusetts (Harwich Port, Sherborn, and Wollaston); New Brunswick (Waweig); New Jersey (Camden); New York (Geneva, Ithaca, Millwood, and Oak Hill in Greene Co.); Northwest Territories (Cameron Bay on Great Bear Lake); Ohio (Hocking Co.); Ontario (Niagara Glen, Ottawa, Sudbury, and Toronto); Pennsylvania (Clarke's Valley in Dauphin Co., Crisp in Westmoreland Co., Huntington, and Spring Brook); Quebec (Montreal); Saskatchewan (Indian Head); South Dakota (Yankton); Texas; Vermont (Laurel Lake near Jacksonville); and Virginia (Meadows of Dan in Patrick Co.).

Adults have been collected from early spring to late fall. The records seem to indicate a spring and early summer emergence, with females living into the fall. The emergence of males is mostly from late April to early June, diminishing into the summer, with unusually 
early and late records as follows: April 29 at Meadows of Dan, Patrick Co., Va.; May 4 at Camden, N. J.; May 10 at Ottawa, Ont.; July 10 and 20 at Ottawa, Ont.; July 29 at Ithaca, N. Y.; and "October" at Toronto. Unusually early and late records of females are: April 29 at Meadows of Dan, Patrick Co., Va.; May 10 and 15 at Ottawa, Ont.; May 15 at Spring Brook, Pa.; October 1 at Ithaca, N. Y.; October 21 at Clark's Valley, Pa.; and October 22 at Lewiston, Idaho and at Yankton, S. Dak.

Rearing records are: $50^{7}, 8 \circ$, from Saperda calcarata, Indian Head, Sask., May 31 to June 8, 1937, K. E. Stewart. o, ovipositing in gall of Saperda concolor, Clark's Valley, Pa., Oct. 21, 1928, J. N. Knull. ㅇ, from Saperda concolor, Westboro, Pa., Apr. 5, 1921, F. C. Craighead. $\sigma^{T}$, from Saperda moesta in Populus tremuloides, Riggins, Idaho, Mar. 10, 1915, L. O. Swartz.

This subspecies in its typical form is in the Canadian and Transition zones of eastern North America, but in Canada and northern United States specimens identifiable as this subspecies occur westward to Idaho and British Columbia, into the range of the subspecies sparsus. Males occur mostly from early spring to mid-summer, but females persist in numbers to late in the fall. It has been reared from Saperda in Salix and Populus.

\section{8c. Dolichomitus messor messor (Gravenhorst), new combination}

Ephialtes messor Gravenhorst, 1829, Ichneumonologia europaea, vol. 3, p. 232;

q. Type: , Volhynia, Russia (Wroclaw).

Male: Face with moderate-sized, dense punctures and dense hairs; front trochanters and femur as described for the subspecies $D$. messor perlongus; outer side of middle coxa with a faint median swelling; punctures on outer side of middle coxa a little denser than elsewhere on the coxa.

Black. Clypeus mostly ferruginous; spot on scape in front stramineous; palpi pale ferruginous, brown basally; tegula pale yellow; extreme hind corner of pronotum tinged with fulvous; mesosternum and lower part of mesopleurum sometimes light brown; legs fulvous, the under side of trochanters and of femur, the front side of tibia, and all of tarsus pale yellowish; middle leg fulvous, the femur in front at apex, tibia except behind, and tarsus pale yellowish; hind coxa, trochanters, and femur fulvous, the apex of femur sometimes with a faint infuscation; hind tibia medium brown, pale brown on basal 0.2 and on basal 0.6 of lower edge; hind tarsus medium brown, the base of each segment light brown; stigma light brown, its edges dark brown.

Female: Approximately like the female of $D$. messor perlongus except that the hairs on the hind femur are a little denser and that the stigma is light brown bordered with darker. 
Described from $3 \sigma^{7}, 3$ ㅇ from Germany and Poland, including a male reared from Saperda populnea.

\section{Dolichomitus irritator (Fabricius), new combination}

Figures 333,h; 351

Ichneumon irritator Fabricius, 1775, Systema entomologiae, . . ., p. 336;. Type: $q$, America (London).

Male: Front wing 6.0 to $10.5 \mathrm{~mm}$. long; face rather narrow, with very fine, moderately dense punctures; prepectal carina ending near level of lower 0.12 of hind margin of pronotum; propodeum partly weakly rugulose, with large, weak, scattered punctures; median longitudinal carinae of propodeum indistinct but indicated by rugulosity and weak elevations; front coxa prolonged below, the prolongation concave anteromesally; first trochanter of front leg with a median ventral tubercle; middle coxa externally with a basal, median, and apical tubercle, excised between the tubercles; concave margin of front coxa, underside of trochanters of front leg, and outer side of middle coxa with a very fine, mat sculpture; first tergite about 1.7 as long as wide; second tergite about 1.5 as long as wide; subgenital plate as in figure $333, \mathrm{~h}$; genitalia as in figure 351 .

Black. Clypeus and mandible tinged with ferruginous; palpi, tegula, and front and middle legs except femur, white, their tibiae and tarsi often stained with pale fulvous; front and middle femora fulvous, white apically in front, the middle femur the more extensively white; extreme base of front and middle coxae dark brown; hind coxa blackish; hind first trochanter dark brown; hind second trochanter brownish fulvous; hind femur fulvous, its extreme apex stramineous; hind tibia and tarsus fulvous to reddish brown, the basal 0.15 of the tibia paler; second to fifth or sixth tergites red, with an apicolateral transverse black spot, the spots of each side joined on the more distal segments to make an apical black band. In smaller males the abdomen may be entirely black.

Female: Front wing 8.7 to $14.5 \mathrm{~mm}$. long; face moderately narrow, rather evenly covered with moderately small, sharp punctures whose interspaces are about twice their diameter; prepectal carina ending dorsally near level of lower 0.2 of hind margin of pronotum; propodeum transversely rugulose medially, its median longitudinal carinae irregularly rugulose but distinct, extending about 0.65 the length of propodeum; punctures of propodeum moderately coarse and close, the sublateral ones subadjacent or crowded; hind femur about 4.8 as long as deep, its front face with rather small, moderately sharp punctures that are separated by about 2.5 their diameter; bristlelike hairs on middle tibia fine and weak; first tergite about 1.5 as long as wide; 
second tergite about 1.15 as long as wide; third tergite polished, its tubercles prominent and with moderately small punctures whose interspaces are about 2.5 their diameter, the punctures surrounding the tubercles coarser and much denser; ovipositor sheath about 1.45 as long as front wing; ovipositor tip as in D. messor (fig. 330,f).

Black. Clypeus stained with ferruginous; palpi dark brown; tegula white; coxae black or blackish; front and middle trochanters whitish; hind first trochanter blackish brown, fulvous apically; hind second trochanter fulvous, yellowish in front; femora fulvous, the front and middle femora pale yellow at apex and partly in front; tibiae light fulvous, the front tibia yellowish above and the hind tibia a little paler basally; tarsi yellowish fulvous, the hind tarsus a little darker; second and following tergites red, the second to fifth tergites with progressively smaller lateroapical transverse black spots.

The black hind coxa immediately distinguishes this species from others in the Nearctic region. The abdomen is mostly red except in some smaller males. In the other Nearctic species the abdomen is always black.

Specimens (200 $\sigma^{\top}, 591$ ) : From Alabama (Littleville in Colbert Co. and Mobile); Connecticut (Colebrook, East Haddam, Hartford, Lyme, Redding, Voluntown, and Westport); District of Columbia (Washington); Florida (Bratt in Escambia Co. and Valpariso); Georgia (Austell); Illinois (Algonquin, Champaign, Chicago, and Urbana); Indiana (Gibson Co. and Lafayette); Iowa (Henry Co.); Kansas (Baldwin, Cherokee Co., Lawrence, Leavenworth, Montgomery Co., and Osage Co.); Kentucky; Maine (Lincoln Co.); Maryland (Beltsville, Bethesda, Bowie, Cabin John, "Club Hill," College Park, Crownsville, Glen Echo, Great Falls, Hagerstown, Hyattsville, Maryland shore near Plummers Island, and Takoma Park); Massachusetts (Springfield, Taunton, and Waltham); Michigan (Ann Arbor, Antrim Co., Chatham, Clare Co., Coloma, Detroit, East Lansing, George Reserve in Livingston Co., Gratiot Co., Grosse Ile near Detroit, Gull Lake Biological Station in Kalamazoo Co., Ionia Co., Iosco Township in Livingston Co., Kalkaska Co., Keweenaw Co., Lake City, Lenawee Co., Mecosta Co., Midland Co., Oakland Co., Roscommon Co., Saginaw, Sanilac Co., Shiawassee Co., Warren Woods in Berrien Co., and Whitefish Point in Chippewa Co.); Minnesota (Brownsville, Cotton, Eitzen, Lamoille, Nerstrand Woods in Rice Co., Olmsted Co., St. Anthony Park in Ramsey Co., and St. Paul) ; Mississippi (Oxford); Missouri (Azalea Mts. near Van Buren, and Boonville); New Jersey (Alpine, Camden, Clementon, Elwood, Englewood, Moorestown, Ridgewood, Riverton, "Sea Cliff," Seaside Park, and Tabernacle); New York (Bemus Point, Colden, Dix Hills 
near Huntington, Ellis Hollow, Fort Montgomery, Fredonia, Geneva, Grand Island, Greene Co. at 2,500 ft., Hempstead Plains, Hudson, Huntington, Ithaca, Lockport, Ludlowville, McLean Bogs Reserve in Tompkins Co., Niagara Falls, Nyack, Oswego, Pelham, Poughkeepsie, Rochester, Rock City in Cattaraugus Co., Rockaway, Sea Cliff, Shokan, Virgil, Wading River on Long Island, West Farms in New York City, West Point, Woodbury Farms, Woodhaven, Yaphank, and Yonkers); North Carolina (valley of Black Mts., "Blue Mts.," Bryson City, Hamrick, Raleigh, Southern Pines, and Tryon); Ohio (Akron, Barberton, Cedar Swamp in Champaign Co., Cleveland, Columbus, Coshocton Co., Hinckley in Medina Co., Hocking Co., Medina, Montgomery Co., New Bremen, Puritas Springs in Cuyahoga Co., South Bass Island at Put-in-Bay, and Smithfield); Ontario (Ancaster, Bothwell, Fort Erie, Gravenhurst in the Muskoka District, Harold, Jordan, Leamington, Merivale, Niagara Glen, Oreston, Ottawa, Point Pelee, Prince Edward Co., Ridgeway, Rondeau Park, and Toronto); Pennsylvania (Allegheny Co., Aspinwall, Beaver Co., Bowmansdale, Carlisle Junction, Castle Rock in Delaware Co., Charter Oak, Crisp in Westmoreland Co., Glenside, Harrisburg, Heckton Mills, near Highspire, Hummelstown, "Livingston," Marsh Run in York Co., "Mont Alto," New Hope, North East, Oak Station in Allegheny Co., Overbrook, Philadelphia, Pittsburgh, Presque Isle in Erie Co., Rockville, Roxborough, Shiremanstown, South Mt. in Lancaster Co., Spring Brook, Trout Run, Valley Forge, and Washington Co.); Rhode Island (Westerly); South Carolina (Columbia and Greenville); Tennessee (Blount Co., Burrville, Fall Creek State Park in Bledsoe Co., Monteagle at 2,000 ft., and State Road to Newfound
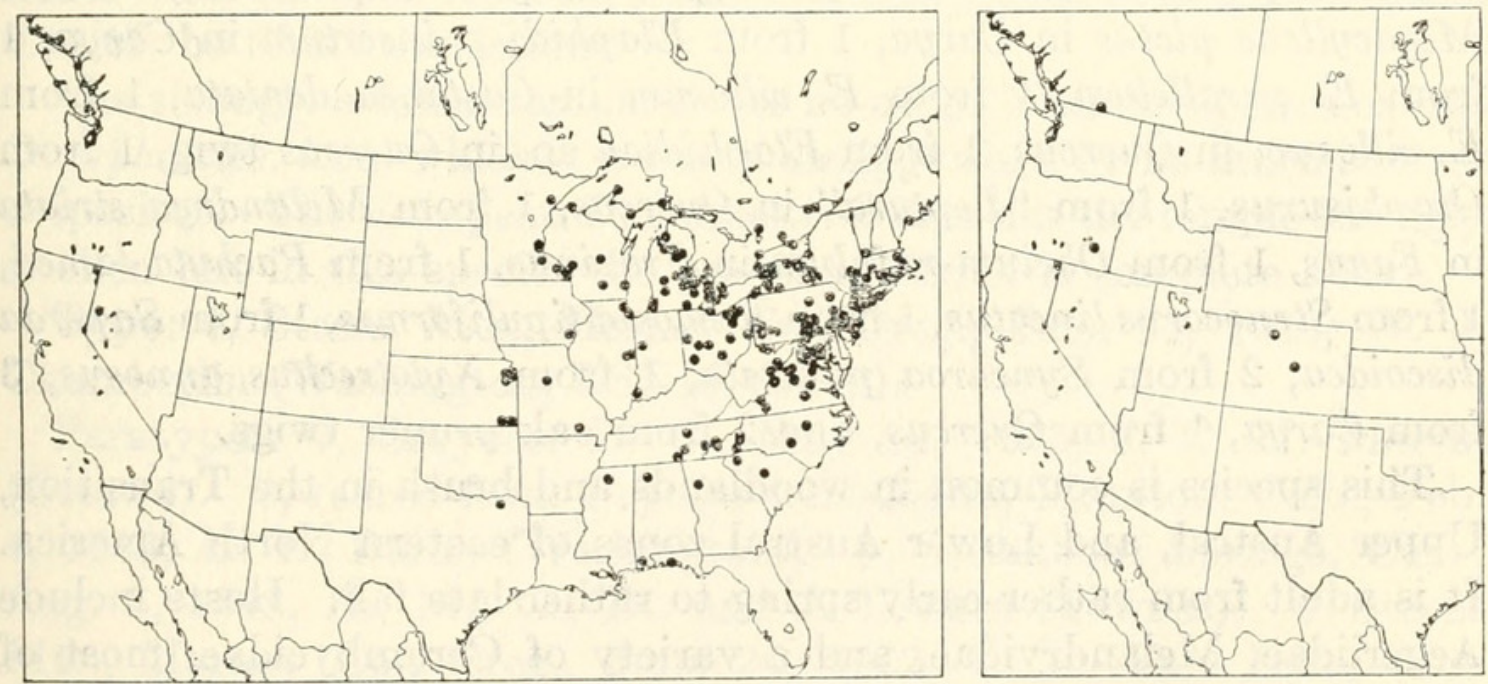

Figures 56, 57.-Localities: 56 (leit), Dolichomitus irritator; 57 (right), D. buccatus. 
Gap at 3,500 ft.); Texas (Paris); Vermont (Laurel Lake near Jacksonville); Virginia (Appalachian Trail, Arlington, Bluemont, Camp Pickett, Chain Bridge near McLean, Charlottesville, Dayton, Difficult Run in Fairfax Co., Falls Church, Glencarlyn near Washington, Great Falls, Gunston Cove on the Potomac River, Hot Springs, Lewis Falls in the Shenandoah, Meadows of Dan in Patrick Co., Mount Vernon, Mountain Lake Biological Station in Giles Co., Nelson Co., Richmond, Rosslyn, Turkey Run, Vienna, Summit in Whitetop Mts., and "Willis Mt."); West Virginia (Bolivar, Cheat Mt. at 2,000 ft. in Randolph Co., Cheat River, Morgantown, and Spruce Knob at 4,860 ft.) Wisconsin (Bayfield, Jackson Co., Madison, Milwaukee, Portage Co., and "Wyarno").

This species is the most spectacular of the common ichneumonids to reward the collector who feels the urge to look for insects in the first warm days of spring or the last ones of fall, and can be found throughout the growing season. Over most of its range it is on the wing from about April 20 to mid-October, earlier and later in the South. In our experience, this species flies in hardwood woods and brush, rather near the ground. Noteworthy early and late records are: March 24 at Oxford, Miss.; March 28 at Littleville, Ala.; April 6 and 7 at Southern Pines, N. C.; April 10 at Clementon, N. J., at Chicago, Ill., and at Falls Church, Va.; April 12 at Greenville, S. C. and in Rice Co., Minn.; April 13 at Camp Pickett, Va.; April 14 at Lawrence, Kans.; April 15 at Ann Arbor, Mich.; April 20 at Madison, Wis.; April 21 and 22 at Ithaca, N. Y.; October 8 in Hocking Co., Ohio; November 3 at Arlington, Va.; November 14 at Raleigh, N. C.; November 17 and 19 at Takoma Park, Md.; November 20 at Mobile, Ala.; and November 25 at Austell, Ga.

Rearing records are: 1 from Anoplodera proxima in Acer, 1 from Megacyllene pictus in Carya, 1 from Elaphidion incertum in Carya, 1 from $E$. parallelum, 1 from $E$. villosum in Castanea dentata, 1 from E. villosum in Quercus, 1 from Elaphidion sp. in Quercus twig, 1 from Graphisurus, 1 from "Leptura" in Quercus, 1 from Melandrya striata in Fagus, 1 from Obrium rufulum in Fraxinus, 1 from Pachyta lamed, 1 from Stenocorus lineatus, 1 from Ramosia tipuliformis, 1 from Saperda discoidea, 2 from Synchroa punctata, 1 from Xylotrechus annosus, 3 from Carya, 1 from Quercus, and 2 from oak pruner twigs.

This species is common in woodlands and brush in the Transition, Upper Austral, and Lower Austral zones of eastern North America. It is adult from rather early spring to rather late fall. Hosts include Aegeriidae, Melandryidae, and a variety of Cerambycidae, most of them borers in hardwoods, in a large percentage of the cases in hardwood branches lying on the ground. 


\section{Dolichomitus buccatus, new species}

Male: Unknown.

Female: Front wing 11 to $15.7 \mathrm{~mm}$. long; face rather wide, with moderately coarse punctures that are separated by about twice their diameter; temple long and swollen, about 1.0 as long as the eye, the head across temples a little wider than across eye (the temple shorter and not swollen to near outer tangent of eye in the other Nearctic species of the Irritator group); flagellum unusually short, the fifth segment from the end about 1.1 as long as wide; upper end of prepectal carina fading out near level of lower 0.3 of hind margin of pronotum; propodeum unusually short, weakly transversely rugulose medially, with moderately coarse, weak punctures which are nearly all basad of the middle; median longitudinal carinae of propodeum indistinct; hind femur about 4.8 as long as deep, its front face with rather sparse, small, weak punctures that are separated by about three times their diameter; bristlelike hairs on middle tibia strong; first tergite about 1.4 as long as wide; second tergite about 1.1 as long as wide; third tergite transversely rugulose, its tubercles prominent, the tubercles with only weak rugulosity and moderate-sized, weak punctures whose interspaces are about 1.5 their diameter; ovipositor sheath about 1.45 as long as front wing; dorsal lobe of the lower valve of ovipositor rather small.

Black. Clypeus and mandible often more or less ferruginous; palpi brown, the labial palpus darker; tegula yellowish, its apicolateral edge brownish; extreme hind corner of pronotum often fulvous; front and middle legs fulvous, the apex of their femora in front, basal 0.12 of their tibiae above, and front and upper side of front tibia, paler or yellowish fulvous; hind coxa, trochanters, and femur fulvous, the femur with its apex fuscous; hind tibia and tarsus fuscous, the basal 0.15 of the tibia stramineous.

The strongly swollen temple is like no other Nearctic species except $D$. cephalotes, from which it is easily distinguished by its much shorter ovipositor. The European D. crassicornis also has the temple strongly swollen but in this species the prepectal carina is complete above.

Type: o, Steens Mts., Harney Co., Oreg., June 24, 1922, W. J. Chamberlin (Washington, USNM 63690).

Paratypes: ㅇ, Osoyoos, B. C., May 13, 1953, J. E. H. Martin (Ottawa). \&, reared from Populus tremuloides, Manitou, Colo., Feb. 4, 1916, H. E. Burke (Washington). o, Steamboat Springs, Colo., Aug. 5, 1948, H., M., G., D., and J. Townes (Townes). क् Steens Mts., Harney Co., Oreg., June 24, 1922, E. C. Van Dyke (San Francisco).

This is an uncommon species of the West, probably restricted to the Canadian zone. 


\section{Dolichomitus flexilis, new species}

\section{Male: Unknown.}

Female: Front wing 10 to $13.5 \mathrm{~mm}$. long; face of moderate width, with moderate-sized punctures that are separated by about twice their diameter; upper end of prepectal carina above midheight of hind edge of pronotum, curved forward toward front edge of mesopleurum, the upper part of the prepectal carina often weak; median longitudinal carinae of propodeum rather strong, strongly divergent, extending about 0.6 the length of propodeum; propodeal punctures rather small, crowded sublaterally but elsewhere rather sparse; hind femur about 6.0 as long as deep, its front face with numerous small weak punctures that are separated by about twice their diameter; bristlelike hairs on middle tibia small and weak; first tergite about 1.65 as long as wide; second tergite about 1.35 as long as wide; third tergite with weak transverse rugulosity, its tubercles moderately prominent, without distinct rugulosity, covered with rather small punctures whose interspaces are about equal to their diameter; ovipositor sheath about 2.7 as long as front wing; tip of ovipositor rather similar to that of $D$. messor (fig. 330, f).

Black. Clypeus and mandible stained with ferruginous; maxillary palpus brown, its basal segment dark brown; labial palpus dark brown; tegula and hind corner of pronotum whitish; mesosternum and lower part of mesopleurum sometimes light brown; front and middle coxae, trochanters, and femora fulvous, the apex of the femora pale yellowish in front; front and middle tibiae fulvous, somewhat infuscate above (especially the middle tibia), their basal 0.12 and apex in front pale yellowish; front and middle tarsi fulvous, the middle tarsus a little darker; hind coxa and trochanters fulvous; hind femur rather dark brown, its base somewhat fulvous or sometimes the basal half mostly fulvous; hind tibia and tarsus fuscous, the basal 0.12 of the tibia stramineous above.

The dark brown hind femur and the long ovipositor $(2.7 \pm$ as long as the front wing) distinguish this species. The male is unknown but presumably has the hind femur dark, which would distinguish it from all other known Nearctic members of the irritator group except $D$. pygmaeus.

Type: \&, Gillam, Man., July 17, 1950, J. F. McAlpine (Ottawa).

Paratypes: + , Great Slave Lake region, N. W. T., July 31, 1927 (Townes). ९, Snag, Yukon, Aug. 1943, Beresford Smith (Ottawa). , Yukon (Pittsburgh).

This is a species of northern Canada, 


\section{Dolichomitus aciculatus (Hellén), new combination}

Figures $333, \mathrm{i} ; 352$

Ephialtes aciculatus Hellén, 1915, Acta Soc. Fauna Flora Fennica vol. 40, p. 25;

१. Type: १, "Bothn. Or." (Helsinki).

Male: Front wing $10 \mathrm{~mm}$. long; face moderately wide and flat, its punctures fine, separated by about 2.5 their diameter; prepectal carina ending near lower 0.12 of hind margin of pronotum; propodeum with weak, very indistinct punctures and some fine, irregular, mostly transverse wrinkling; median longitudinal carinae of propodeum rather strong, blunt, moderately divergent, extending about 0.6 the length of propodeum; first tergite 1.85 as long as wide; second tergite 1.45 as long as wide; second to fifth tergites with unusually fine, weak punctures and in the depressions with distinct, mostly transverse, aciculation; subgenital plate as in figure 333 ,i; genitalia as in figure 352 .

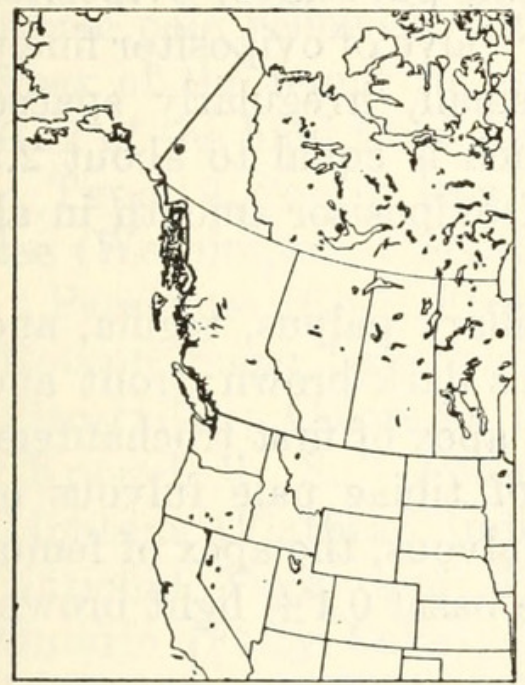

Figures 58, 59.-Localities: 58 (left), Dolichomitus flexilis; 59 (right), D. aciculatus.

Black. Clypeus tinged with ferruginous; palpi stramineous to whitish, the basal half of their basal segment infuscate; scape with a small white spot apically in front; hind corner of pronotum entirely black; coxae fulvous, the apical $0.3 \pm$ of front and middle coxae whitish in front; front and middle trochanters whitish; hind trochanters fulvous, the second trochanter whitish below; femora fulvous, the apex of front and middle femora tinged with whitish and apex of hind femur narrowly infuscate; front and middle tibiae fulvous, whitish fulvous basally, especially above; hind tibia infuscate, its basal 0.2 and lower edge except on apical 0.3 , pale brown; front and middle tarsi brownish fulvous; hind tarsus fuscous, brownish at extreme base.

Female: Front wing 9.5 to $11.5 \mathrm{~mm}$. long; face of moderate width, with medium-sized, sharp punctures that are rather evenly distributed 
and separated by about 2.5 their diameter; clypeus very weakly convex, the impression near its apical margin not as strong as in most other members of the genus; upper end of prepectal carina curved forward almost to reach front edge of mesopleurum, its upper end near midheight of hind margin of pronotum; median longitudinal carinae of propodeum represented by rather strong, blunt ridges which extend about 0.6 the length of propodeum and are almost parallel except near their apex, where they diverge more strongly; propodeal punctures rather weak and rather large, separated by about 0.7 their diameter; hind femur about 4.6 as long as deep, its front face with numerous small, weak punctures that are separated by about twice their diameter; bristlelike hairs on middle tibia small and weak; first tergite about 1.6 as long as wide; second tergite about 1.2 as long as wide; third tergite with moderately strong tubercles, the area surrounding the tubercles with rather strong fine wrinkles, on the tubercles and subapically with moderate-sized, rather weak punctures; ovipositor sheath about 2.7 as long as front wing; lower valve of ovipositor finely roughened laterally and with a row of small, irregularly spaced tubercles the average distance between which is equal to about 2.5 the depth of the ovipositor (lower valve of ovipositor smooth in all other species of the genus).

Black. Clypeus dusky ferruginous; maxillary palpus, tegula, and hind corner of pronotum white; labial palpus dark brown; front and middle legs fulvous, the second trochanters, apex of first trochanters, extreme apex of femora, and upper side of tibiae pale fulvous or whitish; hind coxa, trochanters, and femur fulvous, the apex of femur infuscate; hind tibia and tarsus fuscous, the basal $0.1 \pm$ light brown; wings with a faint brownish tinge.

This is the only species of Dolichomitus in which the lower valve of the ovipositor is roughened and tuberculate. Other distinctive features are the long ovipositor sheath ( $2.7 \pm$ as long as front wing), largely fulvous hind femur, and rather strongly aciculate tergites. The male is described from one of the series reared and described and figured by Noskiewicz and Chuboda (1951, Polskie Pismo Entomologiczne, vol. 21, p. 43).

Specimens: 4우, Lower Post, B. C., June 17 and 20, 1948, W. R. M. Mason (Ottawa). , Robson, B. C., June 1, 1948, H. R. Foxlee (Ottawa). †, Laniel, Que., May 31, 1934 (Ottawa). †, Dawson, 1,100 ft., Yukon, July 19, 1949, P. F. Bruggemann (Ottawa). $\sigma^{7}$, reared from Tetropium gabrieli in Larix europea, Krakow, Poland, March 1950 (Townes).

This is a scarce species of the Canadian zone. It occurs in Europe, where it is also scarce. The only host record is from a cerambycid in Larix. 


\section{Dolichomitus foxleei, new species}

Male: Unknown.

Female: Front wing 9.3 to $14 \mathrm{~mm}$. long; propodeum rather short, weakly transversely rugulose across the middle, its punctures rather large and weak, the sublateral punctures subadjacent; median longitudinal carinae of propodeum rather strong, strongly divergent, extending about 0.6 the length of propodeum; first tergite about 1.6 as long as wide; second tergite about 1.15 as long as wide; ovipositor sheath about 1.6 as long as front wing. Structure otherwise as described for D. californicus.

Black. Clypeus and mandible more or less stained with ferruginous; labial palpus and basal two segments of maxillary palpus dark brown; last three segments of maxillary palpus medium brown; tegula white; small hind corner of pronotum dull ferruginous to black; front and middle legs fulvous, the apex of their femora and base of their tibiae pale yellowish; hind coxa, trochanters, and femur fulvous, the apex of the femur fuscous; hind tibia and tarsus fuscous, the basal 0.12 of the hind tibia dusky fulvous.

Type: ㅇ, "on fir logs," Robson, B. C., Sept. 25, 1938, H. R. Foxlee (Washington, USNM 63691).

Paratypes (63\%): From Alberta (Banff); British Columbia (Kaslo, Robson, Sugar Lake, and Trinity Valley); California (Fallen Leaf and Placerville); Colorado (North Cheyenne Canyon); Idaho (Burke, "Krassel R. S.," Potlatch, and Wallace); Maine (Bar Harbor); Montana (Flathead Indian Reservation, Lake Macdonald in Glacier National Park, and Thompson Falls); Nova Scotia (Kentville); Ontario (Fairy Lake); Oregon (Detroit and Government Camp on Mount Hood); Quebec (Laniel); and Washington (Kent and Metaline Falls).

Collecting dates are from spring to late in the fall but about 60 percent of the specimens were taken in September and October. Unusually early and late seasonal records are: April 24 at Robson, B. C.; May 15 in Trinity Valley, B. C.; June 1 at Kentville, N. S.; October 6 and 9 at Potlatch, Idaho; October 1, 6, 16, 21, 22, and 25 at Robson, B. C.; and October 18 at Wallace, Idaho.

Thirteen of the specimens are labeled "on fir logs," which in this case probably means Pseudotsuga taxifolia. One specimen is labled "on Abies concolor," one labled "Pinus ponderosa," one labeled "on Pinus montana," one labeled "Pinus scopulorum," one labeled "Pseudotsuga taxifolia," and there are more exact biological records as follows: 2 , ovipositing in log of Pseudotsuga taxifolia infested by Melanophila drummondi and Semanotus ligneus, Kent, Wash., Burke. o, ovipositing in $\log$ of Pseudotsuga taxifolia infested with Melanophila drummondi, Flathead Indian Reservation, Wash., Sept. 10 to 14, 
1912, Josef Brunner. $\$$, ovipositing on pupa of Acanthocinus, Metaline Falls, Wash., July 3, 1930, DeLeon.

This species is transcontinental in northern coniferous forests but is much commoner in the West. It is adult throughout the growing season. The hosts are coleopterous borers under the bark of Coniferae.
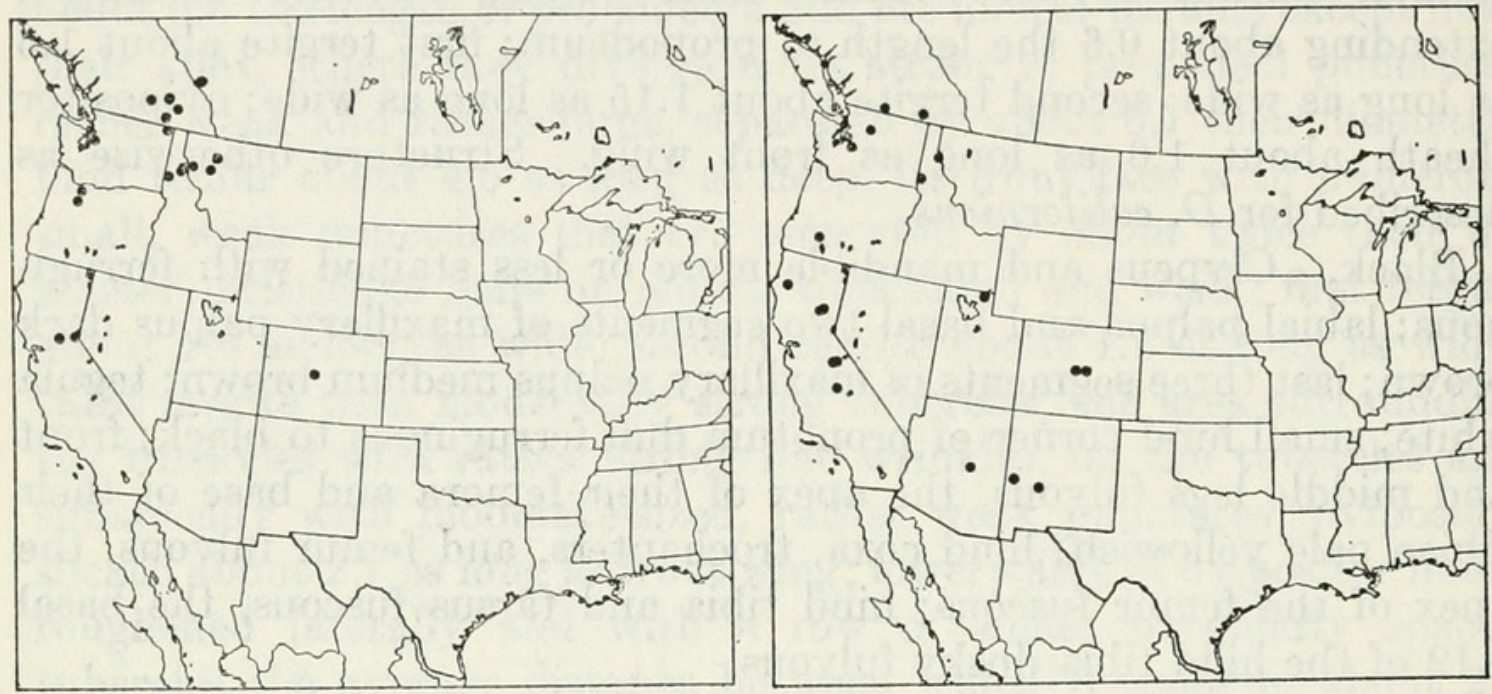

Figures 60, 61.-Localities: 60 (left), Dolichomitus foxleei; 61 (right), D. californicus.

\section{Dolichomitus californicus, new species}

Figures $333, \mathrm{j} ; 353$

Male: Front wing 6.2 to $9.8 \mathrm{~mm}$. long; face of moderate width, with rather small, sharp punctures whose interspaces are about 0.8 their diameter; prepectal carina weak above, often traceable to a little above mid-height of hind margin of pronotum, where it curves forward toward front margin of mesopleurum; propodeum rather long, with rather sparse large punctures, its median longitudinal carinae rather strong, moderately divergent, extending about 0.7 its length; front coxa not specialized; front first trochanter a little concave; under side of front trochanters and of base of front femur with small sharp punctures whose interspaces are about 0.7 their diameter; outer edge of middle coxa with a faint median swelling and a narrow vertical band of moderately dense, fine punctures; first tergite about 2.1 as long as wide; second tergite about 1.7 as long as wide; subgenital plate as in figure $333, \mathrm{j}$; genitalia as in figure 353 .

Black. Clypeus and mandible stained with ferruginous; front of scape and pedicel varying from entirely black to entirely whitish; palpi white; tegula and hind corner of pronotum white; front and middle coxae and trochanters white, the coxae fulvous basally behind; front and middle femora fulvous, whitish apically in front; front and middle tibiae and tarsi whitish or very pale fulvous, the tibiae more or less fulvous below and behind, and the middle tarsus brownish apically; 
hind coxa fulvous; hind trochanters whitish, largely fulvous above; hind femur fulvous with its apex brownish to brown, with its base brownish fulvous, its extreme apex white; hind tibia fuscous, the basal 0.15 and basal half of under side white; hind tarsus fuscous. Males from Arizona have the whitish markings on the legs a little reduced.

Female: Front wing 11 to $16.5 \mathrm{~mm}$. long; face of moderate width, with moderate-sized punctures that are separated by about 1.2 their diameter; temple moderately convex; upper end of prepectal carina weak, ending near mid-height of hind edge of pronotum, where it usually curves forward almost to reach front edge of mesopleurum; propodeum moderately long, transversely rugulose across the middle and near the longitudinal carinae, its punctures of moderate size, the sublateral punctures separated by about 0.7 their diameter; median longitudinal carinae of propodeum rather strong, moderately divergent, extending about 0.7 the length of propodeum; hind femur about 5.7 as long as deep, its front face with numerous small weak punctures that are separated by about twice their diameter; spinelike bristles on middle tibia of moderate strength, rather sparse; first tergite about 2.0 as long as wide; second tergite about 1.6 as long as wide; third tergite with weak transverse rugulosity and punctured, its tubercles moderately prominent, hardly at all rugulose, covered with moderatesized punctures whose interspaces are about 0.8 their diameter; ovipositor sheath about 1.8 as long as front wing; ovipositor tip similar to that of $D$. messor (fig. $330, \mathrm{f}$ ).

Black. Clypeus and mandible stained with ferruginous; palpi whitish or pale stramineous, their basal segment dark brown; tegula and hind corner of pronotum white; front and middle legs fulvous, the apex of their first trochanter, most of second trochanter, apex of femur in front, basal 0.12 of tibiae above, and tinge on front of tibiae, pale yellowish; hind coxa, trochanters, and femur fulvous, the apex of the femur fuscous; hind tibia and tarsus fuscous, the basal 0.12 of the tibia stramineous, and under side of tibia light brown on its basal half.

Type: ㅇ, near Glacier Point, Yosemite Park, Calif., July 18, 1948, H., M., G., D., and J. Townes (Washington, USNM 63692).

Paratypes $\left(460^{x}, 33 \%\right)$ : From Arizona (Workman Creek in the Sierra Ancha); British Columbia (Manning Park at 4,000 ft., and Robson); California (Buck's Lake in Plumas Co., Giant Forest in Tulare Co., near Glacier Point in Yosemite Park, Meadow Valley at 4,000 to 5,000 ft., Smoky Jack Camp in Yosemite Park, and Trinity Co. at 6,000 ft.); Colorado (Williams Canyon and Ute Pass, both in El Paso Co.); Idaho (Moscow at 2,000 ft. and Murray); New Mexico (Apache National Forest and Magdalena Mts.); Oregon (Crater Lake); Utah (Logan Canyon); and Washington (Kent, Lyman Lake in Chelan Co., and Mount Rainier at 2,900 ft.). 
Collection dates are from early spring to fall. Unusually early and late dates of capture are: April 28 and 30 and May 1 and 3 at Workman Creek, Sierra Ancha, 5,300 ft., Ariz.; April 30 at Yosemite Park, Calif.; May 20 in Trinity Co. at 6,000 ft., Calif.; September 2 at Murray, Idaho; and October 17 at Robson, B. C.

Reared specimens are: $2 \sigma^{7}, 5 \%$, from Abies concolor, Williams Canyon, Colo., May 20, 1917, and June 2 and 9, 1916, George Hofer. + , from Oeme costata in Pinus edulis, Ute Pass, El Paso Co., Colo., June 1, 1914, A. B. Champlain. o, emerged from wood together with Semanotus nicolas, Logan Canyon, Utah, April 1936, William Nye.

This species is in the Canadian and Transition zones in western North America. Adults occur throughout the growing season. It has been reared from cerambycids in Coniferae.

\section{Dolichomitus vitticrus, new species}

Figures $333, \mathrm{k} ; 354$

Male: Front wing 6 to $8.5 \mathrm{~mm}$. long; face rather narrow, with rather small, rather weak punctures whose interspaces are about 0.8 their diameter; prepectal carina weak above, often traceable to a little above midheight of hind margin of pronotum, where it curves forward to front margin of mesopleurum; propodeum rather long, with rather large, weak punctures and irregular rugulosity, its median longitudinal carinae moderately strong, moderately divergent, extending about 0.6 its length; front and middle coxae and trochanters not specialized; first tergite about 2.3 as long as wide; second tergite about 1.95 as long as wide; subgenital plate as in figure $333, \mathrm{k}$; genitalia as in figure 354 .

Black. Clypeus and mandible stained with ferruginous; scape and pedicel whitish, their outer posterior side and the base of scape dark brown; palpi, tegula, hind corner of pronotum, front and middle coxae and tibiae, and all trochanters white; front and middle femora pale fulvous, white at apex and in front; front tarsus whitish, stramineous apically; middle tarsus light brown, whitish basally; hind coxa and femur fulvous, the femur infuscate subapically, its extreme apex white; hind tibia with its basal 0.15 and under side except apically, whitish, the rest dusky, darkest apically; hind tarsus fuscous, its basitarsus pale basally.

The correct association of this male with the female described below is not certain, but seems probable.

Female: Front wing 10.4 to $15.5 \mathrm{~mm}$. long; temple rather strongly convex; median longitudinal carinae of propodeum moderately strongly divergent, extending about 0.6 the length of propodeum; first tergite about 1.65 as long as wide; second tergite about 1.2 as long as wide; punctures on tubercles of third tergite rather small and 
weak, their interspaces about half their diameter; ovipositor sheath about 1.6 as long as front wing. Structure otherwise as in the female of D. californicus.

Colored like the female of $D$. californicus except that entire upper side of front and middle tibiae is whitish.

Type: $\circ$, Cornell University Campus, Ithaca, N. Y., June 4, 1938, P. P. Babiy (Washington, USNM 63693).

Paratypes: ㅇ, Lawrence, Kans., May 24, 1941, H. K. Townes (Townes). + , Aweme, Man., June (Washington). 2ᄋ, Forest Hills, near Boston, Mass., June 1916, A. M. Wilcox (Washington). 2ᄋ, Midland Co., Mich., June 16, 1957, R. and K. Dreisbach (Dreisbach). , Big Indian Valley, Catskill Mts., N. Y., Sept. 1918 (Washington). ㅇ, Grand Island, N. Y., June 26, 1910, M. C. Van Duzee (San Francisco). $\quad \sigma^{7}$, Ithaca, N. Y., June 9, 1916 (Ithaca). 6o, Ithaca, N. Y., May 30, 1938, June 3, 1939, June 4, 1938, June 19, 1937, and July 1937, P. P. Babiy (Townes). ' , Ithaca, N. Y., June 29, 1947 (Ottawa). , Ottawa, Ont., May 30, 1941, G. S. Walley (Ottawa). $0^{7}$, Harrisburg, Pa., June 6, J. N. Knull (Washington). ơ, Deschênes, Que., June 23, 1933, G. S. Walley (Ottawa). क, Hemmingford, Que., June 15, 1926, G. H. Hammond (Ottawa). ơ', Manchester, Vt., June 8, 1910, W. Johnson (Cambridge). o , Gays Mills, Wis., June 3, 1933 (Madison).

This species occurs in the Alleghanian fauna.

\section{Dolichomitus pygmaeus (Walsh), new combination}

Figures 333,$1 ; 355$

Ephialtes pygmaeus Walsh, 1873, Trans. Acad. Sci. St. Louis, vol. 3, p. 111; . Type: + , ? Illinois (destroyed in Chicago fire of 1871).

Male: Front wing 5.4 to $6.4 \mathrm{~mm}$. long; face rather narrow, with fine punctures whose interspaces are about 0.8 their diameter; dorsal end of prepectal carina a little above midheight of hind margin of pronotum, curved forward toward front edge of mesopleurum; propodeum rather long, with medium-sized scattered punctures; median longitudinal carinae of propodeum rather strong, moderately divergent, extending most of the length of propodeum; apex of front coxa on inner side somewhat truncate and with very small, very dense, setiferous punctures; front first trochanter a little flattened below, with very small, very dense punctures; under side of front second trochanter and of base of front femur with moderately small, rather dense punctures; outer side of middle coxa with the punctures toward its base a little denser than elsewhere on the coxa, otherwise unspecialized; first tergite about 2.3 as long as wide; second tergite about 2.0 as long as wide; eighth and ninth tergites completely fused (not 


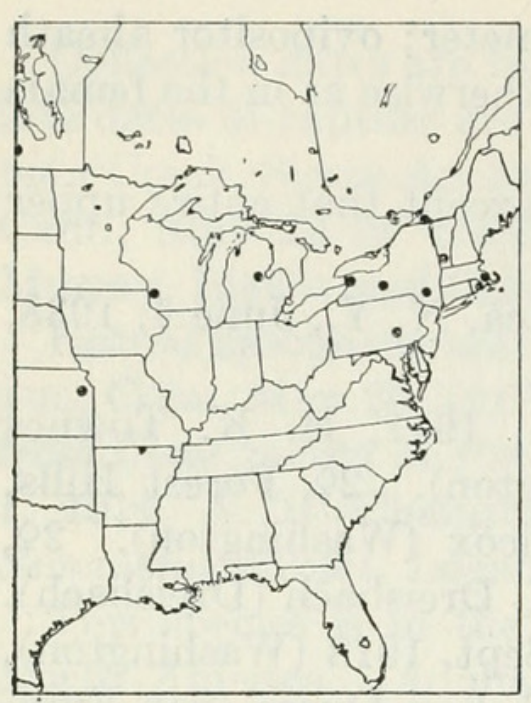

Figures 62, 63.-Localities: 62 (left), Dolichomitus vitticrus; 63 (right), D. pygmaeus

fused in the other Nearctic species of the genus); subgenital plate as in figure 333,1 ; genitalia as in figure 355 .

Black. Clypeus fulvoferruginous; mandible usually stained with ferruginous; front of pedicel and of apical margin of scape, pale yellowish; palpi, tegula, and trochanters whitish; extreme hind corner of pronotum fulvous to black; front coxa whitish, fulvous behind; middle coxa fulvous, its apex whitish; front and middle femora fulvous, whitish apically in front; front and middle tibiae whitish, more or less fulvous or pale brownish behind toward the apex; front tarsus whitish, the apical half of its last segment brownish; middle tarsus fuscous, its basitarsus stramineous basally; hind coxa fulvous; hind femur dark brown, its apical margin stramineous; hind tibia whitish on its basal 0.15 , distad of which is an obscure infuscate band that is a little paler below, distad of the fuscous band infuscate but whitish below, the apical 0.3 of tibia entirely fuscous; hind tarsus fuscous, the base of its basitarsus pale.

Female: Front wing 7 to $12 \mathrm{~mm}$. long; face moderately narrow, with rather fine punctures whose interspaces are about 1.4 their diameter; temple unusually long and swollen; propodeum rather long, a little rugulose near its median carinae and beyond the middle, its punctures rather small and sparse, the sublateral punctures separated by about their diameter; median longitudinal carinae of propodeum rather strong, moderately divergent, extending about 0.75 the length of propodeum; hind femur about 5.2 as long as deep; first tergite about 1.75 as long as wide; second tergite about 1.2 as long as wide; ovipositor sheath about 1.45 as long as front wing. Structure otherwise as described for female of $D$. californicus. 
Black. Clypeus fulvoferruginous; mandible sometimes stained with ferruginous; maxillary palpus white, its basal segment brown; labial palpus brown; tegula white; extreme hind corner of pronotum black to brownish fulvous; coxae fulvous; first trochanters pale fulvous; second trochanters whitish and pale fulvous; front and middle femora fulvous, yellowish at apex in front; front tibia fulvous, its basal 0.15 pale stramineous, beyond which is a faint fuscous band, then a paler area, then fulvous to the apex; middle tibia repeating colors of front tibia but a little darker, its apical part light brown; front tarsus stramineous, its apex brown; middle tarsus brown; hind femur fulvous to brown, with always at least a subapical infuscation, its extreme apex stramineous; hind tibia with its basal 0.15 whitish, beyond which is a dark brown band, then medium brown with its apical 0.33 dark brown; hind tarsus fuscous, the base of its basitarsus light brown.

The type of Ephialtes pygmaeus Walsh has been destroyed, so the application of the name must be determined from the description. This description seems applicable to either a large specimen of the species above or to a small specimen of $D$. vitticrus, but more likely to the present species because Walsh does not mention the white stripe on the upper side of the front and middle tibiae, which is characteristic of $D$. vitticrus.

The genitalia and subgenital plate of this species have some features in common with those of $D$. sericeus, indicating a possible relationship between the two.

Specimens (3 $\left.\sigma^{7}, 37 \%\right)$ : From British Columbia (Nanaimo Biological Station and Wellington); California (Chester); Maryland (Bowie); Michigan (Brevort, Dickinson Co., and Gull Lake Biological Station in Kalamazoo Co.); New Hampshire (Pinkham Notch); New York (Allegheny Park, Ithaca, and Rock City in Cattaraugus Co.); North Carolina (Forney Creek in Great Smoky Mountains National Park and Mount Pisgah at 5,000 to 5,749 ft.); Ontario (Constance Bay); Oregon ("Boyer," and Diamond Lake in Douglas Co.); Pennsylvania (Furnace); and West Virginia (Cheat Mt. at 2,000 ft. in Randolph Co.).

Collecting records for the three males are June 8 at Brevort, Mich.; June 24 at Bowie, Md.; and August 1 in Allegheny Park, N. Y. Records for females are from June 9 to August 1, except for six records as follows: May 22 at Ithaca, N. Y.; May 26 at Wellington, B. C.; May 30 at Constance Bay, Ont.; August 5 at Gull Lake Biological Station, Kalamazoo Co., Mich.; August 22 in Dickinson Co., Mich.; and September 5 at 5,000 to 5,749 ft. on Mount Pisgah, N. C.

A female was taken from borings of Plectrura spinicauda at Wellington, B. C., July 23, 1947, by Richard Guppy.

This species is transcontinental in the Transition zone. 


\section{IMPERATOR GROUP}

Median segments of male flagellum not widened; punctures (and hairs) on face of male only moderately dense, the punctures of medium size except near eye, where they are small; interspaces of facial punctures of male about equal to their diameters; punctures on face of female moderately coarse, separated by about 1.0 to 2.0 their diameter; pronotum entirely black or its hind corner white or pale; prepectal carina extending dorsad to near midheight of hind margin of pronotum, then curved forward toward front edge of mesopleurum; lower half of mesepimeron almost bare, with a few hairs near its hind margin above; front and middle coxae and trochanters of male not specialized, the hair on the outer side of the middle coxa not unusually dense; nervellus broken above the middle; ovipositor sheath about 1.9 to 2.3 as long as front wing; ovipositor unusually slender, the dorsal lobe of its ventral valve rather small with two widely spaced subvertical ridges (fig. 330, g).

This group includes the two Holarctic species described below and two Japanese species, one undescribed and one named Ephialtes manifestator var. matsumurai by Uchida in 1928, and again in 1936 by Uchida as Ephialtes nonmanifestator. Dolichomitus matsumurai (new combination) seems to be a distinct species, close to $D$. imperator.

\section{Dolichomitus pterelas (Say), new combination}

\section{Figures $333, \mathrm{~m} ; 356$}

Ichneumon (Pimpla) pterelas Say, 1829, Contr. Maclurian Lyceum Arts Sci., Philadelphia, vol. 1, p. 71 (Leconte ed., vol. 1, p. 376); + Type: , Indiana (destroyed).

Male: Front wing 6.7 to $10.0 \mathrm{~mm}$. long; propodeum without distinct median longitudinal carinae; first tergite about 2.4 as long as wide, about 1.1 as long as second tergite; second tergite about 2.0 as long as wide; subgenital plate as in figure $333, \mathrm{~m}$; genitalia as in figure 356.

Black. Front of scape and pedicel, palpi, tegula, and extreme hind corner of pronotum, whitish; flagellum brown beneath; front and middle legs whitish (sometimes partly tinged with fulvous), their femora more or less fulvous behind except at apex, the middle tarsus brown apically; hind coxa fulvous; hind trochanters whitish; hind femur fulvous with a subapical infuscate band, its extreme apex whitish; hind tibia light brown to fuscous, its basal 0.2 and more or less of its under side toward base, whitish; hind tarsus fuscous or brown, the base of its basitarsus stramineous.

Female: Front wing 9.5 to $16 \mathrm{~mm}$. long; face of moderate width, its punctures separated by about 2.0 their diameter; median longi- 
Figure 64.-Localities for Dolichomitus pterelas.

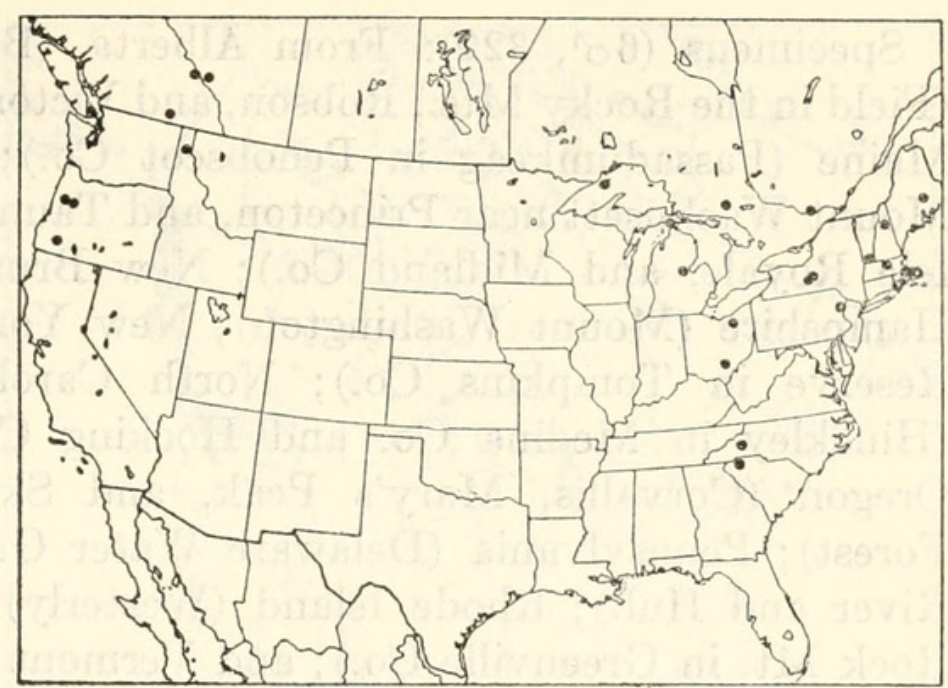

tudinal carinae of propodeum divergent, obsolescent, distinct only on basal 0.15 to 0.4 of the propodeum; abdomen narrow at base, the rest much broader; first tergite about 1.7 as long as wide, about 1.1 as long as second tergite; second tergite about 1.1 as long as wide, about 0.7 as wide at base as at apex; third tergite polished, its tubercles rather prominent, covered with moderately coarse punctures whose interspaces are about equal to their diameter; ovipositor sheath about 1.5 as long as front wing; tip of lower valve of ovipositor as in $D$. imperator (fig. $330, \mathrm{~g}$ ).

Black. Clypeus and mandible more or less stained with ferruginous; scape and pedicel fulvous to brown or black in front; under side of flagellum dark brown; palpi stramineous or the labial palpus often brown; tegula white; hind corner of pronotum fulvous; coxae and femora fulvous, the apex of hind femur infuscate and its extreme apex fulvous; front trochanters whitish; front tibia and tarsus pale fulvous; middle trochanters pale fulvous, the second trochanter the paler; middle tibia and tarsus fulvous, the base of the tibia yellowish fulvous and the tarsus tinged with brown; hind tibia and tarsus reddish brown to fuscous, the basal 0.2 of the tibia fulvous.

The male of this species has the scape and pedicel entirely white in front and the propodeum without median carinae. The female has only two ridges on the lobe of the lower valve of the ovipositor and the abdomen strongly tapered basally, polished, and with moderately coarse punctures.

We have two females from Japan which may represent a subspecies or a distinct species. They have the coxae black and some additional, less conspicuous, color differences.

The type of Ichneumon pterelas Say is destroyed. The original description agrees with $D$. pterelas as determined here, and probably as well with some others. We hereby restrict the name to the species described as $D$. pterelas above. 
Specimens $\left(6 \sigma^{7}, 32\right.$ ) : From Alberta (Banff); British Columbia (Field in the Rocky Mts., Robson, and Victoria); Idaho (Priest Lake); Maine (Passadumkeag in Penobscot Co.); Massachusetts (Minot, Mount Wachusett near Princeton, and Taunton); Michigan (Brevort Isle Royale, and Midland Co.); New Brunswick (St. John); New Hampshire (Mount Washington); New York (Ithaca, and McLean Reserve in Tompkins Co.); North Carolina (Black Mts.); Ohio (Hinckley in Medina Co. and Hocking Co.); Ontario (Sudbury); Oregon (Corvallis, Mary's Peak, and Skillet Creek in Umpqua Forest); Pennsylvania (Delaware Water Gap); Quebec (Cascapedia River and Hull); Rhode Island (Westerly); South Carolina (Table Rock Mt. in Greenville Co.); and Vermont (Laurel Lake near Jacksonville). We also have five females from several localities in Germany.

Dates of capture begin in early summer and extend well into the fall. The three earliest and latest dates are: June 8 at Brevort, Mich.; June 11 at Westerly, R. I.; June 17 in the Black Mts., N. C.; September 28 in Hocking Co., Ohio; October 3 at St. John, N. B. and at Robson, B. C.; and October 28 at Table Rock Mt., Greenville Co., S. C.

This is a Holarctic species. In America it is mostly in the Transition zone. It is adult from early summer into the fall. There are no rearing records.

\section{Dolichomitus imperator (Kriechbaumer), new combination}

\section{Figures $330, \mathrm{~g} ; 333, \mathrm{n} ; 357$}

Ephialtes imperator Kriechbaumer, 1854, Ent. Zeitung Stettin, vol. 15, p. 156; . Type: \&, Germany (?Munich).

Ephialtes occidentalis Cresson, 1865, Proc. Ent. Soc Philadelphia, vol. 4, p. 269;. Type: $\&$, Colorado (Philadelphia).

Male: Front wing 8 to $13 \mathrm{~mm}$. long; median longitudinal carinae of propodeum ridgelike, extending more than half the length of propodeum; first tergite about 2.5 as long as wide, about 1.0 as long as second tergite; second tergite about 2.1 as long as wide; subgenital plate as in figure $333, \mathrm{n}$; genitalia as in figure 357 .

Black. Clypeus and mandible stained with ferruginous; apical margin of scape light brown in front; palpi stramineous, their basal segments mostly blackish; tegula pale yellow or pale fulvous; extreme hind corner of pronotum fulvous; front and middle legs light yellowish fulvous, their coxae fulvous and their femora fulvous except more or less of their front side and apex; hind coxa, trochanters, and femur fulvous, the femur somewhat infuscate apically, its apical margin paler; hind tibia and tarsus fuscous, the basal 0.15 of hind tibia stramineous. 
Figure 65.-Localities for Dolichomitus imperator.

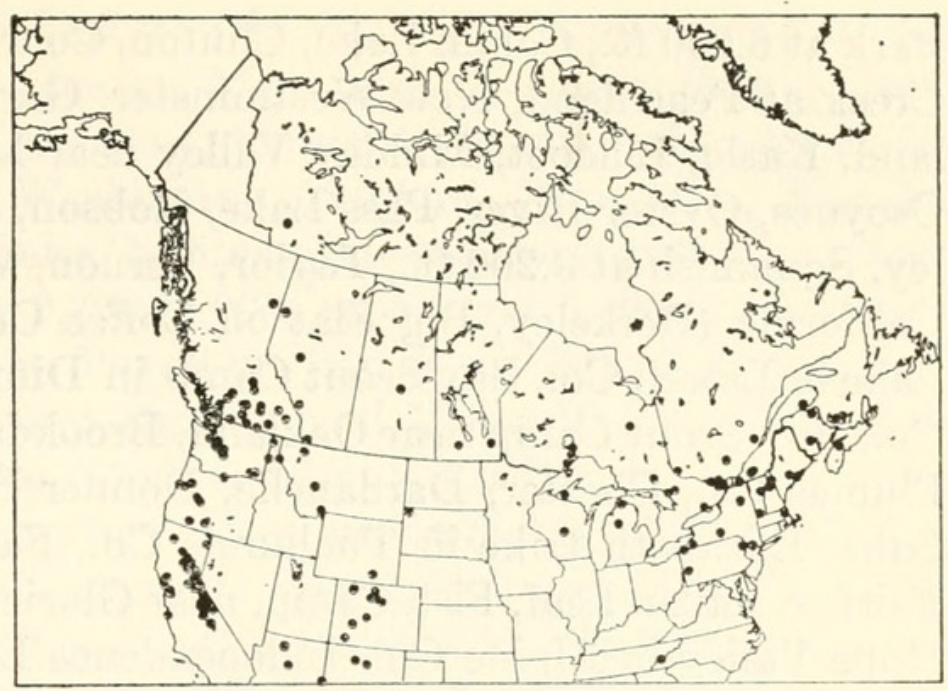

Female: Front wing 10 to $20 \mathrm{~mm}$. long; face rather narrow, weakly narrowed ventrad, its punctures separated by about 1.5 their diameter; median longitudinal carinae of propodeum ridgelike, subparallel, distinct on the basal 0.4 or more of propodeum; abdomen unusually long and parallel-sided; first tergite about 2.5 as long as wide and about 0.95 as long as second tergite; second tergite about 2.0 as long as wide, about 0.85 as wide at base as at apex; third tergite mat with fine, irregular, transverse aciculation, its tubercles rather flat, long-oval, covered with small, indistinct, weak punctures whose interspaces are about equal to their diameter; ovipositor sheath about 2.25 as long as front wing; tip of lower valve of ovipositor as in figure $330, \mathrm{~g}$.

Black. Clypeus and mandible stained with ferruginous; palpi brown, their basal segments mostly blackish; tegula and small hind corner of pronotum fulvous; front and middle legs fulvous, their femora apically in front and their tibiae in front yellowish fulvous; hind coxa, trochanters, and femur fulvous, the apex of femur infuscate, its apical margin paler; hind tibia and tarsus dark reddish brown, the tibia fulvous basally; wings often tinged with reddish brown.

The long, narrow abdomen with very long first tergite, fine, weak, irregular aciculation, and fine weak punctures are distinctive of females of this species. The length and slenderness of the abdomen are variable, however, and when the abdomen is relatively short and stout the ovipositor tip and the shape and punctation of the face are needed for confirmation of a determination. The male is most easily distinguished by its tapered genital clasper and the scape that has only its apical margin pale.

Specimens $\left(138 \sigma^{\top}, 284\right.$ ) : From Alaska (Glacier near Skagway at $6,000 \mathrm{ft}$. and Seward); Alberta (Banff, Beaverlodge, Wabamun, and Waterton Lakes National Park); Arizona (near Alpine, Flagstaff, Grand Canyon, and Mount Lemmon in the Santa Catalina Mts. at $9,150 \mathrm{ft}$. ); British Columbia (Adams Lake, Blackwater in Manning 
Park at 6,000 ft., Canim Lake, Clinton, Courtenay, Cultus Lake, Deep Creek at Peachland, New Westminster, Garnet Valley near Summerland, Kaslo, Lillooet, Midday Valley near Merritt, Nanaimo, Nicola, Osoyoos, Oyster River, Pass Lake, Robson, Salmon Arm, Skagit Valley, Squamish at 3,200 ft., Taylor, Vernon, Victoria, and Wellington); California (Berkeley, Big Flat on Coffee Creek in Trinity Co., Blue Lake in Lassen Co., Boy Scout Camp in Dimond Canyon in Alameda Co., Boy Scout Camp near Oakland, Brookdale Lodge, Buck's Lake in Plumas Co., Chester, Dardanelle, Donner Pass, East Oakland, Echo Lake, Elizabeth Lake in Tuolumne Co., Faith Valley in Alpine Co., Fairfax, Fallen Leaf, Fish Camp, near Glacier Point in Yosemite Park, Hope Valley in Alpine Co., Independence Lake in Sierra Co., Lassen National Park, Leevining, Lone Pine, Mammoth Lakes, 3 miles north of Manzanita Lake in Shasta Co., May Lake at 10,500 ft. in Yosemite Park, Meadow Valley in Plumas Co., Mesa Grande in Sonoma Co., Meyers, Mono Lake at 9,700 ft., Muir Woods, Oakland, Hills back of Oakland, Onion Valley in Plumas Co., Pebble Beach, Pollock Pines, Portola, Sagehen near Hobart Mills, Smoky Jack Camp in Yosemite Park, Snow Flat in Yosemite Park at 8,700 ft., near Sonora Pass at $8,500 \mathrm{ft}$., Viola, 5 miles east of Webber Lake in Sierra Co., and Wright's Lake in El Dorado Co.); Colorado (Durango, near Estes Park, Lake City, Nelson Rock in Peaceful Valley in Boulder Co., Phantom Valley at 9,400 ft. in Rocky Mountain National Park, Pingree Park in Larimer Co., Steamboat Springs, Tennessee Pass at 10,240 ft., and Waldo Canyon); Idaho (Hauser Lake, "Moores Lake," Priest Lake, and Wallace); Maine (Augusta and Lincoln Co.); Manitoba (Sandilands on the Dawson Road and Onah); Massachusetts (Forest Hills); Michigan (Cheboygan Co., Douglas Lake, Isle Royale, Lake City, and Lake Gogebic in Ontonagon Co.); Montana (Helena, Rock Creek and Madison River in Gallatin National Forest, and Summit Station at 5,200 ft. in Glacier National Park); New Brunswick (Bathurst and Fredericton); New Hampshire (Dolly Copp Camp in the White Mts. and Franconia); New Jersey (Greenwood Lake); New Mexico (Beulah at $8,000 \mathrm{ft}$. and Jemez Springs); New York (Bemus Point, Ithaca, and Mount Marcy); Northwest Territories (Fort Simpson); Nova Scotia (Kentville); Ontario (Burks Falls, Harold, Macdiarmid on Lake Nipigon, Merivale, Nipigon, Ottawa, Smoky Falls on the Mattagami River, Sudbury, Thunder Bay Beach, and Waubamik); Oregon (Albany, Bly, Horse Lake in the high Cascade Mts. of Lane Co., Lake of the Woods in Klamath Co., Mary's Peak at 4,950 ft., Rufus, Talent, and Yachats); Pennsylvania (North East, Paupack, and Wall); Prince Edward Island (Brackley Beach and Dalvay House in Canadian National Park); Quebec (Aylmer, Brome, Cascapedia, Covey Hill, Knowlton, Laniel, Montigny, Norway Bay, and Stoneham); Saskatchewan 
(Christopher Lake); South Dakota (Harding Co.); Tennessee (Ramsay Cascades Trail in Great Smoky Mountains National Park); Utah (Lambs Canyon in Salt Lake Co.); Vermont (Laurel Lake near Jacksonville and Plainfield); Washington (Ashford, Blue Mts., Kanaka Bay on San Juan Island, Lake Cushman, Mount Constitution on Orcas Island, Mount Rainier at 2,700, 2,900, 4,700, and 5,000 ft., Paradise Valley on Mount Rainier, Puyallup, San Juan Island, Spanaway, Summerland Trail on Mount Rainier, and Walla Walla); Wisconsin (Wood Co.); and Wyoming (Centennial at 8,000 ft.).

The great majority of capture dates are from May 20 to July 31 . The few records outside of this range are: April 1 and May 12 and 15 at Robson, B. C.; April 12 at Fairfax, Marin Co., Calif.; April 17 at Berkeley, Calif.; April 20 at Spanaway, Wash.; April 24 at lthaca, N. Y.; April 28 at Brookdale Lodge, Calif.; April 30 at Oakland, Calif.; May 16 at Merivale, Ont.; "August" at Oakland, Calif., at Priest Lake, Idaho, and at Walla Walla, Wash.; August 6 at Helena, Mont.; August 12 at 6,000 ft. in Manning Park, Blackwater, B. C.; August 15 at 3,200 ft. on Diamond Head Trail, near Squamish, B. C.; and October 22 at Robson, B. C.

Reared specimens are as follows: + , labeled "parasitic on larva $S m$. ophthalm." $\sigma^{7}$, reared from Pinus ponderosa infested with Asemum nitidum and Xiphydria sp., Talent, Oreg., May 14, 1913, B. T. Harvey. Other lots are labeled "Abies magnifica," "Pinus murrayana," "P. scopulorum," and "P. ponderosa" (two lots). Presumably these were reared from or collected on these kinds of trees. In our own collecting we have found the species common in coniferous woods.

This species is Holarctic. In America it is transcontinental in the Hudsonian, Canadian, and Transition zones, where it is often common in coniferous forests. It is adult mostly from late May to the end of July. The usual hosts appear to be borers in conifers, particularly Pinus, but definite rearing records are very scanty.

\section{SERICEUS GROUP}

Median segments of male flagellum enlarged, about twice as wide as the basal segments; basal rim of clypeus unusually strongly elevated and set off from rest of clypeus and with an unusually well-developed row of long, suberect hairs; temple moderately swollen; pronotum entirely black; dorsal end of prepectal carina slanted toward and almost reaching front edge of mesopleurum, ending at a level just above middle of hind margin of pronotum; thorax with exceptionally long, dense hair; mesepimeron with long hairs all over; nervellus broken above the middle; hind femur of female about 5.4 as long as deep; ovipositor sheath about 1.95 as long as front wing; dorsal lobe near 
tip of lower valve of ovipositor rather abruptly tapered posteriorly, with about six vertical ridges (fig. $330, \mathrm{~h}$ ).

This group includes the one Holarctic species described below.

\section{Dolichomitus sericeus (Hartig), new combination}

\section{Figures 330 , h; 333,o; 358}

Closterocerus sericeus Hartig, 1847, Ber. Naturw. Ver. Hartz for 1846, p. 18; $\sigma^{7}$. Type: $\sigma^{7}$, Claus Valley, Hartz Mts., Germany (lost).

Male: Front wing 9.1 to $11.5 \mathrm{~mm}$. long; face of moderate width, with fine, dense, sharp punctures; median segments of flagellum strongly swollen and slightly flattened, the swelling including about the seventh to nineteenth segments, the greatest swelling on about the thirteenth to seventeenth segments, which are about 0.85 as long as wide and about twice as wide as the basal flagellar segments; first trochanter of front leg concave anteroventrally; outer side of middle coxa with fine dense hairs, concave but with a postmedian transverse compressed tubercle; first tergite about 1.75 as long as wide; second tergite about 1.55 as long as wide; subgenital plate as in figure 333,0; genitalia large, as in figure 358 .

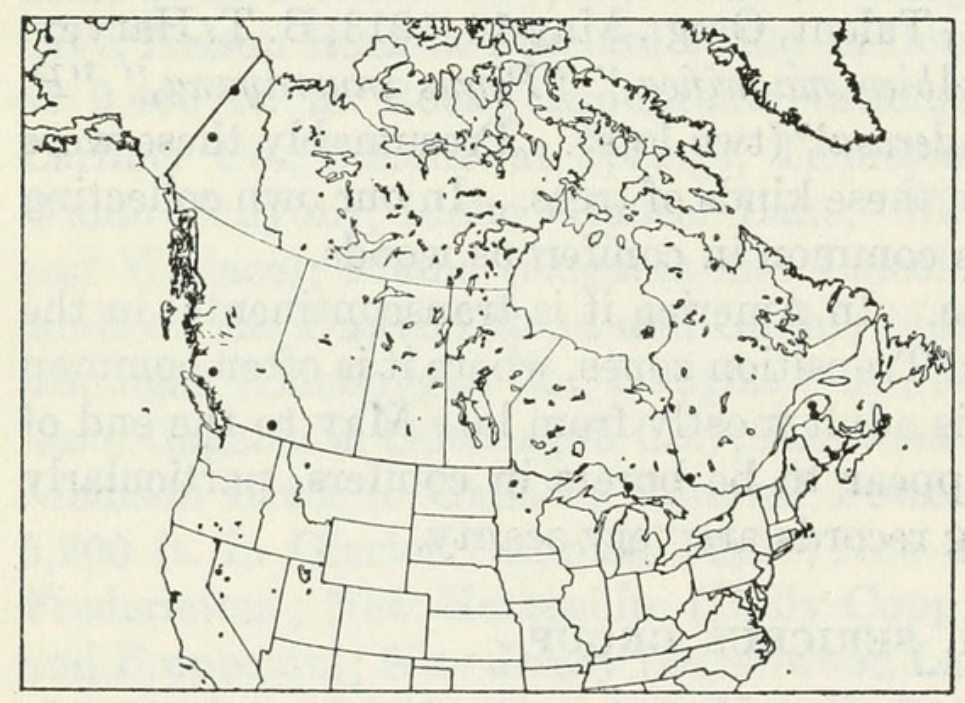

Figure 66.--Localities for Dolichomitus sericeus.

Black. Clypeus and mandible ferruginous; large spot on under side of scape pale yellow; swollen part of flagellum stramineous below, brown above, the incisures between the wider segments with a median blackish spot extended laterally as a black stripe; palpi and tegula white; front and middle legs light fulvous, their front side, trochanters and front tarsus entirely, and the basal 0.2 of their tibiae pale yellow, the middle tarsus somewhat brownish; hind coxa fulvous; hind trochanters pale yellow; hind femur fulvous, infuscate above and apically; hind tibia brown,its underside and basal 0.2 stramineous; hind tarsus brown. 
Female: Front wing 13 to $14 \mathrm{~mm}$. long; first tergite about 1.50 as long as wide; second tergite about 1.35 as long as wide; third tergite with moderately swollen tubercles, polished and covered with moderate-sized sharp punctures, separated by about 1.0 their diameter; ovipositor sheath about 1.95 as long as front wing; tip of lower valve of ovipositor as in figure 330 ,h.

Black. Clypeus, mandible, and often a tinge on lower part of cheek, ferruginous; maxillary palpus pale stramineous, its first segment mostly blackish; labial palpus brown; tegula stramineous; mesosternum and lower part of mesopleurum often somewhat fulvous or tinged with fulvous; front and middle legs fulvous, the middle tarsus tinged with brown; hind coxa and trochanters fulvous; hind femur dark brown, its base fulvous, its lower half more or less tinged with fulvous; hind tibia fuscous, its basal 0.15 whitish, its lower edge brown; hind tarsus dark brown.

The mesepimeron completely covered with hair and the medially thickened male antenna are recognition characters of this species.

This species was described from a single male. The type is lost. We have seen a second European male, from Prague (Vienna museum). Comparison of this with a Nearctic male disclosed no basis for even a subspecific separation of the Nearctic population.

Specimens: + , Ketchikan, Alaska (Pittsburgh). $\odot$, on ice, Mystery Mt. (Mount Waddington), B. C., Aug. 6, 1927, Mundy (Washington). , Robson, B. C., Aug. 22, 1950, H. R. Foxlee (Ottawa). , ovipositing on buprestid borer in Picea, St. John, N. B., Sept. 24, 1910 (Ottawa). $\sigma^{7}$, o, Frater, Ont., June 13, 1925, H. Fleming and E. B. Watson (Townes and Ottawa). o, Cascapedia River, Que., July 16, 1934,

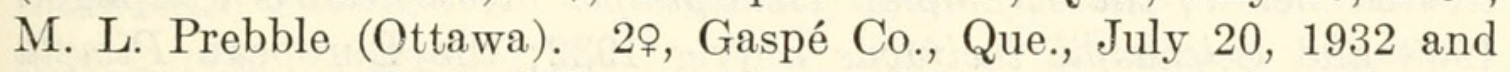
Aug. 15, 1933, E. B. Watson (Ottawa). $2 \sigma^{7}$, reared from log of Picea canadensis infested by Tetropium cinnamopterum, Laniel, Que., June 19 and 20, 1933 (Ottawa). o, Mount Lyall, 1,500 ft., Que., Aug. 11, 1933, W. J. Brown (Ottawa). o, Dawson, Yukon, Sept. 5, 1912, J. M. Jessup (Washington). 2ㅇ, Rampart House, Yukon, Aug. 25 to 29, 1912, J. M. Jessup (Washington).

This Holarctic species is very rare in Europe and uncommon in America. In America it is transcontinental in the Canadian zone.

\section{Acropimpla, new genus}

Figure 289, a

Selenaspis Roman, 1910, Ent. Tidskr., vol. 31, p. 191. Name preoccupied. Type: Hemipimpla alboscutellaris Szépligeti; original designation.

Front wing 3.5 to $11.5 \mathrm{~mm}$. long; body moderately long and slender; clypeus and often more or less of face of male white or yellow, the 
clypeus definitely convex with its apex impressed and with a deep median apical notch; frons black or concolorous with rest of head; occipital carina complete, dipped a little on the midline, in a Philippine species obsolete near the midline; hair on mesoscutum moderately dense, evenly distributed; submetapleural carina complete; propodeum rather short and convex, basally with or without median longitudinal carinae; areolet triangular, oblique, receiving second recurrent vein at its outer corner or sometimes (as in the Nearctic A. pronexus) a little before its outer corner, sometimes the areolet lacking (as in some Ethiopian species and occasionally in Nearctic specimens); nervellus broken below the middle; first tergite short and broad, its lateral and median longitudinal carinae rather strong; second tergite with short, moderately strong, oblique grooves cutting off its laterobasal corners; third and fourth tergites with distinct tubercles, their apical impunctate band occupying about 0.2 their length; subgenital plate usually completely sclerotized but sometimes with a median basal membranous area; ovipositor straight, compressed, its apex as in figures $330, \mathrm{i}$ and 331 , a (the point slender, usually concave above, and the ridges of its basal teeth very oblique); ovipositor sheath 0.4 to 0.7 as long as front wing.

Genotype: Charitopimpla leucostoma Cameron. It is our intention that leucostoma be the type species of the new genus Acropimpla and also to indicate that the unavailable name Selenaspis applies to the same zoological group as Acropimpla.

Most species of this genus are in the Oriental region and eastern Palaearctic. The species we include in it are the two Nearctic species treated below; the Ethiopian Hemipimpla alboscutellaris Szépligeti 1908 and Selenaspis lucifugus Seyrig 1932; the European Pimpla pictipes Gravenhorst 1829 and P. didyma Gravenhorst 1829; Pimpla yezoensis Matsumura 1926, from Japan; Charitopimpla leucostoma Cameron 1907, from the Oriental region; Pimpla latifoveata Cameron 1899, P. bicarinata Cameron 1899, Charitopimpla flavoscutis Cameron 1907, and C. nigroscutis Cameron 1907, from India; Charitopimpla nigrescens Cushman 1933, and C. uchidai Cushman 1933, from Formosa; and seventeen undescribed or undetermined species from the Oriental region and eastern Palaearctic. All of these are new combinations in Acropimpla. Exeristes pulchella Morley 1913, and Epiurus taiwanensis Uchida 1928, are synonyms of leucostoma (new synonymies).

The European species pictipes, an undescribed species from Japan, and the two Nearctic species form a compact group, not all of which may be specifically distinct. This group is more Scambus-like than most species of Acropimpla in coloration, more swollen temples, and more elongate body. 


\section{Key to the Nearctic species of Acropimpla}

1. Apical part of male clasper short (fig. 359); ovipositor preapically with an even dorsal curvature (fig. 330,i); second recurrent vein usually conspicuously before outer end of areolet; apical fuscous area on hind femur occupying about 0.25 the length of the femur, not sharply limited basally (fig. 321,h).

1. pronexus, new species

Apical part of male clasper long (fig. 360); ovipositor preapically with a weak dorsal angle (fig. 331,a); second recurrent vein usually at or very near outer end of areolet; apical fuscous area on hind femur occupying about 0.15 the length of the femur, sharply limited basally (fig. 321 ,i).

2. alboricta (Cresson)

\section{Acropimpla pronexus, new species}

Figures $321, \mathrm{~h} ; 330, \mathrm{i} ; 359$

Front wing 4.0 to $7.7 \mathrm{~mm}$. long. Similar to $T$. alboricta except in the characters mentioned in the key. The black bands on the hind tibia are rather frequently connected ventrally by a brownish stripe.

This new species is very close to $A$. alboricta but is certainly distinct. We are indebted to G. S. Walley for calling our attention to it, and for supplying most of the specimens on which the description is based.

Type: $\sigma^{\top}$, reared from Glypta fumiferanae, Searchmont, Ont., emerged in incubator Feb. 19, 1944, W. R. Brown (Ottawa).

Paratypes: $\sigma^{7}$, Beaverlodge, Alta., June 21, 1931, E. H. Strickland (Townes). $2 \sigma^{x}$, reared from Choristoneura fumiferana, Kootenay Park, B. C., 1943 (Ottawa). \&, reared from Choristoneura fumiferana, Monashee Summit, B. C., Feb. 26, 1945 (Ottawa). \&, Summers Creek near Princeton, B. C., June 1938, J. M. Fraser (Ottawa). $0^{\top}, 2$, reared from overwintering foliage of Abies, Charlo, N. B., April 1955, D. R. Macdonald (Ottawa). $\sigma^{7}$, Narrows Brook, N. B., July 15, 1955 (MacDonald). ণ , ং, Nictau, N. B., June 15, 1955 and

Figure 67.-Localities for Acropimpla pronexus.

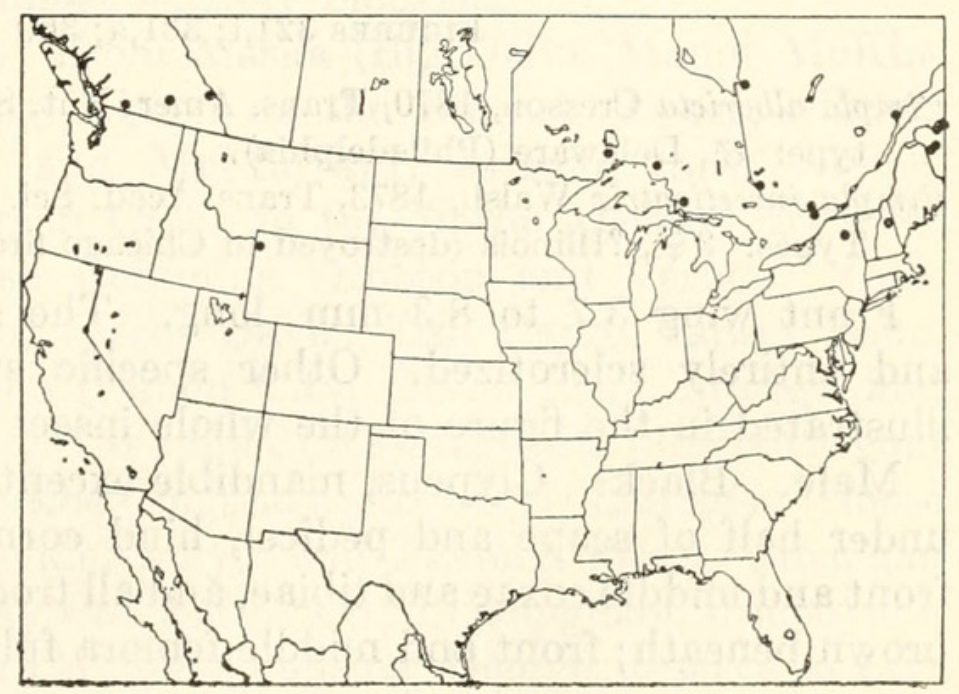


July 12, 1955 (MacDonald). $\sigma^{\top}$, reared from Choristoneura fumiferana, Ritchie Brook, N. B., July 23, 1955, D. R. Macdonald (Ottawa). ๑, "Thom," N. B., Aug. 14, 1915, A. B. Baird (Ottawa). $2 \sigma^{\top}$, reared from overwintering foliage of Abies, Tobique, N. B., April 1955, D. R. Macdonald (Ottawa). $0^{x}$, reared from overwintering foliage of Abies, Upsalquitch, N. B., April 1955, D. R. Macdonald (Ottawa). o, Bigelow Lawn, Mount Washington at 5,400 ft., N. H., Aug. 8, 1954, Becker, Monroe, and Mason (Ottawa). $\sigma^{7}$, reared from Choristoneura fumiferana, Saranac Lake, N. Y., Mar. 31, 1948 (Washington). 7우 (2 of these labeled "flying about Picea"), Bells Corners, Ont., June 24 and 25, 1935 and Aug. 2, 1941, G. S. Walley (Ottawa). o, reared from Choristoneura fumiferana, Hurkett, Ont., July 22, 1947 (Ottawa). \&, reared from Choristoneura fumiferana, Mobert, Ont., July 21, 1948 (Ottawa). $\sigma^{7}$, reared from Glypta fumiferanae, Searchmont, Ont., Feb. 20, 1944, W. R. Brown (Ottawa). ㅇ, "Twp. 30," Ont., Aug. 19, 1943 (Ottawa). ㅇ, Forestville, Que., Aug. 11, 1950, R. de Ruette (Ottawa). 2甲, Laniel, Que., June 24, 1944 and July 4, 1944, A. R. Brooks (Ottawa). o, Rupert House, Que., July 19, 1949, D. P. Gray (Ottawa). ㅇ, Wakefield, Que., June 21, 1946, G. S. Walley (Ottawa). क, Bechler River, Yellowstone, Wyo., July 27, 1929, R. E. Balch (Washington). ㅇ, reared from Choristoneura fumiferana, collected July 16, 1953, emerged July 18, 1953 (Ottawa).

Considering the host records cited and the results of the more careful rearing work, it seems likely that this species is never a primary parasite of Choristoneura fumiferana but a secondary, with Glypta fumiferanae as its primary host.

This species is transcontinental in the Canadian zone. It has been collected as an adult from June 21 to August 19. Its host is Glypta fumiferanae.

\section{Acropimpla alboricta (Cresson), new combination}

Figures $321, \mathrm{i} ; 331, \mathrm{a} ; 360$

Pimpla alboricta Cresson, 1870, Trans. Amer. Ent. Soc., vol. 3, p. 147; б. Lectotype: $\sigma^{7}$, Delaware (Philadelphia).

Pimpla investigatrix Walsh, 1873, Trans. Acad. Sci. St. Louis, vol. 3, p. 142; .

Types: 3 q, ? Illinois (destroyed in Chicago fire of 1871).

Front wing 3.7 to $8.3 \mathrm{~mm}$. long. The subgenital plate is large and entirely sclerotized. Other specific structural characters are illustrated in the figure of the whole insect or described in the key.

Male. Black. Clypeus, mandible except at base and apex, palpi, under half of scape and pedicel, hind corner of pronotum, tegula, front and middle coxae and tibiae, and all trochanters, white; flagellum brown beneath; front and middle femora fulvous, their apex whitish; 
front and middle tarsi whitish with fulvous tinges, the apical half of last segment of middle tarsus fuscous; hind coxa and femur fulvous, the femur with an apical fuscous area occupying about 0.15 its length, the extreme apex narrowly white; hind tibia white, with moderately wide, sharply defined black bands, the bands usually not connected ventrally by a brownish stripe; hind tarsus white, the segments with a blackish apex, the last segment almost entirely black.

Figure 68.-Localities for Acropimpla alboricta.

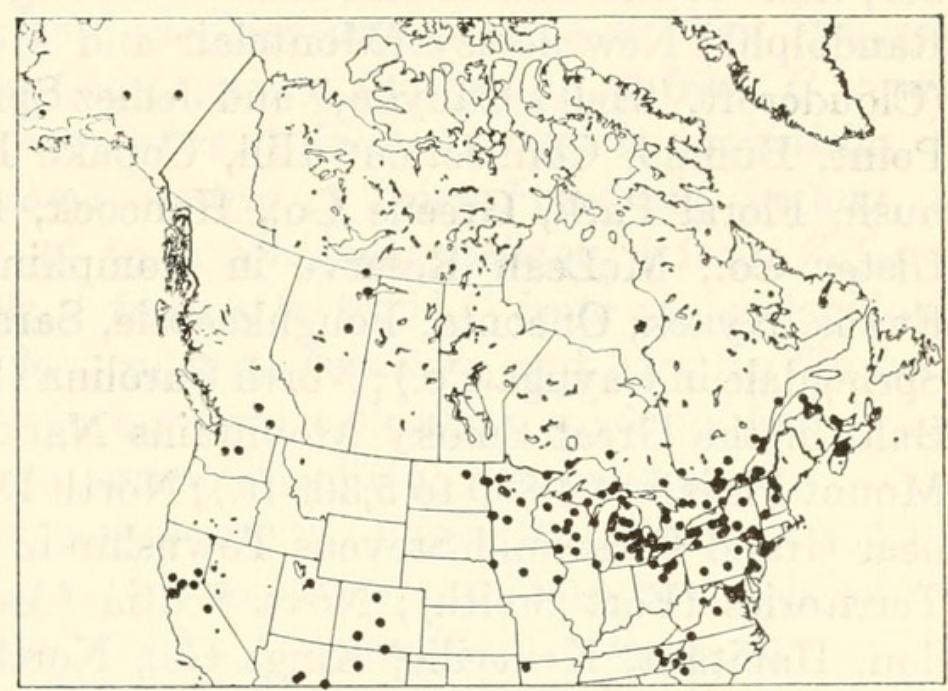

Female. Black. Clypeus dark brown; palpi white to light brown, the apex of labial palpus darker; pedicel and flagellum reddish brown beneath; hind corner of pronotum and tegula white; front and middle legs fulvous, the apex of their femora whitish and their trochanters, especially the front of front trochanters, more or less white or whitish; hind coxa, trochanters, and femur fulvous, the femur with its apical $0.15 \pm$ fuscous, its extreme apex stramineous; hind tibia white, with sharply defined moderately wide black bands, the bands sometimes connected ventrally by a light brown stripe; hind tarsus whitish or light brown, the apex of each segment very broadly blackish, the last two or three segments almost entirely blackish.

Specimens $\left(78 \sigma^{7}, 274\right.$ ) $)$ : From Alaska (Big Delta, Mount McKinley at 1,600 ft., and King Salmon on the Naknek River); Alberta (Chipewyan, Edmonton, and McMurray); Arizona (near Alpine, Parker Creek and Workman Creek in the Sierra Ancha); Arkansas (Washington Co.); British Columbia (Robson and Vernon); California (Berkeley, Camino, Cisco, Davis, Fish Camp, Lower Lake, and Sacramento); Colorado (Canon City, Grand Lake, Morley, and Pagosa Springs); District of Columbia (Washington); Illinois (Algonquin); Iowa (Ames, Muscatine Co., and Sioux City); Labrador (Goose Bay); Maryland (Hughesville, Mayo, and Takoma Park); Michigan (Alger Co., Ann Arbor, Bay Co., Benzie Co., Birmingham, Cheboygan Co., Clare Co., Dickinson Co., East Lansing, George Reserve in Liv- 
ingston Co., Gogebic Co., Gull Lake Biological Station in Kalamazoo Co., Isabella Co., Lapeer Co., Leelanau Co., Luce Co., Mackinac Co., Manistee Co., Mecosta Co., Midland Co., Missaukee Co., Saginaw Co., Sanilac Co., Shiawassee Co., Wayne Co., and Whitefish Point in Chippewa Co.); Minnesota (Crookston, Itasca Park, Kawishiwi River, Lake Itasca, Mille Lacs, Plummer, Pope Co., and Traverse Co.); New Brunswick (Charlo and Pokemouche); New Hampshire (Center Harbor, Lake of the Clouds on Mount Washington, Pinkham Notch, and Randolph); New Jersey (Montclair and Moorestown); New Mexico (Cloudcroft, "Hell's Canyon," and Jemez Springs); New York (Bemus Point, Buffalo, Connecticut Hill, Copake Falls, Farmingdale, Flatbush, Floral Park, Greene Co., Hancock, Ithaca, Lake Mohonk in Ulster Co., McLean Reserve in Tompkins Co., Millwood, North Evans, Nyack, Oneonta, Poughkeepsie, Saranac, Shokan, Sodus, and Springdale in Cayuga Co.) ; North Carolina (Forney Ridge on Andrews Bald in the Great Smoky Mountains National Park, Hamrick, and Mount Pisgah at 4,800 to 5,300 ft.); North Dakota (Greenwood slough near Grand Forks and Stevens Township in Ramsey Co.); Northwest Territories (Fort Smith); Nova Scotia (Aldershot, Berwick, Blomidon, Habitant, Kentville, Kings Co., Northville, Starr's Point, and Weston); Ohio (Hinckley in Medina Co., Olmsted, Puritas Springs in Cuyahoga Co., Put-in-Bay, and Wooster); Ontario (Amyot, Bells Corners, Bobcaygeon, Carleton City in Napean Township, Constance Bay, Fort William, Gananoque, Gravenhurst in Muskoka District, Guelph, Jordon, Ingersoll, Kearney, Kinloss, Merivale, Norfolk, Normandale, Ottawa, Rockcliffe, "Salines," Simcoe, Southampton, Sudbury, Tweed, and Vineland Station); Pennsylvania (Carlisle Junction, Crisp in Westmoreland Co., Delaware Co., Roxborough, and Spring Brook); Prince Edward Island (Alberton and Portage); Quebec (Aylmer, Brome, Cap Rouge, Cascapedia River, Duchesney, Forestville, Georgeville, Hemmingford, Hull, Kazabazua, Knowlton, Laniel, Montreal, Mount Lyall, Nominingue, and Stoneham); South Carolina (Greenville); Tennessee (Knox Co.); Utah (Vivian Park); Vermont (Laurel Lake near Jacksonville); Virginia (Charlottesville, Falls Church, Galax, and Pimmit Run in Fairfax Co.); Washington (Ashford and Wenatchee); West Virginia (Cheat Mt. at 2,000 ft. in Randolph Co.); and Wisconsin (Door Co., Gays Mills, Green Lake, Laona, Madison, Rib Mountain State Park, Sawyer Co., Wood Co., and Worden Township in Clark Co.).

Collection dates are mostly in June, July, and August, not so many in September, and only stragglers after September. The few records that are earlier than June or later than October 15 are: April 27 at Merivale, Ont.; April 28 at Workman Creek, Sierra Ancha, Ariz.; May 2 at Parker Creek, Sierra Ancha, Ariz.; May 5 at Hinckley in 
Medina Co., Ohio; May 10 at Lower Lake, Lake Co., Calif.; May 15 at Ottawa, Ont.; May 23 and 30 at Roxborough, Pa.; May 26 at Madison, Wis.; May 30 in Leelanau Co., Mich. and in Sanilac Co., Mich.; October 17 at Hull, Que.; October 19 and 25 and November 1 and 2 at Charlottesville, Va.; October 21 at Mille Lacs, Minn.; October 27 at Mayo, Md.; November 1 at Falls Church, Va.; and November 9 in Knox Co., Tenn.

Rearing records are as follows: 1 reared from Acrobasis betulella, 1 from Anacampsis sp,, 3 from Archips argyrospilus, 2 from Argyrotaenia pinatubana, 1 from Choristoneura fumiferana, 1 from C. rosaceana?, 2 from Episimus argutanus, 1 from Gracillaria rhoifoliella, 1 from cocoons of Malacosoma disstria, 1 from Pandemis limitata, 3 from Pantographa limata, 14 from Spilonota ocellana, 1 from Zotheca tranquilla, 2 from noctuids, 1 from a tortricid, 1 from a microlepidopteran on Cornus, 1 from a leaf roller on Fraxinus, and 1 from a "brown scavenger lepidopteran." In our own collecting, we have found the species moderately common among deciduous trees and shrubs.

This species is transcontinental in the Canadian, Transition, and Upper Austral zones, where there are deciduous forests. It is adult mostly in summer and early fall. It parasitizes a large variety of smaller Lepidoptera on deciduous trees and bushes whose cocoons are among the foliage.

\section{Genus Iseropus}

Figure 289,b

Iseropus Foerster, 1868, Verh. Naturh. Ver. Rheinlande, vol. 25, p. 164. Type: (Ichneumon graminellae Schrank)=stercorator Fabricius; included by Woldstedt, 1877.

Front wing 4.5 to $8.5 \mathrm{~mm}$. long; body moderately long and slender; clypeus and more or less of face of male white; clypeus of female black to fulvous; face of female black; frons of both sexes entirely black; clypeus convex, its apex impressed, its apical margin with a median notch; occipital carina complete, with a moderate dip on the midline; hairs on mesoscutum moderately dense, evenly distributed; submetapleural carina complete; propodeum of moderate length, rather flat, with median longitudinal carinae; areolet subtriangular, about as long as high, receiving second recurrent vein at or just beyond the middle; nervellus broken usually above the middle, but broken at the middle in the Palaearctic $I$. inquisitor and I. hakonensis; first tergite rather short and wide, its lateral and median longitudinal carinae strong; basolateral oblique grooves in second tergite moderately strong; third and fourth tergites with distinct tubercles, their impunctate apical band occupying about 0.2 their length; female subgenital plate completely sclerotized; ovipositor straight, compressed, its apex as in 
figure $331, \mathrm{~b}$ (the point slender, concave above, the ridges of its basal teeth very oblique); ovipositor sheath about 0.5 as long as front wing.

This is a small genus of Holarctic distribution. It includes the three Nearctic species treated below (one of which is Holarctic); an undescribed species in Mexico; the Japanese Iseropus orientalis Uchida 1928 and I. epicnapterus Uchida 1928; the Indian Pimpla himalayensis Cameron 1899 and Epiurus satanus Morley 1913; the Oriental Epiurus hakonensis Ashmead 1906; and the European Ichneumon inquisitor Scopoli 1763. The last four species have not previously been referred tô Iseropus (new combinations). Epiurus quersifoliae Uchida 1928, E. mencianae Uchida $1935, E$. nankingensis Uchida 1931, and $E$. kimishimae Uchida 1942, we regard as synonyms of hakonensis (new synonymies). E. satanus and Pimpla himalayensis are probably also the same as hakonensis, but we have not been able to verify the synonymy by comparison of specimens with types. There are certainly other Palaearctic species that belong to Iseropus, some of which have already been referred to it, but we have not had the opportunity to study them, and so they are not listed.

The species of Iseropus are common parasites of flimsy lepidopterous cocoons in exposed situations, as on tree trunks. Lymantriidae, Lasiocampidae, and Notodontidae commonly serve as hosts. The parasite larvae are gregarious, several developing on a single host and spinning their cocoons together, within the host cocoon.

\section{Keys to the Nearctic species of Iseropus}

\section{MALES}

1. Face white medially, the lateral 0.2 black; temple strongly convex; second recurrent vein meeting areolet at or near its middle.

2. californiensis Cushman

Face entirely white; temple moderately convex; second recurrent vein meeting areolet distinctly beyond its middle .

2. Clasper with a short apical point, not projecting conspicuously (fig. 361 ); dark bands on hind tibia and tarsus relatively wide, that on second segment of tarsus occupying about 0.4 to 0.6 its length . . 1. stercorator (Fabricius)

Clasper with an attenuate apical point, projecting conspicuously (fig. 363); dark bands on hind tibia and tarsus relatively narrow, that on second segment of hind tarsus occupying about 0.2 to 0.3 its length.

3. coelebs (Walsh)

\section{FEMALES}

1. Labial palpus pure white; dark bands on hind tibia and tarsus relatively narrow, that on apex of second segment of hind tarsus occupying 0.25 to 0.35 its length (fig. 321,1 ) . . . . . . . . . . 3. coelebs (Walsh)

Labial palpus brown; dark bands on hind tibia and tarsus relatively wide, that on apex of second segment of hind tarsus occupying 0.45 to 0.8 its length (figs. $321, \mathrm{j}, \mathrm{k}$ ). 
2. Apical and subbasal dark bands on hind tibia separated by a complete pale band (fig. 321,j); temple moderately convex; second recurrent vein distinctly beyond middle of areolet . . . . . . . 1. stercorator (Fabricius)

Apical and subbasal dark bands on hind tibia connected ventrally by a dark stripe (fig. $321, \mathrm{k}$ ); temple strongly convex; second recurrent vein at or very near middle of areolet . . . . . . . . 2. californiensis Cushman

\section{Iseropus stercorator (Fabricius)}

Figures $331, \mathrm{~b} ; 361$

Front wing 4.5 to $7.8 \mathrm{~mm}$. long; punctures on face moderately coarse; temple moderately convex; propodeum moderately broad, rather weakly convex in profile, sublaterally with few punctures, dorsolaterally sharply rounded and with a more or less distinct rounded longitudinal ridge; second recurrent definitely beyond middle of areolet; male clasper with a short apical point, not conspicuously projecting.

Male: Black. Face, clypeus, palpi, extreme hind corner of pronotum, and tegula, white; under side of scape blackish to light brown, or sometimes white; flagellum stramineous beneath, at apex blackish beneath; front and middle coxae largely or mostly ivory, the rest fulvous; hind coxa fulvous; trochanters ivory; femora fulvous, the front and middle femora ivory apically and the hind femur often with a fuscous apical mark; front and middle tibiae and tarsi ivory variously tinged with or replaced by light fulvous; hind tibia white to dusky fulvous, with broad subbasal and apical black bands; first four segments of hind tarsus white, their apices broadly black, the apical 0.4 to 0.6 of the second segment black; fifth segment of hind tarsus black, narrowly paler at base.

Female: Black. Clypeus reddish brown, blackish basally; flagellum fulvous brown beneath; maxillary palpus whitish to blackish brown; labial palpus light brown to blackish; flagellum fulvous brown beneath; extreme hind corner of pronotum usually stramineous or whitish; tegula white to stramineous and brown; front and middle legs almost entirely fulvous, the front coxa more or less infuscate except at apex; hind coxa, trochanters, and femur fulvous, the femur often fuscous at apex; hind tibia white to fulvous, broadly banded with black; first four segments of hind tarsus white to pale brown, their apices broadly black, the second segment with its apical 0.45 to 0.7 black; fifth segment of hind tarsus black, narrowly paler at base.

There is a European and a Nearctic subspecies, as keyed below:

1. Hind femur without a distinct apical fuscous mark; tegula of female stramineous, the apical half more or less brownish; range: Europe.

1a. stercorator stercorator (Fabricius)

Hind femur with a conspicuous apical fuscous mark (fig. 321,j), except in some specimens from central and southern California; tegula of female white; range: North America. .... 1b. stercorator orgyiae (Ashmead) 


\section{1a. Iseropus stercorator stercorator (Fabricius)}

Ichneumon stercorator Fabricius, 1793, Entomologia systematica . . . , vol. 2, p.

$172 ;\left[\sigma^{7}\right] . \quad$ Type: $\sigma^{x}$, Kiel, Germany (lost).

Tegula of female stramineous, its apical half more or less brownish; apex of hind femur without a distinct fuscous area; hind corner of female pronotum usually very narrowly and inconspicuously stramineous; hind tibia of female white to dusky fulvous, with broad subbasal and apical black bands.

Described from $4 \sigma^{x}, 8$ 우 from Sweden and Germany.

\section{1b. Iseropus stercorator orgyiae (Ashmead)}

\section{Figure 321,j}

Ictoplectis (!) orgyiae Ashmead, 1896, Trans. Amer. Ent. Soc., vol. 23, p. 213; ه’, ㅇ. Types: $3 \sigma^{\top}, 1$, Alameda, Calif. (Washington).

Pimpla (Epiurus) brunneifrons Viereck, 1909, Ent. News, vol. 20, p. 291; هో, ९ .

New synonymy. Types; $3 \sigma^{7}, 4 q$, Summerdale, Calif. (Washington).

Iseropus brunneifrons septentrionalis Cushman, 1940, Proc. Ent. Soc. Washington, vol. 42 , p. $56 ; \sigma^{7}$, + . Type: $q$, Sault Sainte Marie, Mich. (Washington). Brology: Patch, 1921, Bull. Maine Agr. Exp. Sta. no. 302, p. 318 (misdetermined here as coelebs).

Tegula of female whitish; apex of hind femur with a conspicuous fuscous area, or this area reduced or absent in some specimens from central and southern California (including the types of $I$. orgyiae); hind corner of female pronotum very narrowly whitish; hind tibia of female white with broad subbasal and apical black bands.

The types of $I$. orgyiae represent the southern California race of this subspecies and are paler and with coarser facial punctures than usual. The faces of the male types of $P$. brunneifrons are stained so that they are brownish, but appear to have been originally white. The types of $I$. septentrionalis are rather typical of the subspecies.

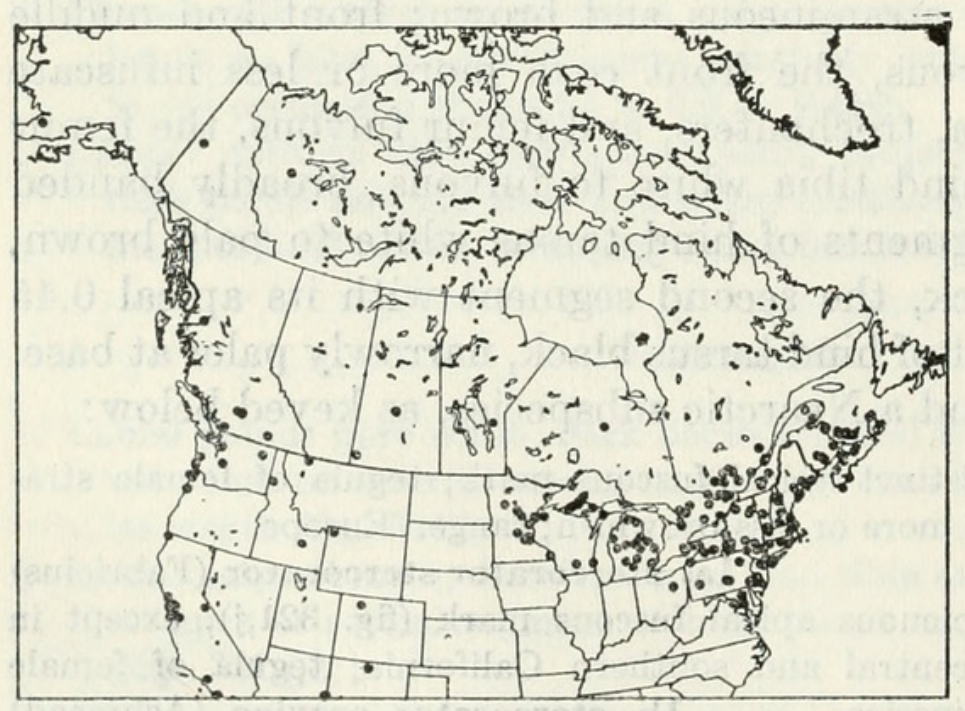

Figure 69.-Localities for Iseropus stercorator orgyiae. 
Specimens (310 $\sigma^{\top}, 422$ \%): From Alaska (King Salmon on the Naknek River); Arizona (near Alpine); British Columbia (Agassiz, Hatzic Lake, Langley, Robson, Terrace, and Victoria); California (Alameda Co., Big Pine Creek in Inyo Co., Crescent City, Glendale, Inverness, Miramar, Mountain View, Pescadero, San Francisco, San Jose State College in San Jose, and "Summerdale"); Colorado (Cold Springs at 5,915 ft. and Steamboat Springs); Connecticut (Canterbury and Colebrook); District of Columbia (Washington); Idaho (Bear Pass Creek in Butte Co., and Moscow Mt.); Maine (Blue Hill, Hancock, Lincoln Co., Medomak, Orono, and Pittson); Manitoba (Berens River); Maryland (Baltimore and Mayo); Massachusetts (Boston, Gloucester, Holliston, Ipswich, and Mount Greylock); Michigan (Arenac Co., Bay Co., Birmingham, Cheboygan Co., Clare Co., Delta Co., Detroit, Eaton Co., Gladwin Co., Gogebic Co., Houghton Co., Ionia Co., Iosco Co., Iron Co., Isle Royale, Keweenaw Co., Lake Co., Lakewood in Marquette Co., Manistee Co., Ontonagon Co., Port Austin, Presque Isle Co., Sanilac Co., Sault Ste. Marie, and Shiawassee Co.); Minnesota (Cass Co., Cramer, Finland, Hennepin Co., Houston Co., Itasca Park, Lake Co., Lake Itasca, Mille Lacs, Minneapolis, Pine City, St. Paul, University Farm in Ramsey Co., and Willow River); Montana (Glacier National Park); New Brunswick (Campbellton, Fredericton, Moncton, Nerepis, and Tabusintac); Newfoundland (Carbonier and St. John's); New Hampshire (Center Harbor, Durham, Jaffrey, Lake of the Clouds on Mount Washington at 5,000 ft., Mount Madison, and Randolph); New Jersey (Camden, Hackensack, Moorestown, Ramsey, Riverton, "Snake Hill," and Vincentown); New Mexico (Honelo Canyon in Taos Co.); New York (Buffalo, Elmira, Farmingdale, Flatbush, Greene Co., Hancock, Ithaca, Maspeth, McLean, Mount McIntyre in Essex Co., New York City, North Fairhaven, Oneonta, Oswegatchie, Peekskill, Portage, Potsdam, Poughkeepsie, Ringwood in Tompkins Co., Sardinia, Shokan, Slaterville, and summit of Whiteface Mt.); Northwest Territories (Norman Wells); Nova Scotia (Annapolis Co., Barrington Passage, Cheticamp, Kings Co., Millsville, Parrsboro, Truro, and White Point Beach in Queens Co.); Ohio (Akron); Ontario (Constance Bay, Glenburnie, Golden Lake, Lisle, Marmora, Muskoka, Normandale, Norway Point on Lake of Bays, Ogoki, Ottawa, Petawawa Reservation, Simcoe, Vineland Station, and Waubamik); Oregon (Cannon Beach, Newport, Seaside, and Warrenton); Pennsylvania (Harrisburg, New Cumberland, North East, Philadelphia, Pittsburgh, Roxborough, and Spring Brook); Prince Edward Island (Alberton, Brackley Beach, Charlottetown, and Dalvay House in Prince Edward Island National Park); Quebec (Alcove, Aylmer, Cap Rouge, Cascapedia, Clement, Fulford, Knowlton, Lac Mercier, Lacoste, Louiseville, Mount Alberton $526527-60-12$ 
the Gaspé Peninsula, "N. D. des Laurentides," Nominingue, Norway Bay, Pointe a la Croix on the Gaspé Peninsula, Quebec City, St. Bernart at Packington, Sainte Agathe des Monts, Stoneham, Sweetsburg, Valley Junction, Wakefield, and Wright); Rhode Island (Westerly); Saskatchewan (Cypress Hills and Waskesiu Lake); Vermont (Laurel Lake near Jacksonville and Rutland); Virginia (Chain Bridge near McLean); Washington (Colville, Hoquiam, Mount Rainier at 5,000 ft., Seattle, Seaview, and Westport); Wisconsin (Gordon, Madison, and Milwaukee); Wyoming (Riverside in Yellowstone Park); and Yukon (Dawson).

Most of the collection dates are in June, July, and August but a moderate number are as early as May 25 or late as September 20. A few records are even earlier or later, as follows: May 8 at Akron, Ohio; May 9 at Pescadero, Calif.; May 13 at Ottawa, Ont.; May 16 at New Cumberland, Pa.; May 17, 21, and 24 at Ithaca, N. Y.; May 21 at Pine City, Minn. and at Jaffrey, N. H.; September 25 at McLean, N. Y., at Aylmer, Que., and at Cross Point, Que.; September 26 at Pittsburgh, Pa.; October 6 at Inverness, Calif.; and October 27 at Mayo, Md. We have found the species frequently common in northern deciduous woods.

Rearing records are as follows: 1 rearing from Choristoneura rosaceana, 1 from Ctenucha virginica, 2 from Halisidota, 7 from Hemerocampa leucostigma, 2 from $H$. vetusta, 6 from Hemerocampa sp., 2 from Malacosoma disstria, 2 from Malacosoma sp., 1 from Simyra henrici, 1 from pine tussock, 1 from pupa on white thorn, and 1 from cocoon on apple tree.

This subspecies is transcontinental in the Canadian and Transition zones. Adults occur from late spring to early fall. It is a gregarious parasite of moderately large moth cocoons in exposed situations.

\section{Iseropus californiensis Cushman}

\section{Figures $321, \mathrm{k} ; 362$}

Iseropus californiensis (as I. californicus in key) Cushman, 1940, Proc. Ent. Soc. Washington, vol. 42 , p. 58; $\sigma^{7}$, $\uparrow$. Type: $q$, Yosemite, Calif. (Washington).

Front wing 5.6 to $7.8 \mathrm{~mm}$. long; punctures on face fine; temple unusually full and convex; propodeum rather broad, strongly convex in profile, sublaterally with very few punctures, dorsolaterally sharply rounded but without a distinct ridge; second recurrent at or very near middle of areolet; break of nervellus averaging higher than in the other Nearctic species; male clasper with a short apical point, not conspicuously projecting, very similar to the clasper of $I$. stercorator.

Male: Black. Central 0.6 of face, clypeus, palpi, tegula, and front coxa and trochanters, white; hind corner of pronotum narrowly white or stramineous; front and middle femora fulvous, whitish at the apex; 
front and middle tibiae whitish with faint narrow subbasal and broad apical fulvous bands; front and middle tarsi white, the apices of their first four segments pale fulvous and the last segment mostly brown; middle coxa and trochanters fulvous behind, the front white; hind coxa fulvous; hind trochanters fulvous, whitish below; hind femur fulvous, without an apical fuscous area; hind tibia white with exceptionally wide subbasal and apical black bands; first four segments of hind tarsus white, their apices very broadly black, the apical $0.65 \pm$ of the second black; fifth segment of hind tarsus black, narrowly pale at base.

Female: Colored like the female of Iseropus stercorator orgyiae except that the hind femur never has a distinct fuscous mark, the subbasal and apical black bands on hind tibia are connected ventrally by a dark brown or fuscous stripe, the black bands on the hind tibia and tarsus average somewhat wider, and that the front and middle tibiae have indistinct external basal and premedial whitish marks. These marks on the front and middle tibiae are faintly indicated also in some specimens of $I$. stercorator orgyiae.

Specimens $\left(32 \sigma^{7}, 66 \%\right)$ : From Arizona (Oak Creek Canyon, and Parker Creek and Workman Creek in the Sierra Ancha); California (Big Pine Creek in Inyo Co. at 7,500 ft., Brentwood, Camino, Dardanelle, Fish Camp, Gold Lake in Sierra Co., Huntington Lake in Fresno Co., Los Angeles, Marion Mt. Camp in the San Jacinto Mts., Mount Diablo, San Francisco, Stanford, and Yosemite); Colorado (Platt Canyon); and Washington (Bellevue).

Collection dates are from April 19 (in the Sierra Ancha, Ariz.) to July 19 (at Fish Camp, Calif.), plus one record for August 15 at Bellevue, Wash., and another for September 8 at San Francisco, Calif. We have found it common from mid-spring to early summer (before the dry part of the summer), usually among the shrubby growth in the semiarid areas between desert and forest. We have not however, collected within its range late in the season. It may be common then also.

Host records are: 1 rearing from Malacosoma californicum, 2 from $M$. fragile, 1 from $M$. pluviale, and 1 from Malacosoma sp.

This species is common among dense, shrubby growth in semiarid parts of western United States, in the Transition zone. It is adult from mid-spring into the summer. Malacosoma spp. serve as hosts.

\section{Iseropus coelebs (Walsh)}

Figures 321,$1 ; 363$

Ichneumon inquisitor Say, 1829, Contr. Maclurian Lyceum Arts Sci., Philadelphia, vol. 1, p. 71 (Leconte ed. vol. 1, p. 375); $९$. Name preoccupied. Type: \% Indiana (destroyed). 
Pimpla coelebs Walsh, 1873, Trans. Acad. Sci. St. Louis, vol. 3, p. 141; $\sigma^{7}$. Type: $\sigma^{\top}$, ?Illinois (destroyed in Chicago fire of 1871).

Pimpla inquisitoriella Dalla Torre, 1901, Catalogus hymenopterorum, vol. 3, p. 435. New name for Ichneumon inquisitor Say.

Brology: Howard, 1897, Bull. U. S. Dep. Agr., Div. Ent., no. 7, p. 16; 1897, Tech. Ser. U. S. Dep. Agr., Div. Ent., no. 5, pp. 8-17, 23, 51, 54; 1898, Ann. Rep. Ent. Soc. Ontario, no. 28, p. 88.-Fiske, 1903, Tech. Bull. New Hampshire Agr. Exp. Sta., no. 6, pp. 198-200.-Cushman, 1926, Proc. Ent. Soc. Washington, vol. 23, p. 33 - Schaffner and Griswold, 1934, Misc. Publ. U. S. Dep. Agr., no. 188, p. 143.

Front wing 4.7 to $8.5 \mathrm{~mm}$. long; punctures on face rather coarse; temple unusually flat and weakly convex; propodeum moderately broad, moderately convex in profile, sublaterally with a moderate number of coarse punctures, dorsolaterally rather sharply rounded and without a distinct ridge; second recurrent definitely beyond middle of areolet; male clasper with a long attenuate point that projects conspicuously.
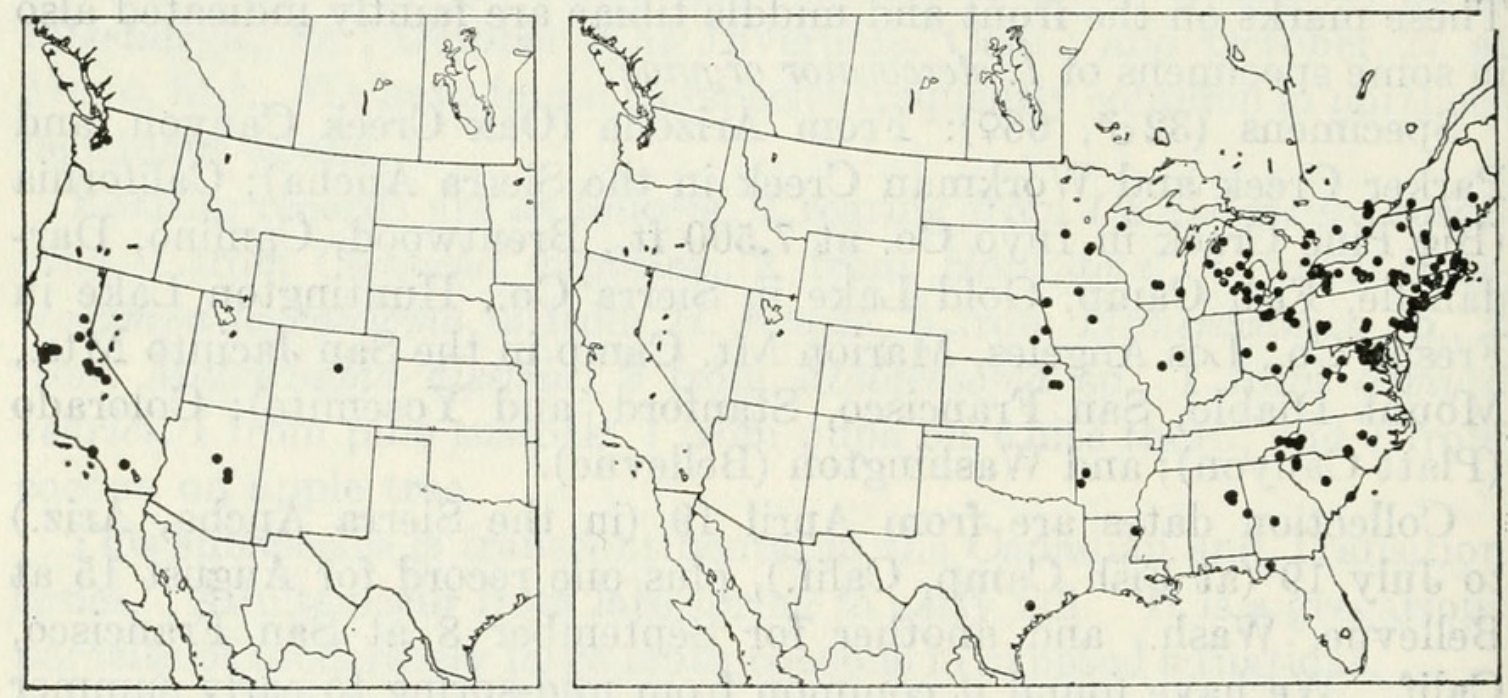

Figures 70, 71-Localities: 70 (left), Iseropus californiensis; 71 (right), I. coelebs.

Male: Black. Face, clypeus, palpi, under half of scape and pedicel, hind corner of pronotum, tegula, front and middle coxae except for fulvous tinges (especially on middle coxa), trochanters, and apex of front and middle femora, white; under side of flagellum stramineous, brownish apically; front and middle tibiae and tarsi mostly white, the apical half of fifth segment of middle tarsus brown; hind femur fulvous, with a strong fuscous apical mark; hind tibia white, with rather narrow subbasal and apical black bands; first four segments of hind tarsus white, the apex of each segment rather narrowly blackish, the black on the second segment occupying about 0.25 its length; fifth segment of hind tarsus blackish, its base whitish.

Female: Black. Clypeus light reddish brown; palpi entirely white; under side of flagellum fulvous brown; tegula and hind corner of pronotum white; coxae fulvous, the front coxa a little infuscate 
basally; trochanters fulvous, the fore and middle trochanters a little paler or partly whitish; femora fulvous, the front and middle femora narrowly whitish on apex and the hind femur conspicuously fuscous on apex; hind tibia and tarsus colored as in male but the black bands averaging a little wider.

Specimens $\left(584 \sigma^{\top}, 603\right.$ \%): From Alabama (Cheaha State Park, Coleta, Langdale, and Pyriton); Arkansas (Polk Co. and Scott Co.); Connecticut (Bear Mt. near Salisbury, Bethlehem, Manchester, Stamford, and Wallingford); District of Columbia (Anacostia and Washington); Delaware ("Wood Kill"); Florida (Tallahassee); Georgia (Myrtle); Illinois (Decatur and Urbana); Iowa (Ames, Kossuth Co., and Sioux City); Kansas (Lake View in Douglas Co., Lawrence, and Onaga); Louisiana (Mound); Maine (Augusta, Casco, and Norway); Maryland (Baltimore, Cabin John, College Park, Hagerstown, "Jackson's," Plummers Island, Riverdale, and Takoma Park); Massachusetts (Belmont, Boston, Duxbury, Holliston, Minot, Petersham, and South Hadley); Michigan (Ann Arbor, Antrim Co., Birmingham, East Lansing, Eaton Co., George Reserve in Livingston Co., Grand Traverse Co., Iosco Co., Kent Co., Mason Co., Mecosta Co., Midland Co., Monroe, Newaygo Co., Oakland Co., and Saginaw Co.); Minnesota (Powder Plant Woods in Ramsey Co., St. Paul, and Sedan); Nebraska (Lincoln and Omaha); New Jersey (Chesilhurst, Edgewater, Hackensack, Moorestown, Newark, New Brunswick, New Lisbon, Paterson, Ramsey, and Riverton); New York (Albany, Babylon, Batavia, Bemus Point, Bethany, Brooklyn, Buffalo, Dix Hills on Long Island, East Hampton, Farmingdale, Fishers Island, Flatbush, Fredonia, Freeville, Geneva, Greene Co., Hancock, Horton, Ithaca, Lancaster, Mclean Bogs in Tompkins Co., Melville on Long Island, Oneonta, Poughkeepsie, Rome, Sea Cliff, Shokan, and summit of Whiteface Mt.); North Carolina (Crabtree Meadows in Yancey Co. at 3,600 ft., Franklin, Mount Mitchell, North Fork of the Swannanoa River in the Black Mts., Pisgah Mt., Southern Pines, Wake Co., and Wilson Co.); Ohio (Cleveland, Columbus, Middle Bass Island, Montgomery Co., Put-in-Bay, Puritas Springs in Cuyahoga Co., Ross Co., Sandusky, and Summit Co.); Ontario (Dunnville, Gananoque, Grand Bend, Gravenhurst, Guelph, Hastings Co., Jordan, Lisle, Ottawa, Ridgeway, Rockcliff, Simcoe, and Vineland Station); Pennsylvania (Dorseyville in Allegheny Co., Germantown, Harrisburg, New Cumberland, Philadelphia, Pittsburgh, and Valley Forge); Quebec (Chelsea and Knowlton); Rhode Island (Kingston and Westerly); South Carolina (Columbia, Greenville, McClellanville, and near Tigerville); Tennessee (Newfound Gap at 5,000 to 5,200 ft.); Texas (Victoria); Vermont (Ascutney and Woodstock); Virginia ("Camp Peary," Dayton, Falls Church, 
Great Falls, Richmond, Rosslyn, and Vienna); West Virginia (Baldwin, Bolivar, Cheat Mt. at 2,000 ft. in Randolph Co., and Lost River State Park in Hardy Co.); and Wisconsin (Corliss, Dane Co., Door Co., Madison, and Sawyer Co.).

The dates of capture show first emergence of the species late in May over most of its range, increase to a peak in July and August, and decrease into fall, the last survivors disappearing before the middle of October. Unusually early and late captures are: March 7 at Mound, La.; April 1 at Tallahassee, Fla.; April 23 in Wake Co., N. C.; May 7 and 28 at Washington, D. C.; May 8 near Tigerville, S. C.; May 13 at McClellanville, S. C.; May 23 at Lawrence, Kans.; May 24 at Dix Hills, Long Island, N. Y.; May 29 at Ithaca, N. Y. and at Columbia, S. C.; May 30 in Eaton Co., Mich.; October 12 in Wilson Co., N. C.; October 11 at Jordan, Ont.; and October 13 at Madison, Wis.

The host records on the pin labels are: 26 rearings from Hemerocampa leucostigma, 1 from Hemerocampa sp.; 3 from Malacosoma americanum, 1 from $M$. disstria, 1 from Metallus rubi, 2 from Olene sp., 10 from tussock moth, 1 from slug larva, 1 from pupa under log, 1 from cocoons on Malus, 1 from lepidopterous cocoon, and 1 from mud wasp cells. In our own collection we have found the species very common among deciduous woods or isolated trees.

There are several notes on the biology of this species, and an extensive account by Howard, 1897 (pp. 8-17). Oviposition is on prepupae or occasionally on fresh pupae within their cocoons. In summer, adults hatch about 15 days after the egg is laid. Single hosts (Hemerocampa leucostigma) mature one to about twenty parasites. Overwintering is as larvae in their cocoons within the host cocoon.

This species is in the Alleghanian, Carolinian, and Austroriparian faunas, where it is common among deciduous trees. Adults occur from midspring to midfall. Its hosts are moderately large, flimsy lepidopterous cocoons on tree trunks, usually those of Malacosoma and Hemerocampa.

\section{Genus Tromatobia}

Figure 290,a

Tromatobia Foerster, 1868, Verh. Naturh. Ver. Rheinlande, vol. 25, p. 164. Type: Pimpla variabilis Holmgren; designated by Viereck, 1914.

Austropimpla Brèthes, 1913, Anal. Mus. Nac. Hist. Nat. Buenos Aires, vol, 24,

p. 40. Type: Austropimpla hübrichi Brèthes; original designation.

Front wing 3.5 to $7.8 \mathrm{~mm}$. long; body moderately long and slender; clypeus of male white or pale yellow; face of male white, black, or concolorous with rest of head; face and clypeus of female variously colored, usually black or blackish, the face marked with white on the sides and the clypeus partly white; frontal orbit marked with white 
or pale yellow except in T. variabilis; clypeus convex, its apex a little impressed, its apical margin weakly concave or approximately truncate; occipital carina complete, not dipped on the midline; mesoscutum with moderately dense, evenly distributed hairs or in some Neotropic species with sparse hairs and some bare areas; submetapleural carina complete, partly absent, or represented only by a tubercle behind middle coxa; propodeum rather short and convex, with or without median longitudinal carinae; areolet subtriangular, absent, or in $T$. variabilis subpentagonal, receiving second recurrent vein before its outer corner; nervellus broken at or above the middle, first tergite short, broad, its lateral and median longitudinal carinae rather strong; second tergite with weak, basolateral oblique grooves; third and fourth tergites with distinct tubercles, their apical impunctate band occupying about 0.15 their lengtb; female subgenital plate completely sclerotized or with a median basal membranous area that varies from small to so large that it occupies most of the area of the sternum; ovipositor compressed, straight, its lower valve with a weakly wrinkled surface, its point as in figure 331,c; ovipositor sheath 0.35 to 0.60 as long as front wing.

This genus is Holarctic and Neotropic. There are four Nearctic species.

All species of the genus are gregarious parasites of spider egg cocoons. It is common to open a large egg cocoon of an orb weaver spider and find several Tromatobia larvae or cocoons and most or all of the spider eggs destroyed. The biology, larva, and pupa of the European T. oculatoria was described in detail by Nielsen (1923, Entomologiske Meddelelser, vol. 14, pp. 189-194). There have been no similar publications on the Nearctic species.

\section{Key to the Nearctic species of Tromatobia}

1. Frons entirely black; propodeum with a prominent sublateral longitudinal ridge; face of male black; hind tibia ferruginous with dusky subbasal and and apical bands (fig. 322,a). VARIABILIS GROUP (p. 176).

1. variabilis (Holmgren)

Frons white next to eye, at least in part; propodeum without a distinct sublateral longitudinal ridge; face of male white. . . . . . . . . . . . 2

2. Carina between metapleurum and metasternum (submetapleural carina) present only basally, not complete to hind coxa. Notator group (p. 186) The only Nearctic representative of this group has the thorax entirely fulvous . . . . . . . . . . . . . . . 4. notator (Fabricius)

Carina between metapleurum and metasternum (submetapleural carina) complete, extending from in front of hind coxa to front of metapleurum; thorax usually largely or entirely black. Oculatoria group (p. 178). . . . . . 3

3 . Tergites $1-5$, or $2-5$ with a white preapical band; areolet absent.

3. zonata (Davis)

Tergites 1 to 5 without a white band; areolet present . . 2. ovivora (Boheman) 


\section{VARIABILIS GROUP}

Areolet present or absent, when present broadly sessile above; carina between metapleurum and metasternum complete; propodeum with a rather strong dorsolateral longitudinal ridge.

Face and frons entirely black.

This group includes a single Holarctic species.

\section{Tromatobia variabilis (Holmgren)}

Figures $322, a ; 364$

Pimpla variabilis Holmgren, 1856, Svenska Vetensk.-Akad. Handl., ser. 3, vol. 42,

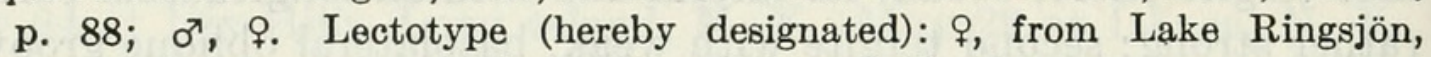
Scania, Sweden, labeled "Sc.," "Hgn.," "type" (Stockholm).

Pimpla rufovariata Cresson, 1870, Trans. Amer. Ent. Soc., vol. 3, p. 149; . Lectotype: $\uparrow$, Pennsylvania (Philadelphia).

Polysphincta cingulata Provancher, 1875. Naturaliste Canadien, vol. 3, p. 141;

\%. Type: , Quebec (Quebec).

Polysphincta forsiusi Hellén, 1915, Acta Soc. Fauna Flora Fennica, vol. 40, p. 45;

$\sigma^{x}$, . New synonymy. Types: $\sigma^{x}, \uparrow$, Pernå, Tammerfors, and Säräisniemi, Finland (Helsinki).

Front wing of male 4.2 to $5.5 \mathrm{~mm}$. long, of female 3.7 to $5.5 \mathrm{~mm}$. long; areolet present or absent; ovipositor sheath about 0.43 as long as front wing. A stout-bodied species.

Black. Clypeus of male pale yellow, of female brown or black; palpi of male ivory, of female pale stramineous; flagellum brown, paler below; hind corner of pronotum often whitish; mesopleurum except above, mesosternum, metapleurum, and propodeum often more or less ferruginous; tegula pale yellow to brown; front and middle legs of male fulvous, their trochanters, coxae apically, and tinges on knees and front of front femur and tibia pale yellow, their coxae often fuscous basally; front and middle legs of female fulvous, their coxae often more or less fuscous and their trochanters sometimes

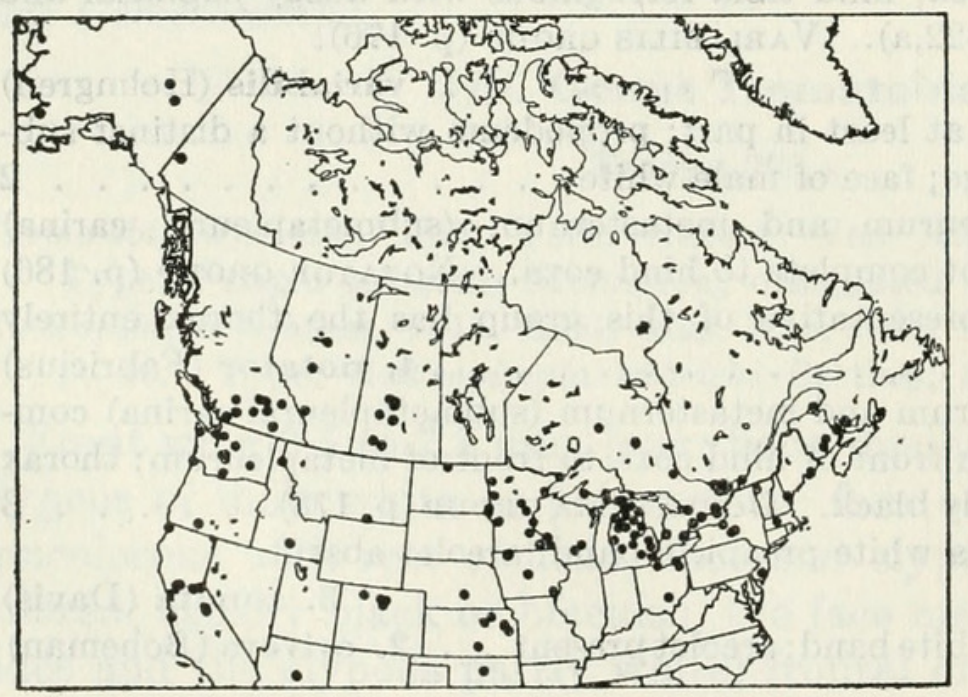

Figure 72.--Localities for Tromatobia variabilis 
infuscate; hind coxa black to fulvous; hind first trochanter pale fulvous in male, fulvous to fuscous in female; hind second trochanter pale yellow in male, light fulvous in female; hind femur fulvous; hind tibia pale fulvous, with an indistinct subbasal infuscate band and its apical $0.15 \pm$ fuscous; hind tarsus stramineous, the segments infuscate apically; abdomen entirely black, to ferruginous with only its apex and apical sublateral spots on median tergites black, most often with an intermediate amount of ferruginous.

This species is aptly named, as the color is unusually variable and the areolet may be either present or absent. Specimens from the eastern half of North America tend to have less extensive black markings than specimens from the western half, and specimens from warmer situations tend to have less black than those from colder areas.

Specimens (145 $\sigma^{\top}, 130$ ) : From Alaska (Big Delta, Fairbanks, and King Salmon on the Naknek River); Alberta (Banff, Slave Lake, and Wabamun); Arizona (Oak Creek Canyon); British Columbia (Agassiz, Blue Lake W. of Lytton at 7,000 ft., Hatzic Lake, Merritt, Mount Revelstoke at 6,000 ft., Okanagan Valley, and on shore of Shuswap Lake near Salmon Arm); California (Camino, Crescent City, Davis, Fish Camp, near Glacier Point in Yosemite Park, Pacific Grove, Putah Canyon in Solano Co., and Strawberry); Colorado (near Estes Park, Lyons, Phantom Valley in Rocky Mountain National Park at 9,400 ft., and Rabbit Ears Pass); Idaho (Burley and Wallace); Iowa (Ames, Jackson Co., and Mount Pleasant); Kansas (Baldwin, Douglas, Lawrence, Onaga, and Riley Co.); Maine (Fryeburg and Southwest Harbor); Manitoba ("Red Deer Reservation"); Massachusetts (Amherst); Michigan (Alger Co., Alpena, Alto, Ann Arbor, Baraga Co., Brevort, Cheboygan Co., Douglas Lake, Emmet Co., Grand Traverse Co., Gratiot Co., Iosco Co., Isle Royale, Lancaster Lake in Cheboygan Co., Lapeer Co., Leelanau Co., Mackinac Co., Menominee Co., Midland Co., Missaukee Co., Oakland Co., Oceana Co., Oscoda Co., Otsego Co., Schoolcraft Co., Wayne Co., and Wexford Co.); Minnesota (Cook Co., Crookston, Fillmore Co., Garrison, Goodhue Co., Grand Marais, Houston Co., John Latsch State Park, Mille Lacs Co., Norman Co., Ortonville, Two Harbors, Washington Co., and Winona Co.); Montana (Bighorn Mts.); Nebraska (Grand Island); New Brunswick (Douglas Harbor on Grand Lake, Nerepis, and Shediac); New Jersey (Hammonton); New York (Ithaca, McLean Reserve in Tompkins Co., and Wayne Co.); North Dakota (Bottineau and Wahpeton); Ohio (Bedford, Cleveland, Hocking Co., and Put-in-Bay); Oklahoma (Stillwater); Ontario (Belleville, Blackburn, Bowmanville, Britannia, Grand Bend, Ogoki, Ottawa, Parr Island in East Spence Lake, "Scuttle Hole", Simcoe, Smoky Falls on the Mattagami River, Timagami, and Toronto); 
Oregon (Bare Island in Klamath Lake and Warrenton); Prince Edward Island (Dalvay House in Canadian National Park); Quebec (Aylmer, Burbridge, Cascapedia, Montreal, Norway Bay, and "St. John"); Saskatchewan (Atten Lake, Bateman, Christopher Lake, Prince Albert National Park, Saskatoon, Swift Current, and Waskesiu); South Dakota (Vernon); Vermont (Grand Isle); Washington (Big Four, Dungeness, Forks, Mount Rainier at 2,900, 5,300 and 5,700 ft., O'Sullivan Dam in Grant Co., Snoqualmie Pass, Thorpes in Klickitat Valley, and White River on Mount Rainier); Wisconsin (Columbus and Madison); and Yukon Territory (Snag). We have specimens also from Cherkes Forest on Cyprus and from Vladivostock in Siberia.

Most dates of capture are from about May 20 to late August. The only records prior to May 20 and after August 31 are: April 18 in Douglas Co., Kans.; May 2 in Midland Co., Mich.; May 7 in Washington Co., Minn., at Alto, Mich., and at Cleveland, Ohio; May 10 at Mount Pleasant, Iowa; May 12 at Ames, Iowa, and at Davis, Calif.; May 11 in Putah Canyon, Solano Co., Calif.; May 16 in Bedford Co., Ohio; September 1 at Timagami, Ont.; September 4 at Crookston, Minn.; September 8 at Garrison, Minn.; September 15 and October 18 at Davis, Calif.; September 18 in Midland Co., Mich.; and October 22 in Mille Lacs Co., Minn.

This species is Holarctic. In America, it is transcontinental in the Canadian and Transition zones. Adults occur mostly from midspring to early fall.

\section{OCULATORIA GROUP}

Areolet present except in $T$. zonata, when present pointed above or narrowly sessile; carina between metapleurum and metasternum complete; propodeum without a distinct dorsolateral longitudinal ridge.

Face of male white, of female white to black, usually black with white orbital marks; frons with narrow to wide white orbital mark.

Two species of this group occur in our region. All of the Palaearctic species that we have seen except $T$. variabilis belong here, and we have seen species of the group also from South America, including Tromatobia lineiger Morley 1914, described from Montevideo.

\section{Tromatobia ovivora (Boheman)}

Figures 331,c; 365

Front wing of male 3.5 to $6.5 \mathrm{~mm}$. long, of female 4.2 to $8.0 \mathrm{~mm}$. long; areolet present; upper and lateral faces of propodeum with punctures that are separated by about 1.0 to 1.5 their diameter; ovipositor sheath 0.36 to 0.6 as long as front wing. 
Color as described under the subspecies.

This is a Holarctic species, with two Nearctic subspecies as keyed and described below:

\section{MALES}

1. Apical $0.4 \pm$ of hind basitarsus fuscous; metapleurum black to fulvous; range: most of America north of Mexico . . . 2a. ovivora ovivora (Boheman) Apical $0.2 \pm$ of hind basitarsus fuscous; metapleurum fulvous; range: Carolinian fauna. Not always distinguishable from male of $T$. ovivora ovivora.

2b. ovivora rufopectus (Cresson)

\section{FEMALES}

1. Face 0 to 30 percent white, the rest black; ovipositor sheath 0.36 to 0.43 as long as front wing; apical $0.38 \pm$ of hind basitarsus fuseous (fig. 322,b); metapleurum entirely black to entirely ferruginous or fulvous.

2a. ovivora ovivora (Boheman)

Face 30 to 100 percent white, the rest black or brown; ovipositor sheath 0.43 to 0.60 as long as front wing; apical $0.20 \pm$ of hind basitarsus fuscous (fig. 322, c); metapleurum always fulvous.

2b. ovivora rufopectus (Cresson)

\section{2a. Tromatobia ovivora ovivora (Boheman)}

FIGURe $322, \mathrm{~b}$

Pimpla ovivora Boheman, 1821, Svenska Vetensk.-Akad. Handl., ser. 3, vol. 9, p. 336 ; $\sigma^{\top}$, ㅇ Lectotype: (hereby designated): ㅇ, Smolandia, Sweden (Stockholm).

Pimpla scriptifrons Cresson, 1870, Trans. Amer. Ent. Soc., vol. 3, p. 148; New synonymy. Lectotype: + , Delaware (Philadelphia).

Pimpla vidua Walsh, 1873, Trans. Acad. Sci. St. Louis, vol. 3, p. 140; $\subsetneq$. Type: \& , ?Illinois (destroyed in Chicago fire of 1871).

Pimpla defensator Davis, 1898, Trans. Amer. Ent. Soc., vol. 24, p. 367; . Lectotype: \& , Agricultural College, Mich. (Philadelphia).

Pimpla landerensis Viereck, 1906, Trans. Amer. Ent. Soc., vol. 32, p. 243; . Type: + , near Lander, Wyo. (Lawrence).

Apechtis rugulosa Morley, 1914, Revision of the Ichneumonidae ... in the British Museum ...., vol. 3, p. 34; ․ Type: 잉 Inverness, Woodcock's

Landing at mouth of the river Skeena, B. C. (London).

Biology: Nielsen, 1923, Entomologiske Meddelelser, vol. 14, pp. 194-195.Shaw, 1930, Journ. New York Ent. Soc., vol. 38, p. 465.

Front wing of male 4.0 to $7.0 \mathrm{~mm}$. long, of female 4.3 to $7.8 \mathrm{~mm}$. long; upper and lateral faces of propodeum with punctures that are separated by about 1.0 to 1.5 their diameter; ovipositor sheath 0.36 to 0.43 as long as front wing.

Male: Black. Face, frontal orbits to top of eye, clypeus, basal half of mandible, palpi, under side of scape and pedicel, upper margin of pronotum, tegula, subtegular ridge, apex of scutellum, postscutellum, usually a lateroapical spot on propodeum, front and middle coxae, trochanters, tibiae, and tarsi, and hind trochanters, white; flagellum whitish or pale brown below, fuscous above; mesosternum 
usually, usually lower half and often more of mesopleurum, sometimes metapleurum more or less, and rarely more or less of mesoscutum fulvous or fulvoferruginous; front and middle femora pale fulvous, whitish on apex and in front; middle tarsus white, the apical half of fifth segment and extreme apex of first to fourth segments infuscate; hind coxa fulvous, its extreme apex whitish; hind femur fulvous, white on apex and with a preapical infuscate band; hind tibia white, its subbasal $0.15 \pm$ and apical $0.28 \pm$ fuscous; hind tarsus white, the first to fifth segments with their apical $0.4 \pm, 0.5 \pm, 0.5 \pm, 0.5 \pm$, and $0.7 \pm$ respectively, fuscous.

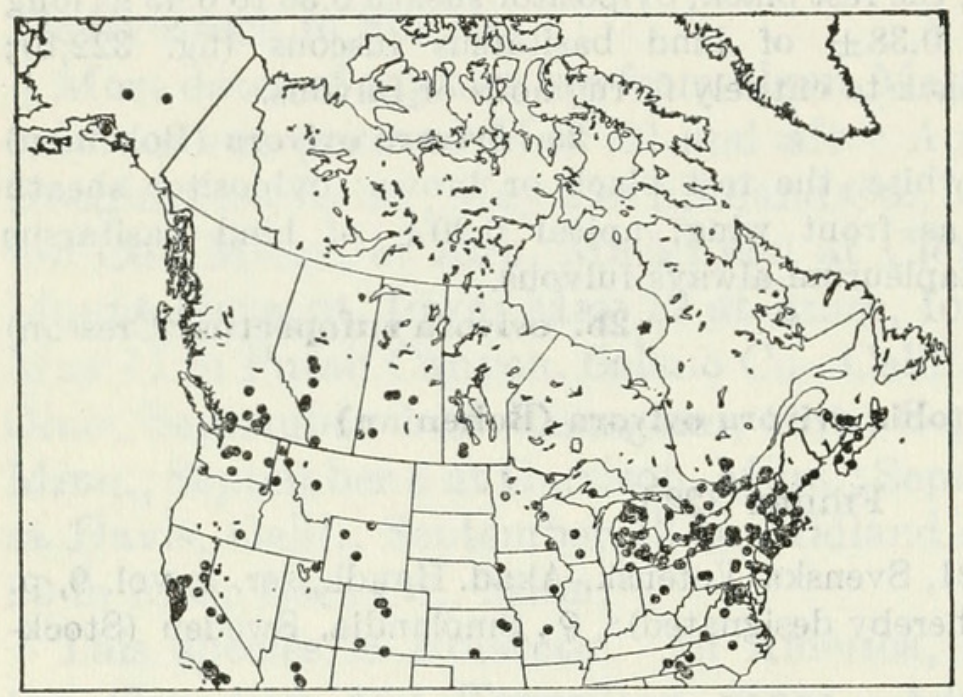

Figure 73.-Localities for Tromatobia ovivora ovivora

Female: Colored like the male except as follows: face black, usually with a narrow white mark laterally and a transverse white spot below each antennal socket; white mark on frontal orbit narrower; clypeus sometimes entirely white but usually white with the central part brown or black, sometimes entirely blackish; mandible usually white at base but sometimes entirely black; palpi white to tan; lower side of scape light brown to black, of pedicel whitish or stramineous; under side of flagellum pale brown, the rest darker; upper margin of pronotum sometimes entirely white but usually white only posteriorly; front and middle legs more or less suffused with fulvous, usually only their trochanters being entirely whitish.

This subspecies is quite variable in the Nearctic region, and the varieties have some geographic restriction. We have not, however, been able to segregate them as separate subspecies. Specimens from the North tend to resemble specimens from Europe very closely. These are relatively small, narrow in build, with the white lateral mark on face restricted or absent, clypeus dark with a lateral white area, fulvous areas on thorax restricted, and fuscous bands on hind tibia both broad and sharply defined. In the Western States the species tends to be more robust, with more extensive fulvous areas on thorax, 
and the fuscous marking on hind tibia and tarsus either tending to be diffuse as in the European Tromatobia angens, or not diffuse but with the basal fuscous band on the hind tibia very narrow. This latter variation seems to occur in arid localities. These illustrate the types of variation that may be found, but the total number of combinations of variations is more extensive. The subspecies is present in Hawaii, where it is represented by a race similar in appearance to that in southwestern California (as at San Diego). Presumably it was introduced into Hawaii from that area.

Specimens $\left(227 \sigma^{x}, 611\right.$ ) $)$; From Alaska (Fort Wrangle, Lawing on the Kenai Peninsula, Mount McKinley at 1,600 ft., and Shaw Creek at Mile 289 on the Richardson Highway); Alberta (Banff at 4,000 ft., Bilby, Laggan, Sylvan Lake, Vermillion Lake near Banff at 4,500 ft., Wabamun, and Waterton); Arizona (Oak Creek Canyon, and Parker Creek and Workman Creek in the Sierra Ancha); British Columbia (Chilliwack, Cultus Lake, Inverness, Keremeos, Lorna, Okanagan Falls, 100 Mile House, Ruskin, Sumas Prairie, Vernon, and Warfield); California (Alameda Co., Alum Rock Park in Santa Clara Co., Berkeley, Big Pine Creek in Inyo Co., Bolinas, Camino, Capistrano, Carmel, Cisco, Davis, "Fieldbrook," Fish Camp, Glendale, Hallelujah Junction in Lassen Co., Hayward, La Jolla, Lagunitas, Leevining, Los Angeles, Mesa Grande in Sonoma Co., Mill Valley, Mount Diablo, Mountain View, Mountain Home in San Bernardino Co., Oakland, Orange, Palmdale, Pasadena, Redlands, Sacramento, Samuel Spring in Napa Co., San Diego, Vallejo, Watsonville, and South Pasadena); Colorado (near Estes Park, Morley, Pagosa Springs, Phantom Valley in Rocky Mountain National Park at 9,400 ft., and University of Colorado Campus at Boulder); Connecticut (East Hartford, Voluntown, and West Haven); District of Columbia (Washington); Idaho (Cornwall, Priest Lake, and Wallace); Iowa (Henry Co. and Sioux City); Kansas (Baldwin, Cowley Co., La Cygne, and Lawrence); Maine (Casco, Southwest Harbor, and Lincoln Co.); Manitoba (Aweme and Douglas Lake); Maryland (Bowie, Cabin John, Glen Echo, near Great Falls, Plummers Island, and Takoma Park); Massachusetts (Amherst, Essex, Holliston, and Nahant); Michigan (Alpena Co., Ann Arbor, Bay Co., Branch Co., Cheboygan Co., East Lansing, Emmet Co., Gaylord, Kent Co., Manistee Co., Marquette Co., Mecosta Co., Midland Co., Newaygo Co., Osceola Co., Presque Isle Co., Shiawassee Co., George Reserve in Livingston Co., Springvale in Charlevoix Co., and Wexford Co.); Minnesota (Houston Co., Itasca Park, Kawishiwi River, and Willow River); Missouri (Columbia); Montana (Goldcreek); New Brunswick (Tabusintac); New Hampshire (Franconia, Jaffrey, Pinkham Notch, and Mount Washington); New Jersey (Bergen Co., Moorestown, 
Pemberton, and Ramsey); New Mexico (Rio Ruidoso in the Sierra Blanca at 6,500 ft.); New York (Barrytown, Bemus Point, Buffalo, Cold Spring Harbor, Connecticut Hill in Tompkins Co., Downsville, East Bethany, Elmira, Farmingdale, Flatbush, Floral Park, Granville, Greene Co. at 2,500 ft., Hancock, Heart Lake in Essex Co., Ithaca, Keene Valley in Essex Co., Lake Mohonk in Ulster Co., Lake Sebago in Bear Mountain Park, Lakeside Park in Orleans Co., Ludlowville, McLean Bogs Reserve in Tompkins Co., top of Mount MacIntyre in Essex Co., New York City, Niagara Falls, North Evans, Oneonta, Oswego, Poughkeepsie, Sag Harbor, Shokan, Taughannock, and Wayne Co.); North Carolina (Crabtree Meadows in Yancey Co. at 3,600 ft., Mount Pisgah at 4,600 ft., and Wake Co.); Nova Scotia (Annapolis Royal, Baddeck, Kentville, Truro, and White Point Beach); Ohio (Cleveland, Columbus, Montgomery Co., Puritas Springs in Cuyahoga Co., and Put-in-Bay); Ontario (Bells Corners, Bothwell, Bowmanville, Constance Bay, Galetta, Go Home Bay, Golden Lake, Grimsby, Hastings Co., Ingersoll, Marmora, Merivale, Niagara Falls, Orillia, Ottawa, Point Pelee, Simcoe, Southampton, Sudbury, and Toronto); Oregon (Antelope Mt. in Harney Co., Forest Grove, and Joseph); Pennsylvania (Crisp in Westmoreland Co., Harrisburg, Ingram, "near Cookshire," Philadelphia, Presque Isle in Erie Co., Roxborough, Spring Brook, Stoverdale in Dauphin Co., and Valley Forge) ; Prince Edward Island (Alberton and Brackley Beach and Dalvay House in Canadian National Park); Quebec (Aylmer, Brome, Chelsea, Enlaugra near Sutton, Hemmingford, Knowlton, Lacoste, Montigny, Montreal, Nominingue, Sutton, and Sweetsburg); Rhode Island (Kingston and Westerly); Saskatchewan (Christopher Lake, Cypress Hills, Swift Current, Waskesiu, and White Fox); South Carolina (Greenville and near Tigerville); Tennesee (Gatlinburg); Texas (Austin); Utah (Mount Logan); Vermont (Laurel Lake near Jacksonville, Rutland, and Woodstock); Virginia (Arlington, Bluemont, Charlottesville, Dunn Loring, Falls Church, Glencarlyn, Great Falls, Meadows of Dan in Patrick Co., and Vienna); Washington (Ashford, Mount Baker, Mount Rainier at 2,700, 2,900, 3,500, 4,200, 4,700, and 5,000 ft., Snoqualmie Pass, Spokane, Union Gap, and Wenatchee); West Virginia (Bolivar); Wisconsin (Madison, Polk Co., and Portage Co.); Wyoming (Lander, mts. near Sheridan, and Shoshone Canyon at 6,500 ft.): Mexico ("Descanso" in Baja California and El Pedregil in Distrito Federal); and Hawaii (Waimea).

Collection dates are from rather early spring to late fall, but the species is commonest in the summer months. Unusually early and late seasonal records are: January 25 at Glendale, Calif.; March 25 at Berkeley, Calif., April 3 and 12 at Berkeley, Calif.; April 11 at 
Mill Valley, Calif.; April 12 in the Union Gap Mts., Wash.; April 18 and 25 at Takoma Park, Md.; April 20 and 21 at Parker Creek, Sierra Ancha, Ariz.; April 26 at Bowie, Md.: April 15 and 17 at Ithaca, N. Y.; October 4 at Robson, B. C.; October 13 at Madison, Wis.; November 7 and 10 at Arlington, Va.; November 8 at Ramsey, N. J.; November 11 at Cabin John, Md.; November 12 at Haywood, Calif.; November 15 and 19 at Takoma Park, Md.; and December 25 at Carmel, Calif.

Rearing records are from eggs of spiders, as follows: 1 from Araneus diadema, several from $A$. angulatus, 1 from Argiope avara, 1 from A. argentata, 1 from Cyrtophora californiensis, 1 from C. californiensis?, and 12 from "spider eggs." The usual habitat is rank shaded vegetation.

This subspecies is transcontinental in the Hudsonian, Canadian, Transition, and Upper Austral zones. Adults occur throughout the growing season. Egg sacs of various argiopid spiders serve as hosts.

\section{2b. Tromatobia ovivora rufopectus (Cresson), new status}

Figure 322 , c

Pimpla rufopectus Cresson, 1870, Trans. Amer. Ent. Soc., vol. 3, p. 148; $q$. Type: , Pennsylvania (Philadelphia).

Biology: Champlain, 1922, Psyche, vol. 29, p. 97.

Front wing of male 3.5 to $6.3 \mathrm{~mm}$. long, of female 4.2 to $7.0 \mathrm{~mm}$. long; upper and lateral faces of propodeum with punctures that are separated by about 1.0 to 1.2 their diameter; ovipositor sheath 0.43 to 0.60 as long as front wing. This subspecies averages a very little stouter than $T$. ovivora, with the tergites a little more convex and coarsely punctured, but this difference is not sufficiently great or constant enough to be of real assistance in distinguishing between them.

Colored as in T. ovivora ovivora except for the following differences: Face of female with a conspicuous transverse white bar below the antennal sockets and laterally with a broad white stripe, these white markings covering at least 30 percent of the face, or sometimes the entire face white; lower part of thorax extensively fulvous, the metapleurum entirely fulvous; blackish markings on legs a little less extensive than in $T$. ovivora ovivora, the apical fuscous band on hind basitarsus covering its apical $0.20 \pm$. Sometimes in females the black of the body is suffused with ferruginous, or rarely it is almost entirely replaced by ferruginous.

This subspecies can usually be distinguished from the subspecies ovivora in the female with little difficulty, on account of the longer ovipositor and larger amount of white on the face, though intermedi- 
ate specimens are not rare. Many males, however, are often difficult or impossible to determine with certainty.

Specimens (84 $\sigma^{7}, 205$ ) : From Connecticut (Lyme); District of Columbia (Washington); Florida (2 miles W. of Archer and Gainesville) ; Iowa (Dickinson Co. and Webster Co.); Kansas (Douglas Co. and Franklin Co.); Maine (near Bethel); Maryland (Hagerstown, Hughesville, Hyattsville, Plummers Island, and Takoma Park); Massachusetts (Holliston and Lexington); Michigan (Bay Co., Crawford Co., East Lansing, Gladwin Co., Ionia Co., Iosco Co., Kalkaska Co., Lake Co., Livingston Co., Mecosta Co., Midland Co., Portage Lake, and Saginaw Co.); New Jersey (Edgewater, Moorestown, Ridgewood, Short Hills, and Tabernacle); New York (Babylon, Barker, Dix Hills near Huntington, Farmingdale, Flatbush, Ithaca, Lake Mohonk in Ulster Co., Milford Center, Poughkeepsie, Rockaway, and Syracuse); North Carolina (Murfreesboro and Raleigh); Ohio (Columbus, Dayton, Montgomery Co., and Ross Co.); Ontario (Ingersoll, Leamington, Simcoe, and Wellington); Pennsylvania (Harrisburg, New Cumberland, Philadelphia, Pittsburgh, and Wilkes-Barre); Rhode Island (Charleston and Westerly); South Carolina (Greenville); Texas (Austin); and Virginia (East Falls Church, Falls Church, Glencarlyn, Norfolk, and Vienna).

Collecting dates are from spring to late fall, with most of the specimens taken during the summer and few before June or after August. The earliest and latest dates of capture are: April 1 at Raleigh, N. C.; April 20 at Greenville, S. C.; May 3 at Falls Church, Va.; October 4 at East Lansing, Mich.; October 20 and November 15 at Takoma Park, Md.; November 1 at Charlottesville, Va.; and November 25 in Franklin Co., Kans.

It has been reared from the egg sacs of spiders as follows: 8 rearings from Argiope aurantia, 2 from A. aurantia?, 1 from $A$. trifasciata, 3 from "Epeira" sp.; and 3 from "spider eggs." We have several times found the larvae or cocoons in the egg sacs of Argiope aurantia and occasionally reared it out. A large number of individuals mature from these large egg sacs. Overwintering is as cocoons within the spider egg sac. In collecting, we find the adults usually among bushes and rank weeds in overgrown fields or the edges of woods, in the same habitat that is occupied by Argiope aurantia.

This subspecies occurs in the Austroriparian and Carolinian faunas. It is adult throughout the growing season. The usual host is the egg sacs of Argiope aurantia, while the subspecies ovivora attacks smaller egg sacs. In habitats, where the two subspecies are sympatric, this subspecies is in brushy places and overgrown fields, while typical ovivora is usually in the rank undergrowth of moist woods. 


\section{Tromatobia zonata (Davis)}

Figures 322,d; 366

Clistopyga zonata Davis, 1895, Ent. News, vol. 6, p. 198; + Type: $\uparrow$, Illinois (Philadelphia).

Biology: Hubbell, 1932, Ann. Ent. Soc. America, vol. 35, p. 504.

Front wing of male about $4.5 \mathrm{~mm}$. long, of female 4.7 to $6.2 \mathrm{~mm}$. long; areolet absent; upper and lateral faces of propodeum with sharp punctures that are separated by about 0.8 their diameter; ovipositor sheath about 0.36 as long as front wing. This species is a little stouter in build than others of its species group.

Black. Face except for a dorsomedian area in some females, orbits of frons and occiput, cheek, clypeus, basal half of mandible, palpi, usually scape beneath, upper margin of pronotum, tegula, subtegular ridge, postscutellum, apex of scutellum, small lateral apical spot on propodeum, trochanters, front and middle tibiae, front tarsus, usually narrow subapical band on first tergite, and always narrow subapical band on second to fifth tergites, white; usually mesopleurum except above, metapleurum, mesosternum, metasternum, and sometimes most of mesoscutum fulvous, the rest of thorax fulvous to black, usually black; front and middle coxae white, tinged with fulvous basally; front and middle femora fulvous, their apex white; middle tarsus white, the apical half of fifth segment and narrow apex of first to fourth segments light brown to fuscous; hind coxa fulvous; hind femur fulvous with its apex white and a subapical infuscate band; hind tibia white with sharp apical and subbasal fuscous bands; hind tarsus white, the apical half of fifth segment and narrow apex of first to fourth segments fuscous; black ground color of abdomen sometimes more or less replaced by ferruginous.
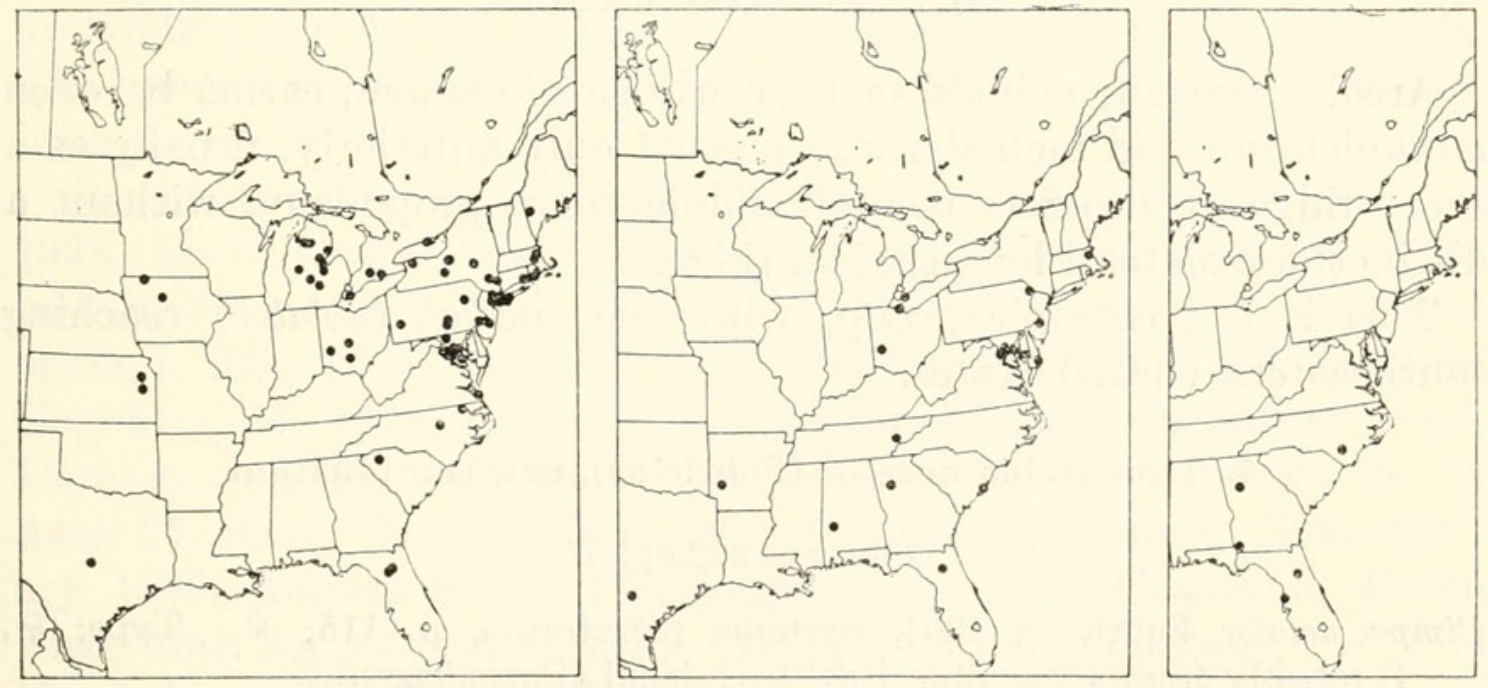

Figures 74-76.-Localities: 74 (left), Tromatobia ovivora rufopectus; 75 (center), T. zonata; 76 (right), T. notator. 
Specimens (3 $\sigma^{x}, 27$ \%): From Alabama (Thomasville); Arkansas (Howard Co.); District of Columbia (Rock Creek Park); Florida (Newman's Lake in Alachua Co.); Georgia (Atlanta); Illinois; Maryland (Cambridge, Mayo, Ocean City, and Takoma Park); Massachusetts (Cambridge); New Jersey (Moorestown); Ohio (Montgomery Co. and Put-in-Bay); Ontario (Point Pelee); Pennsylvania (Paupack); South Carolina (McClellanville); Tennessee (Knoxville); Texas (Mitchell Lake at San Antonio); and Virginia (Falls Church).

Collection dates are from mid-spring to mid-fall. Unusually early and late dates of interest are: April 16 at Atlanta, Ga.; April 20 at Thomasville, Ga.; May 4 at Falls Church, Va.; May 13 in Howard Co., Ark.; September 14 and October 27 at Mayo, Md.; September 24 and 29 at Falls Church, Va.; October 27 at Takoma Park, Md.; and November 23 at Newman's Lake, Alachua Co., Fla.

Hubbell (loc. cit.) reports this species in considerable numbers on the webs of spiders on the shore of Newman's Lake, Alachua Co., Fla., walking about on the surface of the webs, or crawling through their meshes. We have studied one of his specimens and report his locality above. Other biological data are on pin labels as follows: $0^{7}$, ㅇ, reared from spider nest, Cambridge, Mass., Apr. 12, 1917, A. M. Wilcox. $ᄋ$, reared from spider eggs, Wilcox. 2 , reared from spider eggs, Put-in-Bay, Ohio, Mary Anten. eggs, Mitchell Lake, San Antonio, Tex., May 15, 1914. Three of the nine times we have collected the species it has been taken in woods at the edges of lakes, where spiders were common because of the abundance of midges and other aquatic insects.

This species occurs in the Austroriparian and Carolinian faunas. It is adult throughout the growing season.

\section{NOTATOR GROUP}

Areolet present, pointed or narrowly sessile above; carina between metapleurum and metasternum present only anteriorly, usually as a short ridge or tubercle behind middle coxa; propodeum without a distinct dorsolateral longitudinal ridge.

This is a Neotropic group, with one species (notator) reaching southeastern United States.

\section{Tromatobia notator (Fabricius), new combination}

Figures 322 ,e; 367

Pimpa notator Fabricius, 1804, Systema piezatorum, p. 115; $\stackrel{\text {. Type: }}{\text {, }}$ [Probably from Essequibo, British Guiana] (Copenhagen).

Clistopyga? lateralis Cresson, 1865, Proc. Ent. Soc. Philadelphia, vol. 4, p. 34; $\sigma^{\Upsilon}, \uparrow$. New synonymy. Lectotype: $\uparrow$, Cuba (Havana). 
Ephialtes cressoni Dewitz, 1881, Berliner Ent. Zeitschr., vol. 25, p. 205; q . Lectotype (hereby designated): $\uparrow$, Puerto Rico, labeled lectotype by Townes in 1958 (Berlin).

Front wing of male about $6 \mathrm{~mm}$. long, of female 5.5 to $7.0 \mathrm{~mm}$. long; carina between metapleurum and metasternum present anteriorly as a short ridge; propodeum medially with sharp, mediumsized punctures, elsewhere with few or no punctures; third and fourth tergites with rather close sharp punctures except that a small median basal area and their apical $0.18 \pm$ are impunctate; ovipositor sheath about 0.35 as long as front wing.

Head white, the frons and vertex medially and occiput brownish fulvous; clypeus and mouth parts white; antenna brown, paler below; thorax fulvous, the mesosternum and lower part of propleurum more or less whitish, the hind corner of pronotum often narrowly whitish, and the propodeum with a small black spot on each side of its apex; tegula whitish or fulvous; front and middle legs pale fulvous, their coxae, trochanters, and often femora and tibiae in front more or less whitish; hind coxa, trochanters, and femur fulvous, the apex of femur paler; hind tibia fulvous, a basal band and its median part faintly paler to whitish; hind tarsus whitish, the apex of the first four segments and apical half of last segment fulvous to infuscate; abdomen fulvous, the second to sixth tergites with an apical sublateral black spot, the apical tergites often brownish; ovipositor sheath blackish.

Fabricius stated that the type of $P$. notator was from "America meridionali Dom Smidt. Mus. Dom. Lund." The material reported by Fabricius from "South America" collected by Smidt, in the Lund and Sehestedt collections in Copenhagen, is in most cases labeled "Essequibo, Smidt." Essequibo is both a river and a county in British Guiana. The type of P. notator is labeled "Am. mer. Smidt." It is probably from the lot of material collected by Smidt in Essequibo. The species is not, however, yet known from additional specimens from that area.

Specimens: $\sigma^{7}$, 6\%, Baragua, Cuba, July 24, 1929 and Aug. 8, 1928, L. C. Scaramuzza (Cambridge and Washington). क, Interlachen, Fla., Apr. 2, 1951, H. and M. Townes (Townes). \&, Tarpon Springs, Fla., Mar. 14, 1950, H. K. Townes (Townes). क, Atlanta, Ga., May 14, 1929, P. W. Fattig (Washington). $\sigma^{x}$, Spring Creek, Decatur Co., Ga., July 16, 1929 (Ithaca). \&, Elizabethtown, N. C., April 25, H. K. Townes (Townes). , Aguadilla, Puerto Rico, January 1899, August Busck (Washington). $\sigma^{x}$, $\%$, Cuayama, Puerto Rico, Mar. 25, 1934, A. S. Mills (Townes and Washington). $\sigma^{7}$, Hell Road, Mona Isl., Puerto Rico, Oct. 28, 1955, W. H. Cross (Washington). $2 \sigma^{7}$, Lares, Puerto Rico, Sept. 8, 1921, G. N. Wolcott and F. Sein (Washington). $\sigma^{\top}$, Mayagüez, Puerto Rico, May 16, 1935, R. 
Bonilla (Cambridge). ㅇ, Mayagüez, Puerto Rico, Apr., 12, 1915, R. H. Van Zwaluwenburg (Washington). $\sigma^{\pi}$, Palo Seco, Puerto Rico, May 24, 1937, A. S. Mills (Washington). ' ${ }^{x}$, Ponce, Puerto Rico, December 1933, V. Godieau (Townes). $\sigma^{x}$, San Juan, Puerto Rico (Washington).

This species is known from the tropical and subtropical parts of the Southeastern States, and from the West Indies.

\section{Genus Zaglyptus}

Figure 290,b

Zaglyptus Foerster, 1868, Verh. Naturh. Ver. Rheinlande, vol. 25, p. 166. Type: Polysphincta varipes Gravenhorst; included by Wolstedt, 1877.

Front wing 3.0 to $9.6 \mathrm{~mm}$. long; body a little less long and slender than most other Pimplini; face and clypeus variously colored, white to black; frons sometimes with whitish orbital mark; clypeus strongly convex, its apex impressed, its apical margin concave; occipital carina complete, without a median dip; hair on mesoscutum moderately dense, sparse, or lacking; submetapleural carina complete or incomplete; propodeum moderately long, without median longitudinal carinae, with a lateral subapical tubercle which is weak in the male and very prominent in the female; areolet absent; nervellus broken usually above the middle but in some non-Nearctic species broken near or a little below the middle; first tergite short and broad, with an oblique groove on each side just beyond the middle, its median and lateral longitudinal carinae present or absent; second tergite with rather sharp oblique basolateral grooves and oblique apicolateral grooves which together delimit a median, raised, rhombic area; third and fourth tergites with strong transverse tubercles, their apical impunctate band occupying about 0.22 their length; female subgenital plate sclerotized apically and lateroapically, the rest membranous; ovipositor straight, compressed, its tip as in figure 331,d (the basal tooth enlarged and forming a long free barb); ovipositor sheath about 0.47 as long as front wing.

Zaglyptus is worldwide in distribution but contains relatively few species. Three Nearctic species are known, but only one of these is widely distributed. $Z$. varipes attacks spider eggs as described under that species. The rest of the species probably have similar habits.

\section{Key to the Nearctic species of Zaglyptus}

1. Carina between metasternum and metapleurum complete; abdomen black or more or less ferruginous . . . . . . . . . 1. varipes (Gravenhorst)

Carina between metasternum and metapleurum almost absent, present only anteriorly as a short ridge or blunt tooth; abdomen white laterally, darker medially 
2. Hairs on mesoscutum moderately dense; head black, white near antennal sockets; pronotum mostly white . . . . . . 2. arizonicus, new species

Hairs on mesoscutum very sparse; head ferruginous, the face and orbits white; pronotum ferruginous . . . . . . . . . 3. pictilis, new species

\section{Zaglyptus varipes (Gravenhorst)}

Figures 331,d; 368

Front wing of male 3.0 to $4.7 \mathrm{~mm}$. long, of female 4.6 to $5.6 \mathrm{~mm}$. long; occiput not impressed medially, so that the head does not appear to be broadly notched behind; male flagellum with strong and conspicuous broad notches between the sixth and seventh and the seventh and eighth segments; mesoscutum rather densely hairy, the hair sockets separated by about 0.6 the length of the hairs; carina between metasternum and metapleurum complete; front leg of male with two broad weak notches on under side of femur toward apex and on under side of tibia toward base; abdomen with rather dense coarse punctures which are a little smaller and sparser on the paired swellings and absent from the apical 0.2 of each tergite.

This is a Holarctic species, with American and European subspecies. The biology of the European subspecies has been described by Nielsen (1935, Entomologiske Meddelelser, vol. 19, p. 206-215). It attacks nest-making spiders of the genera Cheiracanthium, Attus, and Clubiona that place their egg cocoons within the nests. The parasite finds a nest containing eggs, stings to death the female in the nest with the eggs, and lays one to eight eggs on the egg cocoon, or sometimes some or all of them on the body of the spider. The ichneumonid larvae consume both the eggs and most of the spider. In some cases it attacks spiders in nests without eggs.

The two subspecies are distinguishable on color:

1. Hind coxa of male black; tegula of female brown; range: Europe.

1a. varipes varipes (Gravenhorst)

Hind coxa of male fulvous; tegula of female usually white; range: Nearctic region . . . . . . . . . 1b. varipes incompletus (Cresson)

\section{1a. Zaglyptus varipes varipes (Gravenhorst)}

Polysphincta varipes Gravenhorst, 1829, Ichneumonologia europaea, vol. 3, p. 117; $\sigma^{7}$. Type: $\sigma^{7}$, Warmbrunn, Germany (lost during World War II).

Black. Clypeus dark brown; palpi stramineous; antenna brown, stramineous apically and basally below; extreme hind corner of pronotum not pale; tegula stramineous to fuscous, the tegula of female brown; front coxa dark brown; middle and hind coxae of male fuscous, paler at apex, the middle coxa not so dark as hind coxa; middle and hind coxae of female fulvous; legs otherwise as in $Z$. varipes incom- 
pletus; median abdominal tergites usually more or less ferruginous, most often ferruginous only basally and laterally.

Described from $60^{7}$, 4 우 from Ireland, England, Germany, and Austria.

\section{1b. Zaglyptus varipes incompletus (Cresson)}

Figure $322, \mathrm{f}$

Pimpla incompleta Cresson, 1870, Trans. Amer. Ent. Soc., vol. 3, p. 147; $\wp^{\circ}$ Type: + , Illinois (Philadelphia).

Pimpla animosa Cresson, 1872, Trans. Amer. Ent. Soc., vol. 4, p. 165; ㅇ T Type: ○, Bosque Co., Texas (Philadelphia).

Polysphincta rubricapensis Provancher, 1873, Naturaliste Canadien, vol. 5, p. 470 ; $\$$. Type: $\$$, Quebec (Quebec).

Cylloceria lemoinei Provancher, 1873, Naturaliste Canadien, vol. 5, p. 471; ه7.

Type: $\sigma^{\top}$, ?Quebec (Quebec).

Polysphincta pimploides Walsh, 1873, Trans. Acad. Sci. St. Louis, vol. 3, p. 145;

§. Type: $\uparrow$, ?Illinois (destroyed in Chicago fire of 1871).

Polysphincta rufigaster Ashmead, 1890, Proc. U. S. Nat. Mus., vol. 12, p. 447;

१. Type: $q$, Texas (Washington).

Polysphincta spinosa Davis, 1898, Trans. Amer. Ent. Soc., vol. 24, p. 368; .

Type: $q$, Urbana, Ill. (Philadelphia).

Black, or the black ground color sometimes more or less replaced with ferruginous or fulvous. Clypeus dark brown; palpi stramineous; antenna brown, stramineous apically and basally below; extreme hind corner of pronotum usually stramineous to white; tegula white, in female sometimes more or less brown; coxae fulvous, rarely the front coxa more or less infuscate, or sometimes whitish; front trochanters pale yellowish; middle and hind trochanters fulvous; femora fulvous, the front femur paler at apex, the hind femur fuscous at apex; front tibia fulvous, paler at base; middle tibia fulvous, more or less tinged with brown, with a basal whitish band and another whitish band just basad of middle, the bands incomplete below; hind tibia whitish, with broad apical and subbasal fuscous bands; front and middle tarsi

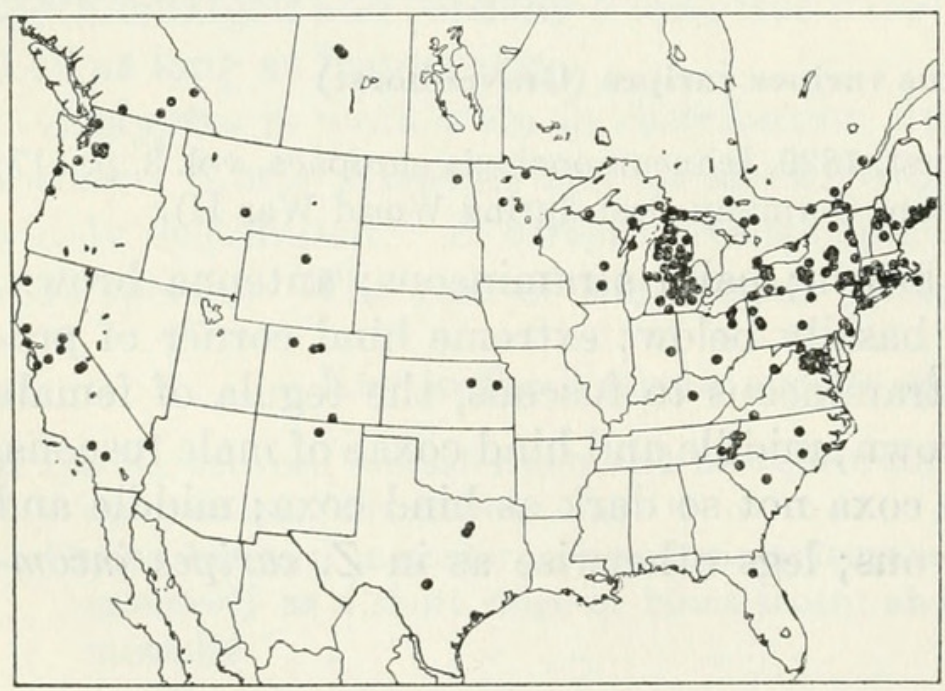

FiguRe 77.-Localities for Zaglyptus varipes incompletus. 
stramineous, the segments of middle tarsus brownish apically; hind tarsus of male fuscous, the fifth segment light brown and the first to fourth segments pale basally; hind tarsus of female whitish, the fourth and fifth segments pale brown and the first to third segments infuscate apically.

Specimens (202 $\sigma^{7}, 235$ ) : From Alaska (Anchorage and Mount McKinley at 2,000 ft.); Alberta (Slave Lake); British Columbia (Bear Lake, Carbonate on the Columbia River at 2,600 ft., Kaslo, Oliver, and Robson); California (Camino, Cazadero, Colton, Fish Camp, Humboldt Co., Inverness, Mokelumne Hill in Calaveras Co., Needles, Ripley, Santa Cruz Mts., and Tracy); Colorado (near Estes Park, Morley, Phantom Valley in Rocky Mountain National Park at 9,400 ft., and Steamboat Springs); Connecticut (Colebrook, Lebanon, Ledyard, North Stonington, Stonington, and Storrs); Florida (Alachua Co.); Illinois (Urbana); Kansas (Douglas Co. and Riley Co.); Kentucky (Lexington); Maine (Casco, Great Pond on Mount Desert, Hulls Cove, Knox Co., Liberty, Lincoln Co., Little Deer Island, Machias, and Southport); Maryland (Cabin John, Glen Echo, Hughesville, Mayo, Patuxent Research Refuge near Bowie, and Takoma Park); Massachusetts (Amherst, Chester, Holliston, Humarock, Monterey, Nantucket, and South Hadley); Michigan (Alger Co., Alpena Co., Ann Arbor, Antrim Co., Arenac Co., Bay Co., Cheboygan Co., Chippewa Co., Clare Co., Clinton Co., Delta Co., Douglas Lake, Drummond Island, East Lansing, Genesee Co., Gladwin Co., Gogebic Co., Grand Traverse Co., Gratiot Co., Gull Lake Biological Station in Kalamazoo Co., Iosco Co., Isabella Co., Jackson Co., Kalkaska Co., Livingston Co., Mackinac Co., Mecosta Co., Midland Co., Missaukee Co., Montcalm Co., Newaygo Co., North Manistique Lake in Luce Co., Oakland Co., Oceana Co., Osceola Co., Oscoda Co., Otsego Co., Roscommon Co., Saginaw Co., St. Joseph Co., Shiawassee Co., Tuscola Co., and Wexford Co.); Minnesota (Cass Co., Chisago Co., Itasca Park, and Koochiching Co.) ; Montana (Bozeman); New Brunswick (Nerepis); New Hampshire (Center Harbor, Franconia, Glen House, Mount Washington at 4,700 ft., and Pinkham Notch); New Jersey (Moorestown and Tabernacle); New Mexico (Cimarron at 6,800 and 9,500 ft.); New York (Bemus Point, Big Island in Orange Co., Canajoharie, Cold Spring Harbor, Farmingdale, Grand Island, Hague, Ithaca, Lake George, Lake Mohonk in Ulster Co., Lancaster, Mclean Reserve in Tompkins Co., New Rochelle, North Blenheim, Olean, Oneonta at 1,900 ft., Otsego Lake, Peekskill, Poughkeepsie, Salisbury Center, Saranac Lake, Shandakan, Shokan, Slaterville, South Trenton, Springdale in Cayuga Co., Syracuse, and Troy); North Carolina (Cedar Mt., Crabtree Meadows in Yancey Co. at 3,600 ft., Elizabethtown, Hamrick, Lake Junaluska, Mount Mitchell at 5,200 
and 6,400 ft., Mount Pisgah at 5,000 to 5,749 ft., New River, and Wake Co.); North Dakota (Stump Lake in Nelson Co.); Nova Scotia (Cape Breton); Ohio (Hinckley in Medina Co., Hocking Co., North Olmsted, and Puritas Springs in Cuyahoga Co.); Ontario (Coniston, Kearney, Muskoka District, Ottawa, Parr Island in East Spence Lake, Ridgeway, Toronto, and Waubamik); Oregon (Cannon Beach and Newport); Pennsylvania (Allegheny Co., Hartstown, Hummelstown, Mansfield, Milford, Mud Creek in Butler Co., North East, Philadelphia, and Presque Isle in Erie Co.); Quebec (Isle de Perrot near Montreal, St. Esprit, St. Johns, and Stoneham); Rhode Island (Ashaway and Westerly); Saskatchewan (Prince Albert National Park and Waskesiu); South Carolina (Columbia and Greenville); Texas (Bosque Co., Dallas, Port Lavaca, and San Antonio); Virginia (Arlington, Chain Bridge near McLean, Dead Run in Fairfax Co., Falls Church, Galax, Glencarlyn, and Mount Vernon); Washington (Ashford, Barnes State Park, Bothell, Elbe, Mount Rainier at 2,700, 2,900, and 4,700 ft., and Snoqualmie Pass); West Virginia (Bolivar and Cheat Mt. at 2,000 ft. in Randolph Co.); Wisconsin (Door Co., Green Lake Co., and Madison); and Wyoming (Buffalo).

Dates of capture record adults mostly from about May 20 to September 15, with some few specimens earlier and later. Captures before May 1 and after September 30 are scanty. Those on record are as follows: January 27 in Alachua Co., Fla.; March 26 at Dead Run, Fairfax Co., Va.; April 3 at San Antonio, Tex.; April 10 and 15 at Takoma Park, Md.; April 13 and 30 at Elizabethtown, N. C.; April 22 at Hughesville, Md.; April 23 in Wake Co., N. C.; October 1, 7, and 10 at Madison, Wis.; October 4 at Cedar Mt., N. C.; October 6 at Inverness, Calif.; October 8 at Greenville, S. C.; October 9 at Bowie, Md.; October 27 at Mayo, Md.; and December 15 at Port Lavaca, Tex.

This subspecies is transcontinental in the Hudsonian, Canadian, Transition, and Upper Austral zones and occurs sporadically in the Lower Austral zone. It is adult from mid-spring to mid-fall. Its habitat is coarse grasses in damp places, also shrubbery, weeds and undergrowth in woods.

\section{Zaglyptus arizonicus, new species}

\section{Figure $322, \mathrm{~g}$}

Female type: Front wing $5.2 \mathrm{~mm}$. long; occiput not impressed medially so that the head does not appear to be broadly notched behind; mesoscutum rather densely hairy, the hair sockets separated by about 0.6 the length of the hairs; carina between metasternum and metapleurum present only anteriorly as a very short ridge; abdomen with rather dense coarse punctures which are much sparser on the paired swellings and absent from the apical 0.2 of each tergite. 
Head black with a white area around each antennal socket; clypeus and side of face dark brown; palpi whitish; antenna ivory, brown above and pale brown apically; thorax fulvoferruginous, the pronotum ivory with a fulvous anterocentral area, propleurum whitish, mesoscutum ivory along part of its anterolateral edge, mesopleurum with an ivory spot near middle coxa, tegula and subtegular ridge whitish, apex of scutellum ivory, propodeal tubercles entirely ivory, and propodeum blackish around the foramen of the abdominal extensor tendon; legs ivory, the middle coxa tinged with fulvous basally, middle femur with faint anterodorsal and posterodorsal fuscous stripes, hind femur with weak anterodorsal and posterodorsal fuscous stripes and fuscous at base, hind tibia with a moderately narrow subbasal and apical brown band, apical 0.35 of first segment of hind tarsus infuscate, and apical 0.35 of second segment of hind tarsus brownish. The ground color of the hind tibia and tarsus is white rather than ivory. Abdomen ferruginous, broadly white along the side, its tergal swellings and apical margins of tergites brownish, and median part of its apical tergites infuscate.

Type: + , Parker Creek, Sierra Ancha, Ariz., May 2, 1947, H. and M. Townes (Washington, USNM 63694).

We have seen specimens generally similar to $Z$. arizonicus from Mexico, Venezuela, and Brazil, but which differ among themselves and from $Z$. arizonicus in some minor features of the color pattern, and particularly from arizonicus in having the color markings more contiasted. These may represent subspecies of $Z$. arizonicus, but for the present we classify the lot as four distinct species. One of the four is (Pimpla) Zaglyptus simonis (Marshall) 1892 (new combination).
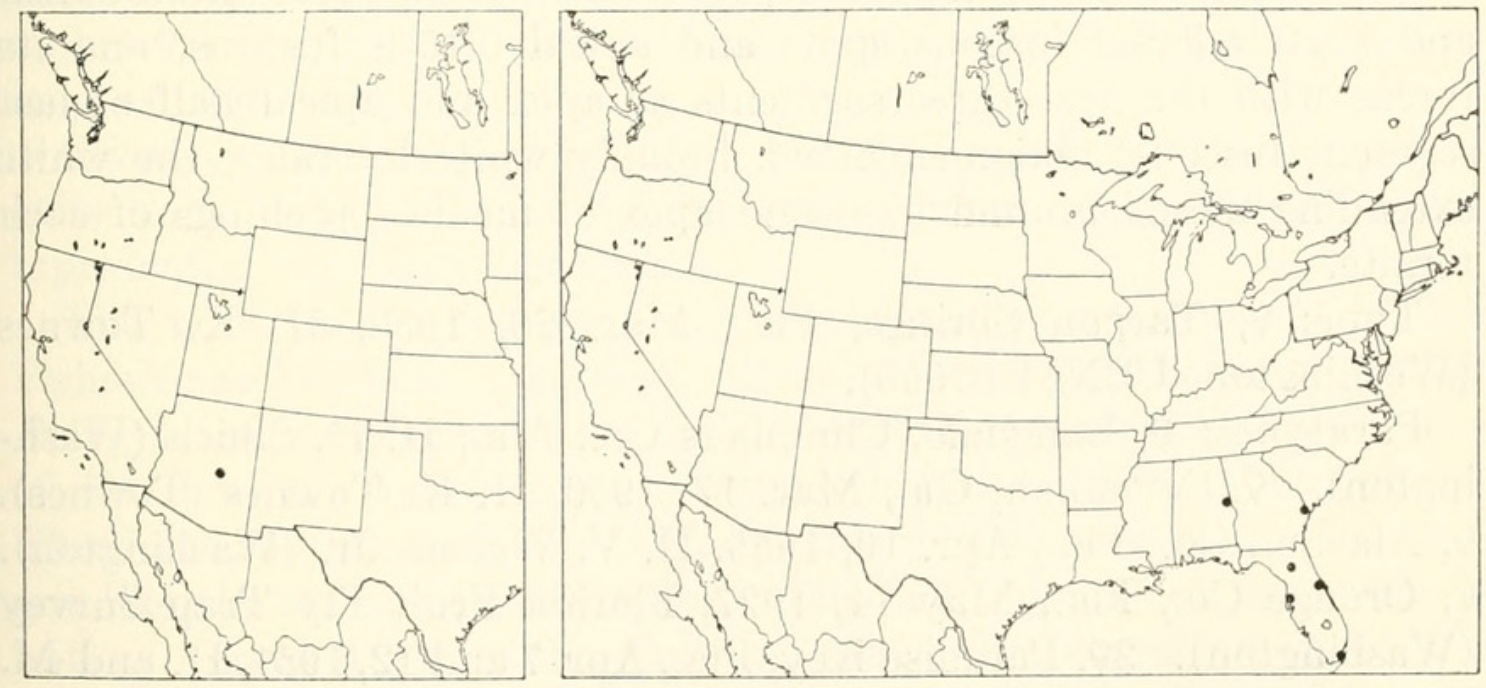

Figures 78, 79.-Localities: 78 (left), Zaglyptus arizonicus; 79 (right), Z. pictilis. 


\section{Zaglyptus pictilis, new species}

Figures 322 ,h; 369

Front wing of male 3.3 to $3.8 \mathrm{~mm}$. long, of female 4.0 to $4.7 \mathrm{~mm}$. long; occiput weakly impressed medially so that the head appears to be broadly, weakly notched behind; male flagellum simple, not notched between the sixth and seventh and the seventh and eighth segments; mesoscutum with a few hairs in front but almost none elsewhere; carina between metasternum and metapleurum present only anteriorly as a very short ridge; abdomen of male with rather dense coarse punctures except on the apical 0.2 of the tergites; abdomen of female also with dense punctures but the punctures almost absent from the apical tergites and from the paired median swellings of the second to fifth tergites.

Head white, the occiput brownish fulvous, front and vertex except near eyes brownish fulvous, and sometimes the face with a narrow median pale fulvous stripe; clypeus white to fulvous; mouth parts white, the apical 0.4 of mandible black; antenna dark brown, whitish basally below, light brown apically; thorax fulvous, the propleurum mostly white and propodeum with a narrow apical black margin; tegula of male pale fulvous, of female white; front leg white, the femur with a light fuscous posterodorsal stripe and often also with a faint anterodorsal fuscous stripe; middle leg white, the femur and first trochanter fuscous at base above, the femur with a broad posterodorsal and narrow weak anterodorsal fuscous stripe, the tibia fuscous on extreme apex, the first three tarsal segments fuscous on apex, and apical half of last tarsal segment brownish; hind leg wbite, its coxa with a large anteroventral blackish spot, its first trochanter and femur fuscous at base, its femur with anterodorsal and posterodorsal fuscous stripes and extreme apex fuscous, its tibia with subbasal anterodorsal and posterodorsal fuscous spots and apical $0.15 \pm$ fuscous, and its tarsus with the first three segments at apex and apical half of last segment fuscous; abdomen black, broadly white laterally, the white extending mesad around base and apex of median swellings of each tergite.

Type: ㅇ, Tarpon Springs, Fla., Mar. 20, 1950, H. K. Townes (Washington, USNM 63695).

Paratypes: ㅇ, Langdale, Chambers Co., Ala., H. H. Smith (Washington). \&, Savannah, Ga., Mar. 17, 1950, H. K. Townes (Townes). , Alachua Co., Fla., Apr. 10, 1955, H. V. Weems, Jr. (Washington). , Orange Co., Fla., May 14, 1927, Florida Fruit Fly Trap Survey (Washington). 2o, Paradise Key, Fla., Apr. 7 and 12, 1951, H. and M. Townes (Townes). $2 \sigma^{\top}, 2$, Tarpon Springs, Fla., Mar. 19 and 20, 1950, H. K. Townes (Townes). †, on plane from Havana, Cuba, Jan. 24, 1952 (Washington). 
This species occurs in the tropical and subtropical parts of the Southeastern States. Our collections were from the undergrowth of damp deciduous woods.

\title{
12. Genus Clistopyga
}

\author{
Figure 291,a
}

Clistopyga Gravenhorst, 1829, Ichneumonologia europaea, vol. 3, p. 132. Type: Ichneumon incitator Fabricius; designated by Westwood, 1839.

Ichneumonoglypta Blanchard, 1941, Rev. Soc. Ent. Argentina, vol. 11, p. 9.

Type: Ichneumonoglypta lopez-richinii Blanchard; original designation. Hymenomacropyga Uchida, 1941, Ins. Matsumurana, vol. 15, p. 116. Type: Hymenomacropyga latifrontalis Uchida; original designation.

Front wing 3.4 to $11 \mathrm{~mm}$. long; body long and slender; face, clypeus, and frontal orbits partly or entirely white; clypeus narrow, convex, somewhat flattened apically, its apical margin concave; occipital carina complete, not dipped medially above; hairs on mesoscutum usually moderately dense and evenly distributed, sparse in some Neotropic species; submetapleural carina complete or incomplete; propodeum moderately long to very long, its median longitudinal carinae weak or absent; areolet absent; nervellus broken below the middle or not broken; first tergite moderately long, its median and lateral longitudinal carinae present or absent; second tergite with long sharp, oblique, basolateral grooves, which together with weaker and more transverse apicolateral grooves bound a large median subrhombic area; third and fourth tergites with weak or faint tubercles, otherwise smooth, without a distinct apical impunctate band; female subgenital plate large, shovel-shaped with a rounded apex, its apex projecting a little; ovipositor compressed, tapered from base to apex, its surface mat (polished in all other Pimplini except for weak wrinkling on the lower valve in Tromatobia), its basal $0.5 \pm$ straight, and apical $0.5 \pm$ upcurved (figs. $332, \mathrm{a}, \mathrm{b}$ ); ovipositor sheath about 0.3 as long as front wing.

Clistopyga is widely distributed, but the species are very scarce in collections. We have seven Nearctic species, only two of them represented by many specimens.

The position of Clistopyga in the taxonomic arrangement of the Ephialtinae has been unsettled. Usually it has been associated with Polysphincta or placed in the Polysphinctini, because of the absence of the areolet, short, tapered ovipositor, and general body form. There are some features in the adult morphology, however, that are not like the other Polysphinctini. The last segment of the tarsus is not as enlarged as in the Polysphinctini, the tarsal claws of the female are not as short and broad as usual for the Polysphinctini, and the course of the prepectal carina is more like that of the Pimplini 
than the Polysphinctini. The ovipositor is like that of no other ichneumonid. In its shortness and its long tapered point it is like the Polysphinctini, but its surface is mat rather than polished and the submedian swelling present in the Polysphinctini is lacking in Clistopyga. The female subgenital plate is large and scoop-shaped, and thus is like no other genus of its subfamily. A minor character, but one of interest, is that in some species of Clistopyga the apex of the hind tarsus is paler than the preapical part, a color pattern that often occurs in the genera Zaglyptus and Tromatobia. This color character shows up sometimes also in the primitive Polysphinctini.

The adult morphology gives conflicting evidence, and for more indications of its true relationships, we turn to the early stages and biology. Here too the evidence is conflicting, but though the genus has been reported as parasitic on a diverse assemblage of hosts, it seems very probable that the true hosts are spiders or their egg sacs, and that records of other hosts are due to overlooking parasitized spiders or their eggs among the other material from which rearings were made.

Nielsen has published the most circumstantial account of the biology of Clistopyga (1929, Entomologiske Meddelelser, vol. 16, pp. 366-368). He reared Clistopyga incitator in Germany as a gregarious parasite in an egg sac of Sergestria senoculata. The larval and pupal morphology, as he figures them, are very similar to those of Tromatobia and Zaglyptus, and different from those of the Polysphinctini. With these data and a consideration of additional evidence, which is admittedly fragmentary and inconclusive, it appears that Clistopyga is parasitic in the egg sacs of those spiders whose egg sacs are placed in various kinds of crevices, and that the genus is rather closely related to Tromatobia and Zaglyptus, in the Pimplini.

\section{Key to the Nearctic species of Clistopyga}

1. Frontal orbit white or partly white; temple weakly convex, in profile as long as eye . . . . . . . . . . . . . . . . . . 2

Frontal orbit not white but usually a white orbital mark at top of eye; temple moderately convex, in profile 0.6 to 0.7 as long as eye. . . . . . . . . 4

2. Submetapleural carina complete; range: eastern North America.

7. recurva (Say)

Submetapleural carina present only on front third of metapleurum; range: western North America . . . . . . . . . . . . . . . . . 3

3. Hind tibia without a subbasal brown band; white orbital mark on frons interrupted just above antennal socket; propodeum exceptionally short and flat. . . . . . . . . . . . . 5. nigrifrons Cushman

Hind tibia with a subbasal brown band; white orbital mark on frons not interrupted; propodeum moderately long, rather strongly convex.

6. manni Cushman

4. Abdomen largely fulvous; hind tibia fulvous with an apical and subbasal infuscation; mesopleurum and metapleurum rather strongly mat.

4. alutaria, new species 
Abdomen black; hind tibia black with a median white band; mesopleurum and metapleurum polished or subpolished . . . . . . . . . . . . . . 5

5. Metapleurum and much of mesopleurum fulvous; white on hind corner of pronotum extending forward as a narrow stripe along upper edge.

3. maculifrons Cushman

Metapleurum and mesopleurum entirely black; white on hind corner of pronotum not extending forward along upper edge . . . . . . . . . . . 6

6. Metapleurum punctate all over; temple of male without a transverse ridge just behind lower corner of eye; ovipositor a little more slender.

1. atrata Cushman

Metapleurum punctate on about its posterior half, the rest impunctate; temple of male with a transverse ridge just behind lower corner of eye; ovipositor a little stouter . . . . . . . . . . . . 2. canadensis Provancher

\section{Clistopyga atrata Cushman}

Clistopyga atrata Cushman, 1921, Proc. U. S. Nat. Mus., vol. 60, art. 4, p. 14; $\sigma^{x}$, + Type: $q$, Berkeley, Calif. (Washington).

Front wing about $4.8 \mathrm{~mm}$. long in both sexes; temple of male not specialized near lower end of eye; metapleurum polished, covered with small punctures that are separated, on the average, by about three times their diameter, the punctures a little sparser anteriorly; propodeum moderately short and convex, subpolished, with rather coarse punctures except in the petiolar area, medially rugulose and a little mat; first tergite about 1.1 as long as wide; ovipositor moderately stout, a very little more slender than in C. canadensis. Otherwise structurally similar to $C$. canadensis.

Colored as in $C$. canadensis except that in all the specimens at hand the antenna is blackish with the pedicel and flagellum tinged with brown below.

Specimens: $\odot$, near Alpine, Ariz., May 23, 1947, H. and M. Townes (Townes). ㅇ (type), Berkeley, Calif., September 1914, E. P. Van Duzee (Washington). $\sigma^{\top}$ (paratype), taken from gallery of Calopus angustus in Pinus murrayana, Yosemite National Park, Calif., Aug. 10, 1917, J. E. Patterson (Washington).

This species bas been taken in the Transition and Canadian zones of California and Arizona.

\section{Clistopyga canadensis Provancher}

Figure 332 ,a

Polysphincta acuta Provancher, 1880, Naturaliste Canadien, vol. 12, p. 44 (Faune, p. 465); $\uparrow$. Type: $\uparrow$, Cap Rouge, Que. (Quebec).

Clistopyga Canadensis Provancher, 1880, Naturaliste Canadien, vol. 12, p. 46 (Faune, p. 467);. Type: $\$$, Cap Rouge, Que. (Quebec).

Front wing of male 3.9 to $4.9 \mathrm{~mm}$. long, of female 4.0 to $5.7 \mathrm{~mm}$. long; body rather short and stout; temple of male with a strong transverse ridge just behind lower corner of eye; temple moderately convex, 

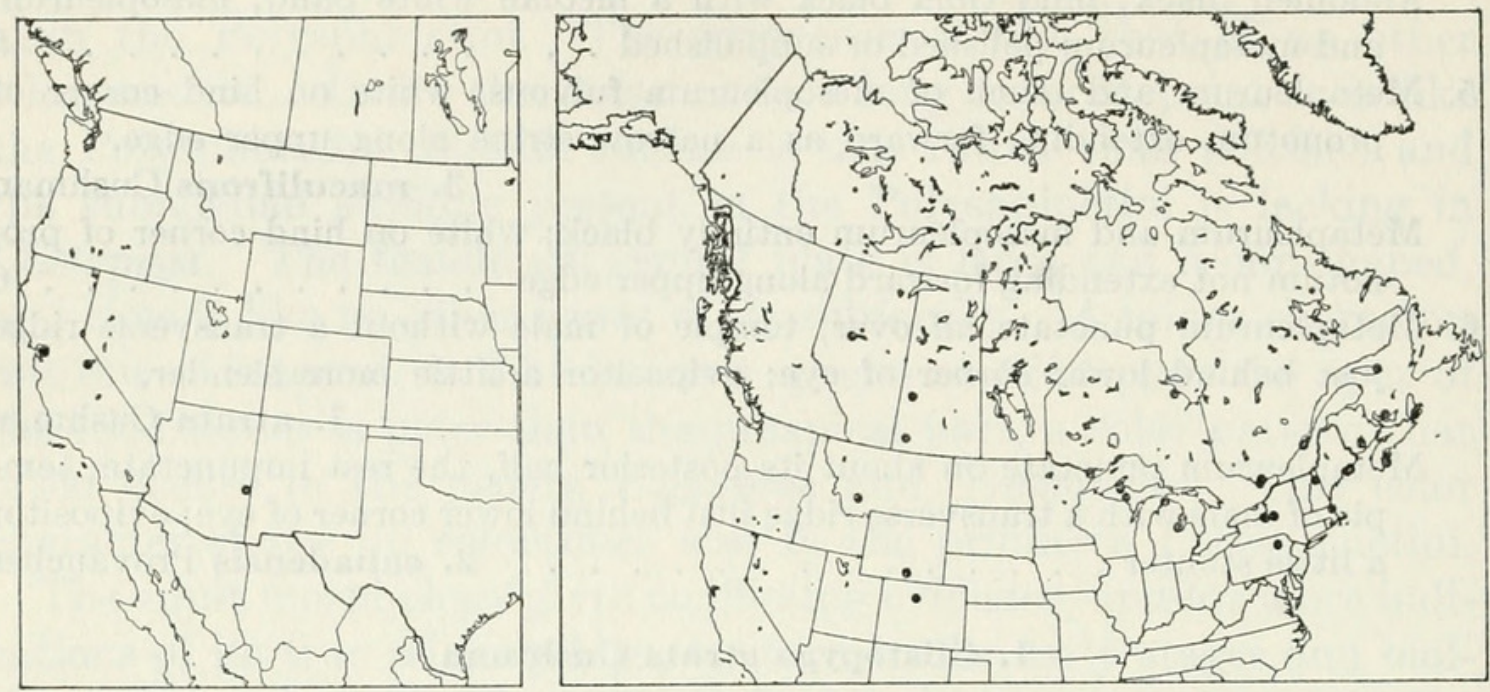

Figures 80, 81.-Localities: 80 (left), Clistopyga atrata; 81 (right), C. canadensis.

in profile about 0.60 as long as eye; epomia moderately long; metapleurum polished or subpolished, its posterior $0.5 \pm$ punctate, the rest almost or quite impunctate; submetapleural carina complete; propodeum moderstely short, convex but somewhat flattened apically, subpolished with its apical declivity mat (especially near midlength of propodeum), with rather coarse punctures except on its apical declivity; median longitudinal carinae of propodeum weak, discernible on about its basal 0.4 ; nervellus broken near its lower 0.3 , the discoidella rather weak; hind tibia of female about 1.05 as long as hind femur; first tergite about 1.1 as long as wide in male, about 1.0 as long as wide in female, its median longitudinal carinae sharp on about its basal 0.85 in male, on about its basal 0.7 in female; second tergite polished, with rather coarse punctures that are separated by about 0.5 their diameter; ovipositor rather stout, its basal 0.6 straight, its apical 0.4 upcurved (fig. 332 ,a).

Black. Male usually with a short whitish orbital stripe at top of eye and sometimes with a longer pale yellow orbital stripe below antennal socket and a similar but broader triangular yellowish area on face below antennal socket; cylpeus brown; palpi stramineous; scape blackish brown, its apical margin often pale brown in front; pedicel and flagellum brown, brown to pale brown beneath; tegula and hind corner of pronotum white; front and middle coxae of male and all trochanters of male yellowish white, the coxae, trochanters, and femora otherwise fulvous; hind femur often with a weak apical infuscation; hind tibia fuscous, its median 0.3 white; first three segments of hind tarsus fuscous, whitish at base; last two segments of hind tarsus brownish fulvous; middle tibia and tarsus largely fulvous or stained with fulvous but weakly repeating the color pattern of hind tibia and tarsus; front tibia and tarsus fulvous, faintly repeating color pattern of hind tibia and tarsus. 
We have two females of Clistopyga sauberi Brauns, 1898, from Germany which appear to be only subspecifically distinct from $C$. canadensis. Reduction to subspecific status, however, would not be wise till a longer series and males could be compared.

Specimens (9 $\sigma^{x}, 35$ ㅇ): From Alberta (Slave Lake); Colorado (Glen Haven); Maine (Bar Harbor, "Elizabeth," and Southwest Harbor); Massachusetts (Middlesex Fells); Michigan (Alston, Dickinson Co., Douglas Lake in Cheboygan Co., Iosco Co., Midland Co., and Twin Lakes in Houghton Co.); Minnesota (Kawishiwi River); Montana (Jefferson Island); New Brunswick (Nerepis); New Hampshire (Randolph); New York (Oswego and Rome); Newfoundland ("Harmon Field"); Nova Scotia (Bridgewater, St. Peters, and White Point Beach in Queens Co.); Ontario (Constance Bay and Moosonee); Pennsylvania (Spring Brook); Prince Edward Island (Brackley Beach in the Canadian National Park); Quebec (Cap Rouge, East Cape on Anticosti Island, "Lake Island," Meach Lake, and Quebec); Saskatchewan (Atten Lake at Cut Knife and Swift Current); Wyoming (Saratoga); and Yukon ("Snus").

Dates of collection are distributed from May 15 (at Ottawa, Ont.) to September 15 (in Midland Co., Mich.), with most of them falling in July and August. A female specimen from Meach Lake, Que., is labeled as bred from Malacosoma disstria, July 27, 1951. Another female from Bar Harbor, Maine, is labeled as having been bred from lepidopterous budworms on Picea by A. E. Brower, Aug. 4, 1938. Since the genus Clistopyga is presumed to parasitize spider egg sacs, these records are questionable.

This species occurs in the Canadian zone and in the cooler part of the Transition zone, from the Atlantic Ocean to the Rocky Mountains. It is adult throughout the growing season, with most adults occurring in July and August.

\section{Clistopyga maculifrons Cushman}

Clistopyga maculifrons Cushman, 1921, Proc. U. S. Nat. Mus., vol. 60, art. 4, p. 10 ; ㅇ. Type: $q$, Texas (Washington).

Front wing of male about $3.6 \mathrm{~mm}$. long, of female 4.2 to $5.0 \mathrm{~mm}$. long; body of moderate stoutness; metapleurum polished, its posterior half punctate; propodeum of moderate length, rather strongly convex, mat medially, polished or subpolished marginally, its punctures rather small and weak, its median longitudinal carinae represented by weak ridges extending about 0.35 its length; basal half of ovipositor straight, its apical half weakly upcurved. Otherwise similar in structure to C. canadensis.

Black. Small orbital mark at top of eye, face of male except lower margin, orbital mark on face of female extending downward from 
level of antennal socket, submedian pair of stripes on face of female extending downward from antennal sockets, palpi, tegula, hind corner of pronotum, and narrow mark on upper margin of pronotum extending forward from its hind corner part way to notaulus, white or whitish; clypeus dark brown; antenna stramineous or light brown beneath, especially toward base, but its scape sometimes not pale beneath; mesosternum behind prepectus, mesopleurum behind prepectus except for about its upper third, and metapleurum fulvous; sometimes scutellum, part of prepectus, and stains on mesoscutum more or less fulvous; front coxa of female, front and middle coxae of male, and trochanters whitish, the first trochanter of hind leg of female mostly pale fulvous; middle coxa of female pale fulvous; hind coxa of female fulvous; hind femur fulvous with an apical infuscation, its extreme apex pale brown; hind tibia white, its apical 0.3 and a subbasal band infuscate; hind tarsus white, the apex of each segment fuscous; middle femur, tibia, and tarsus repeating color pattern of hind leg but the infuscations much paler; front femur, tibia, and tarsus very pale fulvous, with a faint repetition of the color pattern of the hind leg.

Specimens: + , Springfield, Mass., Allen (Cambridge). ㅇ, Ottawa Co., Mich., Aug. 17, 1945, R. R. Dreisbach (Dreisbach). \&, Lake City, Minn., July 7, 1927, C. E. Mickel (St. Paul). ơ , Otsego Lake, N. Y., June 28, 1935, H. Townes (Townes). क, Mount Pisgah at 4,600 ft., N. C., Sept. 2, 1950, H. and D. Townes (Townes). $\sigma^{\top}$, Cleveland, Ohio, May 19, 1934, F. D. De Gant (Columbus). (type), Texas, Belfrage (Washington). $\%$, on window of King Hall, University of Wisconsin, Madison, Wis., July 18, 1955, L. K. Smith (Madison).

This species is widespread in eastern United States. Except possibly for the type, all specimens have been taken in areas of deciduous forests in the Transition zone.

\section{Clistopyga alutaria, new species}

Front wing of male $4.2 \mathrm{~mm}$. long, of female 3.8 to $4.8 \mathrm{~mm}$. long; body rather slender; temple of male with a faint transverse swelling just behind lower corner of eye; temple moderately convex, in profile about 0.7 as long as eye; epomia long; metapleurum entirely mat, covered with small punctures that are separated by about 2.5 their diameter; submetapleural carina complete; propodeum moderately long, strongly convex, completely mat, its punctures fine and inconspicuous, without median longitudinal carinae, or with weak ones extending about 0.3 its length; hind tibia of female about 1.05 as as long as hind femur: nervellus broken near its lower 0.3 , the discoidella weak; first tergite 1.3 as long as wide in male, about 1.2 as long as wide in female, its median longitudinal carina sharp on its basal 

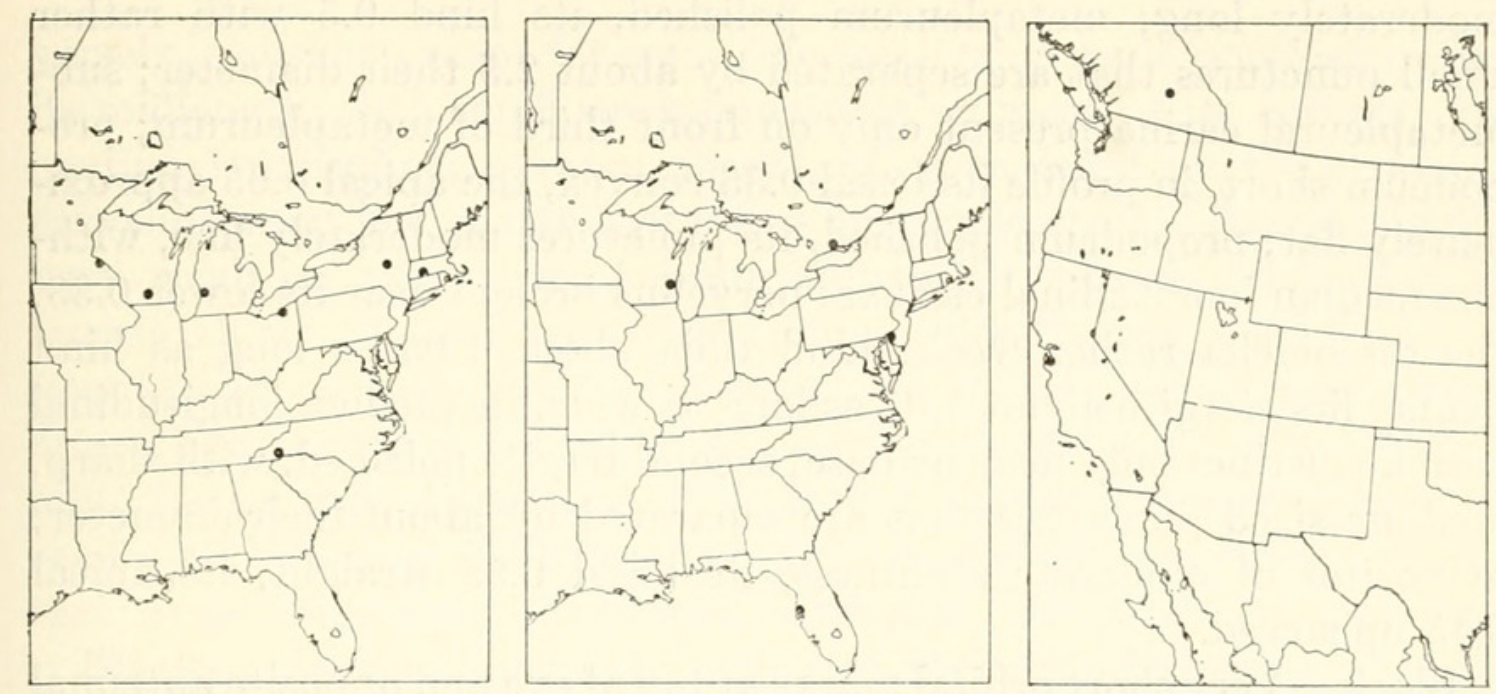

Figures 82-84.--Localities: 82 (left), Clistopyga maculifrons; 83 (center), $C$. alutaria; 84 (right), C. nigrifrons.

0.8 in male, on its basal $0.55 \pm$ in female; second tergite mat, with rather small, weak punctures that are separated by about 0.7 their diameter; ovipositor stout, its basal 0.4 straight, its apical 0.6 upcurved.

Fulvous. Head black; antenna blackish brown, pale brown in front toward base; palpi white; prothorax, mesonotum, upper front part of mesopleurum, and sometimes upper part of propodeum brownish fulvous to black; tegula and hind corner of pronotum white; front coxa and trochanters and middle trochanters of male whitish; hind femur with a narrow weak apical infuscation; hind tibia and tarsus dusky fulvous to fuscous, the central 0.25 of the tibia and narrow base of each tarsal segment fulvous; middle femur, tibia, and tarsus with a weak repetition of color pattern on hind leg; front tibia and tarsus with a faint repetition of color pattern on hind leg.

Type: + , from wheat stubble, Newark, Del., E. D. Eaton (Washington, USNM 63696).

Paratypes: ㅇ, Sarasota Co., Fla., Mar. 3, 1937 (Washington). +. Marmora, Ont., July 10, 1932, J. R. Vockeroth (Ottawa). ๙ Muskego, Wis., July 18, to 25 1936, P. B. Lawson (Lawrence).

This species is widely distributed in eastern North America, but rare in collections. Its coloration suggests open grasslands as the habitat.

\section{Clistopyga nigrifrons Cushman}

Clistopyga nigrifrons Cushman, 1921, Proc. U. S. Nat. Mus., vol. 60, art. 4, p. 11 ;. Type: $\uparrow$, Mountain View, Calif. (Washington).

Male: Unknown.

Female: Front wing 4.3 to $5.0 \mathrm{~mm}$. long; body moderately stout; temple weakly convex, in profile about 4.2 as long as eye; epomia 
moderately long; metapleurum polished, its hind 0.5 with rather small punctures that are separated by about 2.5 their diameter; submetapleural carina present only on front third of metapleurum; propodeum short, in profile its basal 0.35 convex, the apical 0.65 approximately flat; propodeum polished, its punctures moderately fine, without median longitudinal carinae; nervellus broken near its lower 0.33 , the discoidella rather weak; hind tibia about 1.05 as long as hind femur; first tergite about 1.05 as long as wide, its median longitudinal carinae distinct only near its base; second tergite polished, with sharp, medium-sized punctures that are separated by about their diameter; ovipositor of moderate stoutness, its basal 0.55 straight, its apical 0.45 upcurved.

Black. Very short orbital marks at top of eye and opposite antennal socket, longer orbital mark on frons (sometimes connected with orbital mark at top of eye), sometimes spot just below antennal socket, clypeus, maxilla, labium, tegula, stripe on upper margin of pronotum, sometimes subtegular ridge, apex of scutellum, and postscutellum, white; antenna blackish brown, paler beneath; mesosternum, mesopleurum except large quadrate mark above, side lobes of mesoscutum, scutellum, and metapleurum, fulvous, the prepectus black except on its upper ends; front leg ivory, the femur fulvous behind and the tarsus pale fulvous; middle leg fulvous, the coxa apically, trochanters, femur apically and in front, and tibia above except toward apex white, the base of the tarsal segments pale fulvous or whitish; hind coxa, trochanters, and femur fulvous, the second trochanter and apex of femur whitish; hind tibia whitish, its apical 0.3 , its lower edge, and a suggestion of a narrow incomplete subbasal band brown or brownish fulvous; hind tarsus light brown, the segments darker at apex and paler at base.

Specimens: 2 우 (type and paratype) reared from spider nest, Mountain View, Calif., July 1898, Earhorn (Washington). ㅇ, Salmon Arm, B. C., Aug. 1, 1925, A. A. Dennys (Ottawa).

This species has been collected in California and British Columbia.

\section{Clistopyga manni Cushman}

Clistopyga manni Cushman, 1921, Proc. U. S. Nat. Mus., vol. 60, art. 4, p. 12; 9 Type: + , Pacific Grove, Calif. (Washington).

Front wing of male 3.8 to $4.0 \mathrm{~mm}$. long, of female 4.0 to $6.9 \mathrm{~mm}$. long; body rather slender; temple of male without a transverse ridge near lower corner of eye; temple rather flat, in profile about 0.35 as long as eye; epomia rather short; metapleurum polished, its hind 0.3 to 0.7 with very fine, weak punctures; submetapleural carina present only on front third of metapleurum; propodeum moderately long, moderately convex longitudinally, rather strongly convex trans- 
versely, polished except for some fine weak transverse rugulosity near its midlength, with small weak punctures on most of its surface, its median longitudinal carinae absent, often replaced by weak ridges; nervellus unbroken or weakly broken near its lower 0.2 , the discoidella very weak or absent; hind femur unusually slender; hind tibia of female about 1.0 as long as hind femur; first tergite about 1.35 as long as wide in male, about 1.0 as long as wide in female, its median dorsal carinae sharp for about 0.5 its length; second tergite weakly mat, its central raised area with rather coarse punctures that are separated by about 0.4 their diameter, its margins less densely punctate; ovipositor slender, its basal 0.65 straight, its apical 0.35 upcurved.

Black or blackish brown, the abdomen often reddish brown. Orbits in front and at top of eye, face and cheek of male, spot or vertical stripe below antennal socket of female (this mark usually connected laterally with orbital mark), large mark on cheek of female, clypeus, basal 0.65 of mandible, maxilla, labium, front of scape and pedicel, tegula, stripe on upper margin of pronotum, collar, lower end of propleurum, subtegular ridge, usually two short longitudinal dashes on center of mesoscutum, apex of scutellum, and postscutellum, white; flagellum brown, paler beneath; mesothorax except sometimes upper part of mesopleurum, metathorax, and often more or less of propodeum, fulvous; front leg whitish, the femur often brownish fulvous behind; middle leg whitish, the femur with a stramineous or brown dorsoposterior stripe and the tibia and tarsus with infuscations that faintly repeat the pattern on the hind tibia and tarsus; hind coxa fulvous, white apically; hind trochanters white, the first trochanter fulvous or brown basally, especially above; hind femur whitish, its base and front and back faces largely stramineous, brownish, or fulvous; hind tibia whitish, its basal and apical 0.3 infuscate, the basal infuscate band more or less subdivided by a whitish band; hind tarsus infuscate, the segments whitish basally.

There is one cocoon in our material. It is elongate elliptic, moderately dense, white, and with some loose silk on the surface. There is no hole visible at the hind end.

Specimens: $\sigma^{7}$, Robson, B. C., Oct. 23, 1938, H. R. Foxlee (Townes). \%, Carmel, Calif., Nov. 7, 1926, L. S. Slevin (Townes). क, Carmel, Calif., Dec. 30, 1925, L. S. Slevin (San Francisco). ㅇ, reared from either egg case or mature spider of Agelenopsis sp., Fish Canyon, San Gabriel Mts., Apr. 29, 1945, E. I. Schlinger (Schlinger). क reared from cocoon found beside body of dead salticid spider, Fish Canyon, San Gabriel Mts., Calif., Jan. 26, 1950, E. I. Schlinger (Townes). $\sigma^{7}$, Orinda, Contra Costa Co., Calif., Sept. 14, 1953, M. Wasbauer (Berkeley). क (type), Pacific Grove, Calif., W. M. Mann (Washington). $\quad$ \&, Santa Ana, Calif., Apr. 27, 1943 (Washington). $\sigma^{7}$, Vista, 
Calif., Sept. 2, 1955, D. J. Ott (Townes). ๆ, Mescalero Indian Reservation, White Mts., Otero Co., N. Mex., June 15 to 30, 1927, O. C. Poling (Ann Arbor).

This species has been collected in British Columbia, California, and New Mexico.
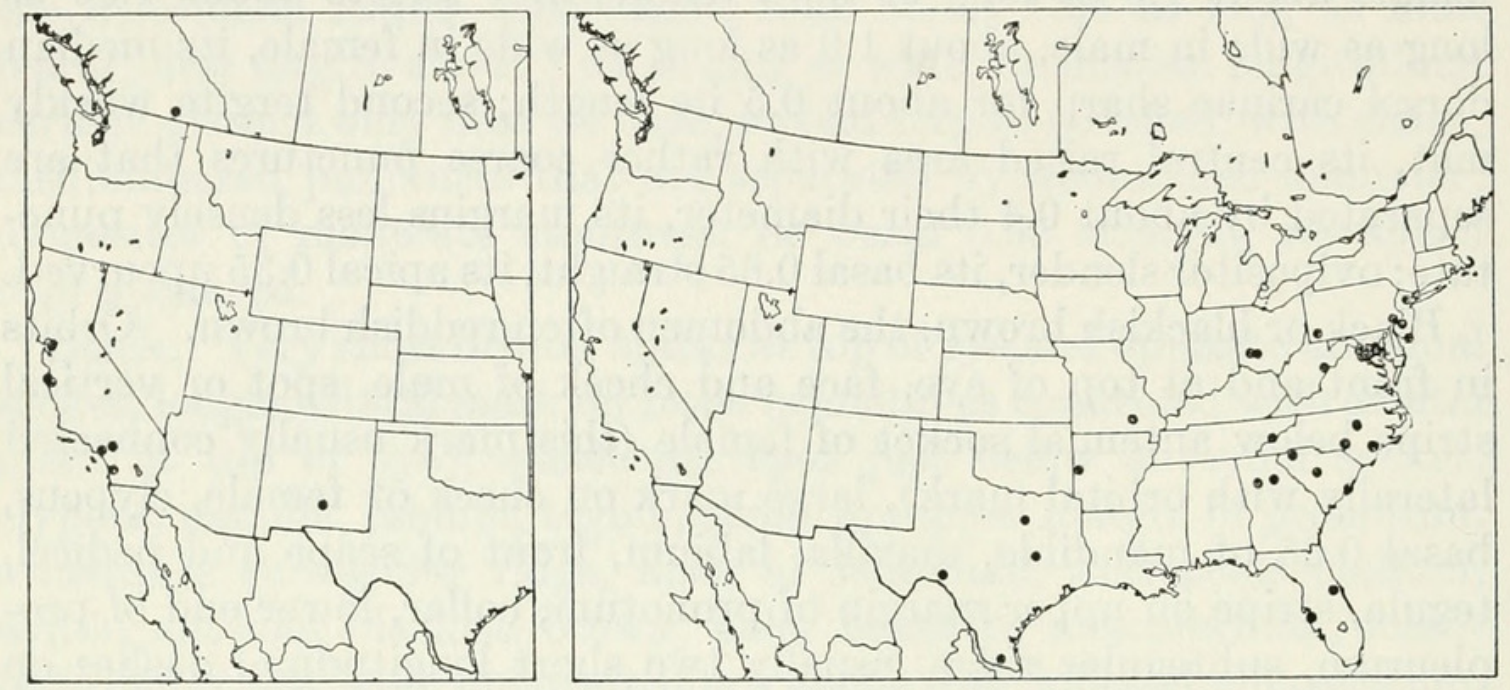

Figures 85, 86.-Localities: 85 (left), Clistopyga manni; 86 (right), C. recurva.

\section{Clistopyga recurva (Say)}

Figure $332, \mathrm{~b}$

Anomalon recurvus Say, 1836, Boston Journ. Nat. Hist., vol. 1, p. 243 (Leconte ed., vol. 2, p. 698); $\sigma^{\top}$, $\subsetneq$. Types: $\sigma^{\top}, ~ \subsetneq$ (destroyed).

Clistopyga annulipes Cresson, 1870, Trans. Amer. Ent. Soc., vol. 3, p. 150; ;. Type: $q$, Massachusetts (Philadelphia).

Clistopyga pulchripicta Ashmead, 1890, Proc. U. S. Nat. Mus., vol 12, p. 448; $\subsetneq$. New synonymy. Type: $\uparrow$, Texas (Washington).

Front wing of male 3.5 to $6.5 \mathrm{~mm}$. long, of female 4.3 to $8.8 \mathrm{~mm}$. long; body, especially the thorax, narrow and long; temple of male without a transverse ridge near lower corner of eye; epomia short; metapleurum polished, its hind half with sparse scattered punctures and faintly wrinkled; submetapleural carina complete; propodeum long, moderately convex longitudinally, strongly convex transversely, medially with fine transverse wrinkling, elsewhere smooth, its punctures fine and sharp, the median longitudinal carina lacking; hind tibia of female about 0.92 as long as hind femur; hind tarsus very long; first tergite about 1.6 as long as wide in male, about 1.2 as long as wide in female, its median longitudinal carina distinct on its basal 0.5 ; second tergite with rather fine oblique punctures; ovipositor moderately stout, its basal 0.7 straight, its apical 0.3 strongly upcurved (fig. 332,b).

Male: Black. Face, clypeus, orbit of frons and at top of eye, cheek, mandible except apex, maxilla, labium, under side of scape and 
pedicel, tegula, stripe on upper margin of pronotum, sometimes collar and a pair of longitudinal dashes on center of mesoscutum, sometimes lower part of propleurum, apex of scutellum, and postscutellum, white; flagellum blackish brown, paler below, its base stramineous below; mesosternum, mesopleurum except above, most or all of metapleurum, sometimes mesoscutum except marginally, sometimes scutellum and occasionally part of propodeum, fulvous, the prepectus usually mostly black; hind coxa fulvous, its apex usually white; hind trochanters white; hind femur fulvous with its apex broadly white to mostly white with its base and much of hind side brownish fulvous; hind tibia white with a broad apical and basal fuscous band, the basal band sometimes more or less divided into narrow basal and subbasal bands; hind tarsus infuscate, the segments white basally, the basal segments more broadly white at base; front and middle legs white, the middle tibia and tarsus with a faint repetition of the fuscous marking of the hind leg.

Female: Black. Orbit in front and at top of eye, spot below antennal socket (sometimes continuous with orbital mark), large spot on cheek, clypeus, basal half of mandible, maxilla, labium, under side of scape and pedicel, tegula, stripe on upper margin of pronotum, sometimes spot on subtegular ridge and a pair of short median dashes on mesoscutum, apex of scutellum, and postscutellum, white; flagellum black to brown, paler beneath, especially at base; mesosternum, lower part of mesopleurum, lobes of mesoscutum, metapleurum, and dorsolateral areas on propodeum sometimes more or less ferruginous; hind coxa, trochanters, and femur fulvous; hind tibia fuscous, its median 0.3 white; first three segments of hind tarsus fuscous, white basally; last two segments of hind tarsus brown, whitish at base; middle leg fulvous, its trochanters and apex of femur whitish, its tibia and tarsus with a weak repetition of the color pattern of hind leg; front coxa and trochanters whitish; front femur pale fulvous, paler in front; front tibia and tarsus pale fulvous, the apex of the tarsal segments and the upper edge of tibia brownish fulvous, the stripe on upper side of tibia with a subbasal interruption.

There is one cocoon among our material. This is elongate elliptic, white, moderately dense, with a little loose silk on the surface, and no hole in the hind end.

Specimens (19 $\sigma^{\top}, 41$ ) : From Arkansas (Rich Mt. Summit at 2,600 ft.); District of Columbia (Washington); Florida (Manatee Co. and Seminole Co.); Georgia (Athens and Lost Mount in Cobb Co.); Maryland (Bowie, Mayo, Plummers Island, and Takoma Park); Massachusetts; Mississippi; Missouri (Van Buren); New Jersey (Anglesea, Boonton, and Moorestown); New York (West Farms at New York City); North Carolina (Raleigh, Southern Pines, and 
Wallace); Ohio (Clifton and Montgomery Co.); Pennsylvania (Charleroi in Washington Co. and Valley Forge) ; South Carolina (Columbia, Greenville, and McClellanville); Tennessee (Great Smoky Mountains National Park at 2,000 ft.); Texas (Brazos Co., Dallas Co., Hidalgo Co., and Val Verde Co.); Virginia (Arlington, Dunn Loring, Falls Church, and Vienna); and West Virginia (Cheat Mt. at 2,000 ft. in Randolph Co.).

The collection dates are distributed through most of the growing season, with concentrations in mid-spring and in fall and late summer. Unusually early and late dates of collections are: March 22 in Manatee Co., Fla.; March 26 in Dallas Co., Tex.; April 11 in Brazos Co., Tex.; April 21 at Columbia, S. C. and at Raleigh, N. C.; May 13 at Washington, D. C.; October 20 and November 3 at Takoma Park, Md.; October 31 at Athens, Ga.; and October 27 at Mayo, Md. There is one reared specimen in the material as follows: $\sigma^{7}$, emerged from cocoon found under bark, Vienna, Va., February 1938, J. C. Bridwell (Washington).

One of the female specimens was taken at light. A female observed by us was seen to flip its wings like a psammocharid while crawling along a dead branch.

This species belongs to the Carolinian and Austroriparian faunas. Adults occur mostly from mid-spring to mid-fall.

\section{Genus Alophosternum}

Figure 291,b

Alophosternum Cushman, 1933, Proc. U. S. Nat. Mus., vol. 82, p. 7. Type: Alophosternum foliicola Cushman; original designation.

Front wing 2.7 to $6.0 \mathrm{~mm}$. long; body rather short and stout; face, frontal orbits, and clypeus more or less white; clypeus strongly convex but its apex rather strongly impressed, the apical margin strongly concave; occipital carina present laterally, absent above; hairs on mesocutum moderately dense, evenly distributed; prepectal carina absent (present in other Nearctic Pimplini except Dolichomitus cuspidatus); submetapleural carina complete; propodeum of moderate length, without median longitudinal carinae; areolet obliquely triangular or subtriangular, receiving second recurrent vein at or basad of its outer corner; nervellus broken a little below the middle; basal tooth on tarsal claws of female sometimes lacking on the hind claws (present on all claws of females in all other Nearctic genera of Pimplini except Perithous); first tergite moderately long, tapered basally, its lateral and median longitudinal carinae not strongly developed; third and fourth tergites very short, with weak, transverse, subbasal and preapical impressions, their impunctate apical band occupying about 0.25 
their length; female subgenital plate completely but weakly sclerotized, or with a large median basal membranous area; ovipositor weakly compressed, decurved but its apical part straight; ovipositor sheath about 0.33 as long as front wing.

This genus includes only the genotype, which is transcontinental in the Canadian and Transition zones of North America, and an undescribed species in Japan.

\section{Alophosternum foliicola Cushman}

Figdre 370

Alophosternum foliicola Cushman, 1933, Proc. U. S. Nat. Mus., vol. 82, p. 8; $\sigma^{\top}$, + . Type: $q$, Ashburnham, Mass. (Washington).

Front wing 2.7 to $5.8 \mathrm{~mm}$. long. Differs structurally from an undescribed Japanese species in having the second recurrent nearer the apex of the areolet, the first tergite broader, the hind tarsal claws of the female with a basal lobe, and female subgenital plate with a large median basal membranous area.

Male: Black. Face, frons, cheek, clypeus, mouth parts, scape and pedicel except above, lower part of propleurum and adjacent part of pronotum, large hind corner of pronotum, tegula, subtegular ridge, coxae, trochanters, and front and middle femora and tibiae, whitish; flagellum fuscous, a little paler beneath, its basal few segments whitish beneath; front tarsus whitish, its apex brownish; middle basitarsus whitish, its apex brown; second to fourth segments of middle tarsus brown; fifth segment of middle tarsus brown,its basal half stramineous; hind femur pale fulvous; hind tibia white, with a narrow subbasal and a broader apical fuscous band; hind tarsus infuscate, the basal half of its first segment whitish and the basal half of its last segment light brown; second to sixth tergites narrowly stramineous on apex, the base of second tergite sometimes also narrowly stramineous.

Figure 87.-Localities for Alophosternum foliicola.

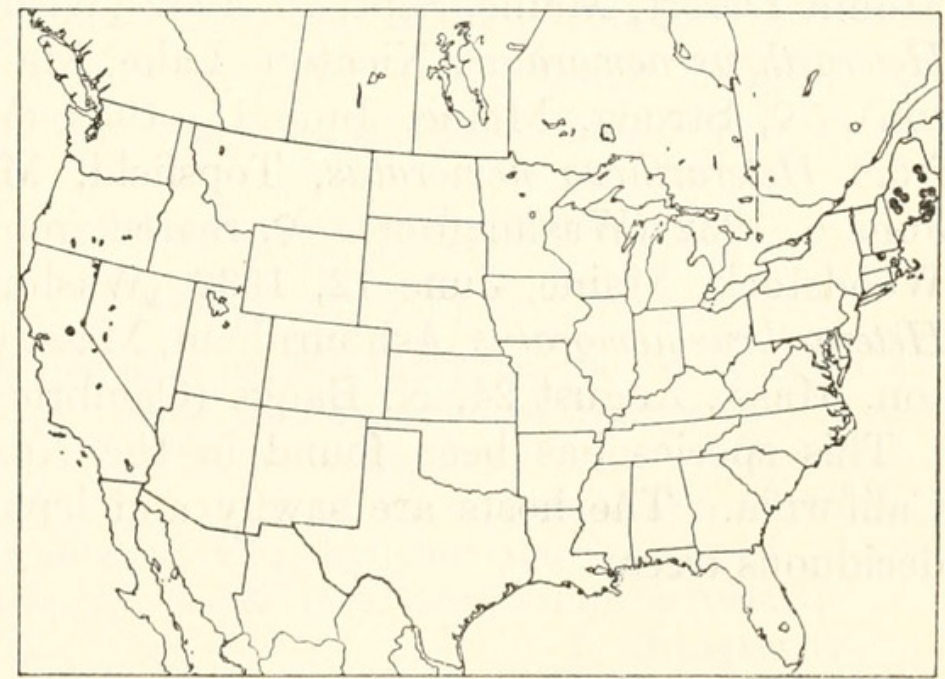


Female: Black. Frontal orbit rather broadly pale yellow; facial orbit black or rather narrowly pale yellow; clypeus brown, its apical half paler; mandible whitish, brownish apically; palpi whitish; scape, pedicel, and basal part of flagellum whitish externally; hind corner of pronotum, tegula, and more or less of subtegular ridge, whitish; mesopleurum, metapleurum, and propodeum often fulvoferruginous with the margins black; mesonotum sometimes partly fulvoferruginous; hind coxa fulvous, its extreme apex white; hind trochanters white; hind femur fulvous, its apex whitish; hind tibia white, with narrow subbasal and moderately narrow apical fuscous bands, the bands somewhat narrowed dorsally and ventrally connected by a complete or incomplete infuscate stripe; hind tarsus white, narrow apex of its first three segments, all of its fourth segment, and apical half of its fifth segment, infuscate; front and middle legs similar in color pattern to the hind legs, but much paler and the dark markings very faint or obsolete; front coxa mostly white.

Specimens: 2o, Camino, Calif., June 27 and 28, 1948, H., M., G., and D. Townes (Townes). 2o, reared from Heterarthrus nemoratus, Aurora, Maine, June 13 and 15, 1932 (Washington). o, reared from Cameraria aceriella?, Bar Harbor, Maine, May 29, 1934 (Washington). 3우, reared from Heterarthrus nemoratus, Bar Harbor, Maine, June 6, 1934, Sept. 15, 1933, and Oct. 14, 1933 (Washington). o, reared from Heterarthrus nemoratus, Bryant's Pond, Maine, May 1931 (Washington). $\%$, reared from Heterarthrus nemoratus, side of Cadillac Mt., Bar Harbor, Maine, emerged June 28 to 30, 1935, A. E. Brower (Townes). $\quad$, reared from Heterarthrus nemoratus, Cherryfield, Maine, June 23, 1932 (Washington). 우 reared from Heterarthrus nemoratus, Eustis, Maine, June 15, 1932 (Washington). \&, reared from Heterarthrus nemoratus, Hersey, Maine, June 12, 1932 (Washington). $\sigma^{\top}$, reared from Paraclemensia acerifoliella, Little Duck Island, Maine, Aug. 6, 1931 (Washington). $\sigma^{7}$, reared from Heterarthrus nemoratus, Mount Desert, Maine, Sept. 16, 1932 (Washington). ㅇ, reared from Heterarthrus nemoratus, Nicatous Lake, Maine, May 1931 (Washington). ㅇ, Strong, Maine, June 15, 1932 (Washington). 3ㅇ, reared from Heterarthrus nemoratus, Topsfield, Maine, June 2, 1930 and June 6, 1932 (Washington). , reared from Heterarthrus nemoratus, Woodstock, Maine, June 12, 1932 (Washington). 4우, reared from Heterarthrus nemoratus, Ashburnham, Mass. (Washington). ㅇ, Holliston, Mass., August 24, N. Banks (Cambridge).

This species has been found in the Northeastern States and in California. The hosts are sawfly and lepidopterous leaf miners on deciduous trees. 


\title{
14. Genus Perithous
}

\author{
Figure 292,a
}

Perithous Holmgren, 1859, Öfvers. Svenska Vetensk.-Akad. Förh., vol. 16, p. 123.

Type: Ephialtes albicinctus Gravenhorst; designated by Viereck, 1914.

Front wing 6 to $13 \mathrm{~mm}$. long; body long and slender; face, frontal orbits, and clypeus white or partly white; clypeus usually convex basally, its apical $0.6 \pm$ flat or a little concave, its apical margin with a deep median notch; occipital carina complete, without a median dip above; hairs on mesoscutum moderately dense, evenly distributed; submetapleural carina complete; propodeum rather short and strongly convex, without median longitudinal carinae, its petiolar area large, often completely bounded by a carina; areolet roughly an equilateral triangle, receiving second recurrent vein basad of its apical corner; nervellus broken at or above the middle; tarsal claws of female without a basal tooth (with a large basal tooth in all other Nearctic Pimplini); first tergite moderately long, its basolateral angle prominent, its lateral longitudinal carina very strong, its median longitudinal carinae distinct only at base; second tergite with short, transverse, basolateral grooves and more distinct apicolateral oblique grooves; third and fourth tergites with moderately developed tubercles, their apical impunctate margin indistinct, occupying about 0.1 their length; female subgenital plate sclerotized laterally and apically, the rest membranous; ovipositor compressed, weakly upcurved, its apex as in figures $331, \mathrm{e}, \mathrm{f}$, or in an Old World subgenus the apex sinuate and with a different arrangement of teeth; ovipositor sheath 0.9 to 1.8 as long as front wing.

This genus occurs mostly in the Palaearctic and Oriental regions. There are only two species in our fauna, one of which was introduced from Europe and the other a naturally Holarctic species represented in North America by two subspecies. The species parasitize the nests of aculeate Hymenoptera in canes and twigs. Our two species have a bright distinctive coloration, the abdomen being narrowly banded with white and the thorax largely ferruginous. Among the Nearctic Ephialtinae, only Tromatobia zonata has a similar coloration.

\section{Key to the Nearctic Species of Perithous}

\section{MALES}

1. Second tergite about 1.5 as long as wide (but this proportion unusually variable); hind tibia and tarsus usually with strongly contrasting fuscous and white markings; mesoscutum varying from ferruginous with only the lateral edges black to entirely black . . . . . . . . . . 1. mediator (Fabricius)

Second tergite about 1.1 as long as wide; hind tibia and tarsus with weakly contrasting brown and stramineous markings; mesoscutum ferruginous with only the lateral edges black.

2. divinator (Rossi) 


\section{FEMALES}

1. Apical tooth-bearing part of lower valve of ovipositor about 4.5 as long as deep (fig. 331,e); ovipositor sheath about 1.6 as long as front wing; second tergite about 1.25 as long as wide . . . . . . . . . 1. mediator (Fabricius) Apical tooth-bearing part of lower valve of ovipositor about 2.5 as long as deep

(fig. 331,f); ovipositor sheath about 1.0 as long as front wing; second tergite about 1.05 as long as wide . . . . . . . . 2. divinator (Rossi)

\section{Perithous mediator (Fabricius)}

\section{Figure 331,e}

Front wing 4.5 to $9 \mathrm{~mm}$. long in male, 6 to $10 \mathrm{~mm}$. long in female; body form slender; second segment of middle tarsus about 4.2 as long as wide; second tergite about 1.50 as long as wide in male, about 1.25 as long as wide in female; ramellus short; ovipositor sheath about 1.6 as long as front wing; lower valve of ovipositor with about 12 ridgelike teeth, the apical tooth-bearing part of the valve about 4.5 as long as deep.

This is a Holarctic species with four subspecies, as keyed out below. Some of the subspecies are colored very much like $P$. divinator, others rather differently.

1. Mesopleurum entirely black; hind tibia and tarsus blackish brown, the tibia medium brown beneath; front and middle coxae of female ivory, fulvous beneath; punctures on abdomen of female moderately coarse and dense; range: Japan . . . . . . . . . 1d. mediator japonicus Uchida

Mesopleurum mostly or entirely ferruginous; hind tibia and tarsus partly or mostly pale (white to fulvous) . . . . . . . . . . . . . . . . . 2

2. Hind tibia and tarsus of female dark fulvous, the apex of the tibia and of the tarsal segments a little infuscate; front and middle coxae of female entirely fulvous; punctures on abdomen of female rather fine and sparse; male rather similar to male of $P$. mediator neomexicana; range: Europe.

1c. mediator mediator (Fabricius)

Hind tibia and tarsus of female whitish to stramineous, with dark fuscous markings; front and middle coxae of female partly ivory; punctures on abdomen of female moderately coarse and dense; range: North America . 3

3. Apex of hind femur infuscate for a distance about equal the depth of the femur, the extreme apex of femur whitish (fig. 322,j); hind tibia of female whitish or stramineous between its subbasal swelling and its base, the extreme base sometimes brown; range: temperate North America east of Rocky Mountains . . . . . . . . . . . 1a. mediator pleuralis (Cresson)

Apex of hind femur weakly and narrowly infuscate, the extreme apex whitish (fig. 322,i); hind tibia of female brownish on front and back sides between its subbasal swelling and its base; range: temperate North America in Rocky Mountains and westward . lb. mediator neomexicanus (Viereck) 


\section{1a. Perithous mediator pleuralis (Cresson), new status}

Figure $322, \mathrm{j}$

Perithous pleuralis Cresson, 1868, Canadian Ent., vol. 1, p. 46; $\uparrow$. Type: $q$, Grimsby, Ont. (lost).

Biologr: Champlain, 1922, Psyche, vol. 29, p. 97.--Reinhard, 1929, Nature Mag., vol. 13, pp. 155, 156, 157.

Punctures on abdomen of female moderately coarse and dense; male flagellum without tyloids or with very narrow weak tyloids on about the tenth to fourteenth segments.

Male: Black. Face, frontal orbits, clypeus, mouth parts, scape and pedicel beneath, upper margin of pronotum, tegula, subtegular ridge, all or most of mesepimeron, apex of scutellum, postscutellum, crescent on apical carina of propodeum, spot at middle of apex of first tergite, and apex of second to seventh tergites, white, the white apex of the second to seventh tergites usually interrupted sublaterally by a brown spot; flagellum brown, light brown below; mesosternum and mesepisternum except for an area of variable size below and behind subtegular ridge, ferruginous; mesoscutum mostly ferruginous or fuscoferruginous; scutellum ferruginous, its apex white; front and middle legs whitish, the femora fulvous behind, the coxae, tibiae, and tarsi with some pale fulvous tinges, and apex of each segment of middle tarsus fuscous; hind coxa fulvous; bind trochanters whitish; hind femur fulvous, its extreme base brown, extreme apex whitish, and subapical $0.17 \pm$ infuscate; hind tibia white with an anterodorsal fuscous stripe beginning at its subbasal swelling and extending to apex, at apex expanding into a broad band around tibia and at its base expanded into a narrow subcomplete band around tibia; hind tarsus whitish, the apex of each segment fuscous; wings hyaline.

Female: Colored like the male except as follows: Face black, white next to eye; clypeus black, more or less white basally and along apical margin; coxae fulvous, the front and middle coxae whitish dorsally; first trochanters light fulvous and whitish; second trochanters mostly whitish; front and middle femora fulvous, paler in front; hind tibia and tarsus as in the male but the ground color stramineous and the fuscous markings more extensive; middle tibia and tarsus with a washed-out repetition, and front tibia and tarsus with a faint repetition of the colors of the hind tibia and tarsus.

Specimens (96 $\left.\sigma^{7}, 117 \%\right)$ : From Alaska (Anchorage, Chitina, and Rampart); Connecticut (Canterbury, Lyme, and Voluntown); District of Columbia (Anacostia); Iowa (Sioux City); Kansas (St. George); Louisiana (Shreveport); Maine (Lincoln Co.); Maryland (Bowie, Glen Echo, Hagerstown, Plummers Island, and Woodstock); Massachusetts 
(Cambridge, Cohasset, Forest Hills, Holliston, Humarock, Milton, Petersham, Roslindale, and Roxbury); Michigan (Aurelius, Cheboygan Co., Delta Co., Douglas Lake, East Lansing, George Reserve in Livingston Co., Gogebic Co., Gull Lake Biological Station in Kalamazoo Co., Iron Co., Keweenaw Co., Midland Co., Missaukee Co., and Presque Isle Co.); Minnesota (Chisago, Duluth, Fillmore Co., Houston Co., Itasca Park, Olmsted Co., St. Anthony Park, and Wabasha Co.); Mississippi (Oxford); New Hampshire (Franconia, Mount Washington, and Pinkham Notch); New Jersey (Moorestown); New York (Albany, Bemus Point, Buffalo, Farmingdale, Flatbush, Freeville, Gasport, Greene Co., Hancock, Huguenot, Huntington, Ithaca, Lake Sebago in Bear Mountain State Park, McLean, Milford Center, New Baltimore, Nyack, Orient, Pelham, Poughkeepsie, Sea Cliff, Slaterville, Syracuse, Taughannock Falls, and Tuxedo); North Carolina (Crabtree Meadows in Yancey Co. at 3,600 ft., Raleigh, Southern Pines, and Tryon); North Dakota (Turtle Mts.); Ohio (Cleveland, Columbus, Montgomery Co., and Puritas Springs in Cuyahoga Co.); Ontario (Grimsby and Kearney); Pennsylvania (Clearfield, Harrisburg, Highspire, Ingram, Presque Isle, and Philadelphia); Quebec (Montreal Island, St. Hilaire, and Stoneham); Rhode Island (Ashaway); Saskatchewan (Waskesiu); South Carolina (Columbia, Greenville, and near Tigerville); Tennessee (Burrville); Vermont (Jacksonville, Laurel Lake near Jacksonville, Plainfield, and Woodstock); Virginia (Arlington and Black Pond in Fairfax Co.); West Virginia (Bolivar and Cheat Mt. at 2,000 ft. in Randolph Co.); and Wisconsin (Dane Co., Madison, Muskego, and Sawyer Co.).

Most of the specimens were collected during the summer months but records in late spring and early fall are moderately common.
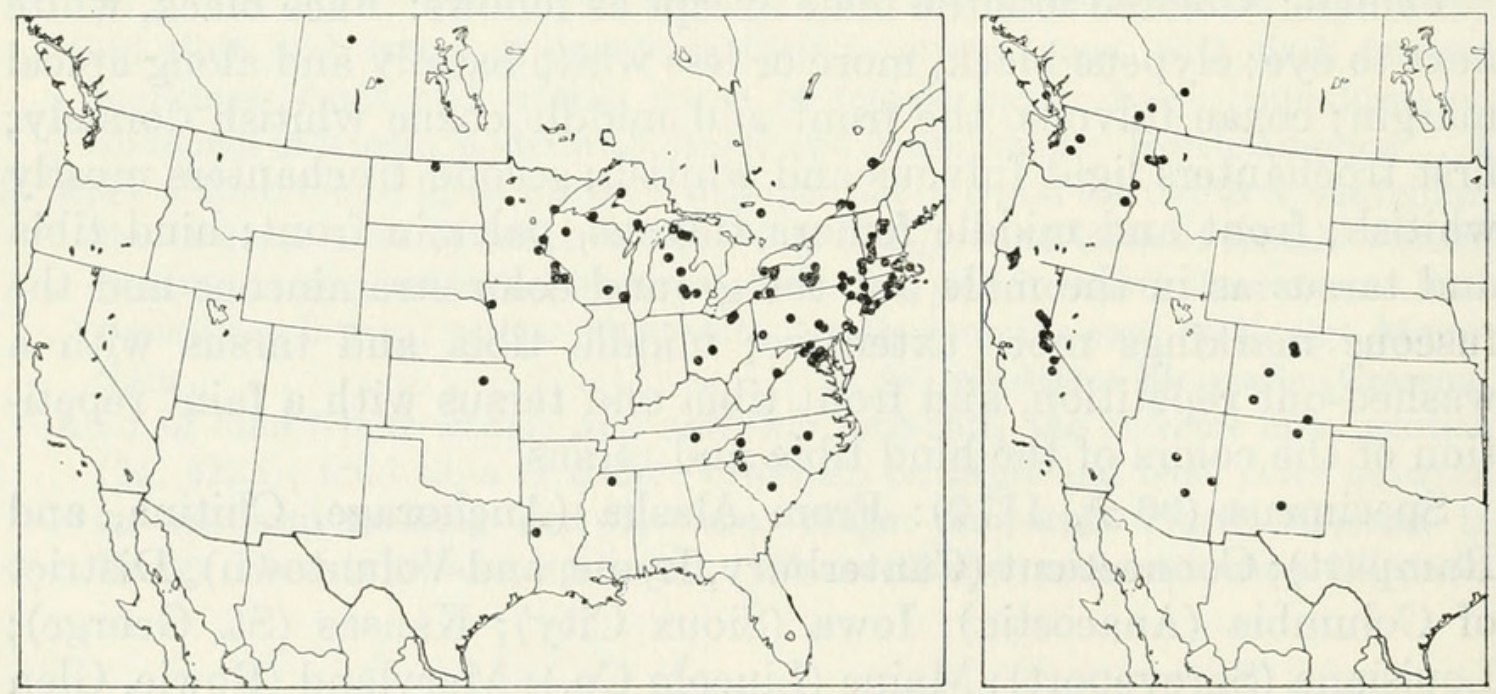

Figures 88, 89.-Localities: 88 (left), Perithous mediator pleuralis; 89 (right), P. m. neomexicanus. 
Representative early and late dates of capture are: April 11 and 15 at Columbia, S. C.; May 3 and 13 at Greenville, S. C.; May 18 at St. Anthony Park, Minn.; May 20 in Fillmore Co., Minn.; May 24 at Buffalo, N. Y.; May 25 and 30 at Ithaca, N. Y.; September 17 at Milton, Mass. and at Madison, Wis.; September 19 at Bolivar, W. Va.; September 24 at Ithaca, N. Y. and at Harrisburg, Pa.; September 26 at Gasport, N. Y.; and November 8 at Southern Pines, N. C.

Biological notes on pin labels are as follows: one rearing from Pemphredon concolor, one from $P$. inornatus, one from larva of Pemphredon sp., one from "bee stem," one from "?stalk borer in Sassafras stem," one from Crataegus, one from dead Salix, one from dead Sambucus stem, one from "piazza posts," and one "reared with Macremphytus." Champlain (loc. cit.) records it from "cocoons found in old (borer?) burrows in Platanus occidentalis." Reinhard (loc. cit.) describes the biology of this species as a parasite of prepupae of Pemphredon concolor, in nests in a stump.

One female that we caught was noted to give off an odor like that of Coccygomimus, but if such an odor is usual with the species it must be relatively weak because we did not notice it on other occasions.

This subspecies occurs east of the Rocky Mountains and also in Alaska. Its zonal range is from the Canadian to the Lower Austral. It is adult from late spring to early fall. Rearings have been made from nests of Pemphredon and from various twigs and dead wood that probably contained nests of wasps or bees.

\section{1b. Perithous mediator neomexicanus (Viereck), new status}

Figure 322 , i

Pimpla neomexicana Viereck, 1903, Trans. Amer. Ent. Soc., vol. 29, p. 87;. Type: + , Beulah, N. Mex. (Philadelphia).

Punctures on abdomen of female moderately coarse and dense; male flagellum with narrow weak tyloids on about the ninth to seventeenth segments.

Colored like $P$. mediator pleuralis except that the mesocutum is usually entirely ferruginous with only the edges blackish, the mesepisternum is usually entirely ferruginous except dorsoposteriorly, the subapical infuscation of the hind femur is faint and restricted to about 1.0 of the length of the femur (or sometimes absent), and the fuscous leg markings average a little broader in the male. In the female the ground color of the tibiae and tarsi is a little darker stramineous than in the subspecies mediator, and the fuscous markings are more extensive, on the hind tibia extending to the base of the tibia on the front and back sides. 
Specimens $\left(23 \sigma^{\nearrow}, 36\right.$ 우): From Alberta (Banff); Arizona (near Alpine, Oak Creek Canyon, and Parker Creek in the Sierra Ancha); British Columbia ("Atila," Bear Lake, Kaslo, Robson, and Wellington); California (Carson Pass, Dardanelle, Donner Pass, Echo Lake in Eldorado Co., Fish Camp, Gold Lake in Sierra Co., Lake Tahoe, Leevining, Strawberry in El Dorado Co., and Webber Lake in Nevada Co.); Colorado (Boulder Co. at 9,500 ft., near Estes Park, Gothic, Granite Peaks Camp at Bayfield at 9,000 ft., Morley, and Silverton at 9,800 ft.); Idaho (Cataldo, Lewiston, and Wallace at 3,000 ft.); Montana (Thompson); New Mexico (Cimarron at 6,800 ft. and Rio Ruidoso in the Sierra Blanca at about 6,500 and 8,200 ft.); Oregon (Joseph); and Washington (Easton and Peshastin).

Collection dates are from midspring into the fall. The earlier and later recorded dates of capture are: May 4 at Parker Creek, Sierra Ancha, Ariz.; May 18, 19, and 21 at Oak Creek Canyon, Ariz.; May 21 at Robson, B. C.; Sept. 26 at Peshastin, Wash.; Oct. 18 at Lewiston, Idaho; and Oct. 22 at Robson, B. C.

This subspecies occurs in and west of the Rocky Mountains, in the Canadian and Transition zones. It is adult throughout the growing season.

\section{1c. Perithous mediator mediator (Fabricius)}

Pimpla mediator Fabricius, 1804, Systema piezatorum, p. 117; $\uparrow$. Type: $\uparrow$, Moravia (location unknown).

This is the subspecies of Europe. The ferruginous on the mesoscutum and mesopleurum covers nearly all of these structures, the female hind tibia and tarsus is almost uniformly dark fulvous with only weak infuscation at apex of tibia and of the tarsal segments, the female fore and middle coxae are without ivory marking, and the female abdomen has the punctures exceptionally small and sparse. The male is rather similar to that of $P . m$. neomexicanus but with abdominal punctures a little smaller and sparser, and very narrow tyloids on about the eighth to eighteenth segments.

Specimens: $6 \sigma^{7}, 7$, from England and Germany.

\section{1d. Perithous mediator japonicus Uchida, new status}

Perithous japonicus Uchida, 1928, Journ. Fac. Agr. Hokkaido Univ., vol. 25, p. $91 ; \sigma^{7}$, ㅇ. Types: $2 \sigma^{\top}, 3 \uparrow$ from several Japanese localities (Sapporo).

This is the Japanese subspecies, characterized by entire lack of ferruginous areas on the thorax, and dark, almost black, hind tibia and tarsus.

Specimens: 6 \% from Japan, including one compared by the authors with Uchida's types. 


\section{Perithous divinator (Rossi)}

Figures 322,k; 331,f

Ichneumon divinator Rossi, 1790, Fauna Etrusca, vol. 2, p. 48; + . Type:, province of Firenze or of Pisa, Italy (location unknown).

Front wing 6.1 to $6.6 \mathrm{~mm}$. long in male, 5.8 to $8 \mathrm{~mm}$. long in female; body form rather stout; male flagellum without tyloids; second segment of middle tarsus about 3.7 as long as wide; second tergite about 1.10 as long as wide in male, about 1.05 as long as wide in female; ramellus usually long, especially in female; ovipositor sheath about 1.0 as long as front wing; lower valve of ovipositor with about 14 ridgelike teeth, the apical tooth-bearing part of the valve about 2.6 as long as deep.

Colored almost exactly like $P$. mediator mediator (a European subspecies) and rather similar to the two Nearctic subspecies of $P$. mediator, differing from one or both of them as follows: mesoscutum always entirely ferruginous except for blackish lateral edges; mesepisternum entirely ferruginous except that the subtegular ridge is white and its upper hind corner is infuscate; hind femur fulvous with its extreme base brown and extreme apex whitish; hind tibia and tarsus of male with the pale areas whitish stramineous and the dark areas dark brown (and thus a little less contrasting than in the American forms of $P$. mediator); and tibiae and tarsi of female ferruginous, the hind tibia and tarsus tinged with brown.

Figure 90.-Localities for Perithous divinator.

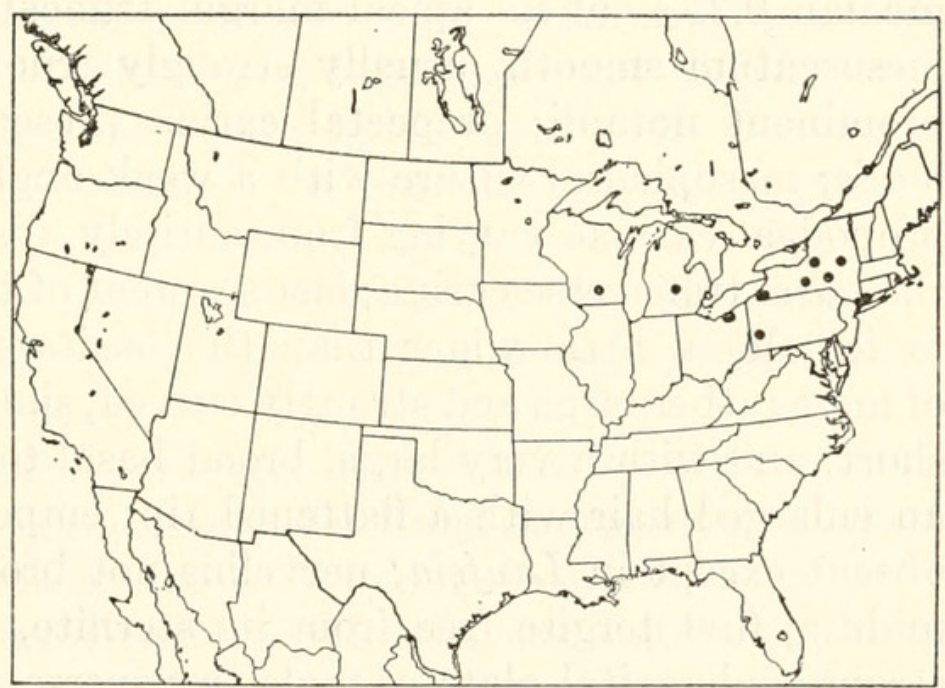

Specimens $\left(6 \sigma^{7}, 26 \%\right)$ : From Connecticut (New Canaan); Michigan (East Lansing); New York (Bemus Point, Canajoharie, Chautauqua, Gilbertsville, Ithaca, New Rochelle, and Syracuse); Ohio (Cleveland and Puritas Springs in Cuyahoga Co.); Pennsylvania (Pittsburgh); Quebec (Quebec); and Wisconsin (Madison). We have also studied $13 \sigma^{x}, 18$ 의 from Europe (France, Belgium, and Germany). 
Collection dates are from rather late spring to fall. The earlier and later dates are: May 24 at Pittsburgh, Pa.; May 31 at Ithaca, N. Y.; September 15 and 19 at Cleveland, Ohio; and September 21 at Puritas Springs, Ohio. Since this is an introduced species, the earliest year date on American specimens is of interest. This is borne by a female collected by F. D. De Gant, "on dead twig of rose," Cleveland, Ohio., Sept. 13, 1931. There are also two males and five females reared or collected by F. D. De Gant in 1934, at Cleveland, Ohio, and at Puritas Springs, Ohio.

Rearing records on the specimens studied are: $2 \sigma^{x}$, reared from nest of Pemphredonini in stem of Rosa, Jan. 5, 1934, Cleveland, Ohio. \%, taken dead from nest in twig of sumac (Rhus), October 1938, W. G. Bodenstein. $\sigma^{\gamma}$, reared, Feb. 10, 1933, F. De Gant. $7 \sigma^{\gamma}, 89$, reared from Pemphredon unicolor, Reuil, France, June 1955, H. Janvier. \&, reared from Pyrausta nubilalis?, Seine, France, P. Chretien.

This species is European, but was introduced into northeastern United States prior to 1931. It is adult through the growing season. Pemphredon spp. nesting in pithy stems serve as hosts.

\section{Tribe Polysphinctini}

Figures 292,b-297,b

Front wing 2.3 to $18 \mathrm{~mm}$. long; clypeus more or less swollen, usually transverse, its apex often a little flattened or impressed, the median $0.35 \pm$ of its apical margin truncate, often a little reflexed; mesoscutum smooth, usually strongly trilobed by reason of baving prominent notauli; prepectal carina present except in Hymenoepimecis; mesopleural suture with a weak angle just above the middle; propodeal carinae varying from entirely absent to all present except the basal transverse carina; last segment of tarsus enlarged (especially in female) a little wider than the basitarsal segment; tarsal claws of male rather large and strongly curved, simple; tarsal claws of female short, and with a very large, broad basal tooth; tarsal claws without an enlarged hair with a flattened tip; empodium very large; areolet absent except in Laufeia; nervellus not broken or broken below the middle; first tergite free from its sternite, its lateral carina usually strong; subgenital plate of male transverse, its apex usually truncate or retuse; last tergite of female without an apical horn or boss; ovipositor rather short or sometimes hardly surpassing tip of abdomen, with a submedian ventral swelling from whence it is tapered to the apex.

The Polysphinctini are distinguished from the Pimplini by the absence of the areolet, the enlarged fifth segment of the tarsi with short claws and enlarged empodium, and the relatively short ovi- 
positor the point of which is long and tapered. One genus (Laufeia) has the areolet present but has the enlarged fifth tarsal segment and ovipositor shape typical of the tribe. A few of the Pimplini (Zaglyptus, Clistopyga, and a few Tromaiobia and Acropimpla) lack the areolet but do not have the enlarged fifth tarsal segment, nor except in Clistopyga, a long-tapered point on the ovipositor.

The species of Polysphinctini are mostly small or very small. A few are medium sized, and some species of Acrotaphus and Hymenoepimecis are medium large. They are worldwide in distribution. In correlation with their small size and slender bodies, they are commonest in damp habitats. All are parasitic on the bodies of spiders. The adult parasite stings a spider to quiet it, then lays a single egg, usually near the base of the abdomen on the dorsal side. The hatching larva clings to the active spider and feeds on its juices. In most species the larva rests curved over the base of the abdomen on the dorsal side. It is attached to the spider by a saddle of its egg shell and old shed skins, piled one on the other, into which it has two or four pairs of projecting papillae, arising one pair each from the under side of the median abdominal segments. The larva is very securely attached to this saddle and the saddle to the spider. Even if the spider molts, the skin beneath the saddle is not shed and the larva remains in position. Growth of the larva is rapid. At the last molt it acquires four to eight pairs of dorsal tubercles (one pair per segment) covered with small hooks, which are one of the main distinguishing features of larvae of this tribe. When the spider succumbs, a narrow fusiform cocoon is spun, usually in the remains of the web of the spider. The dorsal tubercles beset with hooks are used by the larva for holding to the spider web while finishing off its host and starting the cocoon. The cocoon of the Polysphinctini differs from those of possibly all other Hymenoptera in having an opening at the hind end. Through this the last larval excrement is pushed, and often also the exuvia of the molt at pupation, leaving the cocoon very tidy inside.

The polysphinctines are evidently a specialized offshoot of the Pimplini, and the steps in the biological and morphological change from one tribe to the other are still well preserved. Most of the Pimplini parasitize larvae living in plant tissue, and oviposition is through the plant tissue into the bost larva. Some genera, like Sericopimpla and probably Acropimpla, however, parasitize larvae in cocoons or silken cases and in these genera oviposition is through a silken bag to reach the host. Iseropus is related to these and has the same habit, but in Iseropus several parasites ratber than one develop from a single host. From Iseropus the change to the biology of Tromatobia is a small step. Tromatobia selects spider egg cocoons $526527-60-15$ 
rather than cocoons of caterpillars as hosts. As in Iseropus, several larvae develop in a single cocoon. Zaglyptus selects the egg nest of a spider in which the female stays with the eggs to guard them. The Zaglyptus stings the mother spider to death, then lays several eggs on the batch of spider eggs. Its larvae consume the eggs and usually also the body of the dead spider. Sometimes the parasite eggs are laid on the body of the spider as well as on its eggs. Schizopyga, which is a primitive polysphinctine, selects as host a nest-inhabiting spider. The nest is invaded, the spider stung, and a parasite egg laid on the body of the spider. The more specialized polysphinctines oviposit on free-living spiders. The chain between parasites on larvae in plant tissues, larvae in cocoons, spider-egg cocoons, both spideregg cocoons and their guarding parent, the spider itself in its egg nest, and free-living spiders of various ages is practically complete, with Zaglyptus at the transition point between parasites of spiders or of their eggs. Zaglyptus is also somewhat transitional between the two tribes in lacking the areolet, which has caused many authors to classify species of Zaglyptus in the genus Polysphincta. We place Zaglyptus in the Pimplini, however, because of the shape of the ovipositor and because the larval structure and biology are more like that of Tromatobia.

Clistopyga is a genus placed sometimes in the Polysphinctini. It lacks the areolet and has a long-tapered ovipositor like the Polysphinctini. It does not have the tarsi swollen at the apex, however, the ovipositor surface is rough rather than smooth, and according to Nielsen's account of the biology and the larval morphology, these resemble those of Tromatobia and Zaglyptus. On the strength of these characters, we classify Clistopyga with the Pimplini rather than with the Polysphinctini.

The larvae of Tromatobia, Zaglypius, and Clistopyga have median dorsal tubercles which have paired groups of small hooks. These tubercles with their hooks enable the larvae to move about in the silk of spider egg cocoons. Mature larvae of Polysphinctini have similar dorsal tubercles, but the tubercles themselves are paired rather than single on each segment, apparently the result of subdivision of the single tubercle of Tromatobia and Zaglyptus. The tubercles of the polysphinctine larva are used to cling to spider webbing while the cocoon is being spun, so serve a function somewhat similar to that of the single tubercles of Tromatobia, Zaglyptus, and Clistopyga.

It is relatively common to find spiders with a polysphinctine larva attached to the base of the abdomen. American workers have reared a number of the Nearctic polysphinctines, but except for some brief notes, they have left only host records as a result of their work. The European species have been more extensively investigated and Niel- 
sen has published a rather complete account of several of them, as well as of the biology of Tromatobia, Zaglyptus, and Clistopyga. (See Entomologiske Meddelelser, vol. 14, pp. 137-205 (1923); vol. 16, pp. 152-155 (1928); vol. 16, pp. 366-368 (1929); vol. 19, pp. 192-215 (1935); vol. 20, pp. 25-28 (1937).)

The generic classification of the tribe has taken form very slowly because the representation of species in most collections is scanty, and generic limits are often rather obscure. We have redefined the genera of our fauna, erected some new ones, and added notes on some of the extra-limital species that belong to these redefined or new genera. Some of the genera are of problematic validity, but their status cannot be exactly determined until a larger percentage of the world fauna is known.

\section{Key to the Nearctic genera of Polysphinctini}

1. Areolet present (fig. 292, b) ; eye sparsely hairy in male, more densely hairy in female . . . . . . . . . . . . . . . 1. Laufeia (p. 220)

Areolet absent (figs. 293-297); eye not obviously hairy except in Schizopyga and $Z$ abrachypus . . . . . . . . . . . . . . . . . . . . . . . . . 2

2. Clypeus not separated from face (fig. 293,a); upper end of prepectal carina near front edge of mesopleurum; mandible with a broad thin flange internally; eye hairy . . . . . . . . . . . . . 2. Schizopyga (p. 224)

Clypeus separated from face by a groove (figs. 293,b-297,b); upper end of prepectal carina distant from front edge of mesopleurum (figs. 293,b-297,b); mandible without a flange internally . . . . . . . . . . . . . . . . 3

3. Median lobe of mesoscutum with a sharp vertical carina anteriorly on each side (fig. 294,a) . . . . . . . . . . . . 4. Acrodactyla (p. 230)

Median lobe of mesoscutum without a vertical carina anteriorly on each side . . . . . . . . . . . . . . . . . . . 4

4. Second through fourth tergites without grooves or swellings (fig. 295,a), evenly convex; notaulus absent; mesoscutum strongly mat and densely hairy . . . . . . . . . . . . . . . .6. Piogaster (p. 241)

Second through fourth tergites with oblique or transverse grooves, or with paired median swellings; notaulus strong, though usually not sharp . . . 5

5. Discoidella completely absent and mesoscutum with hairs all over.

10. Sinarachna (p. 258)

Discoidella present and/or mesoscutum hairless or partly hairless . . . 6

6. Third and fourth tergites each with a median pair of large rounded swellings (figs. 295,b-296,b); ovipositor sheath usually 3 to 4 times as long as apical depth of abdomen, or shorter in Oxyrrhexis (figs. 295,b-296,b) . . . . . 7

Third and fourth tergites with oblique grooves which delimit a central rhombic area, or with transverse impressions (figs. 293,b; 294,b; 297,b); ovipositor sheath 1 or 2 times as long as apical depth of abdomen (figs. $293, \mathrm{~b} ; 294, \mathrm{~b} ; 297, \mathrm{~b})$. . . . . . . . . . . . . . . . . . . . . . . 9

7. Epomia absent (fig. 296,b) ; temple flat, concave, or sometimes weakly convex; ocelli usually very large . . . . . . . . . . 9. Acrotaphus (p. 256)

Epomia present (figs. 295,b; 296,a); temple convex, rarely flat; ocelli of normal size. 
8. Abdominal tergites with rather close, coarse punctures; ovipositor sheath $\mathbf{1 . 4}$ to 1.8 as long as apical depth of abdomen (about 1.4 as long in the American species) . . . . . . . . . . . . 7. Oxyrrhexis (p. 242)

Abdominal tergites with sparse punctures or almost impunctate; ovipositor sheath 3 to 4 times as long as apical depth of abdomen.

8. Polysphincta (p. 245)

9. Mesoscutum rather densely hairy all over; abdominal tergites in the American species rather closely punctate, each with a transverse impression.

3. Zabrachypus (p. 228)

Mesoscutum partly or entirely hairless, at least its lateral lobe partly hairless . . . . . . . . . . . . . . . . . . . . . . . 10

10. Epomia absent (fig. 294,b); third tergite with a weak transverse impression.

5. Eruga (p. 238)

Epomia present (fig. 297,b); third tergite with oblique grooves which delimit a median rhombic area . . . . . . . 11. Zatypota (p. 262)

\section{Genus Laufeia}

FiguRE 292,b

Laufeia Tosquinet, 1903, Mém. Soc. Ent. Belgique, vol. 10, p. 381 . Type: Laufeia mira Tosquinet; monobasic.

Front wing 2.9 to $5.8 \mathrm{~mm}$. long; eye with rather short sparse hairs, more conspicuously hairy in female than in male; clypeus transversely hexagonal, convex transversely but almost flat longitudinally, almost in same contour as face but separated from it by a groove; epomia straight, slanted forward a little; mesoscutum polished or subpolished, evenly covered with moderately dense hairs; notaulus long and strong; prepectal carina rather long but ending far from front edge of mesopleurum; pleural carina complete; legs of moderate stoutness; areolet present, subrhombic; nervulus postfurcal by about 0.25 its length; discoidella rather strong; first tergite moderately slender; second to fourth tergites polished, with impressions setting off a median subrhombic area on each, the subrhombic areas swollen a little laterally to make suggestions of paired swellings on each tergite; impressions on tergites 2-4 more or less punctate; ovipositor sheath about 2 times as long as apical depth of abdomen; ovipositor weakly curved upward (fig. 332,c).

The genus Laufeia contains the genotype from the mountains of the East Indies, Polysphincta stigmata Uchida 1941 from Japan, the two Nearctic species described below, and Pimpla pictifrons Thomson 1877 of Europe. The names stigmata and pictifrons have not previously been referred to Laufeia (new combinations). These species seem to be common where they occur. The Nearctic L. slossonae is the commonest polysphinctine in North American collections, and L. navajo is sometimes abundant along the mountain-stream valleys in Arizona. We found L. mira common at 3,000 to $7,800 \mathrm{ft}$. in the mountains of 
the Philippines and took the Japanese species at three localities while on a short collecting trip in Japan.

\section{Key to the Nearctic species of Lavfeia}

1. Propodeum with distinct median longitudinal carinae; first tergite with median longitudinal carinae distinct on the basal $0.7 \pm$; hind tibia with broad apical and subbasal fuscous bands (fig. 332,1) . . . . . . . 1. slossonae (Davis)

Propodeum without median longitudinal carinae; first tergite with median longitudinal carinae distinct on the basal $0.3 \pm$; hind tibia with indistinct apical and subbasal infuscation (fig. 323,a) . . . 2. navajo, new species

\section{Laufeia slossonae (Davis)}

Figures 322,$1 ; 332, \mathrm{c}$

Polysphincta slossonae Davis, 1898, Trans. Amer. Ent. Soc., vol. 24, p. 368; . Type: $q$, Mount Washington, N. H. (Philadelphia).

Front wing of male 2.9 to $5.8 \mathrm{~mm}$. long, of female 3.2 to $5.8 \mathrm{~mm}$. long; body and legs moderately robust; lateral longitudinal carina of propodeum distinct except basally; median longitudinal carinae of propodeum distinct on basal 0.7 of propodeum; petiolar area of propodeum more or less distinct; propodeum with short transverse rugulae between its lateral and pleural carinae and long transverse rugulae near base of its petiolar area; first tergite about 1.87 as long as wide in male, about 1.65 as long as wide in female, its median longitudinal carina distinct on its basal $0.7 \pm$.

Black or blackish brown. Face of male except narrow lateral and ventral margins, spot of variable size on face of female below each antennal socket (the spots sometimes united to make a large whitish blotch in upper part of face), sometimes part or all of clypeus of male, palpi, scape and pedicel except above, more or less of lower part of propleurum and lower corner of pronotum, tegula, hind corner of pronotum, and ground color of legs, ivory, the femora of female usually pale fulvous; flagellum dark brown, paler below, stramineous basally below; mesosternum, lower 0.6 to all of mesopleurum, often the metapleurum, and often more or less of mesoscutum fulvous; scutella ivory to fulvous; very narrow apex of front femur and moderately narrow apex of middle femur infuscate; front tibia with weakly infuscate subbasal and apical bands; front tarsus with a faint apical infuscation on each segment; middle tibia and tarsus with infuscate markings as on the front tibia and tarsus but a little darker; hind femur infuscate basally and apically and usually with a weak longitudinal infuscate stripe on its front side connecting the basal and apical bands; hind tibia with broad apical and subbasal fuscous bands; apex of first four segments of hind tarsus fuscous; fifth segment of hind tarsus fuscous, its base pale. 
This species is close to the European L. pictifrons (Thomson), differing most conspicuously in having more densely punctate tergites.

Specimens $\left(85 \sigma^{\top}, 115\right.$ \%): From Alaska (King Salmon on the Naknek River); Arizona (White Mts.); British Columbia (Carbonate on the Columbia River at 2,600 ft., Downie Creek in the Selkirk Mts., Nanaimo Biological Station, Robson, and Wellington); California (Crescent City, Inverness, Mill Valley in Marin Co., Smith River, Sonoma Co., and Stinson Beach); Colorado; Connecticut (Stonington); Illinois; Maine (Bar Harbor, Baxter State Park at 1,100 ft., Casco, Fort Kent, Liberty, and Machias); Massachusetts (Amherst, Holliston, and South Hadley) ; Michigan (Douglas Lake in Cheboygan Co., East Lansing, Mackinac Co., Midland Co., Muskegon Co., Newaygo Co., Osceola Co., Roscommon Co., and Schoolcraft Co.); Minnesota (Plummer); New Brunswick (Jacquet River and Nerepis); New Hampshire (Mount Madison, Mount Washington, Pinkham Notch, and Randolph); New York (Armonk, Barrytown, Canajoharie, Elizabethtown, Greene Co. at 2,500 ft., Ithaca, Kingston, Lake Mohonk in Ulster Co., Lake Sebago in Bear Mountain State Park, Oneonta, and Poughkeepsie); North Carolina (Crabtree Meadows in Yancey Co. at 3,600 ft., Craggy Gardens in Buncombe Co. at 5,300 ft., Mount Mitchell at 5,200 ft., Mount Pisgah at 5,300 ft., Newfound Gap and Spence Field in Great Smoky Mountains National Park, Sylva, and Wake Co.); Northwest Territories (Norman Wells); Ontario (Dows Swamp near Ottawa, Footes Bay, Kearney, Orillia, Ottawa, and Sudbury); Pennsylvania (White Haven); Quebec (Knowlton, Laniel, Sainte Agathe des Montes, and Stoneham); Rhode Island (Westerly); South Dakota; Tennessee (Gatlinburg); Virginia (Jefferson National Forest and Skyline Drive); Utah (Logan and Uintah Co.); Vermont (Dummerston, Laurel Lake near Jacksonville, Manchester, South Newfane, and Stowe); Washington (Barnes State Park,
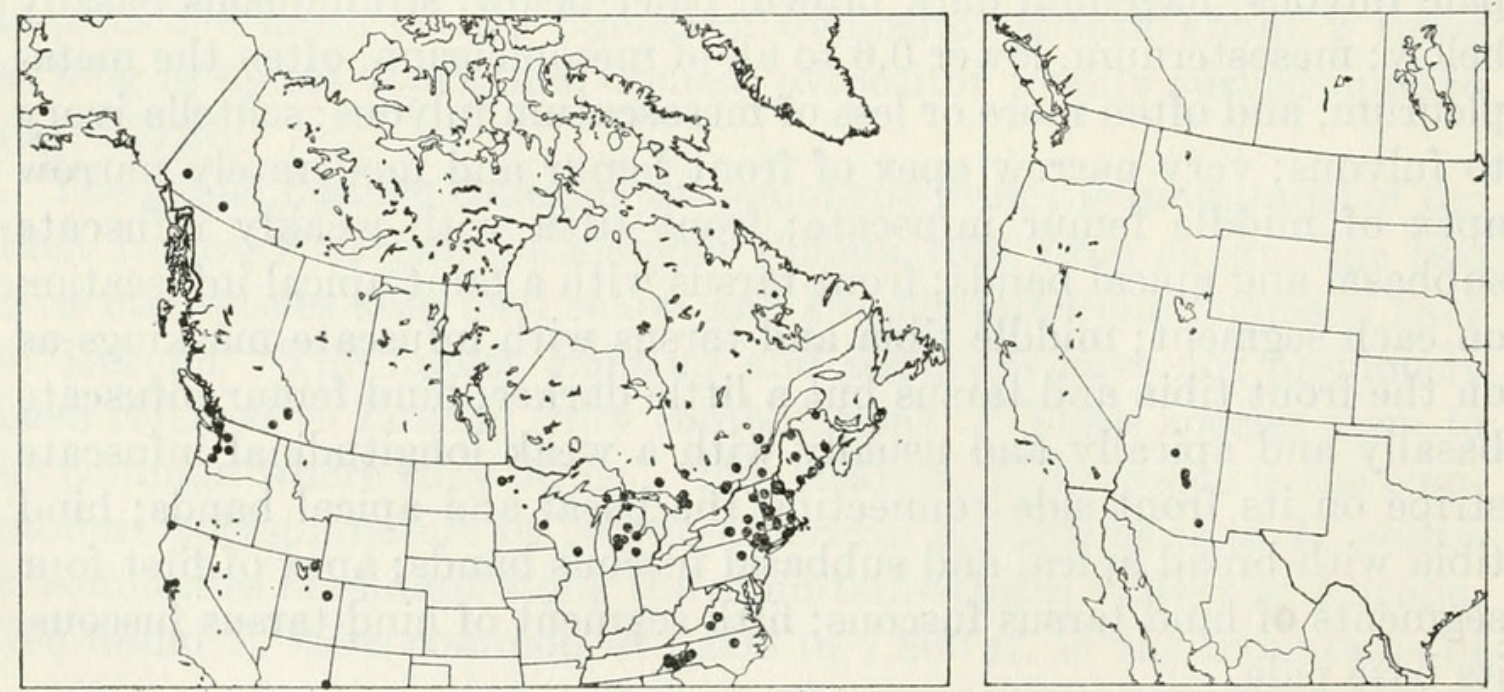

Figures 91, 92.-Localities:韵1 (left), Laufeia slossonae; 92 (right), L. navajo. 
Mount Rainier at 2,900 ft., "Pelvis," San Juan Island, Sultan, and Yelm); Wisconsin (Dunn Co. and Madison); and Yukon (Kluane and Marsh Lake).

Most collecting dates are in July and August and the great majority of the specimens were taken from June 12 to September 12. The only captures outside of this range were: May 22 at South Hadley, Mass.; May 28 at Ottawa, Ont.; May 29 at Ithaca, N. Y.; June 1 at Wellington, B. C.; June 3 at Amherst, Mass.; June 7 at Sylva, N. C. and at South Hadley, Mass.; June 8 at Manchester, Vt.; June 9 at Elizabethtown, N. Y.; September 13 at Liberty, Maine and at Madison, Wis.; September 14 at Holliston, Mass.; and October 6 at Inverness, Calif.

This species is transcontinental in the Transition and Canadian zones. It occurs in rank vegetation in damp deciduous woods. It is adult from early to late summer.

\section{Laufeia navajo, new species}

FIGURE 323, a

Front wing of male 3.2 to $5.7 \mathrm{~mm}$. long, of female 4.2 to $5.8 \mathrm{~mm}$. long; body and legs a little more robust than in L. slossonae; lateral longitudinal carina of propodeum distinct on apical 0.25 of propodeum; median longitudinal carinae of propodeum absent; petiolar area not defined; propodeum smooth or in some areas faintly rugulose; first tergite about 1.77 as long as wide in male, about 1.25 as long as wide in female, its median longitudinal carinae distinct on its basal $0.3 \pm$.

Black. Antenna brown, paler basally, its scape and pedicel ivory except above; palpi, tegula, hind corner of pronotum, often lower corner of pronotum, and legs, ivory; pronotum more or less (especially near hind corner and near lower corner), mesosternum, mesopleurum, metapleurum, mesonotum, and sometimes additional parts of thorax, fulvous; femora often with a vague stramineous stripe above; hind tibia with narrow indistinct apical and subbasal infuscation; fifth segment of front and middle tarsi pale brown, paler basally; fifth segment of hind tarsus infuscate, paler basally; first four segments of hind tarsus stramineous apically.

Type: \&, Workman Creek, Sierra Ancha, Ariz., May 8, 1947, H. and M. Townes (Washington, USNM 63697).

Paratypes: 3ㅇ, Oak Creek Canyon, Ariz., May 16, 1947, H. and M. Townes (Townes). $22 \sigma^{7}, 27$, Workman Creek, Parker Creek, and Pocket Creek, all in the Sierra Ancha, Ariz., Apr. 21 to May 8, 1947, H. and M. Townes (Townes). ㅇ, Sunnyside Canyon in Cochise Co., Ariz., July 9, 1940, R. H. Beamer (Lawrence). ㅇ, Honduras, 1940, W. von Hagen (New York). 
We found this species common along stream sides at around 5,500 ft. altitude in the mountains of Arizona, usually in the coolest, dampest habitats and usually resting on the under side of foliage just above the streams. A species of Pisaurina was common in this habitat and may have been the host.

\section{Genus Schizopyga}

\section{Figure 293, a}

Schizopyga Gravenhorst, 1829, Ichneumonologia europaea, vol. 3, p. 125. Type: Schizopyga podagrica Gravenhorst; monobasic.

Front wing 3.4 to $6.5 \mathrm{~mm}$. long; eye with long conspicuous hairs; clypeus in same contour as face, not at all separated, the combined face and clypeus strongly convex transversely, weakly convex longitudinally; mandible very narrow at apex, its lower tooth internal in position and expanded into a wide flat blade; apex of maxilla very large (these specializations of the mandible and maxilla occur in no other genus of the tribe); temple long, rather flat; epomia weak but placed on a conspicuous angle; mesoscutum subpolished, with moderately dense, evenly distributed hairs; notaulus long but not very strong; prepectal carina complete, its upper end near front margin of mesopleurum; pleural carina of propodeum complete; legs rather stout; areolet absent; intercubitus about as long as second abscissa of cubitus; nervulus postfurcal by about 0.25 its length; discoidella strong; first tergite moderately stout; second to fourth tergites with weak sublateral swellings and a weak postmedian transverse impression, mat, with moderately dense hairs all over, their punctures small and weak; ovipositor sheath about 0.67 as long as apical depth of abdomen; ovipositor stout, upcurved, tapered from base to a sharp point (fig. $332, \mathrm{~d})$.

This genus is Holarctic. There are two Nearctic species, one or both of which occur also in Europe. The biology of a European species has been reported on by Nielsen (1935. Entomologiske Meddelelser, vol. 19; pp. 194-206). He found that the host is Cheiracanthium carnifex, a spider that lives in nests. The adult female enters the nest by biting a hole in the silk (which may explain the peculiar mandibles of this genus). Its egg is laid on the cephalothorax of the host, near the apex.

\section{Key to the Nearctic species of Schizopyga}

1. Hind tibia white, with broad apical and subbasal blackish bands (fig. $323, \mathrm{~b}$ ) ; abdomen entirely black; propodeum subpolished . . . 1. frigida Cresson Hind tibia fulvous, with a broad apical but no subbasal blackish band (fig. $323, c)$; abdomen usually partly fulvous; propodeum mostly mat.

2. pulchra Walley 


\section{Schizopyga frigida Cresson}

Figures 323,b; 332,d

Schizopyga frigida Cresson, 1870, Trans. Amer. Ent. Soc., vol. 3, p. 159; Type: $q$, Hudson Bay Territory (Philadelphia).

Schizopyga atra Kriechbaumer, 1887, Ent. Nachr., vol. 13, p. 87; $0^{7}$, ㅇ. New synonymy. Types: $\sigma^{\top}, \uparrow$, Germany (?Munich).

Polysphincta pontiaci Viereck, 1917, Bull. Connecticut Geol. Nat. Hist. Surv., vol. 22 , p. 317 ; $\sigma^{\top}$. Type: $\sigma^{7}$, Cheshire, Conn. (New Haven).

Front wing 3.4 to $6.2 \mathrm{~mm}$. long in male, 4.5 to $6.5 \mathrm{~mm}$. long in female; head about 1.55 as wide as long; propodeum subpolished; second tergite mat and with distinct longitudinal rugulae in the depressions.

Black. Antenna brown, its lower half pale brown, toward the base pale stramineous, the scape of male mostly dark brown; maxilla and labium whitish; tegula white; coxae fulvous to black, the front and middle coxae whitish apically; trochanters whitish or pale fulvous; femora fulvous, the apex of hind femur broadly fuscous, and apex of front femur pale fulvous; apex of middle femur pale fulvous or sometimes with a narrow weak infuscation; front tibia and tarsus light fulvous; middle tibia and tarsus light fulvous, often both a little

Figure 93.-Localities for Schizopyga frigida.

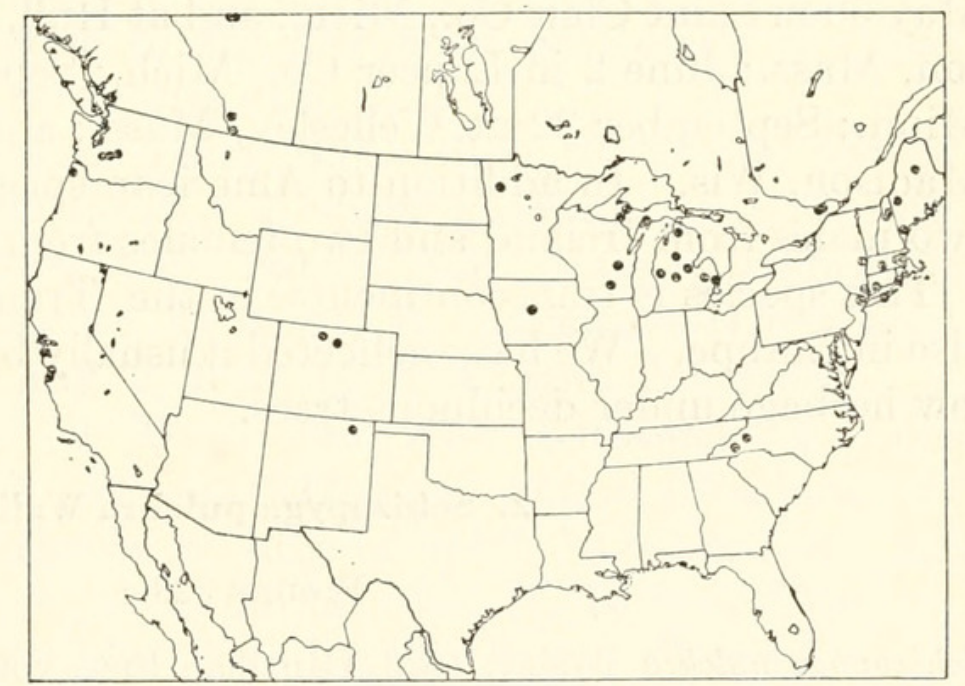

infuscate at apex; hind tibia and tarsus white, the tibia with broad apical and subbasal blackish bands and each tarsal segment fuscous apically. Specimens from colder localities are likely to have the coxae largely black while those from warmer localities have them entirely fulvous. European specimens seem always to have the coxae mostly black.

We have compared two males from Ireland and two females from Germany with American specimens of this species. The European specimens seem to be identical with American specimens having black coxae. 
Specimens (13 $\sigma^{\top}, 38$ \%): From Alberta (Bilby, Frank, Wabamun, and Waterton Lakes); British Columbia (Diamond Head Trail near Squamish at 4,600 ft. and Mission City); California (Black Point in Marin Co., Carmel, Monterey, and San Francisco); Connecticut (Cheshire); Colorado (Phantom Valley in Rocky Mountain National Park at 9,400 ft. and Rabbit Ears Pass); Iowa (Ames); Maine (Casco, Mount Katahdin at 5,200 ft., and Oquossoc); Massachusetts (Holliston, South Hadley, Wellesley, and Wollaston); Michigan (Cheboygan Co., Delta Co., Iron Co., Lapeer Co., Marquette Co., Midland Co., Montcalm Co., Newaygo Co., Roscommon Co., and St. Clair Co.); Minnesota (Plummer); New Hampshire (Mount Washington and Pinkham Notch); New Jersey (Ramsey); New Mexico (Cimarron Canyon); New York (Poughkeepsie, Quogue, and Troy); North Carolina (Black Mt. and Crabtree Meadows in Yancey Co. at 3,600 ft.); Ontario (Dows Swamp near Ottawa, and Ottawa); Oregon (Seaside); Rhode Island (Westerly); Washington (Ashford, Elbe, and Mount Rainier at 2,700 and 2,900 ft.); and Wisconsin (Green Lake Co. and Madison).

Dates of collection are distributed from late spring to mid-fall, the earlier and later dates being as follows: March 24 at Carmel, Calif.; May 21 and 29 at Ottawa, Ont.; May 22 at South Hadley, Mass.; May 30 in Saint Clair Co., Mich., and at Hull, Que.; June 1 at Wollaston, Mass.; June 2 in Lapeer Co., Mich.; September 18 at Plummer, Minn.; September 22 at Wellesley, Mass.; and October 10 and 21 at Madison, Wis. In addition to American specimens, we have studied two males from Ireland and two females from Germany.

This species is transcontinental in the Transition zone and occurs also in Europe. We have collected it usually by sweeping partly sunlit low herbage under deciduous trees.

\section{Schizopyga pulchra Walley}

\section{Figure 323,c}

Schizopyga pulchra Walley, 1936, Canadian Ent., vol. 68, p. 20;. Type: , Moosonee, Ont. (Ottawa).

Front wing of male 4.0 to $5.8 \mathrm{~mm}$. long, of female 4.0 to $5.0 \mathrm{~mm}$. long; head about 1.42 as wide as long; propodeum mat, its petiolar area subpolished; second tergite mat, without distinct rugulae.

Black. Flagellum of male brown below; antenna of female brown, paler below, basally stramineous below; maxilla and labium whitish to light brown; tegula white to fulvous; front coxa and front and middle trochanters light fulvous to whitish; femora, hind trochanters, and middle and hind coxae fulvous, the apex of hind femur broadly blackish; tibiae fulvous, the middle and hind tibiae blackish apically; front 
and middle tarsi of both sexes and hind tarsus of female light fulvous, their last segment apically infuscate; hind tarsus of male fuscous, the segments fulvous basally; first five tergites of male with a variable amount of fulvous, usually almost entirely fulvous, but with the apex of the first three tergites fuscous, sometimes entirely black; first five tergites of female usually entirely fulvous but sometimes more or less infuscate.

Figure 94.-Localities for Schizopyga pulchra.

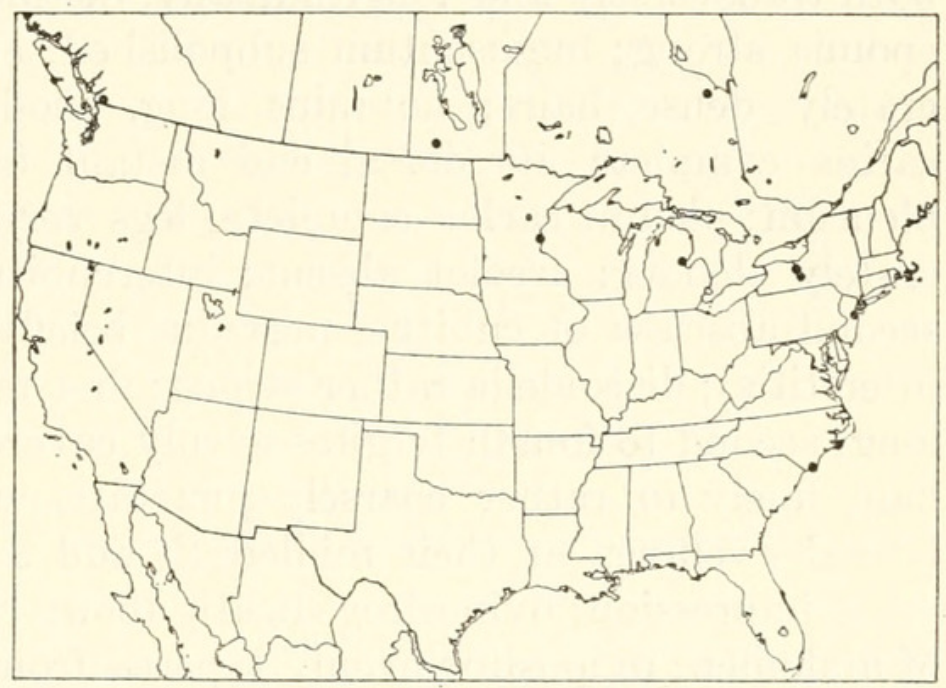

This species is very close to the European Schizopyga circulator (Panzer), and may be a subspecies of it.

Specimens: $3 \circ^{7}, 2$, Hatzic Lake, B. C., July 20, 22, 26, and 30, 1953, W. R. M. Mason (Ottawa). o, Stockton, Man., Aug. 25, 1928, R. M. White (Washington). $\sigma^{7}$, Woods Hole, Mass. (Cambridge). $\sigma^{7}$, Bay Co., Mich., May 26, 1951, R. R. Dreisbach (Dreisbach). क, Taylors Falls, Minn., Aug. 5, 1922, H. H. Knight (Madison). $\sigma^{7}$, Morgan, N. J., August 30, Weiss and West (Ottawa). ㅇ, Long Beach, Long Island, N. Y., July 9, 1927, F. M. Schott (Washington). $0^{7}$, taken on ericaceous shrubs at edge of heath bog, McLean Bogs Reserve, Tompkins Co., N. Y., Sept. 24, 1938, H. Townes (Townes). ㅇ, Sea Cliff, N. Y., September 5 to 18, N. Banks (Townes). $\sigma^{7}$, Springlake, Cayuga Co., N. Y., July 20, 1918 (Ithaca). $2 \sigma^{7}$, taken in short vegetation near beach, Morehead City, N. C.,

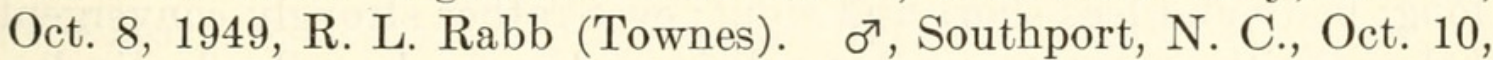
1948, C. W. Sabrosky (Washington). क (type), Moosonee, Ont., July 17, 1934, G. S. Walley (Ottawa).

This species is transcontinental and occurs in all zones from the Canadian to the Lower Austral, but is scarce. It seems that its habitat is low plants in marshy places, and that adults are commonest late in the season. 


\section{Genus Zabrachypus}

Figure 293,b

Zabrachypus Cushman, 1920, Proc. U. S. Nat. Mus., vol. 58, p. 37 . Type: Zabrachypus primus Cushman; original designation.

Front wing 3.4 to $10.5 \mathrm{~mm}$. long; eye conspicuously hairy to almost bare; clypeus broadly lenticular to transversely hexagonal, convex both transversely and longitudinally, distinctly separated from face; epomia strong; mesoscutum subpolished, evenly covered with moderately dense hairs; notaulus long, moderately sharp; prepectal carina complete, its dorsal end distant from front edge of mesopleurum; pleural carina complete; legs very short and stout to moderately slender; areolet absent; intercubitus 0.5 to 1.0 as long as second abscissa of cubitus; nervulus briefly postfurcal or sometimes interstitial; discoidella rather strong; first tergite short to moderately long; second to fourth tergites evenly covered with moderately dense hair, finely to rather coarsely punctate, with a pair of weak sublateral swellings at their midlength and a weak postmedian transverse impression; ovipositor sheath about 1.8 as long as apical depth of abdomen; ovipositor evenly tapered from base to a rather slender point, weakly upcurved (fig. 332,e).

Zabrachypus includes one Nearctic species and four from the eastern Palaearctic as follows: (Polysphincta) Zabrachypus nikkoensis Uchida 1928, (Polysphincta) Zabrachypus tenuiabdominalis Uchida 1941, and an undescribed species each from Japan and China. Z. nikkoensis and $Z$. tenuiabdominalis have not previously been referred to Zabrachypus (new combinations). The Palaearctic species are rather different from the Nearctic $Z$. primus in being of more slender build and in having the eyes only inconspicuously hairy.

\section{Zabrachypus primus Cushman}

Figures 323,d; 332,e

Zabrachypus primus Cushman, 1920, Proc. U. S. Nat. Mus., vol. 58, p. 37;. Type: $q$, Montana (Washington).

Front wing of male 3.4 to $4.2 \mathrm{~mm}$. long, of female 3.4 to $5.5 \mathrm{~mm}$. long; body and legs short and stout; eyes rather strongly convergent below, with conspicuous long hairs; clypeus broadly lenticular, separated from face by a strong impression; intercubitus about 0.65 as long as second abscissa of cubitus; propodeum evenly convex, with moderate-sized punctures, its median longitudinal carinae represented by faint ridges; tarsi extremely short, especially in female, the third segment of hind tarsus about 1.6 as long as deep in male, about 0.9 as long as deep in female; abdomen rather broad, with rather coarse, sharp punctures whose interspaces are about 0.6 their 
diameter, the tergites with a broad, weak, postmedian transverse impression basad of which they are weakly swollen; third tergite about 0.72 as long as wide in male, about 0.63 as long as wide in female; ovipositor sheath about 0.45 as long as abdomen.

Figure 95.-Localities for Zabrachypus primus.

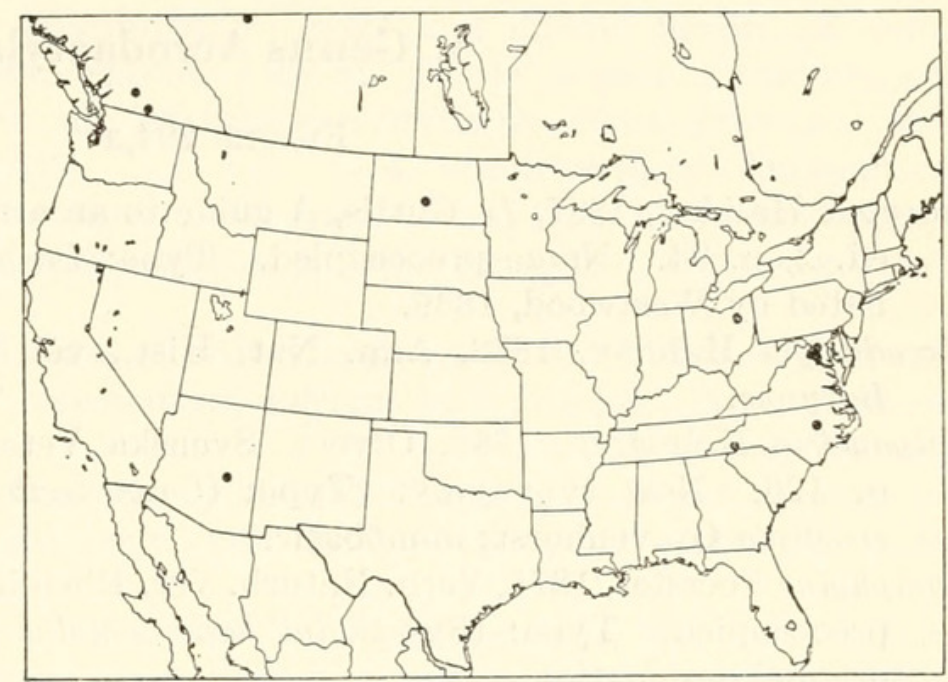

Black. Clypeus, mandible, and antenna dark brown; palpi and tegula white; extreme hind corner of pronotum fulvous; front and middle coxae light fulvous, often more or less whitish apically; trochanters pale stramineous; front and middle femora fulvous, their apices whitish; front and middle tibiae white or whitish, pale fulvous below toward apex; front and middle tarsi stramineous or light brown; hind coxa and femur fulvous, the apical margin of the femur infuscate and the base of the coxa often brown; hind tibia infuscate, with a broad, indefinitely limited, whitish subbasal band; hind tarsus fuscous or brown, the basal half of its first segment stramineous. In a male specimen from Wilton, N. Dak., the coxae are blackish, the trochanters infuscate basally, and the pale band on the hind tibia obsolescent.

Specimens: $2 \sigma^{\text {T}}$, Edmonton, Alta., June 17, 1947, and July 22, 1947, E. H. Strickland (Townes). 3\%, Edmonton, Alta., July 6, 1940, and Aug. 4 and 24, 1947, E. H. Strickland (Townes). $\sigma^{7}$, Parker Creek, Sierra Ancha, Ariz., Apr. 21, 1947, H. and M. Townes (Townes). , Merritt, B. C., Aug. 3, 1931, H. T. Peters (Lawrence). 4웅, Oliver, B. C., May 11, 15, 16, and 31, 1923, C. B. Garrett (Ottawa and Townes). $2 \sigma^{\text {T}}$, Takoma Park, Md., May 6, 1943, H. and M. Townes (Townes). \& (type), Montana (Washington). $\sigma^{7}$, Flat Rock, N. C., Aug. 23, 1939, H. and M. Townes (Townes). o , Johnston Co., N. C., June 16, 1949, H. Townes (Townes). ơ', Wilton, N. Dak., June 4, 1939, H. S. Telford (St. Paul). ণ , Summit Co., Ohio, June 11, 1937, Louis J. Lipovsky (Lawrence). क, Dunn Loring, Va., Aug. 22, 1948, Karl V. Krombein (Townes). ơ, Falls Church, 
Va., Aug. 31, N. Banks (Cambridge). $\sigma^{\top}$, Mount Vernon, Va., July 16, 1944, H. Townes (Townes).

This species is transcontinental in the Transition and Upper Austral zones. Its habitat is the underbrush of dry, rather open deciduous woods.

\section{Genus Acrodactyla}

Figure 294,a

Barypus Haliday, 1837, In Curtis, A guide to an arrangement of British insects, ed. 2, p. 94. Name preoccupied. Type: Barypus degener Haliday; designated by Westwood, 1839 .

Acrodactyla Haliday, 1838, Ann. Nat. Hist., vol. 2, p. 117. New name for Barypus.

Colpomeria Holmgren, 1859, Öfvers. Svenska Vetensk.-Akad. Förh., vol. 16, p. 126. New synonymy. Type: (Colpomeria laevigata Holmgren)=quadrisculpta Gravenhorst; monobasic.

Symphylus Foerster, 1871, Verh. Naturh. Ver. Rheinlande, vol. 28, p. 105. Name preoccupied. Type: (Symphylus hadrodactylus Foerster)=degener Haliday; original designation.

Polemophthorus Schulz, 1911, Zool. Ann., vol. 4, p. 22. New name for Symphylus.

Front wing 2.7 to $6.0 \mathrm{~mm}$. long; eye bare; clypeus broadly lenticular, separated from face by a groove, strongly convex in both transverse and longitudinal directions, the apical half a little flattened and the apical margin weakly reflexed; epomia strong, straight, transversing ventral marginal swelling of pronotum; mesoscutum polished, largely or almost entirely bare, its median lobe on each side in front with a short, sharp, vertical carina (this is the only genus of Polysphinctini with this character); notaulus long and strong; prepectal carina complete, its dorsal end distant from front edge of mesopleurum; pleural carina complete; legs moderately slender to very slender; areolet absent; intercubitus 0.1 to 0.4 as long as second abscissa of cubitus; nervulus postfurcal by 0.25 to 0.6 its length; discoidella present or absent, usually present but weak; first tergite rather elongate; second to fourth tergites polished, hardly at all punctate, their hairs sparse and usually restricted to the sides and the transverse grooves, each of the segments with a central transverse rhombic area weakly bounded by broad grooves, the rhombic areas weakly swollen laterally; ovipositor sheath about 2.0 as long as apical depth of abdomen; ovipositor with a weak median swelling, gradually tapered thence to the apex, the apical third weakly upcurved (fig. 332 ,f).

The cocoons of three species of Acrodactyla (degener, ocellata, and quadrisculpta) are known. In all three the cocoons are rather dense, spindle-shaped, and with four longitudinal ribs which make them quadrate in cross section. The cocoon of Eruga is similar in shape, but in the other Polysphinctini it is always round in cross section. 
This genus is Holarctic and Oriental. The species are small, delicate, and occur usually in damp habitats. There are two species groups, as described below.

\section{Key to the species groups and to the American species of Acrodactyla}

1. Metapleurum coarsely rugosopunctate; front and middle femora of female swollen, in the American species with an obtuse median tooth beneath; fourth tergite with hairs only laterally and in the transverse grooves. QuADRISCULPTA GROUP (p. 235). . . . . . . 4. quadrisculpta (Gravenhorst)

Metapleurum with fine punctures, otherwise smooth; front and middle femora of female not swollen and without a tooth beneath. Degener Group (p. 231). . . . . . . . . . . . . . . . . . 2

2. Lateral ocellus separated from eye by about 1.4 its long diameter; median part of median lobe of mesoscutum without hairs; discoidella often absent.

3. degener (Haliday)

Lateral ocellus separated from eye by about 1.0 its long diameter; median part of median lobe of mesoscutum with moderately sparse hairs; discoidella always present. . . . . . . . . . . . . . . . . . . . . . . . . . 3

3. Hind femur fulvous, its apex ivory (fig. 323,e); second and third tergites weakly mat; third segment of hind tarsus about 3.0 as long as deep; median lobe of mesoscutum with hairs all over . . . . . 1. jubata, new species

Hind femur pale stramineous, brown at base and with an indefinite brown stripe on front face and a faint indefinite brown stripe on hind face (fig. $323, \mathrm{f})$; second and third tergites polished; third segment of hind tarsus about 3.5 to 4.0 as long as deep; median lobe of mesoscutum with few or no hairs near its center . . . . . . . . . . 2. ocellata, new species

\section{DEGENER GROUP}

Lateral lobe of mesoscutum with very few hairs or none; median lobe of mesoscutum with a variable amount of hair; metapleurum with fine, rather weak punctures, otherwise smooth; front and middle femora of female not swollen, without a tooth beneath; discoidella present or absent; fourth tergite evenly hairy all over or sometimes the hairs sparse or absent medially.

This group includes the three Nearctic species below (one of which is Holarctic), an undescribed species from Japan, and another from the Philippines.

\section{Acrodactyla jubata, new species}

Figure 323,e

Female: Front wing 4.8 to $5.3 \mathrm{~mm}$. long; lateral ocellus separated from eye by about 1.0 its long diameter; median part of mesoscutum completely covered with hairs, the bases of which are separated by a little less than the lengths of the hairs; hind femur about 5.2 as long as deep; third segment of hind tarsus about 3.0 as long as deep; discoidella present; second and third tergites weakly mat; fourth tergite with moderately dense hairs all over. 
Black. Front of scape and pedicel, front and middle coxae, and all trochanters ivory or stramineous; mandible light brown; palpi, tegula, and hind corner of pronotum white; subtegular ridge and mesepimeron brown; front and middle legs beyond trochanters pale fulvous, the apex of front tarsus and most of middle tarsus brown; hind coxa fulvous, ivory apically; hind femur fulvous, its apex whitish; hind tibia whitish, its extreme base and a narrow subbasal band brown, its apical 0.3 fuscous; hind tarsus fuscous, brown basally.

Type: o, near Estes Park, Colo., June 12, 1948, H., M., G., D., and J. Townes (Washington, USNM 63698).

Paratypes: ㅇ, Ashford, Wash., Aug. 18, 1940, H. and M. Townes (Townes). क, White River, Mount Rainier, Wash., July 23, 1924, A. L. Melander (Cambridge). ㅇ, Whitehorse, Yukon, Aug. 5, 1948, Mason and Hughes (Ottawa).
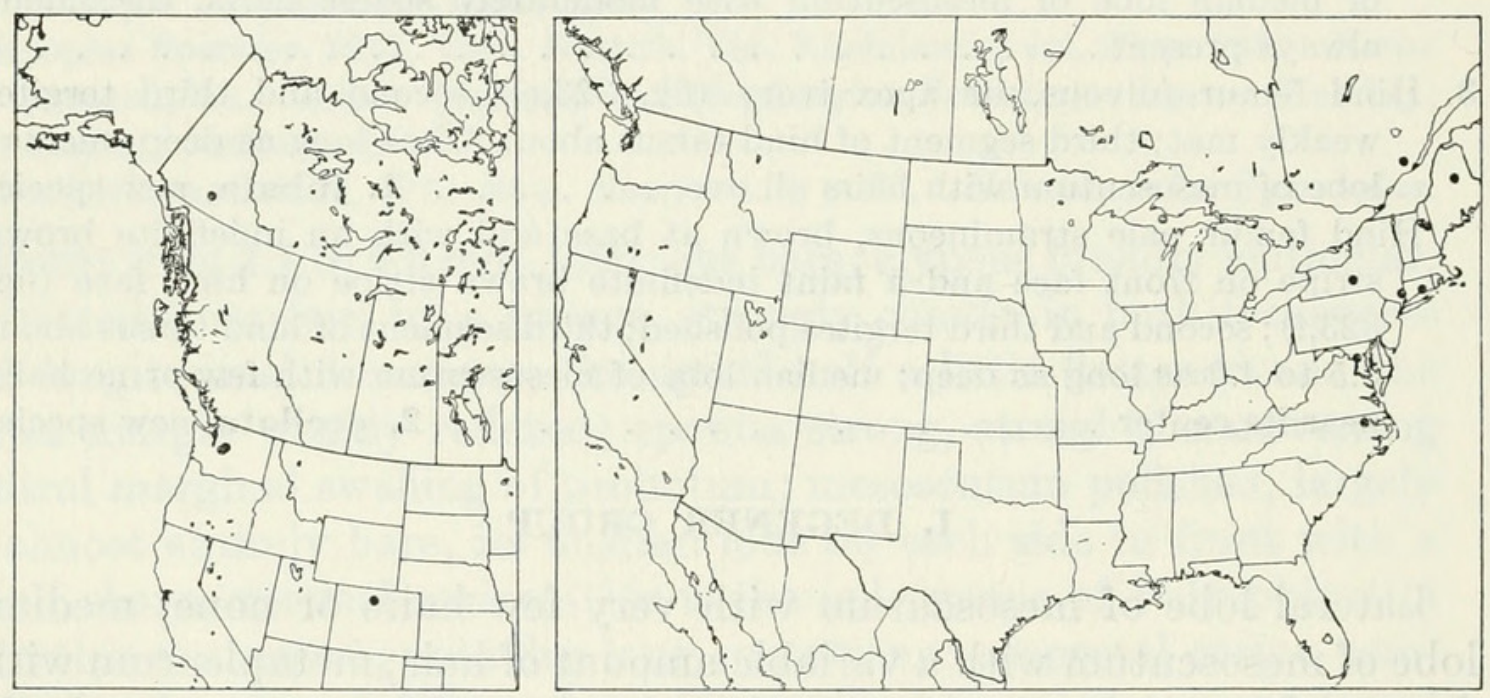

Figures 96, 97.-Localities: 96 (left), Acrodactyla jubata; 97 (right), A. ocellata.

\section{Acrodactyla ocellata, new species}

FigURe $323, \mathbf{f}$

Front wing of male 3.7 to $4.2 \mathrm{~mm}$. long, of female 3.7 to $5.3 \mathrm{~mm}$. long; lateral ocellus separated from eye by about 0.95 its long diameter; median part of mesoscutum with considerable rather sparse hair, but the central part of median lobe bare or almost bare; hind femur of male about 4.8 as long as deep, of female about 6.0 as long as deep; third segment of hind tarsus about 3.5 as long as deep in male, about 4.0 as long as deep in female; discoidella present; second and third tergites polished; fourth tergite with rather sparse hairs and usually a postmedian bare area.

Black. Mandible whitish to light brown; front of scape and pedicel, palpi, tegula, hind corner of pronotum, coxae, and trochanters white or whitish, the hind coxa light brown basally, especially below; mese- 
pimeron brown; front legs beyond trochanters pale stramineous, the extreme base of tibia, a narrow subbasal band on tibia, and apex of tarsus brownish; middle leg beyond trochanters generally pale stramineous, with a faint repetition of color pattern of hind leg; hind femur pale stramineous, its base brown (more extensively brown on front side), its front side with a broad, indefinite brown stripe, and its hind side with a shorter, paler, less definite brown stripe; hind tibia whitish, its extreme base brown, a narrow subbasal band, and its apical 0.3 infuscate; hind tarsus fuscous, brownish at base.

The cocoon is fusiform, pale brown, of papery texture, and with four longitudinal ribs so that its cross section is quadrangular. It has the opening at the hind end, as usual in the Polysphinctini.

Type: o, Ithaca, N. Y., June 2, 1936, H. Townes (Washington, USNM 63699).

Paratypes: $\sigma^{7}$, reared from Linyphia phrygiana, collected Apr. 14, 1936, emerged Apr. 27, 1936, Killingworth, Conn., B. J. Kaston (Washington). क, Baxter State Park, Maine, Sept. 3, 1950, H. Dietrich (Ithaca). ᄋ, Takoma Park, Md., Aug. 7, 1943, H. and M. Townes (Townes). $\sigma^{x}$, , , Marquette Co., Mich., Aug. 26, 1952, R. R. Dreisbach (Dreisbach). $\sigma^{\top}$, ㅇ, Pinkham Notch, N. H., Aug. 23, 1951, H., M., and D. Townes (Townes). ㅇ, Randolph, N. H., July 3, 1946, J. Peck and M. Townes (Townes). $\sigma^{7}$, $\circ$, same data as type (Townes). $\sigma^{7}$, Ithaca, N. Y., May 23, 1936, H. Townes (Townes). o, Ithaca, N. Y., June 18, 1936 (Townes); o, Ithaca, N. Y., July 30, 1935 (Townes). ơ', Poughkeepsie, N. Y., July 15, 1936, H. Townes (Townes). \&, Poughkeepsie, N. Y., Aug. 2, 1936, H. Townes (Townes). क, Murfreesboro, N. C., Oct. 13, 1938, G. E. Burdick (Townes). ㅇ, Stoneham, Que., June 21, 1938, H. and M. Townes (Townes).

This species occurs in eastern North America from the Canadian to the Lower Austral zone. It is adult from late spring to fall.

\section{Acrodactyla degener (Haliday)}

\section{FigURE $323, \mathrm{~g}$}

Cryptus (Acrodactyla) degener Haliday, 1838, Ann. Nat. Hist., vol. 2, p. 117; $\sigma^{7}$, + . Types: $\sigma^{7}$, $q$, Ireland (?Dublin).

Symphylus hadrodactylus Foerster, 1871, Verh. Naturh. Ver. Rheinlande, vol. 28, p. $106 ; \sigma^{\top}, q$. New synonymy. Types: $1 \sigma^{\top}, 2$, near Aachen, Germany (Munich).

Biology: Morley, 1913, Ichneumonologia britannica, vol. 3, pp. 133-134.Nielson, 1923, Entomologiske Meddelelser, vol. 14, pp. 163-170 [incorrectly determined as Polysphincta pallipes in this reference, the determination corrected in 1928, Entomologiske Meddelelser, vol. 16, p. 154].

Front wing of male 2.7 to $3.5 \mathrm{~mm}$. long, of female 2.9 to $4.0 \mathrm{~mm}$. long; lateral ocellus separated from eye by about 1.4 its long diameter; 
mesoscutum with sparse hairs along sides, front, and hind end of its median lobe, elsewhere almost or quite bare; hind femur of male about 4.6 as long as deep, of female about 5.8 as long as deep; third segment of hind tarsus about 3.0 as long as deep in male, about 3.7 as long as deep in female; discoidella present or absent, absent in about half of the specimens, usually absent in smaller specimens; second and third tergites polished; hairs on fourth tergite moderately sparse to very sparse, evenly distributed, or absent from more or less of the mediobasal part of the tergite.

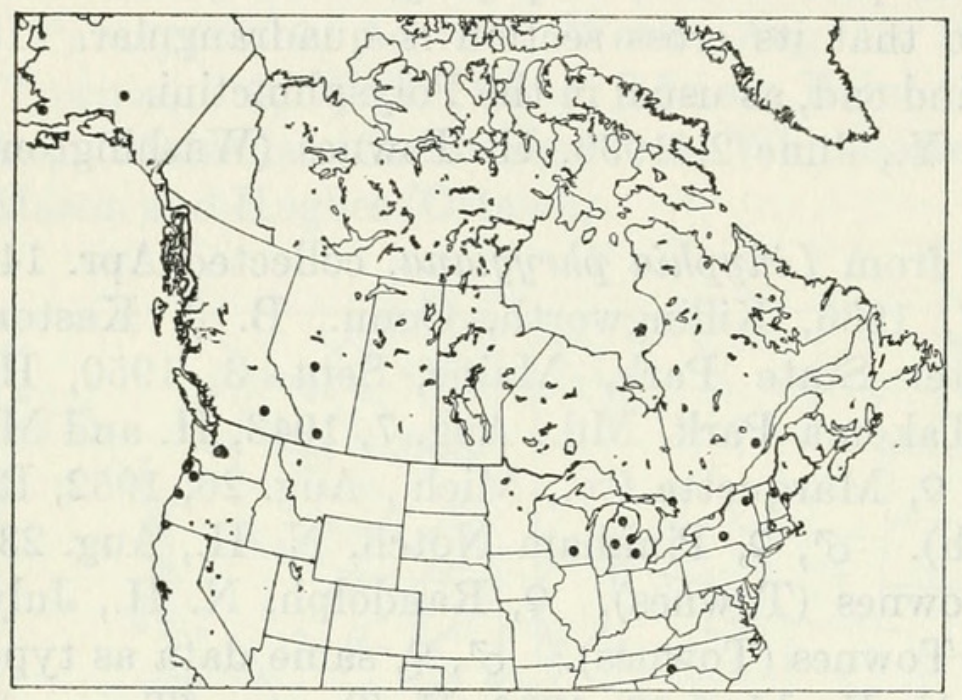

Figure 98.-Localities for Acrodactyla degener.

Black. Clypeus often dark brown; scape and pedicel stramineous in front; mandible stramineous or brown; palpi, tegula, and hind corner of pronotum white; front and middle coxae and all trochanters ivory; front leg beyond trochanters stramineous with a tinge of fulvous, its tarsus brownish at apex and sometimes a faint, narrow, brownish, subbasal ring on its tibia; middle leg beyond trochanters stramineous fulvous, its tarsus brownish and its tibia with a faint, narrow, subbasal brownish ring; hind coxa pale fulvous to dark brown, its apex ivory; hind femur light fulvous to brown, its apex and a dorsal stripe paler (often ivory); hind tibia stramineous, a little darker below, with a narrow subbasal band and its apical 0.3 brown; hind tarsus brown.

Mr. J. F. Perkins of the British Museum (Natural History) has sent us a female from Sweden, which seems not to differ from North American specimens. We have compared the types of hadrodactylus in Munich with this specimen from Sweden and found them to represent the same species. It seems likely that Symphylus politus Foerster 1868 is also the same species. We have seen the types of politus in Munich, but did not study them carefully.

Specimens $\left(86 \sigma^{7}, 25\right.$ ) : From Alaska (Cold Bay, King Salmon on the Naknek River, and Mount McKinley at 1,600 ft.); Alberta 
(Edmonton and Lethbridge); British Columbia (shore of Shuswap Lake at Salmon Arm); California (Crescent City and Inverness); Maine (Casco); Massachusetts (Amherst); Michigan (Crawford Co., Livingston Co., Mecosta Co., and Midland Co.); New Hampshire (Randolph); New York (between Ellis and Slaterville, and Saranac Lake); North Carolina (Mount Pisgah at 4,800 to 5,300 ft.); Ontario (Waubamik); Oregon (Cannon Beach, McMinnville, Seaside, and Takenitch Lake); Quebec (Stoneham); Washington (Ashford, Elbe, and Mount Rainier at 2,900 ft.); Wisconsin (Madison); and Sweden.

Collecting dates are from early summer to early fall, with a peak in July and August. Unusually early and late collecting dates are: June 5 in Livingston Co., Mich.; June 13 between Ellis and Slaterville, N. Y.; June 17 in Crawford Co., Mich.; June 21 on Mount Pisgah, N. C., and at Stoneham, Que.; September 8 at McMinnville, Oreg.; September 17 in Midland Co., Mich.; September 21 and October 2 at Madison, Wis.; and October 6 at Inverness, Calif.

This species is transcontinental in the Hudsonian, Canadian, and Transition zones, occurring in dense shaded vegetation in damp habitats. It occurs also in Europe. Adults fly most actively on moist, cloudy days. The biology has been described in some detail by Nielsen (loc. cit.).

\section{QUADRISCULPTA GROUP}

Mesoscutum almost without hairs; metapleurum coarsely rugosopunctate; front and middle femora of female swollen submedially, more slender apically than basally, usually with an obtuse, compressed median ventral tooth which is continuous distad with a short median ventral carina; discoidella present; fourth tergite with hairs only laterally and in its transverse grooves.

This group includes the Holarctic A. quadrisculpta (Gravenhorst), an undescribed species from the Oriental region, and (Polemophthorus) Acrodactyla orientalis Cushman, 1933 (new combination) of Formosa and the Philippines. The species orientalis differs from the other two of its group in lacking the tooth on the front and middle femora of the female. This tooth is lacking occasionally also on the middle femur of small females of $A$. quadrisculpta.

\section{Acrodactyla quadrisculpta (Gravenhorst), new combination}

Figures 323 ,h; $332, \mathrm{f}$

Ichneumon quadrisculptus Gravenhorst, 1820, Mem. Accad. Sci. Torino, vol. 24, p. 378; $\sigma^{x}$. Type: $\sigma^{7}$, northern Italy (lost during World War II).

Zaglyptus kincaidii Ashmead, 1894, Insect life (U. S. Dep. Agr.), vol. 6, p. 260;

$\sigma^{7}$, $\uparrow$. New synonymy. Type: $q$, Olympia, Wash. (Washington).

Colpomeria mellithorax Cushman, 1920, Proc. U. S. Nat. Mus., vol. 58, p. 19,

. Type: $q$, no locality data (Washington). 
Polysphincta takewakii Uchida, 1927, Ins. Matsumurana, vol. 1, p. 172; ๙̛ , ․

New synonymy. Types: $2 \sigma^{7}, 3 q$, Toyama, Honshu, Japan (Sapporo).

Biology: Nielsen, 1937, Entomologiske Meddelelser, vol. 20, pp. 25-27.

Front wing of male 3.3 to $4.4 \mathrm{~mm}$. long, of female 3.2 to $5.8 \mathrm{~mm}$. long; front femur and nearly always also middle femur of female with a blunt median tooth beneath; hind femur about 4.8 as long as deep in male, about 5.3 as long as deep in female.

Black. Scape and pedicel partly or entirely white or pale brownish in front; mouth parts, tegula, subtegular ridge, and hind corner of pronotum white; front and middle coxae and all trochanters ivory, or in specimens from Europe and northern North America often stramineous; hind part of pronotum, mesoscutum except for median stripe, scutellum, and mesopleurum partly or entirely fulvous in many North American specimens, particularly in larger specimens and from southern part of the range; front and middle legs beyond trochanters ivory to light fulvous, the last segment of their tarsi largely dark brown; hind coxa ivory or fulvous, sometimes blackish basally; hind femur fulvous, its apex and usually a stripe on upper margin white; hind tibia white, with rather narrow infuscate subbasal band and its apical 0.25 fuscous; hind tarsus stramineous, brownish apically, the apex of each segment dark brown.

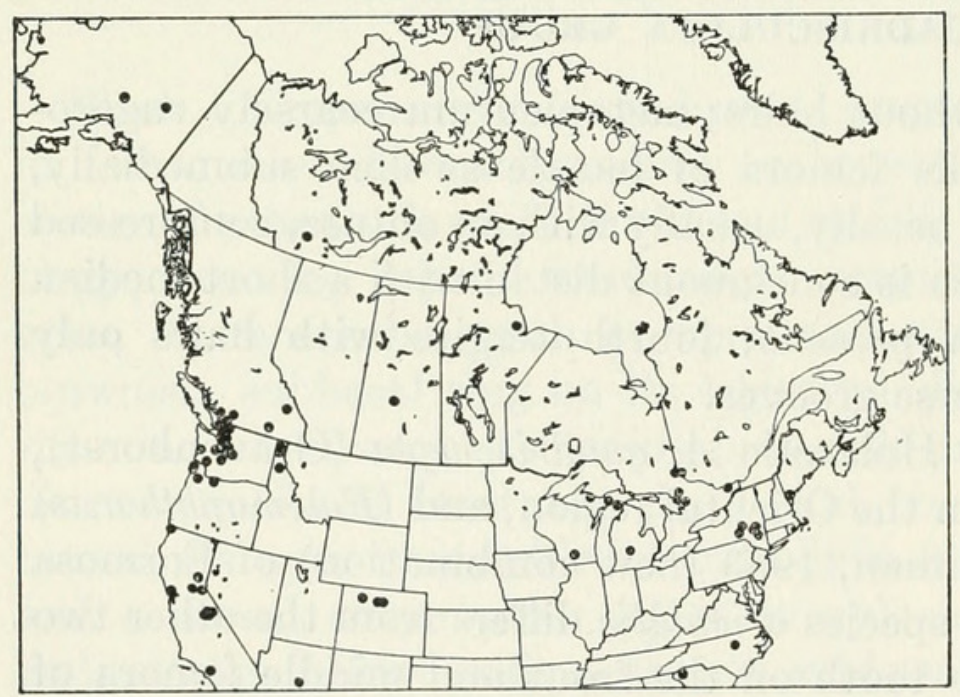

Figure 99.-Localities for Acrodactyla quadrisculpta.

One specimen ( o , Fish Creek, Douglas Island, Alaska, Aug. 6, 1958, W. C. Frohne) is peculiar in having the fulvous color of the hind coxa and femur replaced by black and the normal infuscate markings on the legs unusually dark.

The one cocoon at hand is fusiform but square in cross section, with four prominent longitudinal corners, papery in texture, and of a light brown color. Meconium is partially pushed through a hole at the hind end, and in the front end an irregular hole has been made by the emerging adult. 
Specimens $\left(51 \sigma^{7}, 162\right.$ ) ): From Alaska (Fish Creek on Douglas Island, Mount McKinley at 1,600 ft., and Shaw Creek at Mile 289 on the Richardson Highway); Arizona (Oak Creek Canyon); British Columbia (Cultus Lake, Downie Creek in the Selkirk Mts., McGillivray Creek Game Preserve near Chilliwack, Pender Harbor, and Robson); California ("Agusa," Camino, Cisco, Crane Flat in Yosemite Park, Crescent City, Fish Camp, Glendale, Muir Woods, Strawberry, Tamarack Flat in Yosemite Park, and Yosemite Valley); Colorado (near Estes Park, Phantom Valley in Rocky Mountain National Park at 9,400 ft., and Steamboat Springs); Idaho (Chatcolet Lake, Lookout Mt. at Priest Lake, and Priest Lake); Maine (Casco); Manitoba (Herchmer); Michigan (Beaver Island in Charlevoix Co., "Cedarwood," Clinton Co., Marquette Co., and Schoolcraft Co.); New York (Canajoharie, Greene Co., Otsego Lake, Prattsville, and Shokan); North Carolina (Raleigh); Northwest Territories (Fort Simpson); Nova Scotia (Kentville); Ontario (Bala, Go Home Bay, Ottawa, Timagami, and Waubamik); Oregon (Cannon Beach, Hood Rapids on Mount Hood, McMinnville, and Seaside); Quebec (Laniel); Saskatchewan (Waskesiu); South Carolina (Table Rock State Park); Washington (Ashford, Big Four, Glacier, Kelso, Marietta Co., Mount Ararat in Mount Rainier National Park at 4,900 ft., Mount Rainier at 2,700, 2,900, and 4,700 ft., Olympia, San Juan Island, Skagit Co., Snoqualmie Pass, Sumas Co., Whatcom Co., and Westport); Wisconsin (Madison); Ireland; Germany; and Japan.

Most dates of collection are in July and August, but a number are in the latter part of June and early September, and a few are even earlier or later. Early and late dates of special interest are: April 28 at Pender Harbor, B. C.; May 16 in Oak Creek Canyon, Ariz.; June 6 in Whatcom Co., Wash.; June 7 in Skagit Co., Wash.; June 12 near Estes Park, Colo.; September 22 in Clinton Co., Mich.; September 23 at Robson, B. C.; September 30 at Raleigh, N. C.; and October 22 at Cultus Lake, B. C.

One reared specimen is at hand, a $\circ$, reared as an external parasite of Tetragnatha laboriosa, "Agusa," Calif., May 20, 1942, E. I. Schlinger.

This species is transcontinental in the Hudsonian, Canadian, and Transition zones and occurs also in Eurasia. It occurs in dense vegetation in damp places. Adults are on the wing from early summer to early fall, with a peak of abundance in July and August. Nielsen reared the species from Tetragnatha obtusa in Denmark and reported on its biology and pupal morphology (loc. cit.). The type of the synonym takewakii was reared from Meta reticulata. In America, the species has been reared from Tetragnatha laboriosa. 


\section{Eruga, new genus}

FIGURE 294,b

Front wing 2.8 to $4.0 \mathrm{~mm}$. long; eye bare; clypeus small, broadly elliptic, separated from face by a broad groove, strongly convex both transversely and longitudinally; epomia entirely absent; mesoscutum polished, almost or quite hairless; notaulus represented by a rather short, weak depression; prepectal carina complete, its upper end rather distant from front edge of mesopleurum; pleural carina of propodeum complete; median carinae of propodeum absent or vestigial; areolet absent; intercubital 0.1 to 0.3 as long as second abscissa of cubitus or obliterated by the approximation of the cubital and radial veins; nervulus postfurcal by 0.3 to 0.5 its length; discoidella present but weak, or sometimes absent; first tergite moderately long; second to fourth tergites rather short, polished or subpolished, with sparse or very sparse hairs, with a broad, weak, postmedian transverse impression and a less distinct basal transverse impression; ovipositor sheath about 1.5 as long as apical depth of abdomen; ovipositor with a swelling at, or just before its middle, abruptly tapered thence toward point, the apical 0.4 of ovipositor very slender and faintly upcurved (fig. $332, \mathrm{~g}$ ).

Genotype: Eruga lineata, new species.

The name is from the Latin ex (without), plus ruga (wrinkle), referring to the absence of the epomia.

Besides the three Nearctic species described below, this genus includes the Madagascan Acrodactyla erratica Seyrig 1932 and A. viatrix Seyrig 1932, the Belgian Congo Acrodactyla lubumbashica Benoit 1953, A. paulisiana Benoit 1953, and A.rutshurica Benoit 1953, and an undescribed species from Ecuador.

\section{Key to the Nearctic species of Eruga}

1. Mesoscutum entirely black; hind coxa black except at apex.

1. atrata, new species

Mesocutum partly or entirely pale; hind coxa pale . . . . . . . . . . . 2

2. Mesoscutum blackish, with longitudinal yellow stripes; hind tarsus moderately long, its third segment about 2.7 as long as deep . . 2. lineata, new species

Mesoscutum fulvous, with indistinct yellow areas; hind tarsus rather short, its third segment about 2.0 as long as deep . . . . 3. rufa, new species

\section{Eruga atrata, new species}

Front wing 3.5 to $3.9 \mathrm{~mm}$. long; propodeum moderately convex, weakly mat, finely rugulose medially and laterally; hind tarsus long, its third segment about 4.0 as long as deep; first tergite about 1.75 as long as wide in male, about 1.58 as long as wide in female.

Black. Scape and pedicel blackish brown, the apex of pedicel yellowish; mandible brown; palpi, tegula, hind corner of pronotum, 
front and middle coxae, and all trochanters, pale yellow; front and middle legs beyond trochanters light fulvous, their tarsi shading to brown at the apex; hind coxa black, its apex pale yellowish; hind femur fulvous; hind tibia fulvous brown, its basal 0.3 faintly darker and its apical 0.3 distinctly darker; hind tarsus brown; second to fourth tergites brown at base.

Type: +, Oak Creek Canyon, Ariz., May 19, 1947, H. and M. Townes (Washington, USNM 63700).

Paratypes: $9 \sigma^{\Im}$, 5ㅇ, Oak Creek Canyon, Ariz., May 13, 14, 16, 17, 18, 19, and 20, 1947, H. and M. Townes (Townes). , Workman Creek, Sierra Ancha, Ariz., May 8, 1947, H. and M. Townes (Townes). ○, Hood River, Oreg., June 30, 1917, A. L. Melander (Cambridge). $\sigma^{7}$, Tuxpan at 7,500 ft., Mexico, Aug. 12, 1954, R. R. Dreisbach (Dreisbach).

This species occurs in the Transition zone of western United States and in Mexico.

\section{Eruga lineata, new species}

Figures 323,i; 332,g

Front wing 2.8 to $4.0 \mathrm{~mm}$. long; propodeum moderately convex, subpolished or in part weakly mat, basally always subpolished, usually somewhat rugulose medially and laterally; hind tarsus moderately long, its third segment about 2.7 as long as deep; first tergite about 1.7 as long as wide in male, about 1.5 as long as wide in female.

Black. Scape stramineous, brown above; pedicel light brown; flagellum brown, a little paler basally; mouth parts, tegula, subtegular ridge, hind corner of pronotum, broad anterolateral part of mesoscutum, attached pair of longitudinal stripes on mesoscutum (which are often fused postmedially), upper part of mesepimeron,
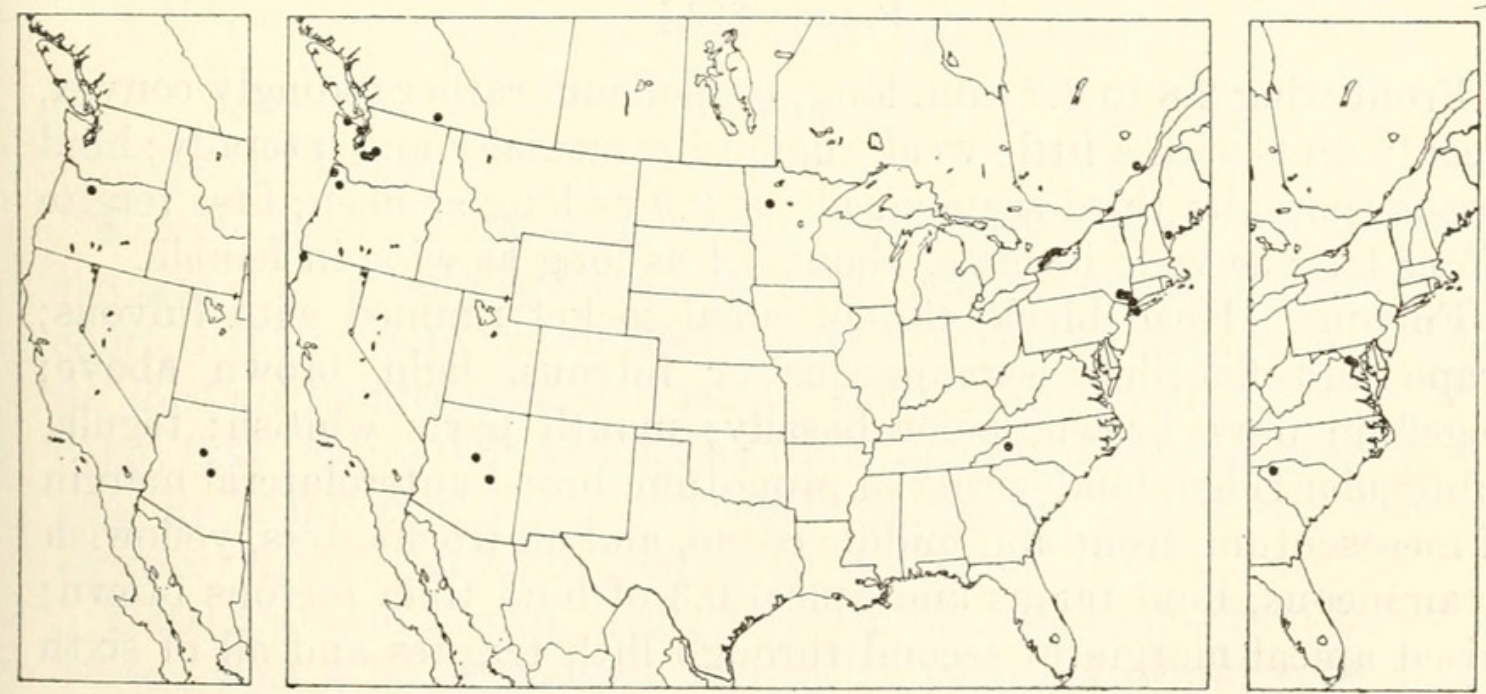

Figures 100-102.-Localities: 100 (left), Eruga atrata; 101 (center), E. lineata; 102 (right), E. rufa. 
front and middle coxae, and all trochanters, pale yellow or whitish; front and middle femora and tibiae light fulvous; front and middle tarsi light brownish fulvous to light brown, darker apically; hind coxa light brownish fulvous, pale yellow apically, a little darker basally; hind femur fulvous, its apical margin paler; hind tibia brownish fulvous, brown apically and with a narrow, faint brownish band at its basal 0.35 ; hind tarsus brown; abdomen dark brown or blackish brown, the basal $0.5 \pm$ of third to fifth tergites and raised apical margin of second to sixth tergites, pale brown.

Type: ㅇ, McMinnville, Oreg., Aug. 19, 1947, K. M. Fender (Washington, USNM 63701).

Paratypes (26 $\left.\sigma^{\top}, 12 \%\right)$ : From Arizona (Oak Creek Canyon and Parker Creek in the Sierra Ancha); British Columbia (Robson); California (Crescent City); Maine (Casco); Minnesota (Itasca State Park); New York (Farmingdale, Lake Mohonk in Ulster Co., Millwood, and Poughkeepsie); North Carolina (Bald Knob in the Mitchell Range); Oregon ("Boyer," Cannon Beach, and McMinnville); Quebec (Stoneham); and Washington (Ashford, Elbe, Christine Falls on Mount Rainier, Lake Crescent at Fairholm, and Quilcene).

Most collection dates are in July and August. Those outside of these two months are: May 20 and 21 in Oak Creek Canyon, Ariz.; June 21 at Bald Knob in the Mitchell Range, N. C., at Millwood, N. Y., and at Stoneham, Que.; June 26 at Lake Crescent near Fairholm, Wash.; September 2 and 15 at McMinnville, Oreg.; and "Sept." in Itasca State Park, Minn.

This species is transcontinental in the Canadian and Transition zones, occurring in moist woods with heavy vegetation. Adults occur mostly in July and August.

\section{Eruga rufa, new species}

FiguRe $323, \mathrm{j}$

Front wing 2.8 to $3.7 \mathrm{~mm}$. long; propodeum rather strongly convex, weakly mat, with a little weak rugulosity medially and laterally; hind tarsus short, its third segment about 2.0 as long as deep; first tergite 1.6 as long as wide in male, about 1.4 as long as wide in female.

Fulvous. Head black, the antennal socket rimmed with fulvous; scape and flagellum stramineous or fulvous, light brown above; flagellum dark brown, paler basally; mouth parts whitish; tegula, subtegular ridge, hind corner of pronotum, broad anterolateral margin of mesoscutum, front and middle coxae, and all trochanters, yellowish stramineous; hind tarsus and apical 0.3 of hind tibia fulvous brown; raised apical margin of second through fifth tergites and all of sixth and seventh tergites, brown.

The type specimen is accompanied by the cocoon from which it 
emerged. This is spindle shaped, dense, light brown, square in cross section with a longitudinal rib at each of the four corners, and has the usual hole at the hind end. The cocoon is essentially like that of Acrodactyla, indicating that Eruga is probably related to that genus.

Type: o, reared June 27, 1945, from parasitized spider collected June 13, 1945, Bethesda, Md., J. M. Davis (Washington, USNM 63702).

Paratypes: 2ᄋ, Takoma Park, Md., July 19 and 24, 1943, H. and M. Townes (Townes). $\quad \sigma^{7}$, Greenville, S. C., Oct. 6, 1941, H. and M. Townes (Townes).

\section{Genus Piogaster}

FIGURE 295, a

Piogaster Perkins, 1959, Entomologist, vol. 91, p. 263. Type: Piogaster rugosa Perkins; original designation.

Front wing 3.4 to $5.2 \mathrm{~mm}$. long; eye bare; clypeus strongly swollen, sharply separated from face; epomia absent; mesoscutum with close punctures, dense evenly distributed hairs, and usually strongly mat; notaulus absent; prepectal carina complete, its upper end approaching but not reaching front edge of mesopleurum; pleural carina complete, but weak; legs rather short; areolet absent; intercubitus about 0.4 as long as second abscissa of cubitus; nervulus postfurcal by about 0.5 its length; discoidella present or absent; nervellus strongly inclivous; first tergite broad and short; second through fourth tergites strongly mat, evenly covered with dense hairs, without grooves or swellings; ovipositor sheath 2.5 as long as apical depth of abdomen; ovipositor tapered from base toward apex, with a faint post-median enlargement, its point not as slender as in most Polysphinctini.

This is a Holarctic genus, with three species in Europe and one in California.

\section{Piogaster maculata, new species}

FIGURE $323, \mathrm{k}$

Male: Unknown.

Female type: Front wing $3.4 \mathrm{~mm}$. long; entire head and body very strongly mat, evenly covered with rather short dense hairs; propodeum short, strongly convex, its lateral longitudinal carina present apically, its median longitudinal carinae lacking; hind femur 3.7 as long as deep; first tergite 0.67 as long as wide, its dorsal carinae present only near its basal corners, otherwise smooth above; second and following tergites smooth, without grooves or swellings.

Head blackish brown, reddish brown on cheek and front orbit, the vertex with a large elongate triangular yellowish white spot next to eye; thorax blackish brown, the mesopleurum, pronotum, lateral part 


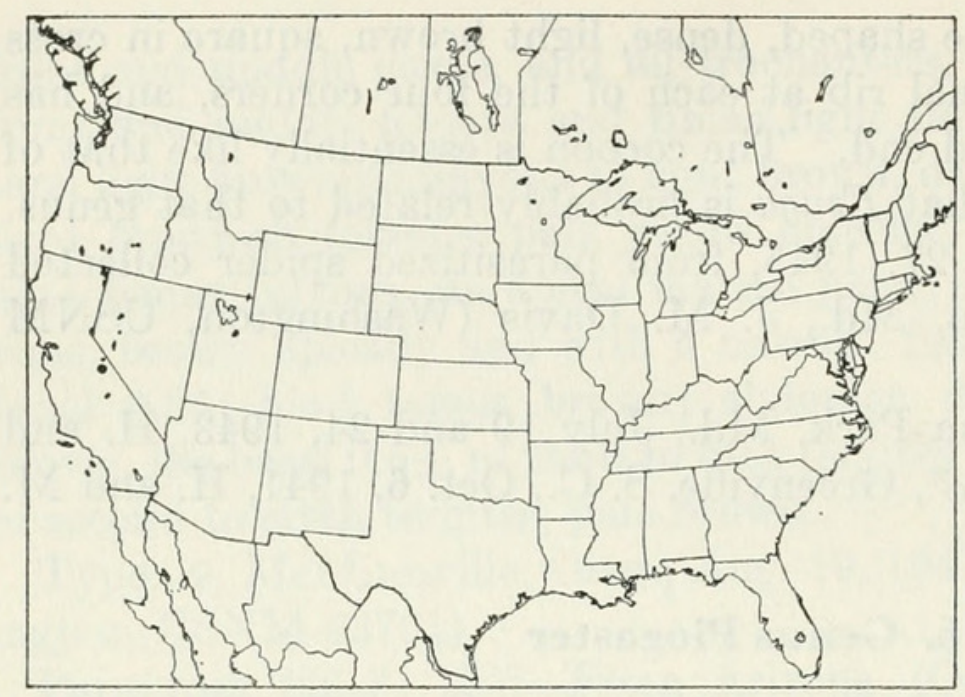

FiguRe 103.-Locality for Piogaster maculata.

of propleurum, anterolateral margin of mesoscutum, and stain on metapleurum dull ferruginous; legs whitish grey with irregular darkbrown spots, the spots lined up in two longitudinal stripes on upper side of femora and one longitudinal stripe on upper side of tibiae, the tarsi dark brown, paler beneath; costa and front margin of stigma whitish, rest of veins and stigma pale brown; abdomen blackish brown.

Type: + , swept from shoulder-high branches of a conifer at edge of mountain meadow, Crane Flat, Yosemite Park, Calif., July 25, 1948, H., M., G., D., and J. Townes (Washington, USNM 63703).

\section{Genus Oxyrrhexis}

FiguRe 295,b

Oxyrrhexis Foerster, 1868, Verh. Naturh. Ver. Rheinlande, vol. 25, p. 166.

Type: Cryptus carbonator Gravenhorst; included by Schmiedeknecht, 1888.

Differs from Polysphincta in slightly stouter build, abdominal tergites rather densely, coarsely, punctate, and the ovipositor shorter (its sheath about 1.4 to 1.8 as long as the apical depth of the abdomen).

It is questionable whether this genus should be maintained as distinct from Polysphincta. It contains the Holarctic O. carbonator and the Japanese (Polysphincta) Oxyrrhexis tuberculata Uchida, 1932 (new combination).

\section{Oxyrrhexis carbonator (Gravenhorst)}

Figure 332 , h

Front wing of male 3.7 to $5.5 \mathrm{~mm}$. long, of female 5.2 to $7.6 \mathrm{~mm}$. long; median part of apical margin of clypeus subtruncate; punctures on propodeum moderately dense; paired swellings on third and fourth tergites a little transverse; ovipositor sheath about 1.4 as long as apical depth of abdomen. 
Coloration as described under the subspecies.

There is a Nearctic and a European subspecies as keyed and described below.

1. Hind femur with or without a faint subapical infuscate band; coxae usually partly fuscous, the rest fulvous; banding on hind tibia relatively obscure; range: Europe . . . . . . la. carbonator carbonator (Gravenhorst)

Hind femur with a strong subapical infuscate band (fig. 323,1 ); coxae entirely fulvous; banding on hind tibia relatively sharp; range: Nearctic America.

1b. carbonator texana (Cresson)

\section{1a. Oxyrrhexis carbonator carbonator (Gravenhorst)}

Cryptus carbonator Gravenhorst, 1807, Vergleichende Uebersicht des Linneischen und einiger neuern zoologischen Systeme . . . , p. 264. Type: ?Germany (lost during World War II).

Differs from the subspecies texana principally as noted in the key. Described from a male and female from Sweden and a female from Germany.

\section{1b. Oxyrrhexis carbonator texana (Cresson)}

\section{Figure 323,1}

Polysphincta texana Cresson, 1870, Trans. Amer. Ent. Soc., vol. 3, p. 149; Type: + , Texas (Philadelphia).

Polysphincta vicina Provancher, 1873, Naturaliste Canadien, vol. 5, p. 470; ه Type: $\sigma^{\top}$, Quebec Province (Quebec).

Polysphincta bicarinata Davis, 1898, Trans. Amer. Ent. Soc., vol. 24, p. 368; ه্ .

Name preoccupied. Type: $\sigma^{7}$, Moscow, Idaho (Philadelphia).

Biology: Cushman, 1913, Proc. Ent. Soc. Washington, vol. 15, p. 157.

Black. Clypeus more or less reddish brown; mandible brown; palpi white to pale brown; pedicel and flagellum dark brown; front coxa of male mostly whitish, of female fulvous with the apical part whitish; middle and hind coxae fulvous; trochanters of male whitish, of female pale fulvous or partly whitish; front and middle femora fulvous, in male their apex and the front of the front femur white, in female their

Figure 104.-Localities for Oxyrrhexis carbonator texana.

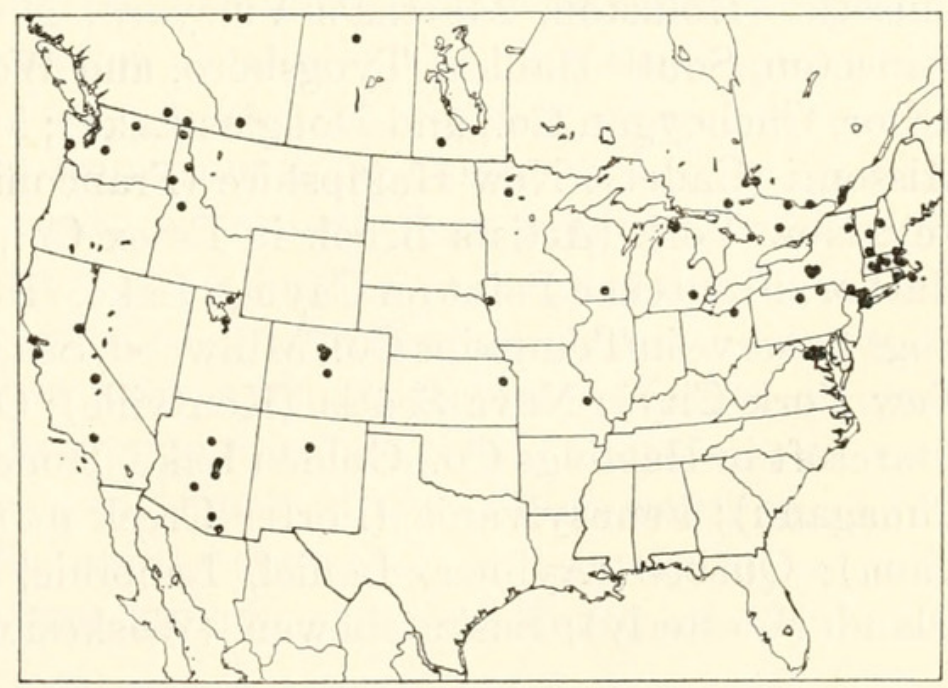


extreme apex whitish preceded by a faint infuscation; hind femur fulvous with a conspicuous subapical fuscous band, its extreme apex whitish; front and middle tibiae of male white above, fulvous below; front and middle tibiae of female fulvous, largely whitish above, with a subbasal fuscous spot above; hind tibia with its apex broadly, its under side, and a relatively narrow subbasal band fuscous, the rest white; front tarsus of male whitish, of female pale fulvous, in both sexes fulvous apically; hind tarsus fuscous, the basal 0.3 to 0.6 of its basitarsus white; middle tarsus whitish to light fuscous, with a faint repetition of the color pattern of the hind tarsus. The white areas on the hind tibia and tarsus are more extensive in the male than in the female. In the male the subbasal fuscous mark on the hind tibia is often only a dorsal spot. Specimens from western North America have the colors of the hind leg somewhat intermediate to the European subspecies.

A good figure of a female has been published by Cushman (1920, Proc. U. S. Nat. Mus., vol. 58, p. 22).

The cocoon is of open texture, short fusiform, round in cross section, and of coarse, irregularly looped silk. Its color varies from whitish to very pale brown.

Specimens (23 $\sigma^{7}, 137$ ) $)$ : From Alberta (Edmonton, Lethbridge, and Wabamun); Arizona (Bear Wallow in the Santa Catalina Mts., Flagstaff, Huachuca Mts., Parker Creek and Pocket Creek in the Sierra Ancha, Phoenix, and Workman Creek in the Sierra Ancha); British Columbia (Creston and Robson); California (Fish Canyon in San Gabriel Mts., Giant Forest in Sequoia National Park at 6,000 to 7,000 ft., Lake Forest at Lake Tahoe, Marin Co., and Menlo Park); Colorado (Boulder, Chimney Gulch, Green Mt. Falls, and Ward); Idaho (Lookout Mt. near Priest Lake, Moscow, Wallace, and Warren); Iowa (Sioux City); Kansas (University of Kansas Natural History Reserve in Douglas Co.); Manitoba (Aweme and Teulon); Maryland (Beltsville, Glen Echo, Plummers Island, and Takoma Park); Massachusetts (Holliston, Martha's Vineyard, Northampton, Petersham, Princeton, South Hadley, Tyngsboro, and Wellesley); Michigan (Ann Arbor, Cheboygan Co., and Douglas Lake); Minnesota (Lake Itasca); Missouri (Cadet); New Hampshire (Franconia); New Mexico (Santa Fe); New York (Artists Brook in Essex Co., Bear Mt., Cold Spring Harbor, Frontenac Point on Cayuga Lake, Huguenot, Ithaca, McLean Bogs Reserve in Tompkins Co., Millwood, Sea Cliff, and West Farms at New York City); Nova Scotia (Kentville); Ohio (Hinckley); Ontario (Barcroft in Hastings Co., Golden Lake, Honey Harbor, Sudbury, and Timagami); Pennsylvania (Porter Creek at Carter Camp and Wilawana); Quebec (Aylmer, Laniel, Lanoraie, and Montreal); Rhode Island (Westerly); Saskatchewan (Waskesiu); Texas; Utah (Logan 
and Murray); Vermont (Laurel Lake near Jacksonville and Woodstock); Virginia (Falls Church and Vienna); Washington (Mount Rainier at 2,900 ft., Okanogan, and Westport); and Wisconsin (Madison).

Dates of capture are from mid-spring to mid-fall. The majority are collected in the summer months. One of the specimens was taken at light.

Reared specimens are as follows: $\sigma^{7}$, parasitic on Steatoda borealis (host with large parasite larva found May 3, 1942; larva about $9.5 \mathrm{~mm}$. long May 5; larva had killed and discarded host May 9; larva still spinning cocoon May 11; pupated May 18; emerged as adult May 26, 1942), Fish Canyon, San Gabriel Mts., Calif., May 26, 1942, E. I. Schlinger. $\sigma^{7}$, emerged from cocoon with freshly formed pupa found near dead Steatoda borealis (cocoon found Apr. 27, 1949; adult emerged Apr. 30, 1949), Fish Canyon, San Gabriel Mts., Calif., E. I. Schlinger. o, emerged from cocoon found near dead Steatoda borealis (cocoon found Apr. 27, 1949; adult emerged May 8, 1949), E. I. Schlinger. ㅇ, reared from spider, Falls Church, Va., May 13, 1956, O. L. Cartwright.

This American subspecies is transcontinental in the Transition and Upper Austral zones. Its habitat seems to be moderately dry, open deciduous woods or shrubs. Adults occur throughout the growing season. It has been reared from Steatoda borealis.

\section{Genus Polysphincta}

Figure 296,a

Polysphincta Gravenhorst, 1829, Ichneumonologia europaea, vol. 3, p. 112. Type: Polysphincta tuberosa Gravenhorst; designated by Westwood, 1839.

Front wing 3.7 to $7.0 \mathrm{~mm}$. long; eye bare; clypeus broadly lenticular, its apical margin truncate medially, moderately convex transversely, its basal half moderately convex longitudinally, its apical half almost flat with the apical margin a little reflexed; epomia strong; mesoscutum subpolished or polished, densely hairy to sparsely hairy or bare; notaulus long, moderately strong; prepectal carina complete, its upper end far from front margin of mesopleurum; pleural carina of propodeum present or absent; legs moderately slender; areolet absent; intercubitus about 0.3 to 0.4 as long as second abscissa of cubitus; nervulus interstitial or briefly postfurcal; discoidella present, rather strong; first tergite short; second to fourth tergites weakly mat or polished, their punctures fine, weak, and sparse or very sparse, each tergite with a median pair of tuberclelike swellings; hairs on second through fourth tergites sparse to moderately dense; ovipositor sheath about 4 times as long as apical depth of abdomen; 
ovipositor straight, with a weak swelling just beyond the middle, tapered gradually from this swelling to the apex (fig. 332 ,i).

As defined above, the genus Polysphincta includes the six Nearctic species described below (one of which is Holarctic), an undescribed species from the Philippines, Epimecis thoracicus Cresson 1874 from Mexico, two undescribed Neotropic species, and the European Polysphincta rufipes Gravenhorst 1829, and Polysphincta boops Tschek 1868. There are doubtless others, but these are all of the true Polysphincta that we have been able to study. The European $P$. rufipes is closely related to $P$. burgessii, $P$. thoracica and the two undescribed Neotropic species are related to $P$. eboripes, and the Philippine species is an isolated one, perhaps nearest to $P$. limata.

Polysphincta drewseni Holmgren 1860 is a synonym of $P$. rufipes and Polysphincta taschenbergi Woldstedt 1876 is a synonym of $P$. tuberosa (new synonymies). We have seen the types of drewseni and of taschenbergi, but the part of the Gravenhorst collection containing the types of tuberosa and rufipes was lost during World War II. We apply these last two names according to the original descriptions and European tradition.

\section{Key to the Nearctic species of Polysphincta}

1. Abdomen mostly fulvous . . . . . . . . . . 6. albipes Cresson Abdomen entirely black . . . . . . . . . . . . . . . . . . . 2

2. Submetapleural carina present and complete. . . . . . . . . . . . . . 3

Submetapleural carina entirely absent, or in $P$. tuberosa sometimes present as a faint vestige . . . . . . . . . . . . . . . . . . . . . 4

3. Hair on mesoscutum moderately dense and evenly distributed; propodeum strongly mat at its midlength; mesosternum and lower half of mesopleurum usually fulvous, the rest of mesopleurum usually black.

1. burgessii Cresson

Hair on mesoscutum rather sparse and not evenly distributed; central part of the lateral lobe of mesoscutum usually without hairs or with very few; propodeum weakly or not at all mat at its midlength; mesosternum and lower half of mesopleurum black, or if more or less fulvous then the upper part of mesopleurum also more or less fulvous . . . . . . . . 2. limata Cresson

4. Mesoscutum with moderately dense hairs that are evenly distributed; mesoscutum of female usually entirely black; pronotum in profile without a distinct tubercle below front end of mesoscutum.

3. tuberosa Gravenhorst

Mesoscutum with a few scattered hairs but mostly hairless; mesoscutum largely or entirely fulvous; pronotum in profile with a forward-projecting tubercle below front end of mesoscutum . . . . . . . . . . . . . . 5

5. Femora mostly fulvous; hind tibia infuscate at apex below; metapleurum discally with sparse hairs . . . . . . . . . . 4. koebelei Howard

Femora entirely whitish; hind tibia not infuscate at apex; metapleurum discally bare or sometimes with a few hairs . . . . . . 5. eboripes, new species 


\section{Polysphincta burgessii Cresson}

FigURE $324, a$

Polysphincta Burgessii Cresson, 1870, Trans. Amer. Ent. Soc., vol. 3, p. 149; $\sigma^{7}$. Type: $\sigma^{7}$, Beverly, Mass. (Philadelphia).

Polysphincta rufopectus Provancher, 1875, Naturaliste Canadien, vol. 7, p. 140;

†. Type: $\uparrow$, Quebec Province (Quebec).

Polysphincta (Polysphincta) venatrix DeGant, 1933, Proc. U. S. Nat. Mus., vol.

84, p. 4; + . Type: , Parr Island, East Spence Lake, Ont. (Washington).

Front wing of male 3.7 to $5.5 \mathrm{~mm}$. long, of female 4.7 to $6.8 \mathrm{~mm}$. long; hairs on mesoscutum rather short, dense, and evenly distributed; metapleurum evenly covered with moderately dense hairs; submetapleural carina strong and complete; propodeum distinctly mat except basally and apically, where it is subpolished; median longitudinal carinae of propodeum blunt but prominent; pleural carina of propodeum weak but complete; intercubitus about 0.3 as long as second abscissa of cubitus; first tergite about 1.15 as long as wide in male, about 1.05 as long as wide in female; second through fourth tergites weakly mat with their median swellings and apical $0.25 \pm$ subpolished.

FIgURE 105.-Localities for Polysphincta burgessii.

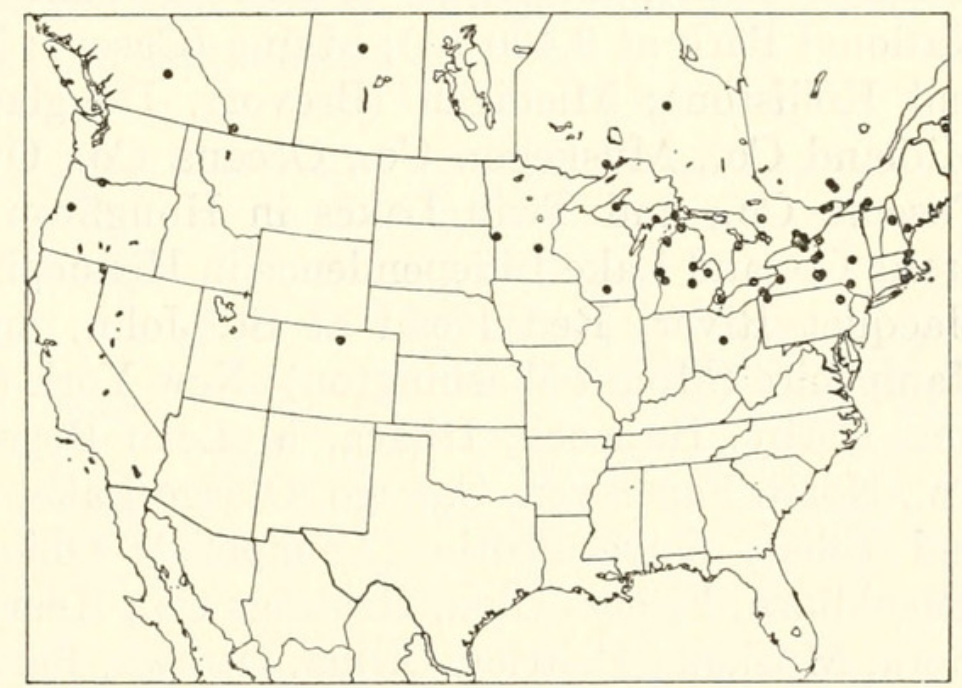

Male: Black. Clypeus brown, blackish basally; mandible white, its base and apex brown; palpi white; apical 0.6 of scape in front and pedicel in front stramineous; flagellum brown, paler below; tegula, hind corner of pronotum, and mesepimeron white; mesosternum, metapleurum, and scutellum fulvous; lower half of mesepisternum more or less fulvous; upper half of mesepisternum sometimes stained with fulvous; trochanters and front and middle coxae whitish, the middle coxa stained with fulvous basally; hind coxa fulvous; femora fulvous, their apex and front side of front femur whitish, the hind femur with a faint preapical infuscation; front and middle tibiae and tarsi white, the under side of tibiae, apex of basal three tarsal segments, and all of last two tarsal segments, pale fulvous; hind tibia whitish, the apical $0.2 \pm$ brown, the brown extending farthest basad 
on the sides; basal four segments of hind tarsus whitish with their apex fuscous; fifth segment of hind tarsus fuscous, its base pale.

Female: Black. Apical half of clypeus, median part of mandible, and flagellum dark brown; palpi whitish; tegula and hind corner of pronotum white; scutellum, mesosternum and lower $0.6 \pm$ of mesopleurum usually fulvoferruginous, but sometimes these are largely or entirely black; front leg fulvous, its trochanters and apex of its coxa pale fulvous, the apex of its femur, upper side of its tibia, and basal half of its basitarsus whitish; hind coxa, trochanters, and femur fulvous, the femur with a faint preapical infuscation and its extreme apex stramineous; hind tibia whitish, its apical 0.25 and under side blackish brown, subbasally the dark color on the basal side extended dorsally a little to suggest or sometimes to complete a narrow subbasal band; basal three segments of hind tarsus whitish, their apex broadly fuscous; apical two segments of hind tarsus fuscous; coloration of middle leg similar to that of hind leg but the darker areas only weakly infuscate.

Specimens $\left(80^{x}, 91\right.$ ) $)$ : From Alberta (Waterton); British Columbia (Salmon Arm); Colorado (Phantom Valley in Rocky Mountain National Park at 9,400 ft.); Maine (Casco); Massachusetts (Beverly and Holliston); Michigan (Brevort, Douglas Lake, Leelanau Co., Midland Co., Muskegon Co., Oceana Co., Owosso, Schoolcraft Co., Tuscola Co., and Twin Lakes in Houghton Co.); Minnesota (Big Stone Co. and Lake Independence in Hennepin Co.); New Brunswick (Jacquet River, Red Head at St. John, and Pokemouche); New Hampshire (Mount Washington); New York (Bluff Island near Clayton, Derby, Hancock, Ithaca, McLean Bogs Reserve in Tompkins Co., North Fairhaven, Oswego, Otsego Lake, and between Slaterville and Ellis); Nova Scotia (Annapolis); Ohio (Columbus); Ontario (Blackburn, Fishers Glen, Hastings Co., Kearney, Leamington, Marmora, Muskoka District, Orillia, Ottawa, Parr Island in East Spence Lake, Smoky Falls on the Mattagami River, Southampton, Thunder Bay Beach, and Trenton); Oregon (Hood River and Springfield); Pennsylvania (Lake Pleasant in Erie Co., Presque Isle in Erie Co., and Spring Brook); Quebec (Cascapedia, Fulford, Knowlton, Lac Mercier, and Nominingue); Rhode Island (Westerly); Saskatchewan (Prince Albert National Park); and Wisconsin (Dane Co.).

Collecting dates are distributed from late spring to early fall. Particularly early and late dates of capture are: May 25 in Tuscola Co., Mich.; May 30 at Leamington, Ont., and at Ottawa, Ont.; June 3 at Westerly, R. I.; June 4 at Nominingue, Que.; June 5 at Thunder Bay Beach, Ont.; September 5 at Ottawa, Ont.; September 6 at Derby, N. Y.; September 13 and 15 at Trenton, Ont.; and October 1 at Annapolis, N. S. Two of the specimens were taken at light. 
This species is transcontinental in the Transition zone, but is relatively scarce in the western part of the country. Adults occur from late spring to early fall.

\section{Polysphincta limata Cresson}

FigURE $324, \mathrm{~b}$

Polysphincta limata Cresson, 1870, Trans. Amer. Ent. Soc., vol. 3, p. 150; Type: $\uparrow$, Massachusetts (Philadelphia).

Front wing of male 3.7 to $5.8 \mathrm{~mm}$. long, of female 4.7 to $7.0 \mathrm{~mm}$. long; hairs on mesoscutum rather sparse and not evenly distributed, the central part of lateral lobe of mesoscutum with only sparse hairs or none; metapleurum evenly covered with moderately dense hairs; submetapleural carina strong and complete; propodeum subpollished, near its midlength weakly mat and weakly rugulose; median eongitudinal carinae of propodeum blunt and rather weak, near midlnngth of propodeum somewhat obscured by rugulosity; pleural carina of propodeum weak and incomplete; intercubitus about 0.4 as lowg as second abscissa of cubitus; first tergite about 1.2 as long as wide; median swellings and apical 0.25 of second through fourth tergites polshed, the rest faintly mat to subpolished.

Figure 106.--Localities for Polysphincta limata.

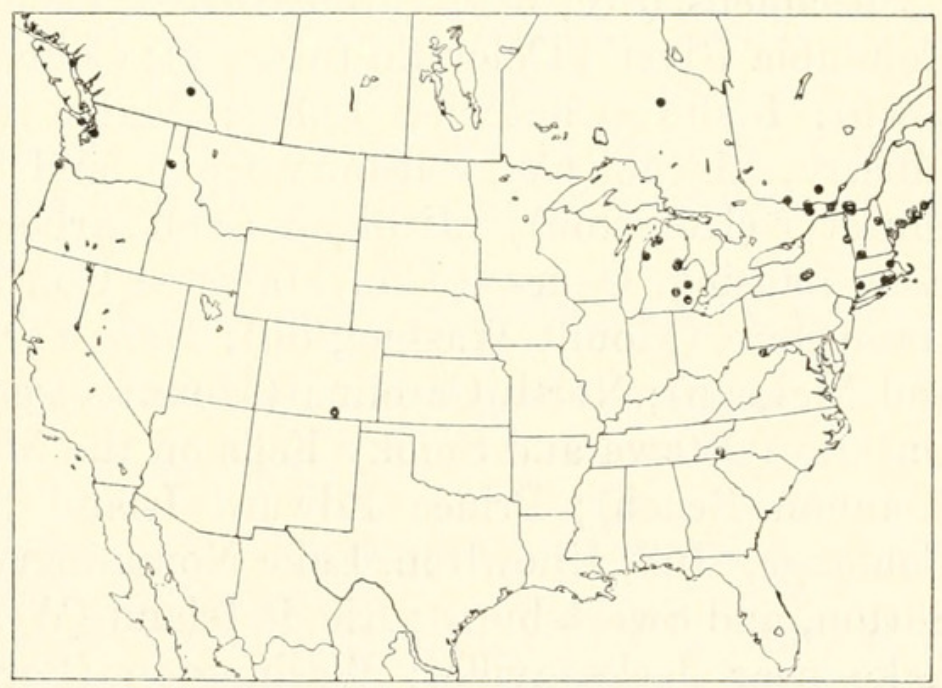

Male: Black. Apical half of clypeus brownish; mandible light brown, its base and apex darker; palpi, tegula, and hind corner of pronotum white; apical margin of scape and pedicel stramineous in front; flagellum dark brown, paler below; scutellum and sometimes mesothorax fulvoferruginous or stained with this color; trochanters and front and middle coxae whitish, the coxae basally and hind side of first hind trochanter stained with fulvous; femora fulvous, stramineous at apex, the hind femur somewhat infuscate preapically; front 
tibia and tarsus pale fulvous, the tibia with a subbasal band that is darker fulvous; middle tibia pale fulvous with a narrow subbasal band and broad apical band weakly infuscate; basal three segments of middle tarsus stramineous, their apex brown; apical two segments of middle tarsus brown, paler at base; hind tibia whitish with a narrow subbasal band, broad apical band, and stripe below extending from the apical band to near base of tibia, brownish fuscous; basal three segments of hind tarsus pale stramineous, their apex dark brown; apical two segments of hind tarsus dark brown, a little paler at base.

Female: Black. Apical half of clypeus dark brown; mandible brown, its base and apex darker; palpi, tegula, and hind corner of pronotum white; flagellum dark brown; hind coxa and hind first trochanter fulvous; hind second trochanter whitish; hind femur fulvous, with a conspicuous subapical fuscous band, its extreme apex stramineous; hind tibia whitish, with a narrow subbasal band, broad apical band, and stripe beneath extending from apical band nearly to base of tibia, fuscous; basal three segments of hind tarsus whitish, their apex fuscous; apical two segments of hind tarsus fuscous; front and middle legs fulvous, their trochanters whitish, knees stramineous, and the middle tibia and tarsus weakly repeating the color pattern of the hind tibia and tarsus.

Specimens $\left(80^{7}, 68\right.$ ) : From British Columbia (Carbonate on the Columbia River); Colorado (Morley); Connecticut (Kent and Voluntown); Idaho (Chatcolet Lake); Maine (Casco, Kennebunkport, Liberty, Lincoln Co., Salsbury Cove, and Squirrel Island); Massachusetts (Holliston); Michigan (Ann Arbor, Antrim Co., Bay Co., East Lansing, Genesee Co., Manistee Co., and Midland Co.); New Hampshire (Mount Washington); New York (Ithaca, Lake George, and McLean); North Carolina (Mount Pisgah at 5,000 to 5,749 ft.); Ontario (Ottawa and Smoky Falls on the Mattagami River); Oregon (Cannon Beach); Prince Edward Island (Portage); Quebec (Fort Coulonge, Hull, Knowlton, Lake Nominingue in Labelle Co., Rigaud, Sutton, and Sweetsburg); Rhode Island (Westerly); Vermont (Laurel Lake near Jacksonville); Washington (Port Angeles and Seattle); West Virginia (Terra Alta); and Yukon (Kluane).

Most collection dates are in July and August. Those outside of these two months are: June 19, in Genesee Co. Mich.; June 29 at Terra Alta, W. Va.; June 30 at Knowlton, Que.; September 2 at Ann Arbor, Mich.; September 5 at Ottawa, Ont., and on Mount Pisgah, N. C. at 5,000 to 5,749 ft.; and September 13 at Liberty, Maine.

This species is transcontinental in the Transition zone. Adults occur mostly in July and August. 


\section{Polysphincta tuberosa Gravenhorst}

Figure 332,i

Front wing of male 4.2 to $5.3 \mathrm{~mm}$. long, of female 4.5 to $7.0 \mathrm{~mm}$. long; hairs on mesoscutum moderately sparse, evenly distributed; metapleurum evenly covered with moderately dense hairs; submetapleural carina absent, or sometimes present as a vestige; propodeum smooth, sometimes weakly and narrowly mat at its apical 0.55 ; median longitudinal carinae of propodeum usually weak, sometimes almost lacking; pleural carina of propodeum lacking; intercubitus about 0.35 as long as second abscissa of cubitus; first tergite about 1.4 as long as wide in male, about 1.2 as long as wide in female; second through fourth tergites polished.

Coloration as described under the subspecies.

There is a northern Nearctic and a European subspecies as keyed and described below:

1. Hind coxa black; range: Europe. . . . . 3a. tuberosa tuberosa Gravenhorst Hind coxa fulvous; range: North America. . 3b. tuberosa bruneti Provancher

\section{3a. Polysphincta tuberosa tuberosa Gravenhorst}

Polysphincta tuberosa Gravenhorst, 1829, Ichneumonologia europaea, vol. 3, p.

115 ; $\subsetneq$. Types: $q$ \& Austria and Italy (lost during World War II).

Front and middle coxae of male whitish, blackish basally; hind coxa of male and all coxae of female mostly black; first trochanter of hind leg of male and of all legs of female partly blackish; ground color of hind femur fulvous to dark brown. Color otherwise as described for P. tuberosa bruneti.

Described from a male and four females from Ireland and Germany.

\section{3b. Polysphincta tuberosa bruneti Provancher, new status}

FiguRe 324,c

?Polysphincta Bruneti Provancher, 1873, Naturaliste Canadian, vol. 5, p. 471; ․ Type: $\&$, Quebec Province (Quebec).

Polysphincta (Polysphincta) elongata Cushman, 1920, Proc. U. S. Nat. Mus., vol. 58 , p. 25; ;. New synonymy. Type: $q$, Mount Washington, N. H. (Washington).

Male: Black. Clypeus and mandible dark reddish brown; palpi white; pedicel in front and apex of scape in front, stramineous; tegula and hind corner of pronotum white; scutellum fulvous; most of mesocutum and mesopleurum fulvous or stained with fulvous; front and middle coxae whitish, pale fulvous at base; hind coxa fulvous; trochanters whitish, the first trochanter of hind leg fulvous basally; front and middle femora pale fulvous, whitish at apex and stained 
with whitish in front; front and middle tibiae and tarsi whitish stramineous, the tibiae pale fulvous below, the apex of first three segments and all of last two segments of middle tarsus fulvous; hind femur fulvous, its apex white, a narrow pale fulvous stripe extending basad from apex along upper edge; hind tibia white, with a small brown subbasal spot on front side and its apex rather narrowly fuscous brown, the apical dark band extended a little basad on front side; first three segments of hind tarsus stramineous, their apex broadly fuscous brown; last two segments of hind tarsus fuscous brown, a little paler at base.

A male from Lower Tonsina, Alaska, is essentially similar but with more intensive and extensive dark markings on the legs. This one has the hind coxa apically a little infuscate and the hind femur chestnut brown.

Female: Black. Apical two-thirds of clypeus dark reddish brown; palpi stramineous or pale brown; tegula and hind corner of pronotum white; scutellum usually more or less fulvous; mesoscutum and mesopleurum sometimes more or less fulvous; coxae fulvous; first trochanters fulvous, whitish at apex, often a little darkened or infuscate basally, especially the hind first trochanter; second trochanter mostly whitish; femora fulvous, a little paler at apex, the hind femur sometimes brownish fulvous to chestnut brown, in which case the upper margin near apex is paler; front tibia and tarsus fulvous; middle tibia fulvous, its upper face mostly whitish, and with a faint, narrow, brownish subbasal band; first three segments of middle tarsus stramineous, their apex brown; last two segments of middle tarsus brown; hind tibia brown, whitish above from base almost to apex except for a narrow subbasal brown interruption; first segment of hind tarsus stramineous, its apex broadly fuscous; second to fifth segments of hind tarsus fuscous, paler at base.

We studied the type of bruneti, at Quebec, in 1941. At that time, however, we did not know the distinction between the species limata and tuberosa, so our notes are of little value. In 1958 we tried to get additional information on the type, but it could not be found. The original description fits the present species better in the color of the hind tibia but fits limata better in "les trochantins blanc." We assign the name bruneti to the present form, unless rediscovery of the type shows this to be an error.

Specimens: $\sigma^{7}$, Lower Tonsina, Alaska, Aug. 21, 1953, W. C. Frohne (Washington). क, Cultus Lake, B. C., Oct. 22, 1938, J. K. Jacob (Ottawa). \&, Robson, B. C., Sept. 14, 1938, H. R. Foxlee (Townes). $\quad \sigma^{7}$, Redwood Meadows, Tulare Co., Calif., Aug. 3, 1915 (Ithaca). \& (type of elongata), Mount Washington, N. H. (Washington). क, Greene Co., N. Y., August (Pittsburgh). क, Knowlton, 
Que., June 24, 1929, L. J. Milne (Ottawa). ㅇ, Knowlton, Que., Aug. 6, 1929, G. S. Walley (Ottawa). क, Strawberry Daniel Pass, Utah, June 19, 1948, H., M., G., and D. Townes (Townes). +, Mount Rainier at 5,300 ft., Wash., Aug. 16, 1940, H. and M. Townes (Lawrence). $\sigma^{7}, 26$ 우, Mount Rainier at 1,700, 2,900, 4,200, 4,700, 5,300, and at 6,500 ft., Wash., July 7, 11, 15, 21, and 22, 1940, and Aug. 15, 16 , and $17,1940, \mathrm{H}$. and M. Townes (Townes).

This American subspecies is transcontinental in the Canadian and Hudsonian zones.
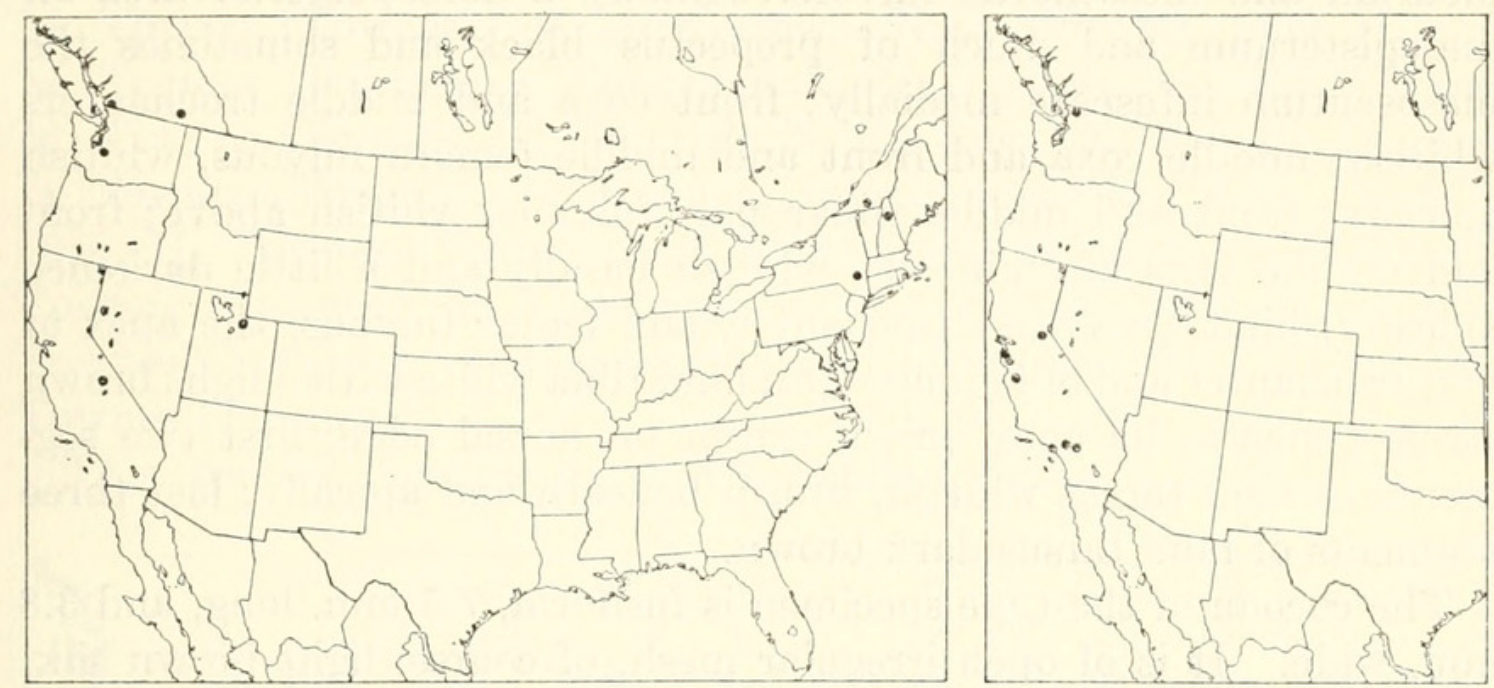

Figures 107, 108.-Localities: 107 (left), Polysphincta tuberosa bruneti; 108 (right), P. koebelei.

\section{Polysphincta koebelei Howard}

Figure 324,d

Polysphincta (Zaglyptus) koebelei Howard, 1892, Proc. Ent. Soc. Washington, vol. 2, p. 293; ․ Type: ${ }_{+}$, Santa Cruz Mts., Calif. (Washington).

Front wing of male 4.8 to $5.5 \mathrm{~mm}$. long, of female 5.5 to $7.0 \mathrm{~mm}$. long; pronotum in profile with a forward-projecting tubercle just below front end of mesoscutum (this structure present also in $P$. eboripes but absent in the other Nearctic species of the genus); mesoscutum with a very few scattered hairs but mostly hairless; metapleurum with sparse, rather evenly distributed hairs; submetapleural carina absent; propodeum smooth, polished, without carinae or rugulae, its pleural carina absent; intercubitus about 0.3 as long as second abscissa of cubitus; first tergite about 1.35 as long as wide in male, about 1.30 as long as wide in female; second through fourth tergites polished

Male: Black. Most of mandible and apical half of clypeus stramineous; palpi white; apex of scape and pedicel light brown in front; tegula, hind corner of pronotum, and front and middle legs, white, the front and middle femora partly pale fulvous; mesothorax fulvo- 
ferruginous, the upper hind part of mesepisternum, often a large part of prepectus, and sometimes median lobe of mesoscutum blackish; hind coxa, first trochanter, and femur fulvous, the apex of first trochanter and of femur white; hind second trochanter white; hind tibia white with an elongate apical infuscate triangle on front and back faces; hind tarsus white, the apex of its first four segments narrowly darkened, its fifth segment infuscate with its base paler.

Female: Black. Apical half of clypeus dark brown; mandible light brown; palpi, tegula, and hind corner of pronotum, white; metapleurum and mesothorax fulvoferruginous, a dorsoposterior area on mesepisternum and much of prepectus black and sometimes the mesoscutum infuscate medially; front coxa and middle trochanters whitish; middle coxa and front and middle femora fulvous, whitish apically; front and middle tibiae pale fulvous, whitish above; front and middle tarsi stramineous, whitish basally and a little darkened apically; hind coxa, first trochanter, and femur fulvous, the apex of first trochanter and of femur white; hind tibia white with a light brown stripe beneath, its apex brown except on dorsal edge; first two segments of hind tarsus whitish, brown beneath and apically; last three segments of hind tarsus dark brown.

The cocoon of the type specimen is fusiform, $7.5 \mathrm{~mm}$. long, and 3.8 $\mathrm{mm}$. wide. It is of open irregular mesh, of coarse, light brown silk, with loosely looped strands on the outside.

Specimens: 29, Camino, Calif., June 27 and 30, 1948, H., M., G., and D. Townes (Townes). \&, Los Angeles Co., Calif. (Washington). $\sigma^{7}$, Menlo Park, Calif., January 1905, F. Hornung (Washington). ㅇ, Muir Woods, Calif., Feb. 23, 1947, U. N. Lanham (Ann Arbor). $\sigma^{x}$, Mountain Home, San Bernardino Co., Calif., Sept. 12, 1953, J. C. Hall (Davis). , beat from Ceanothus cuneatus, Pinnacles National Monument, Calif., Apr. 6, 1951, E. J. Taylor (Townes). \& (type) reared from either Epeira strix or E. scolopetaria, Santa Cruz Mts., Calif., A. Koebele (Washington). †, Tanbark Flat, Los Angeles Co., Calif., July 10, 1952, W. V. Garner (Berkeley). $\sigma^{7}$, Glacier, Wash., Aug. 9, 1925, A. L. Melander (Cambridge).

This species occurs from Washington State to southern California.

\section{Polysphincta eboripes, new species}

Figure 324,e

Front wing of male 4.3 to $4.8 \mathrm{~mm}$. long, of female 5.0 to $6.8 \mathrm{~mm}$. long; metapleurum with a few hairs anteriorly and posteriorly, sometimes also with a very few hairs discally. Structure otherwise as described for $P$. koebelei.

Black. Mandible and apical half of clypeus stramineous or brown; palpi, tegula, and hind corner of pronotum, white; legs ivory white, 
the apex of segments of hind tarsus often narrowly infuscate, the fifth segment of hind tarsus fuscous with its base paler; upper part of pronotum and all or nearly all of mesothorax except usually for a fuscous area in upper hind part of mesepisternum, fulvoferruginous. Sometimes the metapleurum is also fulvoferruginous, and in the two specimens from Kansas the entire prothorax is fulvoferruginous.

Type: ㅇ, Mount Holly Springs, Pa., July 7, 1918, R. M. Fouts (Washington, USNM 63704).

Paratypes: $\sigma^{\top}$, ㅇ, Lawrence, Kans., Aug. 11 and 13, 1896, Hugo Kahl (Washington). 2o, Takoma Park, Md., Nov. 2, 1946, H. and M. Townes (Townes). o, Moorestown, N. J., July 23, 1939, H. and M. Townes (Townes). o, Farmingdale, N. Y., July 26, 1938, H. and M. Townes (Townes). o, Hamrick, N. C., Aug. 19, 1950, H., M., and D. Townes (Townes). क, Mount Pisgah at 5,300 ft., N. C., Sept. 2, 1950, H. Townes (Townes). व̛', Raleigh, N. C., June 25, 1951, H. Townes (Townes). $0^{\Upsilon}$, Greenville, S. C., Apr. 20, 1952, G. and L. Townes (Townes). क, Greenville, S. C., Oct. 11, 1941, H. and M. Townes (Townes).

This species belongs to the Carolinian fauna.
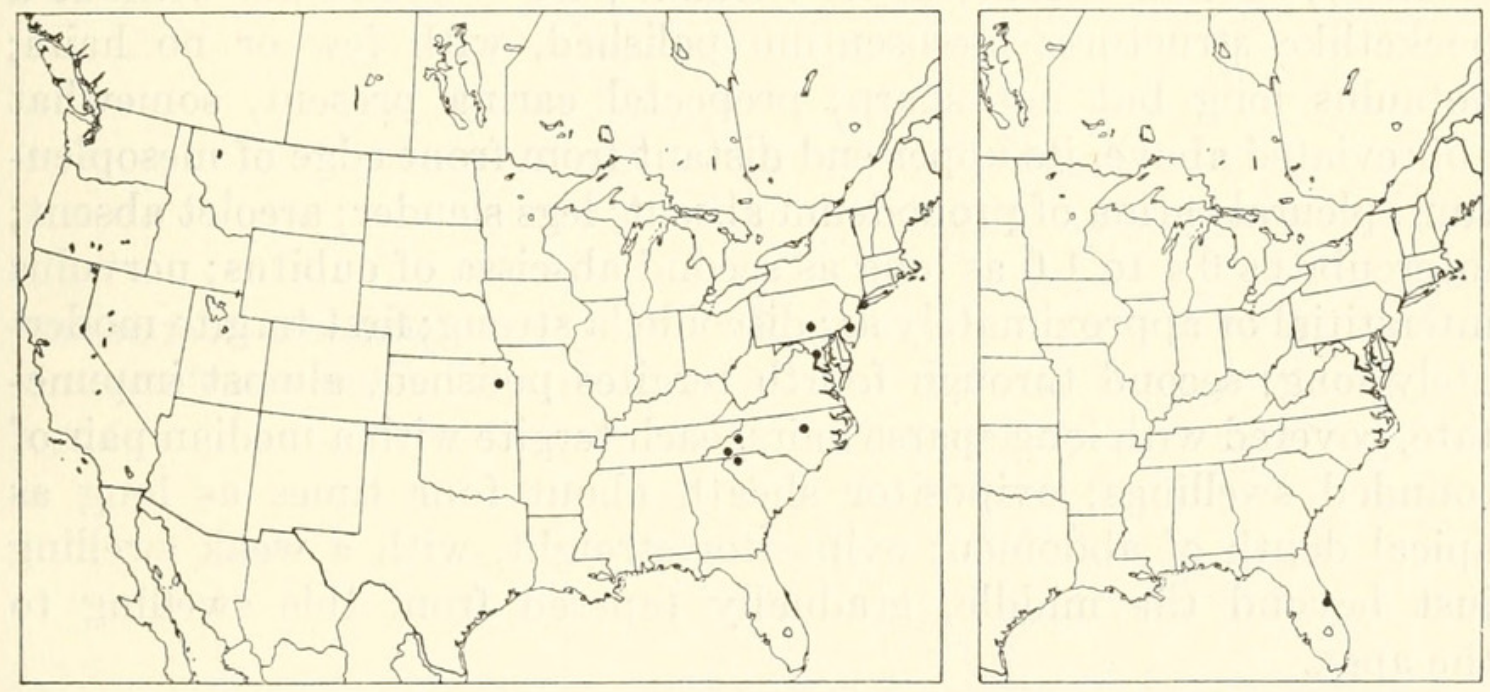

Figures 109, 110.-Localities: 109 (left); Polysphincta eboripes; 110 (right), P. albipes.

\section{Polysphincta albipes Cresson}

Polysphincta albipes Cresson, 1880, Ann. Rep. U. S. Dep. Agr. for 1879, p. 208; $\sigma^{7}$. Type: $\sigma^{7}$, Rock Ledge, Fla. (lost).

Polysphincta albipes Hubbard, 1885, Insects affecting the orange, p. 153. Description, biological note, reared from ?Platynota rostrana.

The type of this species is lost and no specimen has since been collected which fits the description. The original description is as follows:

"Male.-Sanguineous, smooth and polished; head black; clypeus, mandibles and palpi, white; antennae long, slender, black; tegulae and 
dot before, white; wings hyaline, subiridescent, nervures and stigma fuscous; legs, including coxae, white, tips of tarsi blackish; second and following segments of abdomen with a transverse black spot on each side at tip, and a transverse deeply impressed line near base and apex, the lateral middle being therefore more or less swollen; basal segment with a median shallow groove above, and a short, stout tubercle on each side; venter yellowish-white. Length, .28 inch.

"Hab.-Rockledge, Florida. Found on an orange leaf." [Bred from cocoons found on an orange leaf.]

\section{Acrotaphus, new genus}

Figure 296,b

Front wing 7.5 to $18 \mathrm{~mm}$. long; body slender; eye bare; clypeus moderately long, moderately convex basally, the rest in longitudinal direction weakly convex, flat, or weakly concave, its apex truncate and weakly reflexed; temple concave, flat, or weakly convex; occipital carina usually high and reflexed; ocelli usually very large (in the other Nearctic genera the temple is more convex and the ocelli smaller); epomia absent; upper median part of pronotum without a pocketlike structure; mesoscutum polished, with few or no hairs; notaulus long but not sharp; prepectal carina present, somewhat abbreviated above, its upper end distant from front edge of mesopleurum; pleural carina of propodeum absent; legs slender; areolet absent; intercubitus 0.4 to 1.0 as long as second abscissa of cubitus; nervulus interstitial or approximately so; discoidella strong; first tergite moderately long; second through fourth tergites polished, almost impunctate, covered with long sparse hairs, each tergite with a median pair of rounded swellings; ovipositor sheath about four times as long as apical depth of abdomen; ovipositor straight, with a weak swelling just beyond the middle, gradually tapered from this swelling to the apex.

Genotype: Epimecis wiltii Cresson.

The generic name is from the Greek "a" (without) plus "krotaphos" (the temple), referring to the narrow temple.

Acrotaphus is a New World genus, including the Nearctic $A$. wiltii and a number of Neotropic species, among them Epimecis fuscipennis Cresson 1865, from Cuba; Epimecis fasciata Brullé 1846, from Brazil; Epimecis tibialis Cameron 1886, from Central America; and Epimecis latifasciatus Cameron 1911, from British Guiana. The species of this genus have a strong superficial resemblance to Hymenoepimecis. Hymenoepimecis differs from Acrotaphus, however, in lacking the prepectal carina and in having a forward-opening, pocketlike structure on the neck region of the pronotum above. 


\section{Acrotapus wiltii (Cresson), new combination}

Figure 324,f

Epimecis Wiltii Cresson, 1870, Trans. Amer. Ent. Soc., vol. 3, p. 143; ㅇ. Type: Ohio (Philadelphia).

Biology: Shannon, 1913, Proc. Ent. Soc. Washington, vol. 15, p. 162.

Front wing of male 7.5 to $11 \mathrm{~mm}$. long, of female 7.5 to $15 \mathrm{~mm}$. long; ocelli very large, the lateral ocellus almost touching eye; temple weakly concave; occipital carina very high, a little reflexed.

Fulvous. Head and antenna black, the clypeus brown apically; mouth parts stramineous; apex of abdomen, beginning with the sixth or seventh segment, black or infuscate; wings light fulvous, the front wing with a median and apical transverse fuscous band, the hind wing with a weak infuscation centered at origin or radius.

Shannon (loc. cit.) reports finding the larva of this species attached to the thorax (!) of Epeira trivittata, on Sept. 14, 1913. The spider was put in a breeding jar, where it spun a web. The larva grew rapidly, killed the spider on the sixth day, spun its cocoon in the spider's web, and emerged as an adult on Oct. 1, 1913.

Figure 111.-Localities for Acrotaphus wiltii.

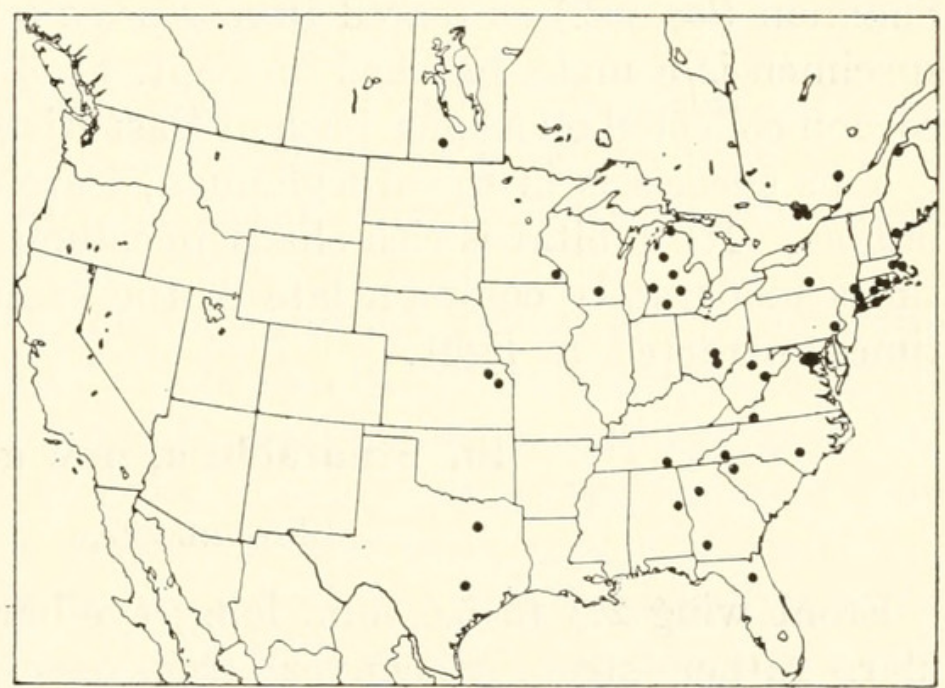

The cocoon of Shannon's specimen is fusiform, $7 \mathrm{~mm}$. by $20 \mathrm{~mm}$, more densely woven than in Polysphincta but still rather loose and somewhat transparent, with a weakly wrinkled surface, and surrounded by a thin layer of looser silk. It is medium brown in color and has a small hole at the hind end.

Specimens (52 $\sigma^{\Upsilon}, 65$ ㅇ): From Alabama (Pyriton); Connecticut (East River, Lebanon, and Voluntown); Florida (Gainesville); Georgia (Atlanta and Dewitt); Kansas (Lawrence and Onaga); Maine (Casco and Kokadjo); Manitoba (Aweme); Maryland (Cabin John, Glen Echo, and Plummers Island); Massachusetts (Cohasset and Sherborn); Michigan (Cheboygan Co., East Lansing, Gull Lake Biological Station in Kalamazoo Co., Isabella Co., Lake City, and Muskegon Co.); 
Minnesota (5 miles south of La Moille in Winona Co.); New York (Farmingdale, Ithaca, Millwood, Poughkeepsie, and Yaphank); North Carolina (Garland and Hendersonville); Ohio (Fairfield Co. and Good Hope Township in Hocking Co.); Ontario (Constance Bay and Ottawa); Pennsylvania (Valley Forge); Quebec (Kirks Ferry, Lac Mondor at Sainte Flore, and Norway Bay); South Carolina (Greenville); Tennessee (Monteagle at 2,000 ft.); Texas (Austin and Handley); Virginia (Black Pond near mouth of Difficult Run in Fairfax Co., Galax, and Glencarlyn); West Virginia (Cheat Mt. at 2,000 ft. in Randolph Co. and Jackson's Mill in Lewis Co.); and Wisconsin (Madison).

Collecting dates are throughout the warmer season, with peak abundance in July, August, and early September. Unusually early and late dates of capture of special interest are: May 15 at Constance Bay, Ont.; June 13 at Aweme, Man.; June 21 at Norway Bay, Que.; September 11 at Madison, Wis.; September 19 at Ithaca, N. Y.; and October 5 at Plummers Island, Md.

Six of the female specimens were collected coming to lights at night, at six different localities. One of the specimens is the one reported by Shannon (loc. cit.) as reared from Epeira trivittata. A second reared specimen is a male, hatched on Sept. 11, 1914, by C. R. Ely from a cocoon collected on a spice bush at East River, Conn., on September 2.

This species is in the Alleghanian, Carolinian, and Lower Austral faunas. Its habitat is rich shady deciduous woods, where it is sometimes moderately common late in the summer. Females are sometimes attracted to light.

\section{Sinarachna, new genus}

Figure 297,a

Front wing 2.3 to $5.0 \mathrm{~mm}$. long; eye bare; clypeus broadly lenticular, rather strongly convex transversely, weakly convex longitudinally; epomia strong; mesoscutum subpolished, evenly covered with moderately dense hairs; notaulus long and sharp; prepectal carina complete, its dorsal end far from front margin of mesopleurum; pleural carina of propodeum complete; legs moderately slender to stout; areolet absent; intercubitus very short or almost obliterated by approximation of radial and cubital veins; nervulus postfurcal by 0.15 to 0.35 its length; discoidella completely absent; first tergite rather short; second through fourth tergites largely or entirely polished, sparsely hairy, with oblique impressions or grooves which delimit a central rhombic area on each, the rhombic areas often swollen laterally to make a weak pair of tubercles; ovipositor sheath 1.8 to 2.5 as long as apical depth of abdomen; ovipositor straight, weakly to distinctly swollen near middle, tapered from middle to apex. 
Genotype: Polysphincta pallipes Holmgren.

The generic name is derived from the Greek "sinis" (a plunderer) plus "arachna" (a spider), referring to the host relationship.

This genus contains two Holarctic species, the European Polysphincta nigricornis Holmgren 1860, the Oriental Polysphincta ceylonica Ashmead 1896, and two undescribed species from Japan and India. Of these, $S$. anomala differs from the rest of the species in so many ways that it might be placed in a separate genus. For the present, however, it seems best to treat it as an aberrant species of Sinarachna.

\section{Key to the Nearctic species of Sinarachna}

1. Third tergite about 0.85 as long as wide; mesoscutum entirely black; flagellum of male with about 22 segments, of female with about 24 segments.

1. pallipes (Holmgren)

Third tergite about 0.55 as long as wide; mesoscutum dark brown, usually its anterolateral margins and broad stripes along the notauli yellowish; flagellum with about 14 segments in male, with about 16 segments in female.

2. anomala (Holmgren)

\section{Sinarachna pallipes (Holmgren), new combination}

\section{FiguRe $324, g$}

Front wing 3.5 to $4.9 \mathrm{~mm}$. long; body and legs rather slender; flagellum of male with about 22 segments, of female with about 24 segments; third segment of hind tarsus about 3.0 as long as deep; third tergite about 0.85 as long as wide.

Black. Scape and pedicel of male whitish, brownish above; scape and pedicel of female whitish to brown in front; flagellum of male pale brown basally below; mouth parts, tegula, subtegular ridge, hind corner of pronotum, and front and middle legs white or pale stramineous; mesepimeron brown to stramineous; hind coxa ivory, light fulvous basally; hind trochanters ivory; hind femur ivory, its base and most of its front and hind faces except near base and apex, light brown; hind tibia white with a narrow, faint, subbasal infuscate ring and its apical 0.2 fuscous; hind tarsus fuscous, the basal $0.75 \pm$ of its first segment and sometimes also of its second and third segments whitish to light brown.

There are European and American subspecies, distinguished by whether or not the thorax is partly fulvous.

1. Mesothorax without fulvous markings, entirely black except for the white subtegular ridge; scape and pedicel of female whitish in front; range: Europe. . . . . . . . . . . . . 1a. pallipes pallipes (Holmgren)

Mesothorax more or less fulvous, at least the upper hind part of mesopleurum fulvous; scape and pedicel of female dark brown or partly light brown in front; range: Nearctic America . . . . 1b. pallipes strigis (Howard) 


\section{1a. Sinarachna pallipes pallipes (Holmgren), new combination}

Polysphincta pallipes Holmgren, 1860, Svenska Vetensk.-Akad. Handl., ser. 4, vol. 3 , part 10, p. 33; $\sigma^{7}$, + . Lectotype (hereby selected): $\uparrow$, from Stockholm, Sweden, labeled "Hlm.," "Bhn.," and "type" (Stockholm).

Polysphincta caudata Thomson, 1888, Opuscula entomologica, fasc. 12, p. 1253; .

New synonymy. Type: $\uparrow$, Rönnemölla, Scania, Sweden (Lund).

Biology: Nielsen, 1928, Entomologiske Meddelelser, vol. 16, pp., 152-155.

Scape and pedicel whitish in front; mesothorax entirely black except that subtegular ridge is white.

We studied a female of this species from Sweden, determined by A. Roman, and the types of pallipes and caudata. These differ from Nearctic material only a little in color as indicated in the key. Nielsen reared the subspecies in Denmark from Theridium lunatum, Epeira diademata, and E. quadrata, and described its early stages (loc. cit.).

\section{1b. Sinarachna pallipes strigis (Howard), new combination}

Polysphincta (Zatypota) strigis Howard, 1892, Proc. Ent. Soc. Washington, vol.

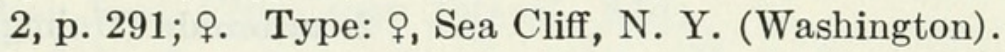

Differs from the European subspecies as noted in the key. The entire mesothorax and prothorax may be reddish fulvous, or only the mesopleurum, or only a posterodorsal area of the mesopleurum.

The cocoon of the type is cylindric, with rounded ends, $6 \mathrm{~mm}$. long by $2 \mathrm{~mm}$., of densely spun yellow-brown silk with a small amount of loose silk on the outside.

Specimens $\left(15 \sigma^{7}, 40\right.$ ) : From Alaska (Mount McKinley at 1,600 and 2,500 ft.); Alberta (Edmonton); British Columbia (Lillooet, Robson, shore of Shuswap Lake at Salmon Arm, and Vancouver); California (Fish Camp); Maine (Bar Harbor, Casco, and Machias); Michigan (Marquette Co.); New Hampshire (Dolly Copp Camp in the White Mts., Mount Madison, Pinkham Notch, and Randolph); New York (Ithaca, Lancaster, McLean Bogs Reserve in Tompkins

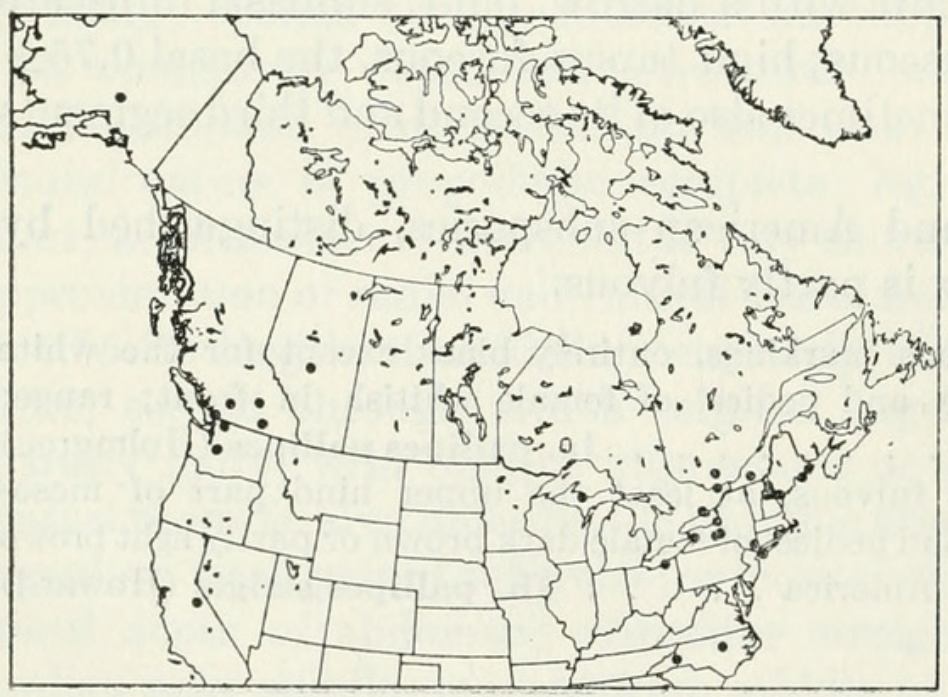

Figure 112.--Localities for Sinarachna pallipes strigis. 
Co., Oswego, Poughkeepsie, and Sea Cliff); North Carolina (Hamrick and Wake Co.); Ohio (Cleveland); Ontario (Trenton); Quebec (Hull, Kazabazua, and Knowlton); Rhode Island (Westerly); and Washington (Ashford, Glacier, and "Pelvis").

Most dates of capture are between June 26 and August 25. The only dates outside of this range are: May 17 at Lillooet, B. C.; May 25 at Sea Cliff, N. Y.; June 6 at Hull, Que.; and June 18 at Trenton, Ont. The type specimen was reared from Epeira strix by Nathan Banks at Sea Cliff, N. Y. The larva was found May 11, 1891, its cocoon was spun May 14, and the adult emerged May 25.

This American subspecies is transcontinental in the Transition, Canadian, and Hudsonian zones. Adults occur mostly from June 26 to August 25.

\section{Sinarachna anomala (Holmgren), new combination}

Figure 324 ,h

Polysphincta anomala Holmgren, 1860, Svenska Vetensk. Akad. Handl., ser. 4, vol. 3 , part 10, p. 34 ; . Lectotype (hereby selected): $\uparrow$, from Stockholm, Sweden, labeled "Hlm.," "Bhn.," and "type" (Stockholm).

Polysphincta dictynae Howard, 1888, Insect Life (U. S. Dep. Agr.), vol 1, p. 107;

$\sigma^{7}$. New synonymy. Type: $\sigma^{\top}$, [Waltham, Mass.] (Washington).

Polysphincta minuta Davis, 1898, Trans. Amer. Ent. Soc., vol. 24, p. 369;

Type: $\uparrow$, Michigan (Philadelphia).

Front wing of male 2.3 to $2.7 \mathrm{~mm}$. long, of female 2.8 to $3.3 \mathrm{~mm}$. long; body and legs very short and stout; flagellum of male with about 14 segments, of female with about 16 segments; third segment of hind tarsus about 2.0 as long as deep; third tergite about 0.55 as long as wide.

Blackish brown, with pale markings typically as follows: face and clypeus of male except near clypeal foveae, more or less of upper $0.35 \pm$ of face of female, apical half of clypeus of female, scape and pedicel except above, mouth parts, tegula, hind corner of pronotum,

Figure 113.-Localities for Sinarachna anomala.

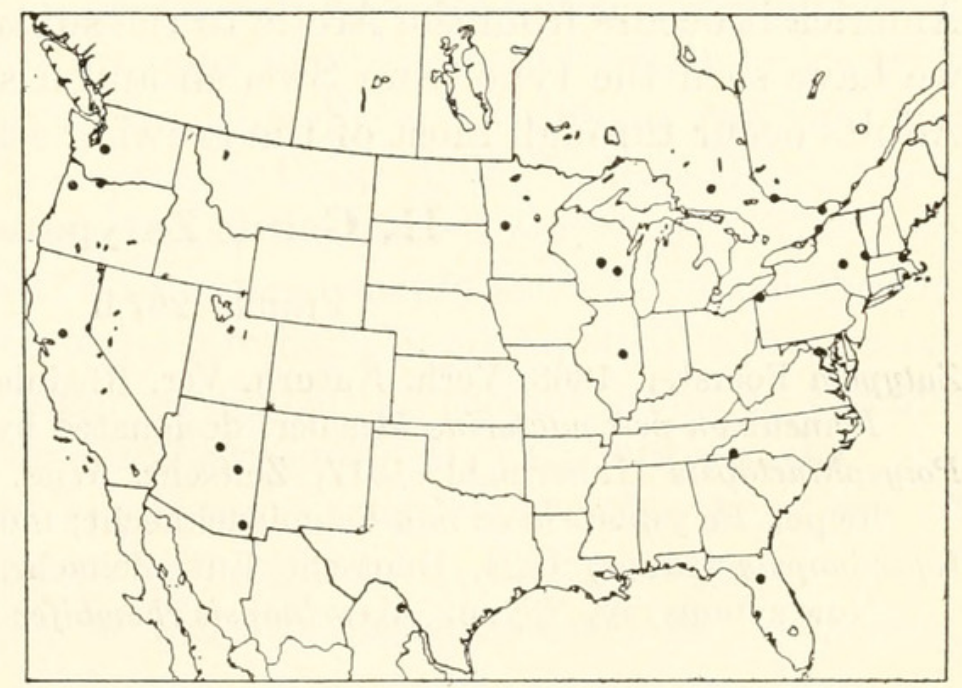


subtegular ridge, front and sides of mesoscutum connecting with long stripes along the notauli, scutellum, front and middle legs, and first five tergites except for their raised median areas, light yellowish stramineous; flagellum light brown basally beneath; hind leg light yellowish stramineous, the coxa brownish at base, the tibia brownish apically and the tarsus entirely brownish. The extent of pale markings varies considerably, and specimens from the far north may have the thorax and abdomen almost entirely blackish and the hind coxa basally blackish. The type of $P$. anomala is one of these dark-colored specimens. The adult is figured by Howard in his description of $P$. dictynae.

Howard (loc. cit.) describes the cocoon and a bit of the life history of the type specimen. The larva was found May 15, 1887, attached to the abdomen of a young Dictyna volupis. The spider was killed by the larva, and cocoon spinning began on May 18. The larva changed to a pupa on May 25 and emerged as an adult on June 1. The cocoon of the type is lost. It is no longer with the type specimen.

Specimens $\left(7 \sigma^{7}, 29\right.$ ) : From Alaska (Mount McKinley at 2,000 and 2,500 ft. and Shaw Creek at Mile 289 on the Richardson Highway); Arizona (Chiricahua Mts., Oak Creek Canyon, and Pocket Creek in the Sierra Ancha); California (Davis); Colorado; Florida (LevyWarburg Lake in Alachua Co.); Illinois (White Heath); Maryland (Cabin John and Takoma Park); Massachusetts (Waltham); Minnesota (Alexandria); New York (Johnsonville and Otsego Lake); North Carolina (Mount Pisgah at 4,800 to 5,000 ft.); Nova Scotia (Fountain Head); Ontario (Biscotasing, Gananoque, Ottawa, and Point Alexander); Oregon (Hood River and McMinnville); Pennsylvania (near Pond of Woods at Presque Isle in Erie Co.); Washington (Mount Rainier at 2,700 ft.); Wisconsin (Nekoosa and Green Lake Co.); and Mexico (Cuernavaca in Morelos).

The collecting dates are from mid-spring to August 30, and one specimen was taken September 6 at Johnsonville, N. Y.

This species is Holarctic and widespread, but uncommon. In North America it occurs from the Arctic to the subtropics. In the Old World we have seen the type from Sweden and a specimen from Palestine. Adults occur through most of the growing season.

\section{Genus Zatypota}

Figure 297,b

Zatypota Foerster, 1868, Verh. Naturh. Ver. Rheinlande, vol. 25, p. 166. Type: Ichneumon percontatorius Mueller; designated by Viereck, 1914.

Polysphinctopsis Habermehl, 1917, Zeitschr. Wiss. Ins.-Biol., vol. 13, p. 167. Type: Polysphincta eximia Schmiedeknecht; monobasic.

Lycorinopsis Haupt, 1954, Deutsche Ent. Zeitschr., new series, vol. 1, p. 110. New synonymy. Type: Lycorinopsis rhombifer Haupt; original designation. 
Front wing 2.5 to $5.5 \mathrm{~mm}$. long; eye bare; clypeus medium sized to large, weakly to sharply separated from face, weakly or moderately convex; epomia rather strong; mesoscutum polished to mat, usually almost bare or with a number of hairs on the front part of its median lobe, rarely covered with hairs except for median part of lateral lobes, which is almost or quite bare; notaulus long, usually sharp; prepectal carina complete, its upper end distant from front edge of mesopleurum; pleural carina complete; legs slender to rather stout; areolet absent; intercubitus 0.1 to 0.3 as long as second abscissa of cubitus, or almost obliterated by approximation of cubital and radial veins; nervulus postfurcal, or rarely interstitial, usually postfurcal by about 0.4 its length; discoidella present or absent; first tergite of moderate length; second to fourth tergites mat to polished, with long sparse hairs, with sharp oblique impressions or grooves which delimit a large median rhombic area on each; ovipositor sheath about 1.4 as long as apical depth of abdomen; ovipositor straight or its apical third weakly upcurved, with a median swelling apicad of which it is usually rather abruptly tapered, the point usually very long and slender (figs. $332, \mathrm{j}, \mathrm{k}$ ).

There are two rather distinct species groups in Zatypota, but because they are difficult to define we have not made formal use of them in the classification below. The first ten species treated below, plus an undescribed species from Brazil, constitute one group. In this, the lower end of the epomia turns posteriorly along the ventral swelling of the pronotum, the discoidella is often present, the propodeum mat, the petiolar area of propodeum usually not well defined basally, the lateral longitudinal carina of propodeum short, and the rhombic areas of tergites mat. The second group includes the last three species treated, five undescribed species from Brazil, Peru, India, Formosa, and the Philippines, the European Polysphincta discolor Holmgren 1860 and Polysphincta eximia Schmiedeknecht 1907, the Japanese Polysphincta japonica Uchida 1927, and the Ethiopian Zatypota prima Benoit 1953. The description of Lycorinopsis rhombifer Haupt 1954 indicates that it also belongs to the second group, but we have not seen specimens of it. This second group has the epomia straight and continuing across the lower swelling of pronotum, the discoidella never present, the propodeum polished or mat, the petiolar area of propodeum completely bounded by a sbarp carina, the lateral carina of propodeum long, and the rhombic areas on tergites sharply set off and polished or weakly mat. Were it not for a number of species with rather intermediate characters, one might recognize the second group as a genus or subgenus, with the name Polysphinctopsis. It happens that the most nearly intermediate species is percontatoria, the genotype of Zatypota. It could about as well be placed in either group.

We have seen the types of the Madagascan Zatypota inexpectata 
Seyrig 1932 and of the European Polysphincta picticollis Thomson 1888 and $P$. pulchrator Thomson 1877. These three belong in Zatypota, but our notes do not show to which species group. The specific names japonica Uchida and rhombifer Haupt, mentioned above, are new combinations in the genus Zatypota.

\section{Key to the Nearctic species of Zatypota}

1. Petiolar area of propodeum not completely enclosed by a strong carina and/or mesoscutum mat; propodeum entirely mat; discoidella often present . . 2

Petiolar area of propodeum completely enclosed by a strong carina and mesoscutum polished; propodeum often polished, at least on basal half; discoidella never present . . . . . . . . . . . . . . . . . 10

2. Lateral lobe of mesoscutum quite polished . . . . . . . . . . . . . 3

Lateral lobe of mesoscutum mat (with micro-reticulation) . . . . . . . 6

3. Mesosternum and mesopleurum largely or entirely fulvous . . . . . . . 4

Mesosternum and mesopleurum blackish . . . . . . . . . . . . . . . 5

4. Hind coxa ivory white, with a brown area basally above (fig. $324, \mathrm{j}$ ); hind femur ivory white with its base broadly brown and usually with a dorsolateral paler brown stripe in front and another behind (fig. 324,j); hind tibia with strong fuscous basal marking ... . . . . . . 2. parva (Cresson)

Hind coxa ivory white with a fulvous tinge basally, to almost entirely fulvous, without a basal brown area (fig. $324, \mathrm{k}$ ); hind femur ivory white to fulvous with its apex white, not broadly brown at base (fig. $324, \mathrm{k})$; hind tibia with faintly infuscate basal marking . . . . . 3. patellata, new species

5. Third tergite about 0.8 as long as wide, its median rhombic area strongly mat; nervulus opposite basal vein . . . . . . . 4. favosa, new species

Third tergite about 0.6 as long as wide, its median rhombic area moderately mat; nervulus distad of basal vein by about 0.5 its length.

5. exilis, new species

6. Median 0.4 of mesoscutum with uniformly dense hairs; ovipositor gradually tapered from its middle to apex, its apical 0.3 rather stout (fig. $332, \mathrm{j}$ ); discoidella present; clypeus stramineous apically.

1. bohemani (Holmgren)

Median 0.4 of mesoscutum with a few hairs anteriorly, elsewhere almost bare; ovipositor abruptly tapered just beyond the middle, its apical 0.3 very slender (fig. 332,k) . . . . . . . . . . . . . . . . . 7

7. Discoidella present, or rarely absent; clypeus either entirely blackish or mostly white . . . . . . . . . . . . . . . 8

Discoidella absent, or rarely present; clypeus blackish with its apical third stramineous or brown . . . . . . . . . . . . . . . . . . . . . . 9

8. Clypeus blackish; hind tibia fuscous on basal $0.12 \pm$ (fig. 325 ,b); temple weakly convex . . . . . . . . . . . . . 6. cingulata, new species

Clypeus white, infuscate basally; hind tibia whitish on basal $0.12 \pm$ (fig. $325, \mathrm{c}$ ); temple flat . . . . . . . . . 7. arizonica, new species

9. Hind tibia with a basal dark band; first trochanter of middle leg of female subcylindric, not specialized . . . . . . . 8. walleyi, new species

Hind tibia with a subbasal dark band, its basal $0.12 \pm$ whitish (fig. 325 ,d); first trochanter of middle leg of female triangularly produced below.

10. Frontal orbit and face entirely black . . . . . . . . . . . . 11

Frontal orbit and more or less of face white . . . . . . . . . . . . . 12 
11. First four segments of hind tarsus fuscous, more or less whitish at base (fig. $325, \mathrm{e})$; propodeum mostly mat . . . . . 10. percontatoria (Mueller)

First four segments of hind tarsus uniformly stramineous (fig. 325,f); propodeum mostly polished. . . . . . . . . . 11. luteipes, new species

12. Median rhombic area of second through fifth tergites black; hind femur about 3.8 as long as deep (fig. 325 ,g) . . . . . . . 12. crassipes, new species

Median rhombic area of second through fifth tergites entirely or partly white or whitish, the rest of these tergites black; hind femur about 5.0 as long as deep (fig. $325, \mathrm{~h}$ ) . . . . . . . . . . 13. alborhombarta (Davis)

\section{Zatypota bohemani (Holmgren)}

Figures $324, \mathrm{i} ; 332, \mathrm{j}$

Polysphincta Bohemani Holmgren, 1860, Svenska Vetensk.-Akad. Handl., ser. 4,

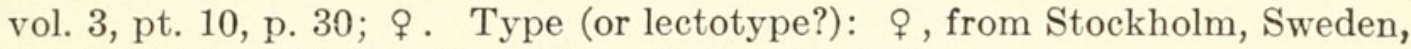
labeled "Hlm.," "Bhn.," and "type" (Stockholm).

Front wing of male 3.3 to $3.5 \mathrm{~mm}$. long, of female 3.8 to $4.0 \mathrm{~mm}$. long; mesoscutum strongly mat, with rather dense hairs all over except for a median longitudinal area on each lateral lobe, which is almost bare; metapleurum subpolished; propodeum strongly mat all over; petiolar area bounded laterally by the lateral longitudinal carinae, which are strong and sharp along the petiolar area but absent or abruptly obsolete basad of petiolar area; petiolar area bounded basally by a carina which is usually irregular and weak; median longitudinal carinae represented by ridges between petiolar area and base of propodeum, which vary from sharp and strong to almost obsolete; nervulus varying from almost opposite basal vein to distant from it by 0.25 its length; hind femur about 4.75 as long as deep; third segment of hind tarsus about 3.0 as long as deep; third tergite mat, its rhombic area more strongly mat, its grooves with fine irregularly longitudinal wrinkles; ovipositor gradually tapered from middle to apex, the apical 0.4 of ovipositor stouter than in any other species of the genus (fig. $332, \mathrm{j})$. Structure otherwise as described for $Z$. parva.

Head black. Rim of antennal socket and apical half of clypeus stramineous; basal half of clypeus brown; mouth parts, scape, and pedicel whitish, the scape and pedicel brown above; flagellum dark brown, paler below. Thorax fulvous. Propleurum except below, part of front part of pronotum, notal areas behind wing bases, and propodeum dark brown; tegula, subtegular ridge, hind corner of pronotum, anteroventral margin of pronotum, scutellum, postscutellum, front and middle coxae, and all trochanters, yellowish white; front and middle legs beyond trochanters very pale fulvous (or in the male nearer to yellowish white), the middle tibia and tarsus with a faint repetition of markings on hind tibia and tarsus; hind coxa of male yellowish white with a fulvous tinge; hind coxa of female and hind femur fulvous, the femur with a narrow, faint apical infusca- 
tion; hind tibia brown, its basal 0.15 stramineous and its median 0.33 stramineous except below; hind tarsus brown, the segments stramineous at base; abdominal tergites brown, their median rhombic areas darker brown.

Specimens: $0^{7}$, Vancouver, B. C., July 9, 1938, W. G. Mathers (Ottawa). ণ, Whitehall, Mont., July 11, 1917, H. G. Dyar (Washington). $\odot$, no data (Washington). $\%$, near Limassol, Cyprus, Nov. 15, 1946, Mavroumoustakis (Townes).

This species has been taken in British Columbia and Montana, and is widespread in Europe.

\section{Zatypota parva (Cresson)}

Figure 324,j

Glypta? parva Cresson, 1870, Trans. Amer. Ent. Soc., vol. 3, p. 155; ㅇ. Type: $\uparrow$, Illinois (Philadelphia).

Front wing of male 3.7 to $4.5 \mathrm{~mm}$. long, of female 3.7 to $5.0 \mathrm{~mm}$. long; clypeus rather narrow, a little projecting, sharply separated from face by a deep groove, its foveae deeply impressed; eye large, bulging; temple weakly convex; upper $0.6 \pm$ of epomia vertical, the ventral $0.4 \pm$ curved obliquely backward onto marginal swelling of pronotum; mesoscutum polished, with very sparse, scattered hairs, the hairs a little denser on front part of its median lobe; metapleurum polished; propodeum entirely mat but less strongly mat near base; median longitudinal carinae of propodeum lacking, or represented only by faint longitudinal ridges; lateral longitudinal carinae of propodeum present only on apical $0.2 \pm$ of propodeum; petiolar area of propodeum not distinctly defined basally; hind femur about 5.75 as long as deep; hair on upper side of hind tarsus about 0.8 as long as depth of tarsus; third segment of hind tarsus about 2.5 as long as deep; nervulus usually distad of basal vein by about 0.35 its length; discoidella always present, usually distinctly pigmented; third tergite polished, its grooves with fine longitudinal wrinkles and its rhombic area mat; ovipositor rather abruptly tapered from just basad of middle to apex, its apical 0.4 very slender.

Black. Rim of antennal socket light brown; mouth parts white; antenna dark brown, its scape and pedicel white except above and base of its flagellum whitish below; propleurum of male, often more or less of propleurum of female, anteroventral part of pronotum of male, often narrow anteroventral margin of pronotum of female, tegula, hind corner of pronotum, mesepimeron, much of prepectus of male, and indefinite spot on mesepisternum next to hind coxa, white or whitish; mesothorax fulvous, blackish near wing base; postscutellum 
and apex of scutellum stramineous; metapleurum fulvous, black, or intermediate in color; coxae and trochanters white, the hind coxa with a dorsobasal brown area; front leg beyond trochanters ivory to stramineous, the front femur of female brownish above; middle leg beyond trochanters stramineous, the femur with an anterodorsal and posterodorsal, indefinite, light-brown stripe, the tibia and tarsus with a faint repetition of the color pattern of the hind tibia and tarsus; hind femur ivory white, with a more or less definite, indistinctly margined, broad, brownish, anterodorsal stripe, and often a similar but paler and smaller posterodorsal stripe; base of hind femur brown, more broadly brown above; hind tibia whitish, its basal and apical thirds fuscous, its basal brown mark often partly subdivided into narrow basal and subbasal fuscous rings; hind tarsus fuscous, the basal 0.4 of its basitarsus whitish; second through fourth tergites usually brownish basally.

Specimens( $12 \sigma^{\top}, 32$ ) : From Connecticut (Voluntown); Illinois; Massachusetts (Holliston, Humarock, and Nantucket); Michigan (Manistee Co. and Midland Co.); New Jersey (Moorestown); New York (Bolton, Farmingdale, and Poughkeepsie); North Carolina (Crabtree Meadows in Yancey Co. at 3,600 ft. and Hamrick); Quebec (St. Esprit); Rhode Island (Westerly); and Wisconsin (Dane Co.).

Most collection dates are from August 2 to September 1. Records outside of this span are: July 2 at Holliston, Mass., and at Humarock, Mass.; July 16 in Dane Co., Wis.; September 16, 17, and 21 in Dane Co., Wis., and September 29 in Midland Co., Mich.

This species occurs in the Alleghanian fauna. Adults occur mostly in August. We have collected it in and along the borders of deciduous woods.
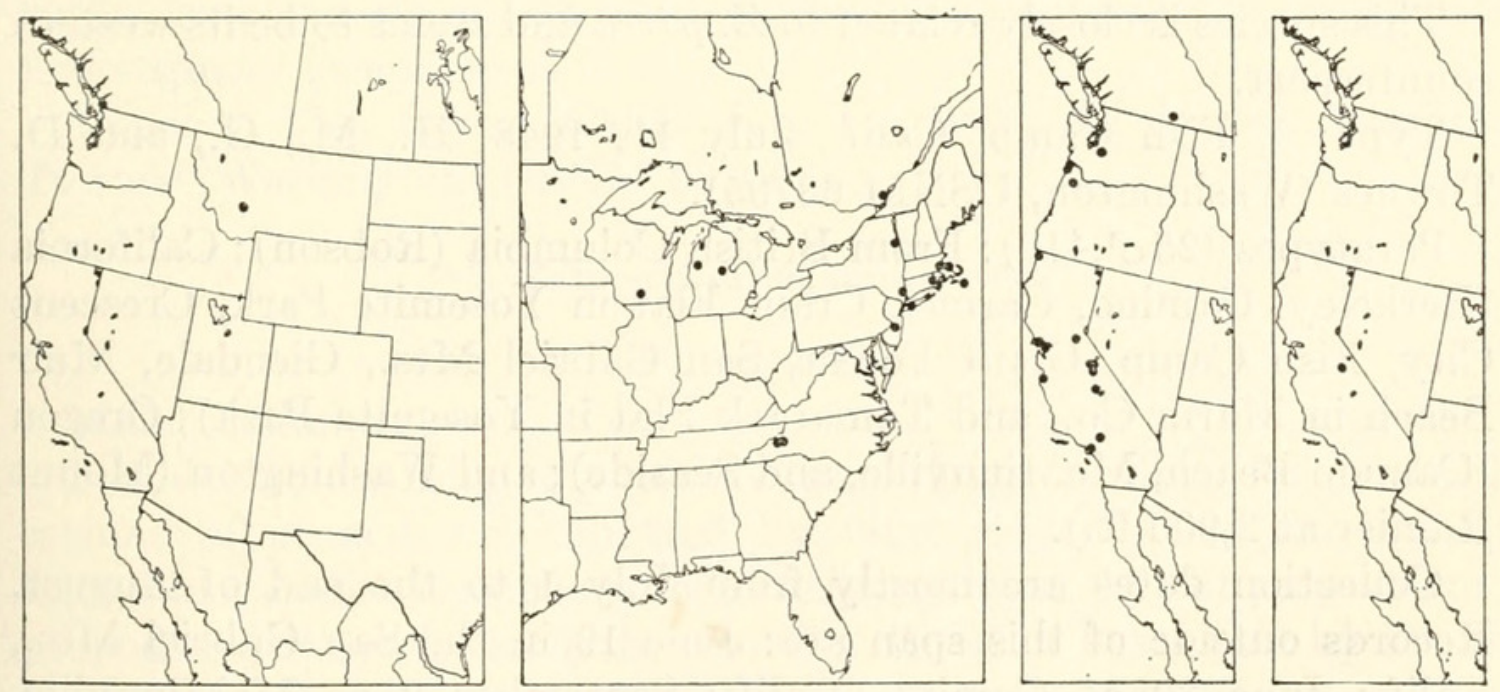

Figures 114-117.-Localities: 114 (left), Zatypota bohemani; 115 (center, left), Z. parva; 116 (center, right), Z. patellata; 117 (right), Z. favosa. 


\section{Zatypota patellata, new species}

FIGURE $324, \mathrm{k}$

Front wing of male 3.5 to $4.3 \mathrm{~mm}$. long, of female 3.5 to $5.5 \mathrm{~mm}$. long; nervulus varying from opposite basal vein to distad of it by about 0.25 its length; discoidella present or absent, usually absent in smaller specimens, very weak in medium-sized specimens, and rather weak but pigmented in larger specimens. Otherwise structurally indistinguishable from $Z$. parva.

Black. Rim of antennal socket and apex of clypeus light brown; mouth parts, scape and pedicel except above, tegula, subtegular ridge, hind corner of pronotum, propleurum of male, usually part of propleurum of female, anteroventral part of male pronotum, often some of anteroventral margin of female pronotum, much of hinder part of pronotum of male, most of mesepimeron, most of prepectus of male, and small indefinite mark on mesepisternum next to middle coxa, white or whitish; flagellum blackish brown, its base whitish below; mesothorax, often much or most of pronotum, postscutellum, and metapleurum, fulvous; front and middle coxae and all trochanters white; front and middle legs beyond trochanters whitish in male, stramineous or pale fulvous in female; hind coxa of male whitish, tinged with fulvous basally; hind coxa of female fulvous; hind femur fulvous, its apex white; hind tibia white, its basal third usually tinged with pale brown, especially below, its apical 0.3 fuscous, the fuscous a little more extensive below and less extensive above; hind tarsus brown, the apex of the segments darker and the basal 0.3 of the basal segment almost white.

The cocoon is elongate elliptic, yellowish white, and made of an open mesh of rather regularly looped, coarse silk.

This species is closely related to $Z$. parva and seems to be its western counterpart.

Type: ㅇ, Fish Camp, Calif., July 11, 1948, H., M., G., and D. Townes (Washington, USNM 63705).

Paratypes $\left(25 \sigma^{7}, 41\right.$ \%): From British Columbia (Robson); California (Berkeley, Camino, Carmel, Crane Flat in Yosemite Park, Crescent City, Fish Camp, Giant Forest, San Gabriel Mts., Glendale, Muir Beach in Marin Co., and Tamarack Flat in Yosemite Park); Oregon (Cannon Beach, McMinnville, and Seaside) ; and Washington (Mount Rainier at 2,900 ft.).

Collection dates are mostly from July 1 to the end of August. Records outside of this span are: June 19 in the San Gabriel Mts., Calif.; June 30 at Camino, Calif.; September 2 at McMinnville, Oreg.; September 8 and "Oct." at Berkeley, Calif.; and September 14 at Carmel, Calif. 
There are three reared specimens as follows: $\sigma^{x}$, reared from ichneumonid larva found in web with dead theridiid spider, Glendale, Calif., found Sept. 14, 1943, emerged Sept. 22, 1943, E. I. Schlinger. $\sigma^{x}$, reared from larva on abdomen of small theridiid spider, Glendale, Calif., April 1942, E. I. Schlinger. ㅇ, reared from larva on spider, collected Mar. 14, 1954, cocoon spun March 16, emerged Mar. 28, 1954, Muir Beach, Marin Co., Calif., H. B. Leach.

This species occurs in British Columbia and the Pacific States, mostly in the Transition zone. It is found among dense vegetation in damp places. Adults occur mostly in July and August.

\section{Zatypota favosa, new species}

Figure 324,1

Male: Unknown.

Female type: Front wing $3.2 \mathrm{~mm}$. long; temple moderately convex; metapleurum subpolished; front half of median lobe of mesoscutum rather densely hairy; propodeum mat, without carinae or ridges except for a remnant of the lateral longitudinal carina on its apical 0.12 ; nervulus opposite basal vein; third tergite about 0.8 as long as wide, strongly mat, apicad of its apical transverse groove weakly mat to subpolished, in the transverse grooves with a tendency toward fine longitudinal wrinkling. Structure otherwise as described for Z. parva.

Black. Scape and pedicel below, mouth parts, tegula, subtegular ridge, narrow hind corner of pronotum, front and middle coxae, and all trochanters, white or whitish; mesothorax with a reddish brown tinge; front and middle legs beyond trochanters stramineous; hind coxa, femur, and tibia medium brown, the tibia with a narrow subbasal band and its apical third dark brown; hind tarsus brown, its first segment stramineous basally.

Type: ㅇ, Fish Camp, Calif., July 14, 1948, H., M., G., and D. Townes (Washington, USNM 63706).

\section{Zatypota exilis, new species}

Figure 325 , a

Male: Unknown.

Female: Front wing 3.3 to $3.7 \mathrm{~mm}$. long; median longitudinal carinae of propodeum indicated by faint ridges on its basal 0.7 ; lateral longitudinal carinae present only on apical 0.25 of propodeum; propodeum otherwise smooth; nervulus distad of basal vein by about 0.5 its length; third tergite about 0.6 as long as wide, rather weakly mat, subpolished apicad of apical transverse carina. Structure otherwise as described for $Z$. parva. 
Coloration as in $Z$. favosa except that the hind legs are a little paler brown and that the brownish tinge on the mesothorax is absent or indistinct.

Type: $\odot$, Pinkham Notch, N. H., Aug. 23, 1951, H., M., and D. Townes (Washington, USNM 63707).

Paratype: ㅇ, Stoneham, Que., June 21, 1938, H. and M. Townes (Townes).

\section{Zatypota cingulata, new species}

Figure 325 ,b

Front wing of male 3.2 to $4.4 \mathrm{~mm}$. long, of female 3.7 to $4.4 \mathrm{~mm}$. long; clypeus unusually narrow; mesoscutum mat; metapleurum subpolished; propodeum strongly mat; hind femur about 4.7 as long as deep; nervulus usually distad of basal vein by about 0.3 its length; third tergite strongly mat, its apical margin subpolished, its grooves with fine longitudinal wrinkling. Structure otherwise as described for Z. parva.

Black. Lower rim of antennal socket usually brown; mouth parts, scape and pedicel below, tegula, subtegular ridge, and hind corner of pronotum, white; flagellum whitish basally below; front and middle coxae and all trochanters, ivory; front and middle legs beyond trochanters stramineous but in male their femora ivory; hind coxa ivory to fulvous, usually pale fulvous basally and ivory apically, sometimes brownish near base; hind femur varied with ivory and stramineous, brownish at base; hind tibia white, its basal and apical $0.3 \pm$ infuscate, the basal 0.3 often only weakly infuscate or brownish; hind tarsus brown, the segments darker at apex and pale basally; second through fifth tergites usually whitish to light brown basad of basal transverse groove.
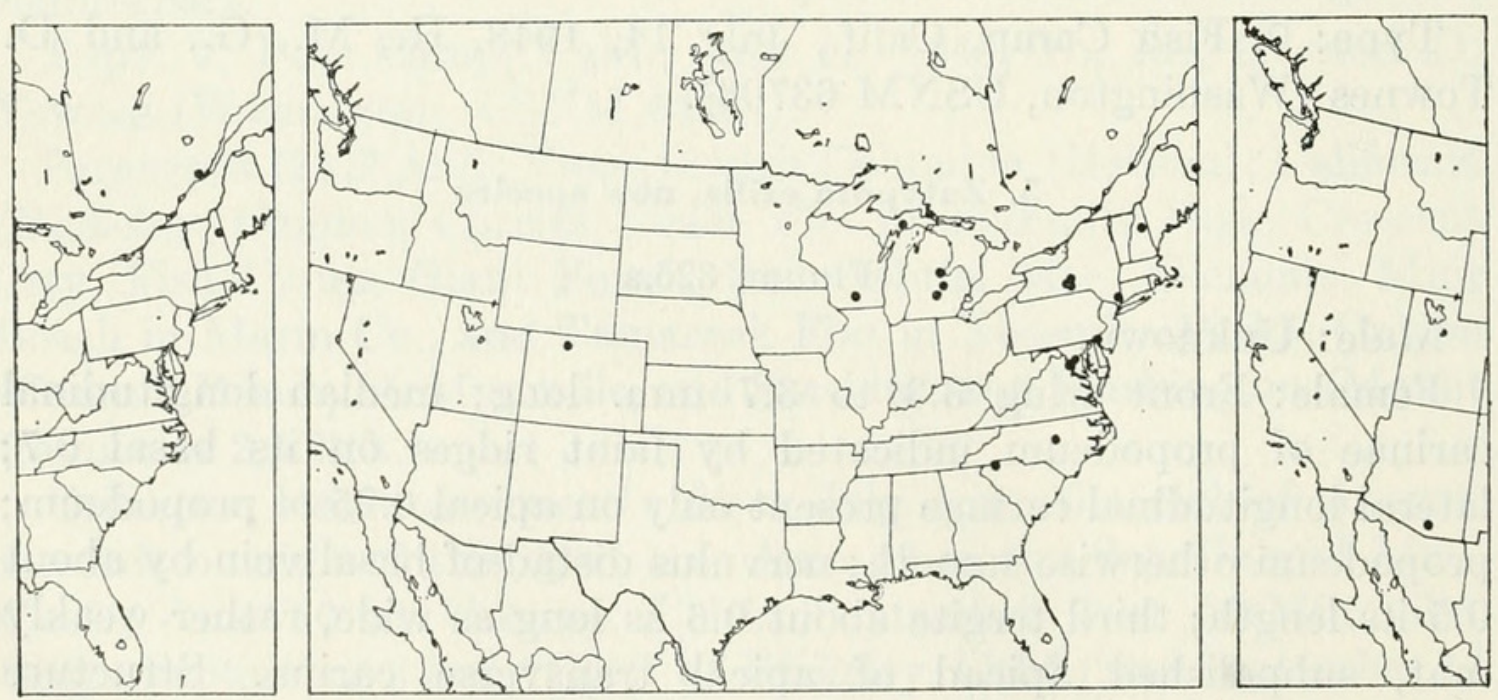

Figdres 118-120.-Localities: 118 (left), Zatypota exilis; 119 (center), Z. cingulata; 120 (right), Z. arizonica. 
In the material at hand there are four cocoons from which adults have emerged. These are very similar to the cocoons of $Z$. nigriceps but seem to have a weave that is a little closer and more regular.

Type: \&, Wilmington, Del., July 31, 1951, D. F. Bray (Washington, USNM 63708).

Paratypes: $\sigma^{\Upsilon}$, Steamboat Springs, Colo., Aug. 5, 1948, H., M., G., D., and J. Townes (Townes). $\sigma^{7}$, Wilmington, Del., July 24, 1951, D. F. Bray (Washington). ๑, Glen Echo, Md., R. M. Fouts (Washington). \&, East Lansing, Mich., June 5, 1937 (East Lansing). $0^{7}$, Genesee Co., Mich., Sept. 20, 1956, R. R. Dreisbach (Dreisbach). $\sigma^{7}$, Midland Co., Mich., June 24, 1952, R. R. Dreisbach (Dreisbach). ㅇ, Schoolcraft Co., Mich., Aug. 24, 1952, R. R. Dreisbach (Dreisbach). $\sigma^{7}$, reared from Abies balsamea foliage infested with Adelges, "F'ton," N. B., June 26, 1948, N. R. Brown (Ottawa). क, reared from Abies balsamea foliage infested with Adelges, McNamee, N. B., July 27, 1947, N. R. Brown (Ottawa). $2 \sigma^{7}$, Pinkham Notch, N. H., Aug. 23, 1951, H., M., and D. Townes (Townes). ค, Ithaca, N. Y., July 26, 1889 (Ithaca). $0^{x}$, McLean Bogs Reserve, Tompkins Co., N. Y., July 14, 1947 (Ottawa). ㅇ, Poughkeepsie, N. Y., July 19, 1936, H. Townes (Townes). $\sigma^{7}$, Slaterville, N. Y., July 11, 1936 (Townes). क, Wake Co., N. C., Apr. 23, 1950, H. and M. Townes (Townes). $\sigma^{7}$, Truro, Nova Scotia, July 26, 1913, R. Matheson (Ithaca). ণ Point aux Pines, Ont., Aug. 1, 1941, H. S. Parish (Townes). ㅇ, near Tigerville, S. C., May 8, 1944, H. and M. Townes (Townes). \&, reared from cocoon on bark of Pinus virginiana, Falls Church, Va., cocoon collected May 25, 1917, adult emerged May 29, 1917, A. B. Champlain (Washington). $\sigma^{7}$, Dane Co., Wis., Oct. 10, 1951, L. K. Smith (Madison).

This species occurs in eastern North America, in the Canadian, Transition, and Upper Austral zones. Adults have been collected throughout the growing season.

\section{Zatypota arizonica, new species}

FiguRe 325 ,c

Male type: Front wing $4.7 \mathrm{~mm}$. long; temple quite flat; mesoscutum strongly mat; petiolar area of propodeum bounded by an evenly curved carina which is strong laterally but weak and almost interrupted dorsally; lateral longitudinal carina of propodeum continued basad of petiolar area for a distance equal to 0.15 the length of propodeum; propodeum without carinae or ridges except as described; hind femur 5.0 as long as deep; nervulus distad of basal vein by the width of the basal vein; third tergite mat, its rhombic area more strongly so, its grooves with fine irregular longitudinal wrinkles. Structure otherwise as described for Z. parva. 
Black. Rim of antennal socket narrowly brown; clypeus white, its base brownish; mouth parts, scape, and pedicel except above, tinge on base of flagellum below, tegula, subtegular ridge, hind corner and anteroventral part of pronotum, propleurum, lateral and anterolateral edge of mesoscutum broadly, narrow stripe on inner margin of lateral lobe of mesoscutum, margin and apex of scutellum, postscutellum, much of prepectus, spot on mesopleurum next to middle coxa, mesepimeron, coxae, trochanters, and front and middle femora, white or whitish; mesothorax and metathorax fulvous; propodeum fulvous, infuscate apically and basally; front and middle tibiae and tarsi light brown, the tibiae whitish above, somewhat darker brownish apically; hind femur light fulvous, whitish at apex and below; hind tibia whitish, brown below, on the apical 0.3 , and in a narrow subbasal band; hind tarsus fuscous, the first segment stramineous at base; second through fifth tergites narrowly light brown at base.

Female: Unknown.

Type: $\sigma^{7}$, Santa Rita Mts., Ariz., Aug. 18, 1935, R. H. Beamer (Lawrence).

\section{Zatypota walleyi, new species}

Front wing of male 3.1 to $3.5 \mathrm{~mm}$. long, of female 3.5 to $4.4 \mathrm{~mm}$. long; mesoscutum uniformly mat; metapleurum subpolished; propodeum uniformly mat, its petiolar area not defined, its median longitudinal carinae indicated by faint rounded ridges which extend about 0.7 its length, its lateral longitudinal carina sharp on its apical third and represented more basad by a low rounded ridge; hind femur about 4.9 as long as deep; nervulus distad of basal vein by about 0.5 its length; discoidella always absent; nervellus a little inclivous; third tergite mat, less strongly mat apicad of apical transverse groove, its grooves with short, fine, longitudinal wrinkling. Structure otherwise as described for Z. parva.

Colored like $Z$. nigriceps except that the hind femur is fulvous with only a faint apical infuscation and that the entire basal third of hind tibia is more or less brown, usually dark brown at base of tibia and becoming paler toward apex of the brown area.

Type: $\odot$, Sweetsburg, Que., July 7, 1936, G. S. Walley (Ottawa).

Paratypes: ㅇ, Casco, Maine, Aug. 12, 1944, J. C. Bradley (Ithaca). $\sigma^{\Upsilon 7}$, Otsego Co., Mich., July 4, 1953, R. R. Dreisbach (Dreisbach). ㅇ, Holliston, Mass., N. Banks (Cambridge). \&, Georgetown, Ont., Sept. 1, 1893 (Ottawa). क, Lucknow, Ont., July 13, 1951 (Ottawa). $\sigma^{\top}$,, , Aylmer, Que., July 4 and 18, 1924, C. H. Curran (Ottawa). 


\section{Zaiypota nigriceps (Walsh)}

FigURE $325, \mathrm{~d} ; 332, \mathrm{k}$

Polysphincta nigriceps Walsh, 1873, Trans. Acad. Sci. St. Louis, vol. 3, p. 144; $\sigma^{7}$, . Types: $\sigma^{\top}$, $q$, ?Illinois (destroyed in Chicago fire of 1871).

?Polysphincta nigrita Walsh, 1873, Trans. Acad. Sci. St. Louis, vol. 3, p. 144; $\sigma^{7}$. Type: $\sigma^{7}$, ?Illinois (destroyed in Chicago fire of 1871).

Clistopyga nigrocephala Davis, 1898, Trans. Amer. Ent. Soc., vol. 24, p. 369; ه্ . Type: శా, Illinois (Philadelphia).

Polysphincta (Zatypota) braucheri Cushman, 1920, Proc. U. S. Nat. Mus., vol. 58, p. $33 ; \sigma^{7}$,. Type: + , Douglas Lake, Mich. (Washington).

Polysphincta (Zatypota) californiensis Cushman, 1920, Proc. U. S. Nat. Mus., vol. 58, p. 34; . Type: , Santa Cruz Mts., Calif. (Washington).

Polysphincta (Zatypota) crosbyi Cushman, 1920, Proc. U. S. Nat. Mus., vol. 58, p. $35 ; \sigma^{\top}$, . Type: $\subsetneq$, Oswego, N. Y. (Washington).

Front wing of male 2.7 to $4.0 \mathrm{~mm}$. long, of female 2.5 to $4.5 \mathrm{~mm}$. long; eye a little smaller and less bulging than in $Z$. parva; temple moderately convex; mesoscutum strongly mat; metapleurum mat; propodeum strongly mat, its median longitudinal carinae represented by weak to strong ridges which extend about 0.65 its length; lateral longitudinal carina strong and sharp on apical 0.3 of propodeum, abruptly obsolete more basad; petiolar area of propodeum usually weakly and incompletely defined basally; first trochanter of middle leg of female with a large triangular projection below (this structure absent in other species of the genus); hind femur about 5.5 as long as deep; nervulus distad of basal vein by about 0.5 its length; discoidella absent or rarely present and weak; nervellus a little inclivous; third tergite strongly mat all over, in its grooves with a tendency toward fine longitudinal wrinkling. Structure otherwise as described for Z. parva.
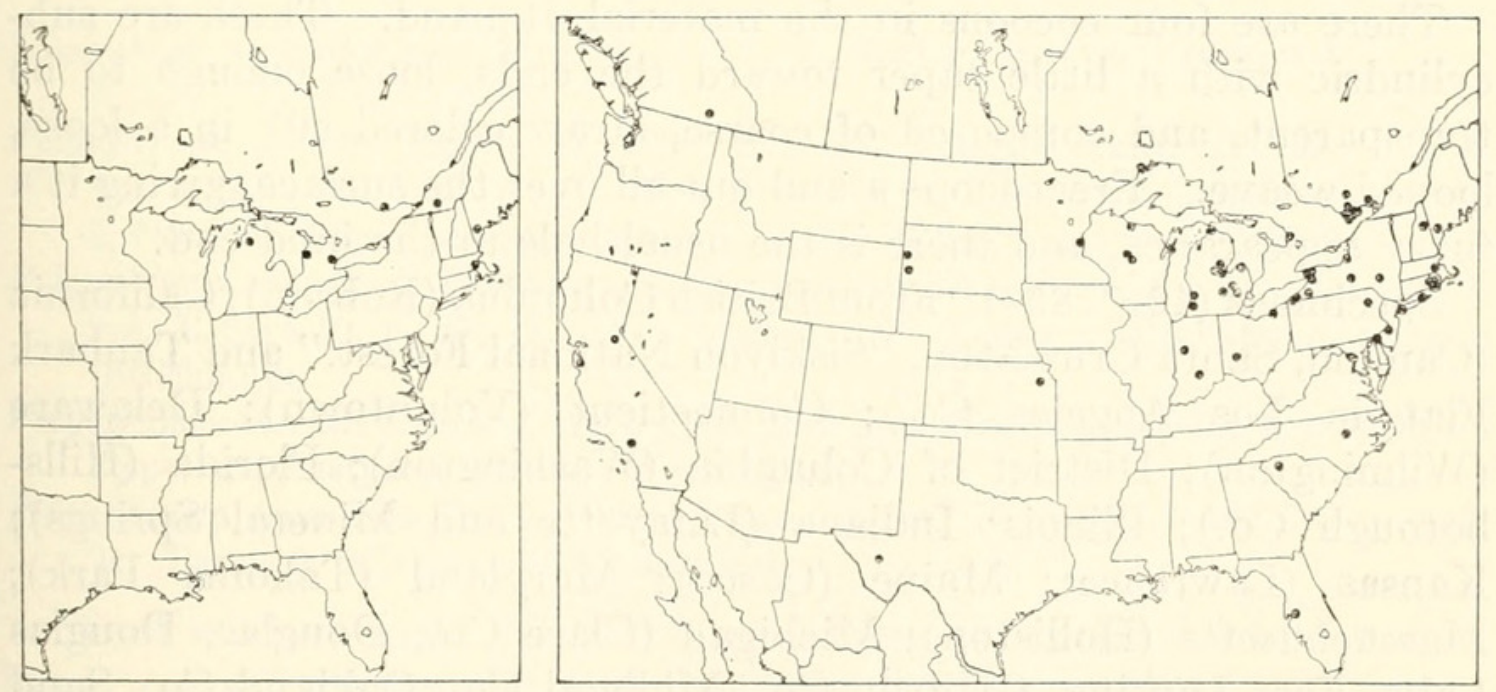

Figures 121, 122.-Localities: 121 (left), Zatypota walleyi; 122 (right), Z. nigriceps. 
Head black. Apical 0.3 of clypeus light brown or whitish; mouth parts, scape and pedicel except above, tegula, subtegular ridge, hind corner of pronotum, front and middle coxae, and all trochanters white or whitish; flagellum blackish brown, paler at base; thorax (except as noted above) varying from entirely fulvous to entirely blackish, commonly fulvous with the propodeum, front part of prothorax, and front part of mesoscutum dark brown, often the fulvous areas including brownish areas; front and middle legs beyond trochanters light fulvous; hind femur fulvous, with a preapical infuscation and its extreme apex stramineous; hind tibia stramineous with a broad subbasal band and its apical 0.35 fuscous; hind tarsus fuscous, its first segment pale brown at base; tergites entirely black to entirely fulvous, usually brown to blackish, paling to fulvous at base.

This species is very common. Though variable in color the banding on the hind femur and tibia is distinctive, and structurally the female is unique in having the first trochanter of the middle leg triangularly produced below. I am indebted to Mr. G. S. Walley for showing this very useful character.

Walsh's description of Polysphincta nigriceps, while not entirely consistent, describes the leg banding in enough detail to make it almost certain that this is the species he had. His description of $P$. nigrita, however, is more contradictory and his statements that the basal third of the hind tibia is dull rufous and that the first tergite is without oblique subapical grooves could not apply to $Z$. nigriceps. The tibial coloration is more like that of $Z$. walley $i$ while the absence of oblique subapical grooves is foreign to all known species of Zatypota. It must be that some of his observations were faulty. For want of a better disposition the name nigrita is left in synonymy under nigriceps, but with a question.

There are four cocoons in the material at hand. These are subcylindric with a little taper toward the ends, loose enough to be transparent, and composed of coarse, straw colored silk in a loose, looped weave. Erect loops stand out all over the surface, giving it a fuzzy appearance, and there is the usual hole in the hind end.

Specimens (42 $\sigma^{7}, 85$ \%): From British Columbia (Robson); California (Camino, Santa Cruz Mts., "Siskiyou National Forest," and Tanbark Flat in Los Angeles Co.); Connecticut (Voluntown); Delaware (Wilmington); District of Columbia (Washington); Florida (Hillsborough Co.); Illinois; Indiana (Lafayette and Mineral Springs); Kansas (Lawrence); Maine (Casco); Maryland (Takoma Park); Massachusetts (Holliston); Michigan (Clare Co., Douglas, Douglas Lake, East Lansing, Gladwin Co., Midland Co., Oakland Co., Sand Point in Huron Co., Shiawassee Co., and Van Buren Co.); Minnesota (Chisago Co.); New Hampshire (Pinkham Notch); New Jersey 
(Moorestown); New York (Bemus Point, Farmingdale, Lancaster, McLean, Niagara Falls, Oneonta, Orient, Oswego, and Youngstown); North Carolina (Wake Co.); Nova Scotia (Aldershot and Waterville); Ohio (Cleveland and Montgomery Co.); Ontario (Bells Corners, Constance Bay, Dunrobin, The Narrows on Go Home Bay, Ottawa, and Thunder Bay Beach); Pennsylvania (DuPont, North East, and Presque Isle in Erie Co.); Prince Edward Island (Brackley Beach in Canadian National Park); Quebec (Deschenes, Gauvreau Lake, Gracefield, Lac Mercier, and La Trappe); Rhode Island (Ashaway, Charlestown, and Westerly); South Carolina (Greenville); South Dakota (Custer and Spearfish); Texas (Davis Mts.); and Wisconsin (Griffith State Nursery in Wood Co., Port Edwards, Sturgeon Bay in Door Co., and Trout Lake Nursery in Vilas Co.).

Most collecting dates are between June 23 and September 4. Those outside of this range are: February 1 in Hillsborough Co., Fla.; April 21 and 30 and May 4 at Greenville, S. C.; May 23 at Washington, D. C.; June 18 at Go Home Bay, Ont.; June 21 at La Trappe, Que.; September 17 and 19 in Midland Co., Mich.; September 28 at Youngstown, N. Y.; October 9, 10, and 11 at Greenville, S. C.; October 20 at Lawrence, Kans.; and November 7 at Takoma Park, Md.

One of the specimens was taken at light and four were reared from cocoons found on Alnus and Malus trees.

This species is transcontinental, mostly in the Transition and Upper Austral zones. Most adults are on the wing from late in June to early in September. It has been reared a number of times from cocoons found on deciduous trees and bushes.

\section{Zatypota percontatoria (Mueller)}

FiguRe 325 ,e

Ichneumon percontatorius Mueller, 1776, Zoologiae danicae prodromus . . . , p. 154. Type destroyed.

Polysphincta gracilis Holmgren, 1860, Svenska Vetensk.-Akad. Handl., ser. 4, vol. 3 , part 10, p. $32 ; \sigma^{7}$, + . New synonymy. Lectotype (hereby selected): , from Smolandia, Sweden, labeled "Sm.," "Bhn.," and "type" (Stockholm). Polysphincta scutellaris Holmgren, 1860, Svenska Vetensk.-Akad. Handl., ser. 4, vol. 3 , part 10, p. $33 ; \sigma^{\top}$. New synonymy. Type: $\sigma^{\top}$, Stockholm, Sweden (Stockholm).

Polysphincta theridii Howard, 1892, Proc. Ent. Soc. Washington, vol. 2, p. 292; ه'. Type: $\sigma^{7}$, Eastport, Maine. (Washington).

Polysphincta granulosa Davis, 1898, Trans. Amer. Ent. Soc., vol. 24, p. 369; +. Type: + , Michigan (Philadelphia).

Front wing of male 2.7 to $4.8 \mathrm{~mm}$. long, of female 3.4 to $5.0 \mathrm{~mm}$. long; eye a little smaller and less bulging than in $Z$. parva; temple moderately convex; epomia intermediate between that of $Z$. parva and $Z$. luteipes; mesocutum polished; metapleurum subpolished; propodeum mat, near base subpolished, its median longitudinal 
carinae present as strong sharp ridges from base to petiolar area; petiolar area an irregular hexagon, bounded laterally by very strong carinae, basally by weaker carinae which are often irregular or obsolescent; lateral longitudinal carina usually extending basad of petiolar area as a short spur; hind femur about 4.75 as long as deep; nervulus distad of basal vein by about 0.5 its length; discoidella absent; nervellus weakly inclivous; third tergite strongly mat, weakly mat apicad of apical transverse carina, its apical margin subpolished; grooves of third tergite with fine longitudinal wrinkling. Structure otherwise as described for Z. parva.

Black. Apical 0.3 of clypeus stramineous or light brown; scape and pedicel whitish to light brown, dark brown above; flagellum dark brown, paler at base; mouth parts, tegula, subtegular ridge, and hind corner of pronotum, white; thorax varying from entirely black (except for white areas as described) to fulvous with propodeum and front part of prothorax dark brown, often black with the scutellum fulvous and rest of mesothorax more or less fulvous; front and middle coxae and all trochanters whitish; front and middle legs beyond trochanters fulvous, the apex of the femora and upper part of tibiae white; hind coxa and femur fulvous, the femur with a weak subapical infuscation, its extreme apex whitish; hind tibia white, its apical 0.3 fuscous and often with a faint, narrow, subbasal fuscous band; hind tarsus fuscous brown, the segments light brown basally.

The type of percontatoria is lost, and it is quite impossible to recognize the species intended from the brief original description. The name is applied according to Gravenhorst's interpretation, as first reviser. The part of the Gravenhorst collection containing percontatoria was lost during World War II, but there seems to be no doubt about the species he identified as this.
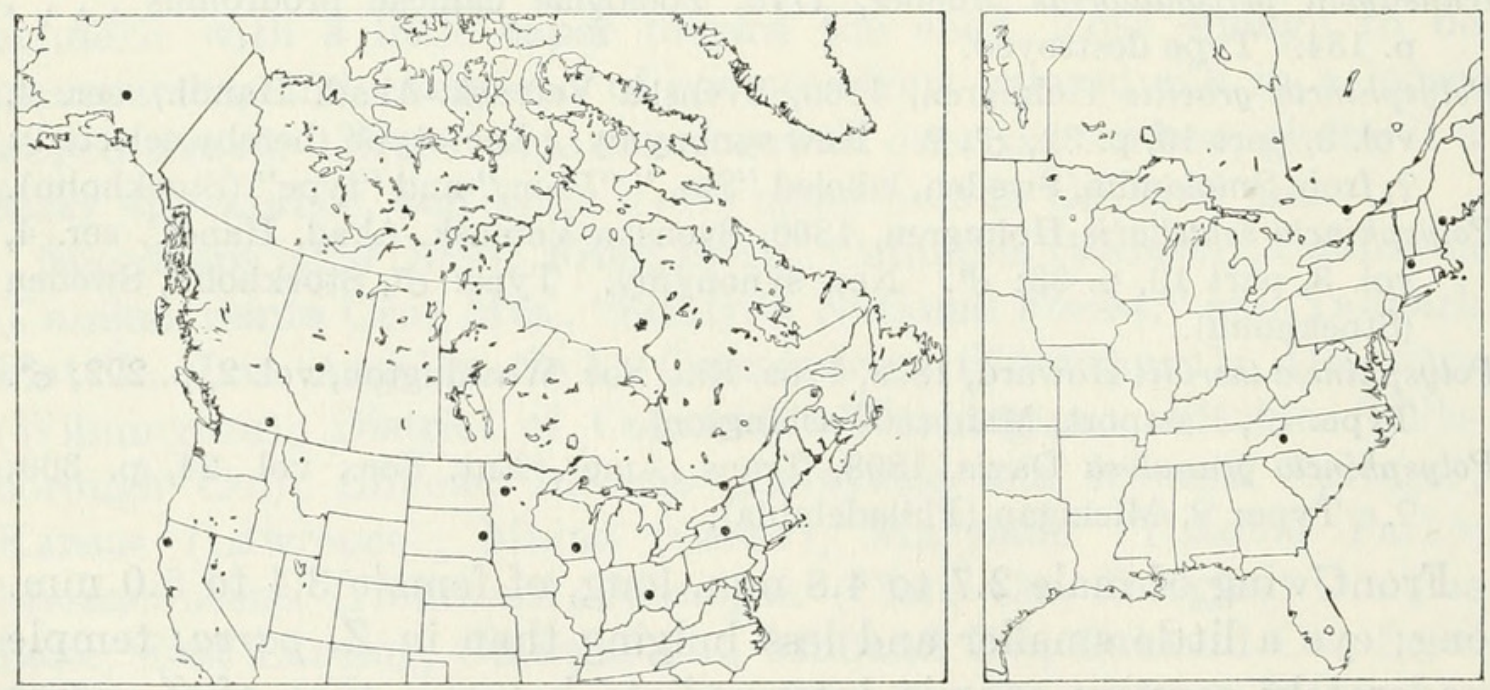

Figures 123, 124.-Localities: 123 (left), Zatypota percontatoria; 124 (right), Z. luteipes. 
Specimens (17 $\sigma^{\top}, 12$ ) ): From Alaska (Mount McKinley at 1,700 ft.); Alberta (Edmonton); British Columbia (Robson); California (Trinity Co.); Maine (Eastport); Michigan (Alger Co. and Keweenaw Co.); Minnesota (Itasca State Park); New York (Ithaca); Ohio (Montgomery Co.); Ontario (Bells Corners); Quebec (St. Jean River on the Gaspé Peninsula); South Dakota (Brookings); Washington (Naselle); Wisconsin (Madison); Ireland; England; Sweden; Germany; and Cyprus.

Collecting dates in America are in July and August, with the following exceptions: June 25 at Bells Corners, Ont.; September 1 at Edmonton, Alta.; "Sept." in Itasca State Park, Minn.; and October 12 in Montgomery Co., Ohio.

One specimen was reared from a cocoon found on an apple tree and one specimen was collected at light.

This species is transcontinental, and is widespread in Europe. It is mostly in the Canadian zone but has been taken also in the Hudsonian and Transition zones. Adults occur mostly in July and August.

\section{Zatypota luteipes, new species}

\section{Figure 325,f}

Front wing of male $3.7 \mathrm{~mm}$. long, of female 3.2 to $3.8 \mathrm{~mm}$. long; clypeus rather narrow, separated basally by a weak groove, not projecting apically from plane of face, its foveae deeply impressed; temple rather strongly convex; epomia vertical, straight, extending ventrally across marginal swelling of pronotum to its lower edge; mesoscutum polished, with a few hairs on front part of median lobe, elsewhere with almost no hairs; metapleurum polished; propodeum polished, weakly mat near its midlength; petiolar area bounded by strong carinae; median longitudinal carinae complete, moderately strong; lateral longitudinal carina extending basad from petiolar area to near spiracle; hind femur about 4.5 as long as deep; hair on upper side of hind tarsus about 1.5 as long as depth of tarsus; third segment of hind tarsus about 2.5 as long as deep; nervulus distad of basal vein by about 0.4 its length; discoidella absent; nervellus vertical; third tergite polished or subpolished, its grooves with short longitudinal wrinkles; ovipositor rather abruptly tapered from just basad of middle to apex, its apical 0.4 very slender.

Black. Apical half of clypeus and scape and pedicel except above, stramineous; mouth parts, tegula, subtegular ridge, and hind corner of pronotum, white; mesothorax mostly or entirely fulvous, sometimes the scutellum and two longitudinal lines on mesoscutum luteous; front and middle legs ivory, the apical 0.6 of middle tarsus brown; hind legs ivory, the second trochanter and elongate postmedian areas 
on front and back of femur, brown; basal and apical 0.3 of hind tibia and all of fifth tarsal segment, fuscous.

Type: ㅇ, Casco, Maine, Aug. 6, 1944, J. C. Bradley (Washington, USNM 63709).

Paratypes: + , Casco, Maine, Aug. 8, 1944, J. C. Bradley (Townes). $\sigma^{7}$, Cummington, Mass., Aug. 22 to 27, 1947, H. E. Evans (Ottawa). ㅇ, Crabtree Meadows, Yancey Co., 3,600 ft., N. C., Aug. 21, 1950, H., M., D., and J. Townes (Townes). क, Constance Bay, Ont., Aug. 9, 1933, G. S. Walley (Ottawa).

\section{Zatypota crassipes, new species}

Figure 325,g

Male: Unknown.

Female type: Front wing $4.5 \mathrm{~mm}$. long; clypeus wide and rather flat, weakly separated from face, a little impressed near the foveae; temple moderately convex; metapleurum subpolished; petiolar area of propodeum rather large, subcircular; hind femur about 3.8 as long as deep; third segment of hind tarsus about 1.9 as long as deep; nervulus distad of basal vein by about 0.3 its length; nervellus rather strongly inclivous; third tergite subpolished, its rhombic area quite polished, its grooves with short longitudinal wrinkles; ovipositor rather slender, rather uniformly tapered from middle to apex. Structure otherwise as described for Z. luteipes.

Head black. Orbital mark from lower third of face to top of eye and continued back behind hind ocellus, upper 0.4 of face, apical 0.6 of clypeus, cheek, and mouth parts, ivory; face, basal 0.4 of clypeus, and antenna brown. Thorax fulvous, the tegula, subtegular ridge, hind corner of pronotum, and broad anterolateral margin of mesoscutum, white; propodeum reddish brown. Legs ivory except as
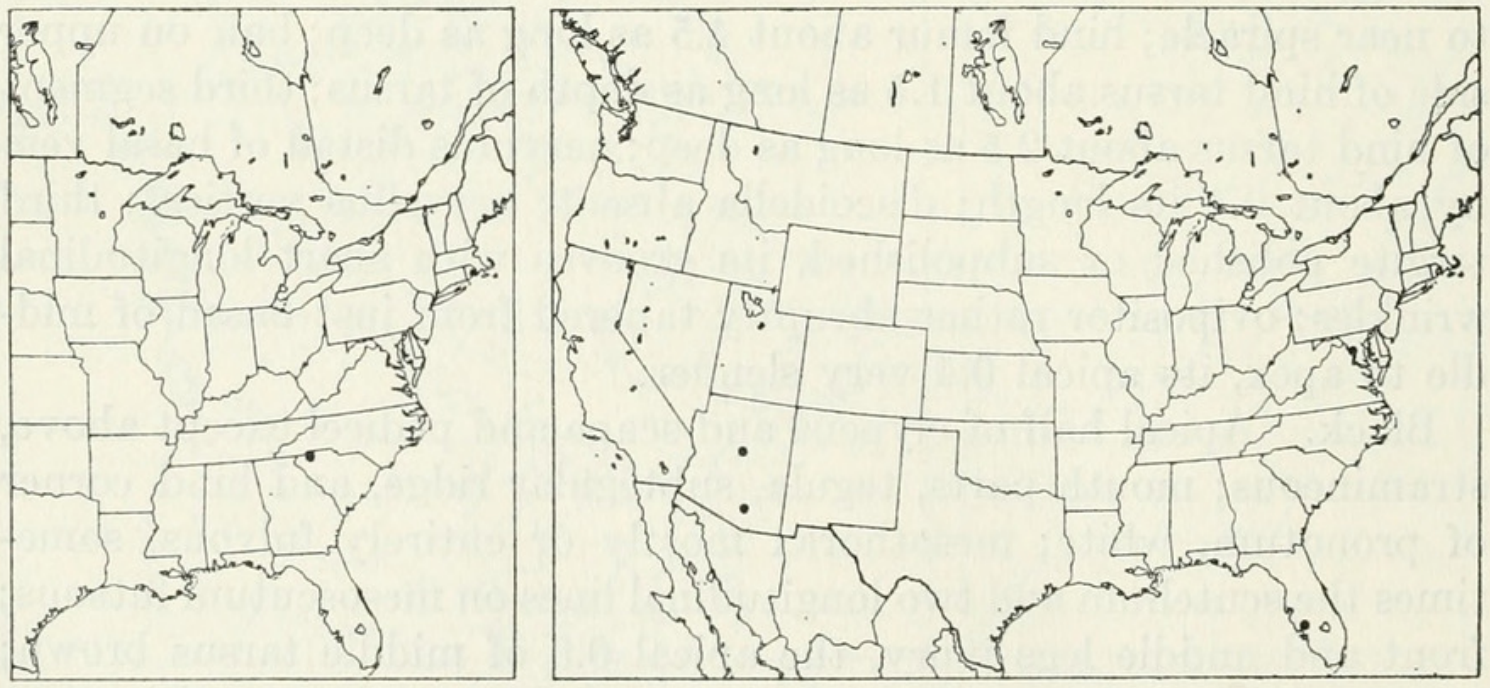

Figures 125, 126.-Localities: 125 (left), Zatypota crassipes; 126 (right), Z. alborhombarta. 
follows: front femur, tibia, and tarsus pale fulvous; middle femur, tibia, and tarsus with repetition in pale fulvous of dark markings on hind leg; hind femur basally and in postmedian irregular area on front and back sides, light reddish brown; hind tibia white, its basal and apical 0.3 dark brown, the basal brown mark containing a dorsal whitish stripe; hind tarsus dark brown, the basal 0.4 of its first segment medium brown. Abdomen black.

Type: + , Venus, Greenville Co., S. C., Oct. 4, 1941, H. and M. Townes (Washington, USNM 63710).

\section{Zatypota alborhombarta (Davis)}

Figure 325 , h

Clistopyga alborhombarta Davis, 1895, Ent. News, vol. 6, p. 198; . Type: \& , [Charlotte Harbor], Florida (Philadelphia).

Front wing of male 2.8 to $2.9 \mathrm{~mm}$. long, of female 3.8 to $4.0 \mathrm{~mm}$. long; clypeus a little narrower than in Z. crassipes; petiolar area of propodeum rather angular; hind femur about 5.0 as long as deep; third segment of hind tarsus about 3.0 as long as deep. Structure otherwise as described for Z . crassipes.

Black. Broad mark on side of frons and extending on occiput to behind lateral ocellus (expanded on occiput), face, clypeus, cheek, mouth parts, scape and pedicel except above, tegula, subtegular ridge, broad anterolateral part of mesoscutum, connecting pair of longitudinal stripes on mesoscutum, scutellum, postscutellum, lower part of prosternum and adjacent pronotum, and all or most of rhombic areas on second through fifth or sixth tergites, ivory; flagellum brown, whitish at base below; all or much of mesosternum and mesopleurum, often metapleurum, and sometimes lateral part of propodeum, fulvous; coxae and trochanters ivory, the hind coxa of female sometimes tinged with fulvous; front leg beyond trochanters pale fulvous, the apex of its femur white and the tibia with faint markings; middle leg beyond trochanters light fulvous, the femur white on apex and the tibia and tarsus with a pale repetition of the markings on hind leg; hind femur fulvous, its apex white, before the white apex faintly infuscate; hind tibia white, its basal and apical 0.3 fuscous; hind tarsus fuscous, its first segment stramineous or light brown basally.

Specimens: $\sigma^{7}$, Oak Creek Canyon, Ariz., May 20, 1947, H. and M. Townes (Townes). $\sigma^{7}$, Sabino Canyon, Ariz., Apr. 16, 1947, H. and M. Townes (Townes). o (type), Charlotte Harbor, Florida (Philadelphia). \&, Rosslyn, Va., July 11, 1913, R. C. Shannon (Washington). क, Peñas, Banderas Bay, Mexico, Nov. 15, 1937, Zaca Expedition (New York).

This appears to be a tropical species whose range extends into the southern United States, as far north as Virginia. 


\section{Tribe Ephialtini}

Figures 284; 298; 299,a

Front wing 2.5 to $25 \mathrm{~mm}$. long; clypeus usually a little swollen basally, flattened or concave apically, its apex truncate or with a median emargination; mesoscutum without transverse wrinkling, its notauli strong to obsolete; prepectal carina complete; mesopleural suture without an angulation near the middle or sometimes with a weak angulation; propodeal carinae varying from complete (in some Xanthopimpla) to absent, often represented only by short, basal, median longitudinal carinae (and the pleural carina); propodeal spiracle elongate; last segment of tarsus sometimes enlarged; tarsal claws large, in male simple, in female sometimes with a basal tooth, the claws in three extra-limital genera with an enlarged hair with a flattened tip; areolet present except in some Xanthopimpla; nervellus broken always above the middle; first tergite free from its sternite, its lateral carina usually strong; subgenital plate of male elongate, with an acute or rounded apical point, rarely truncate or medially emarginate; ovipositor stout, very short to moderately long, usually weakly decurved, its apex a little depressed; in one genus hooked downward at apex.

Members of this tribe in most parts of the world are among the commonest of all ichneumonids. These species are internal parasites of pupae, usually of exposed or semiexposed pupae of Lepidoptera. Species of Itoplectis are sometimes secondary parasites. The host range of an individual species is usually very wide and, since hosts of various sizes are attacked, the size of the parasite species varies enormously. Males average smaller than females, which is the result of the fact that an ovipositing female will usually lay a male (unfertilized) egg in a relatively small host and a female (fertilized) egg in a larger host. It appears that a relatively large host will stimulate the ovipositing parasite to open its spermatheca when the egg is laid so that it becomes fertilized, while a small host does not stimulate the parasite thus and receives an unfertilized egg which, as in most Hymenoptera, produces a male offspring. Oviposition is into pupae or prepupae. Emergence is always from the pupa. There is one parasite per pupa. Overwintering is in the host pupa, or rarely as an adult.

There are seven genera in the tribe. Xanthopimpla, Echthromorpha, Lissopimpla, and Strongylopsis are exotic so are not treated here. A key to all but Strongylopsis may be found in Townes (1940, Ann. Ent. Soc. America., vol. 38 , p. 288). The three genera occurring in the Nearctic region are keyed below. 


\section{Key to the Nearctic genera of Ephialtini}

1. Inner margin of eye weakly concave above antennal socket (fig. 299,a); face of male black; tarsal claws of female without a basal tooth.

3. Coccygomimus (p. 311)

Inner margin of eye rather strongly concave at antennal socket (fig. 298,a,b); face of male white, yellow, or black; front tarsal claws of female usually with a large tooth . . . . . . . . . . . . . . . . . . . . . . . . 2

2. Ovipositor straight; face and orbits of both sexes entirely black (at least in the Nearctic species) . . . . . . . . . . . . . 1. Itoplectis (p. 281)

Ovipositor hooked downward at tip (fig. 298,b); face of male largely or entirely white or yellow; orbit of female narrowly whitish in front. 2. Ephialtes (p. 302)

\section{Genus Itoplectis}

Figure 298,a

Itoplectis Foerster, 1868, Verh. Naturh. Ver. Rheinlande, vol. 25, p. 164. Type: Ichneumon maculator Fabricius; designated by Morley, 1913.

Nesopimpla Ashmead, 1906, Proc. U. S. Nat. Mus., vol. 30, p. 180. Type: Nesopimpla naranyae Ashmead; monobasic.

Exeristesoides Uchida, 1928, Journ. Fac. Agr. Hokkaido Univ., vol. 25, p. 51. Type: (Pimpla spectabilis Matsumura)=alternans spectabilis Matsumura; original designation.

Front wing 2.5 to $12.5 \mathrm{~mm}$. long; front tarsal claws of female usually with a tooth, the middle and hind claws of female and all claws of male simple. Similar otherwise to Ephialtes except as stated in the key.

This genus is almost worldwide but has relatively few species. They are parasitic mostly on lepidopterous pupae but some $(e . g ., I$. conquisitor) are sometimes secondary parasites on ichneumonoids and some (e.g., I. fustiger and I. clavicornis) seem to be normally secondary parasites. Adults occur among herbage, shrubbery, or trees. Unlike Coccygomimus and Ephialtes, most species of Itoplectis do not give off a strong odor when disturbed.

There are eight Nearctic species, as treated below. Some of these are among our most important general parasites of Lepidoptera.

Walkley (1958, U. S. Dep. Agr., Agr. Monogr., no. 2, 1st. suppl., p. 38) has recorded the establishment of the European Itoplectis maculator (Fabricius) 1775, in Marion Co., Oreg. Her record is based on an introduction to control Cnephasia longana. According to communications from Miss Walkley and Dr. R. G. Rosensteil, the main facts are as follows: Specimens of Cnephasia longana parasitized by $I$. maculator were received from Europe at Albany, Calif. The parasites were reared and adults released by Dr. Rosensteil at Salem, Oreg., in 1952 and at Canby, Oreg., in 1954. In 1955, Dr. Rosensteil reared 7 specimens of $I$. maculator from field collected larvae of C. longana. Identifications were made by Miss Walkley. 
This is a common species in Europe, and if permanently established may become an important parasite in America. Specimens will key to $I$. behrensii, which they resemble superficially, but may be distinguished from behrensii by the facts that the first trochanters are fuscous and yellowish rather than fulvous and yellowish, and the under side of the flagellum is yellowish rather than fuscous.

\section{Key to the Nearctic species of Itoplectis}

1. Hind tibia uniformly fulvoferruginous; coxae and first trochanters black (fig. $325, \mathrm{k}$ ) . . . . . . . . . . . 3. viduata (Gravenhorst)

Hind tibia white in or near the middle, black or blackish at base and apex; coxae and first trochanters usually fulvous but sometimes partly or entirely black . . . . . . . . . . . . . . . . . . . . . . 2

2. Flagellum clavate, the subapical segments fully as wide as long; middle tibia and tarsus white . . . . . . . . . . 7. fustiger, new species

Flagellum linear, not or sligbtly thickened apically, the subapical segments longer than wide; middle tibia and tarsus white banded with darker, or rather uniformly fulvous ..... . . . . . . . . . . . . 3

3. Median longitudinal carinae of propodeum extending about 0.7 its length; third through fifth tergites with very strong swellings and depressions; ovipositor sheath about 0.9 as long as first tergite; front claws of female without a median tooth . . . . . . 8. curticauda (Kriechbaumer)

Median longitudinal carinae of propodeum extending about 0.3 to 0.5 its length; third through fifth tergites with moderate swellings and depressions; ovipositor sheath 1.1 to 3.8 as long as first tergite; front claws of female usually with a median tooth . . . . . . . . . . . . . . . . . . . . 4

4. Tergites with a distinct white band on hind margin; abdomen narrower (third tergite of male about 1.0 as wide as long, of female about 1.6 as wide as long); fourth and fifth tergites of male polished and with well-separated punctures.

2. conquisitor (Say)

Tergites without a distinct pale band along hind margin, or if such bands are present they are tan rather than whitish; abdomen broader (third tergite of male about 1.8 as wide as long, of female about 2.1 as wide as long); fourth and fifth tergites of male mat and with crowded punctures . . . . . . 5

5. Temple rather strongly convex; face unusually wide; ovipositor sheath about 3.6 as long as first tergite; front tarsal claws of female without a tooth; ovipositor distinctly decurved ......... 4. evetriae Viereck

Temple rather weakly convex; face of moderate width; ovipositor sheath about 2.4 as long as first tergite; front tarsal claws of female with a tooth except in most specimens of I. vesca . . . . . . . . . . . . . . . . . 6

6. Tergites 2-7 ferruginous laterally; coxae blackish, pale at extreme apex; front tarsal claws of female with a small, acute median tooth.

5. behrensii (Cresson)

Tergites 2-7 entirely black except for paler apical margins; coxae fulvous to black; front tarsal claws of female each with a large tooth, a very small tooth, or without a tooth . . . . . . . . . . . . . . . . 7

7. Middle and hind first trochanters entirely fulvous; notaulus absent; front tarsal claws of female with a broad postmedian tooth.

1. quadricingulata (Provancher)

Middle and hind first trochanters largely or entirely fuscous; notaulus present but weak; front tarsal claws of female with a minute median tooth or without a tooth ............. 6. vesca, new species 


\section{Itoplectis quadricingulata (Provancher)}

Figures 284,b; 325,i

Pimpla 4-cingulatus Provancher, 1881, Naturaliste Canadien, vol. 12, p. 38

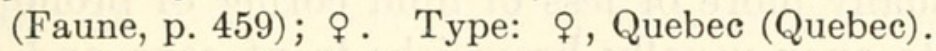

Pimpla (Itoplectis) Kolthoffi Aurivillius, 1890, Bih. Svensk. Vetensk.-Akad. Handl., vol. 15, p. 29; $\sigma^{x}$, + . Lectotype (hereby designated): $\sigma^{\top}$, labeled “Nunasarnausak, June 19 to 20, Nordskj. Exped., 83," Greenland (Stockholm).

Itoplectis obesus Cushman, 1917, Proc. U. S. Nat. Mus., vol. 53, p. 467; ه⿱一 , .

Type: + , Wenatchee, Wash. (Washington).

Ephialtes (Itoplectis) latus Cushman, 1920, Proc. U.S. Nat. Mus., vol. 58, p. 345;

․ Type: $q$, Albee, Oreg. (Washington).

Ephialtes (Itoplectis) leavitti Cushman, 1920, Proc. U. S. Nat. Mus., vol. 58, p. 345 ; ㅇ. Type: ㅇ, St. John, N. B. (Washington).

Ephialtes (Itoplectis) pacificus Cushman, 1920, Proc. U. S. Nat. Mus., vol. 58, p. 345 ; $․$ Name preoccupied. Type: 으, Menlo Park, Calif. (Washington). Ephialtes (Itoplectis) montana Cushman, 1920, Proc. U. S. Nat. Mus., vol. 58, p. 346 ; + . Type: $\uparrow$, Colorado (Washington).

Ephialtes cacoeciae Viereck, 1924, Canadian Ent., vol. 56, p. 64; ơ', ․ Type: ㅇ, Vernon, B. C. (Ottawa).

Ephialtes (Itoplectis) esuchus Cushman, 1924, Proc. Ent. Soc. Washington, vol. 26, p. 221. New name for Ephialtes pacificus Cushman.

Front wing 3.5 to $9.0 \mathrm{~mm}$. long; temple moderately convex, about 0.65 as long as eye; face moderately wide; flagellum very weakly enlarged apically, the sixth segment from apex about 1.4 as long as wide; punctures on mesoscutum and mesopleurum rather fine and weak; notaulus absent; propodeum short, its median longitudinal carinae extending about 0.4 its length; front tarsal claws of female with a large, broad, postmedian tooth; third tergite about 0.5 as long as wide; tergites 2-7 with moderately strong depressions and elevations; ovipositor sheath about 2.2 as long as first tergite.

FigURE 127.-Localities for Itoplectis quadricingulata.

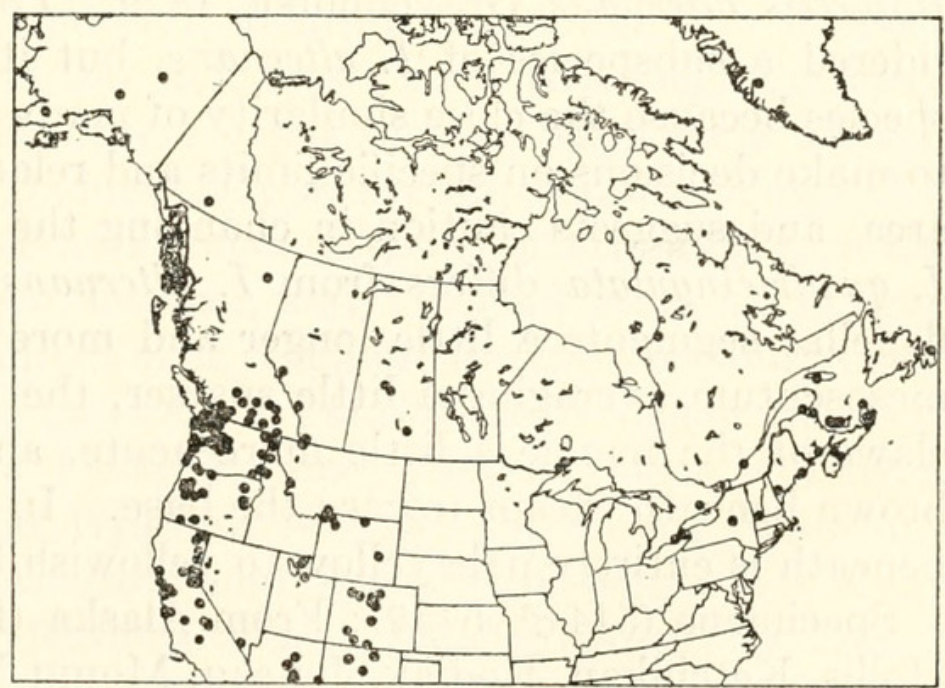


Black. Palpi of male white, of female whitish to fuscous; scape sometimes marked with white in front; flagellum dark reddish brown below, the first one or two segments of the male flagellum often stramineous below; usually more or less of hind corner of pronotum white; tegula white, its apex usually brownish; front coxa and trochanters of male white, the coxa more or less fuscous basally; front femur, tibia, and tarsus of male fulvous, the femur and tibia pale fulvous or yellowish in front; front leg of female fulvous, its coxa partly or entirely fuscous; middle coxa and trochanters of male white, the coxa more or less fulvous and/or fuscous basally; middle coxa and trochanters of female fulvous, the coxa often more or less fuscous except at apex; middle femur fulvous; middle tibia fulvous, with a premedian whitish band, basad of which and a little apicad of which the tibia is more or less infuscate; middle tarsus fulvous to fuscous brown, the segments whitish basally; hind coxa, trochanters, and femur fulvous, the coxa often more or less blackish; hind tibia blackish, with a broad white submedian band; hind tarsus fuscous, the first three segments white basally and the fifth segment with a variable amount of white basally; hind margin of tergites dark brown to stramineous.

In specimens from many localities the hind corner of the pronotum is narrowly white and the last segment of the hind tarsus is white at the base below, but not above. In specimens from other localities the hind corner of the pronotum may lack the white and the last segment of the hind tarsus have a complete basal white ring. In those from still other localities there may be other combinations or intermediate conditions in these color characters. We have not been able to use these differences for distinguishing definite subspecies, so leave them with this brief discussion, at the same time realizing that they are of value for distinguishing populations.

This species is very close to the widespread and common Palaearctic Itoplectis alternans Gravenhorst, 1829. Possibly it should be considered a subspecies of $I$. alternans, but it is treated as a distinct species because the close similarity of many species of Itoplectis tends to make decisions on specific limits and relations very difficult in this area, and suggests caution in changing the traditional classification. I. quadricingulata differs from $I$. alternans in having the subapical flagellar segments a little longer and more slender, the hair on the mesoscutum averaging a little sparser, the tooth on the front tarsal claws of the female a little more acute, and the flagellum blackish brown beneath except toward the base. In I. alternans the flagellum beneath is entirely pale yellow to yellowish brown.

Specimens (514 $0^{\top}, 545$ ) ): From Alaska (Big Delta, Fort Wrangle, Hollis, Ketchikan, Kodiak, Juneau, Mount McKinley at 1,600, 1,700, 
2,000 and 2,500 ft., Prince of Wales Island, Savonoski, and "Whale Passage"); Alberta (Banff, Jasper, and Waterton Lakes); Arizona (near Alpine, Oak Creek Canyon, Rustler's Park in the Chiricahua Mts., San Francisco Mts. in Coconino Co., and Sierra Ancha at Parker Creek, at Rose Creek, and at Workman Creek); British Columbia (Agassiz, Alaska Highway at Mile 213, "Chelkat Pass," Chilliwack, Colwood, Cowichan Lake, Creston, Cultus Lake, Diamond Head Trail near Squamish, Duncan, Glacier Park, near Edgewood, Jesmond, Kaslo, Malahat, Mission City, Oliver, Peachland, Revelstoke in the Selkirk Mts., Robson, Trinity Valley, Vancouver, Vernon, Victoria, and Wigwam Inn near Vancouver); California (Alameda Co., Bangor, Berkeley, Black Lake in San Luis Obispo Co., Boca, Buck Creek Canyon in Modoc Co., California Hot Springs, Carmel, Cisco, Crane Flat in Yosemite Park, Crescent City, Crescent Meadows in Sequoia National Park, Fallen Leaf Lake, Fish Camp, Giant Forest, near Glacier Point in Yosemite Park, Gold Lake in Sierra Co., Goose Lake in Modoc Co., Hallelujah Junction in southern Lassen Co., Huntington Lake at 9,000 ft., Inverness, Jordan Peak in Sequoia National Park, Lake Tahoe, Leevining, Menlo Park, Mill Valley, Monterey, Onion Valley in Plumas Co., Pacific Grove, San Francisco, Sonora Pass at 8,000 ft. and at 9,000-10,000 ft., Stanford University at Palo Alto, Summit in Placer Co., Tamarack Lake at 7,700 ft. in El Dorado Co., Truckee, Walnut Creek, and Wright's Beach in Sonoma Co.); Colorado (Canon City, near Estes Park, Fort Collins, Grand Lake, "Green Falls," Lake City, Morley, Pagosa Springs, Phantom Valley in Rocky Mountain National Park at 9,400 ft., Rabbit Ears Pass, Steamboat Springs, and Tolland); Greenland ("Auleitsivik," "Nunasarnausak," and Sondrestrom Air Base); Idaho (Burley, Coeur d'Alene, Coolin, Mount Moscow, and Priest Lake); Maine (Bridgton, and Mount Desert); Montana (Darby, Gardiner, and Glacier National Park); Nevada (Charleston Mt. in Clark Co.); New Brunswick (Caraquet and St. John); Newfoundland (St. John's); New Mexico (Beulah, Cimarron at 9,500 ft., Cloudcroft, Jemez Springs, and Rio Ruidoso in the Sierra Blanca at 8,500 ft.); New York (Richfield Springs); Northwest Territories (Reindeer Depot on the Mackenzie Delta); Nova Scotia (Aldershot, Baddeck, Cape Breton, Halifax, Kings Co., and St. Peters); Ontario (Fort Frances, Hymers, Marmora, Merivale, Niagara Falls, Normandale, Ottawa, and Vineland Station); Oregon (Albee, Alsea Mt., Ashland, Baker, Cannon Beach, Corvallis, Gresham, Haines, Hood River, La Grande, Lake of the Woods in Klamath Co. at 4,950 ft., Mary's Peak, Monroe, Mount Angel, Portland, Seaside, Sweet Home, and Whitewater Ridge on Mount Jefferson); Prince Edward Island (Alberton and Brackley Beach and Dalvay House both in Canadian National Park); Quebec (Anticosti Island, 
Berthierville, Cross Point on the Gaspé Peninsula, Great Whale River, Hemmingford, Hull, Aylmer, and Rupert House); Rhode Island (Westerly); Saskatchewan (Indian Head, La Plonge Lake, and Waskesiu Lake in Prince Albert National Park); Utah (Park City, Petersboro, and Wellsville); Vermont (Laurel Lake near Jacksonville); Washington (Anacortes, Ashford, Bellingham, Blue Mts., Clark Co., Copalis Beach, Easton, Elbe, Forks, Godman Spring at 6,000 ft., Greenwater River, Ilwaco, Loon Lake, Mount Rainier at 2,700, 2,900, 4,700, 5,000, and 5,300 ft., Montesano, Mount Yakima, Naselle, Northport, Pullman, San Juan Island, Sappho, Seattle, Shelton, Snoqualmie Pass, South Bellingham, South Bend, Weiser Lake in Whatcom Co., Wenatchee, Westport, and Yelm); Wyoming (Careyhurst, Mammoth Hot Springs in Yellowstone Park, Mts. near Sheridan, Snake River, and West Yellowstone); and Yukon Territory (Canyon Creek and Snag).

Collection dates are throughout the growing season, with no particular peak of abundance. We have found the species out with the earliest growth of herbage along the stream bottoms in spring, just as tree buds were beginning to swell, and Foxlee has collected it in numbers in late fall at Robson, B. C. The earliest and latest dates of capture are April 13 at Berkeley, Calif., and October 28 at Robson, B. C. The usual habitat is around northern coniferous trees (Picea, Abies, Tsuga, Pseudotsuga, etc.), where it is often very common. Adults fly around the tips of the branches and "inside" the trees from about one meter to several meters height, probably higher also but observations above four meters are difficult.

The hosts include many small Lepidoptera on various trees and shrubs, particularly on Coniferae. Rearing records are as follows: 11 rearings or series of rearings from Acleris variana, 1 from ?Ancylis comptana, 2 from Anthophila pariana, 8 from Archips argyrospilus, 3 from $A$. rosanus, 1 from Argyrotaenia sp. on Pinus contorta, 1 from Corcina quercana, 2 from Carpocapsa pomonella, 10 from Choristoneura fumiferana, 1 from $C$. pinus, 2 from Cnephasia longana, 2 from $D e-$ pressaria sp., 1 from Dioryctria reniculella, 1 from Euceratia castella, 1 from Gracilaria sp. on leaf of Rosa, 3 from Lambdina fiscellaria lugubrosa, 1 from Malacosoma disstria, 1 from Malacosoma sp., 1 from Nepytia phantasmaria, 1 from Pteronea sp. on Rubus, 1 from Platyptilia sp., 1 from Pterophoridae, 3 from Rhyacionia buoliana, 3 from Spilonota ocellana, 1 from Taniva albolineana, 1 from a bud moth, 1 from Pseudotsuga taxifolia infested with "bud moth," 1 from a leaf roller, 1 from Diptera, 3 from Neodiprion tsugae, 1 from Neodiprion on Tsuga, and 1 from Neodiprion sp.

This species is transcontinental in the Canadian and Hudsonian zones, with some overlap into the Transition and Arctic areas. It is 
abundant in the West, rather uncommon in the East. Adults occur throughout the growing season. It is an important parasite of small Lepidoptera feeding on the foliage or growing tips of trees and shrubs.

\section{Itoplectis conquisitor (Say)}

FiguRe 325 ,j

Cryptus conquisitor Say, 1836, Boston Journ. Nat. Hist., vol. 1, p. 232 (Leconte ed., vol. 2, p. 689); $\subsetneq$. Type: $\subsetneq$, Indiana (destroyed).

Cryptus pleurivinctus Say, 1836, Boston Journ. Nat. Hist., vol. 1, p. 235 (Leconte ed., vol. 2, p. 691); $\sigma^{x}$,. . Types: $\sigma^{x}$, , Maryland (destroyed).

Pimpla pictipes Walsh, 1873, Trans. Acad. Sci. St. Louis, vol. 3, p. 137; ð7 Name preoccupied. Types: $\sigma^{\top}, \uparrow$, ?Illinois (destroyed in Chicago fire of 1871).

Pimpla walshii Dalla Torre, 1901, Catalogus hymenopterorum, vol. 3, p. 454. New name for Pimpla pictipes Walsh.

Ephialtes (Itoplectis) temnopleuris Cushman, 1920, Proc. U. S. Nat. Mus., vol. 58, p. 347 ; ㅇ․ Type: $\subsetneq$, United States (Washington).

Biology: Gorham, 1847, Comm. Rev. South and West, vol. 3, pp. 539-541.Brackett, 1865, Pract. Ent., vol. 1, p. 19.-Comstock, 1879, Report upon Cotton Insects . . . , pp. 198-200.-Riley, 1886, Rep. U. S. Dep. Agr. Ent. Comm., no. 4, pp. 111-113.-Weed and Fiske, 1900, Bull. U. S. Dep. Agr., Div. Ent., no. 26, pp. 33-34.-Weed, 1900, Bull. N. H. Agr. Exp. Sta., no. 75 , p. 123.-Fiske, 1903, Tech. Bull. N. H. Agr. Exp. Sta., no. 6, pp. 187198.-Smith, 1907, Ann. Rep. N. J. Agr. Exp. Sta., no. 28, p. 419.-Howard and Fiske, 1911, Bull. U. S. Dept. Agr., Bur. Ent., no. 91, pp. 137, 138, 144, 147-149, 238.-Johnston, 1913, Journ. Econ. Ent., vol. 6, pp. 144-147.Baird, 1918, Agr. Gaz. Canada, vol. 5, pp. 770-771.-Cushman, 1920, Proc. U. S. Nat. Mus., vol. 58, p. 347; 1926, Proc. Ent. Soc. Washington, vol. 28, p. 41; 1927, Journ. Agr. Res., vol. 34, p. 619.-Criddle, 1924, Ann. Rep. Ent. Soc. Ontario, no. 54, pp. 17-18.-Schedl, 1931, Zeitschr. Angew. Ent., vol. 18, pp. 258-260.-Crowell, 1932, Psyche, vol. 39, p. 102.-Schaffner and Griswold, 1934, Misc. Pub. U. S. Dep. Agr., no. 188, p. 142.Daviault, 1935, Naturaliste Canadien, vol. 62, pp. 245, 318, 319.-Haden, 1935, Bull. Univ. Del. Agr. Exp. Sta., no. 194, pp. 20-35.-Doner, 1936, Ann. Ent. Soc. America, vol. 29, p. 228.-Balduf, 1937, Proc. Ent. Soc, Washington, vol. 39, p. 173.-Twinn, 1938, Ann. Rep. Ent. Soc. Ontario. vol. 69, p. 131.-Townes, 1939, Bull. Brooklyn Ent. Soc., vol. 34, p. 29; 1940, Ann. Ent. Soc. America, vol. 33, pp. 286, 316.

Front wing 3.5 to $12.5 \mathrm{~mm}$. long; temple rather weakly convex, about 0.62 as long as eye; face moderately wide; flagellum weakly enlarged apically, the sixth segment from the apex about 1.5 as long as wide; punctures on mesoscutum and mesopleurum of moderate size and strength; notaulus absent; propodeum short, its median longitudinal carinae extending about 0.3 its length; front tarsal claws of female with a large, broad, postmedian tooth; third tergite about 1.0 as long as wide in male, about 0.63 as long as wide in female; fourth and fifth tergites of male polished and with widely separated punctures (these tergites more or less mat and with close punctures in both sexes of the other Nearctic species); tergites $2-7$ with rather 


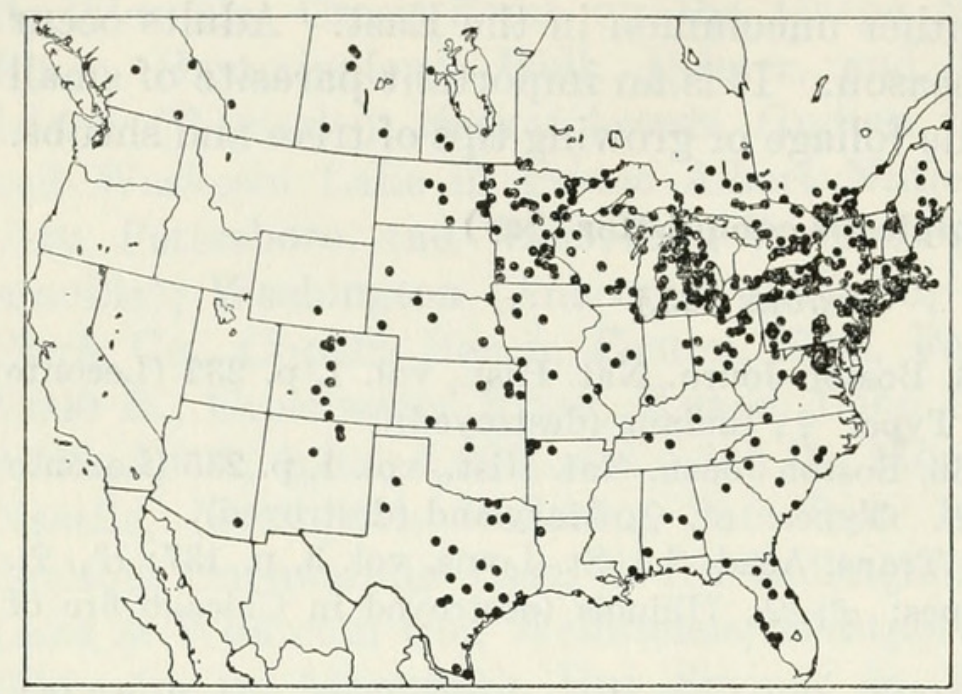

Figure 128.--Localities for Itoplectis conquisitor.

weak depressions and elevations; ovipositor sheath about 2.2 as long as first tergite.

Black. Palpi of male white; maxillary palpus of female white; labial palpus of female light brown; scape and pedicel of male white in front; flagellum reddish brown beneath, more extensively so in male; tegula and rather large hind corner of pronotum white; front coxa of male and front and middle trochanters of male whitish, with pale fulvous stains; front coxa of female fulvous, its basal half infuscate; front and middle trochanters of female fulvous, often paler in front; front femur fulvous, often whitish above; front tibia pale fulvous, whitish above and in the female usually with a median brownish spot above; front tarsus whitish or pale stramineous; middle coxa fulvous; middle femur fulvous, its apex whitish in front; middle tibia fulvous, usually pale brown above, with a premedian white band; middle tarsus white, the apex of its segments brown and the fourth segment entirely brown; hind coxa, trochanters, and femur fulvous, the apex of the femur fuscous; hind tibia fuscous with a broad submedian white band; hind tarsus white, the apex of its segments blackish and the fourth segment entirely black; tergites each with a narrow but conspicous apical white band, the band brown laterally.

Specimens (763 $\sigma^{\top}, 1,634$ ㅇ): From Alabama (Deer Park, Hawkinsville, Montgomery, and Selma); Alberta (Millarville); Arizona (Rustler's Park in Cochise Co. at 8,000 ft.); Arkansas (Baldwin, Bentonville, Hedges, and Siloam Springs); British Columbia (Kicking Horse River in Yoho National Park, Lillooet, Mile 415 on Alaska Highway, and Robson); Colorado (Canon City, Colorado Springs, Estes Park, Fort Collins, Glen Haven, Huerfano Co., Larkspur, Morley, and Rocky Mountain National Park); Connecticut (Colebrook, East River, Litchfield Co., Lyme, Meriden, Stamford, Storrs, Wallingford, West Cornwall, Westport, and Wilton); District of 
Columbia (Washington); Delaware (Newark and Woodside); Florida (Alachua Co., Bradenton, Bratt in Escambia Co., Clearwater, Englewood, Grahamville, Jacksonville, Lake City, Monticello, Punta Gorda, and Sanford); Georgia (Athens); Illinois (Algonquin, Chicago, Decatur, Peoria, "Plant City," and Urbana); Indiana (Evansville and Wells Co.); Iowa (Ames, Fort Dodge, and Ruthven); Kansas (Clark Co., Emporia, Lawrence, Leavenworth, Manhattan, Miami Co., and Winfield); Kentucky (Crailhope); Louisiana (Shreveport); Maine (Ashland, Augusta, Blue Hill, Bristol, Brunswick, Hartland, Lincoln Co., Medomak, Mount Katahdin, Orono, and Southport); Manitoba (Aweme, Brandon, Red Deer River, and Teulon); Maryland (Baltimore, Boonsboro, Cabin John, College Park, Glen Echo, Hagerstown, Plummers Island, Ringgold, and Takoma Park); Massachusetts (Amherst, Beach Bluff, Blue Hills Reservation, Boston, Cambridge, Chelsea, Cohasset, Dorchester, Hardwick, Holliston, Humarock, Lexington, Malden, Marblehead, Martha's Vineyard, Melrose, Mount Tom, Muskeget Island, Nahant, Nantucket, Princeton, Reading, Salem, Somerville, Tyngsboro, Wareham, Wellesley, Westport, Winchendon, Winthrop, Woburn, and Woods Hole); Michigan (Alcona Co., Alston, Ann Arbor, Arenac Co., Aurelius, Baraga, Bay City, Benzonia, Birmingham, Calhoun Co., Cheboygan Co., Clare Co., Crawford Co., Dickinson Co., Douglas, Douglas Lake, East Lansing, Eaton Co., Emmet Co., Escanaba, Gaylord, George Reserve in Livingston Co., Gratiot Co., Higgins Lake in Roscommon Co., Ionia Co., Isle Royale, Jackson Co., Kalkaska Co., Kent Co., Keweenaw Co., Lapeer Co., Leland, Ludington, Manistee Co., Marquette, Mecosta Co., Menominee Co., Midland Co., Missaukee Co., Monroe Co., Muskegon Co., Newaygo Co., Norwood Township in Charlevoix Co., Nottawa, Onata Township in Alger Co., Ontonagon Co., Oscoda, Osceola Co., Presque Isle Co., Raco, Saginaw Co., St. Ignace, St. Joseph, Sand Point in Huron Co., Sault Ste. Marie, near Scottville, Shiawassee Co., Tuscola Co., near Vanderbilt, Van Buren Co., Wayne Co., West Branch, Wexford Co., and White Fish Point in Chippewa Co.); Minnesota (Ada, Bemidji, Bovey, Brown Co., Cambridge, Cass Co., Cloquet, Cook Co., Crookston, Duluth, Ely, Fairbault, Finland, Fish Hatchery in Le Sueur Co., Fridley Sand Dunes in Anoka Co., Garrison, Grand Meadow, "Gray Cloud Island," Minnesota Experiment Station in Hennepin Co., Itasca State Park, Lake of the Woods Co., Lancaster, Laporte, Lincoln Co., Luverne, Mississippi Blufis in Hennepin Co., "Northern Pine Camp," Plummer, Polk Co., Ramsey Co., Redwood Co., Roosevelt, St. Anthony Park, St. Paul, Shevlin, Traverse Co., Two Harbors, Washington Co., Washington Island in Basswood Lake, West Concord, and Yellow Medicine Co.); Mississippi (Biloxi and Horn Island); Missouri (Columbia, 
Kirkwood, Moselle, and Savannah); Nebraska (Halsey, Lincoln, Moril Co., Nebraska National Forest, and Omaha); New Brunswick (Campbellton); New Hampshire (Bath, Center Conway, Mount Washington at Bigelow Lawn, at Lake of the Clouds, in Carex meadows at 5,900 ft., and at Summit House, and Pittsburgh); New Jersey (Browns Mills, Burlington, Englewood, Fort Lee, Jamesburg, Mashipacong Pond in Sussex Co., Medford, Moorestown, Newark, New Brunswick, Passaic Junction, Ramsey, Riverton, Rutherford, and Trenton); New Mexico (Koehler, Santa Fe, and Springer); New York (Atlantic Beach, Aurora, Barker, Barrytown, Bemus Point, Brooklyn, Buffalo, Canadarago Lake, Caroline-Harford area, Delmar, East Aurora, Egleston's Glen on Lake Keuka, Elmira, Farmingdale, Fine, Fish Creek Pond, Fishers Island, Flatbush, Freeville, Frontenac Point on Lake Cayuga, Gasport, Grand Island, Greene, Hancock, Horton, Huntington, Ithaca, Lake George, Little Genesee, Lockport, Ludlowville, Malloryville, McLean Reserve in Tompkins Co., Medina, Millwood, Minetto, top of Mount McIntyre, Mount Skylight in Essex Co. at 4,800 to 4,920 ft., Mount Whiteface, New Rochelle, New York City, North Fairhaven, Nyack, Oneonta, Oswego, Penn Yan, Peru in Clinton Co., Portageville in Wyoming Co., Poughkeepsie, Prospect Park on Long Island, Rochester Junction, Rockaway, Rock City in Cattaraugus Co., Shokan, Slingerlands, Sodus Springs, Spring Lake in Cayuga Co., Steamburg in Cattaraugus Co., Syracuse, Tuxedo, Ulster Co., Waterville, Watkins Glen, West Point, summit of Whiteface Mt., Yonkers, and Youngstown); North Carolina (Clinton, Crabtree Meadows in Yancy Co. at 3,600 ft., Elizabethtown, Franklin, and Southern Pines); North Dakota (Devils Lake, Edgeley, Fargo, Grand Forks, Kindred, Knox, Sulleys Hill National Game Preserve in Benson Co., and Tower City); Nova Scotia (Cape Breton, Kentville, and Kings Co.); Ohio (Ashland Co., Barberton, Cedar Point, Cleveland, Columbus, "Gillespie," Hocking Co., Hudson, Licking Co., Mercer Co., Montgomery Co., New Philadelphia, Puritas Springs in Cuyahoga Co., Put-in-Bay, Sandusky, Scioto Co., and Wayne Co.); Oklahoma (Stillwater); Ontario (Alfred, Belleville, Bells Corners, Bewdley, Biscotasing, Blackburn, Blind River, Bobcaygeon, Bowmanville, Carp, Chalk River, Cloyne, Cobden, Constance Bay, Footes Bay, Frater, Gananoque, Golden Lake, Grand Bend, Gravenburst in the Muskoka District, Haileybury, Hespeler, Hymers, Ingersoll, Jordan, "Lyntock," Marmora, Milnet, Niagara Glen, Nicholson, Norfolk, Normandale, North Bay, Ottawa, Parr Island in East Spence Lake, Pelee Island, Perrytown, Point Pelee, Port Colborne, Port Rowan, Rainy River District, Reamsville, Ridgeway, St. Catherines, St. Davids, "Salines," Simcoe, Spencerville, Strathroy, Sudbury, Swastika, "Tealake," Tilbury, Trenton, Tweed, 
Vineland Station, Waubamik, and Westree); Pennsylvania (Allegheny Co., Arendtsville, Bryn Mawr, Camp Hill, Castle Rock in Delaware Co., Crafton, Edgemere, Eightyfour, Finleyville, Ford City, Harrisburg, Highspire, Hummelstown, "Inglenook," Ingram, Lehigh Gap, Linglestown, "Muscatine," New Cumberland, North East, Notch, Paupack, Pecks Pond, Philadelphia, Pittsburgh, Presque Isle in Erie Co., Spring Brook, West Chester, and Youngwood); Prince Edward Island (Alberton and Brackley Beach in Canadian National Park); Quebec (Aylmer, Berthierville, Cap Rouge, Cascapedia, Covey Hill, Cross Point on the Gaspé Peninsula, Franklin, Hull, Joliette, Kazabazua, Knowlton, Lac Brûle, Lachine, Laniel, Mont Joli, Montreal, Norway Bay, Rigaud, St. Ann's, Shawbridge, and Wakefield); Rhode Island (Ashaway, Kingston, and Westerly); Saskatchewan (Christopher Lake, Katepwa Park, Saskatoon, Swift Current, and Waskesiu Lake); South Carolina (Charleston, Columbia, and Greenville); South Dakota (Chamberlain, Elk Point, and Hot Springs); Tennessee (Clarksville and Lebanon); Texas (Bexar Co., Brownsville, Brownwood, Calvert, Colorado Co., College Station, Cypress Mills, Dallas, Galveston, Hamilton, Hunt Co., Landa Park in Comal Co., Lindsay in Cook Co., Lubbock, Maxwell in Caldwell Co., Palo Dura State Park in Randall Co., San Antonio, Sherman, Smith Point in Chambers Co., Victoria, Weslaco, West Columbia, and Wharton Co.); Vermont (Laurel Lake near Jacksonville, Rutland, and Stowe); Virginia (Arlington, Bellview to Difficult Run in Fairfax Co., Charlottesville, Dayton, Falls Church, Glencarlyn, Great Falls, Herndon, Luray Caverns, Meadows of Dan in Patrick Co., Oaks in Fairfax Co., Plummers Island, Rosslyn, "Stratton Mts.," and Vienna); West Virginia (Bolivar, Cheat Mt. at 2,000 ft. in Randolph Co., and Cheat River); Wisconsin (Columbus, Cranmoor, Door Co., Eau Claire, Gays Mills, Gordan, Hakoma in Dane Co., Madison, Milwaukee, Rib Mountain State Park, Sawyer Co., Siren, and Wood Co.); Wyoming (Carbon Co.); and Bermuda Islands.

Adults occur from rather early in the spring to late in the fall. After the first frosts of the fall they are still easy to find on warm days, and because other ichneumonids are scarcer then, this species seems to be relatively common. The hundreds of collection dates available indicate that it has no real peaks of abundance except as influenced by local conditions, and can be collected any time during the growing season. The characteristic habitat is the shrubby growth of rather open woods or overgrown fields.

The species has been reared more than any other Nearctic ichneumonid. Rearing records on the pin labels of the specimens studied are as follows: 1 rearing or reared lot from Acleris hastiana, 2 from $A$. minuta, 1 from Acleris sp. on Carpinus, 2 from Acrobasis betulella, 
1 from $A$. caryivorella, 3 from $A$. juglandis, 1 from $A$. kearfottella, 5 from Acrobasis sp., 5 from Alabama argillacea, 5 from Anisota rubicunda, 4 from Anomis erosa, 10 from Archips argyrospilus, 4 from $A$. cerasivoranus, 3 from A. fervidanus, 2 from Archips sp., 1 from Argyrotaenia pinatubana, 2 from A. guercifoliana, 1 from Choristoneura conflictana, 10 from $C$. fumiferana, 3 from $C$. pinus, 1 from C. rosaceana, 1 from Cingilia catenaria, 1 from Coleophora pruniella, 1 from Diaphania hyalinata, 1 from Dichomeris marginella 2 from Dioryctria reniculella, 2 from Ennomos subsignarius, 1 from Epermenia cicutaella, 1 from Exyra semicrocea, 3 from Grapholitha molesta, 6 from Hemerocampa leucostigma, 2 from Hemerocampa sp., 2 from Hemileuca sp., 2 from Hyaloscotes sheppardi, 2 from Hyphantria cunea, 1 from Lascoria ambigualis, 4 from Malacosoma americanum, 8 from $M$. disstria, 1 from $M$. fragile, 4 from Malacosoma sp., 1 from Nematocampa limbata, 1 from Oiketicus abbotii, 2 from Orgyia antigua, 1 from Papilio marcellus, 1 from Pieris rapae, 1 from Polychrosis viteana, 1 from Pterophorus periscelidactylus, 3 from Pyrausta nubilalis, 1 from Rheumaptera hastata, 1 from Rhyacionia buoliana, 3 from $R$. frustrana, 1 from $R$. frustrana bushnelli, 1 from Simyra henrici, 1 from Sparganothis flavibasana, 1 from $S$. pettitana, 1 from Sparganothis sp. on Lonicera, 2 from Spilonota ocellana, 12 from Thyridopteryx ephemeraeformis, 5 from Trichoplusia ni, 1 from Urbanus proteus, 38 from various Lepidoptera not determined to genus, 1 from Oncideres cingulatus, 1 from Phobocampe pallipes, and 1 from Rhogas terminatus. Besides these, there are some additional host records in literature, for a record of which, see Townes (1945, Mem. Amer. Ent. Soc., vol. 11, pp. 76-77). There are 5 records on pin labels of captures on flowers: 1 on Ceanothus, 1 on Cirsium lanceolatum, 2 on Daucus carota, and 1 on Euphorbia commutata. It has also been taken at nectaries of Vigna sinensis. Three females and one male were collected at lights.

There are many published accounts of the biology. These have been summarized by Townes (1940, Ann. Ent. Soc. America, vol. 33, pp. 319-320). This species attacks almost any exposed or weakly protected lepidopterous pupa or prepupa on trees, shrubs, or herbage. Occasionally it parasitizes ichneumonid or braconid cocoons, and is thus a secondary parasite. Sometimes it serves as host itself, its most frequent parasite being Theronia atalantae. Correlated with its wide host range it is extremely variable in size. Development from egg to adult requires about 20 days.

This species is abundant in open woods and bushy country from the Atlantic to the hundredth meridian, and occurs also in the eastern edge of the Rocky Mountains and in scattered localities farther west. Its normal range is from the Transition to the Lower Austral zones. 
Adults occur from early spring to late fall. A wide variety of exposed or weakly protected lepidopterous pupae or prepupae serve as hosts, and it is sometimes a secondary parasite.

\section{Itoplectis viduata (Gravenhorst)}

Fugure $325, \mathrm{k}$

Pimpla viduata Gravenhorst, 1829, Ichneumonologia europaea, vol. 3, p. 214; $\sigma^{7}$.

Types: $\sigma^{\top} \sigma^{\top}$, "circe Hanoveram, Trajectum ad Moenum et in Austria" (Wroclaw).

Pimpla atrocoxalis Cresson, 1870, Trans. Amer. Ent. Soc., vol. 3, p. 145; + Type: , Hudson Bay Territory (Philadelphia).

Front wing 7.5 to $11.5 \mathrm{~mm}$. long; temple rather flat, about 0.62 as long as eye; face moderately wide; flagellum of almost uniform thickness throughout, the segment sixth from the apex about 1.45 as long: as wide; punctures on mesoscutum and mesopleurum rather coarse and strong; notaulus absent; propodeum short, its median longitudinal carinae extending about 0.4 its length; propodeal spiracle long oval (short oval in the other Nearctic species); front tarsal claws of female with a big, rather narrow, postmedian tooth; third tergite about 0.58 as long as wide in male, about 0.47 as long as wide in female; tergites 2-7 with rather strong depressions and elevations; ovipositor sheath about 2.4 as long as first tergite.

Black. Palpi fuscous; flagellum blackish brown, reddish brown beneath, the basal half of its first segment entirely black; tegula stramineous with its outer apical part fuscous, to entirely fuscous; wings faintly infuscate; legs beyond trochanters fulvoferruginous, the hind tarsus a little infuscate, especially toward the apex and on the apex of the basal segments; second trocbanters blackish, ferruginous apically.

It seems possible that Palaearctic and Nearctic specimens could be distinguished as subspecies on minor differences in color. We do not have enough Palaearctic material, however, to come to a decision on this. The above color description is drawn from only Nearctic specimens.

Specimens (49 $\sigma^{\top}, 72$ ) : From Alberta (Lethbridge, Sylvan Lake, and Waterton); Arizona (Parker Creek in the Sierra Ancha and San Francisco Peaks in Cononino Co.); British Columbia (Chilliwack, Delta, Hazelton, Kamloops, Mount Revelstoke National Park, Pitt River, Revelstoke, and Vernon); California (Alameda Co., Apple Valley in San Bernardino Co., Berkeley, Buck's Lake in Plumas Co., Cajon Pass, Camp Richardson, Davis, Giant Forest, Hallelujah Junction in Lassen Co., Indio, Lake Tahoe, Lone Pine, Palm City, San Jacinto Mts., Santa Clara, Tahquitz Valley on Mount San Jacinto in Riverside Co., Tamarack Lake at 7,700 ft. in El Dorado Co., Tracy, 
Tub Lake in Siskiyou Co., Twin Lakes in Mono Co., Westwood Hills in Los Angeles Co., and Woodlake); Colorado (Cameron Pass in Medicine Bow Range, Eldora, Glen Haven, Pingree Park in Larimer Co., Poudre Lake at 11,000 ft. in Rocky Mountain National Park, and Steamboat Springs); Idaho (Hailey and Targhee National Forest); Montana (Helena); Nevada (Austin and "Doton"); New Mexico (Cloudcroft, Eagle Creek in the Sierra Blanca at 8,000 ft., Rio Ruidoso in the Sierra Blanca at 7,600 ft., Sacramento Mts. at 6,000 ft., Sapello Canyon near Las Vegas, and Santa Fe); Northwest Territories (Norman Wells and Padley); Oregon (Crater Lake, Graham, Onion Creek Meadows in Grant Co. at 7,700 ft., Sparta, Suttle Lake, and Wilton); Saskatchewan (Pike Lake and Saskatoon); Utah (Delta and "Granite"); Washington ("Dartford," Mount Rainier at 5,000 ft., and Wawawai); Washington Territory (Nelson's on the Yakima River); Wyoming (Albany Co., Cheyenne, and Riverside in Yellowstone Park); Europe; and Manchuria.

Collection dates are throughout the growing season. Unusually early and late dates of capture are: January 19 at Westwood Hills, Los Angeles Co., Calif.; March 22 at Davis, Calif.; April 29 at Parker Creek, Sierra Ancha, Ariz.; April 30 at Indio, Calif.; May 5 at Saskatoon, Sask.; May 8 at Lethbridge, Alta.; September 14 at Hazelton, B. C.; October 2 in the Sacramento Mts., N. Mex.; and October 15 at Woodlake, Tulare Co., Calif.

Rearing records on the pin labels of these specimens are as follows: 1 rearing from Ancylis comptana, 2 from Autographa californica, 1 from Choristoneura rosaceana, 1 from Colias eurytheme, 2 from Hemerocampa pseudotsugata, 1 from Hemileuca oliviae, 1 from Malacosoma disstria, 1 from $M$. fragile, 2 from Malacosoma sp., 1 from tussock moth, 1 from tent caterpillar, and 1 from a lepidopteran.
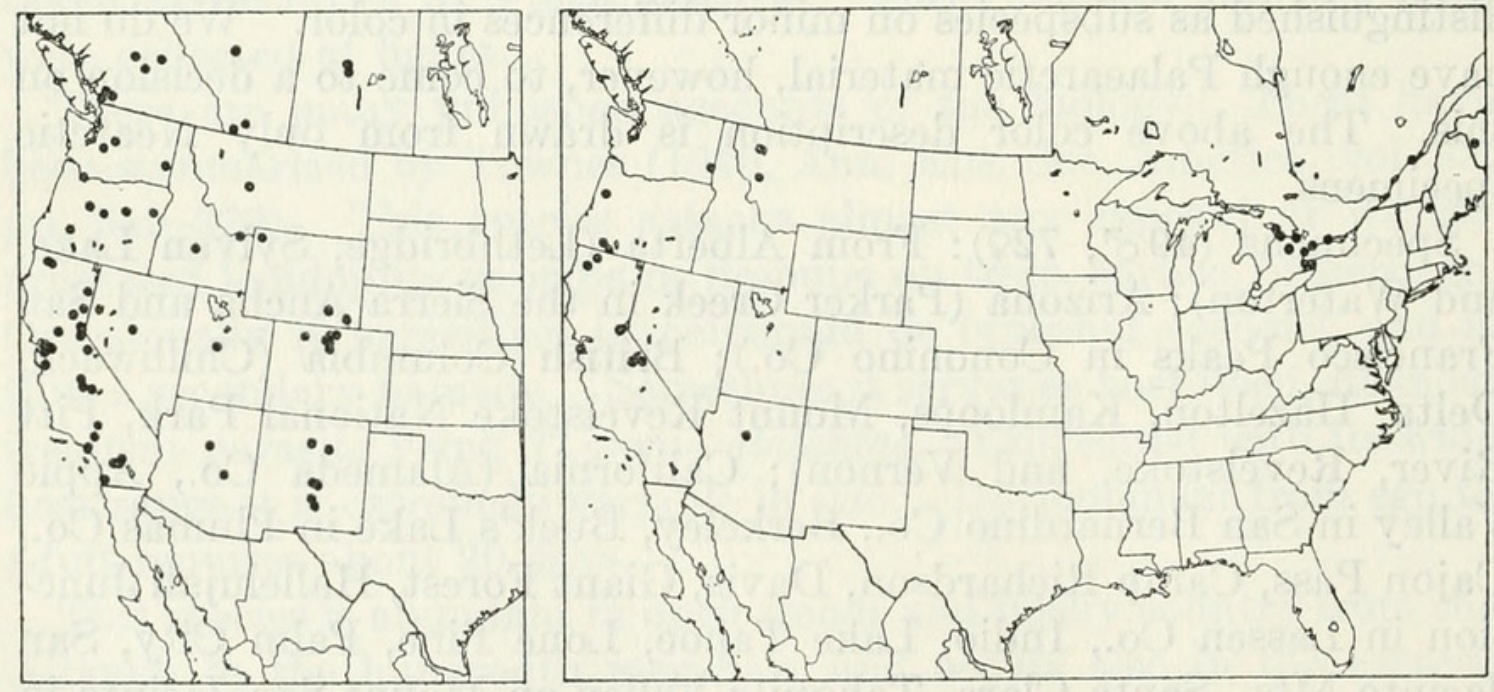

Figdres 129, 130.-Localities: 129 (left), Itoplectis viduata; 130 (right), I. evetriae. 
This species is widespread but not very common from the Rocky Mountains, westward. It occurs also in Eurasia. The zonal range is from the Hudsonian to the Upper Austral. Adults occur throughout the growing season. The hosts are a wide variety of Lepidoptera with exposed or poorly protected pupae.

\section{Itoplectis evetriae Viereck}

Figure 325,1

Itoplectis evetriae Viereck, 1913, Proc. U. S. Nat. Mus., vol. 44, p. 565; هొ. Type: $\sigma^{7}$, Yreka, Calif. (Washington).

Itoplectis plesia Rohwer, 1914, Proc. Ent. Soc. Washington, vol. 15, p. 182;

․ Type: $q$, Camas, Mont. (Washington).

Front wing 4.0 to $8.5 \mathrm{~mm}$. long; temple strongly convex, about 0.73 as long as eye; face very wide; flagellum of uniform width throughout, the sixth segment from apex about 1.6 as long as wide; punctures on mesoscutum and mesopleurum rather coarse and strong; notaulus absent; propodeum short, its median longitudinal carinae extending about 1.4 its length; front tarsal claws of female without a tooth; third tergite of male about 0.7 as long as wide, of female about 0.55 as long as wide; tergites $2-7$ with rather strong depressions and elevations; ovipositor sheath about 3.6 as long as first tergite; ovipositor strongly decurved (weakly decurved or almost straight in the other Nearctic species).

Black. Maxillary palpus white or mostly whitish; labial palpus dark brown, sometimes partly whitish; flagellum dark brown beneath; tegula and extreme hind corner of pronotum white; front coxa entirely blackish or more or less ferruginous apically; front leg beyond coxa fulvous, the first trochanter sometimes infuscate; middle and hind coxae fulvous or blackish; middle and hind trochanters and femora fulvous, the apex of hind femur a little infuscate; middle tibia fulvous, with a subbasal white band, basad of the band and a little beyond it often somewhat infuscate; middle tarsus fulvous to brown, the segments, especially the basal ones, whitish basally; hind tibia black with a broad submedian white band; hind tarsus black, the segments, especially the basal ones, more or less white basally.

Specimens $\left(39 \sigma^{\top}, 45\right.$ ) $)$ : From Arizona (Snow Bowl in San Francisco Peaks of Coconino Co.); California (Carrville at 2,400 to 2,500 ft., Leevining, Mammoth Lakes, Pacific, San Francisco, Snow Flat in Yosemite Park at 8,700 ft., and Yreka); Montana (Flathead and Missoula); New Brunswick (Forks of the Miramichi in Carleton Co.); Newfoundland (Grand Falls at Trio Lake); New Hampshire (Lake of the Clouds on Mount Washington); Ontario (Bowmanville, Brighton, Lions Head, Lorraine, New Lowell, Niagara Falls, Primrose, Sauble 
Forest at Hepworth, and Toronto): Oregon (Ashland, Colestin, and Corvallis); Quebec (Quebec City); and Washington (Pullman).

The majority of the specimens at hand were laboratory reared, so there is little information on the seasonal distribution of adults in nature. The earliest and latest dates for collected adults are April 15 at San Francisco, Calif., and July 25 at Snow Bowl, San Francisco Peaks, Coconino Co., Ariz.

Rearing records are as follows: 2 rearings from Barbara colfaxiana siskiyouana, 8 from $B$. colfaxiana taxifoliella, 2 from B. mappana, 1 from Barbara sp., 2 from Choristoneura fumiferana, 1 from Dioryctria cambiicola, 19 from Rhyacionia buoliana, 1 from a host on Pseudotsuga taxifolia, and 1 from a host on Fraxinus oregona.

This species is transcontinental in the Canadian zone. The usual hosts are Lepidoptera feeding in the cones or growing tips of Coniferae.

\section{Itoplectis behrensii (Cresson)}

Figure 326,a

Pimpla Behrensii Cresson, 1878, Proc. Acad. Nat. Sci. Philadelphia, vol. 1878, p. $377 ; \sigma^{7}$, . Lectotype: $\&$, California (Philadelphia.)

Front wing 6.5 to $8.0 \mathrm{~mm}$. long; temple moderately convex, about 0.58 as long as eye; face moderately wide; flagellum very weakly enlarged apically, the sixth segment from the apex about 1.5 as long as wide; punctures on mesoscutum and on mesopleurum rather coarse and strong; notaulus present but weak; propodeum short, its median longitudinal carinae extending about 0.4 its length; front tarsal claws of female with a small, acute, median tooth; third tergite about 0.58 as long as wide; tergites $2-7$ with moderately strong depressions and elevations; ovipositor sheath about 1.55 as long as first tergite.

Black. Palpi of male white; maxillary palpus of female whitish; labial palpus of female brownish; tegula and rather large hind corner of pronotum white; coxae black, their extreme apex whitish or fulvous; trochanters of front leg white or whitish, the first trochanter with a brown stripe above; front femur fulvous with a whitish stripe above; front tibia whitish above, the rest mostly fulvous; front tarsus white to stramineous; middle trochanters fulvous, those of male white in front; middle femur fulvous, the apex whitish in front; middle tibia pale brown, with a subbasal whitish band which is elongate above; middle tarsus whitish stramineous, the segments brownish apically; hind trochanters and femur fulvoferruginous, the femur infuscate at apex; hind tibia fuscous, with a premedian white band, the fuscous of its apical half more or less replaced by reddish brown, hind tarsus fuscous, the segments white basally except that the fourth segment is entirely fuscous; tergites ferruginous laterally, each with a narrow apical margin of stramineous which does not reach the lateral margin. 
Specimens (83 $\sigma^{7}, 110$ \%): From California (Alameda, Auburn, Benicia, Berkeley, Brisbane, Carmel, Fairfax, Los Gatos, Mill Valley, Moraga Valley, Mount Tamalpais, Mountain View, Muir Woods, Napa Co., Oakland, Orange Co., Pacific Grove, Palo Alto, Petaluma, Point Richmond, San Francisco, San Gabriel Mts. at 2,500 ft., San Jose, Santa Barbara, Stanford University at Palo Alto, and Wildcat Creek in Contra Costa Co.).

The seasonal records of adults (both collecting and rearing) indicate that the species is on the wing every month of the year, with peaks of abundance in the spring and fall.

Rearing records comprise 11 lots of specimens from Phryganidia californica but none from other hosts.

This species is restricted to western California, from Marin Co. southwards. It is an important parasite of Phryganidia californica. Adults can be collected throughout the year.
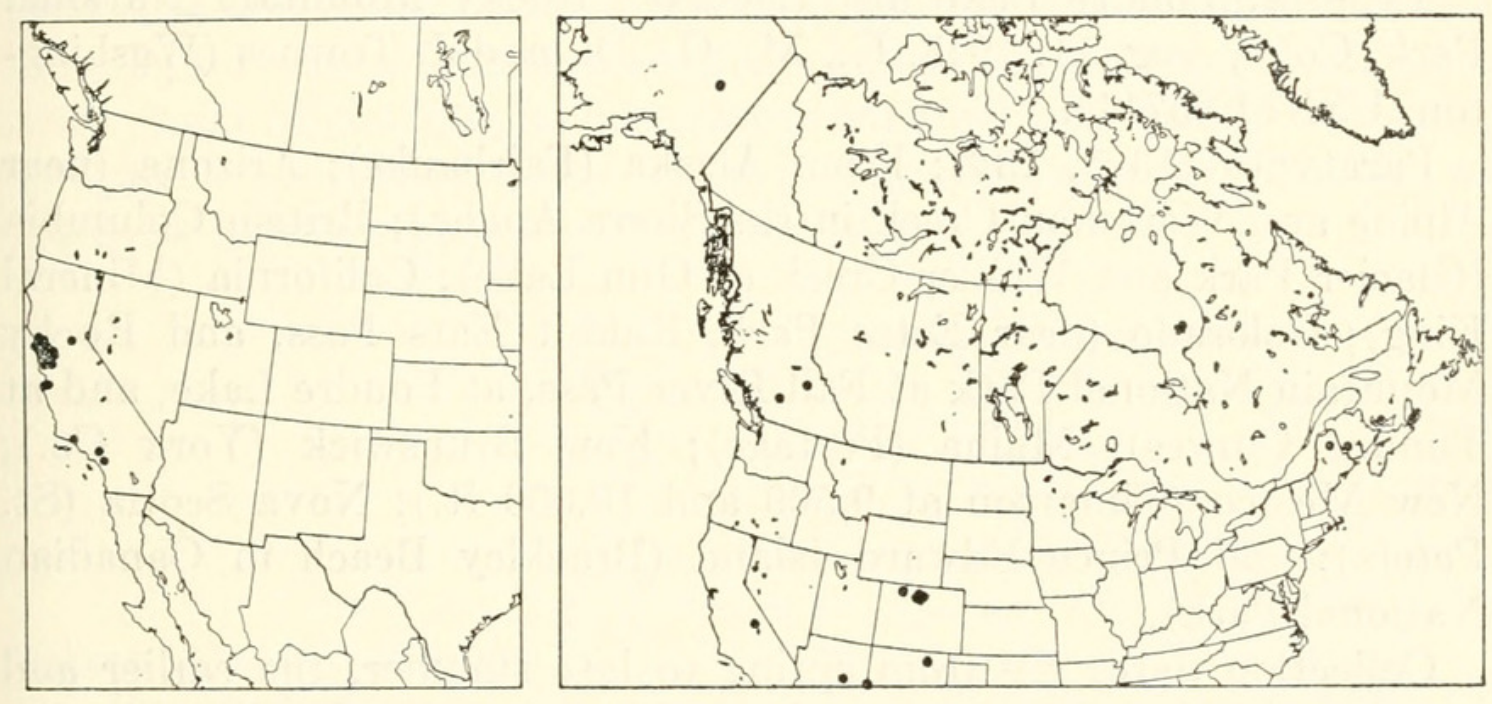

Figures 131, 132.-Localities: 131 (left), Itoplectis behrensii; 132 (right), I. vesca.

\section{Itoplectis vesca, new species}

Figure 326,b

Front wing 2.5 to $5.3 \mathrm{~mm}$. long; front tarsal claws of female either simple or with a very small median tooth; notaulus present but weak; punctures of mesopleurum and mesoscutum slightly stronger than in I. quadricingulata. Otherwise structurally similar to I. quadricingulata.

Black. Palpi of "male white; maxillary palpus of female mostly whitish; labial palpus of female brown; tegula and extreme hind corner of pronotum white; all coxae entirely black; first trochanters black or fuscous, that of front leg whitish in front; second trochanters fuscous to fulvous; front femur and tibia pale stramineous, the femur brown above and below and the tibia brown behind; front tarsus 
stramineous, a little darker apically; middle femur fulvous, whitish apically in front and often light brown above; middle tibia fulvous or brownish, with a premedian whitish band, in the male more or less whitish in front; middle tarsus brown, the segments white basally except that fourth segment is entirely dark; hind femur fulvous, its apex more or less infuscate; hind tibia black with a broad submedian band of white; hind tarsus black, the segments white basally except that the fourth segment is entirely black; apex of tergites narrowly margined with pale brown.

This species shows close relationship with $I$. behrensii in the presence of the notaulus, small acute tooth on front tarsal claws of female (when this is present), and in several features of the leg coloration. Superficially, however, it looks more like $I$. quadricingulata. We are indebted to G. S. Walley for calling attention to this distinct new species and for the loan of specimens.

Type: $\odot$, Poudre Lake at 11,000 ft., Rocky Mountain National Park, Colo., Aug. 11, 1948, H., M., G., D., and J. Townes (Washington, USNM 63711).

Paratypes (13 $\sigma^{7}, 23$ \%): From Alaska (Fairbanks); Arizona (near Alpine and Workman Creek in the Sierra Ancha); British Columbia (Glacier Park and Walker Creek at Gun Lake); California (Mineral King); Colorado (near Estes Park, Rabbit Ears Pass, and Rocky Mountain National Park at Fall River Pass, at Poudre Lake, and at Tundra Curves); Maine (Portage); New Brunswick (York Co.); New Mexico (Cimarron at 9,500 and 10,000 ft.); Nova Scotia (St. Peters); and Prince Edward Island (Brackley Beach in Canadian National Park).

Collection dates are from spring to late summer, the earlier and later dates being: May 3, 6, and 8 at Workman Creek, Sierra Ancha, Ariz.; May 24 near Alpine, Ariz.; June 12 near Estes Park, Colo.; August 12 at 11,000 ft. in Rocky Mountain National Park, Colo.; and August 23 and 25 at Cimarron, N. Mex. at 9,500 and 10,000 ft.

Rearing records comprise 2 reared lots from Acleris variana, 2 from Coleophora laricella, 1 from Recurvaria milleri, and 1 from a lepidopterous pupa.

This species is transcontinental in the Hudsonian and Canadian zones. It is adult from spring to late summer.

\section{Itoplectis fustiger, new species}

Figdre 326,c

Itoplectis clavicornis Townes, 1940, Ann. Ent. Soc. America, vol. 33, p. 315. Misdetermination of clavicornis Thomson, in part.

Front wing 5.0 to $7.2 \mathrm{~mm}$. long; temple almost flat, about 0.4 as long as eye; face very narrow; cheek about 0.12 as long as basal width 
of mandible (about 0.25 to 0.45 as long as basal width of mandible in the other Nearctic species); flagellum strongly enlarged apically, the sixth segment from apex about 0.9 as long as wide; punctures on mesoscutum and mesopleurum rather fine and weak; notaulus absent; propodeum short, its median longitudinal carinae extending about 0.25 its length; front tarsal claws of female with a large, broad, postmedian tooth; first tergite exceptionally flat above; third tergite about 0.8 as long as wide; second through seventh tergites with moderate depressions and elevations; ovipositor sheath about 1.15 as long as first tergite.

Black. Palpi white; antenna whitish to pale stramineous, blackish brown above; tegula and hind corner of pronotum white; front and middle legs of male white; front legs of female white, the coxa basally and the femur behind tinged with pale fulvous; middle coxa and femur of female fulvous, the femur white at apex; middle trochanters, tibia, and tarsus of female white, the first trochanter pale fulvous behind; hind coxa and femur fulvous; first trochanter of hind leg mostly white in male, fulvous in female; second trochanter of hind leg of both sexes white; hind tibia white, its base rather narrowly and weakly infuscate, its apex fuscous; hind tarsus white, its segments narrowly blackish at apex, its fourth segment entirely blackish.

Figure 133.-Localities for Itoplectis fustiger.

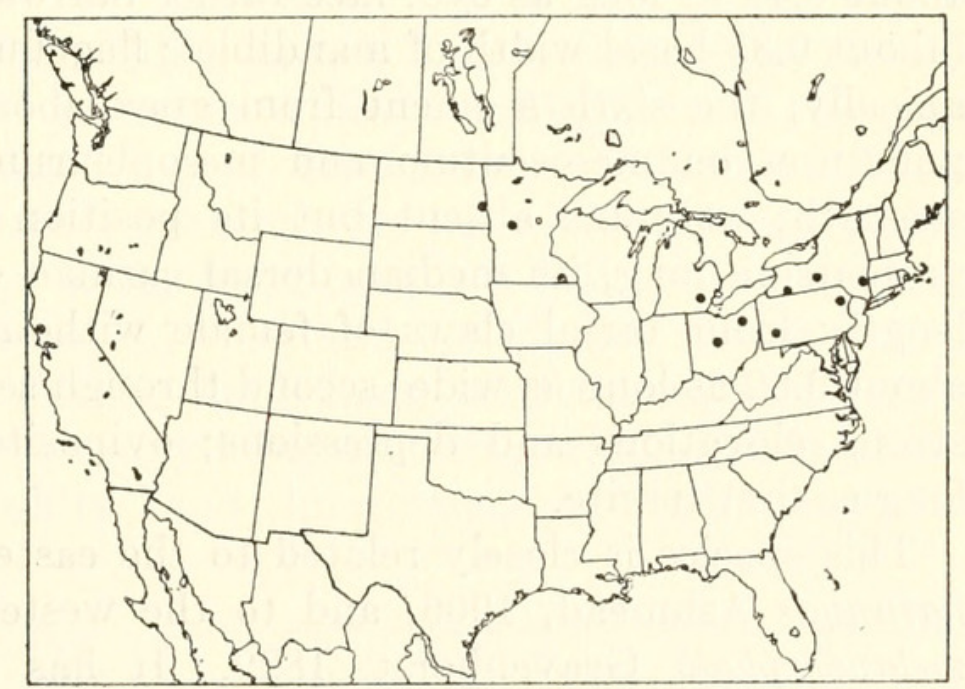

In 1940 (loc. cit.) this species was thought to be only a Nearctic variant of the European Itoplectis clavicornis Thomson, 1889. It is now considered to be a distinct species, differentiated by the more elongate body and flagellum, entirely fulvous hind coxa, less fuscous at base of hind tibia, and less fulvous on front and middle legs.

Type: $\%$, in rich woods of stream bottom, between first and second reservoirs of Six Mile Creek, Ithaca, N. Y., June 2, 1936. H. Townes (Washington, USNM 63712). 
Paratypes (21 $\left.\sigma^{7}, 20 \%\right)$ : From California (Cazadero); Michigan (Washtenaw Co.); Minnesota (Camp Carlos at Alexandria and Fillmore Co.); New York (Ithaca, Rhinebeck, and Rock City in Cattaraugus Co.); North Dakota (Fargo); Ohio (Akron and Delaware Co.); Pennsylvania (Spring Brook and Youngwood); and Quebec (Canton).

Collecting dates are mostly from May 15 to June 2. Those outside of this range are: March 31 at Cazadero, Calif.; June 26 at Camp Carlos, Alexandria, Minn.; and July 27 at Rhinebeck, N. Y. We have found the species in rich, deciduous woods, flying among the undergrowth and around the tips of branches at 0.2 meter to 0.6 meter above the ground.

The only rearing record is: $\sigma^{x}$, reared from Neuroptera, Canton, Que., C. T. Masham. The closely related Itoplectis clavicornis, of Europe, has been reared as a secondary parasite of Macrocentrus and of two species of Phobocampe. I. fustiger may have the same habits.

This species is transcontinental in the Transition zone. It is adult in late spring and early summer.

\section{Itoplectis curticauda (Kriechbaumer)}

Front wing 7.7 to $9.0 \mathrm{~mm}$. long; temple rather weakly convex, about 0.47 as long as eye; face rather narrow; cheek unusually short (about 0.35 basal width of mandible); flagellum very weakly enlarged apically, the sixth segment from apex about 1.3 as long as wide; punctures on mesoscutum and mesopleurum of moderate size and strength; notaulus absent but its position marked by rugulosity; propodeum long, its median dorsal carinae extending about 0.7 its length; front tarsal claws of female without a tooth; third tergite about 0.80 as long as wide; second through seventh tergites with very strong elevations and depressions; ovipositor sheath about 0.9 as long as first tergite.

This species is closely related to the eastern Palaearctic Itoplectis naranyae Ashmead, 1906, and to the western Palaearctic Itoplectis melanocephala Gravenhorst, 1829. It has two subspecies, one in Europe and one in eastern North America, separable on color as keyed and described below:

1. Hind femur faintly infuscate at apex; middle tibia with an indistinct whitish subbasal band or with none; combined basal area and areola about 2.5 as long as wide; range: Europe . 8a. curticauda curticauda (Kriechbaumer)

Hind femur strongly infuscate at apex (fig. 326 ,d); middle tibia with a distinct whitish subbasal band; combined areola and basal area about 3.2 as long as wide; range: North America . . . 8b. curticauda brevacus Townes 


\section{8a. Itoplectis curticauda curticauda (Kriechbaumer)}

Pimpla curticauda Kriechbaumer, 1887, Ent. Nachr., vol. 13, p. 120; ९. Type: q, near Munich (?Munich).

Black. Flagellum light reddish brown, fuscous above; palpi dark brown; tegula and hind corner of pronotum pale yellow to fulvous; front leg fulvous, its coxa more or less fuscous and its femur apically in front and its tibia and tarsus more or less pale fulvous or yellowish; middle leg fulvous, its tibia often with a faint subbasal yellowish ring; hind coxa, trochanters, and femur fulvous, the hind femur very faintly infuscate at apex; hind tibia blackish brown, with a premedian white band; hind tarsus fuscous, the basal $0.8,0.7,0.6$, and 0.3 of the first through fourth segments respectively, whitish, the basal 0.3 of the fifth segment dirty whitish.

Described from one male and six females from four localities in Germany. This subspecies seems to be widespread in Europe, but usually scarce.

\section{8b. Itoplectis curticauda brevacus Townes, new status}

Figure 326,d

Itoplectis brevacus Townes, 1940, Ann. Ent. Soc. America, vol. 33, p. 315; .

Type: + , Bar Harbor, Maine (Washington).

Black. Flagellum light reddish brown below; palpi dark brown; tegula and hind corner of pronotum white; front leg fulvous, its coxa more or less infuscate; middle coxa, trochanter, and femur fulvous, the femur whitish at extreme apex; middle tibia fulvous, with a subbasal whitish band, basad of the band usually a little infuscate; middle tarsus fulvous, the basal $0.7,0.6$, and 0.3 of first through third segments respectively, whitish; hind coxa, trochanters, and femur fulvous, the femur rather broadly infuscate at apex; hind tibia blackish, with a premedian white band; hind tarsus blackish, the basal

Figure 134.-Localities for Itoplectis curticauda brevacus.

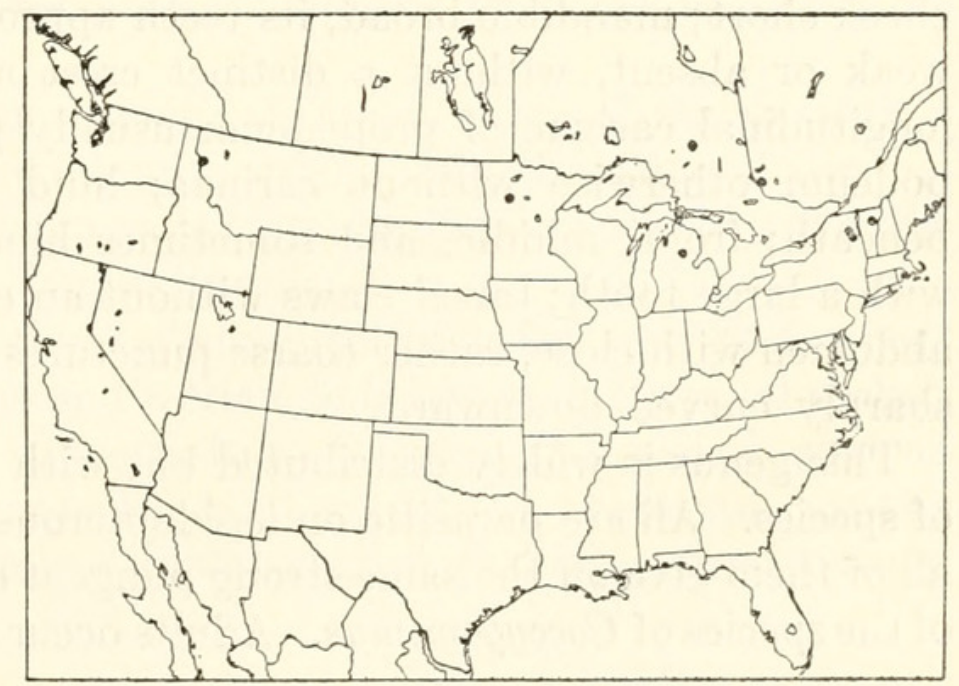


$0.8,0.7,0.6$, and 0.3 of the first through fourth segments respectively, white, the extreme base of fifth segment pale.

Specimens: $\odot$ (type), Bar Harbor, Maine, July 5, 1935 (Washington). ㅇ, Roscommon Co., Mich., July 3, 1945, R. R. Dreisbach (Ann Arbor). $\quad \sigma^{\top}$, Rudyard, Mich., June 4, 1957, H. Townes (Townes). ९, Itasca State Park, Minn., July 4, 1954, K. J. Kraft (St. Paul). o, Haugan, Mont., Aug. 9, 1931, R. H. Beamer (Lawrence). क, Heart Lake on Mount Marcy at 2,150 ft., N. Y., July 4, 1938, C. P. Alexander (Townes). $\sigma^{\top}$, Saranac Lake, N. Y., June 8, 1946, R. T. Mitchell (Townes). \%, Smoky Falls on the Mattagami River, Ont., July 26, 1934, G. S. Walley (Ottawa). ค, Laniel, Que., July 8, 1944, A. R. Brooks (Ottawa). o, Mount Lyall, Que., July 27, 1933, W. J. Brown (Ottawa). ㅇ, Plainfield, Vt., July 20-24, 1941, R. H. McCauley (Townes).

This subspecies occurs from the Atlantic to Montana, in the Canadian zone. It is scarce in collections.

\section{Genus Ephialtes}

Figure 298,b

Ephialtes Schrank, 1802, Fauna boica, vol. 2, p. 316. Type: Ichneumon compunctor Linnaeus; monobasic.

Apechthis Foerster, 1868, Verh. Naturh. Ver. Rheinlande, vol. 25, p. 164. Type: (Pimpla rubata (!) Gravenhorst)=rufatus Gmelin; designated by Ashmead, 1900.

Apechtis Thomson, 1889, Opuscula entomologica, fasc. 12, p. 1410. Type: Apechtis flavonotata (Holmgren); designated by Viereck, 1914.

Taiwatheronia Sonan, 1936, Trans. Nat. Hist. Soc. Formosa, vol. 26, p. 256. Type: (Taiwatheronia mahasenae Sonan)=taiwana Uchida; original designation.

Parapechthis Blanchard, 1936, Anal. Soc. Cient. Argentina, vol. 122, p. 404. New synonymy. Type: Parapechthis bazani Blanchard; original designation.

Front wing 5 to $13 \mathrm{~mm}$. long; inner margin of eye rather strongly concave opposite antennal socket; labrum hidden beneath clypeus; cheek short; mandible broad, its teeth approximately equal; notaulus weak or absent, without a distinct crest at its front end; median longitudinal carinae of propodeum usually present basally, the propodeum otherwise without carinae; hind femur without a tooth beneath; front, middle, and sometimes hind tarsal claws of female with a large tooth; tarsal claws without an enlarged, flat-tipped hair; abdomen with close, rather coarse punctures; tip of ovipositor always sharply curved downward.

This genus is widely distributed but with only a moderate number of species. All are parasitic on lepidopterous pupae. When captured all of them give off the same strong pungent odor that is characteristic of the species of Coccygomimus. Adults occur mostly among the under- 
growth of forests at 0.5 to 2 meters above the ground, but it might be that $E$. ontario, which we have seldom seen in life, flies higher. There are five Nearctic species.

\section{Key to the Nearctic species of Ephialtes}

(The female of E. componotus is unknown; it will probably trace to pacificus.)

1. First tergite in side view convex above, but not pyramidally elevated near the middle; hind tarsal claws of female without a tooth.

5. ontario (Cresson)

First tergite in side view pyramidally elevated near the middle; hind tarsal claws of female with a large internal tooth . . . . . . . . . . . . 2

2. Males . . . . . . . . . . . . . . . . . . . . . 3

Females . . . . . . . . . . . . . . . . . . . . . 6

3. Mesoscutum entirely black . . . . . . . . . . . . . . . . 4

Mesoscutum with a white mark at front end of notaulus . . . . . . . . 5

4. Basal two segments of hind tarsus black, or brown with their apices black; face yellowish white, usually with a central biack stripe and a black triangle under each antennal socket. . . . . . . . . 1. picticornis (Cresson)

Basal two segments of hind tarsus white, their apices blackish; face entirely white . . . . . . . . . . . . 2. annulicornis (Cresson)

5. Mesosternum and propleurum entirely black . . . 3. pacificus (Cushman) Mesosternum and propleurum white . . . . . 4. componotus (Davis)

6. Mesoscutum with a white mark at front end of notaulus.

3. pacificus (Cushman)

Mesoscutum entirely black . . . . . . . . . . . . . . . . . . . . 7

7. Tegula mostly brown or blackish; basal two segments of hind tarsus brown with their apices darker (fig. 326,e); hind tibia with a yellowish white band that covers less than a third of its length. . . . 1. picticornis (Cresson)

Tegula white; basal two segments of hind tarsus white with their apices blackish (fig. 326,f); hind tibia with a white band that covers a little less than half its length.

2. annulicornis (Cresson)

\section{Ephialtes picticornis (Cresson)}

Figure 326,e

Pimpla picticornis Cresson, 1870, Trans. Amer. Ent. Soc., vol. 3, p. 146; ه Type: $\sigma^{\top}$, New Jersey (Philadelphia).

Apechthis ornatulus Walley, 1929, Canadian Ent., vol. 61, p. 190; ఠ'. Type: $\sigma^{\top}$, Aweme, Man. (Ottawa).

Front wing 7.3 to $13 \mathrm{~mm}$. long; all tarsal claws of female with a prominent basal tooth; first tergite subpyramidally elevated just behind the middle. The abdomen is very slightly less coarsely and distinctly punctate than in E. annulicornis.

Male: Similar in coloration to female except as follows: Face except usually for a central stripe and a triangle below each antennal socket, small spot at top of eye, clypeus, front of scape and pedicel, spot on mandible, palpi, tegula, usually hind corner of pronotum, usually subtegular ridge, and rarely a discal pair of dashes on mesoscutum, 
white or yellowish white; hind tarsus entirely black except for base of first segment or base of first and second segments.

Female: Black. Small orbital mark just below antennal socket and spot near base of mandible pale yellow; front of scape more or less reddish; flagellum in front yellowish white, grading to orange at apex; apical one or two segments of maxillary palpus somewhat orange; tegula brown or blackish, yellowish laterally; apex of scutellum and of metanotum white; most of front coxa and narrow apex above of hind femur blackish; apical $0.5 \pm$ and basal $0.23 \pm$ of hind tibia, apices of first three segments of hind tarsus, and all of last two segments of hind tarsus black, the rest of the tibia and tarsus brownish yellow; rest of legs fulvous, the front and middle legs varied with whitish.

Specimens (93 $\sigma^{\top}, 111$ ) : From Alberta (Banff, Beaverlodge, Edmonton, Elkwater Park, and Waterton); British Columbia (Mount Revelstoke and Robson); California (Berkeley, Inverness, Leona Heights in Oakland, Mesa Grande, Mill Valley, Niles, Oakland, Ryan Creek in Mendocino Co., Shingle Spring in El Dorado Co., Sonoma Co., and Zenia); Colorado (near Estes Park and Steamboat Springs); Maine (Bar Harbor, Fort Kent, and Mount Katahdin); Manitoba (Aweme); Massachusetts (Brookline and Lexington); Michigan (Bay Co., Cheboygan Co., Clare Co., Dickinson Co., Douglas Lake, Gladwin Co., Gratiot Co., Gull Lake Biological Station in Kalamazoo Co., Huron Mt. in Marquette Co., Iosco Co., Iron Co., Kalkaska Co., Keweenaw Co., Luce Co., Mackinac Co., Midland Co., Missaukee Co., Ontonagon Co., Osecola Co., Presque Isle Co., Roscommon Co., St. Clair Co., and Whitefish Point in Chippewa Co.); New Brunswick (Campbellton, Fredericton, Kings Co., and Nerepis); New Hampshire (Pinkham Notch and Randolph); New Mexico (Cimarron at 6,800 ft., Hondon Canyon in Taos Co., and Jemez Springs); New York (Bemus Point, Crystal Lake in Cattaraugus Co., Greene Co., Ithaca, Oneonta, Shokan, and Troy); North Carolina (Mount Mitchell); North Dakota (Greenwood's Slough near Grand Forks); Nova Scotia (Aldershot, Baddeck, Berwick, Big Intervale Camp at Cape Breton Highlands National Park, "Grafton," Kentville, Smiths Cove, and Starr's Point); Ontario (Bancroft, Bells Corners, Brent, "Cloud Bay," Flint, Hymers, Kapuskasing, Nicholson, Ottawa, and Woodlawn); Prince Edward Island (Brackley Beach in Canadian National Park); Quebec (Aylmer, Cap Chat, Cap Rouge, Covey Hill, Cross Point on Gaspé Peninsula, Gracefield, Kazabazua, Lac Mercier, Lacoste, Montigny, Montreal Island, Norway Bay, Ste. Agathe des Monts, Stoneham, and Sweetsburg); Utah (Salt Lake); Vermont (Laurel Lake near Jacksonville); Washington (Ashford, Bead Lake near Newport, and Randle); and West Virginia (Cheat Mt. in Randolph Co.).

Dates of collection are mostly in the summer, but some are in late 
spring and early fall. The seasonal range is longer in California than elsewhere. Unusually early and late dates of capture are: March 13, 28, and 30, and April 2, 12, 21, 22, 24, and 30 at Berkeley, Calif.; April 10, 11, 18, and 23 at Oakland, Calif.; May 17 and 22 at Ithaca, N. Y.; September 3 at Troy, N. Y.; September 19 at Niles, Calif.; September 24 at Campbellton, N. B.; October 4 at Robson, B. C.; October 6 at Inverness, Calif.; and November 5 and 6 at Oakland, Calif. According to our collecting, the usual habitat is deciduous woods with undergrowth.

Rearing records are: 1 rearing from Choristoneura conflictana, 3 from $C$. rosaceana, 1 from $C$. rosaceana?, 1 from Sciaphila sp., 1 from Geometridae, 2 from Noctuidae, 1 from Tortricidae, and 1 from "Cacoecia" on Quercus.

This species is transcontinental in the Canadian and Transition zones. Adults occur in the undergrowth of woods, mostly in summer. It has been reared from several Lepidoptera, mostly Tortricidae.
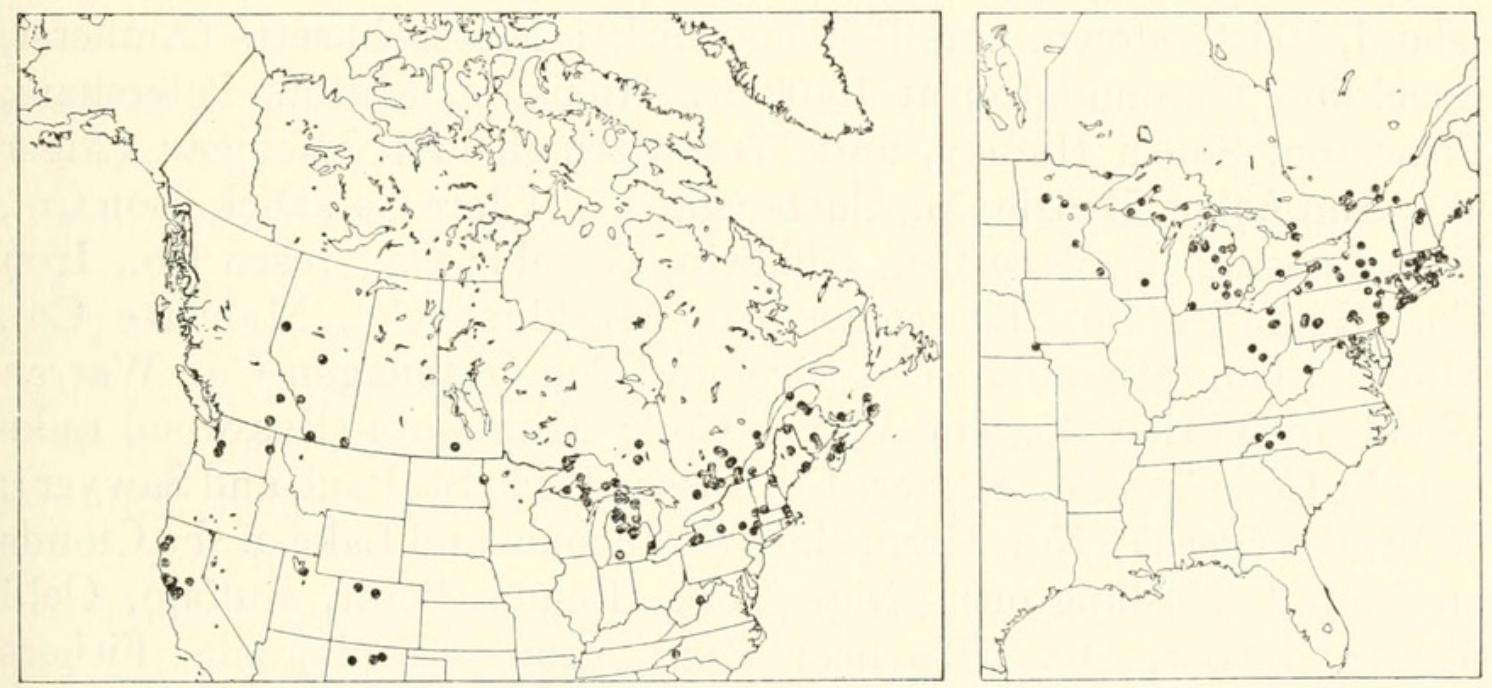

Figures 135, 136.-Localities: 135 (left), Ephialtes picticornis; 136 (right), E. annulicornis.

\section{Ephialtes annulicornis (Cresson)}

Figure $326, \mathrm{f}$

Pimpla annulicornis Cresson, 1870, Trans. Amer. Ent. Soc., vol. 3, p. 147; $\sigma^{\top}$, $ๆ$. Lectotype: $\sigma^{\top}$, Illinois (Philadelphia).

Front wing 8 to $12 \mathrm{~mm}$. long; all tarsal claws of female with a prominent basal tooth; first tergite subpyramidally elevated just behind the middle. The abdomen is very slightly more coarsely and distinctly punctate than in E. picticornis.

Male: Similar to female coloration except as follows: Face, clypeus, palpi, subtegular ridge, and most of front coxa, white; white markings on front and middle legs somewhat more extensive than in female; 
white band on hind tibia occupying slightly more than half of its length.

Female: Black. Most of front orbit, often a small orbital spot at top of eye, front of scape and pedicel, hind corner of pronotum, tegula, and apex of scutellum and of metanotum, white; flagellum in front yellowish white basally, grading to orange apically; spot on mandible whitish; apical three or four segments of maxillary palpus and apical segment of labial palpus pale; basal $0.65 \pm$ of front coxa blackish; apex of hind femur above dusky; hind tibia black with a white band occupying slightly less than its middle half; hind tarsus whitish, the apex of first three segments and all of last two segments except sometimes their extreme bases, blackish; rest of legs fulvous, the front and middle legs varied with whitish.

Specimens (121 $0^{x}, 170$ \%): From Alberta (McMurray); Connecticut (Canaan, Ledyard, North Stonington, South Windsor, and Stonington); District of Columbia (Washington); Maine (Medomak); Maryland (Bowie, Cabin John, Glen Echo, Hagerstown, Plummers Island, Reisterstown, and Takoma Park); Massachusetts (Amherst, Brookline, Cummington at 1,400 ft., Holliston, Milton, Petersham, Princeton, South Hadley, and West Springfield); Michigan (Alger Co., Ann Arbor, Benzie Co., Cheboygan Co., Clare Co., Dickinson Co., East Lansing, Genesee Co., Gladwin, Gogebic Co., Iosco Co., Iron Co., Kalkaska Co., Keweenaw Co., Mackinac Co., Manistee Co., Midland Co., Missaukee Co., Ogemaw Co., Ontonagon Co., Warren Woods in Berrien Co., and Wayne Co.); Minnesota (Basswood Lake in Lake Co., Cass Co., Filmore Co., Itasca Park, St. Paul, and Sawyer); Nebraska (Peru); New Hampshire (Franconia and Lake of the Clouds on Mount Washington); New York (Bemus Point, Buffalo, Cold Spring Harbor, Dix Hills near Huntington, Farmingdale, Fishers Island, Geneva, Greene, Hancock, Huntington, Ithaca, Millwood, New Berlin, New York City, North Petersburg, Nyack, Oliverea, Oswego, Otter Lake, Poughkeepsie, Rome, Saranac, Sea Cliff, Tarrytown, and Tonawanda Indian Reservation in Genesee Co.); North Carolina (Crabtree Meadows in Yancey Co. at 3,600 ft. and Pisgah Mt. at 4,800 to 5,300 ft.); Ohio (Akron, "Ash," Barberton, Columbus, Hocking Co., and Puritas Springs in Cuyahoga Co.); Ontario (Gravenhurst, Merivale, Orillia, Ottawa, Simcoe, and Toronto); Pennsylvania (Castle Rock in Delaware Co., Crisp in Westmoreland Co., Enola, Hummelstown, Inglenook in Dauphin Co., Kennywood, North East, Philadelphia, Pittsburgh, Paupack, Roxborough, Spring Brook, and Swiftwater); Quebec (Knowlton, Montreal, Old Chelsea, St. Esprit, and Wakefield); Rhode Island (Westerly); Tennessee (Newfound Gap at 5,000 to 6,200 ft.); Virginia (Great Falls); West Virginia 
(Bolivar and Cheat Mt. at 2,000 ft. in Randolph Co.); and Wisconsin (Madison).

Dates of collections are rather evenly distributed from spring to early fall. Unusually early and late records are: April 15 at Holliston, Mass.; April 24 at Cold Spring Harbor, Long Island, N. Y.; May 1 at Madison, Wis.; May 5 in Wayne Co., Mich.; May 7 at Hagerstown, Md.; September 11 and 13 at Madison, Wis.; September 23 at St. Paul, Minn.; September 26 at Bolivar, W. Va.; and October 2 in Midland Co., Mich. In our collecting, we have found it in undergrowth of deciduous woods.

There are two rearing records: $\sigma^{\top}$, reared from Choristoneura fumiferana, Saranac, N. Y., July 27, 1948. $\sigma^{7}$, reared from Choristoneura rosaceana, Old Chelsea, Que., July 27, 1937, G. A. Hobbs.

This is a species of the Alleghanian fauna. Adults occur from spring to early fall. Two species of Choristoneura are recorded as hosts.

\section{Ephialtes pacificus (Cushman)}

Figure 326 ,g

Apechthis pacificus Cushman, 1920, Proc. U. S. Nat. Mus., vol. 58, p. 353; ðヤ, ๆ .

Type: $q$, Portland, Oreg. (Washington).

Front wing 7.5 to $10.5 \mathrm{~mm}$. long; all tarsal claws of female with a prominent basal tooth; first tergite subpyramidally elevated just behind the middle. The abdominal punctation is a little denser and stronger than in E. annulicornis.

Male: Face except for a central stripe and a triangle below each antennal socket, clypeus, and palpi, white. Otherwise similar in color to the female.

Female: Black. Most of front orbit and a small orbital mark at top of eye, spot on hind orbit ventrally, small lateral spot on clypeus, mandible, front of pedicel, hind corner of pronotum, tegula, subtegular ridge, triangle on each side of mesoscutum at notaulus, a pair of discal dashes on mesoscutum, and apex of scutellum and of metanotum, white; clypeus brown; maxillary palpi white, brown behind; labial palpi brown; flagellum below dull orange, whitish basally; front coxa blackish, white apically; middle tibia with a broad white premedian band, somewhat dusky basad and apicad of the band; apex of hind femur fuscous; hind tibia black with a submedian white band occupying about 0.4 its length; first segment of hind tarsus white, its apical $0.3 \pm$ infuscate; second segment of hind tarsus fuscous, its basal 0.25 whitish; third through fifth segments of hind tarsus fuscous; rest of legs fulvous, the front and middle legs varied with whitish.

This "species" may prove to be only a subspecies or race of $E$. componotus, with reduced white markings. 
Specimens: ণ, Mount Campbell, B. C., July 17, 1947 (Ottawa). 2 ㅇ, Victoria, B. C., Sept. 2 and 16, 1917, W. B. Anderson (Ottawa). , Victoria, B. C., Sept. 24, 1904, A. U. Hanham (Ottawa). ㅇ, reared from "looper," Victoria, B. C., J. R. Anderson (Ottawa). ণ, Antelope Mt. at 6,500 ft., Harney Co., Oreg., Aug. 11, 1931, D. K. Frewing (Washington). + , Antelope Mt. at 6,500 ft., Harney Co., Oreg., Aug. 23, 1931, D. K. Frewing (Townes). $4 \sigma^{\top}, 3$ 우 (type and paratypes), reared from Orgyia antiqua, Portland, Oreg., Apr. 18, 22, and 24, and May 3, 1918, E. J. Newcomb (Washington).

This species is known only from British Columbia and Oregon.

\section{Ephialtes componotus (Davis)}

Pimpla componotus Davis, 1898, Trans. Amer. Ent. Soc., vol. 24, p. 367; ơ . Type: $\sigma^{x}$, Moscow, Idaho (Philadelphia).

Male: Front wing about $8.0 \mathrm{~mm}$. long. Structure similar to that of E. pacificus.

Black. Face, clypeus, front orbit, subtriangular area at top of eye, cheek, stripe next eye on lower part of temple, mouthparts except apical part of mandible, scape and pedicel in front, base of flagellum in front, lower half of propleurum, large hind corner of pronotum, large subtriangular area on mesoscutum at front end of notaulus, a median pair of longitudinal stripes on mesoscutum, apical $0.6 \pm$ of scutellum, postscutellum, part of prepectus, most of mesosternum, and subtegular ridge, white; front coxa, trochanters, tibia, and tarsus white, the tibia above tinged with fulvous and with a faint submedian infuscation; front femur fulvous, whitish in front; middle coxa fulvous, white below; middle trochanters and femur fulvous, the femur white at apex and in front, and the second trochanter pale fulvous; middle tibia white, its base infuscate, with an elongate subapical fuscous
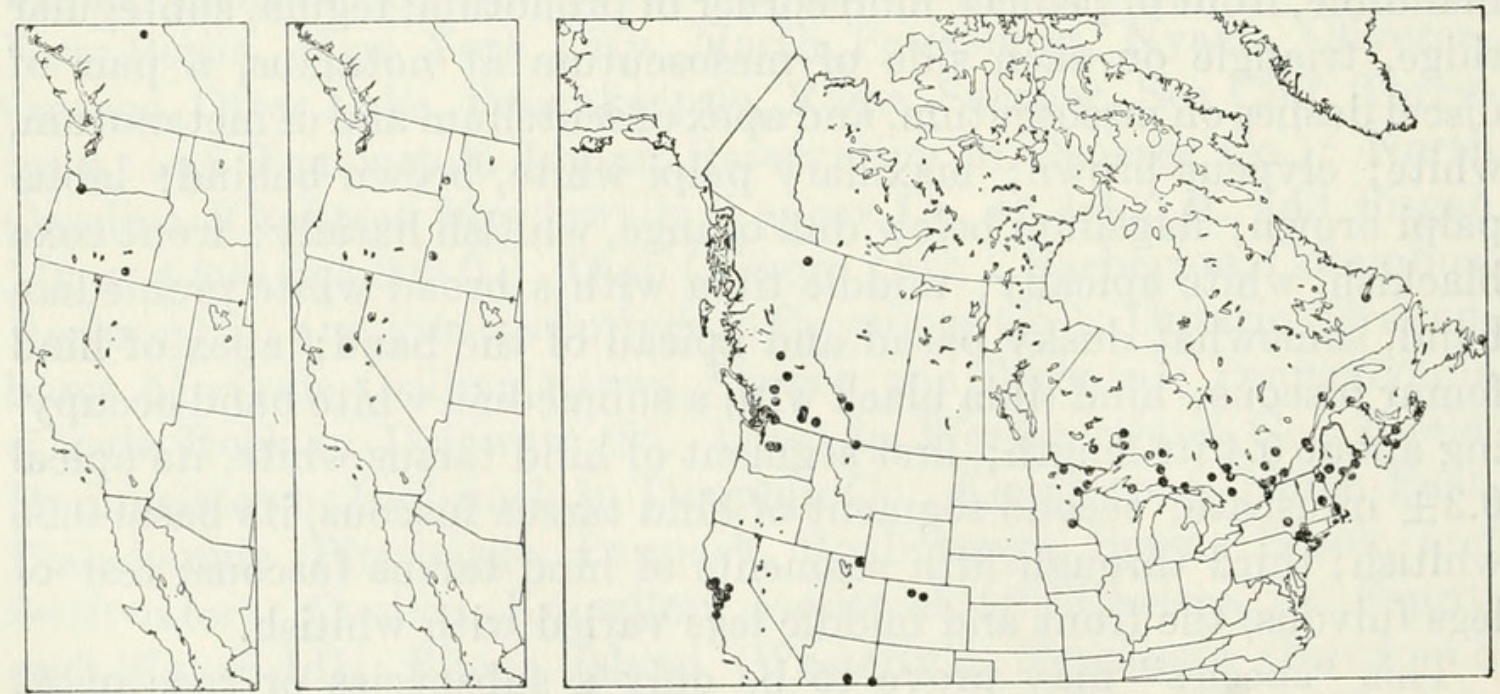

Figures 137-139.-Localities: 137 (left), Ephialtes pacificus; 138 (center), E. componotus; 139 (right), E. ontario. 
blotch dorsally; middle tarsus white, the apex of segments 1-4 brownish, the apical 0.3 of segment 5 fuscous; hind coxa, first trochanter, and femur fulvous, the apical $0.17 \pm$ of the femur fuscous; hind second trochanter pale fulvous; hind tibia blackish, with a broad premedian white band; hind tarus whitish, the apex of first three segments, all of fourth segment, and apical 0.6 of fifth segment blackish.

Female: Unknown.

Specimens: $\sigma^{7}$, "Abies concolor", North Fork of Mokelumne River, Calif., Aug. 11, 1954, G. L. Downing (Washington). $\sigma^{7}$ (type), Moscow, Idaho, J. M. Aldrich (Philadelphia). $\sigma^{7}$, from Hemerocampa leucostigma, Silver City, Idaho, Sept. 10, 1957, W. E. Cole (Washington).

\section{Ephialtes ontario (Cresson)}

FiguRE 326 ,h

Pimpla ontario Cresson, 1870, Trans. Amer. Ent. Soc., vol. 3, p. 146; ð'. Type: $\sigma^{7}$, Canada (Philadelphia).

Front wing 5.2 to $11 \mathrm{~mm}$. long; front and middle tarsal claws of female each with a prominent basal tooth; hind tarsal claw of female simple; first tergite rather weakly elevated at about two-thirds its length.

Male: Similar in coloration to female except that face, front orbit, clypeus, mandible, palpi, scape beneath, and tegula are white, and that the legs have slightly more extensive white markings.

Female: Black. Front orbit below antennal socket, sometimes above antennal socket, and at summit, narrowly yellowish white; clypeus orange to black; front of pedicel and of flagellum whitish, the flagellum grading to dusky orange toward apex; mandible usually with a pale spot; maxillary palpus orange; labial palpus dusky orange; tegula white to brown; hind corner of pronotum, apex of scutellum, and apex of metanotum, white; front coxa blackish at base; middle tibia with a distinct white band, more or less dusky basad of the band and sometimes dusky apicad of it; hind tibia black or sometimes dusky fulvous, with a white band occupying from one-fourth to nearly half its length; hind tarsus blackish, the first segment except its apex and usually the base of second segment whitish; rest of legs fulvous, the front and middle legs varied with whitish.

Specimens (99 $\sigma^{\Upsilon}, 208$ ) : From Alaska (Kodiak); Alberta (Banff and Lake Louise); Arizona (near Alpine and Workman Creek in the Sierra Ancha); British Columbia (Alaska Highway at Mile 415, Burrard Inlet near Vancouver, Chilliwack, Clinton, Colwood, Cultus Lake, Diamond Head Trail in Garibaldi Provincial Park near Squamish, Genoa Bay at Duncan, Golden, Haines, Indian River, Jesmond, Lytton, Malahat on Vancouver Island, Robson at 1,450 ft., Salmon 
Arm, Stanley, Vancouver, Vernon, Victoria, and Wellington); California (Berkeley, Big Basin, Inverness, Mill Valley, Oakland, hills back of Oakland, Pacific Grove, Portola State Park in San Mateo Co., Walnut Creek, and Woodacre in Marin Co.); Colorado (near Estes Park and Rabbit Ears Pass); Labrador (Goose Bay); Maine (Calais, Isle au Haut, Liberty, Rangeley, and Roque Bluffs); Massachusetts (Boston and Nahant); Michigan (Marquette Co. and Whitefish Pointin Chippewa Co.); Minnesota (Basswood Lake in Lake Co., Koochiching Co., Ramsey Co., Sawyer, and St. Louis Co.); Montana (Glacier National Park); New Brunswick (Pokemouche); Newfoundland (St. John's); New Hampshire (Lake of the Clouds on Mount Washington and Mount Monadnock); New York (Copake Falls, Fire Island, Flatbush, New Rochelle, Nyack, swamp near Oneonta at 1,900 ft., and Slide Mt. at 2,800 to 4,000 ft.); Nova Scotia (Cape Breton, Halifax, Kentville, St. Peters, and Truro); Ontario (Abitibi region, Algonquin, Almonte, Biscotasing, Frater, Geraldton, "Haywood," "Hobon Lake," Ignace, Mattawa, Merivale, Ombabika, Ottawa, Regan, Thessalon, Westree, and White River); Quebec (Cap Rouge, Cross Point on the Gaspé Peninsula, Forestville, Laniel, Montigny, Montreal Island, Mount Joli, Nominingue, Quebec, and St. Godefroy); Utah (Spring Hollow in Logan); and Washington (Ashford and Mount Rainier).

Most dates of collection are from June to September, but in the West there are a number of dates in April, May, and October, two in March, and one in November. Most of the March to May specimens are from the San Francisco area. Noteworthy early and late dates of capture in the West are: March 21 at Pacific Grove, Calif.; March 28 at Woodacre, Calif.; April 29 at Berkeley, Calif.; April 30 at Oakland, Calif.; April 30 and May 1 at Workman Creek, Sierra Ancha, Ariz.; May 6 at Robson, B. C.; October 19 at Chilliwack, B. C., and at Wellington, B. C.; October 22 at Cultus Lake B. C.; and November 8 in hills back of Oakland, Calif. Early and late dates of capture in the East are: May 15 at Ottawa, Ont.; May 26 at Isle au Haut, Maine: May 31 at Rangeley, Maine; September 18 at Rockcliffe, Ont.; September 20 at Calais, Maine; and September 24 at Kentville, N. S. Judging from the data on the pin labels and from our own relatively infrequent captures, the species seems to occur mostly around northern Coniferae.

Reared specimens comprise: 27 reared lots from Choristoneura fumiferana, 2 from Lambdina fiscellaria, 1 from ?Nepytia canosaria, and 3 from undetermined Lepidoptera.

This species is transcontinental in the Canadian zone and occurs locally in the Transition zone. Adults occur mostly from late spring to early fall. The usual hosts are Lepidoptera on northern Coniferae. 


\section{Genus Coccygomimus}

Figure 299,a

Pimpla of many authors, not of the genotype.

Ephialtes of certain American authors, not of the genotype.

Coccygomimus Saussure, 1892, In Grandidier, Histoire physique, naturelle et politique de Madagascar, vol. 20 (Hyménoptères), pt. 1, pl. 14, fig. 12. Type: Coccygomimus madecassus Saussure; monobasic.

Habropimpla Cameron, 1900, Mem. Proc. Manchester Lit. Philos. Soc., vol. 44, p. 96. New synonymy. Type: Habropimpla bilineata Cameron; monobasic. Lissotheronia Cameron, 1905, Spolia Zeylanica, vol. 3, p. 139 . Type: Lissotheronia flavipes Cameron; monobasic.

Phytodiaetoides Morley, 1913, Fauna of British India . . Hymenoptera, vol. 3, p. 221. New synonymy. Type: (Phytodiaetoides megaera Morley)= flavipalpis (Cameron); monobasic.

Pimplidea Viereck, 1914, Proc. U. S. Nat. Mus., vol. 83, p. 117. Type: Pimpla pedalis Cresson; original designation.

Liotheronia Enderlein, 1919, Sitz.-Ber. Ges. Naturf. Freunde Berlin, vol. 1919, p. 147. New synonymy. Type: Liotheronia kriegeri Enderlein; original designation.

Dihyboplax Enderlein, 1919, Sitz.-Ber. Ges. Naturf. Freunde Berlin, vol. 1919, p. 148. New synonymy. Type: Dihyboplax flavipennis Enderlein; original designation.

Neogabunia Brèthes, 1927, Ent. Mitt., vol. 16, p. 322. New synonymy. Type: Neogabunia paulistana Brèthes.

Opodactyla Seyrig, 1932, Mém. Acad. Malgache, vol. 11, p. 60. Type: Pimpla (Opodactyla) waterloti Seyrig; original designation.

Oxypimpla Noskiewicz and Chudoba, 1951, Polskie Pismo Entomologisezne, vol.

21, p. 42,56 . New synonymy. Type: Pimpla turionellae Linnaeus; monobasic.

Front wing 3.2 to $17.5 \mathrm{~mm}$. long; inner margin of eye weakly concave above antennal socket; labrum hidden beneath clypeus; cheek usually long; mandible broad, its apical teeth approximately equal; notaulus weak or absent, without a distinct crest at its front end; median longitudinal carinae of propodeum usually present basally, the propodeum otherwise without carinae (except sometimes for a sublateral longitudinal ridge); hind femur without a tooth beneath; tarsal claws of both sexes large, simple, without an enlarged hair with a flattened tip; abdomen usually with close punctures but sometimes sparsely punctured or almost impunctate; ovipositor approximately straight, its tip not sharply curved downward.

This is a worldwide genus with many species. Their habitat is usually in woods, on low vegetation near the ground. Females spend much time on the ground and on low vegetation. The usual hosts are probably pupae and prepupae under ground litter. All the species give off a strong, pungent odor when captured. Many of the species are very common. 
The genus Strongylopsis is close to Coccygomimus and possibly represents only an aberrant group of species. We have seen three species of Strongylopsis (the genotype and two undescribed species), all from eastern Europe. They differ from typical Coccygomimus in a more depressed, elongate form, wider and more convex face, and wider, flatter clypeus. In some species the apical margin of the male subgenital plate is weakly concave rather than prolonged.

The species of Coccygomimus are divisible into more or less natural groups, of which four occur in the Nearctic region. The main characters for distinguishing the Nearctic species groups are in the widths of the epipleura. It is probable that these groups, as defined, are only partially natural, but they are nevertheless useful. The species hesperus and stricklandi present the main difficulty in the practical application of the groupings, as on the basis of epipleural characters the males of these two would go in the sodalis group and the females in the CONTEMPLATOR group. They are assigned, rather arbitrarily, to the contemplator group. If these two species were eliminated it would be practical to make a key to the Nearctic species following relatively natural lines, but with their presence it has seemed better to resort to an artificial key, as below.

Some judgment and experience are needed in the interpretation of the epipleural characters, as in individual specimens the epipleural widths vary somewhat with the sex and size. Males tend to have all epipleura narrower than females, and small specimens of both sexes tend to have them narrower than larger specimens of the same sex and species.

Walkley (1958, U. S. Dep. Agr., Agr. Monogr., no. 2, 1st. suppl., p. 38) has recorded the European Coccygominus turionellae (Linnaeus) 1758, as introduced into Canada and C. aethiops (Curtis) 1828, as occurring in Greenland. According to a letter from her, the record of C. aethiops is based on a published record by Lesse (1952, Bull. Soc. Ent. France, vol. 57, p. 55).

Lesse's specimen has been borrowed from the Paris museum and found to be a small, abnormally dark-colored male of $C$. sodalis, so aethiops can be removed from the list of Nearctic species. It has not, so far, been possible to verify the establishment of $C$. turionellae in Canada, but neither have we found reasons to consider the record incorrect. This species is not included in the treatment below. Specimens will key to $C$. sodalis, from which they differ in having shorter and paler hairs, a premedian white band on the hind tibia, and narrower epipleura on tergites 4 and 5 . 


\section{Artificial key to the Nearctic species of Coccygomimus}

1. Thorax and head entirely ferruginous; abdomen black banded with white.

10. marginellus (Brullé)

Thorax and head black; abdomen black, fulvous, or ferruginous, not banded with white . . . . . . . . . . . . . . . . . . . 2

2. Abdomen ferruginous or fulvous .................. 3

Abdomen black, sometimes the apicolateral corners and the apical margins of its tergites more or less fulvous . . . . . . . . . . . . . . . 4

3. Coxae black; epipleura of third and fourth tergites about 3.5 as long.as wide.

4. ellopiae (Harrington)

Coxae fulvous; epipleura of third and fourth tergites about 1.5 as long as wide. . . . . . . . . . . . . 17. dimidiatus, new species

4. Hind tibia entirely black, without a submedian pale band; nervulus usually postfurcal; first tergite rather long; epipleura of third and fourth tergites about 4.0 as long as wide . . . . . . . . . . . . . . . . . . 5

Hind tibia not entirely black, when largely black or blackish it has a submedian pale band (but entirely black in occasional specimens of $C$. aquilonius exareolatus); nervulus interstitial or briefly postfurcal; first tergite short . . . . . . . . . ... . . . . . . . . . . . . 7

5. Middle and hind coxae fulvous . . . . . . . . 2. pedalis (Cresson)

Middle and hind coxae black . . . . . . . . . . . . . . . . . . 6

6. Hind femur mostly fulvoferruginous; wings hyaline . 1. silvicola (Walley)

Hind femur black; wings moderately infuscate in male, strongly infuscate in female . . . . . . . . . . . . . 3. maurus (Cresson)

7. Trochanters black except that second trochanter of hind leg may be fulvous; coxae black; hairs on head and thorax dark brown . . 6. sodalis (Ruthe)

Trochanters fulvous, or rarely some of them black; coxae fulvous or sometimes black; hairs on head and thorax light gray . . . . . . . . 8

8. Epipleurum of fourth tergite more than 4.0 as long as wide in male, more than 2.2 as long as wide in female (fig. $329, \mathrm{j}$ ); front of scape of male usually marked with white; punctures and hairs on body and legs unusually dense.

5. aquilonius (Cresson)

Epipleurum of fourth tergite less than 3.0 as long as wide in male, less than 2.2 as long as wide in female (figs. $329, \mathrm{k}, \mathrm{l}$ ); front of scape of male entirely black . . . . . . . . . . . . . . . . . . . . . . . 9

9. Hind femur with its apical $0.2 \pm$ fuscous; hind tibia black with a distinct whitish band ..... . . . . . . . . . . . . . . . 10

Hind femur entirely fulvous, or its apical $0.1 \pm$ sometimes faintly infuscate; hind tibia varying from entirely fulvous to black with a white band . 14

10. Epipleurum of second tergite very narrowly wedge-shaped, more than 3.0 as long as wide (fig. 329,k); tegula black . . . . . 7. tenuicornis (Cresson)

Epipleurum of second tergite broadly wedge-shaped, less than 3.0 as long as wide (fig. 329,1); tegula white, brown, or black . . . . . . . . . 11

11. Males. (Males of three species are not distinguishable with certainty. The male of C. nudus is not definitely known.) . . 13. aequalis (Provancher)

14. nudus (Townes)

15. annulipes (Brullé)

Females 
12. Dorsal edge of hind tibia sparsely hairy, some of the hair sockets separated by more than the length of the hairs; tegula black; wings slightly infuscate.

14. nudus (Townes)

Dorsal edge of hind tibia closely hairy, the hair sockets separated by less than the length of the hairs and not sparser than on the rest of the tibia; tegula white, brownish, or rarely black; wings hardly at all infuscate . 13

13. Face sparsely punctate; metapleurum densely punctate and more or less striolate; front tibia moderately swollen at middle; middle tibia dusky fulvous basad of its white band . . . . . . 13. aequalis (Provancher)

Face densely punctate; metapleurum rather sparsely punctate; front tibia rather strongly swollen at middle; middle tibia blackish basad of its white band . . . . . . . . . . . . . 15. annulipes (Brulle)

14. Males . . . . . . . . . . . . . . . . . . . . . . . . 15

Females . . . . . . . . . . . . . . . . 18

15. Epipleurum of second tergite about 2.2 as long as wide; tegula white.

16. punicipes (Cresson)

Epipleurum of second tergite 4.0 to 8.0 as long as wide; tegula white to black, or white basally and brownish apically . . . . . . . . . . . 16

16. Hind tibia uniformly fulvous with its apical $0.1 \pm$ somewhat infuscate; punctures on lower hind part of mesopleurum moderately coarse, their interspaces nearly always less than their diameter; front wing 5.4 to $9.0 \mathrm{~mm}$. long; second to fourth segments of maxillary palpus brown.

\section{9. sanguinipes (Cresson)}

Hind tibia usually more or less infuscate with a more or less distinct paler band subbasally; punctures on lower hind part of mesopleurum rather fine, their interspaces about twice their diameter; front wing 3.5 to $7.2 \mathrm{~mm}$. long . . . . . . . . . . . . . . . . . . . . . 17

17. Tegula entirely white or whitish basally and brownish or blackish apically, sometimes entirely brown or blackish; epipleurum of second tergite about 6.0 as long as wide. (Often not separable with certainty from the following two species)............. 8. varians, new species

Tegula usually entirely white, entirely brown, or black; epipleurum of second tergite about 4.5 as long as wide. (Not separable with certainty from the above species.) . . . . . . . . . 11. hesperus, new species

12. stricklandi, new species

18. Epipleurum of second tergite very narrowly wedge-shaped, about 4.2 as long as wide . . . . . . . . . . . . . . . . . . . . . 19

Epipleurum of second tergite more broadly wedge-shaped, about 2.0 as long as wide . . . . . . . . . . . . . . . . . . . . 20

19. Punctures on lower part of mesopleurum fine and distant, separated by about twice their diameter, the mesopleurum near base of middle coxa sometimes with fine oblique wrinkles in addition to the punctures; metapleurum with fine oblique wrinkles and finely punctate; hind tibia varying from uniformly fulvous to fuscous with a pale submedian band .. 8. varians, new species

Punctures on lower part of mesopleurum coarse and close, separated by less than their diameter, the mesopleurum near base of middle coxa usually with moderately coarse, oblique wrinkles between the punctures; metapleurum moderately, strongly, obliquely rugosopunctate; hind tibia uniformly fulvous except that its apex may be infuscate.

9. sanguinipes (Cresson) 
20. Temple in profile about $\mathbf{0 . 4}$ as long as eye in profile; punctures on submedian part of face moderately dense, separated by about 0.8 their diameter; tegula with its apical 0.3 to $0.8 \pm$ brown or black, the base whitish.

16. punicipes (Cresson)

Temple in profile about 0.6 as long as eye in profile; punctures on submedian part of face rather sparse to very sparse, separated by about 1.0 to 3.0 their diameter; tegula usually uniformly fulvous, brown, or blackish but sometimes whitish at base . . . . . . . . . . . . . . . . . 21

21. Median part of mesoscutum with rather sparse, fine punctures, the punctures separated by a little less than the length of the hairs; punctures on submedian part of face rather sparse, separated by about 1.4 their diameter.

11. hesperus, new species

Median part of mesoscutum with very sparse punctures, the punctures separated by about three times the length of the hairs; punctures on submedian part of face very sparse, separated by about 2.5 their diameter.

12. stricklandi, new species

\section{INSTIGATOR GROUP}

Front wing 5.5 to $15 \mathrm{~mm}$. long; body rather slender; nervulus usually briefly postfurcal; hind tibia without a pale submedian band; propodeum rather long, often with weak sublateral longitudinal ridges, its median longitudinal carinae often distinct on its basal $0.3 \pm$; abdomen finely mat to subpolished, usually rather closely punctate; first tergite rather long, with a rather prominent dorsal hump centered just beyond the middle; epipleura very narrow throughout, all of them more than 3 times as long as wide; upper valve of ovipositor not or only weakly flattened apically and without distinct transverse ridges.

This group is predominantly Holarctic. It includes the four Nearctic species below; the Mexican Pimpla viridescens Morley 1914 and P. thoracica Morley 1914; P. sedula Cameron 1886 from Panama; the Palaearctic $P$. arctica Zetterstedt 1838, Ichneumon instigator Fabricius 1793, and Pimpla luctuosa Smith 1874; the Himalayan $P$. erebus Cameron 1899, P. flavipalpis Cameron 1899, P. indra Cameron 1897, and P. laöthoë Cameron 1897; the Celebes P. nigricolor Tosquinet 1903; and some undescribed species. The species named are all new combinations in the genus Coccygomimus. Pimpla nepe Cameron 1897 and P. poesia Cameron 1899 are synonyms of Coccygomimus läthoë, and Phytodiaetoides megaera Morley 1913 is a synonym of $C$. flavipalpis (new synonymies).

\section{Coccygomimus silvicola (Walley)}

Figure 326,i

Pimpla silvicola Walley, 1941, Canadian Ent., vol. 73, p. 164; ð', ๆ. Type: Steelhead, B. C. (Ottawa).

Front wing 5.0 to $12 \mathrm{~mm}$. long; body rather slender; face with close, medium-sized punctures; apical margin of female clypeus with 
a very weak, broad notch; metapleurum with close small punctures and oblique fine wrinkles.

Black. Palpi of male more or less stramineous; tegula and hind corner of pronotum whitish in male, dark brown in female; front and middle legs beyond trochanters fulvous to reddish brown; hind femur and tibia fulvoferruginous, the femur very narrowly fuscous basally and narrowly fuscous apically, the tibia faintly infuscate basally and with moderate infuscation apically; hind tarsus fuscous to light reddish brown; wings subhyaline.

Specimens: + , Mystery Glacier on Mount Waddington at 4,000 ft., B. C., Aug. 6, 1927, Mundy (Washington). \&, Princeton Summit at 6,000 ft., B. C., July 17, 1909 (Cambridge). 2 ㅇ (type and paratype), Steelhead, B. C., June 2 and 19, 1933, H. B. Leach (Ottawa and Washington). o, Vancouver, B. C., March 28, 1939, R. H. Lengmore (Townes). 29, "Boyer," Oreg., Apr. 27, 1935, and Aug. 13, 1934 (Ottawa). 4 $4 \sigma^{7}, 8$, "Boyer," Oreg., Apr. 27, May 15 and 24, June 2 and 24, July 2, 21, and 28, and Sept. 10, 1934 to 1938 (Washington). $\sigma^{7}$, Corvallis, Oreg., June 26, 1929, Robert L. West (Washington). \&, Corvallis, Oreg., Aug. 7, 1925, D. G. Gillespie (Washington). ๆ, Waldport, Oreg., June 5, 1925, J. E. Davis (Washington). $\sigma^{7}$, Copalis, Wash., July 25, 1931, H. T. Peters (Lawrence). ๑, Friday Harbor, Wash., May 29, 1906, J. M. Aldrich (Washington). $2 \sigma^{7}$, Ilwaco, Wash., June 28 and July 1, 1925, A. L. Melander (Cambridge and Townes). ค, Mount Rainier at 4,200 ft., Wash., July 15, 1940, H. and M. Townes (Townes).

This species is known from British Columbia, Washington, and Oregon, near the coast.

\section{Coccygomimus pedalis (Cresson)}

Figures 284,a; 326,j

Pimpla pedalis Cresson, 1865, Proc. Ent. Soc. Philadelphia, vol. 4, p. 268; $\sigma^{\top}$. Type: $\sigma^{7}$, Colorado (Philadelphia).

Biology: Provancher, 1873, Naturaliste Canadien, vol. 5, p. 450.-Weed, 1900, Bull. New Hampshire Agr. Exp. Sta., no. 75, p. 123.-Patch, 1908, Bull. Maine Agr. Exp. Sta., no. 161, p. 140.-Howard and Fiske, 1911, Bull. U. S. Dep. Agr., Bur. Ent., no. 91, pp. 137-138, 144, 147-149, 237-239.Schedl, 1931, Zeitschr. Angew. Ent., vol. 18, pp. 268-270.-Schaffner and Griswold, 1934, Misc. Pub. U. S. Dep. Agr., no. 188, p. 142.-Townes, 1939, Bull. Brooklyn Ent. Soc., vol. 34, p. 29.-Townes, 1940, Ann. Ent. Soc. America, vol. 33, pp. 286, 301.

Front wing 5 to $13 \mathrm{~mm}$. long; body of normal proportions; face of male with medium-sized, rather close punctures; face of female with rather small and distant punctures; apical margin of female clypeus weakly concave, sometimes with a weak median notch; upper half of metapleurum with fine, weak, rather sparse punctures and often more 
or less distinct fine oblique wrinkles; lower half of metapleurum without punctures and smooth or with weaker oblique wrinkles.

Black. Scape of male often with a white spot in front; palpi dark brown to black; tegula often brownish basally; legs fulvous, the front coxa blackish except toward apex, the apex of hind femur black, and the hind tibia and tarsus black. Wings hyaline to distinctly infuscate.
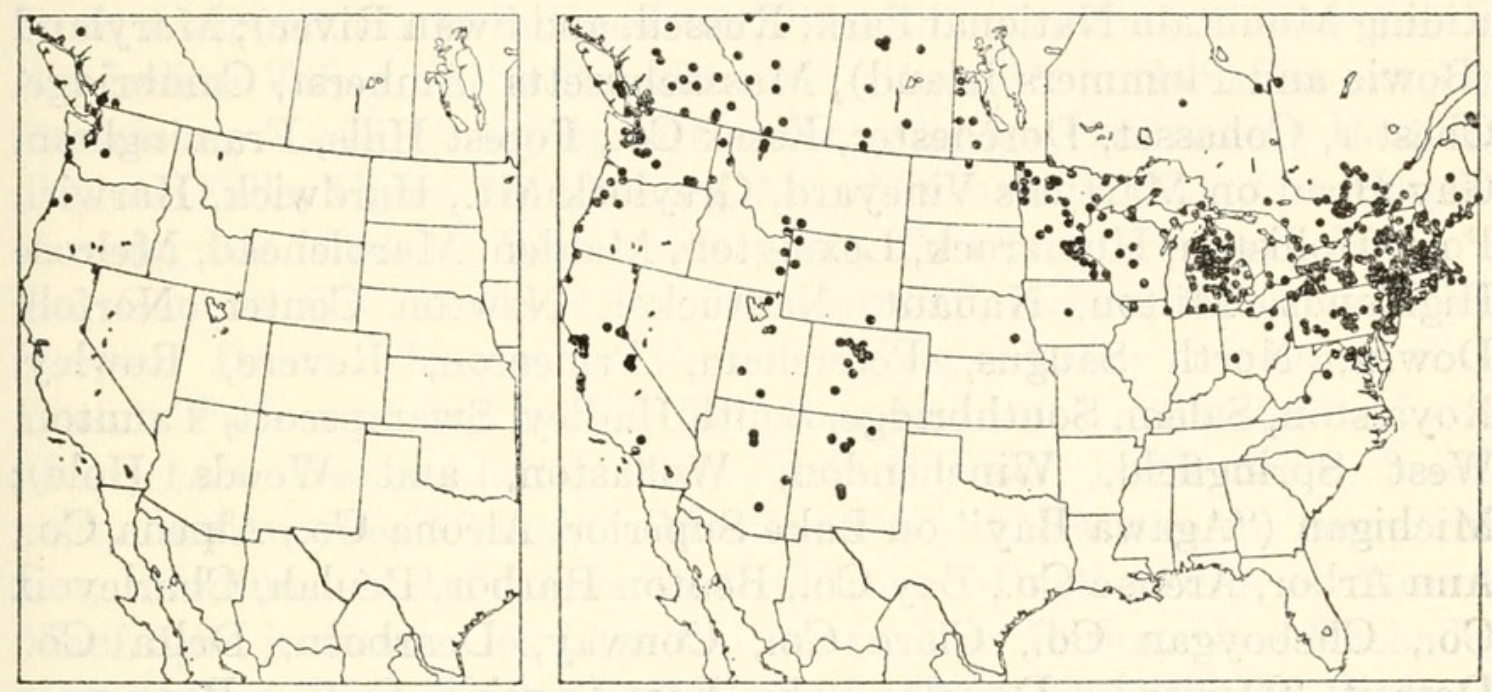

Figures 140, 141.-Localities: 140 (left), Coccygomimus silvicola; 141 (right), C. pedalis.

Specimens from the Rocky Mountains and westward, particularly those from the drier parts of this area, have the wings a little infuscate. Specimens from east of the Rocky Mountains always have the wings hyaline or subhyaline.

Specimens (783 $0^{7}, 808$ ) : From Alberta (Armena, Banff, Bilby, Calgary, Lethbridge, McMurray, Red Deer, Shovel Pass in Jasper Park, Waterton, and Waterton Lakes); Alaska (Matanuska); Arizona (near Alpine, Flagstaff, Mount Lemmon in the Santa Catalina Mts., and Snow Bowl in the San Francisco Peaks); British Columbia (Agassiz, Barkerville, Brilliant, Clinton, Courtenay, Fort George, Jesmond, Kaslo, Keremeos, Lake Errock near Deroche, Midday Valley near Merritt, Mission City, Mount Lolo near Kamloops, Mount Revelstoke National Park, Nanaimo, Prince Rupert, Robson, Salmon Arm, Steelhead, Vancouver, Vavenby, Victoria, and Wellington); California (Berkeley, Big Sur, Crescent City, Eureka, Fairfax, near Glacier Point in Yosemite Park, Inverness, Lake Tahoe, Leevining, "Maxtus" in Placer Co., Monterey, Oakland, Orange Co., Pacific Grove, Riverside, Stillwater Cove in Sonoma Co., Tallac on Lake Tahoe, and Yosemite at 3,800 to 4,000 ft.); Colorado (Aspen, Boulder, Burns, near Estes Park, Glen Haven, Lake City, Nederland, Phantom Valley at $9,400 \mathrm{ft}$. in Rocky Mountain National Park, 
Rabbit Ears Pass, south of St. Vrain at $8,000 \mathrm{ft}$., and Steamboat Springs); Connecticut (Colebrook, Groton, Litchfield Co., Iyme, New Canaan, and Stamford); Idaho (Ashton, Lookout Mt. near Priest Lake, Victor, Waha, and Wallace); Illinois (Apple River and Chicago); Iowa (Boone); Labrador (Hebron); Maine (Bath, Blackwood Camp in Acadia National Park, "Livingston," Machias, Medomak, Mount Katahdin at 5,215 ft., Norway, Orono, Phillips, and Southport); Manitoba (Aweme, Birch River, Gillam, Red Deer River, Riding Mountain National Park, Russell, and Swan River); Maryland (Bowie and Plummers Island); Massachusetts (Amherst, Cambridge, Chester, Cohasset, Dorchester, Essex Co., Forest Hills, Framingham, Gay Head on Martha's Vineyard, Greylock Mt., Hardwick, Harwich Port, Holliston, Humarock, Lexington, Malden, Marblehead, Melrose Highlands, Milton, Nahant, Nantucket, Newton Center, Norfolk Downs, North Saugus, Petersham, Princeton, Revere, Rowley, Royalston, Salem, Southbridge, South Hadley, Swampscott, Taunton, West Springfield, Winchendon, Wollaston, and Woods Hole); Michigan ("Agawa Bay" on Lake Superior, Alcona Co., Alpena Co., Ann Arbor, Arenac Co., Bay Co., Benton Harbor, Beulah, Charlevoix Co., Cheboygan Co., Clare Co., Conway, Dearborn, Delta Co., Detroit, "Deward," Douglas Lake, East Lansing, George Reserve in Livingston Co., Gladwin Co., Gogebic Co., Interlochen, Ionia Co., Iosco Co., Isabella Co., Isle Royale, Kalkaska Co., Keweenaw Co., Lake Co., Leland, Mackinac Island, Manistee Co., Mason Co., Mecosta Co., Menominee Co., Midland Co., Missaukee Co., Muskegon Co., Nottawa, Oakland Co., Ogemaw Co., Onota Township in Alger Co., Ontonagon Co., Osceola Co., Oscoda Co., Otsego Co., Owosso, Port Austin, Roscommon Co., Rose Lake in Clinton Co., Saginaw Co., St. Ignace, Sanilac Co., Schoolcraft Co., Shelby, Tuscola Co., Wexford Co., and Whitefish Point in Chippewa Co.); Minnesota (Afton, Aitkin, near Alexandria at Camp Carlos, Basswood Lake in Lake Co., Blackduck, Bunker Lake in Anoka Co., Cass Co., Chisago Co., Cook Co., Crookston, Duluth, Echo Trail in St. Louis Co., Euclid, Garrison, Halstad, Hay Creek Township in Goodhue Co., John Latsch State Park, Kelliher, Kawishiwi River, Kittson Co., Lake Itasca, Lancaster, Long Lake, Marshall Co., Mille Lacs Co., Minneapolis, Mississippi bluffs at state line in Houston Co., Newport, Pine City, Plummer, Preston, Rochester, St. Anthony Park, St. Croix River near Lakeland, St. Paul, Snake River in Pine Co., Todd Co., near Vineland in Mille Lacs Co., and Warroad); Montana ("Beaver Creek at 6,300 ft.," Cold Creek, Gardiner, Glacier Park Station at 4,800 ft., Lake McDonald in Glacier Park, and Rock Creek and Madison River in Gallatin National Forest); Nebraska (Lincoln); New Brunswick (Bathurst, Campbellton, Caraquet, and St. John); New Hampshire (Bartlett, 
Dolly Copp Camp in the White Mts., Dublin, Durham, Franconia, Jaffrey, Mount Lafayette, Mount Monadnock, and Mount Washington); New Jersey (Bloomfield, Fort Lee, Greenwood Lake, Jersey City, Medford, Moorestown, Mount Holly, Palisades, Paterson, Ramsey, Riverton, Short Hills, and Trenton); New Mexico (Aspen Branch in Santa Fe Co., Catron Co., Cimarron at 10,000 ft., Eagle Creek in the Sierra Blanca at 8,000 ft., Jemez Springs, Rio Ruidosa in the Sierra Blanca at 6,500 ft., and Santa Fe); New York (Allegany State Park, Avalanche Lake in Essex Co., Bear Mt., Bedford, Bemus Point, Big Indian Valley in the Catskill Mts., Blue Mt. in the Adirondacks, Canadarago Lake, Canajoharie, Caroline, Chafee, Cold Spring Harbor, Copake Falls, Cuba, Donderberg Mt., Downsville, East Greenbush, Farmingdale, Fishers Island, Flatbush, Fort Montgomery, Genesee Co., Geneva, Greene Co., Hancock, Harrison, Hilton, Honeoye Falls, Horton, Ithaca, Jamesville, Jericho, Keene Valley in Essex Co., Kissina Park on Long Island, Labrador Lake in Cortland Co., Lake Clear, Lake George, Larchmont, Little Genesee, Little Neck, Lockport, Ludlowville, Mahopac, Mastic, McLean Reserve in Tompkins Co., Medina, Melville, Milford Center, Minetto, top of Mount MacIntyre in Essex Co., New Baltimore, New Berlin, New Rochelle, New Russia, New York City, Niagara Falls, Nyack, Oak Orchard Swamp near Batavia, Ogdensburg, Olcott, Oliverea, Oneonta, Oswego, Otsego Lake, Otto, Patterson, Portageville, Potsdam, Poughkeepsie, Rhinebeck, Riverhead, Rome, Sea Cliff, Shokan, Slaterville, Slide Mt., Spring Lake in Cayuga Co., Staten Island, Syracuse, Taughannock Falls, Troy, Utica, West Point, Whitesville, Wildwood State Park on Long Island, and Yonkers); North Dakota (Grand Forks and Turtle Mts.); Northwest Territories (Salt Plain); Nova Scotia (Annapolis, Baddeck, Bridgetown, Cape Breton, Kentville, Smiths Cove, and Truro); Ohio (Akron, Cleveland, Montgomery Co., Put-inBay, and Steubenville); Ontario (Bells Corners, Bobcaygeon, Bowmansville, Bradford, Chalk River, Cold Stream, Constance Bay, Effingham, Gananoque, Georgetown, Gravenhurst, Grimsby, Jockvale, Jordan, "Lonely Lane," Manotick, Marmora, Merivale, Miners Bay, Moose Factory, Normandale, Norway Point on Lake of Bays, Orillia, Osgoode, Ottawa, Parry Sound, Port Hope, Queenston, "Salines," Simcoe, Smoky Falls on the Mattagami River, Southampton, Strathroy, Sudbury, Wallacetown, and Waubamik); Oregon (Alsea, Amity, Cascade Mts. in Marion Co., Forest Grove, Marshfield, Portland, and "Triangle Lake"); Pennsylvania (Camp Hill, Charter Oak in Huntingdon Co., Clark's Valley in Dauphin Co., Crisp in Westmoreland Co., Gladwyne, Harrisburg, Highspire, Inglenook in Dauphin Co., Lake Pleasant in Erie Co., Linglestown, New Bloomfield, New Paris, Numidia, Philadelphia, Pike Co., Pittsburgh, Presque Isle in 
Erie Co., Robinson Township in Allegheny Co., Rockview in Centre Co., State College, and Windgap); Prince Edward Island (Alberton, Brackley Beach and Dalvay House in Canadian National Park, and Portage); Quebec (Aylmer, Beechgrove, Boucherville, Cap Rouge, Cascapedia, Covey Hill, Cross Point on the Gaspé Peninsula, Fort Coulonge, Gatineau Park, Gracefield, "Grand Bend," Hemmingford, Hull, Isle Perrot near Montreal, Joliette, Kazabazua, Knowlton Lac Tremblant, Laval Co., Montigny, Montreal, Mount Lyall, Nominingue, Old Chelsea, Rupert House, Ste. Agathe des Monts, Sherbrooke, Sutton, Wakefield, Westmount, and Wright); Rhode Island (Kingston and Westerly); Saskatchewan ("Carleton," Christopher Lake, Eaglehill Creek, Prince Albert National Park, Regina, Val Marie, Waskesiu, and White Fox); Utah (Beaver, "Beaver Creek," Logan, Navajo Lake in Kane Co., and Provo); Vermont (Hartland, Laurel Lake near Jacksonville, Mount Mansfield, Rutland, and Woodstock); Virginia (Burkes Garden in Middlesex Co. at 3,300 ft., Dayton, Falls Church, Frederick Co., Mountain Lake, and Vienna); Washington (Ashford, Elbe, Kalama River, Kent, Lake Cushman in Mason Co., Mill Creek, Mount Rainier at 2,700, 4,700, and 5,300 ft., Nooksack River on Mount Baker, San Juan Island, Seattle, Shelton, Tampico, and Walla Walla); Wisconsin (Cranmoor in Wood Co., Dane Co., Door Co., Gordan, Madison, Rib Mountain State Park, Sawyer Co., and Worden Township in Clark Co.); Wyoming (Grand Teton National Park, Mount Washburn in Yellowstone National Park, mountains near Sheridan, and Summit in Albany Co. at 8,500 ft.); and Mexico (Manzano National Forest).

Collection dates are mostly from mid-spring to early fall, but there are scattered records all over the range from the first week in May to about October 10. A few dates are earlier or later than this range, as follows: March 30 and April 26 at Robson, B. C.; April 9 at New York, N. Y.; April 19 at Ottawa, Ont.; April 20 at Swampscott, Mass.; April 23 at Bath, Maine; April 30 at South Hadley, Mass.; October 11 at Brilliant, B. C.; October 12 at Lac Tremblant Nord, Que.; October 14 at Falls Church, Va.; October 16 at Cultus Lake, B. C.; October 21 at Aweme, Man.; November 5 at Oakland, Calif.; and November 10 at Ann Arbor, Mich. There are 7 records of specimens collected on flowers, 3 records on Pastinaca sativa, and 1 each on Ceanothus americana, Cicuta maculata, Daucus carota, Heracleum lanatum, and Solidago. Two males and six females were collected at light, on six different occasions. In our own collecting we have found the species among the herbage and undergrowth of northern deciduous woods, where it is often abundant.

Rearing records on the pin labels include 4 rearings from Halisidota caryae, 2 from Lambdina fiscellaria somniaria, 3 from Malacosoma 
sp., 2 from Malacosoma pluviale, and 1 rearing each from Malacosoma americanum, M. fragile, Apatela americana, Apatela sp., Archips argyrospilus, Ctenucha virginica, Epargyreus clarus, Hemerocampa leucostigma, Leucania linita, Olene plagiata, Orgyia antiqua badia, arctiid cocoon, pyraustid on Helianthus, Noctuidae, lepidopterous pupa, Xylotrechus sp., and Diprion hercyniae.

This species is transcontinental in the Canadian and Transition zones, where it is often very common in woods. Moderately large Lepidoptera are the usual hosts.

\section{Coccygomimus maurus (Cresson)}

FIGURE $326, \mathrm{k}$

Pimpla maura Cresson, 1870, Trans. Amer. Ent. Soc., vol. 3, p. 145; ㅇ Type: ㅇ, Texas (Philadelphia).

Front wing 9 to $15 \mathrm{~mm}$. long; body moderately stout; punctures of face coarse, close medially, sparser laterally; apex of female clypeus very weakly concave; metapleurum with coarse punctures and oblique striae or rugulosity.

Male: Black. Front of scape, tegula, scutellum, postscutellum, front and middle tarsi except for the apices of their segments, spot on front coxa, usually spot on middle coxa, front femur in front, apex or more of middle femur in front, front and middle tibiae except for a stripe behind, and incomplete subbasal band on hind tibia, white; wings lightly infuscate, the basal 0.4 paler.

Female: Black. Sometimes front part of tegula, sometimes spot on scutellum, more or less of front femur and tibia in front, and apex of middle femur in front, white; sometimes lateral apical corners of tergites 3 to 6 obscurely whitish; wings dark fuscous.

Specimens: , Alachua Co., Fla., April 1, 1949, F. N. Young (Ann Arbor). $\quad \sigma^{\top}$, reared from Hemerocampa leucostigma, Brookfield, Fla., Apr. 20, 1918 (Washington). क, Gainesville, Fla., May 6, 1948, H. V. Weems, Jr. (Washington). (Washington). + , Orange Co., Fla., April 6, Alexander and Walker (Ann Arbor). ণ, Paradise Key, Fla., April 1, 1919, C. A. Mosier (Washington). $\sigma^{\top}$, Paradise Key, Fla., April 7, 1951, H. and M. Townes (Townes). $\sigma^{7}$, reared from Orgyia sp. from cypress swamp, Fla., 1912 (New York). †, Waccamaw Lake, N. C., April 1920 (Washington). , Wallace, N. C., June 17, 1949, H. Townes (Townes). $\sigma^{7}$, Fairfield Co., Ohio, June, A. E. Waller (Townes). 2ᄋ, Colorado Co., Tex., April 7 and 21, 1922, Mrs. Grace Wiley (Lawrence and Townes). $\%$, reared from cocoon found on live oak bark, Victoria, Tex., June 1, 1915, J. D. Mitchell (Washington). \&, Hunt Co., Tex., June 11, 1939 (Townes). $\sigma^{\top}$, ?, Texas, Belfrage 
(Washington). $\quad$, Texas (Cambridge). $\quad$ (type), Texas (Philadelphia).

This species is in the Austroriparian fauna, but has been collected also in Ohio. Adults occur in spring and early summer.
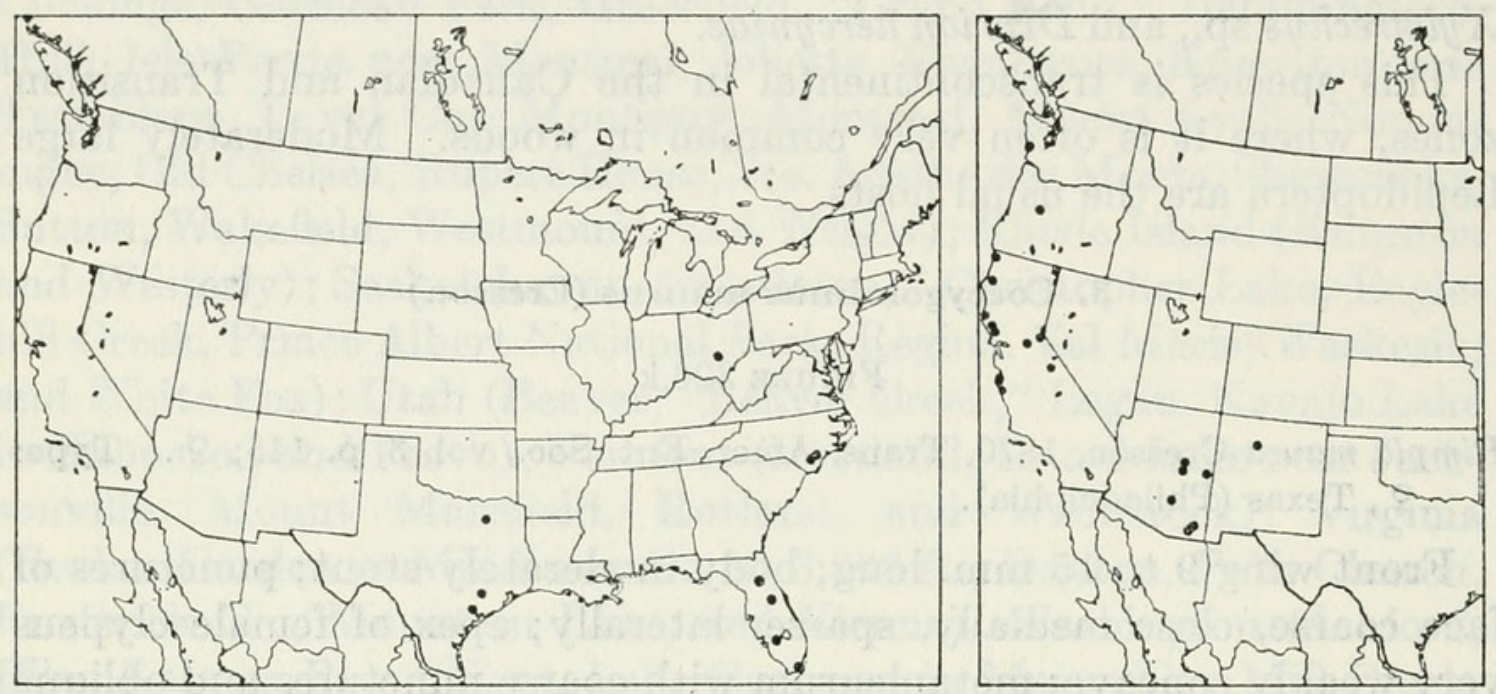

Figures 142, 143.-Localities: 142 (left), Coccygomimus maurus; 143 (right), C. ellopiae.

\section{Coccygomimus ellopiae (Harrington)}

Figure 326,1

Pimpla ellopiae Harrington, 1892, Canadian Ent., vol. 24, p. 99; ه’, $\subsetneq$. Types: ơ, \&, Victoria, B. C. (Ottawa).

Front wing 3.5 to $12 \mathrm{~mm}$. long; body moderately slender; face with close medium-sized punctures; apical margin of female clypeus broadly notched; metapleurum with fine oblique wrinkles which more or less obscure small dense punctures; nervulus briefly postfurcal or sometimes interstitial.

Black. Maxillary palpus of male largely light brown; front of front femur, of front tibia, and of front tarsus of male, apex of middle femur and of middle tibia of male, pale yellowish; front and middle tibiae and tarsi dark reddish brown except where described as yellowish; hind femur and hind tibia black to ferruginous; wings faintly infuscate; abdomen dark ferruginous, the ovipositor sheath black.

Specimens from the northern part of the range have the hiad femur and tibia black, while those from the southern part have the hind femur and often the hind tibia ferruginous. The zone of intergrades for this color difference seems to be broad, so it seems inadvisable to erect a new subspecies for the southern type of coloration. We have seen specimens with both ferruginous and black hind femora and also intermediates from Stillwater Cove, in Sonoma County, 
Calif. Coccygomimus thoracicus (Morley) 1914, from Guerrero, Mexico, may represent an extreme southern race of this species.

Specimens $\left(11 \sigma^{\top}, 31\right.$ ) $)$ : From Arizona (near Alpine, Chiricahua Mts., Hereford, Mount Lemmon at 6,000 and at 8,000 ft., and Parker Creek and Workman Creek in the Sierra Ancha); British Columbia (Vancouver Island); California (Big Sur, Carmel, Crescent City, Echo, Echo Lake, Elk, Fish Camp, Humboldt Co., Kyburz, Pacific Grove, "Pohono Trail" at 7,000 to 7,750 ft., and Stillwater Cove in Sonoma Co.); New Mexico (Jemez Springs at 6,400 ft.); Oregon (Mount Jefferson); Washington (Westport); and Mexico (near Cortez Pass at 10,000 ft.).

The majority of the collecting dates are in early spring to early summer (April 20 to June 15) but a number are in July and August, one October 25 at Carmel, Calif., and one November 19 at Hereford, Ariz.

One of the syntype series was reared, a male from Lambdina fiscellaria somniaria, Vancouver Island, B. C., Mar. 1, 1891.

This species occurs from Vancouver Island to Arizona, New Mexico, and Mexico. It is adult mostly in spring and early summer.

\section{TURIONELLAE GROUP}

Front wing 3.5 to $13 \mathrm{~mm}$. long; body rather stout; nervulus usually interstitial; hind tibia often with a pale submedian band; propodeum short, rounded, with or without median longitudinal carinae at its base; abdomen weakly mat or polished, with close punctures; first tergite short and wide; epipleura narrow, the fourth and fifth epipleura a little wider than the first through third, but less than 0.25 as wide as long in male and less than 0.45 as wide as long in female (fig. 329, j); upper valve of ovipositor not, or only weakly flattened apically, and without distinct transverse ridges.

This group is Palaearctic, but includes one species (aquilonius) which is Holarctic. The rest of the species of the group known to us are: Pimpla disparis Viereck 1911, Ichneumon illecebrator Villers 1789, Pimpla pluto Ashmead 1906, Ichneumon turionellae Linnaeus 1758, and an undescribed species from Japan. Except for aquilonius, these names are new combinations in Coccygomimus.

\section{Coccygomimus aquilonius (Cresson)}

\section{Figure 329, j}

Front wing 3.5 to $9 \mathrm{~mm}$. long; body short and stout; face of male with moderate sized, rather close punctures; face of female with rather small, distant punctures; apex of female clypeus with a deep $V$-shaped notch; metapleurum with fine, moderately dense punctures and often more or less distinct oblique wrinkling, the lower half usually smoother and often without punctures. 
Black. Palpi of male, nearly always a spot of variable size on front of scape of male, sometimes scutellum of male, hind corner of pronotum of male, and tegula of male, white or whitish; palpi of female fuscous; scape, scutellum, hind corner of pronotum, and tegula of female black; legs fulvous, the hind tibia and tarsus blackish, the tibia almost always with a submedian pale band. The apex of the hind femur is often fuscous. Wings hyaline.

This is a Holaretic species, with two subspecies in North America and two in Eurasia. Of the two North American subspecies, typical aquilonius occurs east of the Rocky Mountains and the subspecies exareolatus from the Rocky Mountains westward. Alaskan populations tend to be intermediate but the majority of them seem assignable to the subspecies aquilonius. For example: a series from Naknek, Alaska, and another from King Salmon on the Naknek River, Alaska (both series in Ottawa), contain specimens assignable to the subspecies aquilonius, some intermediate specimens, and a few assignable to exareolatus. The type series of yakutatensis, from Yakutat Bay, Alaska, is also intermediate. In Europe there is the subspecies C. aquilonius flavicoxis (Thomson) 1877 (new status), which is intermediate in leg color between the two American subspecies and perhaps not distinguishable from the Alaskan population. There is also an undescribed subspecies in Japan, with the apex of the hind femur extensively infuscate. We have a series of it from Sapporo.

The American subspecies are keyed below:

1. Apical 0.05 or less of hind femur fuscous (fig. 327 ,a); pale band on hind tibia grayish or brownish white, occupying about 0.20 the length of the tibia; range: Rocky Mountains to Pacific, and part of Alaska.

5a. aquilonius exareolatus (Ashmead)

Apical $0.15 \pm$ of hind femur fuscous (fig. $327, \mathrm{~b}$ ); pale band on hind tibia whitish, occupying about 0.23 the length of the tibia; range: east of Rocky Mountains and part of Alaska . . 5b. aquilonius aquilonius (Cresson)

\section{5a. Coccygomimus aquilonius exareolatus (Ashmead)}

Figure 327 ,a

Itoplectis exareolatus Ashmead, 1901, Psyche, vol. 9, p. 147;. Type: , Las Vegas Range between Pecos and Sapella Rivers, 11,000 ft., N. Mex. (Washington).

Pimpla yakutatensis Ashmead, 1902, Proc. Washington Acad. Sci., vol. 4, p. 200; $\sigma^{\top}$. Lectotype (hereby selected): $\sigma^{7}$, labeled "type" by Ashmead, Yakutat, Alaska, June 21, 1899, T. Kincaid (Washington).

Male usually but not always with some white on front of scape; hind femur with very little fuscous on its apex, sometimes with none; pale band on hind tibia grayish white or brownish white, occupying about 0.20 the length of the tibia, sometimes narrower or rarely absent.

Specimens (187 $\sigma^{x}, 74$ ) : From Alberta (Vermillion Lake near Banff at 4,500 ft.); Alaska (Anchorage, Cold Bay at $163^{\circ} \mathrm{W}$., Popoff Island, 
Seward, Sitka, and Yakutat); British Columbia (Chilliwack, Cultus Lake, Diamond Head Trail near Squamish at 3,500 ft., Jesmond, Keremeos, Lake Errock near Deroche, Mount Revelstoke at 6,000 ft., Mount Revelstoke National Park at 4,400 ft., Robson at 1,400 ft., Stanley, and Steelhead); California (Berkeley, Crescent City, Dardanelle, Eureka, Inverness, Leevining, Mill Valley, Muir Woods, Round Mountain, and Smith River); Colorado (near Estes Park, Grand Lake, Phantom Valley at 9,400 ft. in Rocky Mountain National Park, and Poudre Lake at 11,000 ft. in Rocky Mountain National Park); Montana (Georgetown Lake at 6,500 ft.); New Mexico (Las Vegas Range between Pecos and Sapello rivers at 11,000 ft.); Oregon (Cannon Beach, McMinnville, and Seaside); Saskatchewan (Prince Albert National Park); and Washington (Ashford, Bellingham, Elbe, Everett, Glacier, Ilwaco, Mount Constitution, Mount Rainier at 2,900 ft., Mukilteo, "Pelvis," Puget, Skyline Trail on Mount Baker, Tacoma, and Westport). We have found the species abundant among herbage growing in the damper parts of coniferous forests.

Collection dates are all in June, July, and August except as follows: April 5 at Berkeley, Calif.; May 27 at Tacoma, Wash.; September 5 in Muir Woods, Calif.; October 5 at Robson, B. C.; and October 6 at Inverness, Calif.

This subspecies occurs in the Rocky Mountains and westward, and northward to Alaska. It ranges from the Transition to the Hudsonian zone. It intergrades with the subspecies aquilonius in the northern part of its range.

\section{5b. Coccygomimus aquilonius aquilonius (Cresson)}

Figure 327 ,b

Pimpla aquilonia Cresson, 1870, Trans. Amer. Ent. Soc., vol. 3, p. 145; $\sigma^{7}$. Type: $\sigma^{7}$, Maine (Philadelphia).

Meniscus marginatus Provancher, 1883, Naturaliste Canadien, vol. 14, p. 15 (Faune, p. 802); ㅇ. Type: $\$$, Quebec, Que. (Quebec).

Bassus cylindricus Provancher, 1889, Additions et corrections au volume II de la faune entomologique du Canada traitent des hyménoptères, p. 111; $\sigma^{\top}$, + . Lectotype: $\sigma^{\top}$, Ottawa, Ont. (Quebec).

White always on front of scape of male; apex of hind femur infuscate for about 0.10 to 0.18 its length; pale band on hind tibia whitish, occupying about 0.23 the length of the tibia.

Many specimens from Alaska and some from Alberta are intermediate to the subspecies exareolatus.

Specimens $\left(2940^{7}, 380\right.$ ) : From Alberta (Bilby, Vermillion Lake near Banff, and Waterton Lakes); Alaska (Anchorage, Cold Bay at $163^{\circ}$ W. longitude, "Cooper Landing on the Kenai Peninsula," Reindeer Camp at Golofnin, Hope on the Kenai Peninsula, Igloo Creek, King Salmon on the Naknek River, Mount McKinley at 

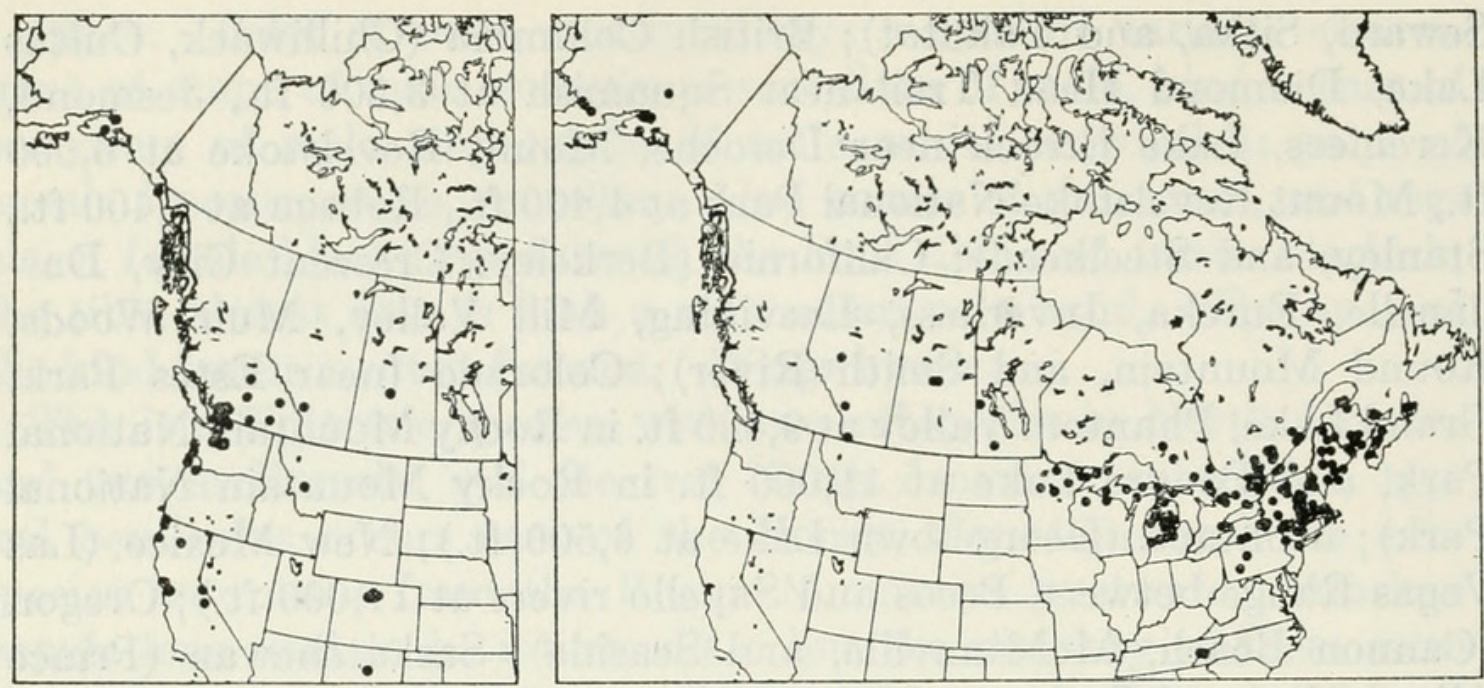

Figures 144, 145.-Localities: 144 (left), Coccygomimus aquilonius exareolatus; 145 (right), C. a. aquilonius.

1,600 and 2,500 ft., Naknek, Nome, Savonoski, Seward at 1,000 ft., and Sunrise on the Kenai Peninsula); Connecticut (Candlewood Lake); Maine (Acadia National Park, Ashland, Ashland Junction, Bar Harbor, Bingham, Bridgewater, Capens, Damariscove Island, Fort Kent, Hartland, Liberty, Mount Desert, Mount Katahdin, Seal Harbor, Southwest Harbor, and Winthrop); Manitoba (Aweme and Swan River); Massachusetts (Amherst, Chester, Cohasset, Fitchburg, Holliston, Nahant, North Adams, Petersham, South Hadley, and Washington); Michigan (Alger Co., Charlevoix Co., Cheboygan Co., Chippewa Co., Clare Co., Crawford Co., Delta Co., Douglas Lake, Drummond Island, Gladwin Co., Gogebic Co., Iosco Co., Isabella Co., Isle Royale, Kalkaska Co., Marquette Co., Midland Co., Muskegon Co., Ogemaw Co., Ontonagon Co., Osceola Co., Oscoda Co., Roscommon Co., St. Ignace, and Wexford Co.); Minnesota (Basswood Lake in Lake Co., Cass Co., Cook Co., Grand Marais, Itasca Park, Kawishiwi River, Koochiching Co., and Virginia); New Brunswick (Burpee Brook, Fredericton, Jaquet River, Nerepis, St. Andrews, St. John, and St. Stephen); Newfoundland ("Bay d'Espoir"); New Hampshire (Crawford Notch, Dolly Copp Camp in the White Mts., Fabian, Glen House, Gorham, Jaffrey, Mount Lafayette, Mount Madison, Mount Washington at 3,000 and 3,900 ft., and Pinkham Notch); New Jersey (Englewood); New York (Allegany Park, Axton in the Adirondack Mts., "Blue Mt. Lake," Greene Co., Heart Lake in Essex Co., Herkimer, lthaca, Keene Valley in Essex Co., Labrador Lake in Cortland Co., "Long Lake," Ludlowville, McLean Reserve in Tompkins Co., North Fair Haven, Oliverea, Oneonta, "Otter Lake," Poughkeepsie, Ringwood in Tompkins Co., Rock City in Cattaraugus Co., Shokan, Slaterville, Slide Mt. at 2,800 to 4,000 ft., Upper Ausable Lake in Essex Co., and 
White Lake); North Carolina (Newfound Gap at 5,000 to 5,200 ft.); Nova Scotia (Baddeck, East Folly Mt. in Colchester Co., Englands Brook near Digby, Kentville, Kings Co., Millsville, and Smiths Cove); Ontario (Almonte, Biscotasing, Bobcaygeon, Footes Bay, Gravenhurst, Jordan, Manotick, Merivale, Orillia, Ottawa, Parry Sound, Rockcliff near Ottawa, Smoky Falls of the Mattagami River, Sudbury, Timagami, Trenton, Vineland Station, and Waubamik), Pennsylvania (Du Bois, Jeannette, and Pike Co.); Prince Edward Island (Brackley Beach and Dalvay House in Canadian National Park); Quebec (Aylmer, Burbridge, Cap Rouge, Cascapedia, Cross Point on the Gaspé Peninsula, Kazabazua, Knowlton, Lac Brûle, Lac Mercier, Lac Tremblant, Maniwaki, Meach Lake near Hull, Montreal, Norway Bay, Nun's Island, Quebec City, Ste. Agathe des Monts, Sherbrooke, and Stoneham); Saskatchewan (Prince Albert National Park, and Waskesiu); Tennessee ("Chimneys C. Gr." in Great Smoky Mountains National Park); Vermont (Laurel Lake near Jacksonville, Manchester, Mount Ascutney, Mount Equinox, "Mt. Haystack," Rutland, Stamford, and Woodstock); and Wisconsin (Sawyer Co. and Vilas Co.).

Dates of collection are mostly from late spring to early fall. A few are in mid-spring and mid-fall. Unusually early and late dates are: April 28 at Englewood, N. J.; May 4 in Osceola Co., Mich.; May 8 in Isabella Co., Mich.; May 8 and 9 at Ithaca, N. Y.; September 23 at St. John, N. B.; September 24 at Aylmer, Que., and at Kentville, N. S.; September 25 at Ithaca, N. Y.; and October 24 at Aweme, Man. We have found the species common in the summer months, among herbage in woods of the Canadian zone, less common in the Transition zone.

Rearing records are as follows: $3 \sigma^{\top}$, reared from Coleophora salmani, Bar Harbor, Maine, July 20, 1929, and Aug. 6, 1929, R. L. Taylor. \&, from Lambdina fiscellaria, Bay d'Espoir, Newfoundland, Sept. 12, 1947. $\sigma^{\top}$, from Psilocorsis faginella, East Folly Mt., Colchester Co., N. S., Mar. 30, 1953.

This subspecies occurs in the Canadian and Transition zones from the Atlantic to the Rocky Mountains, and in parts of Alaska. It is adult throughout the growing season but most common during the summer months.

\section{SODALIS GROUP}

Front wing 3.2 to $11 \mathrm{~mm}$. long; body usually rather stout; nervulus interstitial or briefly postfurcal; hind tibia with a submedian pale band; propodeum rather broad and short, its sublateral longitudinal ridges absent or weak, its median longitudinal carinae present at its base, short and divergent, its surface punctate and with more or less fine transverse wrinkling; abdomen subpolished, with rather close 
punctures; first tergite rather short; epipleurum of second tergite narrow, more than 4.0 as long as wide; epipleurum of third tergite wider; epipleura of fourth and following tergites very wide (fig. 329 ,k; usually about 2.2 as long as wide in male and about 1.6 as long as wide in female); upper valve of ovipositor not flattened apically and without transverse ridges.

This group is Holarctic, Neotropic, and Ethiopian. It includes the five species treated below as Nearctic; the Japanese Pimpla alboannulata Uchida 1928; the Himalayan Pimpla instigator var. intermedia Morley 1913 and Pimpla cameronii Dalla Torre 1901; three unnamed species from China; a species from Africa; Pimpla cyanipennis Brullé 1846 from South America; and an unnamed species from South America. The species named above are all new combinations in Coccygomimus. C. intermedius (Morley) 1913 is a distinct species, not a variety of instigator (new status).

\section{Coccygomimus sodalis (Ruthe)}

Front wing 3.7 to $8.7 \mathrm{~mm}$. long; hairs on head and thorax longer than usual; temple long, in a medium-sized female its profile about 0.85 as long as eye in profile; cheek very long, in a medium-sized female about 1.2 as long as basal width of mandible; metapleurum with strong, fine, oblique striation interspersed with small punctures; hairs on metapleurum evenly distributed over its entire surface, moderately dense.

Black. Hairs of head and thorax dark brown; tegula, coxae, and trochanters black, the second trochanter of hind leg often fulvous; legs beyond trochanters fulvoferruginous, the apices of front and middle tarsi brownish, the hind tibia and tarsus often more or less infuscate; wings faintly to rather strongly infuscate, darkest in females.

This is a Holarctic species with two subspecies as described below. It is restricted to Hudsonian and Arctic or Arctic-Alpine areas.

1. Apical $0.35 \pm$ of hind tibia infuscate (fig. $327, \mathrm{c}$ ); hind tarsus fuscous; range: arctic and subarctic North America, Iceland, and Europe.

6a. sodalis sodalis (Ruthe)

Apex of hind tibia not infuscate or not more than the apical 0.1 infuscate (fig. 327, d) ; hind tarsus reddish brown; range: Hudsonian and ArcticAlpine areas of western United States. (In some dwarf specimens the hind tibia and tarsus may be as infuscate as in the subspecies sodalis.)

6b. sodalis longigenalis (Cushman)

\section{6a. Coccygomimus sodalis sodalis (Ruthe)}

Figure 327,c

Pimpla sodalis Ruthe, 1859, Ent. Zeitung, Stettin, vol. 20, p. $371 ; \sigma^{7}$, . Lectotype (hereby designated): $\uparrow$, Iceland, segregated as type in British Museum, Natural History (London). 
Pimpla nordenskiöldii Holmgren, 1872, Öfvers. Svenska Vetensk.-Akad. Förh., vol. 29 , part 6 , p. 97 ; . Lectotype (hereby designated): $९$, labeled "Grönland, Nordenskj. Exp.," and labeled lectotype by Townes in 1958 (Stockholm).

Hind tibia fulvoferruginous, its apical $0.4 \pm$ infuscate or fuscous and its basal $0.6 \pm$ often weakly infuscate; hind tarsus fuscous; wings averaging a little paler than in the subspecies longigenalis. In diminutive males, the legs are sometimes mostly blackish.

European and American specimens of this form are very similar, but according to our material American specimens have the femora a little darker ferruginous and a little less densely hairy. There is a second Arctic or Arctic-Alpine species in Europe that is currently confused with the subspecies sodalis. In this second species the body hairs are much longer than in $C$. sodalis and the petiolar region of the propodeum has dense recurved hairs. In true sodalis the petiolar region of the propodeum is hairless. This second species does not occur in America, so it need not be considered further at this time. Specimens from Iceland, the type locality of sodalis, are all sodalis as interpreted here.

Specimens: $2 \sigma^{7}, 3$, , Mount McKinley National Park, Alaska, 1932, F. W. Norand (Washington). $\sigma^{\top}$, Nazan Bay, Atka, Aleutian Islands, Alaska, July 28, 1907, E. C. Van Dyke (Ithaca). ㅇ, Lake Harbor, Baffin Island, N. W. T., Aug. 6, 1935, W. J. Brown (Ottawa). ত', $69^{\circ} 45^{\prime}$ N., west Greenland, July 4, H. de Lesse (Paris. This specimen was reported erroneously as $C$. aethiops by de Lesse, 1952, Bull. Soc. Ent. France, vol. 57, p. 55). $9 \sigma^{7}$, 옹 Sondrestrom Air Base, Greenland, June 11 to 18, 1952, W. J. Brown (Ottawa). $\sigma^{7}$, Churchill, Man., July 3, 1934, A. M. Heydweiler (Townes). क , Fort Churchill, Man., July 11, 1952, J. G. Chillcott (Ottawa). o o', Reindeer Depot,
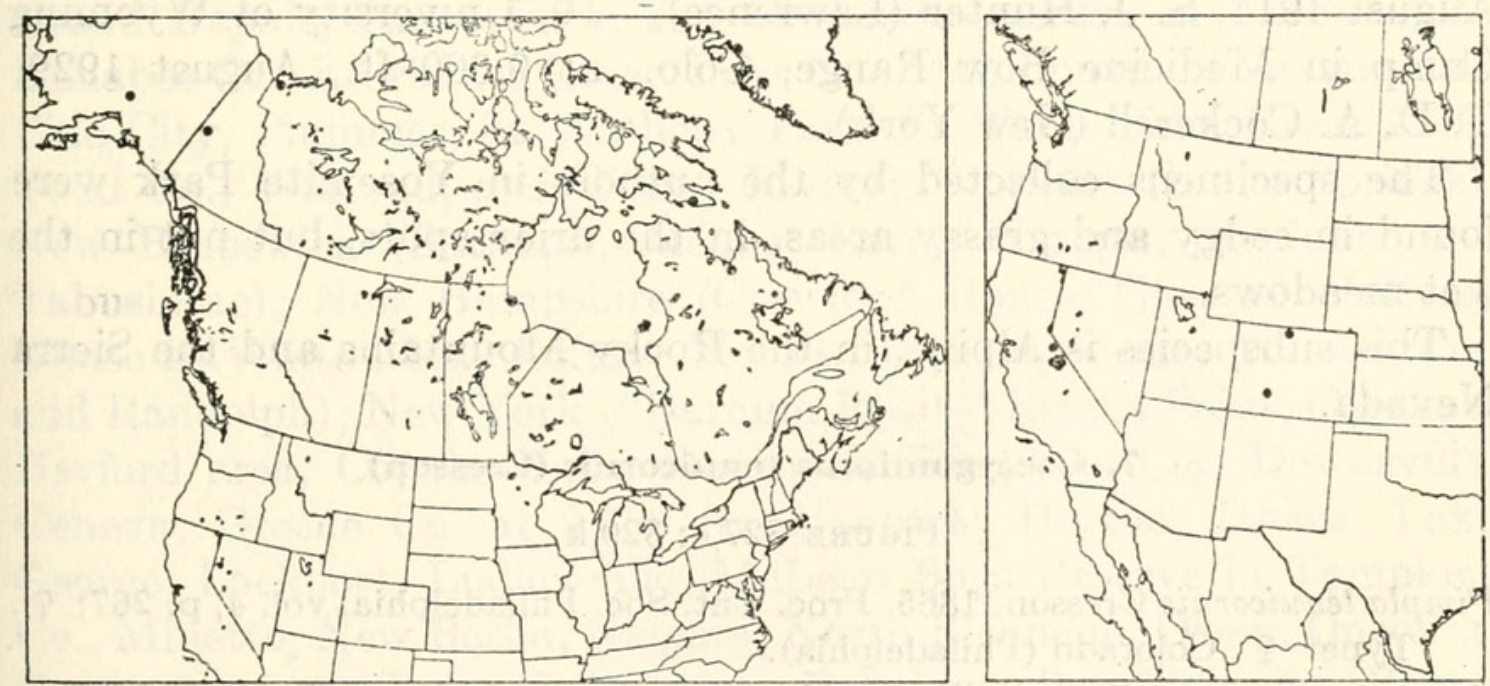

Figures 146, 147.--Localities: 146 (left), Coccygomimus sodalis sodalis; 147 (right), C. s. longigenalis. 
Mackenzie Delta, N. W. T., July 16, 1948, J. R. Vockeroth (Ottawa). ९, Fort Chimo, Que., July 9, 1948, H. R. MacLeod (Ottawa). ๙", Solomon Dome at 4,048 ft., Dawson, Yukon, July 3, 1949, P. F. Bruggemann (Ottawa).

This subspecies is in the Arctic zone. It occurs also in Iceland and in the Arctic parts of Europe.

\section{6b. Coccygomimus sodalis longigenalis (Cushman), new status}

Figure 327,d

Ephialtes (Ephialtes) longigenalis Cushman, 1920, Proc. U. S. Nat. Mus., vol. 52 , p. 332 ; . Type: $~+$, Tuolumne Meadows, Calif., at 8,600 ft. (Washington).

Hind tibia fulvoferruginous, the apical $0.1 \pm$ of hind tibia sometimes a little infuscate; hind tarsus reddish brown to fuscous; wings averaging a little darker than in the subspecies sodalis. In one very small male (front wing $3.7 \mathrm{~mm}$. long) the legs are abnormally dark, with the femora piceous, apical half of the hind tibia infuscate, and the hind tarsus fuscous.

Specimens: $2 \sigma^{7}$, Blanco's Corral, White Mt., Mono Co., Calif., at $10,000 \mathrm{ft}$., June 23, 1953, W. D. McLellan (Davis). $\sigma^{7}$, Blanco's Corral, White Mt., Mono Co., Calif., at 10,000 ft., July 24, 1953, J. T. Brooks (Berkeley). $5 \sigma^{7}, 2$ ㅇ, May Lake, Yosemite Park, Calif., at 10,500 ft., July 26 and 27, 1948, H., M., G., D., and J. Townes (Townes). $4 \sigma^{7}$, , Snow Flat, Yosemite Park, Calif., at 8,700 ft., July 22 and 23, 1948, H., M., G., D., and J. Townes (Townes). $\sigma^{7}$, near Sonora Pass, Calif. at 8,500 ft., July 7, 1948, H., M., G., and D. Townes (Townes). \&, Tioga Pass, Yosemite Park, Calif., July 29, 1936, W. T. McKean (Lawrence). ค, White Mt., Mono Co., Calif., at 14,000 ft., W. D. McLellan (Davis). क, Creede, Colo., at 8,844 ft., August 1914, S. J. Hunter (Lawrence). $\quad$ क, University of Wyoming Camp in Medicine Bow Range, Colo., at 9,600 ft., August 1929, T. D. A. Cockerell (New York).

The specimens collected by the authors in Yosemite Park were found in sedgy and grassy areas, in the drier spots, but not in the wet meadows.

This subspecies is Alpine, in the Rocky Mountains and the Sierra Nevada.

\section{Coccygomimus tenuicornis (Cresson)}

Figure 327 ,e; 329 , $\mathrm{k}$

Pimpla tenuicornis Cresson, 1865, Proc. Ent. Soc. Philadelphia, vol. 4, p. 267; ㅇ.

Type: $q$, Colorado (Philadelphia).

Brology: Townes, 1939, Bull. Brooklyn Ent. Soc., vol. 34, p. 29.

Front wing of male 3.7 to $8.4 \mathrm{~mm}$. long, of female 4.7 to $8.5 \mathrm{~mm}$. long; face sparsely and weakly punctate; temple moderately long, its 
profile in a medium-sized female about 0.78 as long as eye in profile; cheek long, in medium-sized females about 1.25 as long as basal width of mandible; mesopleurum with rather sparse, fine, weak punctures; metapleurum with moderately dense, weak punctures and some weak oblique wrinkles; hairs on metapleurum moderately dense, evenly distributed.

Black. Hairs of head and thorax light gray; palpi fuscous or black; tegula entirely black or blackish; legs fulvous, the front coxa fuscous, front and middle tarsi brownish apically, apical $0.1 \pm$ of hind femur fuscous, and hind tibia and tarsus fuscous, the tibia with a whitish subbasal band; wings hyaline or subhyaline.

Specimens (467 $\sigma^{7}, 246$ \%): From Alberta (McMurray and Slave Lake); British Columbia (Downie Creek in the Selkirk Mts.); Colorado (Steamboat Springs); Maine (Augusta, Bangor, Hancock, Knox Co., Lincoln Co., and Southwest Harbor); Manitoba (Deepdale, Keld, Norway House, Riding Mountain National Park, Teulon, and Treesbank); Massachusetts (Amherst, Beach Bluff, Boston, Holliston, Lexington, Petersham, Rutland, and South Hadley); Michigan (Alcona Co., Alger Co., Alpena Co., Ann Arbor, Antrim Co., Arenac Co., Baraga Co., Bay Co., Benzonia, Beulah, Branch Co., Cheboygan Co., Clare Co., Clinton Co., Delta Co., Dickinson Co., Douglas Lake, Drummond Island, East Lansing, Genesee Co., Gogebic Co., Grand Traverse Co., Gratiot Co., Houghton Co., Iosco Co., Iron Co., Isabella Co., Jackson Co., Kalkaska Co., Keweenaw Co., Lapeer, Lake Co., Mackinac Co., Manistee Co., Marquette Co., Mason Co., Mecosta Co., Midland Co., Missaukee Co., Muskegon Co., Newaygo Co., Ogemaw Co., Ontonagon Co., Owosso, Port Austin, Presque Isle Co., Redford, Saginaw Co., St. Clair Co., Schoolcraft Co., and Wexford Co.); Minnesota (Cass Lake, Cooncreek, Floodwood, Grand Marais, Grand Rapids, Itasca Park, Jay Cooke State Park in Carlton Co., Kanabec Co., Kawishiwi River, Lake Co., Mahtomedi, Mille Lacs Co., Pine City, Plummer, St. Anthony Park, St. Paul, Thief River Falls, Todd Co., Warroad, and Willow River); Nebraska (Idaho Springs); New Brunswick (Bathurst, Jacquet River, Nerepis, St. John, and Tabusintac); New Hampshire (Crawford House, Glen to Halfway House in White Mts., Jaffrey, Mount Madison, Mount Washington, and Randolph); New York ("Barnum Point," Bemus Point, CarolineHarford area, Copake Falls, Danby in Tompkins Co., Downsville, Geneva, Greene Co. at 2,500 ft., Hancock, Horton, Ithaca, Lake George, Lockport, Ludlowville, McLean Bogs Reserve in Tompkins Co., Minetto, New Berlin, Niagara, North Blenheim, Olean, Oneonta, Oswego, Otsego Lake, Penn Yan, Potsdam, Poughkeepsie, Rome, Saranac Lake, Seneca Junction, Shokan, Spring Lake in Cayuga Co., Stony Island, Utica, and White Lake); Nova Scotia (Kentville, 
St. Peters, and Truro); Ohio (Ashtabula Co.); Ontario (Almonte, Bells Corners, Blackburn, Bobcaygeon, Britannia, Constance Bay, Cornwall, Gananoque, Gravenhurst, Harold, Jockvale, Jordan, Parr Island in East Spence Lake, Port Hope, Prince Edward Co., "Salines," Simcoe, Smoky Falls on the Mattagami River, Southampton, South March, Sudbury, Tillsonburg, Trenton, Tweed, and Waubamik); Pennsylvania (Le Boeuf Lake in Erie Co.); Prince Edward Island (Alberton, and Brackley Beach and Dalvay House in Canadian National Park); Quebec (Aylmer, Beach Grove, Burbridge, Cascapedia, Coffin Island in the Magdalen Islands, Gatineau Park, Giffard, Gracefield, Hemmingford, Hull, Kazabazua, Kirks Ferry, Knowlton, Lac Mercier, Lac Sainte Marie, Lake Nominingue, Laniel, Louiseville, Montigny, Montreal, Norway Bay, St. Esprit, Ste. Agathe des Monts, Sherbrooke, Stoneham, Wakefield, and Wright); Rhode Island (Westerly); Saskatchewan (Cypress Hills, Prince Albert National Park, and Waskesiu Lake); Vermont (Caledonia Co., Laurel Lake near Jacksonville, Rutland, and Woodstock); Wisconsin (Rib Mountain State Park, Sawyer Co., Sturgeon Bay, and Worden Township in Clark Co.); and Wyoming (Sheridan).
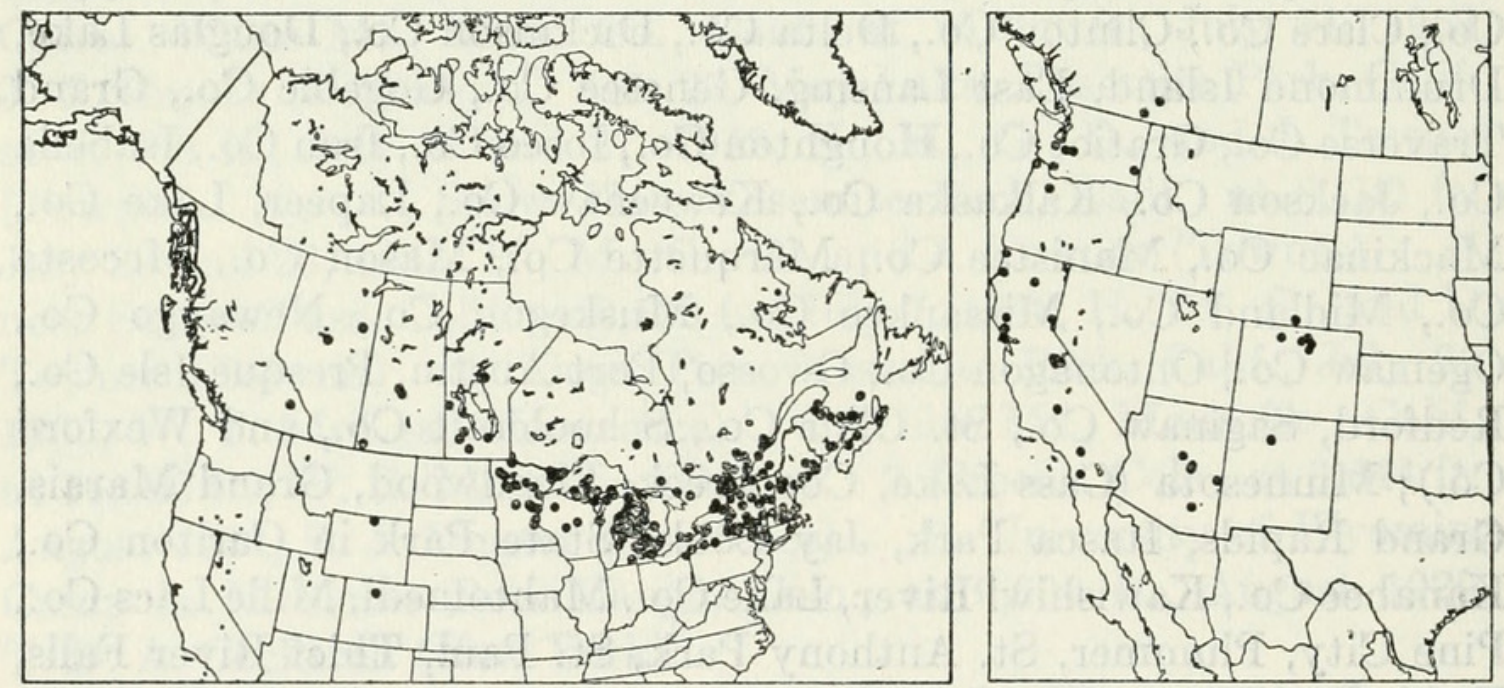

Figures 148, 149.-Localities: 148 (left), Coccygomimus tenuicornis; 149 (right), C. varians.

Collection dates are mostly from mid-spring to early fall. Unusually early and late dates of capture are: May 4 and 10 in Osceola Co., Mich.; May 8 and 10 at Ithaca, N. Y.; May 9 in Cooper Woods, Oakland Co., Mich., and at St. Anthony Park, Minn.; September 17 at Ithaca, N. Y.; September 25 at Geneva, N. Y.; September 26 at Plummer, Minn.; October 5 at Beach Grove, Que., and October 8 at St. Peters, N.S. The species is often common in woods in the summer.

The only reared specimen at hand is a female from Semiothisa sp., Treesbank, Man., May 11, 1939. 
This species occurs in the Transition and Canadian zones, from the Atlantic to the Rocky Mountains, but in the East it has not been found south of northern Pennsylvania. There are a few records from west of the Rocky Mountains in southern Canada. It is very common from New England to Minnesota.

\section{Coccygomimus varians, new species}

Front wing of male 3.5 to $7.2 \mathrm{~mm}$. long, of female 4.0 to $7.5 \mathrm{~mm}$. long; temple short, its profile in a medium-sized female about 0.58 as long as eye in profile; cheek moderately long, in a medium-sized female about 1.07 as long as basal width of mandible; mesopleurum with fine, weak, distant punctures, sometimes also with fine, weak wrinkles near attachment of middle coxa; metapleurum with fine oblique wrinkles and finely punctate; hairs on metapleurum moderately sparse, evenly distributed.

Black. Hairs of head and thorax light gray; palpi fuscous or black; tegula varying from entirely white to entirely black, in the male usually whitish basally with the rest brownish or blackish, in the female brownish or blackish, its base sometimes whitish; legs fulvous, the front coxa fuscous or fuscoferruginous, front and middle tarsi a little darkened apically, hind tarsus brown to blackish, and hind tibia variable. Often in smaller males the middle and hind coxae are more or less infuscate or black. Usually the hind tibia is fuscoferruginous, with an indistinct subbasal pale band. When the tibia is darker in color the pale band is more distinct, and when paler it is usually less distinct. Sometimes, especially in larger specimens, the hind tibia is almost uniformly fulvous with the apex and usually the base somewhat infuscate. Wings hyaline or subhyaline.

A specimen with the hind tibia almost uniformly fulvous looks much like Coccygomimus sanguinipes, and the finer and weaker sculpture on the mesopleurum and metapleurum must be used for distinguishing it. Larger males of this species and smaller males of C. sanguinipes are sometimes so nearly alike in both color and sculpture that certain distinction is not possible. In females, however, the difference in pleural sculpture is more definite and females can nearly always be distinguished.

The range of this species partially overlaps those of C. tenuicornis, C. stricklandi, and $C$. hesperus. It is relatively easy to distinguish from $C$. tenuicornis by the lack of fuscous at the apex of the hind femur and usually with a pale area at the base of the tegula. Females can be distinguished from those of $C$. hesperus and $C$. stricklandi on epipleural characters, but in males the differences in the epipleura are sometimes so subtle that many cannot be distinguished with certainty. The coloration of the tegula (as described in the key) is 
often a helpful character for males, but not a reliable one. In spite of the epipleural differences and the assignment to different species groups, $C$. varians and $C$. hesperus are very similar, and even females of the two are sometimes difficult to distinguish.

Type: $\odot$, Fish Creek at 2,900 ft., Mount Rainier, Wash., Aug. 14, 1940, H. and M. Townes (Washington, USNM 63713).

Paratypes (59) : From Arizona (near Alpine, Mount Lemmon in the Santa Catalina Mts. at 7,800 ft., Oak Creek Canyon, and Parker Creek and Workman Creek in the Sierra Ancha); British Columbia (Kaslo and Robson); California (Crescent City, Cuyamaca Mts. in San Diego Co., Donner Pass, near Glacier Point in Yosemite Park, Inverness, Kernville, Laurel Beach in Lake Co., May Lake in Yosemite Park at 10,500 ft., Muir Woods, Redwood Creek at Blair's Ranch in Humboldt Co., Round Mt. in Shasta Co., San Jacinto Park at 7,000 to 10,000 ft., Snow Flat in Yosemite Park at 8,700 ft., Sonoma Co., and Tamarack Flat in Yosemite Park); Colorado (Campus of the University of Colorado at Boulder, near Estes Park, Fort Collins, Greeley, and Steamboat Springs); New Mexico (Jemez Springs at $6,400 \mathrm{ft}$.); Oregon (Seaside and Silver Creek Falls in Marian Co.); Washington (Elbe, Kalama River, Mount Rainier at 2,900, 4,200, and 5,300 ft., Olympia, and Pullman); and Wyoming (Centennial). In addition to females we have about 150 males that appear to belong to this species, but since males are often difficult or impossible to determine with certainty, they are not listed above. Most of the males are from the same localities as the females.

Most collecting dates are in June, July, and August, but the species is on the wing from mid-spring to mid-fall. Unusually early and late dates of capture are: April 19, 21, 26, 28, 29, and 30 at several localities in the Sierra Ancha, Ariz.; October 6 at Inverness, Calif.; and October 30 at Round Mt., Calif. We have found the species often abundant among herbage in damp spots in forests.

There is a single rearing record: $\circ$, from Carpocapsa pomonella, Fort Collins, Colo., C. P. Gillette.

This species occurs from the Rocky Mountains to the Pacific, in the Canadian and Transition zones. It is adult throughout the growing season.

\section{Coccygomimus sanguinipes (Cresson)}

Front wing of male 5.4 to $9.0 \mathrm{~mm}$. long, of female 6.3 to $10.5 \mathrm{~mm}$. long; temple of moderate length, in a medium-sized female its profile about 0.65 as long as eye in profile; cheek moderately long, in a medium-sized female about 1.05 as long as basal width of mandible; 
mesopleurum with rather coarse punctures, on its lower part the punctures rather close (especially in female), separated by less than their diameter, the lower hind part of mesopleurum usually with moderately coarse irregularly oblique wrinkling (especially in female); metapleurum with moderately strong oblique wrinkling and indistinct punctures; hairs on metapleurum moderately dense, evenly distributed.

Black. Hairs of head and thorax light gray; palpi fuscous or black; tegula varying from mostly white to entirely black, usually brown or blackish with the base whitish; legs fulvous, the front coxa fuscous or mostly fuscous, front and middle tarsi a little darkened apically, apex of hind tibia often infuscate, and hind tarsus brownish fulvous to blackish; wings of male subhyaline, of female subhyaline to distinctly infuscate.

This is a species of semidesert areas of the West and Southwest. There are two subspecies distinguished in the female as below. The males of the two subspecies look alike.

1. Most of front face of hind femur of female with moderately dense hairs, the sockets of the hairs separated by about 0.7 the length of the hairs; range: southern Texas and adjacent Mexico.

9a. sanguinipes sanguinipes (Cresson)

Most of front face of hind femur of female with sparse hairs, the sockets of the hairs separated by about 2.0 the length of the hairs; range: Rocky Mountains to Pacific

9b. sanguinipes erythropus (Viereck)

\section{9a. Coccygomimus sanguinipes sanguinipes (Cresson)}

Pimpla sanguinipes Cresson, 1872, Trans. Amer. Ent. Soc., vol. 4, p. 165; $९$. Type: $\subsetneq$, Bosque Co., Tex. (Philadelphia).

Punctures and wrinkling of mesopleurum and metapleurum averaging a little denser and finer than in the subspecies erythropus; most of front face of hind femur of female weakly mat and with moderately dense hairs, the bases of the hairs separated by about 0.7 the length of the hairs, the femur smoother and with sparser hairs on the lower 0.3 of its front face.

Wings of both sexes subhyaline or faintly infuscate.

Specimens: ㅇ (type), Bosque Co., Tex., G. W. Belfrage (Washington). $\sigma^{x}$, Brownsville, Tex., C. H. T. Townsend (Washington). $\uparrow$, reared from pupa of Alabama argillacea, Brownsville, Tex., October 1926, T. C. Barber (Townes). \&, Chisos Mts., Tex., July 9, 1936,

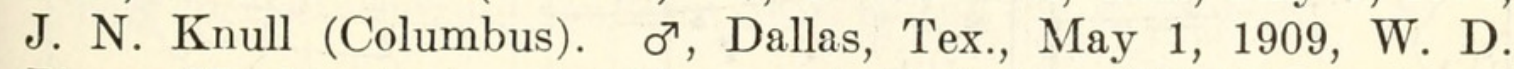
Pierce (Washington). $\sigma^{\top}$, “Townsendville," Tex. (Washington). \&, Buena Vista, Sierra del Carmen, 7,000 ft., Coahuila, Mexico, July 7, 1938, Rollin H. Baker (Lawrence).

This subspecies occurs in southern Texas and adjacent Mexico. 


\section{9b. Coccygomimus sanguinipes erythropus (Viereck), new status}

Pimpla (Pimpla) erythropus Viereck, 1909, Ent. News, vol. 20, p. 291; ․ Type: , Summerdale, Calif. (Washington).

Brology: Pack, 1930, Bull Utah Agr. Exp. Sta., no. 216, pp. 10-11. [Determined here as $C$. sanguinipes].

Punctures and wrinkling of mesopleurum and metapleurum averaging a little less dense, and coarser than in the subspecies sanguinipes; most of front face of hind femur of female polished and with sparse hairs, the bases of the hairs separated by about 2.0 the length of the hairs, but the front face of femur with denser pubescence apically and near its dorsal edge.

Wings of male and of some females subhyaline; wings of most females moderately infuscate.

Males of this subspecies seem to be indistinguishable from those of the subspecies sanguinipes.

Specimens (40 o $0^{7}, 54$ ) ): From Arizona (Oak Creek Canyon, "Palmerlee," Parker Creek in the Sierra Ancha, Rustlers Park in the Chiricahua Mts., and Santa Rita Mts.); British Columbia (Vancouver); California (Alameda, Corning, Covina, Davis, Dutch Flat in Placer Co., Green Valley in Solano Co., Hastings Reservation in the Santa Lucia Mts. of Monterey Co., Jacumba, Leevining, Pasadena, Sacramento, Santa Anita Canyon at 2,000 ft., Santa Cruz Mts., Santa Monica, "Summerdale," Westwood Hills in Los Angeles Co., and Woodland); Idaho (Moscow Mts.); New Mexico (Berino, Isleta Marsh, Jemez Springs at 6,400 ft., Koehler, Maxwell, Santa Fe, and Springer); Oregon (Hood River); Utah (Bountiful and Wellsville); Washington (Kent, Shelton, and Wenass Valley at Pressey's); and Mexico (20 miles north of Toluca at 8,500 ft.).
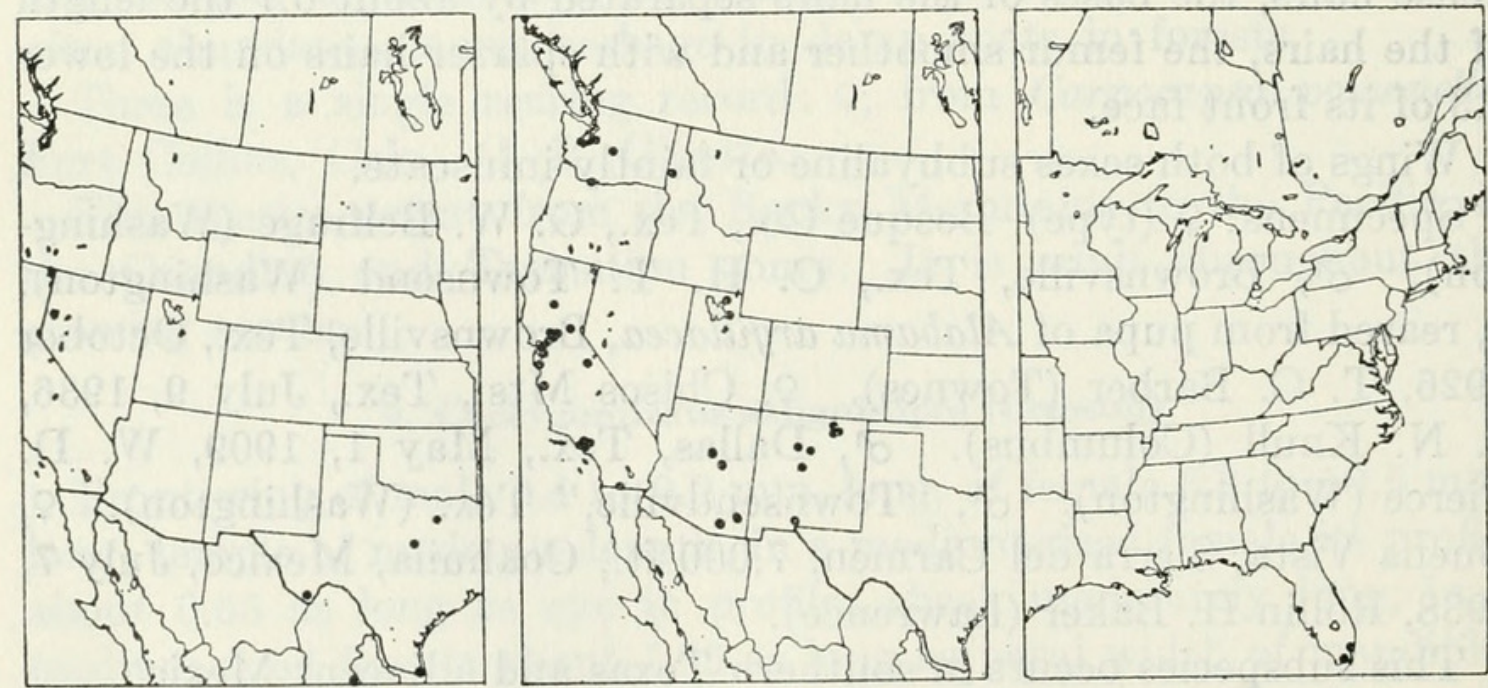

Figures 150-152.-Localities: 150 (left), Coccygomimus sanguinipes sanguinipes; 151 (center), C. s. erythropus; 152 (right), C. marginellus. 
Collection dates are evenly distributed through the growing season, the earlier and later ones being: March 26 at Pasadena, Calif.; April 3 at Davis, Calif.; April 16 at Covina, Calif. and at Sacramento, Calif.; October 23 at Barino, N. Mex.; and December 13 at Sacramento, Calif. We have found the species in grass in the damper spots of semidesert areas.

Rearing records comprise 2 rearings from Malacosoma sp., 1 rearing or reared lot each from Diacrisia virginica, Carpocapsa pomonella, Hemerocampa vetusta, Hemileuca sp., Malacosoma fragile, Prochoerodes forficaria, Tholeria reversalis, Zophodia sp., and 1 lot (the type and some of the paratypes) from a host on Abies concolor.

This subspecies occurs in the Transition, Upper Austral, and Lower Austral zones of the West, mostly in dry areas. It parasitizes a variety of medium-sized Lepidoptera.

\section{Coccygomimus marginellus (Brullé)}

Pimpla marginella Brullé, 1846, in Lepeletier, Histoire naturelle des insects, hyménoptères, vol. 4, p. 107; ㅇ. Type: ㅇ, Cuba (Paris).

Front wing 4.5 to $8.0 \mathrm{~mm}$. long; temple short, in a medium-sized female its profile about 0.4 as long as eye in profile; cheek short, in a medium-sized female about 0.85 as long as basal width of mandible; metapleurum with dense small punctures and hairs posteriorly and in its upper front corner, with moderately dense small punctures and hairs along its upper edge, the rest of its surface smooth and hairless.

Fulvoferruginous. Pedicel reddish brown; flagellum brown, reddish brown basally; palpi brown; extreme hind corner of pronotum white; tegula white, its apical $0.5 \pm$ dark brown; pleura tinged with white next to coxal attachments; first seven tergites black with an apical broad white band, the basal half of first tergite more or less ferruginous; abdomen of male blackish beyond seventh tergite, of female fulvoferruginous beyond sixth tergite, except for the apical white band on seventh tergite.

Specimens: $2 \sigma^{\top}$,, , Paradise Key, Fla., Apr. 9 and 12, 1951, H. and M. Townes (Townes). $\sigma^{7}, 3 \circ$, Matheson Hammock, Fla., Apr. 9 and 11, 1951, H. and M. Townes (Townes). Also: $13 \sigma^{7}, 11$, from Cuba, Haiti, and Puerto Rico, Our collections were from the undergrowth of the mixed hardwood forests known in Florida as "hammock."

This species occurs in southern Florida and the West Indies.

\section{AEQUALIS GROUP}

Front wing 3.2 to $9.5 \mathrm{~mm}$. long; body stout; nervulus interstitial or briefly postfurcal; hind tibia usually with a submedian pale band; propodeum rather short, rounded, most of it densely punctate and often also with some fine transverse wrinkling; median longitudinal 
carinae of propodeum usually distinct on its basal $0.3 \pm$, subparallel; abdomen rather closely punctate; first tergite short and wide; epipleura wide throughout, except in males of stricklandi and hesperus; upper valve of ovipositor not depressed apically and without transverse ridges. The epipleura of the second, third, and fourth tergites are respectively somewhere near $2.8,2.0$, and 1.7 as long as wide in males and somewhere near 2.0, 1.7, and 1.5 as long as wide in females (fig. 329,l).

This group is mostly Holarctic and Neotropic. Besides the seven species treated below as Nearctic, it includes the European Ichneumon contemplator Müller 1776, Pimpla melanacrias Perkins 1941, and Pimpla spuria Gravenhorst 1829; the Japanese Pimpla nipponica Uchida 1928 (described as a variety of $P$. spuria); the South American Pimpla rufipes Brulle 1846; the Chilean Pimpla fuscipes Brullé 1846, (=P. fuscipennis Spinola, 1851, new synonymy); an undescribed species from Chile; and Pimpla sordidella Holmgren 1868, from Tahiti. These species are new combinations in the genus Coccygomimus.

\section{Coccygomimus hesperus, new species}

Male: Front wing 3.7 to $4.7 \mathrm{~mm}$. long; epipleura of second, third, and fourth tergites respectively about $4.5,3.1$, and 1.85 as long as wide.

Colored like the male of $C$. stricklandi except that the maxillary palpus and sometimes the labial palpus is mostly white, the tegula is basally white to entirely white, and that the pale band on middle tibia is a little more distinct; wings subhyaline.

Female: Front wing 3.5 to $6.0 \mathrm{~mm}$. long; face with moderately sparse punctures, the punctures separated by about 1.4 their diameter; mesoscutum with dense hairs anteriorly, the rest of its surface with the hairs moderately sparse, their sockets separated by about 0.7 their length; epipleura of second, third, and fourth tergites respectively about $2.5,1.5$, and 1.4 as long as wide. Otherwise structurally similar to the female of $C$. stricklandi.

Coloration as in the female of $C$. stricklandi except that the hind tibia and tarsus vary from blackish with a poorly defined submedian pale band on the tibia (as in C. stricklandi) to entirely fulvous.

There is a distinguishable race in southern Arizona and New Mexico which has the tegula of the female fulvous or light brown (rather than brown or black) and the metapleurum usually with a moderately large ferruginous mark next to the hind coxa.

This species is compared with $C$. stricklandi because it is in the same species group, but it is also very similar to $C$. varians. Males are hardly distinguishable from those of varians. Females differ from those of varians in having the epipleura of the second tergite wider, 
striation on metapleurum averaging a little weaker, and hairs on seventh and eighth tergites averaging a little longer.

Type: $\%$, collected among rank herbage in a grove behind beach, Crescent City, Calif., Aug. 2, 1940, H. and M. Townes (Washington, USNM 63714).

Paratypes $\left(4 \sigma^{7}, 27\right.$ ) : From Alaska (Dutch Harbor and Skagway); Arizona (Chiricahua Mts. and Oak Creek Canyon); California (Bolinas, Botanical Gardens at Berkeley, Crescent City, Marysville, Mountain Home, Muir Woods, Oxnard, San Francisco, and "Wats. Crossing”); Colorado; Nebraska (Halsey); Nevada (Wells); New Mexico (Beulah and Las Cruces); Oregon (Seaside); South Dakota (Rapid City); and Utah (South Creek in Beaver Co.). The four males cited as paratypes are from a reared lot containing females, so their identity seems certain. We have many additional males which are probably this species, but since the specific characters of the male are so poorly developed we cannot be certain of their determination and do not list their localities or make them paratypes.

Collection dates are throughout the growing season, the earliest being May 13 at Oak Creek Canyon, Ariz., and the latest December 20 at "Wats. Crossing," Calif. A large portion of the specimens were taken later in the season, from August to December.

Reared specimens are as follows: $4 \sigma^{x}, 4$, from Rhyacionia frustrana bushnelli, Sept. 21 to 30, 1926, L. G. Baumhofer. \&, from Anarsia lineatella, Marysville, Calif., May 11, 1932, L. S. Jones. $\subsetneq$, from Udea rubigalis, Oxnard, Calif., Dec. 15, 1916, B. L. Boyden (Washington).

This species is in the western half of the United States and Alaska, where it occurs in the Transition zone.

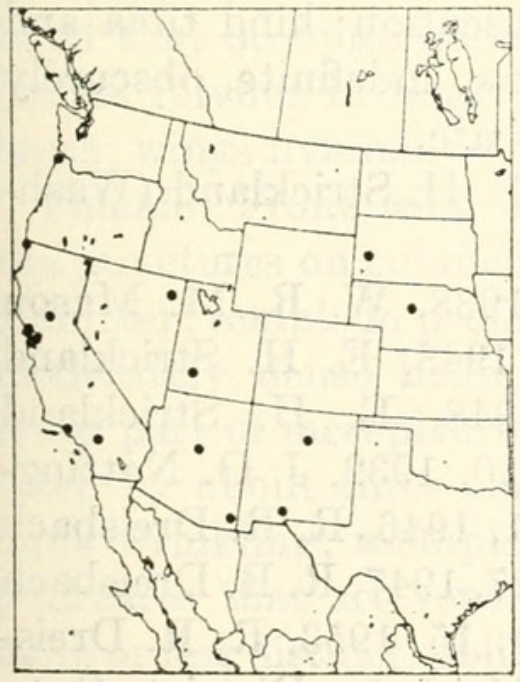

Figures 153, 154.-Localities: 153 (left), Coccygomimus hesperus; 154 (right), C. stricklandi. 


\section{Coccygomimus stricklandi, new species}

Figure 327,f

Male: Front wing 4.0 to $6.2 \mathrm{~mm}$. long; epipleura of second, third, and fourth tergites respectively about $4.0,2.8$, and 1.8 as long as wide.

Black. Labial palpus dark brown; maxillary palpus brownish to whitish; tegula entirely brown or blackish; front coxa black; front trochanters blackish or infuscate fulvous; front legs beyond trochanters fulvous, a little darker apically; middle coxa fulvous to black; middle trochanters fulvous or more or less infuscate; middle leg beyond trochanters fulvous, its tibia and tarsus often weakly infuscate, the tibia with a faint subbasal paler band; hind coxa fulvous to black; hind trochanters and femur fulvous, the femur without apical infuscation; hind tibia and tarsus blackish, the tibia with a narrow submedian whitish band; wings subhyaline.

Female: Front wing 3.0 to $6.8 \mathrm{~mm}$. long; face sparsely punctate, the punctures separated by about 2.5 their diameter; temple in profile about 0.70 as long as eye in profile; mesoscutum with very sparse hairs but these denser anteriorly, on most of its surface the hair sockets separated by about three times the length of the hairs; lower half of mesopleurum with small sparse punctures that are separated by about three times their diameter; metapleurum with small weak punctures that are separated by about 1.7 their diameter, near the hind coxa with weak, fine, irregular, oblique wrinkling; front tibia with a moderately strong median swelling; epipleura of second, third, and fourth tergites respectively about $2.0,1.7$, and 1.2 as long as wide.

Black. Labial palpus dark brown; maxillary palpus light brown; tegula blackish; front coxa brown to black; front leg beyond coxa fulvous, the trochanters and tarsus somewhat brownish; middle leg fulvous, the tarsus somewhat brownish; hind coxa, trochanters, and femur fulvous, the femur without apical infuscation; hind tibia and tarsus blackish, the tibia with a rather narrow, indefinite, obscurely fulvous, submedian band; wings weakly infuscate.

Type: $\odot$, Edmonton, Alta., July 12, 1948, E. H. Strickland (Washington, USNM 63715).

Paratypes: , Edmonton, Alta., Aug. 9, 1938, W. R. M. Mason (Townes). 2ᄋ, Edmonton, Alta., July 25, 1948, E. H. Strickland (Townes). o, Clymont, Alta., Aug. 1, 1948, E. H. Strickland (Townes). o, Cheboygan Co., Mich., Aug. 10, 1932, J. O. Nottingham (Townes). \&, Delta Co., Mich., Aug. 31, 1946, R. R. Dreisbach (Dreisbach). \&, Houghton Co., Mich., Aug. 27, 1947, R. R. Dreisbach (Dreisbach). \&, Schoolcraft Co., Mich., Aug. 15, 1953, R. R. Dreisbach (Dreisbach). क , Gravenhurst in the Muskoka District, Ont., Aug. 12, 1918 (New York). $\sigma^{7}$, Ellis Bay, Anticosti Island, Quebec, September 4 (Cambridge). \&, Dafoe, Sask., July 7, 1943, J. G. Rempel 
(Townes). क, Quill Lake at Kandahar, Sask., July 3, 1938, R. W. Salt (Townes). , Manitou, Sask., Aug. 16, 1938, J. G. Rempel (Townes). $2 \sigma^{\top}$, , Prince Albert National Park, Sask., July 19, 1941 and July 25, 1940, J. G. Rempel (Townes). $\sigma^{x}$, ㅇ, Regina, Sask., Aug. 5, 1941, J. G. Rempel (Townes). क, Waskesiu, Sask., June 15, 1938, J. G. Rempel (Townes). ㅇ, Waskesiu, Sask., July 22, 1938, J. S. Thompson (Townes).

This species is in the Canadian zone, from the Atlantic to the Rocky Mountains.

\section{Coccygomimus aequalis (Provancher)}

Figures $327, \mathrm{~g} ; 329,1$

Pimpla aequalis Provancher, 1880, Naturaliste Canadien, vol. 12, p. 36 (Faune, p. 457); + . Type: $\uparrow$, Quebec (Quebec).

Meniscus ashmeadii Provancher, 1888, Additions et corrections au volume II de la faune entomologique du Canada traitent des hyménoptères, p. 430 ; Type: + , Jacksonville, Fla. (Quebec).

Pimpla conquisitor var. rufuscula Davis, 1898, Trans. Amer. Ent. Soc., vol. 24, p. 368 ; $\uparrow$. Lectotype: $q$, northern Illinois (Philadelphia).

Brology: Breakey, 1930, Ann. Ent. Soc. America, vol. 23, p. 187.-Townes, 1939, Bull. Brooklyn Ent. Soc., vol. 34, p. 29; 1940, Ann. Ent. Soc. America, vol. 33 , p. 308 .

Male: Front wing 3 to $7.5 \mathrm{~mm}$. long; epipleura of second, third, and fourth tergites respectively about $2.9,1.9$, and 1.7 as long as wide.

Black. Palpi and tegula white; flagellum dark brown; front and middle legs fulvous, their tarsi pale fulvous but brownish at the apex, the front tibia with a faint subbasal whitish band, and the middle tibia with a moderately distinet subbasal whitish band; hind coxa, trochanters, and femur fulvous, the apical $0.14 \pm$ of the femur infuscate; hind tibia and tarsus blackish, the tibia with a premedial white band that occupies about 0.3 its length; underside of abdomen more or less fulvous in larger specimens, especially in those from warmer areas; wings hyaline.

Female: Front wing 3.3 to $9.5 \mathrm{~mm}$. long; face sparsely punctate, the punctures on submedian part of face separated by about 1.5 their diameter; temple in profile about 0.55 as long as eye; mesoscutum with moderately dense hairs, the hairs a little sparser on lateral lobes; lower part of mesopleurum with small sparse punctures that are separated by about three times their diameter, often also with some oblique wrinkling; metapleurum with moderately dense, medium-sized punctures that are separated by about 1.4 their diameter, also with more or less distinct, oblique wrinkling (the metapleurum is mucb more densely punctate than the face); front tibia with a moderately strong median swelling; epipleura of second, third, and fourth tergites respectively about $1.9,1.7$, and 1.4 as long as wide. 
Black. Palpi light brown; scape and flagellum brown; tegula white, its apical part usually brownish, sometimes in northern specimens mostly brown; front and middle legs fulvous, the middle tibia with an indistinct whitish subbasal band; hind coxa, trochanters, and femur fulvous, the apical $0.11 \pm$ of the femur more or less infuscate; hind tibia blackish, with a premedian white band that occupies about 0.25 its length; hind tarsus brown to blackish; sometimes under side of abdominal segments 2-4 fulvous and apicolateral corners or apical margin of these tergites fulvous, especially in larger specimens from more southern localities; wings subhyaline.

Specimens (904) : From Alabama (Coleta, Coosa River in Chilton Co., and Pyriton); Arkansas (Bentonville); Connecticut (Canterbury, Lyme, Milford, New Haven, and Stonington); District of Columbia (Washington); Florida (Apopka, Bradenton, Crescent City, Dunedin, Gainesville, Jackson Co., Larkins in Dade Co., Ocala, Orlando, Tarpon Springs, and White City in St. Lucie Co.); Georgia (Macon); Illinois (Algonquin, Chicago, Elsah, Fort Sheridan, and Urbana); Indiana; Iowa (Muscatine and Okoboji); Kansas (Cowley Co., La Cygne, Lawrence, Marion Co., Miami Co., Montgomery Co., Riley Co., Wallace, and Wellington); Kentucky (Crailhope); Louisiana (Opelousas); Maine (Mount Desert Island and Pittston); Maryland (Beltsville, Bowie, Cabin John, Chevy Chase, Glen Echo, Plummers Island, Reisterstown, Ringgold in Washington Co., and Takoma Park); Massachusetts (Arlington, Boston, Cambridge, Cohasset, Forest Hills, Holliston, Malden, Milton, Provincetown, Sagamore, South Hadley, Tyngsboro, Wellesley, and Wollaston); Michigan (Alger Co., Ann Arbor, Arenac Co., Barry Co., Bay Co., Cheboygan Co., Clinton Co., Detroit, East Lansing, Eaton Co., Genesee Co., George Reserve in Livingston Co., Gladwin Co., Gratiot Co., Huron Co., Ionia Co., Lake Co., Manistee Co., Mason Co., Mecosta Co., Midland Co., Monroe Co., Muskegon Co., Nottawa, Oceana Co., Ogemaw Co., Ontonagon Co., Osceola Co., Owosso, Roscommon Co., St. Clair Co., and Tuscola Co.); Minnesota (Afton, Chisago Co., Detroit Lakes, Fort Snelling, Houston Co., Lake Itasca, John Latsch State Park, Medicine Lake in Hennepin Co., Mille Lacs Co., Norman Co., St. Anthony Park, Traverse Co., and Vineland); Missouri (Atherton, Columbia, and St. Louis); Nebraska (Omaha); New Hampshire (Hanover, Lake of the Clouds on Mount Washington, Pinkham Notch, and Randolph); New Jersey (Elizabeth, Elizabethport, Fort Lee, Moorestown, Ocean Grove, Ramsey, Riverton, "Snake Hill," and Wildwood); New York (near Arena, Aurora, Babylon, Barren Island near Brooklyn, Bear Mt., Bemus Point, Brooklyn, Buffalo, Canadarago Lake, Canajoharie, Caroline, Cold Spring Harbor, Dix Hills near Huntington, Downsville, Farmingdale, Fishers Island, 
Flatbush, Gardiners Island, Greene Co., Hancock, Horton, Ithaca, Kissina Park on Long Island, Lake George, Letchworth State Park, Long Beach, Ludlowville in Tompkins Co., Mastic, McLean Reserve in Tompkins Co., Medina, Milford Center, Millwood, New Rochelle, North Beach on Long Island, Nyack, Oneonta, Oswego, Pelham, Penn Yan, Portage, Poughkeepsie, Rochester Junction, Rock City in Cattaraugus Co., Sea Cliff on Long Island, Shokan, Slide Mt. at 2,800 to 4,000 ft., Syracuse, Taughannock Falls, Utica, Wildwood State Park in Suffolk Co., and Wyandanch); North Carolina (valley of the Black Mts., Crabtree Meadows in Yancey Co. at 3,600 ft., Elizabethtown, Hamrick, Highlands, Kill Devil Hills, Murfreesboro, Southern Pines, north fork of the Swannanoa River, Tryon, and Wilkesboro); Nova Scotia ("Pgh. S. Hill"); Ohio (Adams Co., Akron, Bedford, Cantwell Cliffs, Cedar Point, Cleveland, Columbus, Delaware Co., Eagleville, Hinckley in Medina Co., Hocking Co., Jug Run near Smithfield, Massillon, Medina, Montgomery Co., Muskingum Co., Put-in-Bay, Sandusky, Urbana, and Wooster); Ontario (Brockville, Callander, Gananoque, Ingersoll, Jordan, Marmora, Niagara Glen, Normandale, Orillia, Ottawa, Point Pelee, Pelee Island, Rondeau Park, Simcoe, Toronto, Trenton, and Vineland Station); Pennsylvania (Allegheny Co., Arendtsville, Bloomsburg, Carlisle Junction, Crisp in Westmoreland Co., Delaware Co., Enola, Fairview in Luzerne Co., Harrisburg, High Spire, Hillsgrove, Inglenook in Dauphin Co., Jeannette, Laurel Hill in Somerset Co., Laurelton, Lebanon Co., Linglestown, New Paris, North East, Ohiopyle, Paupack, Philadelphia, Pittsburgh, Presque Isle in Erie Co., Roxborough, Shiremanstown, and Washington Co.); Quebec (Ellis Bay on Anticosti Island and Hull); Rhode Island (Alton, Ashaway, Charlestown, and Westerly);
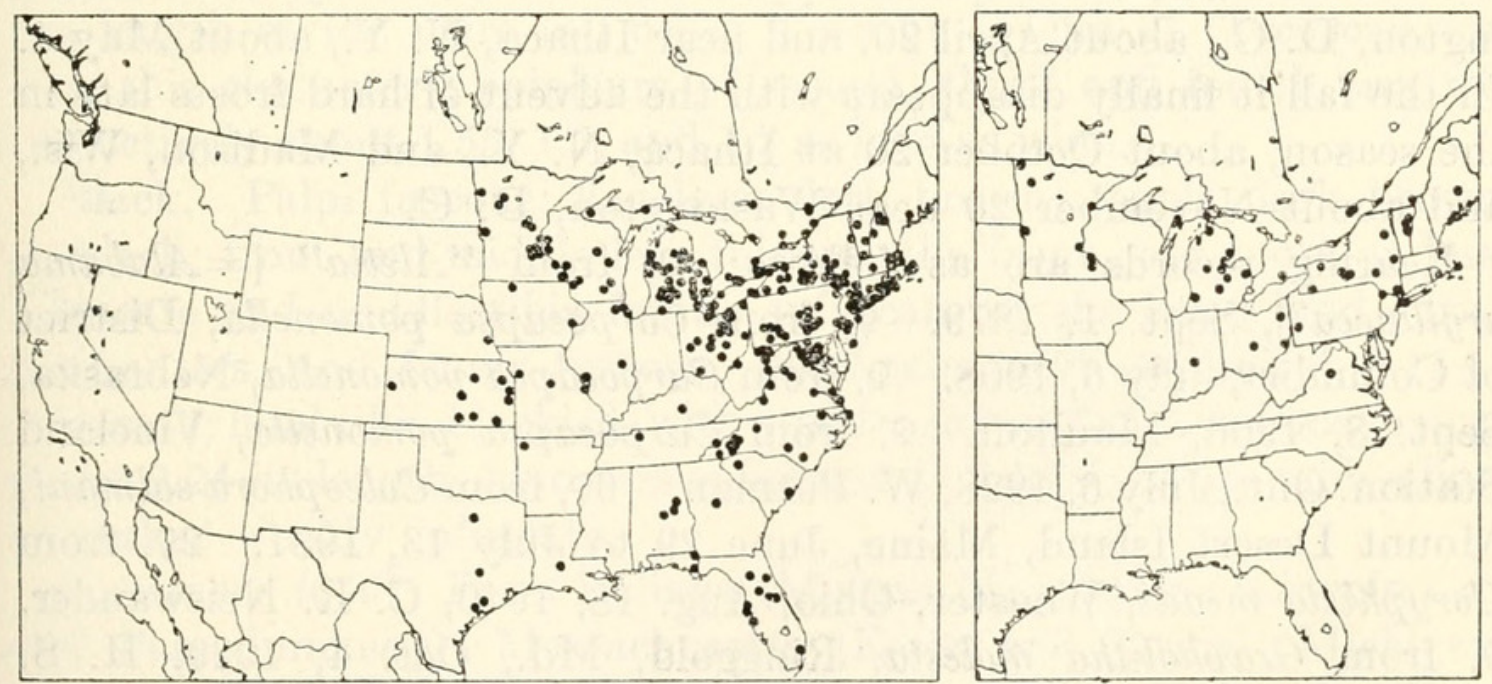

Figures 155, 156.-Localities: 155 (left), Coccygomimus aequalis; 156 (right), C. nudus. 
South Carolina (Greenville and McClellanville); Tennessee (Clarksville and Headquarters of Great Smoky Mountains National Park); Texas (College Station, Dallas, Victoria, and Wharton Co.); Vermont (Laurel Lake near Jacksonville, Stowe, and Woodstock); Virginia (Chain Bridge near McLean, Charlottesville, Dayton, Dixie Landing in Mathews Co., Falls Church, Glencarlyn, Great Falls, Middle Mt., Mountain Lake in Giles Co., Norfolk, Petersburg, Rosslyn, Vienna, Virginia Beach, and Warm Springs Mt. in Bath Co. at 3,300 ft.); West Virginia (Bolivar, Cheat Mt. in Randolph Co. at 2,000 ft., Cheat River, Kanawha Station, Morgantown, Philippi, and Terra Alta); and Wisconsin (Columbus, Gays Mills, Madison, Polk Co., Rib Mountain State Park, Richland Co., St. Croix Co., Trempealeau Co., and Waupaca Co.).

In addition to the females reported above, we have seen about 1,800 males, which are certainly or probably this species. Since it is often not possible to be sure that an individual male belongs here rather than under annulipes or nudus, we have not listed the localities from which there are only male specimens. A list of them would add little geographic information of value and might be partially in error.

We have found the species abundant in mesophytic or damp deciduous woods where there is some ground cover. In eastern United States it is probably the commonest member of the family. It is nearly always close to the ground and females spend much time crawling over and sometimes under the dead leaves of the forest floor, often flipping their wings in a manner reminiscent of psammocharids. Considering its abundance it has been reared rather seldom, probably because there are relatively few rearings from pupae collected from under the litter of forest floors.

Dates of capture are throughout the season of green foliage. In Florida and Texas the species appears first in February, near Washington, D. C., about April 20, and near Ithaca, N. Y., about May 1. In the fall it finally disappears with the advent of hard frosts late in the season, about October 20 at Ithaca, N. Y., and Madison, Wis., and about November 20 near Washington, D. C.

Rearing records are as follows: o, from "Aletia" [=Alabama argillacea?], Sept. 1, 1879. $\%$, from Carpocapsa pomonella, District of Columbia, July 6, 1908. $\%$, from Carpocapsa pomonella, Nebraska, Sept. 8, 1906, Moulton. क, from Carpocapsa pomonella, Vineland Station, Ont., July 6, 1928, W. Putman. 6\%, from Coleophora salmani, Mount Desert Island, Maine, June 29 to July 13, 1931. 2\%, from Coryphista meadi, Wooster, Ohio, Aug. 18, 1940, C. R. Neiswander. ㅇ, from Grapholitha molesta, Ringgold, Md., Oct. 4, 1929, H. S. McConnell. 2\%, from Mineola sp., Bentonville, Ark., June 6 and 27, 1918, R. D. Isely. 2o, from Polychrosis viteana, Chatauqua Co., 
N. Y., E. F. Taschenberg. क, from Tolype velleda, Long Island, N. Y., June 23, 1905, G. P. Engelhardt.

This is an exceptionally common species, occurring in the Alleghanian, Carolinian, and Austroriparian faunas. Its habitat is deciduous woods with ground cover. Adults occur throughout the growing season.

\section{Coccygomimus nudus (Townes)}

Pimpla nuda Townes, 1940, Ann. Ent. Soc. America, vol. 33, p. 306; ㅇ. Type: , Bear Mt. State Park, N. Y. (Townes).

Male (not known with certainty but several males probably of this species are as follows): Front wing about $6.5 \mathrm{~mm}$. long; similar to the male of $C$. aequalis except that the epipleura of the second tergite seem to be slightly wider and the hind femur has the apical $0.18 \pm$ fuscous, which is a little more fuscous than usually found in $C$. aequalis. These differences are not great or certain enough to permit a definite separation between males of the two species. Unlike the female, these supposed males of $C$. nudus have the tegula white and lack the bald area along the upper edge of the hind tibia.

Female: Front wing 4.5 to $8.0 \mathrm{~mm}$. long; face sparsely punctuate, the punctures on the submedian part of face separated by about 2.5 their diameter; temple in profile about 0.46 as long as eye; mesoscutum with moderately dense hairs anteriorly, the rest with sparse, scattered hairs; lower part of mesopleurum with fine sparse punctures that are separated by about 3.0 their diameter, without wrinkling; metapleurum with fine punctures that are separated by about 2.0 their diameter, and with some oblique wrinkling in its lower hind part; front tibia with a moderately strong median swelling; upper edge of hind tibia with hairs much sparser than elsewhere on the tibia, in some places on the upper edge the hair sockets separated by more than the length of the hairs (all other Nearctic species of Coccygomimus lack this character); epipleura of second, third, and fourth tergites respectively about $1.55,1.3$, and 1.2 as long as wide.

Black. Palpi fuscous; flagellum dark brown; tegula dark brown to black; front and middle legs fulvous, the front coxa more or less infuscate and middle tibia faintly infuscate at the base; hind coxa, trochanters, and femur fuscous, the femur with its apical $0.15 \pm$ infuscate; hind tibia blackish, with a white submedian band occupying about 0.24 its length; hind tarsus fuscous or brown; wings subhyaline or rather weakly infuscate.

Specimens (65): From Indiana (Morgan Co.); Maine (Lincoln Co. and Passadumkeag); Massachusetts (Essex and Truro); Michigan (Bay Co., Burt Lake State Park in Cheboygan Co., Delta Co., East Lansing, Iosco Co., Mackinac Co., Mecosta Co., Midland Co., Sanilac $526527-60-23$ 
Co., Shiawassee Co., and Van Buren Co.); Minnesota (Browns Valley, Duluth, Kittson Co., Lake City, Olmsted Co., Plummer, and St. Paul); New Jersey; New York (Albion, Allegany State Park, Bear Mountain State Park, Ithaca, Long Beach, McLean Bogs Reserve in Tompkins Co., Milford Center, Taughannock Falls, Troy, and Upper Ausable Lake in Essex Co.); Nova Scotia (Baddeck); Ohio (Columbus, Jerusalem, and Portage Co.); Ontario (Merivale, Ottawa, and Simcoe); Pennsylvania (Milford, "Mooresville," and Pittsburgh); Quebec (St. Malo); Vermont (Caledonia Co., Plainfield, and Woodstock); and Virginia (Shenandoah National Park at 3,200 ft.). We have seen several males that probably belong to this species and certainly many more have passed through our hands but could not be distinguished from males of $C$. aequalis. Since there is no certain way of identifying a male of this species we do not attempt to report any.

Dates of collection are from late spring to mid-fall. The earlier and later dates are: May 28 in Sanilac Co., Mich.; May 29 at Simcoe, Ont.; May 30 in Shiawassee Co., Mich. and at Merivale, Ont.; September 19 in Ramsey Co., Minn.; and September 29 at 3,200 ft. in Shenandoah National Park, Va.

Reared specimens are as follows: $2 \circ$, from Pyrausta nubilalis, Jerusalem, Ohio, July 10, 1929, M. Schlosberg. \&, from Neodiprion sp., Passadumkeag, Maine, Oct. 9, 1939. \&, from pupa of Lepidoptera, Apr. 28, 1916, F. A. Fenton.

This species occurs in the Alleghanian fauna. It is adult from spring to fall.

\section{Coccygomimus annulipes (Brullé)}

Pimpla annulipes Brullé, 1846, in Lepeletier, Histoire naturelle des insectes, hyménopères, vol. 4, p. 102; ๆ. Type: , "South America" (Paris). Pimpla inflata Townes, 1940, Ann. Ent. Soc. America, vol. 33, p. 306, ơ, $\$$. New synonymy. Type: $q$, Bear Mountain State Park, N. Y. (Townes).

Male: Similar to the male of $C$. aequalis except that the middle tibia averages darker and is usually distinctly infuscate basad of the pale band. Also, the face may be perceptibly more densely punctate than in $C$. aequalis. These differences permit a reasonably safe determination for about 30 percent of the better marked males but the rest are hardly distinguishable from males of $C$. aequalis, and unless there is great need for a name it is usually more prudent not to try to determine the species of any males of this type.

Female: Front wing 4.0 to $8.0 \mathrm{~mm}$. long; face rather densely punctate, the punctures on submedian part of face sharp and moderately coarse, separated by about 0.5 their diameter; temple in profile about 0.50 as long as eye; mesoscutum with moderately dense hairs all over; lower part of mesopleurum with small sharp punctures that are separated by about 2.0 their diameter; metapleurum with small punctures 
that are separated by about 1.5 their diameter and some fine, weak, oblique wrinkles; front tibia with a very strong median swelling; epipleura of second, third, and fourth tergites, respectively about $2.3,1.6$, and 1.5 as long as wide.

Black. Clypeus dark reddish brown; palpi brown; scape and flagellum dark brown; tegula white; front leg fulvous, its coxa often somewhat brownish; middle leg fulvous, the apex of its femur faintly infuscate, its tibia more or less infuscate basally, the fuscous fading toward its apex, also with a subbasal paler band; hind coxa, trochanters, and femur fulvous, the apical $0.17 \pm$ of the femur infuscate; hind tibia blackish, with a premedian white band that occupies about 0.25 its length; hind tarsus fuscous brown; wings subhyaline.

The best diagnostic character for females is that the submedian part of the face is more densely punctate than the metapleurum. In species that might be confused with it the converse is true. Additional, confirmatory characters are the strong swelling at the middle of the front tibia and the distinct infuscation at the base of the middle tibia.

Pimpla annulipes Brullé was described from "South America" but for many years the Nearctic Coccygomimus aequalis and other Nearctic species resembling aequalis were frequently determined as annulipes Brullé. In 1918 Cushman (Proc. Ent. Soc. Washington, vol. 20, p. 9) noted that the type locality was "South America" rather than North America and a difference in color of the middle tibia between the original description of annulipes and the Nearctic specimens. He proposed that the Nearctic specimens formerly classified under annulipes be called by the name aequalis. We studied Brullé's type in 1958 and found that it is a large specimen (front wing $8 \mathrm{~mm}$. long) of Coccygomimus inflatus, which is known only from eastern North America. The type of annulipes has no locality label, only a tag with the numbers "136" and "38." Presumably the locality "South America," given by Brullé, is an error and his type was actually from eastern North America.

Specimens $\left(280^{7}, 171\right.$ ) $)$ : From Arkansas (Bentonville and Siloam Springs); District of Columbia (Washington); Florida (Gainesville, Gulfport, and Monticello); Illinois (Algonquin); Indiana (Vincennes); Kansas (Johnson Co., Lawrence, and Riley Co.); Maine (Casco); Maryland (Glen Echo, Plummers Island, and Ringgold); Massachusetts (Boston, Milton, and South Yarmouth); Michigan (Ann Arbor, East Lansing, Gull Lake Biological Station in Kalamazoo Co., Iron Co., and Livingston Co.); Minnesota (Lake Itasca); Mississippi (near Hattiesburg); Missouri (St. Louis); New Jersey (Bridgeboro, Burlington, Evesboro, Florence, and Masonville); New York (Bear Mt., Bemus Point, Greene Co., Ithaca, Minetto, New Baltimore, Sea 
Cliff, and Shokan); North Carolina (Great Smoky Mountains National Park, Highlands, Jackson Springs, and Walnut); Nova Scotia (Wolfville); Ohio (Dayton); Ontario (Beamsville, Blackburn, Hastings Co., Ottawa, and Vineland Station); Pennsylvania (Arendtsville, Guyasuta Run in Allegheny Co., Harrisburg, New Cumberland, North East, and Shiremanstown); Quebec (Montreal and "St. Anne's"); Texas; Virginia (Arlington, Charlottesville, Falls Church, Glencarlyn, Greenwood, and Vienna); and West Virginia (French Creek, Kearneysville, and Philippi).

Dates of capture are distributed throughout the growing season, starting a little earlier in the spring than usual for species of $\mathrm{Coc}$ cygomimus. Early and late dates of interest are: April 2 at Falls Church, Va.; April 14 at Vienna, Va.; April 30 at Gull Lake Biological Station in Kalamazoo Co., Mich.; September 11 at Ithaca, N. Y.; November 10 at Arlington, Va.; and December 1 at Hattiesburg, Miss. In our own collecting we have found the species in overgrown fields with weeds and bushes, and at the edges of woods. This is a drier and more open habitat than that of aequalis and some other species, and partially explains why annulipes is more frequently a parasite of Lepidoptera attacking orchard trees.

Rearing records comprise 12 rearings or reared lots from Carpocapsa pomonella, 6 from Grapholitha molesta, 1 from Gretchena bolliana, 2 from Laspeyresia nigricana, 1 from Salebriaria tenebrosella, 2 from Synanthedon pictipes, and 1 from Thamnosphecia pyri.

This species is in the Alleghanian, Carolinian, and Austroriparian faunas. It occurs in open habitats such as old fields partially invaded by trees and in orchards. It has been reared mostly from Lepidoptera attacking orchard trees. Adults occur from rather early spring to mid or late fall.
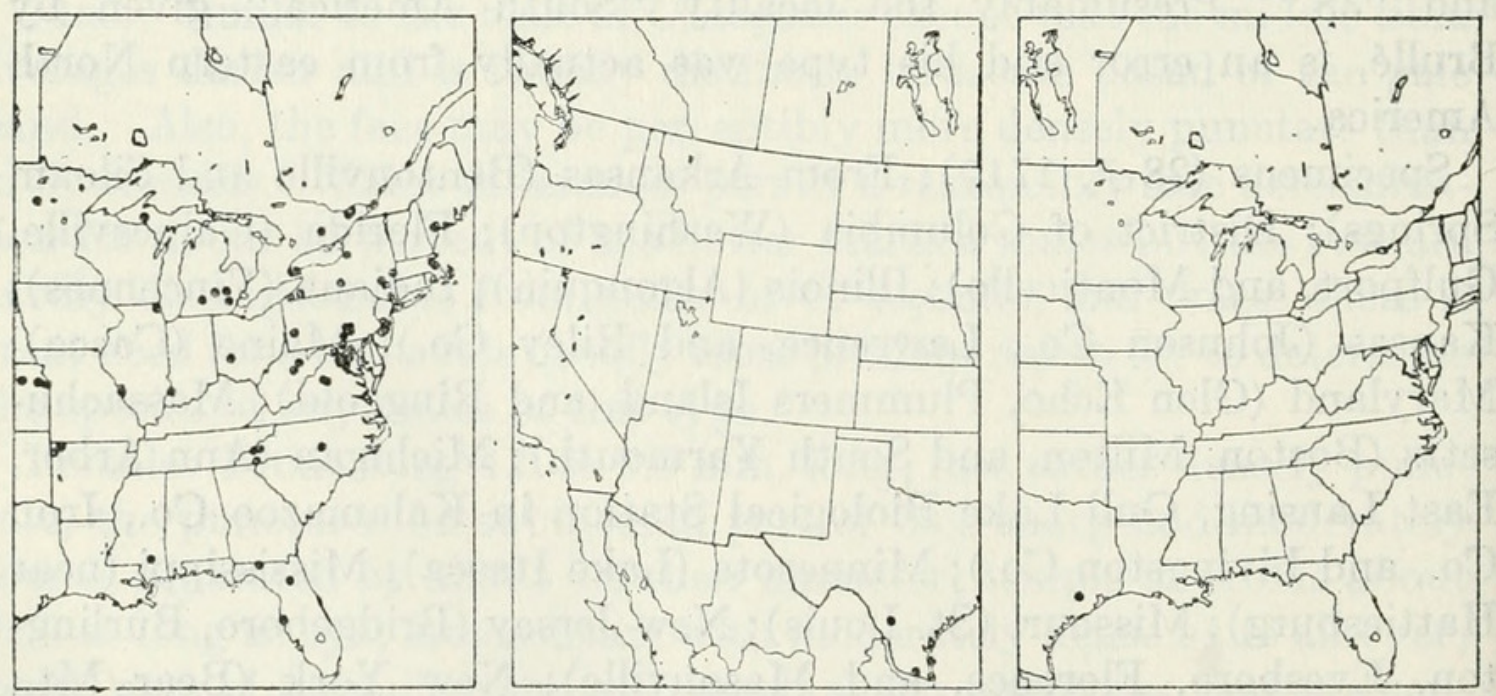

Figures 157-159.-Localities: 157 (left), Coccygomimus annulipes; 158 (center), C. punicipes; 159 (right), C. dimidiatus. 


\section{Coccygomimus punicipes (Cresson)}

Figure $327, \mathrm{~h}$

Pimpla punicipes Cresson, 1873, Proc. Acad. Nat. Sci. Philadelphia, vol. 25, p. 398; ㅇ. Type: $\uparrow$, Orizaba, Mexico (Philadelphia).

Pimpla feralis Cresson, 1873, Proc. Acad. Nat. Sci. Philadelphia, vol. 25, p. 399:

$\sigma^{x}$. Type: $\sigma^{x}$, Orizaba, Mexico (Philadelphia).

Pimpla hawaiiensis Cameron, 1887, Mem. Proc. Manchester Lit. Philos. Soc., ser. 3, vol. 10, p. 239; $\sigma^{x}$. Type: $\sigma^{7}$, Oahu, Hawaii (London).

Pimpla puniceipes Dalla Torre, 1901, Catalogus hymenopterorum, vol. 3, p. 446. Emendation.

Male: Front wing 3.8 to $7.0 \mathrm{~mm}$. long; epipleura of second, third, and fourth tergites respectively about $2.2,2.2$, and 1.7 as long as wide.

Black. Labial palpus stramineous; maxillary palpus white; tegula white; front coxa blackish, its apical $0.3 \pm$ fulvous; front leg beyond coxa fulvous; middle leg fulvous, its tibia with an indistinct paler subbasal band; hind coxa, trochanters, and femur fulvous, the femur without apical infuscation; hind tibia and tarsus black or blackish, the tibia with a submedian whitish band occupying about 0.21 its length; wings subhyaline.

Female: Front wing 4.7 to $8.7 \mathrm{~mm}$. long; face rather densely punctate, submedially the punctures separated by about 0.8 their diameter; temple in profile about 0.5 as long as eye in profile; mesoscutum with moderately dense hairs; lower half of mesopleurum with small punctures that are separated by about 1.7 their diameter; metapleurum with small weak punctures that are separated by about 1.5 their diameter, near the hind coxa with weak, fine, oblique wrinkling; front tibia with a rather strong median swelling; epipleura of second, third, and fourth tergites respectively about $2.0,1.5$, and 1.5 as long as wide.

Black. Labial palpus dark brown; maxillary palpus light brown; tegula ivory, its apex brown, usually about half white and half dark brown; legs uniformly fulvous, the front coxa blackish basally and the tarsi brownish apically; wings faintly infuscate.

Specimens: $\sigma^{\top}$, Brownsville, Tex., J. C. Bridwell (Washington) q, Brownsville, Tex., 1929 (Washington). $\sigma^{\top}$, reared from Malachra capitata, Brownsville, Tex., Nov. 16, 1942, Shiller (Washington). , Crystal City, Tex., Feb. 4, 1950, J. B. Duncan (Washington). $10 \sigma^{7}$, Hidalgo, Tex., Dec. 28, 1945, R. H. Beamer (Lawrence). क, Padre Island, Tex., May 29, 1952, K. O’Neill (Washington). 2ᄋ, 10 miles north of Rockport, Tex., Apr. 18, 1952, Michener, Beamers, Wille, and La Berge (Lawrence). Also $35 \sigma^{7}$, 29 우 from Ecuador, Mexico, Venezuela, and Hawaii.

This species is in southern Texas and ranges southward into South America. It occurs also in Hawaii. 


\section{Coccygomimus dimidiatus, new species}

Male type: Front wing $5.3 \mathrm{~mm}$. long; face with rather dense, medium-sized, subadjacent punctures; temple in profile 0.54 as long as eye; mesopleurum and metapleurum with medium-sized, rather sharp punctures that are separated by about 0.6 their diameter on mesopleurum and somewhat closer on metapleurum, the metapleurum with weak oblique wrinkles; epipleura of second, third, and fourth tergites respectively $1.8,1.65$, and 1.45 as long as wide.

Black. Clypeus dusky fulvous, its basal part blackish; palpi fulvous; antenna fulvous brown; tegula light fulvous; legs fulvous, the apical part of fifth segment of front and middle tarsi light brown, hind tarsus brown, and apical 0.06 of hind tibia a little infuscate; abdomen entirely fulvous; wings hyaline.

Female: Unknown.

Type: $\sigma^{7}$, Hempstead, Tex., Mar. 3, 1942, A. L. Melander (Cambridge).

\section{Tribe Theroninn}

Figures 299,b-300,b

Front wing 5 to $19 \mathrm{~mm}$. long; clypeus transverse, its basal portion weakly convex or almost flat, its apical portion often a little depressed, often divided into two lobes by a notch in its apical margin but in the genera Pseudorhyssa and Atraciogaster with a median apical tubercle; mesoscutum in Pseudorhyssa with close, transverse wrinkles, in other genera without wrinkles; prepectal carina present; mesopleural suture with an angulation near the middle; propodeal carinae bounding the petiolar area and usually bounding the areola more or less distinctly, in some species of Theronia all the carinae present; last segment of tarsus sometimes enlarged; tarsal claws simple, in the genus Theronia with an enlarged hair that is flattened at the tip; areolet present; nervellus broken near, somewhat below, or above the middle; subgenital plate of male usually longer than wide, sometimes with an acute or rounded apical point; last tergite of female without an apical horn or boss; ovipositor short to long, of uniform width, more or less compressed.

As defined here, this tribe includes the genera Theronia, Delomerista, Atractogaster, and Pseudorhyssa. Whether or not they are really related has not been proven, but they do have certain characters in common. The adult characters are described above. The larvae of Theronia, Delomerista, and Pseudorhyssa are similar in having a large internal tooth on the mandible. Larvae of Atractogaster are unknown. We are indebted to Dr. G. H. Thompson, of Oxford, for information about the larva of Pseudorhyssa. 
The genus Theronia is worldwide, Delomerista and Pseudorhyssa Holarctic, and Atractogaster European. Below is a key to the genera occurring in North America.

\section{Key to the Nearctic genera of Theroniini}

1. Abdomen polished; tarsal claws enlarged, each with an enlarged bristle with a spatulate tip; body color usually yellow or fulvous . 1. Theronia (p. 351) Abdomen strongly mat; tarsal claws not enlarged, without an enlarged bristle with a spatulate tip; body color black . . . . . . . . . . . . 2

2. Clypeus without a median apical notch; nervellus broken at or below the middle. . . . . . . . . . . . . . . 2. Delomerista (p. 362)

Clypeus with a median apical tooth; nervellus broken far above the middle.

3. Pseudorhyssa (p. 373)

\section{Genus Theronia}

FigURE 299,b

Theronia Holmgren, 1859, Öfvers. Svenska Vetensk.-Akad. Förh., vol. 16, p. 123. Type: (Pimpla flavicans Fabricius) =atalantae (Poda); monobasic.

Pseudacoenites Kriechbaumer, 1892, Ent. Nachr., vol. 18, p. 219. Type: (Pseudacoenites moravicus Kriechbaumer)=laevigata (Tschek); monobasic.

Neotheronia Krieger, 1898, Sitz.-Ber. Naturf. Ges. Leipzig, vol. 14-15, p. 119. Type: Theronia tolteca Cresson; original designation.

Epimecoideus Ashmead, 1900, Proc. U. S. Nat. Mus., vol. 23, p. 52. Type: Epimecoideus apicalis Ashmead; original designation.

Poecilopimpla Cameron, 1903, Journ. Straits Branch of the Roy. Asiatic Soc., vol. 39, p. 141. New synonymy. Type: Poecilopimpla lucida Cameron; monobasic.

Erythrotheronia Cameron, 1905, Spolia Zeylanica, vol. 3, p. 134. Type: Erythrotheronia flavolineata Cameron; monobasic.

Orientotheronia Morley, 1913, Fauna of British India, including Burma and Ceylon, Hymenoptera, vol. 3, pt. 1, p. 146. Type: Orientotheronia rufescens Morley; original designation.

Front wing 5 to $13 \mathrm{~mm}$. long; body form moderately stout to rather slender; apex of clypeus truncate or with a median notch, without a pointed median apical tooth; propodeal carinae strong; tarsal claws very large, simple, but with an enlarged bristle arising subbasally below and extending to apex of claw, the tip of the bristle with a spatulate enlargement; nervellus broken far above the middle; abdomen polished, its hairs usually sparse and arising from fine inconspicuous punctures; ovipositor short to moderately long, cylindric, its sheath usually about 0.45 as long as front wing.

Poecilopimpla is synonymized with Theronia on the basis of the original description. We have not seen the genotype.

There are some rather well-defined groups within this genus, which might be recognized as species groups or as subgenera, but since there are only four Nearctic species, definitions of subgenera or species groups is not attempted here. Of our four, the species bicincta and 
septemtrionalis are related to Neotropic species, while atalantae and hilaris are representatives of a large group of species centered in the Oriental region.

The species of Theronia are medium-sized ichneumonids with the ovipositor sheath about half as long as the abdomen, or longer or shorter in a few of the exotic species. They inhabit mostly dense forests. Some of them fly close to the ground, but others commonly fly up to waist or shoulder height if there is undergrowth at those levels. Nearly all are pale-colored, usually pale yellow to ferruginous, and frequently banded with blackish. In flight they make a conspicuous pale streak through the dark forest. When caught they sink their large sharp claws into the net or their captor and are often hard to disengage without breaking the claws. This habit and the presence of a large fluid-filled pocket in each claw at the usual place of breaking has led to speculation as to whether the claws may function as a sort of poison fang (Townes, 1940, Ann. Ent. Soc. America, vol. 33, pp. 285-287). Definite evidence on this question is still lacking. Probably most species are primary or secondary parasites of a variety of Lepidoptera. A Philippine species, however, has been reared from a nest of Stenogaster (Vespidae), this rearing having been reported as an unidentified parasite by Williams (1919, Bull. Experiment Sta. Hawaiian Sugar Planters Assoc., Ent. Ser., vol. 14, p. 173).

The Nearctic species of Theronia were treated by Townes in 1940 (Ann. Ent. Soc. America, vol. 33, pp. 289-298). The treatment below is similar to that.

\section{Key to the Nearctic species of Theronia}

1. Front wing with a definite dark spot near the apex; propodeum with a transverse carina across its middle and no carinae basad of the transverse carinae (fig. 314,c). . . . . . . . . 3. septemtrionalis (Krieger)

Front wing without a definite dark spot near the apex; propodeum with a less regular transverse carina across its middle and with definite longitudinal carinae basad of the transverse carina (figs. $314, \mathrm{a}, \mathrm{b}, \mathrm{d}$ ) . . . . . . . . 2

2. Prepectal carina incomplete above, its upper end far from front edge of mesopleurum; abdomen banded with brown and yellow . 4. bicincta (Cresson)

Prepectal carina complete above, turned forward toward and almost reaching front edge of mesopleurum; abdomen in Nearctic forms uniformly fulvous, or sometimes the tergites brown basally . . . . . . . . . . 3

3. Hind femur sharp beneath for part of its length, and in all except unusually small specimens with a weak irregularly serrate carina (fig. 299,b); head yellow and light fulvous .......... . . 1. atalantae (Poda)

Hind femur rounded beneath, never with a carina; head black, the face often more or less ferruginous

2. hilaris (Say) 


\section{Theronia atalantae (Poda)}

FigURE 314 ,a

Front wing 7.5 to $12.5 \mathrm{~mm}$. long; apical edge of clypeus slightly concave; prepectal carina roundly curved forward, almost reaching pronotum; scutellum not carinate laterally; metapleurum separated from propodeum by a complete carina; median and lateral propodeal carinae present, the latter usually fading out opposite propodeal spiracle; lateral section of apical transverse carina weak; petiolar area rather regularly hexagonal, its lateral bounding carinae stronger than others on propodeum; apical half of femur with a ventral ridge which in all but the smallest specimens bears several blunt teeth, a character present in no other species of the genus (fig. 299,b); first tergite about 1.5 as long as wide, its dorsal carinae strong on basal $0.67 \pm$; ovipositor sheath about 1.5 as long as hind femur.

Fulvous with some indefinite yellowish markings. The more definite of the yellow markings are on the face, subtegular ridge, scutellum, postscutellum, and knee of middle leg. Flagellum brown; prepectus near lower corner of pronotum blackish; ovipositor sheath black. There are often dark brown markings on the head, thorax, coxae, and middle and hind femora, and basal dark brown bands or paired transverse spots on the abdominal tergites, the extent and frequency of these dark markings being dependent on the population. North American specimens rarely have them, European specimens often have them, and Japanese and Korean specimens always have them. The average frequency and extent of the dark markings is the basis for separating the population of Japan and Korea as a distinct subspecies, as in the key below. Wings faintly tinged with yellowish brown.

\section{Key to the subspecies of Theronia atalantae}

1. Abdominal tergites each with a dark brown basal band or pair of transverse spots occupying about their basal 0.3 to 0.4 ; thorax with extensive dark brown markings; range: Japan and Korea.

1a. atalantae gestator (Thunberg)

Abdominal tergites uniformly fulvous or sometimes each with a restricted basal brown band or pair of transverse spots; thorax with or without restricted dark brown markings . . . . . . . . . . . . . . . . . . 2

2. Flagellum brownish fulvous; range: Europe. 1b. atalantae atalantae (Poda) Flagellum fuscous brown; range: North America.

1c. atalantae fulvescens (Cresson) 


\section{1a. Theronia atalantae gestator (Thunberg), new status}

Ichneumon gestator Thunberg, 1822, Mém. Acad. Imp. Sci. St. Pétersbourg, vol. 8, p. 262 ;. . Type: , “in Indiis" (Uppsala). Redescription of type: Roman, 1912, Zool. Bidr. Uppsala, vol. 1, p. 257.

Theronia japonica Ashmead, 1906, Proc. U. S. Nat. Mus., vol. 30, p. 181, . New synonymy. Type: $q$, Sapporo, Japan (Washington).

This subspecies is not particularly distinct in that some European specimens and rare Nearctic specimens approach it, or are similar in the amount of dark coloration. The Japanese and Korean populations are rather uniform, however, in having extensive dark brown markings and most individual specimens can be distinguished on this basis from the great majority of European and American specimens. The flagellum is reddish brown.

Thunberg's type of Ichneumon gestator is labeled "Ind. Or." and the species has always been considered an Oriental one, though a second specimen has never been reported. We studied the type in 1958 and found it to represent the Japanese subspecies of Theronia atalantae, which is known only in Japan and Korea.

Specimens: $3 \sigma^{x}, 17$ f from Japan and Korea.

\section{1b. Theronia atalantae atalantae (Poda)}

Ichneumon atalantae Poda, 1761, Insecta musei graecensis, p. 106. Type: Europe (location unknown).

There are also numerous synonyms of this subspecies.

Coloration variable, paler specimens resembling the subspecies fulvescens and darker specimens the subspecies japonica. The majority are intermediate but closer to fulvescens. The flagellum is brownish fulvous.

Specimens: $60^{x}, 4$ 우 from Belgium and Germany.

This subspecies occurs in Europe.

\section{1c. Theronia atalantae fulvescens (Cresson)}

Pimpla fulvescens Cresson, 1865, Proc. Ent. Soc. Philadelphia, vol. 4, p. 268; $\sigma^{7}$. Type: $\sigma^{7}$, Colorado (Philadelphia).

Theronia fulvescens var. mellipennis Viereck, 1903, Trans. Amer. Ent. Soc., vol. 29, p. 87 ; 9 . Type: $\subsetneq$, Beulah, N. Mex. (Philadelphia).

Theronia atalantae var. americana Krieger, 1906, Zeitschr. Syst. Hymen. Dipt., vol. 6, p. $240 ; \sigma^{\top}$, $\subsetneq$. Lectotype (hereby designated): $\uparrow$, labeled "Heyme Bay, B. C." (Berlin).

Bıology: Weed and Fiske, 1900, Bull. U. S. Dep. Agr., Div. Ent., vol. 26, p. 33.Fiske and Thompson, 1909, Journ. Econ. Ent., vol. 2, pp. 455-457.-Howard and Fiske, 1911, Bull. U. S. Dep. Agr., Bur. Ent., vol. 91, pp. 141, 142, 144, 147-149, 236-237, 304.-Aldrich, 1912, Journ. Econ. Ent., vol. 5, pp. 87-88.Evenden, 1924, The Timberman, vol. 25, May, p. 54.-Townes, 1939, Bull. Brooklyn Ent. Soc., vol. 34, p. 30; 1940, Ann. Ent. Soc. America, vol. 33, pp. 286, 295-297. 
Specimens of this subspecies usually have the dark markings on body restricted to a blackish mark on prepectus near lower corner of pronotum. Additional, dark brown marks are sometimes present on the thorax and sometimes on the abdominal tergites basally. The flagellum is fuscous brown, tinged with fulvous below. Specimens from the southwestern United States tend to have the yellowish brown tinge on the wings a little stronger than usual. This difference seems to have helped persuade Viereck to propose the varietal name mellipennis for some specimens from New Mexico, but the difference is so slight that a separate name for that population seems unwarranted.

Specimens $\left(194 \sigma^{7}, 199\right.$ ) : From Arizona (Flagstaff, Mount Lemmon Lodge in the Santa Catalina Mts., Oak Creek Canyon, and Parker Creek and Workman Creek in the Sierra Ancha); British Columbia (Agassiz, Ainsworth, Colwood, Duncan, Robson, St. John, Shawnigan on Vancouver Island, Vancouver, Victoria, and Wellington); California (Berkeley, Crescent City, Lake City, McCloud, Menlo Park, Moss Landing in Monterey Co., Muir Woods in Marin Co., Pinecrest, Ryan Creek in Mendocino Co., Santa Clara Valley, Santa Cruz Mts., and Santa Rosa); Colorado (Glen Haven, Nederland, and University of Colorado campus at Boulder); Idaho (Boise National Forest, Fraser, New Meadows, and Priest Lake); Kentucky (Crailhope); Maine (Augusta and Orono); Manitoba (Cedar Lake, "Red Deer Reservation," and The Pas); Maryland (Plummers Island and Takoma Park); Massachusetts (Amherst, Cambridge, Dorchester, Forest Hills, Holliston, Melrose Highlands, Mt. Toby near Sunderland, Natick, North Saugus, Petersham, Princeton, Sharon, Taunton, and Woods Hole); Michigan (Alcona Co., Bay Co., Cheboygan Co., Chippewa Co., Clare, Douglas Lake, Iosco Co., Iron Co., Midland Co., and Osceola Co.); Minnesota (Basswood Lake in Lake Co., Cass Co., Itasca Co., Rice Co., and St. Louis Co.) ; Montana (Glacier Park Station at 4,800 ft.); Nebraska (Omaha); New Brunswick (Fredericton and Fundy National Park); New Jersey (Moorestown, Palisades, and Riverton); New Mexico (Aspen Ranch in Santa Fe Co., Beulah, Cimarron at 6,800 ft., Jemez Springs at 6,400 ft., "Manzano National Forest," Rio Ruidoso in the Sierra Blanca, Santa Fe, and South Fork of Eagle Creek in the Sierra Blanca at 8,000 ft.); New York (Bear Mt., Bemus Point, Dutchess Co., Farmingdale, Flatbush, Geneva, "Indian Ladder," Ithaca, Lake Mohonk in Ulster Co., McLean, Montauk, Pike, Poughkeepsie, Shokan, Slingerlands, and Troy); Ohio (Puritas Springs in Cuyahoga Co.); Ontario (Grimsby, Hamilton, and Hymers); Oregon (Antelope Mt. in Harney Co. at 6,500 ft., Blodgett, Forest Grove, Independence, Seaside, and Waldo); Pennsylvania (Dauphin, Edgemere in Pike Co., Gladwyne, Hummelstown, North East, Philadelphia, and Wistar Woods in Philadelphia); Quebec (Clarenceville); Rhode 
Island (Westerly); Utah (Logan Canyon at 5,000 ft., Mount Timpanogos, and Park City); Virginia (Arlington and Dayton); Washington (Ashford, Barnes State Park, Dartford, Garfield, Mount Rainier at 2,700 ft., Pullman, Seattle, and Woodland); West Virginia (Bolivar); and Wisconsin (Washburn Co.).

Dates of collection are mostly from late spring to early fall, but a few specimens were taken earlier or later. The earliest and latest dates of capture are April 3 at Sharon, Mass.; April 8 and 12 at Robson, B. C.; April 28 at Forest Hills, Mass.; October 20 at Flatbush, Long Island, N. Y.; October 26 at Holliston, Mass. and Mount Toby, Mass.; November 7 at Arlington, Va.; and November 28 at Riverton, N. J.

There is some evidence that the species overwinters as an adult female. This is as follows: 1. Two females were taken "under bark" at Natick, Mass., on Apr. 23, 1944, by C. A. Frost. 2. We have seen six females labeled "Quercus alba," Hummelstown, Pa., Jan. 1, 1917, J. N. Knull. These presumably were collected in a log or stump of this tree or under bark. 3. In spring of 1947 we were collecting intensively in the Sierra Ancha of Arizona, at 5,000 to 6,000 ft. elevation. On May 1 and 2 females (only) of $T$. atalantae became suddenly abundant in two of the stream valleys we had been working and remained abundant during the rest of our stay, but no males were found. Prior to May 1 no specimens at all were seen in these two places. This seems to be a case of emergence from hibernation as adults. If it had been emergence from pupae, rather than as overwintering adults, males would have appeared with the females.

In our own collecting we have found the species nearly always in mesophytic or damp woods, usually in deciduous woods.

This species has been reared many times as a parasite of mediumsized or larger Lepidoptera, and sometimes as a secondary parasite of ichneumonids. It is an important parasite of some of the pests of forests. Its biology is rather well known. For a summary of the published information see Townes, 1940 (Ann. Ent. Soc. America, vol. 33 , pp. 286, 295-297). Host records on the pin labels of specimens we have studied are: 2 rearings or reared lots from Choristoneura fumiferana, 1 from Lambdina fiscellaria somniaria, 2 from Malacosoma americanum, 1 from $M$. californicum, 3 from $M$. fragile, 4 from Malacosoma sp., 2 from Neophasia menapia, 1 from Nepytia phantasmaria, 1 from Nymphalis californicus, 1 from Oreta rosea, 1 from Porthetria dispar, 1 from cocoon in prune orchard, 1 from cocoon on Corylus leaves, and 3 from tussock moth. The additional host records in literature concern the same type of Lepidoptera, plus several ichneumonid hosts. 

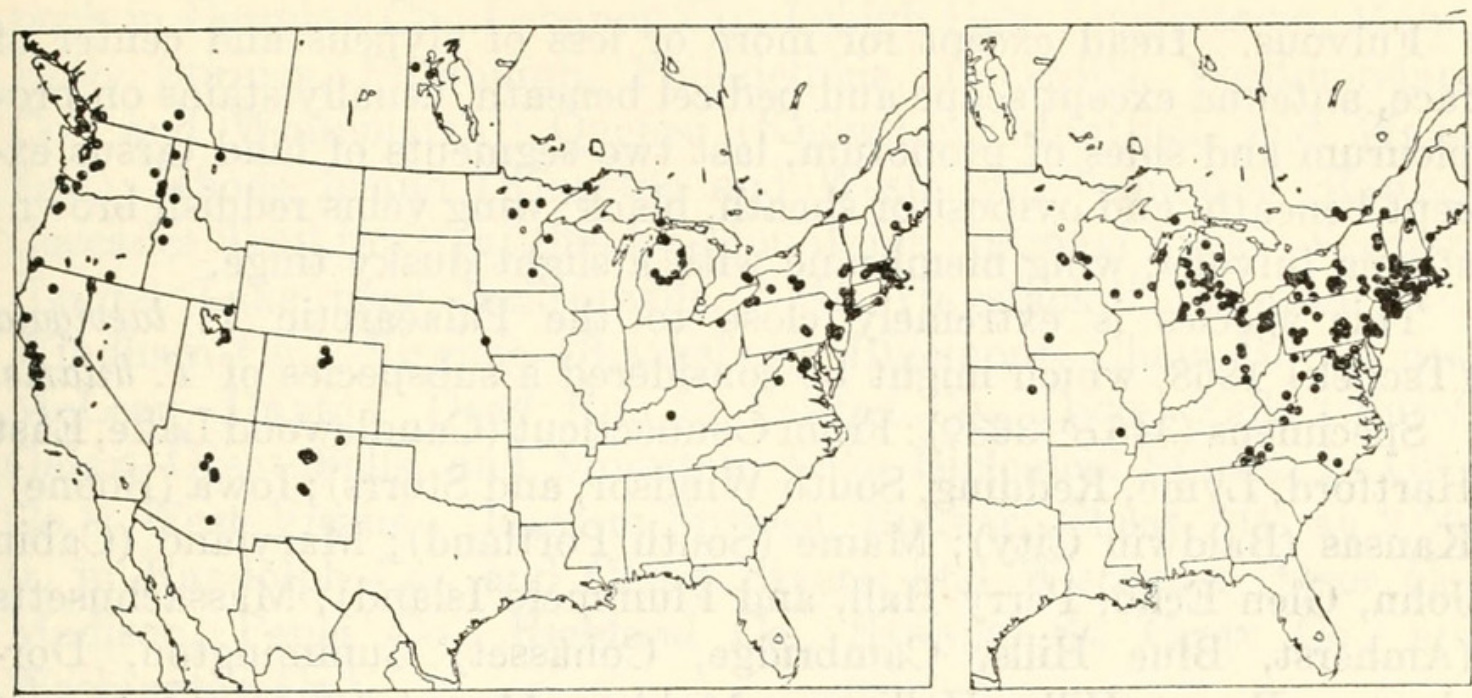

Figures 160, 161.-Localities: 160 (left), Theronia atalantae fulvescens; 161 (right), T. hilaris.

This subspecies is transcontinental in the Canadian and Transition zones. Its habitat is various kinds of mesophytic or damp woods. Adults occur throughout the growing season. Hibernation appears to be as adult females. Various larger or medium-sized Lepidoptera in forests serve as hosts, particularly those pupating on tree trunks. Sometimes it parasitizes other ichneumonids attacking these same Lepidoptera.

\section{Theronia hilaris (Say)}

FiguRe 314,b

Ichneumon hilaris Say, 1829, Contrib. Maclurian Lyceum Arts Sci., vol. 1, p. 71 (Leconte ed., vol. 1, p. 376); $\sigma^{\top}$. Type: $\sigma^{x}$, Indiana (destroyed).

Pimpla melanocephala Brullé, 1846, in Lepeletier, Histoire naturelle des insectes, hyménoptères, vol. 4, p. 99 ; $\uparrow$. Name preoccupied. Type: $q$, North America (Paris).

Biology: Townes, 1939, Bull. Brooklyn Ent. Soc., vol. 34, p. 39; 1940, Ann. Ent. Soc. America, vol. 33, p. 291.

Front wing 5.5 to $11.5 \mathrm{~mm}$. long; apical edge of clypeus concave; prepectal carina near its upper end curving sharply forward toward and nearly reaching front margin of mesopleurum; lateral carina of scutellum high at extreme base, thence abruptly obsolete; metapleurum separated from propodeum by a complete carina; median and lateral longitudinal carinae complete basad of apical transverse carina; costula faint or absent; all the other propodeal carinae sharp and moderately strong; space between median longitudinal carinae about 2.0 as long as wide, separated from petiolar area by a distinct carina; petiolar area regularly hexagonal; first tergite about 1.6 as long as wide, in profile the tergite abruptly curved at its midlength, its median carinae extending about 0.8 its length; ovipositor sheath about 1.4 as long as hind femur. 
Fulvous. Head except for more or less of clypeus and center of face, antenna except scape and pedicel beneath, usually stains on propleurum and sides of pronotum, last two segments of hind tarsus except beneath, and ovipositor sheath, black; wing veins reddish brown; stigma fulvous; wing membrane with a slight dusky tinge.

This species is extremely close to the Palaearctic $T$. laevigata (Tschek) 1868, which might be considered a subspecies of T. hilaris.

Specimens $\left(346 \sigma^{7}, 363\right.$ \%) : From Connecticut (Candlewood Lake, East Hartford, Lyme, Redding, South Windsor, and Storrs); Iowa (Boone); Kansas (Baldwin City); Maine (South Portland); Maryland (Cabin John, Glen Echo, Perry Hall, and Plummers Island); Massachusetts (Amherst, Blue Hills, Cambridge, Cohasset, Cummington, Dorchester, Forest Hills, Holliston, Malden, Mount Greylock, Mount Toby near Sunderland, North Adams, Petersham, South Hadley, South Natick, and Woods Hole); Michigan (Alcona Co., Alger Co., Ann Arbor, Augusta, Bay Co., Benzie Co., Berrien Co., Cheboygan Co., East Lansing, George Reserve in Livingston Co., Gladwin Co., Gratiot Co., Gull Lake Biological Station in Kalamazoo Co., Macomb Co., Mecosta Co., Midland Co., Muskegon Co., Osceola Co., Owosso, Saginaw Co., Sanford, Van Buren Co., Wayne Co., and Wexford Co.); Minnesota (Fort Snelling, Hennepin Co., and Winona Co.,); Missouri (Ozark Mts. at Van Buren); New Hampshire (Franconia and Mount Washington); New Jersey (Moorestown and Ramsey); New York (Bemus Point, Boston, Buffalo, Connecticut Hill in Tompkins Co., Copake Falls, Downsville, Farmingdale, Flatbush, Fort Montgomery, Gardiners Island off Long Island, Grand Island, Greene Co., Hamburg, Hancock, Huntington, Indian Falls, Ithaca, Jones Beach, Long Beach, Ludlowville, McLean, Millwood, New Rochelle, New Russia, New York City, North River, Nyack, Olcott, Oneonta, Oswego, Peekskill, Poughkeepsie, Ridgewood, Rock City in Cattaraugus Co., Roslyn, Sea Cliff, Shokan, Slide Mt. in Ulster Co. at 1,500 and 2,800 to 4,000 ft., Syracuse, Taughannock Falls in Tompkins Co., Troy, Wildflower Reserve near Slaterville, and Wilmington); North Carolina (Crabtree Meadows in Yancey Co. at 3,600 ft., Elizabethtown, Lake Toxaway in Transylvania Co. at 2,000 ft., Nantahala Gorge, Riverton, Swannanoa at 3,000 ft., and Waynesville); Ohio (Akron, Barberton, Bedford, Blendon Township in Franklin Co., Cleveland, Columbus, Delaware Co., Greene Co., Hinckley in Medina Co., Painesville, Puritas Springs in Cuyahoga Co., Put-in-Bay, Ross Co., Sandusky, Scioto Co., and Summit Co.); Ontario (Grimsby, Jordan, Niagara Glen, Ottawa, Point Pelee, and Ridgeway); Pennsylvania (Allegheny Co., Buena Vista, Carlisle, Chaffee in Elk Co. at 2,000 ft., Du Bois, Enola, Gladwyne, Harrisburg, Hecton Mills, Highspire, Hummelstown, Hunter's Run, Ingle- 
nook in Dauphin Co., Lebanon Co., Lehigh Gap, Linglestown, Mount Holly Springs, Pittsburgh, Philadelphia, Rockville, Westmoreland Co., and Whitemarsh); Quebec (Knowlton, Montreal, and Wakefield); Rhode Island (Kingston and Westerly); Tennessee (Ramsey Cascades Trail in Great Smoky Mountains National Park); Vermont (Laurel Lake near Jacksonville, "Mt. Haystack," Stamford, and Windham Co.); Virginia (Blacksburg, Bluemont, Chain Bridge near McLean, Dayton, Dead Run in Fairfax Co., Dyke, Falls Church, Galax, Great Falls, and Mountain Lake Biological Station in Giles Co.); West Virginia (Bargers Springs, Bolivar, Cheat Mt. at 2,000 ft. in Randolph Co., and Cheat River); and Wisconsin (Door Co., Madison, Pepin Co., Richland Co., Sawyer, St. Croix Co., and Washington Co.).

Dates of collection are from rather early spring to early fall. Unusually early and late dates of capture are: April 5 at Hecton Mills, Pa.; April 14 at Enola, Pa.; May 2 in Delaware Co., Ohio; May 4 at Ithaca, N. Y.; October 10 at South Hadley, Mass.; October 11 and 13 at Falls Church, Va.; and October 15 in Delaware Co., Ohio. The species occurs in deciduous woods and is often very common. It is usually on low shrubs or herbage, or on the forest floor.

Considering its abundance as an adult, rearing records are scanty. Those on the pin labels of specimens before us are: $\odot$, from Halisidota caryae, May 25, 1908. क, from Halisidota sp., Ithaca, N. Y., Apr. 26, 1925, P. P. Babiy. क, from pupa of Halisidota?, Pittsburgh, $\mathrm{Pa}$.

This species is in the Alleghanian and Carolinian faunas. Its habitat is the undergrowth of deciduous woods, where it is often very common. Adults occur from spring to early fall. It has been reared from Halisidota.

\section{Theronia septemtrionalis (Krieger)}

Figure 314,c

Neotheronia septemtrionalis Krieger, 1905, Zeitschr. Syst. Hymen. Dipt., vol.

5, p. 305; $\sigma^{7}$. Type: $\sigma^{7}$, North Carolina (Berlin).

Neotheronia winnemanae Viereck, 1913, Proc. U. S. Nat. Mus., vol. 44, p. 567;

․ Type: $\uparrow$, Plummers Island, Md. (Washington).

Biology: Townes, 1940, Ann. Ent. Soc. America, vol. 33, p. 290.

Front wing 8.5 to $11 \mathrm{~mm}$. long; apical edge of clypeus convex; prepectal carina near its upper end bent sharply forward and reaching almost to front margin of mesopleurum; lateral carina of scutellum high at extreme base, thence abruptly fading out; metapleurum separated from propodeum by a complete carina; apical transverse carina of propodeum strong and evenly curved; propodeal carinae basad of transverse carina obsolete; petiolar area bounded laterally by a strong but blunt carina, at the upper end of which the transverse carina is 
somewhat stronger than it is medially; first tergite about 2.1 as long as wide, its dorsal carinae fading out before the spiracles; ovipositor sheath about as long as hind femur.

Lemon yellow. Top of head, hind legs, tarsi, and apical part of abdomen a little suffused with fulvous; three long stripes on mesoscutum, short narrow stripe above tegula, groove at base of scutellum, band across base of propodeum and in front of propodeal spiracles, last two segments of hind tarsus except beneath, extreme base and broad band on middle of first tergite, and subbasal band on second to sixth tergites (occupying about 0.25 their length), black; front wing with a fuscous spot around tip of radial vein, the wing membrane otherwise hyaline.

Specimens $\left(25\right.$ o $^{7}, 42$ ) $)$ : From Alabama (Coleta and Pyriton, both in Clay Co.); Arkansas (Fayetteville); Florida (Camp Torreya in Liberty Co., Gainesville, and Manatee); Georgia (Atlanta); Indiana (Clark Co. and Spencer); Louisiana (Tallulah); Maryland (Cabin John, Plummers Island, and Takoma Park); Missouri (Van Buren and Willard); North Carolina (Crestmont in Haywood Co., Flat Rock, Garland, Hamrick, Havelock, Hollis in Rutherford Co., Lumberton, Murfreesboro, Southern Pines, and Wake Co.); Ohio (Carbondale, Fairfield Co., Hocking Co., Ross Co., and Scioto Co.); Oklahoma (Broken Bow and Flint); South Carolina (Calahan Mt. in Greenville Co., Greenville, McClellanville, Spartanburg, Table Rock State Park, and Venus in Greenville Co.); Tennessee (Smoky Mts. and Gatlinburg); Virginia (Falls Church); and West Virginia (Cheat Mt. at 2,000 ft. in Randolph Co.).

Dates of collections are from June 5 (at Spartanburg, S. C.) to October 23 (at Plummers Island, Md.), with the addition of one record of March 18 at Gainesville, Fla. The species seems to be commonest in late summer. The fact that it has not been taken in spring or later in the fall may be due only to lack of more collections. We have found the species moderately common in dense deciduous woods, flying about 0.15 to 0.3 meters from the ground, and occasionally alighting on low foliage. In flight it looks like a lemon yellow streak, and is rather conspicuous in the poor light of a dense woods. Sometimes it looks deceptively like a small, slender Vespula.

This species is moderately common in deciduous woods of the Austroriparian and Carolinian faunas. Adults occur mostly from June to September.

\section{Theronia bicincta (Cresson)}

Figure 314,d

Front wing 7.5 to $11.5 \mathrm{~mm}$. long; apical edge of clypeus concave; prepectal carina obsolete above but a trace of it curving forward toward front edge of mesopleurum; scutellum without lateral carina; 
metapleurum separated from propodeum basally by a carina, the carina fading out just before reaching transverse carina; median longitudinal carinae of propodeum moderately strong, reaching base of propodeum; lateral longitudinal carinae vestigial; apical transverse carina moderately strong, dipped at juncture with strong carina bounding petiolar area laterally; first tergite about 2.0 as long as wide, its dorsal carinae fading out just in front of spiracle; ovipositor sheath about 1.25 as long as hind femur.
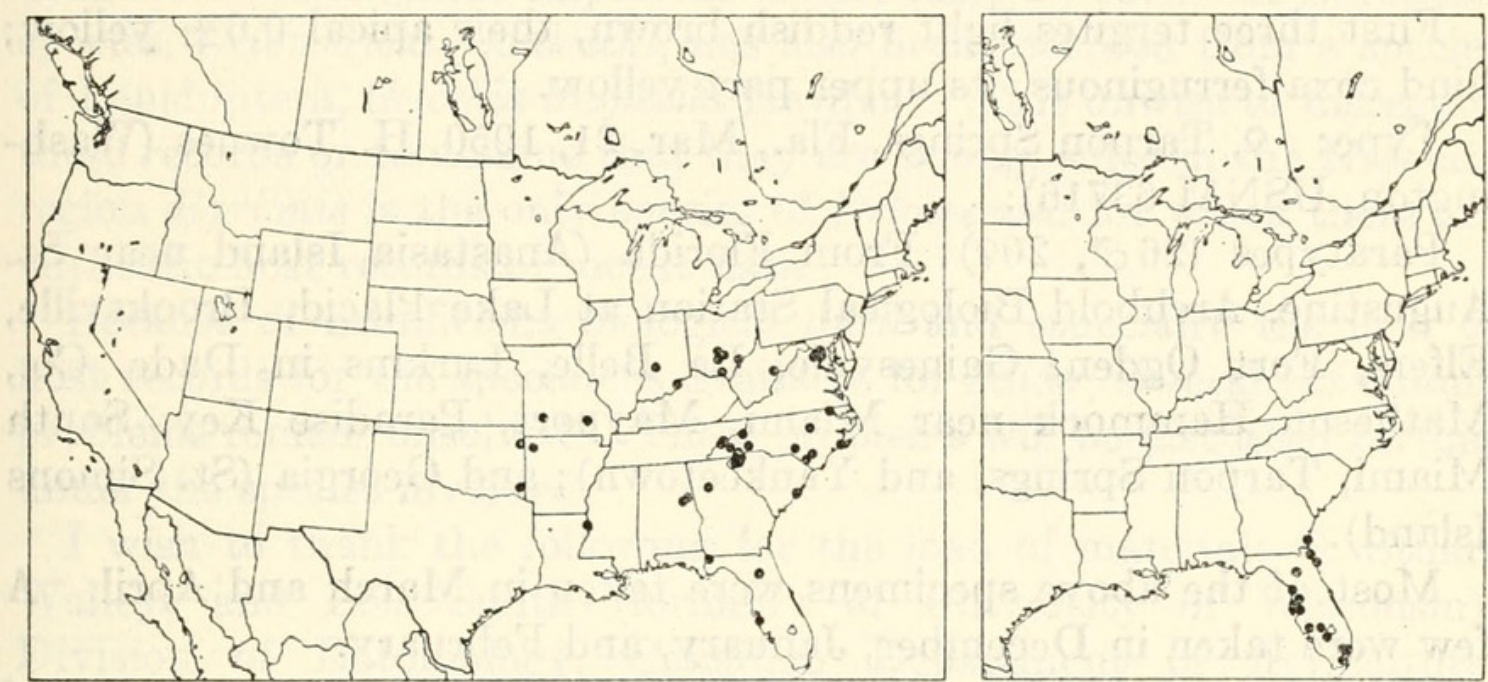

Figures 162, 163.-Localities: 162 (left), Theronia septemtrionalis; 163 (right), $T$. bicincta floridana.

Head yellow, a dusky band connecting lateral ocellus with eye, and vertex with a ferruginous mark just above occipital carina; flagellum ferruginous; thorax yellow, with three long ferruginous stripes on mesoscutum, short line above tegula, groove at base of scutellum, area surrounding postscutellum, stripe on upper two-thirds of hind margin of pronotum, stripe along front edge of mesopleurum, band from just above middle coxa across base of propodeum, stripe along lower half of mesopleural suture, and band on hind end of metapleurum and propodeum, blackish; front and middle legs yellow, varied with pale fulvous; hind legs fulvous and ferruginous, with trochanters, basal three segments of tarsus, and part of coxa, yellow; color of first three abdominal tergites variable, according to the subspecies; fourth and following tergites brownish ferruginous; ovipositor sheath yellow on basal $0.45 \pm$ shading to black at apex; wings strongly tinged with orange brown, apically a little infuscate.

There is a Floridian and a Cuban subspecies, distinguished mainly on the color of the third abdominal tergite:

1. Third tergite almost uniformly reddish brown; range: Cuba.

4a. bicincta bicincta (Cresson)

Third tergite light reddish brown on its basal 0.4 , the rest yellow; range:

Georgia and Florida . . . . . 4b. bicincta floridana, new subspecies 


\section{4a. Theronia bicincta bicincta (Cresson)}

Pimpla bicincta Cresson, 1865, Proc. Ent. Soc. Philadelphia, vol. 4, p. 38; . Type: $\uparrow$, Cuba (Philadelphia).

First three tergites reddish brown, the apical $0.4 \pm$ of the first two tergites yellow; hind coxa ferruginous, above with a yellow or yellowish area.

Specimens $\left(5 \sigma^{\top}, 3\right.$ ㅇ): From Cuba.

\section{4b. Theronia bicincta floridana, new subspecies}

First three tergites light reddish brown, their apical $0.6 \pm$ yellow; hind coxa ferruginous, its upper part yellow.

Type: ㅇ, Tarpon Springs, Fla., Mar. 21, 1950, H. Townes (Washington, USNM 63716).

Paratypes $\left(26 \sigma^{\top}, 20 \%\right)$ : From Florida (Anastasia Island near St. Augustine, Archbold Biological Station at Lake Placid, Brooksville, Elfers, Fort Ogden, Gainesville, La Belle, Larkins in Dade Co., Matheson Hammock near Miami, Mayport, Paradise Key, South Miami, Tarpon Springs, and Yankeetown); and Georgia (St. Simons Island).

Most of the above specimens were taken in March and April. A few were taken in December, January, and February.

The only reared material of this species is a series of four dwarf males reared from Tromatobia rufopectus cocoons in the egg sac of a spider (Argiope aurantia) at Gainesville, Fla., February 1925, by W. A. Murrill.

This subspecies occurs in Florida and the subtropical part of Georgia.

\section{Genus Delomerista}

Figure 300 ,a

Delomerista Foerster, 1868, Verh. Naturh. Ver. Rheinlande, vol. 25, p. 164. Type: Pimpla mandibularis Gravenhorst; included and designated by Schmiedeknecht, 1888.

Front wing 5 to $10.5 \mathrm{~mm}$. long; body form rather slender; apex of clypeus with a median notch, without a median point; propodeal carinae rather weak; tarsal claws simple, of moderate size, without an enlarged bristle with a spatulate tip; nervellus broken at or below the middle; abdomen strongly mat, its hairs rather dense, ovipositor moderately compressed, its apex not sinuate, its sheath usually about 0.45 as long as front wing but of variable length.

\section{The Genus Delomerista}

By Luella M. WalkLey ${ }^{2}$

${ }^{2}$ Entomology Research Division, Agricultural Research Service, U. S. Department of Agriculture. 
Fourteen species have been described in the genus Delomerista Foerster, a Holarctic genus of northern distribution. Three of them occur in the Nearctic region. In this paper three new Nearctic species are described and D. diprionis, the commonest Nearctic species, becomes a synonym.

Delomerista species seem to be predominantly parasitic on sawflies of the family Diprionidae. However, there are a number of early references ${ }^{3}$ to Nearctic species reared from lepidopterous hosts and even from Mononychus vulpeculus (Fabricius), a weevil. A European species, Delomerista pfankuchi, has also been recorded from a species of Lepidoptera, Gelechia tragicella Heyden. ${ }^{4}$ It is unwise to disregard these records or to assume that they are wrong, since in the Nearctic region diprionis is the only species of Delomerista for which there are authentic host records of recent date.

Because of insufficient biological data and especially the lack of host records for the specimens available for study, several taxonomic problems remain unsolved. These problems will be discussed further under the species involved.

I wish to thank the following for the loan of material: G. Stuart Walley, and Lois Smith (formerly of University of Wisconsin), Division of Entomology, Canadian Department of Agriculture, Ottawa, Ont.; H. K. Townes, University of Michigan, Ann Arbor, Mich.; and R. C. Brown (formerly of Northeast Forest Insects Laboratory), New Haven, Conn. I am grateful to J. F. Perkins, British Museum (Natural History), London, for the gift of several Delomerista specimens.

The figures were drawn by Arthur D. Cushman.

Delomerista is one of the many genera established by Foerster without included species. In his handwritten manuscript he designated Pimpla mandibularis Gravenhorst as type of Delomerista. For some reason, perhaps because many of the species he had selected as types of his new genera were undescribed, he did not include the type species when he had the manuscript published. It is fortunate that the present genotype is Foerster's unpublished selection.

Foerster included Delomerista in his family Pimploidae. Later it was usually considered a subgenus or synonym of Pimpla and placed in the Pimplini. Then Hellén (1915, Acta Soc. Fauna Flora Fennica, vol. 40, pt. 6, pp. 15-17 and 48) placed the genus in the "subtribe Delomeristini, tribe Pimplides." More recently the genus has been placed in the Ephialtini ${ }^{5}$ and considered closely related to Perithous.

\footnotetext{
3 Riley and Howard, 1891, Insect life, vol. 3, p. 461.-Dimmock, 1898, Proc. Ent. Soc. Washington, vol. 4, p. 154.

- Schutze and Roman, 1931, Isis budissima, vol. 12, p. 5.

s This is the same as Pimplini of H. K. Townes. While I agree that priority strictly followed would enable each of us to solve most of the nomenclatural problems which arise, I am following the rules, opinions, etc., of the International Commission on Zoological Nomenclature.
} 
My inclination is to follow Hellén and place the genus in the tribe Delomeristini or in the Theroniini of Townes. Generic relationships will be more clear when the larvae and biology of the species are better known.

This genus comprises species that are very similar in general appearance. The North American species can be placed in two more or less natural groups which I call the Novita group and the JAPONICA group. The shape of the apical portion of the ovipositor is the single character used to distinguish the two. It may be that the members of the JAPONICA group are parasitic only on sawflies and those of the Novita group parasitic on Lepidoptera or other insects in certain ecological niches.

Although the black color and habitus of the species of this genus are typical of the Ephialtini, the sculpture of the abdomen and the presence of an areola and petiolar area on the propodeum will quickly identify them. The abdomen of Delomerista species is usually finely granular, shagreened or coriaceous with very fine shallow scattered punctures, and sometimes more or less polished. Species of ephialtine genera have the abdomen more polished with comparatively large, coarse punctures. The Delomerista females can be further distinguished by the pale malar space and mandibles. They can also be separated from all ephialtine species, except those of Perithous, by the complete lack of a large basal tooth on the claws.

The compressed ovipositor is also found in some other ephialtine species, but in the Nearctic region only a few species of Scambus have it as compressed as in Delomerista.

The males of the genus, except those of texana (Cresson), are not included in the specific descriptions. They have been placed only in species groups. Genitalic dissections failed to show characters for further separation.

It is entirely possible that there are additional species in the material studied, but until more specimens and further biological facts are available the variations can only be noted.

\section{Keys to the Nearctic species of Delomerista}

\section{MALES}

1. Clypeus convex; abdominal tergites finely granular in sculpture.

1. texana (Cresson)

Clypeus not convex; abdominal tergites beyond the third segment coriaceous ..................... . . 2

2. Hind tibia fully as long as femur and trochanters combined. Novita Group Hind tibia not as long as femur and trochanters combined. JAPONICA GROUP 


\section{FEMALES}

1. Clypeus convex; malar space about as long as, or longer than, basal width of mandible; temples, viewed dorsally, as long as, or longer than eyes; wings usually dark brown. . . . . . . . . . . . 1. texana (Cresson)

Clypeus more or less flat; malar space definitely shorter than basal width of mandible; temples, viewed dorsally, not as long as eyes; wings light brown or hyaline . . . . . . . . . . . . . . . . . . . . . . . . . . . . 2

2. Ovipositor with a strong dorsal curve apically (figs. 313,k,m). JAPONICA GROUP. . . . . . . . . . . . . . . . . . . . . . . 3

Ovipositor without a strong dorsal curve apically (figs. $313,1,0, p$ ). Novita GROUP. . . . . . . . . . . . . . . . . . . . . . 4

3. Ovipositor heavy, depth near apex greater than width of front tibia at its widest (fig. $313, \mathrm{~m}$ ) . . . . . . . . . 2. gelida, new species

Ovipositor not beavy, depth near apex less than width of front tibia at its widest (fig. 313,k) . . . . . . . . . . . 3. japonica Cushman

4. Ovipositor point ${ }^{\circ}$ very gradually narrowed, tenuous, at least five or six times as long as its depth; apical third or more of hind femur fuscous or blackish.

4. lepteces, new species

Ovipositor point much less gradually narrowed, not more than four times as long as its depth; hind femur usually with much less than apical third fuscous or blackish (when, as in some specimens of novita, approximately the apical third of hind femur is fuscous, then the white area of tibia is much more extensive) . . . . . . . . . . . . . . . . . . . . . . . . 5

5. Hind tibia and tarsus blackish, sometimes tibia pale at extreme base, tarsus entirely dark brown or blackish . . . . . . . 5. borealis, new species

Hind tibia with pale annulus at base and ventrally with varying amount of pale color extending toward apex; tarsus with at least first segment pale at base . . . . . . . . . . . . . . . . 6

6. All abdominal segments more or less finely punctate . . 6. pfankuchi (Brauns) Abdominal segments 1-3 more or less coriaceous or finely granular.

7. novita (Cresson)

\section{Delomerista texana (Cresson)}

Figures $313, \mathrm{n} ; 316, \mathrm{i}$

Pimpla texana Cresson, 1870, Trans. Amer. Ent. Soc., vol. 3, p. 145; ㅇ․ Type: Texas (Philadelphia).

Pimpla laevifrons Thomson, 1877, Opuscula entomologica, fasc. 8, p. 750.Townes, 1944, Mem. Amer. Ent. Soc., no. 2, pp. 48-49; ఠ, ․ Types: $\sigma^{\top}$, \& , Sweden (Lund).

Delomerista texana (Cresson) Cushman, 1922, Proc. U. S. Nat. Mus., vol. 61, art. 8, p. 11.

The characters that quickly separate this species from all others in the JAPONICA group are the long malar space, convex clypeus and temples, and the finely granular sculpture of the abdominal tergites.

Further characters noted are: Small shallow punctures on face separated by one to three times their diameter with none or very few on central area; ovipositor sheaths varying in length from a little more than half to a little more than two-thirds the length of abdomen.

- That apical portion of ovipositor beginning where the depth of ovipositor changes its dimension and narrows to apex, or slightly enlarges and then narrows to apex. 
The male may be further identified by the black or blackish coxae and trochanters, black face with pale clypeus and pale or white triangular area on each side of face. In one specimen from Great Whale River, Que., this area is so dark as to be barely discernible.

Females vary in length from $7.5 \mathrm{~mm}$. to $10.5 \mathrm{~mm}$., males from 5.5 $\mathrm{mm}$. to $9.7 \mathrm{~mm}$. The Nearctic specimens generally have darker wings, blacker hind tibiae and almost buccate temples. However, a European specimen from "Abisko, Lapland, North Sweden," sent to me by J. F. Perkins of the British Museum (Natural History) has darker wings and hind tibiae than a specimen taken at the same locality earlier by J. R. Vockeroth, Ottawa, Ont., while a male and female from Chesterifeld, Northwest Territories, both have hind tibiae the same reddish color as the femora and have the hind tarsi only slightly darker. The wings, too, are lighter.

Distribution: Europe; Alaska; Canada: Quebec (Fort Chimo and Great Whale River), Northwest Territories; United States: New Hampshire, Maine.

Host: Unknown.

\section{Delomerista gelida Walkley, new species}

Figures $313, \mathrm{~m} ; 316, \mathrm{j}$

This species has been misidentified in collections as $D$. texana. It can be readily distinguished, however, by the difference in abdominal sculpture (the abdomen being mostly coriaceous rather than granular), by the more robust ovipositor, shorter malar space, and flat clypeus.

Holotype female: Body, $10 \mathrm{~mm}$.; ovipositor sheaths, $4.3 \mathrm{~mm}$.

Head: Finely punctate; face with the punctures separated usually by a distance less than, and never more than, the diameter of the punctures; malar space not more than half basal width of mandibles; temples somewhat convex but not as long as the eyes; clypeus flat, emarginate; antenna with 32 segments.

Thorax: Length to width as 4 to 3 ; sternauli reaching only to disk, mesopleurum finely, sparsely punctate, polished; areola of propodeum only a little longer than wide; costulae not complete; metapleuron smooth and finely, sparsely punctate; dorsum of propodeum somewhat reticulate, rough only in comparison with metapleuron. Wings with slight brownish tinge; ramellus short, with color line extending well into discocubital cell; tegulae largely brownish.

Abdomen: Length nearly $7 \mathrm{~mm}$.; first segment dorsally rugose, except on disk which is more coriaceous; second tergite somewhat granular in sculpture and about $1 / 5$ wider at apex than its length; remaining segments mostly coriaceous; silvery pubescence of abdominal tergites longer laterally than dorsally; blackish chitinous areas on second abdominal sternite at least twice as long as wide, those 
on remaining sternites less than twice as long as wide; ovipositor deeper than that of any other Delomerista species, its apex abruptly curved dorsally; sheaths a little less than two-thirds length of abdomen.

Black except the following: All femora, middle and hind coxae, tegulae, tips of ovipositor sheaths, mandibles (except teeth), clypeus, malar space, thin line at apex of segments $4-7$, brownish or reddish brown; and mandibles, malar space, inner surfaces of front femora and tibiae, apices of middle femora, dorsolateral corner of pronotum, and annulus at base of hind tibia, pale or whitish.

Described from holotype female in U. S. National Museum Collection under Type No. 64090.

Type locality: Cameron Bay, Great Bear Lake, N. W. T. The two paratypes are from Waskesiu, Sask., and Great Whale River, Que. Paratypes are in the collection of H. K. Townes and in the Canadian National Collection.

Further distribution: Alaska; Canada: Alberta, British Columbia, Northwest Territories, Ontario, Quebec; United States: Arizona, California, Colorado, New York, Pennsylvania.

Host: Unknown.

Variations: Ovipositor depth from barely wider to more than $1 / 5$ wider than widest part of front tibia; length of ovipositor sheaths from $5 / 8$ to nearly $7 / 8$ length of abdomen; antennal segments varying in number from 28 to 32 ; front coxae blackish or reddish; outside of front femora, and front and middle tibiae, from brownish or reddish brown to dark brown or blackish; hind tibiae black, except for pale basal annulus, to blackish with pale area extending apically on ventral side.

While I believe all these specimens are the same species, I have hesitated to consider them all paratypes without more knowledge of the biology of the species.

\section{Delomerista japonica Cushman}

Figure $313, \mathrm{k}$

Delomerista japonica Cushman, 1937, Ins. Matsumurana, vol. 12, pp. 35-36; $\sigma^{7}$, ๆ. Type: $\subsetneq$, Nagawa-Mura, Nagano-Ken, Japan (Washington).

Delomerista diprionis Cushman, 1939, Journ. Washington Acad. Sci., vol. 29, pp. 398-400; $\sigma^{x}$,. New synonymy. Type: $\uparrow$, Oakville, Ontario, Canada (Washington).

The original descriptions are adequate. The differences in the two descriptions are merely intraspecific and in the additional material at hand those differences can be found in specimens from either geographic region. The species varies in length from $5.5 \mathrm{~mm}$. to $11 \mathrm{~mm}$.

It is possible that japonica comprises two incipient species: one parasitizing Diprion spp. and the other Neodiprion spp. The differ- 
ences are by no means clear-cut. Certainly those specimens reared from $N$. tsugae, and often those from $N$. abietis, can be recognized in Nearctic material of japonica. In this connection the several hundred reared specimens from Canada helped immeasurably. The specimens reared from $N$. tsugae not only are usually smaller but have an ovipositor that often appears more delicate, with the apical ridges less apparent, and is somewhat paler in color. Other differences often noted are: Face longer in proportion to width and sometimes less punctate in central area; wing veins as well as ovipositor generally paler in color; hind tibiae usually with more white. It must be stressed, however, that any of the above variations can be found in specimens reared from Diprion spp. but with less frequency. Here, again, the percentage of occurrence might be greater if a larger number of specimens reared from Diprion spp. were available.

A biological study involving the rearing of this species from the several hosts belonging to one genus and then rearing the progeny from hosts belonging to the other genus might solve the taxonomic problem. Until such a study is made, it seems best to assume that there is only one species with host-associated variation.

R. A. Cushman, in his description of japonica, mentioned a possible relationship to $D$. laevis (Gravenhorst) which he knew only by description but which he considered distinct. The two specimens of laevis I have seen (one identified by G. Heinrich and the other by J. F. Perkins) differ from japonica in possessing a much longer ovipositor (about three-fourths the length of the abdomen), and almost unicolorous reddish legs, with only the hind tibiae and tarsi and last tarsal segment of middle and front legs slightly darker.

Distribution: Japan; Alaska; Canada: Alberta, British Columbia, Manitoba, New Brunswick, Nova Scotia, Northwest Territories, Ontario, Quebec, Yukon Territory; United States: California (mountainous areas), Connecticut, Idaho, Maine, Michigan, Minnesota, New Hampshire, New Jersey (Moorestown), New York, North Carolina (mountainous areas), Oregon, Vermont, Washington, Wisconsin.

Hosts: Diprion nipponicus Rohwer (in Japan); $D$. hercyniae (Hartig); D. similis (Hartig); D. frutetorum (Fabricius); Neodiprion abietis (Harris) complex; N. tsugae Middleton; Neodiprion sp. or spp.

\section{Delomerista lepteces Walkley, new species}

Figure 313,1

This species belongs to the Novita group and is easily distinguished from other species in the group by the very slender ovipositor with its tenuous apical portion. This character is the reason for the name lepteces. The blackish apical third of the hind femur is another iden- 
tifying character. The holotype and two paratype females are the only specimens of this species known to me.

Holotype female: Body, $7.8 \mathrm{~mm}$; ovipositor sheaths, about $4 \mathrm{~mm}$.

Head: Polished, finely punctate, face a little more coarsely so; eyes slightly convergent anteriorly; malar space about one-half as long as basal width of mandible; face one and one-half times as wide as long; antenna with 31 segments.

Thorax: Fully twice as long as deep; mesoscutum finely punctate, polished; sternaulus evident only anteriorly; mesopleurum more finely and sparsely punctate, punctures becoming obsolete posteriorly; dorsal face of propodeum a little longer than posterior face; areola a little longer than wide; pubescence of propodeum sparse and becoming longer laterally, center of areola lacking pubescence; wings hyaline and slightly infumate, veins dark, stigma black except for white spot at extreme base. Hind legs with tibia about as long as femur and trochanters combined. (All of left front leg except coxa and first trochanter missing in type specimen.)

Abdomen: Polished, about one and one-half times as long as head and thorax combined; first three tergites more or less granular, remaining tergites very finely coriaceous; pubescence of tergites laterally more sparse and only slightly longer; ovipositor sheaths about threefourths length of abdomen; ovipositor very slender and apical fourth attenuated to a fine point.

Color: Black, except clypeus, middle and hind coxae, basal twothirds of hind femora, middle femora (dusky apically) reddish; apices of front coxae, apices and inner face of front first trochanters, inner face of front femora, front tibiae, apical spots on outer face of front femora, inner and outer faces of middle femora, outer and front faces of middle tibiae to within $1 / 4$ distance to apex, anterior half of tegula and spot on pronotum just in front of tegula, mandibles except teeth, malar space, and base of hind wing, whitish; maxillary and labial palpi brownish; pale area on inner face of hind tibiae barely visible.

Variations: Antenna 31 to 32 segmented; extent of white on inner face of hind tibia varying from the barely visible streak of type specimen and from a spot near center, to a central streak covering nearly half of length to apex; punctation of face varying in degree. The clypeus of the type specimen is bent inward apically-probably an abnormality.

Described from holotype female in the U. S. National Museum Collection under Type No. 21395.

Type locality: Mount McKinley, Alaska, collected at an altitude of 1,600 ft., Aug. 6, 1954, by David Townes.

Paratype localities: Laurentide Park, Mare du Sault, Montmorency 
Co., Que., July 12, 1954, altitude 2,540 ft., collected by A. Klots, F. and P. Rindge; Poudre Lake, Colo., Rocky Mountain National Park, 11,000 ft., Aug. 12, 1948, collected by H., G., and D. Townes. These paratypes belong to the Townes Collection.

Host: Unknown.

\section{Delomerista borealis Walkley, new species}

This species belongs in the Novita group and can be separated from D. novita (Cresson) by its color pattern: Black tegulae, black hind tibiae and tarsi, and fuscous palpi.

Holotype female: Body, $13 \mathrm{~mm}$; ovipositor sheaths, $6.5 \mathrm{~mm}$.

Head: Eyes almost parallel; face 1.75 times as wide as long; antenna 31-segmented; malar space a little more than one-third basal width of mandible; very finely, sparsely punctate except face which is more coarsely punctate with punctures of central area separated by about twice their diameter and by a little less than their diameter in adjoining area.

Thorax: Width to length as 3.5 to 5 ; mesopleurum finely punctate, especially ventroanteriorly, becoming less so dorsoposteriorly; propodeum with dorsal area as long as posterior area; petiolar area somewhat rugosely sculptured.

Abdomen: Nearly twice as long as thorax; second tergite and third tergite at base more or less granular in sculpture; tergites beyond second coriaceous, with fine, scattered punctures; ovipositor about seven-eighths as long as abdomen.

Black or blackish, except mandibles (but not teeth) and malar space whitish; clypeus, front and middle legs (tibiae and tarsi a little infuscate), hind coxae, trochanters, femora, ovipositor, tips of ovipositor sheaths, and spot on outer side of base of hind tibia, reddish.

Described from holotype female in U. S. National Museum Collection under Type No. 21394.

Type locality: Long. $141^{\circ}$ W., lat. $69^{\circ} 20^{\prime}$ N. (evidently on the northern border between Alaska and Yukon Territory). Collected Aug. 4 to 8, 1912, by J. M. Jessup.

Eleven paratypes, two in the U. S. National Museum Collection, four in the Townes Collection, and five in the Canadian National Collection. Paratype localities: Alaska: Mount McKinley at 2,500 ft., Aug. 10, 1954, David Townes; Canada: Reindeer Depot, Mackenzie Delta, N. W. T., July 10, 1948, J. R. Vockeroth; Rampart House, Y. T., two specimens July 11 and 20, 1951, J. E. H. Martin; Norman Wells, N. W. T., two specimens June 29 and July 10, 1949, J. E. H. Martin; Fort Chimo, Que., Aug. 7, 1948, R. H. MacLeod; Great Whale River, Que., July 7, 1949, J. R. Vockeroth; United States: Fall River Pass, Rocky Mountain National Park, 11,600 ft., 
Colo., Aug. 12, 1948, H., G., and D. Townes; Poudre Lake, Rocky Mountain National Park, 11,000 ft., Colo., two specimens Aug. 12, 1948, H., G., and D. Townes.

Variation: The two specimens from Rampart House have the ventral surface of hind tibia extending from pale basal area to the apex, reddish; the front coxae and trochanters of all the specimens except type and two of the three from Colorado (these two have them more or less infuscate) are blackish; specimens vary from $7 \mathrm{~mm}$. to $13 \mathrm{~mm}$. in length; ovipositor sheaths vary from little more than half (one specimen from Norman Wells, N. W. T.) to fully as long as abdomen.

Two specimens from Alaska are placed here. One, from Naknek River, while possessing the blackish palpi, tegulae, and longer ovipositor sheaths, has a definite white streak on the hind tibia. The other, from Teller, Alaska, has the ovipositor barely one-half the length of the abdomen.

Host: Unknown.

Either this species or novita (Cresson), or both, may prove to be Delomerista mandibularis (Gravenhorst). ${ }^{7}$ Certainly borealis is the same as the specimens in the U. S. National Museum Collection identified as mandibularis by A. Roman, and also the same as those from G. Heinrich's collection and identified by him as mandibularis (Gravenhorst). However, Gravenhorst's original description states "postici tibiis basi summa fusca, annulo pallido, obsoletiore aut distinctiore, ante basin, apice, vel latere toto supero usque ad annulum pallidum, fusco, tarsis fuscis" which better describes the hind tibiae of novita. Many of the species Gravenhorst placed in Pimpla at that time possessed hind tibiae with a central pale area which circled the tibia completely, hence his stressing the fact that mandibularis had the upper surface and sides fuscous. Because the type specimen is unavailable to me and because Gravenhorst's description of the hind legs of mandibularis better fits novita I have described this Nearctic species as new.

\section{Delomerista pfankuchi (Brauns)}

Figure 313,p

[Pimpla] (Delomerista) Pfankuchi Brauns, 1905, Zeitschr. Syst. Hymen. Dipt., vol. 5, p. 131 ; . Type: $\subsetneq$, Bremen, Germany (Berlin).

This species, belonging to the Novita group, may not be present in the Nearctic region. The single specimen before me is from the A. D. Hopkins Collection and the label reads only "Accession No. 5928. A. D. Hopkins, W. Va." Whether the specimen came to Dr. Hopkins

\footnotetext{
'Dr. Townes, who saw the \& type specimen of D. mandibularis on a European trip (made since this MS. was written), informs me that the ovipositor has a strong dorsal curve apically. Therefore mandibularis would fall in the JAPONICA group and may prove to be conspecific with japonica ( $=$ diprionis) as Uchida suggested.
} 
from Europe or was taken in West Virginia I have been unable to ascertain. Nothing available under the accession number was pertinent.

While Brauns' original description is still diagnostic for the species, it should be mentioned that some of the characters given may or may not be present in each specimen of pfankuchi. The areolation of the propodeum which Brauns stressed shows as much or more intraspecific as interspecific variation. However, the color pattern and sculpture of the abdominal tergites are excellent characters for separating pfankuchi from other species of the Novita group. Variation in the degree of coloration of the light areas of the abdominal tergites has been noted. Brauns refers to these pale areas as white. In the two specimens before me these light areas are testaceous or castaneous rather than white. The pale area on the vertral side of the hind tibia is more or less broken by a fuscous area and varies with the specimens.

The distinguishing character for this species is the finely punctate sculpture of the abdominal tergites with the lack of any granulation and especially on tergites 1, 2, and 3. All other species of Delomerista known to me have some granulation on at least parts of the first two or three tergites.

\section{Delomerista novita (Cresson)}

Figures 313,$0 ; 327, \mathrm{i}$

Pimpla novita Cresson, 1870, Trans. Amer. Ent. Soc., vol. 3, p. 145; . Type: \&, Massachusetts (Philadelphia).

Delomerista novita (Cresson) Cushman, 1925, Journ. Washington Acad. Sci., vol. 15, p. 392.

The definitive characters in Cresson's original description are color pattern and shape of ovipositor. The latter character does not separate novita, mandibularis, and borealis. As previously stated, I am not at all certain that more than one species is involved with the three names. ${ }^{7 \mathrm{a}}$ But since I have not seen the type of mandibularis, and since, on the basis of the material at hand, I can separate novita and borealis I have chosen to keep the three distinct at present.

$D$. novita varies in length from 6 to $13 \mathrm{~mm}$., and the ovipositor sheaths from $2 / 3$ to approximately $\% / 7$ the length of abdomen. The following parts are white or whitish and of specific importance: Palpi; lateral membranous margins of abdominal tergites; tegulae; area of each dorsolateral posterior corner of pronotum extending farther anteriorly than ventrally; basal third of hind basitarsus; basal annulus and ventral surface of hind tibia extending at least two thirds of distance to apex.

Though specimens of the NOvITA complex from alpine areas are usually borealis, four specimens, two from Mount Rainier, Washington,

7. See footnote on page 371 . 
at altitudes of 4,700 and 5,300 ft., one from Saskatoon, Saskatchewan, and one from Pipestone Pass, Montana, seem definitely to be novita. They possess all the whitish areas mentioned above except that on the hind basitarsus.

Distribution: Canada: British Columbia, Ontario, Quebec, Saskatchewan; United States: California, Connecticut, Maine, Maryland, Massachusetts, Michigan, Minnesota, New Hampshire, New York, Virginia, Washington, West Virginia, Wisconsin.

Hosts: Sawfly larva in elder stem (collected by J. C. Bridwell in Vienna, Virginia); Mononychus vulpeculus (Fabricius); Acrobasis rubrifasciella Packard (=Phycis rubrifasciella (Packard)) (parasites reared by Dimmock and identified by Ashmead); Exartema olivaceanum Riley; Eublemma minima (Guenée) (=Thalpochares carmelita Morrison). The last two records are doubtful, as the collector and identifier are not given. Host records are so meager for this species that I make no effort to evaluate them further.

\section{Genus Pseudorhyssa}

\section{FigURE $300, \mathrm{~b}$}

Pseudorhyssa Merrill, 1915, Ann. Ent. Soc. America, vol. 41, p. 150. Type: Pseudorhyssa sternata Merrill=ruficoxis (Kriechbaumer); original designation.

Front wing 7 to $19 \mathrm{~mm}$. long; body form elongate; apex of clypeus with a strong median point; propodeal carinae weak; tarsal claws simple, of moderate size, without an enlarged bristle with a spatulate tip; nervellus broken far above the middle; abdomen strongly mat, its hairs rather dense; ovipositor strongly compressed, slender, its apex not sinuate, its sheath about 1.9 as long as front wing.

This genus contains the European Pseudorhyssa alpestris (Holmgren), 1859, and the Holarctic species described below.

\section{Pseudorhyssa ruficoxis (Kriechbaumer), new combination}

"Rhyssa approximator (Fabricius)" of authors, not of Fabricius.

Rhyssa approximator var. ruficoxis Kriechbaumer, 1887, Ent. Nachr., vol. 13, p. 250 ; $\subsetneq$. Type: $\uparrow$, between Beuerberg and St. Heinrich, Starnbergersee, Germany (Munich).

Pseudorhyssa sternata Merrill, 1915, Trans. Amer. Ent. Soc., vol. 41, p. 150; 9. New synonymy. Type: $q$, Toronto, Ont. (Philadelphia).

Front wing 7 to $12.5 \mathrm{~mm}$. long in male, 10 to $19 \mathrm{~mm}$. long in female; first tergite about 1.95 as long as wide, its dorsal longitudinal carinae sharp on its basal $0.4 \pm$, continuing as blunt ridges to near its apical $0.7 \pm$; ovipositor sheath about 1.9 as long as front wing.

Male: Black. Face, under side of face and pedicel, obscure blotch on base of mandible, palpi, hind corner of pronotum, tegula, front 


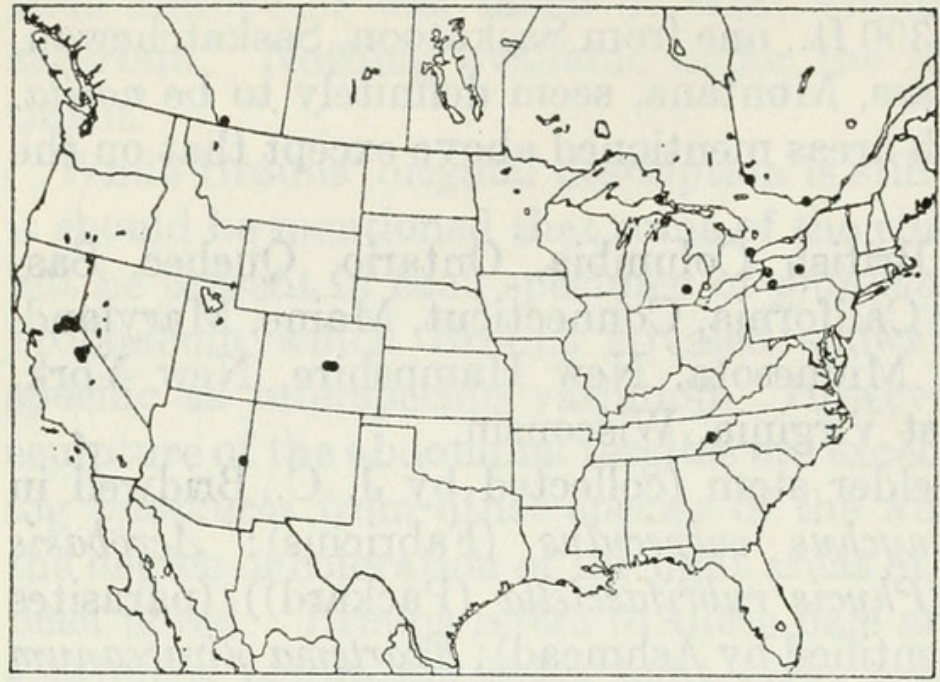

Figure 164.--Localities for Pseudorhyssa ruficoxis.

coxa and trochanters, under side of middle coxa and trochanters, and epipleura, white or ivory; clypeus ferruginous; front side of front and middle femora and tibiae more or less whitish or ivory; front and middle tarsi infuscate, paler in front; front and middle legs fulvous except as described otherwise; hind coxa fulvous or sometimes black, its lower edge ivory; trochanters ivory below, fulvous above; hind femur brownish, more or less fulvous below and at base, darker brown or blackish at apex; hind tibia fuscous, ivory to brown below except apically; hind tarsus fuscous; narrow apical margin of abdominal tergites sometimes stained with ferruginous; wings hyaline. This description is based on American males. We have seen none from Europe. According to the literature these usually have the coxae mostly blackish.

Female: Black. Face with two large, poorly defined, vertical whitish areas; mandible with a whitish area at base; clypeus dusky ferruginous; scape whitish or fulvous below; labial palpus brown; maxillary palpus stramineous; hind corner of pronotum and tegula, white; front and middle coxae fulvous or blackish brown, whitish at apex in front; trochanters more or less whitish, fulvous dorsally; front and middle femora and tibiae fulvous, more or less whitish in front; front and middle tarsi light brownish fulvous; hind coxa fulvous to blackish; hind femur fulvous, its apex infuscate; hind tibia and tarsus fuscous brown, the tibia a little paler at base and beneath, except toward apex; narrow apical margin of second to fourth tergites usually stained with ferruginous; epipleura white; wings hyaline. American specimens have the coxae fulvous, except for the whitish apical marks. In European specimens the coxae are usually blackish, but sometimes fulvous.

Specimens (8 $\sigma^{7}, 31$ ) $)$ : From Alberta (Waterton); Arizona (near Alpine); California (Camino, Echo Lake at 7,400 ft., Fish Camp, near Glacier Point in Yosemite Park, Glen Alpine Creek at Lake Tahoe, 
Hope Valley in Alpine Co., Leevining, Placerville, Smoky Jack Camp in Yosemite Park, and Snowline Camp in El Dorado Co.); Colorado (Williams Canyon in El Paso Co.); Maine (Bar Harbor); Michigan (Ann Arbor, Douglas Lake, and Whitefish Point in Chippewa Co.); New York (Allegany State Park, Erie Co., and Frontenac Point on Cayuga Lake); Ontario (Toronto); Quebec (Aylmer and Laniel); and Tennessee (Great Smoky Mountains National Park). We also have studied a number of females from southern Germany.

The above American specimens were all collected from June 10 to July 21, except for a male taken May 25 near Alpine, Ariz.

Biological data on pin labels are as follows: $\circ$, ovipositing in Pinus ponderosa containing Melanophila, Placerville, Calif., F. B. Herbert. \&, reared from Abies concolor, El Paso Co., Colo., June 10, 1904, H. B. Kirk. 6o, parasitic on siricid in Abies concolor, Williams Canyon, Colo., June 12, 1916, George Hofer. $0^{x}$, $\odot$, parasitic on borer in Larix trunk, Bar Harbor, Maine, 1944, A. E. Brower. 2ᄋ, "Larix," Erie Co., N. Y., Blackman. $\$$, reared from Picea mariana infested by Monochamus sp. and Tetropium cinnamopterum, Laniel, Que., June 10, 1933. क , reared from Abies, Queens Park, Aylmer, Que., June 27, 1921, F. C. Craighead.

This species is transcontinental in the Canadian zone and occurs also in Europe. It parasitizes siricids and perhaps also Coleoptera boring in conifer trunks. Adults occur mostly in June and July.

\section{Tribe Poemeninn}

Figures 301,a,b; 302,a

Front wing 4 to $13 \mathrm{~mm}$. long; clypeus varying from moderately large, lenticular, and evenly convex to small, quadrate, and rather flat; mesoscutum smooth or sometimes wrinkled along the notauli and medially, the notauli often very prominent; prepectal carina always absent; mesopleural suture usually with a distinct median angulation; propúdeum without carinae; last segment of tarsus not enlarged; tarsal claws simple or with an accessory tooth, without an enlarged hair with a flattened tip except on the outer hind claw of Eugalta; areolet present or absent; nervellus broken above the middle; first tergite rather long and straight, more or less fused with its sternite, without a distinct lateral longitudinal carina except sometimes in Deuteroxorides; male subgenital plate subrectangular; apex of last tergite of female often elongate but without an apical horn or boss; ovipositor slender, compressed, moderately long or quite long.

This tribe includes seven genera, which bave recently been revised by Townes (1957, Proc. Ent. Soc. Washington, vol. 59, pp. 16-20). The three Nearctic genera are treated below. The revision of the 
genus Poemenia (below) is a separate, joint paper by Habeck and Townes, included in this monograph for convenience of publication.

\section{Key to the Nearctic genera of Poemeniini}

1. Mandible with two apical teeth, the upper tooth smaller; clypeus evenly convex, about 2.0 as wide as long; upper balf of temple without a coarsely scabrous area; areolet usually present . . . . . . 1. Poemenia (p. 376)

Mandible without two apical teeth, its apex truncate and chisel-shaped; clypeus basally convex and apically impressed, about 1.2 to 1.5 as wide as long; upper half of temple with a coarsely scabrous area; areolet absent . . . . . . 2

2. Tarsal claws with a subapical appressed tooth; second and third tergites densely punctate . . . . . . . . . . . . 2. Podoschistus (p. 387)

Tarsal claws simple; second and third tergites often not distinctly punctate.

3. Neoxorides (p. 390)

\section{The Nearctic species of Poemenia Holmgren}

By Dale Habeck ${ }^{8}$ and Henry Townes

\section{Genus Poemenia}

FiguRE 301,a

Poemenia Holmgren, 1859, Ofvers. Svenska Vetensk.-Akad. Förh., vol. 16, p. 130. Type: Poemenia notata Holmgren; monobasic.

Calliclisis Foerster, 1868, Verh. Naturh. Ver. Rheinlande, vol. 25, p. 169. Type: Ephialtes hecticus Gravenhorst; designated by Viereck, 1914.

Phthinodes Tschek, 1868, Verh. Zool.-Bot. Ges. Wien, vol. 18, p. 272. Type: Ephialtes hecticus Gravenhorst; monobasic.

Euxorides Cresson, 1870, Trans. Amer. Ent. Soc., vol. 3, p. 167. Type: Euxorides americanus Cresson; monobasic.

Lissonotopsis Habermehl, 1917, Zeitschr. Wiss. Ins.-Biol., vol. 13, pp. 234, 306. Type: (Lissonotopsis rufa Habermehl) = notata Holmgren; monobasic.

Clypeus moderately large, about 2.0 times as wide as long, evenly convex, covered with rather long hairs, its apical margin concave; mandible moderately long, with two apical teeth, the upper tooth shorter; temple in profile about 0.53 times as long as eye, its dorsal half sometimes with a weakly scabrous area; mesoscutum moderately trilobed; notauli strong anteriorly, fading out on disc of mesoscutum; areolet present or absent, when absent the intercubitus about 0.8 times as long as second abscissa of cubitus; nervulus usually opposite basal vein, but sometimes before or a little beyond; tarsal claws simple, those of the hind legs sharply curved in a right angle turn; first tergite about 2.0 to 3.5 times as long as wide; second and third tergites with fine dense punctures.

This is a rather small, Holaretic genus. In North America there are four species. Most of them occur in forests and are parasitic on hosts

8 North Carolina State College, Raleigh, N.O. 
in dead wood. Like other species with these hosts, they are sometimes found on the windows of garages, etc., where firewood is stored. $P$. americana, however, is parasitic on borers in pine cones.

\section{Keys to the Nearctic species of Poemenia}

\section{MALES}

1. Areolet absent; hind ocellus separated from eye by about 0.9 its long diameter; propleurum entirely black; mesoscutum, mesopleurum, and metapleurum ferruginous; tyloids usually on flagellar segments 8 to 11 , linear.

4. pacifica, new species

Areolet usually present; hind ocellus separated from eye by about 1.1 to 1.4 its long diameter; propleurum white ventrally; mesoscutum and metapleurum, and nearly always the mesopleurum, black; tyloids on flagellar segments 6 to 8 , rather broadly elliptic. . . . . . . . . . . . . . . . 2

2. First sternite about 0.55 as long as its tergite; white on hind corner of pronotum extending forward more than half the distance to notaulus; first tergite 1.9 to 2.7 as long as wide. . . . . . . . . . . . 3. americana (Cresson)

First sternite 0.65 to 0.75 as long as its tergite; white on hind corner of pronotum restricted to its extreme apex; first tergite 2.8 to 3.5 as long as wide . . . . 3

3. Scape about 50 percent white, the rest infuscate. . . 1. thoracica (Cresson) Scape about 65 percent white, the rest infuscate. . . 2. albipes (Cresson)

\section{FEMALES}

1. Abdominal segments 2 to 5 with two pairs of short ventral scleromes; ovipositor sheath about 0.55 as long as front wing . 3. americana (Cresson)

Abdominal segments 2 to 5 with one pair of long ventral scleromes; ovipositor sheath 0.9 to 1.4 as long as front wing . . . . . . . . . . . . . . . . 2

2. Areolet absent; lateral ocellus separated from eye by about 1.0 its diameter; flagellum with 27 to 30 segments; mesoscutum always mostly ferruginous.

4. pacifica, new species

Areolet present; lateral ocellus separated from eye by about 1.0 to 1.3 its diameter; flagellum with 27 to 36 segments; mesoscutum black to ferruginous, usually black . . . . . . . . . . . . . . . . . . . . . . . . . . 3

3. Scape brownish in front; first sternite about 0.55 as long as its tergite; ovipositor sheath about 1.3 as long as front wing . . . 1. thoracica (Cresson)

Scape white in front; first sternite about 0.66 as long as its tergite; ovipositor sheath about 1.05 as long as front wing . . . . 2. albipes (Cresson)

\section{Poemenia thoracica (Cresson)}

Ephialtes thoracicus Cresson, 1878, Proc. Acad. Nat. Sci. Philadelphia, vol. 1878,

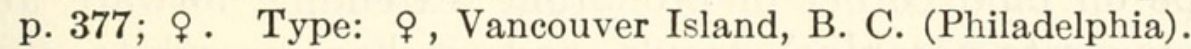

Euxorides Vancouveriensis Provancher, 1883, Additions et corrections au volume II de la faune entomologique du Canada traitent des hyménoptères, p. 369 ; $q$. New synonymy. Type: $q$, Vancouver Island, B. C. (Quebec).

Ephialtes vancouverensis Harrington, 1894, Canadian Ent., vol. 26, p. 249; . Type: $\uparrow$, Victoria, B. C. (Ottawa).

Male: Front wing 4.6 to $6.7 \mathrm{~mm}$. long; punctation of head and body fine; hind ocellus separated from eye by about 1.1 its long diameter; flagellum with 27 to 31 segments, with rather broadly elliptic tyloids $526527-60-25$ 
on segments 6 to 8 ; areolet present or rarely absent; first tergite 2.8 to 3.5 as long as wide; first sternite about 0.67 as long as its tergite.

Black. Apical half of clypeus and most of mandible tinged with ferruginous; palpi white; scape and pedicel whitish on front and lateral sides, the whitish area about 50 percent of their total area, the rest of surface brown or infuscate; under side of flagellum brown, the rest darker; stripe along lower edge and extreme hind corner of pronotum whitish; lower 0.4 of propleurum whitish; tegula white; front and middle legs whitish, the middle tarsus fuscous; hind coxa fulvous, whitish at apex; hind trochanters whitish, each with an infuscate area above; hind femur fulvous, whitish at apex and extreme base, with a faintly infuscate area subbasally above and a stronger infuscate area subapically; hind tibia and tarsus fuscous, the tibia basally and narrow base of each tarsal segment stramineous. Rarely the sterna and lower part of pleura of meso- and metathorax are tinged with ferruginous.

Female: Front wing 5.7 to $9.2 \mathrm{~mm}$. long; lateral ocelli separated from each other by 1.0 to 1.15 their diameter, separated from eye to 1.0 to 1.2 their diameter; face and vertex punctate, the punctures separated by 1.0 to 1.5 their diameter; temple scabrous from top of eye down 0.67 the distance to mandible; flagellum with 33 to 36 segments; pronotal trough smooth and highly polished; mesoscutum punctate, the punctures separated by their diameter; propodeum rugoso-punctate, with a median longitudinal furrow; areolet present; first tergite about 2.2 as long as wide; first sternite about 0.55 as long as its tergite; second tergite 1.14 to 1.53 as long as wide; second through fifth sternites each with one pair of scleromes which extend 0.70 to 0.85 their length; thyridia comma-shaped or sometimes round; first tergite densely punctate; punctation on second and following tergites gradually less dense, the punctures on sixth tergite separated by about twice their diameter; ovipositor sheath about 1.3 as long as front wing.

Black. Apical half of clypeus and most of mandible stained with ferruginous; palpi white; scape and pedicel brown in front, narrowly stramineous on apex in front; stripe along lower edge of pronotum, short stripe on hind corner of pronotum (extending forward about 0.6 the distance to notaulus), tegula, and trochanters, white; thorax black, or often partly or mostly ferruginous, the black color persistent in groove of pronotum, around wing bases and scutella, and apex of propodeum; front coxa white, fulvous basally; middle coxa fulvous, sometimes white above; front and middle femora and tibiae white, pale fulvous above and behind; front tarsus stramineous, brown apically; middle tarsus brown, pale at incisures; hind coxa, trochanters, and femur fulvous, the trochanters paler below, the second trochanter 
brown above, and the femur brownish at base and apex above; hind tibia and tarsus fuscous, the tarsus paler at incisures.

Specimens (16 $0^{x}, 56$ ) : From British Columbia (Canim Lake, Creston, Diamond Head Trail near Squamish at 3,200 and 3,800 ft., Fort Nelson, Keremeos, Lake Cowichan, Robson, Salmon Arm, Trinity Valley, Vancouver, Victoria, and Wellington); California (Big Bear Mt. in Plumas Co., Bluff Falls Public Camp in Tehama Co., Camino, Dardanelle, Echo Lake at 7,400 ft. in El Dorado Co., Fish Camp, Glendale, Glen Alpine Creek near Tahoe, near Glacier Point in Yosemite Park, Gold Lake in Sierra Co., Lake Forest near Lake Tahoe, Lake Tahoe, Leevining, May Lake at 10,500 ft. in Yosemite Park, Smoky Jack Camp in Yosemite Park, Susan River Camp in Lassen Co., and Tamarack Flat in Yosemite Park); Colorado (El Paso Co., Granite Peaks Camp near Bayfield at 9,000 ft., Muddy Pass, and Westcliffe); Idaho ("Camp Creek at the Krassel Ranger Station" and Wallace); Montana ("Avalanche Creek 40 miles south of Cascade Glen" and Lake Roman in Lake Co.); Oregon (Austin, Joseph, and Parkdale); Saskatchewan (Waskesiu); and Wyoming (Buffalo Bill Reservoir).

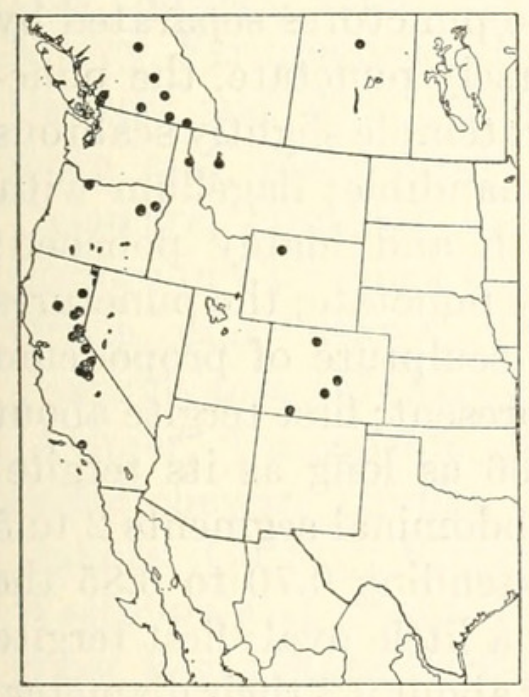

Figures 165, 166.-Localities: 165 (left), Poemenia thoracica; 166 (right), $P$. albipes.

Most dates of collection are from mid-June to early August. Unusually early and late dates are: May 3 near Tahoe, Calif.; June 6 at Robson, B. C.; June 13 at Fort Nelson, B. C.; June 14 near Estes Park, Colo.; August 2 at Buffalo Bill Reservoir, Wyo.; August 9, 10, 13, and 19 on Diamond Head Trail, near Squamish, B. C.; and August 15 at Joseph, Oreg.

The only biological records with these specimens are: , reared from Pinus ponderosa, El Paso Co., Colo., May 22, 1914, A. B. 
Champlain. ㅇ, "Abies concolor," Austin, Oreg., June 24, 1914, W. J. Chamberlin.

This species occurs in the Transition and Canadian zones of western Northern America. It is adult from mid-June to early August. It has been reared from coniferous trees.

\section{Poemenia albipes (Cresson)}

Ephialtes albipes Cresson, 1870, Trans. Amer. Ent. Soc., vol. 3, p. 143; . Type: $\uparrow$, New Jersey (Philadelphia).

Male: Front wing 4.2 to $6.8 \mathrm{~mm}$. long; punctation of head and body fine; hind ocellus separated from eye by about 1.1 its long diameter; flagellum with 27 to 31 segments, with rather broadly elliptic tyloids on segments 6 to 8 ; areolet present or rarely absent; first tergite 2.8 to 3.5 as long as wide; first sternite about 0.70 as long as its tergite.

Colored like the male of $P$. thoracica except that the scape and pedicel are about 65 percent white, only about 35 percent of their area (on the upper and inner sides) being brown.

Female: Front wing 4 to $8.5 \mathrm{~mm}$. long; lateral ocelli separated from each other by 0.8 their diameter, separated from eye by 1.1 to 1.3 their diameter; face densely punctate, the punctures separated by 0.5 to 1.5 their diameter; vertex finely, sparsely punctate, the punctures separated by 2 to 3 times their diameter; temple slightly scabrous from top of eye down 0.4 the distance to mandible; flagellum with 27 to 35 segments; pronotal trough smooth and highly polished; mesoscutum and propodeum densely coarsely punctate, the punctures separated by about 0.3 their diameter, the sculpture of propodeum tending toward transverse rugosity; areolet present; first tergite about 2.8 as long as wide; first sternite about 0.66 as long as its tergite; second tergite 1.15 to 1.75 as long as wide; abdominal segments 2 to 5 with one pair of ventral scleromes, these extending 0.70 to 0.85 the lengths of their segments; thyridia round or a little oval; first tergite densely punctate, the punctures separated by about 0.3 their diameter; second and following tergites gradually less densely punctate, the punctures on the sixth tergite separated by about twice their diameter; ovipositor sheath about 1.05 as long as front wing.

Black. Apical half of clypeus and most of mandible stained with ferruginous; palpi white; scape and pedicel white on the outer front half; flagellum brown ventrolaterally toward base; narrow stripe along lower edge of pronotum, more or less of lower part of propleurum, extreme apex of pronotum, tegula, and trochanters, white; thorax nearly always black but sometimes more or less ferruginous in specimens from western United States; front coxa white, its base tinged with fulvous; middle coxa fulvous, white apically; front and middle 
femora white, more or less pale fulvous behind; front and middle tibiae white, with a faint brown stripe above; front tarsus whitish basally, shading to brown apically; middle tarsus brown, paler at incisures; hind coxa fulvous, whitish on extreme apex; hind trochanters infuscate, whitish below and on base and apex; hind femur fulvous, a little brownish above subbasally and subapically, the extreme base and apex, especially the apex, whitish; hind tibia dark brown, whitish at base and on extreme apex; hind tarsus fuscous, pale at incisures.

Specimens $\left(24 \sigma^{x}, 84\right.$ ) : From Alberta (Edmonton and Midnapore); British Columbia (Clinton, Keremeos, Victoria, and Wellington); California (Blue Lake in Humboldt Co., Camino, and Mill Valley); Colorado (Elk Creek at Fraser, Lyons, Morley, and Phantom Valley at 9,400 ft. in Rocky Mountain National Park); Delaware (Newcastle Co.); Georgia (Clayton at 2,000 ft.); Idaho ("Collins"); Kansas (Lawrence); Louisiana (Baton Rouge); Maine (Bangor and Northeast Harbor); Manitoba (Gillam); Maryland (Cabin John and Takoma Park); Massachusetts (Amherst, Boston, and South Hadley); Michigan (Ann Arbor, Oakland Co., and Shiawassee Co.); Montana (Missoula); New Brunswick (Bathurst); New Hampshire (Conway and Mount Monadnock); New Jersey (New Brunswick); New Mexico (Las Vegas Hot Spring); New York (Bemus Point, Bushnell Falls on Mount Marcy, Farmingdale, Heart Lake in Essex Co., Honeoye Falls, Ithaca, Oswego, and West Farms in New York City); North Carolina (Biltmore and Wake Co.); Nova Scotia (Baddeck); Ohio (Cleveland, Delaware, Hinckley in Medina Co., Montgomery Co., and Puritas Springs in Cuyahoga Co.); Oklahoma (Broken Bow); Ontario (Frater, Orillia, and Ottawa); Oregon (Cascadia, Corvallis, and Meacham); Pennsylvania (McAlveys Fort and Presque Isle in Erie Co.); Quebec (Aylmer, Cascapedia River, Knowlton, Laniel, and La Trappe); Saskatchewan (Indian Head); South Carolina (Greenville); South Dakota (Custer); Virginia (Arlington, Falls Church, Great Falls, and Westmoreland State Park in Westmoreland Co.); West Virginia (Lost River State Park in Hardy Co.); and Wisconsin (Nekoosa).

Specimens have been collected from late spring to early fall. The earliest and latest dates of capture are: April 22 and May 24 at Greenville, S. C.; April 25 at Baton Rouge, La.; May 8 at Clayton, Ga. at 2,000 ft.; May 28 at New Brunswick, N. J.; June 2 at Hinckley, Ohio; June 12 in Shiawassee Co., Mich.; September 2 at Hinckley, Ohio; September at La Trappe, Que.; and September 20 at Falls Church, Va. The great majority of the specimens were collected in June and July.

The only biological data on pin labels is with one specimen labeled "dead Picea excelsa" and with another "in wood cellar." 
This species is transcontinental in the Transition and Upper Austral zones. Most adults occur in June and July but some occur earlier or later.

\section{Poemenia americana (Cresson)}

Male: Front wing 4.4 to $6.4 \mathrm{~mm}$. long; punctures on head and body fine; hind ocellus separated from eye by about 1.2 its long diameter; flagellum with 29 or 30 segments, with rather short, broadly elliptic tyloids on segments 6 to 8 ; areolet present; first tergite 1.95 to 2.7 as long as wide; first sternite about 0.55 as long as its tergite.

Coloration as described under the two subspecies, below.

Female: Front wing 4 to $7.5 \mathrm{~mm}$. long; lateral ocelli separated from each other by 1.0 to 1.1 their diameter, separated from eye by 1.1 to 1.25 their diameter; face densely punctate, the punctures separated by about 0.5 their diameter; vertex somewhat mat; temple scabrous from top of eye down 0.5 the distance to mandible; flagellum with 27 to 31 segments; pronotal trough with cross ridges; mesoscutum densely punctate, the punctures separated by about 0.5 their diameter; propodeum rugoso-punctate, with a weak median longitudinal furrow; areolet present; first sternite about 0.60 as long as its tergite; first tergite 1.65 to 2.1 as long as wide; second tergite 0.93 to 1.95 as long as wide; abdominal segments 2 to 5 with two pairs of ventral scleromes, the front pair of each segment about half as long as the hind pair; first tergite rugoso-punctate, the following tergites gradually less densely punctate, the punctures on sixth tergite separated by about twice their diameter; thyridia circular; ovipositor sheath about 0.55 as long as front wing.

There are two subspecies separable on color, as indicated below.

\section{MALES}

1. Base of hind tibia dark brownish; hind femur fulvous below and on extreme apex, the rest brownish fulvous; apex of hind coxa fulvous; range: Canada and western United States .. . 3a. americana nebulosa, new subspecies

Base of hind tibia whitish; femur whitish below and on extreme apex, the rest brown; apex of hind coxa whitish; range: northeastern United States and adjacent Canada . . . . . . 3b. americana americana (Cresson)

\section{FEMALES}

1. Pronotum without a well-developed whitish stripe along its anteroventral margin; hind tibia entirely fuscous; middle coxa fulvous, its extreme apex paler; range: Canada and western United States.

3a. americana nebulosa, new subspecies

Pronotum with a broad whitish stripe along its anteroventral margin; hind tibia fuscous, stramineous at base; middle coxa fulvous, its apical $0.3 \pm$ whitish; range: northeastern United States and adjacent Canada

3b. americana americana (Cresson) 


\section{3a. Poemenia americana nebulosa Habeck and Townes, new subspecies}

Male: Black. Apical half of clypeus and most of mandible tinged with ferruginous; palpi white; front half of scape and pedicel whitish; flagellum brown at base, palest below; stripe along lower edge of pronotum whitish; hind corner of pronotum covered by a small triangle of white, the white extending forward about 0.7 the distance to notaulus; lower 0.4 of propleurum whitish; tegula white; front and middle legs whitish, the front tarsus brown apically, the middle tarsus brown, paler basally; hind coxa fulvous; hind trochanters brownish above, whitish below; hind femur brownish fulvous, brown basally and apically, paler below, its extreme apex fulvous; hind tibia and tarsus fuscous, the tibia somewhat paler at base.

Female: Black. Scape and pedicel brown in front; apical third of clypeus and most of mandible tinged with ferruginous; palpi pale stramineous; hind corner of pronotum whitish, with a narrow forward extension of the white mark that reaches half way to notaulus; lower front edge of pronotum sometimes tinged with stramineous; tegula white; front leg pale fulvous, the coxa apically, the trochanters, and the femur basally and apically and more or less in front, whitish, the tarsus brownish apically; middle leg fulvous, the extreme apex of its coxa, the trochanters, and apex of femur pale stramineous and the tarsus brown; hind coxa fulvous; hind trochanters fulvous, infuscate above; hind femur fulvous, a little infuscate basally above and more distinctly infuscate apically above, the extreme apex a little paler; hind tibia and tarsus fuscous, the tibia faintly paler at base.

Type: \&, near Glacier Point, Yosemite Park, Calif., July 19, 1948, H., M., G., D., and J. Townes (Washington, USNM 63716).

Paratypes $\left(8 \sigma^{x}, 40\right.$ o $)$ : From Arizona (Parker Creek and Workman Creek both in the Sierra Ancha); British Columbia (Diamond Head Trail near Squamish at 3,300 ft., Keremeos, Pavilion Lake, Salmon Arm, and Wellington); California (Angora Lake near Tahoe, Chester, Dardanelle, Del Norte, Echo Lake in El Dorado Co., Fallen Leaf Lake near Tahoe, near Glacier Point in Yosemite Park, Glen Alpine Creek near Tahoe, Hope Valley in Alpine Co., Inyo Co. at 9,700 ft., Moore Camp in Shasta Co., and north slope of Mount St. Helena in Napa Co.); Colorado (Evergreen, Gothic at 9,000 ft., Ragged Mt. in Gunnison Co., and Westcliffe); Nova Scotia (Baddeck); Oregon (Corvallis, Dixie Mt. at 5,200 to 6,000 ft. in Blue Mts., and Grant Co.); and Quebec (Laniel and Mt. Lyall at 1,500 ft.).

Most of the field-collected specimens are dated June 27 to July 19. The dates outside of this "normal" range are: April 20 and May 2 at Parker Creek, Sierra Ancha, Ariz.; May 8 at Workman Creek, Sierra Ancha, Ariz.; June 7 at Pavilion Lake, B. C.; June 8 at Laniel, 
Que.; June 23 at Chester, Calif.; August 12 on Dixie Mt. at 5,200 to 6,000 ft., in the Blue Mts., Oreg.; August 19 and 31 on Diamond Head Trail, near Squamish, B. C.; and September 5 at Del Norte, Calif.

Reared specimens are as follows: $\sigma^{7}$, from Laspeyresia toreuta (no further data). $2 \sigma^{\top}, 1$, from Paratimia conicola in Pinus attenuata, Del Norte, Calif., collected Oct. 12, 1913, emerged Mar. 18, 1914, P. D. Sergent. $\quad$ क, from Paratimia conicola, Mount St. Helena, Napa Co., Calif., June 19, 1930, E. C. Van Dyke. $\sigma^{\top}$,, , from cones of Pinus tuberculata, Mount St. Helena, Napa Co., Calif., Mar. 26, 1951, J. Helfer, E. C. Van Dyke, J. W. Greene, and H. B. Leech.

This subspecies occurs in the Canadian and Transition zones of the West, and extends eastward in the Canadian zone to Quebec. It has been reared from lepidopterous and coleopterous borers in cones of Pinus.

\section{3b. Poemenia americana americana (Cresson)}

Euxorides americanus Cresson, 1870, Trans. Amer. Ent. Soc., vol. 3, p. 167;.

Type: $\uparrow$, Pennsylvania (Philadelphia).

Male: Similar to the male of P.a.nebulosa except as stated in the key.

Female: Black. Scape and pedicel pale brown in front; apical third of clypeus and most of mandible tinged with ferruginous; palpi white; hind corner of pronotum white, with a narrow forward extension of white that reaches half way to notaulus; front lower edge of pronotum with a broad white stripe; tegula white; front coxa white, fulvous basally; front and middle trochanters white; front and middle femora light fulvous, whitish at apex and at extreme base, and tinged with white in front; front and middle tibiae whitish, faintly tinged
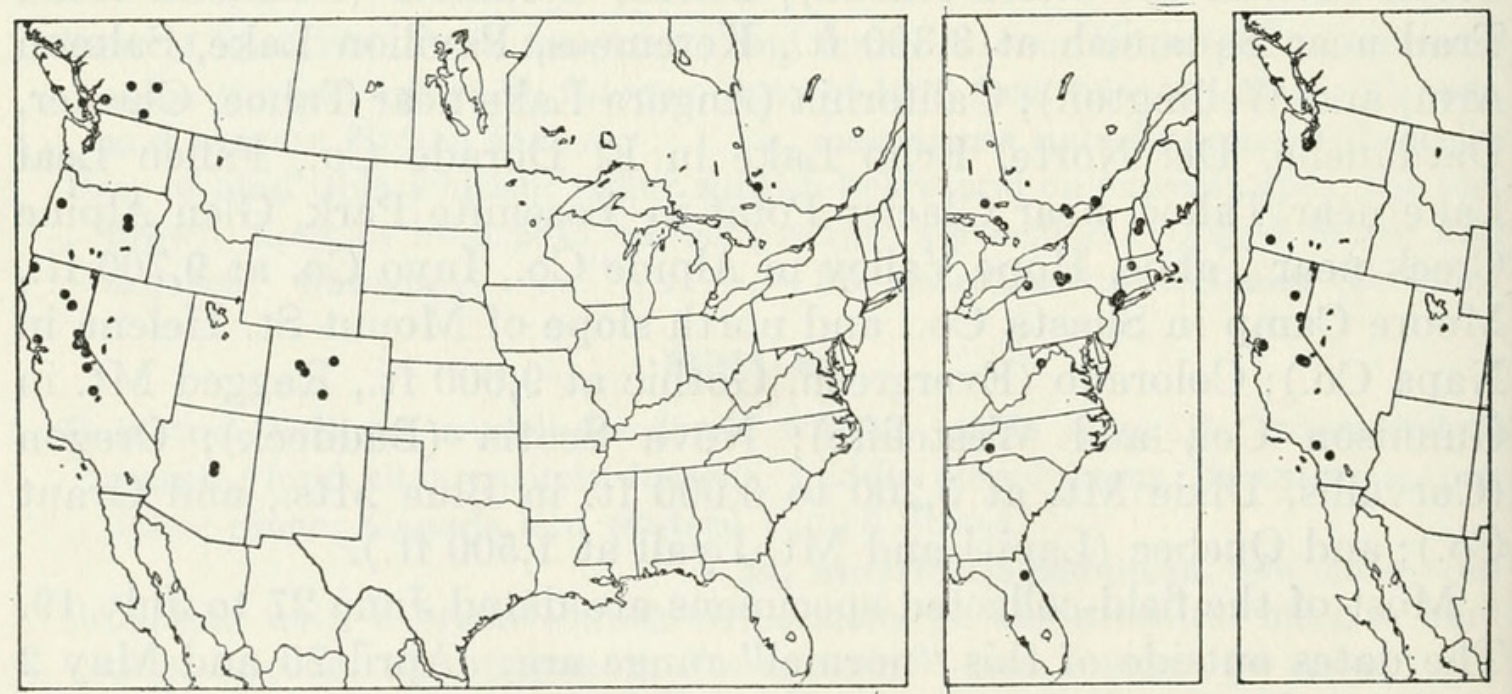

Figures 167-169.-Localities: 167 (left), Poemenia americana nebulosa; 168 (center), P. a. americana; 169 (right), P. pacifica. 
with fulvous; front tarsus stramineous, brown toward apex; middle coxa fulvous, its apical $0.3 \pm$ whitish; middle tarsus brown; hind coxa fulvous; hind first trochanter fulvous, fuscous above; hind second trochanter mostly whitish; hind femur fulvous, infuscate basally and subapically, its apex whitish; hind tibia fuscous, stramineous at base; hind tarsus fuscous, the base of each segment narrowly light brown.

Specimens (3 $\sigma^{x}, 34$ \%): From Florida (Crescent City); Massachusetts (Amherst); New Hampshire (Squam Lake and White Mts.); New Jersey (Ramsey); New York (Ellis Hollow in Tompkins Co., Frontenac Point on Cayuga Lake, Gowanda, Ithaca, Millwood, West Farms in New York City, and Yonkers); North Carolina (Biltmore); Nova Scotia (Kentville and Smith's Cove); Ontario (Merivale, Parry Sound, Sudbury, and Waubamik); Pennsylvania; Quebec (Aylmer and La Trappe); and West Virginia (Lost River State Park in Hardy Co.).

The above specimens were all collected between June 8 and July 13, except for five dates outside of this range, as follows: May 28 at Ramsey, N. J.; June 1 at Ithaca, N. Y.; June 2 at Yonkers, N. Y.; July 15 at Parry Sound, Ont.; and August 2 at Ellis Hollow, Tompkins Co., N. Y.

This subspecies occurs in the East, ranging from the Transition zone to the Lower Austral zone. Adults occur mostly in June and the first half of July.

\section{Poemenia pacifica Habeck and Townes, new species}

Male: Front wing 3.8 to $4.1 \mathrm{~mm}$. long; punctation of head and body moderately fine (unusually coarse for the genus); hind ocellus separated from eye by about 0.9 its long diameter; flagellum with 27 to 31 segments, its tyloids linear, beginning on about the eighth segment and present on this and the next three or four segments; areolet absent; first tergite 2.8 to 3.5 as long as wide; first sternite about 0.55 as long as its tergite.

Black. Apical half of clypeus and most of mandible tinged with ferruginous; palpi white; front half of scape and pedicel white; broad hind corner of pronotum, broad lower margin of pronotum, tegula, sometimes obscure mark on subtegular ridge, and front and middle legs, white, the last segment of front tarsus brown and the middle tarsus pale brown basally, shading to medium brown apically; mesoscutum except its front and side margin, scutellum, mesopleurum, mesosternum, and metapleurum, ferruginous; hind coxa fulvous; hind trochanters stramineous, infuscate above; hind femur brownish fulvous, a little paler below and faintly darker basally and subapically; hind tibia dark brown, stramineous at base; hind tarsus dark brown, the base of each segment stramineous. 
Female: Front wing 4 to $7 \mathrm{~mm}$. long; lateral ocelli separated from each other by 1.1 to 1.25 their diameter, separated from eye by 1.0 their diameter; face with rather coarse, dense punctures, the punctures separated by 0.5 their diameter; vertex less densely punctate than face, the punctures separated by about their diameter; temple finely reticulate, not scabrous; flagellum with 25 to 30 segments; pronotal trough smooth and highly polished; mesoscutum and propodeum densely, rather coarsely punctate, the punctures separated by 0.5 their diameter or less; propodeum with a shallow medium longitudinal furrow; areolet always absent; first tergite about 2.1 as long as wide; first sternite about 0.55 as long as its tergite; second tergite 0.94 to 1.35 as long as wide; abdominal segments 2 to 5 with one pair of sternal sclerites, these extending 0.67 to 0.75 the length of their segment; thyridia absent or obscure; first tergite densely, rather coarsely punctate, the punctures separated by less than 0.5 their diameter; second and following tergites gradually less densely punctate, the punctures on the sixth tergite separated by twice their diameter; ovipositor sheath about 1.0 as long as front wing.

Black. Apical half of clypeus and most of mandible tinged with ferruginous; palpi white; scape and pedicel stramineous in front; fiagellum brown basally below, the rest blackish; stripe on lower edge of pronotum, line on hind corner of pronotum (reaching forward about 0.7 the distance to notaulus), tegula, much or most of mesepimeron, and front and middle coxae and trochanters, white; mesoscutum except in front and laterally, scutellum, postscutellum, meso- and metasternum, meso- and metapleurum except mesepimeron and sometimes upper part of mesopleurum, and sometimes more or less of propleurum and of propodeum next to metapleurum, ferruginous; front and middle femora and tibiae white with a light brown stripe above, the tibiae also faintly brownish medially; front tarsus whitish basally, shading to brown apically; middle tarsus brown, white basally; hind coxa fulvous, with an ivory spot basally above and its extreme apex yellowish fulvous; hind first trochanter brown, whitish below; hind second trochanter white, fuscous basally above; hind femur fulvous, brownish at base and apex, its extreme apex pale fulvous; hind tibia fuscous, whitish at base and stramineous at apex; hind tarsus fuscous, each segment stramineous at base; apex of tergites 2 to 6 narrowly whitish.

This species is very closely related to Poemenia notata Holmgren 1859, of Europe. It differs from $P$. notata in having a more contrasted color pattern, with more fulvous on the thorax and more distinct white and fuscous markings; ocelli slightly larger; and the mesopleurum and metapleurum more polished and with sharper, closer 
punctures. It may prove to be only a subspecies of $P$. notata. We have compared our series of pacifica with two females of notata from Europe, but not with males.

Type: , on dead Pinus contorta, near Glacier Point, Yosemite Park, Calif., July 17, 1948, H., M., G., D., and J. Townes (Washington, USNM 63717).

Paratypes: + , Bridge Creek Camp, Lassen Co., Calif., July 9, 1949, J. E. Gillaspy (Berkeley). ㅇ, Donner Pass, Calif., Aug. 1, 1948, H., M., G., and D. Townes (Townes). 14으, on dead Pinus contorta, near Glacier Point, Yosemite Park, Calif., July 16, 17, 18, 19, and 20, 1948, H., M., G., D., and J. Townes (Townes, Ottawa, and Madison). $2 \sigma^{7}$, reared from galls of Disholcaspis truckeensis, Idyllwild, Calif., Apr. 5 and 8, 1923 (Washington). ণ, Miami Ranger Station, Mariposa Co., Calif., May 22, 1942, Arthur J. Walz (Berkeley). , reared from Quercus wializenii, Upland, Calif., emerged May 24, 1918, L. H. Weld (Washington). ㅇ, reared from Quercus agrifolia, Walnut Creek, Calif., Aug. 20, 1911, J. C. Bridwell (Berkeley). ค, Yosemite, Calif. at 3,880 to 4,000 ft., May 16, 1931, E. O. Essig (Berkeley). $2 \sigma^{\top}$, reared from oak galls, Grants Pass, Oreg., emerged May 16, and 18, 1899, A. D. Hopkins (Washington). क, La Grande, Wash., Aug. 6, 1945 (Townes). 2o, Fort Lewis, Pierce Co. Wash., June 24 and 28, 1951, R. Schuster (Berkeley).

This species occurs from Washington to California. It has been reared from cynipid galls on Quercus.

\section{Genus Podoschistus}

\section{Figure $301, \mathrm{~b}$}

Podoschistus Townes, 1957, Proc. Ent. Soc. Washington, vol. 59, p. 18. Type: Xorides vittifrons Cresson; original designation.

Front wing 6 to $14 \mathrm{~mm}$. long; clypeus small, quadrate, about 1.2 as wide as long, basally convex, the rest impressed, its apex truncate or concave; mandible short, its apex chisel-shaped, without teeth; temple in profile about 0.55 as long as eye, its upper half coarsely scabrous; mesoscutum rather strongly trilobed; notauli strong, convergent and almost meeting on disc of mesoscutum; areolet absent, the intercubitus about 0.5 as long as second abscissa of cubitus; nervulus opposite basal vein; tarsal claws with a median, appressed, pointed tooth; first tergite about 2.3 to 3.0 as long as wide; second and third tergites mat, with moderate-sized punctures.

This genus includes the European Xorides scutellaris Desvignes 1856, the Japanese Xorides alpensis Uchida 1928, and Xorides vittifrons Cresson 1868 from North America, 


\section{Podoschistus vittifrons (Cresson)}

Front wing 6 to $13 \mathrm{~mm}$. long; ovipositor sheath about 1.45 as long as front wing.

There is an eastern and a western subspecies, separable on color as in the key below:

1. Hind tibia entirely fuscous; range: Utah

1a. vittifrons schlingeri, new subspecies

Hind tibia fuscous, white at base; range: eastern North America.

1b. vittifrons vittifrons (Cresson)

\section{1a. Podoschistus vittifrons schlingeri, new subspecies}

Female type: Front wing $13 \mathrm{~mm}$. long.

Black. Palpi, stripe the length of upper margin of pronotum, and tegula, white; frontal orbit with a faint stramineous stripe; coxae and front and middle trochanters fulvous; front and middle femora fulvous, a little paler in front, infuscate at apex above; front and middle tibiae light brown, infuscate dorsally; tarsi fuscous, the hind tarsus darkest: hind trochanters blackish, fulvous below; hind femur fulvous, infuscate above, especially at base and apex; hind tibia fuscous, its base a very little paler; hind margin of third and following tergites white, the white interrupted sublaterally.

Type: $\odot$, Mantua, Box Elder Co., Utah, June 19, 1952, E. I. Schlinger (Davis).

We have a male from Estes Park, Colo., collected June 15, 1948, by H., M., G., D., and J. Townes (Townes) which may be the male of this subspecies or an intermediate. It is like the male of the subspecies vittifrons except that the collar is only faintly marked with whitish, and that the front and middle coxae and trochanters are mostly fulvous.
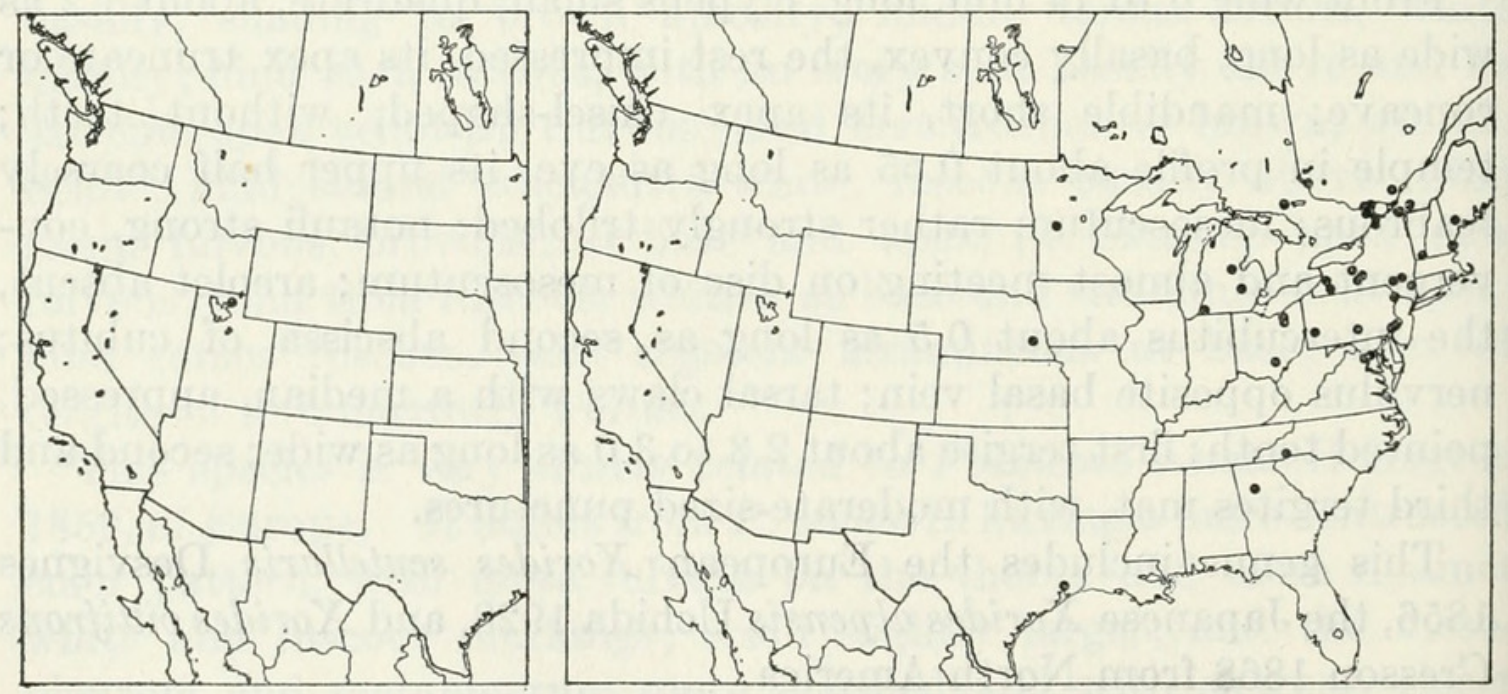

Figures 170, 171.-Localities: 170 (left), Podoschistus vittifrons schlingeri; 171 (right), P.v. vittifrons. 


\section{1b. Podoschistus vittifrons vittifrons (Cresson)}

Xorides vittifrons Cresson, 1868, Canadian Ent., vol. 1, p. 37;. Type: $q$, London, Ont. (Philadelphia).

Black. Frontal orbit, face of male, more or less of face of female, palpi, collar (entirely or with a median interruption), stripe on lower front margin of pronotum of male, stripe the length of upper margin of pronotum, tegula, sometimes a spot on subtegular ridge, upper part of mesepimeron, apical half of scutellum, postscutellum, front and middle coxae and trochanters of male, and narrow apical band on tergites, white; front and middle coxae and trochanters of female fulvous, the coxae white basally on the outer side and the trochanters often partly whitish; hind coxa fulvous with an elongate, dorsobasal whitish spot; front and middle femora fulvous, white at apex and whitish in front; front and middle tibiae brownish, whitish at base, apex, in front, and behind, more extensively so in male; tarsi fuscous, the hind tarsus darkest; hind first trochanter fulvous below, the rest infuscate; hind second trochanter of male mostly white, of female white behind, brown above, and the rest fulvous; hind femur fulvous, infuscate at base and apex; hind tibia fuscous, its base white.

Specimens $\left(27 \sigma^{7}, 50\right.$ o $)$ : From Georgia (Atlanta); Maine (Monmouth); Maryland (Takoma Park); Michigan (George Reserve in Livingston Co., Midland Co., and Warren Woods in Berrien Co.); Minnesota (Alexandria); Nebraska (Lincoln); New Hampshire (Hampton); New York (Cattaraugus Co., Colden, Downsville, Greene Co. at 2,500 ft., Ithaca, McLean Bogs Reserve in Tompkins Co., Poughkeepsie, Stanley, and Waddington); North Carolina (Tryon); Ohio (Akron, Brecksville, and Hocking Co.); Ontario (Blackburn, Cornwall, Ottawa, and Sudbury); Pennsylvania (Carlisle, Overbrook, Pike Co., Pittsburgh, and Roxborough); Quebec (Brome, Covey Hill, Hemmingford, Hull, Joliette, and Laniel); Texas (Liberty); Vermont (Laurel Lake near Jacksonville); and Virginia (Rosslyn).

Dates on pin labels are mostly from late spring to early fall. The following are the earliest and latest dates: May 22 at Blackburn, Ont.; May 28 at Ithaca, N. Y.; June 3 in Livingston Co., Mich.; September 4 at Pittsburgh, Pa.; September 8 at Overbrook, Pa.; and November 20 at Liberty, Tex., this one a reared specimen.

Specimens with biological data on the pin labels are: $\circ$, ovipositing into Acer, Ottawa, Ont., June 16; $\odot$, reared from buprestid in decayed Quercus, Liberty, Tex., Nov. 20, 1918; and specimens labeled Castanea dentata, Ulmus americana, and Acer, meaning probably that they were reared from, or taken resting on these kinds of trees.

This subspecies occurs in the Alleghanian and Carolinian faunas. It parasitizes borers in various hardwoods. 


\section{Genus Neoxorides}

Figure 302,a

Neoxorides Clément, 1938, Festschrift zum 60. Geburtstage von Professor Dr.

Embrik Strand, vol. 4, p. 517. Type: Xorides nitens Gravenhorst; original designation.

Front wing 7 to $14 \mathrm{~mm}$. long; clypeus small, quadrate, about 1.5 as wide as long, convex basally, the rest impressed, its apical margin subtruncate; mandible short, its apex chisel shaped, without teeth; temple in profile about 0.6 as long as eye, its upper half coarsely scabrous; mesoscutum strongly trilobed; notauli strong, approximate on disc of mesoscutum; areolet absent, the intercubitus about 0.4 as long as second abscissa of cubitus; nervulus opposite basal vein; tarsal claws simple, moderately curved; first tergite about 2.0 to 3.0 as long as wide; second and third tergites subpolished, mat, microscopically transversely aciculate, with fine punctures, weak punctures, or often not distinctly punctate.

We have seen six species of this genus: The European Xorides nitens Gravenhorst 1829, the Palaearctic Xorides collaris Gravenhorst 1829, the Japanese Xorides matsuyamensis Uchida 1928, and the three Nearctic species described below.

\section{Key to the Nearctic species of Neoxorides}

1. Mesopleurum with a broad white longitudinal stripe in its lower half; mesoscutum with two pairs of longitudinal white dashes; mesopleurum and metapleurum punctate and subpolished . . . . . 3. caryae (Harrington)

Mesopleurum entirely black; mesoscutum entirely black . . . . . . . . 2

2. Second to fourth sterna of male with four longitudinal sclerites that are separated by narrow membranous joints; second and third tergites of female with hairs moderately dense, separated by about 0.8 their length; mesopleurum and metapleurum mat, not distinctly punctate . . 1. pilulus, new species Second to fourth sterna of male with a single large sclerite; second and third tergites of female with hairs very sparse, separated by about 2 to 3 times their length; mesopleurum and metapleurum weakly mat, with distinct punctures . . . . . . . . . . . 2. borealis (Cresson)

\section{Neoxorides pilulus, new species}

Front wing 4.4 to $9.5 \mathrm{~mm}$. long; head more spherical than usual for the genus; mesopleurum and metapleurum mat, their punctures fine, weak, and inconspicuous; first tergite of male about 2.2 as long as wide, of female about 1.65 as long as wide; second and third tergites mat, usually with weak, rather dense punctures; hairs on tergites moderately dense, separated by about 0.8 their lengths; last tergite of female moderately long; second through fourth sterna of male with four longitudinal sclerites; ovipositor sheath about 0.67 as long as front wing. 
FIGURE 172.-Localities for Neoxorides pilulus.

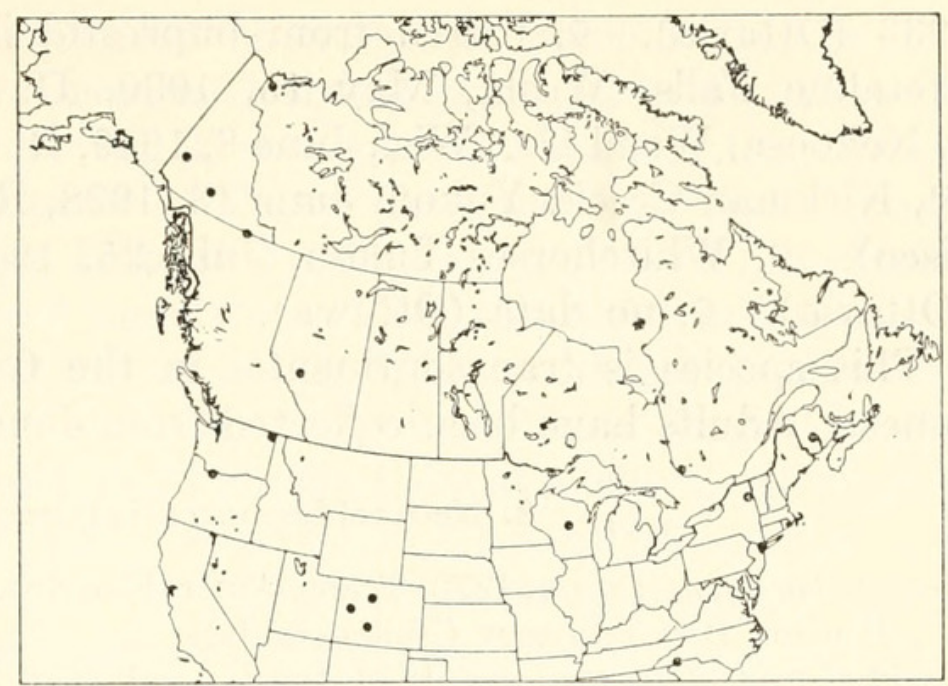

Black or blackish brown. Frontal orbit, face of male, triangular orbital mark on face of female above and often also below, often whitish blotches on face of female and entire facial orbit of female, palpi of male, front of scape of male, lower part of propleurum of male, broad stripe on lower edge of pronotum, and tegula, white, the tegula sometimes brownish apically; palpi of female whitish to light brown; front of scape of female and upper part of mesepimeron fulvous or brown; much of metapleurum often ferruginous and sometimes part of lower part of mesopleurum also ferruginous; legs colored as in $N$. occidentalis except that the front and middle coxae, trochanters, femora, and tibiae, and the hind second trochanter tend to be a little more extensively white, especially in the male.

Type: ㅇ, reared from Castanea dentata, Tryon, N. C., W. F. Fiske (Washington, USNM 63747).

Paratypes: 2ᄋ, Nordegg, Alta., July 25 and 30, 1921, J. McDunnough (Ottawa). ९, Lower Post, B. C., June 20, 1948, W. R. M. Mason (Ottawa). $\odot$, Boulder Co. at 9,500 ft., Colo., June 18 to July 19, 1933, J. C. Jones (St. Paul). \&, reared from "P. engelmanni," New Castle, Colo., July to August, 1944, C. L. Massey (Washington). , Waldo Canyon, Colo., July 7, 1916, W. D. Edmonston (Washington). \&, Colorado (Washington). o, Poplar Lake, Cook Co., Minn., July 14, 1929, L. W. Orr (St. Paul). क, Fredericton, N. B., June 22, 1933, C. E. Atwood (Ottawa). o, Palisades, N. J., June 28, E. G. Love (Washington). †, reared from Castanea dentata, Tryon, N. C., W. F. Fiske (Washington). \&, Mount Marcy, N. Y., June 19, J. N. Belkin (Townes). $\sigma^{x}$, + , Reindeer Depot, Mackenzie Delta, N. W. T., July 4 and 9, 1948, J. R. Vockeroth (Ottawa). , Mount Hood, 3,000 to 6,000 ft., Oreg., June 22, 1925, E. C. Van Dyke (Townes). , reared from Abies concolor, Pinehurst, Oreg., F. P. Keen (Washington). 2o, Laniel, Que., June 7, 1934 and Aug. 14, 
1933 (Ottawa). \%, reared from buprestid in Pseudotsuga taxifolia, Metaline Falls, Wash., May 15, 1930, D. DeLeon (Washington). ㅇ, Nekoosa, Wood Co., Wis., June 8, 1949, R. D. Shenefelt (Madison). $\sigma^{7}$, Kirkman Creek, Yukon, June 13, 1928, R. E. Barrett (San Francisco). ㅇ, Whitehorse, Yukon, July 25, 1948, Mason and Hughes (Ottawa). \%, no data (Ottawa).

This species is transcontinental in the Canadian and Transition zones. Adults have been collected from June 13 to August 14.

\section{Neoxorides borealis (Cresson)}

Xorides borealis Cresson, 1870, Trans. Amer. Ent. Soc. vol. 3, p. 167; 9 Type: Hudson Bay Territory (Philadelphia).

Xorides occidentalis Cresson, 1878, Proc. Acad. Nat. Sci. Philadelphia, vol. 1878, p. 380 ; 9 . Type: $\uparrow$, Vancouver Island, B. C. (Philadelphia).

Front wing 8 to $15.5 \mathrm{~mm}$. long; mesopleurum and metapleurum weakly mat and with rather close, weak, moderate-sized punctures; first tergite of male about 2.4 as long as wide, of female about 1.85 as long as wide; second and third tergites of male subpolished and finely punctate, of female very finely transversely rugulose; hairs on tergites of female sparse, usually separated by 2 to 3 times their length; second through fourth sterna of male with a single large sclerite; last tergite of female elongate; ovipositor sheath about 1.4 as long as front wing.

Black. Inner front margin of eye, front of scape of male, entire face of male, palpi, sometimes lower part of propleurum of male, broad stripe on lower edge of pronotum, upper part of mesepimeron, and tegula, white, the apex of tegula often brown; face of female with dim whitish blotches subdorsally; front and middle coxae, trochanters, and femora fulvous, the front coxa in front, front trochanters, second trochanter of middle leg, and femora apically in front, whitish in male, pale fulvous in female; front of scape of female and subtegular ridge sometimes fulvous; front and middle tibiae pale whitish in front in male, pale fulvous in front in female, the rest brownish, usually with a short basal whitish stripe above; front and middle tarsi brownish, the middle tarsus darker; hind coxa and trochanters fulvous, the second trochanter more or less paler below and darker above and apically; hind femur fulvous with its base and apex narrowly brownish, to mostly brownish but paler subbasally; hind tibia and tarsus fuscous, the base of tibia more or less whitish or stramineous, especially in females.

This species is very close to the European $N$. collaris and may prove to be a subspecies of it.

Specimens $\left(32 \sigma^{x}, 51\right.$ \%): From Arizona (near Alpine and Workman Creek in the Sierra Ancha); British Columbia (Aspen Grove, Cultus 
Lake, Diamond Head Trail near Squamish at 3,300 ft., Gabriola Island, Lake Errock near Deroche, Robson, Seton Lake at Lillooet, and Wellington); California (Big Tree Grove in Mariposa Co., Echo Lake at 7,400 ft., Giant Forest in Tulare Co., near Glacier Point in Yosemite Park, Huntington Lake in Fresno Co. at 7,000 ft., Kyburz Sta., and Meadow Valley in Plumas Co. at 3,500 to 4,000 ft.); Colorado (near Estes Park); "Hudson Bay Territory"; Idaho (Boise); Manitoba (Aweme); Montana (Columbia Falls); Oregon (Ashland, Eagle Creek, Forest Grove, Klamath Falls, and Pamelia Lake at 3,000 ft. on Mount Jefferson); Utah (Kamas); and Washington (Elbe and Hoquiam).

Dates of collections are mostly during the summer months. The earliest and latest dates are: May 6 at Workman Creek, Sierra Ancha, Ariz.; May 20 and 26 at Aspen Grove, B. C.; May 29 near Alpine, Ariz.; August 19 on Diamond Head Trail near Squamish, B. C., at Robson, B. C., and at Wellington, B. C.; September 16 on Gabriola Island, B. C.; September 24 at Forest Grove, Oreg.; and November 16 at Klamath Falls, Oreg.
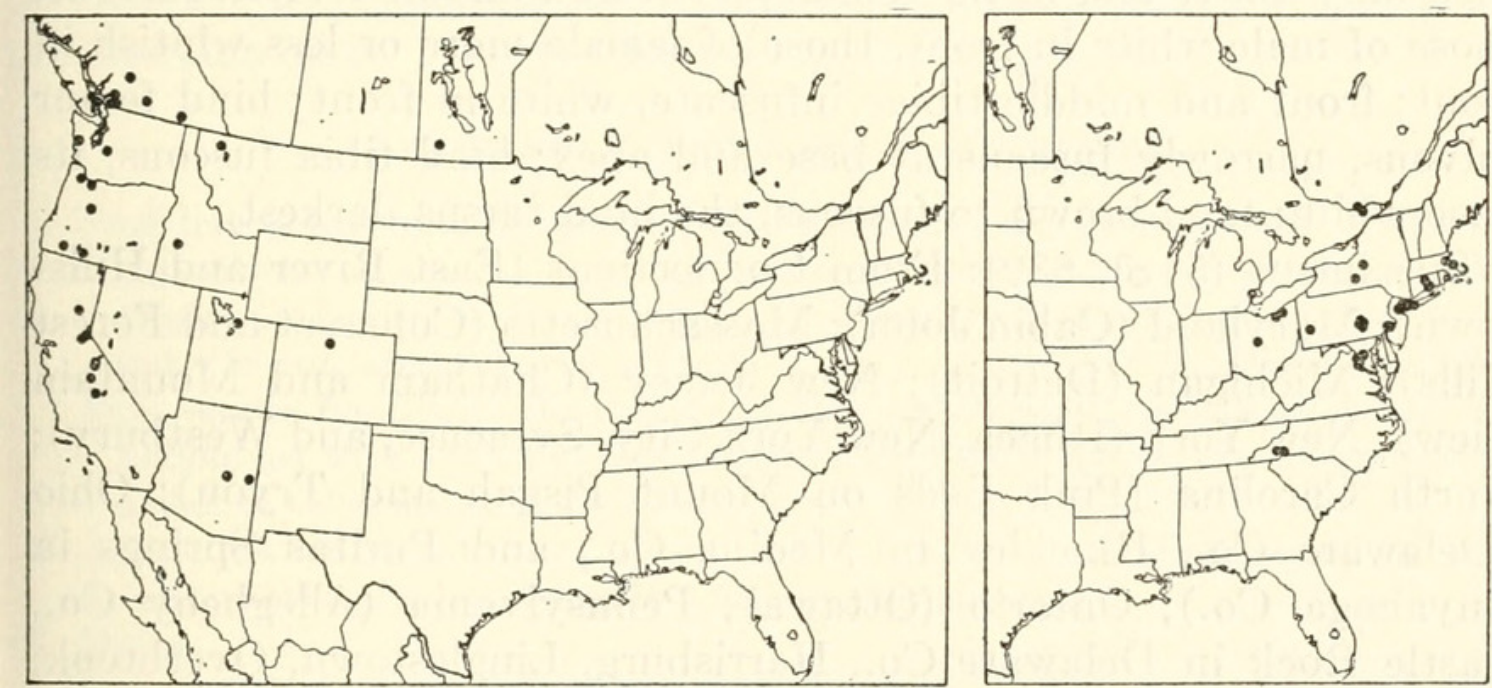

Figures 173, 174.-Localities: 173 (left), Neoxorides borealis; 174 (right), $N$. caryae.

Rearing records are as follows: 1 rearing from Melanophila drummondi in Pseudotsuga taxifolia, 1 from a buprestid gallery in Pseudotsuga taxifolia, 1 from Laspeyresia toreuta, 1 from Abies lasiocarpa, 1 from Juniperus scopulorum, 1 from Larix, 1 from Libocedrus decurrens, 1 from Picea, 1 from Pinus ponderosa, 1 from P. scopulorum, 1 from Pseudotsuga menziesii, and 4 from P. taxifolia.

This species occurs in the western half of the continent, in the Canadian and Transition zones. It parasitizes borers in various conifers. 


\section{Neoxorides caryae (Harrington)}

Xorides caryae Harrington, 1891, Canadian Ent., vol. 23, p. 132; $\sigma^{7}$, ᄋ. Types: $2 \sigma^{7}, 4$ ㅇ, ?Ottawa, Ont. (Ottawa).

Bıology: Blackman and Stage, 1924, Techn. Publ. New York State Coll. Forestry, Syracuse Univ., vol. 17, p. 182.

Front wing 7 to $13 \mathrm{~mm}$. long; mesopleurum and metapleurum punctate and subpolished; ovipositor sheath about 0.8 as long as front wing. Otherwise structurally similar to $N$. borealis.

Black. Inner front margin of eye, entire face of male, palpi, most of propleurum of male, broad stripe on lower edge of pronotum, extreme hind corner of pronotum, longitudinal stripe on side of middle lobe of mesoscutum, longer and narrower longitudinal stripe on mesal side of lateral lobe of mesoscutum, apical half of scutellum, postscutellum, broad stripe along lower edge of mesopleurum, male front coxa except medially, female front coxa externally, middle coxa externally, and narrow short dorsobasal stripe on hind coxa, white; coxae fulvous except as described otherwise; trochanters white in male, white to pale fulvous in female, the first trochanters darker, especially above and in the female; front and middle femora fulvous, those of male white in front, those of female more or less whitish in front; front and middle tibiae infuscate, white in front; hind femur fulvous, narrowly fuscous at base and apex; hind tibia fuscous, its base white; tarsi brown to fuscous, the hind tarsus darkest.

Specimens $\left(54 \sigma^{x}, 63 \%\right)$ : From Connecticut (East River and Hillstown); Maryland (Cabin John); Massachusetts (Cohasset and Forest Hills); Michigan (Detroit); New Jersey (Chatham and Mountain View); New York (Ithaca, New York City, Syracuse, and Westbury); North Carolina (Pink Beds on Mount Pisgah and Tryon); Ohio (Delaware Co., Hinckley in Medina Co., and Puritas Springs in Cuyahoga Co.); Ontario (Ottawa); Pennsylvania (Allegheny Co., Castle Rock in Delaware Co., Harrisburg, Linglestown, Overbrook, Shiremanstown, and Stoverdale); Quebec (Hull); and Virginia (Falls Church and Veitch in Arlington Co.).

Collected specimens have been taken only during the summer months, except for one collection on May 31 at Ithaca, N. Y. Reared specimens, mostly from central Pennsylvania, extend the dates for adult specimens from May 2 to September 17.

Biological data on pin labels are as follows: specimens from 9 different localities are labeled "Carya"; 1 specimen is labeled as reared from a cocoon found under bark of Carya, 1 specimen is labeled "Carya glabra," 1 labeled "Castanea dentata," and 1 labeled as reared from Saperda discoidea at Harrisburg, Pa., by W. S. Fisher.

This species occurs in the Alleghanian and Carolinian faunas. It parasitizes coleopterous borers in hardwoods, particularly in Carya. Adults occur from mid-spring to early fall. 


\section{Tribe Rhyssini}

Figures 302,b-304,a

Front wing 6 to $30 \mathrm{~mm}$. long; clypeus small, subrectangular, with a median apical tubercle and/or lateral apical tubercles; mesoscutum covered with sharp, irregular, transverse wrinkles, in profile usually flat above and abruptly declivous at front end, its notauli usually long; prepectal carina present except sometimes in Epirhyssa; mesopleural suture straight or almost straight; propodeum without carinae; last segment of tarsus not enlarged; tarsal claws simple, without an enlarged hair with a flattened tip; areolet present or absent; nervellus broken above the middle; first tergite free from its sternite or fused with it, without a distinct lateral longitudinal carina; male subgenital plate transverse, its apical margin retuse or sometimes truncate; apex of last tergite of female prolonged, ending in a short polished horn that is truncate at the end or in a polished marginal boss; ovipositor moderately long to very long, compressed.

The Rhyssini are almost worldwide in distribution. Many of the species are large and spectacular, and are among the best known of all ichneumonids. Our species belong to four genera.

\section{Key to the Nearctic genera of Rhyssini}

1. First tergite free from its sternite, with a glymma; second trochanter of middle leg without a ventral longitudinal ridge; sternites 3 to 6 of female with a pair of tubercles near their midlength; clypeus with a median apical tubercle but without lateral apical tubercles . . . . . . . 1. Rhyssa (p.396)

First tergite fused with its sternite, without a glymma; second trochanter of middle leg with a ventral longitudinal ridge; sternites 3 to 6 of female with a pair of tubercles near their base . . . . . . . . . . . . . . . 2

2. Areolet always absent . . . . . . . . . . 3. Epirhyssa (p.413) Areolet present, rarely absent in abnormal specimens . . . . . . . . . . 3

3. Males. . . . . . . . . . . . . . . . . . . . . 4

Females. . . . . . . . . . . . . . . . . . . . . 5

4. Clasper without a groove paralleling its lower inner edge, nor with a longitudinal groove apicolaterally; tergites 3 to 6 moderately concave apically, without a median longitudinal submembranous area. (See the note on dwarf males of Megarhyssa in the second half of the couplet.) . . . 2. Rhyssella (p.409)

Clasper with a strong setiferous groove close to and paralleling the apical $0.7 \pm$ of its lower inner edge, and with a short, longitudinal setiferous groove apicolaterally; tergites 3 to 6 of male strongly concave apically and with a median apical or subapical longitudinal submembranous area. Note: These generic characters hold for normal males, but dwarf males do not have them developed and will key to the genus Rhyssella . 4. Megarhyssa (p.415)

5 . Tergites 3 to 5 covered with transverse aciculation except laterally.

2. Rhyssella (p.409)

Tergites 3 to 5 entirely or largely without transverse aciculation.

4. Megarhyssa (p.415) 


\section{Genus Rhyssa}

Figure $302, \mathrm{~b}$

Rhyssa Gravenhorst, 1829, Ichneumologia europaea, vol. 3, p. 260. Type: Ichneumon persuasorius Linnaeus; designated by Westwood, 1839.

Cryptocentrum Kirby, 1837, in Richardson, Fauna boreali americana, pt. 4, p. 260.

Type: Cryptocentrum lineolatum Kirby; monobasic.

Pararhyssa Walsh, 1873, Trans. Acad. Sci. St. Louis, vol. 3, p. 109. Type:

Ichneumon persuasorius Linnaeus; designated by Viereck, 1914.

Front wing 6 to $24 \mathrm{~mm}$. long; clypeus with a median apical tubercle but without lateral apical tubercles; junction of occipital and hypostomal carinae distant from base of mandible by about 0.4 the basal width of mandible; mandibular teeth of equal length, the lower tooth pointed at apex, the upper tooth chisel-shaped; second trochanter of middle leg without a ventral longitudinal ridge; stigma about 6.5 as long as wide; areolet present, sometimes absent in small males; first tergite free from its sternite, with a distinct glymma; tergites 3 to 6 of male cylindric or weakly compressed, with a transverse mat sculpture, with moderately dense hairs, their apical margins very weakly concave medially; tergites 3 to 6 of female with a transverse mat or finely aciculate sculpture, with sparse short hairs; sternites 3 to 6 of female with a pair of tubercles near their midlength; apical tergite of female with a median apical horny point whose apex is truncate; male clasper short, evenly convex and rather densely hairy, its apex broadly rounded and with a broad shallow notch.

This genus is Holarctic. All species seem to be parasitic on borers in conifers, particularly in the northern conifers. They are common in our Canadian zone. Except for $R$. hoferi, which has a reddish brown color, the species are mostly black with numerous large white spots. Certain details in the white spotting are useful for distinguishing species.

\section{Key to the Nearctic species of Rhyssa}

1. First four tergites with a narrow whitish apical margin, the margin of even width and continuous across the middle or a little narrower and sometimes a little interrupted medially (figs. $317, \mathrm{a}, \mathrm{b}$ ); third tergite of both sexes with short hairs that are moderately dense and evenly distributed. Hoferi GROUP . . . . . . . . . . . . . . . . . . . . 2

First four tergites with white apical spots that do not form a continuous band from one side to the other (figs. 317,c-g); second and third tergites with short hairs that are sparse to moderately dense in male, sparse and usually irregularly distributed in female . . . . . . . . . . . . . . . . . . 3

2. Body ground color black; fore wing hyaline, not marked.

1. howdenorum, new species

Body ground color rufous; fore wing marked with rufous brown (fig. 319,a).

2. hoferi Rohwer 
3. Second through fourth sterna of male a single, convex, undivided sclerite; second through fourth sterna of female with an apical membranous area extending forward between the paired sternites for about 0.25 their length; face more sparsely hairy medially than laterally; apical margin of male subgenital plate broadly concave; flagellum without a white band; temporal orbit partly or entirely white. Persuasoria group . 7. persuasoria (Linnaeus)

Second through fourth sterna of male each with 3 longitudinal sclerites (a broader median sclerite, a pair of narrower lateral sclerites); second through fourth sterna of female with an apical membranous area extending forward between the paired sternites for about 0.35 the length of the sternites; face more densely hairy medially than laterally; apical margin of male subgenital plate convex, subtruncate, or with a broad weak median notch; flagellum with or without a white band; temporal orbit black or partly or entirely white. Amorna group. . . . . . . . . . . . . . . . . . . . . . 4

4. Flagellum entirely black; range: western North America . . . . . . . . 5

Flagellum with a white band except in occasional small males (with front wing less than $8.5 \mathrm{~mm}$. long) . . . . . . . . . . . . . . . . . . . 6

5. Temple with a sharp narrow white stripe next to eye (fig. 317 ,c); face of male black medially, white next to eyes; apex of male subgenital plate with a broad median notch . . . . . . . . 3. ponderosae, new species

Temple entirely black or blackish brown, or rarely with a poorly defined whitish blotch; face of male entirely white; apex of male subgenital plate truncate . . . . . . . . . . . . . . . . 4. alaskensis Ashmead

6. Hind coxa without a white mark dorsobasally, or sometimes with a small white mark restricted to its constricted base; white mark on metapleurum prolonged forward along upper margin of metapleurum (fig. 317,e), thus having a subtriangular shape (this mark absent or very much reduced in some males); paramedial white spots of female fourth and fifth tergites about 2.0 as wide as high . . . . . . . . . . . 5. crevieri (Provancher)

Hind coxa with a white mark dorsobasally, usually in the form of a small dash but in larger females often enlarged and irregular in shape or covering the entire upper face of the coxa; white mark on metapleurum constricted next to upper margin of metapleurum (fig. $317, \mathrm{f}$ ), thus having a somewhat rounded shape (this mark absent or very much reduced in some males); paramedial spots of female fourth and fifth tergites about 1.5 as wide as high.

6. lineolata (Kirby)

\section{HOFERI GROUP}

Face with sparse hairs all over except along the midline, where they are very sparse or absent; lateral portion of prepectal carina short, weak; first tergite 1.2 to 2.0 as long as wide; second through sixth tergites mat, with dense, fine, weak punctures; third tergite of both sexes with dense short hairs the sockets of which are separated by about length of the hairs; second through fourth sterna of male each with three longitudinal sternites (a wide median sternite and a pair of narrow lateral sternites); apical membranous area of female second through fourth sterna not appreciably extended forward medially between the paired sternites; apical margin of male subgenital plate weakly sinuous. 
Flagellum uniformly colored or with a broad pale subapical band; temporal orbit white or pale yellow; second through fourth tergites with a narrow, whitish, complete or subcomplete apical margin; seventh tergite of female fulvous, or black with an apical band that is of rather uniform width except for a median interruption (figs. $317, a, b$ ).

This group includes two Nearctic species, one from the southern Rocky Mountains and the other from the Carolinian fauna.

\section{Rhyssa howdenorum, new species}

Figure 317 ,a

Front wing of male about $11 \mathrm{~mm}$. long, of female 10 to $13 \mathrm{~mm}$. long; hairs on second tergite rather sparse, their sockets separated by about twice the length of the hairs.

Black. Face (except in female for a broad, black, vertical stripe under each antenna), orbits (interrupted at top and at bottom of eye), clypeus, palpi, median, anteroventral, and dorsal parts of pronotal margin, tegula, subtegular ridge, usually a small spot on mesepisternum next middle coxa, mesepimeron, often postscutellum and apex of scutellum, often a small spot in upper hind corner of metapleurum, lateroapical spot on propodeum, and narrow apical band on first to seventh tergites, ivory, the apical bands on tergites curved forward on sides to an increasing degree toward hind segments and sublaterally with a more or less distinct brown area that sometimes interrupts the bands; apical ivory band on seventh tergite of female of uniform width except for a median interruption; eighth tergite of female margined with ivory except medially; mesosternum, usually metasternum, usually lower $0.6 \pm$ of mesepisternum, usually metapleurum, and legs fulvous, the tibiae paler at base, the hind tibia infuscate except at base, and the hind tarsus fuscous, its first segment paler at base; wings hyaline, faintly infuscate around apex of radial vein.

The name of the species is for Henry and Anne Howden, two indefatigable entomologists who collected one of the paratypes.

Type: ㅇ, reared from Pinus virginiana, Minora Hill, Falls Church, Va., May 10, 1913, Wm. Middleton (Washington, USNM 63718).

Paratypes: 9 , Halsey, Nebr., July 31, 1957, R. Henzlik (Washington). $९$, Raleigh, N. C., Apr. 29, 1938 (N. C. State College at Raleigh). $\sigma^{7}$, Raleigh, N. C., June 5, 1953, H. and A. Howden (Townes). ㅇ, Wake Co., N. C., May 10, 1950, H. Townes (Townes). $\sigma^{x}$, reared from Pinus, Minora Hill, Falls Church, Va., Apr. 22, 1913, Wm. Middleton (Washington).

The species is known from the Carolinian fauna of Virginia, North Carolina, and Nebraska. 

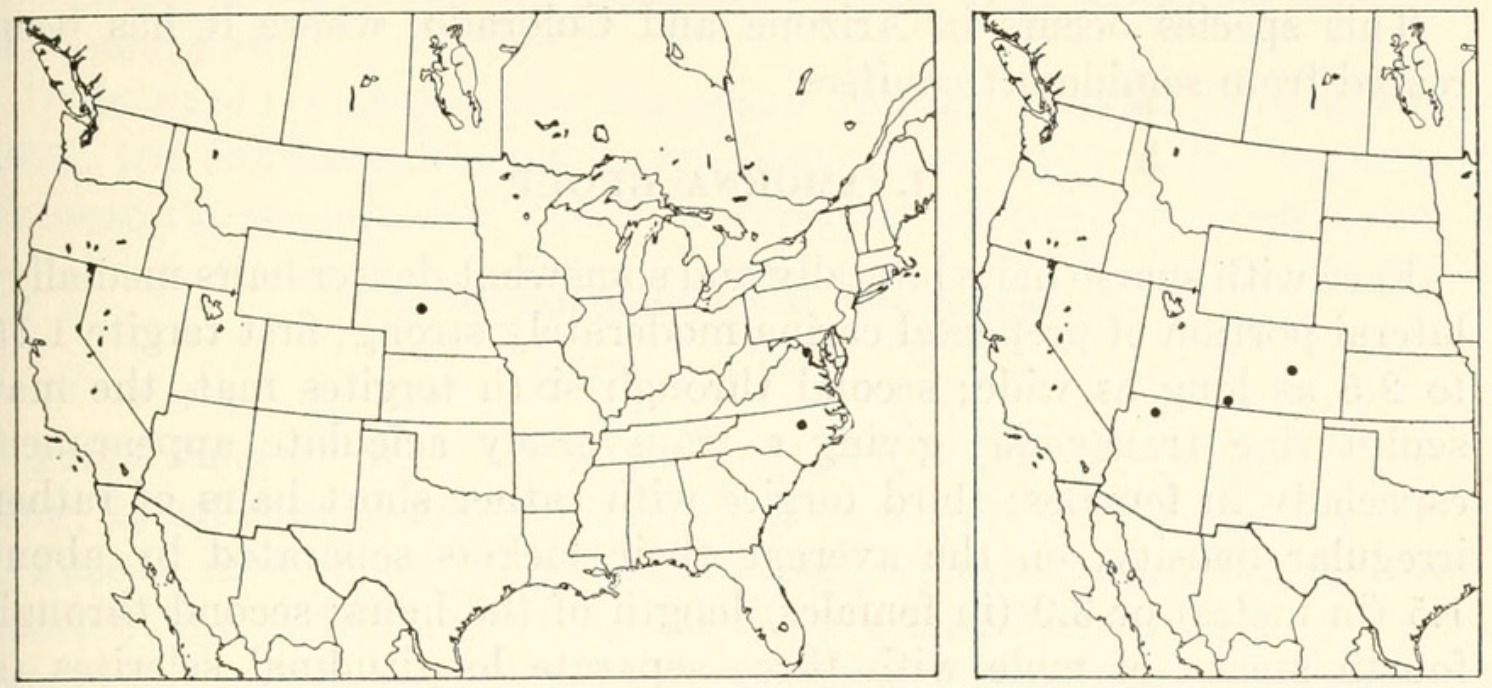

Figures 175, 176.-Localities: 175 (left), Rhyssa howdenorum; 176 (right), $R$. hoferi.

\section{Rhyssa hoferi Rohwer}

Figures $317, \mathrm{~b} ; 319$,a

Rhyssa hoferi Rohwer, 1920, Proc. U.S. Nat. Mus., vol. 57, p. 421; $९$. Type: \& , Garden of the Gods, Colo. (Washington).

Front wing of male $11.5 \mathrm{~mm}$. long, of female 12 to $19 \mathrm{~mm}$. long; hairs on second tergite moderately dense, their sockets separated by about the length of the hairs.

Rufous. Face, orbit (interrupted at top and bottom of eye), clypeus, anteroventral and dorsal edges of pronotum, tegula, subtegular ridge, scutellum except basally, postscutellum, front tibia, basal half and front side of middle tibia, basal 0.4 of hind tibia of male, and narrow apical band on basal four or five tergites, pale yellow; flagellum with a broad subapical yellowish band in female (flagellum broken in the male specimen at hand); thoracic sutures, bases of coxae, and a basal band on the first four to six tergites, brown; wings faintly tinged with brown, the front wing with its anterior $0.65 \pm$ light brown with a paler area in the radial cell and another in basal half of discocubital cell.

This is the only Rhyssa with a rufous ground color, or with definite markings on the wings.

Specimens: $\sigma^{7}$, Grand Canyon, Ariz., June (Washington). $\sigma^{7}$, Grand Canyon, Ariz., June 15, 1953, A. and H. Dietrich (Ithaca). 2o, (type and paratype) ovipositing in Pinus edulis infested with Buprestidae, Garden of the Gods, Colo., June 23, 1915, Geo. Hofer (Washington). \&, Garden of the Gods, Colo., June 15, Geo. Hofer (Townes). ९, ovipositing in Juniperus, Mesa Verde, Colo., Aug. 2, 1927, J. M. M. (Berkeley). 
This species occurs in Arizona and Colorado, where it has been reared from semidesert conifers.

\section{AMOENA GROUP}

Face with sparse hairs laterally and somewhat denser hairs medially; lateral portion of prepectal carina moderately strong; first tergite 1.15 to 2.5 as long as wide; second through sixth tergites mat, the mat sculpturing transverse, giving a transversely aciculate appearance, especially in females; third tergite with rather short hairs of rather irregular density, on the average their sockets separated by about 1.5 (in males) or 3.0 (in females) length of the hairs; second through fourth sterna of male with three separate longitudinal sclerites (a median wider sclerite and two narrower lateral ones); apical membranous area of female second through fourth sterna extending forward between paired sternites or about 0.35 length of the sternites; apical margin of male subgenital plate convex, subtruncate, or with a broad weak median notch.

There is a strong tendency in this species group and in the PERSUASORIA group for the coloration to vary with size. Larger specimens tend to have the white markings more extensive than normal and smaller specimens to have not only the white markings reduced in size but the fulvous of the legs replaced by fuscous. These same correlations of color with size occur in a great many Hymenoptera, but in such species as Rhyssa lineolata the unusually extensive white markings of larger females is so striking that the specimens appear to belong to a separate species.

The general coloration is black with white markings distributed about as described for $R$. persuasoria, but all species of the present group differ from persuasoria in tending to have a white vertical bar or splotch in the hind part of the mesepisternum, this bar or splotch often broken into two spots, one near the middle coxa and one more dorsad. These two spots may be of about equal size or the more dorsad one larger and more persistent. In persuasoria the mesepisternum has a large white spot next to the middle coxa, and other white areas which may be present are smaller and less persistent. In both groups of species there is constantly a white spot on the subtegular ridge. An additional difference between this group and persuasoria is that in persuasoria the seventh tergite of the female has two large spots on each side (a long one in front and a shorter one behind), which are sometimes more or less fused. In the AMOENA group there is a long broad band in this position, which is of even width or weakly lobed (figs. $317, \mathrm{c}-\mathrm{f}$ ). The individual species of the AMoena group differ in color pattern as described below. Color 
markings not specified for each species are in general like those of $R$. persuasoria.

This group includes the European Rhyssa amoena Gravenhorst 1829, the Japanese Rhyssa jozana Matsumura 1912, some unnamed Palaearctic species, and the four Nearctic species described below.

\section{Rhyssa ponderosae, new species}

FIgURE $317, \mathrm{c}$

Front wing of male 7.5 to $9.5 \mathrm{~mm}$. long, of female 13 to $19 \mathrm{~mm}$. long; apical edge of male subgenital plate with a broad median notch.

Face of male black, white next to eyes; temporal orbit white on its lower $0.65 \pm$; flagellum without a white band; thorax entirely black except for anteroventral and upper margins of pronotum, spot on subtegular ridge, and postscutellum, which are white; front and middle coxae blackish, the front coxa with a white spot on outer side, in male sometimes mostly pale or whitish; middle coxa of male more or less white on outer side; hind coxa entirely black; femora fulvous, the hind femur of male sometimes weakly infuscate; abdominal white markings reduced in size, the paramedial white spots on fourth and fifth tergites of female about 1.5 as wide as long.

Type: 으, on Pinus ponderosa, Bass Lake, Calif., 1937, G. R. Struble (Washington, USNM 63719).

Paratypes: $3 \sigma^{x}$, on Pinus ponderosa, Bass Lake, Calif., 1937, G. R. Struble (Washington and Townes). $\sigma^{\pi}$, parasite of Sirex areolatus, Berkeley, Calif. (Berkeley). ㅇ, Berkeley, Calif., Apr. 14, 1926 (Berkeley). 4ㅇ, Berkeley, Calif., Apr. 16, 1926 (Berkeley and Townes). ㅇ, Lake Tahoe, Calif., June 21, 1915, Bilsing Coll. (Berkeley). †, Oakland, Calif., Apr. 23, 1950, B. Adelson (Townes). ㅇ, Yosemite, Calif., at 3,800 to 4,000 ft., May 22, 1921, E. O. Essig (Townes).

This species is known only from central California.

\section{Rhyssa alaskensis Ashmead}

Figure 317 ,d

Rhyssa alaskensis Ashmead, 1902, Proc. Washington Acad. Sci., vol. 4, p. 199; $९$.

Type: $\uparrow$, Fox Point, Alaska (Washington).

Rhyssa skinneri Viereck, 1903, Trans. Amer. Ent. Soc., vol. 29, p. 86; $\subsetneq$. Type: , Beulah, N. Mex. (Philadelphia).

Front wing of male 6.5 to $15 \mathrm{~mm}$. long, of female 9 to $22 \mathrm{~mm}$. long; apical edge of male subgenital plate straight.

Face of male entirely white; temple black or blackish brown, sometimes largely pale brown and occasionally with on ill-defined whitish splotch; flagellum without a white band; metapleurum often with a white spot in male, usually with a white spot in female, the spot pro- 

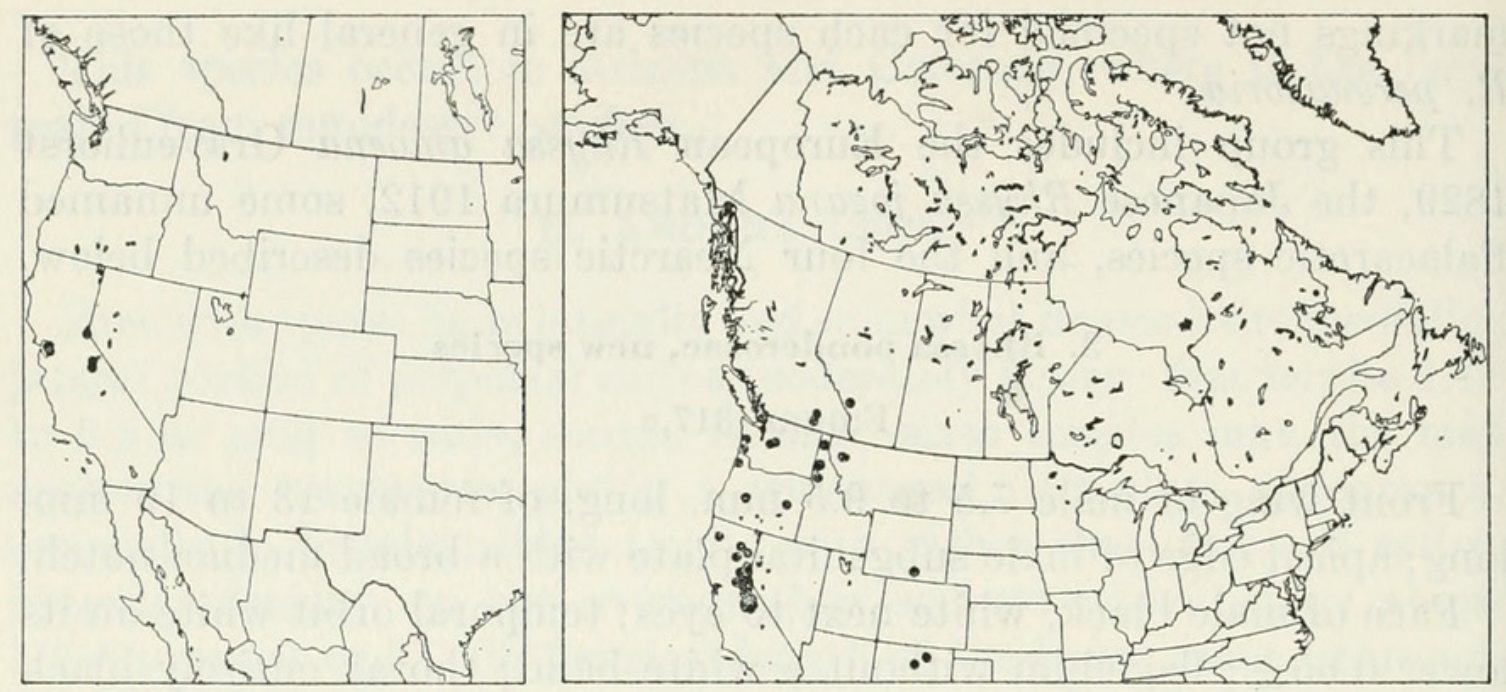

Figures 177, 178.--Localities: 177 (left), Rhyssa ponderosae; 178 (right), $R$. alaskensis.

longed forward on upper edge of metapleurum so that it is subtriangular in shape; front and middle coxae fulvous to blackish brown, white on outer side and in male white also on front side, or almost entirely white; hind coxa fulvous to black, sometimes with a small whitish streak on upper side of its basal constricted part; femora fulvous, the front and middle femora of male whitish in front, the hind femur of male rarely blackish; paramedial white spots on fourth and fifth tergites of female about 1.4 as high as long.

Specimens $\left(91 \sigma^{\top}, 68 \%\right)$ : From Alaska (Fox Point and Skagway); Alberta (Banff Loop at 4,500 ft.); British Columbia (Kaslo, Robson, and Wellington); California (Bridge Canyon Camp in Lassen Co., Buck's Lake in Plumas Co., Camino, Cisco, Coffee Canyon in Trinity Co., Crane Flat in Yosemite Park, Dardanelle, Dodge Ridge Sports Area at Pinecrest in Tuolumne Co., Echo Lake in El Dorado Co., Fallen Leaf Lake at 6,300 ft., near Glacier Point in Yosemite Park, Glen Alpine Creek near Lake Tahoe, Hat Creek, Hope Valley in Alpine Co., Lake Tahoe at 6,225 ft., Leevining, Meyers, Pinecrest, Sagehen near Hobart Mills, Sierraville, Snow Flat in Yosemite Park at 8,700 ft., Snowline Camp in El Dorado Co., near Sonora Pass at 8,500 ft., Tamarack Flat in Yosemite Park, and Tuolumne Meadows in Yosemite Park); Idaho (Cedar Mt. near Moscow, Moscow Mts., Priest Lake, and Waha); Montana (Lake Ronan in Lake Co.); New Mexico (Beulah and Cimarron at 9,500 ft.); Oregon (Cannon Beach, Crescent Lake, and Strawberry Lake in Grant Co. at 6,400 to 6,500 ft.); Washington (Ashford, Hoquiam, Ilwaco, Mount Rainier at 2,900, 4,700, and 5,500 ft., and San Juan Island); and Wyoming (Saratoga).

Collection dates are from late spring to late summer. The earliest and latest are: May 22 and 31 at Wellington, B. C.; May 26 at 
Hoquiam, Wash.; June 3 at Dardanelle, Calif.; August 23 at Cimarron, N. Mex. at 9,500 ft. and at Banff Loop, Alta. at 4,500 ft.; August 24 at Skagway, Alaska; and September 9 at Wellington, B. C.

We have found the species common in various kinds of coniferous woods, and among the above specimens are rearings from Picea sitchensis, Pinus contorta murrayana, and Abies lasiocarpa, but without definite host records.

This species occurs in the West, in coniferous forests from Alaska to New Mexico, in the Hudsonian, Canadian, and Transition zones. Adults occur mostly in the summer months.

\section{Rhyssa crevieri (Provancher)}

Figure 317,e

Epirhyssa Crevieri Provancher, 1880, Naturaliste Canadien, vol. 12, p. 17 (Faune, p. 449); هా. Type: $\sigma^{\top}$, Quebec (Quebec).

Front wing of male 6 to $10.5 \mathrm{~mm}$. long, of female 9 to $17 \mathrm{~mm}$. long; apical edge of subgenital plate of male weakly convex, with a weak median notch. The front wing of the male usually lacks the areolet.

Face of male entirely white; temporal orbit white on its lower $0.8 \pm$, the white never continuous across top of eye; flagellum with a wide white band, or the band restricted in width in smaller males or sometimes absent in very small males; metapleurum with a white spot except in some males, the spot prolonged forward along upper margin of metapleurum so that it is subtriangular in shape; front and middle coxae of male white, of female fulvous to blackish brown, mostly white on outer side; hind coxa fulvous to blackish, sometimes with a white mark on upper side of its constricted basal part, which rarely may be prolonged on upper side of the main body of coxa as a narrow streak; femora fulvous with the apex infuscate, often entirely infuscate in males and occasionally entirely infuscate in females; paramedial white spots on fourth and fifth tergites of female about 2.0 as high as long.

We have not been able to study the type of crevieri since 1941, and at that time we had no clear distinction between this species and lineolata. But on the basis of recent notes on the type supplied to us by Gerd Heinrich, it seems very likely that crevieri is the present species.

Specimens $\left(9 \sigma^{7}, 42\right.$ ) : From Maine (Bangor, Camp Kennedy on Mount Katahdin at 3,000 ft., Machias, and Mount Desert Island); Michigan (Detroit, Douglas Lake, and Isle Royale); Minnesota (Basswood Lake in Lake Co., Itasca Park, and Lake Itasca); New Brunswick (Bathurst and Fundy National Park); New Hampshire ("Gale River" and Mount Madison); New Jersey (Atsion); New York (Boreas River in Essex Co., Catskill Mts., Ithaca, Keene Valley 
in Essex Co., and Mount MacIntyre); North Carolina (Clingmans Dome and Mount Mitchell at 6,800 ft.); Nova Scotia (Baddeck on Cape Breton Island); Ontario (Timagami Forest Reserve); and Quebec (Aylmer, Joliette, Montreal, Quebec, and Stoneham).

Collection dates are all in the summer months, with 16 out of a total of 26 in June. The earliest and latest dates are: June 4 at Montreal, Que.; June 11 on top of Mount MacIntyre, Essex Co., N. Y.; June 12 at Lake Itasca, Minn.; August 18 at Baddeck, N. S.; and August 25 to 26 at Camp Kennedy at 3,000 ft. on Mount Katahdin, Maine.

Rearing records are as follows: $3 \sigma^{\pi}, 19$, from Urocerus albicornis, Mount Desert Island, Maine, June 15, 1943, Wm. Procter. 2ᄋ, reared from Abies balsamea, Gale River, N. H., June 29, 1931, H. J. MacAloney.

This species occurs in the East, mostly in the Canadian zone. It is adult from about mid-June to mid-August.
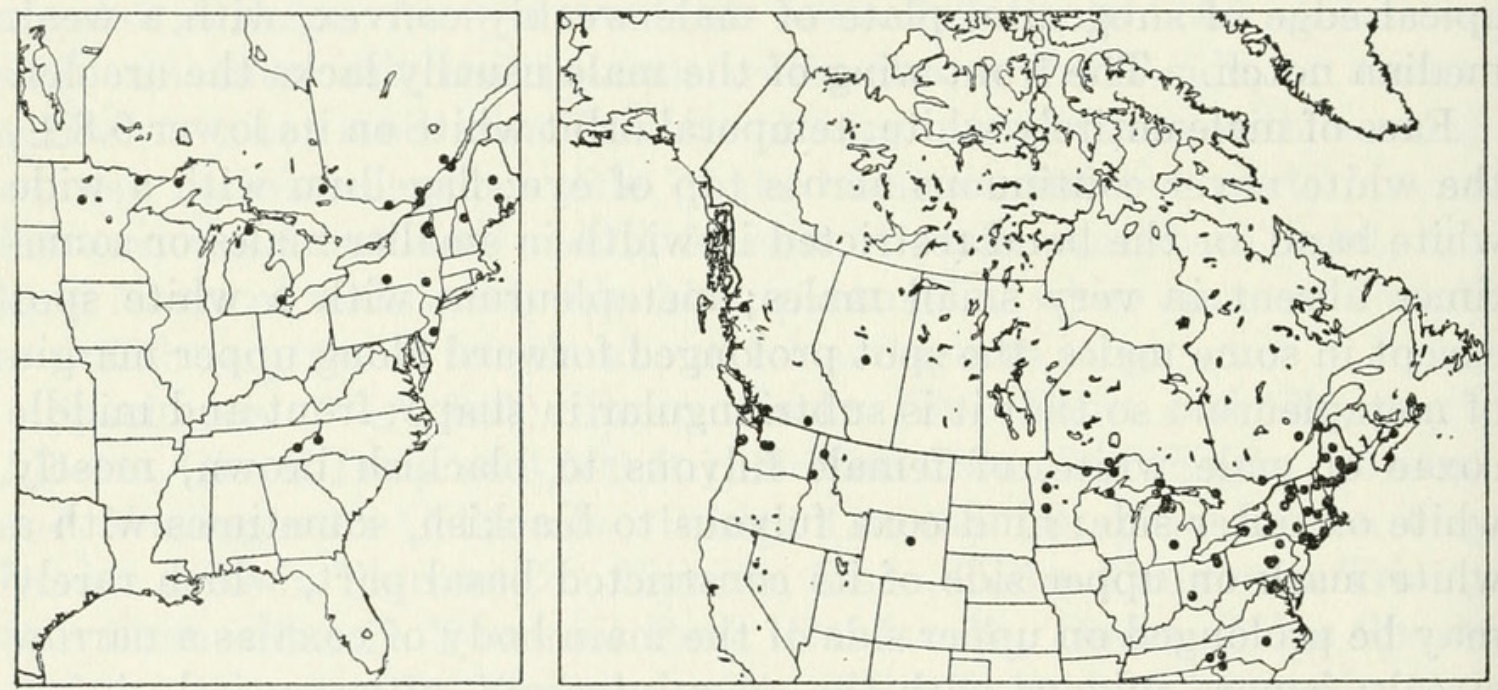

Figures 179, 180.-Localities: 179 (left), Rhyssa crevieri; 180 (right), R. lineolata.

\section{Rhyssa lineolata (Kirby)}

FigURE $317, \mathrm{f}$

Cryptocentrum lineolatum Kirby, 1837, in Richardson, Fauna boreali americana, pt. 4, p. $260 ; \sigma^{x}$. Type: $\sigma^{7}$, North America at $65^{\circ} \mathrm{N}$. latitude (London).

Rhyssa albomaculata Cresson, 1864, Proc. Ent. Soc. Philadelphia, vol. 3, p. 318; ๆ. Type: , N. J. (Philadelphia).

Front wing of male 7 to $16 \mathrm{~mm}$. long, of female 17.5 to $22 \mathrm{~mm}$. long; apical margin of male subgenital plate a little convex, often with a weak median notch. In smaller males the front wing often lacks the areolet.

Face of male entirely white; temporal orbit white for most or all of its length, often the white continuing across top of eye to frontal 
orbital white mark; flagellum with a broad white band; metapleurum with a white spot (rarely lacking) which is a little constricted next to upper margin of metapleurum, the spot thus roundish or rounded rectangular; front and middle coxae of male white, of female fulvous or more or less white on outer side, in larger females often mostly white; hind coxa fulvous with a short dorsal basal white stripe, or this stripe more or less enlarged, in larger females often covering the entire upper side of coxa; hind femur fulvous, its apex usually narrowly infuscate, or sometimes the entire femur is more or less infuscate; paramedial white spots on fourth and fifth tergites of female about 1.5 as high as long.

The white mark of the temporal orbit is continuous across the top of eye to the frontal orbit in most females and a few males from eastern North America. Nearly all specimens from western North America have the white orbital mark interrupted above. This difference between the eastern and western populations, though obvious, does not seem constant enough for the recognition of separate subspecies.

Specimens (39 $\sigma^{\top}, 121$ ) : From Alberta (Edmonton); British Columbia (Mount Benson at 3,000 ft., Robson, Terrace, Vancouver, and Wellington); Colorado (near Denver); Connecticut (Lyme); District of Columbia (Washington); Idaho (Wallace and Waha); Maine (Bangor, Baxter State Park, Brewer, East Blue Hill, Jackman, Lincoln Co., Monmouth, Mount Desert Island, Orono, and Paris) ; Maryland (Cabin John); Massachusetts (Cambridge, Petersham, Weston, and Woods Hole); Michigan ("Aden," Bear Island in Charlevoix Co., Douglas Lake, East Lansing, Gogebic Co., Isle Royale, Naubinway in Mackinac Co., Vanderbilt, and Whitefish Point in Chippewa Co.); Minnesota (Alexandria, Basswood Lake in Lake Co., and Itasca Park); New Hampshire (Canobie Lake, Durham, Franconia, and Mount Washington); New York (Adirondack Mts., Big Indian Valley in the Catskill Mts., Boreas River in Essex Co., Erie Co., Fire Island off Long Island, Fort Montgomery, Ithaca, Long Beach on Long Island, McLean in Tompkins Co., Mount Whiteface at 2,000 to 4,000 ft., New Russia, and Oswego); North Carolina (Black Mts., Clingmans Dome, and Wake Co.); Nova Scotia (Cape Breton Island, Medway and vicinity in Queens Co., and Truro); Ohio (Bedford, Cleveland, and Greene Co.); Ontario (Hymers and Waubamik); Oregon (Cannon Beach); Pennsylvania (Harrisburg, Heckton Mills in Dauphin Co., New Bloomfield, and Spring Brook); Quebec (Aylmer, St. Alexandre, and Stoneham); South Carolina (near Tigerville); Vermont (Laurel Lake near Jacksonville and Plainfield); Virginia (Great Falls); Washington (Ashford, Hoquiam, Mount Rainier, San Juan Island, and Westport); and West Virginia. 
Most collecting dates are from June 8 to September 18 . Those outside of this range are: May 8 near Tigerville, S. C.; May 30 at Ithaca, N. Y. and Plainfield, Vt.; June 2 and 4 at Ithaca, N. Y.; September 19 at Mount Benson, B. C. at 3,000 ft.; September 20 and October 10 at Wallace, Idaho; and October 13 at Naubinway, Mich.

Specimens have been reared from Picea sitchensis, Picea sp., Tsuga canadensis, Abies lasiocarpa, and A. balsamea, but there are no definite host records.

This species is transcontinental in the Canadian, Transition, and Upper Austral zones. Most adults occur from early summer to early fall.

\section{PERSUASORIA GROUP}

Face with sparse hairs sparser medially than laterally; lateral portion of prepectal carina moderately strong; first tergite about 1.6 as long as wide; second through sixth tergites weakly mat in males, strongly mat in females, the mat sculpturing transverse, giving a transversely aciculate appearance, especially in females; third tergite with short hairs the sockets of which are separated by about 1.7 (in males) or 5.0 (in females) length of the hairs; second through fourth sterna of male each with a single, large, uniformly convex sternite; apical membranous area of female second through fourth sterna extending forward between the paired sternites for about 0.25 the length of the sternites; apical margin of male subgenital plate broadly concave.

Flagellum black; temporal orbit marked with white; mesepisternum with a white spot on subtegular ridge, usually a subcircular white spot next middle coxa, and sometimes other white marks; second through fourth tergites with large apical white spots all or mostly disconnected; seventh tergite of female with a large transverse lateral white spot and a smaller submedian white spot, the lateral and submedian white spots sometimes partly fused with each other (fig. $317, \mathrm{~g}$ ).

This group includes only the Holarctic $R$. persuasoria.

\section{Physsa persuasoria (Linnaeus)}

FIGURE $317, \mathrm{~g}$

Ichneumon persuasorius Linnaeus, 1758, Systema naturae, ed. 10, vol. 1, p. 562. Types: $\sigma^{x}$, $q$, Europe (Linnean Society of London).

Front wing of male 7.5 to $15.5 \mathrm{~mm}$. long, of female 11 to $24 \mathrm{~mm}$. long. Structural characters as described for the species group.

Male: Black. Face, frontal orbit, part or all of temporal orbit, palpi, spot on anteroventral swelling of pronotum, sometimes a pair of spots on collar, stripe on upper margin of pronotum extending from epomia to near hind corner, tegula, spot on subtegular ridge, usually a spot on mesopleurum near middle coxa, usually apex of scutellum, 
postscutellum, rarely spot on hind part of metapleurum, usually subapicolateral spot on propodeum, some or all of front and middle coxae, usually front trochanters, often part of middle and hind trochanters, narrow apicolateral stripe on first tergite (sometimes continuous across entire apex and sometimes broken into a pair of spots, or lacking), and four apical spots on second through seventh tergites, white, the spots apicolateral and paramedian in position, the apicolateral spot wedge-shaped and extending forward on lateral edge of tergite, the paramedian spots broadly elliptical; apicolateral and paramedian spots of the second tergite usually more or less fused; apex of front and middle femora and often extreme apex of front and middle tibiae ivory in front; hind tibia infuscate brownish; hind tarsus fuscous; legs fulvous except as described otherwise, the hind coxa, trochanters, and femur sometimes more or less infuscate.

Figure 181.--Localities for Rhyssa persuasoria.

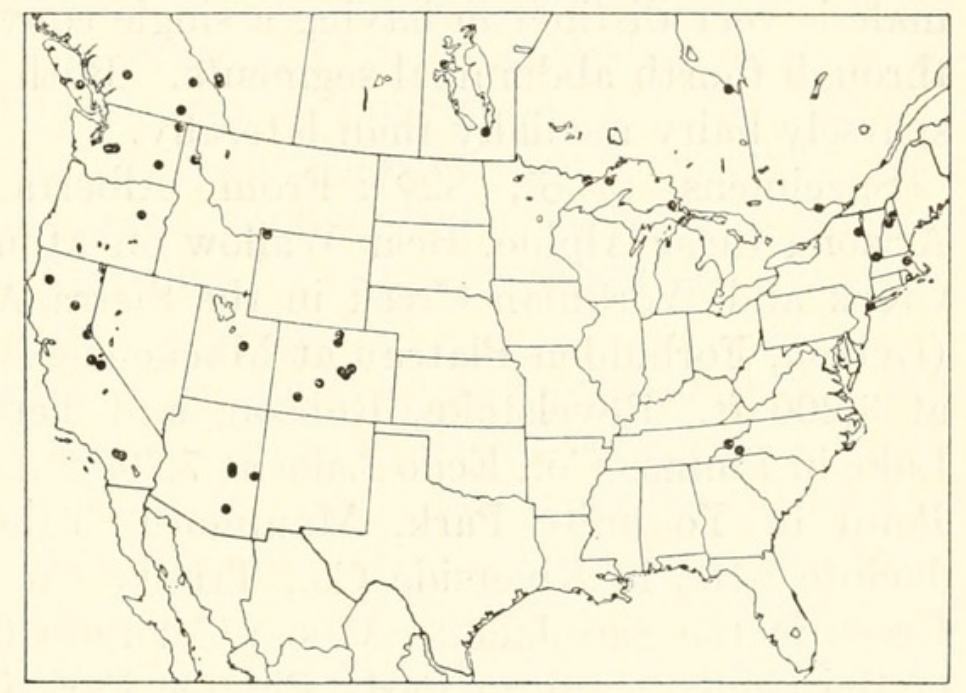

Female: Black. Orbits (widest on face, narrow or interrupted above and posterodorsally, always broadly interrupted below), a pair of triangular spots on collar, curved stripe along anteroventral margin of pronotum, broad upper margin of pronotum from near epomia almost to hind corner, tegula, subtegular ridge, nearly always a roundish spot on mesopleurum near middle coxa, mesepimeron except below, rarely an oblique dash in center of mesopleurum, large subapical blotch on metapleurum, scutellum except basally and basolaterally, postscutellum, large subapicolateral blotch on propodeum (rarely connected with blotch on opposite side), sometimes more or less of front and middle coxae in front, rarely part of top of hind coxa, stripe along lateral edge of first and second tergites beginning near spiracle and continuing around apical corner but usually not reaching midline (the stripe on second tergite sometimes broken into two pairs of elongate spots), large wedge-shaped spot along apical part of lateral margin of third through seventh tergites, oval or triangular paramedian 
spots on these tergites, and sometimes narrow stripe along part of lower edge of eighth tergite, white, the paramedian and apicolateral spots of seventh tergite sometimes partly fused but not making a uniform band as in the AMOENA group of species; palpi light brown; hind tibia fuscous brown; hind tarsus fuscous; legs fulvous except as described otherwise, the extreme apex of hind femur somewhat infuscate and the coxae and hind trochanters and femur sometimes more or less infuscate. The hind coxa, trochanters, and femur are more frequently infuscate in Nearctic than in European specimens.

Colorational features which particularly characterize this species are: flagellum without white band; temporal orbit partly or entirely white; mesopleurum with a white spot near middle coxa but usually without any other white except on subtegular ridge and mesepimeron, and seventh tergite of female with a pair of spots (a long one and a short one) on each side that are not or only incompletely fused. The male is very distinct in having a single convex sternite on the second through fourth abdominal segments. Both sexes have the face more sparsely hairy medially than laterally.

Specimens (34 $\left.0^{x}, 82 \%\right)$ : From Alberta (Banff and Laggan); Arizona (near Alpine, Bear Wallow on Mount Lemmon, and Pocket Creek and Workman Creek in the Sierra Ancha); British Columbia (Lytton, Forbidden Plateau at Mackenzie Lake on Vancouver Island at 3,200 ft., Revelstoke, Robson, and Terrace); California (Buck's Lake in Plumas Co., Echo Lake at 7,200 ft., "Fieldrock," near Glacier Point in Yosemite Park, Mammoth, Tahquitz Valley in the San Jacinto Mts. in Riverside Co., Trinity Co. at 6,000 ft., and Willow Creek in the San Jacinto Mts.); Colorado (near Estes Park, Garden of the Gods, Manitou Park, Pingree Park in Larimer Co., Silverton at 9,500 ft., Waldo Canyon in Fremont Co., and Williams Canyon in El Paso Co.); Idaho (Wallace); Manitoba (Cedar Lake and Kettle Rapids near Winnipeg); Massachusetts (Walden); Michigan (Isle Royale, Mackinac Island, and Whitefish Point in Chippewa Co.); Minnesota (Cook Co.); New Brunswick (Bathurst); Newfoundland (St. Johns); New Hampshire (Franconia and Mount Madison); New Jersey; New York (Boreas River in Essex Co. and New York City); North Carolina (Pisgah Ridge); Oregon (Grant Co.); Ontario (Moose Factory on James Bay); Quebec (Aylmer); Tennessee (Great Smoky Mountains National Park at 5,000 to 6,000 ft.); Texas; Utah (Scofield at 8,000 ft.); Vermont (Laurel Lake near Jacksonville); Washington (Bumping River, Metaline Falls, Mount Rainier at 4,000 ft., and Ritzville); and Wyoming (Camp Roosevelt in Yellowstone Park). We have additional specimens from France, Germany, and Italy.

Dates of capture are mostly in June, July, and August, but a few are in late May, and we found the species moderately common in the 
Sierra Ancha of Arizona April 30 to May 5, which is rather early spring: for that area. There is also a record for October 1 at Wallace, Idaho.

One male was reared from Sirex areolatus at Berkeley, Calif., and a number of specimens have pin labels indicating rearings from various conifers, but without the name of the host insect. The conifers thus recorded are: Abies balsamea, A. concolor, Pinus edulis, P. ponderosa P. scopulorum, and Pseudotsuga taxifolia.

This species is transcontinental in the Canadian zone. It occurs also in Eurasia, where it is the commonest member of the tribe.

\section{Genus Rhyssella}

Figure 303,a

Rhyssella Rohwer, 1920, Proc. U. S. Nat. Mus., vol. 57, p. 422. Type: Rhyssa nitida Cresson; original designation.

Front wing 5.5 to $15 \mathrm{~mm}$. long; tergites 3 to 6 of male depressed, polished, with fine sparse punctures, without a median apical submembranous area, their apical margin broadly concave; tergites 3 to 6 of female covered with transverse aciculation except ventrally; male clasper evenly convex, its apex rounded and containing a rounded notch, without grooves as described for Megarhyssa males. Structure otherwise similar to that of Megarhyssa.

This genus contains the two Nearctic species treated below, Ichneumon approximator Fabricius 1793 and Rhyssa obliterata Gravenhorst 1829, of Europe, and Rhyssa furannus Matsumura 1912, of Japan. The species approximator, obliterata, and furannus have not before been referred to Rhyssella (new combinations). Rhyssa dubiosa Matsumura, 1912, is a synonym of furannus; and Rhyssa curvipes Gravenhorst, 1829, is a synonym of approximator (new synonymies). So far as known, all species of Rhyssella parasitize Xiphyriidae.

\section{Key to the Nearctic species of Rhyssella}

1. Thorax and abdomen without white spots (fig. 318 ,a); metapleurum black; upper part of pronotum with rather dense fine punctures.

1. nitida Cresson

Thorax and abdomen with conspicuous white spots (fig. 318,b); metapleurum and often additional areas on thorax fulvous; upper part of pronotum with very sparse fine punctures. . . . . . . . . . . . 2. humida (Say)

\section{Rhyssella nitida (Cresson)}

Figdre 318 ,a

Rhyssa nitida Cresson, 1864, Proc. Ent. Soc. Philadelphia, vol. 3, p. 119; $\sigma^{7}$. Type: $\sigma^{7}$, Virginia (Philadelphia).

Rhyssa canadensis Cresson, 1868, Canadian Ent., vol. 1, p. 35; . Type: , "Quebec" (Philadelphia). 
Epirhyssa clavata Provancher, 1886, Additions et corrections au volume II de la faune entomologique du Canada traitent des hyménoptères, p. 115; $ᄋ$. Type: $\uparrow$, Cap Rouge, Que. (lost).

Front wing of male 7 to $11 \mathrm{~mm}$. long, of female 7 to $16 \mathrm{~mm}$. long; face with sparse, small punctures which are usually denser and larger on central part of face; central part of face with some fine, mostly transverse wrinkling or almost smooth; upper part of pronotum with rather dense, fine punctures; first tergite usually strongly swollen near base, especially in males.

Black or blackish brown. Face of male, moderately wide orbital stripes on face of female, short band on front orbit of both sexes, palpi of male, and tegula, white; palpi of female white to brown; flagellum often brown beneath, especially toward apex; legs fulvous, usually front coxa of female, more or less of front trochanters, base of front femur, often more or less of front femur of male, apex of front and middle femora, base of front and middle tibiae, and usually dorsoposterior face of front tibia, yellowish white; apex of hind femur fuscous; hind tibia infuscate, its base and most of its ventral side paler (white to light brown), its apical 0.3 and a dorsal subbasal area darker; hind tarsus brownish. Wings hyaline or with a faint brown tinge.

Specimens from British Columbia are rather different from those from the Transition zone in the East, but specimens from the Canadian zone in the East are rather intermediate. British Columbia specimens have the wings tinged with brown, lack the posterodorsal white stripe on the front tibia, and in the single British Columbian male at hand the central 0.6 of the face is black. Male specimens from other areas have the face entirely white.

This species is close to the European Rhyssella approximator (Fabricius) 1793 , and may prove to be only subspecifically distinct. The European species differs in lacking the infuscation at the apex of the hind femur, having the hind tibia uniformly fulvous, and in having the punctation of the body and head, especially of the face, averaging a little coarser and denser. It has usually been known under the name of Rhyssa curvipes Gravenhorst 1829, which is a synonym. We have seen the type of Gravenhorst's name in Wroclaw and of Fabricius' name in Copenhagen. The name approximator has usually been applied (erroneously) to a species of Pseudorhyssa, which in Europe is placed in the genus Rhyssa.

Specimens $\left(79 \sigma^{\top}, 130 \%\right)$ : From British Columbia (Oliver and Robson); Iowa (Iowa City); Maine (Lunksos Lake on the East Branch of the Penobscot River); Maryland (Plummers Island); Massachusetts (Amherst, Cummington at 1,200 ft., Mount Wachusett near Princeton, and Petersham); Michigan (Alcona Co., Ann Arbor, Aurelius, Bay Co., Benzie Co., Cheboygan Co., Chippewa Co., Detroit, East Lansing, 
Mackinac Co., Mackinaw City, Manistique, Marquette Co., Midland Co., Onota in Alger Co., Saginaw Co., Sanilac Co., and Schoolcraft Co.); Minnesota (Garrison, Itasca Park, St. Croix Recreation Area, and St. Paul); New Hampshire (Pinkham Notch); New Jersey (Clementon, Fort Lea, and Rancocas Park); New York (Allegany State Park, Bemus Point, Caroline-Harford area, Heart Lake in Essex Co., Ithaca, Keene Valley in Essex Co., Maplecrest, McLean Bogs Reserve in Tompkins Co., Mount Whiteface at 2,000 to 4,000 ft., New Russia, Nyack, Poughkeepsie, Taughannock Falls near Ithaca, and Waterloo); Ohio (Akron, Bedford, Delaware Co., Hinckley in Medina Co., Puritas Springs in Cuyahoga Co., and Put-in-Bay); Ontario (Ottawa and Waubamik); Pennsylvania (Jeannette and Pittsburgh); Quebec (Montreal); Rhode Island (Kingston and Westerly); South Carolina (Columbia); Tennessee (State Road to Newfound Gap); Vermont (Laurel Lake near Jacksonville); and Wisconsin (Door Co. and Sawyer Co.).

Collection dates are from early spring (early May in Upper Austral localities) to late summer (end of August). Captures outside of this range are: April 22 at Rancocas Park, N. J.; April 27 at St. Paul, Minn.; September 2 at 3,500 ft. in Great Smoky Mts., Tenn. and at Midland, Mich.; September 20 at Aurelius, Mich.; and September 27 at Petersham, Mass.

There is a series of $37 \sigma^{7}, 36$ 우 reared from Xiphydria maculaia in Acer rubrum, Plummers Island, Md., April 22 to June 6, 1913, by H. S. Barber, T. E. Snyder, and S. A. Rohwer.

This species occurs in the Canadian, Transition, and Upper Austral zones of the eastern half of North America, and has been collected also in British Columbia. It is adult from rather early spring to late summer. The host is Xiphydria.
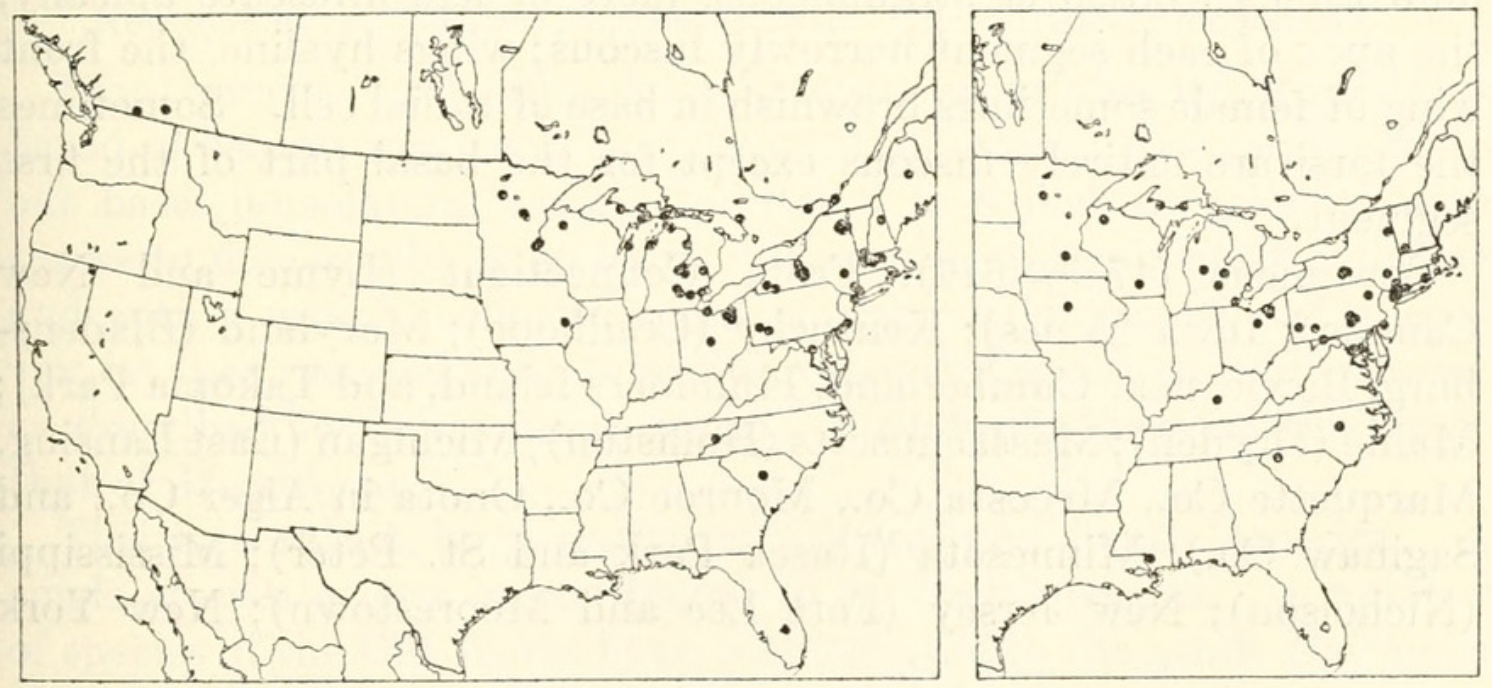

Figures 182, 183.-Localities: 182 (left), Rhyssella nitida; 183 (right), R. humida. 


\section{Rhyssella humida (Say)}

Figure $318, \mathrm{~b}$

Pimpla humida Say, 1836, Boston Journ. Nat. Hist., vol. 1, p. 224 (Leconte ed., vol. 2, p. 683); $q$. Type: $\uparrow$, Indiana (destroyed).

Front wing of male 5.7 to $7.5 \mathrm{~mm}$. long, of female 8 to $12 \mathrm{~mm}$. long; face with very sparse fine punctures and usually also with more or less distinct, fine, transverse wrinkling on its median part; upper part of pronotum with very sparse, fine punctures; base of first tergite weakly swollen.

Black. Face of male, orbital stripe on face of female, short broad orbital stripe on frons, scape of male except above, long broad orbital stripe on temple, upper part and lower corner of pronotum, tegula, subtegular ridge, sometimes a median pair of dashes on mesoscutum, apex of scutellum, postscutellum, often a small lateral subapical spot on second tergite, large lateral subapical spot on third through seventh tergites, and band along lateroventral margin of eighth tergite of female, white; metasternum, metapleurum, usually more or less of mesosternum and mesopleurum, and often lateral part of propodeum, fulvous; propodeum often with a small lateral subapical blotch of white and fulvous; front leg whitish in male, fulvous in female with some paler areas, the narrow apex of its tarsal segments brownish and apical third of its fifth tarsal segment infuscate; middle leg ivory with some fulvous tinges, the coxa of female and femur of female except at apex entirely fulvous, the tibia with a narrow apical and usually a narrow subbasal infuscate band, and the tarsus more or less infuscate toward apex with the apex of each segment a little darker; hind coxa fulvous; hind first trochanter entirely whitish or partly fulvous; hind second trochanter dusky fulvous or infuscate; hind femur fulvous, its apex usually with a narrow infuscation; hind tibia whitish or stramineous, its apical 0.2 to 0.3 fuscous and a subbasal band or area infuscate; hind tarsus whitish or stramineous, more or less infuscate apically, the apex of each segment narrowly fuscous; wings hyaline, the front wing of female sometimes brownish in base of radial cell. Sometimes the tarsi are entirely fuscous except for the basal part of the first segment.

Specimens (47 $\sigma^{x}, 61$ ) : From Connecticut (Lyme and New Canaan); Iowa (Ames); Kentucky (Crailhope); Maryland (Bladensburg, Bowie, near Cumberland, Plummers Island, and Takoma Park); Maine (Dryden); Massachusetts (Holliston); Michigan (East Lansing, Marquette Co., Mecosta Co., Monroe Co., Onota in Alger Co., and Saginaw Co.); Minnesota (Itasca Park and St. Peter); Mississippi (Nicholson); New Jersey (Fort Lee and Moorestown); New York 
(Fort Montgomery, Hartsdale, Ithaca, McLean Bogs Reserve in Tompkins Co., Millwood, North River, Onteora Mt. in Greene Co., Poughkeepsie, and Slaterville); North Carolina (Wake Co.); Ohio (Ashland Co., Bedford, Cleveland, and Puritas Springs in Cuyahoga Co.); Pennsylvania (Crisp in Westmoreland Co., Harrisburg, Hummelstown, Rockville in Dauphin Co., Spring Brook, and West View); South Carolina (Greenville); Vermont (Laurel Lake near Jacksonville); and Wisconsin (Madison and Sawyer Co.).

Collection dates are from late spring to early fall. The following are the earliest and latest dates: April 6 at Nicholson, Miss.; May 11 at Ames, Iowa; May 22 at Spring Brook, Pa.; May 23 at Plummers Island, Md. and at Crailhope, Ky.; September 10 at Cleveland, Ohio and at Dryden, Maine; September 12 at Plummers Island, Md.; September 16 at Fort Montgomery, N. Y.; September 17 near Cumberland, Md.; and September 24 at East Lansing, Mich. In our own collecting we have found the species sparingly in deciduous woods.

Rearing records comprise: $3 \sigma^{7}$, from Xiphydria sp. in Tilia, Harrisburg, Pa., Sept. 2, 1913. $\sigma^{7}$, from Xiphydria abdominalis, Plummers Island, Md., Sept. 12, H. S. Barber. $\sigma^{7}$, reared from Carpinus infested with Xiphydria, Rockville, Pa., A. B. Champlain. There are also five rearings from Carpinus caroliniana, and one from "white birch," without specification of the insect host.

This species is in the Alleghanian and Carolinian faunas, occurring in deciduous woods. It is adult from late spring to early fall. Several species of Xiphydria serve as hosts.

\section{Genus Epirhyssa}

\section{Figure 303,b}

Epirhyssa Cresson, 1865, Proc. Ent. Soc. Philadelphia, vol. 4, p. 39. Type: Epirhyssa speciosa Cresson; designated by Viereck, 1914.

Rhyssonota Kriechbaumer, 1890, Ann. Naturh. Hofmus. Wien, vol. 5, p. 489. New synonymy. Type: Rhyssonota tristis Kriechbaumer; monobasic.

Front wing 8.5 to $23 \mathrm{~mm}$. long; areolet always absent; intercubitus basad of second recurrent by 0.2 to 1.0 its length; first tergite without basal dorsolateral carina; tergites 3 to 6 mat to polished with sparse to moderately dense hairs, in the male approximately cylindric and with a weakly concave apical margin; male clasper evenly convex, its apex rounded and containing a rounded notch, without grooves as described for Megarhyssa males. Structure otherwise similar to that of Megarhyssa.

This is a rather large genus, of Central and South America. A single species occurs in our fauna, in southern Arizona. A number of species of the Old World have been referred to the genus Epirhyssa 
because they lack the areolet. We have some of these species and find that they are not true Epirhyssa but belong to Hierax (a preoccupied name) and to some undescribed genera.

\section{Epirhyssa dietrichi, new species}

Front wing of male $20 \mathrm{~mm}$. long, of female 19 to $23 \mathrm{~mm}$. long; prepectal carina present; first tergite about 2.1 as long as wide in male, about 1.85 as long as wide in female; tergites 3 to 6 polished, with moderately close, fine, weak, setiferous punctures; ovipositor sheath about 1.55 as long as front wing.

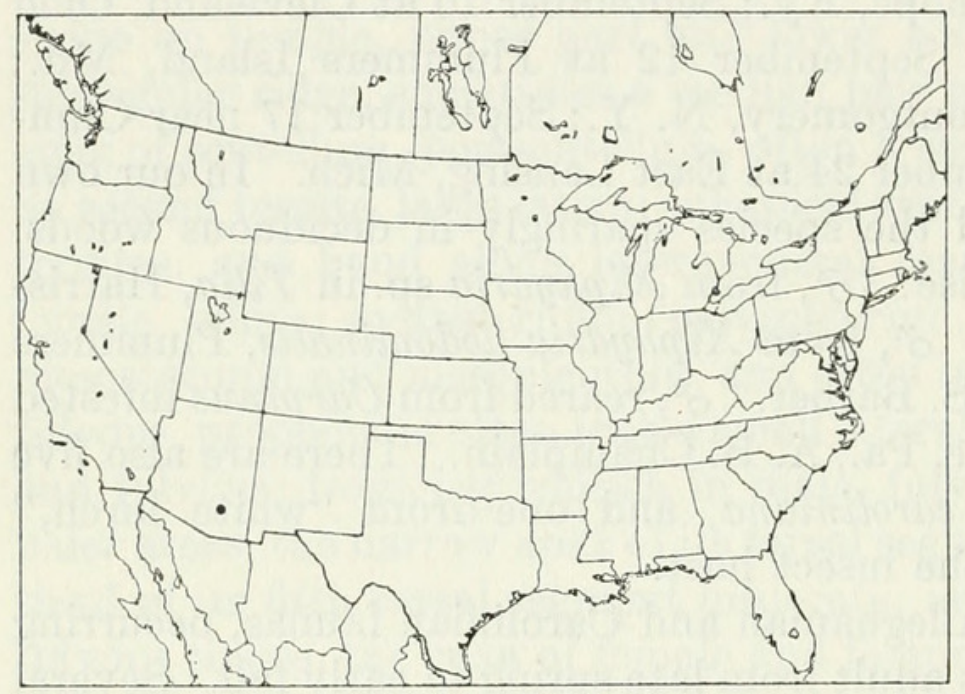

Figure 184.- Locality for Epirhyssa dietrichi.

Fulvous. Much or most of head, much of front part of thorax, most of front leg, subtegular ridge, a pair of median longitudinal stripes on center of mesoscutum, and scutella, yellowish; head with a narrow stripe between top of eyes and a narrow stripe over upper part of occipital carina blackish; scape blackish above; most of pedicel and all of flagellum except the ring joint blackish; pronotum medially in front, margins and notauli of mesoscutum, a stripe on front edge of mesopleurum, a narrow transverse band at base of propodeum and metapleurum, narrow band on apical margin of propodeum, a narrow band on apex of first six tergites, and narrow band on base of second through fifth tergites, black; middle and hind tibiae yellowish, fulvous basally; wings strongly tinged with fulvous, the front wing faintly infuscate apically; stigma fulvous brown.

Type: , Bear Wallow, Mount Lemmon, Santa Catalina Mts., Ariz., June 23, 1953, A. and H. Dietrich (Ithaca).

Paratypes: $\sigma^{\Upsilon}, 6$, , same locality and collectors as type, June 23 and 24, 1953 (Ithaca and Townes). 


\title{
4. Genus Megarhyssa
}

\author{
Figure 304,a
}

Thalessa Holmgren, 1859, Őfvers. Svenska Vetensk.-Akad. Förh., vol. 16, p. 122. Name preoccupied. (Ichneumon clavator Fabricius) =histrio (Christ); designated by Ashmead, 1900.

Megarhyssa Ashmead, 1900, Canadian Ent., vol. 32, p. 368. New name. Megalorhyssa Schulz, 1906, Spolia hymenopterologica, p. 115. Emendation. Eurhyssa Derksen, 1941, Zeitschr. Morph. ..., vol. 37, p. 721. Type: Ichneumon superbus Schrank; designated by Townes, 1951.

Front wing 10 to $30 \mathrm{~mm}$. long; clypeus small, transversely rectangular, its apicolateral corner produced as a small blunt point, sometimes also a small blunt point at middle of its apical margin; junction of occipital and hypostomal carinae distant from base of mandible by about 0.4 the basal width of mandible; mandibular teeth of equal length, the lower tooth pointed at apex, the upper tooth more or less chisel-shaped; second trochanter of middle leg with a sharp ventral longitudinal ridge; stigma about 5.5 as long as wide; areolet present except in occasional dwarf males; first tergite immovably attached to its sternite, without a glymma; tergites 3-6 of male strongly depressed, polished, with scattered small punctures, with a median longitudinal apical or subapical membranous area, their apical margin with a broad, deep, V-shaped notch; tergites 3-6 of female usually smooth, sometimes with large aciculate areas but never aciculate all over, with rather numerous setiferous punctures; sternites 3-6 of female with a pair of tubercles near the base; last tergite of female with an apical hornlike process which is truncate at the tip; male clasper lanceolate, strongly depressed, with a sharp setiferous groove paralleling most of its inner lower margin and a short setiferous groove on its outer edge near the apex.

In dwarf males of all the Nearctic species and of at least some of the Old World species the abdominal and genitalic specializations are lost to some degree. In these the tergites tend to be less depressed, more densely hairy, less deeply notched at apex, and lack the median submembranous area. The clasper tends to be shorter, less depressed, and the grooves as described above tend to be broad, short, and shallow, so as to be indistinct or in extreme cases to be lacking entirely.

This genus is Holaretic and Oriental. It contains some very large species. Large females of the four North American species are our largest ichneumonids, rivaled only by some species of Conocalama. The facts that they are very large, have a spectacularly long ovipositor, and are moderately common make our Megarhyssa species the best known of the ichneumon flies, and in fact the only ichneumon flies familiar to a large number of people. They have been figured and discussed in textbooks, encyclopaedias, dictionaries, magazine 
articles, and technical papers. Most amateur insect collections possess at least one specimen. The superficial aspects of their biology have been described and discussed in many places. Some of the early observations and speculation make interesting reading in the light of our present information.

An observation by Lintner (1889, Rep. New York State Ent., no. 4, pp. 35-36) is an example. He stated that: "I recall an instance observed by me several years ago, when what I think must have been Rhyssa lunator, was earnestly engaged in placing its eggs in the following singular manner in a colony of a species of Datana, feeding upon a branch of hickory: Its ovipositor was bent beneath it, extending between its legs, with its tip projecting in front of its head, enabling it with perfect ease to select one catepillar after another for the reception of its eggs. Why would not this be a much better method of using the long ovipositor than the one generally ascribed to it? There would certainly be no hap-hazard work in such oviposition, or any waste of material. In the instance above recorded, each thrust told, as was seen in the well-known alarm-jerk of these larvae, at once communicated from the victim to the entire group."

A more carefully reported observation was recorded by Walsh and Riley in 1868 (American Ent., vol. 1, p. 77) from an article in the New Orleans Christian Advocate, entitled "The Stiletto Wasp." The article stated that: "The wasp was about one and a half inches long, black and yellow, with a sting three and a half inches long, and as large as a small needle; there were also two hair-like appendages of similar length. One of the insects had struck at a boy several times. Finally, making a desperate effort, the boy dodged behind a tree just at the moment that the insect, throwing up its tail to strike, lost sight of him and thus plunged the tail a full inch into a sweet gum tree, from which it could not withdraw it. The father of the boy being near with an axe, cut out a chip, and the sting was found to have gone through it to the depth already stated."

It is well known, now, that the species of Megarhyssa are parasitic on wood-boring Siricidae. In the bibliographies under the species $M$. atrata and $M$. macrurus are references to many articles which describe the interesting drilling operations of the female to parasitize the hosts, the mating behavior, and some of the morphological specializations. There remain, however, many unanswered biological questions, and the matter of the ecological separation between M. atrata, M. macrurus, and M. greenei has not yet been touched upon. All three of these are dependent on the same host, in the same geographic area, and frequently in the same tree or log, yet each one remains moderately common and is not eliminated by competition with its congeners. 


\section{Keys to the Nearctic species of Megarhyssa}

\section{MALES}

1. Front wing marked with brown, at least with a brown spot in base of radial cell (fig. 319 ,d); median apical membranous area of tergites $3-5$ extending about 0.5 their length; apicolateral angle of tergites $3-5$ usually about $60^{\circ}$.

4. macrurus (Linnaeus)

Front wing hyaline or subhyaline, without a definite brown mark though its apex may be faintly infuscate; median apical membranous area of tergites 3-5 extending about 0.2 to 0.4 their length; apicolateral angle of tergites $3-5$ usually about $75^{\circ}$ to $90^{\circ}$.

2. Mesopleurum blackish brown, the subtegular ridge yellow; general color of thorax darker than that of abdomen; cheek about as long as apical width of mandible. . . . . . . . . . . . . . . . . . . 1. nortoni (Cresson)

Mesopleurum partly yellowish brown, the subtegular ridge yellow; general color of thorax not darker than that of abdomen; cheek about 0.8 as long as apical width of mandible. . . . . . . . . . . . . . . . . . . . 3

3. Hind femur entirely light brown; abdomen light brown; hind edge of first sternite far beyond spiracle of first tergite... . 2. greenei Viereck

Hind femur partly blackish, at least its hind face mostly blackish; abdomen dark brown; hind edge of first sternite a little beyond spiracle of first tergite.

3. atrata (Fabricius)

\section{FEMALES}

1. Thorax and abdomen almost or quite entirely black (fig. $318, \mathrm{e}$ ).

3. atrata (Fabricius)

Thorax and abdomen light brown to blackish, with conspicuous yellow markings (figs. $318, \mathrm{c}, \mathrm{d}, \mathrm{f}, \mathrm{g}$ ) . . . . . . . . . . . . . . . . . . . . . . . 2

2. Tergites 4-6 each with a sharply defined, round yellow spot on each side (fig. 318,c); cheek about 1.4 as long as apical width of mandible; front wing with a uniform yellowish brown tinge . . . . 1. nortoni (Cresson)

Tergites 4-6 with an angulated subapical yellowish band on each side, or with a large irregular yellow blotch, or most of the tergite yellow (figs. 318,d,f,g); cheek about 1.0 as long as apical width of mandible . . . . . . . . . 3

3. Front wing entirely clear along basal vein (fig. 319, b) or in a Florida subspecies the entire wing dark brown (fig. 319,c); fourth tergite with dense punctures on less than half its surface, the rest almost impunctate; middle of hind margin of first sternite usually beyond hind margin of spiracle of first tergite; ovipositor sheath about 1.4 as long as head and body.

2. greenei Viereck

Front wing more or less brown or brownish along basal vein (figs. 319,e,f,g); fourth tergite with dense punctures on more than half its surface; middle of hind margin of first sternite in front of hind margin of spiracle of first tergite; ovipositor sheath about 1.9 as long as head and body.

4. macrurus (Linnaeus)

\section{Megarhyssa nortoni (Cresson)}

Male: Front wing 9.5 to $20 \mathrm{~mm}$. long; cheek about 1.0 as long as apical width of mandible; median part of apical edge of first sternite at or a little beyond hind edge of spiracle of first tergite; median apical membranous streak of third through fifth tergites extending 
about 0.2 the length of the tergite; apicolateral angles of tergites 3-5 about $75^{\circ}$ to $90^{\circ}$.

Head black or blackish brown, the lateral 0.3 of face, side of frons, and temple yellow; thorax black or blackish brown, often light brown above, a spot on side of pronotum, subtegular ridge, scutellum, postscutellum, subapical spot on mesopleurum, and lateral subapical spot on propodeum, yellow; coxae blackish or the front coxa brown; trochanters yellow or the first trochanter of middle and hind legs more or less brown or blackish; front and middle legs beyond trochanters yellow, the basal half of middle femur mostly brown or blackish; hind femur blackish, its base and apex yellow; hind tibia yellowish brown, yellow basally and apically; hind tarsus yellow; abdomen brown, the tergites usually darker medially, the first two tergites with a median subapical yellow spot; wings uniformly tinged with fulvous brown.

Female: Front wing 13 to $29 \mathrm{~mm}$. long; cheek about 1.3 as long as apical width of mandible; median part of apical edge of first sternite just in front of spiracle of first tergite; apicolateral angles of tergites 3-5 about $110^{\circ}$; fourth tergite mostly polished, with fine, moderately dense punctures basally and near the ventral edge, the rest almost impunctate; ovipositor sheath about 2.7 as long as front wing.

Light reddish brown to blackish brown, the abdomen usually a little paler than the thorax. Head, thorax, legs, and wings colored as in the male except that dark markings on legs are a little more extensive. Subtriangular median subapical spot on first and second tergites, large round yellow spot on side of tergites $3-5$, and vertical yellow blotch on side of sixth and seventh tergites, yellow.

This species is closely related to the European Megarhyssa superba (Schrank). It has weakly differentiated eastern and western subspecies, as keyed and described below:

1. Mesoscutum usually entirely black, sometimes partly or entirely reddish brown; general color of abdomen medium reddish brown to blackish brown; range: western half of North America, in Canadian and colder part of Transition zones, rarely in the East . . 1a. nortoni nortoni (Cresson)

Mesoscutum reddish brown; general color of abdomen light to medium reddish brown; range: eastern half of North America, in Canadian and colder pari of Transition zones . . . . 1b. nortoni quebecensis (Provancher)

\section{1a. Megarhyssa nortoni nortoni (Cresson)}

\section{FigURE 318,c}

Rhyssa nortoni Cresson, 1864, Proc. Ent. Soc. Philadelphia, vol. 3, p. 117; . Type: $q$, Colorado (Philadelphia).

Biology: Essig, 1926, Insects of western North America, pp. 795, 796.

This is the western subspecies. It has the ground color generally dark reddish brown or blackish, as noted in the key. 
Specimens $\left(750^{7}, 102\right.$ ) : From Alaska (Tanana); Alberta (Lethbridge and Waterton); Arizona (Greer); British Columbia (Chilcotin, Fish Lake near Summerland, Gabriola Island, near Haney in Garibaldi Park, Island Lake near Fernie, Kaslo, Lumby, Maple Bay, Midday Valley near Merritt, Mission City, Pass Lake, "Payne Mine near McGuigon," Robson, Sidney, Squamish, Sugar Lake, Terrace, Victoria, and Wellington); California (Bluff Lake in San Bernardino Co., Camino, Cisco, "Cow Creek," Dardanelle, Dodge Ridge Sports Area near Pinecrest in Tuolumne Co., Fallen Leaf Lake at 6,300 to $7,000 \mathrm{ft}$., Field Brook in Humboldt Co., Giant Forest in Sequoia National Park at 6,700 ft., near Glacier Point in Yosemite Park, Glen Alpine Creek at Tahoe, Hope Valley in Alpine Co., Kelly, Leevining, Marble Fork on Kings River Trail in Sequoia National Park, May Lake in Yosemite Park at 10,500 ft., Meyers, Modoc National Forest, Pescadero, Sagehen near Hobart Mills, Snow Crest Camp in San Bernardino Co., Strawberry in Tuolumne Co., Summit Camp in Lassen Co., Tamarack Flat in Yosemite Park, and Vade); Colorado (near Nederland at 10,000 ft., Phantom Valley in Rocky Mountain National Park at 9,400 ft., San Miguel Mts., and Williams Canyon in El Paso Co.); Idaho (Bear, Bear Pass Creek in Butte Co., Mount Moscow, Waha, and Wallace); Michigan (Isle Royale and Whitefish Point in Chippewa Co.); Montana (Thompson Falls); New Mexico (Cienega Canyon in the Sandia Mts. in Bernalillo Co.); Oregon (Antelope Mts. in Harney Co. at 6,500 ft., Colton, Corvallis, Crater Lake, Hurricane Creek in the Wallowa Mts., Little Strawberry Lake in Grant Co. at 6,800 ft., Oceanside, Pamelia Lake on Mount Jefferson at about 3,000 ft., Portland, and Sumpter); Ontario (20 miles south of Nipigon); Utah ("Beaver Canyon," Kamas, North Fork of Provo Canyon, Ogden Canyon, Panguitch, Scofield at 8,000 ft., and Wasatch Mts.); Vermont (Laurel Lake near Jacksonville); and Washington (Barnes State Park, Easton, Hoquiam, Mount Rainier at 2,900 and 3,500 ft., San Juan Island, Satsop, and Sheep Lake in Yakima Co. at 6,000 ft.).

Among the above there are $2 \sigma^{7}, 5$ ㅇ from Laurel Lake, near Jacksonville, Vt., and a female from Isle Royale, Mich., which are colored like this subspecies but are in the range of the subspecies quebecensis. A female from Whitenish Point, Mich., and another female from twenty miles south of Nipigon, Ont., are intermediate in coloration but nearer to the subspecies nortoni. It is not surprising to find some specimens that do not follow the character and distribution typical of the two subspecies, as their sole distinguishing character is rather variable.

Collection dates are mostly from June 12 to August 30, with only the following dates outside of this range: May 25 at Robson, B. C.; May 26 at Hoquiam, Wash.; May 28 at Victoria, B. C.; May 29 at 

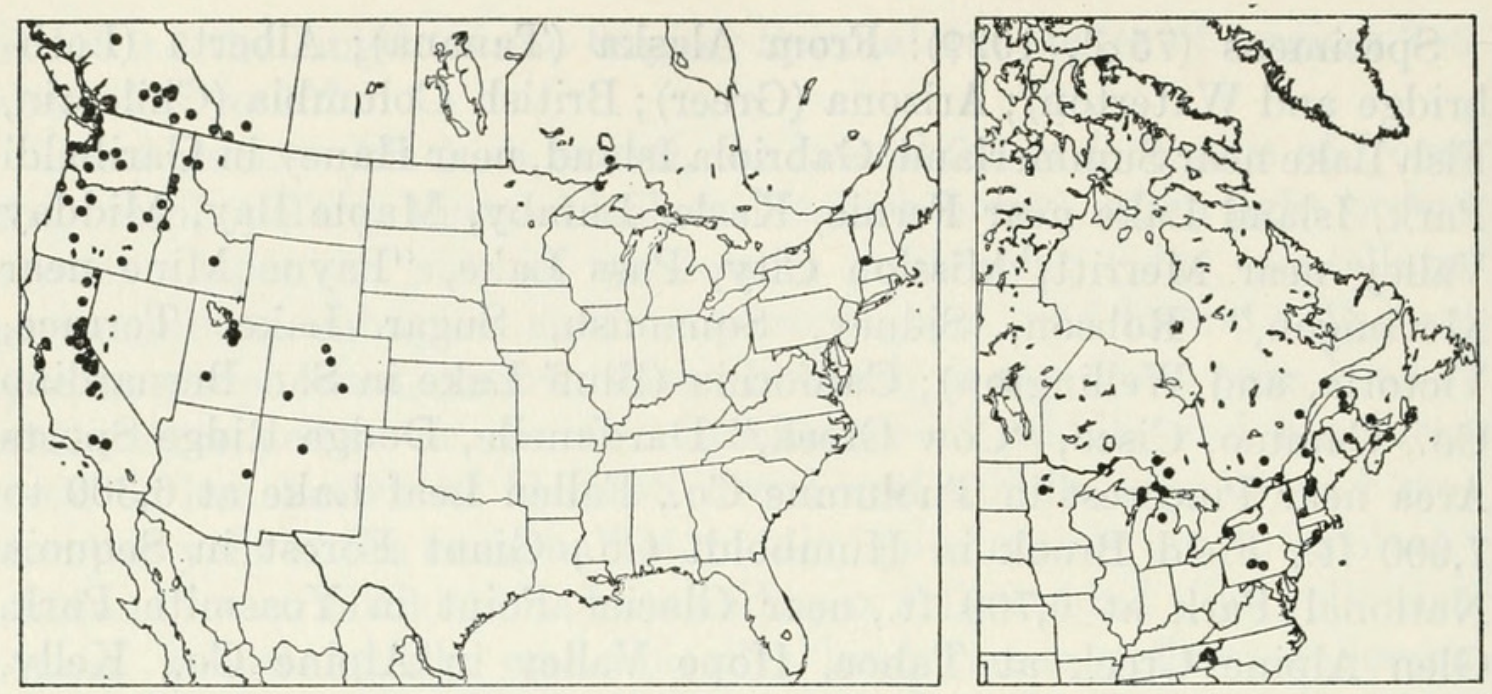

Figures 185, 186.--Localities: 185 (left), Megarhyssa nortoni nortoni; 186 (right), M. n. quebecensis.

Field Brook, Calif.; September 1 at Sugar Lake, B. C.; September 4 at Kelly, Calif.; September 7 at Glen Alpine Creek, Lake Tahoe, Calif.; September 16 on Gabriola Island, B. C.; and "Sept." at Maple Bay, B. C. We have found the species often common in forests of Pseudotsuga taxifolia, on or around logs or stumps of this tree.

There are many records of rearings from wood or occurrence of specimens on certain kinds of trees or stumps, but the only suggestion of an actual host association is on the pin label of a female labeled: "Chrysobothris, Corvallis, Oreg., Apr. 9, 1916, W. J. Chamberlin." The tree species with which the pin labels associate specimens are: Abies concolor, A. grandis, A. lasiocarpa, A. magnifica, Picea sitchensis, Pinus contorta murrayana, $P$. jeffreyi, $P$. ponderosa, Pseudotsuga taxifolia, and "cedar."

This subspecies occurs in the West, except that occasional specimens from the East appear to be assignable to it. It is in coniferous forests in the Canadian and Transition zones. Most adults occur from about June 12 to August 30. Its hosts, as reported in literature, are several species of siricids.

\section{1b. Megarhyssa nortoni quebecensis (Provancher)}

Thalessa Quebecensis Provancher, 1873, Naturaliste Canadien, vol. 3, p. 447; $\sigma^{\top}$, ․ Types: $\sigma^{7}, \uparrow$, Quebec (lost).

Biology: Proctor, 1938, Biological survey of the Mount Desert region, vol. 1, p. 406.

This is the eastern subspecies. The ground color is light reddish brown, as noted in the key.

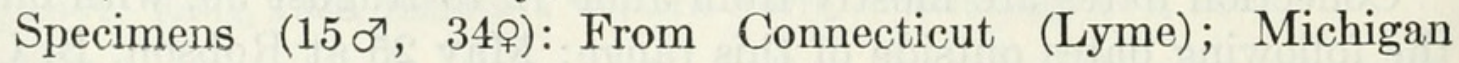


(Alger Co., Hartwick Pines State Park in Crawford Co., Sault Ste. Marie, Schoolcraft Co., and Whitefish Point in Chippewa Co.); Minnesota (Itasca Park and Lake Itasca); New Brunswick (Fredericton); Newfoundland (Hopedale in Labrador and Salmonier); New Hampshire (Pinkham Notch and Rumney); New York (Cliff Mt. in Essex Co. at 3,000 ft. and Ithaca); North Carolina (Pisgah Mt. at $5,600 \mathrm{ft}$. ) ; Nova Scotia (Grand River and Truro); Ontario (Ancaster, Hymers, Missanabic, and Ramsay); Pennsylvania (Charter Oak in Huntingdon Co. and New Bloomfield); Prince Edward Island (Alberton); Quebec (Cascapedia, Harrington Lake in Gatineau Park, Montigny, Montreal, Mount Albert in Gaspé Co., Pentecost, Saguenay River, and Valley Junction); Tennessee (Clingmans Dome in Great Smoky Mountains National Park at 6,400 ft. and Great Smoky Mountains National Park at 6,000 ft.); and Vermont (Laurel Lake near Jacksonville).

Dates of collection are during the summer, the earliest and latest dates being June 4 at 6,000 ft. in Great Smoky Mountains National Park; June 7 at Ithaca, N. Y.; and August 9 at Missanabic, Ont.

A female from Lyme, Conn., is labeled "ovipositing in Tsuga canadensis infested with siricids."

This subspecies occurs in the Canadian zone of the East.

\section{Megarhyssa greenei Viereck}

Male: Front wing 10 to $16 \mathrm{~mm}$. long; cheek about 1.0 as long as apical width of mandible; median part of apical edge of first sternite distinctly beyond hind edge of spiracle of first tergite; median apical membranous streak of tergites $3-5$ extending about 0.3 the length of the tergite; apicolateral angle of tergites $3-5,75^{\circ}$ to $90^{\circ}$.

Female: Front wing 12 to $27 \mathrm{~mm}$. long; cheek about 1.0 as long as apical width of mandible; median part of apical margin of first sternite about opposite hind edge of spiracle of first tergite; apicolateral angles of tergites $3-5$ about $95^{\circ}$; fourth tergite mostly polished, with fine, moderately dense punctures basally and near ventral edge, the rest almost impunctate; ovipositor sheath about 1.8 as long as front wing.

There are two subspecies, one in Florida and the other in most of the rest of eastern North America, ranging from the Canadian to the Upper Austral zone:

1. Wings hyaline or almost so, the front wing of the female usually with a brown spot in base of radial cell and apex of discocubital cell (fig. 319,b); range: eastern North America from Canadian to Upper Austral zone.

2a. greenei greenei Viereck

Wings rather uniformly dark brown (fig. 319,c), at least in the female (male unknown); range: Florida . . . . 2b. greenei floridana, new subspecies 


\section{2a. Megarhyssa greenei greenei Viereck}

Figures 318 ,d $319, \mathrm{~b}$

Megarhyssa greenei Viereck, 1911, Proc. U. S. Nat. Mus., vol. 40, p. 191; $\nmid$ ( ( misdetermined). Type: $\$$, Harrisburg, Pa. (Washington).

Biology: Procter, 1938, Biological survey of the Mount Desert region, vol. 6, p. 406.-Fattig, 1949, Ent. News, vol. 40, pp. 70-71.

Morphology: Pratt, 1939, Ann. Ent. Soc. America, vol. 32, p. 737.

Male: Light fulvous brown. Head mostly yellow, with a dark brown band between tops of eyes (enclosing ocelli) and the hind part of head mostly fulvous; mandible black except basally; scape and pedicel brown above; flagellum brown, paler below; hind edge of pronotum, anterolateral margin of mesoscutum, front and hind margins of mesopleurum and mesosternum, area surrounding subtegular ridge, front and hind margins of metapleurum, and apex of propodeum, blackish or dark brown; propleurum except dorsally, wide upper margin of pronotum, more or less of anteroventral and hind margins of pronotum, inner and outer edges of lateral lobe of mesoscutum, scutellum, postscutellum, an irregular submarginal band around mesopleurum, hind part of metapleurum, and apicolateral part of propodeum, pale yellow; front and middle legs pale fulvous or their tibiae and tarsi largely yellowish, the front coxa in front, more or less of middle coxa basolaterally, front and middle trochanters, and femora in front, with a variable amount of pale yellow; hind coxa basodorsally and apex of hind femur pale yellow; posteroventral part of hind coxa usually brownish; extreme apex of first tergite, base of third tergite, and base, apex, and side of second tergite dark brown; first two or three tergites with a short preapical yellowish band; third through sixth tergites usually brownish medially; wings hyaline, the apex of front wing faintly infuscate.

Female: Head, thorax, and legs colored as in the male; abdomen light fulvous brown, the tergites darker brown near apex and each tergite with a yellow subapical band that parallels its apical margin, the bands on the third and following tergites interrupted on the midline; wings with a faint yellowish-brown tinge, the apex of front wing faintly infuscate and the front wing usually with a large brown spot in basal half of radial cell and apex of discocubital cell.

Female specimens from the Canadian zone usually lack the brown spot in the front wing. Those from the colder parts of the Transition zone may or may not have the spot or may have it weakly developed. Females from more southern zones always have the spot.

Specimens $\left(245 \sigma^{x}, 261\right.$ ㅇ) : From Alabama (Coosa River in Chilton Co.); Connecticut (Colebrook); Delaware (New Castle Co.); District of Columbia (Rock Creek Park); Georgia (Atlanta and Burton at 1,800 ft.); Illinois (Chicago, Edgewood, Moline, and Riverside); 
Indiana (Monroe-Morgan State Forest in Morgan Co.); Iowa (Henry Co. and Madison Co.); Kansas (Douglas Co. and Topeka); Maine (Bar Harbor, Lincoln Co., and Monmouth); Maryland (Cabin John, Glen Echo, and Plummers Island); Massachusetts (Amherst, Boston, Duxbury, Forest Hills, Milton, Mount Wachusett near Princeton, Pepperell, and Winchendon); Michigan (Ann Arbor, Aurelius, Branch Co., Cass Co., Detroit, Douglas Lake in Cheboygan Co., East Lansing, George Reserve in Livingston Co., Genesee Co., Gratiot Co., Jackson Co., Lake City, Midland Co., Port Austin, Saginaw, Sanilac Co., and Williamston); Minnesota (Camp Carlos near Alexandria, Fish Hatchery in Le Sueur Co., Goodhue, Hennepin Co., Houston Co., Itasca Park, Lake City, Mille Laes Co., Norman Co., and St. Anthony Park); New Hampshire (Bartlett and Mount Washington); New
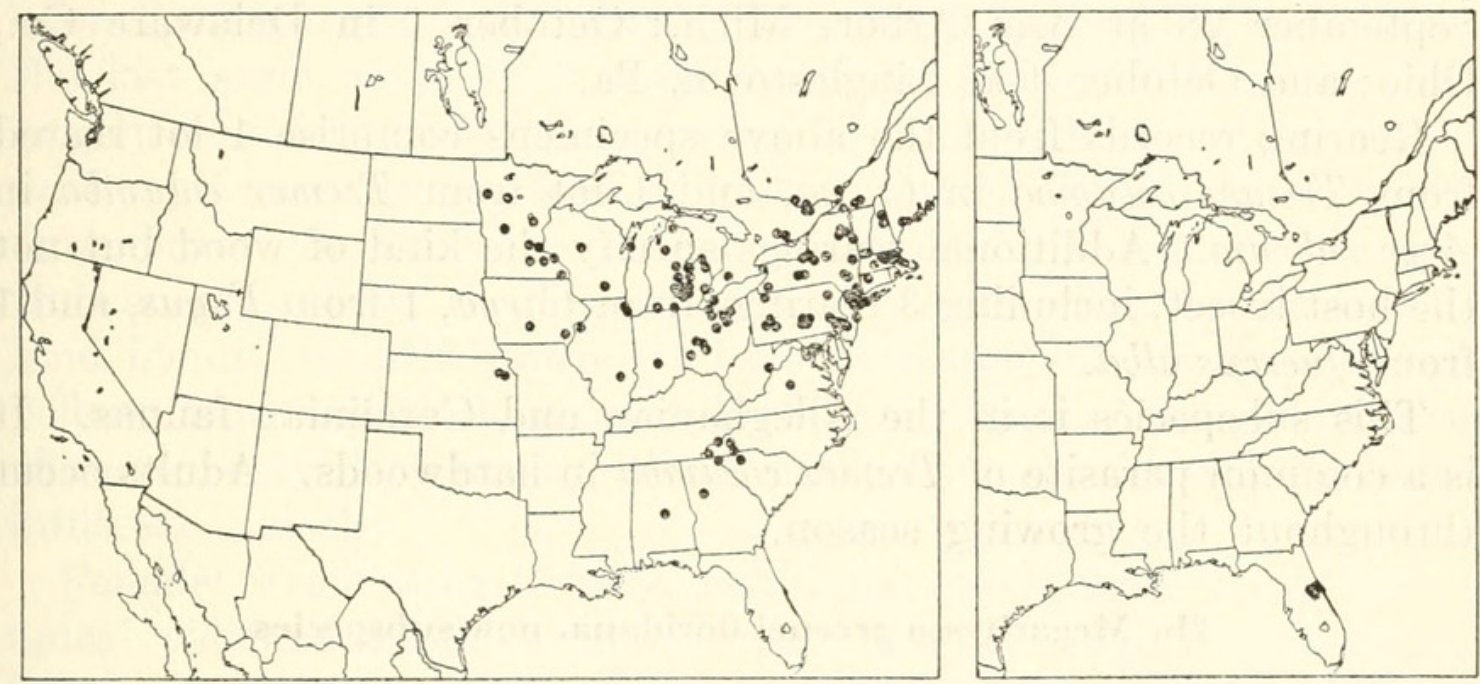

Figures 187, 188.-Localities: 187 (left), Megarhyssa greenei greenei; 188 (right), M. g. floridana.

Jersey (Allaire State Park in Monmouth Co., Englewood, Fort Lee, Greenwood Lake in Passaic Co., Medford Lakes, Palisades, Ramapo Mts., and Ramsey); New York (Beaver Pond in Michigan Hollow at Danby, Bemus Point, Bronxville, Farmingdale, Flushing, Fort Ann, Greene Co. at 2,500 ft., Heart Lake in Essex Co., Ithaca, Keene Valley in Essex Co., top of Mount MacIntyre in Essex Co., New Rochelle, North Fairhaven, New York City, Oliverea in the Catskills, Oswego Co., Poughkeepsie, Rome, Syracuse, Troy, Wading River, and West Farms in New York City); North Carolina (Murphy, North Fork of the Swannanoa River in the Black Mts., and Tryon); Nova Scotia (Kentville); Ohio (Akron, Ashland Co., Delaware Co., Erie Co., Greene Co., Hardin Co., Hinckley in Medina Co., Montgomery Co., Puritas Springs in Cuyahoga Co., Put-in-Bay, and Salt Rock Township in Marion Co.); Ontario (Britannia, Foxborough, Harold, London, Merivale, Niagara Glen, Ottawa, and Point Pelee); 
Pennsylvania (Castle Rock in Delaware Co., Corry, Germantown, Harrisburg, Jeannette, Linglestown, Overbrook, Philadelphia, Pittsburgh, Pottstown, Sharpsburg, Shiremanstown, Spring Brook, Stoverdale in Dauphin Co., and Valley Forge); Quebec (Aylmer, Fort Coulonge, Hemmingford, Joliette, Knowlton, and Sherbrooke); South Carolina (Greenville); Tennessee (Headquarters of Great Smoky Mountains National Park); Virginia (Black Pond in Fairfax Co., Falls Church, Great Falls, and Nelson Co.); Vermont (Jacksonville and Laurel Lake near Jacksonville); West Virginia (Cheat Mt. at 2,000 ft. in Randolph Co.); and Wisconsin (Door Co., Madison, and Worden Township in Clark Co.).

Collection dates are from rather early spring to mid-fall, the earliest and latest dates being: May 2 in Delaware Co., Ohio; May 5 at Falls Church, Va.; May 8 at Ithaca, N. Y., and at Harrisburg, Pa.; September 28 at Ann Arbor, Mich.; October 1 in Delaware Co., Ohio; and October 4 at Linglestown, Pa.

Rearing records from the above specimens comprise 1 lot reared from Tremex columba in Carya, and 1 lot from Tremex columba in Acer rubrum. Additional rearings specify the kind of wood but not the host insect, including 3 rearings from Carya, 1 from Fagus, and 1 from Quercus alba.

This subspecies is in the Alleghanian and Carolinian faunas. It is a common parasite of Tremex columba in hardwoods. Adults occur throughout the growing season.

\section{2b. Megarhyssa greenei floridana, new subspecies}

Figure 319,c

\section{Male: Unknown.}

Female: Coloration similar to female of $M$. greenei greenei except that ground color is more reddish brown, yellow markings a little reduced, and wings almost uniformly dark brown.

Type: $\circ$, in trap, Winter Park, Fla., Apr. 1, 1936, O. D. Link (Washington, USNM 63720).

Paratypes: $\odot$, in trap, Maitland, Fla., Sept. 9, 1936, O. D. Link (Washington). \&, Orlando, Fla., March 1944, R. and G. Bohart (Townes).

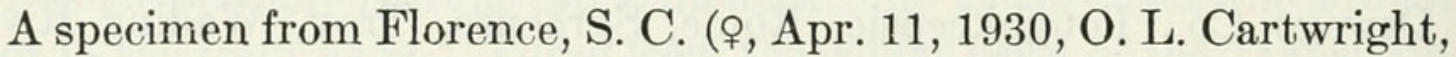
Townes collection) is intermediate between this subspecies and typical greenei, the wings being light brown with a darker area in the basal half of radial cell and apex of discocubital cell.

\section{Megarhyssa atrata (Fabricius)}

Male: Front wing 16 to $22 \mathrm{~mm}$. long; cheek about 1.0 as long as apical width of mandible; median part of apical edge of first sternite 
at or a little beyond spiracle of first tergite; median longitudinal membranous streak of tergites $3-5$ extending about 0.25 the length of the tergite; apicolateral angles of tergites $3-5,75^{\circ}$ to $90^{\circ}$.

Head yellow, a band between tops of eyes (enclosing ocelli) and a band of variable width along upper part of occipital carina, dark brown; mandible blackish apically, brown medially, and yellowish basally; antenna dark brown, paler below, the scape yellowish in front; thorax blackish brown; propleurum except above, broad upper margin of pronotum, variable marks along front, lower, and hind edges of pronotum, a pair of median longitudinal stripes on mesoscutum, a narrow stripe on mesoscutum next base of front wing, scutellum, postscutellum, subtegular ridge, a large area occupying most of posterodorsal half of mesopleurum, broad longitudinal sublateral blotches or stripes on propodeum, and narrow stripe along posterodorsal margin of metapleurum, yellow; front and middle legs yellow, the last segment of their tarsi yellowish brown, the middle coxa largely blackish brown except dorsally, the middle first trochanter partly blackish brown, and the basal part of middle femur partly dark brown or blackish; hind coxa blackish, yellow above; hind trochanters yellow, the first trochanter usually dark brown basally; hind femur blackish brown, its base narrowly and its apex broadly yellow; hind tibia and tarsus yellowish, the apex of tarsus brownish; abdomen very dark brown; wings subhyaline, the front wing faintly infuscate apically.

Female: Front wing 15 to $30 \mathrm{~mm}$. long; cheek about 1.1 as long as apical width of mandible; median part of apical edge of first sternite just in front of spiracle of first tergite; apicolateral angles of fourth and fifth tergites about $105^{\circ}$; fourth tergite with fine, rather dense punctures basally and ventrally, the rest with fine, indistinct, sparse punctures; ovipositor sheath about 3.7 as long as front wing.

Black. Head yellow with a narrow brown band between tops of eyes (enclosing ocelli); mandible blackish, its base yellow; palpi and antenna yellow; thorax sometimes with a small yellow spot on posterodorsal corner of pronotum, rarely with yellow markings on some or all of: subtegular ridge, scutella, and a pair of narrow median longitudinal stripes on mesoscutum; coxae black; trochanters black except that front trochanters are more or less brown or yellow; front femur yellow; middle and hind femora black, the middle femur and sometimes the hind femur yellow at apex; tibiae and tarsi yellow, the tarsi brownish apically; wings hyaline with the apex of front wing faintly infuscate, or entirely black, according to the subspecies.

This is the largest Nearctic ichneumonid. Females measure up to $4.0 \mathrm{~cm}$. in length without the ovipositor and up to $16 \mathrm{~cm}$. with the 
ovipositor. There is a northern and a more southern subspecies, distinguishable in the female on wing color. Differentiating characters have not yet been found for the males.

Although the two subspecies are rather easily distinguished in the female, a number of intermediate females have been seen from localities where the ranges border or overlap. The localities of these are as follows: Connecticut (South Windsor); Massachusetts (Milton and Northampton); Michigan (Midland Co.); New York (Ithaca, Roslyn, and Taughannock Falls); Ontario (Ancaster and Leamington); and Pennsylvania (Spring Brook).

A key distinguishing females of the two subspecies is below:

1. Wings of female hyaline or subhyaline; range: Canadian zone of eastern North America and cooler parts of Alleghanian fauna.

3a. atrata lineata Porter

Wings of female blackish; range: Alleghanian, Carolinian, and Austroriparian faunas. . . . . . . . . . . . 3b. atrata atrata (Fabricius)

\section{3a. Megarhyssa atrata lineata Porter}

Megarhyssa atrata lineata Porter, 1957, Ent. News, vol. 68, p. 206; 9 .

Types: 2 , Franconia, N. H. (New York).

Male: Indistinguishable from male of $M$. atrata atrata.

Female: Yellow markings on thorax, as described under the species, more frequent and more extensive than in the subspecies $M$. atrata atrata; wings varying from hyaline with a faint infuscation on apex of front wing, to weakly infuscate.

Specimens (85o): From Maine (Bar Harbor); Michigan (Cheboygan Co., Floodwood in Dickinson Co., and Owosso); New Brunswick (Fredericton); New Hampshire (Franconia); Nova Scotia (South Milford and Wolfville); New York (Allegany State Park, Bemus Point, Heart Lake in Essex Co., Ithaca, Labrador Lake in Cortland Co., McLean Bogs Reserve in Tompkins Co., New York City, Nineveh, Onteora Mt. in Greene Co., Spencer, Taughannock Falls, and West Farms in New York City); Ontario (Arnprior, Britannia, Harold, Marmora, Merivale, Niagara Glen, and Ottawa); Pennsylvania (Corry); Quebec (Chambly, Covey Hill, Hemmingford, Knowlton, and Lac McGregor); Vermont (Jacksonville and Laurel Lake near Jacksonville); and Wisconsin (Baileys Harbor).

There are a number of males taken with these females, or in the same general area. Although most of them could be assigned to the subspecies lineata on the basis of locality alone, they cannot be distinguished from males of the subspecies atrata, so are not listed.

Collection dates are from late spring to late summer, the earliest and latest dates being: May 27 and 28 at Ithaca, N. Y.; May 29 at Taughannock Falls, N. Y.; June 5 at Ottawa, Ont.; August 1 at Flood- 
wood, Dickinson Co., Mich.; and August 21 and 26 at Bemus Point, N. Y.

Two of the above females were reared from Tremex columba in Acer rubrum, at Bar Harbor, Maine, by A. E. Brower.

This subspecies occurs in the Canadian zone and in some cooler parts of the Transition zone.
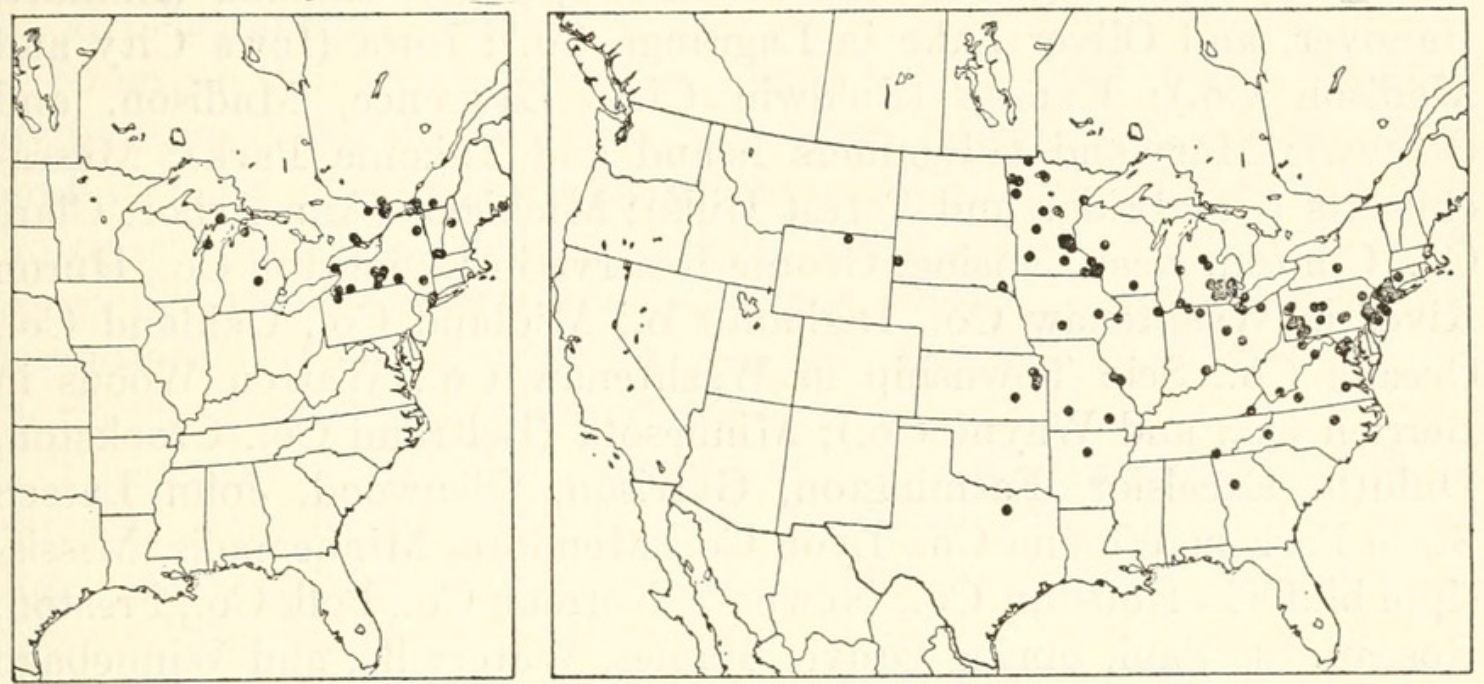

Figures 189, 190.-Localities: 189 (left), Megarhyssa atrata lineata; 190 (right), M. a. atrata.

\section{3b. Megarhyssa atrata atrata (Fabricius)}

Figure 318 ,e

Ichneumon atratus Fabricius, 1781, Species insectorum, vol. 1, p. 436; 우 Type: q, North America (lost).

Ichneumon tenebrator Thunberg, 1822, Mém. Acad. Imp. Sci. St. Pétersbourg, vol. 8, p. 266. New name.

Rhyssa laevigata Brullé, 1846, in Lepeletier: Histoire naturelle des insectes, hyménoptères, vol. 4, p. 78; $\sigma^{7}$. Lectotype (hereby designated): $\sigma^{7}$, labeled lectotype by Townes, no data on specimen (Paris).

Biology: Harris, 1842, . . I Insects . . . injurious to vegetation, p. 391.Walsh, 1867, Pract. Ent., vol. 2, p. 118.-Walsh and Riley, 1868, Amer. Ent., vol. 1, p. 77.-Harrington, 1882, Canadian Ent., vol. 14, p. 82.-Lintner, 1883, Cultivator and Country Gentleman, vol. 48, p. 561.-Harrington, 1883, Ann. Rep. Ent. Soc. Ontario, no. 13, pp. 23-24; 1887, Canadian Ent., vol. 19, pp. 206-209; 1888, Ann. Rep. Ent. Soc. Ontario, no. 18, p. 25.-Lintner, 1897, Cultivator and Country Gentleman,vol. 62, p. 506.-Fyles,1916, Ann.Rep. Ent. Soc. Ontario, no.46, pp. 54, 57.-Macnamara, 1916, Ann. Rep. Ent. Soc. Ontario, no. 46, p. 59.-Champlain, 1921, Ent. News, vol. 32, p. 241.-Blackman and Stage, 1924, Techn. Publ. New York State Coll. Forestry, Syracuse Univ., no. 17, p. 178.-Klugh, 1932, Amer. Photography, vol. 26, p. 158.-Kaston, 1937, Bull. Connecticut Agr. Exp. Sta., no. 396, p. 359.-Proctor, 1938, Biological survey of the Mount Desert region, vol. 6, p. 406.-Fattig, 1949, Ent. News, vol. 40, pp. 69-71.

Morphology: Snodgrass, 1933, Smithsonian Misc. Coll. vol., 89, no. 8, pp. $112-114$. 
Male: Indistinguishable from the male of $M$. atrata lineata.

Female: Upper hind corner of pronotum sometimes with a small yellow mark, the thorax otherwise entirely black; wings blackish or strongly infuscate.

Specimens (2719): From Arkansas (Clinton); Connecticut (Litchfield); District of Columbia (Rock Creek Park); Florida; Georgia (Atlanta); Illinois (Moline and Willow Springs); Indiana (Elkhart, Hanover, and Oliver Lake in Lagrange Co.); Iowa (Iowa City and Madison Co.); Kansas (Baldwin City, Lawrence, Madison, and Ottawa); Maryland (Plummers Island and Takoma Park); Massachusetts (Cambridge and Forest Hills); Michigan (Ann Arbor, Clare Co., Clinton, East Lansing, George Reserve in Livingston Co., Huron River in Washtenaw Co., Ingham Co., Midland Co., Oakland Co., Oceana Co., Scio Township in Washtenaw Co., Warren Woods in Berrien Co., and Wayne Co.); Minnesota (Beltrami Co., Crookston, Duluth, Excelsior, Farmington, Garrison, Glenwood, John Latsch State Park in Winona Co., Lyon Co., Mendota, Minneapolis, Mississippi bluffs in Houston Co., Newport, Norman Co., Polk Co., Preston, Roseau, St. Paul, Spring Grove, Staples, Waterville, and Winnebago Creek Valley in Houston Co.); Missouri (Creve Coeur Lake in St. Louis Co., Van Buren, Webster Groves, and Willard); New Jersey (Allaire State Park in Monmouth Co., Boonton, Branchville, Englewood, Moorestown, Paterson, and Princeton); New York (Bronxville, Fort Montgomery, Greenwood Lake, North Beach on Long Island, Poughkeepsie, Rockland Co., Taughannock Falls near Ithaca, Van Courtland Park in New York City, West Farms in New York City, and Wyandanch); North Carolina (Raleigh and valley of the Black Mts.); Ohio (Cedar Point, Columbus, Hinckley in Medina Co., Logan Co., and Put-in-Bay); Ontario (Pelee Island); Pennsylvania (Angora in Philadelphia Co., Camp Deer Creek, Charter Oak in Huntingdon Co., Easton, Eberly's Mill in Cumberland Co., Guyasuta Run in Pittsburgh, Jeannette, Linglestown, Manor, Markleton, Mount Blaine near Canonsburg, Ohiopyle, Overbrook, Philadelphia, Pittsburgh, Portersville, Rockview in Centre Co., Slippery Rock, and Spring Brook); South Dakota (Black Hills and Yankton); Tennessee (Chattanooga); Texas (Dallas); Virginia (Allegheny Springs, Dead Run in Fairfax Co., Great Falls, Petersburg, and Stone Creek in Lee Co.); West Virginia (Lost River State Park in Hardy Co., along mountain ridge near Crumpler in McDowell Co., and Preston Co.); Wisconsin (Madison and Worden Township in Clark Co.); and Wyoming (Sheridan). There are a large number of males taken with these females, or in the same general area. They can be assigned to the subspecies on the basis of locality, but are not listed because they are indistinguishable as specimens from the subspecies lineata. 
Most specimens were collected from mid-spring to early fall. Unusually early and late dates of capture are: April 17 in Norman Co., Minn.; April 27 in Van Cortland Park, New York City; May 2 in Black Mts., N. C. and at Plummers Island, Md.; May 10 at Clinton, Ark. and at Linglestown, Pa.; September 9 at Madison, Wis.; September 15 at Plummers Island, Md.; September 20 on Mount Blaine, near Canonsburg, Pa.; September 30 at Columbus, Ohio; and October 11 at Chattanooga, Tenn.

Some of the above specimens were reared from wood or found ovipositing in wood. There are 2 rearings from Carya, 1 from Fagus, and 1 record of a female ovipositing in Carya. The subspecies has, however, been observed ovipositing scores of times and there are some published records (see references above) of miscellaneous observations. It is considered to be always parasitic on Tremex columba boring in dead or dying hardwoods.

This subspecies is in the Alleghanian, Carolinian, and Austroriparian faunas. It is found flying through hardwood forests, or on or about logs, trees, or stumps infested with Tremex columba. Adults occur from mid-spring to early fall.

\section{Megarhyssa macrurus (Linnaeus)}

Male: Front wing 7 to $21 \mathrm{~mm}$. long; cheek about 0.7 as long as apical width of mandible; median part of apical edge of first sternite at or a little beyond spiracle of first tergite; median membranous streak of tergites $3-5$ extending about 0.5 the length of the tergite; apicolateral angles of tergites $3-5$ about $60^{\circ}$.

Female: Front wing 18 to $29 \mathrm{~mm}$. long; cheek about 0.9 as long as apical width of mandible; median part of apical edge of first sternite about opposite middle of spiracle of first tergite; apicolateral angles of fourth and fifth tergites about $85^{\circ}$; fourth tergite covered with fine, rather dense punctures except near apex; ovipositor sheath about 3.0 as long as front wing.

There are three subspecies, as keyed and described below:

MALES

1. First and second tergites without a subapical yellow band, or rarely with a trace of a band; wings suffused with yellowish brown and with darker yellowish brown spots; range: west of Rocky Mts.

4c. macrurus icterosticta Michener

First and second tergites with a subapical yellow band; wings hyaline or suffused with brown, also with brown spots . . . . . . . . . . . . . 2

2. Wings hyaline, the front wing with brown spots (fig. 319,d); range: Canadian, Transition, and Upper Austral zones east of Rocky Mts.

4a. macrurus lunator (Fabricius)

Wings suffused with brown, the front wing with brown spots; range: Lower Austral zone east of Rocky Mts, . . . 4b. macrurus macrurus (Linnaeus) 


\section{FEMALES}

1. Tergites 4-6 with a large yellow blotch on each side that covers much or most of the side (fig. $318, \mathrm{~g}$ ) ; wings suffused with yellowish brown and with darker yellowish-brown blotches (fig. 319,g); range: west of Rocky Mts.

4c. macrurus icterosticta Michener

Tergites 4-6 with a narrow, angular, yellow subapical band on each side (fig. $318, \mathrm{f}$ ). . . . . . . . . . . . . . . . . . . . . . . . . . 2

2. Wings hyaline or with a light brown suffusion, the front wing with brown markings (fig. 319,e); range: Canadian, Transition, and Upper Austral zones east of Rocky Mts. . . . . . . 4a. macrurus lunator (Fabricius)

Wings brown, the front wing with paler areas (fig. 319,f); range: Lower Austral zone east of Rocky Mts. . . 4b. macrurus macrurus (Linnaeus)

\section{4a. Megarhyssa macrurus lunator (Fabricius)}

\section{Figures 318,f; 319,d,e}

Ichneumon lunator Fabricius, 1781, Species insectorum, vol. 1, p. 430; $\uparrow$. Type: \&, North America (lost).

Thalessa? histrio Kriechbaumer, 1890, Ann. Naturh. Hofmus, Wien, vol. 5, p. 487; $\sigma^{\top}$. Name preoccupied in Megarhyssa by Christ. Type: $\sigma^{\top}$, White Mts. of North America [probably New Hampshire] (Vienna).

Biology: Harris, 1842, . . . Insects . . . injurious to vegetation, p. 391.-Emmons, 1854, Agriculture . . . , in Natural History of New York, pt. 5, vol. 5, p. 194.-D'Urban, 1865, Ent. Monthly Mag., vol. 2, p. 71.-Riley, 1870, Amer. Ent., vol. 2, p. 96, 128.-Fletcher, 1881, Ann. Rep. Ent. Soc. Ontario, no. 11, p. 67.-Harrington, 1882, Canadian Ent., vol. 14, p. 82; 1883, Ann. Rep, Ent. Soc. Ontario, no. 13, pp. 23-24.-Gade, 1884, Bull. Brooklyn Ent. Soc., vol. 7, p. 103.--Lintner, 1884, Cultivator and Country Gentleman, vol. 49, p. 331.-Riley, 1885, Bull. Brooklyn Ent. Soc., vol. 7, p. 123.-Smith, 1885. Bull. Brooklyn Ent. Soc., vol. 7, p. 124.-Riley, 1886, Proc. Ent. Soc, Washington, vol. 1, p. 15.-Harrington, 1887, Canadian Ent., vol. 19, pp, 206-209.-Lintner, 1888, Rep. New York State Mus. Nat. Hist., no. 41. pp. 35-42.-Harrington, 1888, Ann. Rep. Ent. Soc. Ontario, vol. 18, pp. 25-27.-Riley, 1888, Insect life (U. S. Dep. Agr.), vol. 1, pp. 168-179.Lintner, 1889, Rep. New York State Ent., no. 4, pp. 35-36; 1893, Rep. New York State Mus. Nat. Hist., no. 45, pp. 163-166; 1897, Cultivator and Country Gentleman, vol. 62, p. 506.-Ashmead, 1900, Ann. Rep. New Jersey State Board Agr., suppl. to no. 27, p. 572.-Fyles, 1911, Ann. Rep. Ent. Soc. Ontario, vol. 41, p. 80.-Douglas, 1912, Ann. Rep. State Ent. Indiana, no. 4, p. 105.-Baldwin, 1914, Ann. Rep. State Ent. Indiana, no. 6, p. 51.-Fyles, 1916, Ann. Rep. Ent. Soc. Ontario, no. 46, pp. 54, 57; 1917, Ann. Rep. Ent. Soc. Ontario, vol. 47, p. 28.-Barlow, 1921, Ent. News, vol. 32, p. 291.Cushman, 1926, Proc. Ent. Soc. Washington, vol. 28, p. 32.-McDaniel, 1933, Spec. Bull. Michigan Agr. Exp. Sta., no. 238, p. 37.-Woodbury, 1933, Ecol. Monogr., vol. 3, p. 191.-Abbott, 1934, Journ. New York Ent. Soc., vol. 42, pp. 127-133; 1934, Psyche, vol. 41, pp. 238-240; 1937, Ent. News, vol. 47, pp. 263-264.-Kaston, 1937, Bull. Connecticut Agr. Exp. Sta., no. 396, p. 359.-Kelley, 1939, Nature Mag., vol. 32, pp. 379-380.-Townes, 1939, Bull. Brooklyn Ent. Soc., vol. 34, p. 29.-Fattig, 1949, Ent. News, vol. 40 , pp. 69-71.

Morphology: Abbott, 1934, Journ. New York Ent. Soc., vol. 42, pp. 127-133; 1934, Bull. Brooklyn Ent. Soc., vol. 29, pp. 39-41; 1935, Bull. Brooklyn Ent. Soc., vol. 30, pp. 10-13.-Peck, 1937, Canadian Journ. Res., sect. D 
(Zool. Sci:), vol. 15, pp. 237-240, 246, 247, 251.-Pratt, 1939, Ann. Ent. Soc. America, vol. 32, p. 733.-Snodgrass, 1941, Smithsonian Misc. Coll., vol. 99 , no. 14 , pp. 33,34 .

Male: Brown. Head yellow, with vertical stripe on face below each antennal socket, area on frons above each antennal socket, stripe from eye to base of mandible, stripe between tops of eyes (enclosing ocelli), and stripe on and in front of occipital carina, brown; mandible black, yellow basally; palpi yellowish; scape and pedicel light brown except above; flagellum dark brown, its apical half paler; side and sometimes bottom edge of propleurum, broad band along upper margin of pronotum, variable marks along front, anteroventral, and hind edges of pronotum, a pair of median longitudinal stripes on mesoscutum (interrupted at notauli), lateral margin of mesoscutum, most of scutellum, postscutellum, subtegular ridge, stripe bordering front, lower, and hind margins of mesepisternum, apicolateral areas on propodeum, and most of mesopleurum, yellow; front leg yellow, its tarsus yellowish brown apically, its coxa and femur brown behind, and its tibia with a subbasal brownish mark behind; middle leg colored like front leg but with more brown on its coxa and femur, and base of its first trochanter brown; hind coxa brown, its base above and more or less of its anterodorsal and posterodorsal edges, yellow; first hind trochanter brown, yellow apically; second hind trochanter yellow; hind femur light brown, its apex and often some or all of its dorsal edge yellow; hind tibia yellowish, with a brownish area subbasally above; hind tarsus yellow; wings hyaline, with a spot in basal half of radial cell and apex of discocubital cell and its apex brownish; first and second tergites with a short subapical yellow band.

Female: Head, thorax, and legs colored as in the male except that brown markings on legs are usually a little more extensive. First tergite with a short preapical yellow band; second tergite with a similar but longer band; third and following tergites with a preapical

Figure 191.-Localities for Megarhyssa macrurus lunator.

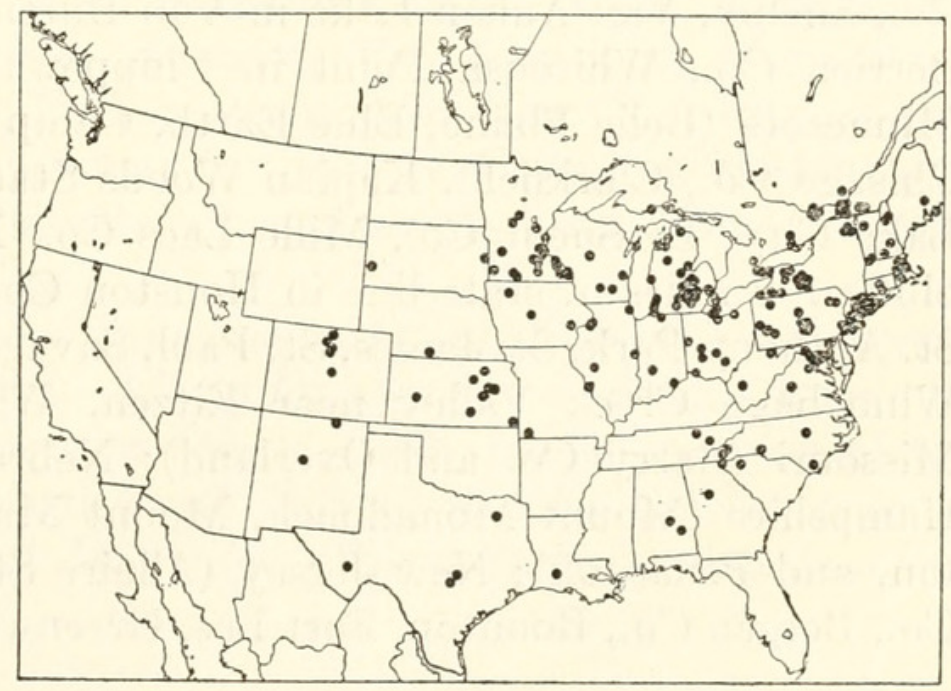


yellow band paralleling the apical margin, the band interrupted on the midline on all except the seventh tergite. The yellow markings on all of the abdominal tergites are margined with darker brown or fuscous so that they contrast sharply with the ground color; wings hyaline or lightly suffused with brown, with brown markings approximately as in figure 319 ,e, there always being at least a little brown along the basal vein.

This subspecies intergrades freely along the southern edge of its range with the subspecies macrurus. It is a weak subspecies whose distinguishing character, the less extensive brown coloration of the wings, is in the nature of a geographic cline, and whether it is worth distinguishing is a matter of opinion.

Specimens (390 $\sigma^{x}, 410$ ) $)$ : From Alabama (Coosa River in Chilton Co. and Tuskega Army Airfield in Macon Co.); Colorado (Boulder, Brighton, Colorado Springs, Denver, and Fort Collins); Connecticut (New Haven, South Meriden, and Westport); District of Columbia (Georgetown and Rock Creek Park); Georgia (Atlanta and Black Rock Mt. in Rabun Co. at 3,500 ft.); Illinois (Chicago, Danville, Jacksonville, Moline, and Rock Island); Indiana (Elkhørt, Hanover, and Monroe-Morgan State Forest in Morgan Co.); Iowa (Ames, Iowa City, and Ruthven); Kansas (Cherokee Co., "Colbert," Emporia, Garden City, Lawrence, Manhattan, Onaga, Topeka, and Wichita); Louisiana (Bayou Nezpique in Acadia Parish); Maine (Bangor and Bar Harbor); Maryland (Baltimore Co., Bowie, Glen Echo, Plummers Island, and Takoma Park); Massachusetts (Boston, Cambridge, Forest Hills, Holliston, Lexington, and Reading); Michigan (Ann Arbor, Antrim Co., Aurelius, Base Lake in Wastenaw Co., Benton Harbor, Branch Co., Calhoun Co., Coloma, Detroit, Douglas Lake in Cheboygan Co., East Lansing, Flint, George Reserve in Livingston Co., Gladwin Co., Lake Charlevoix, Lake City, Lansing, Leelanau Co., Manchester, Midland Co., Milford, Onota Township in Alger Co., Owosso, Paw Paw Lake, Saginaw Co., Scio Township in Washtenaw Co., Shelby, Van Auken Lake in Van Buren Co., Warren Woods in Berrien Co., Whitefish Point in Chippewa Co., and Wyandotte); Minnesota (Belle Plaine, Blue Earth, Camp Carlos near Alexandria, Chisago Co., Clarkfield, Kaplan Woods State Park near Owatonna, Lake City, Le Sueur Co., Mille Lacs Co., Minneapolis, Mississippi bluffs 1-2 miles n. state line in Houston Co., Olmsted Co., Preston, St. Anthony Park, St. James, St. Paul, Savage, Spring Grove, Staples, Winnebago Creek Valley near Eitzen, Winona, and Woodstock); Missouri (Barry Co. and Overland); Nebraska (Cambridge); New Hampshire (Mount Monadnock, Mount Madison, Mount Washington, and Penacook); New Jersey (Allaire State Park in Monmouth Co., Bergen Co., Boonton, Fort Lee, Greenwood Lake in Passaic Co., 
Maplewood, Moorestown, Paterson, Princeton, Ramsey, Riverside, Riverton, and Springfield); New Mexico (Albuquerque and Raton); New York (Allegany State Park, Bemus Point, Bronxville, Dundee, Dyker Heights in Brooklyn, Elmira, Farmingdale, Flushing, Fort Montgomery, Hastings on Hudson, Ithaca, Maspeth, McLean Bogs Reserve in Tompkins Co., top of Mount Marcy, New York City, "North Beach" on Long Island, North Elba, Old Tappan, Portageville, Port Chester, Rochester Junction, Sea Cliff, Schuyler Co., Staten Island, Taughannock Falls, West Farms in New York City, Westport, White Plains, Wilmington, Wyandanch, and Yonkers); North Carolina (Bryson City at 3,000 to 5,000 ft., Durham, Gastonia, Lake Waccamaw, and Nantahala Gorge at 2,000 ft.); Ohio (Cincinnati, Columbus, Hinckley in Medina Co., Hocking Co., Logan Co., Mendon, Montgomery Co., Put-in-Bay, and Sandusky); Ontario (Ancaster, Britannia, Guelph, Harold, Leamington, Merivale, Niagara Glen, Ottawa, Pelee Island, St. Catherines, and Trenton); Pennsylvania (Angora in Philadelphia Co., Corry, Craigheads in Cumberland Co., Eberly's Mill in Cumberland Co., Guyasuta Run in Pittsburgh, Harrisburg, Jeannette, Linglestown, New Cumberland, North East, Overbrook, Philadelphia, Pittsburgh, Portersville, Rockview in Centre Co., Scranton, Shiremanstown, and Spring Brook); Quebec (Hemmingford, Hull, Joliette, Kirk's Ferry, Knowlton, Missisquoi River at Bolton, Montreal, Rigaud, and Vaudreil); Rhode Island (Providence); South Carolina (Greenville); South Dakota (Black Hills and Volga); Tennessee (Oak Ridge and Fentress Co.); Texas (Alpine, Gillespie Co., Hunt Co., and Kerrville); Vermont (Jacksonville, Laurel Lake near Jacksonville, and Stowe); Virginia (Falls Church, Great Falls, Manassas, and Nelson Co.); West Virginia (Bolivar, Kanawha Co. and Preston Co.); and Wisconsin (Bailey's Harbor, Cedar Lake, Jefferson, Madison, and Worden Township in Clark Co.).

Most of the above specimens were collected between mid-spring and early fall. The earliest and latest dates of capture are: April 2 in Hunt Co., Tex.; April 16 at Waccamaw Lake, N. C.; April 22 at Kerrville, Tex.; April 30 at Scranton, Pa.; May 3 at Manhattan, Kans.; May 8 at Ithaca, N. Y.; October 8 at New York City and at Ann Arbor, Mich.; October 9 at Durham, N. C. and at Washington, D. C.; October 18 at Danville, Ill. and at Madison, Wis.; and November 16 at Austin, Tex.

The subspecies has about the same habits as all the other Nearctic Megarhyssa except nortoni. Adults fly about in deciduous woods or often in parks and the edges of cities. They occur in numbers about logs, stumps, or trees infested with Tremex columba, usually in company with $M$. greenei and $M$. atrata. The published accounts of its 
biology, particularly its ovipositing habits, are numerous. See the list of references above.

The specimens before us contain one lot reared from Tremex columba at Bar Harbor, Maine, by A. E. Brower and a number of lots reared from or found ovipositing in various woods without indication of the insect host. These records include 1 from Acer negundo, 1 from Acer rubrum, 4 from Acer sp., 3 from Carya, 1 from Celtis, 1 from Fagus, 1 from Quercus alba, and 1 from Ulmus.

This subspecies is in the Canadian, Transition, and Upper Austral zones east of the bundredth meridian and occurs also on the eastern slopes of the Rocky Mountains. There are a few scattered records in other, but adjacent areas. See the distribution map. Adults occur mostly from mid-spring to early fall.

\section{4b. Megarhyssa macrurus macrurus (Linnaeus)}

Figure $319, \mathbf{f}$

Ichneumon macrurus Linnaeus, 1771, Mantissa plantarum, vol. 2, p. 540; Type: + , near Charleston, S. C. (lost).

Ichneumon Georgicus Megerle, 1802, Appendix ad catalogum insectorum, quae mense Novembris 1802 Vienne Austriae auctionis lege vendita fuere, p. 16. New synonymy. Type: $\uparrow$, Georgia (lost).

Megarhyssa lunator phaeoptila Michener, 1939, Pan-Pacific Ent., vol. 15, p. 129; ๆ. New synonymy. Type: $\uparrow$, Victoria, Tex. (Washington).

Distinguished from the subspecies lunator by the more extensive brown markings of the wings, as shown in figure $319, \mathrm{f}$ and as defined in the keys. Typical females of this subspecies have the wings mostly medium brown with clearer areas. Specimens intermediate to the subspecies lunator are so common where the ranges of the two subspecies are adjacent, that a sharp distinction in character or range is not possible.

The type locality of Ichneumon macrurus was stated as "Habitat in Carolina. D[ono] D[edit] Garden." Alexander Garden was a botanical correspondent of Linnaeus, living at Charleston, S. C. This fact alone would indicate that it belonged to the Austroriparian darkwinged form rather than to the northern form. Further evidence is in the description itself, which states: "Alae fuscae: primoribus fasciis duabus hyalinis: altera in medio, altera prope apicem." For these reasons we are applying the subspecific name macrurus to the southern subspecies, with phaeoptila treated as a synonym. The northern subspecies, previously called macrurus macrurus, becomes macrurus lunator.

The original description of Ichneumon georgicus is as follows: "ex Georg. Stat. et magn. persuas. ruf. Ant. Lut. Thor. Flav. Abd. segm. 1.2 et fem. annulo nig." The type is lost (probably destroyed). We could not find it in the Vienna museum. The "shape and size of 
Rhyssa persuasoria" mentioned in the original description and "rufous" ground color point only to Megarhyssa macrurus and M. greenei. The type may have come from anywhere in Georgia, but most likely from the coastal area (Savannah?), which was the most accessible part around the year 1802. This would indicate that the subspecies was either Megarhyssa macrurus macrurus or $M$. greenei floridana, with the choice between the two rather arbitrary. The name georgicus is hereby assigned to the synonymy of $M$. macrurus macrurus.
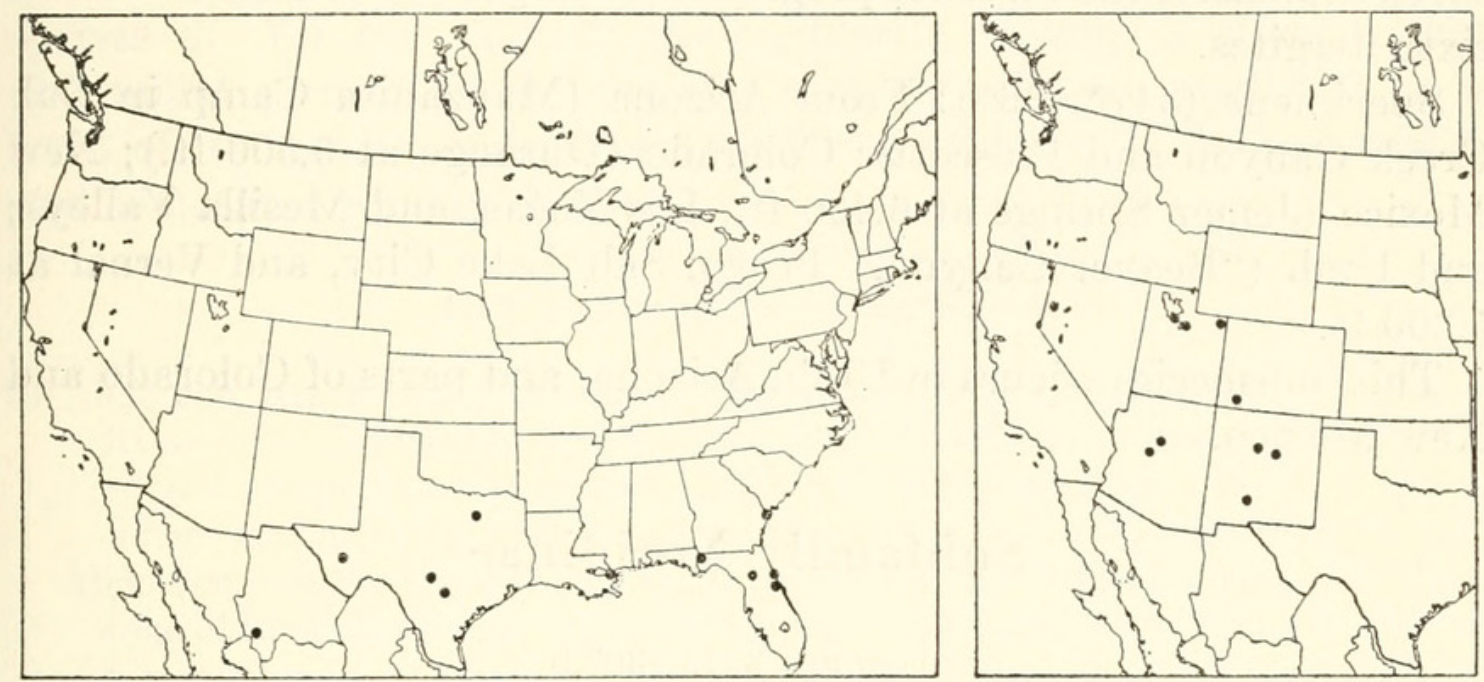

Figures 192, 193.-Localities: 192 (left), Megarhyssa macrurus macrurus; 193 (right), M. m. icterosticta.

Specimens: $\sigma^{7}$, Enterprise, Fla., May 13 (Washington). $3 \sigma^{\top}$, Gainesville, Fla., July 11, 1922, F. W. Walker (Ann Arbor). क, Gainesville, Fla., Sept. 23, 1934, T. H. Hubbell (Ann Arbor). †, Ormond Beach, Fla., May 1956, R. O. Dall? (Washington). $2 \sigma^{7}$, , Torreya State Park, Liberty Co., Fla., June 23, 1956, Ted Cohn (Ann Arbor). ㅇ, Savannah, Ga., Oct. 10, 1946, M. H. Mead (Ithaca). ㅇ, New Orleans, La., F. O. Minor (Washington). ㅇ, Dallas, Tex., Boll (Cambridge). o, Fort Davis, Tex., Oct. 7, 1930 (Ithaca). 2ᄋ, Gillespie Co., Tex., June 14, 1934, J. N. Knull (Columbus). ㅇ, Saldo Creek, Bexar Co., Tex., July 1, 1952 (Berkeley). , 63 miles west of Santa Barbara, Chihuahua, Mexico, July 20, 1947, Spieth (New York).

This subspecies occurs in the Austroriparian fauna.

\section{4c. Megarhyssa macrurus icterosticta Michener}

Figures $318, \mathrm{~g} ; 319, \mathrm{~g}$

Megarhyssa lunator icterosticta Michener, 1939, Pan-Pacific Ent., vol. 15, p. 130; $\sigma^{\top}, \uparrow$. Type: $\uparrow$, Durango, Colo. (Washington).

This is a distinctively colored subspecies, especially in the female. In comparison with $M$. macrurus lunator, the ground color is a paler, 
more yellowish brown; the yellow markings on the head and thorax more extensive and less definitely limited; the antenna ochraceous; the wings suffused with yellowish brown and with darker brown spots or mottling; and the abdominal markings differing as follows: First and second tergites of male without a preapical yellow band; first tergite of female without a preapical yellow band or rarely with a small one; third and following tergites of female with large lateral yellow blotches (in place of the subapical yellow bands of the subspecies lunator), the blotches progressively larger toward the fifth and sixth tergites.

Specimens $\left(34 \sigma^{x}, 36\right.$ ) : From Arizona (Manzanita Camp in Oak Creek Canyon and Prescott); Colorado (Durango at 6,500 ft.); New Mexico (Jemez Springs at 6,400 ft., Las Vegas, and Mesilla Valley); and Utah ("Beaver Canyon," Provo, Salt Lake City, and Vernal at $5,300 \mathrm{ft}$.).

This subspecies occurs in Utah, Arizona, and parts of Colorado and New Mexico.

\section{Subfamily Xoridinae}

\section{Figures 304,b-307,b}

Front wing 2.8 to about $25 \mathrm{~mm}$. long; apical margin of clypeus truncate or somewhat concave medially, or thin and rather strongly convex; labrum semicircular, mostly exposed when apex of clypeus is truncate or concave, otherwise with only its apex showing; propodeum more or less completely areolated, the costula usually present; tarsal claws simple or rarely in the female with a large basal tooth; first sternite completely fused with its tergite and sometimes the vestige of the suture obliterated; first tergite without a glymma, straight, decurved, or upcurved, its spiracle near, in front of, or rarely behind its middle; epipleura moderately wide to very wide; apical half of abdomen cylindric; female subgenital plate weakly sclerotized, transversely rectangular, usually membranous medially.

The larvae of this subfamily are similar to larvae of the subfamily Gelinae. The antenna is well developed, mandible rather large and with fine teeth, and the sclerotic spur of the hypostoma reaches the stipital sclerite before its apex, which is upcurved beyond the point of contact with the sclerotic spur.

The subfamily Xoridinae includes a small number of rather distinctive genera, which are distributed in five small tribes. Because of their structural diversity and their scattered geographic distribution they seem to be relics of a group that once was much larger and more homogeneous. The affinities of some of the genera, particularly Labium, Poecilocryptus, and the Brachycyrtini have been the 
subject of much disagreement, and the evidence of their relationships is so inadequate or conflicting that we bring them together in the Xoridinae with considerable hesitation. With the meager information available, however, they seem better placed here than in any other subfamily, unless each were placed in a separate subfamily of its own.

The Xoridinae seem to be more closely related to the Gelinae, tribe Gelini, that to any other group. They differ from the Gelini in lacking a long deep sternaulus (but the sternaulus is long in some species of Xorides), having less regularly pentagonal areolet, first abdominal segment straighter and with its spiracle usually at or in front of its middle, and flagellum with a tendency to be less flexible and sometimes weakly clavate.

\section{Key to the tribes of Xoridinae}

1. Abdomen attached high on the propodeum, in lateral view the lower edge of its socket considerably above upper edge of hind coxa; hind coxa of female with a strong internal groove for holding the ovipositor. Western Hemisphere and Australian region . . . . . . . . . . . 2. Labenini (p. 530)

Abdomen attached rather low on the propodeum, in lateral view the lower edge of its socket below upper edge of hind coxa; hind coxa of female without a groove on inner side . . . . . . . . . . . . . . . . . . . . . 2

2. Apical margin of clypeus truncate or a little concave, exposing most of labrum; apex of costellan vein with a row of about 6 strong hamuli. Australian, Neotropic, and Nearctic regions . . . . . . . . . . 3. Labiini (p. 537)

Apical margin of clypeus convex, covering all but the apex of labrum; apex of costellan vein with one or two strong hamuli, or in the Brachycyrtini sometimes with several hamuli . . . . . . . . . . . . . . . . . . . 3

3. Areolet present; front and middle tarsal claws of female with an internal lobe. Australian region . . . . . . . . . 4. Poecilocryptini (p. 541)

Areolet absent; front and middle tarsal claws of female simple . . . . . . 4

4. Thorax long, often somewhat depressed; spiracle of first tergite near its middle. Worldwide . . . . . . . . . . . . . 1. Xoridini (p. 437)

Thorax very short and high; spiracle of first tergite near its apical 0.35. Worldwide . . . . . . . . . . . 5. Brachycyrtini (p. 541)

\section{Tribe Xoridini}

Figures 304,b-306,a

Front wing 2.8 to $25 \mathrm{~mm}$. long; clypeus covering most of labrum, its apical margin thin, convex in outline; flagellum filiform, rather flexible, tapered apically or in some females of Xorides thickened at the tip; thorax elongate, depressed or cylindric; abdomen attached low on propodeum; female hind coxa without an internal groove for holding ovipositor; tarsal claws simple; areolet absent; apex of costellan vein with one or two hamuli; spiracle of first abdominal segment at or in front of the middle. 
There are four genera of this tribe, all of which occur in our area. Their larvae parasitize coleopterous borers in dead wood and the adults may be collected on dead tree trunks or in forests where there is dead wood.

The revision of the genus Aplomerus (below) is a separate contribution under the joint authorship of Henry Townes and George Townes, published as part of this monograph for the convenience of having all members of the subfamily treated in one place.

\section{Key to the genera of Xoridini}

1. Mandible without two teeth, its apex chisel-shaped; epomia long and strong, usually projecting dorsally as a tooth; female antenna curved or elbowed subapically, at the curve or elbow with one, two, or a series of peglike setae. Worldwide. . . . . . . . . . . . . . . .4. Xorides (p. 489)

Mandible with two subequal teeth (as normal); epomia absent or short and weak, not projecting dorsally; female antenna not specialized subapically (as described above) . . . . . . . . . . . . . . . . . . . . . . .2

2. Hind femur with a strong median ventral tooth. Holarctic.

3. Odontocolon (p. 448)

Hind femur without a median ventral tooth . . . . . . . . . . . . . . 3

3. Frons with a strong median horn or tubercle; body subcylindric. Holaretic.

1. Ischnoceros (p. 438)

Frons without a median horn or tubercle; body flattened. Nearctic.

2. Aplomerus (p. 439)

\section{Genus Ischnoceros}

Figure 304,b

Ischnoceros Gravenhorst, 1829, Ichneumonologia europaea, vol. 2, p. 949 . Type: Ichneumon rusticus Fourcroy; designated by Viereck, 1914.

Head and body not depressed; apex of mandible with two subequal teeth; frons with a strong median horn or tubercle that is often hollowed out above; female flagellum not specialized as in Xorides; epomia absent; hind femur not thickened, without a tooth beneath; first abdominal segment short, stout, rather strongly bent at the middle; second tergite with weak oblique basal grooves; second and third tergites punctate or transversely aciculate; apical part of ovipositor weakly compressed, the ventral valve with about five ridges, basad of which there is no roughened area.

There are several Palaearctic species and one in the United States.

\section{Ischnoceros clivulus Townes}

Ischnoceros clivulus Townes, 1957, Proc. Ent. Soc. Washington, vol. 59, p. 21; .

Type: $\uparrow$, Cinder Cone, Lassen National Park, Calif. (Berkeley).

Male: Unknown.

Female: Front wing 7 to $8 \mathrm{~mm}$. long; frons with rather fine punctures and a large, median, moundlike, weakly compressed tubercle 
whose apex is weakly grooved vertically; mesoscutum polished, with small punctures whose interspaces are about 1.5 their diameter; mesopleurum polished, with moderately large, weak punctures whose interspaces are about equal to their diameter; area dentipara with a weak transverse apical tooth; first tergite without a dorsolateral carina beyond the spiracle; second tergite smooth, except near the apical margin covered with microscopic transverse aciculation; ovipositor sheath about 0.67 as long as front wing.

FIGURE 194.--Localities for Ischnoceros clivulus.

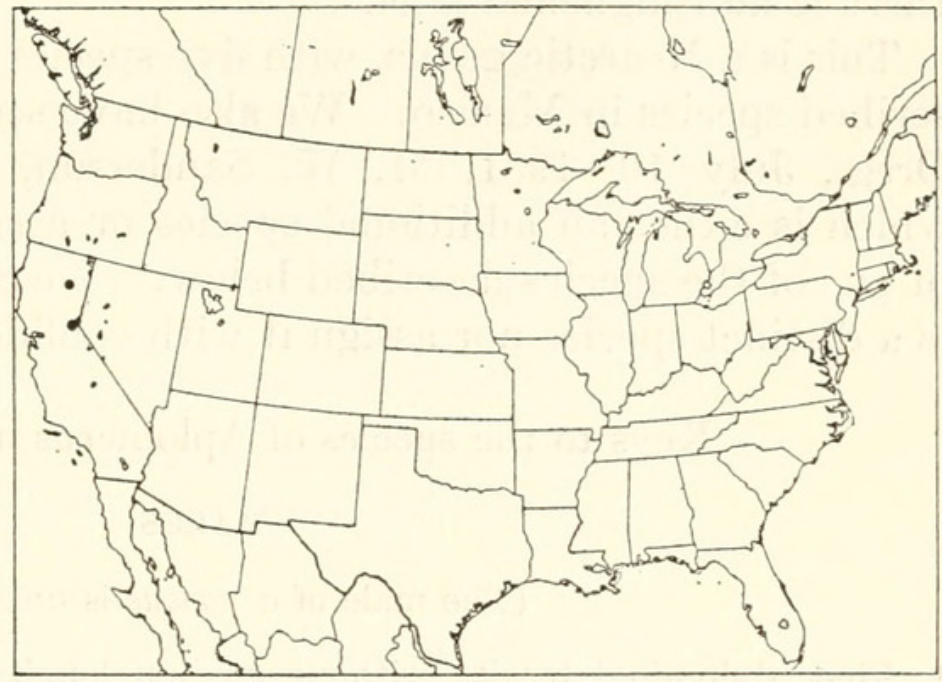

Black. Tegula, base of front wing, and base of hind tibia dorsally, whitish; legs fulvous, the hind tibia with a weak apical infuscation; abdomen brownish ferruginous basally, darkening to brown apically; ovipositor sheath blackish, brownish fulvous at apex; wings faintly tinged with brown.

Specimens (3웅 type and paratypes): From California (Cinder Cone in Lassen National Park and Wright's Lake in El Dorado Co.).

This species occurs in the Canadian zone of California.

\section{The Nearctic species of Aplomerus}

\section{By Henry Townes and George Townes ${ }^{9}$}

\section{Genus Aplomerus}

\section{Figure 305,a}

Platysoma Provancher, 1885, Canadian Ent., vol. 17, p. 115. Name preoccupied. Type: Platysoma tibialis Provancher; monobasic.

Aplomerus Provancher, 1886, Additions et corrections au volume II de la faune entomologique du Canada traitent des hyménoptères, p. 119. New name. Anodontomerus Ashmead, 1900, Proc. U. S. Nat. Mus., vol. 23, p. 61. Type: Aplomerus tibialis Provancher; original designation.

Haplomerus Dalla Torre, 1901, Catalogus hymenopterorum, vol. 3, p. 392. Emendation.

\footnotetext{
${ }^{9}$ Greenville, S.C.
} 
Head and body distinctly flattened; apex of mandible with two subequal teeth; frons without a median horn or tubercle; female flagellum not apically specialized as in Xorides; epomia absent; hind femur not thickened, without a tooth beneath; first abdominal segment depressed, its spiracle near its basal 0.3 ; second tergite without oblique basal grooves; first and second tergites polished or with various aciculation or fine wrinkling; apical part of ovipositor weakly compressed, the ventral valve with about five ridges, basad of which there is no roughened area.

This is a Nearctic genus, with five species in our area and an undescribed species in Mexico. We also have seen a specimen (o , Haines, Oreg., July 10, 1931, M. W. Sanderson, in Lawrence collection) which is either an additional species or a small, aberrant individual of one of the species described below. We can neither be sure that it is a distinct species nor assign it with confidence to one of the others.

\section{Keys to the species of Aplomerus north of Mexico}

\section{MALES}

(The male of arugosus is unknown.)

1. First abdominal tergite without median longitudinal carinae, 1.7 to 1.9 as long as wide, with moderately small, irregular punctures but not distinctly striate; punctures on temple small, separated by about 2.5 their diameter.

5. buprestivorus Rohwer

First abdominal tergite with sharp median longitudinal carinae on its basal $0.5 \pm$, more than 2.0 as long as wide, with strong longitudinal striae or wrinkling; punctures on temple coarse, separated by about 0.5 to 1.0 their diameter . . . . . . . . . . . . . . . . . . . . . 2

2. First abdominal tergite 2.2 to 3.0 as long as wide; wrinkling or striation of third tergite mostly transverse or oblique, covering usually less than the basal 0.8 of the tergite; temple a little longer and less rounded.

3. tibialis (Provancher)

First abdominal tergite 3.2 to 3.9 as long as wide; wrinkling or striation of third tergite longitudinal, covering the basal $0.8 \pm$ of the tergite; temple a little shorter and more rounded . . . . . . . . . . . . . . . . . 3

3. Longer hairs near upper edge of hind femur about 0.45 as long as depth of femur; front and middle coxae clear fulvous; punctures on temple separated by about 0.7 their diameter; range: east of Rocky Mts.

1. lineatulus (Say)

Longer hairs near upper edge of hind femur about 0.25 as long as depth of femur; front and middle coxae more or less fuscous or black; punctures on temple separated by about 0.5 their diameter; range: west of Rocky Mts. .............. 2. robustus, new species

\section{FEMALES}

1. Third and fourth tergites completely covered with fine, sharp transverse striae . . . . . . . . . . . . . . . . . . . 2

Third and fourth tergites smooth, or sometimes partly covered with fine, weak transverse striae 
2. Hind femur with scattered long suberect hairs that are about 0.3 to 0.45 as long as depth of femur; abdomen black beyond third segment; range: east of Rocky Mts. . . . . . . . . . . . . . . . . . . 1. lineatulus (Say)

Hind femur without long hairs, with only the short clothing hairs which are about 0.2 as long as depth of femur; abdomen entirely ferruginous except sometimes for the first segment; range: west of Rocky Mts.

2. robustus, new species

3. Femora fuscous; punctures on temple separated by about 1.5 their diameter; first abdominal tergite without a median longitudinal depression.

5. buprestivorus Rohwer

Femora fulvous

4. Head depressed, about 0.73 as high as long; punctures on temple separated by about 0.5 their diameter, or confluent in rows; first abdominal tergite with a weak median longitudinal depression . . . 3. tibialis (Provancher)

Head rounded, about 0.85 as high as long; punctures on temple separated by about 0.7 their diameter; first abdominal tergite without a median longitudinal depression . . . . . . . . 4. arugosus, new species

\section{Aplomerus lineatulus (Say)}

Anomalon lineatulus Say, 1836, Boston Journ. Nat. Hist., vol. 1, p. 244 (Leconte ed., vol. 2, p. 699); $\sigma^{7}$. Type: $\sigma^{7}$, Indiana (destroyed).

Aplomerus foutsi Rohwer, 1920, Proc. U. S. Nat. Mus., vol. 57, p. 454; 우 Type: , Cabin John, Md. (Washington).

Aplomerus decorus Viereck, 1926, Canadian Ent., vol. 58, p. 55; 9 . Type: Fort Coulonge, Que. (Ottawa).

Male: Front wing 2.8 to $7.0 \mathrm{~mm}$. long. Structure similar to male of $A$. robustus except that hairs tend to be longer, most noticeably longer on the hind femur. The longer hairs near upper edge of hind femur are about 0.3 to 0.45 as long as depth of femur. In robustus and other species of Aplomerus these hairs are not more than about 0.25 as long as depth of femur.

Black. Palpi stramineous; tegula and front and middle legs fulvous; hind coxa entirely blackish or more or less stained with fulvous; hind trochanters brownish fulvous; hind femur blackish, its extreme base and apex brown; hind tibia fuscous, its basal $0.15 \pm$ brownish stramineous; hind tarsus brown; wings subhyaline.

Female: Front wing 5.7 to $7.5 \mathrm{~mm}$. long; hairs on head, thorax, and legs longer than in any other species, some of the hairs exceptionally long and suberect, these longer hairs on hind femur about 0.4 as long as depth of femur (other species lack these long hairs and the hairs on hind femur are less than 0.2 as long as depth of femur); flagellum with 25 to 28 segments; head not strongly depressed, about 0.87 as high as long; temple moderately bulged and rounded; punctures on temple coarse, separated by about 0.9 their diameter, sometimes partly in irregular rows and with a weak wrinkle between each row; notaulus foveolate; propodeal areola with strong bounding carinae; sculpture of lateral propodeal areas weak; first abdominal tergite 
uniformly convex and almost completely covered with rather regular longitudinal striae; second tergite almost completely covered with close striae, which are longitudinal basally and more or less curved or oblique apically; third and fourth tergites completely covered with very fine but sharp transverse striae; fifth and following segments with progressively finer and failing transverse striae; ovipositor sheath about 1.4 as long as front wing.

Black. Palpi, tegula, and legs fulvous; abdomen ferruginous, blackish beyond third segment and usually the first three segments partly infuscate; ovipositor sheath light brown, darker apically; wings subhyaline.

Specimens: $\sigma^{7}$, Ames, lowa, June 28, 1951, W. S. Craig (Washington). 2ᄋ, Baldwin, Kans., May 15, J. C. Bridwell (Washington). ণ, Onaga, Kans., Crevecoeur (Washington). \&, Kentucky (Cambridge). \&, Brooksville, Maine, August, F. A. Eddy (Cambridge). ㅇ (type of foutsi), Cabin John, Md., R. M. Fouts (Washington). $6 \sigma^{7}$, Cabin John, Md., May 26, 1943, Raúl Cortez and H. Townes (Townes). $\sigma^{\top}$, Glen Echo, Md., R. M. Fouts (Washington). $3 \sigma^{\top}$, Takoma Park, Md., July 4, 1942, and July 9, 1944, H. and M. Townes (Townes). ๆ, Petersham, Mass., 1934 (Townes). ơ, Elizabethtown, N. C., Apr. 20, 1950, H. and M. Townes (Townes). ơ', Wake Co., N. C., July 1, 1951, H. and M. Townes (Townes). क Cleveland, Ohio, F. D. DeGant (Washington). क, Cleveland, Ohio, July 28, 1934, F. Becker (Columbus). $\sigma^{x}$, + , Delaware Co., Ohio, June 21 and August 18, D. J. and J. N. Knull (Columbus). $\sigma^{7}$, ㅇ, Fairfield Co., Ohio, July 19, D. J. and J. N. Knull (Columbus). क A Allegheny Co., Pa. (Pittsburgh). $\sigma^{7}$, Pittsburgh, Pa., September 8 to 14 (Pittsburgh). + (type of decorus), Fort Coulonge, Que., July 8, 1917,
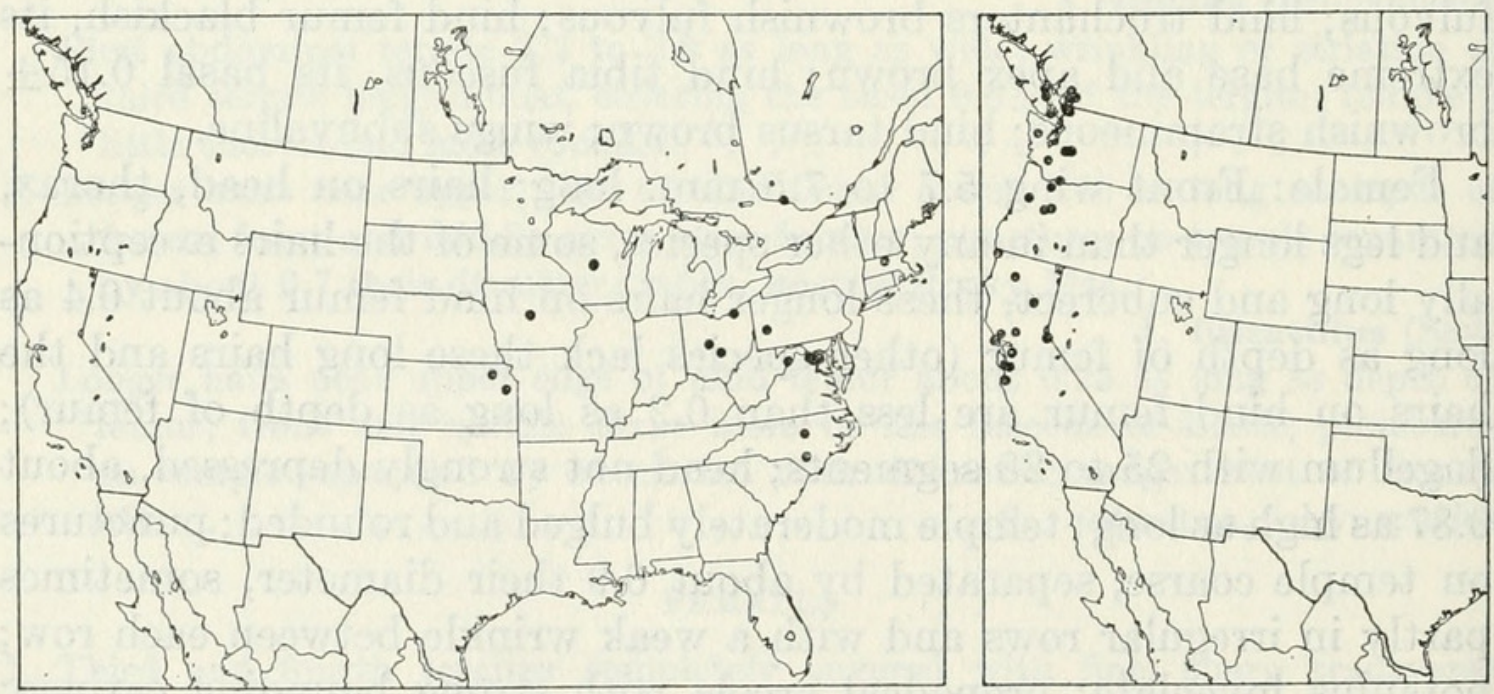

Figures 195, 196.-Localities; 195 (left), Aplomerus lineatulus; 196 (right), $A$. robustus. 
J. I. Beaulne (Ottawa). శ', Dunn Loring, Va., Sept. 9, 1951, Karl V. Krombein (Townes). $0^{x}$, Great Falls, Va., May 12, N. Banks (Cambridge). $2 \sigma^{\nwarrow}$, Lost River State Park, Hardy Co., W. Va., June 18, 1951, Karl V. Krombein (Townes). व $\sigma^{7}$, Nekoosa, Wis., Sept. 2, 1948, W. W. Barrett (Madison). ণ $\sigma^{\top}$, Wood Co., Wis., Aug. 14-15, 1948, R. D. Shenefelt (Madison).

\section{Aplomerus robustus Townes and Townes, new species}

Male. Front wing 3.0 to $6.5 \mathrm{~mm}$. long; temple long, most of it weakly rounded but posteriorly rather strongly rounded to the occipital carina; punctures on temple coarse, separated by about 0.5 their diameter; first abdominal tergite 3.2 to 3.9 as long as wide, its basal half with sharp median longitudinal carinae between which it is weakly concave, most of its surface covered with close, moderately fine, longitudinal wrinkling; second tergite covered with fine, rather regular, sharp longitudinal wrinkles; third tergite with finer, less distinct longitudinal wrinkling that covers its basal $0.8 \pm$; fourth and fifth tergites with some very fine irregular transverse wrinkling.

Black. Palpi light brown; tegula brown; front and middle legs varying from light fulvous to blackish brown, their coxae always more or less fuscous or black, their trochanters usually infuscate at least basally, and their tarsi infuscate apically; hind coxa blackish; hind trochanters light brown to blackish; hind femur dark brown to black, its base and extreme apex usually paler; hind tibia and tarsus dark brown; wings subhyaline.

Female: Front wing 4.7 to $9.0 \mathrm{~mm}$. long; body, especially the abdomen, unusually stout; flagellum with 25 to 29 segments; head not strongly depressed, about 0.84 as high as long; temple moderately rounded, not distinctly bulged; punctures on temple coarse, subadjacent, tending to be confluent in irregular rows that result in weak rugose furrows; notaulus foveolate; propodeal areola with strong bounding carinae, lateral propodeal areas strongly rugose; first abdominal tergite uniformly convex or medially with a faint flattening, its surface covered with fine, irregular longitudinal wrinkles; tergites 2-4 with fine but sharp striae on all but their polished apical margins; striae on tergite 2 longitudinal basally, oblique lateroapically, and irregularly transverse medioapically; striae on tergite 3 transverse but medially with a gentle curve; striae on tergite 4 transverse; fifth and following tergites with progressively finer and failing transverse striae; ovipositor sheath about 1.4 as long as front wing.

Black. Palpi dark fulvous; tegula dusky ferruginous; legs and abdomen ferruginous, the basal tergite sometimes partly infuscate; ovipositor sheath fulvous, its apical expanded part brownish fulvous; wings weakly infuscate. 
Type: , Ashford, Wash., Aug. 19, 1940, H. and M. Townes (Washington, USNM 63721).

Paratypes $\left(35 \sigma^{x}, 22 \%\right)$ : From British Columbia (Cultus Lake, Diamond Head Trail near Squamish at 3,400 ft., Harrison Mills, Mission City, Biological Station at Nanaimo, Victoria, and Wellington); California (Big Basin in Santa Cruz Co., Buck's Lake in Plumas Co., Carrville, Crescent City, Elkhorn Ferry in Yolo Co., hills back of Oakland, Hope Valley in Alpine Co., Inverness, Mesa Grande in Sonoma Co., Monterey Co., and Santa Cruz Mts.); Oregon (Corvallis, Hood River, Lucky Boy Camp on Blue River, McKenzie Bridge, and Sandy River at Brightwood); and Washington (Ashford, Barnes State Park, Gulf Road in Whatcom Co., Forks, Lake Quinault and Mount Rainier at $2,900 \mathrm{ft}$.).

Dates of collection are distributed from May 21 to August 25, and there is a record of December 31 in the "hills back of Oakland, Calif."

One specimen was reared from buprestid borings at Wellington, B. C., Apr. 17, 1945, by R. Guppy. A female from Monterey Co., Calif., is labeled "Pinus radiata." In our own collecting we have found the species in Pseudotsuga forests. At Mount Rainier, Wash., we collected a series of both sexes around a pile of coniferous firewood.

This species is in coniferous forests, from British Columbia to a little south of San Francisco, in the Transition zone. It has been reared from a buprestid.

\section{Aplomerus tibialis (Provancher)}

Platysoma tibialis Provancher, 1885, Canadian Ent., vol. 17, p. 115; 9 . Type: \&, Vancouver Island, B. C. (Ottawa).

Male: Front wing 3.5 to $6.0 \mathrm{~mm}$. long; temple very long, weakly rounded, a little more strongly rounded near occipital carina; punctures on temple coarse, subadjacent, often tending to be confluent in rows; first abdominal tergite 2.2 to 3.0 as long as wide, its basal half with sharp median longitudinal carinae between which it is weakly concave, most of its surface covered with moderately fine, irregular, sharp longitudinal wrinkles, often also with weak punctures evident among the wrinkles; second tergite with small punctures and irregular longitudinal wrinkling, the relative strength of the punctures and wrinkles variable; third tergite with small punctures and a variable amount of irregular wrinkling which is mostly transverse or oblique and occupies the basal $0.6 \pm$ of the tergite; fourth and fifth tergites with or without some very fine transverse wrinkling.

Black. Palpi fulvous to dark brown; tegula dark brown; front and middle legs fulvous to fuscous, usually fulvous with their coxae, more or less of trochanters, and tarsi apically infuscate; hind coxa 
black or blackish; hind leg beyond coxa varying from brownish fulvous with its second trochanter and femur mostly clear fulvous (the femur infuscate apically), to blackish brown; median part of abdomen sometimes stained with ferruginous; wings subhyaline.

Female: Front wing 4.0 to $7.8 \mathrm{~mm}$. long; flagellum with 23 to 27 segments (but with 21 segments in a dwarf specimen); head strongly depressed, about 0.73 as high as long; temple long, not bulged, weakly rounded; punctures on temple very coarse and close, many of them more or less confluent in irregular rows between which are rounded rugae; punctures on vertex coarse, some adjacent or confluent and others distant from each other; notaulus foveolate; propodeal areola with strong bounding carinae; lateral propodeal areas strongly rugose; first abdominal tergite with a weak median longitudinal depression, with strong longitudinal striae and scattered, indistinct punctures, the sculpture weak in the median depression; second tergite with fine but strong longitudinal to oblique striae on its basal 0.2 to 0.7 , the rest smooth; third and fourth tergites smooth and polished or the third tergite sometimes with faint, fine transverse striae; ovipositor sheath about 1.7 as long as front wing.

Black. Palpi fulvous to brown; tegula dusky ferruginous; legs ferruginous, the front coxa often more or less infuscate; abdomen ferruginous, its first segment usually more or less infuscate or blackish and its second and following segments sometimes more or less infuscate; ovipositor sheath fulvous, its apical expanded part brownish fulvous; wings weakly infuscate.

Specimens (133 $0^{x}, 20$ ) : From British Columbia (Fernie and Vancouver Island); California (Bridge Creek Camp in Lassen Co., Camino, Cisco, Coffee Creek in Trinity Co., Dardanelle, Donner Pass, Echo Lake, Fawn Lodge in Trinity Co., near Glacier Point in Yosemite Park, Hackamore in Modoc Co., Hope Valley in Alpine Co., Independence Lake in Sierra Co., Lake Tahoe, Leevining, Mineralking, Old Station, Pollock Pines in El Dorado Co., Sagehen near Hobart Mills, Snow Flat in Yosemite Park, and Truckee); and Oregon ("Boyer" and Independence).

Dates of collection are rather evenly distributed from May 28 to August 16.

We collected a large number of the species near Glacier Point in Yosemite Park, around fallen trunks of Pinus contorta which had partially lost their bark. They had been killed by Dendroctonus.

This species occurs from British Columbia southward into the central part of the Sierra Nevada of California. It is mostly in the Canadian zone. 


\section{Aplomerus arugosus Townes and Townes, new species}

Male: Unknown.

Female type: Front wing $5.2 \mathrm{~mm}$. long; flagellum with 25 segments; head not strongly depressed, 0.85 as high as long; temple weakly bulged and moderately rounded; punctures on temple coarse, separated by about 0.7 their diameter; punctures on vertex small, separated by about 2.2 their diameter; notaulus foveolate; hairs on lateral part of mesosternum very sparse, their sockets separated by about 1.7 the length of the hairs; propodeal areola with strong bounding carinae; sculpture of lateral propodeal areas weak; first abdominal tergite uniformly convex, with fine, weak, irregularly longitudinal wrinkles; second through fourth tergites smooth and practically impunctate; ovipositor sheath 1.2 as long as front wing.
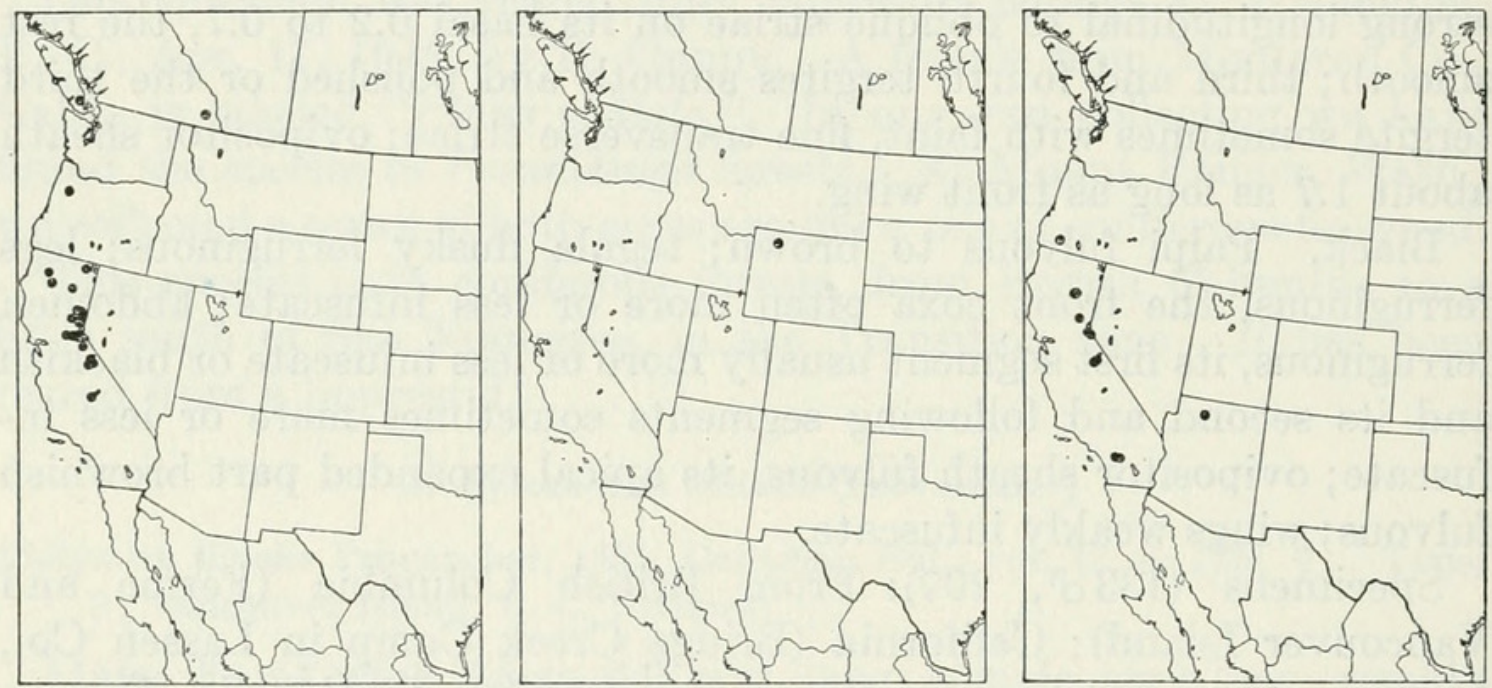

Figures 197-199.-Localities: 197 (left), Aplomerus tibialis; 198 (center), $A$. arugosus; 199 (right), A. buprestivorus.

Black. Palpi and tegula brown; legs and abdomen rufous; wings tinged with brown.

Type: ㅇ, Shoshone Canyon at 6,500 ft., Wyo., June 29, 1940, H. and M. Townes (Washington, USNM 63722).

\section{Aplomerus buprestivorus Rohwer}

Aplomerus buprestivorus Rohwer, 1920, Proc. U. S. Nat. Mus., vol. 57, p. 453; q . Type: + , Ashland, Oreg. (Washington).

Male: Front wing 3.4 to $5.0 \mathrm{~mm}$. long; temple long, weakly rounded, a little more strongly rounded near occipital carina; punctures on temple small, separated by about 2.5 their diameter; first abdominal tergite 1.7 to 1.9 as long as wide, with moderately small, irregular 
punctures but not distinctly striate; second tergite with small, moderately dense punctures and some rugulosity; third through fifth tergites smooth, subpolished, with only minute setiferous punctures.

Black. Palpi dark brown; tegula blackish; coxae, trochanters, and femora blackish brown to black, the trochanters sometimes partly brown; tibiae and tarsi brown; wings subhyaline.

Female: Front wing 5.2 to $6.8 \mathrm{~mm}$. long; flagellum with 21 to 24 segments; head strongly depressed, about 0.77 as high as long; temple rather long, bulging a little, moderately rounded; punctures on temple of moderate size, separated by about 1.5 their diameter; punctures on vertex a little smaller and sparser than on temple; notaulus foveolate or not; hairs on lateral part of mesosternum moderately sparse, their sockets separated by about 0.5 the length of the hairs; propodeal areola with bounding carinae mostly indistinct; lateral areas of propodeum weakly rugose; first abdominal tergite broad, evenly convex, with small, weak, irregular punctures more or less confluent with fine, rather weak striation; second and third tergites smooth except for some fine, weak, transverse striation medially and basally: fourth tergite almost smooth; ovipositor sheath about 1.45 as long as front wing.

Black. Palpi dark brown; tegula black; coxae, trochanters, and femora blackish brown to black; tibiae and tarsi brownish fulvous; abdomen ferruginous, its first tergite black, its second and third tergites usually more or less infuscate and its fourth and following tergites sometimes more or less infuscate; ovipositor sheath light fulvous, its expanded apical part a little darker; wings weakly infuscate.

Specimens: + , north rim of Grand Canyon, 8,000 ft., Ariz., June 1, 1946, R. M. Bohart (Townes). क, Cisco, Calif., July 31, 1948, H., M., G., and D. Townes (Townes). $\sigma^{x}$, Echo Lake, Calif., July 23, 1955, E. I. Schlinger (Davis). $2 \sigma^{\top}, 1$ 우, near Glacier Point, Yosemite Park, Calif., July 18, 1948, H., M., G., D., and J. Townes (Townes). 2o, under bark, Herkey Creek in San Jacinto Mts., Calif., June 4, 1940, R. Husbands (Berkeley). $\sigma^{7}$, Leevining, Calif., June 22, 1948, H., M., G., and D. Townes (Townes). $\odot$, from Abies magnifica, Meyers, Calif., F. B. Herbert (Washington). $\sigma^{7}, 3$ miles southeast of Mount Lassen, Calif., July 8, 1955, J. W. MacSwain (Berkeley). 2\%, San Jacinto Mt. trail, San Jacinto Mts., July 1, 1952, J. W. MacSwain (Berkeley). 2o (type and paratype), reared from cocoons in buprestid galleries in Cercocarpus parvifolius, Ashland, Oreg., Jan. 30, 1914, G. Hofer (Washington).

This species occurs from Washington to Arizona. It has been taken in Transition and Canadian localities. 


\section{Genus Odontocolon}

Figure 305 ,b

Odontomerus Gravenhorst, 1829, Ichneumonologia europaea, vol. 3, p. 851. Name preoccupied. Type: Ichneumon dentipes Gmelin; designated by Westwood, 1839.

Odontocolon Cushman, 1942, Proc. Ent. Soc. Washington, vol. 44, p. 179. New name.

Head and body not, or only moderately flattened; apex of mandible with two subequal teeth; frons without a median tubercle or horn; female flagellum not specialized as in Xorides; epomia absent or rudimentary; hind femur thickened, beneath with a strong median tooth; first abdominal segment rather slender basally and enlarged apically, a little bent near the middle; second tergite without oblique basal grooves; first and second tergites polished, smooth or more or less aciculate or punctate, sometimes more or less mat; apical part of ovipositor weakly compressed, the ventral valve with about five ridges, basad of which there is no roughened area, the dorsal valve with a few weak, very oblique grooves (fig. $331, \mathrm{~g}$ ).

This is a Holaretic genus, with numerous species. There are three species groups, which are better marked in the female than in the male. The distinction of species is in many cases difficult. Our western species related to dichrous (brevicaudus, dichrous, parvum, curtum, and sierrae) are only weakly differentiated. Determination of their males is often difficult and sometimes not possible on the known characters. The "species" dichrous contains a number of distinguishable populations, some of which will probably prove to be distinct species or namable subspecies.

The descriptions of females below are moderately complete, but those of the males sketchy. Males have about the same characters as females of the same species, but with the following exceptions: flagellar segments more evenly cylindric and specific differences in lengths of segments less pronounced than in females; punctation of mesoscutum, hind femur, and second abdominal tergite more uniformly dense, without as great differences in density between species as in the females; propodeum a little longer and flatter, resulting in a relatively shorter petiolar area; propodeal spines tending to be shorter than in female; propodeal differences between species with the same specific tendencies as in female but a little less pronounced; differences in proportions of tarsal segments with the same specific tendencies as in the females but the differences less pronounced; abdomen black in most males, even when the female abdomen is ferruginous. A key to males has been worked out and there is a color description of each under the species, but for most structural characters comparison with 
the descriptions of females should be made, with some allowances for sexual differences.

Odontocolon is parasitic on Coleoptera in dead wood. Adults are moderately common on herbage and underbrush, in forests where there is fallen wood. They are frequently found at honeydew.

\section{Keys to the Nearctic species of Odontocolon}

\section{MALES}

(Males of cilipes, depressum, alaskensis, and dreisbachi are unknown, but are placed in the key according to the characters they are presumed to have.)

1. Longitudinal ridge just distad of ventral tooth on hind femur convex in profile; hind tibia usually with some long hairs in addition to the short clothing hairs (always with these hairs in the Nearctic species); intercubital vein usually less than 0.4 as long as second abscissa of cubitus; thorax unusually long and depressed, and with coarse punctures. Cilipes group (p. 454). 2

Longitudinal ridge just distad of ventral tooth on hind femur straight or concave in profile, or the ridge sometimes short or absent; hind tibia never with long hairs in addition to the short clothing hairs; intercubital vein usually more than 0.3 as long as second abscissa of cubitus . . . . . . 3

2. Tooth on hind femur about 1.0 as high as its basal width, not separated by a distinct notch from the longitudinal ridge just distad of the tooth; intercubitus about 0.4 as long as second abscissa of cubitus.

1. cilipes, new species

Tooth on hind femur about 1.5 as high as its basal width, separated by a rounded notch from the longitudinal ridge just distad of the tooth; intercubitus less than 0.3 as long as second abscissa of eubitus.

2. bicolor (Cresson)

3. First tergite mostly or entirely covered with moderately coarse longitudinal striae; metapleurum entirely rugosopunctate; wings often reduced or vestigial, when well developed often with a long ramellus. Polyмоврнuм GROUP (p.456) . . . . . . . . . . . . . . . . . . . . . . . 4

First tergite mostly smooth, mat, or with a small or moderate amount of longitudinal wrinkling or striae; metapleurum with rather weak punctures, sometimes partly rugosopunctate, or rarely entirely so; wings fully developed; ramellus short or absent. Mellipes group (p. 458) . . . . . 6

4. Head about 1.18 as wide across temples as across eyes.

5. formicoides, new species

Head 0.95 to 1.04 as wide across temples as across eyes . . . . . . . . . 5

5. Head and thorax blackish brown; basal 0.6 of second tergite with rather close, small punctures and a small amount of longitudinal striation.

3. pullum, new species

Head and thorax light brown; basal 0.6 of second tergite longitudinally striate and with some inconspicuous punctation . . 4. polymorphum Cushman

6. Distal side of tooth on hind femur ending abruptly, not continued distally onto hind femur as a ridge; thorax about 2.8 as long as high.

6. depressum, new species

Distal side of tooth on hind femur ending gradually, continued on to adjacent part of femur as a sharp ridge; thorax less than 2.8 as long as high . . . 7 
7. Propodeum and pronotum completely rugulosopunctate so that none of the surface is smooth; thorax about 2.6 as long as high . 7. alaskensis (Rohwer)

Propodeum and pronotum not completely rugulosopunctate, half or more of their surface relatively smooth (though punctate); thorax about 2.4 as long as high . . . . . . . . . . . . . . . . . 8

8. Temples strongly flaring, the head about 1.09 as wide across widest place on temples as across eyes; hind femur partly to entirely black or blackish, at least its apical 0.2 infuscate; middle coxa fulvous . 23. vicinum (Cresson)

Temples not flaring or less strongly flaring, the head not more than 1.05 as wide across temples as across eyes; hind femur fulvous to black, if black or blackish the middle coxa also black or blackish . . . . . . . . . . . 9

9. Hind coxa partly or entirely brown to black. (Some males of parvum and a few of dichrous are variable in this character and will run through either half of the couplet.). . . . . . . . . . . . . . . . . . 10

Hind coxa entirely fulvous . . . . . . . . . . . . . . . . 16

10. Second tergite with sharp fine punctures and with fine wrinkling between the punctures; trough of pronotum with ridges crossing at about a $40^{\circ}$ angle; middle and hind femora black; propodeal spines practically absent.

8. aethiops (Cresson)

Second tergite with weak, very fine punctures, often smooth between the punctures; trough of pronotum with ridges crossing at about an $85^{\circ}$ angle. 11

11. Hind femur black . . . . . . . . . . . . . . . . . . 12

Hind femur fulvous to medium brown . . . . . . . . . . . . . . 13

12. Trough of pronotum with about 8 cross ridges . . 18. atripes (Rohwer)

Trough of pronotum without cross ridges, or with a few weak ones next to the epomia . . . . . . . . . . . . 19. dreisbachi, new species

13. Hind coxa and femur concolorous, both varying from fulvous brown to blackish brown . . . . . . . 15. parvum, new species, in part

Hind coxa (at least in part) much darker than hind femur, the coxa varying from entirely black to fulvous with more or less of its basal part fuscous; hind femur fulvous to medium brown . . . . . . . . . . . . . . 14

14. Hind first trochanter blackish or dark brown, or when fulvous the second tergite entirely ferruginous . . . . . . . 9. abdominale (Cresson)

Hind first trochanter fulvous; abdomen entirely black or rarely with restricted ferruginous areas .................. . 15

15. Propodeal teeth usually about 0.3 as long as their basal width. (Not always separable from males of $O$. dichrous.) . . 16. brevicaudus (Cushman)

Propodeal teeth usually about 0.8 as long as their basal width.

17. dichrous (Rohwer), a few specimens

16. Front face of hind femur with the punctures much sparser at its lower $0.3 \pm$ than at its upper $0.3 \pm$, the punctures on its lower part not more than half as dense as on the upper part; trough of pronotum without transverse ridges; range; eastern half of North America, except for curtum . . . . 17

Front face of hind femur with the punctures nearly as dense at its lower $0.3 \pm$ as on its upper $0.3 \pm$, the punctures on its lower part usually more than half as dense as on its upper part; range: western half of North America, except for canadense . . . . . . . . . . . . . . . . . . . . . 21

17. Second and third tergites ferruginous; flagellum with about 30 segments; range: California . . . . . . . . . 13. curtum, new species

Second and third tergites black (as is the rest of abdomen); flagellum with 35 to 45 segments; range: eastern half of North America . . . . . . . 18 
18. Fif th segment of hind tarsus about 1.4 as long as second segment; first segment of flagellum about 1.4 as long as second segment; segments of flagellum rather short . . . . . . . . . . . . . . . 12. mellipes (Say)

Fifth segment of hind tarsus 0.95 to 1.2 as long as second segment; first segment of flagellum 1.0 to 1.25 as long as second segment; segments of flagellum rather long. . . . . . . . . . . . . . . . . . . . . . 19

19. Hairs on median part of second tergite sparse and irregularly distributed, the hair sockets separated by about 1.5 to 3.0 the length of the hairs; basal $0.25 \pm$ of second tergite with moderately strong wrinkles; mesepimeron with hairs on its entire length except its lower $0.1 \pm$; nervellus broken usually near its middle; hind femur ferruginous with apical $0.1 \pm$ infuscate.

20. albotibiale (Bradley)

Hairs on median part of second tergite moderately dense and evenly distributed, the hair sockets separated by about 0.7 the length of the hairs; basal $0.15 \pm$ of second tergite with rather weak wrinkling; mesepimeron usually lacking hairs from part or all of its lower half; nervellus broken usually near its lower 0.38 . . . . . . . . . . . . . . . . . . . . . . . . 20

20. Mesepimeron with hairs on about its upper $0.5 \pm$ (on upper $0.4 \pm$ near front edge, on upper $0.6 \pm$ on hind edge); hind femur about 2.3 as long as deep, its hairs moderately long and moderately sparse, the setiferous punctures near its lower 0.3 separated by about 2.5 their diameter; hind femur with its apical $0.35 \pm$ often distinctly infuscate. (Not all specimens can be distinguished with certainty from strangaliae on these characters.)

21. ochropus, new species

Mesepimeron with hairs on its upper 0.7 or more; hind femur about 2.1 as long as deep, its hairs unusually long and sparse, the setiferous punctures near its lower 0.3 separated by about 5 times their diameter; hind femur uniformly fulvous or with a weak apical dorsal infuscation.

22. strangaliae (Rohwer)

21. Punctures on mesoscutum and second tergite of medium size, sharp, and rather dense, those on second tergite separated by about 0.7 their diameter; hind femur unusually robust; head about 1.04 as wide across temples as across eyes . . . . . . . . . . . . . . . . . . . . . . . . . . 22

Punctures on mesoscutum and second tergite small, rather weak, rather sparse, those on second tergite separated by at least 1.0 their diameter; hind femur not unusually robust; head 0.95 to 1.04 as wide across temples as across eyes . . . . . . . . . . . . . . . . . . . . . . . . . 23

22. Hind femur without a distinct apical infuscation; hind tibia ferruginous or fuscoferruginous . . . . . . . . . 10. punctatum (Cushman) Hind femur with its apical $0.12 \pm$ distinctly infuscate; hind tibia fuscous.

11. canadense (Provancher)

23. Propodeal teeth usually more than 0.3 as long as their basal width; abdomen entirely black or more or less ferruginous; front wing 3.4 to $10 \mathrm{~mm}$. long. (Not always distinguishable from the species parvum and sierrae.)

17. dichrous (Rohwer), most specimens

Propodeal teeth usually less than 0.3 as long as their basal width; abdomen entirely black; front wing 3.2 to $5.7 \mathrm{~mm}$. long . . . . . . . . . . . 24

24. Second tergite except basally and all of third tergite almost or quite polished; metapleurum with strong wrinkles; lower part of trough of pronotum crossed by several rather long horizontal ridges . 14. sierrae, new species 
Second tergite and basal $0.5 \pm$ of third tergite mat; metapleurum with weak wrinkles or almost smooth; lower part of trough of pronotum without longitudinal ridges or with only short weak ones.

15. parvum, new species, in part

\section{FEMALES}

(The female of formicoides is unknown, but it is placed in the key according to the characters it is presumed to have.)

1. Middle tibia without an oblique groove on posteroventral side. . . . . . 2 Middle tibia with a deep oblique groove on posteroventral side. Mellipes GROUP (p. 458) . . . . . . . . . . . . . . . . . . . . . . 6

2. Tibiae with long suberect hairs in addition to the short clothing hairs; first tergite distinctly punctate, not conspicuously striate; wings always fully developed. Cilipes group (p. 454) . . . . . . . . . . . . . . . . 3

Tibiae without long suberect hairs, with only the short clothing hairs; first tergite with strong longitudinal striation, not conspicuously punctate; wings sometimes short or absent. Polymorphum group (p. 456) . . . 4

3. Front and middle coxae black; tooth on hind femur about 0.6 as long as its basal width, not followed distally by a notch; intercubitus about 0.4 as long as second abscissa of cubitus . . . . . . . 1. cilipes, new species

Front and middle coxae fulvous; tooth on hind femur about 1.4 as high as its basal width, followed distally by a rounded notch that separates it from the ventral ridge on femur; intercubitus less than 0.3 as long as second abscissa of cubitus . . . . . . . . . . 2. bicolor (Cresson)

4. Head about 1.18 as wide across temples as across eyes.

5. formicoides, new species

Head 0.95 to 1.04 as wide across temples as across eyes . . . . . . . . 5

5. Head and thorax blackish; basal 0.4 of second tergite with small sparse punctures, striatopunctate at the extreme base . . . 3. pullum, new species

Head and thorax light brown; basal 0.4 of second tergite longitudinally striate and with some indistinct punctures . 4. polymorphum (Cushman)

6. Abdomen ferruginous, at least beyond the first segment. (O. dichrous is variable in this character and runs through both halves of the couplet.) . . 7

Abdomen entirely black. . . . . . . . . . . . . . . . . . . 12

7. Femora black. . . . . . . . . . . 18. atripes (Rohwer)

Femora ferruginous or fulvous. . . . . . . . . . . . . . . . 8

8. Punctures on mesoscutum dense, in central part of median and lateral lobes of mesoscutum separated by less than 2.5 their diameter.

9. abdominale (Cresson)

Punctures on mesoscutum sparse, in central part of median and lateral lobes of mesoscutum separated by more than 2.5 their diameter . . . . 9

9. Hairs on upper half of front side of hind femur long and sparse, the punctures from which they arise separated by about 3 times their diameter; trough of pronotum without cross ridges except sometimes at the epomia.

22. strangaliae (Rohwer)

Hairs on upper half of front side of hind femur short and dense, the punctures from which they arise separated by about 0.8 their diameter; trough of pronotum usually with numerous cross ridges . . . . . . . . . . . 10

10. Hairs on lower part of front face of hind femur almost as dense as on the rest of the femur . . . . . . . . . . 16. brevicaudus (Cushman)

Hairs on lower part of front face of hind femur much sparser than elsewhere, with an almost bald area occupying the lower 0.2 to 0.5 of the femur. . 11 
11. Flagellum with 29 to 32 segments; second segment of flagellum about 2.0 as long as wide; punctures on temple separated by about 3.0 their diameter.

13. curtum, new species

Flagellum with 35 to 41 segments; second segment of flagellum about 2.25 as long as wide; punctures on temple separated by about 1.0 to 2.0 their diameter . . . . . . . . . 17. dichrous (Rohwer), in part

12. Coxae and femora black . . . . . . . . . . . . . . . . . . . . . . 13

Coxae and femora ferruginous or fulvous . . . . . . . . . . . . . . 14

13. Punctures on mesoscutum dense, separated by about 1.2 their diameter; propodeum without distinct teeth; second tergite somewhat rugulose and with rather dense small punctures . . . . . . . 8. aethiops (Cresson)

Punctures on mesoscutum sparse, separated by about 4.0 their diameter; propodeum with distinct teeth; second tergite polished, almost without punctures . . . . . . . . . . . . 19. dreisbachi, new species

14. Distal side of tooth on hind femur ending abruptly, not continued distally on to femur as a ridge; thorax about 2.8 as long as high; ovipositor sheath about 2.0 as long as front wing . . . . . . . . 6. depressum, new species

Distal side of tooth on hind femur ending gradually, continued on to adjacent part of femur as a sharp ridge; thorax less than 2.8 as long as high; ovipositor sheath less than 2.0 as long as front wing except in occasional specimens of 0. vicinum . . . . . . . . . . . . . . . . . . . . . . . . . . . . . . . . . . 15

15. Propodeum and pronotum completely rugulosopunctate so that none of the surface is smooth; thorax about 2.6 as long as high.

7. alaskensis (Rohwer)

Propodeum and pronotum not completely rugulosopunctate, half or more of their surfaces relatively smooth (though punctate); thorax about 2.1 to 2.6 as long as high . . . . . . . . . . . . . . . . . . 16

16. Mesoscutum densely punctate, the punctures on median part of each of the three lobes separated by about 1.2 their diameter . . . . . . . . . . 17

Mesoscutum less densely punctate, the punctures on median part of each of the three lobes separated by about 1.8 to 5.0 their diameter . . . . 18

17. Hind femur without a distinct infuscation; hind tibia ferruginous or fuscoferruginous; punctation a little coarser . . .10. punctatum (Cushman)

Hind femur with a large apical dorsolateral infuscation; hind tibia fuscous; punctation a little finer . . . . . . . 11. canadense (Provancher)

18. Temple strongly flaring, the head about 1.09 as wide across temples as across eyes; petiolar area of propodeum about 0.31 as long as combined areola and basal area; ovipositor sheath about 1.85 as long as front wing.

23. vicinum (Cresson)

Temple not or only weakly flaring, the head about 0.95 to 1.06 as wide across temples as across eyes; petiolar area of propodeum 0.4 to 0.8 as long as combined areola and basal area; ovipositor sheath about 1.1 to 1.7 as long as front wing . . . . . . . . . . . . . . . . . . . . . . . 19

19. Fifth segment of hind tarsus about 1.9 as long as second segment; second segment of middle tarsus about 1.2 as long as deep; second segment of flagellum about 1.6 as long as first segment, about 1.75 as long as wide.

12. mellipes (Say)

Fifth segment of hind tarsus about 1.2 to 1.7 as long as second segment; second segment of middle tarsus about 1.4 to 1.8 as long as deep; second segment of flagellum about 1.2 to 1.5 as long as first segment, about 2.6 as long as wide . . . . . . . . . . . . . . . . . 20 
20. Punctures near middle of hind side of hind femur moderately dense, most of them separated by about 1.5 their diameter; range: Rocky Mts. and westward . . . . . . . . . . . . . . . . . . . . . . . 21

Punctures near middle of hind side of hind femur sparse, most of them separated by about 3.0 to 5.0 their diameter; range: Atlantic coast to Pacific . . . . . . . . . . . . . . . . . . . . . 22

21. Metapleurum with coarse, strong wrinkles; lower part of trough of pronotum with long horizontal wrinkles . . . . . . 14. sierrae, new species

Metapleurum with weak, rather fine wrinkles or almost smooth; lower part of trough of pronotum smooth or with short horizontal wrinkles.

15. parvum, new species

22. Trough of pronotum with a series of cross ridges; punctures near middle of front side of hind femur separated by about 2.0 their diameter; range: west of Rocky Mountains . . . . . 17. dichrous (Rohwer), in part

Trough of pronotum without cross ridges; punctures near middle of front side of hind femur separated by about 3.0 their diameter; range: Atlantic to Rocky Mountains . . . . . . . . . . . . . . . . . . 23

23. Apical 0.15 of hind femur infuscate; mesepimeron with about 15 hairs on its lower half, these not restricted to the hind margin; basal $0.15 \pm$ of second tergite with rather strong wrinkling . . . . 20. albotibiale (Bradley)

Apex of hind femur not distinctly infuscate; mesepimeron with 0 to about 6 hairs on its lower half, these restricted to its hind margin; basal $0.1 \pm$ of second tergite with rather weak wrinkling . . 21. ochropus, new species

\section{CILIPES GROUP}

Body form unusually long and depressed; metapleurum and propodeum with coarse, close punctures, sometimes a little rugose between the punctures; middle tibia simple, without an oblique groove on its posteroventral side; tibiae and tarsi of female with more or less conspicuous long erect or suberect hairs, in addition to the usual clothing hairs; tibiae and tarsi of male usually with inconspicuous moderately long hairs, in addition to the regular clothing hairs; hind femur in profile with a longitudinal carina with convex outline just distad of its ventral tooth; tooth on hind femur 0.5 to 2.0 as high as its basal width; wings always fully developed; intercubitus varying from 0.5 as long as second abscissa of cubitus to absent because of approximation of cubital and radial veins; ramellus short or absent; first tergite unusually long and slender, with some rather coarse punctures and often some weak striation.

This group includes the two Nearctic species below, the European Odontomerus thomsoni Clément 1938 and O. quercinus Thomson 1877, and an undetermined species from Japan. Judging from the description, the Japanese Odontomerus jezoensis Uchida 1928 belongs here also.

\section{Odontocolon cilipes, new species}

Male: Unknown.

Female type: Front wing $10.8 \mathrm{~mm}$. long; punctures on upper half of front side of hind femur separated by about 1.5 their diameter; 
long hairs on legs moderately numerous, about $60^{\circ}$ from the horizontal, those on tibiae averaging about as long as diameters of the tibiae; tooth on hind femur about 0.6 as high as its basal width, not distinctly separated from the ventral longitudinal ridge on femur just distad of the tooth; intercubitus 0.4 as long as second abscissa of cubitus; nervulus postfurcal by 0.35 its length; apical half of first tergite mostly punctatostriate; most of second tergite and basal $0.6 \pm$ of third tergite with fine close aciculation, this mostly transverse; ovipositor sheath 2.3 as long as front wing.

Black. Tarsi brown, the hind tarsus reddish brown; front tibia blackish brown; middle tibia reddish brown; middle femur, hind coxa, and hind first trochanter, fuscoferruginous; hind second trochanter, hind femur, hind tibia, and abdomen ferruginous; wings weakly infuscate.

Type: , Chiricahua Mts., Ariz., July 17, 1957, D. J. and J. N. Knull (Columbus).

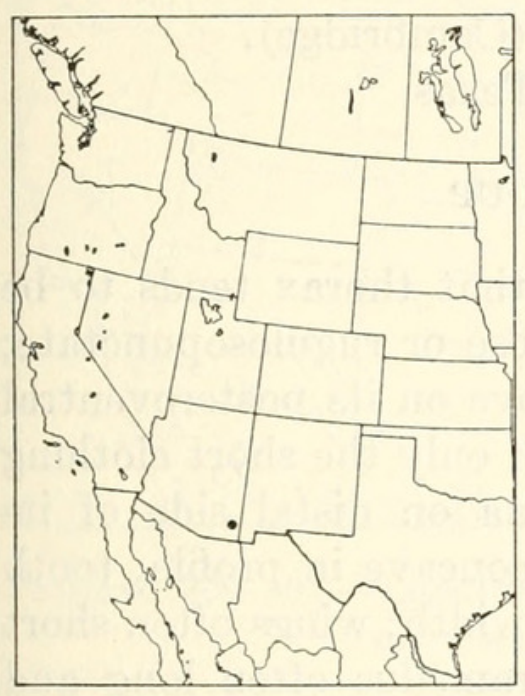

Figures 200, 201.-Localities: 200 (left), Odontocolon cilipes; 201 (right), $O$. bicolor.

\section{Odontocolon bicolor (Cresson)}

Odontomerus bicolor Cresson, 1870, Trans. Amer. Ent. Soc., vol. 3, p. 169, $\Varangle$. Type: + , Pennsylvania (Philadelphia).

Male: Front wing $3.7 \mathrm{~mm}$. long. Structurally similar to the female except for the usual sexual differences. The long hairs on tibia and tarsus are sparser, not so long, and more inclined than in the female.

Blackish brown. Palpi brown; tegula ferruginous; front and middle legs fulvous; hind legs brownish, the coxa darker brown and the trochanters and basal part of femur paler.

Female: Front wing 7.0 to $9.4 \mathrm{~mm}$. long; punctures on upper half of front side of hind femur separated by about 1.8 their diameter; long hairs on legs numerous, about $75^{\circ}$ from the horizontal, those 
on tibiae averaging about 1.2 as long as diameters of tibiae; tooth on hind femur about 1.4 as high as its basal width, distinctly separated by a rounded notch from the ventral longitudinal ridge on femur just distad of the tooth; intercubitus not more than 0.3 as long as second abscissa of cubitus, sometimes almost obliterated by approximation of radial and cubital veins; nervulus postfurcal by about 0.25 its length; apical half of first tergite with sharp irregular punctures and little if any wrinkling or striation; most of second and basal $0.6 \pm$ of third tergite with fine close aciculation, this mostly transverse; ovipositor sheath about 2.1 as long as front wing.

Black. Legs and abdomen fulvoferruginous; wings faintly brownish. Specimens: 2o, Cheaha State Park, Ala., Apr. 26, 1940, E. C. VanDyke (San Francisco and Townes). ㅇ, Rabun Bald, Ga., Aug. 23, 1928, P. W. Fattig (Townes). ㅇ, Stone Mt., Ga., Nov. 18, 1945, P. W. Fattig (Washington). \& (type), Pennsylvania (Philadelphia). $\sigma^{7}$, near Tigerville, Greenville Co., S. C., May 8, 1944, H. and M. Townes (Townes). ㅇ, Call, Tex., Mar. 2, 1905, W. F. Fiske (Washington). ㅇ, Falls Church, Va., N. Banks (Cambridge).

This species occurs from Pennsylvania to Texas.

\section{POLYMORPHUM GROUP}

Body form normal for the genus except that thorax tends to be slender; metapleurum and propodeum rugulose or rugulosopunctate; middle tibia simple, without an oblique groove on its posteroventral side; tibiae and tarsi without long hairs, with only the short clothing hairs; hind femur with a longitudinal carina on distal side of its ventral tooth, the outline of carina weakly concave in profile; tooth on hind femur 0.5 to 1.0 as high as its basal width; wings often short or absent, when fully developed with the ramellus often long and intercubitus about 0.3 to 0.7 as long as second abscissa of cubitus; first tergite rather short, covered with longitudinal striae and sometimes with some inconspicuous punctation.

This group includes the three Nearctic species described below, and possibly, judging by its description, the European Odontomerus appendiculatus Gravenhorst, 1829.

\section{Odontocolon pullum, new species}

Wings absent or present, when fully developed 5.3 to $5.5 \mathrm{~mm}$. long; head and body 5.7 to $7.7 \mathrm{~mm}$. long; head about 1.0 as wide across temples as across eyes; punctures on temple moderately large, weak, separated by about 2.0 their diameter; second tergite of male with sharp, small or medium sized punctures, separated mostly by about their diameter, the basal $0.5 \pm$ of the tergite also with longitudinal wrinkling between the punctures; second tergite of female with sparse 
or very sparse, sharp, small or medium sized punctures, on its basal $0.15 \pm$ also with longitudinal wrinkling; ovipositor sheath about 1.25 as long as front wing, about 1.0 as long as head and body.

Blackish brown. Antenna, palpi, tegula, and legs medium brown; abdomen fulvous brown, beyond the second or third segment darker brown, in the male the first segment mostly blackish brown; wings tinged with brown.

Type: ㅇ (wings fully developed), Robson, B. C., Aug. 13, 1939, H. R. Foxlee (Washington, USNM 63723).

Paratypes: ㅇ (wings absent), Lavington, B. C., May 24, 1947, J. Grant (Ottawa). $\quad \sigma^{7}$ (wings fully developed), Robson, B. C., May 13, 1939, H. R. Foxlee (St. Paul). \& (wings fully developed), Fish Camp, Calif., July 14, 1948, H., M., G., and D. Townes (Townes).
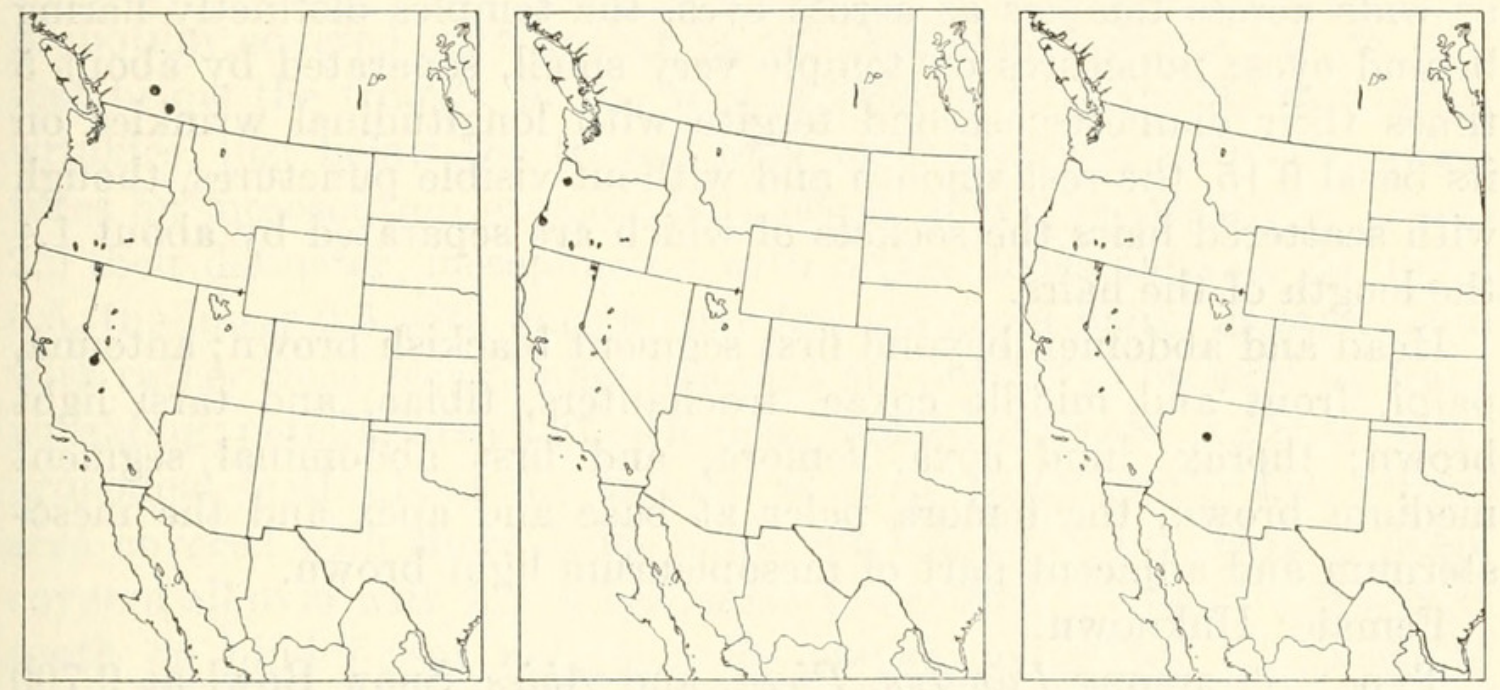

Figures 202-204.-Localities: 202 (left), Odontocolon pullum; 203 (center), O. polymorphum; 204 (right), O. formicoides.

\section{Odontocolon polymorphum Cushman}

Odontocolon polymorphum Cushman, 1942, Proc. Ent. Soc. Washington, vol. 44 , p. 180 ; $\sigma^{\top}$, + . Type: $\uparrow$, Seattle, Wash. (Washington).

Front wing 0 to $5 \mathrm{~mm}$. long (the wings absent, variously brachypterous, or fully developed); head and body 4.7 to $7.0 \mathrm{~mm}$. long; head about 0.95 to 1.03 as wide across temples as across eyes; punctures on temple very small, separated by about 3 times their diameter; basal 0.4 to 0.8 of second tergite with strong longitudinal wrinkling or striation and some inconspicuous small punctures, the rest with a few small punctures; ovipositor sheath about 1.1 as long as head and body.

Light brown, including the appendages; wings tinged with light brown. 
Specimens: 3 (wingless), Wellington, B. C., 1949, Richard Guppy (Townes). $\sigma^{7}$ (wings fully developed), Coos Co., Oreg., Feb. 14, 1917, W. J. Chamberlin (Cambridge). $\sigma^{7}$ (wings fully developed), McMinnville, Oreg., Aug. 16, 1947, K. M. Fender (Townes). $\sigma^{7}, 3$ ㅇ (paratypes, the male with fully developed wings, the females wingless), reared from anobiid larvae in Alnus, Seattle, Wash., Mar. 3, 1942 (Washington and Townes). $\sigma^{\top}$, o (paratypes, the male wingless, the female with partially developed wings), reared from dead Alnus, Seattle, Wash., Apr. 2, 1942 (Washington).

This species is in the Vancouveran fauna. It has been reared from an anobiid.

\section{Odontocolon formicoides, new species}

Male type: Wings absent; head and body $4.4 \mathrm{~mm}$. long; head 1.18 as wide across temples as across eyes, the temples distinctly flaring behind eyes; punctures on temple very small, separated by about 5 times their diameter; second tergite with longitudinal wrinkles on its basal 0.15 , the rest smooth and without visible punctures, though with scattered hairs the sockets of which are separated by about 1.4 the length of the hairs.

Head and abdomen beyond first segment blackish brown; antenna, palpi, front and middle coxae, trochanters, tibiae, and tarsi light brown; thorax, hind coxa, femora, and first abdominal segment medium brown, the femora paler at base and apex and the mesosternum and adjacent part of mesopleurum light brown.

Female: Unknown.

Type: $0^{7}$, among Populus, Picea, and Abies, Snow Bowl at 9,700 ft. on Humphreys Peak, Ariz., July 26, 1952, E. O. Wilson (Cambridge).

\section{MELLIPES GROUP}

Body form usually "normal" for the genus but sometimes depressed and elongate; metapleurum and propodeum with very fine to moderately coarse punctures, not rugulose but rarely rugulosopunctate; middle tibia of female with a deep, sharp, oblique groove on its posteroventral side; tibiae and tarsi without long erect hairs; hind femur usually with a longitudinal carina on distal side of its ventral tooth, the outline of carina concave or straight in profile; tooth on hind femur about 0.7 as high as its basal width; wings fully developed, the intercubitus about 0.5 to 1.0 as long as second abscissa of cubitus, the ramellus short or absent; first tergite moderately long, without coarse punctures or covered with striae, usually with some irregular longitudinal wrinkling or striae and some fine punctures.

This group includes most of the genus. We place in it the eighteen 
Nearctic species described below; the European Odontomerus rufiventris Holmgren 1860, O. hungaricus Clément 1938, O. spinipes Gravenhorst 1829, O. geniculatus Kriechbaumer 1889, O. pinetorum Thomson 1877, and $O$. punctulatus Thomson 1877; the Japanese O. nikkoensis Ashmead 1906 and O. rufus Uchida 1928; O. stejnegeri Cushman 1924, from Robbin Island in the Okhotsk Sea; and four undescribed species from Japan.

\section{Odontocolon depressum, new species}

Male: Unknown.

Female type: Front wing $7.7 \mathrm{~mm}$. long; flagellum with 33 segments, its first segment 1.11 as long as second; head exactly the same width across temples as across eyes; punctures on temple small, separated by about 3 times their diameter; thorax about 2.8 as long as high; pronotum covered with rather small close punctures except in and just below the trough, in the trough with short irregular transverse wrinkles, just below the trough with weak irregular wrinkles; punctures on mesoscutum exceptionally small, sharp, separated by about 2.0 their diameter; mesepimeron with rather dense hairs on its upper 0.5 , the lower 0.5 with only a very few scattered hairs; metapleurum with rather close, weak punctures that are partially obscured by weak wrinkling; petiolar area 0.31 as long as combined areola and basal area; propodeal teeth about 0.3 as long as their basal width; first lateral area covered with short dense hairs; hind femur 2.4 as long as deep, covered all over with fine subadjacent punctures, the hairs very short; tooth on hind femur exceptionally narrow in profile, on its distal side ending abruptly, without a ridge continuing on to under side of femur (in this way differing from other Nearctic species of the MELLIPES group); second segment of middle tarsus 1.6 as long as deep; fifth segment of hind tarsus exactly as long as second segment; first tergite exceptionally short; second tergite smooth, polished, its hair sockets separated mostly by about twice the length of the hairs but denser near lateral margin; ovipositor sheath 2.1 as long as front wing.

Black. Ventrolateral part of face reddish brown; underside of scape, pedicel and first flagellar segment stained with reddish brown; labrum and palpi brown; tegula black; legs uniformly fulvoferruginous; apical 0.4 of first tergite largely reddish brown; wings subhyaline.

This species is recognizable by its depressed shape, long ovipositor, and shape of the tooth on the hind femur. Its nearest known relative is an undescribed species from the Japan Alps.

Type: ㅇ, Phantom Valley, 9,400 ft., Rocky Mountain National Park, Colo., Aug. 9, 1948, H., M., D., and J. Townes (Washington, USNM 63724). 


\section{Odontocolon alaskensis (Rohwer)}

Odontomerus alaskensis Rohwer, 1913, Proc. U. S. Nat. Mus., vol. 45, p. 360; ๆ. Type: $\uparrow$, Sitka, Alaska (Washington).

Male: Unknown.

Female: Front wing about $8.0 \mathrm{~mm}$. long; first flagellar segment about 1.7 as long as second; head about 1.03 as wide across temples as across eyes; punctures on temple very small, separated by about 4.0 their diameter; thorax about 2.70 as long as high; pronotum with rather dense, crowded, moderately coarse punctures, these partially obscured by weak wrinkling in most areas, almost completely obscured by strong, but small irregular wrinkling in trough of pronotum; punctures of mesoscutum small, separated by about 1.3 their diameter, the lateral lobe of mesoscutum with a median longitudinal bare area; mesepimeron with moderately dense hairs over its entire surface; metapleurum with rather dense, medium-sized punctures intermingled with wrinkles that partially obscure the punctures; petiolar area about 0.31 as long as combined areola and basal area; propodeal teeth about 0.5 as long as their basal width; first lateral area with dense hairs all over; hind femur about 2.18 as long as deep, with very small, weak, adjacent punctures all over and short, dense hairs; second segment of middle tarsus about 1.45 as long as deep; fifth segment of hind tarsus about 1.00 as long as second segment; second tergite smooth, mostly polished, medially somewhat rugulose, its punctures so small and weak as to be almost invisible, its hairs rather dense; ovipositor sheath about 1.25 as long as front wing.

Blackish. Mandible, flagellum, and abdomen with ferruginous tinges; palpi and tegula brown; legs entirely fulvous; wings hyaline.

This species can be recognized by its dense coarse punctures and rugulosity on the pronotum and metapleurum. It has been con-
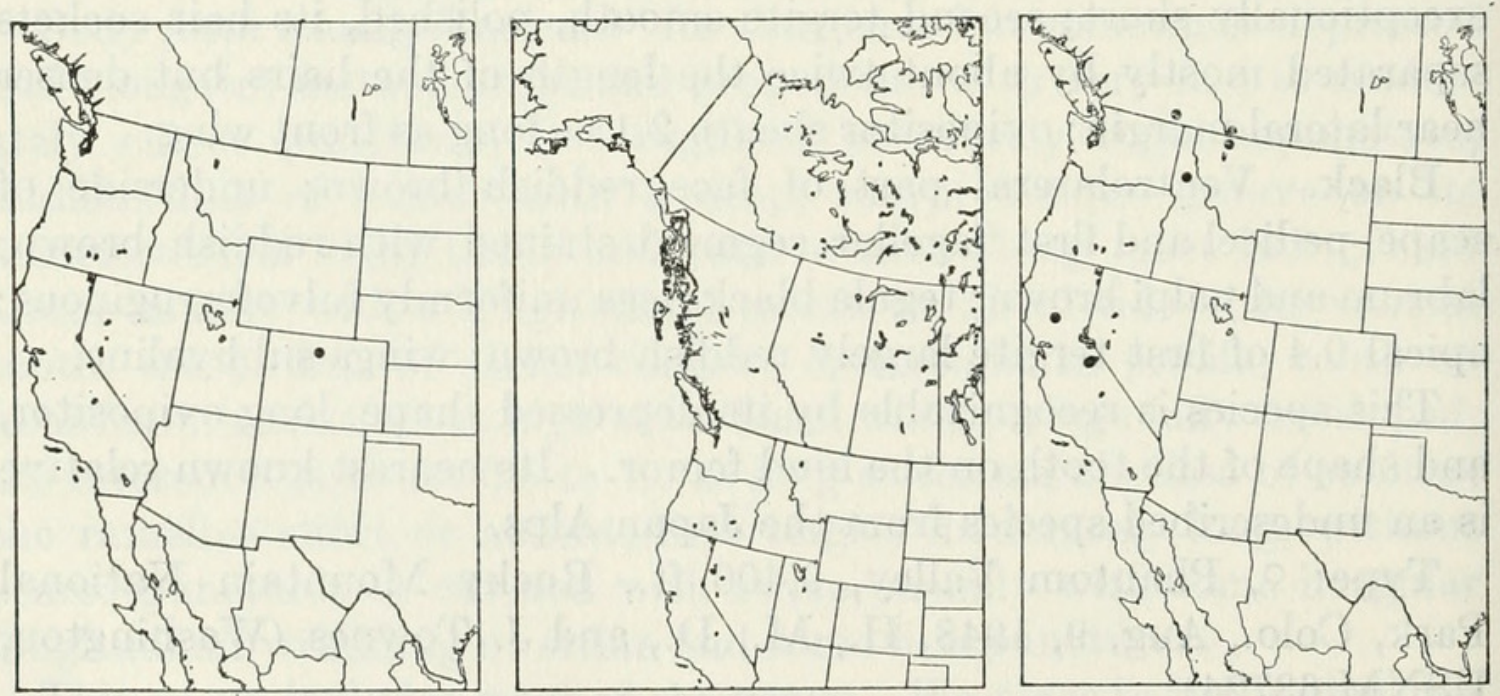

Figures 205-207.-Localities: 205 (left), Odontocolon depressum; 206 (center), O. alaskensis; 207 (right), O. aethiops. 
sidered the same as the European $O$. punctulatum, which is similarly sculptured (see Townes, 1944, Mem. Amer. Ent. Soc., no. 11, p. 113). We find that two females of punctulatum from Europe, however, when compared with specimens of alaskensis differ in having the temples much more closely and coarsely punctate and in lacking the median longitudinal bare area on the lateral lobe of the mesoscutum. In the European punctulatum the temporal punctures are coarse, sharp, and separated by about 1.7 their diameter.

Specimens: +, Kodiak, Alaska, June 10, 1917, James S. Hine (Townes). 2 \% (type and paratype), Sitka, Alaska, T. Kincaid (Washington).

\section{Odontocolon aethiops (Cresson)}

Odontomerus aethiops Cresson, 1865, Proc. Ent. Soc. Philadelphia, vol. 4, p. 289; $\sigma^{\top}$, $\uparrow$. Lectotype: $q$, Colorado (Philadelphia).

Male: Front wing 6.3 to $10.5 \mathrm{~mm}$. long; first segment of flagellum about 1.05 as long as second; punctures on mesoscutum small, sharp, separated by about 2.0 their diameter; propodeum without distinct teeth, the apex of area dentipara only faintly projecting; punctures on upper 0.6 of front face of hind femur rather dense, on lower 0.4 of front face sparse and irregularly spaced; lower $0.2 \pm$ of hind face of hind femur with sparse punctures, the upper $0.8 \pm$ with moderately dense punctures; second segment of middle tarsus about 3.5 as long as deep; fifth segment of hind tarsus about 1.00 as long as second segment; second tergite weakly more or less mat, covered with rather dense, weak setiferous punctures that are intermingled with and partly obscured by fine weak wrinkling.

Entirely and uniformly deep black. Wings weakly infuscate.

Female: Front wing 9.5 to $11.5 \mathrm{~mm}$. long; flagellum with about 40 segments, its first segment about 1.85 as long as second; head about 1.05 as wide across temples as across eyes; punctures on temple moderately small, separated by about 1.2 their diameter; thorax about 2.15 as long as high; upper $0.3 \pm$ of pronotum with moderately coarse punctures that are separated by about 1.5 their diameter; trough of pronotum with moderately coarse wrinkling that is somewhat irregular but crosses it mostly at an angle of about $40^{\circ}$; punctures on mesoscutum of moderate size, sharp, separated by about 0.7 their diameter; hairs on mesepimeron on its upper $0.45 \pm$ but near hind margin extending downward to within $0.35 \pm$ of the bottom; metapleurum with moderate sized, weak, rather dense punctures, near hind coxal attachment with irregular wrinkles, petiolar area about 0.55 as long as combined areola and basal area; propodeal teeth rudimentary, about 0.2 as long as their basal width; first lateral area with rather dense hairs all over; hind femur about 1.84 as long as deep, its upper half with fine close punctures and short hairs, its 
lower half with sparser punctures and the hairs a little longer, near the lower 0.3 the punctures being separated by about 3.5 their diameter; second segment of middle tarsus about 1.1 as long as deep; fifth segment of hind tarsus about 1.58 as long as second segment; second tergite rather strongly rugulose, somewhat smoother apically, its punctures rather small, rather sharp, dense, and only partially obscured by the rugulosity; ovipositor sheath about 1.35 as long as front wing.

Coloration entirely deep black; wings weakly infuscate.

The female of this species has both the legs and abdomen black and the mesoscutal punctures very dense. Our only other species with this color in the female is dreisbachi, which has the mesoscutal punctures very sparse.

Specimens $\left(290^{x}, 9\right.$ ) : From Alberta (Waterton); British Columbia (Robson); California (Colusa, Echo Lake at 7,400 ft., near Glacier Point in Yosemite National Park, Hope Valley in Alpine Co., and Tamarack Flat in Yosemite National Park); Colorado; Idaho (Headquarters); and Montana (Lake McDonald in Glacier National Park).

Collection dates are mostly in July, but range from June 19 (at Waterton, Alta.) to August 29 (at Robson, B. C.). We once found the species moderately common around trunks of Pinus contorta that had been killed by Dendroctonus.

This species occurs in the Canadian zone of the Rocky Mountains and the Sierra Nevada.

\section{Odontocolon abdominale (Cresson)}

Male: Front wing 4.5 to $7.3 \mathrm{~mm}$. long; first segment of flagellum about 1.2 as long as second segment; punctures on mesoscutum small, sharp, separated by about 2.0 their diameter; propodeal teeth weak, about 0.3 as long as their basal width; punctures on hind femur rather dense, their interspaces about 1.5 their diameter, a little sparser near lower edge of femur; second segment of middle tarsus about 3.2 as long as deep; fifth segment of hind tarsus about 0.90 as long as second segment; second tergite smooth, faintly mat, its punctures very fine, evenly covered with hairs the sockets of which are separated by about 0.85 their length.

Female: Front wing 5.8 to $10.0 \mathrm{~mm}$. long; flagellum with about 34 segments, its first segment about 1.43 as long as second; head about 1.01 as wide across temples as across eyes; punctures on temple moderately small, separated by about 1.5 their diameter; thorax about 2.25 as long as high; upper $0.35 \pm$ of pronotum with moderatesized sharp punctures that are separated by about 0.8 their diameter; trough of pronotum crossed at right angles by about 14 strong ridges; punctures on mesoscutum small, dense, separated by about 0.8 their 
diameter; mesepimeron with hairs on its upper $0.8 \pm$, or sometimes on its entire length, sparser below; metapleurum with rather small, sharp, dense punctures and with wrinkling medially, more strongly wrinkled posteriorly; petiolar area about 0.43 as long as combined areola and basal area; propodeal teeth weak, about 0.3 as long as their basal width; first lateral area with rather dense hairs all over; hind femur about 1.92 as long as deep, with sharp dense punctures all over, the punctures finer and denser on its upper half; hairs on hind femur short; second segment of middle tarsus about 1.5 as long as deep; fifth segment of hind tarsus about 1.5 as long as second segment; second tergite smooth, subpolished, weakly rugulose at extreme base, its punctures small, rather sharp, very sparse, separated by about 2.5 the length of the hairs; ovipositor sheath about 1.1 as long as front wing.

The female of the species is the only one in our area with the abdomen red and mesoscutum densely punctate. The closest relative is $O$. pinetorum of Europe.

There are two subspecies as keyed and described below:

\section{MALES}

1. Front and middle femora entirely fulvous or sometimes fuscofulvous; range: Montana to Arizona. (Male specimens frequently not distinguishable from the subspecies fergusoni) . . 9a. abdominale abdominale (Cresson) Front and middle femora entirely fulvous; range: Alberta, British Columbia,

Washington, and Oregon . . 9b. abdominale fergusoni, new subspecies

\section{FEMALES}

1. Hind coxa black or mostly blackish; range: Montana to Arizona.

9a. abdominale abdominale (Cresson)

Hind coxa fulvous, sometimes infuscate basally; range: Alberta, British Columbia, Washington, and Oregon.

9b. abdominale fergusoni, new subspecies

\section{9a. Odontocolon abdominale abdominale (Cresson)}

Odontomerus abdominale Cresson, 1865, Proc. Ent. Soc. Philadelphia, vol. 4, p. 289 ; $\uparrow$. Lectotype: $\uparrow$, Colorado (Philadelphia).

Male: Black. Palpi dark brown; front and middle coxae often more or less tinged with fulvous; first trochanters light brown to blackish; second trochanters, femora, and front and middle tibiae fulvous, the front and middle femora often more or less infuscate, especially toward the base; front and middle tarsi brown, darkest apically; hind tibia brownish fulvous, darker apically and above; hind tarsus fuscous brown; second tergite, apical $0.2 \pm$ of first tergite, and basal $0.3 \pm$ of third tergite often more or less fulvoferruginous, the rest of abdomen blackish but often with fulvoferruginous tinges; wings weakly infuscate. 
Female: Black. Mandible partly dull ferruginous; palpi brown to blackish; tegula reddish brown to blackish; legs beyond first trochanters fulvoferruginous, the last segment of tarsi infuscate; second trochanters sometimes partly infuscate; abdomen fulvoferruginous, its first tergite usually infuscate basally; wings moderately infuscate.

A female from Swift Current, Glacier National Park, Mont., collected July 23, 1936, by A. L. Melander (Cambridge) is intermediate to the subspecies fergusoni. Females from other locations in Glacier National Park seem typical of the subspecies abdominale.

Specimens $\left(130^{\gamma}, 27\right.$ ) : From Arizona (Flagstaff and San Francisco Mts. at 11,500 ft.); Colorado (Brainerd Lake near Ward, near Estes Park, Granite Peaks Camp near Bayfield at 9,000 ft., Longs Peak at 9,000 ft., Phantom Valley in Rocky Mountain National Park at 9,400 ft., and Ward at 10,000 ft.); Idaho (Moscow Mt.); Montana (Avalanche Lake, Grinnell Lake, and Swift Current, all in Glacier National Park); Utah (Uintah Co.); and Wyoming (Centennial at 10,000 ft. and Medicine Bow Range).

Dates of capture are from mid-June to late August (June 12 near Estes Park, Colo., and June 14 on Longs Peak, Colo., to August 29 in the Medicine Bow Range, Wyo.).

This subspecies occurs at higher altitudes in the Rocky Mountains, from Idaho and Montana to Arizona.

\section{9b. Odontocolon abdominale fergusoni, new subspecies}

Male: Similar to the male of the subspecies abdominale except that front and middle femora are never infuscate and that coxae often have more fulvous, the hind coxa sometimes being fulvous with only its base infuscate.
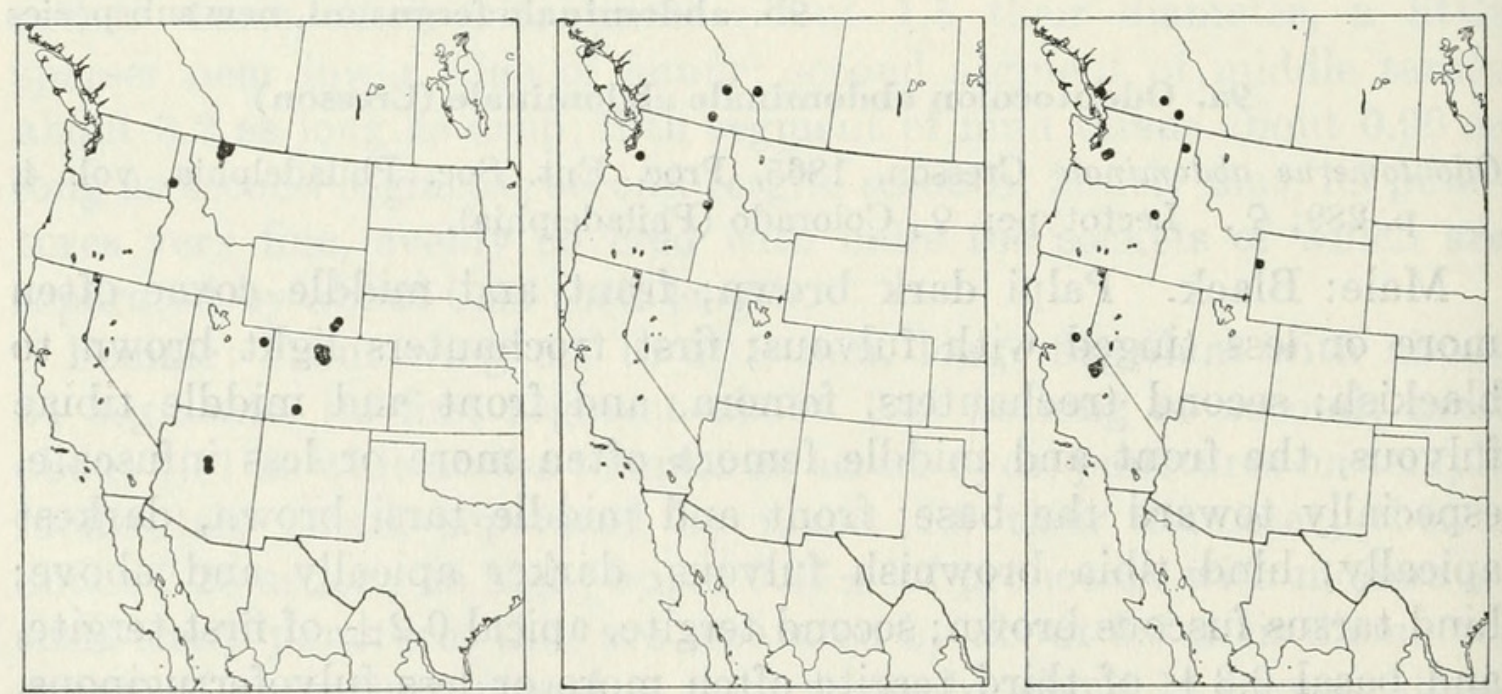

Figures 208-210.-Localities: 208 (left), Odontocolon abdominale abdominale; 209 (center), O. a. fergusoni; 210 (right), O. punctatum. 
Female: Similar to the subspecies abdominale except that the hind coxa is fulvous (sometimes a little infuscate at base), the trochanters and front and middle coxae fulvous or weakly infuscate, and the tegula fulvous or fuscofulvous.

Type: , Hat Point at 7,000 ft., Wallowa Co., Oreg., July 30, 1941, G. R. Ferguson (Washington, USNM 63725).

Paratypes: ㅇ, Banff, Alta., Aug. 5, 1925, O. Bryant (Washington). o, Mount Revelstoke at 5,800 ft., B. C., July 10, 1952, G. P. Holland (Ottawa). क, Port Alice at 3,000 ft., B. C., Aug. 30, 1945, G. R. Wyatt (Ottawa). $7 \sigma^{7}$, Robson, B. C., May 2 to 5, 1949, May 5, 1948, May 20 and 23, 1949, and July 24 and Aug. 27, 1947, H. R. Foxlee (Ottawa). ণ, Robson, B. C., June 9, 1952, H. R. Foxlee (Ottawa). $\sigma^{\nearrow}$, same data as type (Townes). , Summerland Trail on Mount Rainier, Wash., July 24, 1924, A. L. Melander (Cambridge).

This subspecies occurs in the Canadian Rockies and the mountains of Washington and Oregon.

\section{Odontocolon punctatum (Cushman)}

Odontomerus punctatus Cushman, 1930, Proc. U. S. Nat. Mus., vol. 77, art. 3, p. 12 ;. Type: $\subsetneq$, Priest River, Idaho (Washington).

Male: Front wing 5.5 to $9.5 \mathrm{~mm}$. long; first segment of flagellum about 1.1 as long as second segment; punctures on mesoscutum of medium size, sharp, rather dense, separated by about 0.5 their diameter; propodeal teeth rudimentary, practically lacking; punctures on hind femur sharp, dense, covering its entire surface, a little sparser on its lower edge; second segment of middle tarsus about 3.2 as long as deep; fifth segment of hind tarsus about 0.9 as long as second segment; second tergite polished, with sharp, medium sized punctures that are separated by about 0.7 their diameter, basally with some wrinkles between the punctures.

Black. Mandible more or less ferruginous; labrum fulvous; palpus fulvous to brown; tegula ferruginous, often somewhat infuscate; legs fulvous, the apex of hind femur sometimes faintly infuscate, upper half of hind tibia usually somewhat infuscate, and hind tarsus more or less infuscate; wings faintly infuscate.

Female: Front wing 7.0 to $11.4 \mathrm{~mm}$. long; flagellum with about 36 segments, its first segment about 1.25 as long as second; head about 1.04 as wide across temples as across eyes; punctures on temple moderately small, separated by about 1.5 their diameter; thorax about 2.22 as long as high; upper $0.3 \pm$ of pronotum with moderatesized, sharp punctures that are separated by about 0.8 their diameter; trough of pronotum with about 14 very short ridges crossing it at right angles, the ridges longer and irregular anteriorly; punctures on mesoscutum rather small, sharp, separated by about 0.8 their di- 
ameter; hairs on mesepimeron on its upper $0.4 \pm$ in front, on its upper $0.6 \pm$ behind, the rest bare; metapleurum with moderately large, weak, dense punctures that are partially obscured by weak, irregular wrinkling; petiolar area about 0.52 as long as combined areola and basal area; propodeal teeth rudimentary, indistinct, about 0.2 as long as wide at base; hairs in first lateral area rather dense; hind femur about 1.87 as long as deep, with small, sharp, dense punctures all over, the punctures a little coarser ventrally; second segment of middle tarsus about 1.7 as long as deep; fifth segment of hind tarsus about 1.2 as long as second segment; second tergite with moderately small, sharp punctures that are separated by about 2.0 their diameter, in some places a little sparser; surface of second tergite subpolished, more or less rugulose basally; ovipositor sheath about 1.35 as long as front wing.

Black. Palpi brown; tegula blackish brown; legs fulvoferruginous, the hind tarsus and upper half of hind tibia fuscoferruginous; wings hyaline.

Females are recognizable by the black abdomen, fulvous legs, closely punctate mesoscutum and second tergite, somewhat flaring temples, and lack of a fuscous mark on apex of hind tibia. The species is very close to $O$. canadense and may be only a western subspecies of it.

Specimens $\left(15 \sigma^{\top}, 11\right.$ \%): From British Columbia (Lorna, Pender Harbor, and Robson); California (Camino, Crane Flat, near Glacier Point, Tamarack Flat, and Yosemite Valley, all except Camino in Yosemite National Park); Idaho (Priest River); Oregon (Sumpter); Washington (Ashford and Mount Rainier at 2,900 ft.) and Wyoming (Teton Pass).

Dates of collection are mostly in July, but range from June 27 (at Camino, Calif.) to August 31 (at Robson, B. C.).

There are two rearing records: , reared from "Tremex" in Abies, Sumpter, Oreg., July 27, 1911, F. C. Craighead. \& (type), from Leptura obliterata in Abies grandis, Priest River, Idaho.

This species occurs in the Transition and Canadian zones of the West, from southern British Columbia to central California.

\section{Odontocolon canadense (Provancher)}

Odontomerus Canadensis Provancher, 1877, Naturaliste Canadien, vol. 9, p. 16 (Faune, p. 490); ๙⿱乛龰, ㅇ. Lectotype: ㅇ, Quebec (Quebec).

Odontomerus tibialis Cushman, 1930, Proc. U. S. Nat. Mus., vol. 77, art. 3, p. 11; $\sigma^{7}$, + . Type: $q$, Echo Lake, Mount Desert, Maine (Washington).

Male: Front wing 4.3 to $8.7 \mathrm{~mm}$. long; structurally similar to male of punctatum.

Coloration as in the female.

Female: Front wing 6 to $10 \mathrm{~mm}$. long; fifth segment of hind tarsus 
about 1.35 as long as second segment; otherwise structurally similar to female of punctatum, but possibly a little less strongly punctate.

Black. Colored as in punctatum except that legs are a little paler fulvous, apical $0.12 \pm$ of hind femur strongly infuscate, hind tibia entirely fuscous, hind tarsus dark fuscous, and front and middle tibiae infuscate apically.

Specimens (180 10 10\%): From Maine (Bangor, Echo Lake on Mount Desert, and Orono); Michigan (Presque Isle Co.); Minnesota (Basswood Lake in Lake Co.); New Hampshire (Franconia, Mount Madison, and Pinkham Notch); New York (Bemus Point, Boreas River in Essex Co., and McLean in Tompkins Co.); North Carolina (Pisgah Ridge); Nova Scotia (Bridgewater); Ontario (Kearney); and Quebec (Cap aux Os on the Gaspé, Laniel, Montreal, Mount Lyall at 1,500 ft., and Valley Junction).

Dates of collection are throughout the summer, distributed from May 31 (on McLean Reserve, Tompkins Co., N. Y.) to August 25 (Bridgewater, N. S.).

This species occurs in the Canadian zone and cooler part of the Transition zone of the East.

\section{Odontocolon mellipes (Say)}

Anomalon mellipes Say, 1829, Contr. Maclurian Lyceum Arts Sci., vol. 1, p. 75 (Leconte ed., vol. 1, p. 378); †. Type: + , Indiana (destroyed).

Odontomerus errans Rohwer, 1913, Proc. U. S. Nat. Mus., vol. 45, p. 360;

Type: $q$, South Dakota (Washington).

Male: Front wing 4.5 to $9.5 \mathrm{~mm}$. long; first segment of flagellum about 1.4 as long as second segment; all segments of flagellum unusually short and stout; punctures on mesoscutum small, separated by about 2.5 their diameter; propodeal teeth about as long as their basal width; punctures on front and hind faces of hind femur separated by about their diameter on upper half, becoming sparse or very sparse ventrally, separated by about 3 to 5 times their diameter near lower edge; hairs on hind femur often unusually long; second segment of middle tarsus about 2.8 as long as deep; fifth segment of hind tarsus about 1.4 as long as second segment; second tergite smooth, polished except for a little fine wrinkling and weak microreticulations basally, its punctures fine, sparse, but evenly distributed, separated from each other by about the length of the hairs.

Black. Palpi, tegula, and legs light fulvous, the palpi and tegula often a little brownish; last segment of front and middle tarsi and all of hind tarsus somewhat infuscate; hind tibia usually with a fuscous tinge; wings subhyaline.

Female: Front wing 4.5 to $9.7 \mathrm{~mm}$. long; flagellum with about 35 segments, its first segment about 1.60 as long as second; all flagellar segments unusually short and weakly enlarged apically; head about 
1.04 as wide across temples as across eyes; punctures on temple moderately small, separated by about 2.0 their diameter; thorax about 2.22 as long as high; upper $0.3 \pm$ of pronotum with moderatesized, rather weak punctures that are separated by about 2.0 their diameter; trough of pronotum with some irregularly transverse strong wrinkles anteriorly, elsewhere smooth; punctures on mesoscutum small, weak, separated by about 4 times their diameter; hairs on mesepimeron usually on its entire length but sparser below, sometimes absent from its lower $0.2 \pm$; metapleurum with moderate-sized, very weak punctures that are obscured by weak, irregular wrinkling; petiolar area about 0.75 as long as combined areola and basal area; propodeal teeth about 0.9 as long as their basal width; hairs in first lateral area moderately dense to rather sparse; hind femur about 1.97 as long as deep, the punctures on its upper half fine, rather dense, those on its lower half a little coarser and much sparser, separated usually by about 4.0 their diameter but their density unusually variable; hairs on hind femur longer than usual; second segment of middle tarsus about 1.2 as long as deep; fifth segment of hind tarsus about 1.9 as long as second segment; second tergite subpolished, smooth except that basal $0.15 \pm$ is somewhat rugulose and striate, its punctures very small and scattered, separated by about 3 times the length of the hairs; ovipositor sheath about 1.38 as long as front wing.

Black. Palpi and legs pale fulvous, the tarsi somewhat brownish; tegula light brown; wings subhyaline.

This species is distinguished by its black abdomen, pale fulvous legs, short flagellar segments and middle tarsus, and long fifth segment of hind tarsus. The temples are somewhat flaring.

Say's type of Anomalon mellipes is destroyed and his descriptions will fit the present species, ochropus, albotibiale, and vicinum about equally well. Cushman (1930, Proc. U. S. Nat. Mus., vol. 77, art. 3 , p. 10) has restricted the name to the present species, and we follow his lead as first reviser.

Specimens $\left(580^{\top}, 127\right.$ ) : From Connecticut (Branford, East Hartford, Niantic, and Pleasant Valley in Litchfield Co.); District of Columbia (Washington); Illinois (Chicago and Galesburg); Kansas (Lawrence and Riley Co.); Maryland (near Cumberland, "Cupids Bower Island," Glen Echo, Plummers Island, and Takoma Park); Massachusetts (Amherst, Buckland, Cambridge, Dorchester, and Holliston); Michigan (Aurelius, Detroit, East Lansing, George Reserve in Livingston Co., Grosse Isle, Isabella Co., Midland Co., Nottawa, Osceola Co., and Saginaw); Minnesota (Luverne, Olmsted Co., St. Anthony Park in Ramsey Co., and near Shakopee); New Jersey (Bergen Co., Delaware Water Gap, Fort Lee, Lakehurst, Moorestown, New Brunswick, Palisades, and Riverton); New York (Aurora, Bemus 

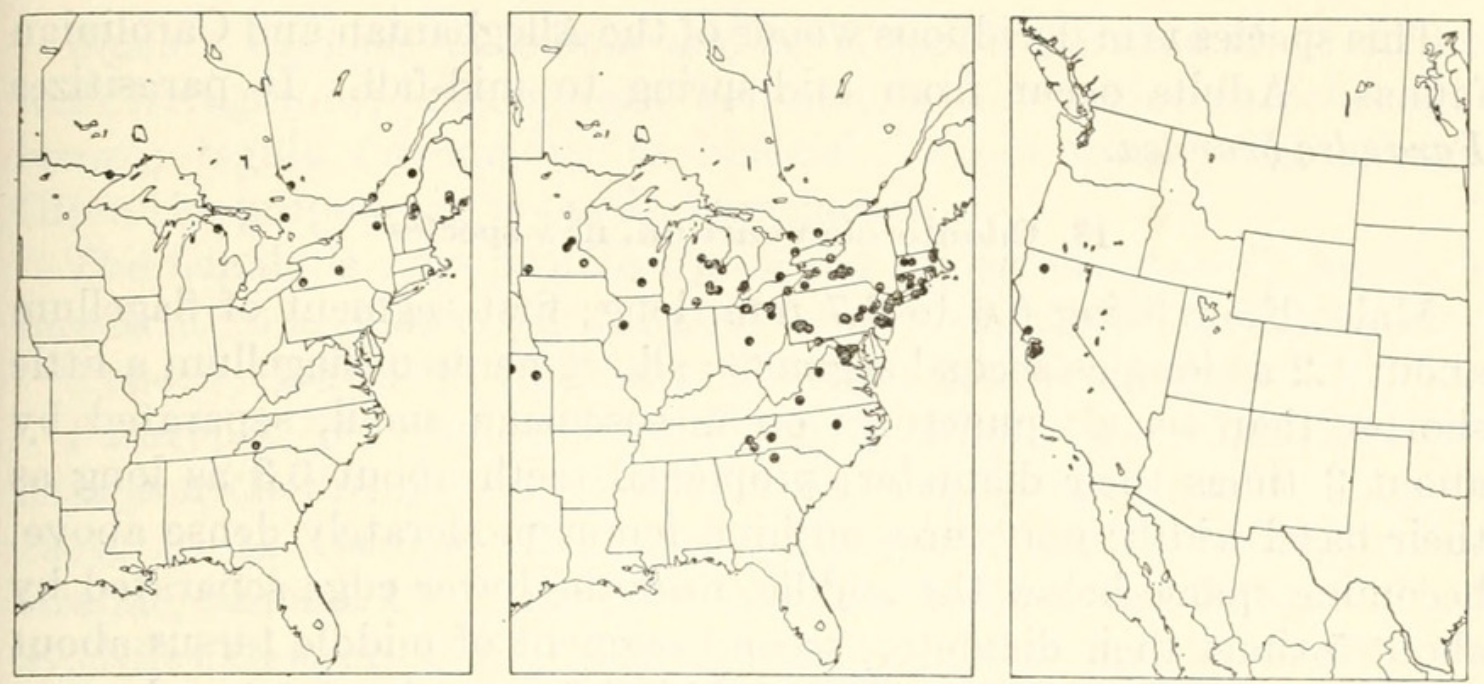

Figures 211-213.-Localities: 211 (left), Odontocolon canadense; 212 (center), O. mellipes; 213 (right), O. curtum.

Point, Bethany, East Aurora, East Hampton, Flatbush, Huguenot, Ithaca, McLean Bogs Reserve in Tompkins Co., New Rochelle, Piermont, Quogue on Long Island, Sodus Point, Taughannock Falls, West Farms in New York City, and Yates Co.); North Carolina (valley of Black Mts., Raleigh, and Sylva); Ohio (Cedar Point in Erie Co., Cleveland, Columbus, Ira, Logan Co., Puritas Springs in Cuyahoga Co., and Put-in-Bay); Ontario (Marmora, Niagara Glen, Normandale, Orillia, and Toronto); Pennsylvania (Aspinwall, Easton, Guyasuta Run in Pittsburgh, Heckton Mills in Dauphin Co., Inglenook in Dauphin Co., Jeannette, Kempton, Lebanon, Pittsburgh, Presque Isle, Roxborough, and Thornhill in Allegheny Co.); Rhode Island (Providence); South Carolina (Greenville); South Dakota; Tennessee (Great Smoky Mts. on the State road to Newfound Gap); Virginia (Blacksburg, Dayton, Dead Run in Fairfax Co., Falls Church, Glencarlyn, Great Falls, Leesburg, Mount Vernon, and "Wolf Gap at 2,300 ft."); West Virginia (Bolivar, Chester, French Creek, and Monongalia Co.); and Wisconsin (Fond du Lac Co. and Madison). Collection dates are rather evenly distributed from mid-spring to mid-fall. Unusually early and late dates are: May 8 at Lawrence, Kans.; May 10 at Riverton, N. J.; May 11 in Midland Co., Mich.; October 12 at New Brunswick, N. J.; October 16 at Taughannock Falls, N. Y.; and October 20 at Takoma Park, Md.

Host records on pin labels are as follows: $ᄋ$, ovipositing in Acer infested with Parandra brunnea, Plummers Island, Md., May 15, 1912, Schwartz and Barber. , parasite on Parandra brunnea, Falls Church, Va., August 1928, A. B. Champlain. brunnea, French Creek, W. Va., F. E. Brooks. 
This species is in deciduous woods of the Alleghanian and Carolinian faunas. Adults occur from mid-spring to mid-fall. It parasitizes Parandra brunnea.

\section{Odontocolon curtum, new species}

Male: Front wing 6.6 to $6.7 \mathrm{~mm}$. long; first segment of flagellum about 1.2 as long as second segment; all segments of flagellum a little sborter than usual; punctures on mesoscutum small, separated by about 3 times their diameter; propodeal teeth about 0.3 as long as their basal width; punctures on hind femur moderately dense above, becoming sparse below the middle, near the lower edge separated by about 5 times their diameter; second segment of middle tarsus about 2.7 as long as deep; fifth segment of hind tarsus about 1.1 as long as second segment; second tergite polished except for weak, very fine rugulosity basally, its punctures very fine, evenly distributed, separated by about 0.8 the length of the hairs.

Black. Clypeus and mandible sometimes largely ferruginous; labrum fulvous; palpi fulvous to brown; tegula brownish fulvous to blackish; legs fulvoferruginous, their coxae a little darkened basally, fifth segment of front and middle tarsi and hind tarsus somewhat infuscate, and hind tibia faintly infuscate; wings faintly infuscate.

Female: Front wing 6.8 to $9.4 \mathrm{~mm}$. long; flagellum with 29 to 32 segments, its segments unusually short, its first segment about 1.40 as long as second; head about 1.03 as wide across temples as across eyes; punctures on temple of mixed medium and small sizes, separated by about 3.5 their diameter; thorax about 2.40 as long as high; posterodorsal $0.3 \pm$ of pronotum with small weak punctures that are separated by about 2.5 their diameter; trough of pronotum with a few weak, very short, transverse wrinkles, otherwise smooth; punctures on mesoscutum small, weak, very sparse, in most areas separated by 5 or more times their diameter; mesepimeron with moderately dense hairs on its upper $0.45 \pm$, the rest bare or with few hairs; metapleurum with moderately strong, irregularly oblique, rugosopunctation; petiolar area about 0.45 as long as combined areola and basal area; propodeal teeth about 0.6 as long as their basal width; hairs in first lateral area sparse to moderately dense; hind femur about 1.80 as long as deep, the punctures on its upper half rather small, rather sharp, and dense, those just below middle somewhat larger and sparser, the lower $0.4 \pm$ of the femur almost without punctures; second segment of middle tarsus about 1.5 as long as deep; fifth segment of hind tarsus about 1.38 as long as second segment; second tergite smooth, polished with its basal $0.15 \pm$ somewhat rugulose, its punctures very small, separated by about 3 times the length of the hairs; ovipositor sheath about 1.45 as long as front wing. 
Black. Clypeus, mandible, and basal part of antenna often stained with ferruginous; labrum, legs, and abdomen ferruginous; palpi light brown; tegula ferruginous to blackish; wings tinted with brown. Often the propodeum is partly ferruginous.

The female is recognizable by its red abdomen, sparsely punctate mesoscutum and lower part of hind femur, and short flagellum.

Type: ㅇ, Redwood City, Calif., Feb. 22, 1923 (Berkeley).

Paratypes: $0^{7}$, o, under bark, Berkeley, Calif., Feb. 19, 1949, E. L Atkinson (Berkeley). क , Coffee Creek, Trinity Co., Calif., Aug. 2, 1931, R. L. Usinger (Berkeley). 2o, reared from "laurel," Mesa Grande, Sonoma Co., Calif., October 1908 (Ithaca and Townes). $\sigma^{\text {, }}$ 3ㅇ, Niles Canyon, Calif., Mar. 4, 1928 (Berkeley and Townes). 3o, same data as type (Berkeley and Townes).

This species occurs in central and northern California, in the lowlands.

\section{Odontocolon sierrae, new species}

Male: Front wing 3.5 to $5.7 \mathrm{~mm}$. long; first segment of flagellum about 1.1 as long as second segment; punctures on mesoscutum of moderate size, rather weak, separated by about 2.5 times their diameter; propodeal teeth low, about 0.4 as high as basal width; punctures on hind femur rather weak, on upper half separated by about their diameter, sparser below the middle, near lower edge separated by about 3 to 4 times their diameter, second segment of middle tarsus about 3.3 as long as deep; fifth segment of hind tarsus about 0.85 as long as second segment; second tergite polished but with fine weak rugulosity basally, its punctures fine, separated by about 0.65 the length of the hairs.

Coloration as in the female.

Female: Front wing 4.4 to $7.4 \mathrm{~mm}$. long; flagellum with about 33 segments, its first segment about 1.35 as long as second; head about 1.005 as wide across temples as across eyes; punctures on temple small, separated by about 3 times their diameter; thorax about 2.10 as long as high; upper $0.25 \pm$ of pronotum with very fine punctures that are separated by about 4 times their diameter; trough of pronotum with irregular transverse ridges in its anterior $0.6 \pm$, the posteroventral $0.4 \pm$ of its length with long horizontal wrinkles; punctures on mesoscutum fine, rather sharp, separated by about 3 times their diameter; mesepimeron with hairs on its upper $0.7 \pm$; metapleurum with strong, irregularly longitudinal wrinkles, not distinctly punctate; petiolar area about 0.47 as long as combined areola and basal area; propodeal teeth about 0.5 as long as their basal width; hairs on first lateral area moderately dense, their sockets separated by about 0.9 the length of the hairs; hind femur about 2.17 as long as deep, with fine, rather weak, close punctures all over, the punctures a little sparser 
ventrally but still moderately dense; second segment of middle tarsus about 1.6 as long as deep; fifth segment of hind tarsus about 1.20 as long as second segment; second tergite polished or weakly mat, its basal $0.25 \pm$ more or less rugulose, its punctures small, moderately sharp, separated by about 2.5 the length of the hairs; ovipositor sheath about 1.05 as long as front wing.

Black. Mandible stained with ferruginous; labrum and palpi fulvous to brown; tegula reddish brown to blackish; legs fulvoferruginous, the front and middle tarsi and the hind tibia fuscoferruginous and the hind tarsus blackish; wings faintly infuscate.

The female is distinct in its small size, black abdomen, fulvoferruginous legs, strong longitudinal wrinkles on metapleurum, and long horizontal wrinkles near lower corner of pronotum. It is most similar to parvum.

Type: , Fish Camp, Calif., July 14, 1948, H., M., G., and D. Townes (Washington, USNM 63726).

Paratypes: o, Camino, Calif., June 30, 1948, H., M., G., and D. Townes (Townes). $\sigma^{7}$, , Dardanelle, Calif., July 8, 1948, H., M., G., and D. Townes (Townes). $3 \sigma^{\top}, 6$ 으, Fish Camp, Calif., July 11, 12, 14, 15, and 19, 1948, H., M., G., and D. Townes (Townes).

This species occurs in the Transition and Canadian zones of the Sierra Nevada of central California.

\section{Odontocolon parvum, new species}

Male: Front wing 3.2 to $5.7 \mathrm{~mm}$. long; first flagellar segment about 1.15 as long as second; punctures on mesoscutum separated by about 1.7 their diameter; propodeal teeth about 0.25 as long as their basal width; punctures on hind femur rather weak, moderately dense, becoming sparser below the middle, near lower edge of femur separated by about 3.5 their diameter; second segment of middle tarsus about 3.8 as long as deep; fifth segment of hind tarsus about 0.85 as long as second segment; second tergite with more or less distinct fine rugulosity, the rugulosity with a weak longitudinal tendency and obsolescent on apical $0.15 \pm$ of the tergite; punctures on second tergite very fine, obscured by the rugulosity; hair sockets on second tergite separated by about 0.5 the length of the hairs.

Black or blackish brown; labrum fulvous; palpi fulvous or brown; tegula light to dark brown; legs fulvous, or sometimes fulvous brown or brown, the hind coxa and femur being a little darker than the rest; hind tarsus and upper half of hind tibia infuscate; wings subhyaline.

Female: Front wing 4.8 to $6.3 \mathrm{~mm}$. long; flagellum with about 30 segments, its first segment about 1.42 as long as second; head about 0.98 as wide across midlength of temples as across eyes; punctures on temple very small, separated by about 3 times their diameter; thorax 
about 2.35 as long as high; upper $0.3 \pm$ of pronotum with fine punctures that are separated by about 3 times their diameter; trough of pronotum with about 7 short, weak, transverse wrinkles, posteroventrally with some short, weak, horizontal ridges; punctures on mesoscutum fine, moderately sharp, separated by about 1.5 their diameter; mesepimeron with hairs on its upper $0.85 \pm$; metapleurum with medium sized, weak, moderately close punctures that are more or less obscured by weak, irregular wrinkling, sometimes rather smooth; petiolar area about 0.43 as long as combined areola and basal area; propodeal teeth about 0.5 as long as their basal width; hairs on first lateral area sparse, their sockets separated by about 1.2 the length of the hairs; hind femur about 2.12 as long as deep, with very fine, weak, dense punctures all over, the punctures a little sparser ventrally but still moderately dense; second segment of middle tarsus about 1.5 as long as deep; fifth segment of hind tarsus about 1.32 as long as second segment; second tergite rather strongly mat, usually also with more or less distinct fine wrinkling that is irregularly transverse, its punctures not distinct, its hairs separated by about 2.0 their length; ovipositor sheath about 1.08 as long as front wing.

Black. Palpi fulvous to dark brown; tegula blackish; legs fulvous, sometimes with faint fuscous tinges, the tarsi brownish apically and hind tibia more or less infuscate, especially its dorsal half; wings subhyaline.

The female is distinctive in its small size, black abdomen, fulvous legs, hairs near lower edge of hind femur moderately dense, punctures on mesoscutum neither dense nor sparse, mat second tergite, head relatively narrow across the temples, and lower part of pronotal trough without long horizontal wrinkles. It is most similar to sierrae.

Type: , Phantom Valley at 9,400 ft., Rocky Mountain National Park, Colo., Aug. 9, 1948, H., M., D., and J. Townes (Washington, USNM 63727).

Paratypes $\left(41 \sigma^{7}, 25 \%\right)$ : From British Columbia (Cultus Lake and Robson); Colorado (Phantom Valley in Rocky Mountain National Park at 9,400 ft.); Idaho (Moscow Mt.); Oregon (McMinnville); Washington (Ashford, Blaine, Elbe, Glacier, Kamiak Butte in Whitman Co., Port Gamble, and Pullman); and Wyoming (Mammoth Hot Spring in Yellowstone Park).

Collection dates are mostly from July 4 to August 19. Those outside this range are: April 1 at Kamiak Butte, Whitman Co., Wash.; May 18 at Robson, B. C.; June 8 at Moscow Mt., Idaho; and August 23 and 24 at McMinnville, Oreg. In our own collecting we have found the species on herbage in moderately damp woods.

This species occurs in the Canadian and Transition zones from British Columbia to Oregon and Colorado.

$526527-60-31$ 

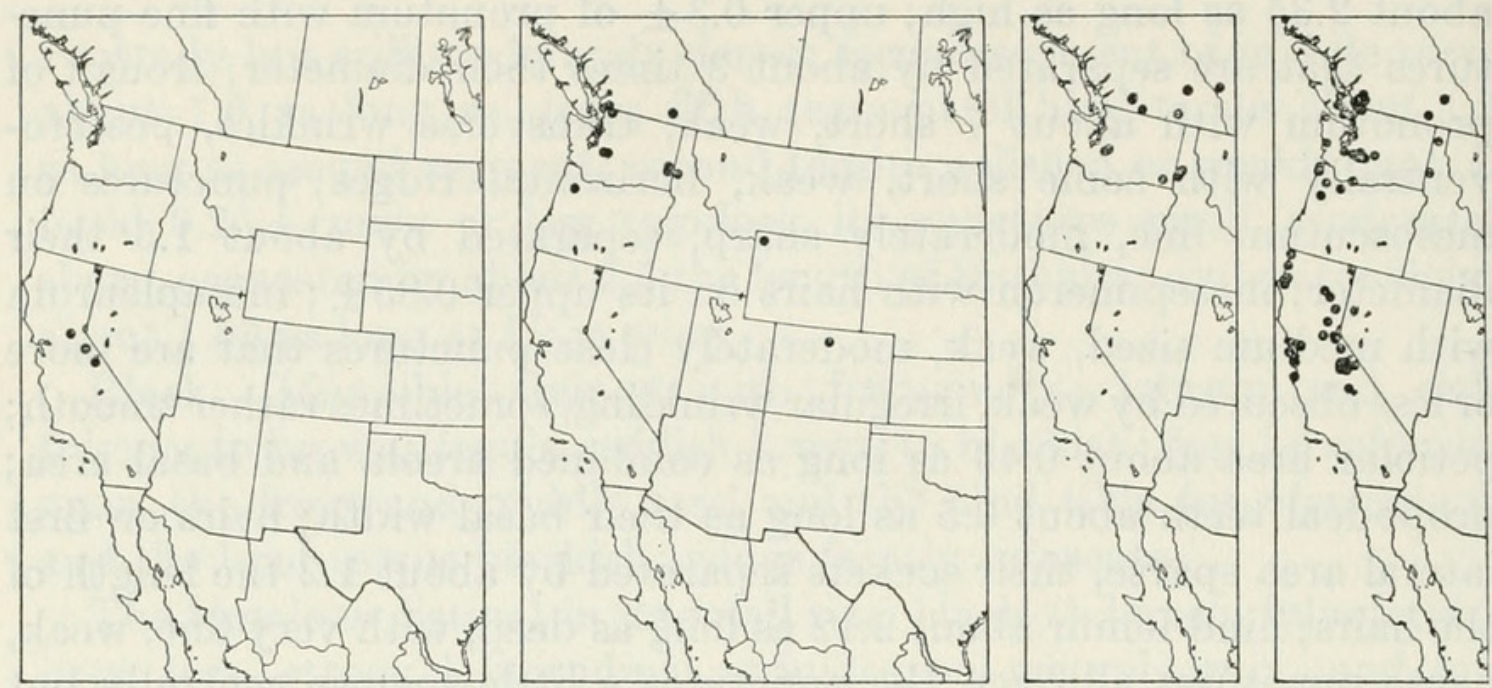

Figures 214-217.-Localities: 214 (left), Odontocolon sierrae; 215 (center, left), O. parvum; 216 (center, right), O. brevicaudus; 217 (right), O. dichrous.

\section{Odontocolon brevicaudus (Cushman)}

Odontomerus brevicaudus Cushman, 1930, Proc. U. S. Nat. Mus., vol. 77, art. 3, p. 7; + . Type: $q$, Hedley, B. C. (Ottawa).

Male: Front wing 4.2 to $8.2 \mathrm{~mm}$. long; first flagellar segment about 1.22 as long as second; punctures on mesoscutum moderately strong, separated by about 1.8 their diameter; propodeal teeth about 0.4 as long as their basal width; punctures on hind femur moderately strong and close, sparser ventrally, near lower edge of femur separated by about 1.7 their diameter; second segment of middle tarsus about 3.4 as long as wide; fifth segment of hind tarsus about 0.88 as long as second segment; second tergite almost or quite polished, its basal $0.15 \pm$ rugulose, its punctures rather sharp, separated from each other by about 2.7 their diameter.

Black. Labrum fulvous; palpi light brown; tegula dark brown; front and middle legs fulvous, their tarsi brownish apically; hind coxa dark brown or blackish, sometimes partly fulvous but at least its base dark colored; hind trochanters and femur fulvous; hind tibia fulvous, its upper half infuscate; hind tarsus infuscate; wings faintly tinged with fuscous.

Female: Front wing 4.4 to $11.4 \mathrm{~mm}$. long; flagellum with about 40 segments, its first segment about 1.4 as long as second; head about 1.00 as wide across temples as across eyes; punctures on temple of moderate size, separated by about 1.5 their diameter; thorax about 2.40 as long as high; upper $0.35 \pm$ of pronotum with small punctures that are separated by about 1 to 3 times their diameter; trough of pronotum with about 10 moderately long transverse ridges and posteroventrally with coarse, irregular wrinkling that is mostly horizontal; punctures on mesoscutum moderately small, moderately sharp, separated by about 3 times their diameter; mesepimeron with hairs all 
over, but somewhat sparser below; metapleurum with sharp, mediumsized, subadjacent punctures that are more or less confluent with and obscured by irregularly oblique wrinkles; petiolar area about 0.45 as long as combined areola and basal area; propodeal teeth about 0.5 as long as their basal width; hairs in first lateral area moderately dense to sparse; hind femur about 1.95 as long as deep, its punctures small, sharp, dense, near the lower edge a little larger and sparser but still rather dense; second segment of middle tarsus about 1.65 as long as deep; fifth segment of hind tarsus about 1.28 as long as second; second tergite subpolished, more or less rugulose and striate basally, its punctures small, separated by about 2.5 the length of the hairs, ovipositor sheath about 1.55 as long as front wing.

Black. Mandible often stained with ferruginous; palpi brown; labrum, legs and abdomen fulvoferruginous, the front and middle tarsi weakly brownish, hind tarsus brown, and hind tibia somewhat darkened apically; first abdominal segment more or less infuscate basally; tegula blackish; wings with a brown tinge.

The female is distinguished by its fulvoferruginous abdomen and legs, sparsely punctate mesoscutum, trough of pronotum with transverse ridges, and hind femur with rather dense punctures all over, not hairless nor very sparsely punctate below. The male is unusual in having the hind coxa mostly fuscous and the hind trochanters and femur fulvous, though a safe determination requires consideration of other characters, also.

Specimens (34 $0^{7}, 36$ o): From Alberta (Banff); British Columbia (Hedley, Mount Revelstoke, Oliver, and Robson); Idaho (Cedar Mt. near Moscow and Cornwall); and Washington (Blue Mt., Eagle Peak on Mount Rainier, and Mount Rainier at 4,000 ft.).

Dates of collections are rather evenly distributed from early spring to early fall. Unusually early and late dates are: April 3 at Oliver, B. C.; April 25 at Robson, B. C.; September 2 at Robson, B. C.; and September 6 at Banff, Alta.

This species is in the Canadian zone of the mountains of northeastern United States and adjacent Canada. Adults occur from early spring to early fall.

\section{Odontocolon dichrous (Rohwer)}

Odontomerus dichrous Rohwer, 1913, Proc. U. S. Nat. Mus., vol. 45, p. 361, ๆ. Type: $q$, Longmire on Mount Rainier, Wash. (Washington).

Male: Front wing 3.4 to $10.0 \mathrm{~mm}$. long; first flagellar segment about 1.25 as long as second; punctures on mesoscutum moderately strong, separated by about 1.5 their diameter; propodeal teeth usually about 0.6 as long as their basal width; punctures on hind femur rather coarse and close, a little sparser ventrally, near the lower edge of femur 
separated by about 1.7 their diameter; second segment of middle tarsus about 3.4 as long as deep; fifth segment of hind tarsus about 0.90 as long as second segment; second tergite polished or subpolished, smooth with a little rugosity at extreme base, its punctures sharp, separated from each other by about 1.5 their diameter.

Black. Mandible stained with ferruginous; tegula fulvous to blackish brown; labrum, palpi, and front and middle legs fulvous, the front and middle tarsi a little brownish apically; hind coxa, trochanters, and femur fulvous; occasionally, in small specimens from the Hudsonian zone, the hind coxa fuscous basally; hind tibia and tarsus brownish fulvous; abdomen entirely black or more or less fulvoferruginous medially, the apical $0.3 \pm$ always black or infuscate; wings subhyaline.

Female: Front wing 5.0 to $11.4 \mathrm{~mm}$. long; flagellum with about 38 segments, its first segment about 1.35 as long as second; head about 1.00 as wide across temples as across eyes; punctures on temple moderately small, separated by an average of about 1.5 to 3.0 their diameter; thorax about 2.35 as long as high; upper $0.25 \pm$ of pronotum with moderate sized, moderately strong punctures that are separated by about 1.5 their diameter; groove of pronotum with about 10 short, rather weak, transverse ridges that are sometimes very faint or absent, especially in smaller specimens; mesoscutal punctures small, sparse, separated by about 5 times their diameter; mesepimeron with hairs on its upper $0.7 \pm$; metapleurum with moderately large, weak, rather close punctures and more or less wrinkled, especially posteriorly; petiolar area about 0.45 as long as combined basal area and areola: propodeal teeth about 0.9 as long as their basal width; hairs in first lateral area moderately dense; hind femur about 2.00 as long as deep, the punctures on its upper half rather small, sharp and dense, much sparser below the middle, its lower third with very sparse punctures or almost none; second segment of middle tarsus about 1.6 as long as deep; fifth segment of hind tarsus about 1.35 as long as second; second tergite polished, with a little rugulosity at its base, its punctures very small, separated by about 3 times the length of the hairs; ovipositor sheath about 1.47 as long as front wing.

Black. Mandible often tinged with ferruginous; labrum and palpi fulvous to brown; tegula fuscoferruginous; legs fulvous or fulvoferruginous, the tarsi often tinged with brown; abdomen black or fulvoferruginous, rarely of intermediate color.

This is an unusually variable species, and difficult to distinguish from some of the closely related forms. Brevicaudus in the north, curtum of lowland California, sierrae in the Sierra Nevada, and parvum in the Cascades and Rocky Mountains are adjacent populations which are only weakly differentiated and split away from 
dichrous. Dichrous itself has weak subdivisions which may prove to be definable subspecies or even species. At higher altitudes in the Cascades and Sierra Nevada this species usually has the abdomen red in the female, tinged with red in the male, and with a stouter build and denser sculpture. The stouter build is particularly evident in the shorter tarsal segments. This form is close to brevicaudus. In the Vancouveran area, at lower altitudes, the species is slender, less densely sculptured, and has the abdomen black in both sexes. Farther south, still at lower altitudes, the slender form is still present with the female abdomen red and the male abdomen usually partly reddish.

Females are distinguished by the fulvous legs, usually more or less distinct transverse ridges in trough of pronotum, sparse mesoscutal punctures, and very sparsely punctate lower third of hind femur. The abdomen may be either fulvous or black.

Specimens (168 $\left.0^{7}, 77 \%\right)$ : From British Columbia (Agassiz, Beaver Mouth in the Selkirk Mts., Cultus Lake, Diamond Head Trail near Squamish at 3,300 ft., between Duncan and Cowichan Lake, Grouse Mt. at 3,700 ft., Robson, Rogers Pass at 4,500 ft., Vancouver, Victoria, and Wellington); California (Agnew Meadows in Madera Co., Camino, Carmel, Cisco, Contra Costa Co., Crane Flat in Yosemite Park, Crescent City, Dardanelle, Dyerville, Echo Lake, Fish Camp, near Glacier Point in Yosemite Park, Gold Lake in Sierra Co., Humboldt Co., Lake Almanor in Plumas Co., Lassen Peak in Shasta Co. at 7,500 ft., Mill Valley, Mineralking, Old Station, Orick, Portola State Park in San Mateo Co., sand hills near Cliff House in San Francisco, Smoky Jack Camp in Yosemite Park, Snow Flat in Yosemite Park at 8,700 ft., "Summit Lake in Shasta Co.," Tamarack Flat in Yosemite Park, Upper Echo Lake at 7,400 ft., and Yosemite Valley); Idaho (Lookout Mt. at Priest Lake and Moscow Mt.); Oregon ("Boyer," Cannon Beach, Corvallis, Hood River, McMinnville, Mount Hood at 3,000 ft., and Seaside); and Washington (Ashford, Elbe, Forks, Glacier, Hoquiam, Kittitas Co., Longmire on Mount Rainier, Mount Constitution on Orcas Island, Mount Rainier at 2,900, 3,500, 4,700, 5,000, and 5,500 ft., Paradise Lake on Mount Rainier, Seattle, Summerland Trail on Mount Rainier, "Union City," White River on Mount Rainier, and Yelm).

Collection dates are from early spring to early fall. Unusually early and late dates are: February 28 at Mill Valley, Calif.; March 1 in Contra Costa Co., Calif.; March 19 at Corvallis, Oreg.; March 31 at Boyer, Oreg.; September 10 at Agassiz, B. C.; September 20 at Victoria, B. C.; and October 15, without locality.

We have found the species common in many localities in damp Transition forests, resting on the foliage of undergrowth.

This species occurs in the Transition and Canadian zones, from 
southern British Columbia to central California. It is adult from early spring to early fall. Damp woods with undergrowth is the usual habitat.

\section{Odontocolon atripes (Rohwer)}

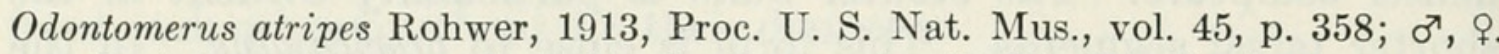
Lectotype (hereby selected): @, Franconia, N. H. (Washington).

Male: Front wing 3.7 to $7.7 \mathrm{~mm}$. long; first flagellar segment about 1.15 as long as second; punctures on mesoscutum moderately sharp, separated by about 1.6 their diameter; propodeal teeth about 0.65 as long as their basal width; punctures on hind femur moderately strong and close, sparser near lower edge, where they are separated by about 1.5 their diameter; second segment of middle tarsus about 3.0 as long as deep; fifth segment of hind tarsus about 1.15 as long as second segment; second tergite subpolished, a little mat and longitudinally rugulose basally, its punctures small, evenly distributed, separated by about 0.4 the length of the hairs.

Black. Labrum fulvous to blackish; palpi and tegula light brown to blackish; front and middle femora and second trochanters dusky fulvous to blackish; front and middle tibiae and tarsi fulvous to dark brown; hind second trochanter, extreme base of hind femur, and narrow apex of hind tibia and of segments of hind tarsus, brown; wings faintly infuscate.

Female: Front wing 4.5 to $9 \mathrm{~mm}$. long; flagellum with about 36 segments, its first segment about 1.50 as long as second; head about 1.01 as wide across temples as across eyes; punctures on temple moderately coarse, separated by about 1.4 their diameter; thorax about 2.40 as long as high; upper $0.3 \pm$ of pronotum with moderately coarse punctures that are separated by about 3 times their diameter; trough of pronotum with a row of about 10 short, strong transverse ridges, the row a little above center of the trough (an unusual feature); mesoscutal punctures small, rather weak, separated by about 5 times their diameter; mesepimeron with hairs all over but sparser below; metapleurum rather strongly rugosopunctate; petiolar area about 0.60 as long as combined areola and basal area; propodeal teeth about 0.65 as long as their basal width; hairs in first lateral area sparse, their sockets separated by about 1.5 the length of the hairs; hind femur about 1.92 as long as deep, the punctures on its upper half rather coarse but weak, closely spaced, just below the middle a little sparser, on lower $0.4 \pm$ of femur very sparse, separated by about 5 times their diameter; second segment of middle tarsus about 1.45 as long as deep; fifth segment of hind tarsus about 1.8 as long as second; second tergite polished, a little rugulose basally, its punctures very small, separated by about 3 times the length of the hairs; ovipositor sheath about 1.35 as long as front wing. 
Black. Labrum, palpi, and tegula dark brown or blackish; front and middle tibiae and tarsi with brownish tinges; abdomen red beyond first segment, the apex of first segment also red; wings weakly infuscate.

The female is distinguished by black legs and red abdomen. No other Nearctic species has this color combination.
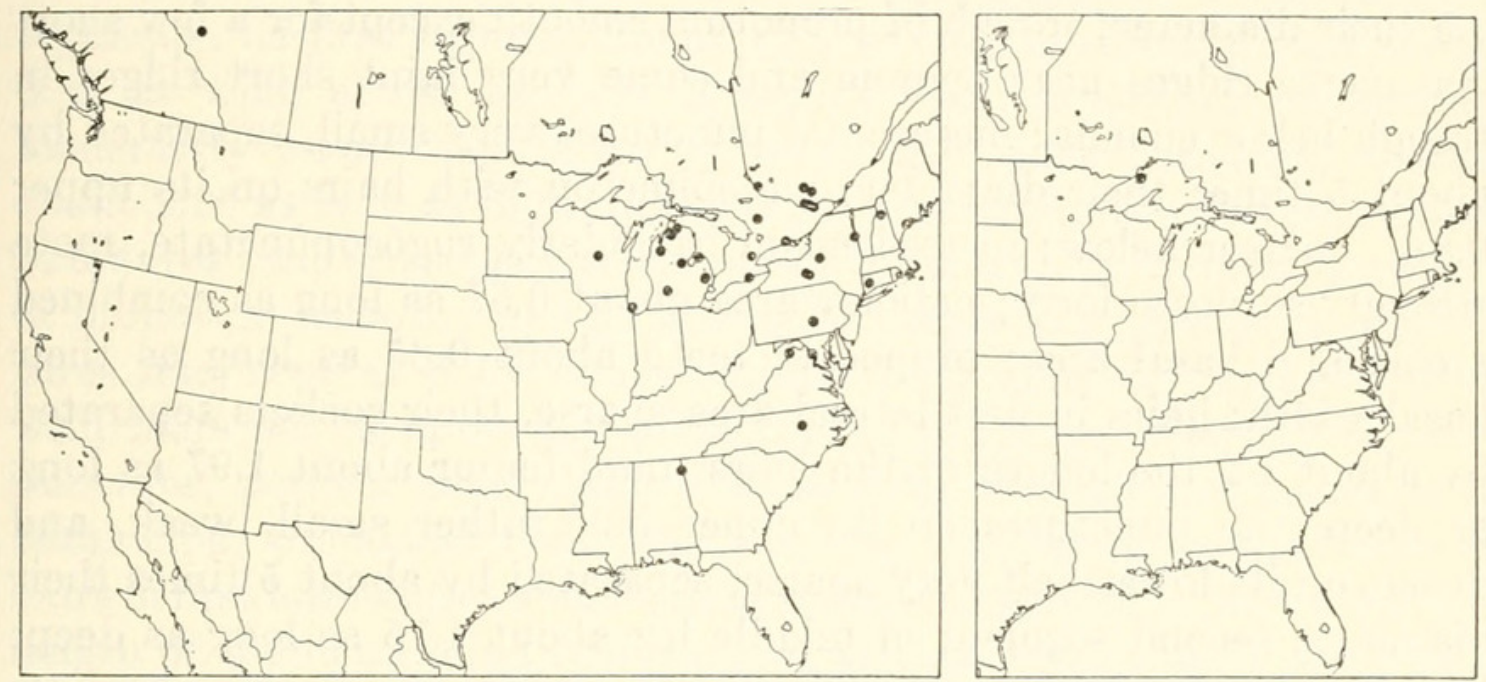

Figures 218, 219.-Localities: 218 (left), Odontocolon airipes; 219 (right), $O$. dreisbachi.

Specimens $\left(17 \sigma^{x}, 32\right.$ ) : From Alabama (De Soto State Park); Alberta (Nordegg); Connecticut (Southington); Illinois (Chicago); Maine (Brunswick); Massachusetts (Woods Hole); Michigan (Beaver Island in Charlevoix Co., Cheboygan Co., Douglas Lake, Gull Lake Biological Station in Kalamazoo Co., High Island in Charlevoix Co., Lapeer Co., Midland Co., Sand Point in Huron Co., and Wexford Co.); New Hampshire (Franconia); New York (Ithaca, between Ithaca and Ellis, Lake George, and Utica); North Carolina (Raleigh); Nova Scotia (Kentville and Smith's Cove); Ontario (Georgetown, Kearney, Ottawa, Port Ryerse, and Trenton); Pennsylvania (Rockville in Dauphin Co.); Prince Edward Island (Brackley Beach and Dalvay House, both in Canadian National Park); Quebec (Aylmer, Lac Ste. Marie, Laniel, Wakefield, and Wright); Virginia (Dunn Loring); West Virginia (Lost River State Park in Hardy Co.); and Wisconsin (Nekoosa).

Collection dates are nearly all in June, July, and August (to August 31). Those outside these months are: May 4 at Raleigh, N. C., and in De Soto State Park, Ala.; and May 30 in Lapeer Co., Mich.

This species is in the Carolinian and Alleghanian faunas. Adults occur from early to late summer. Although it is moderately common in collections, we ourselves have never taken it. 


\section{Odontocolon dreisbachi, new species}

Male: Unknown.

Female: Front wing $8.0 \mathrm{~mm}$. long; flagellum with 36 segments, its first segment about 1.35 as long as second; head about 0.97 as wide across temples as across eyes; punctures on temple small, separated by about 3.0 their diameter; thorax about 2.27 as long as high; upper $0.3 \pm$ of pronotum with fine punctures that are separated by about 3.5 their diameter; trough of pronotum smooth except for a few short transverse ridges near epomia and some very faint short ridges in trough below epomia; mesoscutal punctures very small, separated by about 5 times their diameter; mesepimeron with hairs on its upper $0.8 \pm$, sparser below; metapleurum irregularly rugosopunctate, more strongly so posteriorly; petiolar area about 0.57 as long as combined areola and basal area; propodeal teeth about 0.65 as long as their basal width; hairs in first lateral area sparse, their sockets separated by about 1.2 the length of the hairs; hind femur about 1.97 as long as deep, the punctures on its upper half rather small, weak, and dense, on its lower half very sparse, separated by about 5 times their diameter; second segment of middle leg about 1.75 as long as deep; fifth segment of hind tarsus about 1.45 as long as second segment; second tergite polished, a little rugulose at base, its punctures very small, separated by about 3 times the length of the hairs; ovipositor sheath about 1.35 as long as front wing.

Black, including appendages and abdomen, except that front and middle legs and base of hind femur may be blackish brown rather than black. Wings weakly infuscate.

Type: o, Isle Royale, Mich., Aug. 3 to 7, 1937, R. R. Dreisbach (Washington, USNM 63728).

Paratype: ㅇ, same data as type (Dreisbach).

\section{Odontocolon albotibiale (Bradley)}

Odontomerus albotibialis Bradley, 1918, Bull. Brooklyn Ent. Soc., vol. 13, p. 103;

․ Type: $q$, Chicoree Woods, Ithaca, N. Y. (Ithaca).

Odontomerus striatus Cushman, 1930, Proc. U. S. Nat. Mus., vol. 77, art. 3, p. 14;

. Name preoccupied. Type: $\uparrow$, Lyme, Conn. (Washington).

Odontocolon aciculatus Cushman, 1942, Proc. Ent. Soc. Washington, vol. 44, p. 182.

New name for $O$. striatus.

Male: Front wing 3.5 to $7.6 \mathrm{~mm}$. long; first flagellar segment about 1.22 as long as second; punctures on mesoscutum small, weak, separated by about 2.5 their diameter; propodeal teeth about 0.8 as long as their basal width; punctures on hind femur rather small and weak, moderately dense, much sparser on the lower half, on the lower $0.3 \pm$ of femur separated by about five times their diameter; second segment of middle tarsus about 3.3 as long as wide; fifth segment of hind tarsus about 1.11 as long as second segment; nervellus broken usually 
near its middle; second tergite subpolished, its basal $0.25 \pm$ with moderately strong, mostly longitudinal wrinkling, its punctures small, moderately sharp, on median part of tergite very sparse and separated by about 1.5 to 3.0 the length of the hairs, marginally denser and more regularly distributed, separated by about 0.8 the length of the hairs.

Coloration as in the female.

Female: Front wing 4.4 to $9.5 \mathrm{~mm}$. long; flagellum with about 39 segments, its first segment about 1.35 as long as second; head about 0.98 as wide across temples as across eyes; punctures on temple moderately small, separated by about 3.0 their diameter; thorax about 2.26 as long as high; upper $0.2 \pm$ of pronotum with some small punctures that are separated by about 3 times their diameter; trough of pronotum smooth; epomia absent or very weak; mesoscutal punctures fine, separated by about 5 times their diameter; mesepimeron with hairs on its upper $0.8 \pm$; metapleurum rather coarsely rugosopunctate; petiolar area about 0.57 as long as combined areola and basal area; propodeal teeth about 0.9 as long as their basal width; hairs in first lateral area sparse, their sockets separated by about 1.2 the length of the hairs; hind femur about 2.10 as long as deep, the punctures on its upper $0.4 \pm$ of moderate size, moderately strong, closely spaced, on its lower 0.6 the punctures very sparse, separated by about 5 times their diameter; second segment of middle tarsus about 2.0 as long as deep; fifth segment of hind tarsus about 1.35 as long as second segment; second tergite mostly smooth and polished but its basal $0.3 \pm$ partly rugulose and finely wrinkled, the wrinkles at extreme base transverse, the rest mostly longitudinal; punctures on second tergite very small, separated by about 3 times the length of the hairs; ovipositor sheath about 1.50 as long as front wing.

The female is distinguished by the black abdomen, pale fulvous legs, fuscous apex of hind femur, pronotal trough without transverse wrinkles, sparse punctures on lower part of hind femur, and second segment of middle tarsus about 2.0 as long as deep.

Specimens (59 $\sigma^{7}, 53$ ) : From Connecticut (Lyme); District of Columbia (Washington); Florida (Archer); Illinois (Chicago); Iowa (Henry Co.); Maine (Casco); Maryland (Bowie, Cabin John, Glen Echo, Plummers Island, and Takoma Park); Massachusetts (Framingham and Martha's Vineyard); Michigan (Ann Arbor, Kent Co., Marquette Co., Midland Co., and St. Joseph); Minnesota (Crookston and Itasca Park); New Hampshire (Jaffrey and Pinkham Notch); New Jersey (Moorestown, Ramsey, and Riverton); New York (Bemus Point, Farmingdale, Greene Co., Ithaca, McLean Bogs Reserve in Tompkins Co., Poughkeepsie, Shokan, and White Lake); North Carolina (Tryon and Wake Co.); Nova Scotia (West River); Ohio 
(Bedford, Columbus, and Hinckley in Medina Co.); Ontario (Midland and Ottawa); Pennsylvania (Crisp in Westmoreland Co., Harrisburg, Inglenook in Dauphin Co., Marsh Run in York Co., Ohiopyle, Philadelphia, Pittsburgh, and Spring Brook); Quebec (Brome and St. Esprit); Rhode Island (Hopkinton and Westerly); South Carolina (Greenville); and Virginia (Arlington Junction, Dead Run in Fairfax Co., Dunn Loring, Falls Church, Great Falls, and near Plummers Island).

Collection dates are rather evenly distributed from mid-spring to early fall. Unusually early and late dates are: April 14 at Dead Run, Fairfax Co., Va.; May 5 at Washington, D. C.; May 11 at Tryon, N. C. and at Harrisburg, Pa.; May 18 at Jaffrey, N. H.; September 11 at Pittsburgh, Pa.; September 14 at Riverton, N. J.; September 20 at Greenville, S. C.; and October 30 near Plummers Island, Md. We have collected the species many times in the undergrowth of woods.

This species is in the Alleghanian and Transition faunas. Adults occur from mid-spring to early fall.
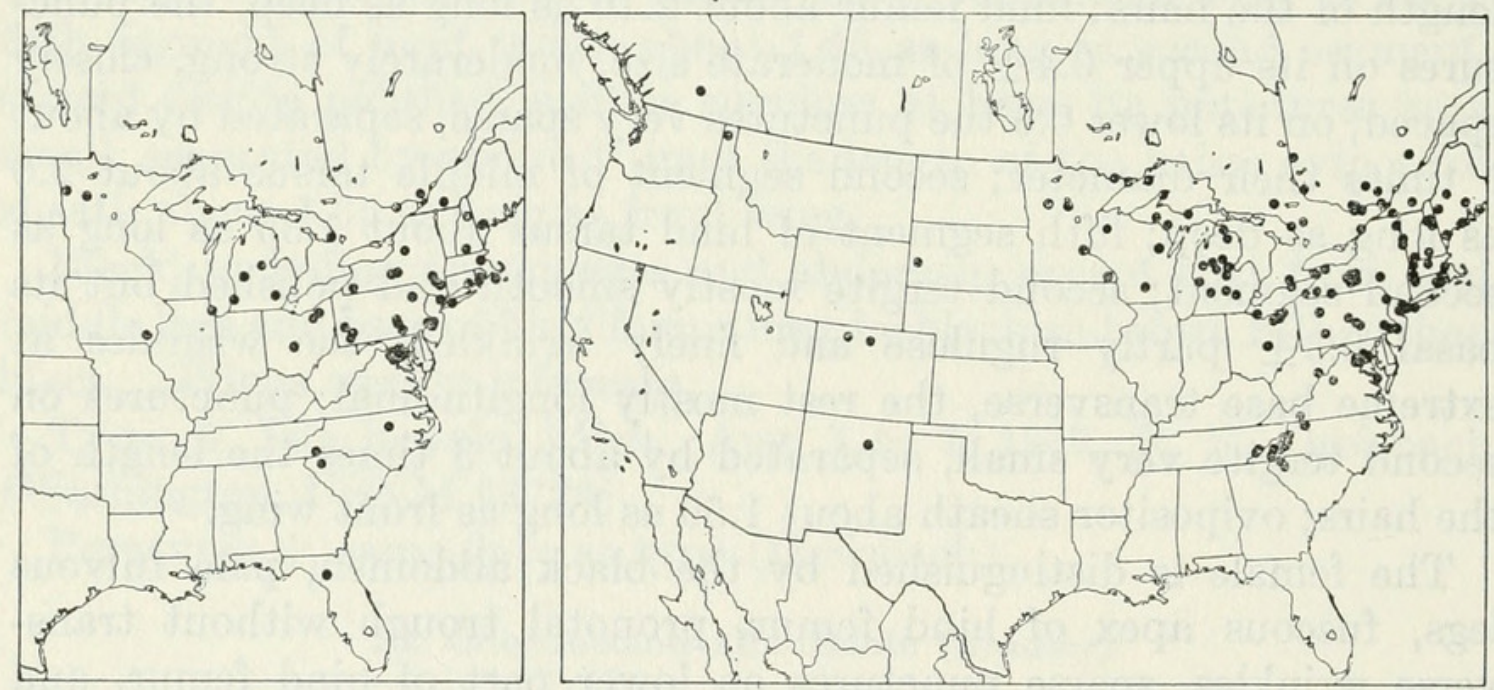

Figures 220, 221.-Localities: 220 (left), Odontocolon albotibiale; 221 (right), O. ochropus.

\section{Odontocolon ochropus, new species}

Male: Front wing 3.5 to $9 \mathrm{~mm}$. long; first flagellar segment about 1.13 as long as second; punctures on mesoscutum small, weak, separated by about 2.5 their diameter; propodeal teeth about 1.0 as long as their basal width; punctures on hind femur moderately strong, moderately dense, sparser below, near lower margin of femur separated by about three times their diameter; second segment of middle tarsus about 3.7 as long as deep; fifth segment of hind tarsus about 0.96 as long as second segment; nervellus broken usually near its lower 
0.38 ; second tergite subpolished, its basal $0.15 \pm$ with rather weak wrinkling, it punctures very small and weak, evenly distributed, separated by about 0.7 the length of the hairs.

Coloration as in the female, except that apical $0.35 \pm$ of hind femur is usually more or less infuscate.

Female: Front wing 6.3 to $11 \mathrm{~mm}$. long; flagellum with about 43 segments, its first segment about 1.30 as long as second; head about 0.985 as wide across temples as across eyes; punctures on temple very small, separated on the average by about 4 to 5 times their diameter; thorax about 2.35 as long as high; upper $0.2 \pm$ of pronotum with some small punctures that are separated by about 4 times their diameter; epomia weak; mesoscutal punctures very fine, separated by about 6 times their diameter; mesepimeron with hairs on its upper $0.4 \pm$ anteriorly, on its upper $0.6 \pm$ posteriorly, the rest bare; metapleurum smooth or with more or less distinct irregular wrinkling, with small weak punctures that are separated by about 3 times their diameter; petiolar area about 0.50 as long as combined areola and basal area; propodeal teeth about 0.9 as long as their basal width; hairs in first lateral area sparse, their sockets separated by about 1.2 their length; hind femur about 2.15 as long as deep, on its upper $0.4 \pm$ with small, weak, close punctures, its lower $0.6 \pm$ with very sparse punctures that are separated by more than 5 times their diameter; second segment of middle tarsus about 1.65 as long as deep; fifth segment of hind tarsus about 1.60 as long as second segment; second segment polished, a little rugulose and finely wrinkled basally, its punctures very small, separated by about 4 times the length of the hairs; ovipositor sheath about 1.55 as long as front wing.

The female is distinguished by the black abdomen, very pale fulvous legs, no distinct infuscation on apex of hind femur, punctures on lower half of hind femur very sparse, no cross ridges in trough of pronotum, and lower half of mesepimeron without hairs.

Type: o, Bemus Point, N. Y., July 12, 1937, H. K. Townes (Washington, USNM 63729).

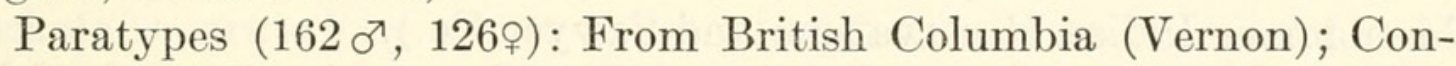
necticut (Colebrook and Voluntown); Colorado (near Estes Park and Steamboat Springs); Idaho (Priest Lake); Maine (Bangor, Bar Harbor, Capens, Casco, Eastport, Lincoln Co., and Oquossoc); Maryland (Bowie, Cabin John, Plummers Island, and Takoma Park); Massachusetts (Holliston, Monterey, Mount Greylock, and Petersham); Michigan (Alger Co., Atlanta, Barry Co., Cheboygan Co., Clare Co., Dickinson Co., East Lansing, George Reserve in Livingston Co., Gratiot Co., Iron Co., Isle Royale, Lake Co., Keweenaw Co., Mecosta Co., Midland Co., Muskegon Co., and Osceola Co.); Minnesota (Basswood Lake in Lake Co., Cass Co., Cook Co., Houston Co., Itasca 
Park, and St. Anthony Park); New Hampshire (Jaffrey, Mount Madison, Pinkham Notch, and Randolph); New Jersey (Moorestown, Ridgewood, and Summit); New Mexico (Beulah); New York ("Avalanch Trail in the Adirondacks," Bemus Point, Black Mt. near Lake George, between Caroline and Harford, foot of "Cliff Mt. in Essex Co. at 3,000 ft.," "Duck Lake in Cayuga Co.," Farmingdale, Flatbush, Freeville, Grand Island, Greene Co., Ithaca, "Lake Charlotte in Columbia Co.," Lake George, Ludlowville, McLean Bogs Reserve in Tompkins Co., Michigan Hollow near Danby, New Russia in Essex Co., Niagara Falls, Oneonta, Ringwood near Ithaca, Rock City in Cattaraugus Co., Taughannock Falls, and West Shelby); North Carolina (Black Mts., between Blowing Rock and Linville at 3,000-4,000 ft., Crabtree Meadows in Yancey Co. at 3,600 ft., Craggy Gardens in Buncombe Co. at 5,300 ft., Doughton Park, Forney Creek in Great Smoky Mountains National Park, Hamrick, Mount Mitchell at 4,000 to 6,300 ft., Pink Beds on Mount Pisgah, Pisgah Mt. 4,800 to 5,300 ft., and North Fork of the Swannanoa River in the Black Mts.); Ohio (Bedford, "Cedar Swamp," Cleveland, Columbus, Hinckley in Medina Co., Licking Co., Puritas Springs in Cuyahoga Co., and Put-in-Bay); Ontario (Kearney, Lyn, Ottawa, Simcoe, Sudbury, Turkey Point, and Waubamik); Pennsylvania (Castle Rock in Delaware Co., Crisp in Westmoreland Co., Cook Forest in Clarion Co., Inglenook in Dauphin Co., New Bloomfield, North East, Perdix in Dauphin Co., Pike Co., Valley Forge, and "Venator"); Quebec (Aylmer, Deschenes, Gaspé Bay, Hemmingford, Knowlton, Lake Opasatika, Laniel, La Trappe, Nominingue, Stoneham, Val Morin, and Wakefield); Rhode Island (Buttonwoods and Hopkinton); South Carolina (Greenville and Mountain Lake in Greenville Co.); South Dakota (near Mount Rushmore in the Black Hills); Tennessee (Spencefield Trail in Great Smoky Mountains National Park); Vermont (Laurel Lake near Jacksonville); Virginia (Black Pond in Fairfax Co., Dixie Landing in Mathews Co., Falls Church, Galax, Great Falls, and Skyline Drive); West Virginia (Cheat Mt. in Randolph Co. at 2,000 ft.); and Wisconsin (Madison, Menominee Indian Reservation, and Sawyer Co.).

Dates of collection are distributed from late spring to early fall. Unusually early and late dates are: April 6 in Midland Co., Mich.; April 28 and 30 on Plummers Island, Md.; May 23 in Houston Co., Minn.; May 24 at Ithaca, N. Y.; September 11 at Bar Harbor, Maine; September 22 at New Bloomfield, Pa.; September 23 near Plummers Island, Md.; September 24 at Great Falls, Va.; and October 4 on Plummers Island, Md. We have collected the species many times on the undergrowth of deciduous woods.

There is one rearing record: $\sigma^{x}$, from Fagus, District of Columbia, Apr. 22, 1909, H. E. Burke. 
This species is in the Transition and Upper Austral zone from the Atlantic to and into the Rocky Mountains. Adults occur from late spring to early fall. It is common in deciduous woods.

\section{Odontocolon strangaliae (Rohwer)}

Odontomerus strangaliae Rohwer, 1917, Proc. U. S. Nat. Mus., vol. 53, p. 158, . Type: + , Ballston, Va. (Washington).

Male: Front wing 3.5 to $7.2 \mathrm{~mm}$. long; first flagellar segment about 1.12 as long as second; punctures on mesoscutum small, weak, separated by about 2.5 their diameter; propodeal teeth about 1.0 as long: as their basal width, punctures on hind femur moderately strong, less dense than usual, much sparser below the middle, near lower edge of femur separated by about five times their diameter; hairs on hind femur unusually long; second segment of middle tarsus about 3.4 as long as deep; fifth segment of hind tarsus about 1.16 as long as second segment; nervellus broken near its lower 0.38 ; second tergite subpolished, its basal $0.15 \pm$ with rather weak wrinkling, its punctures very small and weak, evenly distributed, separated by about 0.7 the length of the hairs.

Coloration as in the female except that abdomen is entirely black, or sometimes with weak fulvous tinges.

Female: Front wing 5.3 to $9.8 \mathrm{~mm}$. long; flagellum with about 41 segments, its first segment about 1.35 as long as second; head about 0.99 as wide across temples as across eyes; punctures on temple moderately coarse, separated by about 2.5 their diameter; thorax about 2.23 as long as high; upper $0.3 \pm$ of pronotum with small punctures that are separated by about 3 times their diameter; trough of pronotum smooth; epomia rather strong; mesoscutal punctures small, separated by about 4 times their diameter; mesepimeron with hairs all over, but these a little sparser below; metapleurum smooth or with more or less distinct irregular wrinkling, its punctures moderate sized, sharp, separated by about 1.5 their diameter; petiolar area about 0.57 as long as combined areola and basal area; propodeal teeth about 0.9 as long as their basal width; hairs in first lateral area sparse, their sockets separated by about 1.2 the length of the hairs; hind femur about 2.05 as long as deep, the punctures on its upper $0.26 \pm$ moderately large and strong, separated by about 1.5 their diameter, the lower $0.75 \pm$ with sparse punctures that are separated by about 5 times their diameter; hairs on hind femur longer and averaging sparser than in any other species of the genus; second segment of middle tarsus about 1.6 as long as deep; fifth segment of hind tarsus about 1.60 as long as second segment; second tergite polished, a little wrinkled at extreme base, with almost no punctures or hairs. 
Black. Labrum, palpi, tegula, legs, and abdomen fulvoferruginous; mandible with a ferruginous stain; propodeum sometimes more or less ferruginous; wings with a weak yellowish brown tinge.

The female is distinguished by the reddish abdomen and legs, lack of wrinkles or transverse ridges on scrobe of pronotum, and long sparse hair on hind femur.

Specimens $\left(102 \sigma^{7}, 73\right.$ ㅇ): From Alabama (Coosa River in Chilton Co. and Pyriton in Clay Co.); Connecticut (Canterbury, Green Falls, and Voluntown); District of Columbia (Washington); Maine (Casco); Maryland (Bowie, Loch Raven, and Takoma Park); Massachusetts (Blue Hills and Lexington); Michigan (Ann Arbor, Douglas Lake, George Reserve in Livingston Co., Gull Lake Biological Station in Kalamazoo Co., Kent Co., Marquette Co., Mecosta Co., Midland Co., Oakland Co., and Osceola Co.) Minnesota (Goodhue Co., Ramsey Co., and St. Louis Co.); New Brunswick (Chamcook); New Jersey (Moorestown); New York (Babylon, Barrytown, Beaver Creek in McLean Reserve in Tompkins Co., Bemus Point, Cold Spring Harbor, Dix Hills near Huntington, "Duck Lake in Cayuga Co.," Eastport, Farmingdale, Greene Co., Hamburg, Huntington, Ithaca, Millwood, Minnetto, Oswego, Poughkeepsie, and Westchester Co.); North Carolina (Crabtree Meadows in Yancey Co. at 3,600 ft., and Wake Co.); Ohio (Bedford, Hocking Co., Puritas Springs in Cuyahoga Co., and Ross Co.); Ontario (Coldstream, Gravenhurst in the Muskoka District, Long Point on Lake Erie, Ottawa, Simcoe, and Waubamik); Pennsylvania (Crisp in Westmoreland Co., Inglenook in Dauphin Co., Montgomery Co., Pittsburgh, and Youngwood); Quebec (Aylmer and Rigaud); Rhode Island (Kingston and Westerly); Tennessee (Elkmont in Great Smoky Mountains National Park); Virginia (Ballston, Dunn Loring, Falls Church, Great Falls, between Kearney and Great Falls, Long Dale in Allegheny Co., and "Whiele"); West Virginia (Cheat Mt. in Randolph Co. at 2,000 ft. and Harpers Ferry); and Wisconsin (Madison, Sawyer Co., Vernon Co., and Waupaca Co.).

Dates of collection are from late spring to early fall. Unusually early and late dates are: May 16 at Washington, D.C.; May 19 at Falls Church, Va.; May 25 at Great Falls, Va.; May 29 at Ann Arbor, Mich., in McLean Bogs Reserve, Tompkins Co., N. Y., and at Youngwood, Pa.; September 14 in McLean Bogs Reserve, Tompkins Co., N. Y.; September 16 in the George Reserve, Livingston Co., Mich.; and September 18 at Long Dale, Alleghany Co., Va. We have found it moderately common on the undergrowth of mesophytic deciduous woods.

Reared specimens are as follows: + , from "Leptura" larvae, Falls Church, Va., May 25, 1914, T. E. Snyder. \& (type), from Strangalina 
luteicornis in Vitis, Mar. 17, 1914, Ballston, Va., F. C. Craighead and H. B. Kirk.

This species occurs in the Alleghanian and Carolinian faunas. It is adult from mid-May to mid-September. Strangaliine Cerambycidae serve as hosts.

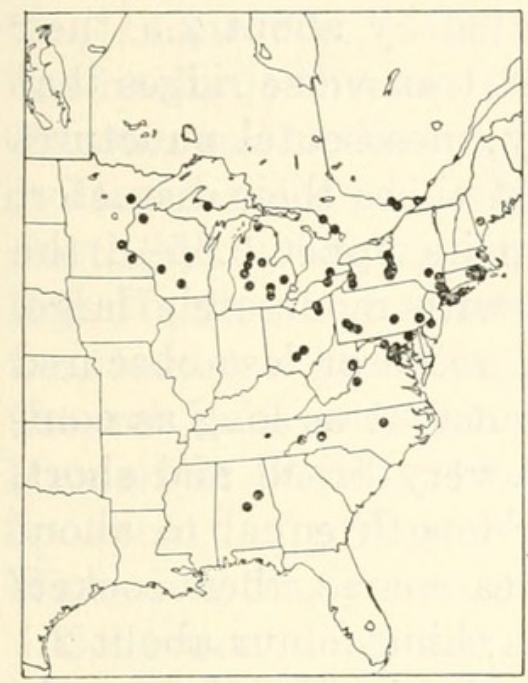

Figures 222, 223.-Localities: 222 (left), Odontocolon strangaliae; 223 (right), O. vicinum.

\section{Odontocolon vicinum (Cresson)}

Odontomerus vicinus Cresson, 1870, Trans. Amer. Ent. Soc., vol. 3, p. 168; ๙ Type: $\sigma^{\top}$, Massachusetts (Philadelphia).

Male: Front wing 3.7 to $10.0 \mathrm{~mm}$. long; first flagellar segment about 1.18 as long as second; punctures on mesoscutum of moderate size, sharp, separated by about 1.7 their diameter; propodeal teeth unusually broad, narrowly separated from each other, about 0.5 as long as their basal width; punctures on hind femur rather sharp, moderately dense, sparser near lower edge of femur where they are separated by about 2.5 their diameter; second segment of middle tarsus about 3.5 as long as deep; fifth segment of hind tarsus about 0.93 as long as second segment; second tergite rugulose, the rugulosity strong basally and weak apically, its punctures moderately sharp but more or less obscured by the rugulosity, the punctures evenly distributed, separated by about 0.7 the length of the hairs.

Black. Labrum, palpi, and front and middle legs fulvous; tegula brown; hind coxa and first trochanter usually blackish but often partly or entirely fulvous, especially in specimens from the MinnesotaOntario area; hind second trochanter fulvous; hind femur usually entirely black or blackish with its base more or less fulvous, sometimes, especially in specimens from the Minnesota-Ontario area, mostly fulvous with its apical part infuscate; hind tibia and tarsus blackish; wings hyaline. 
Female: Front wing 7.5 to $13.3 \mathrm{~mm}$. long; flagellum with about 46 segments, its first serment about 1.28 as long as second; head about 1.09 as wide across temples as across eyes, the temples long and strongly flaring, to give the head a bell-shaped appearance from above; punctures on temple rather small, separated by about 4.0 their diameter; thorax about 2.60 as long as high; posterodorsal $0.3 \pm$ of pronotum with medium-sized punctures that are separated by about 2.5 their diameter; trough of pronotum with weak short transverse ridges that are stronger near epomia and posteroventrally; mesoscutal punctures small, moderately sharp, separated by about 4 times their diameter; mesepimeron with moderately dense hairs on its upper $0.65 \pm$, the rest bare or with sparse hairs; metapleurum with moderately large, rather weak, subadjacent punctures that are more or less obscured by irregular wrinkling; petiolar area only about 0.31 as long as combined areola and basal area; propodeal teeth very broad and short, their bases almost meeting on midline, their length equal to about 0.4 their basal width; hairs in first lateral area sparse, their sockets separated by about 1.5 the length of the hairs; hind femur about 2.1 as long as deep, its upper $0.45 \pm$ with moderate sized, rather weak, close punctures, the rest with very sparse punctures that are separated by about six times their diameter; second segment of middle tarsus about 1.85 as long as deep; fifth segment of hind tarsus about 1.0 as long as second; second tergite weakly mat, its basal $0.4 \pm$ rugulose, its punctures rather small and weak, separated by about 3 times their diameter; ovipositor sheath about 1.85 as long as front wing.

Black. Labrum and palpi light brown; tegula fulvous; legs pale fulvous, the hind tarsus, fifth segment of front and middle tarsi, and more or less of extreme apex of hind femur fuscous; hind tibia somewhat infuscate apically; wings with a faint yellowish brown tinge.

The female is distinct in its black abdomen, pale fulvous legs, strongly flaring temples, sparsely punctate lower half of hind femur, and short petiolar area. Its closest relative seems to be the Japanese O. rufum.

Specimens (1050 $\sigma^{7}$, 103우): From Alberta (McMurray); British Columbia (Robson); Colorado (Steamboat Springs); Connecticut (Stonington); District of Columbia; Maine (Casco); Maryland (near Cumberland and Plummers Island); Massachusetts (Forest Hills and Petersham); Michigan (Ann Arbor, Bay Co., Brevort, Carp Lake in Emmet Co., Crawford Co., Douglas Lake in Cheboygan Co., Gladwin Co., Gogebic Co., Iron Co., Kent Co., Lake City, Livingston Co., Luce Co., Marquette Co., Midland Co., Osceola Co., Roscommon Co., Rudyard, Sanilac Co., and Schoolcraft Co.); Minnesota (Bemidji, Hawley in Clay Co., Itasca Park, Lake Itasca, Lutsen, Rice Co., and Washington Co.); New Hampshire (Bretton Woods, Franconia, and 
Jaffrey); New Jersey (Chatham, Middlesex Co., Moorestown, and Riverton); New York ("Artists Brook in Essex Co.," Beaver Creek in McLean Reserve in Tompkins Co., Bemus Point, Calverton on Long Island, Colden, Greene Co., Hamburg, Ithaca, Keene Valley in Essex Co., and West Farms in New York City); Ohio (Bedford, Cantwell Cliffs in Hocking Co., Delaware Co., Hinckley in Medina Co., Logan Co., Medina, Puritas Springs in Cuyahoga Co., and Put-in-Bay); Ontario (Jockvale, Marmora, Merivale, Niagara Glen, Ottawa, and Sudbury); Pennsylvania (Allegheny Co., Clark's Valley in Dauphin Co., Harrisburg, Inglenook in Dauphin Co., Jeannette, North Mt., Ohiopyle, and Pike Co.); Quebec (Aylmer, Brome, Covey Hill, Harrington Lake in Gatineau Park, Hemmingford, Hull, Knowlton, Lanoraie, La Trappe, St. Johns Co., and Wakefield); Vermont (Laurel Lake near Jacksonville); Virginia (Glencarlyn, Great Falls, Hunter in Fairfax Co., and Rosslyn); Washington (Dartford in Spokane Co.); West Virginia (Cheat Mt. in Randolph Co.); and Wisconsin (Sawyer Co.).

Collection dates are distributed from rather early spring to early fall. Unusually early and late dates are: May 3, 4, and 8 at Ann Arbor, Mich.; May 7 in Washington Co., Minn.; May 15 at Bedford, Ohio; May 20 in Marquette Co., Mich.; September 14 at Riverton, N. J.; September 20 at Bemidji, Minn.; September 21 in McLean Bogs Reserve, Tompkins Co., N. Y.; and September 29 at Calverton, Long Island, N. Y. We have found adults moderately common on the undergrowth of damp, deciduous forests.

There is one reared specimen among our material: $\sigma^{7}$, from buprestid in Betula nigra, Hunter, Fairfax Co., Va., May 14, 1914, S. A. Rohwer. Pechuman (1937, Bull. Brooklyn Ent. Soc., vol. 32, p. 16) records the species as a parasite of Dicerca divaricata.

This species occurs from the Atlantic, to and into the Rocky Mountains in the Transition and Upper Austral zones. It is adult from rather early spring to early fall. Its known hosts are buprestids.

\section{Genus Xorides}

Figure 306,a

Head and body cylindric, weakly flattened, or sometimes strongly flattened; apex of mandible chisel-shaped, without teeth; frons without a median tubercle or horn, or sometimes with a horn or lamella between the antennal sockets; female flagellum subapically elbowed or curved, on the outer side of the elbow or curve with one to several peglike bristles; epomia present, usually strong, long, dorsally turning forward and usually forming a projecting tooth at the turn; hind femur not thickened, without a tooth beneath; first abdominal segment subcylindric or prismatic basally, expanded apically, stout and 
rather short to elongate and slender; second tergite nearly always with an oblique basal groove on each side cutting off basolateral corners, and often with other grooves or impressions; second and third tergites variously sculptured; apical part of ovipositor cylindric or slightly depressed, the lower valve with about eight ridges, basad of which there is a roughened area (fig. $331, \mathrm{~h}$ ).

The species of Xorides are many, and are distributed over almost the entire world. They form a natural, strongly marked group that is easy to recognize. Among them, however, is great structural diversity and the species may be divided into a number of groups of varying size, distinctness, and ease of definition. Most of the more distinct groups have had generic names proposed for them, and whether and which of these to recognize as separate genera has been variously decided by various authors. We prefer to include all of them under a broadly defined genus Xorides. It seems desirable, however, to recognize some of the more distinct groups as subgenera. In the first of the keys below is indicated our version of the subgenera of the World. In the Nearctic region, there are only two subgenera, Exomus and Xorides, so the subgeneric arrangement has relatively little application to our fauna. It is very useful, however, for dealing with the species of the Old World tropics.

We are indebted to Mr. J. F. Perkins of the British Museum (Natural History) for permitting us to study his manuscript key to the subgroups of these insects. Although we have verified his work and modified it, most of the better characters given below were suggested to us by his key. The subgeneric synonymy is according to our studies of the types of the genotypes, of which we have seen all but the types of Ichneumon indicatorius Latreille, Neoxylonomus antennalis Szépligeti, and Xylonomus gracilicornis Gravenhorst. The type of indicatorius is lost, or destroyed. The type of gracilicornis is destroyed. It was lent to Clément along with other Gravenhorst types of this group for his revision of the European species. These types were returned by Clément to the Gravenhorst collection in Wroclaw, but in the case of gracilicornis, only the pin with labels was present in 1958 . The specimen itself was not on the pin.

We are not entirely satisfied with the subgeneric arrangement below, but present it as a basis for future studies, and to bring some order out of the general confusion. The species of Xorides tend to be so scarce in collections that it will be some time before they will be well enough collected to permit a "definitive" classification. The main problem is to predict whether the groups that are definable on the basis of the few species known will remain definable when a larger portion of the fauna is available for study, or when the known species can be gone over in more detail. So many groups that ap- 
peared at first to be very distinct have proved to be joined to other groups by species with intermediate characters (if not also relationships) that one wonders about the durability of the groupings that still seem usable. There is also the question whether it is worthwhile to distinguish those groups that happen to have characters useful for a definition, but suppress those that may be otherwise just as distinct but harder to define. Such taxonomic questions arise frequently, but in the case of Xorides they are unusually hard to answer.

\section{Key to the subgenera of Xorides}

1. Nervulus basad of basal vein; intercubitus basad of second recurrent by not more than its length; Old World species . . . . . . . . . . . . . . 2

Nervulus distad of basal vein; intercubitus basad of second recurrent by more than its length (or the intercubitus obliterated by the touching of radial and cubital veins). . . . . . . . . . . . . . . . . . . . . 6

2. Posterior transverse carina of mesosternum complete and strong; subapical bend of female flagellum involving two or three joints; second segment of hind trochanter, as seen from the front side, about 2.5 as long as first segment. Palaearctic and Oriental . . . . . . . . 1. Gonophonus (p. 494)

Posterior transverse carina of mesosternum broadly interrupted in front of each middle coxa; subapical bend of female flagellum a sharp angle at a single joint . . . . . . . . . . . . . . . . . . . . . . 3

3. Prepectal carina present; Oriental and Australian species . . . . . . . . 4

Prepectal carina absent; Ethiopian species . . . . . . . . . . . . . . . 5

4. Second segment of trochanter of front and middle legs without a tooth at apex on front side . . . . . . . . . . . . . 2. Cyanoxorides (p. 494)

Second segment of trochanter of front and middle legs with a tooth at apex on front side . . . . . . . . . . . . . . 3. Epixorides (p. 494)

5. Propodeum with apical transverse carina and median longitudinal carinae more or less distinct; notaulus more or less distinct . 4. Gonioprymnus (p. 495)

Propodeum without carinae; notaulus not distinct . . . 5. Moansa (p. 495)

6. Second trochanter of front leg with an acute apical tooth on the front side . . 7

Second trochanter of front leg without a distinct tooth . . . . . . . . . 8

7. Median lobe of mesoscutum without a median longitudinal groove; temple without striae, or with some weak oblique striae; second trochanter of middle leg with an acute apical tooth on front side. Palaearctic.

6. Moerophora (p. 495)

Median lobe of mesoscutum with a broad, median longitudinal groove; temple with strong, mostly longitudinal striae (fig. 315,h); second trochanter of middle leg without a tooth. Nearctic. . . . . . . . 7. Exomus (p. 496)

8. Second trochanter of hind leg, as seen from in front, about 2.5 as long as first trochanter; basal half of female flagellum with large, suberect hairs. Neotropic . . . . . . . . . . . . . . 8. Periceros (p. 501)

Second trochanter of hind leg, as seen from in front, about 1.5 as long as first trochanter; basal half of female flagellum with small, appressed hairs . . . 9

9. Scutellum without a subapical conical elevation; propodeum without a lateral subapical tubercle. Mostly Holarctic, but some species in Old World tropics . . . . . . . . . . . . . 9. Xorides (p. 501)

Scutellum with a subapical conical elevation; propodeum with a strong, lateral subapical tubercle. Neotropic . . . . . 10. Pyramirhyssa p. 530) 


\section{Key to the Nearctic subgenera, species groups, and species of Xorides}

1. Median lobe of mesoscutum with a broad median longitudinal groove; second trochanter of front leg with a subapical thorn in front; temple with strong, mostly longitudinal striae (fig. $315, \mathrm{~g}$ ); tooth at upper end of epomia exceptionally strong and projecting. Subgenus Exomus.

1. humeralis (Say)

Median lobe of mesoscutum without a median longitudinal groove; second trochanter of front leg without a thorn; temple often with striae, but when present these are usually oblique. Subgenus Xorides . . . . . . . . . 2

2. Temple conspicuously marked with white, its lower half obliquely striate. AlBopictus GROUP (p.515) . . . . . . . . . . . . . . . . . . . 3

Temple not marked with white except in $X$. pictus, in which the temple is not striate . . . . . . . . . . . . . . . . . . . 4

3. Basal four abdominal tergites entirely blackish in male, entirely ferruginous in female; occipital carina complete . . . . . 13. calidus (Provancher)

Basal four abdominal tergites black with prominent white marks; occipital carina narrowly interrupted medially above . . 14. albopictus (Cresson)

4. Occipital carina incomplete above, broadly interrupted medially . . . . 5

Occipital carina complete . . . . . . . . . . . . . . . . . . 11

5. First abdominal segment relatively stout, its basal third strongly arched above, the rest almost straight; striae on upper half of temple, when distinct, subhorizontal (fig. 316,g). MAUdAe GROUP (p. 520). . . . . . . 6

First abdominal segment slender, its basal third moderately arched, the rest weakly arched or almost straight; striae on upper half of temple, when present, subvertical (fig. 316, h). Stigmapterus group (p. 522). . . . 8

6. Temple not swollen beyond outside tangent of eye, its upper third without distinct striae; basitarsi of middle and hind legs white basally, the rest brown or black . . . . . . . . . . 15. atrox, new species

Temple swollen a little beyond outside tangent of eye, its upper third with longitudinal striae; basitarsi uniformly dark brown . . . . . . . 7

7. Scutellum laterally and pronotum at upper end of notaulus, ivory; flagellum of female entirely blackish; top of head without transverse rugulae.

16. maudae (Davis)

Scutellum and pronotum without ivory marks; flagellum of female with a narrow white band; top of head with weak transverse rugulae.

17. neoclyti (Rohwer)

8. Tibiae and basitarsi white basally, the rest black or the front basitarsus sometimes entirely white; body always black . . . . . . . . . . . . 9

Tibiae and basitarsi uniformly fulvous to black, not white at base; body black to fulvous . . . . . . . . . . . . . . . . . 10

9. First tergite rather broad, its sternite surpassing spiracle by about 0.5 the average width of the sternite in male, ending at the spiracle in female; first and second segments of front tarsus entirely white; median longitudinal carinae of first tergite obsolete apicad of the spiracle; upper face of front tibia of male entirely white; segments of female flagellum at the subapical bend about 0.8 as long as wide (fig. 329 ,a) . . 18. harringtoni (Rohwer)

First tergite narrow, its sternite surpassing spiracle by about 1.3 the average width of the sternite in male, by about 0.5 the average width of sternite in female; first and second segments of front tarsus black or infuscate, the base of first segment white; median longitudinal carinae extending beyond spiracle as distinct ridges; upper face of front tibia of male blackish, its base white; segments of female flagellum at subapical bend about 1.1 as long as wide (fig. 329,b) . . . . . . 20. stigmapterus (Say) 
10. First tergite rather broad, its sternite surpassing spiracle by about 0.5 the average width of the sternite in male, ending at the spiracle in female; punctures on mesopleurum rather dense, their interspaces about 0.8 their diameter . . . . . . . . . . 19. californicus (Cresson)

First tergite narrow, its sternite surpassing spiracle by about 1.5 the average width of the sternite in male, by about 1.0 the average width of the sternite in female; punctures on mesopleurum rather sparse, their interspaces about 1.5 their diameter . . . . . . . . . . 21. cincticornis (Cresson)

11. Lower half of temple with fine vertical striae and inconspicuous small punctures (figs. 316,d,e); female flagellum without a white band. INsUlaris GROUP (p. 509). . . . . . . . . . . . . . . . . . . . . . 12

Lower half of temple with punctures and sometimes (in $X$. boharti) also obliquely rugulose . . . . . . . . . . . . . . . . . . . 16

12. Front orbit and upper margin of pronotum with a broad whitish stripe (the pronotal stripe rarely absent in males); second tergite mostly transversely aciculate . . . . . . . . . . 12. insularis (Cresson)

Front orbit and upper margin of pronotum entirely black; second tergite evenly mat or longitudinally rugulose . . . . . . . . . . . . 13

13. Second tergite longitudinally rugulose; median longitudinal carinae of first tergite strong, extending beyond the spiracle; punctures on top of head rather dense, separated by about 0.7 their diameter . 8. rudis, new species

Second tergite evenly mat; median longitudinal carinae of first tergite absent or weak, not reaching the spiracle; punctures on top of head rather sparse to very sparse, separated by at least 1.5 their diameter . . . . . . . 14

14. Mesopleurum and mesosternum strongly mat; mesoscutum completely flat except at sides and front........ . 9. planus, new species

Mesopleurum polished and punctate, sometimes weakly mat in part; mesoscutum more or less convex, at least the median lobe a little convex . . 15

15. Punctures on top of head separated by about twice their diameter; first tergite of female about 1.75 as long as wide . . 10. medius, new species

Punctures on top of head separated by three or more times their diameter; first tergite of female about 2.5 as long as wide . . 11. eastoni (Rohwer)

16. First tergite with a deep oblique lateral groove just beyond the spiracle; female flagellum without a white band; head and body entirely blackish. Frigidus Group (p. 503) . . . . . . . . 2. frigidus (Cresson)

First tergite without a deep oblique groove just beyond the spiracle; female flagellum with a white band. Riley group (p. 504) . . . . . . . 17

17. Lower half of temple strongly obliquely rugulose (fig. $316, \mathrm{~b}$ ); legs entirely black . . . . . . . . . . . 6. boharti, new species

Lower half of temple punctate, without strong rugulae; legs partly pale, at least the base of tibiae whitish . . . . . . . . . . . . 18

18. Median longitudinal carinae of propodeum approximate but not fused basad of areola; median longitudinal carinae of first tergite distinct to its apex; side of thorax with whitish markings . . . . 3. pictus, new species

Median longitudinal carinae of propodeum fused basad of areola; median longitudinal carinae of first tergite absent beyond middle in female, complete to apex in male; side of thorax without whitish markings . . . . 19

19. First tergite slender basally, the part in front of spiracle about 2.0 as long as wide across spiracles in male, about 1.7 as long as wide across spiracles in female; apical tergites entirely black . . . . . . . 7. rileyi (Ashmead)

First tergite thick basally, the part in front of spiracle about 1.5 as long as wide across spiracles in male, about 0.85 as long as wide across spiracles in female; apical tergites of female bordered with white . . . . . . 20 
20. Thorax fulvous; legs blackish, with white bands at base of tibiae, of basitarsi, and on second trochanters . . . . . . 4. semirufus, new species Thorax blackish; le s varied with fulvous, white, and fuscous.

5. peniculus, new species

\section{Subgenus Gonophonus, new status}

Gonophonus Foerster, 1868, Verh. Naturh. Ver. Rheinlande, vol. 25, p. 169. Type: (Gonophonus mokrzeckii Kokujev) = propinquus (Tschek); included by Kokujev, 1902.

Caenostoma Cameron, 1905, Journ. Straits Branch of the Roy. Asiatic Soc., vol. 44,

p. 125. Type: (Caenostoma filicorne Cameron) = exquisitus (Tosquinet); monobasic.

This subgenus is European and Oriental. The European species are Xylonomus corcyrensis Kriechbaumer 1894, Xylonomus fasciipennis Kriechbaumer 1894, Xylonomus propinquus Tschek 1868, and Xylonomus scaber Gravenhorst 1829. The Oriental species are Moansa exquistus Tosquinet 1903 (of which Caenostoma filicorne Cameron 1905 , is a new synonym) and an undescribed species in the Philippines. The European species apparently have not previously been referred to the genus, and the species exquisitus to neither the genus nor subgenus.

\section{Subgenus Cyanoxorides, new status}

Cyanoxorides Cameron, 1903, Journ. Straits Branch of the Roy. Asiatic Soc., vol. 39, p. 141. Type: Cyanoxorides brookei Cameron; monobasic:

Spiloxorides Cameron, 1903, Journ. Straits Branch of the Roy. Asiatic Soc., vol. 39,

p. 143. Type: Spiloxorides ruficeps; monobasic.

This subgenus is in the Oriental region. The species of which we have studied the types are: Xylonomus abaddon Morley 1913, Cyanoxorides antennalis Szépligeti 1914, Cyanoxorides brookei Cameron 1903, Cyanoxorides caeruleus Cameron 1905, Xylonomus crudelis Turner 1919, Cyanoxorides formosanus Sonan 1936, Giypta maculipennis Smith 1860, Spiloxorides propodeum Cushman 1933, Spiloxorides ruficeps Cameron 1903 (=Spiloxorides erythrocephalus Cameron 1905, new synonymy), Cyanoxorides smithi Schmiedeknecht 1907, Spiloxorides rufipleuralis Cushman 1933, and Moansa spectabilis Tosquinet 1903. The above names, except for Spiloxorides erythrocephalus, are new combinations with the generic or subgeneric name, or with both.

\section{Subgenus Epixorides, new status}

Epixorides Smith, 1862, Journ. Proc. Linn. Soc. London, (Zool.) vol. 6, p. 94. Type: Epixorides chalybeator Smith; monobasic.

Ahyborhyssa Enderlin, 1919, Sitz-Ber. Ges. Naturf. Freunde, Berlin, vol. 1919,

p. 152. Type: (Epirhyssa annulicornis Cameron)=elizabethae (Bingham); original designation.

This subgenus is in the Oriental region. We have studied the types of the following species: Xylonomus caerulescens Morley 1913, 
Epixorides chalybeator Smith 1862, Xylonomus elizabethae Bingham 1898, Cyanoxorides erythrothorax Turner 1919, Xylonomus fracticornis Smith 1860, Xylonomus fulgidipennis Smith 1857, Cyanoxorides rufomaculatus Cameron 1905, and Cyanoxorides vitalisi Turner 1919. All of these are new combinations with the generic name, and except for chalybeator also with the subgeneric name. Epirhyssa annulicornis Cameron 1899, and Xylonomus blanditor Tosquinet 1903, are synonyms of elizabethae (new synonymies). These synonyms, however, may prove to be usable for distinguishable subspecies.

\section{Subgenus Gonioprymnus, new status}

Gonioprymnus Cameron, 1906, Ann. South African Mus., vol. 5, p. 126. Type: Gonioprymnus maculiceps Cameron; monobasic.

Lavaudenia Seyrig, 1932, Mém. Acad. Malgache, fasc. 11, p. 92. Type: Lavaudenia mirabilis Seyrig; original designation.

Gymnacanthus Benoit, 1952, Bull. Ann. Soc. Ent. Belgique, vol. 88, p. 132. New synonymy. Type: Gymnacanthus aciculatus Benoit; original designation.

This is an African subgenus. We have studied the types of the three genotypes listed above, which are to be transferred to Xorides, subgenus Gonioprymnus. Benoit (1952, Bull. Ann. Soc. Ent. Belgique, vol. 88, pp. 129-136) treats some additional species under the generic names Gonioprymnus and Gymnacanthus.

\section{Subgenus Moansa, new status}

Moansa Tosquinet, 1896, Mém. Soc. Ent. Belgique, vol. 5, p. 345. Type: Moansa praestans Tosquinet; monobasic.

This is an African subgenus. We have seen the genotype, and Dr. P. L. G. Benoit has showed us several peculiar African species in the Tervuren Museum, which are related to Moansa. Judging from the species we have seen, the Moansa-Gonioprymnus section of the genus Xorides is restricted to Africa, and there it has developed a complex of peculiar species. They should probably either be in one subgenus, characterized mainly by the absence of the prepectal carina, or possibly be divided into several subgenera. Specimens of a larger percent of the extant species will be needed to show the best arrangement. For the present, we recognize the subgenera Moansa and Gonioprymnus as distinct.

\section{Subgenus Moerophora, new status}

Moerophora Foerster, 1868, Verh. Naturh. Ver. Rheinlande, vol. 25, p. 169. Type: Xylonomus rufipes Gravenhorst; included by Wolstedt, 1881.

Macrosterotrichus Kokujev, 1903, Rev. Russe Ent., vol. 3, p. 287. Type: Xylonomus (Macrosterotrichus) jakolevi Kokujev; monobasic.

This is a Palaearctic subgenus. The species that should be referred to it, of which we have seen the types, are: Xorides immaculatus 
Cushman 1933, Xylonomus investigator Smith 1874, Xylonomus jezoensis Matsumura 1912 (with Xylonomus lineatus Matsumura, 1912, as a synonym), Xylonomus jakolevi Kokujev 1903, and Xylonomus rufipes Gravenhorst 1829. All or most of these are new combinations with either the generic name, subgeneric name, or both.

\section{Subgenus Exomus, new subgenus}

Body slender; female flagellum with a subapical curve that involves several articulations; occipital carina complete; temple with strong striae, the striae in its lower third oblique, elsewhere longitudinal (fig. $315, \mathrm{~g}$ ); tooth at upper end of epomia exceptionally strong and projecting; prepectal carina present; median lobe of mesoscutum with a broad median longitudinal groove; areola transversely pentagonal, basad of which the median longitudinal carinae are fused for a considerable distance; posterior mesosternal carina incomplete, broadly interrupted in front of each middle coxa ; apex of area dentipara sometimes making a low blunt tooth; median longitudinal carinae fused at base of areola; nervulus beyond basal vein by about 0.3 its length (fig. 314,e); intercubitus less than 0.3 as long as second abscissa of cubitus, very short or almost obliterated by approximation of radial and cubital veins; second trochanter of front leg with a strong projecting thorn on its front side; front tibia of female moderately inflated (fig. 313 ,a); bristlelike hairs on front tibia very numerous but so weak as to be hardly differentiated; comb on front of apex of front tibia weak and inconspicuous; nervellus broken near the middle; first tergite coarsely punctate, about 3.1 as long as wide in male, about 2.9 as long as wide in female, rather evenly enlarged from base to apex, sometimes with a trace of a lateral constriction just beyond spiracle; median and sublateral longitudinal carinae of first tergite distinct for most of length of the tergite in male, distinct only basad of spiracle in female; second tergite coarsely punctured, with a sharp oblique groove cutting off its basolateral corner.

Genotype: Anomalon humeralis Say, as interpreted in this paper.

The name is from the Greek "exomos" having the shoulders sticking out, in allusion to the prominent epomia.

This subgenus contains a single polytypic Nearctic species: Anomalon humeralis Say, 1829.

\section{Xorides (Exomus) humeralis (Say), new combination}

Figures 313 ,a; 314,e; 315,g

Front wing of male 4.8 to $9.5 \mathrm{~mm}$. long, of female 8.3 to $16 \mathrm{~mm}$. long. Structure as described for the subgenus. 
This species occurs in most of the United States and in Mexico. It is divisible into six subspecies, as treated below:

1. Hind tibia uniformly black . . . . . . . . . . . . . 2 Hind tibia black with its basal 0.15 much paler (white to light brown). . 3

2. First three tergites and median lobe of mesoscutum black; front and middle femora and tibiae fulvous; range: southern California.

le. humeralis excomptus, new subspecies

First three tergites and much or all of median lobe of mesoscutum ferruginous; front and middle femora and tibiae black; range: southern Arizona.

If. humeralis chiricensis, new subspecies

3. Hind basitarsus light brown; middle femur dark brown to blackish; wings rather strongly infuscate or banded with fuscous . . . . . . . . . . . . . . 4

Hind basitarsus blackish to dark brown, rarely light brown; middle femur fulvous, rarely dark brown; wings subhyaline or faintly infuscate, or indistinctly banded with fuscous . . . . . . . . . . . . . . . . . . . . . . . 5

4. Front wing faintly infuscate, with weak transverse infuscate banding; first three tergites blackish; range: Mexico and part of Texas.

1a. humeralis mexicanus, new subspecies

Front wing rather uniformly brown; first three tergites strongly stained with ferruginous; range: Florida . . . . 1b. humeralis piceatus (Rohwer)

5. Basal 0.15 of tibiae whitish; hind coxa black, rarely fulvous; range: eastern North America except Florida . . . . . . 1c. humeralis humeralis (Say) Basal 0.15 of tibiae fulvous to brown; hind coxa fulvous in female, fulvous or blackish in male; range: California, especially in the Sierra Nevada.

1d. humeralis sierrae, new subspecies

\section{1a. Xorides (Exomus) humeralis mexicanus, new subspecies}

Male: Unknown.

Female: Black with a faint ferruginous tinge. Flagellum black, with a white band; tegula reddish brown; trochanters and narrow apex of tibiae reddish brown; narrow apex of femora and basal 0.15 of tibiae whitish; tarsi pale brown, their fifth segment black; wings with a light fuscous tinge, the front wing with indistinct transverse infuscate bands at the level of the basal vein and at level of apex of stigma, its tip a little darkened.

Type: + , 6 miles west of Antiguo, Mexico, 1,200 ft., July 21, 1954, University of Kansas Mexican Expedition (Lawrence).

Paratypes: $ᄋ$, same data as type (Lawrence). ㅇ, Eastland Co., Tex., Apr. 2, 1921, Grace O. Wiley (St. Paul).

\section{1b. Xorides (Exomus) humeralis piceatus (Rohwer), new combination}

Xylonomus (Moerophora) piceatus Rohwer, 1913, Proc. U. S. Nat. Mus., vol. 45, p. 357 ; . Type: + , Dade Co., Fla. (Washington).

Male: Unknown.

Female: Fuscoferruginous, the coxae, femora, hind tibia, and fourth and following tergites more blackish. Flagellum black, with a white band; tegula, trochanters, base and apex of femora, and front and middle tibiae reddish brown, the apical margin of femora pale fulvous; 
basal 0.15 of tibiae whitish, the front and middle tibiae somewhat infuscate subbasally; tarsi light brown, the fifth segment blackish; wings medium brown, the front wing a little paler basad of stigma.

Specimens: ㅇ, Dade Co., Fla., May 26, 1950 (Townes). ㅇ (type), Dade Co., Fla., E. A. Schwarz (Washington). o , Gainesville, Fla., Mar. 17, 1934, H. T. T. (Townes). क, Gainesville, Fla., Apr. 7, 1947,
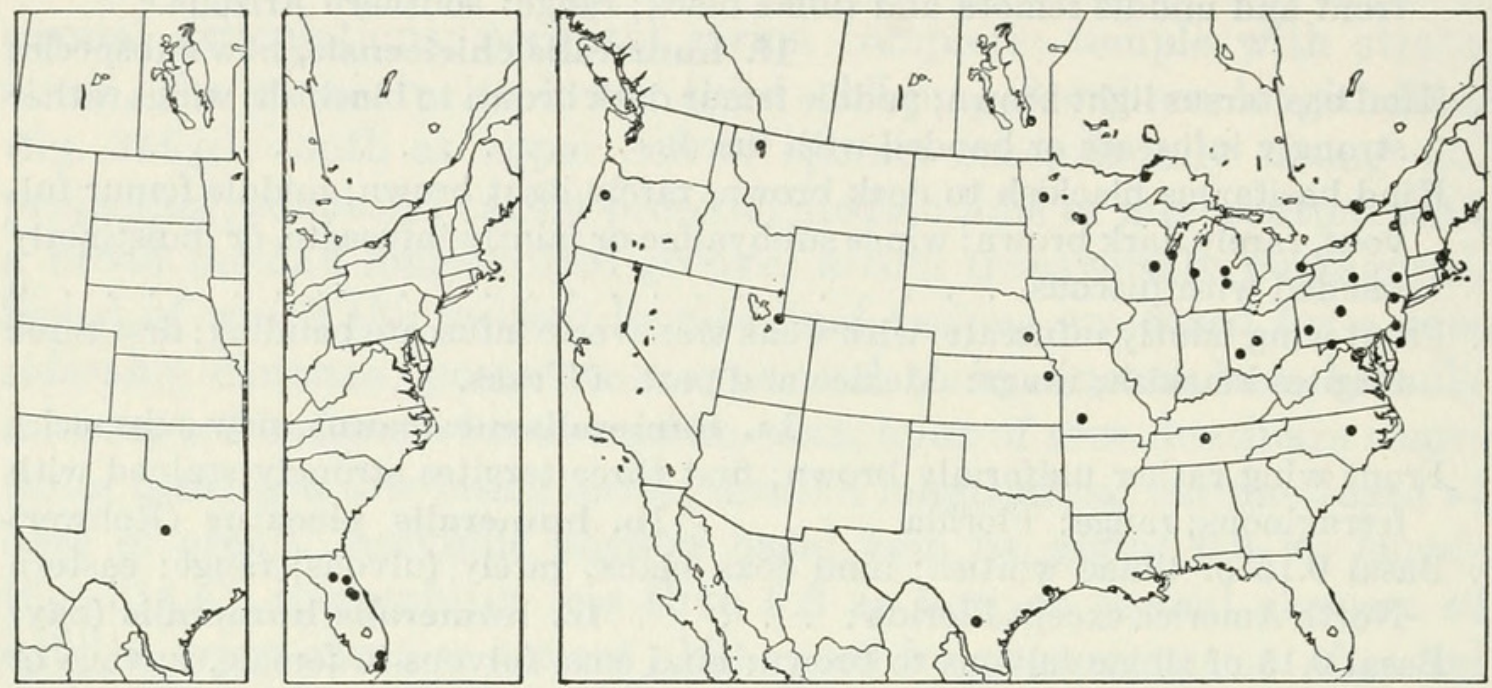

Figures 224-226.-Localities: 224 (left), Xorides humeralis mexicanus; 225 (center), X. h. piceatus; 226 (right), X. h. humeralis.

G. B. Merrill (Washington). ㅇ, Orange Co., Fla., June 29, 1919, W. Storrs (Washington). o, Orlando, Fla., April 1920, R. T. Cotton (Washington). \&, Paradise Key, Fla., Apr. 12, 1951, H. and M. Townes (Townes). $\odot$, Welaka, Fla., July 20, 1950, D. Downes (Washington). ㅇ, Winter Park, Fla., June 14, 1940, H. T. Fernald (Washington).

This subspecies is restricted to Florida.

\section{1c. Xorides (Exomus) humeralis humeralis (Say), new combination}

Anomalon humeralis Say, 1829, Contr. Maclurian Lyceum Arts Sci., vol. 1, p. 74 (Leconte ed., vol. 1, p. 378); ㅇ. Type: $\subsetneq$, Indiana (destroyed).

? Xylonomus australis Cresson, 1870, Trans. Amer. Ent. Soc., vol. 3, p. 167; 9 . Lectotype: $\uparrow$, Louisiana (Philadelphia).

Xylonomus Lavallensis Provancher, 1874, Naturaliste Canadien, vol. 6, p. 59; Type: $q$ Quebec Province (Quebec).

Blackish, the head and hind margins of pronotum stained with ferruginous. Flagellum of female with a white band; palpi of male stramineous, of female brown; tegula fulvous; front and middle coxae, trochanters, femora, and tibiae fulvous, the apex of femora and basal 0.15 of tibiae whitish; narrow apex of front and middle tibiae pale fulvous; front and middle tarsi pale fulvous, the fifth segment fuscous; 
hind trochanters and extreme base of hind femur fulvous brown; apical margin of hind femur and basal 0.15 of hind tibia white; hind tarsus blackish brown to light brown, its fifth segment always black; wings subhyaline.

A female from Raleigh, N. C., has the front and middle coxae, femora, and tibiae infuscate, which makes this specimen somewhat intermediate to the subspecies piceatus. One female from Mahnomen Co., Minn., has the hind coxa fulvous, as in the subspecies sierrae. The type of $X$. australis, from Louisiana, is difficult to classify. It has some of the characteristics of the subspecies piceatus and mexicanus, as well as of the present subspecies. Its placement must be arbitrary until the subspecies of the southern United States are better understood.

Specimens (24 ه , 49ㅇ): From British Columbia ("Bear Lake" at 7,000 ft.); Kansas (Douglas Co.); Labrador (Goose Bay); Manitoba (Victoria Beach); Maryland (near Cumberland, Plummers Island, and Takoma Park); Massachusetts (Boston, Newton Center, and Wayland); Michigan (East Lansing, Isle Royale, Midland Co., and Silver Lake State Park in Oceana Co.); Minnesota (Mille Lacs and Tulaby Lake in Mahnomen Co.); Missouri (Willard); Montana (Belton); Nebraska (Lincoln); New Brunswick (Bathurst); New Hampshire (Mount Washington at 6,200 ft.); New Jersey (Moorestown, South Seaville, and Vernon); New York (Greene Co. at 2,500 ft., Ithaca, and Keene Valley in Essex Co.); North Carolina ("Mt. Graybeard" and Raleigh); Ohio (Delaware Co. and Montgomery Co.); Ontario (Hamilton and Ottawa); Oregon (Corvallis); Pennsylvania (Pittsburgh and Rockview in Centre Co.); Quebec (Aylmer); Tennessee (Lebanon); Texas (Hondo and Houston); Utah (Kamas); Virginia (Falls Church); and Wisconsin (Luxemburg and Waupaca).

Dates of collections are from spring to early fall. The earliest and latest dates are: April 1 at Raliegh, N. C.; April 30 at Willard, Mo.; May 23 at "Mt. Graybeard," N. C.; May 25 at South Seaside, N. J.; August 22 in the Keene Valley, Essex Co., N. Y.; September 17 at Raleigh, N. C.; and September 21 in Montgomery Co., Ohio.

Reared specimens are: $2 \sigma^{x}$, from Dicerca obscura in Diospyros virginiana, Lebanon, Tenn., July 21, 1938, W. L. Baker. $2 \sigma^{7}$, from Neoclytus sp. in Ilex, Houston, Tex., Mar. 23, 1937, W. F. Fiske. $\sigma^{\top}$, from Phymatodes varius in Quercus, Apr. 27, 1914, W. Middleton. There are additional specimens reared from wood or found resting on wood without knowledge of the insect host. These include 2 records for Ulmus sp., and 1 each for Abies lasiocarpa, Acer negundo, Cassia, Carya, Fraxinus, Quercus, and Ulmus americana.

This subspecies is in the Canadian, Transition, and Upper Austral zones east of the hundredth meridian and extends to the Pacific coast 
from southern British Columbia to Oregon. It is adult from midspring to early fall. It parasitizes buprestids and cerambycids in various hardwoods.

\section{1d. Xorides (Exomus) humeralis sierrae, new subspecies}

Similar to the subspecies $h$. humeralis except that the whitish apical margin of the femora and basal 0.15 of the tibiae is replaced by fulvous or brownish, the hind coxa of the female and sometimes of the male is fulvous, the hind trochanters fulvous, and the wings weakly infuscate.

Type: ㅇ, Yosemite Park at 3,880 to 4,000 ft., Calif., June 31, 1931 (Berkeley).

Paratypes: 2o, Antioch, Calif., July 2 and 16, 1954, G. A. Schaefers (Berkeley and Townes). ๆ, Davis, Calif., May 8, 1955, J. C. Downey (Davis). $\quad \sigma^{\top}$, Davis, Calif., May 12, 1955, R. D. Browning (Davis). ㅇ, Fallen Leaf, Calif., July 28, 1915,.F. B. Herbert (Washington). $0^{7}$, Fort Seward, Calif., May 31, 1935, E. O. Essig (Townes). ণ, Snowline Camp, El Dorado Co., Calif., July 14, 1948, J. W. MacSwain (Townes). $2 \sigma^{7}$, Sobre Vista, Sonoma Co., Calif., Apr. 31 and May 12, 1910, J. A. Kusche (San Francisco).

This subspecies occurs in central and northern California.

\section{1e. Xorides (Exomus) humeralis excomptus, new subspecies}

Black, the temple often stained with ferruginous. Flagellum of female with a white band; palpi brown; tegula fulvous; hind margins of pronotum fulvous; often hind half of pronotum ferruginous; front and middle legs fulvous, the fifth segment of their tarsi black and the first four segments of the male tarsi infuscate; hind leg black, its coxa often partly fulvous (basally), its trochanters usually reddish brown,
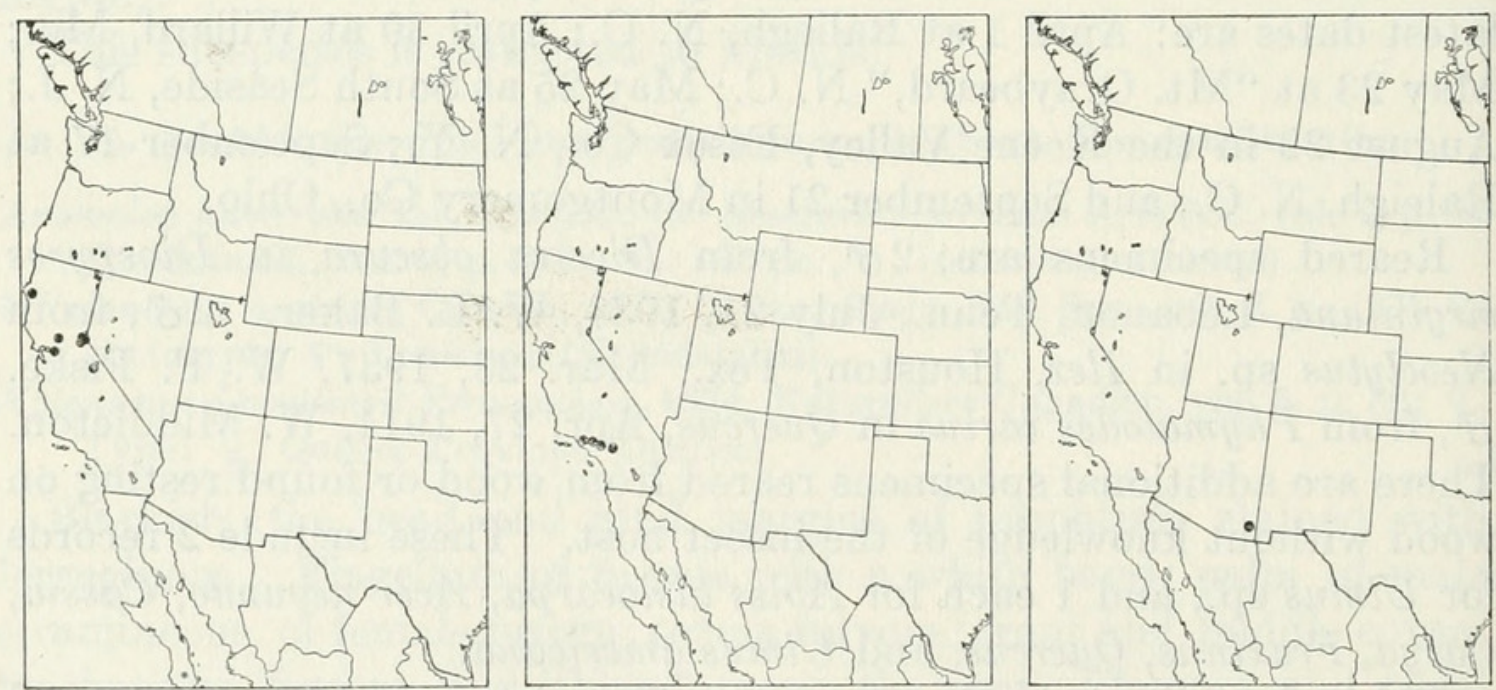

Figures 227-229.-Localities: 227 (left), Xorides humeralis sierrae; 228 (center) X. h. excomptus; 229 (right), X. h. chiricensis. 
and the basal four segments of its tarsus often blackish brown; wings weakly infuscate.

Type: ㅇ, Tanbark Flat, Los Angeles Co., Calif., June 25, 1956, R. C. Bechtel (Davis).

Paratypes: $0^{7}$, Big Dalton Canyon, Los Angeles Co., Calif., July 15, 1956, E. I. Schlinger (Davis). $0^{7}$, Mountain Home, San Bernardino Co., Calif., Sept. 12, 1953, E. I. Schlinger (Townes). ,

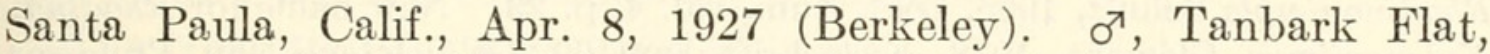
Los Angeles Co., Calif., July 3, 1950, T. R. Haig (Townes).

This subspecies occurs in the vicinity of Los Angeles.

\section{If. Xorides (Exomus) humeralis chiricensis, new subspecies}

Male: Unknown.

Female: Black, the temple more or less stained with ferruginous. Flagellum with a white band; palpi dark brown; tegula blackish; hind $0.4 \pm$ of pronotum and much or all of median lobe of mesoscutum ferruginous; legs black, the basal four segments of their tarsi blackish brown and their trochanters usually stained with ferruginous; first three tergites dull ferruginous; fourth and following tergites fuscoferruginous; wings light brown.

Type: ㅇ, Chiricahua Mts., Ariz., July 20, 1949, Lindsay Kaiser (Washington, USNM 63730).

Paratypes: 2ᄋ, Chiricahua Mts., Ariz., July 4, 1940, R. H. Beamer (Lawrence and Townes). o, Chiricahua Mts., Ariz., July 17, 1957, D. J. and J. N. Knull (Columbus).

\section{Subgenus Periceros, new status}

Perissocerus Smith, 1877, Proc. Zool. Soc. London, vol. 1877, p. 412. Name preoccupied. Type: Perissocerus plumicornis Smith; monobasic.

Periceros Schulz, 1906, Spolia hymenopterologica, p. 99. New name for Perissocerus.

Neoxylonomus Szépligeti, 1914, Ann. Hist.-Natur. Mus. Nat. Hungariei, vol. 12, p. 421. Type: Neoxylonomus antennalis Szépligeti; monobasic.

This is a Neotropic subgenus. It contains the genotype species, listed above, and at least two undescribed or unidentified species. The name Neoxylonomus aniennalis Szépligeti 1914, is a duplicate in the genus Xorides of Cyanoxorides antennalis Szépligeti, published in the same paper. If it proves to be a species different from plumicornis, it or the other antennalis will need a new name. We have not seen the type.

\section{Subgenus Xorides}

Xorides Latreille, 1809, Historie Naturelle . . . des crustacés et des insectes . . ., vol. 4, p. 4. Type: Ichneumon indicatorius Latreille; monobasic.

Xylonomus Gravenhorst, 1829, Ichneumonologia europaea, vol. 3, p. 819. Type: Ichneumon irrigator Fabricius; designated by Curtis, 1831. 
Sterotrichus Foerster, 1868, Verh. Naturh. Ver. Rheinlande, vol. 25, p. 169. Type: (Xylonomus pilicornis Gravenhorst) = fuligator (Thunberg); designated by Viereck, 1914.

Sichelia Foerster, 1868, Verh. Naturh. Ver. Rheinlande, vol. 25, p. 169. Type: Xylonomus filformis Gravenhorst; designated by Viereck, 1914.

Rhadina Foerster, 1868, Verh. Naturh. Ver. Rheinlande, vol. 25, p. 170. Name preoccupied. Type: Xylonomus ater Gravenhorst; included by Schmiedeknecht, 1888.

Rhadinopimpla Schulz, 1906, Zool. Ann., vol. 4, p. 23. New name for Rhadina. Xylonomimus Clément, 1938, Festschrift zum 60. Geburtstage von Professor

Dr. Embrik Strand, vol. 4, p. 539. Type: Xylonomus gracilicornis Gravenhorst; original designation.

Neoxylonomus Clément, 1938, Festschrift zum 60. Geburtstage von Professor Dr. Embrik Strand, vol. 4, p. 566. Name preoccupied. Type: Neoxylonomus strandi Clément; monobasic.

Amphixylonomus Benoit, 1952, Bull. Ann. Soc. Ent. Belgique, vol. 88, p. 136. New synonymy. Type: Xylonomus (Amphixylonomus) konduensis Benoit; original designation.

Body slender to moderately stout; female flagellum with a subapical curve that involves several articulations; occipital carina complete or interrupted above; temple variously punctate, or wrinkled, or striate, the wrinkles or striae oblique or subvertical; tooth at upper end of epomia weak to moderately strong and projecting; prepectal carina present; median lobe of mesoscutum without a median longitudinal groove; posterior mesosternal carina incomplete; propodeal carinae more or less complete; areola subpentagonal, open or closed at the base; apex of area dentipara with or without a tooth; nervulus beyond basal vein, usually by about 0.3 its length; intercubitus about 0.4 as long as second abscissa of cubitus, or shorter, or sometimes obliterated by approximation of radial and cubital veins; all trochanters without teeth; front tibia of female weakly to strongly inflated.

This is a large subgenus which contains a diverse assemblage of species. It is mostly Holarctic in distribution. The genotypes of Xorides, Xylonomus, Sterotrichus, and Amphixylonomus belong to a species group including a number of Palaearctic species but apparently none in North America. We hereby designate this group as the INDICATORIUs group. The genotype of Sichelia belongs in the MAUDAE group, as defined in the treatment of the Nearctic species, below. The genotype of Rhadina is close to the Nearctic insularis, in the INSULARIS group. The genotype of Neoxylonomus is very similar to the Nearctic boharti, in the RILEYI group. The genotype of Xylonomimus is unknown to us, but judging from its description, it is a flattened species of the INsULARIs group.

The European species of the subgenus have been treated by Clément (1938, Festschrift zum 60. Geburtstage von Professor Dr. Embrik Strand, vol. 4, pp. 522-568). He placed the species in his "genera" Xorides, Xylonomimus, Xylonomus, Sichelia, and 
Rhadinopimpla. We refer all of them to the subgenus Xorides, where some probably form new combinations. The other nonNearctic species referable to the subgenus are: Xorides holsaticus Heinrich 1951, in the indicatorius group; Neoxylonomus strandi Clément 1938, in the RILEYI group; and Xorides centromaculatus Cushman 1933, Moansa ornatus Tosquinet 1903, and Xylonomus vitiosus Turner 1919, in the ALBopictus group. The names ornatus and vitiosus are new combinations in Xorides.

The Nearctic species are treated below.

\section{FRIGIDUS GROUP}

Body stout; occipital carina complete; temple with fine sparse punctures and not distinctly striate (fig. 315,h); apex of female flagellum only a little curved, its segments very weakly specialized (fig. $328, \mathrm{~h}$ ); tooth at dorsal end of epomia rather weak; areola almost regularly pentagonal; a low blunt tooth at apex of area dentipara; median longitudinal carinae approaching closely but not fused at base of areola (fig. 314,f); front tibia of female moderately inflated; spinelike bristles on front face of tibia rather numerous, moderately stout (fig. $313, b$ ) ; comb on front of apex of front tibia containing rather weak bristles; nervellus broken near the middle; first tergite of male about 2.0 as long as wide, of female about 1.6 as long as wide, with a deep oblique lateral groove just beyond the spiracle which continues on to the dorsolateral surface; median longitudinal carinae of first tergite complete to the apex but in the female indistinct beyond the middle of tergite; second tergite with a rather strong oblique groove cutting off its basolateral corner.

This group includes only the Nearctic $X$. frigidus. It is close to a large Palaearctic group of species (the INDICATORIUs group) containing the genotypes of Xorides, Xylonomus, and Sterotrichus, which differs from the FRIGIDUs group in having the temple with close fine punctures and subvertically aciculate, and the apex of the female flagellum more strongly curved and specialized.

\section{Xorides (Xorides) frigidus (Cresson)}

Figures 313,b; 314,f; 315,h; 328,h

Xylonomus frigidus Cresson, 1870, Trans. Amer. Ent. Soc., vol. 3, p. 168; . Type: $q$, Hudson Bay Territory (Philadelphia).

Xylonomus (Xylonomus) plesius Rohwer, 1913, Proc. U. S. Nat. Mus., vol. 45, p. 354 ; $\subsetneq$. Type: $\uparrow$, ?United States (Washington).

Xylonomus (Moerophora) yukonensis Rohwer, 1913, Proc. U. S. Nat. Mus., vol.

45 , p. 355 ; $\subsetneq$. Type: $\uparrow$, Fort Yukon, Alaska (Washington).

Front wing of male 5.5 to $7.0 \mathrm{~mm}$. long, of female 7.5 to $10.3 \mathrm{~mm}$. long. Structure as described under the species group.

Blackish. Palpi brown; front and middle legs fulvous, their tarsi 
fuscous at apex; hind leg fuscous or infuscate, its coxa and trochanters fulvous.

Specimens: $\odot$ (type of yukonensis), Fort Yukon, Alaska, L. M. Turner (Washington). क, Rampart, Alaska, June 28, 1903, M. E. Koonce (Pittsburgh). , Sidney, B. C., May 21, 1927, W. H. A. Preice (Washington). $\sigma^{x}$, Campus of University of Colorado, Boulder, Colo., June, T. D. A. Cockerell (Washington). + , Longs Peak Inn at 9,000 ft., Colo., July 2, 1926, E. C. Van Dyke (San Francisco). (type of frigidus), "Hudson Bay territory" (Philadelphia). \&, Lake Waha, Idaho, June 22, 1927, J. M. Aldrich (Washington). ㅇ, Meddybemps, Maine, July 28, 1922, M. Band and R. J. Sim (Townes). б", "Kelly's Camp," Gaspé Peninsula, Que., Aug. 21, 1931, W. A. Ruko (Ottawa). ণ, Montreal, Que., July 4, C. J. Ouellet (Ithaca). ᄋ, Montreal, Que. (Ithaca). ণ, Montreal, Que., Ouellet (Ottawa). ㅇ, Que., July 24, 1944 (Ottawa). ㅇ, St. Pascal, Que., August 1942, O. Richard (Ottawa). ఠ" \%, Sherbrooke, Que., Sept. 23, 1895 (Washington). $\sigma^{7}$, \&, Val Morin, Que., July 28, 1902, and August 14 (Ithaca). ค, Val Morin, Que., August 2, C. J. Ouellet (Ithaca). ণ, Val Morin, Que., July 28, 1902 (Townes). ণ , Rutland, Vt., Aug. 1-15, 1916, Chittenden (Washington). o, Sullivan Lake, Pend Oreille Co., Wash., June 4, 1931, W. O. Scott (Ann Arbor). \&, Carcross, Y. T., July 28, 1919, A. P. Hawes (Ottawa).

This species is transcontinental in the Canadian zone.
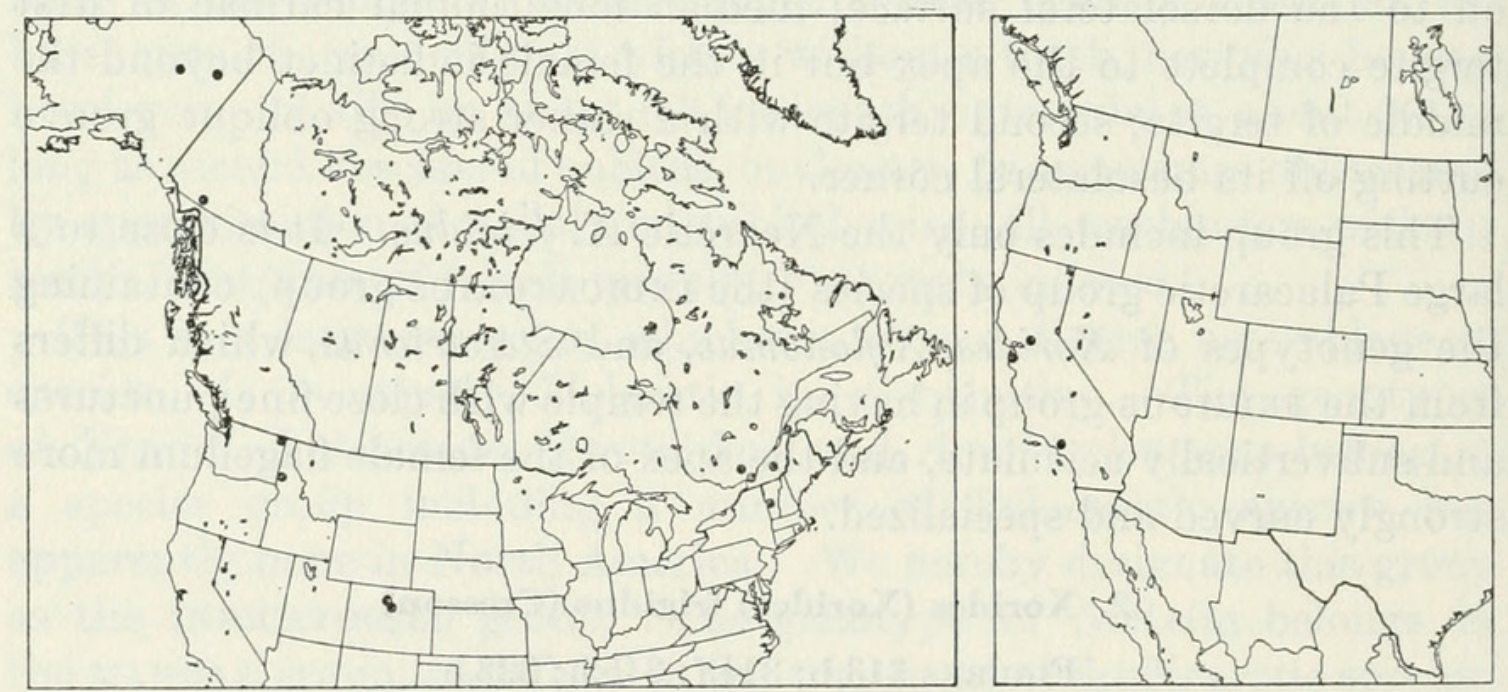

Figures 230, 231.-Localities: 230 (left), Xorides frigidus; 231 (right), X. pictus.

\section{RILEYI GROUP}

Body stout to moderately slender; occipital carina complete; temple punctate and sometimes more or less obliquely rugulose (figs. $316, a, b, c)$; tooth at upper end of epomia moderately strong; areola pentagonal with its posterior side wide; median longitudinal carinae usually fused basad of areola (figs. $314, \mathrm{~g}, \mathrm{~h}$ ); a broadly triangular tooth 
at apex of area dentipara; front tibia of female weakly swollen; bristlelike hairs on front of front tibia stout, few, in a single irregular row or narrow band (figs. $313, \mathrm{c}, \mathrm{d}, \mathrm{e}$ ) ; comb on front of apex of front tibia nearly straight, with rather strong, short bristles; nervellus broken below the middle; first tergite coarsely punctate, its median and lateral longitudinal carinae distinct to near apex in male, distinct basally but usually obsolescent before the middle in female (distinct to the apex in the female of $X$. pictus), beyond spiracle with a weak or distinct oblique dorsolateral groove; second tergite with a sharp oblique groove cutting off its basolateral corner.

This group includes five United States species and Neoxylonomus strandi Clément 1938, from "Nassau."

\section{Xorides (Xorides) pictus, new species}

Figures $313, \mathrm{c} ; 314, \mathrm{~g} ; 316$,a; 328 ,i

\section{Male: Unknown.}

Female: Front wing 7.0 to $8.7 \mathrm{~mm}$. long; temple not rugulose, with rather coarse punctures whose interspaces are about 1.3 their diameter; areola five sided but in the general shape of an equilateral triangle, its basal corner narrowly open; median longitudinal carinae of propodeum approximate basad of areola but not touching; first tergite about 1.8 as long as wide, its median longitudinal carinae distinct to the apex.

Head black, its temple stained with fulvous, its orbits whitish in front at top of eye, and the lower half of its temple with a large whitish mark; apical section of clypeus largely whitish; scape stramineous in front; palpi pale stramineous, a little darker basally; pronotum ferruginous, blackish anteriorly, with a very broad whitish stripe along its upper margin and a moderately wide whitish stripe along its lower margin; propleurum ferruginous, blackish dorsally; mesoscutum and scutellum ferruginous, black marginally and between lobes of mesoscutum; mesosternum ferruginous, blackish along front and hind edges and along midline; mesopleurum ferruginous, a stripe along its lower edge, a short median longitudinal stripe, subtegular ridge, and mesepimeron whitish; metapleurum whitish, ferruginous above; propodeum black, its second and third pleural areas ferruginous; front and middle legs whitish, their femora, tibiae, and tarsi with fulvous stains and the fifth segment of their tarsi fuscous; hind coxa and trochanters whitish, varied with pale fulvous; hind femur fulvous with a weak subapical infuscation, its apical margin paler; hind tibia and tarsus infuscate, the base of tibia and of basitarsus whitish; abdominal tergites blackish, the first two tergites more or less ferruginous laterally and the apical and lateral margins of the second and following tergites, 
particularly the subapical ones, whitish. The whitish apical margins of most of the tergites have a sublateral constriction or interruption and the subapical tergites have their lateral edges very broadly whitish.

Type: ㅇ, Glendale, Calif., June 11, 1949, E. I. Schlinger (Washington, USNM 63731).

Paratypes: $\odot$, Glendale, Calif., Oct. 30, 1949, E. I. Schlinger (Townes). ㅇ, Mix Canyon, Solano Co., Calif., Mar. 4, 1936 (Townes). ণ, San Mateo Co., Calif., May 7, 1916, E. C. Van Dyke (San Francisco).

\section{Xorides (Xorides) semirufus, new species}

\section{Male: Unknown.}

Female type: Front wing $6.3 \mathrm{~mm}$. long; temple polished and with small scattered punctures that are separated by an average of three times their diameter; areola very broadly pentagonal; median longitudinal carinae of propodeum fused for a considerable distance basad of areola; first tergite stout basally, 1.75 as long as wide; second tergite with rather coarse, crowded punctures.

Head and mouth parts brownish ferruginous; antenna black, its flagellum with a white band covering 3.4 segments; thorax and tegula fulvoferruginous; legs blackish, their second trochanters and bases of tibiae and of basitarsi white; abdomen blackish brown, the apical margin of third through seventh tergites whitish with a sublateral interruption.

Type: +2 miles west of Archer, Fla., Mar. 25, 1953, H. F. Howden (Washington, USNM 63732).

\section{Xorides (Xorides) peniculus, new species}

Figures 313,d;328,j

Male: Front wing 4.0 to $5.4 \mathrm{~mm}$. long; temple polished, with small punctures that are separated by 2 to 4 times their diameter; erect hairs on flagellum about twice as long as flagellar diameter, their tip curved over; areola broadly pentagonal; median longitudinal carinae of propodeum fused for a short distance basad of areola; first tergite about 2.0 as long as wide, with a distinct constriction just beyond the spiracle; second tergite with coarse, crowded punctures.

Blackish, often more or less stained with ferruginous or sometimes the thorax mostly ferruginous. Scape in front often whitish apically; clypeus brown; palpi and front and middle coxae white; tegula fulvous; front and middle femora brown, white at base, apically, and often on much of front; front and middle tibiae white, brown below, on apex, and in a narrow subbasal band; middle and hind tarsi brown, the base of their basitarsi white and their fifth segment fuscous; hind coxa and first trochanter fulvous brown to dark brown, the apex of both white; hind second trochanter white; hind femur fulvous, white on extreme 
base and apex, with subbasal and subapical infuscations or the entire femur brownish with the extreme ends white; hind tibia dark brown, its base white and sometimes a preapical area fulvous, the white at its base sometimes extensive and containing a narrow preapical brown band; hind tarsus blackish brown, the base of its basitarsus white.

Female: Front wing 5.5 to $7.5 \mathrm{~mm}$. long; temple, propodeum, and second tergite as described for the male; first tergite about 1.6 as long as wide, very stout basally.

Colored like the male except that the flagellum has a white band covering about 3.5 of its segments, the hind tibia is dark brown with its basal $0.6 \pm$ white (the white area with a narrow subbasal brown band and apically replaced by brown below), the apical margin of the third and following tergites are more or less white, and the front wing has a faint transverse brown band, centered on the apex of the stigma. The apical white margins of the tergites usually have a sublateral constriction or interruption.
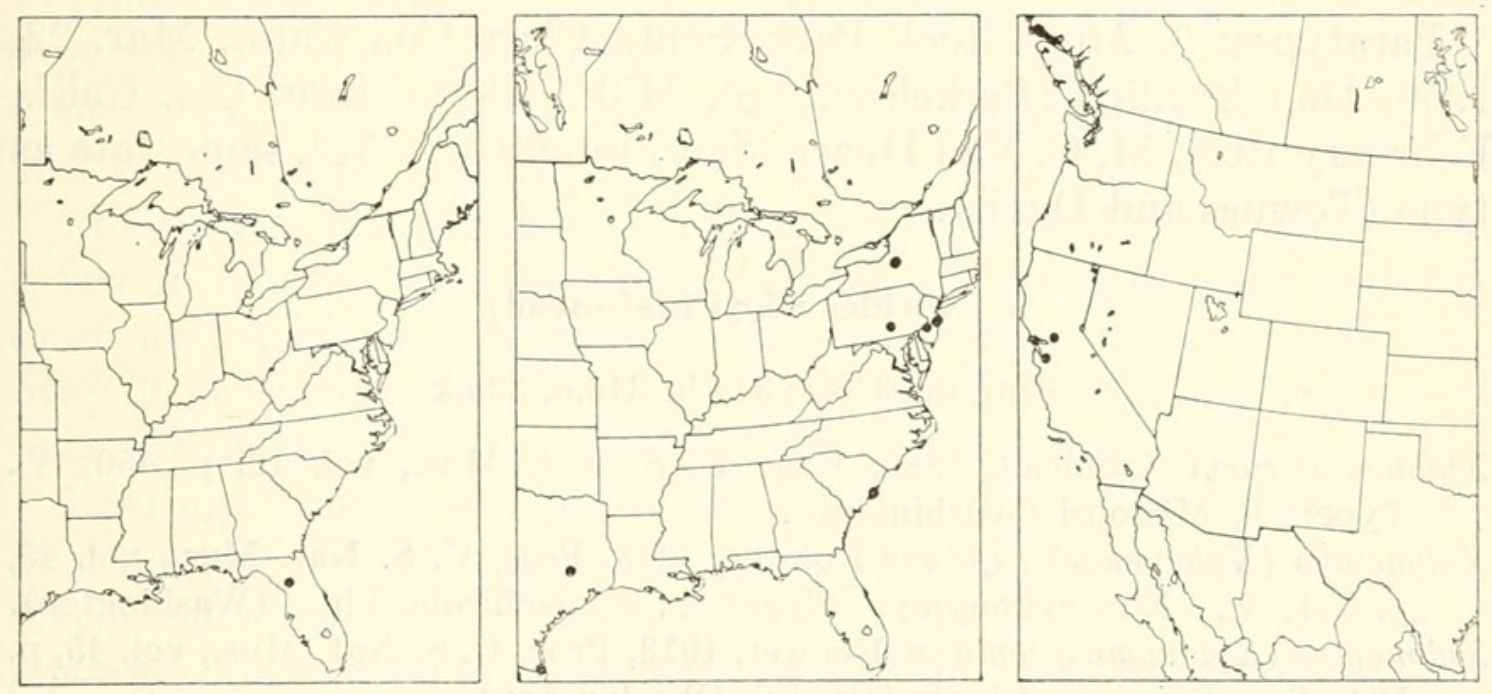

Figures 232-234.--Localities: 232 (left), Xorides semirufus; 233 (center), X. peniculus; 234 (right), X. boharti.

Type: + , reared from Celtis, Hummelstown, Pa., May 8, 1916, J. N. Knull (Washington, USNM 63733).

Paratypes: + , Lakehurst, N. J., August 24 (New York). , Manasquan, N. J., June 16, 1935, M. A. Cazier (New York). ㅇ, Moorestown, N. J., June 28, 1939, H. and M. Townes (Townes). ণ7, Moorestown, N. J., July 2, 1939, H. and M. Townes (Townes). $\sigma^{\nearrow}$, Syracuse, N. Y., M. W. Blackman (Washington). 2o, reared from Celtis occidentalis, Hummelstown, Pa., Dec. 29, 1918, J. N. Knull (Washington). $\sigma^{7}$, McClellanville, S. C., May 10, 1944, H. K. Townes (Townes). \&, Brownsville, Tex., May 22, 1935, J. N. Knull (Townes). ${ }^{7}$, College Station, Tex., May 11, 1935, H. J. Reinhard (Washington). 


\section{Xorides (Xorides) boharti, new species}

\section{Figure $316, \mathrm{~b}$}

Male: Front wing 6.3 to $9.2 \mathrm{~mm}$. long; temple with moderately coarse, very close punctures the interspaces of which tend to shape into rugulae, these rugulae weak and vertical on dorsal part of temple, stronger and oblique on ventral half of temple; erect hairs on flagellum about 0.2 as long as flagellar diameter; first tergite very stout, about 1.55 as long as wide; second tergite rather coarsely reticulate-punctate.

Head, body, and appendages entirely black; wings subhyaline.

Female: Front wing $8.5 \mathrm{~mm}$. long; sculpture as described for the male; flagellum a little enlarged at apex, its apical segment long, the peglike setae at the bend distinctly clavate; front tibia slightly swollen, with four thornlike bristles on its front side; first tergite very stout, about 1.35 as long as wide.

Coloration as in the male.

Type: $\sigma^{\top}$, Mix Canyon, Solano Co., Calif., Mar. 4, 1936, R. M. Bohart (Washington, USNM 63734).

Paratypes: + , Alum Rock Park, Santa Clara Co., Calif., Mar. 22, 1956, Don Burdick (Berkeley). o $\sigma^{\top}$, Mill Valley, Marin Co., Calif., February 1926, M. C. Van Duzee (San Francisco). $5 \sigma^{\top}$, same data as type (Townes and Davis).

\section{Xorides rileyi (Ashmead)}

Figures 313 ,e; $314, \mathrm{~h} ; 316, \mathrm{c} ; 328, \mathrm{k}$

Xylonomus rileyi Ashmead, 1889, Proc. U. S. Nat. Mus., vol. 12, p. 450; . Type: $\uparrow$, Missouri (Washington).

Xylonomus (Xylonomus) ruficoxis Rohwer, 1913, Proc. U. S. Nat. Mus., vol. 45, p. 354 ; $\uparrow$. New synonymy. Type: $ᄋ$, Apalachicola, Fla. (Washington). Xylonomus (Xylonomus) lepturae Rohwer, 1913, Proc. U. S. Nat. Mus., vol. 45, p.

534; $\uparrow$. Type: $\uparrow$, Cherrydale, Va. (Washington).

Male: Front wing 4.6 to $8.0 \mathrm{~mm}$. long; temple polished, with small scattered punctures that are separated by an average of four times their diameter; erect hairs on flagellum about 0.35 as long as flagellar diameter; first tergite about 3.1 as long as wide, with a faint constriction just beyond the spiracle; second tergite with moderately coarse, rather dense punctures and fine, weak transverse rugulosity.

Black, sometimes with an indistinct ferruginous tinge. Clypeus blackish brown; palpi light brown; their first segment and basal part of their second, dark brown; tegula brown; apex of coxae and second trochanters more or less stramineous; extreme apex of femora and basal 0.2 of tibiae, white. Hind coxa sometimes fulvous with its apical part often more or less fuscous.

Female: Front wing 9.5 to $14 \mathrm{~mm}$. long; sculpture of temple and of 
second tergite as described for male; first tergite about 2.3 as long as wide.

Colored like the male except that flagellum has a white band covering about 4.5 segments.

In specimens from the Southeast there is a tendency for the hind coxa to be fulvous and the white band at the base of the tibia to be light brown rather than white. This tendency is well illustrated in the types of the name ruficoxis, from Florida. Two specimens intermediate between these and more typical rileyi are from Tryon, N. C.

This species has a superficial resemblance to Xorides stigmapterus, but besides the structural distinctions it lacks the white band on the basitarsi which is characteristic of stigmapterus.

Specimens (27 $\sigma^{7}, 30$ ) : From District of Columbia (Washington); Florida (Apalachicola); Georgia (Kennesaw Mt.); Indiana (Mill Creek Rest Camp near Manhattan in Putnam Co.); Maryland (Takoma Park); Minnesota (Alexandria, Grant Co., and Houston); Missouri; New York (Ithaca, Lake George, and Tuxedo Lake); North Carolina (Tryon); Ohio (Carbondale, Fairfield Co., and Montgomery Co.); Pennsylvania (Harrisburg and Pittsburgh); Virginia (Blacksburg, Cherrydale, Falls Church, Nelson Co., and Veitch in Arlington Co.); and Wisconsin (Madison).

Most dates of capture are in June and July but some are earlier, a few in August, and one in November. Unusually early and late dates are: April 14 at Kennesaw Mt., Ga.; May 8 at Pittsburgh, Pa.; May 20 at Blacksburg, Va.; May 28 in Houston Co., Minn.; August 24 near Manhattan, Ind.; and November 7 in the District of Columbia.

Rearing records are as follows: $2 \sigma^{7}$, from Phymatodes aereus, Washington, D. C., Mar. 20, 1915, H. G. Champion. ㅇ from Phymatodes testaceus, Pittsburgh, Pa., May 28, 1931. क (type of lepturae), from Anoplodera nitens, Cherrydale, Va., May 20, 1918, R. W. Van Horn. Additional pin label data record the species as reared twice from Castanea dentata, once from Quercus, and once from "black oak." One female is labeled simply "Carya."

This species is in the Alleghanian and Carolinian faunas. It parasitizes borers in hardwoods. Adults occur mostly from late spring to late summer.

\section{INSULARIS GROUP}

Body moderately slender, often more or less depressed; occipital carina complete; temple with rather fine, sparse, or moderately sparse punctures and except above with fine vertical striae (figs. 313,d,e); tooth at upper end of epomia rather weak (for the genus); areola regularly or elongate pentagonal, its basal corner sometimes open; median longitudinal carinae approximate basad of areola, sometimes 

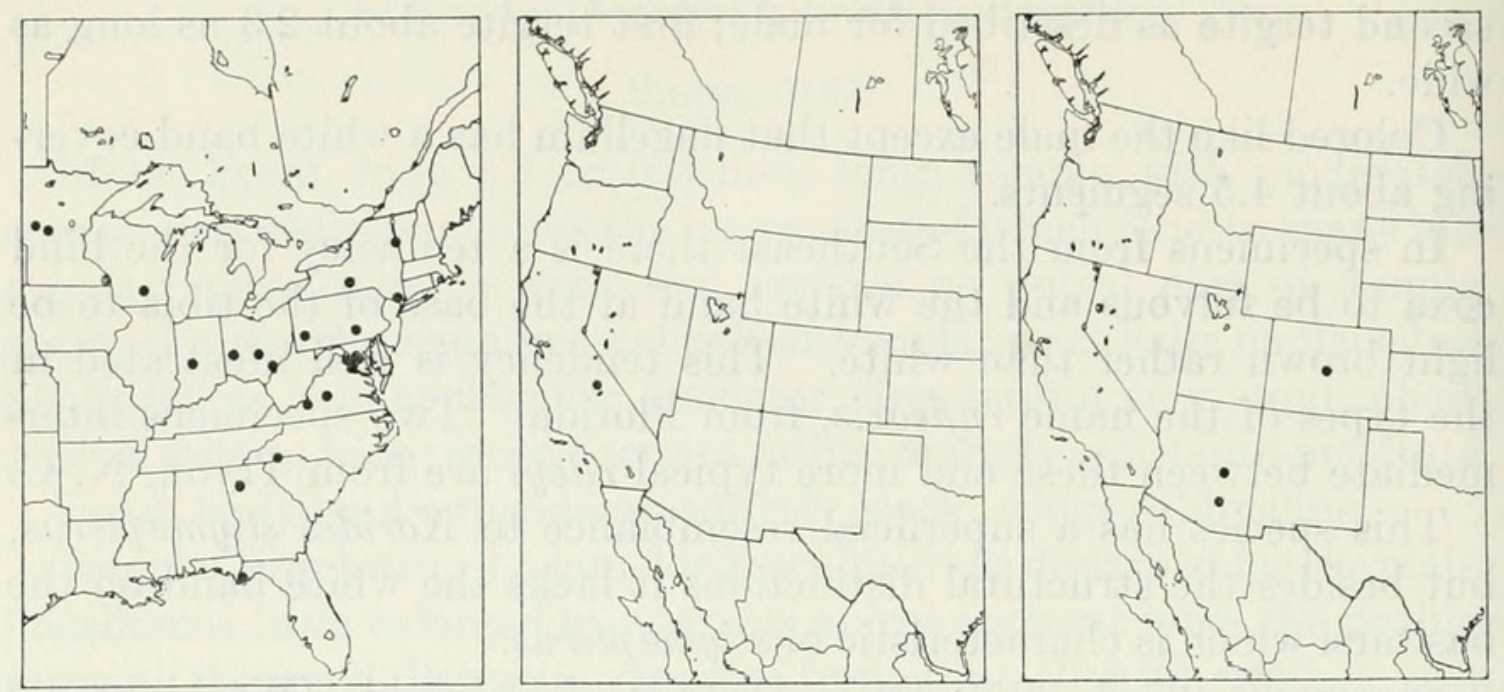

Figures 235-237.-Localities: 235 (left), Xorides rileyi; 236 (center), X. rudis; 237 (right), X. planus.

fused briefly at base of areola (figs. 315 ,a,b. Sometimes most of the propodeal carinae are obsolescent); area dentipara with a blunt or indistinct tooth at its apex; front tibia of female strongly inflated, cylindric except in its basal third; spinelike bristles on front face of female tibia weak, numerous (fig. $313, \mathrm{f}, \mathrm{g}$ ); comb on apex of front side of front tibia with moderately weak bristles; first tergite exceptionally flat, evenly expanded from base to apex, usually without a distinct oblique groove beyond the spiracle but sometimes such a groove is weakly indicated; second tergite evenly convex except for a relatively weak oblique groove that cuts off a small basolateral corner. The female flagellum never has a white band.

This is a Holarctic group, containing five Nearctic species and several in Europe. Among the European species is Xorides ater, the genotype of Rhadinopimpla (=Rhadina, preoccupied). $X$. ater is very closely related to the Nearctic $X$. insularis.

\section{Xorides (Xorides) rudis, new species}

Female type: Front wing $6.7 \mathrm{~mm}$. long; frons with rather close punctures and transversely rugulose; punctures on top of head of moderate size, sharp, separated by about 0.7 their diameter, posterolaterally their interspaces lined up as weak oblique rugulae; temple mat and with vertical fine striae, also with scattered, moderately small punctures; thorax moderately depressed, 2.9 as long as high, its mesoscutum and scutellum weakly convex; mesoscutum subpolished, with moderate sized, close punctures, somewhat rugulose along the notauli; mesosternum and mesopleurum mat with a suggestion of aciculation and with moderately small punctures that are separated by about their diameter; areola pentagonal, a little more 
elongate than a regular pentagon, its basal angle closed; first tergite 1.55 as long as wide, rather coarsely rugulose, its sublateral carinae traceable to the apex, its median carinae sharp to a little beyond the middle but not present beyond this point; second tergite with strong rugulosity which is somewhat longitudinal.

Black, the head with a faint ferruginous tinge. Clypeus and labrum brown; scape and tegula reddish brown; palpi blackish brown; coxae, trochanters, and femora reddish brown, the coxae basally and the hind trochanters infuscate; tibiae brown, a little paler at base, the front tibia whitish in front; tarsi brown.

Type: ㅇ, Lone Pine, Calif., July 28, 1940, R. H. Beamer (Lawrence).

\section{Xorides (Xorides) planus, new species}

Front wing of male $3.7 \mathrm{~mm}$. long, of female 5.2 to $5.3 \mathrm{~mm}$. long; head exceptionally short; frons with scattered, fine, inconspicuous punctures and fine, irregular transverse rugulae; top of head with moderately fine punctures that are separated by about 1.5 their diameter and a little mat and with some weak, fine, transverse aciculation; temple mat, with scattered, fine, inconspicuous punctures and except above with fine vertical aciculation; thorax strongly depressed, about 4.1 as long as high, its mesoscutum and scutellum exactly flat except that the front and sides of the mesoscutum are a little convex; mesoscutum strongly rugulose, the lateral part of its lateral lobe punctate and rather smooth; mesosternum and mesopleurum irregularly mat, not distinctly punctate; carinae on median part of propodeum obsolescent; first tergite of male 2.4 as long as wide, of female about 1.85 as long as wide; first through fourth tergites strongly mat over their entire surface except for a narrow polished apical band; median longitudinal carinae of first tergite discernible only on its basal $0.2 \pm$.

Blackish. Tibiae basally and on extreme apex, and base of basitarsi medium brown; tarsi medium brown to blackish.

Type: \&, Bear Wallow, Mount Lemmon, Santa Catalina Mts., Ariz., May 13, 1953, A. and H. Dietrich (Ithaca).

Paratypes: $\sigma^{7}$, Pocket Creek, Sierra Ancha, Ariz., May 5, 1947, H. and M. Townes (Townes). \&, on sand, Florissant, Colo., June 21, 1908, S. A. Rohwer (Ithaca).

\section{Xorides (Xorides) medius, new species}

Figures 313 ,f; 315,a; 316,d; 328,1

Front wing of male $4.0 \mathrm{~mm}$. long, of female 5.7 to $6.4 \mathrm{~mm}$. long; frons weakly rugulose and with fine, weak, rather close punctures; top of head with fine punctures that are separated by about 2.0 
their diameter, otherwise smooth; temple with fine punctures that are separated by about 1.5 their diameter, below its middle with vertical rugulosity or irregular striae; thorax about 2.6 as long as high, its mesoscutum and scutellum moderately convex; mesoscutum subpolished, with moderate sized, sharp punctures that are separated by about their diameter, the mesoscutum a little rugulose along the notauli or sometimes more or less of the central part of mesoscutum strongly rugulose; mesosternum and mesopleurum subpolished, with moderately sharp punctures that are separated by about 1.5 their diameter; areola regularly pentagonal, its basal corner closed; first tergite 2.4 as long as wide in male, about 1.75 as long as wide in female; first four tergites strongly and rather evenly mat, their apical margin a little smoother; median longitudinal carinae of first tergite distinct on basal 0.15 to 0.3 of the tergite.

Blackish brown. Clypeus, labrum, mandible, palpi, scape, pedicel, and tegula, brown; front and middle legs of male beyond trochanters and hind femur of male fulvous brown, the rest of legs of male dark brown with the hind tibia a little paler basally and at apex; front and middle legs of female brownish fulvous, their coxae a little darker; hind leg of female fulvous brown, the coxa and tibia dark brown with the tibia a little paler at apex and basally.
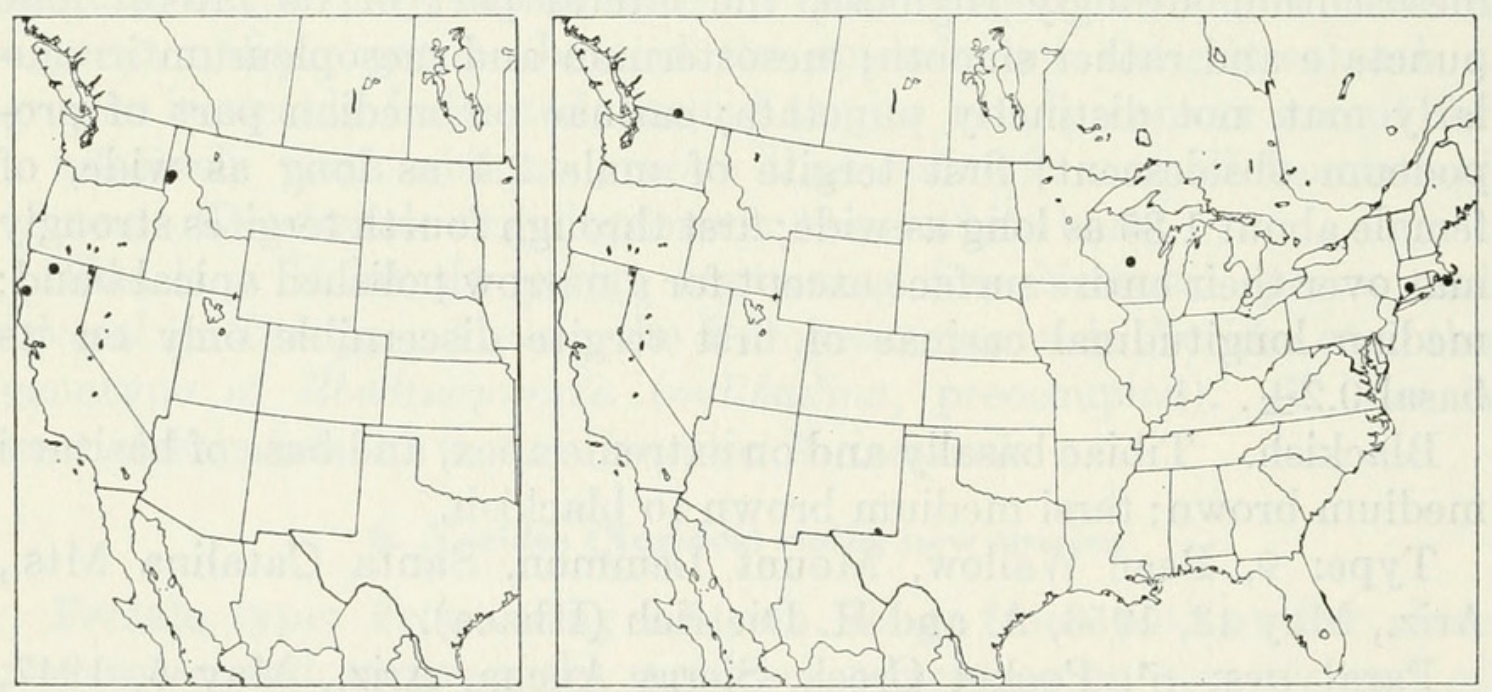

Figures 238, 239.-Localities: 238 (left), Xorides medius; 239 (right), X. eastoni.

Type: 옹 Moscow, Idaho, July 14, 1898, C. V. Piper (Washington, USNM 63735).

Paratypes: + , Fort Seward, Calif., June 3, 1935, H. J. Rayner (Townes). ?, Siskiyou Co., Calif., May 29, 1911, F. W. Nunnenmacher (Washington). $\sigma^{\pi}$, Paradise Ridge at 3,000 ft., Moscow, Idaho, May 30, 1931, Paul Rice (Townes). 


\section{Xorides (Xorides) eastoni (Rohwer)}

Xylonomus (Moerophora) eastoni Rohwer, 1913, Proc. U. S. Nat. Mus., vol. 45, p. 356 ; . Type: $\uparrow$, Fall River, Mass. (Washington).

Male: Unknown.

Female: Front wing 7.5 to $8.5 \mathrm{~mm}$. long; frons with scattered fine punctures and with more or less transverse rugulosity; top of head polished, with small punctures that are separated by about 5 times their diameter; temple with sparse fine punctures, its dorsal 0.3 rather smooth, the rest with fine vertical striae; thorax about 2.8 as long as high; mesoscutum and scutellum moderately convex; mesoscutum with moderate sized, sharp punctures that are separated by about 1.3 their diameter, the mesoscutum centrally rugulose; mesosternum and mesopleurum polished but the surface a little uneven, with medium sized, sharp punctures of irregular distribution, the punctures separated mostly by 1.0 to 3.0 their diameter; areola elongate pentagonal, its basal corner narrowly open; first tergite about 2.5 as long as wide, strongly mat and a little rugulose, without median longitudinal carinae; second tergite strongly, evenly mat.

Black. Front and middle legs fulvous to brown, their tarsi always fulvous with the last segment fuscous; apical margin of front and middle femora and a broad stripe on front of front and middle tibiae whitish; hind leg blackish, its coxa, trochanters, and tinge on basal part of femur often more or less fulvous.

Specimens: ㅇ, Osoyoos, B. C., May 27, 1938, G. S. Walley (Ottawa). ᄋ, Waterbury, Conn., Aug. 4, 1932 (Washington). \%, Martha's Vineyard, Mass., July 15, F. M. Jones (Townes). , Griffith State Nursery, Wood Co., Wis., June 8, 1950, R. D. Shenefelt (Madison).

\section{Xorides (Xorides) insularis (Cresson)}

Figures 313 , g; 315,b; 316,e; 328,m

Poemeria (!) insularis Cresson, 1878, Proc. Acad. Nat. Sci. Philadelphia, vol.

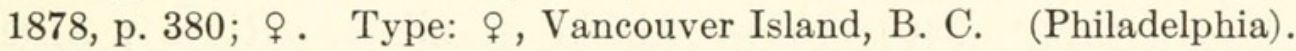

Front wing of male 6.8 to $11 \mathrm{~mm}$. long, of female 6 to $13 \mathrm{~mm}$. long; frons polished, medially with small punctures whose interspaces are about 2.5 their diameter; top of head and upper third of temple polished, with small punctures whose interspaces are about 4 times their diameter; lower two-thirds of temple largely with fine vertical striae; thorax about 2.5 as long as deep, its mesoscutum and scutellum of normal convexity; mesoscutum polished, medially rugulose, with rather weak punctures whose interspaces are about 1.5 their diameter; mesosternum and mesopleurum polished, with moderate sized punctures whose interspaces are about 1.5 to 2.5 their diameter; areolet elongate pentagonal, its basal corner usually open but sometimes closed; first tergite unusually flat above, transversely rugulose, 


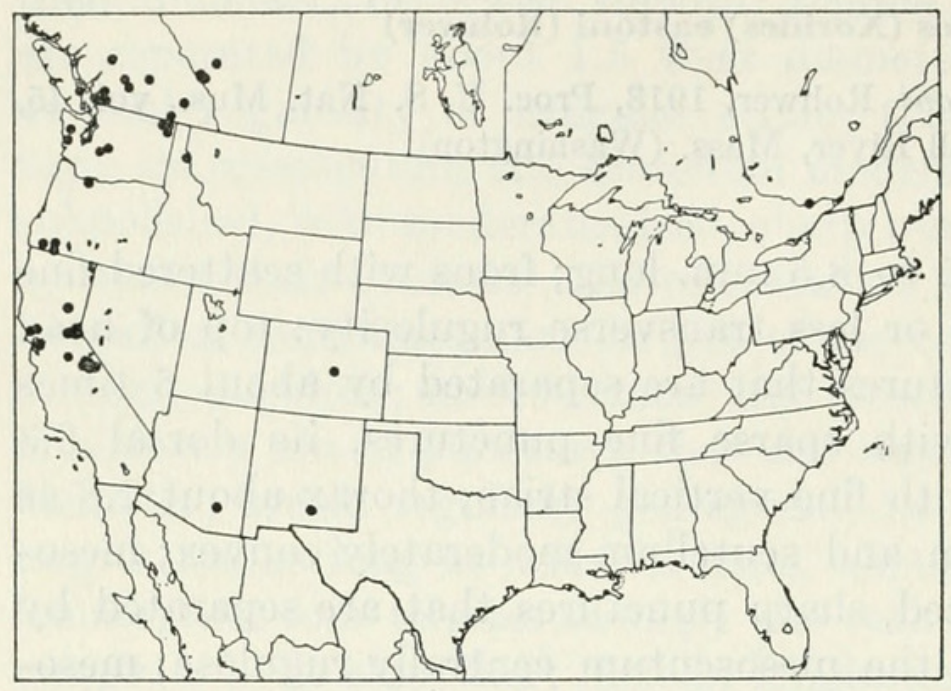

Figure 240.-Localities for Xorides insularis.

in male about 2.85 as long as wide, in female about 2.2 as long as wide; median longitudinal carinae of first tergite sharp on its basal half, obsolescent distad of this point; second through fourth tergites with fine, irregularly transverse aciculation.

Black. Front orbit white; upper margin of pronotum with broad white stripe, in occasional males the stripe narrow, or in rare males abbreviated or absent; clypeus bordered with stramineous; labrum stramineous; base of mandible ferruginous; palpi stramineous to brown; thorax often with ferruginous stains and sometimes the propodeum entirely fulvoferruginous; front and middle legs fulvous, their coxae externally, second trochanters, and apical margin of femora whitish; front of front and middle tibiae of female very pale; fifth segment of front and middle tarsi brown; hind coxa fulvous, sometimes infuscate apically, its apex white; hind leg beyond coxa black or blackish, its trochanters and base of its tibia usually a little paler; narrow apical margin of third and following tergites whitish with a sublateral interruption that divides the white margin into median and lateral portions.

Specimens (57 ठ์, 94 ㅇ): From Alaska (Gulkana River); Alberta (Banff, Lake Louise, and Nordegg); Arizona (Bear Wallow on Mount Lemmon); British Columbia (Aspen Grove, Cultus, Cultus Lake, Kaslo, Lake Errock near Deroche, Midday Valley near Merritt, Robson, Seton Lake near Lillooet, Diamond Head Trail near Squamish, "God Inlet on Vancouver Island," Vancouver, Vernon, and Wellington); California (Berkeley, Big Tree Grove in Mariposa Co., Echo Lake at 7,400 ft., Fallen Leaf, Fallen Leaf Lake, Fish Camp, Florence Lake in Fresno Co., near Glacier Point in Yosemite Park, Guerneville, Miami in Madera Co., Mount St. Helena in Sonoma Co., North Fork, Placerville, Quincy, Riverton, Snowline Camp in El Dorado Co., and Yosemite Park); Colorado (Manitou Springs); Idaho (Wallace); New Mexico (Sacramento Mts.); Oregon (Ashland, 
Jenny Creek, Mount Hood, "Santiam National Forest," and Waldo); Quebec (Aylmer); and Washington (Easton, Hoquiam, Metaline Falls, Mount Rainier, Northport, Quinault and Sullivan Lake).

Most collection dates are in June, July, and August. Those outside of these months are: May 11 at Wellington, B. C.; May 14 and 25 at Robson, B. C.; May 29 at Aspen Grove, B. C.; September 4 at Robson, B. C.; and September 11 at Wallace, Idaho.

Rearing records comprise 3 rearings from Hylotrupes ligneus, 2 from Melanophila drummondi, 1 from Melanophila? sp., 1 from a Scolytus in Pseudotsuga taxifolia, 1 from a cerambycid in Pinus monticola, and 1 from a cerambycid in Thuja plicata. There are additional rearings from various trees without a statement of the insect host. These are: 4 rearings from Pseudotsuga taxifolia, 3 from Pinus ponderosa, 2 each from Libocedrus decurrens and Tsuga heterophylla, and 1 each from Abies amabilis, A. concolor, Chamaecyparis lawsoniana, Cupressus macrocarpa, Picea engelmanni, P. parryana, P. sitchensis, Pinus edulis, Sequoia sempervirens, and "cedar."

This species is widely distributed in the Transition and Canadian zones of the western half of the continent and occurs also in Quebec. It parasitizes various borers in conifers. It is adult mostly in June, July, and August.

\section{ALBOPICTUS GROUP}

Body of average stoutness; occipital carina complete or incomplete medially above; temple conspicuously marked with white, polished, more or less punctate, and in the American species its lower half obliquely striate (fig. 316, f); tooth at upper end of epomia moderately strong; areola pentagonal, a little elongate with its basal corner either closed or narrowly open; median longitudinal carinae close together or briefly fused basad of areola (fig. 315 ,c); tooth at apex of area dentipara acute, rather long; front tibia of female rather strongly swollen; bristlelike hairs on front of front tibia moderately strong, rather numerous (fig. 313,h); comb on front of apex of front tibia with rather strong, short bristles; nervellus broken from a little below middle to a little above middle; first tergite strongly tapered basally, in profile rather strongly arched, its median and sublateral longitudinal carinae rather sharp, complete to the apex; a weak oblique groove on first tergite just beyond its spiracle, extending between the median and sublateral carinae; second tergite with a strong oblique groove cutting off its basolateral corner, the groove sublaterally curved sharply mesad and continued weakly mesad, fading out before reaching center line.

This group includes the two Nearctic species below, Xorides centromaculatus Cushman 1933, from Formosa; Moansa ornatus Tosquinet 1903, from Sumatra; Xylonomus vitiosus Turner 1919, from Indo- 
China; and an undescribed species from the Philippines. The species ornatus and vitosus have not previously been referred to Xorides (new combinations).

\section{Xorides (Xorides) calidus (Provancher)}

Xylonomus calidus Provancher, 1886, Additions et corrections au volume II de la faune entomologique du Canada traitent des hyménoptères, p. 119; . Type: $q$,Ottawa, Ont. (Quebec).

Xylonomus pulcher Ashmead, 1889, Proc. U. S. Nat. Mus., vol. 12, p. 450; 9

Type: $\uparrow$, Cadet, Mo. (Washington).

Aplomerus nasonii Davis, 1895, Trans. Amer. Ent. Soc., vol. 22, p. 32; هొ. Type: $\sigma^{7}$, Algonquin, Ill. (Philadelphia).

Biology: Blackman and Stage, 1924, Techn. Publ. New York State Coll. Forestry, Syracuse Univ., no. 17, p. 180.

Front wing of male 4.0 to $7.4 \mathrm{~mm}$. long, of female 5.7 to $9.0 \mathrm{~mm}$. long; occipital carina complete above, with a small median dip; temple with rather small punctures that are separated by about 1.5 their diameter, its dorsal half otherwise smooth, its ventral half with rather strong oblique striae; first tergite about 2.2 as long as wide in male, about 2.0 as long as wide in female; second tergite with fine rugulosity.

Male: Blackish brown; frontal orbit (interrupted at antennal socket), sometimes a pair of median blotches on face and occasionally entire face, hind orbit (very wide above and either continuous or broken into a large dorsal and a small ventral spot), tegula, and sometimes subtegular ridge, white; mandible ferruginous; front and middle coxae and trochanters white, the coxae fulvous basally; front and middle femora fulvous, white at base and apex; front and middle tibiae whitish with a narrow subbasal brown band; front and middle tarsi pale stramineous to brown, the base of their basitarsi white and their apical segment fuscous; hind coxa and femur fulvous, the femur with its extreme apex white and a subapical infuscation; hind trochanters pale fulvous; hind tibia and tarsus fuscous, the basal 0.2 of the tibia and basal $0.4 \pm$ of the basitarsus white.

Female: Ferruginous. Head blackish brown; broad frontal orbit (interrupted at antennal socket), hind orbit which is enlarged dorsally into a large spot, and sometimes median area on face, white; clypeus and labrum whitish or light brown; mandible ferruginous, blackish apically; palpi brown; antenna blackish with a white band covering about 5 flagellar segments; propleurum, front part of pronotum, mesonotum and more or less of adjacent sclerites, mesosternum, and often front part of mesopleurum, black or infuscate, the scutellum, tegula, and subtegular ridge white; front coxa dark brown; middle coxa brownish ferruginous; hind coxa ferruginous, a little infuscate apically; trochanters dark brown or partly brownish ferruginous; femora ferruginous with the apex white and a subapical infuscation which is weak on front femur and distinct on hind femur; front and 
middle tibiae light brown, their base and front face white, with a narrow subbasal brown band; hind tibia brownish fulvous, its basal 0.12 white followed by an infuscate band, its apex also infuscate; tarsi fulvous, the base of their basitarsi white (narrowly white on front and middle tarsi, broadly white on hind tarsus) and their apical segment darker; front wing with a faint brown spot centered over the intercubitus. In a specimen from Elizabethtown, N. C., the white markings are unusually extensive and there is a white stripe along inner edge of lateral lobe of mesoscutum.

Specimens (37 $\left.\sigma^{x}, 57 \%\right)$ : From Connecticut (Lyme); Illinois (Algonquin and Willow Springs); Iowa; Maryland (Bowie, Cabin John, Chesapeake Beach, College Park, near Cumberland, Fredericktown in Cecil Co., "Jackson's Island," Mayo Beach, Plummers Island, and Takoma Park); Massachusetts (Franklin and Sandwich); Michigan (Detroit); Missouri (Cadet); New Jersey (Greenwood Lake); New York (Bemus Point, Greenwood Lake, Ithaca, and Sea Cliff); North Carolina (Elizabethtown, Raleigh, and Tryon); Ohio (Hinckley in Medina Co. and Montgomery Co.); Ontario (Ottawa); Pennsylvania (Linglestown, Notch in Pike Co., Rockville in Dauphin Co., and State College); Rhode Island (Westerly); Saskatchewan (Indian Head); Texas; Virginia (Falls Church, Great Falls, and Rosslyn); and West Virginia (Lost River State Park in Hardy Co.).

Most dates of collection are in June and July, but the total seasonal spread is from early spring to mid-fall. The earliest and latest dates are: April 22 at Rosslyn, Va.; April 28 at State College, Pa.; May 5 at Detroit, Mich.; May 11 at Lyme, Conn.; September 15 at College Park, Md.; September 21 in Montgomery Co., Ohio; and October 4 at Linglestown, $\mathrm{Pa}$.
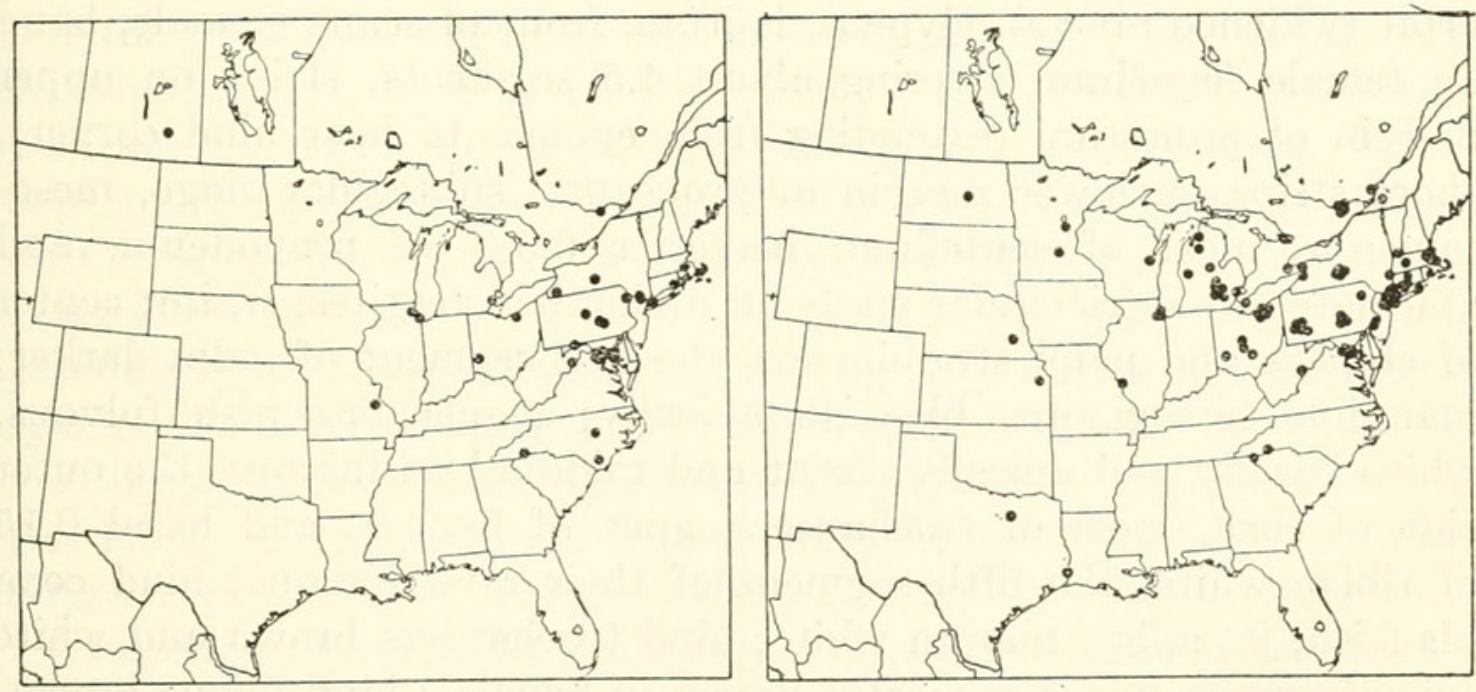

Figures 241, 242.-Localities: 241 (left), Xorides calidus; 242 (right), $X$, albopictus. 
Reared specimens are: $2 \sigma^{\top}$, from Astylopsis macula in Castanea dentata, Notch, Pa., June 26, 1913, F. C. Craighead. \&, from Astylopsis macula in Castanea dentata, Rockville, Pa., June 2, 1913, F. C. Craighead. 2ㅇ, from Juniperus, Tryon, N. C., W. F. Fiske. 3ㅇ, from Castanea dentata, Tryon, N. C., W. F. Fiske. $7 \sigma^{\top}, 10 \%$, from Acer negundo, Indian Head, Sask., May 5 to Sept. 4, 1940, C. R. Douglas.

This species is in the Alleghanian and Carolinian faunas. It parasitizes borers in hardwoods, and there is a rearing from Juniperus on record. Adults occur from early spring to mid-fall.

\section{Xorides (Xorides) albopictus (Cresson)}

Figures $313, \mathrm{~h} ; 315, \mathrm{c} ; 316, \mathrm{f} ; 328, \mathrm{n} ; 331$, h

Xylonomus albopictus Cresson, 1870, Trans. Amer. Ent. Soc., vol. 3, p. 168; $\subsetneq$.

Type: $q$, New York (Philadelphia).

Xorides canadensis Provancher, 1875, Naturaliste Canadien, vol. 7, p. 248; $\sigma^{7}$.

Type: $\sigma^{7}$, Mount Yamaska, Que. (lost).

Xylonomus (Moerophora) duplicatus Rohwer, 1913, Proc. U. S. Nat. Mus., vol.

45, p. 356; $\sigma^{7}$. Type: $\sigma^{7}$, Clark Station (near St. Louis), Mo. (Washington). Biology: Kaston, 1937, Bull. Connecticut Agr. Exp. Sta., no. 396, p. 356.-

Procter, 1938, Biological survey of the Mount Desert region, vol. 6, p. 407.

Front wing 3.0 to $9.5 \mathrm{~mm}$. long in male, 5.8 to $10.5 \mathrm{~mm}$. long in female; occipital carina narrowly (but definitely) interrupted medially above; sculpture of temple and of second tergite as in $X$. calidus except that the temple is more sparsely punctate; first tergite of male about 2.7 as long as wide, of female about 2.5 as long as wide.

Black, the thorax often with ferruginous tinges, especially on lateral lobes of mesoscutum. Face of male except for median longitudinal brown stripe, in female spot below antennal socket, front orbit (constricted or interrupted opposite antennal socket), hind orbit (widened above), clypeus, labrum, front of scape of male, band on female flagellum covering about 4.5 segments, stripe on upper margin of pronotum (extending from epomia to near hind corner), short stripe on lower margin of pronotum, subtegular ridge, mesepimeron, most of scutellum, posterior $0.3 \pm$ of propodeum, and apicolateral subtriangular spots on abdominal tergites, white; center of clypeus and palpi stramineous, the last segment of palpi darker; mandible ferruginous, blackish apically; tegula brownish fulvous, white basally and apically; front and middle legs fulvous, the outer side of coxa, most of trochanters, apex of femora, and basal 0.15 of tibiae white, the fifth segment of their tarsi fuscous; hind coxa blackish, its apical margin white; hind trochanters brown and white (mostly white in male, mostly brown in female); hind femur brown; hind tibia dark brown, its basal 0.15 white and in the female pale 
brown from near its basal 0.3 to near apical 0.2 ; tarsus light brown, its apical segment fuscous and in male the basitarsus dark brown basally.

Specimens (230 ه , 243우): From Connecticut (East River, Hamden, Hartford, and New Haven); District of Columbia (Rock Creek Park); Georgia (Clayton); Illinois (Chicago, Moline, and Willow Springs); Indiana; Kansas (Douglas Co.); Maryland (Bowie, Cabin John, and Takoma Park); Massachusetts (Amherst, Cohasset, Dorchester, Forest Hills, Tewksbury, and West Roxbury); Michigan (Ann Arbor, Antrim Co., Aurelius, Detroit, East Lansing, George Reserve in Livingston Co., Kalkaska Co., Midland Co., Newago Co., and Shiawassee Co.); Minnesota (Carver Co. and Mille Lacs Co.); Missouri (Clark Station near St. Louis); Nebraska (Lincoln); New Jersey (Chatham, East Orange Water Res., and West Caldwell); New York (Armonk, Connecticut Hill at 2,095 ft., East Aurora, Flatbush, Gardiners Island, Hillsdale, Ithaca, Lockport, McLean Bogs Reserve in Tompkins Co., New Rochelle, New York City, Olcott, South Haverstraw, Westbury, Westchester Co., White Plains, and Yonkers); North Carolina (Tryon); North Dakota (Sully's Hill National Park); Ohio (Cleveland, Columbus, Dayton, Delaware Co., Franklin Co., Hinckley in Medina Co., Hocking Co., Puritas Springs in Cuyahoga Co., Summit Co., and Westview); Ontario (Ancaster, Bells Corners, Orillia, Ottawa, and Point Pelee); Pennsylvania (Allegheny Co., Castle Rock in Delaware Co., Crisp in Westmoreland Co., Harrisburg, Jeannette, Linglestown, Natrona, Overbrook, Pittsburgh, Pittstown, Shiremanstown, and Stoverdale in Dauphin Co.); Quebec (Aylmer, Hull, Joliette, and Mount Yamaska); Texas (Dallas and Deweyville); Vermont (Laurel Lake near Jacksonville); West Virginia (Cheat Mt. at 2,000 ft. in Randolph Co.); and Wisconsin (Menasha).

The majority of collection dates are from late May to early August, but the total seasonal range is somewhat greater. The earliest and latest dates are: April 30 in Douglas Co., Kans.; May 5 in Midland Co., Mich.; May 7 at Chicago, Ill.; May 8 at East Lansing, Mich.; September 8 at New Rochelle, N. Y.; September 9 in Rock Creek Park, D. C.; September 20 at Aurelius, Mich.; and October 4 at Flatbush, Long Island, N. Y. We have found the species a number of times on standing dead or nearly dead deciduous trees. It is the commonest species of the genus in eastern North America.

A large portion of the specimens were reared. Records from the pin labels are: 3 rearings (either individuals or reared lots) from Saperda discoidea in Carya, 3 from Saperda tridentata in Ulmus, 1 from Saperda tridentata in an unspecified tree, 9 from Carya, 2 from Fagus, 1 from Ulmus americana, and 5 from Ulmus sp. 
This species is in the Alleghanian and Carolinian faunas. It parasitizes species of Saperda in hardwoods. Adults occur from mid spring to early fall.

\section{MAUDAE GROUP}

Body rather slender; occipital carina broadly interrupted above; top of head with small, close punctures and a tendency toward transverse rugulosity; lower half of temple with oblique aciculation which near midheight of temple approaches horizontal (fig. 316,g); tooth at upper end of epomia weak (for the genus); areola subpentagonal, its basal corner broadly open; median longitudinal carinae of propodeum approximate basad of areola but always well separated (fig. $315, \mathrm{~d})$; area dentipara with a short, strong, acute tooth at its apex; front tibia of female rather strongly swollen, its front side with a moderate number of strong, spinelike bristles; comb of bristles on apex of front tibia on inner side rather weak (fig. 313 ,i); first tergite of male about 2.4 as long as wide, of female about 1.75 as long as wide; basal half of first tergite strongly arched in profile, its apical half almost flat in profile; sublateral longitudinal carina of first tergite strong to the apex; median longitudinal carinae of first tergite sharp on basal half, obsolescent but usually discernible as a low ridge beyond the middle; faint oblique groove beyond the middle of first tergite, extending between median and sublateral longitudinal carinae; second tergite with a sharp oblique groove cutting off its basolateral corner, sublaterally the groove swinging mesad and fading out.

This group is intermediate between the ALBорістUs group and the STIGMAPTERus group. It includes the three Nearctic species below and the European $X$. filiformis (Gravenhorst), 1829. All of these except the Nearctic $X$. atrox are very closely related and may be only subspecifically distinct. Xorides filiformis is genotype of the name Sichelia.

\section{Xorides (Xorides) atrox, new species}

Female type: Front wing $9.5 \mathrm{~mm}$. long; temple not quite reaching outside tangent of eye; upper third of temple with rather close, small punctures and a little rugulosity, not distinctly striate.

Black. Clypeus dark brown, its margins pale brown; labrum pale brown; mandible ferruginous, its apex blackish; palpi blackish brown; flagellum with a white band covering 6.5 segments; basal 0.12 of tibiae, basal 0.6 of front basitarsus, basal 0.4 of middle and hind basitarsi, and third and fourth segments of all tarsi, white.

Type: ㅇ, Robson, B. C., July 13, 1939, H. R. Foxlee (St. Paul). 


\section{Xorides (Xorides) maudae (Davis)}

Xylonomus maudae Davis, 1895, Trans. Amer. Ent. Soc., vol. 22, p. 32; ९ . Type: , ?Seattle, Wash. (Philadelphia).

Front wing of male 6 to $9 \mathrm{~mm}$. long, of female 9.3 to $10 \mathrm{~mm}$. long; top of head without transverse rugulae; temple flared laterally a little beyond outside tangent of eye, its upper half with close horizontal aciculation and some small aciculate punctures.

Dull reddish brown. Part or most of front orbit, small area surrounding upper end of epomia, subtegular ridge, scutellum laterally, apical margin of femora, and basal 0.12 of tibiae, ivory; flagellum blackish brown; front and middle legs brownish fulvous except for ivory markings as described; propodeum and first abdominal segment brownish fulvous; front wing of female with two small faint brown clouds centering on intercubitus and on junctures of basal vein and nervulus with medius. One female from Menlo Park, Calif., has the eleventh flagellar segment medium brown, suggesting a rudimentary pale band on the flagellum as in X. neoclyti.
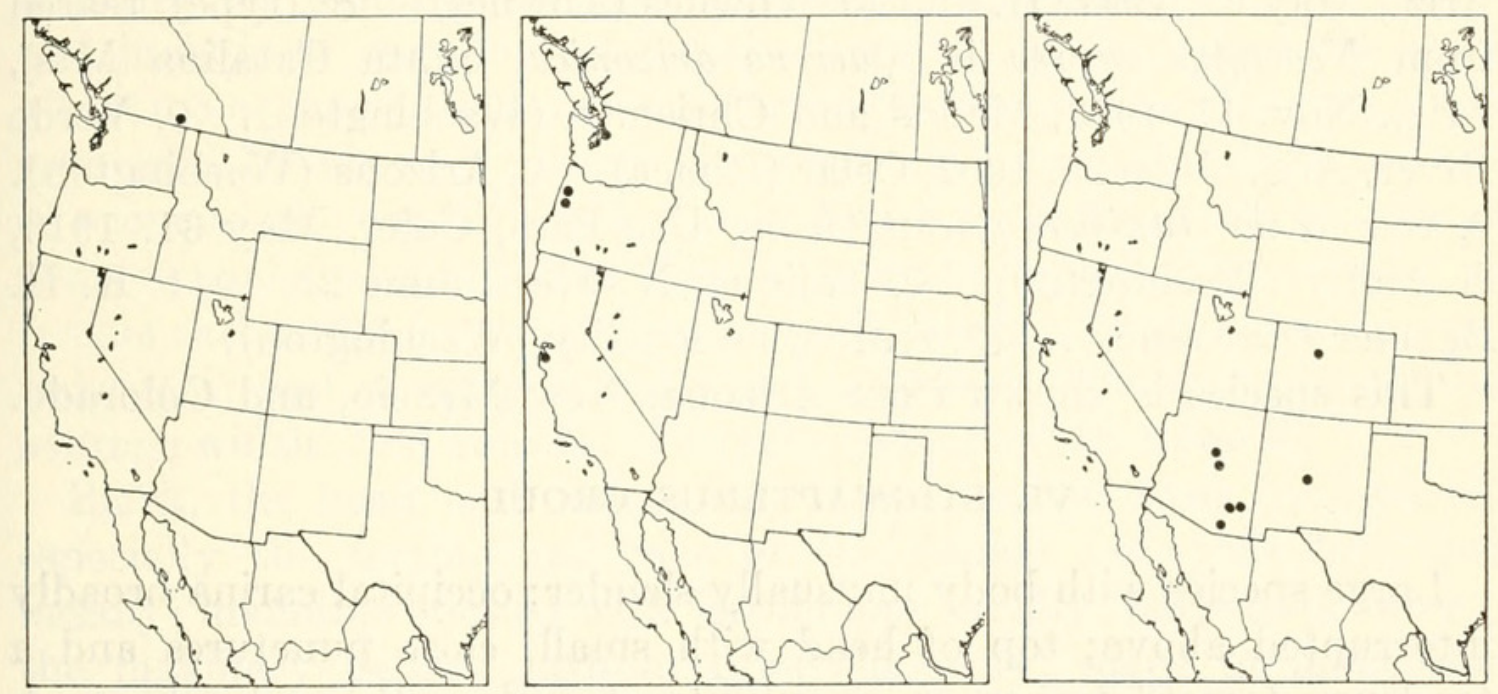

Figures 243-245.-Localities: 243 (left), Xorides atrox; 244 (center), X. maudae; 245 (right), X. neoclyti.

Specimens: †, Menlo Park, Calif., January 1905, F. Hornung (Washington). $\sigma^{\top}$, Corvallis, Oreg., Mar. 26, 1896 (Washington). \%, reared from Pseudotsuga taxifolia, Corvallis, Oreg., May 3, 1919, W. J. Chamberlin (Cambridge). क, Corvallis, Oreg., May 8, 1896 (Washington). $\sigma^{7}$, Corvallis, Oreg., July 18, 1896 (Washington). ণ, Corvallis, Oreg., Sept. 14, 1931, N. P. Larson (Washington). ه", Hoskins, Oreg., Sept. 1907 (Washington). ㅇ (type), ?Seattle, Wash. (Philadelphia).

This species occurs from Washington to the vicinity of San Francisco, near the coast. 


\section{Xorides (Xorides) neoclyti (Rohwer)}

Figures $313, \mathrm{i} ; 315, \mathrm{~d} ; 316, \mathrm{~g}$

Moerophora neoclyti Rohwer, 1915, Proc. U. S. Nat. Mus., vol. 49, p. 223; ๙

Type: $\sigma^{\top}$, Santa Catalina Mts., Ariz. (Washington).

Front wing of male 7 to $9.5 \mathrm{~mm}$. long, of female 11 to $12.5 \mathrm{~mm}$. long; top of head with weak, transverse rugulae. Otherwise structurally similar to $X$. maudae.

Abdomen, propodeum, and metapleurum dull brownish ferruginous, the rest of body and appendages blackish to fuscoferruginous; front orbit, usually a spot or stripe on subtegular ridge, and basal 0.1 of tibiae, ivory; female flagellum with a white band covering about 2.5 of its segments; front wing with a small brownish cloud centered on intercubitus and another centered over junction of basal vein and nervulus with medius, these clouds distinct in female, faint in male.

Specimens: + , Fort Grant in the Pinaleno Mts., Ariz., July 15 to 19, 1917 (Townes). $\sigma^{\top}$, Madera Canyon, Santa Rita Mts., Ariz., Apr. 10, 1947, H. K. Townes (Townes). ণ $\sigma^{7}$, Oak Creek Canyon, Ariz., May 21, 1947, H. and M. Townes (Townes). $\sigma^{\top}$ (type), reared from Neoclytus caprea in Quercus arizonica, Santa Catalina Mts., Ariz., Nov. 17, 1913, Morris and Chrisman (Washington). ㅇ, Verde River, Ariz., June 25, 1902, Oslar (Ithaca). \&, Arizona (Washington). \%, reared on Juniperus scopulorum, Ute Pass, Colo., May 31, 1916, G. Hofer (Washington). क, Tajique, N. Mex., June 25, 1941, R. H. Beamer (Lawrence). $\sigma^{\top}$, reared, no locality (Wasbington).

This species is known from Arizona, New Mexcio, and Colorado.

\section{STIGMAPTERUS GROUP}

Large species with body unusually slender; occipital carina broadly interrupted above; top of head with small, close punctures and a tendency toward transverse rugulosity; temple with moderate sized, rather dense punctures, its lower two-thirds obliquely striatorugulose (fig. $316, \mathrm{~h}$ ); hypostomal carina very high; a carina extending dorsad on temple from hind corner of mandible, somewhat parallel to occipital carina, the carina fading out dorsally into strong aciculations; temple near hypostomal carina with some coarse irregular wrinkling paralleling hypostomal carina; tooth at upper end of epomia moderate; areolet elongate ovoid, its basal end open; median longitudinal carinae of propodeum approximate but separate at base of areola (figs. $315, \mathrm{e}, \mathrm{f}$ ); front tibia of female strongly swollen, cylindric except on its basal 0.25 ; front face of tibia with numerous spinelike bristles (fig. $313, \mathrm{j}$ ); bristles in comb on front of apex of front tibia short, rather weak; first tergite moderately slender to very slender, moderately curved basally, with a faint dorsolateral oblique groove 
beyond the spiracle; sublateral longitudinal carinae of first tergite strong to the apex; median longitudinal carinae of first tergite sharp and distinct on basal balf, more or less obsolescent on apical half, stronger and longer in male than in female; second tergite with a sharp oblique groove that cuts off its basolateral corner, near the lateral edge the groove turning mesad and quickly fading.

This group contains the four Nearctic species below and the European Xorides alpestris (Habermehl), 1904.

\section{Xorides (Xorides) harringtoni Rohwer}

Figures 315 ,e; 329, a

Xylonomus canadensis Harrington, 1891, Canadian Ent., vol. 23, p. 133; ه', ․ Name preoccupied in Xorides by Provancher, 1875. Types: $\sigma^{7}$, ㅇ [near Ottawa, Ont.] (Ottawa).

Xorides harringtoni Rohwer, 1920, Proc. U. S. Nat. Mus., vol. 57, p. 443 . New name.

Front wing of male 10 to $11 \mathrm{~mm}$. long, of female 12 to $16 \mathrm{~mm}$. long; wrinkles on temple near and paralleling hypostomal carina weak and indistinct; segments of female flagellum at the subapical bend about 0.8 as long as wide; mesopleurum faintly rugulose, its punctures separated by about 0.8 their diameter; median longitudinal carinae of propodeum very high and strong; first tergite about 2.2 as long as wide in male, about 2.0 as long as wide in female; first tergite of female rather flat beyond its middle, its median longitudinal carinae indistinct; first sternite of male surpassing spiracle by about 0.5 its average width; first sternite of female ending at the spiracle.

Black, the head and thorax sometimes stained with ferruginous, especially the temple and face of the female. Clypeus brownish basally; mandible stained with ferruginous basally; palpi dark brown, the maxillary palpus medium brown apically; scape of male pale brown in front; flagellum of female with a white band that covers about 5.5 segments; apical margin of femora and of front and middle tibiae, basal 0.12 of tibiae, upper face of male front tibia, basal half of hind basitarsus, and all of first four segments of front and middle tarsi, white or whitish.

This species shares most of its characters with the western $X$. californicus. Collections from localities between the known ranges of $X$. harringtoni and $X$. californicus may produce intermediate specimens which will prove that they are only subspecifically distinct.

Specimens: o, "Betula lutea," Cranberry Lake, N. Y., June 14, 1919, C. J. Drake (Washington). $\sigma^{\top}$, ,, Hymers, Ont., June 1 and 14, 1913 (New York). $2 \sigma^{7}$, Hymers, Ont., June 14, 1913 and June 19, 1912 (Townes). क, North Bay, Ont., June 9, 1905 (Ithaca). \&, Ottawa, Ont., June 1885, W. H. Harrington (Ottawa). क, Ottawa, 
Ont., June 11, 1914, G. Beaulieu (Ottawa). ९, Ottawa, Ont., Harrington (Washington). क, on dead Quercus, Aylmer, Que., May 31, 1903 (Ottawa). $\sigma^{7}$, + , reared from Dicerca divaricata, Laniel, Que., June 2, 1937, P. M. Manley (Ottawa). \&, Pointe-du-lac, Que., Aug. 2, 1929, F. Firmin (Washington). o, Lake Willoughby at 1,200 ft., Vt., June 17 to 29, 1945, C. P. Alexander (Townes). 2\%, Laurel Lake, near Jacksonville, Vt., May 30, 1936 and June 27, 1935, H. D. Pratt (Townes). $ণ$, June (Washington). $\sigma^{7}$, no data (Washington). $\sigma^{7}, 3$, , no data (Ottawa).

This species is known from Ontario, Quebec, Vermont, and New York.
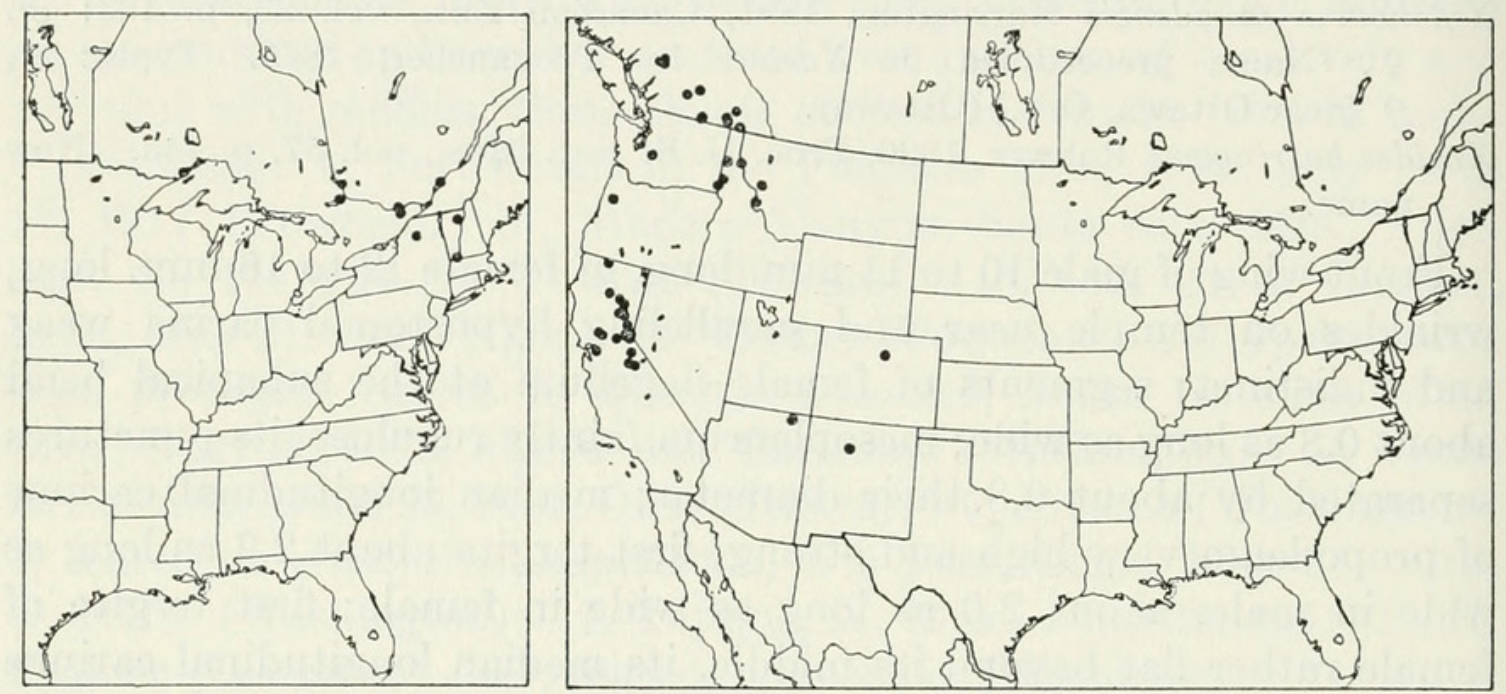

Figures 246, 247.-Localities: 246 (left), Xorides harringtoni; 247 (right), X. californicus.

\section{Xorides (Xorides) californicus (Cresson)}

Xylonomus californicus Cresson, 1878, Proc. Acad. Nat. Sci. Philadelphia, vol. 1878 , p. 380 ; $\uparrow$. Type: $\uparrow$, California (Philadelphia).

Xylonomus catomus Davis, 1898, Trans. Amer. Ent. Soc., vol. 24, p. 372; . Lectotype: $\uparrow$, Moscow, Idaho (Philadelphia).

Front wing of male 9 to $13 \mathrm{~mm}$. long, of female 11 to $16 \mathrm{~mm}$. long; wrinkles on temple near and paralleling hypostomal carina very strong and regular. Structure otherwise as described for $X$. harringtoni.

Ground color pale fulvous to blackish brown, the palest ground colors in Arizona specimens and the darkest ground colors on the average in specimens from the northern parts of the range. Head never dark brown, varying from yellowish fulvous to brownish ferruginous. Mandible blackish; flagellum black, in female with a white band covering about three segments; thoracic sutures, especially those around scutellum, usually blackish when the rest of the thorax is mostly fulvous or ferruginous; tarsi, more or less of trochanters and front femur, and most of front tibia pale brown or fulvous even when 
the rest of the legs are darker, the fifth tarsal segment fuscous; wings strongly tinged with yellowish brown.

Specimens $\left(37 \sigma^{x}, 112\right.$ ) : From Arizona (west of Kayenta in Navajo Co. at 6,900 and $7,200 \mathrm{ft}$.); British Columbia (Clinton, Creston, Garnet Valley near Summerland, Kaslo, Lillooet, Monte Creek, Nicola, Osoyoos, Robson, Seton Lake at Lillooet, and Warfield); California (Buck's Lake in Plumas Co., Chester, China Flat in El Dorado Co., Cisco, Davis, Diamond O. Camp at Mather in Tuolumne Co., Fallen Leaf, Glen Alpine Creek at Tahoe, near Glacier Point in Yosemite Park, Lake Tahoe, "Los Pinos," Meadow Valley in Plumas Co. at 3,500 to 4,000 ft., Onion Valley in Plumas Co., Placerville, Putah Creek in Yolo Co., Quincy, Sagehen near Hobart Mills, Shingletown, Sierra Nevada Mts., Snowline Camp in El Dorado Co., Strawberry in Tuolumne Co., Summerville in Contra Costa Co., Yosemite Park at 3,880 to 4,000 ft., and Yreka); Colorado (Boulder); Idaho (Hauser Lake, Moscow, and Wallace); Montana (Darby and Missoula); New Mexico (Jemez Springs at 6,400 ft.); Oregon (Albany); and Washington (Asotin and Sawmill Flat in Rainier National Forest).

Most collection dates are from the latter part of May to early July. The dates of capture before May 16 and after July 10 are: March 15, 30, and 31 and April 6, 10, 18, and 26 at Davis, Calif.; April 2 at Putah Creek in Yolo Co., Calif.; May 5 in Yosemite Park at 3,880 to 4,000 ft.; May 8 without locality; May 15 at Nicola, B. C.; July 20 near Glacier Point, Yosemite Park, Calif.; July 26 at Robson, B. C.; and August 1 at Fallen Leaf, Calif.

Reared specimens are: क, from Alaus oculatus, Missoula, Mont., Apr. 20, 1916, J. Brunner. $\%$, from Paranthrene robiniae perlucida in Pinus ponderosa, July 6, 1916, J. Brunner. ㅇ, from Buprestis viridisuturalis in Populus trichocarpa, May 3, 1921, R. D. Hartman. $2 \sigma^{\top}, 2$, from Pinus ponderosa, Placerville, Calif., F. B. Herbert and H. E. Burke.

This species is in the Transition and Canadian zones of the West. Adults occur from late spring to mid-summer.

\section{Xorides (Xorides) stigmapterus (Say)}

\section{Figures $313, \mathrm{j} ; 315, \mathrm{f} ; 316$,h; 329,b}

Front wing of male 6.7 to $10 \mathrm{~mm}$. long, of female 10 to $17 \mathrm{~mm}$. long; wrinkles on temple near and paralleling hypostomal carina moderately strong, rather regular; segments of female flagellum at the subapical bend about 1.1 as long as wide; mesopleurum smooth, its punctures separated by about their diameter; median longitudinal carinae of propodeum rather strong; first tergite about 5.8 as long as wide in male, about 2.75 as long as wide in female; first tergite of female with 
a distinctly elevated median area between the median longitudinal carinae; first sternite of male surpassing spiracle by about 1.3 its average width; first sternite of female surpassing spiracle by about 0.5 its average width.

There are two subspecies, separable on color as keyed and described below:

1. Head and thorax black or blackish; range: Canadian, Alleghanian, and Carolinian faunas . . . . . 20a. stigmapterus stigmapterus (Say)

Head and thorax dusky ferruginous or ferruginous; range: Austroriparian fauna . . . . . . . 20b. stigmapterus floridanus (Ashmead)

\section{0a. Xorides (Xorides) stigmapterus stigmapterus (Say)}

Acoenitus stigmapterus Say, 1824, in Keating, Narrative of an expedition to the source of St. Peter's River . . . , vol. 2, appendix, pt. 1, p. 325 (Leconte ed., vol. 1, p. 218); + . Type: $q$, North-west Territory (type destroyed).

Xylonomus tartarus Morley, 1913, Fauna of British India . . ., Hymenoptera,

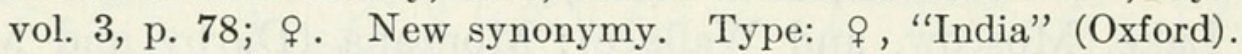

Black, the temple sometimes tinged with ferruginous. Clypeus brownish; mandible tinged with ferruginous; female flagellum with a white band covering about five segments; apical margin of femora, sometimes apical margin of front and middle tibiae of male, basal 0.12 of all tibiae, basal $0.5 \pm$ of basitarsi, fourth segment of tarsi, often more or less of third tarsal segment, and sometimes second segment of front tarsus of male, white; front femur and tibia of male often brownish in front.

The type of Xylonomus tartarus is a specimen from the J. O. Westwood collection, labeled "India." It belongs to the present subspecies. It is not from India, but possibly from Indiana. We have seen two other ichneumonids in the Westwood collection labeled "India" which are actually from eastern North America. One of these is the type of Exochilum diabolus Morley 1913, also described by Morley from "India." E. diabolus is a synonym of Therion tenuipes (Norton) 1863 (new synonymy), from eastern North America.

Specimens $\left(19 \sigma^{\top}, 118\right.$ ) : From Alaska (Eklutna Lake at 1,000 ft.); Alberta (Bilby); British Columbia (Summit Lake at Fort Nelson); Connecticut (Pleasant Valley); Delaware (New Castle Co. and Wilmington); District of Columbia (Washington); Iowa (Ames); Kansas; Labrador (Goose Bay); Maine (Blackwood Camp in Acadia National Park, Brewer, Lincoln Co., and Tim Pond Plantation); Manitoba (Fort Churchill and Gillam); Maryland (Beltsville, College Park, Plummers Island, and Takoma Park); Massachusetts (Amherst, Milton, and Petersham); Michigan (Lake Charlevoix in Charlevoix Co., Chatham, Cheboygan, Douglas Lake in Cheboygan Co., East Lansing, Isle Royale, Lake City, St. Ignace, 12 miles west of Stephenson, Washtenaw Co., and Whitefish Point in Chippewa Co.); Min- 
nesota (Bovey, Cass Co., Itasca Park, and Mille Lacs Co.); New Hampshire (Franconia and Mount Washington); New Jersey (Bound Brook and Moorestown); New York (Big Indian Park in the Catskill Mts., Ithaca, McLean Bogs Reserve in Tompkins Co., New Russia in Essex Co., Slide Mt. in Ulster Co., and Wilmurt); North Carolina (Ramseur); North Dakota (Grand Forks); Nova Scotia (Kentville, Kings Co., and Truro); Ohio (Ashland Co., Puritas Springs in Cuyahoga Co., Scioto Co., and Sugar Grove); Ontario (Chalk River, Constance Bay, Flanders, Frater, Hymers, Kearney, Ottawa, Sudbury, Thunder Bay Beach, Timagami Forest Reserve, and Toronto); Pennsylvania (Charter Oak in Huntingdon Co., Gravity, Huntingdon, Jeannette, Linglestown, Philadelphia, Rockville in Dauphin Co., and Roxborough); Quebec (Aylmer, Forestville, Hemmingford, Kazabazua, Lake Opasatika, Montigny, Mount Lyall, Sherbrooke, and Wakefield); and South Carolina (Greenville).
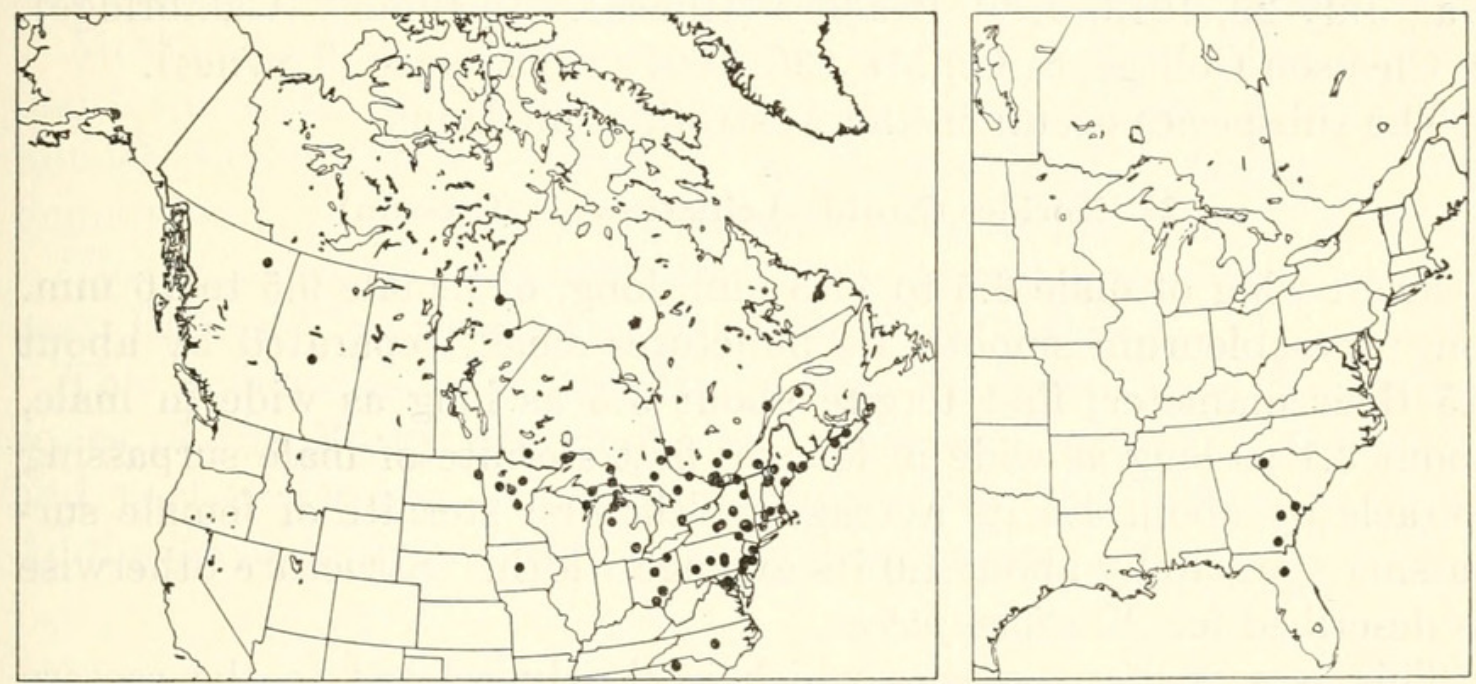

Figures 248, 249.-Localities: 248 (left), Xorides stigmapterus stigmapterus; 249 (right), X. s. floridanus.

Dates of capture are mostly in the summer months, but range from mid-spring to mid-fall. Unusually early and late dates are: May 4 in Iowa; May 10 at Linglestown, Pa.; May 13 at Sugar Grove, Ohio; May 14 in New Castle Co., Del.; September 16 in the Catskill Mts., N. Y.; October 2 at East Falls Church, Va.; October 8 at Beltsville, Md.; and November 1 at College Park, Md. Specimens are usually collected on the trunks of dead or dying hardwoods.

There is a specimen reared from Acer and two with a more definite host indication, as follows: + , parasitic on Anoplodera proxima in Carya, Linglestown, Pa., Mar. 10, 1915, W. S. Fisher. क, reared from Tilia infested with Dryobius sexfasciatus, near Plummers Island, Md., July 18, 1920, H. S. Barber. 
This subspecies is transcontinental, in the Canadian to the Upper Austral zone. In the western half of the continent it is not known from south of Canada. It parasitizes borers in hardwoods. Adults occur from mid-spring to mid-fall.

\section{0b. Xorides (Xorides) stigmapterus floridanus (Ashmead)}

Xylonomus floridanus Ashmead, 1889, Proc. U. S. Nat. Mus., vol. 12, p. 451; ․ Type: ${ }^{\prime}$, Archer, Fla. (Washington).

Similar to the subspecies $X$. stigmapterus stigmapterus except that the head and thorax are largely or entirely ferruginous or dusky ferruginous.

Specimens: $\sigma^{\top}$, Gainesville, Fla., Apr. 10, 1916 (Ann Arbor). , Chester's Island, Okefenokee Swamp, Ga., July 7, 1923 (Townes). , in decayed sweetgum log, Clyo, Ga., May 3, 1922, R. St. George (Washington). $\sigma^{\top}$, Letford on the Cannochee River, Ga., July 29, 1913, J. C. Bradley (Townes). \&, Letford on the Cannochee River, Ga., July 29, 1913, J. C. Bradley (Ithaca). ㅇ, Illinois (Cambridge). ㅇ, Clemson College, S. C., May 30, 1927, S. E. Jones (Townes).

The subspecies occurs in the Austroriparian fauna.

\section{Xorides (Xorides) cincticornis (Cresson)}

Front wing of male 6.5 to $11.5 \mathrm{~mm}$. long, of female 9.5 to $16 \mathrm{~mm}$. long; mesopleurum smooth, its punctures small, separated by about 1.5 their diameter; first tergite about 3.5 as long as wide in male, about 3.1 as long as wide in female; first sternite of male surpassing spiracle by about 1.5 its average width; first sternite of female surpassing spiracle by about 1.0 its average width. Structure otherwise as described for $X$. stigmapterus.

This is a western species which is closely related to the eastern $X$. stigmapterus and may possibly be only subspecifically distinct. It contains two sharply different populations which are treated below as subspecies:

1. Head, abdomen, and thorax black; white band on female flagellum covering about 4.5 segments; range: northwestern United States and adjacent Canada.

21a. cincticornis cincticornis (Cresson)

Head and abdomen ferruginous; thorax more or less ferruginous; white band on female flagellum covering about 3 segments; range: mostly California.

21b. cincticornis rufus, new subspecies

\section{1a. Xorides (Xorides) cincticornis cincticornis (Cresson)}

Xylonomus cincticornis Cresson, 1865, Proc. Ent. Soc. Philadelphia, vol. 4, p. 288; $q$. Type: $q$, Colorado (Philadelphia).

Xylonomus (Moerophora) modestus Rohwer, 1913, Proc. U. S. Nat. Mus., vol. 45, p. 358; $\sigma^{7}$. Type: $\sigma^{7}$, Skykomish, Wash. (Washington).

Black or blackish brown. Clypeus and base of mandible brown; palpi dark brown; female flagellum with a white band covering about 
4.5 segments; front femur and tibia of male largely brown; tarsi brown with the fifth segment fuscous; wings faintly infuscate.

Specimens from Beaver Creek, Mont., Warren, Idaho Co., Idaho, and Drake Peak at 7,000 ft., Lake Co., Oreg. are intermediate in color to the subspecies $X$. cincticornis rufus.

Specimens $\left(32 \sigma^{7}, 44\right.$ ) $)$ : From Alberta (Banff); British Columbia (Courtenay, Diamond Head Trail near Squamish at 3,200 ft. and at 3,700 ft., Garibaldi Park near Haney, Kaslo, Manning Park at 4,000 ft., Peachland, Robson, Sentinel Mt. near Robson at 4,000 to 5,000 ft., and Vernon); Colorado (Creede at 8,844 ft., Elk Creek near Fraser in Grand Co., El Paso Co., Paonia, and Ward); Idaho (Priest Lake, Spirit Lake, and Wallace); Montana ("Beaver Creek at 6,300 ft.”); New Mexico (Jemez Springs at 6,400 ft.); Oregon (Corvallis, Eagle Creek, Hood River Meadows, Scapoose, and Strawberry Mt. in Grant Co.); Washington (Ashford, Fort Lewis in Pierce Co., Lake Cushman in Mason Co., Sunrise on Mount Rainier at 6,380 ft., Skykomish River, and Skykomish); and Wyoming (Big Horn Mts.).

Most collecting dates are in June, July, and August. The earliest and latest dates are: May 18 at Vernon, B. C.; May 23 on the Skykomish River, Wash.; August 24 at Robson, B. C.; August 31 and September 11 in "B. C."; and September 5 in the Big Horn Mts., Wyo.

The only reared specimens are: $\sigma^{7}$, o , reared from Pinus scopulorum, El Paso Co., Colo., Apr. 29, 1915, W. Middleton.

This subspecies is in the Hudsonian, Canadian, and Transition zones of the Rocky Mountains and westward, except in California and part of Oregon, where it is replaced by the subspecies rufus. Adults occur from late May to early September.
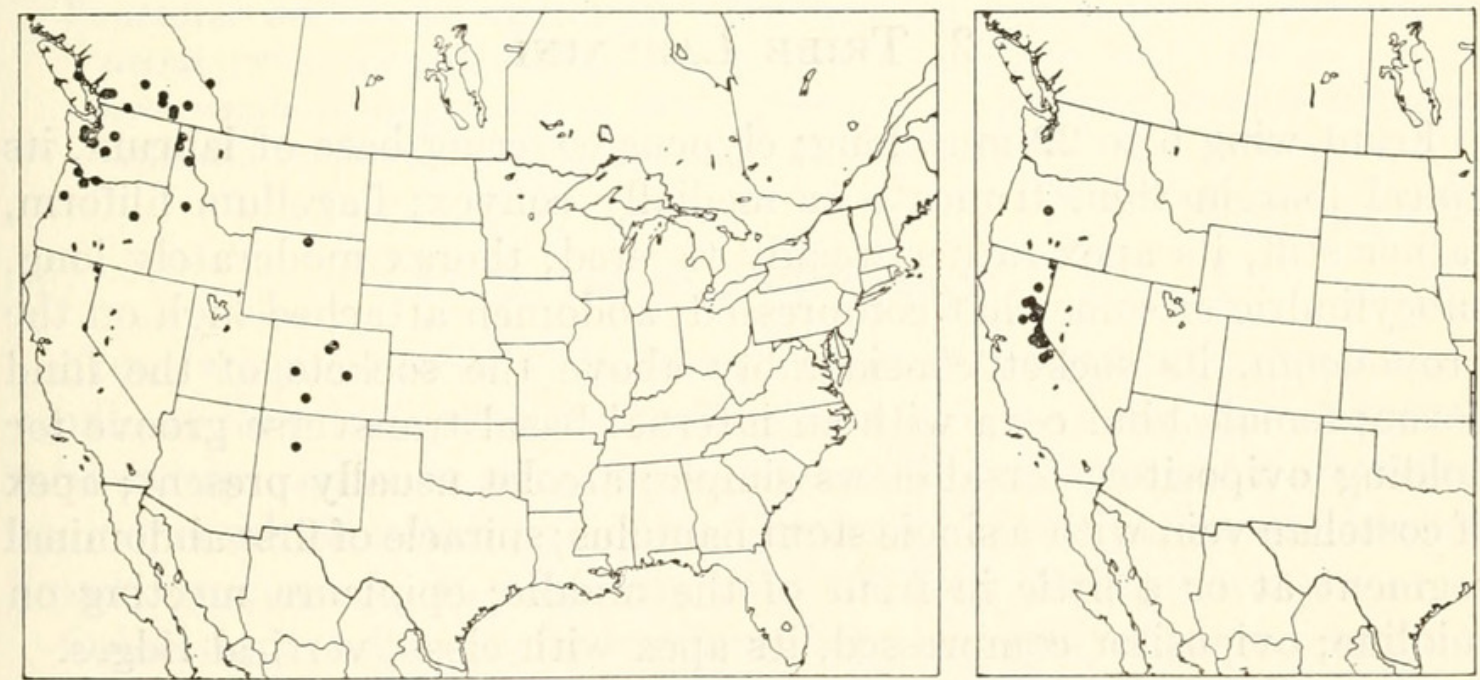

Figure 250, 251.-Localities: 250 (left), Xorides cincticornis cincticornis; 251 (right), X. c. rufus. 


\section{1b. Xorides (Xorides) cincticornis rufus, new subspecies}

Head, legs, and abdomen fulvoferruginous; thorax black with fulvoferruginous areas to entirely fulvoferruginous; flagellum black, the female flagellum with a white band covering about 3 segments.

Besides the color difference, this subspecies has the wrinkles on temple paralleling hypostomal carina a little stronger and the first tregite a little more slender than in $X$. cincticornis cincticornis.

Type: $\sigma^{\top}$, Leevining, Calif., June 25, 1948, H., M., G., and D. Townes (Washington, USNM 63736).

Paratypes $\left(34 \sigma^{7}, 22\right.$ ) $)$ : From California (Buck's Lake in Plumas Co., Camp Celio near Nevada City, Dardanelle, Donner Pass, Echo Lake in El Dorado Co. at 7,400 ft., Fallen Leaf, near Glacier Point in Yosemite Park, Gold Lake in Sierra Co., Hope Valley in Alpine Co., Independence Lake in Sierra Co., Leevining, Mendocino Co., Quincy, Sagehen near Hobart Mills, Sierraville, Sonora Pass at 9,624 ft., Summit Camp in Lassen Co., and Tamarack Lake at 7,700 ft. in El Dorado Co.); and Oregon (Sisters).

Collecting dates are nearly all in July. Those outside of this month are: June 22 at Camp Celio, near Nevada City, Calif.; June 25 at Leevining, Calif.; June 28 at Summit Camp, Lassen Co., Calif.; and August 1 at Donner Pass and Fallen Leaf, Calif.

This subspecies is in the Canadian and Hudsonian zones of California and part of Oregon. Most adults occur in July.

\section{Subgenus Pyramirhyssa, new status}

Pyramirhyssa Mocsáry, 1905, Ann. Hist.-Natur. Mus. Nat. Hungarici, vol. 3, p. $15^{\circ}$

Type: Pyramirhyssa magnifica Mocsáry; monobasic.

There is a single known species, the genotype, from southern Brazil.

\section{Tribe Labenini}

Front wing 6 to $22 \mathrm{~mm}$. long; clypeus covering base of labrum, its apical margin thin, truncate or medially convex; flagellum filiform, rather stiff, its apex rather weakly tapered; thorax moderately long, subcylindric or somewhat compressed; abdomen attached high on the propodeum, its socket considerably above the sockets of the hind coxae; female hind coxa with an internal basal transverse groove for holding ovipositor; tarsal claws simple; areolet usually present; apex of costellan vein with a single stout hamulus; spiracle of first abdominal segment at or a little in front of the middle; epipleura meeting on midline; ovipositor compressed, its apex with close, vertical ridges.

The tribe Labenini has a marsupial type of distribution, with centers in the Australian and Neotropic regions and a few species entering the Nearctic region. The described genera are Labena, 
Certonotus, and Apechoneura, and there is an additional genus, undescribed, in the Australian region. Only the genus Labena occurs in our fauna.

\section{Genus Labena}

FiguRE $306, \mathrm{~b}$

Labena Cresson, 1864, Proc. Ent. Soc. Philadelphia, vol. 3, p. 399. Type: Cryptus grallator Say; designated by Viereck, 1914.

Caryoecus Walsh, 1866, Pract. Ent., vol. 1, p. 30. Type: (Mesochorus fuscipennis Brullé $)=$ grallator $($ Say $)$; monobasic .

Microtritus Kriechbaumer, 1889, Ent. Nachr., vol. 15, p. $307 . \quad$ New synonymy. Type: Microtritus apicalis Kriechbaumer; monobasic.

Dyseidopus Kriechbaumer, 1890, Ann. Naturh. Hofmus. Wien, vol. 5, p. 489.

Type: Dyseidopus sericeus Kriechbaumer; monobasic.

Neonotus Parrott, 1954, Proc. Linn. Soc. New South Wales, vol. 79, p. 230. New synonymy. Type: Neonotus chadwickii Parrott; original designation.

Front wing 6.5 to $19 \mathrm{~mm}$. long; occipital carina complete; mesoscutum without sharp transverse rugae; front tibia with a strong projecting thorn on apex of outer side; areolet present, large; nervellus broken somewhat above the middle, or in some Australian species not broken; eighth tergite of female without an apical projection on each side.

This is a large genus of the Neotropical and Australian regions. There are two species in the United States.

\section{Key to the Nearctic species of Labena}

1. Punctures on thorax moderately coarse, those on mesopleurum separated by about their diameter; temple at its midheight about 0.7 as long as eye; comb on under side of last segment of front tarsus of male obliquely truncate at an angle about $45^{\circ}$ from the transverse . . . . . 1. grallator (Say)

Punctures on thorax moderately fine, those on mesopleurum separated by about twice their diameter; temple at its midheight about 0.9 as long as eye; comb on under side of last segment of front tarsus of male obliquely truncate at an angle about $30^{\circ}$ from the transverse.

2. tinctipennis Rohwer

\section{Labena grallator (Say)}

Front wing 7.3 to $18 \mathrm{~mm}$. long; temple rather strongly convex, in profile at its midheight about 0.7 as long as eye; punctures of thorax moderately coarse, in most places separated by about their diameter; apex of comb on under side of last segment of front tarsus of male obliquely truncate at an angle of about $45^{\circ}$ from the transverse.

Coloration variable between the subspecies, but with some features that occur in all of the subspecies, as follows: top of eyes joined by a blackish stripe that widens to include the ocelli, the ocellar area including two short oblique yellow spots; flagellum brownish fulvous, yellowish postmedially (most conspicuously so in female), black 
apically; usually some thoracic sutures narrowly margined with black; ovipositor sheath yellowish fulvous, a little darker basally, its apical $0.3 \pm$ blackish.

There are five subspecies described below, and probably others are in Mexico. The subspecies are distinguished on color patterns, which seem to have differentiated to conform to local mimicry patterns. Thus the eastern subspecies (grallator), with blackish brown wings and ferruginous body, conforms to one of the common color patterns of the southeastern states, Trogus pennator, Tricyphus elegans vulpinus, Priocnessus nuperus, and Polistes rubiginosus being other representatives of it. These species all occur in open woods or along the edges of woods, and are close mimics. The subspecies ochreata from Arizona has a striking color pattern which is shared with Polistes canadensis navajoe, Mischocyttarus flavitarsis navajo, and Trogus flavipennis. We found Labena grallator ochreata common in the Sierra Ancha of Arizona in the spring of 1947, flying through open deciduous woods at about one meter from the ground. The Polistes and Mischocyttarus of the same color pattern were common at the same time, and it was difficult to distinguish the three in flight.

Besides the material listed under the several subspecies, we have a specimen that seems intermediate between $L$. grallator grallator and L. grallator balteata. It has the dark wing and ferruginous ground color of the subspecies grallator and the tendency toward strong yellow banding of the abdomen of the subspecies balteata. It is a female from Cherry Canyon, Davis Mts., Texas, June 17, 1916, F. M. Gaige (Ann Arbor).

The subspecies are separated by the following key:

1. Third and following tergites ferruginous, sometimes narrowly yellowish at apex; range: east of hundredth meridian . . 1a. grallator grallator (Say)

Third and following tergites mostly or entirely yellow; range: west of hundredth meridian

2. Third through sixth tergites yellow with the base broadly fulvous so that they have a banded appearance; wings subhyaline, the apex of front wing conspicuously darker; range: near Presidio, Texas.

1e. grallator balteata, new subspecies

Third through sixth tergites yellow, the incisures darker; wings uniformly light brown to dark brown . . . . . . . . . . . . . . . . 3

3. Propodeum, hind coxa, and all but apex of first tergite dark brown; wings dark brown; range: Arizona . . . 1c. grallator ochreata, new subspecies

Propodeum, hind coxa, and first tergite fulvous to yellow; wings light brown to medium brown . . . . . . . . . . . . . . . . . . . . 4

4. Metapleurum and propodeum fulvous margined with black; range: New Mexico and Colorado . . . . . . 1b. grallator xutha, new subspecies

Metapleurum and propodeum yellow margined with fulvous; range: southern California

1d. grallator lutea, new subspecies 


\section{1a. Labena grallator grallator (Say)}

Cryptus grallator Say, 1836, Boston Journ. Nat. Hist., vol. 1, p. 236 (Leconte ed., vol. 2, p. 692); ๆ. Type: \&, Indiana (destroyed).

Mesochorus fuscipennis Brullé, 1846, in Lepeletier, Histoire naturelle des insectes, hyménoptères, vol. 4, p. 250; $\subsetneq$. Type: , Carolina (lost).

Labena apicalis Cresson, 1864, Proc. Ent. Soc. Philadelphia, vol. 3, p. 402; ơ. Type: $\sigma^{7}$, Delaware (Philadelphia).

Labena confusa Rohwer, 1920, Proc. U. S. Nat. Mus., vol. 57, p. 411; $\subsetneq$. Type: ○, Texas (Washington).

Labena confusa var. minor Rohwer, 1920, Proc. U. S. Nat. Mus., vol. 57, p. 413; ․ Type: $ᄋ$, Washington, D. C. (Washington).

Head yellowish, ferruginous behind; body and legs ferruginous, the front and middle legs, hind tibia and tarsus, scutellum, various restricted areas on thorax, and narrow apices of tergites largely fulvous or yellowish; wings blackish brown, in smaller males paler brown or subhyaline with the wing apices brown, in some females with a paler area beneath and beyond the stigma. The wing color and the ferruginous ground color tend to average a little darker in specimens from the Austroriparian fauna than in those from more northern localities.

Specimens (95 $\sigma^{\pi}, 169$ ) : From Alabama (Auburn and summit of Cheaha Mt. in Clay Co.); Arkansas (Bentonville); Colorado (Westcliffe and Willow Creek); Connecticut (New Haven); Delaware; District of Columbia (Washington); Florida (Alachua Co., Big Pine Key, Cape Sable, Cortez Beach, Crescent City, Elfers, Englewood, Everglades National Park in Dade Co., Florida City, Fort Lauderdale, Fort Ogden, Georgetown, Gulf Hammock, Haines City, Jacksonville, Key Largo, Lake Co., Lake Worth, Larkins in Dade Co., Lutz, Marco, Matecumbe Key, Matheson Hammock at Miami, Miami, Naples, Newmans Lake near Gainesville, Oneco, Paradise Key, Royal Palm Park, St. Augustine, St. Petersburg, South Bay on Lake Okeechobee, Stuart, Tarpon Springs, Titusville, "Wittfeld in Indian River Co.," and Winter Park); Georgia (Bainbridge, Brunswick, St. Simons Island, Tallulah Falls, Thomasville, and Tifton); Kansas (Lawrence); Louisiana; Maryland (Bowie, Camp Springs, Forest Glen, “Jackson's Island," Mayo Beach, Solomons, and Takoma Park); Massachusetts (Duxbury and Holliston); Michigan (East Lansing, George Reserve in Livingston Co., and Grosse Isle); Missouri (Overland and St. Louis); New Jersey (Moorestown and Paterson); New York (Babylon, Bryn Mawr Park in Westchester Co., Hicksville, Ithaca, Long Beach, Ludlowville, New Brighton, Poughkeepsie, Rockaway, Sea Cliff, and West Shelby); North Carolina (Black Mts., Kill Devil Hills, and Southport); Ohio (Montgomery Co. and Put-in-Bay); Oklahoma (Eufaula); Ontario (Ottawa); Pennsylvania (Allegheny Co., Carlisle Junction, Cresco, Crisp in Westmoreland Co., Harrisburg, Hummelstown, Linglestown, Mont Alto, and Philadelphia); Rhode Island 

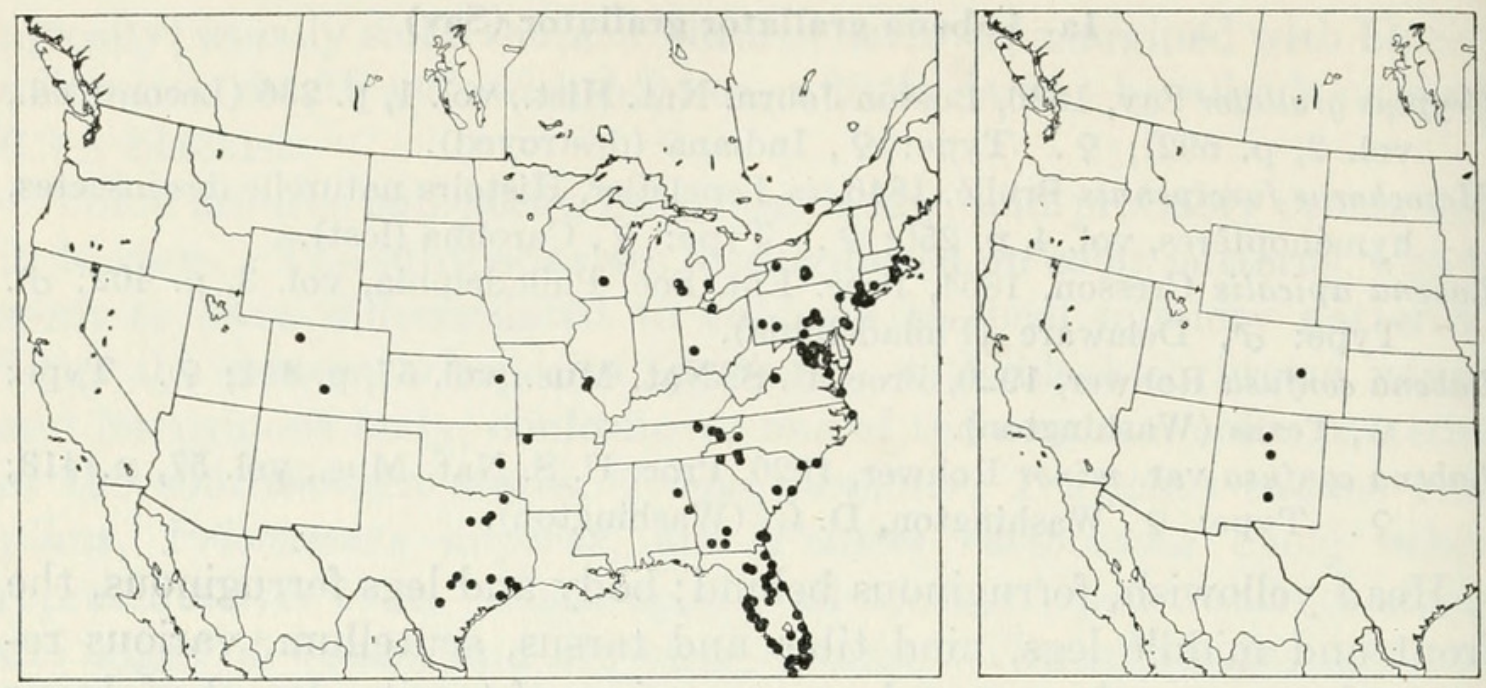

Figure 252, 253.-Localities: 252 (left), Labena grallator grallator; 253 (right), L. g. xutha.

(Manville and Westerly); South Carolina (Greenville, Horry Co., McClellanville, Pregnall, and near Tigerville); Tennessee (Burrville, Greenbrier Cove in Sevier Co., Headquarters of Great Smoky Mountains National Park, and Knoxville); Texas (Austin, Brazos Co., Brazos River in Richmond Co., Cypress Mills, Dallas, Dayton, Fort Worth, Hunt Co., Liberty Hill, Paris, Salado Creek in Bexar Co., and Smith Point); Virginia (Arlington, Bluemont, Falls Church, Glencarlyn, Mount Vernon, Norfolk, Vienna, Warm Springs Mts. in Bath Co. at 1,300 ft., and Westmoreland State Park in Westmoreland Co.); West Virginia (Bolivar); and Wisconsin (Jefferson).

Collection dates are throughout the growing season, with a preponderance of the collections in late spring and the first halt of summer. In Florida and Texas the species is common in March and April, and in southern Florida it has been taken on December 30. At the latitude of Washington, D. C., the earliest spring date is May 2 (at Takoma Park, Md.), and the latest fall dates are Sept. 25 at Bolivar, W. Va. and Oct. 25 at Charlottesville, Va. We find the species common at the edges of woods and in overgrown fields, wherever there are dead bushes or piles of brush. It flies low, about 0.1 to 0.3 meters from the ground, among weeds, around dead wood, or higher over piles of brush, nearly always in the sunshine. In flight, it resembles some species of Polistes.

The species has been reared from borers in many kinds of wood. Specimens with definite host records are: 3 우 (type and paratypes of confusa), from Thrincopyge alacris, Texas, F. M. Webster. ㅇ, from Chion in Quercus alba, Falls Church, Va., May 29, 1916, J. N. Knull. $\sigma^{7}$, from Chrysobothris impressa, Miami, Fla. o, from Saperda puncticollis, Hummelstown, Pa., 1923, J. N. Knull. Rearings from various woods without determination of the insect host include two rearings 
from Quercus and one each from Carya, Pinus rigida?, P. strobus, Rosa, Taxodium distichum, and Vaccinium vacillans.

This subspecies is in the Carolinian, Austroriparian, and Tropical faunas east of the hundredth meridian, and occurs also in Colorado. It parasitizes borers in smaller dead wood lying in the open. Adults occur throughout the growing season but mostly in the first half of summer.

\section{1b. Labena grallator xutha, new subspecies}

Head yellowish, fulvous behind; body and legs fulvous, the front and middle legs, hind tibia and tarsus, scutellum, and various areas on thorax paler fulvous or yellowish, the metapleurum and propodeum mostly fulvous; first and second tergites fulvous, their apices yellow; third and following tergites yellow, the third through fifth tergites narrowly fulvous at base; wings medium fulvous brown.

Type: Woodgate (Ithaca).

Paratypes: , Colorado Springs, Colo., Aug. 20, 1945, I. J. Cantrall (Ann Arbor). \&, Cloudcroft, N. Mex., June 27, 1940, L. J. Lipovsky (Townes). \&, Jemez Springs, N. Mex., John Woodgate, June 21, 1913 (Townes). ơ', Jemez Springs, N. Mex., May 27, 1916, John Woodgate (Ithaca). क, Manzano, N. Mex., June 26, 1941, R. H. Beamer (Lawrence).

This subspecies occurs in New Mexico and part of Colorado.

\section{1c. Labena grallator ochreata, new subspecies}

Head yellowish, fulvoferruginous behind; thorax dark brown, with fulvous areas and yellow markings anteriorly and on mesonotum; front and middle legs fulvous, their coxae, trochanters, and femora more or less brownish; hind coxa dark brown to brownish ferruginous; hind trochanters and femur brown to brownish fulvous; hind tibia and tarsus yellow; first and second tergites medium to dark brown, yellow apically; third and following tergites yellow, the third through fifth tergites narrowly brownish at base; wings rather dark brown.

Type: $\odot$, Parker Creek, Sierra Ancha, Ariz., Apr. 20, 1947, H. and M. Townes (Washington, USNM 63737).

Paratypes: $2 \sigma^{7}$, Oak Creek Canyon, Ariz., May 20 and 21, 1947, H. and M. Townes (Townes). ९, "Palmerlee," Ariz., N. Banks (Cambridge). 2ᄋ, Parker Creek, Sierra Ancha, Ariz., Apr. 19, 1947, H. and M. Townes (Townes). $\sigma^{7}$, Parker Creek, Sierra Ancha, Ariz., May 4, 1947, H. and M. Townes (Townes). $4 \sigma^{7}$, near Roosevelt Lake, Ariz., Apr. 23, 1947, H. and M. Townes (Townes). o, near Roosevelt Lake, Ariz., Apr. 24, 1947, H. and M. Townes (Townes). $\sigma^{7}$, near Roosevelt Lake, Ariz., Apr. 27, 1947, H. and M. Townes (Townes). $2 \sigma^{7}$, Sahuarita, Ariz., Apr. 11, 1947, H. and M. Townes 
(Townes). ఠ’, "San Chern," Ariz., J. Bequaert (Townes). ๆ, Workman Creek, Sierra Ancha, Ariz., May 8, 1947, H. and M. Townes (Townes).

This subspecies is in Arizona, in the chaparral areas and oak woods. Adults occur in April and May.

\section{1d. Labena grallator lutea, new subspecies}

Male type: Pale yellow. Back of head above, three stripes on mesoscutum, narrow stripe along suture between pronotum and mesopleurum, broad upper hind margin of mesepisternum, stripe across base and along lateral edge of propodeum, lateral propodeal carina, front and middle femora behind, hind trochanters, hind coxa and femur except apically, basal 0.75 of first tergite, basal 0.6 of second tergite, and basal blotches on third through fifth tergites, fulvous; flagellum blackish; wings pale fulvous brown.

Type: $\sigma^{x}$, Needles, Calif., Apr. 1-6, 1918, J. C. Bradley (Ithaca).
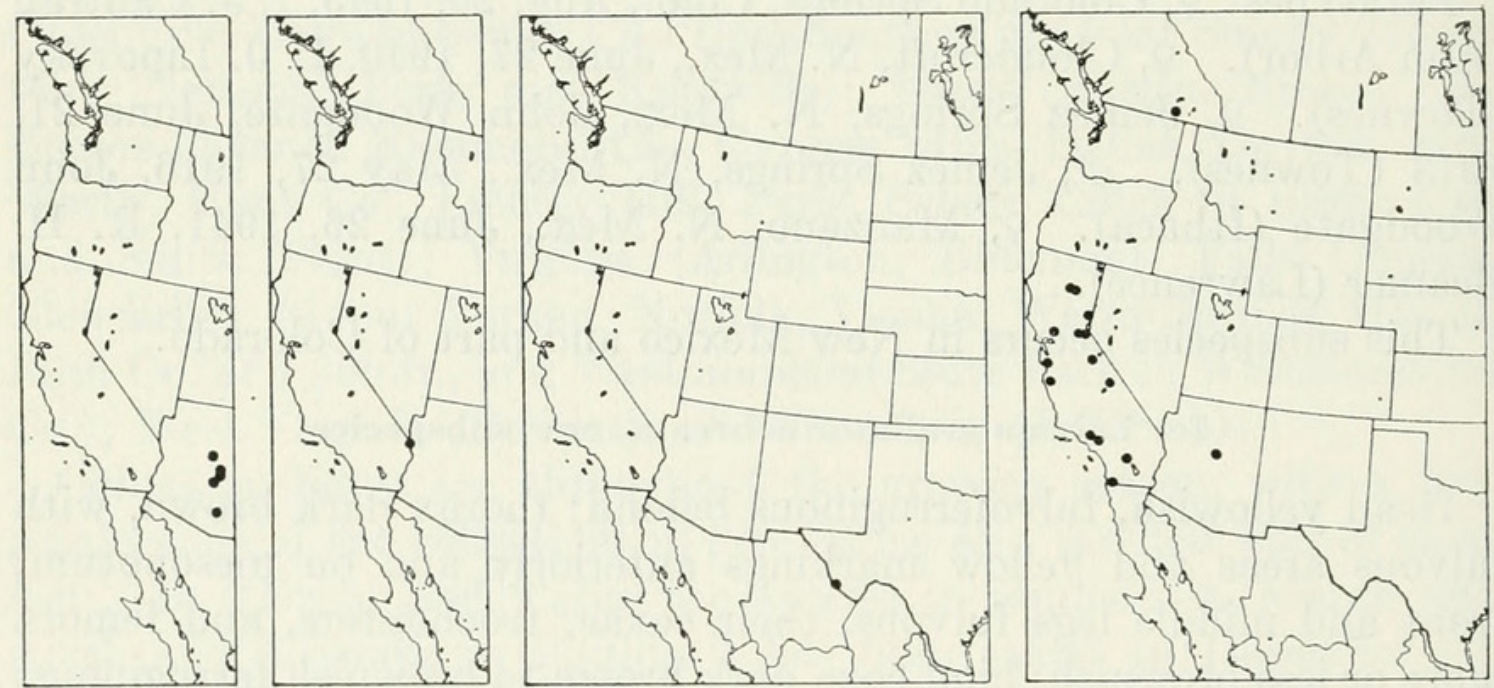

Figure 254-257.-Localities: 254 (left), Labena grallator ochreata; 255 (center, left), L. g. lutea; 256 (center, right), L. g. balteata; 257 (right), L. tinctipennis.

\section{le. Labena grallator balteata, new subspecies}

Yellow. Back of head, three stripes on mesoscutum, narrow areas on mesopleurum, narrow stripe along basal and lateral edge of propodeum, most of front and middle coxae, trochanters, and femora behind (especially in female), hind coxa except apically and at extreme base, most of hind first trochanter, most of hind femur, basal 0.65 of first tergite, basal 0.35 of second tergite, and basal part of third through seventh tergites, fulvous; wings subhyaline, their apices brown.

Type: 웅 reared from tunnels in Lycium berlandieri, near Presidio, Tex., material collected Feb. 20, 1953, adult emerged Feb. 25, 1953. J. H. Russell (Washington, USNM 63738). 
Paratypes: $\sigma^{7}, 2$, reared from Aneflomorpha? tunnels in Lycium belandieri, Presidio, Tex., Feb. 15, 1954, J. H. Russell (Washington). o, same data as type (Townes).

\section{Labena tinctipennis Rohwer}

Labena tinctipennis Rohwer, 1920, Proc. U. S. Nat. Mus., vol. 57, p. 409; . Type: + , Webber Creek, Calif. (Washington).

Front wing 10 to $16.5 \mathrm{~mm}$. long; temple rather weakly convex, in profile at its midheight about 0.9 as long as eye; punctures of thorax moderately fine, in most places separated by about twice their diameter; apex of comb on under side of last segment of front tarsus of male obliquely truncate at an angle about $30^{\circ}$ from the transverse.

Male: Head yellow, its upper half fulvous behind the eyes and a narrow brown stripe connecting the tops of the eyes; mouth parts yellow, the mandible fulvous apically; flagellum black, often with a broad postmedian red-brown band; thorax fulvous, the propleurum, mesosternum, and lower part of mesopleurum yellow, the pronotum, remainder of mesopleurum, and tegula tinged with a variable amount of yellow; many of thoracic sutures narrowly lined with black; wings suffused with reddish brown, the apex of front wing a little darker; front and middle legs yellow, with some fulvous tinges; hind legs fulvous; abdomen fulvous.

Female: Fulvoferruginous. Lower part of head, mouth parts, and lower front part of thorax tinged with yellow; flagellum yellowish, fulvous basally and its apical $0.16 \pm$ blackish; wings suffused with reddish brown, the apex of front wing darker; ovipositor sheath pale fulvous, its apical $0.3 \pm$ blackish.

Specimens (33 $\sigma^{7}, 16$ \% ): From Arizona (Oak Creek Canyon); British Columbia (Robson); California (Big Pine Creek in Inyo Co. at 7,500 ft., Boulevard, Camino, Crystal Lake in Los Angeles Co. at 4,700 ft., Fish Camp, Hat Creek, Jamesburg in the Santa Lucia Mts. of Monterey Co., Keen Camp in the San Jacinto Mts., "Onion Valley," Placerville, Pot Spring in Shasta Co., Sierraville, Soquel, Tanbark Flat in Los Angeles Co., and Winters); and Washington Territory.

All dates of collection are from June 7 to July 30, except for one of May 17 at Keen Camp in the San Jacinto Mts., Riverside Co., Calif. and another of May 18 at Oak Creek Canyon, Ariz.

This species occurs from British Columbia to California and Arizona It is adult mostly in June and July.

\section{Tribe Labiini}

Front wing 3.3 to $9.5 \mathrm{~mm}$. long; apical margin of clypeus truncate or a little concave, exposing most of labrum; flagellum faintly to strongly enlarged apically, rather stiff; thorax short to elongate, 
cylindric or subcylindric; abdomen attached moderately low on propodeum; female hind coxa without an internal groove for holding ovipositor; tarsal claws simple; areolet present; apex of costellan vein with about 5 or 6 strong hamuli; spiracle of first abdominal segment at, or somewhat in front of, or behind the middle.

This is a new tribe, composed of the genera Labium, Macrogrotea, and Grotea. The series of 5 or 6 hamuli at the end of the costal vein, exposed labrum, and the habit of parasitizing bees are among the pecularities of the tribe. Grotea is the only genus in our fauna.

Macrogrotea is in southern South America and Labium in the Australian region. Orthognathella is a synonym of Labium (new synonymy). We studied the type of the genotype of Orthognathella in Berlin.

\section{Genus Grotea}

Figure 307 , a

Grotea Cresson, 1864, Proc. Ent. Soc. Philadelphia, vol. 3, p. 397 . Type: Grotea anguina Cresson; monobasic.

Front wing 4.5 to $10 \mathrm{~mm}$. long; mandible with two apical teeth; clypeus and labrum rather small; epomia absent; upper end of prepectal carina near lower corner of pronotum; first abdominal segment about 1.6 as long as hind femur, slender, upcurved, its spiracle behind its middle.

This genus contains a few species in North and South America. It is parasitic in nests of bees.

\section{Key to the Nearctic species of Grotea}

1. Process at lower end of occipital carina narrow at apex, in profile directed downward and a little backward; basal area of propodeum about 1.4 as long as wide . . . . . . . . . . . . . . . 1. anguina Cresson

Process at lower end of occipital carina broadly rounded at apex, in profile directed downward and rather strongly backward; basal area of propodeum about 0.7 as long as wide . . . . . . . 2. californica Cresson

\section{Grotea anguina Cresson}

Grotea anguina Cresson, 1864, Proc. Ent. Soc. Philadelphia, vol. 3, p. 398; هో Lectotype: $\uparrow$, New Jersey (Philadelphia).

Biology: Graenicher, 1905, Ent. News, vol. 16, pp. 43-49.-Rau, 1922, Trans. Acad. Sci. St. Louis, vol. 24, p. 43; 1938, Ann. Ent. Soc. America., vol. 21, p. 383 .

Front wing 6.5 to $9.5 \mathrm{~mm}$. long. Structurally similar to G. californica except as stated in the key.

Head yellow, suffused with fulvous behind, above, and on frons, black behind occipital carina; mouth parts yellow; antenna light fulvous, with a fuscous band centered over its apical 0.68 , beyond which 
it is yellow; propleurum yellow, often margined with black; pronotum yellow, its lower margin black, its groove fulvous or black; prepectus black; mesosternum and mesopleurum yellow, the mesopleurum with a broad longitudinal fulvous stripe that is often more or less replaced with black; mesepimeron yellow; mesoscutum fulvous, its lateral edges black and position of notauli marked with yellow; scutellum and postscutellum yellow, with adjacent black areas; metapleurum yellow, fulvous medially or sometimes mostly fulvous; metasternum black; propodeum fulvous, yellow apically and basolaterally, black on base, on basal area, and adjacent to lateral longitudinal carina; front and middle legs mostly yellow; hind legs mostly fulvous; first tergite brown, yellow laterally, the rest of abdomen brownish fulvous, paler laterally.

The relative extent of yellow, fulvous, and black markings is variable, but usually stays within the limits described.

The parasitic habits of this species have been described by Graenicher and Rau (see references above). It attacks the nests of bees of the genus Ceratina, which construct their cells, one cell above the other, in the hollowed-out twigs of shrubs and brambles with large pithy centers. The parasite egg is laid on or near the egg of the bee in one of the cells. The hatching parasite larva eats the bee egg or young larva, whichever may be present, next the bee bread, and then invades one or more adjacent cells and eats the bee larvae in them. It pupates in the twig and emerges early the following summer.

Specimens $\left(19 \sigma^{\nearrow}, 82\right.$ ㅇ) : From Arizona (10 miles west of Jacob Lake, Oak Creek Canyon, and Parker Creek in the Sierra Ancha); Colorado (Boulder and near Estes Park); Connecticut (Hartford); Iowa (Sioux City); Maine (Monmouth); Maryland (Beltsville, Glen Echo, Laurel, Plummers Island, and Takoma Park); Massachusetts (Arlington, Holliston, and Martha's Vineyard); Michigan (Ann Arbor, Cheboygan Co., Cooper in Oakland Co., Midland Co., Owosso, and Van Buren Co.); Missouri (St. Louis); New Jersey (Moorestown and Westfield); New York (Arnot Forest in Tompkins Co., Buffalo, Flatbush, Hartsdale, Heathcote, "Indian Ladder," Ithaca, Lockport, New Baltimore, Nyack, Sea Cliff, West Farms in New York City, and Yonkers); North Carolina (North Fork of the Swannanoa River in the Black Mts. and Wake Co.); Ohio (Put-in-Bay); Ontario (Cornwall, Niagara Glen, Ottawa, Point Pelee, and Simcoe); Pennsylvania (Allegheny Co., Dauphin, Ingram, Perdix in Dauphin Co., Perrysville, and Stoverdale in Dauphin Co.); Quebec (Wakefield); South Carolina (Greenville); Tennessee (Knoxville); Texas (Brownsville and Calvert); Virginia (Arlington, Chain Bridge near McLean, Dayton, Falls Church, and Vienna); West Virginia (Cheat Mt. at 2,000 ft. in Randolph Co.); Wisconsin (Madison); and Mexico (15 km. east of Sombrerete in Zacatecas, and "Teotihuacan Pys. Mex."). 


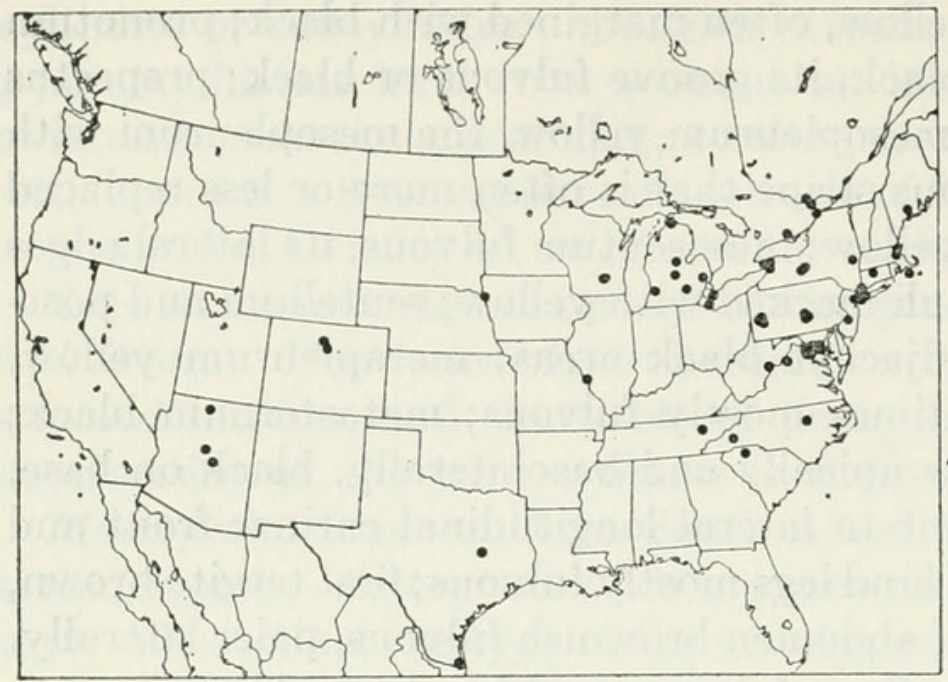

Figure 258, 259.-Localities: 258 (left), Grotea anguina; 259 (right), $G$. californica.

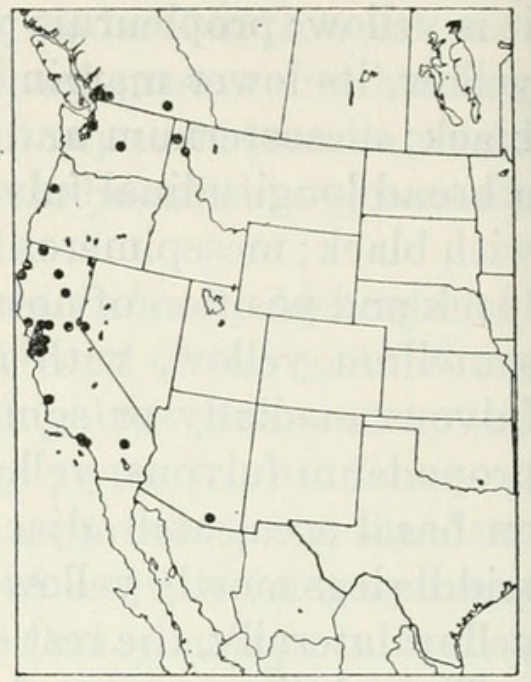

\section{anguina; 259 (right), G.}

All collecting dates are between June 1 and July 9 except as follows: April 19 at Calvert, Tex.; May 9 at Parker Creek, Sierra Ancha, Ariz.; May 18 at Oak Creek Canyon, Ariz.; May 20 at Boulder, Colo., May 27 at "Perdix," Pa.; May 28 at Takoma Park, Md.; July 17 at Holliston, Mass.; and Aug. 21 at Madison, Wis. This seasonal distribution proves that there is a single generation per year and is in agreement with published accounts of the biology. In our own experience the species occurs in open bushy country, along fence rows, and the edges of fields. It flies rather slowly among the tops of weeds, and along the sides and over the tops of bushes. Its long yellow and brown antennae held anterolaterally and its long pale body give it a singular appearance. Once, we found a specimen on flowers of Viburnum.

Rearing records on pin labels are: $\odot$, from sumac, Knoxville, Tenn., 1921, C. N. Ainslie. \&, from sumac stem, Vienna, Va., 1936, J. C. Bridwell. क, from sumac, Nyack, N. Y., Mar. 25, 1884, J. L. Zabriskie. $\sigma^{7}$, from Ceratina dupla, Flatbush, Long Island, N. Y., Sept. 5, 1892, J. L. Zabriskie.

This species is in the Carolinian and Austroriparian faunas and also in Colorado and Arizona. There is one generation per year, emerging in late spring and disappearing before mid-summer. Its hosts are species of Ceratina, nesting in twigs with pithy centers.

\section{Grotea californica Cresson}

Grotea californica Cresson, 1878, Proc. Acad. Nat. Sci. Philadelphia, vol. 1878, p. 370 ; $\uparrow$. Type: $q$, California (Philadelphia).

Front wing 4.5 to $9.5 \mathrm{~mm}$. long. Structure similar to that of $G$. anguina except as stated in the key.

Color similar to that of $G$. anguina except that the postmedian fuscous band on the antenna is less distinct, especially in the male, 
and that the black markings sometimes become more extensive than in G. anguina.

Specimens (42 $0^{x}, 38$ ) : From Arizona (Sonoita); British Columbia (Cultus Lake, Harrison Mills, Mission City, Robson, Ruskin, and Vancouver); California (Alameda Co., Alum Rock Park in Santa Clara Co., Atascadero, Berkeley, Blocksburg, Blue Lake in Humboldt Co., Cache Creek Canyon in Yolo Co., Camino, Eagle Rock Hills in Los Angeles Co, Elkhorn Ferry in Yolo Co., Hat Creek in Shasta Co., Mesa Grande in Sonoma Co., Oakland, Quincy, Pasadena, Pescadero in San Mateo Co., Samuel Spring in Napa Co., San Jose, San Leandro, Siskiyou Co., Snow Crest Camp in San Bernardino Co., and Stanford University); Idaho (Sandpoint and Wallace); Nevada (Valley Hot Spring in Douglas Co.); Oregon (Corvallis); and Washington (Nelsons on the Yakima River and Seattle).

Most collection dates are in May and June, or into early July in the northern parts of the range. Unusually early and late dates of collection are: April 28 at Samuel Spring in Napa Co., Calif.; April 29 at Stanford University, Calif.; April 30 in Cache Creek Canyon in Yolo Co., Calif.; July 14 at Wallace, Idaho; and August 30 at Sonoita, Santa Cruz Co., Ariz.

This species occurs from British Columbia to Arizona. It is adult in late spring and early summer.

\section{Tribe Poecilocryptini}

Front wing 4 to $8.5 \mathrm{~mm}$. long; clypeus covering most of labrum, its apical margin thin, convex in outline; flagellum rather stiff, weakly clavate; thorax moderately short, subcylindric; abdomen attached moderately low on propodeum, higher than in most ichneumonids but not so high as in the Labenini; female hind coxa without an internal groove for holding ovipositor; tarsal claws of male simple; front and middle tarsal claws of female with a large internal tooth as in the Pimplini; hind tarsal claws of female simple; areolet present, apex of costellan vein with a single hamulus in the few specimens studied; spiracle of first abdominal segment near its middle.

This tribe includes the single genus Poecilocryptus of Australia and Tasmania, which has been reared from galls on Acacia and Eucalyptus. The three known species have been reviewed by Parrott (1954, Pacific Sci., vol. 8, pp. 239-242).

\section{Tribe Brachycyrtini}

Head and body about 5 to $9 \mathrm{~mm}$. long; clypeus covering most of labrum, its apical margin thin, convex in outline; flagellum rather stiff, weakly clavate; thorax very short, a little higher than wide; abdomen 
attached rather low on propodeum; female hind coxa without an internal groove for holding ovipositor; tarsal claws simple; areolet present; apex of costellan vein with one to several hamuli; spiracle of first abdominal segment near its apical 0.36.

This tribe includes the Neotropic genus Habryllia and the worldwide genus Brachycyrtus. The species are small and bright colored. They parasitize chrysopid pupae. None of them are common in collections. Walkley (1956, Proc. U. S. Nat. Mus., vol. 106, pp. 315-329) has revised the species of the world. The treatment of the two Nearctic species below is adapted from her publication, which can be referred to for additional information.

We take this opportunity to note that Walkley's treatment omits Brachycyrtus luteoniger Seyrig 1952, from Madagascar; B. luteoniger fianarensis Seyrig 1952, from Madagascar; (Hemigaster) Brachycyrtus eublemmae Rao 1953, from India; and (Xanthocharops) Brachycyrtus primus Morley 1912, from the Seychelles. The first two are in a paper which has only recently become known and was missed by the Zoological Record. The fourth was described as a new genus incorrectly placed in the Porizonini. We saw the type in London and found it to be a typical Brachycyrtus.

\section{Genus Brachycyrtus}

Figure $307, \mathrm{~b}$

Brachycyrtus Kriechbaumer, 1880, Corresp.-Blatt. Zool.-Min. Ver. Regensburg, vol. 34, p. 161. Type: Brachycyrtus ornatus Kriechbaumer; monobasic.

Proterocryptus Ashmead, 1906, Proc. U. S. Nat. Mus., vol. 30, p. 174. Type: Proterocryptus nawaii Ashmead; monobasic.

Xanthocharops Morley, 1912, Trans. Linn. Soc. London, vol. 15, p. 173 . New synonymy. Type: Xanthocharops primus Morley; monobasic.

Vakau Cheesman, 1928, Ann. Mag. Nat. Hist., ser. 10, vol. 1, p. 189. Type: Vakau taitensis Cheesman; original designation.

Brachycyrtomorpha Kreihbohm de la Vega, 1940, Rev. Industr. Agríc. Tucumán, vol. 3, p. 170. Type: Brachycyrtomorpha crossi Kreihbohm de la Vega; monobasic.

Body about 5 to $9 \mathrm{~mm}$. long; occipital carina meeting hypostomal carina before base of mandible; eye deeply or strongly emarginate near antennal socket; flagellum with 24 to 27 segments, the first segment 3 to 4 times as long as wide; temple short, slightly convex; sternaulus usually short but distinct; propodeum perpendicular beyond the short basal area; first sternite straight or more or less upcurved apically; gastrocoeli present.

There are a few, rare or uncommon species in this genus, widely distributed over the World. Two are in Nearctic America. 


\section{Key to the Nearctic species of Brachycyrtus}

1. Thorax fulvous with white markings; areola separated from petiolar area; hind leg marked as in figure $327, \mathrm{k}$; propodeum with pubescence dense, whitish.

1. pretiosus Cushman

Thorax blackish with pale yellow markings; areola confluent with petiolar area; hind leg marked as in figure $327, \mathrm{j}$; propodeum with pubescence not dense.

2. ornatus Kriechbaumer

\section{Brachycyrtus pretiosus Cushman}

Figure $327, \mathrm{k}$

Brachycyrtus pretiosus Cushman, 1936, Proc. U. S. Nat. Mus., vol. 84, p. 19; ه্ , ؟ . Type: + , Hillsboro Co., Fla. (Washington).

TAхоNoмy: Walkley, 1956, Proc. U. S. Nat. Mus., vol. 106, p. 324.

Front wing about $3.5 \mathrm{~mm}$. long. The characters in the key and the figure of the color pattern of the hind leg should make this species easy to distinguish. Cushman (loc. cit.) has given a full description and Walkley (loc. cit.) descriptive notes.

Specimens: $\sigma^{7}$, Hillsboro Co., Fla., Jan. 18, 1930, B. P. Moora (Washington). ㅇ, Lake Co., Fla., July 15, 1929, W. A. Hiers (Washington). \&, Osceola Co., Fla., Aug. 7, 1929, J. J. Kirkland (Washington). \&, Paradise Key, Fla., Apr. 7, 1951, H. and M. Townes (Townes). $\sigma^{7}$, Pinellas Co., Fla., Mar. 8, 1930, B. P. Moora (Washington). Specimen lacking abdomen, Pinellas Co., Fla., February 1929, B. P. Moora (Washington). $2 \sigma^{\top}, 1$ 우, reared from pupae of Chrysopa lateralis, Sloans Grove, Tampa, Fla., June 3, 1952, Fisher (Washington).

This species is restricted to Florida.
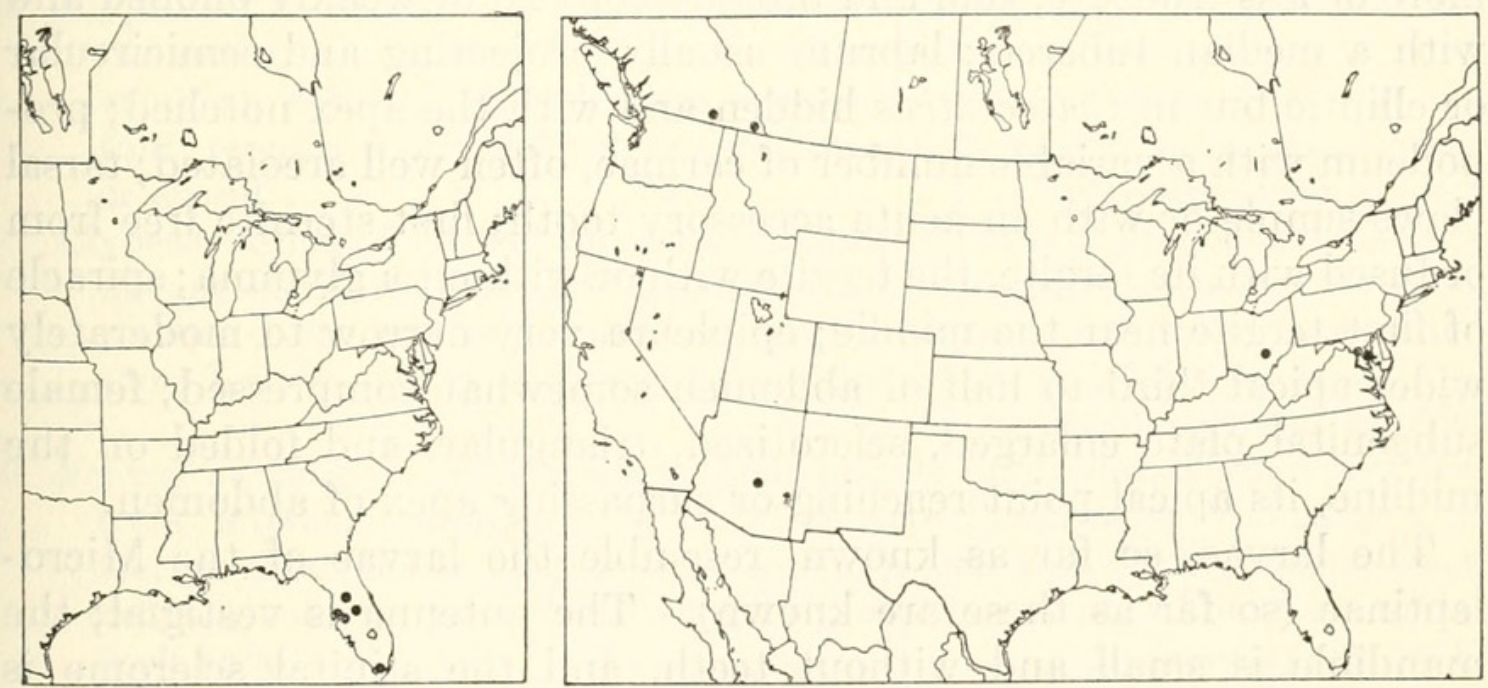

Figure 260, 261.-Localities: 260 (left), Brachycyrtus pretiosus; 261 (right), $B$, ornatus, 


\section{Brachycyrtus ornatus Kriechbaumer}

Figure $327, \mathrm{j}$

Brachycyrtus ornatus Kriechbaumer, 1880, Corresp.-Blatt. Zool.-Min. Ver. Regensburg, vol. 34, p. 163; $\uparrow$. Type: $q$, near Munich, Germany (lost).

Brachycyrtus chrysopae Walley, 1940, Canadian Ent., vol. 72, p. 86; ․ Type:

$\uparrow$, reared from chrysopid, near Baynes Lake, B. C. (Ottawa).

Taxonomy: Walkley, 1956, Proc. U. S. Nat. Mus., vol. 106, p. 325.

Front wing about $3.5 \mathrm{~mm}$. long. The characters in the key and the figure of the color pattern of the hind leg should make this species easy to distinguish. Fuller descriptions are in the references above.

Specimens: 9 , swept from juniper tree in semidesert, near Roosevelt Lake, Ariz., Apr. 27, 1947, H. and M. Townes (Townes). $\quad$ (type of chrysopae), reared from chrysopid, near Baynes Lake, B. C., Aug. 26, 1938, D. H. Ross (Ottawa). , Robson, B. C., Sept. 17, 1947, H. R. Foxlee (Washington). 2ᄋ, Mayo, Md., Oct. 27, 1945, H. and M. Townes (Townes). $\sigma^{\top}, 6$ \% , collected around Pinus virginiana in overgrown fields, Takoma Park, Md., Oct. 7 and 20, 1945, H. and M. Townes (Townes). $\sigma^{7}$, Hocking Co., Ohio, June 26, 1938, C. F. Smith and C. K. Smith (Washington).

This species is transcontinental in the Transition and Upper Austral zones and occurs also in Europe. It occurs around scattered small conifers in relatively dry situations.

\section{Subfamily Acaenitinae}

\section{Figures 308,a-310,a}

Front wing 5.0 to $19 \mathrm{~mm}$. long; apical margin of clypeus thick and more or less truncate, thin and broadly convex, or weakly bilobed and with a median tubercle; labrum usually projecting and semicircular or elliptic but in Coleocentrus hidden and with the apex notched; propodeum with a variable number of carinae, often well areolated; tarsal claws simple or with an acute accessory tooth; first sternite free from or fused with its tergite, the tergite with or without a glymma; spiracle of first tergite near the middle; epipleura very narrow to moderately wide; apical third to half of abdomen somewhat compressed; female subgenital plate enlarged, sclerotized, triangular, and folded on the midline, its apical point reaching or surpassing apex of abdomen.

The larvae, so far as known, resemble the larvae of the Microleptinae (so far as these are known). The antenna is vestigial; the mandible is small and without teeth, and the stipital sclerome is absent.

Regarding the relations of the genera within the tribe, Coleocentrus appears to be a primitive and ancient type, Mesoclistus is related to 
Coleocentrus but more specialized, and the rest of the tribe comprises a group of closely related genera with few similarities to Coleocentrus and Mesoclistus. The differences between Coleocentrus and Mesoclistus on the one hand, and the rest of the tribe on the other, are contrasted in the first couplet of the key to the genera, below. It may be that these two groups of genera are not actually related, but there does not seem to be enough evidence to warrant putting them in separate subfamilies.

The distributional center of the subfamily is in the Old World tropics. Among the genera occurring in the Nearctic region, Coleocentrus and Mesoclistus are Holarctic, Arotes is Holarctic and with at least two species in Central America, Spilopteron is predominantly eastern Palaearctic and eastern Nearctic, and Yezoceryx is IndoAustralian and eastern Palaearctic, with one species in the eastern Nearctic. No members of the tribe are Neotropic except for a few species of Arotes in Central America, and the general distribution of the group gives the impression of origin and development in the Old World and recent invasion of the New World by way of the Bering Strait.

\section{Key to the Nearctic genera of Acaenitinae}

1. Front and middle tarsal claws simple; frons without a strong median longitudinal carina; areolet present except in a few species of Coleocentrus; transverse ridges on apex of ovipositor distinct (fig. 331,i); fifth segment of hind tarsus shorter than, or a little longer than the second segment . . . . 2

Front and middle tarsal claws with an acute accessory tooth; frons with a strong median longitudinal carina; areolet absent; transverse ridges on apex of ovipositor weak or absent (fig. $331, \mathrm{j}$ ) ; fifth segment of hind tarsus conspicuously longer than second segment . . . . . . . . . . . . . 3

2. Clypeus with a median subapical tubercle; spiracle of propodeum 0.35 the distance from its base; first abdominal sternite not fused with its tergite; combined 8th and 9th abdominal tergites elongate; epipleura of second and third tergites poorly defined and not turned under; prepectal carina weak or absent . . . . . . . . . . . . 1. Coleocentrus (p. 546)

Clypeus without a median subapical tubercle; spiracle of propodeum 0.45 the distance from its base; first abdominal sternite not fused with its tergite; combined 8th and 9th abdominal tergites short; epipleura of second and third tergites well defined and turned under; prepectal carina strong.

2. Mesoclistus (p. 560)

3. Ventral swelling of first sternite without hairs or rarely with one or a very few hairs, intercubitus opposite or basad of second recurrent; exposed part of labrum about 0.3 as long as wide; second lateral area of propodeum, when defined, subtriangular; front wing in Nearctic species without an apical dark spot . . . . . . . . . . . . . 5. Yezoceryx (p. 578)

Ventral swelling of first sternite with numerous long erect hairs; intercubitus opposite or distad of second recurrent; exposed part of labrum about 0.6 as long as wide; second lateral area of propodeum subtrapezoidal; front wing in Nearctic species with an apical dark spot. . . . . . . . . . . 4 
4. Hind tarsal claws with a small, acute accessory tooth near the midlength; intercubital beyond second recurrent by 0.4 to 0.6 its length. 3. Arotes (p. 561)

Hind tarsal claws without an accessory tooth; intercubital opposite second recurrent, or beyond it by as much as 0.15 its length . 4. Spilopteron (p. 568)

\section{Genus Coleocentrus}

Figure 308 ,a

Coleocentrus Gravenhorst, 1829, Ichneumonologia europaea, vol. 3, p. 437. Type: Ichneumon excitator Poda; designated by Westwood, 1839.

Macrocoleus Desvignes, 1850, Trans. Ent. Soc. London, n. s., vol. 1, p. 13. Type: (Macrus longiventris Gravenhorst) =excitator (Poda); designated by Viereck, 1914.

The more important generic characters are stated in the key.

The genus Coleocentrus is Holarctic. The species are characteristic of cool moist woods of older trees. An exception to this distribution is $C$. rufus, which is common in rather dry woods, and ranges south into the Upper Austral zone. The hosts are almost certainly in dead (probably decaying) wood, but there are no rearing records for Nearctic species.

There are eight Nearctic species, about half of which are rare in collections. Morphologically the species of the genus are but poorly differentiated. Aside from the absence of the areolet and prepectal carina in $C$. flavipes, the Nearctic species are distinguished best on color, the shape of the male clasper, and the distribution of hairs on the face, clypeus, second tergite, and third sternite.

\section{Keys to the Nearctic species of Coleocentrus}

\section{MALES}

1. Areolet absent; clasper as in figure 378 . . . . 8. flavipes Provancher Areolet present . . . . . . . . . . . . . . . . . . . . . 2

2. Apex of clasper obliquely truncate (figs. 376 and 377). . . . . . . . . . 3 Apex of clasper rounded or squarely subtruncate . . . . . . . . . . . 4

3. Thorax black . . . . . . . . . . . . . . . 6. manni Cushman Thorax ferruginous. . . . . . . . . . . . . . 7. rufus Provancher

4. Tegula black; clasper as in figure 373 . . . . . . . 3. pettiti Cresson Tegula yellow or pale fulvous . . . . . . . . . . . . . . . . . 5

5. Second through fourth segments of hind tarsus dark brown; apex of clasper truncate (fig. 374) . . . . . . . . . 40 harringtoni Cushman

Second through fourth segments of hind tarsus yellowish; apex of clasper rounded.

6. Middle coxa yellowish; subbasal band of hairs on clypeus containing about 15 hairs; clasper as in figure 375 . . . . . . . . . . 5. rufocoxatus Pratt

Middle coxa blackish to fulvous; subbasal band of hairs on clypeus containing about 30 hairs; clasper as in figures 371 and 372

7. Hind coxa black with fulvous stains, to black with the base infuscate; second tergite about 2.4 as long as wide; clasper a little longer than in C. quebecensis; range: western part of Transition and Canadian zones.

1. occidentalis Cresson 
Hind coxa black, its apex yellowish; second tergite about 2.2 as long as wide; clasper a little shorter than in C. occidentalis; range: eastern part of Canadian zone

2. quebecensis Provancher

\section{FEMALES}

1. Areolet absent; prepectal carina absent; front wing 7.5 to $13 \mathrm{~mm}$. long.

8. flavipes Provancher

Areolet present; prepectal carina present (but weak) ventrally; front wing 12 to $19 \mathrm{~mm}$. long . . . . . . . . . . . . . . . . . . . . . . . . 2

2. Subbasal transverse band of hairs on clypeus containing about 35 hairs . . . 3 Subbasal transverse band of hairs on clypeus containing 10 to 20 hairs. . . 4

3. Hairs on second tergite rather sparse, especially medially; second and third tergites reddish brown; hind coxa ferruginous to black, usually black with ferruginous stains; apical membranous margins of tergites 2-7 blackish.

1. occidentalis Cresson

Hairs on second tergite rather dense; second and third tergites black; hind coxa black; apical membranous margins of tergites 2-7 stramineous.

2. quebecensis Provancher

4. Thorax mostly ferruginous; hairs on median part of face very sparse.

7. rufus Provancher

Thorax black; hairs on median part of face dense or moderately dense. . . 5

5. Coxae fulvous . . . . . . . . . . . . . . . . . . . 6

Coxae blackish . . . . . . . . . . . . . . . . . . . . . 7

6. Hind tarsus blackish brown; lateral sternite of third abdominal segment with dense, evenly distributed hairs; ovipositor sheath about 1.15 as long as front wing ............. 4. harringtoni Cushman

Hind tarsus brownish fulvous; lateral sternite of third abdominal segment with sparse, irregularly distributed hairs; ovipositor sheath about 0.95 as long as front wing . . . . . . . . . . . . . . 5. rufocoxatus Pratt

7. Lateral sternite of third abdominal segment with dense, evenly distributed hairs; tegula blackish; front wing 15.5 to $18 \mathrm{~mm}$. long; ovipositor sheath about 1.08 as long as front wing. . . . . . . . . . . 3. pettiti Cresson

Lateral sternite of third abdominal segment with rather sparse, irregularly distributed hairs; tegula usually fulvous; front wing 12 to $14 \mathrm{~mm}$. long; ovipositor sheath about 0.92 as long as front wing . . 6. manni Cushman

\section{Coleocentrus occidentalis Cresson}

\section{FIgURe 371}

Front wing of male 12.5 to $15 \mathrm{~mm}$. long, of female 13 to $19 \mathrm{~mm}$. long; face densely hairy; clypeus about 2.5 as wide as long, subbasally with a transverse band of 30 to 50 hairs arranged in an irregularly double to quadruple row; prepectal carina present ventrally; median longitudinal carinae of propodeum moderately strong; areolet present; second tergite of male about 2.4 as long as wide; hairs on second tergite of female rather sparse, especially medially; hairs on lateral sternite of third abdominal segment moderately dense, evenly distributed; male clasper as in figure 371 ; ovipositor sheath about 1.20 as long as front wing. 
There are two subspecies, distinguished as in the key and descriptions below:

1. Abdomen partly ferruginous but largely blackish; thorax entirely black; wings subhyaline or faintly brown in both sexes; range: British Columbia to Oregon, east to Idaho . . . . . . . . . 1a. occidentalis occidentalis Cresson

Abdomen entirely ferruginous; thorax largely or entirely ferruginous; wings light brown in male, dark brown in female; range: California.

1b. occidentalis pulchripennis Cushman

\section{1a. Coleocentrus occidentalis occidentalis Cresson}

Coleocentrus occidentalis Cresson, 1878, Proc. Acad. Nat. Sci. Philadelphia, vol. 1878 , p. 376 ; $q$. Type: $ᄋ$, Vancouver Island, B. C. (Philadelphia).

Male: Black. Face, palpi, and under side of scape pale yellow, the face sometimes with a median black stripe; tegula, front and middle coxae in front, front and middle trochanters, front and middle femora at apex and in front, and front and middle tibiae and tarsi, yellow; front and middle legs pale fulvous except where described as yellow, their coxae more or less infuscate; hind coxa blackish with fulvous stains to fulvous with the base infuscate; hind trochanters fulvous, yellowish beneath; hind femur fulvous, sometimes infuscate; hind tibia brownish, darkest apically, basally fulvous; hind tarsus yellow, the basal $0.8 \pm$ of its first segment brownish; second to fourth abdominal tergites laterally more or less reddish brown; wings faintly tinged with brown.

Female: Black. Face laterally and scape beneath more or less yellowish fulvous; clypeus largely ferruginous; palpi and legs fulvous, the coxae infuscate basally and sometimes almost entirely blackish; hind tibia brownish, paler basally; hind tarsus yellowish fulvous, the basal $0.6 \pm$ of its first segment reddish brown; abdomen reddish brown, the basal 0.8 of its first segment blackish and the tergites beyond the midlength of abdomen somewhat infuscate, especially above; wings lightly tinged with brown.

Specimens (58 $\sigma^{7}, 71$ ) $)$ : From British Columbia (Copper Mountain, "Cornot Glacier," Courtenay, Cultus Lake, Diamond Head Trail near Squamish, Duncan, near Haney in Garibaldi Park, Goldstream, Kaslo, Nanaimo Lake on Vancouver Island, Osoyoos, Oyster River, Point Holmes near Comox, Robson, Royal Oak, Skagit Valley, Steelhead, Vancouver, Victoria, and Wellington); Idaho (Moscow Mt. and Priest Lake); Montana (Yaak River in Kootenai National Forest); Oregon (Lost Prairie in the Cascade Mts. in Linn Co., Mary's Peak, and Pamelia Lake on Mount Jefferson at 3,000 ft.); and Washington (Ashford, Blue Mt., Easton, Elbe, Fairfax, Forks, Lake Cushman in Mason Co., Lake Keechelus, Mount Constitution on Orcas Island, Montesano, Orcas Island, "Penn Mines in the Cascade Mts.," Quil- 
cene, Red Mt., Round Pass on Mount Rainier, Skyline Ridge on Mount Baker, White River on Mount Rainier, and Yelm).

Collection dates are nearly all from June 1 to August 10. Those outside of this range are: May 26 and 31 at Robson, B. C.; August 11 at Courtenay, B. C.; August 18 at Ashford, Wash.; and October 5 at Lake Keechelus, Wash. We have found the species rather common in Douglas fir forests of the Transition zone, flying about or alighting on the Douglas fir (Pseudotsuga taxifolia) logs and stumps.

There are no host records on the pin labels of the above material. One female, however, is labeled "on log of Pseudotsuga taxifolia" and another female "Pinus contorta".

This subspecies is in the Transition and Canadian zones of British Columbia and northwestern United States. Its characteristic habitat is Douglas fir forests. Adults occur mostly in June and July.

\section{1b. Coleocentrus occidentalis pulchripennis Cushman, new status}

Coleocentrus pulchripennis Cushman, 1920, Proc. U. S. Nat. Mus., vol. 57, p. 512;

ๆ. Type: + , Tuolumne Co., Calif. (Washington).

Male: Ferruginous. Head except face black, the clypeus and stain on lower hind part of temple ferruginous; palpi, under side of scape and pedicel, tegula, and front of front and middle coxae and trochanters, pale yellow; flagellum blackish, reddish brown beneath; propleurum black; pronotum and mesonotum largely infuscate; mesopleurum largely reddish brown; front and middle legs beyond trochanters pale fulvous, paler in front; hind tarsus with its second through fourth segments, apex of first segment, and basal half of fifth segment, yellowish fulvous; wings lightly suffused with brown.

Female: Ferruginous. Flagellum and top of head, blackish; mouth parts dark brown, their palpi yellowish fulvous; front and middle
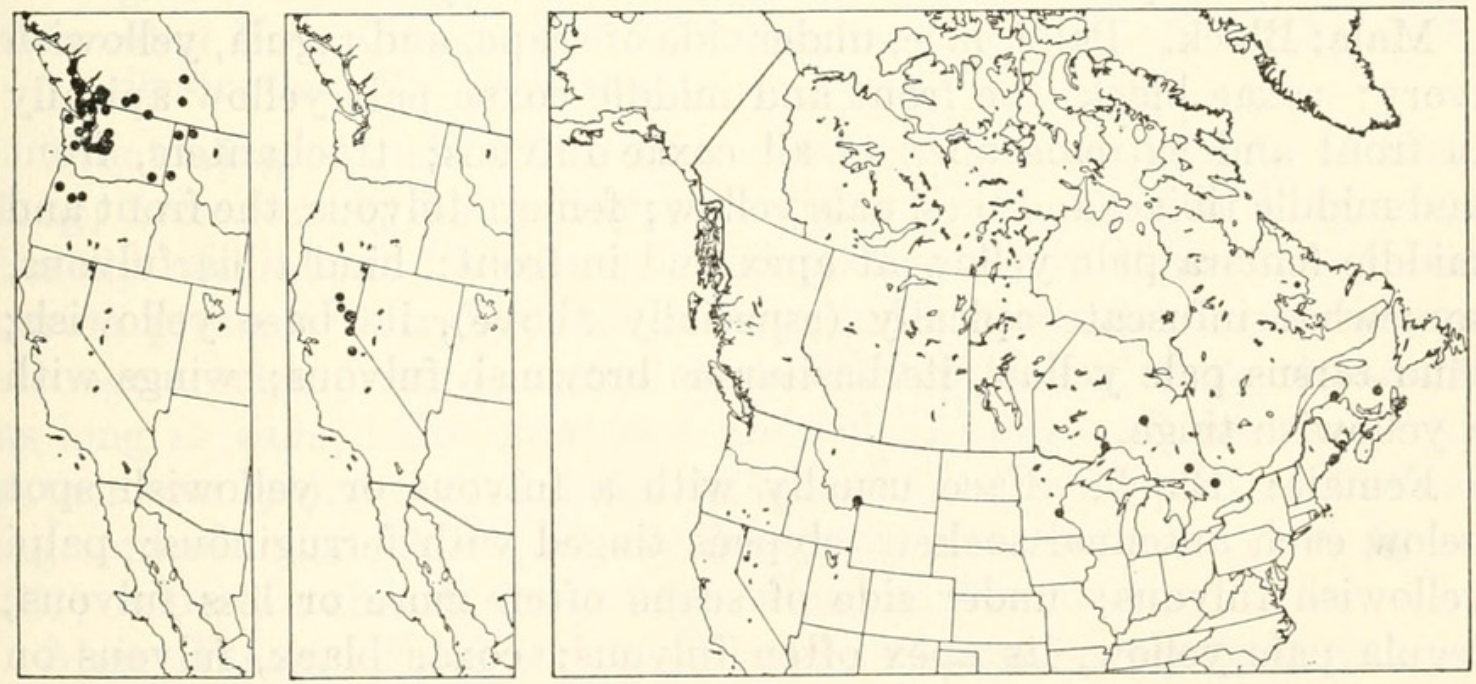

Figure 262-264.-Localities: 262 (left), Coleocentrus occidentalis occidentalis; 263 (center), C. o. pulchripennis; 264 (right), C. quebecensis. 
trochanters and tibiae, front and middle femora in front and at apex, and all tarsi, yellowish fulvous, the basal $0.6 \pm$ of first segment of hind tarsus ferruginous; tegula ferruginous, yellowish basally; wings dark brown with a purple iridescence.

Specimens: \&, Chester, Calif., June 25, 1951, D. J. and J. N. Knull (Columbus). 4오, Independence Lake, Sierra Co., Calif., July 17, 1954, R. C. Blaylock (Davis and Townes). $\sigma^{\nearrow}, 2$, Lake Tahoe, Calif., July 6, 1925, J. D. Gunder (Townes and Washington). ㅇ, 4 miles west of Quincy, Plumas Co., Calif., June 12, 1949, P. D. Hurd (Townes). 9 , 4 miles west of Quincy, Plumas Co., Calif., June 29, 1949, J. N. Simons (Berkeley). ㅇ, Sagehen, near Hobart Mills, Calif., July 16, 1954, G. A. Schaefers (Berkeley). ㅇ, Sierraville, Calif., July 2, 1954, R. M. Bohart (Townes). क, Sierraville, Calif., July 2, 1954, G. A. Schaefers (Townes). ㅇ (type), Tuolumne Co., Calif., D. W. Coquillett (Washington).

This subspecies is restricted to California.

\section{Coleocentrus quebecensis Provancher}

Figure 372

Coleocentrus Quebecensis Provancher, 1874, Naturaliste Canadien, vol. 6, p. 79; ․ Type: $\$$, Quebec (Quebec).

Front wing of male 11 to $12.5 \mathrm{~mm}$. long, of female 14 to $16 \mathrm{~mm}$. long; face densely hairy; clypeus about 2.5 as wide as long, subbasally with a transverse row of 30 to 50 hairs arranged in an irregularly double to quadruple row; prepectal carina present ventrally; median longitudinal carinae of propodeum moderately strong; areolet present; second tergite of male about 2.2 as long as wide; hairs on second tergite of female rather dense; hairs on lateral sternite of third abdominal segment dense, evenly distributed; male clasper as in figure 372 ; ovipositor sheath about 1.03 as long as front wing.

Male: Black. Palpi, face, under side of scape, and tegula, yellowish ivory; coxae black, the front and middle coxae pale yellow apically in front and extreme apex of all coxae fulvous; trochanters, front and middle tibiae, and tarsi pale yellow; femora fulvous, the front and middle femora pale yellow at apex and in front; hind tibia fulvous, somewhat infuscate apically (especially above), its base yellowish; hind tarsus pale yellow, its basitarsus brownish fulvous; wings with a yellowish tinge.

Female: Black. Face usually with a fulvous or yellowish spot below each antennal socket; clypeus tinged with ferruginous; palpi yellowish fulvous; under side of scape often more or less fulvous; tegula pale yellow, its apex often fulvous; coxae black, fulvous on the extreme apex; trochanters and front tibiae and tarsi pale yellowish; femora yellowish fulvous, the front and middle femora pale yellowish 
at apex and in front; hind tibia yellowish fulvous, brownish apically; hind tarsus yellowish, the basal $0.6 \pm$ of its basitarsus with a brownish tinge; wings tinged with yellowish.

We studied the type of quebecensis in 1941, a time when this was considered a synonym of pettiti. On discovering the specific distinctness of the present species, we have referred to the original description of quebecensis and have asked our friend Gerd Heinrich to make notes on the type on his recent visit to Quebec. On the basis of the available information it appears that quebecensis is this species rather than a synonym of pettiti.

Specimens: ㅇ, Bar Harbor, Mount Desert Island, Maine, June 26, 1929, William Proctor (Washington). o, Hennepin Co., Minn., (St. Paul). ㅇ, Rock Creek and Madison River, Gallatin National Forest, Mont., July 17, 1947, Mrs. P. Wibble (Pittsburgh). ণ, St. Andrews, N. B., June 25, 1923, E. M. Walker (Ottawa). $\sigma^{7}, ~ \circ$, Kings Co., N. S., June 22 and 25, 1931, C. E. Atwood (Ottawa). o, Peter Brook, near Baddeck, N. S., June 26, 1936, T. N. Freeman (Ottawa). + , Nipigon, Ont., J. Fletcher (Ottawa). ণ, Sand Lake, Ont., July 5, 1926, F. P. Ide (Ottawa). ९, Smoky Falls on the Mattagami River, Ont., July 7, 1934, G. S. Walley (Ottawa). $20^{\top}, 1$, Sudbury, Ont., June 17, 1892, and June 17, 1922 (Ottawa and Townes). $\sigma^{7}$, + , Sudbury, Ont., W. H. Harrington (Ottawa and Townes). $2 \sigma^{7}$, Cascapedia, Que., June 14, 1933, W. J. Brown (Ottawa). , Madelein Isle, near Amherst, Que., July 17, F. Johansan (Ottawa). , June 16, 1892, (Ottawa).

This species occurs in the Canadian zone from the Atlantic Ocean to the Rocky Mountains.

\section{Coleocentrus pettiti Cresson}

Figure 373

Coleocentrus Pettiti Cresson, 1868, Canadian Ent., vol. 1, p. 35; ९. Type: , Grimsby, Ont. (Philadelphia).

Front wing of male 9.5 to $12 \mathrm{~mm}$. long, of female 15.5 to $18 \mathrm{~mm}$. long; face densely hairy; clypeus about 2.8 as wide as long, subbasally with about 15 hairs in an irregular transverse row; prepectal carina present ventrally; median longitudinal carinae of propodeum strong; areolet present; second abdominal tergite of male about 2.9 as long as wide; hairs on second abdominal tergite of female sparse, rather evenly distributed; hairs on lateral sternite of third abdominal segment of female dense, evenly distributed; male clasper as in figure 373 ; ovipositor sheath about 1.08 as long as front wing.

Male: Black. Palpi and lateral third of face ivory; under side of scape yellowish brown; tegula black or yellow with its apex blackish; coxae black; front and middle legs pale fulvous, their trochanters, 
femora at apex and in front, and tarsi pale yellowish; hind trochanters and femur pale fulvous; hind tibia brown, fulvous at base; hind tarsus pale yellow, the basal half of its first segment more or less brown; wings hyaline.

Female: Black. Apical half of clypeus tinged with ferruginous; palpi brown, the last three segments of maxillary palpi paler; tegula and coxae black; front and middle legs beyond coxae and hind trochanters and femur yellowish fulvous, the femora brown at extreme base; hind tibia dark brown, fulvous at base; hind tarsus yellowish fulvous, the basal half of its first segment more or less brownish; wings subhyaline or lightly tinged with brown.

Specimens $\left(9 \sigma^{7}, 24\right.$ ) $)$ : From Colorado (Toponas at the summit of the Gore Mts.); Maine (Southport); Michigan (Brevort, Marquette Co., and Roscommon Co.); Minnesota (Itasca State Park); New Brunswick (Bathurst and Riley Brook); New Hampshire (Mount Lafayette); New York (Heart Lake in Essex Co. and Otsego Lake); North Carolina (Andrew's Bald in Great Smoky Mountains National Park); Nova Scotia (Kentville); Ontario (Blackburn, Maynooth, Petawawa Reservation, Thunder Bay Beach, and Waubamik); Pennsylvania (Harrisburg, Jeannette, and North Mountain); Quebec (Aylmer and Brome); and Vermont (Jacksonville and Laurel Lake near Jacksonville).

Collection dates are from June 6 to July 14 except for a few earlier and later as follows: May 27 at Blackburn, Ont.; May 31 in Roscommon Co., Mich.; July 19 at Southport, Maine; and July 29 at Kentville, N. S.

This species is in the Canadian zone of the East and there is a single record from Colorado.
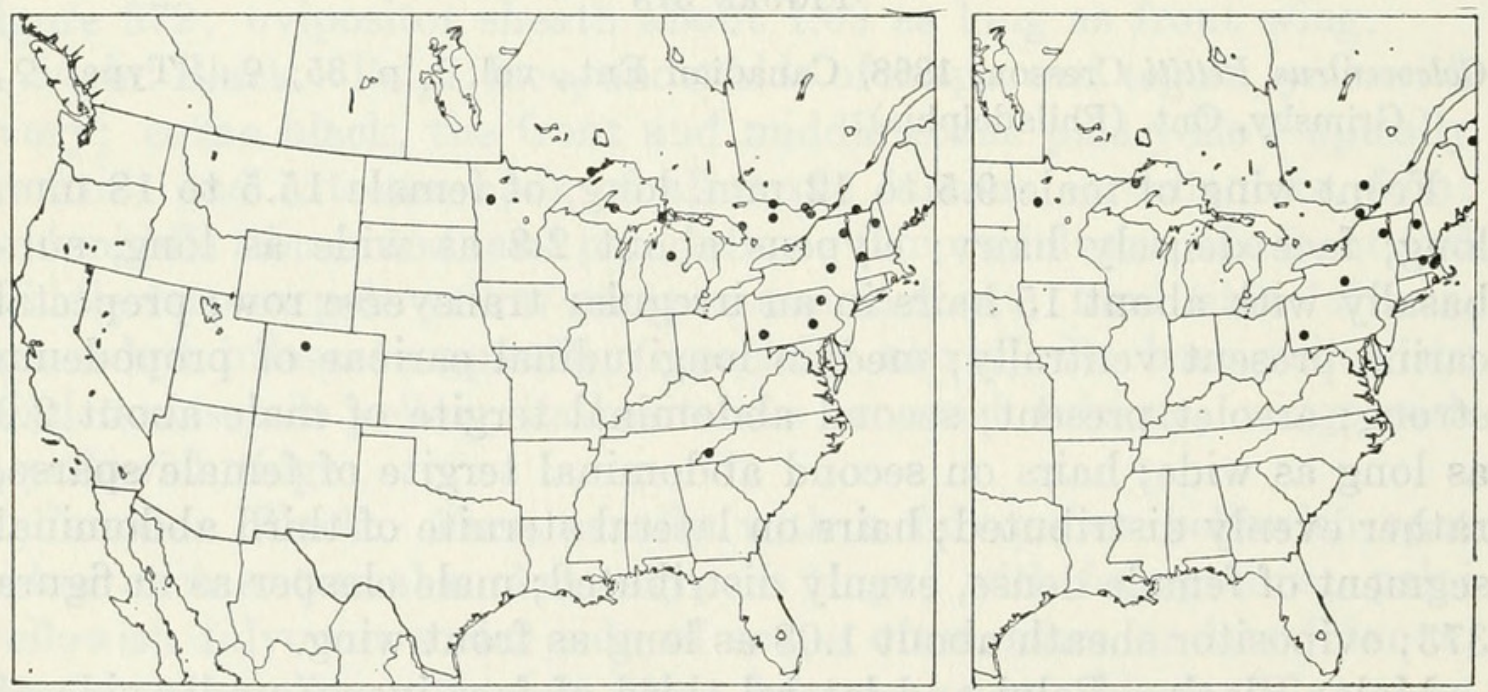

Figure 265, 266.-Localities: 265 (left), Coleocentrus pettiti; 266 (right), $C$. harringtoni. 


\section{Coleocentrus harringtoni Cushman}

Figure 374

Coleocentrus canadensis Harrington, 1892, Canadian Ent., vol. 25, p. 29; . Name preoccupied. Type: $\uparrow$, Casselman, Ont. (Ottawa).

Coleocentrus harringtoni Cushman, 1920, Proc. U. S. Nat. Mus., vol. 57, p. 509. New name.

Front wing of male 10 to $13 \mathrm{~mm}$. long, of female 16.5 to $19 \mathrm{~mm}$. long; face densely hairy; clypeus about 2.5 as wide as long, subbasally with about 18 hairs in an irregular transverse row; prepectal carina present ventrally; median longitudinal carinae of propodeum strong; areolet present; second abdominal tergite of male about 1.6 as long as wide; hairs on second abdominal tergite of female rather dense, evenly distributed; hairs on lateral sternite of third abdominal segment of female dense, evenly distributed; male clasper as in figure 374 ; ovipositor sheath about 1.15 as long as front wing.

Male: Black. Face, palpi, under side of scape, and tegula white, the face with a median black stripe; front and middle legs fulvous, paler on the trochanters, apex of coxae, front and apex of the femora, and the tibiae and tarsi; hind coxa, trochanters, and femur fulvous, the femur infuscate at apex above; hind tibia and tarsus dark brown; clasper with a whitish area basally above; wings hyaline.

Female: Black. Face laterally and under side of scape obscurely tinged with pale fulvous; palpi fulvous; tegula pale fulvous, pale yellowish basally; front and middle legs and hind coxa, trochanters, and femur fulvous, the femur a little infuscate at apex; hind tibia and tarsus dark brown; apical membranous margin of second through seventh tergites stramineous; wings hyaline or lightly tinged with brown.

Specimens: $\sigma^{\top}$, $\odot$, Ashburnham, Mass., Apr. 27 and 29, 1918 (Washington). 2 \% , Boston, Mass., May 12 (Cambridge). $\sigma^{7}$, Newton Center, Mass., June 14, 1928, A. Loveridge (Cambridge). 2 ㅇ, Isle Royale, Mich., Aug. 3-7, 1936, R. R. Dreisbach (Dreisbach and Townes). \&, Isle Royale, Mich., Aug. 3-7, 1936, C. Sabrosky (East Lansing). , Itasca Park, Minn., June 19, 1933, R. N. Orr (St. Paul). $\sigma^{7}$, ᄋ , "Narrows Brook," N. B., June 30, 1955, (MacDonald). क, Nictau, N. B., July 3, 1955 (Townes). क, Franconia, N. H., Mrs. A. T. Slosson (New York). \&, Ithaca, N. Y., July 30 (Ithaca). o , North Elba, N. Y., June 26, 1932 (Washington). , Casselman, Ont., June 26 (Ottawa). ㅇ, Jeannette, Pa., H. G. Klages (Pittsburgh). †, St. Michel des Saints, Que., June 25, 1956, Frere Yres André (Ottawa). 2 우, no data (Washington). 2 \%, no data (St. Paul). East.

This species occurs in the Transition and Canadian zones of the $526527-60-36$ 


\section{Coleocentrus rufocoxatus Pratt}

Figure 375

Coleocentrus rufocoxatus Pratt, 1936, Bull. Brooklyn Ent. Soc., vol. 31, p. 11;

․ Type: ㅇ, Laurel Lake, $1700 \mathrm{ft}$., near Jacksonville, Vt. (Washington).

Front wing of male $12 \mathrm{~mm}$. long, of female 12 to $13.5 \mathrm{~mm}$. long; face with moderately dense hairs; clypeus about 2.3 as wide as long, subbasally with an irregular transverse row of about 18 hairs; prepectal carina present ventrally; median longitudinal carinae of propodeum strong; areolet present; second tergite of male 2.1 as long as wide; hairs on second abdominal tergite of female sparse, rather regularly spaced; hairs on lateral sternite of third abdominal segment of female sparse and irregularly spaced, to dense and regularly spaced; male clasper as in figure 375 ; ovipositor sheath about 0.95 as long as front wing.

Male: Black. Face, tinge on cheek, clypeus, palpi, under side of scape and pedicel, tegula, front and middle coxae, and front and middle trochanters, ivory, the front and middle coxae tinged with pale fulvous; flagellum blackish brown, brown beneath; front and middle legs beyond trochanters ivory-yellow, their femora tinged with fulvous except in front; hind coxa fulvous, ivory beneath; hind trochanters ivory; hind femur fulvous; hind tibia brownish fulvous; hind tarsus pale yellow, the basal 0.4 of its basal segment suffused with fulvous; apical $0.25 \pm$ of first two tergites and sides of second and third tergites partly fulvous; wings hyaline.

Female: Black. Clypeus, palpi, front of scape, tegula, and legs fulvous, the hind tibia brownish above except towards base; wings hyaline.

Specimens: , Middle Brook, N. B., July 17, 1936 (MacDonald). , Halfway House, Mount Washington, N. H., July 6, 1914, C. W. Johnson (Washington). ค, Rockaway, Long Island, N. Y. (New York). , Norman Wells, N. W. T., July 8, 1949, W. R. M. Mason, (Ottawa). ᄋ, Kentville, N. S., June 18, 1914 (Cambridge). ㅇ, Macdiarmid, Ont., June 26, 1921, R. K. B. (Ottawa). ㅇ, Thunder Bay Beach, Ont., June 11, 1939, H. S. Parish (Townes). $\sigma^{7}$, North Mt., Pa., "6.9” (Washington). ㅇ, Hunter River, P. E. I., July 5, 1947, R. H. Wigmore (Ottawa). , Godbout, Que., Aug. 17, 1918, E. M. Walker (Washington). 39, Laurel Lake, near Jacksonville, Vt., June 27, 1935, July 1, 1936, and July 23, 1935, H. D. Pratt (Washington, Townes, and (Ottawa).

This species occurs in the Transition and Canadian zones of the East, and is known also from Northwest Territories. 


\section{Coleocentrus manni Cushman}

\section{Figure 376}

Front wing of male 9 to $12 \mathrm{~mm}$. long, of female 12 to $14 \mathrm{~mm}$. long; face with moderately dense hairs; clypeus about 2.4 as wide as long, subbasally with an irregular transverse row of about 18 hairs; prepectal carina present ventrally; median longitudinal carinae of propodeum strong; areolet present; second abdominal tergite of male about 1.55 as long as wide; hairs on second abdominal tergite of female sparse, irregularly spaced; hairs on lateral sternite of third abdominal segment of female sparse, irregularly distributed; male clasper as in figure 376; ovipositor sheath about 0.92 as long as front wing.

There is a subspecies in the Vancouveran zone and another in Colorado. They are distinguished on the color of the legs as described below:

1. Coxae blackish; hind femur not, or weakly infuscate apically; range: Vancouveran zone. . . . . . . . . . . 5a. manni manni Cushman Coxae fulvous; hind femur distinctly infuscate apically; range: Colorado.

5b. manni coloradensis, new subspecies
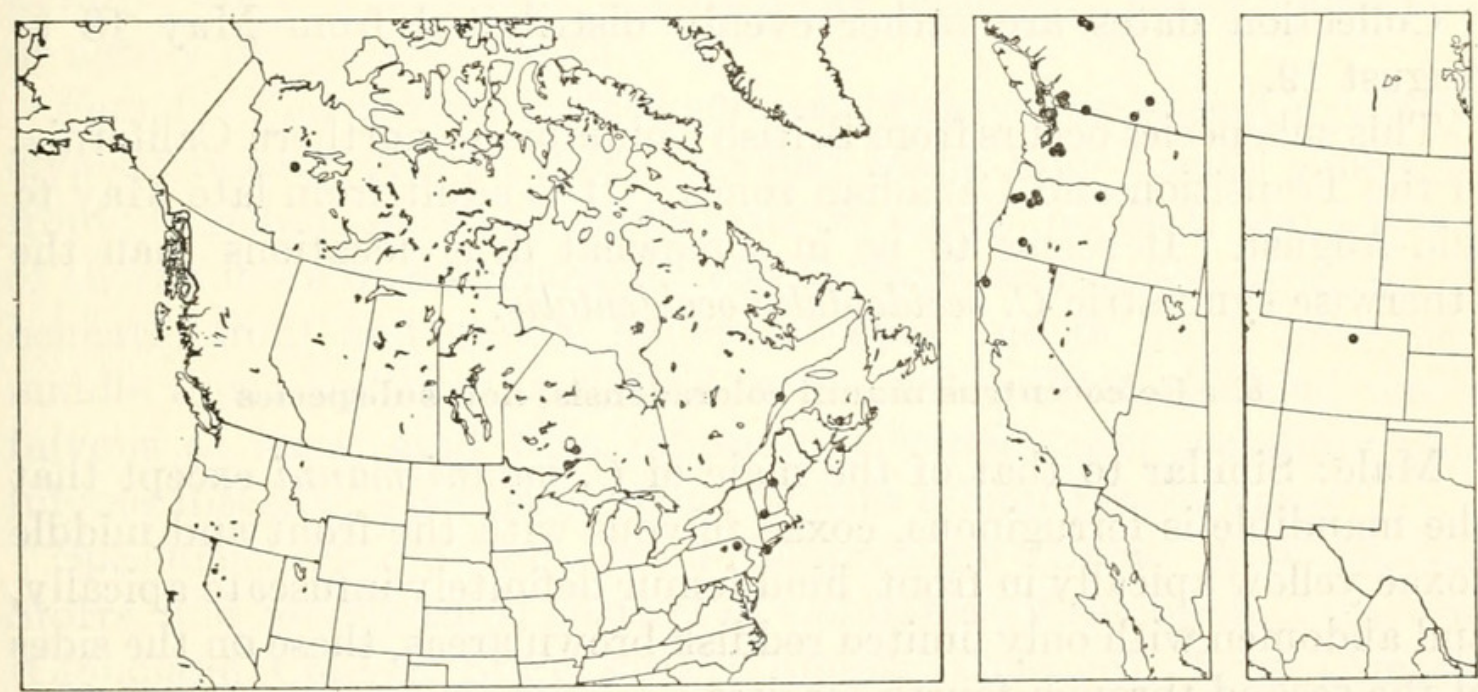

Figure 267-269.-Localities: 267 (left), Coleocentrus rufocoxatus; 268 (center), C. manni manni; 269 (right), C. m. coloradensis.

\section{6a. Coleocentrus manni manni Cushman}

Coleocentrus manni Cushman, 1920, Proc. U. S. Nat. Mus., vol. 57, p. 512; ه' Type: , "Orens Is.," [=Orcas Is.] Wash. (Washington).

Male: Black. Face, clypeus, palpi, scape and pedicel below, tegula, front and middle coxae apically in front, front and middle trochanters except above, front and middle femora at apex and in front, front and middle tibiae and tarsi, and second through fifth segments of hind tarsus, pale yellow or yellow tinged with fulvous; coxae black except where described as yellow, apically sometimes tinged with fulvous; front and middle trochanters and femora fulvous except where de- 
scribed otherwise; hind trochanters fulvous, yellow below; hind femur fulvous, sometimes a little infuscate apically; hind tibia infuscate, fulvous basally; first segment of hind tarsus brownish fulvous, yellow on apical $0.1 \pm$; second through fifth abdominal segments largely reddish brown; wings lightly tinged with brown.

Female: Black. Apical half of clypeus ferruginous; tegula ferruginous to blackish; palpi and legs fulvous, the hind tibia brownish, darker apically; abdomen sometimes partly dark reddish brown; wings lightly tinged with brown.

Specimens $\left(22 \sigma^{x}, 26\right.$ \%): From British Columbia (Cultus Lake, Garibaldi Park near Haney, Ground Hog Basin in the Selkirk Mts. in Big Bend Co., Likely, Manning Provincial Park at 4,000 ft., Nanaimo Lakes on Vancouver Island, Robson, Stanley, Steelhead, Victoria, and Wellington); California (Carlotta); Oregon (Blue Mts., "Boyer," Cascadia, Corvallis, Griffin Creek in Jackson Co., Mary's Peak, Pamelia Lake on Mount Jefferson, and trail from Breitenbush Springs to Lake Leone at 2,222 to 3,900 ft.); and Washington (Ashford, Mount Rainier at 2,700, 2,900, and 4,700 ft., Orcas Island, Paradise Park on Mount Rainier, and San Juan Island).

Collection dates are rather evenly distributed from May 18 to August 19.

This subspecies occurs from British Columbia to northern California, in the Transition and Canadian zones. It is adult from late May to mid-August. It seems to be in somewhat drier locations than the otherwise sympatric $C$. occidentalis occidentalis.

\section{6b. Coleocentrus manni coloradensis, new subspecies}

Male: Similar to that of the male of $C$. manni manni except that the mandible is ferruginous, coxae fulvous with the front and middle coxae yellow apically in front, hind femur definitely infuscate apically, and abdomen with only limited reddish brown areas, these on the sides of the second through fourth tergites.

Female: Unknown.

Type: $0^{7}$, near Estes Park, Colorado, June 12, 1948, H., M., G., D., and J. Townes (Washington, USNM 63739).

Paratype: $\sigma^{\top}$, same data as type (Townes).

\section{Coleocentrus rufus Provancher}

Figures $331, \mathrm{i} ; 377$

Coleocentrus rufus Provancher, 1876, Naturaliste Canadien, vol. 8, p. 316; ㅇ. Type: 오, Cap Rouge, Que. (Quebec).

Coleocentrus similis Cushman, 1920, Proc. U. S. Nat. Mus., vol. 57, p. 514; ه’, ๆ. Type: $\uparrow$, Montgomery Co., Pa. (Washington).

Front wing of male 9 to $10.5 \mathrm{~mm}$. long, of female 12 to $14 \mathrm{~mm}$. long; hairs on face very sparse medially, elsewhere moderately dense; 
clypeus about 2.3 as wide as long, subbasally with about ten hairs in an irregular transverse row; prepectal carina present ventrally; median longitudinal carinae of propodeum weak; areolet present; second abdominal tergite of male about 2.25 as long as wide; hairs on second abdominal tergite of female rather sparse, very sparse or absent centrally, elsewhere regularly spaced; hairs on lateral sternite of third abdominal segment of female sparse, irregularly distributed; male clasper as in figure 377 ; ovipositor sheath about 0.88 as long as front wing.

Male: Ferruginous. Face, suffusion on frontal orbit and cheek, palpi largely, scape and pedicel except above, tegula, scutellum, postscutellum, front and middle coxae apically in front, front and middle trochanters, hind trochanters below, apex and front side of front and middle femora, front and middle tibiae and tarsi, and second through fifth segments of hind tarsus, pale yellow; first segment of hind tarsus fulvous basally, becoming pale yellow near the middle; flagellum brown; occipital carina above, occiput partly, and more or less of thoracic sutures, blackish; hind tibia fuscous, paling to ferruginous basally; apex of abdomen often a little infuscate; wings subhyaline or lightly tinged with brown.

Female: Ferruginous. Face suffused with yellow except medially; clypeus mostly yellow; palpi fulvous; scape tinged with yellow in front; flagellum brown; occipital carina above, occiput, and sutures of thorax more or less blackish; tegula, front and middle trochanters beneath, front and middle femora at apex and in front, front and middle tibiae and tarsi, and hind tarsus, pale yellow, the hind tarsus fulvous at base; hind tibia infuscate towards apex; scutellum pale fulvous discally; wings subhyaline or with a light-brown tinge.

Specimens $\left(650^{x}, 78\right.$ ) : From Connecticut (Lyme, New Haven, Storrs, and Stonington); District of Columbia (Washington); Georgia (Cloudland Canyon State Park); Illinojs (Chicago); Iowa (Ames); Maryland (Bowje, Forest Glen, and Takoma Park); Massachusetts (Amherst, Cummington at 1,800 ft., Dorchester, Florida, Franklin, Lexington, Paradise Trail near Sunderland, Sherborn, and South Hadley); Michigan (Bay Co., East Lansing, George Reserve in Livingston Co., Lake Co., Mason, Midland Co., Oakland Co., and Whitefish Point in Chippewa Co.); New Brunswick (St. Andrews); New Hampshire (Franconia, Mount Madison, Mount Monadnock, and Pinkham Notch); New Jersey (Greenwood Lake, Moorestown, and Summit); New York (Bear Mt., Bemus Point, Dix Hills near Huntington, Fort Montgomery, Ithaca, Newton on Long Island, Oswego, Rochester, and Wyandanch); North Carolina (Wake Co.); North Dakota (Ardoch and Grand Forks); Nova Scotia (near Halifax); Ontario (Jordan, Niagara Glen and Point Pelee); Pennsylvania 

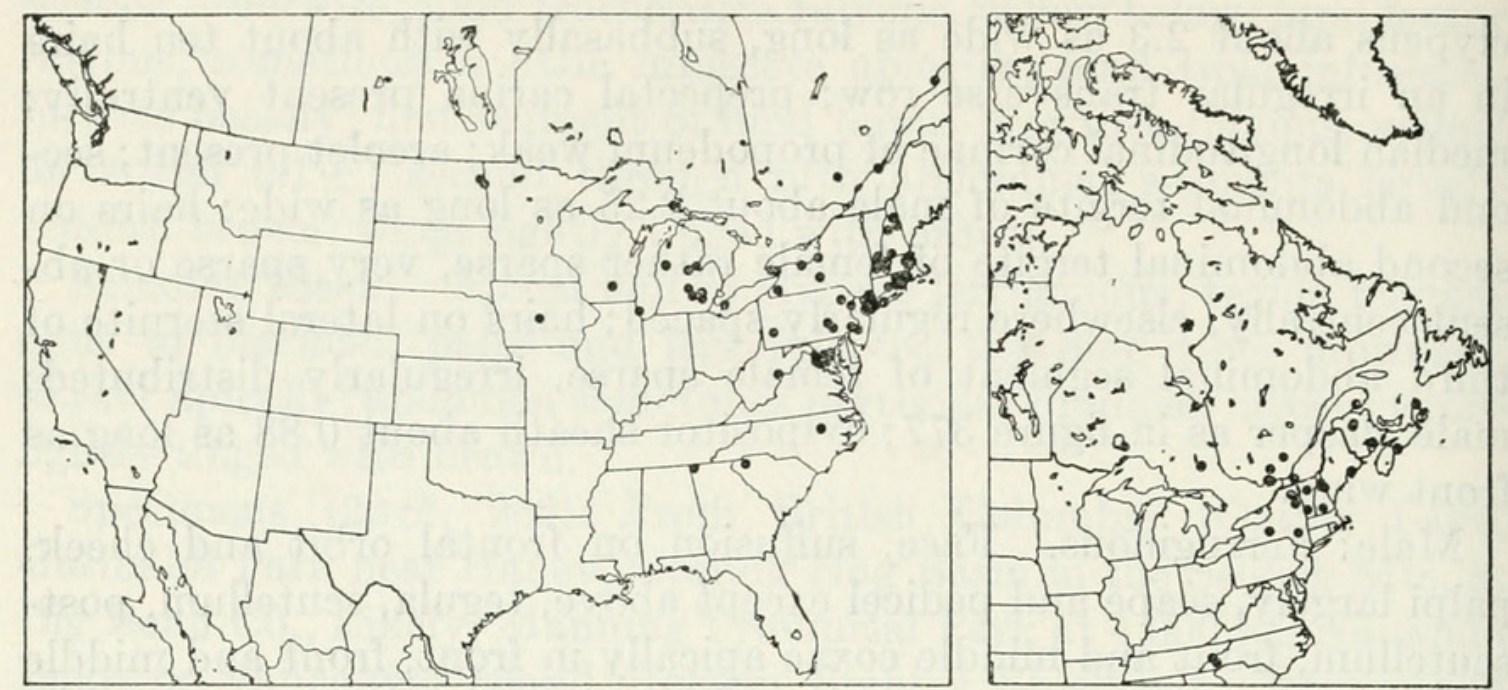

Figure 270, 271.-Localities: 270 (left), Coleocentrus rufus; 271 (right), $C$. flavipes.

(Delaware Water Gap, Hummelstown, Inglenook, Montgomery Co., Pittsburgh, and Spring Brook); Prince Edward Island (Brackley Beach in Canadian National Park); Quebec (Cap Rouge, Montigny, and Pentecost); Rhode Island (Coventry); South Carolina (Greenville); Vermont (Laurel Lake near Jacksonville); Virginia (Dead Run in Fairfax Co., Falls Church, Glencarlyn, Great Falls, and Virginia near Plummers Island); West Virginia (Cheat Mt. at 2,000 ft. in Randolph Co.); and Wisconsin (Madison).

Dates of capture are from rather early spring to mid-summer. In most of its range the species is commonest in June and late May. In the Carolinas it emerges in April (captures April 2 and 20 at Greenville, S. C. and April 19 and 20 in Wake Co., N. C.). In the vicinity of Washington, D. C. the first emergence is in late April and early May (captures April 24 at Washington, D. C. and May 4 at Glencarlyn, Va.). At Ithaca, N.Y. first emergence is in mid-May (captures May 8, 14, and 19). Adults have mostly disappeared by the end of June but in the northern part of the range a few remain into July, and there is one capture in August (August 21 at Ames, Iowa). In our own collecting, we have found the species in rather open, moderately dry, deciduous woods.

This species occurs in the Alleghanian and Carolinian faunas. It is adult from mid-spring through early summer.

\section{Coleocentrus flavipes Provancher}

Figure 378

Acoenites flavipes Provancher, 1874, Naturaliste Canadien, vol. 6, p. 80 ; $\subsetneq$. Type: + , ?Quebec City (Quebec).

Acoenites Canadensis Provencher, 1880, Naturaliste Canadien, vol. 12, p. 10 (Faune, p. 442); $\sigma^{x}$. Type: $\sigma^{x}$, ?Quebec City (Quebec). 
Coleocentrus minor Cushman, 1920, Proc. U. S. Nat. Mus., vol. 57, p. 507;. Type: $\uparrow$, Pisgah Ridge, N. C. (Washington).

Coleocentrus niger Cushman, 1920, Proc. U. S. Nat. Mus., vol. 57, p. 508;. Type: + , Whitefish Point, Mich. (Washington).

Front wing 8.5 to $11 \mathrm{~mm}$. long in male, 7.5 to $13 \mathrm{~mm}$. long in female; face with sparse hairs laterally, elsewhere with very sparse hairs or none; clypeus about 2.5 as wide as long, subbasally with about 12 hairs in an irregular transverse row; prepectal carina completely lacking; median longitudinal carinae of propodeum very weak; areolet absent; second abdominal tergite of male about 1.8 as long as wide; hairs on second abdominal tergite of female very sparse, absent medially, elsewhere regularly spaced; hairs on lateral sternite of third abdominal segment of female irregularly spaced, not dense; male clasper as in figure 378 ; ovipositor sheath about 1.02 as long as front wing. We have seen one male in which the areolet is present (small, with a long petiole, the second intercubitus weak).

Male: Black. Face, palpi, scape and pedicel except above, tegula, front coxa and trochanters, middle coxa and trochanters except above, hind trochanters below, apex of front and middle femora, and much of lower edge of clasper, white; hind femur infuscate apically, especially above; hind tibia and tarsus fuscous, the tibia more or less fulvous basally; legs fulvous except as described otherwise; wings hyaline or subhyaline.

Female: Black. Face laterally, clypeus, and under side of scape, often suffused with dirty white; palpi light brown; tegula white to pale brown; legs fulvous, the apex of hind femur and hind tibia and tarsus brown, the tibia paler basally; wings hyaline or faintly tinged with brown.

Specimens (19 $\sigma^{\Upsilon}, 33$ \%): From Maine (Brooksville); New Brunswick ("Middle Brook," "Narrows Brook," Nictau, and Riley Brook); New Hampshire (Mount Madison, Mount Monadnock, Mount Washington, and Pickham Notch); New York (Heart Lake in Essex Co., Lake Tear at 4,300 to 4,600 ft. in Essex Co., Maplecrest in the Catskill Mts., McLean Reserve in Tompkins Co., and top of Mount Whiteface); Nova Scotia (Cape Breton Highlands National Park and Halifax); Ontario (Macdiarmid on Lake Nipigon, Moose Factory, and Westree); Quebec (Brome, Cascapedia River, Gracefield, Harrington Lake in Gatineau Park, Nominingue, and Wakefield); Tennessee (Great Smoky Mountains National Park); and Vermont (Lake Willoughby at 3,200 ft. and Mount Equinox).

Dates of collection are from late spring to early August, with most of the dates in June. Particularly early and late dates of capture are: May 26 and 29 in McLean Reserve, Tompkins Co., N. Y.; June 5 on Mount Equinox, Vt. and at Nominingue, Que.; August 2 at Westree, Ont.; August 5 in Cape Breton Highlands 
National Park, N. S.; and August 21 at the Cascapedia River, Que. In our collecting we have found the species in forests of Picea and Abies.

This species is in the Canadian zone of the East. Adults occur mostly from late spring to mid-summer.

\section{Genus Mesoclistus}

\section{FJgURe 308,b}

Mesoclistus Foerster, 1868, Verh. Naturh. Ver. Rheinlande, vol. 25, p. 168. Type: Acoenites rufipes Gravenhorst; included by Schmiedeknecht, 1888.

The more important generic characters are stated in the key.

This is a small, Holarctic genus, with one Nearctic representative in Alaska.

\section{Mesoclistus cushmani, new species}

Front wing 8.1 to $8.6 \mathrm{~mm}$. long; cheek about 0.90 as long as basal width of mandible; punctures on mesopleurum medially subadjacent and confused with weak wrinkling, marginally separated by about 0.7 their diameter; petiolar area of propodeum completely covered with fine wrinkles; hairs on third tergite rather uniformly dense; ovipositor sheath 1.15 as long as front wing.

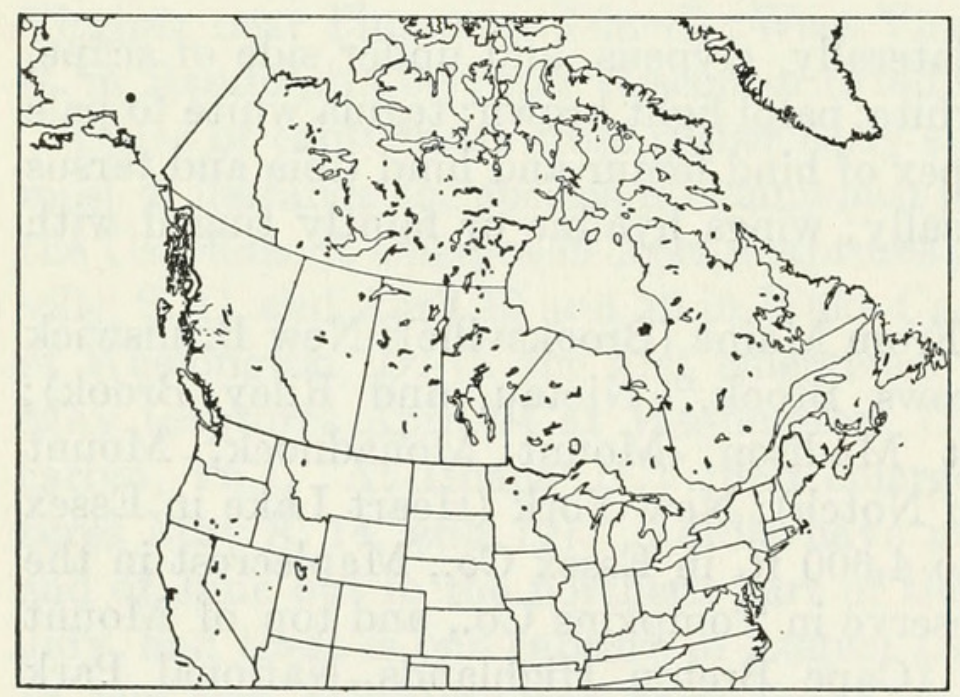

Figure 272.-Locality for Mesoclistus cushmani.

Black. Under side of male scape and basal four segments of flagellum brown; under side of basal third of female flagellum tinged with brown; tegula blackish; legs beyond trochanters fulvous, the apex of hind tibia infuscate and hind tarsus blackish brown; wings tinged with dark brown.

As differentiated from the European Mesoclistus rufipes, this species has a longer cheek, finer and denser punctation, more wrinkling on thorax, denser hairs on tergites, no whitish marks on head, and female hind coxa black. 
Type: , Mount McKinley National Park, Alaska, 1932, F. W. Morand (Washington, USNM 63740).

Paratype: $\sigma^{7}$, same data as type (Washington).

The specific name is in honor of R. A. Cushman, who did much to put the classification of the old subfamily Pimplinae on a sound basis.

\section{Genus Arotes}

Figure 309 ,a

Arotes Gravenhorst, 1829, Ichneumonologia europaea, vol. 3, p. 446. Type: Arotes albicinctus Gravenhorst; monobasic,

Sphalerus Kriechbaumer, 1878, Ent. Nachr., vol. 4, p. 41. Type: (Sphalerus bifasciatus Kriechbaumer)=albicinctus Gravenhorst; monobasic.

Retanisia Cameron, 1886, Biologia Centrali-Americana (Hymenoptera), vol. 1, p. 299. New synonymy. Type: Retanisia facialis Cameron; monobasic.

Arotes is similar to Spilopteron except for the characters in the key. This genus is Holarctic and occurs in Central America.

\section{Key to the Neartic species of Arotes}

1. Lateral lobe of mesoscutum with a whitish stripe next to notaulus . . . . 2 Lateral lobe of mesoscutum black or fulvous next to notaulus, not whitish . . 3

2. Hind femur black, its apex ivory; upper hind third of pronotum with fine, weak punctures . . . . . . . . . . . . . . 1. amoenus Cresson Hind femur fulvous, its base, apex, and sometimes upper edge blackish; upper hind third of pronotum with moderately dense, sharp punctures.

3. decorus (Say)

3. Metapleurum with rather small punctures that are separated by about 1.6 their diameter; male flagellum with a white band, apicad of which the flageilum is brownish for a distance equal to about 0.67 the width of the white band; female flagellum with a white band, apicad of which the flagellum is blackish for a distance equal to about the width of the white band.

4. melleus (Say)

Metapleurum with rather coarse punctures that are subadjacent or crowded; male flagellum with its apical $0.4 \pm$ white, the apical $3 \pm$ segments brownish; female flagellum with a white band, apicad of which the flagellum is blackish for a distance equal to about 0.4 the width of the white band.

2. maurus Rohwer

\section{Arotes amoenus Cresson}

Figures 319,h, 327,1, 331,j

Arotes amoenus Cresson, 1868, Canadian Ent., vol. 1, p. 34; + Type: + , Ontario (Philadelphia).

Front wing 9.5 to $12 \mathrm{~mm}$. long in male, 10.5 to $15.5 \mathrm{~mm}$. long in female; female flagellum about 0.93 as long as front wing; upper hind third of pronotum with fine punctures, separated by about 3.5 their diameter; lower half of mesopleurum with rather small punctures that are separated by about 1.5 their diameter; metapleurum with medium- 
sized punctures that are separated by about 0.6 their diameter; second segment of hind tarsus about 4.0 as long as deep in male, about 3.1 as long as deep in female; ovipositor sheath about 1.25 as long as front wing.

Black. Face, frontal orbit, cheek, temple (for its entire width at and below the middle, for part of its width above), clypeus, labrum, basal 0.6 of mandible, palpi, lower side of antenna of male, part of lower side of scape and pedicel of female, apical 0.35 of male flagellum except extreme tip, broad subapical band on female flagellum, sometimes spot on propleurum, most of anteroventral and upper margins of pronotum, tegula, subtegular ridge, transversely quadrate spot below subtegular tubercle, longitudinal band near lower margin of mesosternum, often a marginal stripe on lower side of sternaulus, mesepimeron, large elliptical area on metapleurum, V-shaped submarginal mark on sides and rear of median lobe of mesoscutum, mesal and lateral edges of lateral lobe of mesoscutum, scutellum, postscutellum and metanotum adjacent to postscutellum, hind $0.4 \pm$ of propodeum, short median basal stripe on first tergite, apical bands on first through sixth tergites (margined apically with blackish on first tergite of male and first and second tergite of female, the apical band on female sixth tergite interrupted medially), and seventh and eighth tergites laterally, ivory; front and middle legs ivory, their coxae blackish at base and their femora mostly brownish behind in female and sometimes in male; hind leg ivory, its coxa except for a large ventral and usually a smaller dorsal area and its femur except at apex and often at base, black; hind tibia infuscate beyond basal 0.4 , in the male ivory below for its entire length; female subgenital plate infuscate, most of its dorsal edge whitish; wings hyaline, the front wing with a broadly crescent-shaped infuscate area on its apex.

Specimens (144 $\sigma^{7}, 258$ ) : From Connecticut (East Haddam, East Hartford, East River, Litchfield, Lyme, "Massor," North Stonington, Storrs, and Voluntown); Iowa (Clinton); Maine (Augusta, Bar Harbor, and Capens); Maryland (Bowie, Cabin John, College Park, Glen Echo, Laurel, Plummers Island, and Sycamore Island); Massachusetts (Amherst, Dorchester, Lexington, Malden, Norwell, Petersham, Savoy, Stony Brook Reserve near Boston, and Wollaston); Michigan (Ann Arbor, Benzie Co., Calhoun Co., Cheboygan Co., Deerfield Township in Lapeer Co., Detroit, Douglas Lake in Cheboygan Co., East Lansing, Gogebic Co., Gull Lake Biological Station in Kalamazoo Co., High Island in Charlevoix Co., Macomb Co., Manistee Co., Marquette Co., Midland Co., Oakland Co., Otsego Co., Saginaw Co., Shiawassee Co., Warren Woods in Berrien Co., and Whitefish Point in Chippewa Co.); Minnesota (Alexandria and Fillmore Co.); New Hampshire (Crawford Notch, Durham, Fitzwilliam, Franconia Notch, 
Littleton, Mount Washington, and Rummey); New Jersey (Lakehurst, Palisades, and Ramsey); New York (Allegany State Park, Ardsley, Babylon, Batavia, Bear Mt., Bedford, Bemus Point, Big Indian Valley in the Catskill Mts., Bronxville, between Caroline and Harford, Chafee, Corona on Long Island, Dix Hills near Huntington, East Hampton, Fort Montgomery, Ithaca, Labrador Lake in Cortland Co., Ludlowville, Milford Center, top of Mount Whiteface, North Beach on Long Island, North River, Patterson, Scarsdale, Trenton Falls, and West Point); North Carolina (Black Mts., Bradley Fork in Great Smoky Mountains National Park, North Fork, and Tryon); Ohio (Cantwell Cliffs in Hocking Co., Cincinnati, Cleveland, Columbus, Delaware Co., Hinckley in Medina Co., Ira, Medina, Montgomery Co., and Warrensville); Ontario (Ahmic Lake in the Parry Sound District, Burk's Falls, Constance Bay, Hamilton, Jordan, Leamington, Marshall's Bay at Arnprior, Merivale, Orillia, Ottawa, Sand Lake, Severn, Waubamik, and "Woodworth's Lake"); Pennsylvania (Allegheny Co., Castle Rock in Delaware Co., Charter Oak in Huntingdon Co., Crafton, Hummelstown, Jeannette, New Cumberland, Ohiopyle, Overbrook, Philadelphia, Pike Co., Pittsburgh, Roxborough, Slippery Rock Creek, Spring Brook, and Wall) ; Quebec (Cascapedia, Hemmingford, Isle de Montreal, Knowlton, Lac Mondor near Sainte Flore, Montreal, Sweetburg, Vaudreuil Co., and Wakefield); Tennessee (Gatlinburg); Texas; Vermont (Jacksonville, Laurel Lake near Jacksonville, and Stowe); Virginia (Big Meadows in Shenandoah National Park, Chain Bridge near McLean, Dead Run in Fairfax Co., Falls Church, Great Falls, Pennington Gap, and Rosslyn); West Virginia (Cheat Mt. at 2,000 ft. in Randolph Co., Lewisburg, and Webster Springs); and Wisconsin (Columbus, Dane Co., Door Co., Eau Claire, Gay's Mills, Milwaukee Co., Sawyer Co., and Shawano Co.).
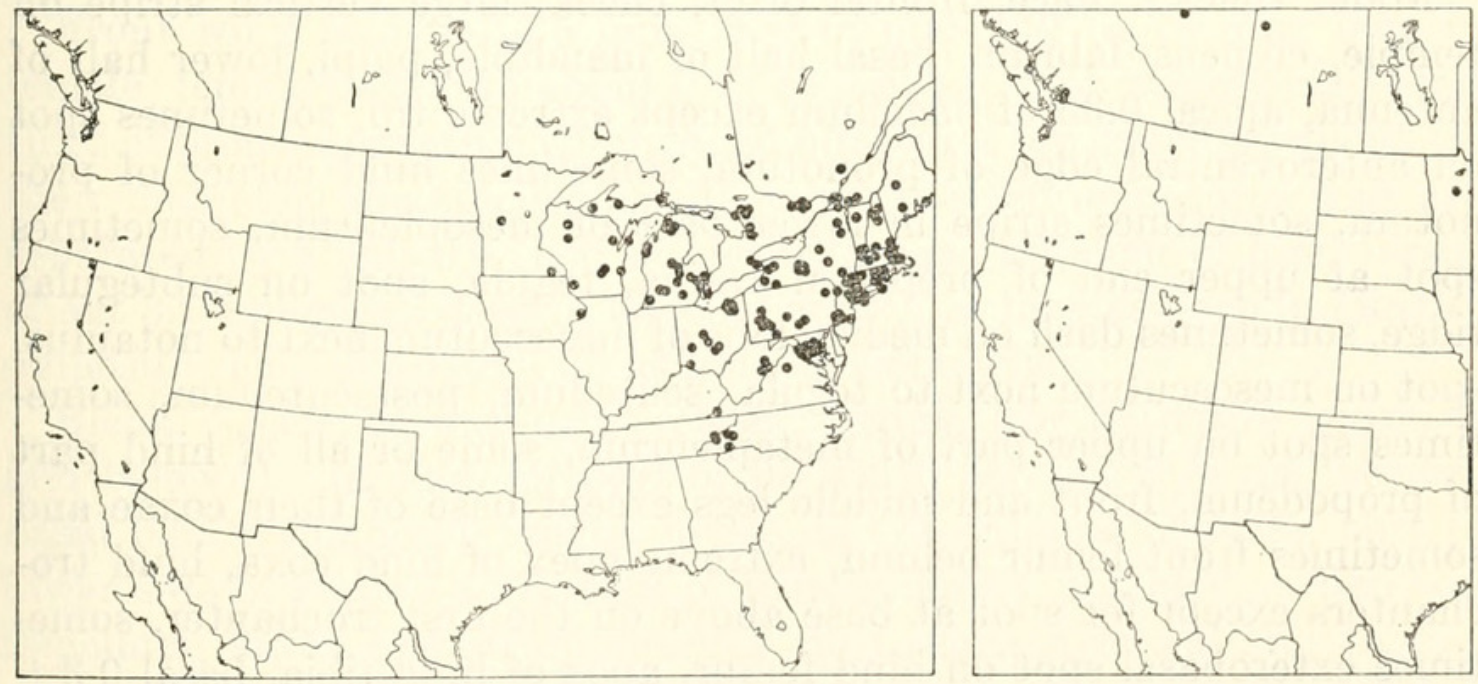

Figure 273, 274.--Localities: 273 (left), Arotes amoenus; 274 (right), A. maurus 
Collection dates are mostly from May 30 to the end of July, more in June than in July. Dates of capture outside of this range are: May 13 in Dane Co., Wis.; May 20 in the Black Mts., N. C.; May 28 in Macomb Co., Mich.; May 29 at Ann Arbor, Mich.; August 4 at Ramsey, N. J.; August 5 in Sawyer Co., Wis.; August 17 at East Lansing, Mich.; August 19 at Lewisburg, W. Va.; and September 6 at Bar Harbor, Maine. We have found the species mostly in rich deciduous woods.

Rearings are as follows: $\sigma^{x}$,, , from Melandrya striata in Betula lenta, May 25 and June 1, 1918, W. S. Fisher. ㅇ, from Melandrya striata in Liriodendron, Falls Church, Va., T. E. Snyder. $2 \sigma^{\top}$, from Melandrya striata, Delaware Co., Ohio, D. J. and J. N. Knull. $\sigma^{7}$, from either "Leptura" or Melandrya striata in Fraxinus, Sycamore Island, Md., May 20, 1917, F. C. Craighead.

This species is in the Alleghanian and Carolinian faunas. It parasitizes Melandrya striata in decaying hardwood logs. Adults occur mostly in June and July.

\section{Arotes maurus Rohwer}

Arotes maurus Rowher, 1920, Proc. U. S. Nat. Mus., vol. 57, p. 517; $\subsetneq$. Type: $q$, Mission, B. C. (Washington).

Front wing of male 11.5 to $13 \mathrm{~mm}$. long, of female 12 to $15 \mathrm{~mm}$. long; female flagellum about 0.93 as long as front wing; upper hind third of pronotum with fine punctures separated by about 3.0 their diameter; lower half of mesopleurum with rather coarse punctures that are subadjacent or separated by as much as therr diameter; metapleurum with rather coarse subadjacent or crowded punctures; second segment of hind tarsus about 4.0 as long as deep in male, about 3.1 as long as deep in female; ovipositor sheath about 1.25 as long as front wing.

Male: Black. Face, frontal orbit, cheek, large vertical stripe on temple, clypeus, labrum, basal half of mandible, palpi, lower half of antenna, apical 0.35 of flagellum except extreme tip, sometimes spot on anteroventral edge of pronotum, sometimes hind corner of pronotum, sometimes stripe in lower part of mesopleurum, sometimes spot at upper end of prepectal carina, tegula, spot on subtegular ridge, sometimes dash on median lobe of mesoscutum next to notaulus, spot on mesoscutum next to tegula, scutellum, postscutellum, sometimes spot on upper part of metapleurum, some or all of hind part of propodeum, front and middle legs except base of their coxae and sometimes front femur behind, extreme apex of hind coxa, hind trochanters except for spot at base above on the first trochanter, sometimes exterobasal spot on hind femur, apex of hind tibia, basal $0.3 \pm$ of hind tibia, hind tarsus, and apical bands on at least the first four 
abdominal tergites, ivory; wings subhyaline, the front wing with a broadly crescent-shaped infuscate area on its apex.

Female: Black. Much of front orbit, area surrounding mouth, basal 0.6 of mandible, palpi, broad subapical band on flagellum, tegula, sometimes spot on subtegular ridge, postscutellum, more or less of scutellum, front and middle legs except for much of their coxae, upper side of their first trochanters, and hind side of their femora except at base and apex, ivory; extreme apex of hind coxa, front side of hind first trochanter, most of hind second trochanter, small exterobasal spot on hind femur, extreme apex of hind femur, basal 0.65 of hind tibia, and all of hind tarsus, ivory; wings subhyaline, the front wing with a broadly crescent-shaped infuscate area on its apex; apical margin of first four tergites more or less ivory.

This species is very close to Arotes amoenus and may prove to be a subspecies of it.

Specimens: , Bilby, Alta., June 20, 1924, G. Salt (Washington). $0^{7}$, Agassiz, B. C., May 14, 1926, R. Glendenning (Ottawa). ㅇ, Courtenay, B. C., July 21, 1930, J. D. G. (Ottawa). $2 \sigma^{x}$, Cultus Lake, B. C., July 13 and 14, 1948, H. R. Foxlee (Ottawa). o, Cultus Lake, B. C., July 21, 1948, H. R. Foxlee (Ottawa). 2 \% (type and paratype), Mission, B. C., July 1904 (Washington). $\sigma^{7}$, Itasca Park,

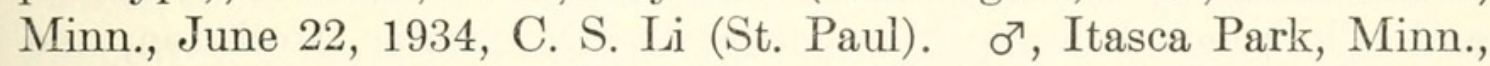
June 23, 1933, L. W. Orr (Townes). ๆ, Yankee Bend, Sask., July 11, 1926, N. J. Atkinson (Ottawa).

This species occurs from Minnesota to British Columbia.

\section{Arotes decorus (Say)}

Figure 328,a

Acaenitus decorus Say, 1836, Boston Journ. Nat. Hist., vol. 1, p. 248 (Leconte ed., vol. 2, p. 702); 우 , ( $\sigma^{7}$ misdetermined). Type: $\uparrow$, Indiana (destroyed).

Front wing 10.5 to $12.5 \mathrm{~mm}$. long in male, 12 to $13 \mathrm{~mm}$. long in female; female flagellum about 0.93 as long as front wing; upper hind third of pronotum with medium sized punctures separated by about 1.5 their diameter; metapleurum with medium-sized punctures that are separated by about 0.6 their diameter; second segment of hind tarsus about 3.7 as long as deep in male, about 2.7 as long as deep in female; ovipositor sheath about 1.35 as long as front wing.

Black. Face, frontal orbit, cheek, temple (for its entire width at and below the middle, for part of its width above), clypeus, labrum, basal 0.45 of mandible, palpi, lower side of antenna of male, part of lower side of scape and pedicel of female, broad postmedian band on flagellum, lower half of propleurum, broad anteroventral and narrow upper margin of pronotum, tegula, subtegular ridge, lower part and most of front part of mesopleurum, marginal stripe on lower side of 
sternaulus (porteriorly joining ivory area on mesopleurum), epimeron, broad $V$-shaped marginal mark on sides and back of middle lobe of mesoscutum, narrow inner and broader outer margins of lateral lobe of mesoscutum, scutellum and postscutellum and areas laterad of both, large oval area covering most of metapleurum, hind $0.5 \pm$ of propodeum, apical bands on all tergites (the bands on basal tergites with a narrow apical blackish margin), ivory; front and middle legs ivory, their coxae dark brown at base, beyond trochanters tinged with fulvous in male, colored pale fulvous in female; hind coxa black with large dorsal and ventral ivory areas that usually fuse posteriorly; hind first trochanter ivory, its base blackish, a stripe on its frent face brown; hind second trochanter blackish, usually with a whitish area below; hind femur fulvous, dark brown at base and apex and often brownish dorsally; hind tibia pale fulvous, ivory below in male, often weakly infuscate at apex in female; hind tarsus ivory in male, stramineous in female; subgenital plate whitish, brownish apically, the apical brownish color extending forward somewhat along the ventral edge; wings hyaline, the apex of front wing with a broadly lenticular fuscous spot.

Specimens (12 $\sigma^{\rtimes}, 62$ ㅇ): From Illinois (Edgebrook and Morgan Park); Kansas (Lawrence and Topeka); Louisiana (Mound); Maryland (Plummers Island); Massachusetts (Dorchester, Holliston, and Woods Hole); Michigan (Detroit, East Lansing, and Midland Co.); Missouri (Babler State Park and Cadet); New Jersey (Boonton, Fort Lee, and Moorestown); New York (Bemus Point, Bronxville, Ithaca, North Collins, and West Farms in New York City); Ohio (Cincinnati, Delaware Co., Hardin Co., Montgomery Co., Puritas Springs in Cuyahoga Co., and Put-in-Bay); Ontario (Ancaster); Pennsylvania (Allegheny Co., Guyasuta Run near Pittsburgh, Harrisburg, Jeannette, Linglestown, Overbrook, Philadelphia, Pittsburgh, Presque Isle in Erie Co., Shiremanstown, and Valley Forge); Texas (Brazos River at Richmond and Dallas); Virginia (Great Falls and Jones Creek in Lee Co.); and Wisconsin (Milwaukee Co.).

Dates of capture are mostly from June 15 to August 10 . Those outside of this range are: June 13 at Cincinnati, Ohio, and at Ithaca, N. Y.; and Aug. 12 at Boonton, N. J., and at Ithaca, N. Y.

Reared specimens include: $1 \sigma^{x}, 2 \circ$, from Tomoxia bidentata in Carya, Linglestown, Pa., May 22 and 26 and Aug. 3, 1915, W. S. Fisher; and rearings from Carya at three localities without specification of the insect host.

This species is in the Alleghanian and Carolinian faunas. It has been reared from cerambycids in Carya. Adults occur mostly from June 15 to August 10. 

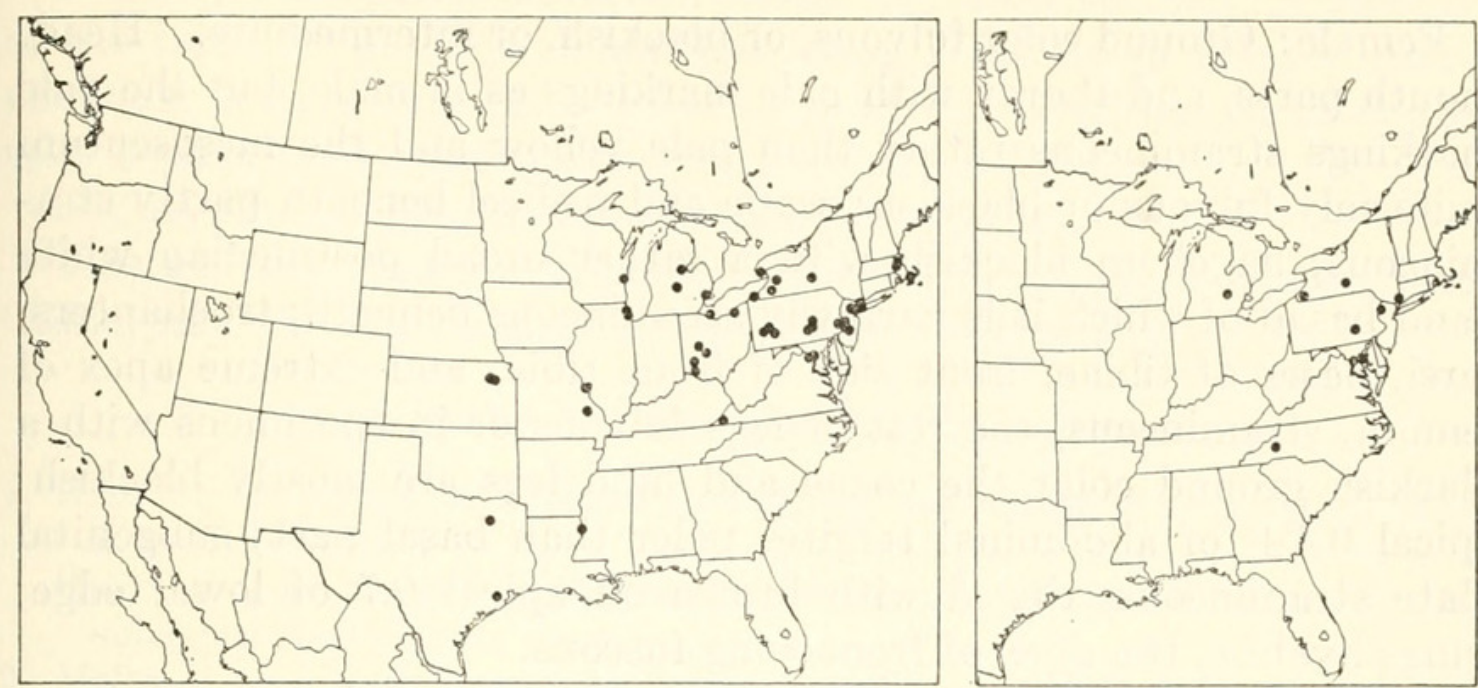

Figure 275, 276.-Localities: 275 (left), Arotes decorus; 276 (right), A. melleus.

\section{Arotes melleus (Say)}

Figure $328, \mathrm{~b}$

Acaenitus melleus Say, 1836, Boston Journ. Nat. Hist., vol. 1, p. 249 (Leconte ed., vol. 2, p. 703); + . Type: $\uparrow$, Indiana (destroyed).

Front wing 9 to $10.5 \mathrm{~mm}$. long in both sexes; female flagellum about 0.78 as long as front wing; upper hind third of pronotum with small punctures, separated by about 2.5 their diameter; metapleurum with rather small punctures that are separated by about 1.5 their diameter; second segment of hind tarsus about 2.7 as long as deep in male, about 2.0 as long as deep in female; ovipositor sheath about 0.93 as long as front wing.

Male: Black. Face, frontal orbit, cheek, lower 0.7 of temple, clypeus, labrum, basal 0.6 of mandible, palpi, under side of antenna, a broad postmedian band on flagellum, lower 0.25 of propleurum, narrow hind corner and anteroventral edge of pronotum, tegula, subtegular ridge, irregular longitudinal area in lower part of mesepisternum and lateral part of mesosternum (sometimes broadened to include most or all of mesosternum), mesepimeron, sometimes longitudinal mark in upper hind part of metapleurum, lateral edge and sometimes central spot on mesoscutum, scutellum and postscutellum and small areas to each side of these, irregular apical $0.3 \pm$ of propodeum, and apical band on each tergite pale yellow, the band on the first two tergites with the apical margin narrowly brownish; mesoscutum sometimes partly fulvous; front and middle legs pale yellow, the front femur with a brownish area behind; hind coxa sometimes largely fulvous, always broadly pale yellow beneath; hind femur blackish or more or less fulvous, the extreme apex pale yellow; hind trochanters and tarsi pale yellow; hind tibia infuscate, pale yellow basally and beneath; wings hyaline, the apex of front wing fuscous. 
Female: Ground color fulvous, or blackish, or intermediate. Head, mouth parts, and thorax with pale markings as in male, but the pale markings stramineous rather than pale yellow and the mesoscutum uniformly fulvous or blackish; scape and pedicel beneath partly stramineous; flagellum blackish with a rather broad postmedian white band basad of which it is narrowly stramineous beneath; trochanters, tarsi, bases of tibiae, front side of front tibia, and extreme apex of femora, stramineous, the rest of legs fulvous or in specimens with a blackish ground color the coxae and hind legs are mostly blackish; apical $0.4 \pm$ of abdominal tergites paler than basal part; subgenital plate stramineous, tinged with brown on apical 0.7 of lower edge; wings hyaline, the apex of front wing fuscous.

The normal ground color of the female is fulvous. In one specimen from Livingston County, Mich., however, it is blackish, and in another from the same locality intermediate between blackish and fulvous.

Specimens: +, Washington, D. C., June 20, 1948 (Washington). $\sigma^{7}$, Bowie, Md., May 30, 1944, H. K. Townes (Washington.) $70^{7}$, , George Reserve, Livingston Co., Mich., June 24, 1956, H. K. Townes (Townes). ㅇ, George Reserve, Livingston Co., Mich., July 1, 1956, H. K. Townes (Townes). \&, Delaware Water Gap, N. J., July 8 (Washington). $\sigma^{\top}, 2$, , Bemus Point, N. Y., July 18, 1937, H. K. Townes (Washington and Townes). क, Millwood, N. Y., June 28, 1936, H. K. Townes (Townes). ㅇ, Ithaca, N. Y., July 2, 1947 (Ottawa). ㅇ, 6 Mile Creek, Ithaca, N. Y., July 21, 1939, P. P. Babiy (Townes). $\sigma^{7}$, Black Mts., N. C., June 10 to 13, 1912, Benten Muller (Ithaca). $\sigma^{\top}$, reared from Anoplodera vittata in Tsuga canadensis, Inglenook, Pa., emerged June 3, 1913, F. C. Craighead (Washington).

This species occurs in the Alleghanian and Carolinian faunas. Our specimens were collected in moist deciduous woods.

\section{Genus Spilopteron, new genus}

Figure $309, \mathrm{~b}$

Front wing 8 to $15 \mathrm{~mm}$. long; clypeus rather short, with a strong, sharp, subapical transverse ridge; exposed portion of labrum about 0.4 to 0.8 as long as wide; occipital carina complete; flagellum long and slender, its median segments about 2.0 as long as wide; intercubitus opposite second recurrent, or distad of it by as much as 0.15 its length; nervellus broken near or a little above the middle; front and middle tarsal claws with an acute accessory tooth near their midlength; hind femur rather slender; hind tarsal claws simple; first sternite with numerous long erect hairs on its swelling; ovipositor apically without transverse ridges or with a very few, fine, widely spaced ridges. See also the characters in the key. 
The Nearctic species all have a subcircular blackish spot in the apex of the front wing. The similar-appearing Nearctic species of Arotes also have a dark spot in the apex of the front wing, but in these the spot is paler, and crescentic rather than subcircular.

Genotype: Spilopteron franclemonti, new species.

This genus includes a number of species in Japan, Formosa, and China, and the four Nearctic species described below.

\section{Key to the Nearctic species of Spilopteron}

1. Hind femur fulvous, its extreme base brown, sometimes its apex with a weak infuscation

Hind femur mostly or entirely black, or sometimes fulvous with a conspicuous subapical blackish area . . . . . . . . . . . . . . . . . . . . . 5

2. Males . . . . . . . . . . . . . . . . . . . 3

Females. . . . . . . . . . . . . . . . . . 4 4

3. Flagellum with a broad postmedian yellowish band; mesopleurum mostly blackish or fulvous . . . . . . . . . . . . . . . 3. vicinum (Cresson)

Flagellum without a yellowish band; mesopleurum mostly yellow.

4. occiputale (Cresson)

4. Third and following tergites dark brown and fulvous, the markings not sharply contrasting . . . . . . . . . . . . . . . . 3. vicinum (Cresson)

Third and following tergites black and yellow, the markings sharply contrasting.

4. occiputale (Cresson)

5. Front wing without a fuscous spot over base of radius, except rarely for a small faint spot in some females (fig. 319,i); punctures on metapleurum separated by 0.2 to 1.0 their diameter; apical $7 \pm$ segments of flagellum blackish; scutellum with indistinct lateral carina extending most of its length.

1. franclemonti, new species

Front wing with a fuscous spot over base of radius, small in males, larger in females (fig. 319,j); punctures on metapleurum dense, subadjacent; apical $13 \pm$ segments of flagellum blackish; scutellum with lateral carina only at base.

2. formosum (Cresson)

\section{Spilopteron franclemonti, new species}

Figures 319 ,i; 328,c

Front wing 11 to $14 \mathrm{~mm}$. long; head about 0.91 as wide across midlength of temples as across eyes; punctures on metapleurum of moderate size, separated by about 0.5 to 0.8 their diameter; scutellum with indistinct lateral carina extending most of its length; ovipositor sheath about 1.04 as long as front wing.

Black. Head yellow with the top of head, frons except laterally, and occiput black. In the female the central part of face is usually partly or entirely black or dark brown, a common pattern being a median longitudinal and a sublateral, concentrically curved, dark brown stripe. Antenna with a subapical broad pale yellow band, the apical $7 \pm$ segments blackish, and more or less pale yellow beneath, basad of the band. Thorax with more or less of lower part of pro- 


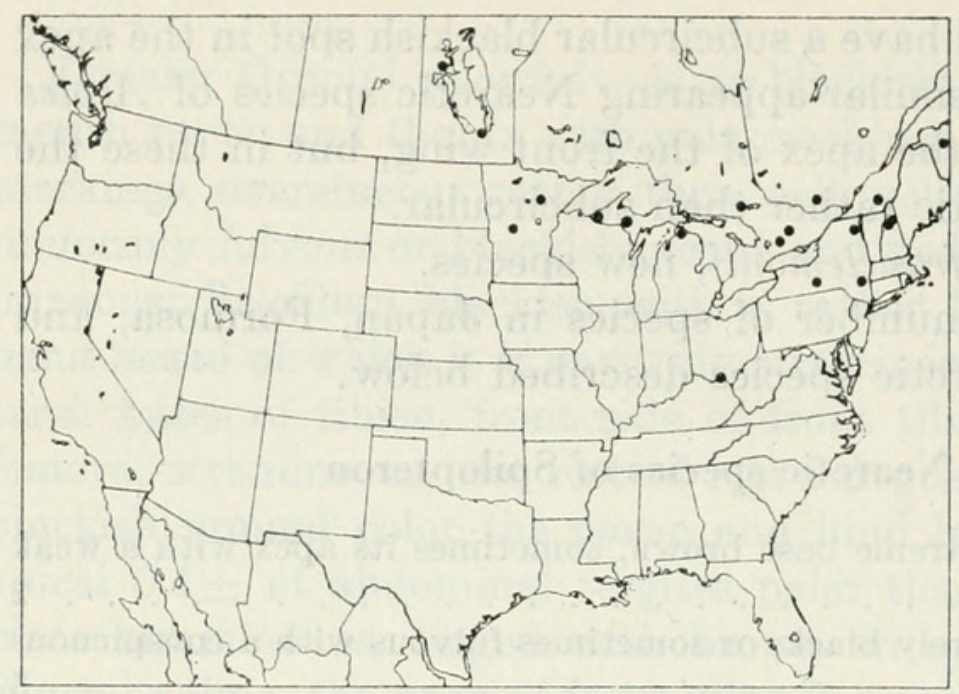

Figure 277.-Localities for Spilopteron franclemonti.

pleurum, narrow anteroventral margin and hind corner of pronotum, tegula, subtegular ridge, usually a spot on mesopleurum next to base of middle coxa, mesepimeron, sometimes a narrow stripe on mesosternum next to sternaulus, large elliptical spot in upper hind part of metapleurum, usually the apex and sides of median lobe of mesoscutum, lateral edge and rarely mesal edge of lateral lobe of mesoscutum, scutellum, postscutellum and adjacent part of metanotum, and apical $0.35 \pm$ of propodeum, pale yellow; front and middle legs pale yellow, in the female the coxae partly black basally and the femora partly pale brown behind; hind coxa black, in the male pale yellow below, its apex narrowly pale yellow; hind trochanters and hind tarsus pale yellow; narrow apex and obscure subbasal ring on hind femur pale yellow, the hind femur of male more or less pale yellow below; hind tibia of male pale yellow basally, below, and at apex, the rest somewhat infuscate; hind tibia of female pale yellow basally, the rest yellowish fulvous, brownish toward apex, but at the extreme apex fulvous; first tergite often more or less pale yellow basally; first four through six tergites of male with a broad pale yellow apical band; first two tergites of female with a broad pale yellow subapical band which does not reach the lateral margin; third through fifth tergites of female with variously developed or interrupted, narrow subapical pale yellow bands; ventral part of fourth through seventh tergites and under side of abdomen pale yellow; female subgenital plate pale yellow with a subventral brown stripe that is strongest apically; wings hyaline, the front wing with a large, subcircular, fuscous spot in its apex, and in some females with a small faint fuscous spot over base of radius.

The specimens from Michigan and Minnesota have the punctures on the metapleurum denser (separated by about 0.5 their diameter) and the yellow markings a little less extensive than in specimens from farther east. They may represent a distinguishable subspecies. 
Type: o , Ithaca, N. Y., Aug. 3, 1940, J. G. Franclemont (Washington, USNM 63741).

Paratypes $\left(4 \sigma^{7}, 21 \%\right)$ : From Manitoba (Cedar Lake and Teulon); Michigan (Cheboygan, Floodwood in Dickinson Co., and Gogebic Co.); Minnesota (Alexandria and Bovey); New Brunswick (Bathurst and Nictau); New Hampshire (Franconia and Mount Washington); New York (Ithaca, summit of Mount Whiteface, and Onteora Mt. in Greene Co.); Ohio (Scioto Co.); Ontario (near Bancroft, Bobcaygeon, and Sudbury); and Quebec (Alcove and Sherbrooke).

Dates of collection are from June 3 to August 3. Most are from June 21 to July 27.

This species is in the Canadian and Transition zones of the east. Most adults occur from about June 20 to the end of July.

\section{Spilopteron formosum (Cresson), new combination}

Figure $319, \mathrm{j}$

Front wing 11.5 to $14.5 \mathrm{~mm}$. long; head about 0.97 as wide across midlength of temples as across eyes; punctures on metapleurum moderately large, separated by about 0.3 their diameter; scutellum with lateral carina only at its base; ovipositor about 1.12 as long as front wing.

Coloration similar to that of $S$. franclemonti but with the following differences: Yellow on temple extending usually about to top of eye (in franclemonti usually ending well below top of eye); apical $13 \pm$ segments of flagellum black; yellow markings on thorax a little more extensive, there being usually a yellow stripe on mesal side of lateral lobe of mesoscutum and usually an irregular yellow stripe in lower part of mesopleurum; hind femur and tibia variable, according to the subspecies; abdomen of both sexes, but especially of female, usually more evenly and completely banded (in female usually the basal five tergites or more with a complete band); subgenital plate of female with a basolateral brown area; and front wing with a fuscous spot over base of radius, small in male, larger in female.

There is a northern and a southern subspecies, with color differences as stated in the key:

1. Hind femur largely or almost entirely blackish (its extreme apex whitish, its base sometimes largely fulvous, and in males a broad stripe on front face yellowish white); hind tibia stramineous, more or less weakly infuscate except basally, at extreme apex, and of ten below (fig. 328,d); range: Alleghanian fauna . . . . . . . 2a. formosum formosum (Cresson)

Hind femur fulvous, its subapical $0.2 \pm$ blackish; hind tibia rather uniformly pale fulvous (fig. 328,e); range: Carolinian and Austroriparian faunas.

2b. formosum australe, new subspecies 


\section{2a. Spilopteron formosum formosum (Cresson)}

Figure 328,d

Arotes formosum Cresson, 1868, Canadian Ent., vol. 1, p. 34; $\sigma^{7}$. Type: $\sigma^{7}$, Ottawa, Ont. (Philadelphia).

The key states the differences between this subspecies and the next.

In two of the males reared at Inglenook, Pa., reported below, the coloration is more like that of S.formosum australe than of the present subspecies. They are assigned to the subspecies formosum, however, because they are within its range and because the coloration may have been shifted toward that of the subspecies australe by abnormal climatic conditions in the laboratory, rather than by genetic factors. Though these two and other specimens show that the subspecific distinction is tenuous, it nevertheless seems a useful one for separating a generally northern from a generally southern population.

Specimens (12 $\sigma^{\gamma}, 27$ ) : From Connecticut (Colebrook); Manitoba (Treesbank); Michigan (Ann Arbor, Floodwood in Dickinson Co., and Mecosta Co.); Minnesota (Cass Co. and Kittson Co.); New Jersey (Alpine); New York (Bluff Island near Clayton and West Point); Ohio; Ontario (Ottawa, Bells Corners, and Thunder Bay Beach); Pennsylvania (Clarks Valley near Dauphin, Harrisburg, and Inglenook in Dauphin Co.); Quebec (Aylmer, Covey Hill, Montreal, North River near St. Adele, and Wakefield); Vermont (Laurel Lake near Jacksonville and West Rupert); and West Virginia (Lewisburg).

Most collecting dates are in July but there are a number in June and August. The earliest and latest dates are: June 5 in Clarks Valley, near Dauphin, Pa.; June 6 in Ohio; June 11 at West Point, N. Y.; June 27 at Alpine, N. J.; August 12 in Kittson Co., Minn.; August 18 at Treesbank, Man.; August 19 at Lewiston, W. Va.; and August 21 at Wakefield, Que.
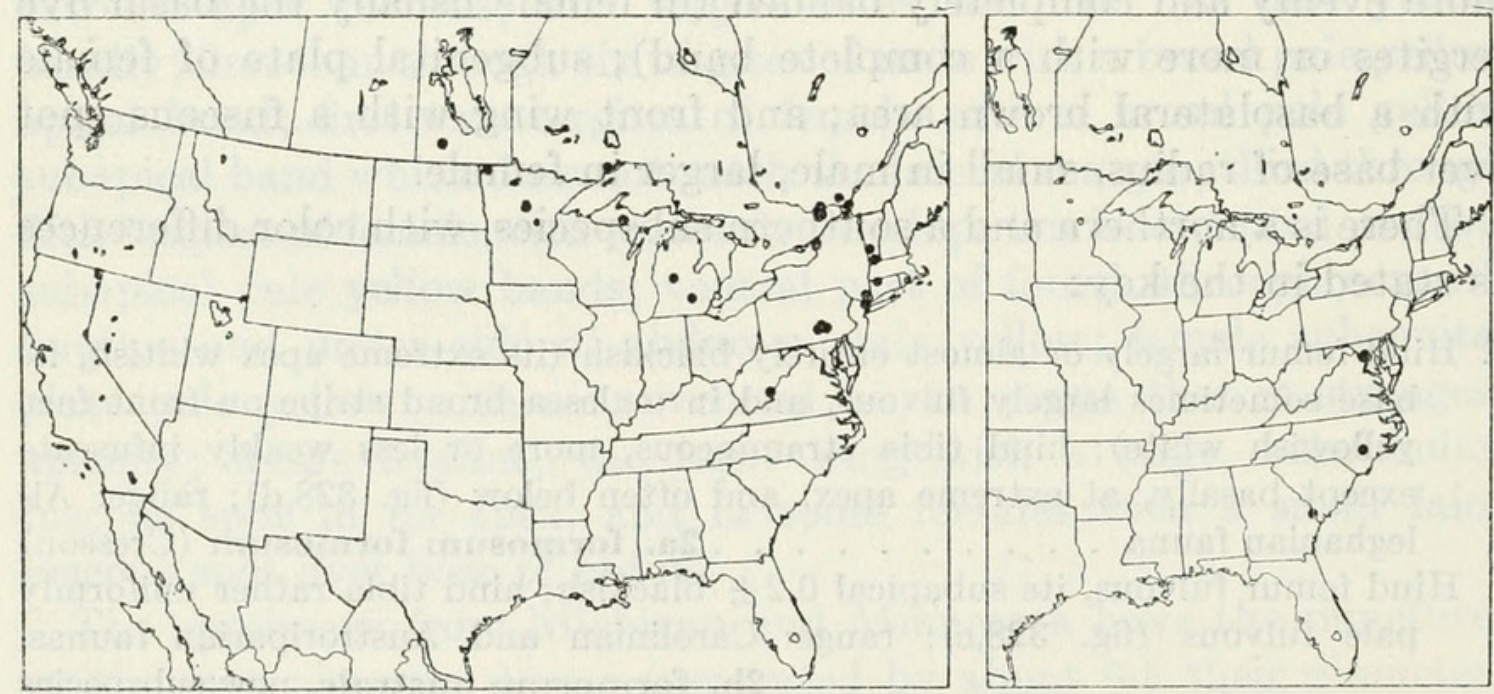

Figure 278, 279.-Localities: 278 (left), Spilopteron formosum formosum; 279 (right), S. f. australe. 
Four males were reared from Bellamira scalaris in Betula nigra, Inglenook, Pa., 1922, Champlain and Knull.

This subspecies is in the Alleghanian fauna. Adults occur mostly in July.

\section{2b. Spilopteron formosum australe, new subspecies}

Figure 328,e

The key states the differences between this subspecies and the one preceding.

Type: ㅇ, Clinton, N. C., May 24, 1951, H. and M. Townes (Washington, USNM 63742).

Paratypes: 2ㅇ, Rock Creek Park, Washington, D. C., July 12, 1906, C. E. Burden (Washington). 2\%, reared from decayed log of Liquidambar, Clyo, Ga., May 3, 1922, R. A. St. George (Washington). ㅇ, Cabin John, Md., June 26, 1916 (Townes). 2ㅇ, Plummers Island, Md., June 6, 1912, H. S. Barber (Washington). $\sigma^{7}$, North Carolina, T. Pergande (Washington).

This subspecies occurs in the Carolinian fauna.

\section{Spilopteron vicinum (Cresson), new combination}

Front wing 10.5 to $14 \mathrm{~mm}$. long; head about 0.90 to 0.95 as wide across midlength of temple as across eyes; punctures on metapleurum moderately coarse, separated by about 1.25 their diameter; scutellum with lateral carina only at its base; ovipositor sheath about 0.93 as long as front wing.

There is an eastern and a western subspecies, separable on color as described below:

1. Mesopleurum black, its subtegular ridge yellow; range: Canadian and Transition zones of eastern North America . . 3a. vicinum vicinum (Cresson)

Mesopleurum mostly fulvous or light brown, its subtegular ridge yellow and restricted areas blackish; range: Minnesota to British Columbia; also Nova Scotia. . . . . . . 3b. vicinum melanderi, new subspecies

\section{3a. Spilopteron vicinum vicinum (Cresson)}

Figure 328 ,f

Arotes vicinum Cresson, 1869, Trans. Amer. Ent. Soc., vol. 2, p. 260; $\sigma^{7}$. Type: $\sigma^{7}$, Massachusetts (Philadelphia).

Arotes venustus Cresson, 1869, Trans. Amer. Ent. Soc., vol. 2, p. 260; ð7, ㅇ. Lectotype: $\uparrow$, Massachusetts (Philadelphia).

Arotes superbus Provancher, 1874, Naturaliste Canadien, vol. 6, p. 81; ơ ,. Lectotype: $q$, Quebec (Quebec).

Head about 0.91 as wide across midlength of temples as across eyes.

Male: Head yellow, the top of head, a finger extending downward on frons toward each antennal socket, most of occiput, and a narrow hind margin on eye blackish brown, an area on cheek medium brown; 
mouth parts yellow; antenna blackish, the scape and pedicel beneath, broad postmedian band on flagellum, and flagellum beneath basad of its band, yellow, the apical $13 \pm$ segments entirely black; thorax blackish, the lower edge of propleurum, irregularly broad anteroventral margin of pronotum, extreme hind corner of pronotum, tegula, subtegular ridge, usually a narrow stripe on mesosternum next to sternaulus, mesoscutum laterally and near notauli, scutellum, postscutellum, and posterior $0.5 \pm$ of propodeum, yellow; front and middle legs yellow, the extreme bases of their coxae blackish brown; hind coxa blackish, yellow below and often with ferruginous areas above; hind trochanters and tarsus yellow; hind femur fulvous, its front face more or less yellowish, its extreme base brown, and sometimes with a small subapical area weakly infuscate; hind tibia yellow to pale fulvous, a little paler basally, its apex sometimes tinged with brown; abdomen blackish brown basally, fulvous brown apically, each tergite with a broad, almost apical yellowish fulvous band, the ventral part of abdomen yellowish fulvous; wings subhyaline, the front wing with a large, subcircular, fuscous spot in its apex and sometimes with a very faint infuscation over base of radial vein.

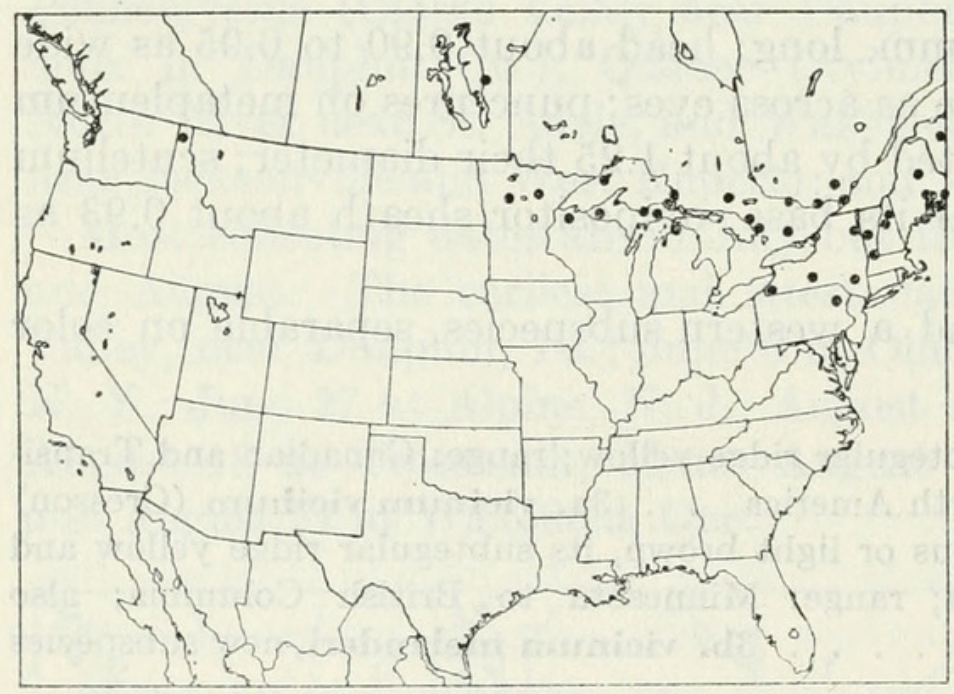

FIgURE 280. --Localities for Spilopteronvicinumvicinum.

Female: Head blackish brown, the face except for a sublateral vertical brown stripe, the frontal orbit, the lower $0.7 \pm$ of temple, cheek except for a median brownish area, clypeus, and mouth parts, brownish yellow; antenna blackish, the scape and pedicel yellowish brown beneath, basal part of flagellum yellowish beneath, and flagellum with a broad postmedian yellow band, its apical $13 \pm$ segments black; thorax black, the propleurum brownish with its lower margin yellowish, pronotum dark brown with light brown near its upper and lower edges, mesoscutum light brown with its three lobes medially dark brown, tegula yellow, subtegular ridge yellow, scutellum and postscutellum yellow, and apical $0.5 \pm$ of propodeum yellow; coxae brown- 
ish fulvous, the hind coxae and to a lesser extent the middle and front coxae more or less blackish brown basally and apically; front and middle legs yellowish fulvous; hind trochanters and tarsus yellow; hind femur fulvous, the extreme base brown and sometimes with a faint brownish subapical area; hind tibia yellowish fulvous; abdomen colored as in male but the colors a little less contrasted; subgenital plate fulvous, its apex blackish, and with a thin blackish line extending forward from the blackish tip just above the ventral edge; wings colored as in male.

Specimens (39 ఠ , 57 $)$ ): From Colorado; Idaho (Priest Lake); Maine (Bangor, Bar Harbor, Baxter State Park, Brewer, Brooksville, Lincoln Co., Machias, "Round Pond Mt.," and Waldoboro); Manitoba (Berens River); Massachusetts; Michigan (Cheboygan Co., Gogebic Co., Isle Royale, Munising, Doyle Township in Schoolcraft Co., and Whitefish Point in Chippewa Co.); Minnesota (Bovey and Lake Itasca); New Brunswick (Bathurst and Nictau); New Hampshire (Franconia and Randolph); New York (Bemus Point, Big Indian Valley in the Catskill Mts., Bluff Island near Clayton, Ithaca, and New Russia); Northwest Territories (Fort Simpson); Ontario (Footes Bay, Frater, Hastings Co., Petawawa Reservation, Sudbury, and Waubamik); Pennsylvania (Spring Brook); Prince Edward Island (Brackley Beach and Dalvay House, both in Canadian National Park); Quebec (Lac Tremblant Nord, Montreal, "N. Tumiskaming," and Queens Park in Aylmer); Vermont (Laurel Lake near Jacksonville and Rutland); West Virginia ("Cranberry Gls."); and Wisconsin (Sawyer Co.).

Dates of collections are from July 11 to Aug. 18, except for the following: April 14 at Willis, Tex.; June 21 at Nictau, N. B.; June 22 at Lake Itasca, Minn.; August 25 at Frater, Ont., and in Baxter State Park, Maine; September 15 at Bar Harbor, Maine; and September 20 at Footes Bay, Ont.

A female was reared from Anoplodera nigrella at N. Tumiskaming, Que., by F. C. Craighead.

This subspecies is in northern coniferous woods, in the eastern half of the continent. Adults occur mostly in mid-summer.

\section{3b. Spilopteron vicinum melanderi, new subspecies}

Head about 0.94 as wide across midlength of temples as across eyes. Coloration as in $S$. vicinum vicinum except that the blackish areas are restricted in area and largely replaced by fulvoferruginous or reddish brown. The mesopleurum is usually less than 20 percent black, the rest being reddish brown or paler, and the metapleurum has its upper front 20 percent usually fulvoferruginous, the rest being blackish brown. 
Occasional specimens, well within the range of this subspecies, have the mesopleurum mostly black as in the subspecies vicinum, but have the temple a little wider than in typical vicinum. Because of their wider temples and their locality, they are assigned to the subspecies melanderi.

Type: o, 4-mile camp at Priest Lake, Idaho, August 1920, A. L. Melander (Cambridge).

Paratypes $\left(3 \sigma^{7}, 21\right.$ ) : From British Columbia (Okanagan Valley, Osoyoos, Robson, and Trinity Valley near Lumby); Idaho (4-mile camp at Priest Lake); Manitoba (Teulon and Victoria Beach); Michigan (Douglas Lake in Cheboygan Co.); Minnesota (Basswood Lake in Lake Co., Caribou Creek in Lake Co., Clear River, Itasca, and Lake Itasca); Nova Scotia (MacNob's Island and Truro); Oregon (Portland); and Wisconsin (Sawyer Co.).

Collection dates are distributed from June 15 to August 19, and there is one capture on September 11, on MacNob's Island, Nova Scotia.

This subspecies is in northern coniferous forests, mostly from Minnesota to British Columbia. Adults occur mostly in mid-summer.

\section{Spilopteron occiputale (Cresson), new combination}

\section{Figure $328, \mathrm{~g}$}

Arotes occiputalis Cresson, 1869, Trans. Amer. Ent. Soc., vol. 2, p. 260; ơ. Type: $0^{7}$, West Virginia (Philadelphia).

Arotes apicatus Davis, 1898, Trans. Amer. Ent. Soc., vol. 24, p. 366; ㅇ. Type: + Agricultural College [=East Lansing], Mich. (Philadelphia).

Front wing 9 to $12 \mathrm{~mm}$. long; head about 0.84 as wide across midlength of temples as across eyes; punctures on metapleurum moderately small, separated by about 1.8 their diameter; scutellum with
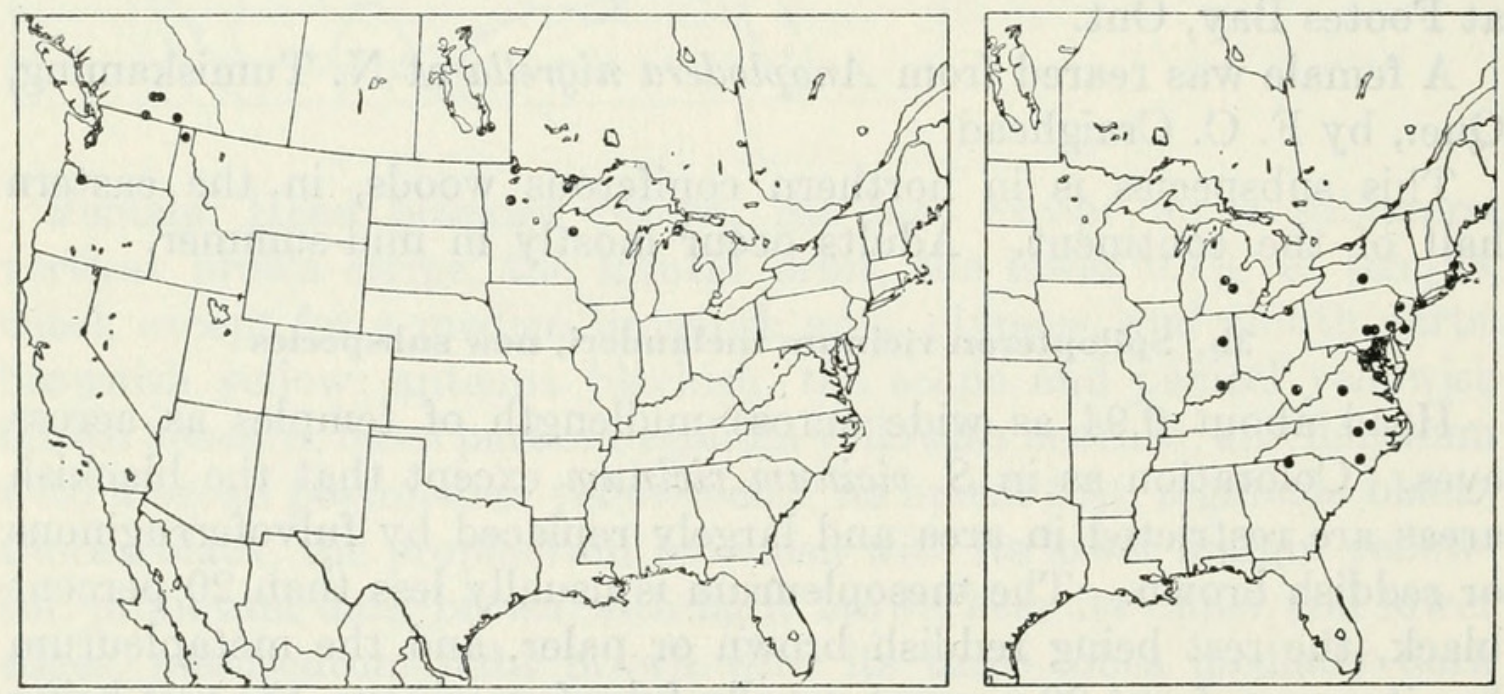

Figure 281, 282.-Localities: 281 (left), Spilopteron vicinum melanderi; 282 (right), S. occiputale. 
lateral carina only at its base; ovipositor sheath about 0.95 as long as front wing.

Male: Lemon yellow. Top of head and upper part of occiput black; antenna blackish brown, yellow or yellowish brown beneath, palest basally; median part of pronotum, usually irregular stripes on mesopleurum, and usually lower part of metapleurum brown or blackish; median stripes on mesoscutal lobes and large basolateral spot on propodeum centering over the first lateral propodeal area, blackish; front and middle tarsi, tibiae apically, and femora behind, tinged with fulvous; hind coxa fulvous, its lower half yellowish, its base and apex above dark brown; hind femur and tibia fulvous, the extreme base of the femur dark brown; median third of first tergite and basal half of second through seventh tergites black; wings hyaline, the front wing with a large, subcircular fuscous spot in its apex.

Female: Head yellow, the top of head, occiput, and frons except laterally, black; face usually with a broad brown to black circular band that encloses a central yellow area, and often with a brownish area next to lateral edge of clypeus; mouth parts yellow; antenna blackish, yellow basally beneath, elsewhere brownish beneath excent at a broad postmedian yellow band, the apical $14.5 \pm$ flagellar segments blackish; thorax black, narrow anteroventral margin and hind corner of pronotum, tegula, subtegular ridge, upper part of mesepimeron, scutellum and postscutellum and areas adjacent to them, and apical $0.4 \pm$ of propodeum, yellow; front and middle legs and hind trochanters and tarsus yellow, somewhat tinged with fulvous; hind coxa fulvous, blackish at base and brown at apex above, rarely almost entirely black; hind femur fulvous, brown at extreme base; hind tibia pale fulvous; abdominal tergites black, the first four tergites with a broad, apical, bright yellow band that does not reach the lateral margin; lower part of fifth through seventh tergites, all of following tergites, and under side of abdomen light yellow; subgenital plate pale yellow, with a subventral brown line that is strongest toward its apex; wings colored as in male.

Specimens $\left(35 \sigma^{7}, 34\right.$ ) : From Indiana (Salamonie River in Huntington Co. and State Forest in Clark Co.); Maryland (Bowie, Cabin John, Fort George G. Meade, Glen Echo, Loch Raven, "Jackson's Island," Odenton, Plummers Island, Reisterstown, and Takoma Park); Massachusetts (Holliston); Michigan (East Lansing and Ionia Co.); New Jersey (Delaware Water Gap and Moorestown); New York (Cold Spring Harbor and Ithaca); North Carolina (Elizabethtown, Rocky Mount, and Wake Co.); Ohio (Puritas Springs in Cuyahoga Co.); Pennsylvania (Carlisle Junction, Laurel, and West Chester); Rhode Island (Kingston and Westerly); South Carolina (Mountain Lake in Greenville Co.); Virginia (Chain Bridge near McLean, Diffi$526527-60-38$ 
cult Run in Fairfax Co., Falls Church, Glencarlyn, Great Falls, Nelson Co., Springfield, and Westmoreland State Park in Westmoreland Co.); and West Virginia (Brush Creek).

Collection dates are mostly from mid-June to early August. The earliest and latest dates of capture are: June 2 at Great Falls, Va.; June 14 at Chain Bridge, Va.; August 5 at Falls Church, Va.; August 6 at Nelson, Va.; and September 7 at Reisterstown, Md. We have found the species moderately common in rich deciduous woods, especially in river and stream bottoms.

A female was reared from Strangalina bicolor in Quercus, at Springfield, Va., May 31, 1912, by T. E. Snyder.

This species is in rich deciduous woods in the Carolinian fauna. Adults occur mostly from mid-June to early August.

\section{Genus Yezoceryx}

Figure 310 ,a

Yezoceryx Uchida, 1928, Journ. Fac..Agr. Hokkaido Univ., vol. 25, p. 36. Type: Yezoceryx scutellaris Uchida; original designation.

Front wing 5 to $11 \mathrm{~mm}$. long; clypeus moderately short to rather long, with a subapical transverse ridge (this ridge obsolescent in the Neartic rupinsulensis); exposed portion of labrum about 0.2 to 0.4 as long as wide; occipital carina complete; intercubitus opposite second recurrent or basad of it by as much as 0.4 its length; nervellus broken near or a little above the middle; front and middle tarsal claws with an acute accessory tooth near their midlength; hind tarsal claws simple; first sternite fused with its tergite, without hairs on its swelling, or rarely in extra-limital species with one or a very few hairs; ovipositor apically without transverse ridges or with a very few, fine, widely spaced ridges.

This is a large genus of the eastern Palaearctic region and the IndoAustralian area. There is a single Nearctic species. It belongs in a species group which has additional representatives in China and Japan.

\section{Yezoceryx rupinsulensis (Cresson)}

Acoenitus rupinsulensis Cresson, 1870, Trans. Amer. Ent. Soc., vol. 3, p. 143; ㅇ. Type: $ᄋ$, Illinois (Philadelphia).

Front wing 7.5 to $8.5 \mathrm{~mm}$. long; temple weakly convex; preapical transverse carina of clypeus obsolescent; flagellum thick and short, in female subclavate, its median segments about 0.75 as long as wide, in male more elongate, the median segments about 1.2 as long as wide; propodeum with a tendency to have irregular rugae across the middle which obscure the carinae, the carinae more distinct in the 
Figure 283.-Localities for Yezoceryx rupinsulensis.

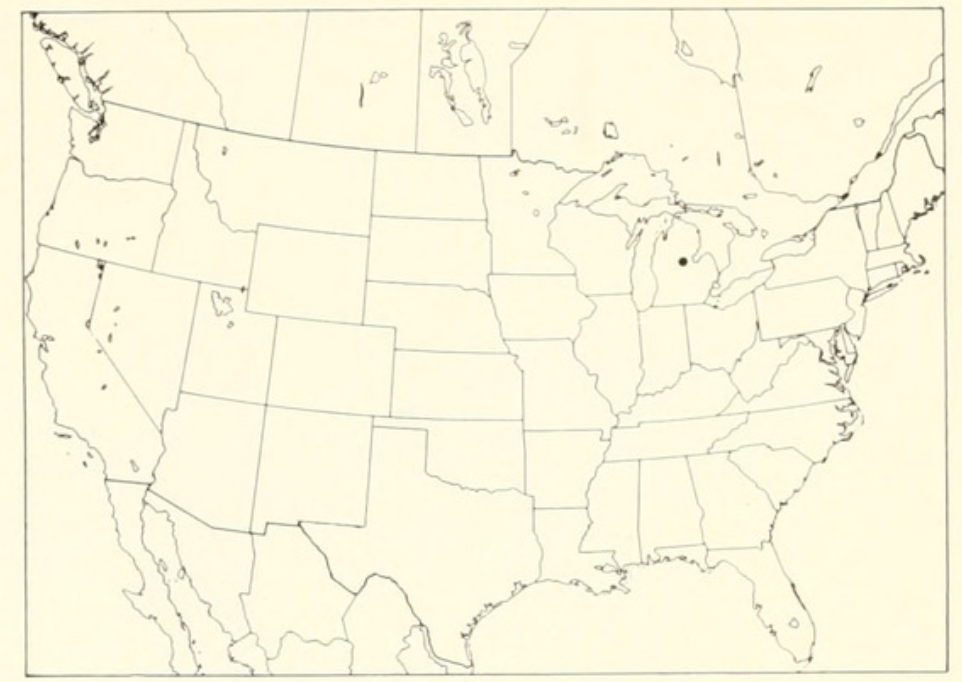

male; intercubitus basad of second recurrent by about 0.4 its length; hind femur about 2.75 as long as deep in male, about 2.6 as long as deep in female; female subgenital plate rather short, its apex narrowly rounded; ovipositor sheath about as long as front wing.

Male: Yellowish fulvous; head mostly yellow, the occiput and upper part of temple fulvous; ocellar area and median 0.45 of frons black; mandible, subtegular ridge, scutellum and the ridge basolaterad of scutellum, apex of femora, and much of front and middle legs yellow or a more yellowish fulvous than body; upper part of propleurum, vague areas on pronotum, most of prepectus and mesosternum, and spot on upper part of mesopleurum with a brown tinge; wings with a fulvous tinge.

Female: Fulvous. Cheek with a brownish area; a broad black stripe extending from ocellar area to top of face; occiput mostly blackish; part of propleurum, groove of pronotum broadly, most of thoracic sternum, and lower part of metapleurum blackish brown; coxae basally and apically, trochanters more or less, and hind femur beneath at apex, brown; ovipositor sheath brown; wings with a fulvous tinge.

Specimens: क (type), Illinois (Philadelphia). ơ , Midland Co., Mich., July 9, 1957, R. and K. Dreisbach (Dreisbach). , Minneapolis, Minn., June 28, 1921, A. A. Nichol (St. Paul). 


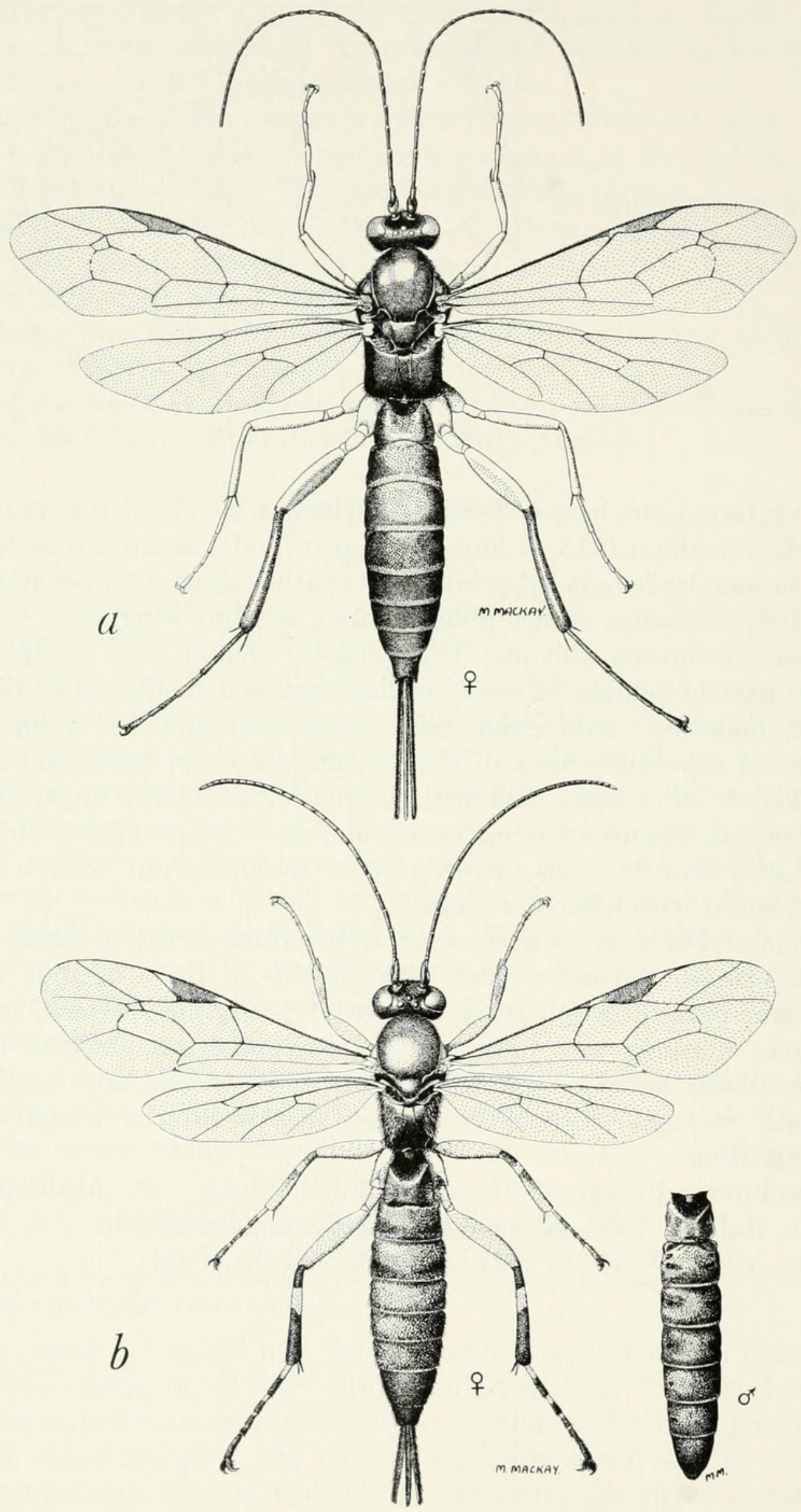

Figure 284.- Habitus of two typical Ephialtinae: a, Coccygomimus pedalis, $q$; b, Itoplectis quadricingulata, $q$, and abdomen of $\sigma^{\top}$. 


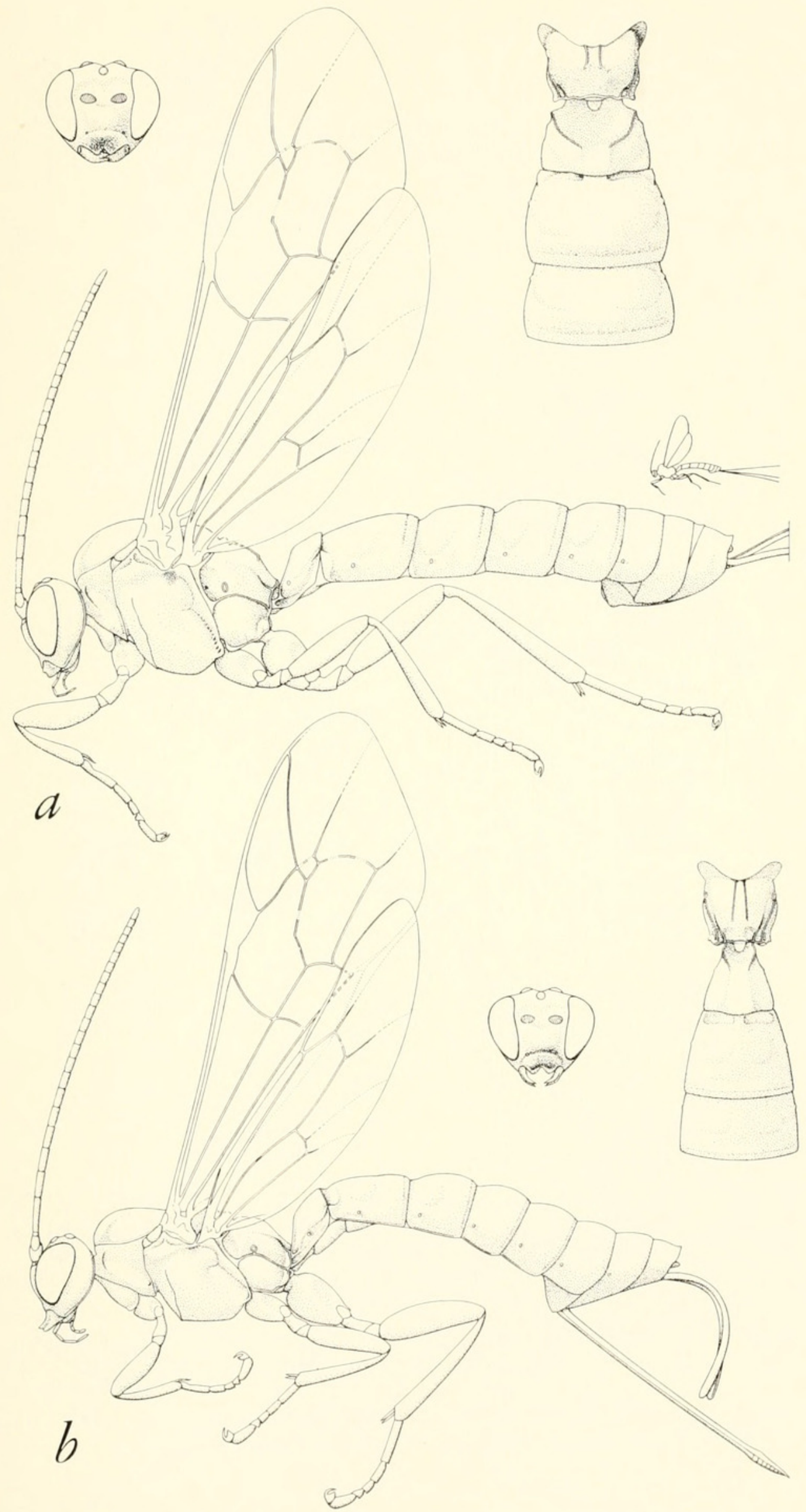

Figure 285.-a, Exeristes roborator, q, genotype of Exeristes; b, Scambus (Endromopoda) detritus, + , a typical species of the subgenus Endromopoda. 


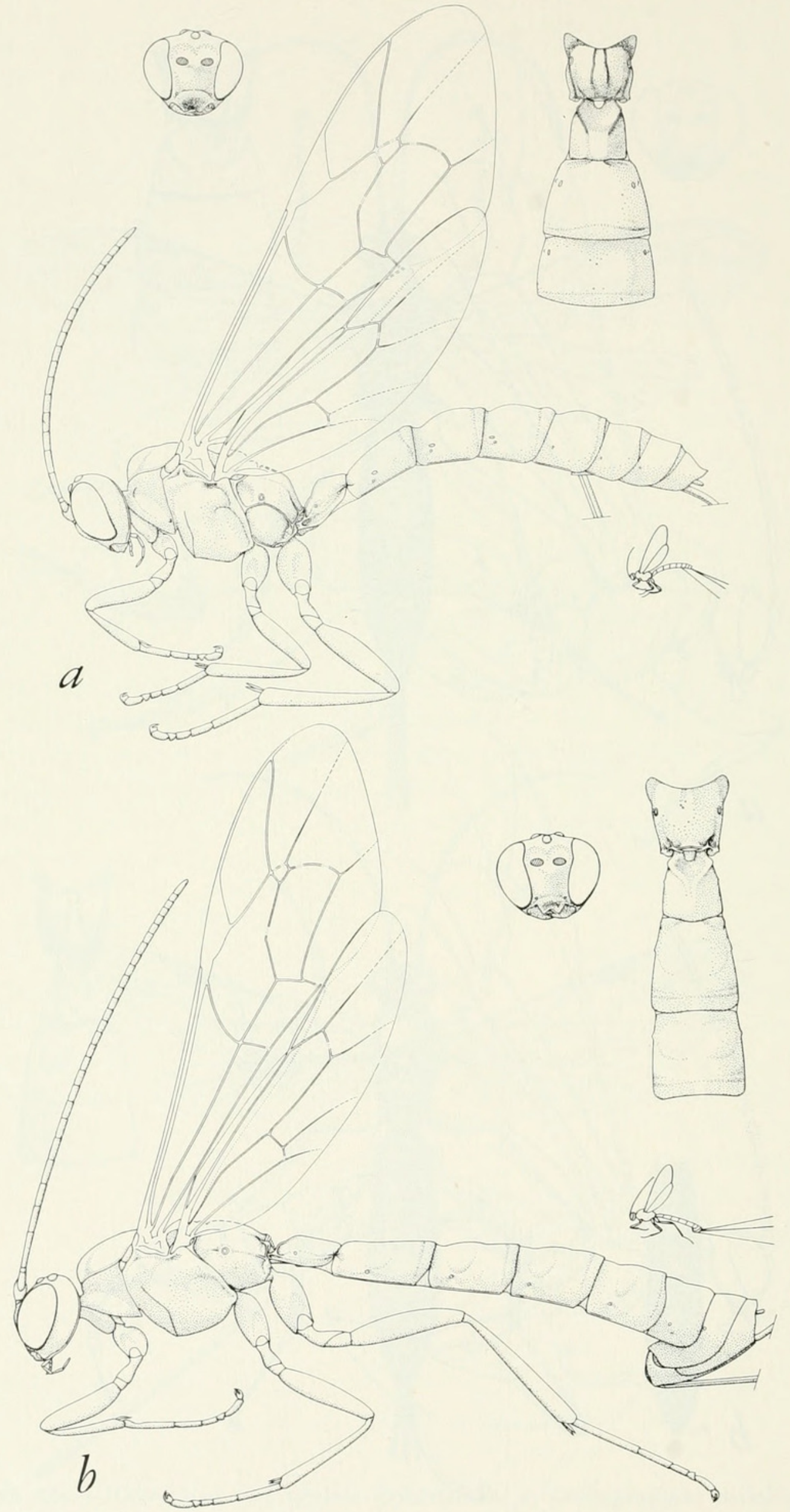

Figure 286.- a, Scambus tecumseh, $q$, a typical species of the subgenus Scambus; b, Calliephialtes grapholithae, $q$, genotype of Calliephialtes. 


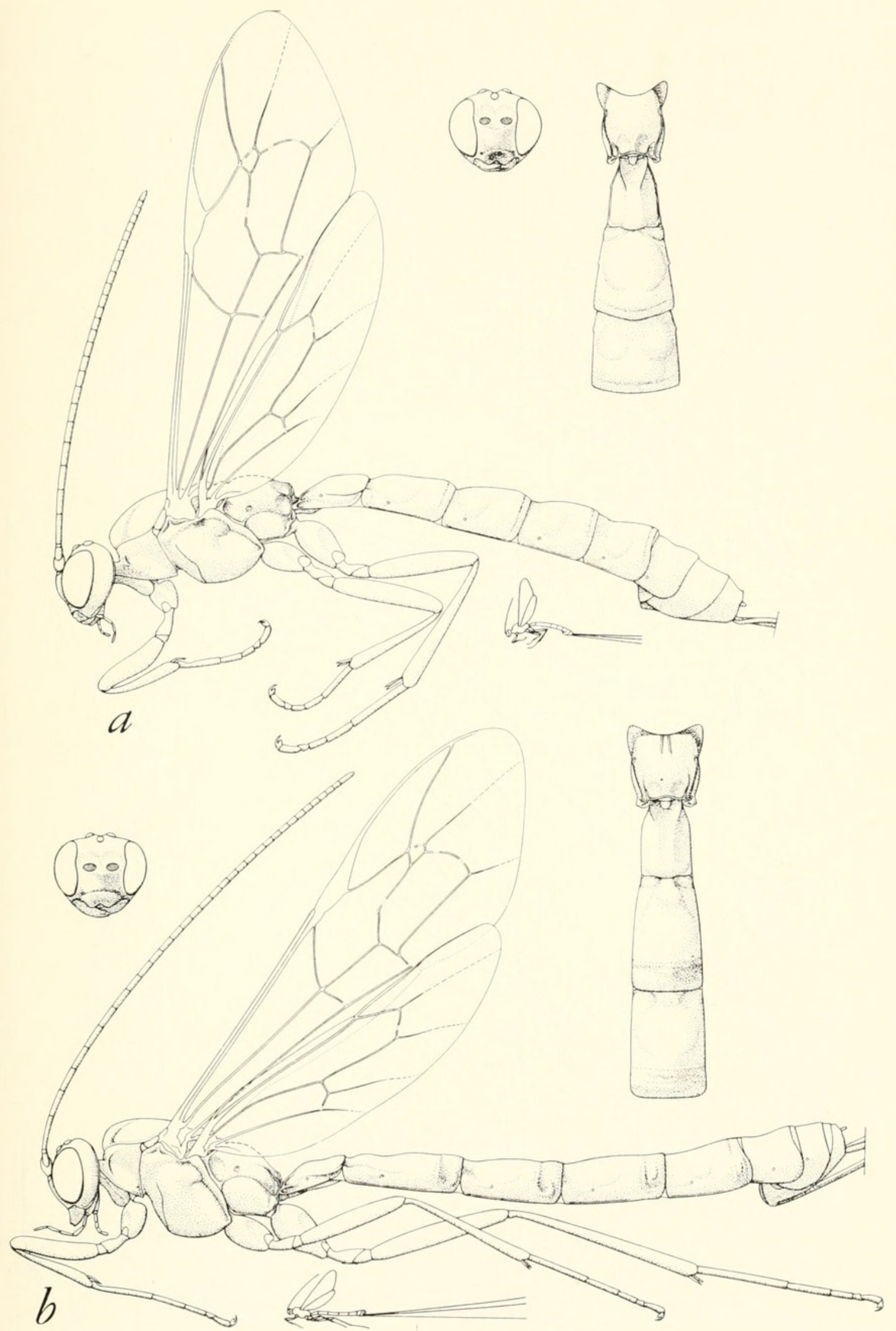

Figure 287.- a, A pistephialtes nucicola, $q$, a typical species of Apistephialtes; b. Pimpla manifestator?, \&, a typical species of Pimpla. 


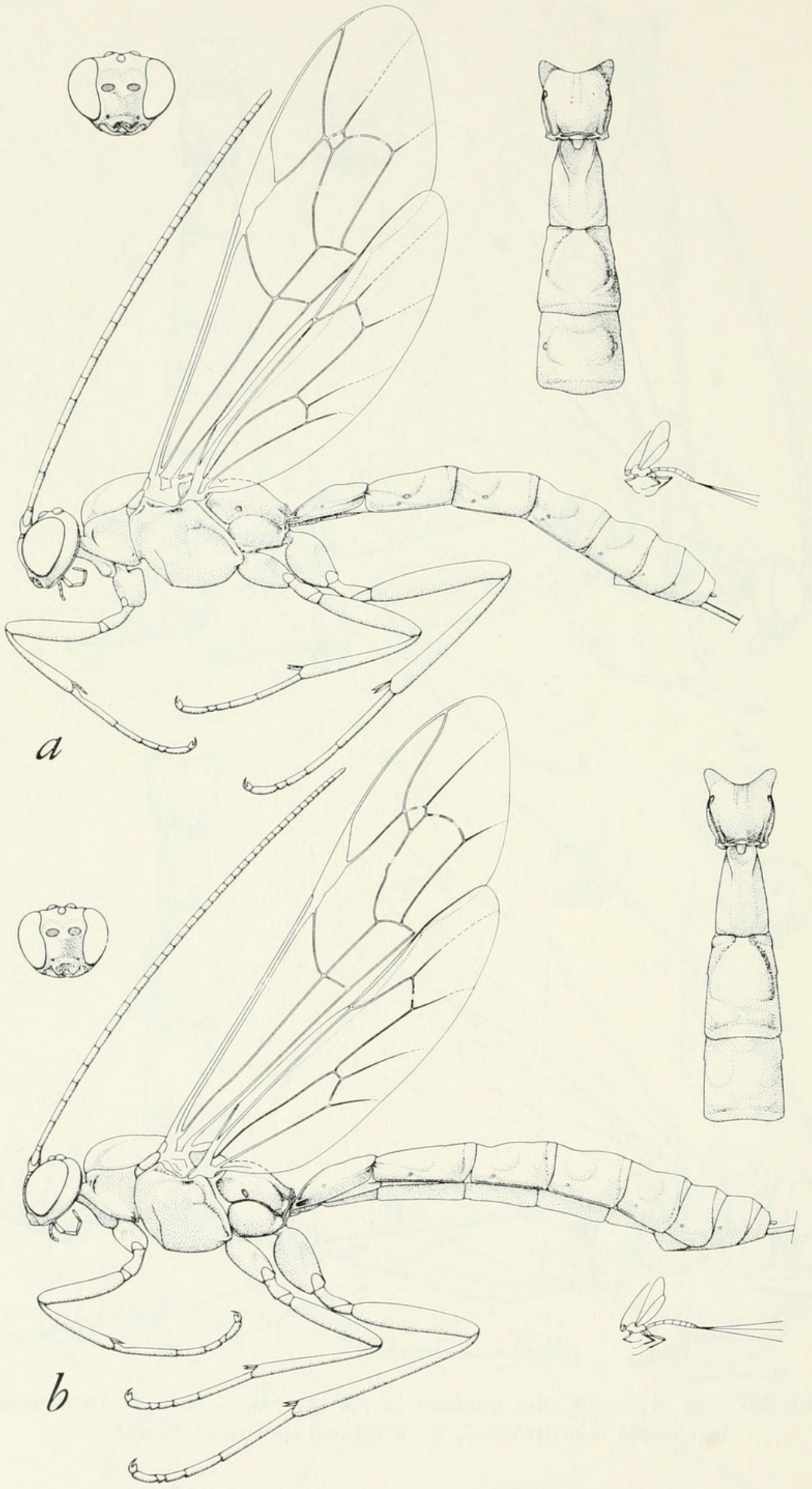

Figure 288.- a, Anastelgis terminalis, $\uparrow$, genotype of Anastelgis; b, Dolichomitus irritator, $\&$, a typical species of Dolichomitus. 


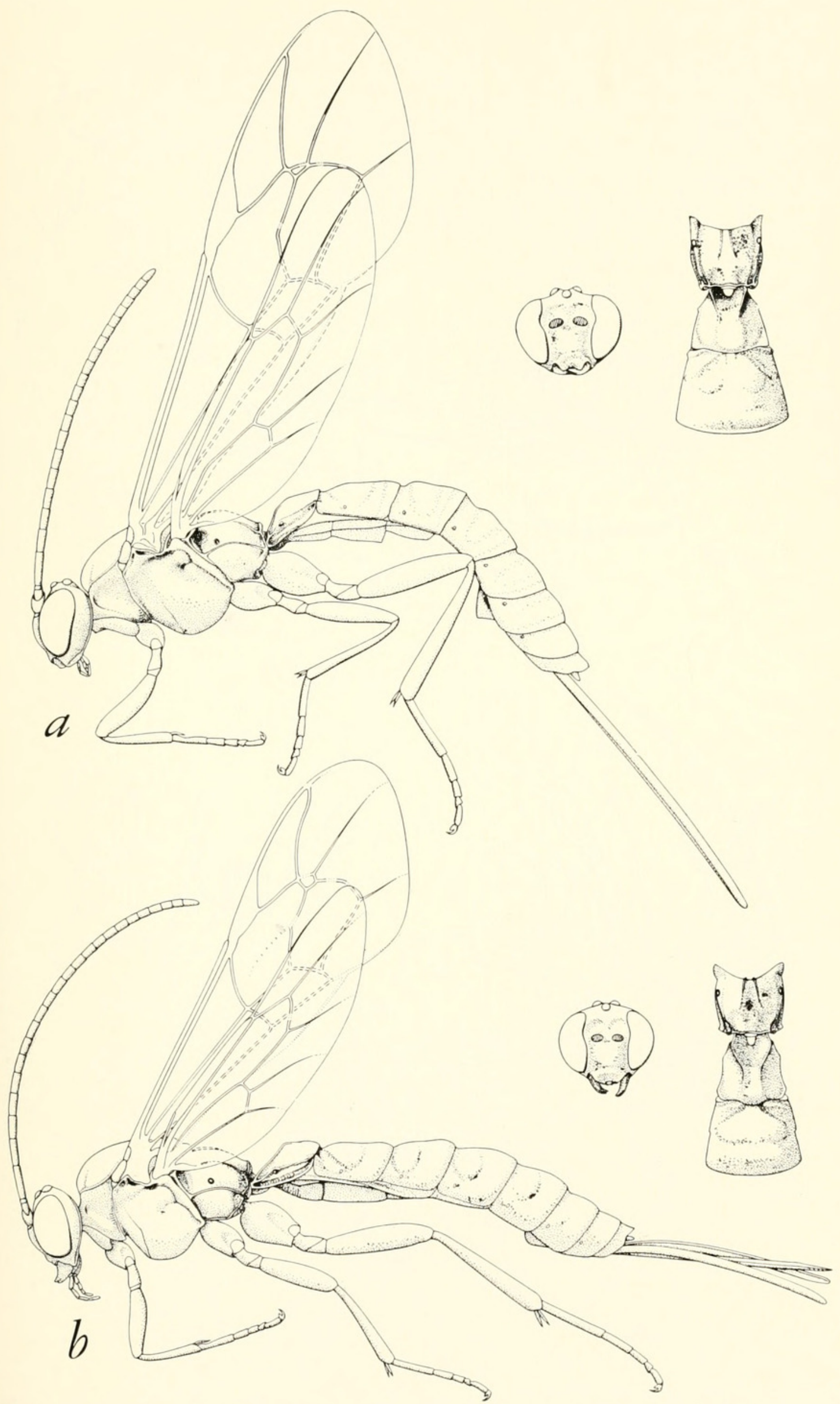

Figure 289.- - a, Acropimpla alboricta, $q$, representing the genus Acropimpla; b, Iseropus stercorator, $q$, genotype of Iseropus. 


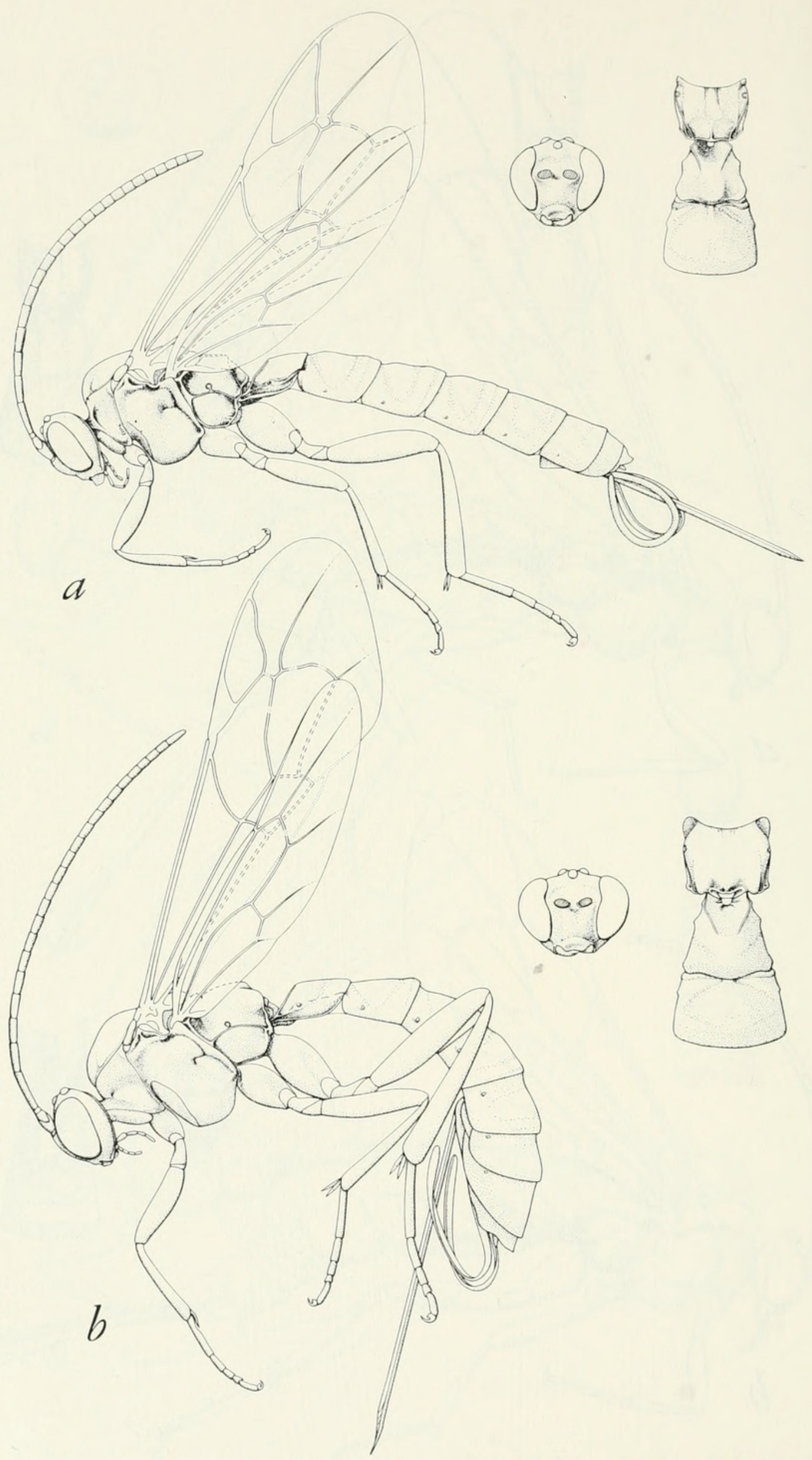

Figure 290.-a, Tromatobia variabilis, $q$, genotype of Tromatobia; b, Zaglyptus varipes, $\uparrow$, genotype of Zaglyptus. 


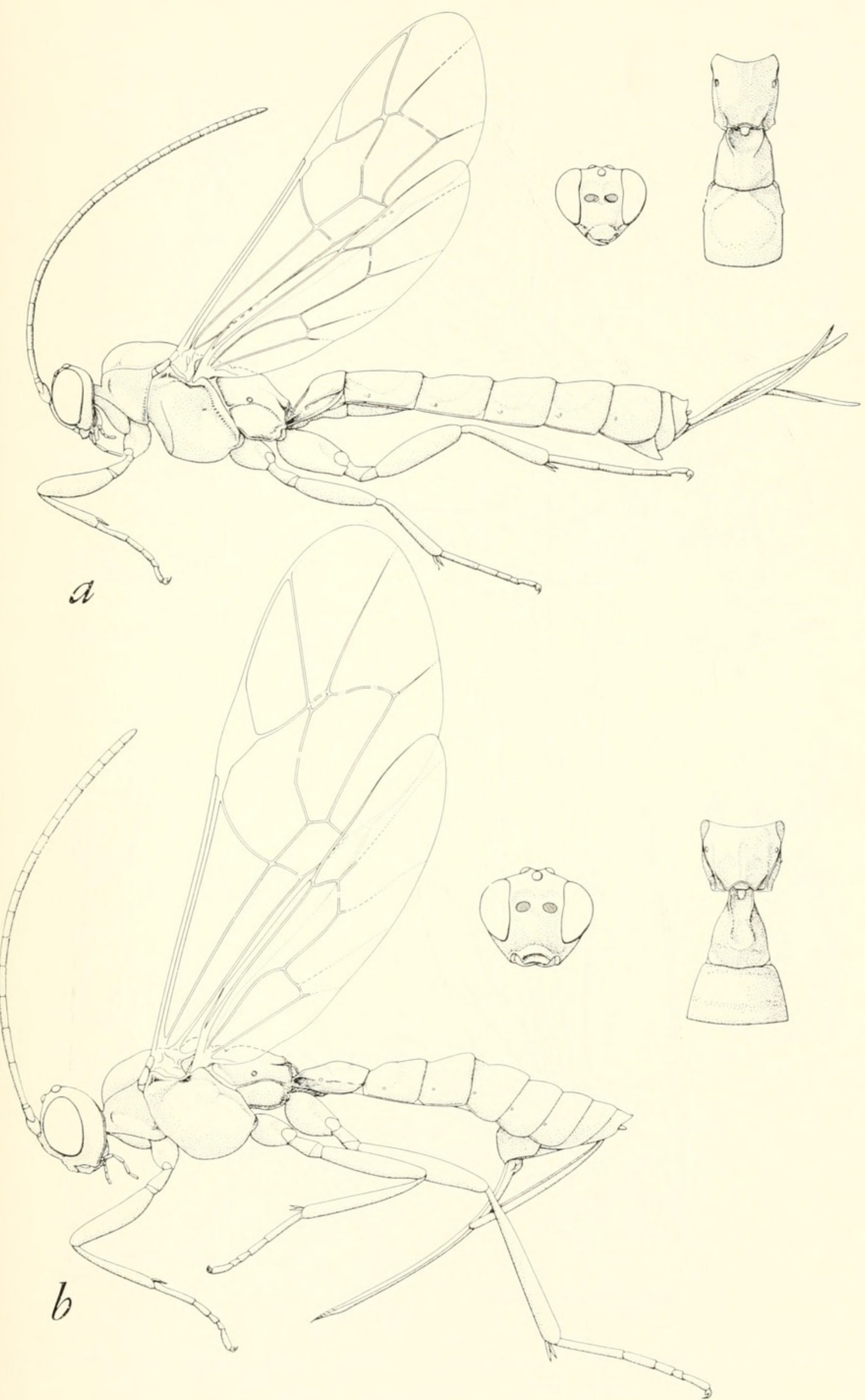

Figure 291.-a, Clistopyga incitator, $₹$, genotype of Clistopyga; b, Alophosternum foliicola, $\uparrow$, genotype of Alophosternum. 


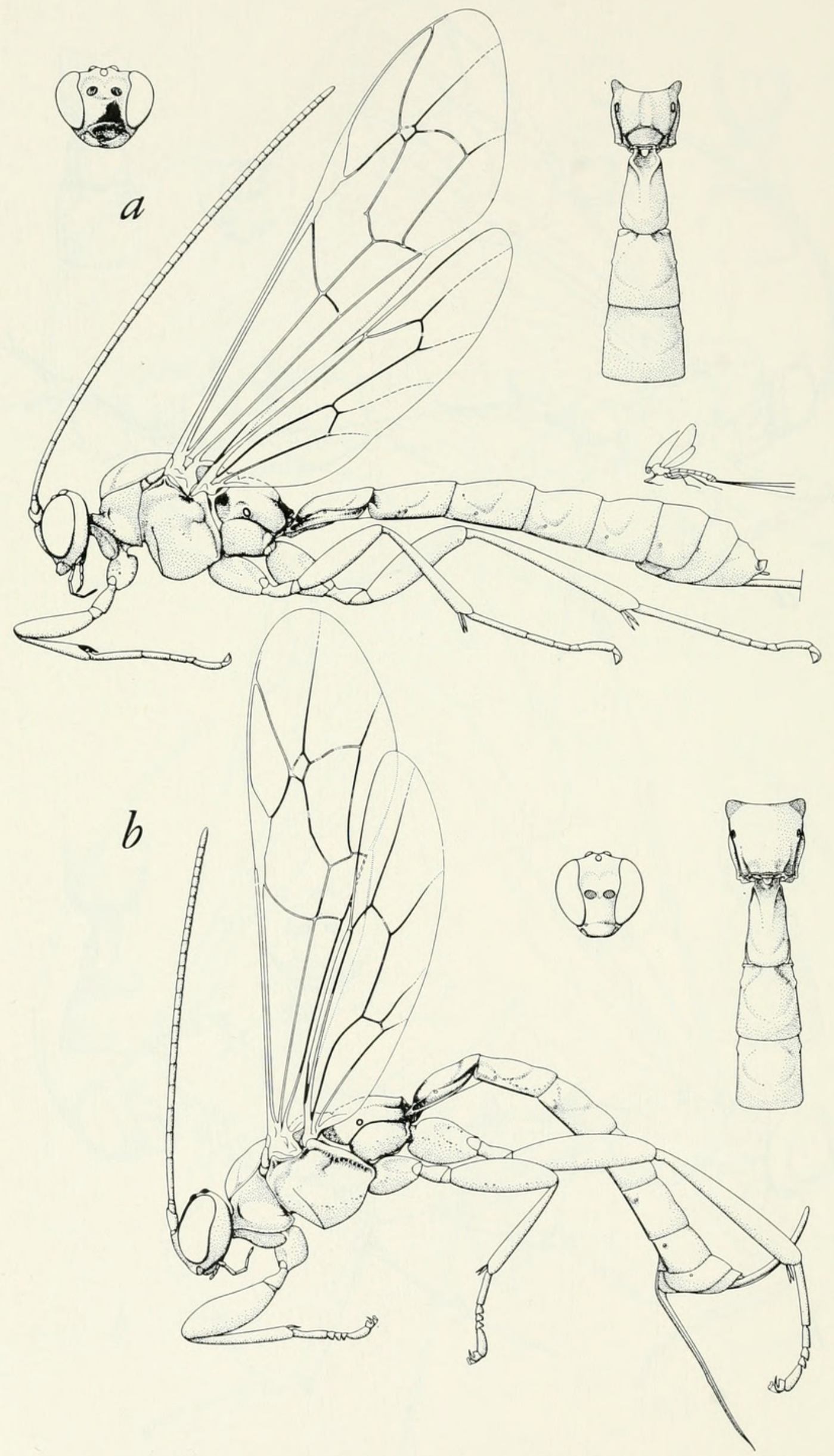

Figure 292.--a, Perithous albicinctus, $q$, genotype of Perithous; b, Laufeia mira, $\uparrow$, genotype of Laufeia. 


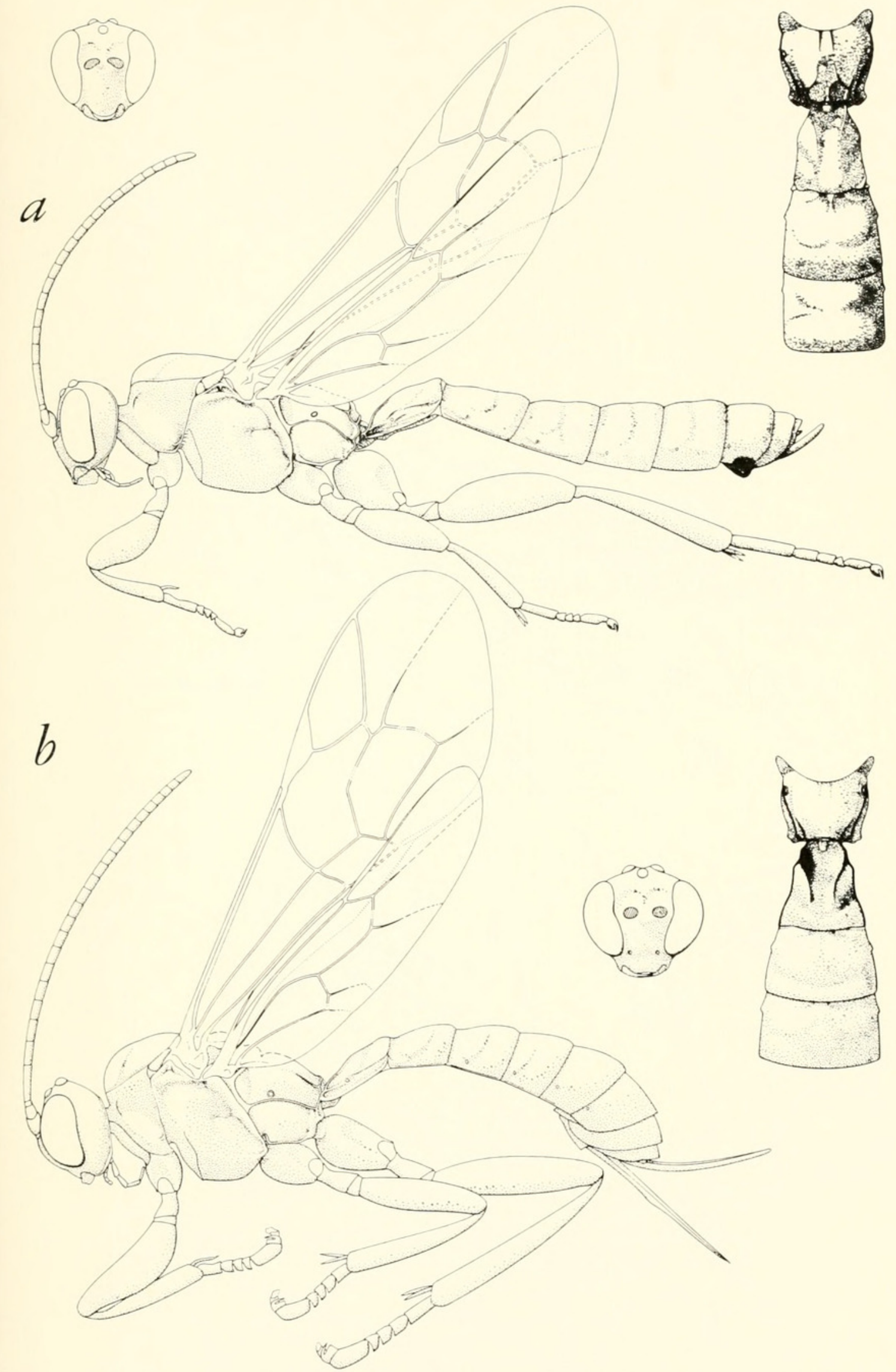

Figure 293.- - a, Schizopyga podagrica, \&, genotype of Schizopyga; b, Zabrachypus primus, + , genotype of Zabrachypus. 


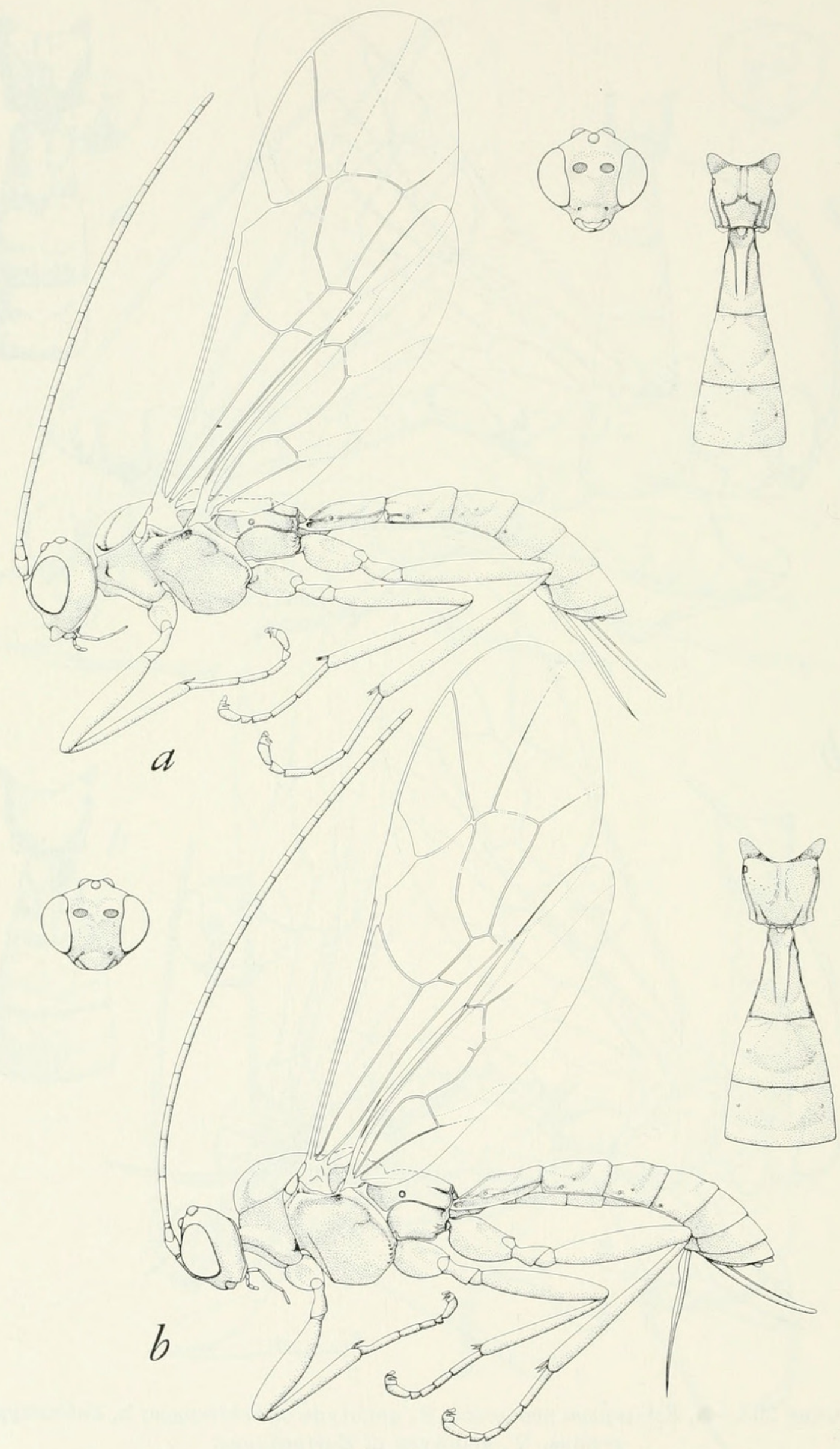

Figure 294.- a, Acrodactyla degener, $\uparrow$, genotype of Acrodactyla; b, Eruga lineata, q, genotype of Eruga. 


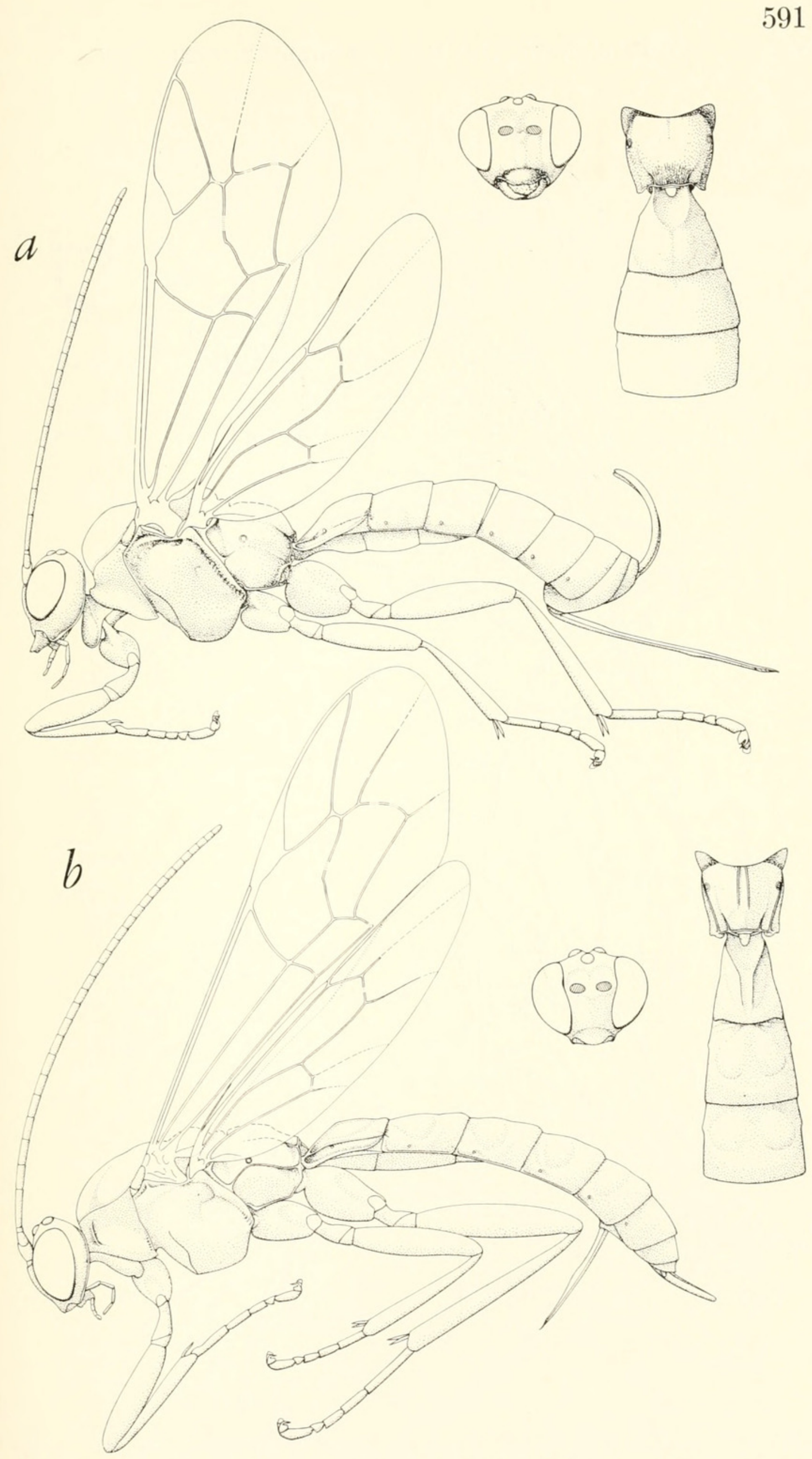

Figure 295.-a, Piogaster rugosa, genotype of Piogaster; b, Oxyrrhexis carbonator, q, genotype of Oxyrrhexis. 


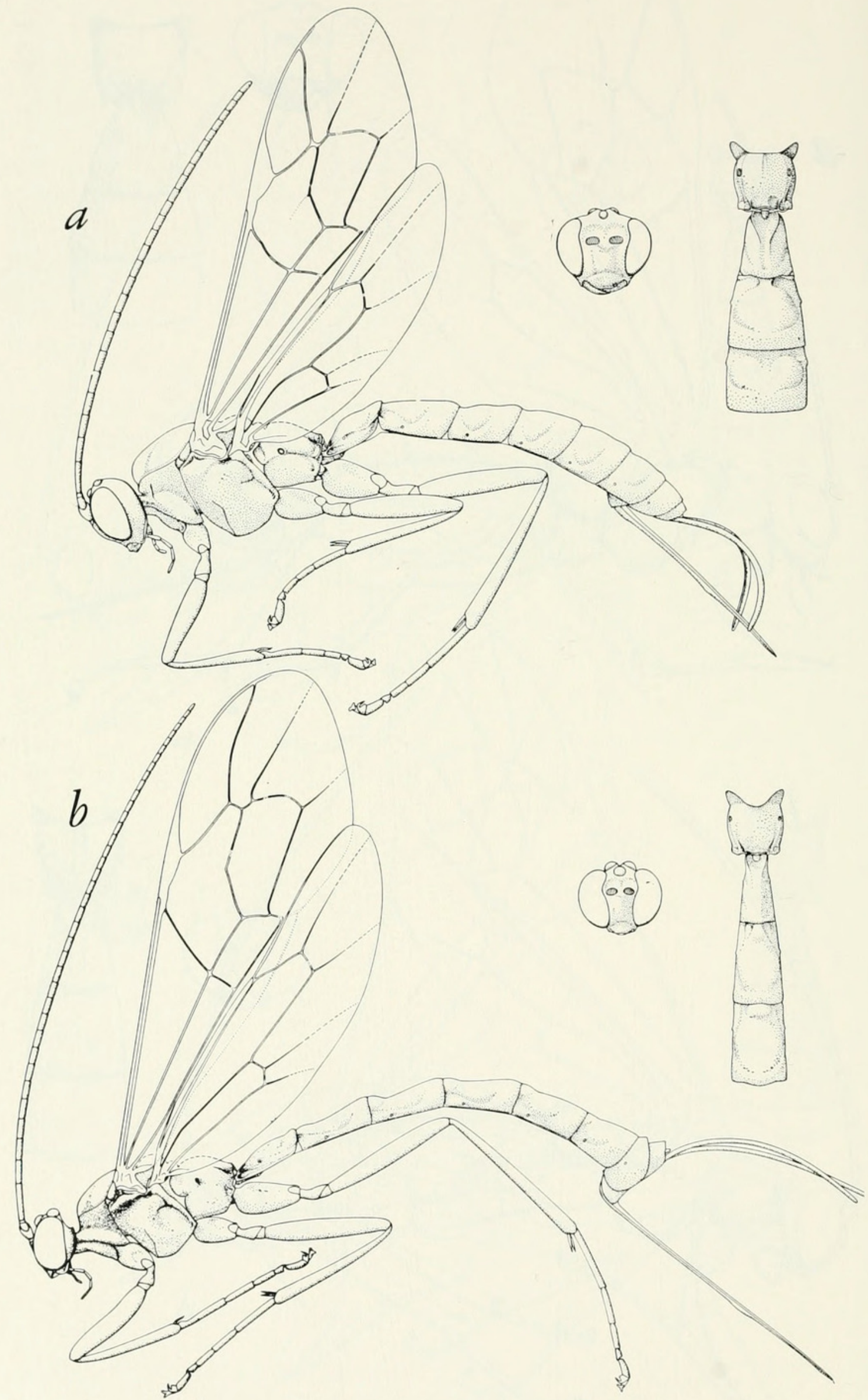

Figure 296.-a, Polysphincta tuberosa, $q$, genotype of Polysphincta; b, Acrotaphus wiltii, $q$, genotype of Acrotaphus. 


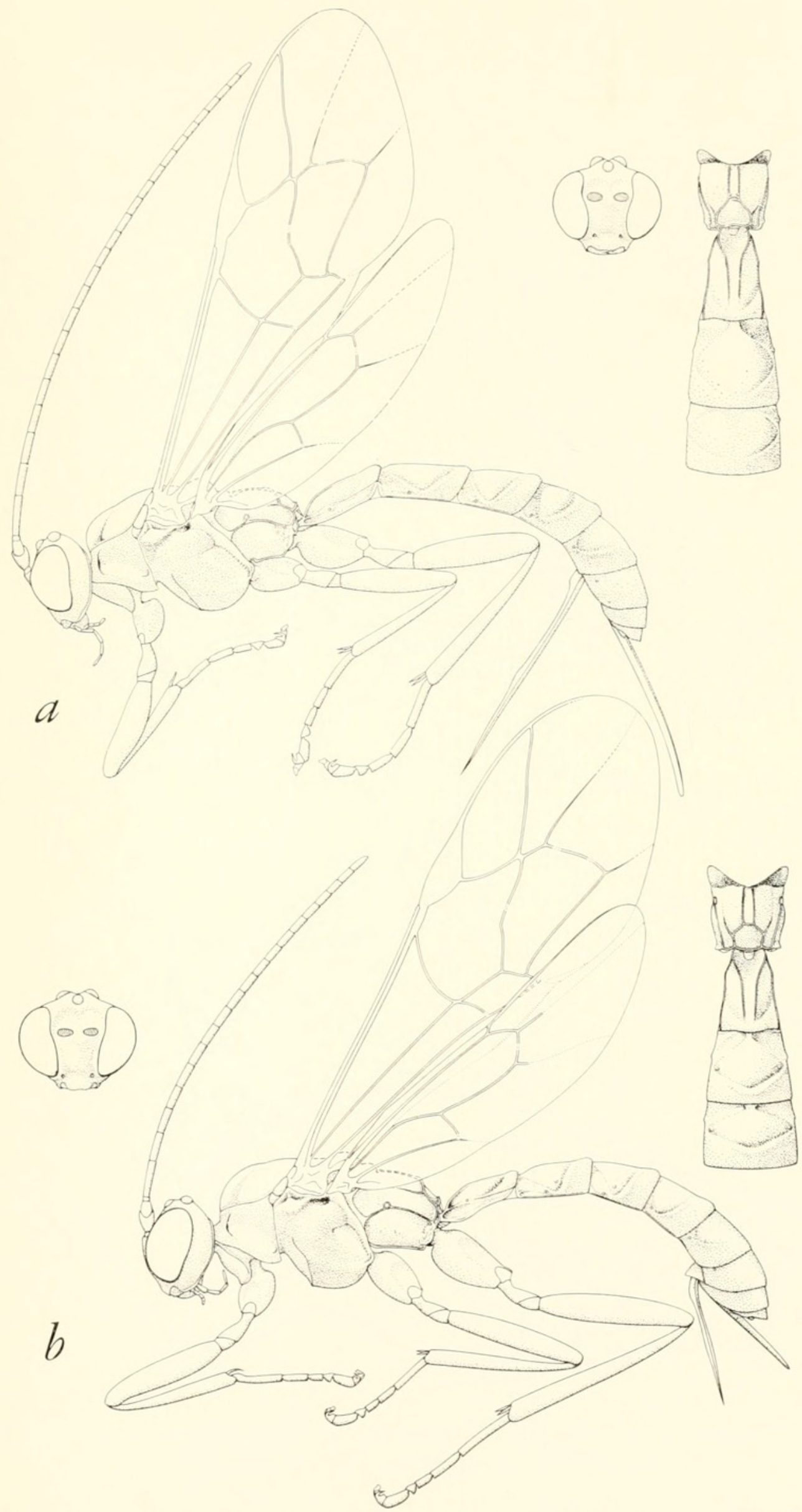

Figure 297.-a, Sinarachna pallipes, + , genotype of Sinarachna; b, Zatypota percontatoria, + , genotype of Zatypota. 


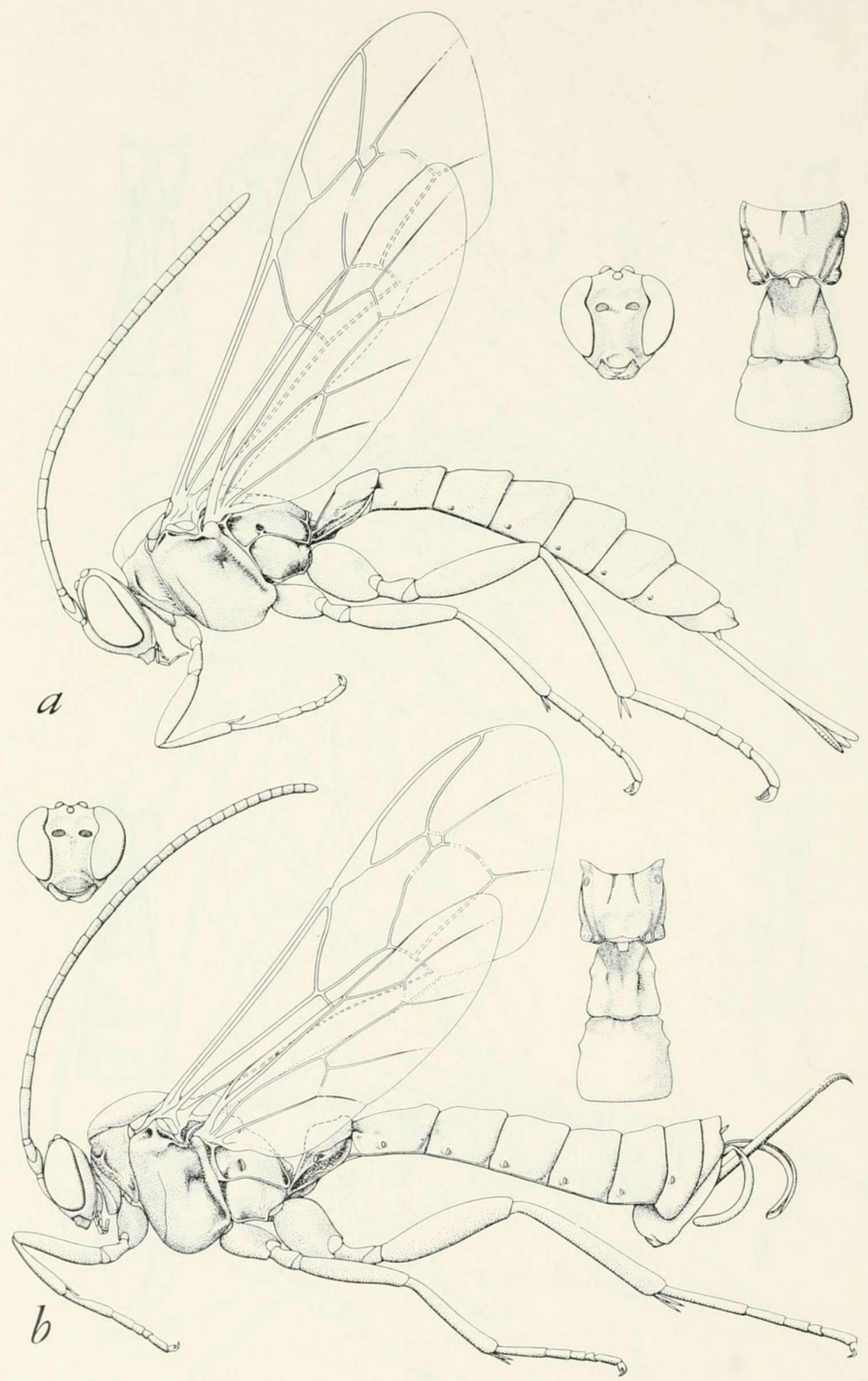

FIGURE 298.- a, Itoplectis maculator, ๆ, genotype of Itoplectis; b, Ephialtes compunctor, $q$, genotype of Ephialtes. 


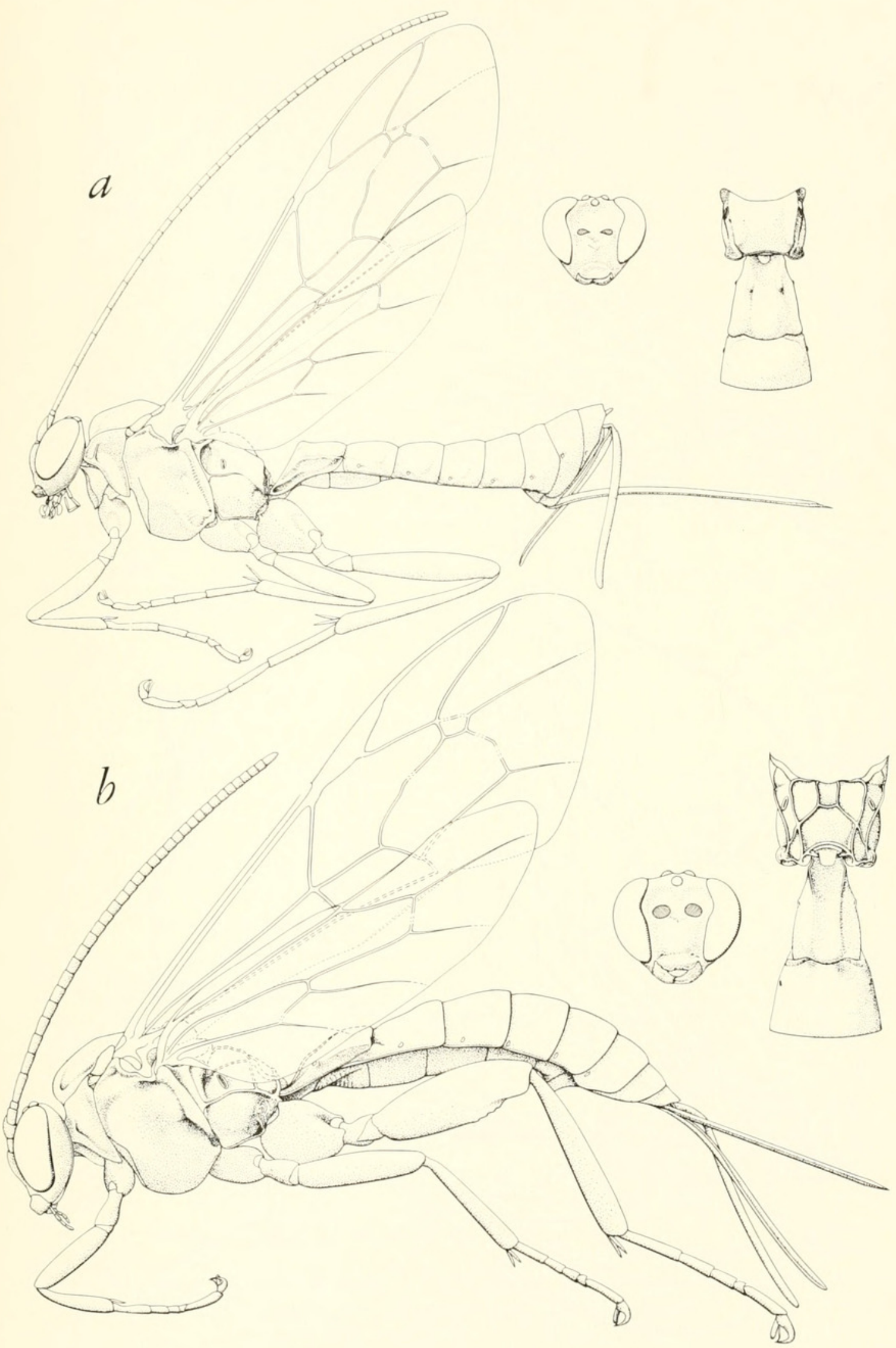

Figure 299.-a, Coccygomimus madecassus, o, genotype of Coccygomimus; b, Theronia atalantae, genotype of Theronia. 


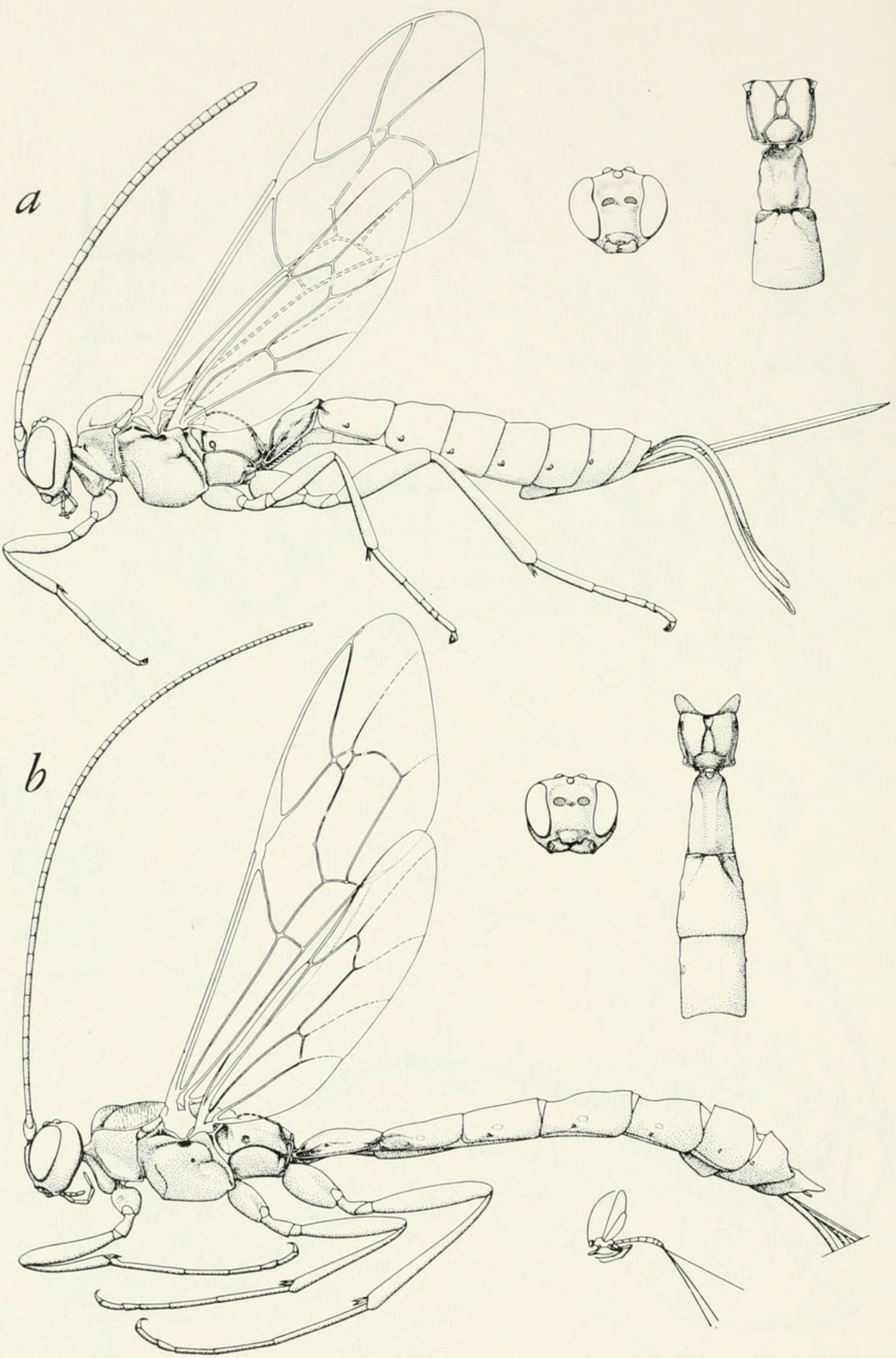

Figure 300.- a, Delomerista novita, $q$, a typical species of Delomerista; b, Pseudorhyssa ruficoxis, + , genotype of Pseudorhyssa. 


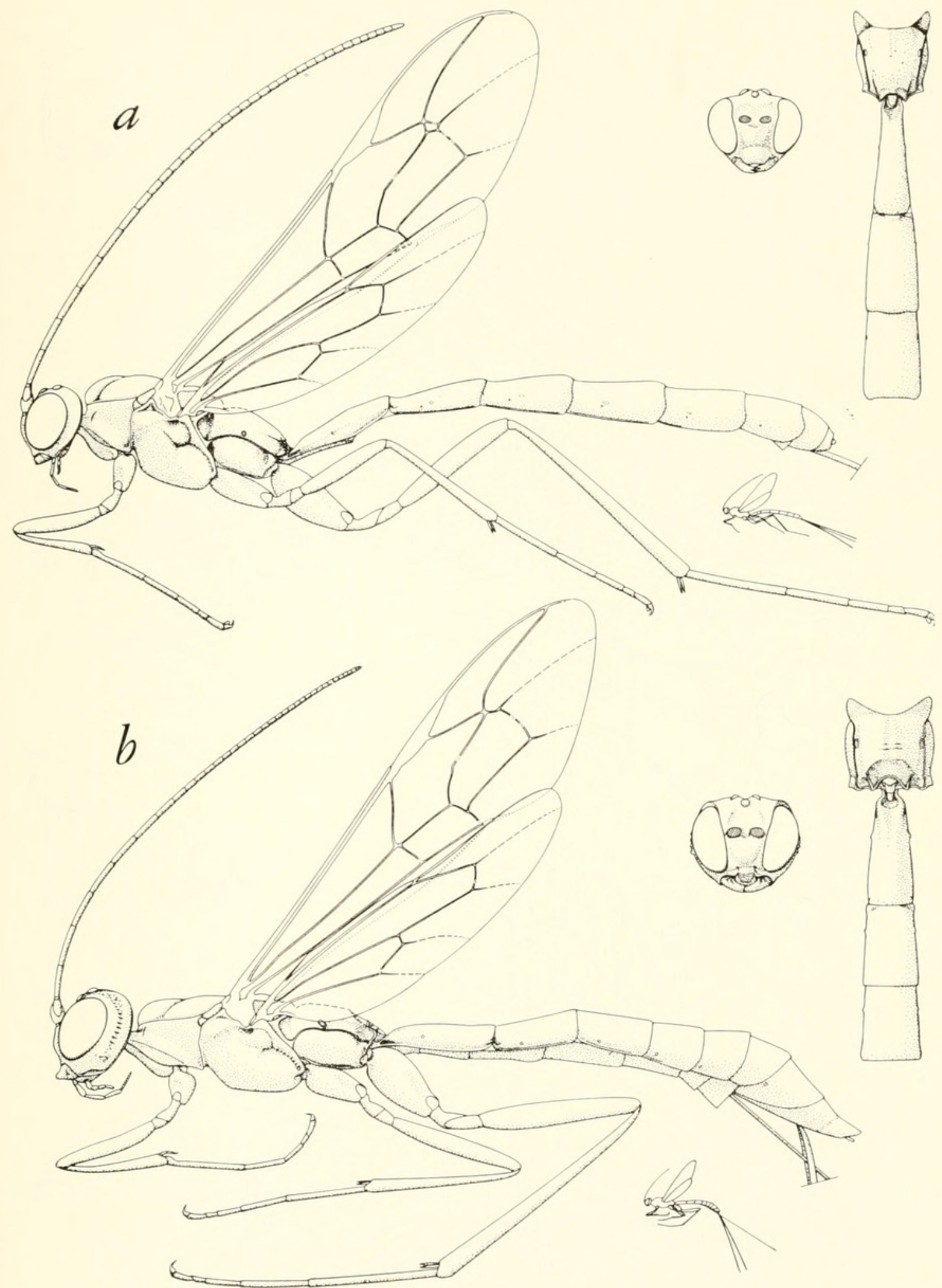

Figure 301.- - a, Poemenia hectica, $q$, a typical species of Poemenia; b, Podoschistus vittifrons, $q$, genotype of Podoschistus. 


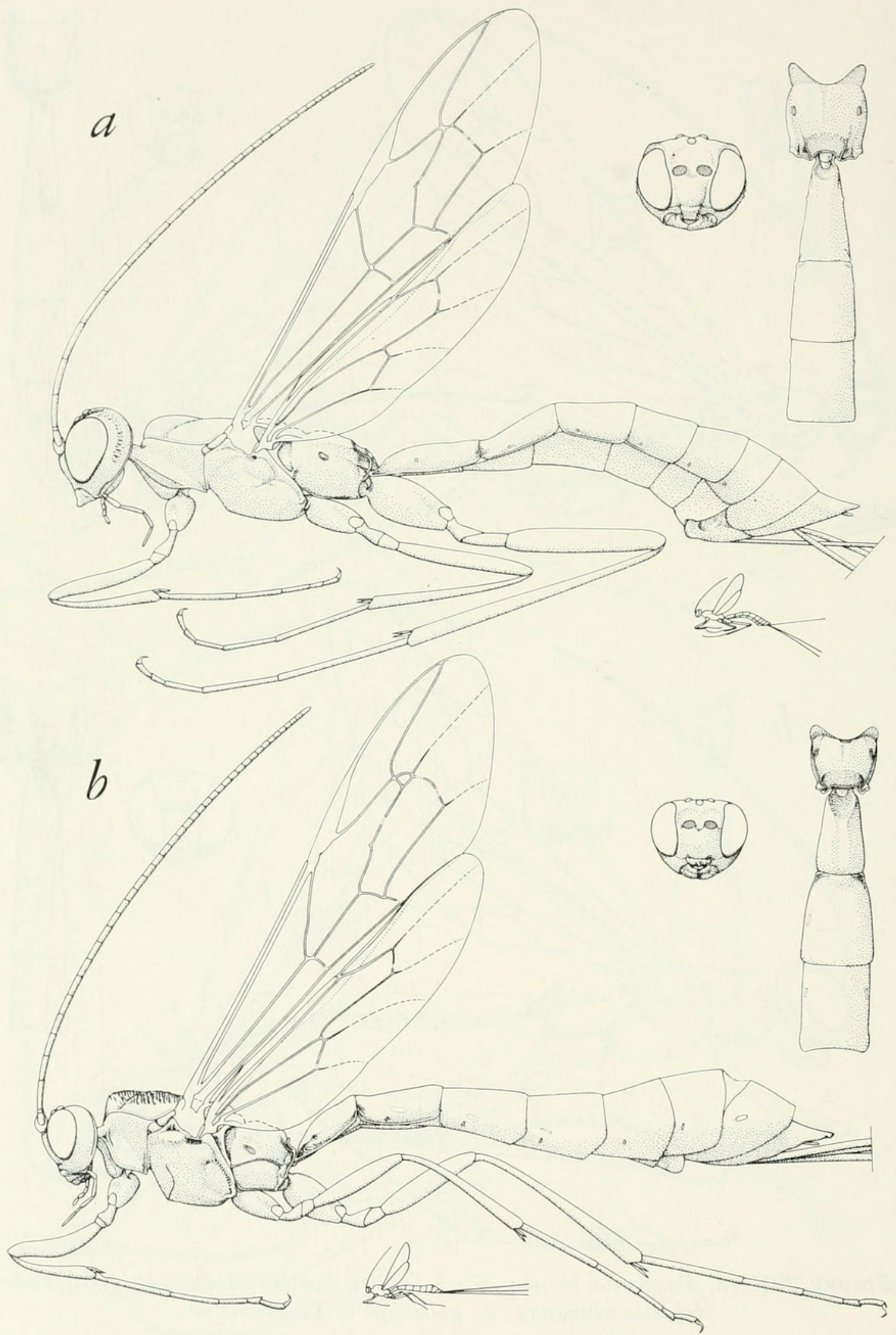

Figure 302.-a, Neoxorides borealis, $q$, a typical species of Neoxorides; b, Rhyssa persuasoria, q, genotype of Rhyssa. 


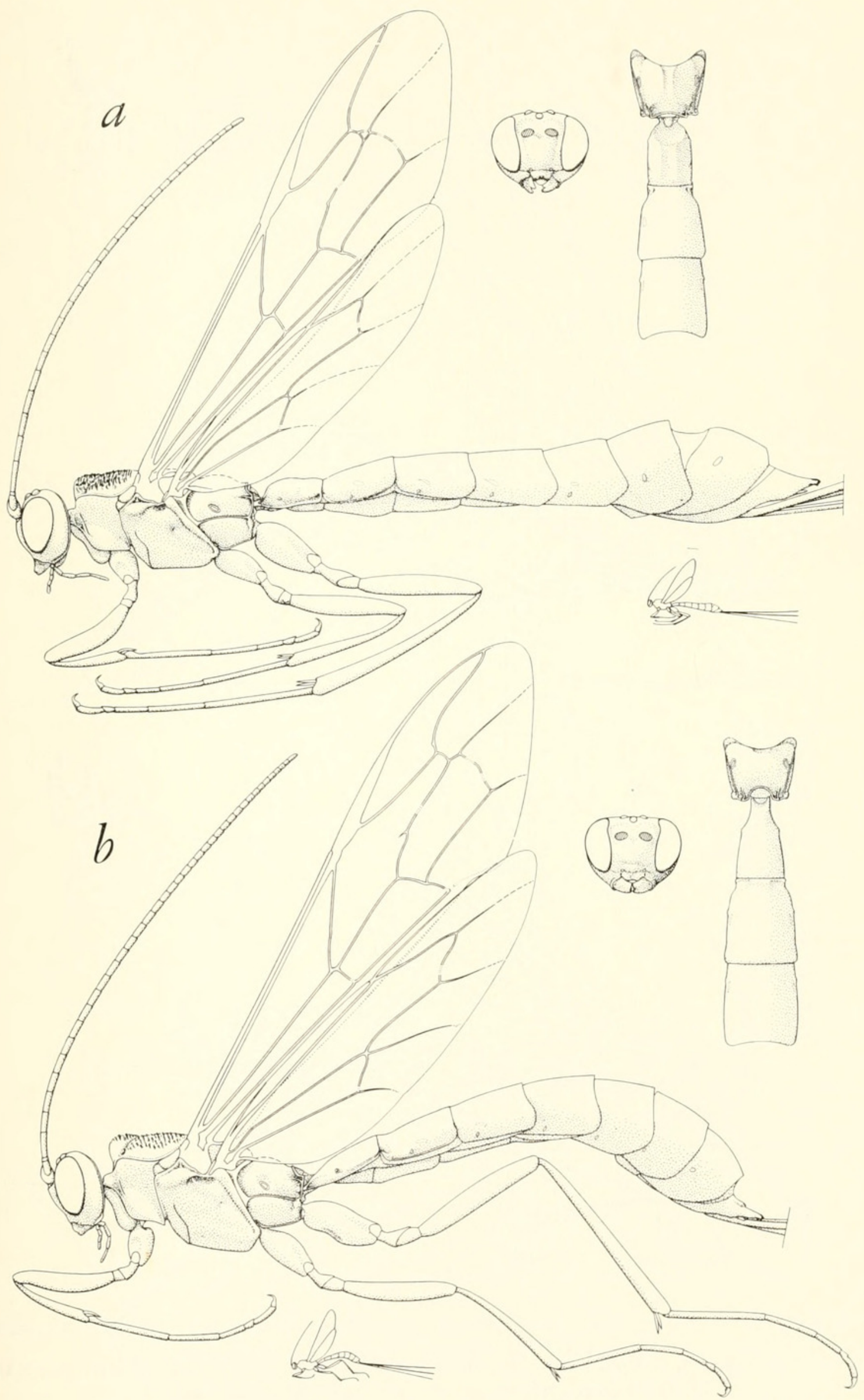

Figure 303.-a, Rhyssella nitida, q, genotype of Rhyssella; b, Epirhyssa dietrichi, $\uparrow$, a typical species of Epirhyssa. 


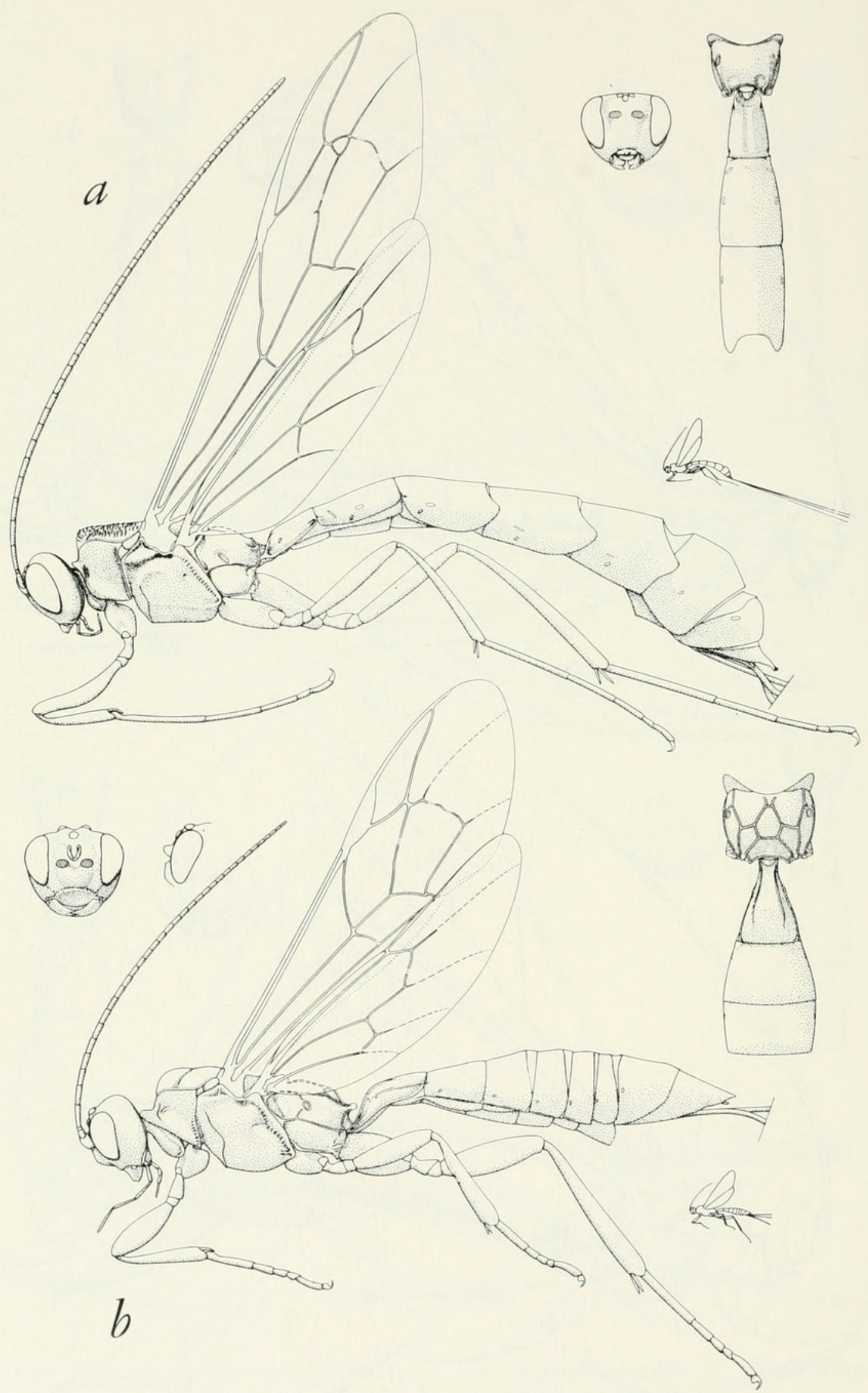

Figure 304.-a, Megarhyssa nortoni, q, a typical species of Megarhyssa; b, Ischnoceros filicornis, + , genotype of Ischnoceros. 


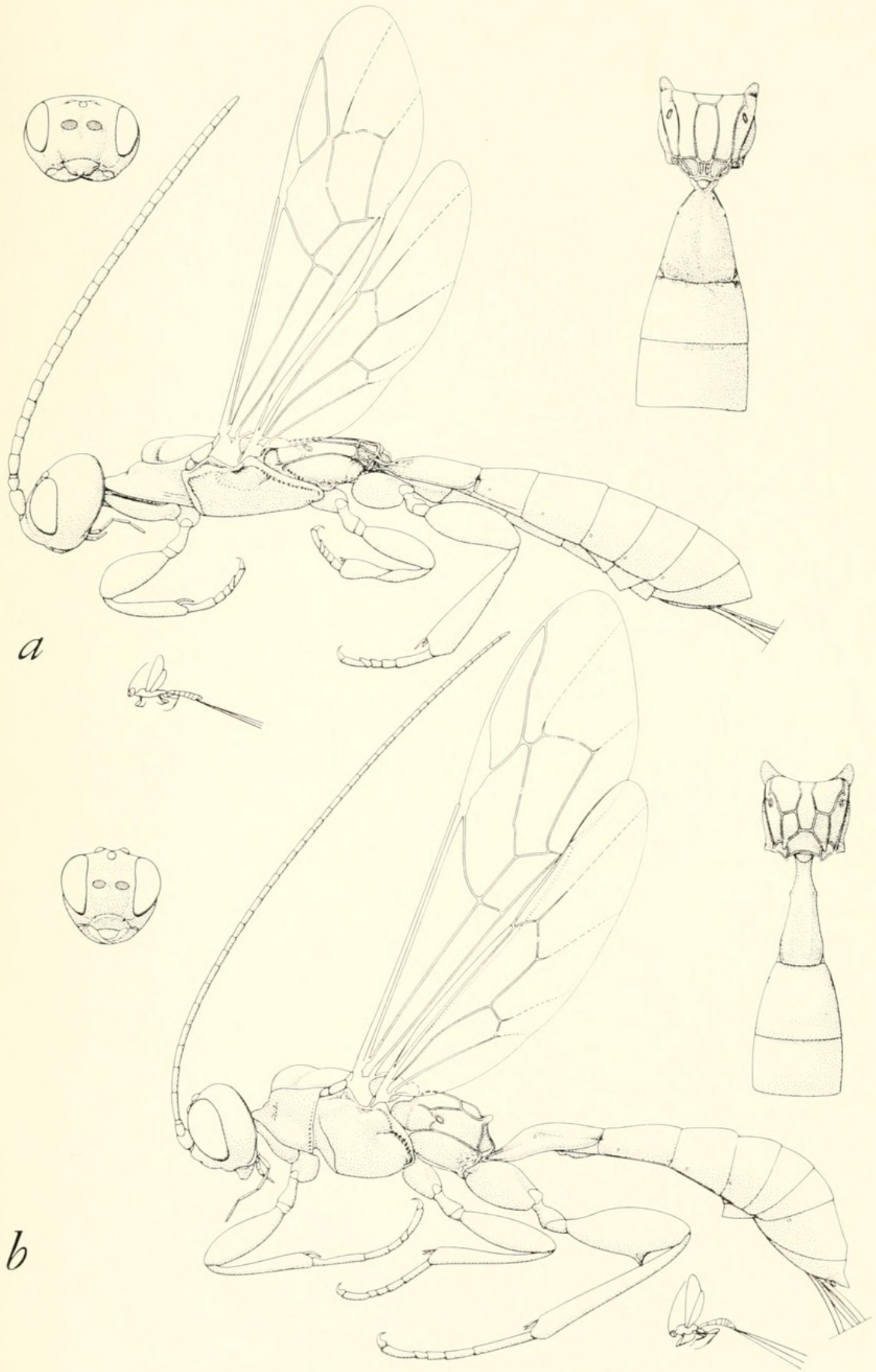

Figure 305.- a, Aplomerus tibialis, q, genotype of Aplomerus; b, Odontocolon ochropus, + , a typical species of Odontocolon. 


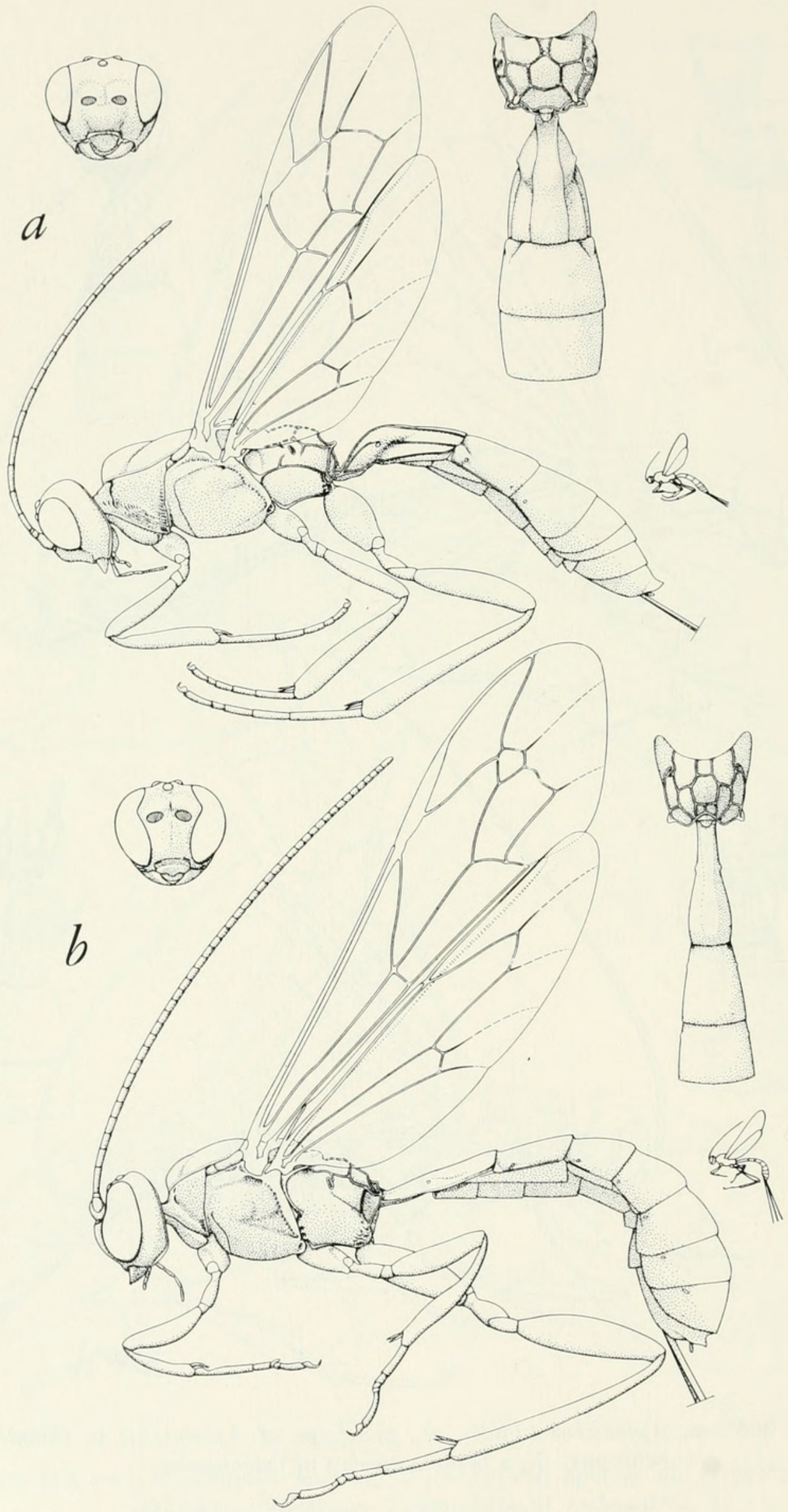

Figure 306.- a, Xorides irrigator, $\uparrow$, genotype of Xorides; b, Labena grallator, $\uparrow$, genotype of Labena. 


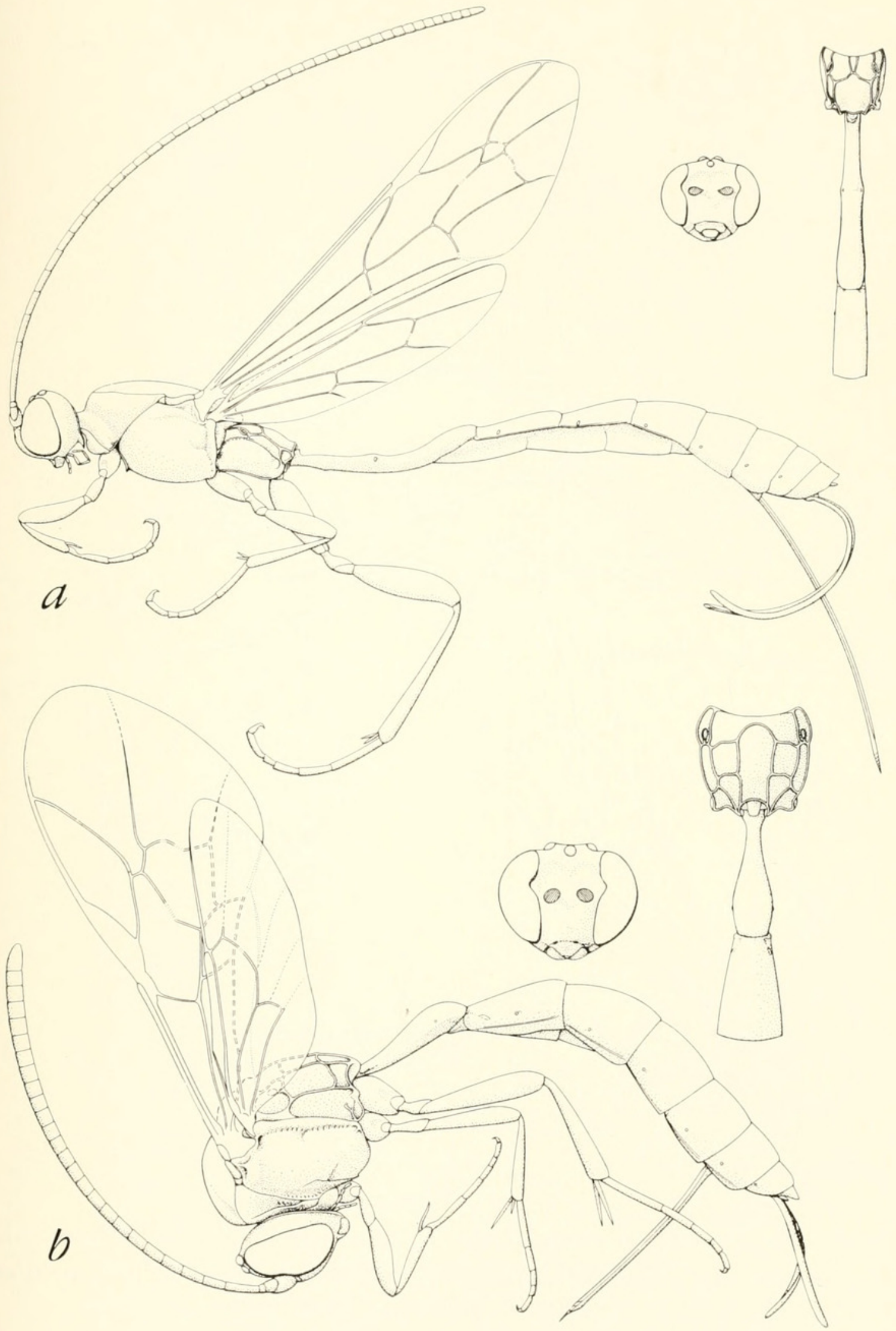

Figure 307.-a, Grotea anguina, ㅇ, genotype of Grotea; b, Brachycyrtus ornatus, q, genotype of Brachycyrtus. 


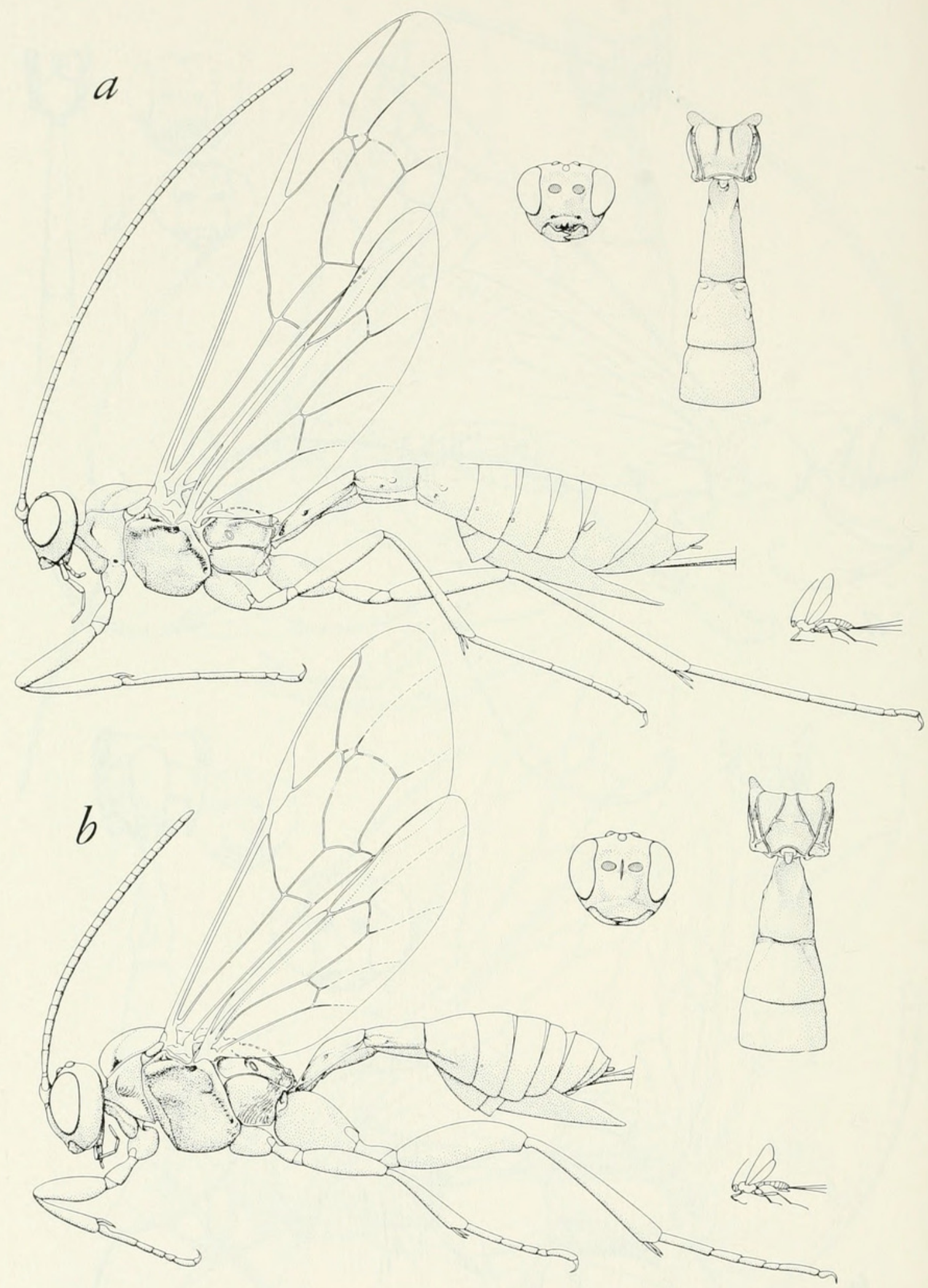

Figure 308.--a, Coleocentrus excitator, $\uparrow$, genotype of Colcocentrus; b, Mesoclistus rufipes, $q$, genotype of Mesoclistus. 


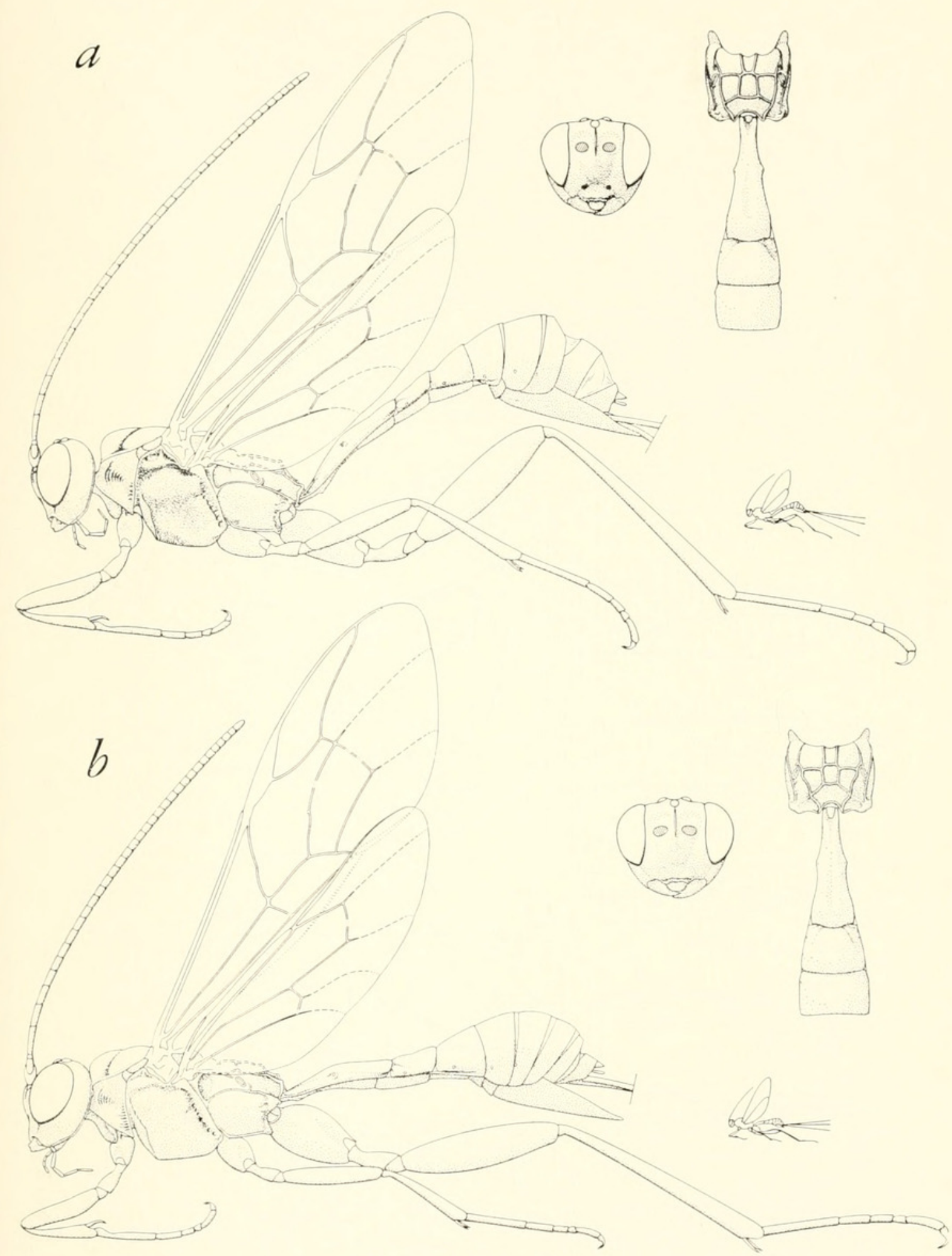

Figure 309.- - a, Arotes amoenus, $\uparrow$, a typical species of Arotes; b, Spilopteron franclemonti, + , genotype of Spilopteron. 

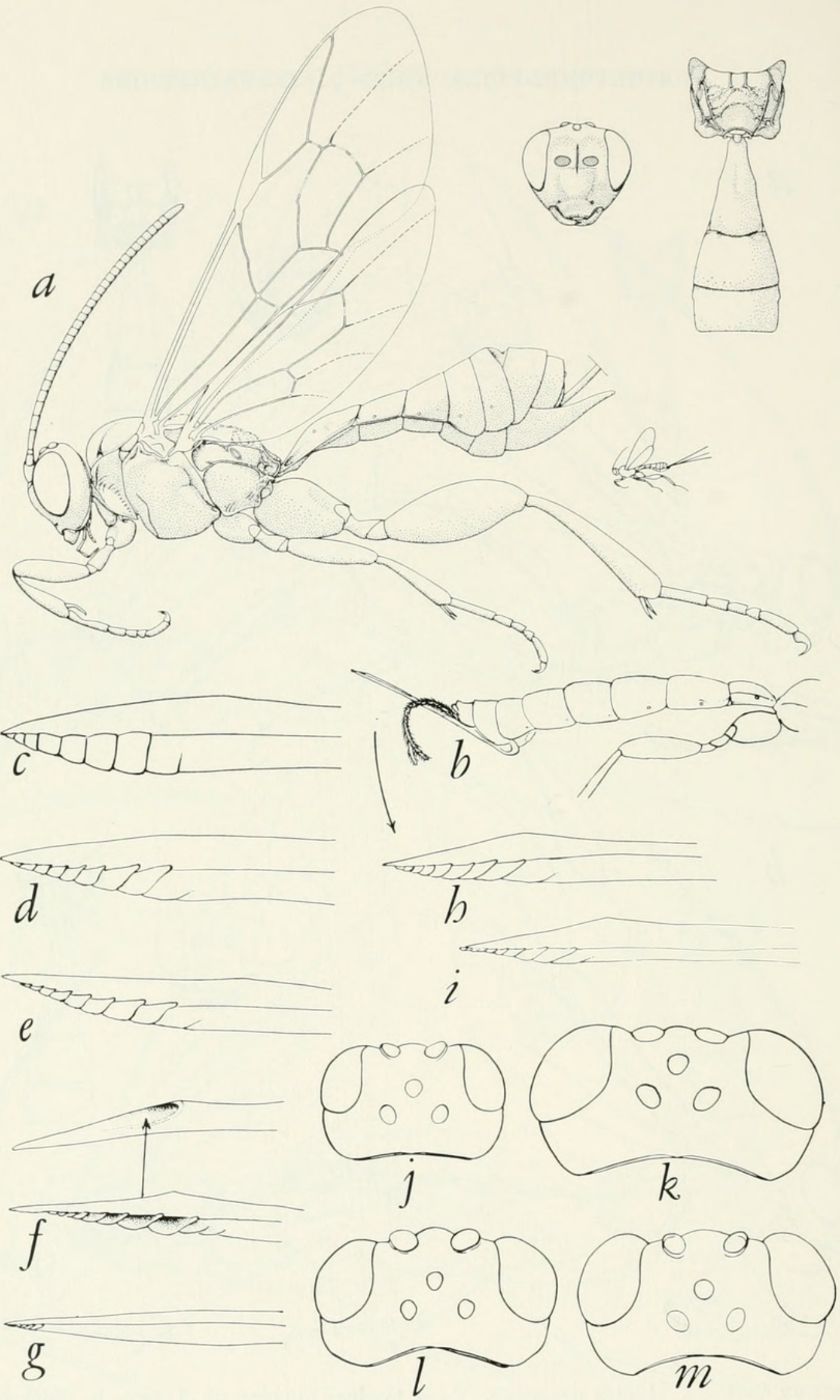

Figure 310.-Habitus drawing to show generic characters of Yezoceryx (a); abdomen of Scambus to show length of ovipositor (b) ; ovipositor tips, of species of Scambus (c-i); and heads, species of Scambus, $q(\mathrm{j}-\mathrm{m})$ :
a, Y. rupinsulensis o
f, S. vesicarius euurae
$\mathrm{j}, \quad$ S. longicorpus
b, S. imparis ?
g, S. atrocoxalis
c, S. detritus
h, S. imparis corpus
d, S. granulosus
i, S. tecumseh
k, S. hispae
e, S. deceptor
1, S. tecumseh
$\mathrm{m}$, S. canadensis

longi- 

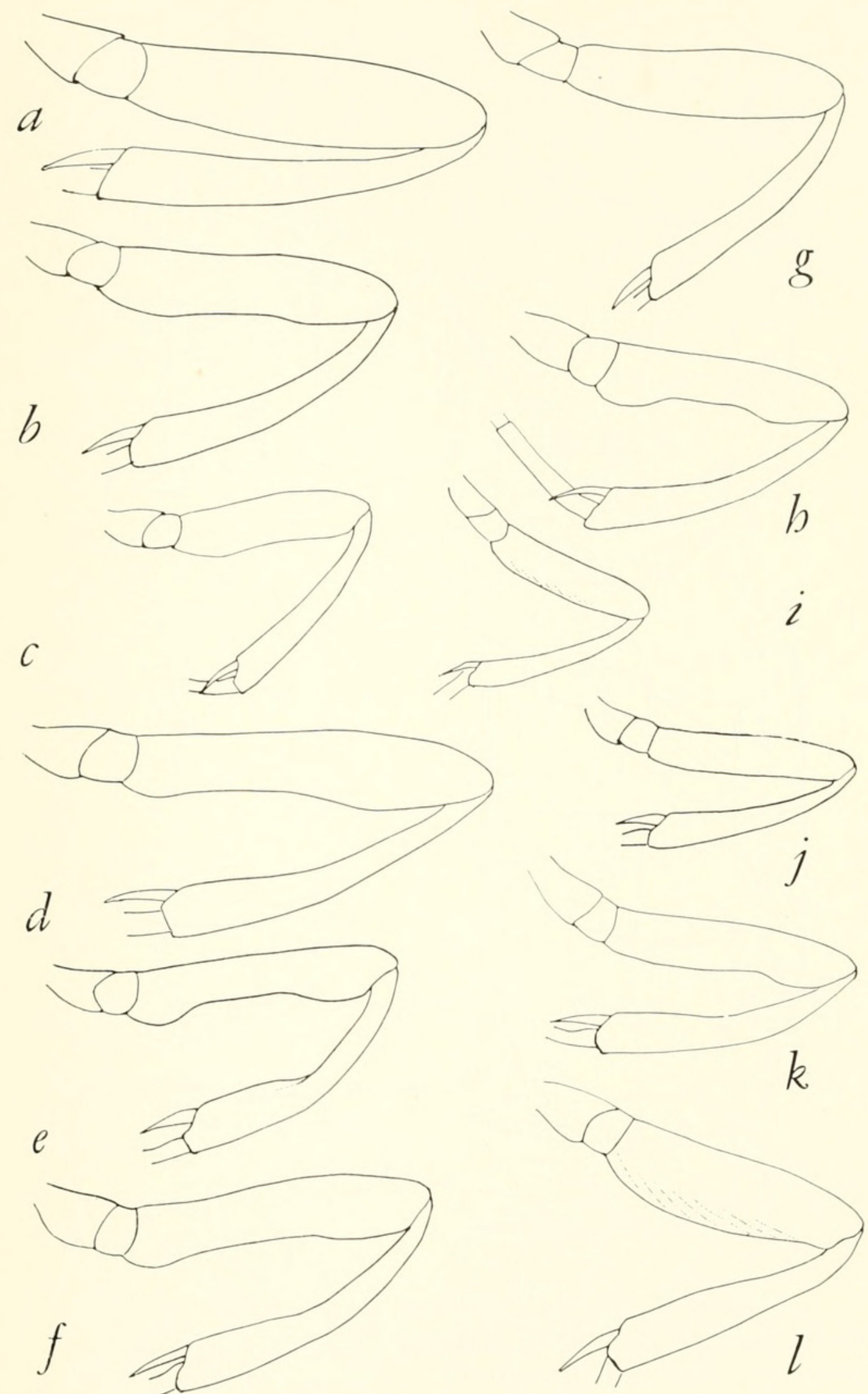

Figure 311.-Left front legs, species of Scambus, $\sigma^{7}$ :
a, rubescens
e, pterophori
$\mathrm{b}$, detritus
f, granulosus
c, productus
$\mathrm{g}$, protentus
$\mathrm{h}$, ephialtoides
$\mathrm{i}$, longicorpus longicorpus
$\mathrm{j}$, vesicarius eurae
$\mathrm{k}$, imparis
l, brevicornis 


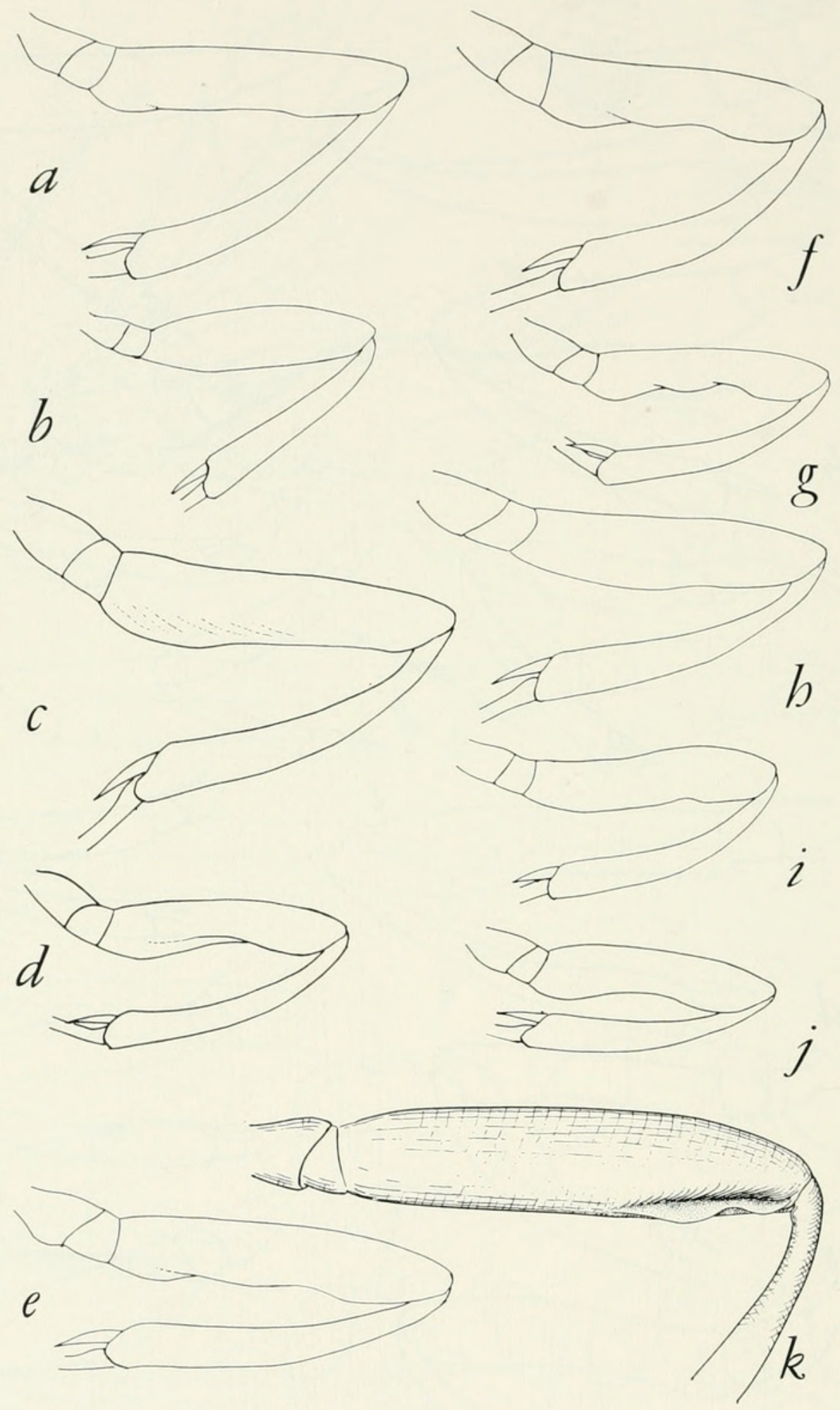

Figure 312.-Left front legs, species of Scambus, ơ :
a, canadensis
e, transgressus
b, tenebrosus
$\mathrm{f}$, tecumseh
i, nigrifrons
c, dioryctriae
g, nucum
$\mathrm{j}$, decorus
d, aplopappi
$\mathrm{h}$, hispae
$\mathrm{k}$, hirticauda 

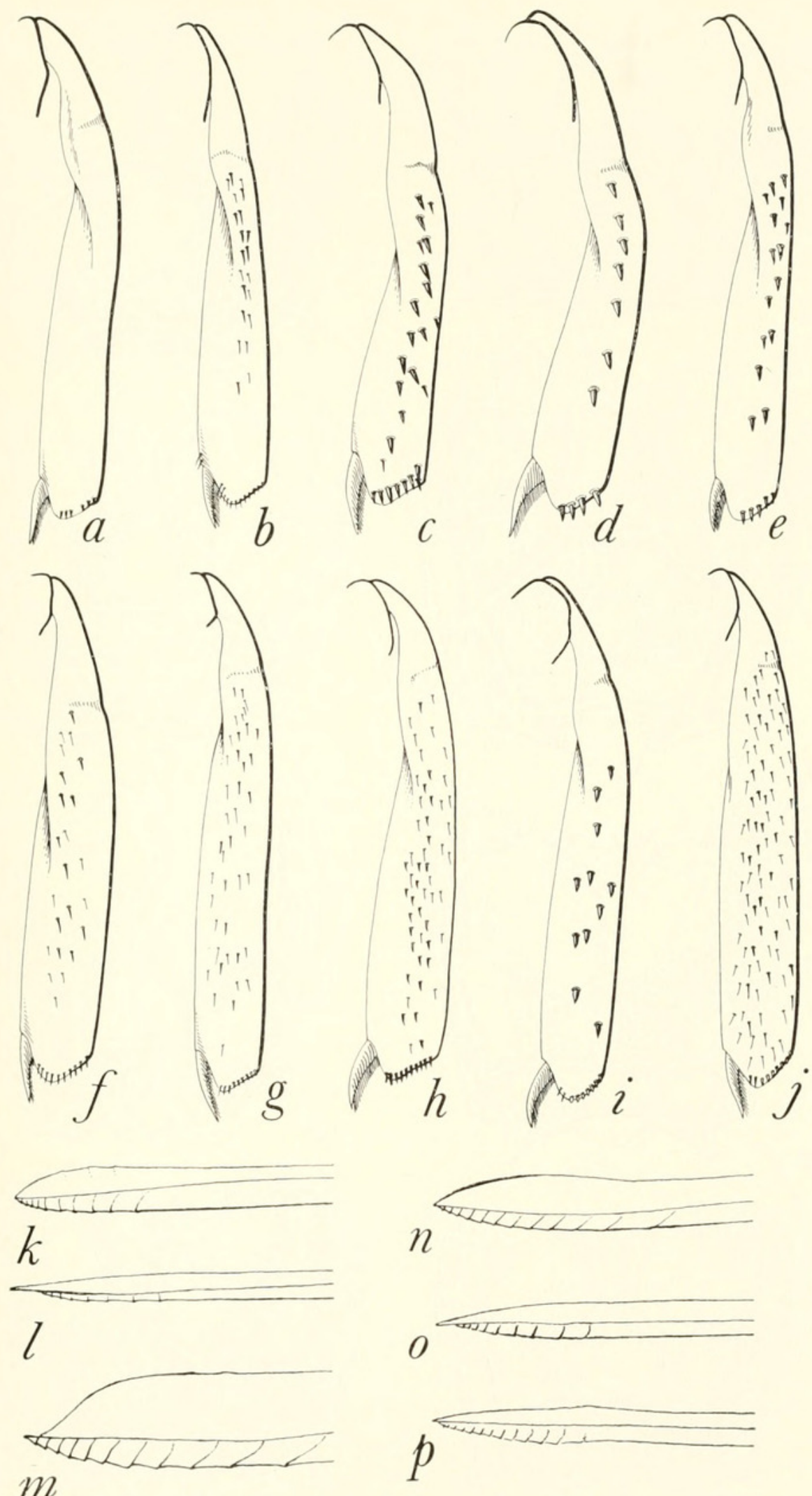

Figure 313.- Left front tibia, species of Xorides, $q(\mathrm{a}-\mathrm{j})$; ovipositor tips, species of Delomerista $(\mathrm{k}-\mathrm{p})$ :
a, X. humeralis
b, $X$. frigidus
c, X. pictus
d, X. peniculus
e, $X$. rileyi

\section{$\mathrm{f}, X$. medius}

$\mathrm{g}, X$. insularis

h, X. albopictus

1, D. lepteces

i, X. neoclyti

j, X. stigmapterus

k, D. japonica

$\mathrm{m}, D$. gelida

n, D. texana

o, D. novita

p, D. pfankuchi 

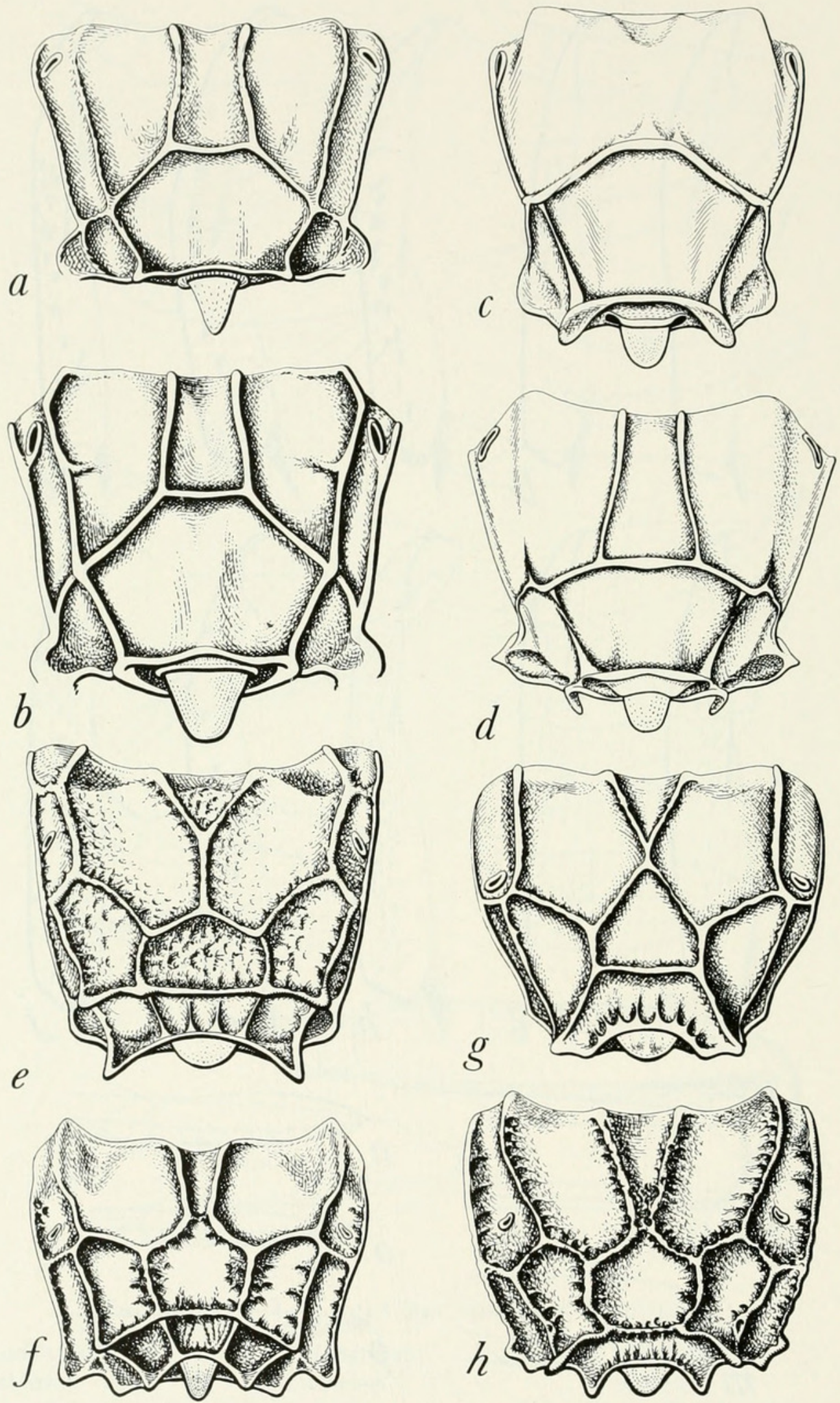

Figure 314.-Propodea, species of Theronia, $q(\mathrm{a}-\mathrm{d})$; and Xorides, $q(\mathrm{e}-\mathrm{h})$ :
a, T. atalantae
d, T. bicincta
b, T. hilaris
e, $X$. humeralis
g, X. pictus
c, T. septemtrionalis
f, $X$. frigidus
$\mathrm{h}, X$. rileyi 

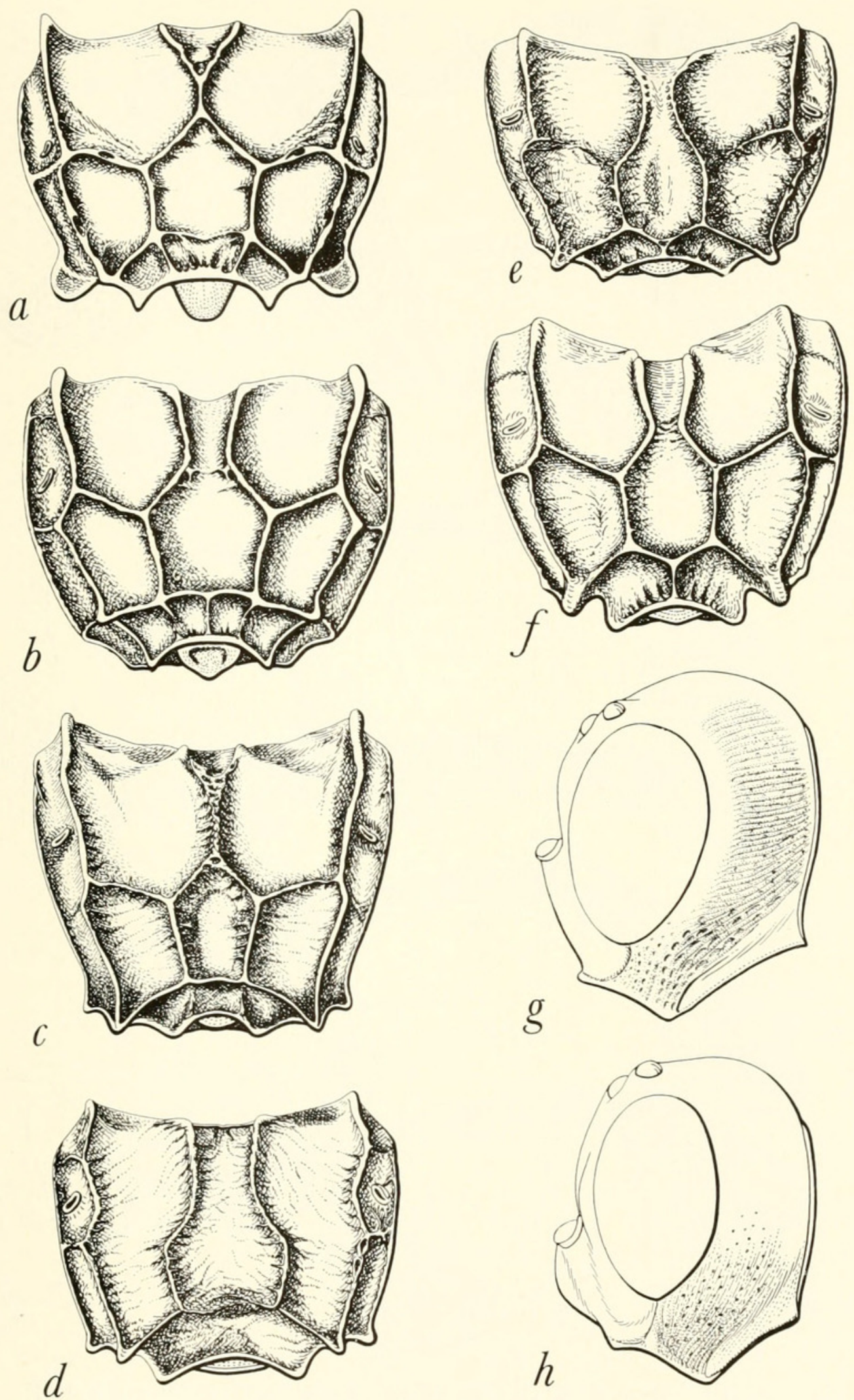

Figure 315.-Propodea, species of Xorides, $q$ (a-f); and heads, species of Xorides, $₹(\mathrm{~g}-\mathrm{h})$ :
a, medius
d, neoclyti
g, humeralis
$\mathrm{b}$, insularis
e, harringtoni
$\mathrm{h}$, frigidus
c, albopictus
$\mathrm{f}$, stigmapterus 

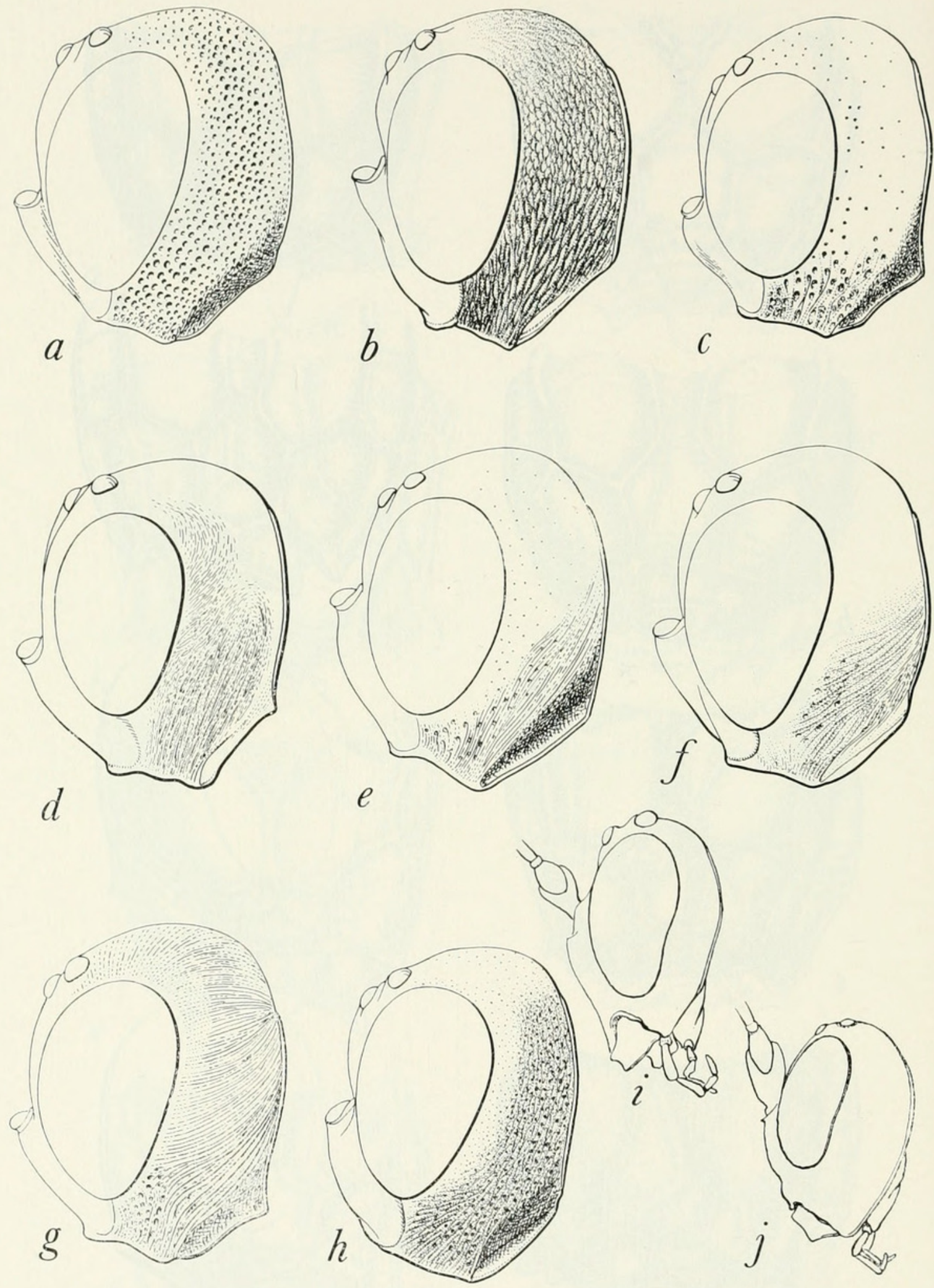

Figure 316.-Heads, species of Xorides (a-h); and Delomerista (i-j):
a, X. pictus o
$\mathrm{e}, X$. insularis $q$
h, X. stigmapterus q
b, X. boharti or
f, $X$. albopictus $q$
i, D. texana q
c, $X$. rileyi +
g, X. neoclyti q
j, D. gelida $q$
d, X. medius q 
a

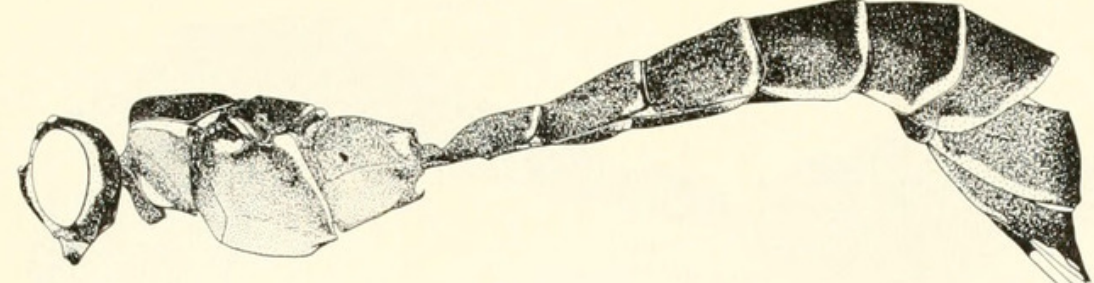

b

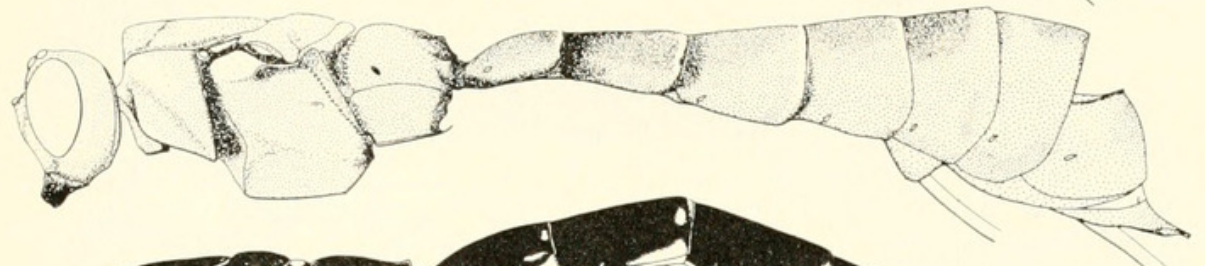

c

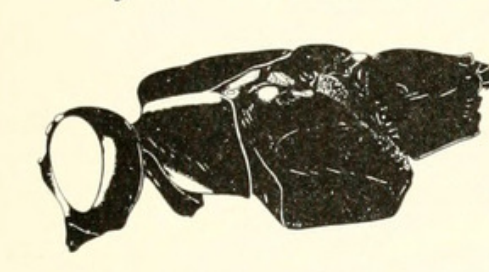

d

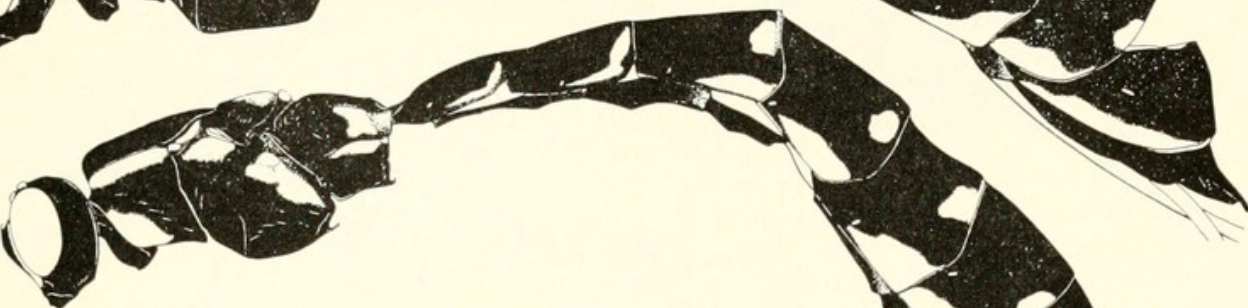

e

$f$
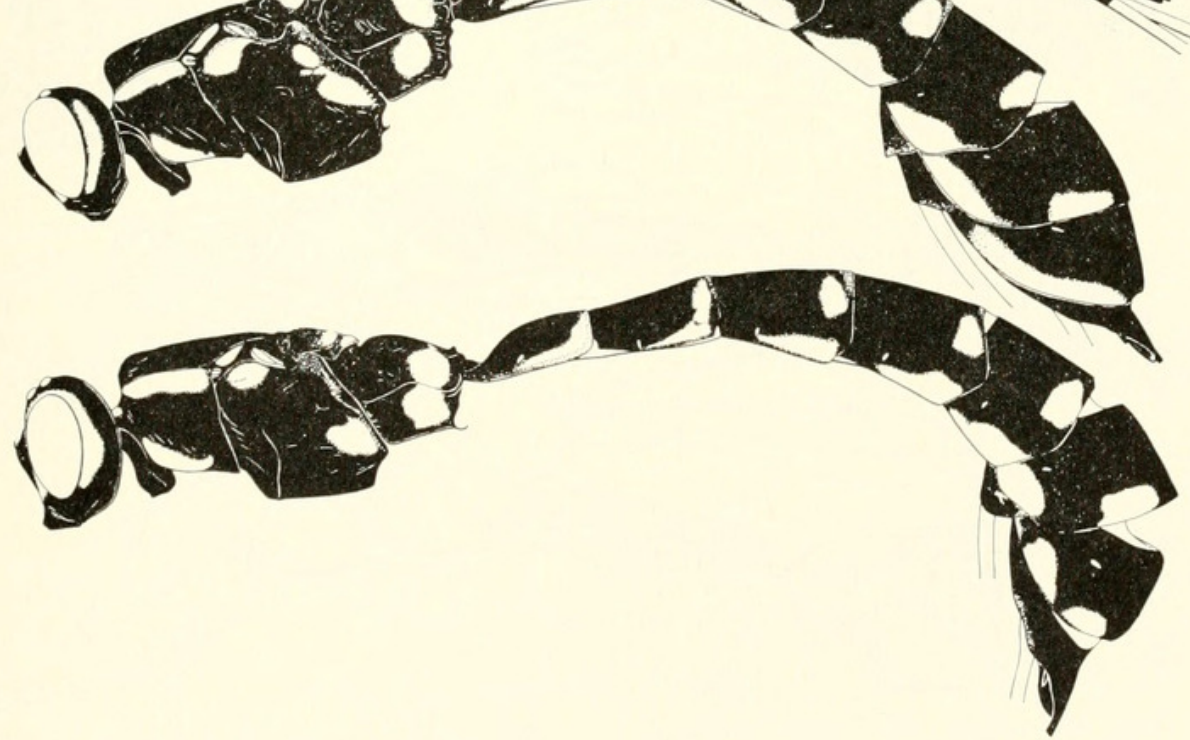

Figure 317.-Head and torso, species of Rhyssa, $q$ :
a, howdenorum
$\mathrm{d}$, alaskensis
$\mathrm{f}$, lineolata
$\mathrm{b}$, hoferi
e, crevieri
$\mathrm{g}$, persuasoria
c, ponderosae 

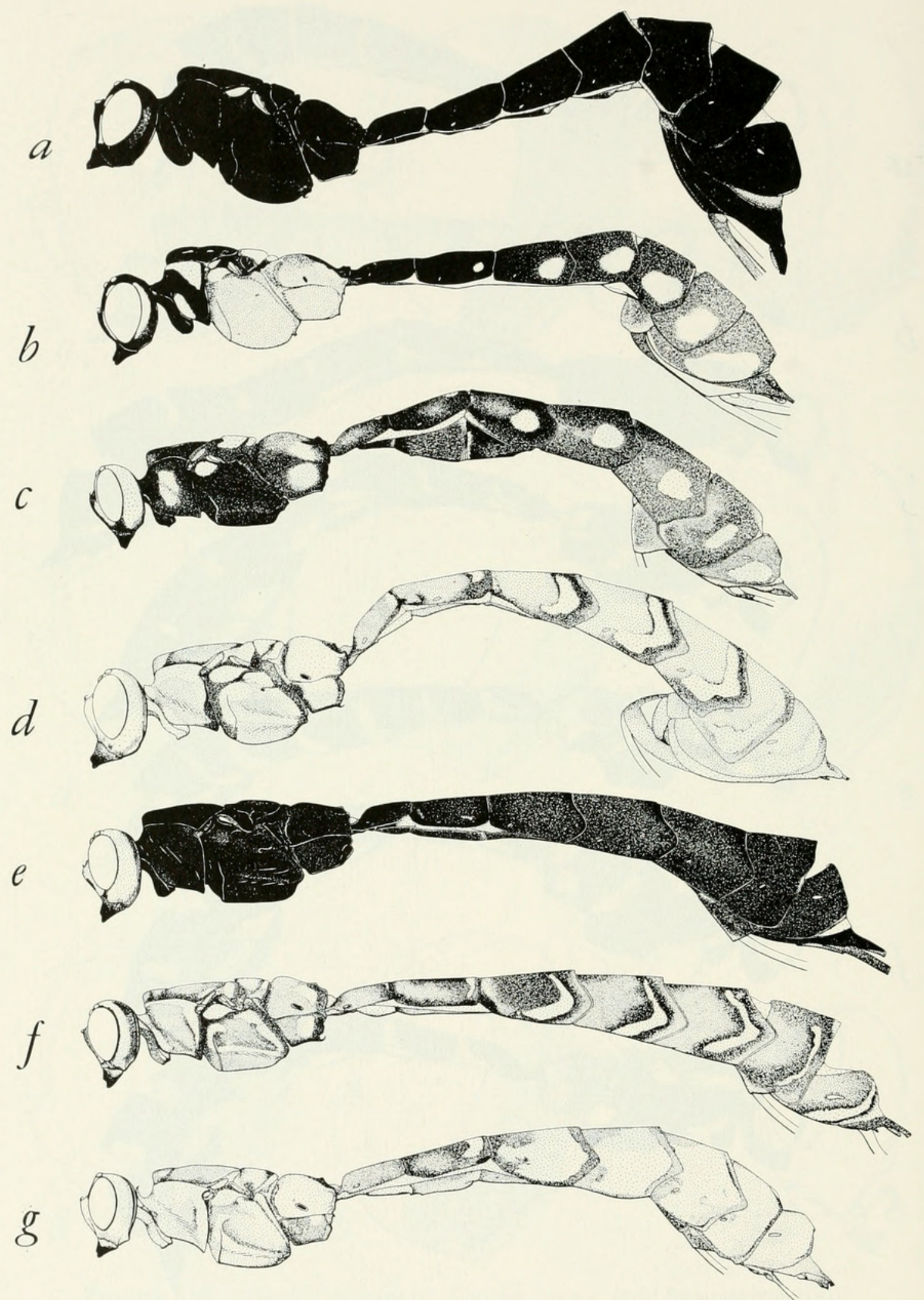

Figure 318.- - Head and torso, species of Rhyssella, $\uparrow$ (a-b); and Megarhyssa, of $(\mathrm{c}-\mathrm{g})$ :
a, R. nitida
b, R. humida
d, M. greenei greenei
f, M. macrurus lunator
c, $M$. nortoni nortoni
e, M. atrata atrata
g, M. macrurus icterosticta 

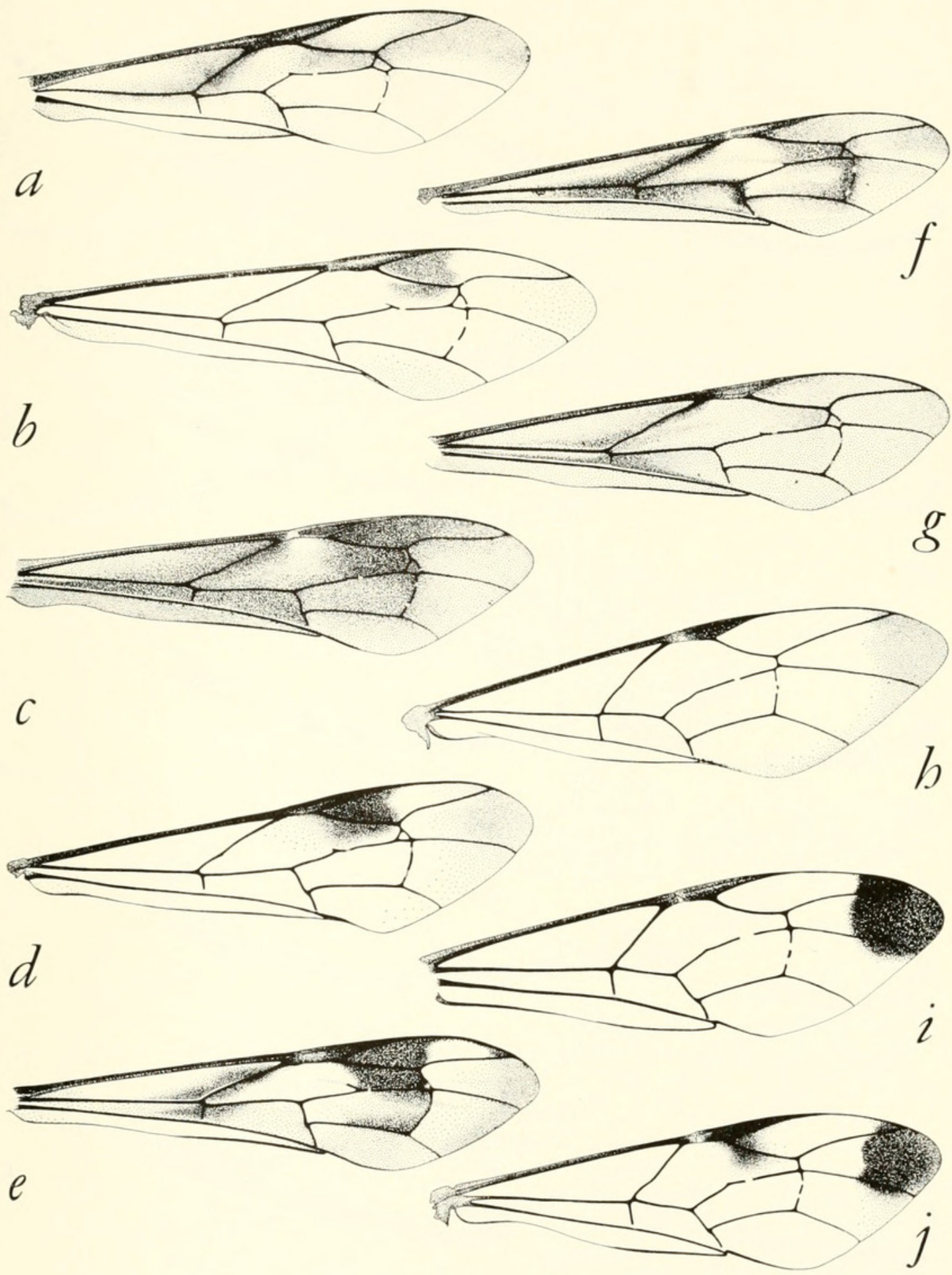

Figure 319.-Front wings, species of Rhyssa (a); Megarhyssa (b-g); Arotes (h); and Spilopteron $(\mathrm{i}-\mathrm{j})$ :
a, R. hoferi o
b, M. greenei greenei o
e, M. macrurus lunator $q \mathrm{~h}$, A. amoenus $q$
c, $M$. greenei floridana
d, M. macrurus lunator or
f, M. macrurus macrurus $q$ i, S. franclemonti $q$
g, M. macrurus ictero- j, S. formosum q sticta ? 

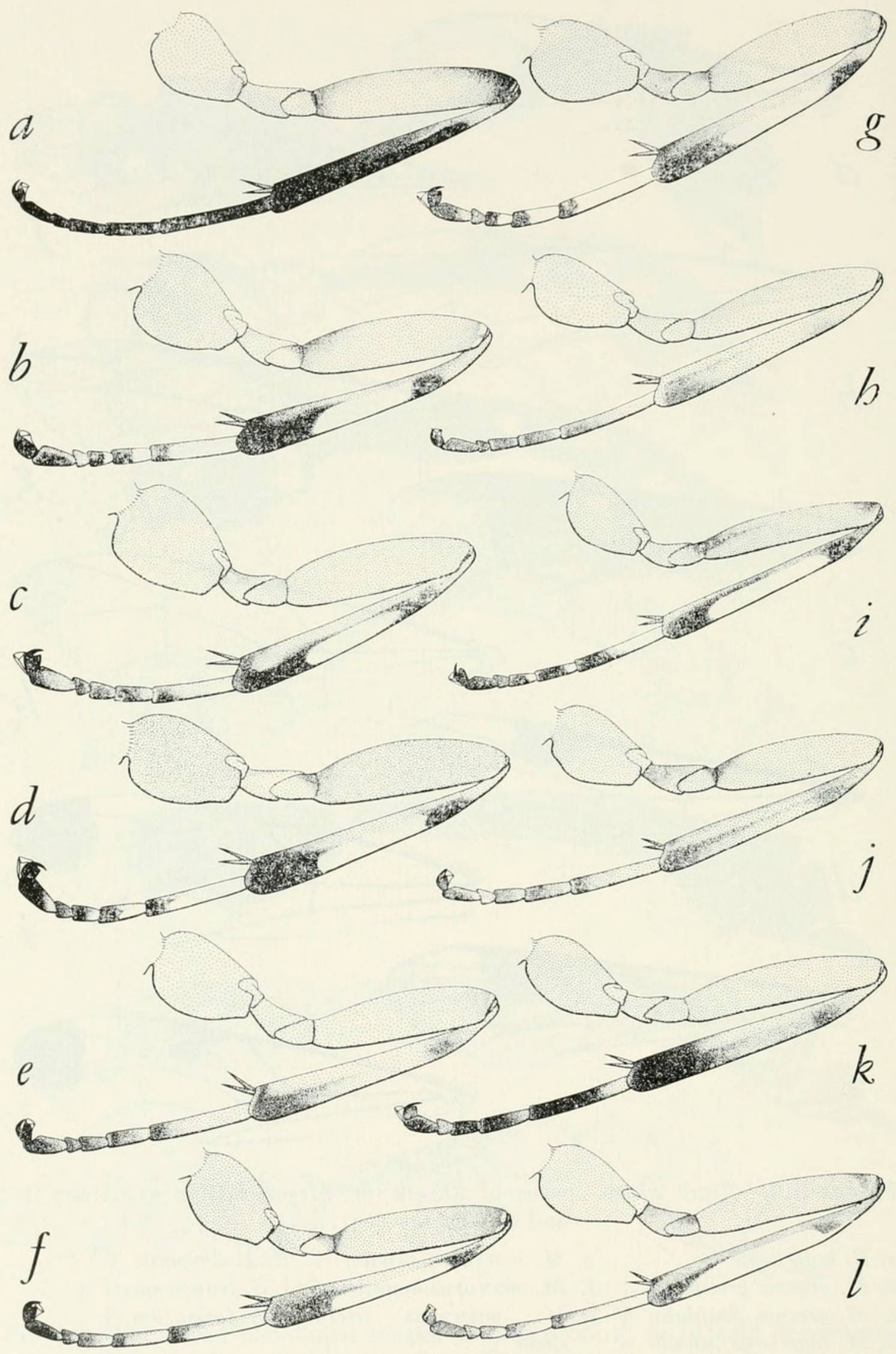

Figure 320.- Left hind legs, species of Exeristes, $q$ (a); and Scambus, $q$ (b-l):
a, E. comstockii
e, S. pterophori
b, S. rubescens
f, S. granulosus
i, S. vesicarius eurrae
c, S. detritus
g, S. deceptor
$\mathrm{j}$, S. brevicornis
d, S. productus
h, S. vesicarius vesicarius 1, S. aplopappi 


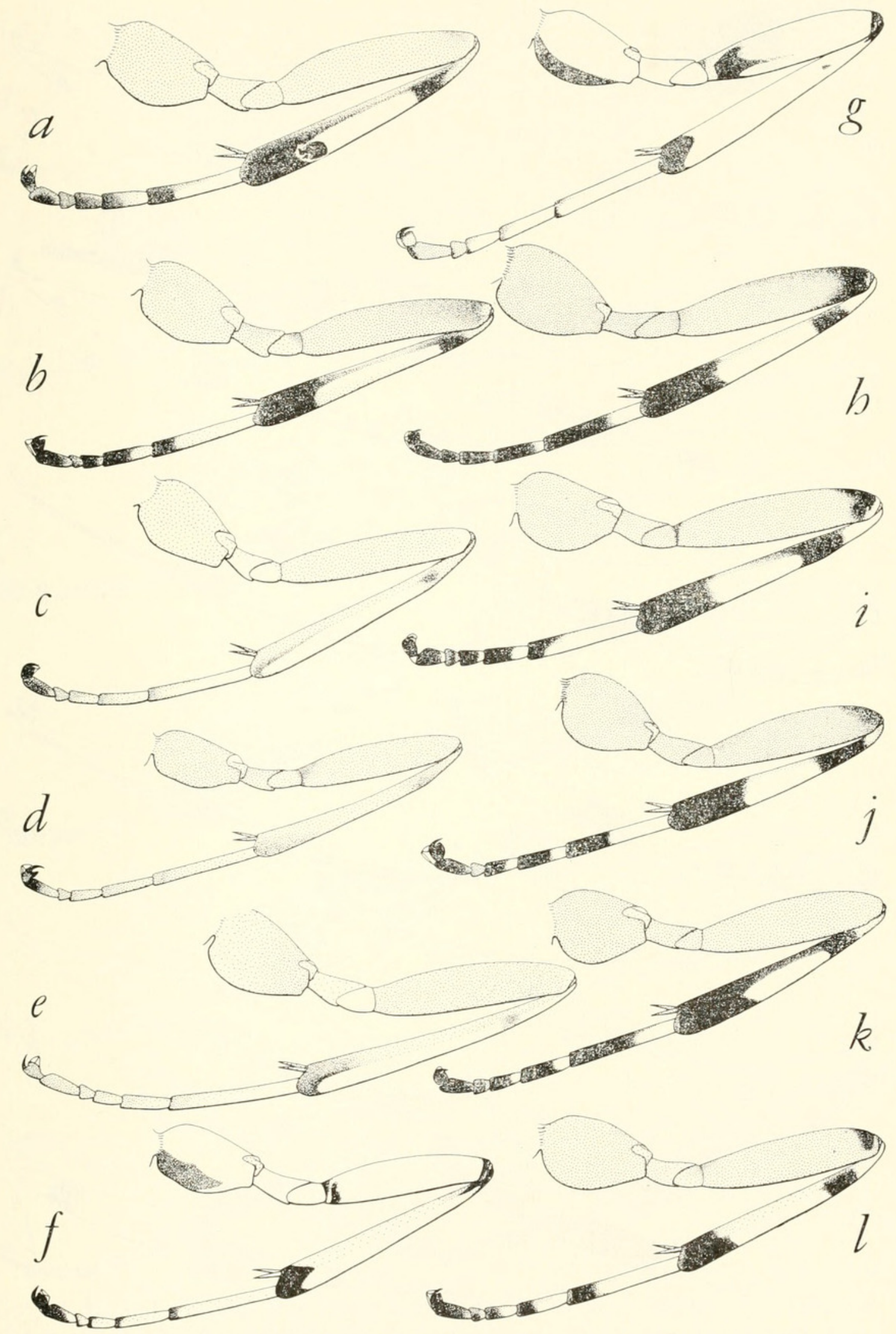

Figure 321.- - Left hind legs, species of Scambus, $q$ (a-c); Calliephialtes, $q$ (d-g); Acropimpla, $q$ (h-i); and Iseropus, o (j-1):
a, S. tecumseh
e, C. thurberiae
i, A. alboricta
b, S. hispae
f, C. grapholithae
j, I. stercorator orgyiae
c, S. hirticauda
g, C. ferrugineus
$\mathrm{k}, I$. californiensis
d, C. notandus
h, A. pronexus
1, I. coelebs 


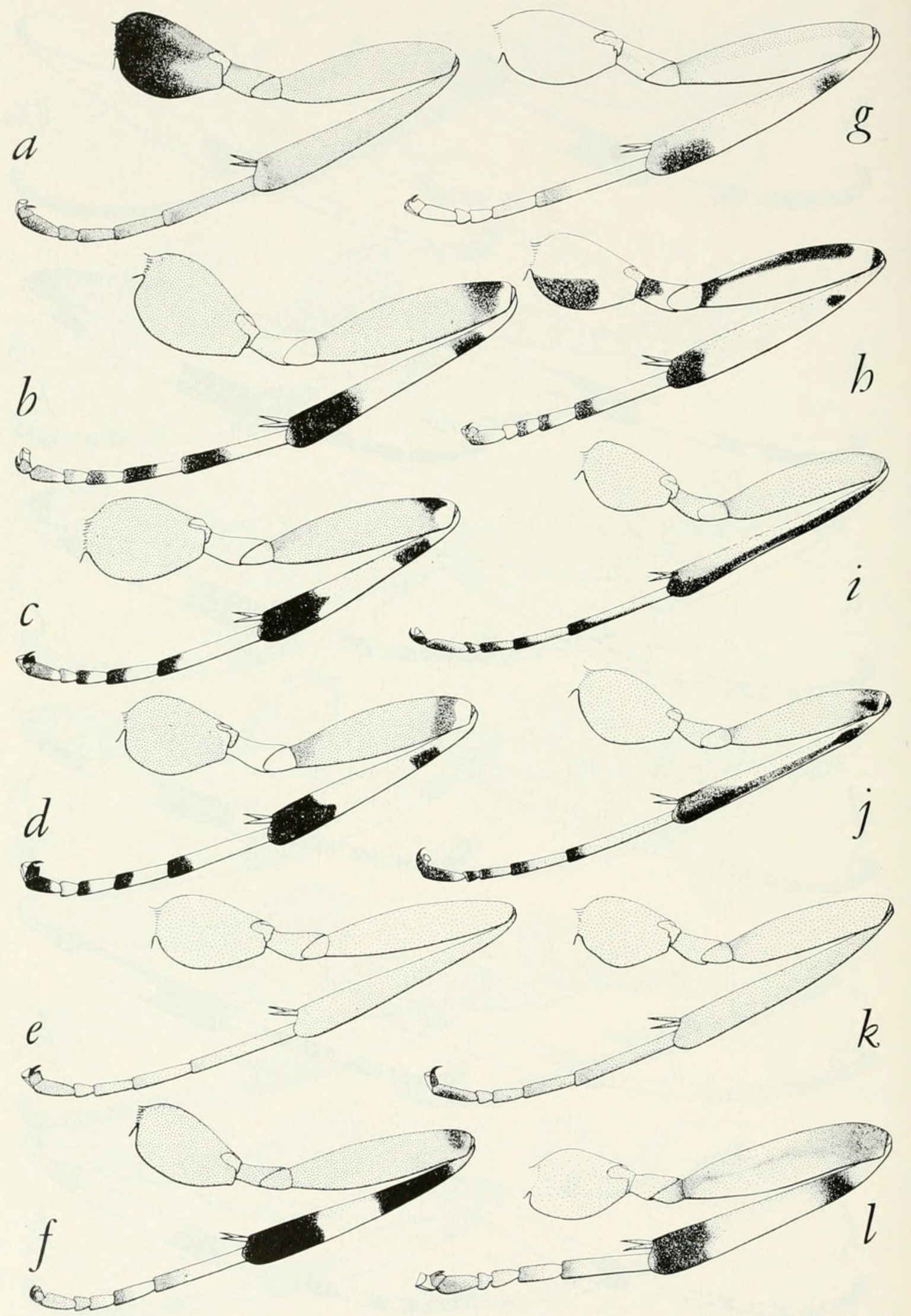

Figure 322.-Left hind legs, species of Tromatobia, $q$ (a-e); Zaglyptus, $q$ (f-h); Perithous, $q$ (i-k); and Laufeia, $q$ (l):
a, T. variabilis
b, T. ovivora ovivora
e, T. notator
f, $Z$. varipes incompletus
i, P. mediator neomexicanus
c, T. ovivora rufopectus
g, Z. arizonensis
j, P. mediator pleuralis
d, T. zonata
$\mathrm{h}, Z$. pictilis
$\mathrm{k}, P$. divinator
1, L. slossonae 


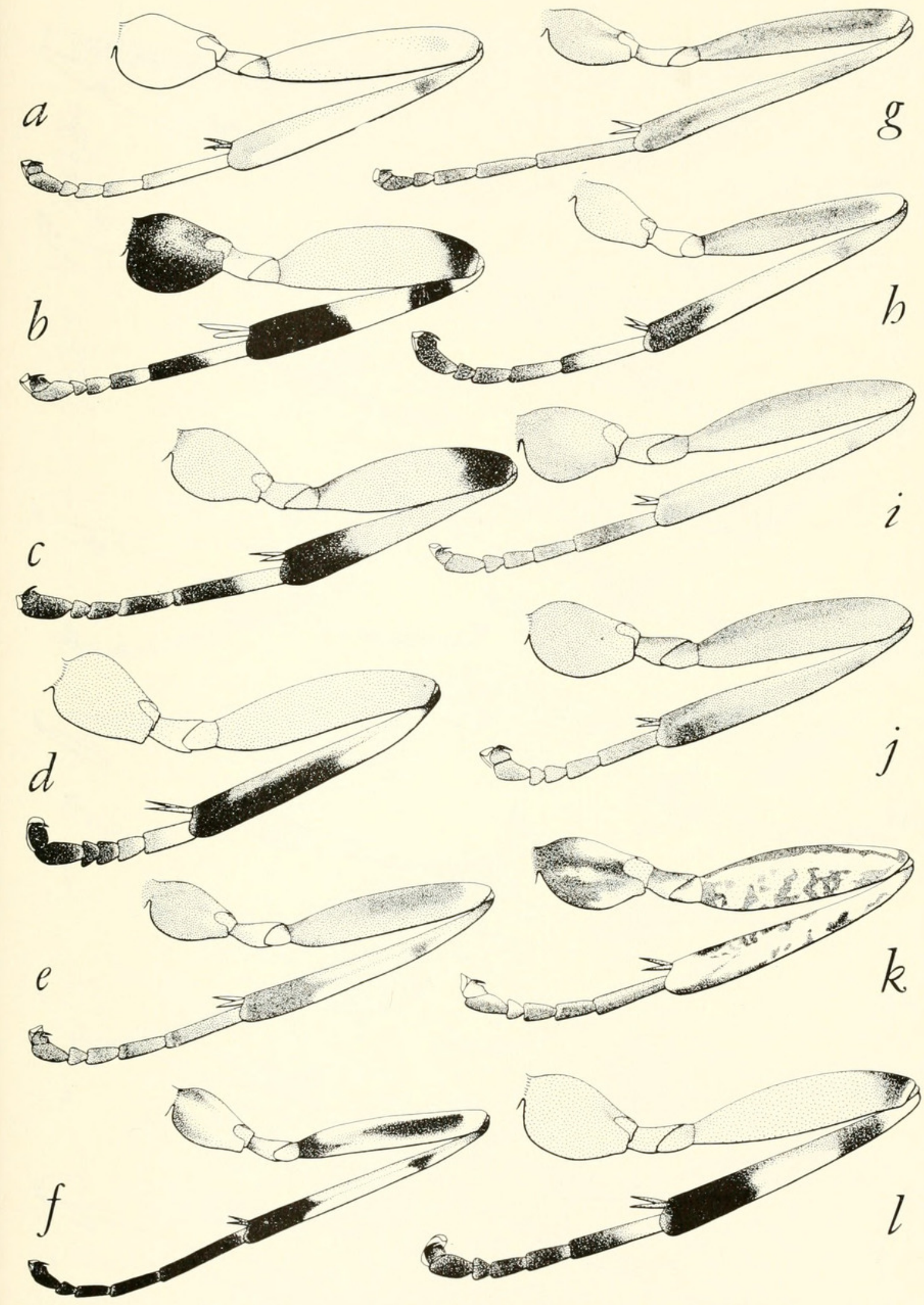

Figure 323.- - Left hind legs, species of Laufeia, $q$ (a); Schizopyga, $q$ (b-c); Zabrachypus, + (d) ; Acrodactyla, $q$ (e-h); Eruga, $q(\mathrm{i}-\mathrm{j})$; Piogaster, $q$ (k) ; and Oxyrrhexis, $q$ (1):
a, L. navajo
e, A. jubata
i, E. lineata
b, S. frigida
f, A. ocellata
j, E. rufa
c, S. pulchra
g, A. degener
k, P. maculata
d, Z. primus
h, A. quadrisculpta
1, O. carbonator texana 
620

U. S. NATiONAL MUSEUM BULletin 216

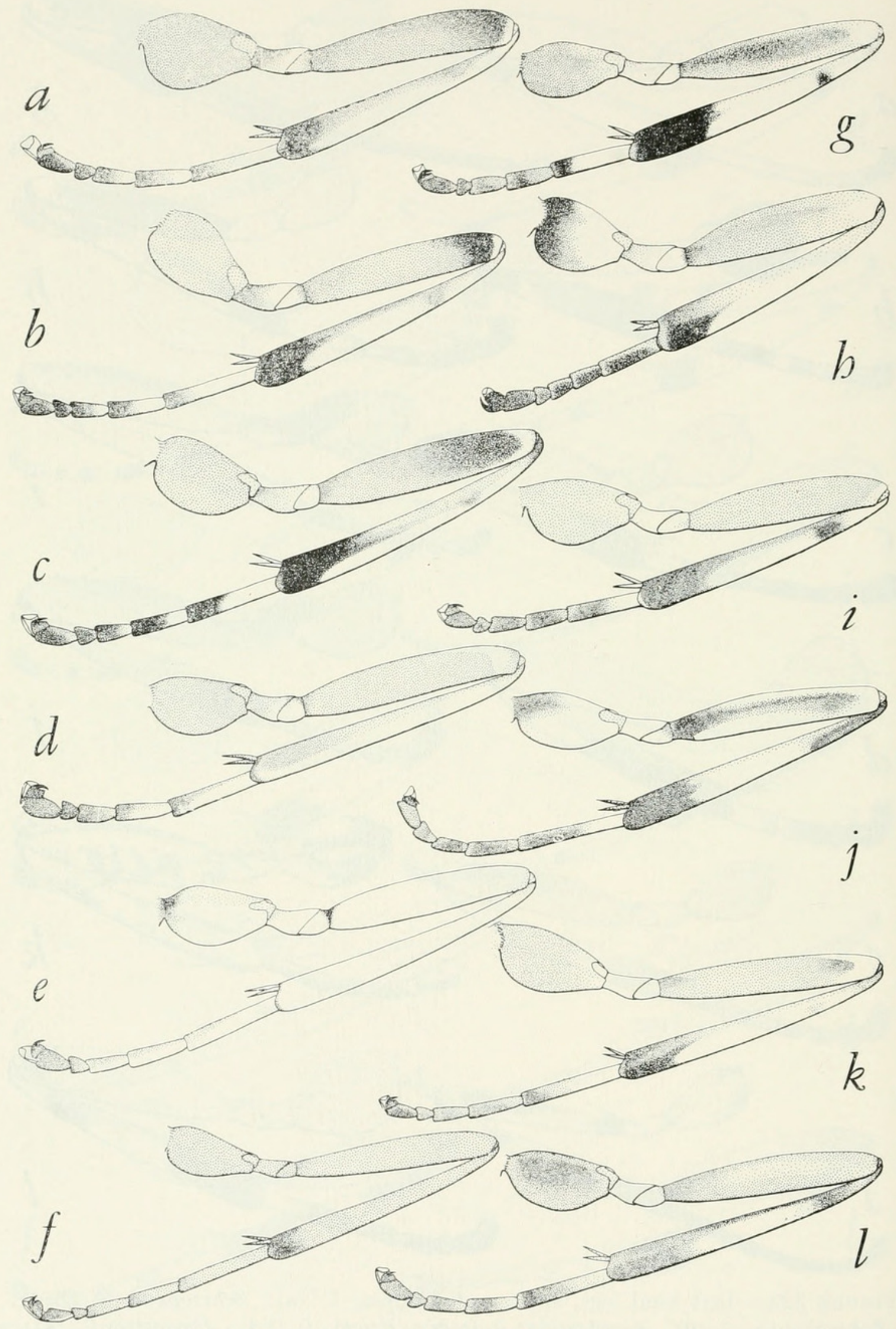

Figure 324.-Left hind legs, species of Polysphincta, $q$ (a-e); Acrotaphus, $q$ (f); Sinarachna, $₹(\mathrm{~g}-\mathrm{h})$; and Zatypota, $+(\mathrm{i}-\mathrm{l})$ :

a, P. burgessii

e, P. eboripes

b, P. limata

f, A. wiltii

i, Z. bohemani

c, P. tuberosa bruneti

g, S. pallipes strigis

j, Z. parva

d, P. koebelei

h, S. anomala

$\mathrm{k}, Z$. patellata

1, Z. favosa 


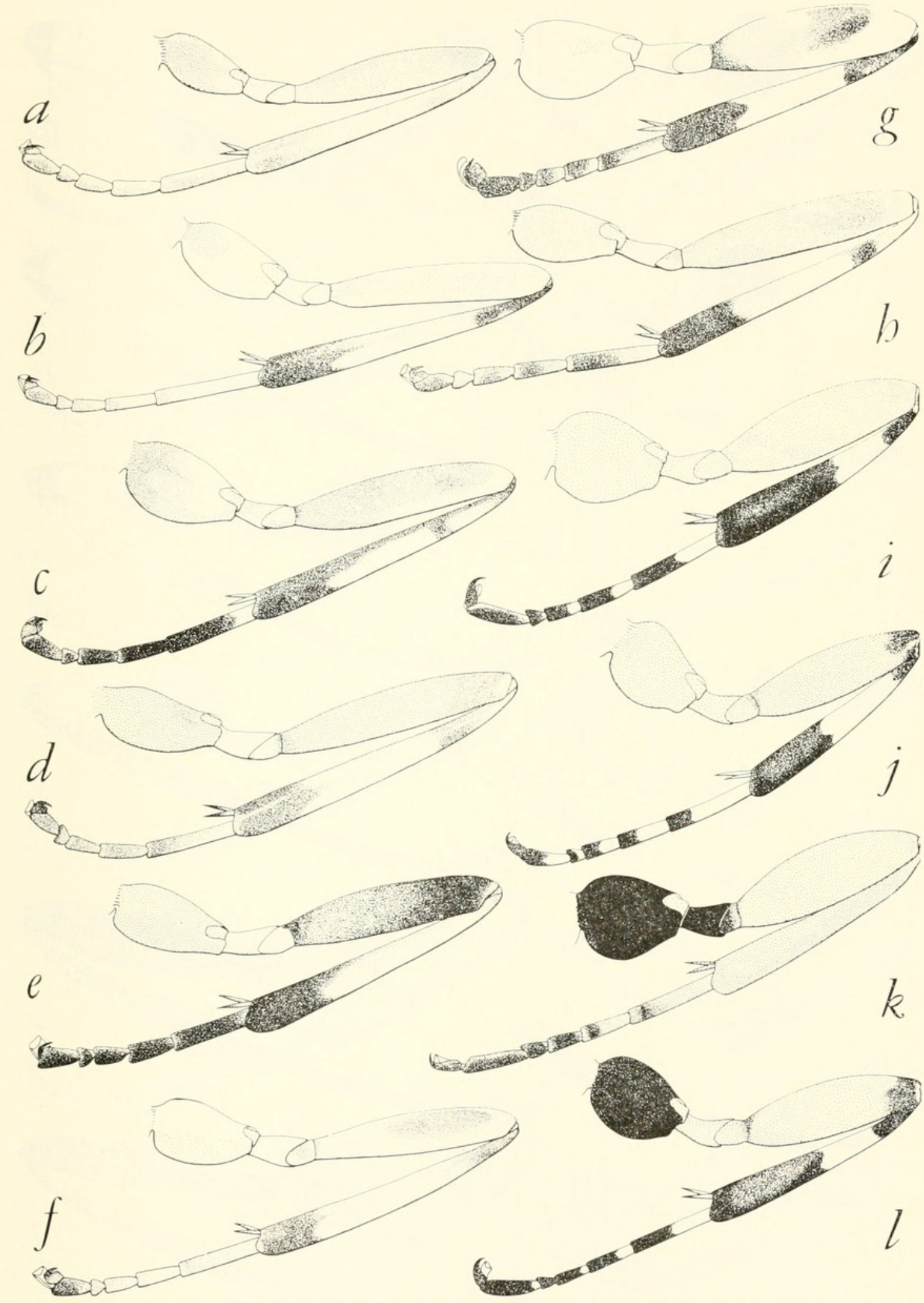

Figure 325.- - Left hind legs, species of Zatypota, $q(\mathrm{a}-\mathrm{h})$; and Itoplectis, $q(\mathrm{i}-1)$ :
a, $Z$. exilis
e, Z. percontatoria
i, I. quadricingulata
b, Z. cingulata
f, Z. luteipes
j, I. conquisitor
c, Z. arizonica
g, Z. crassipes
$\mathrm{k}, I$. viduata
d, Z. nigriceps
h, Z. alborhombarta
l, I. evetriae 


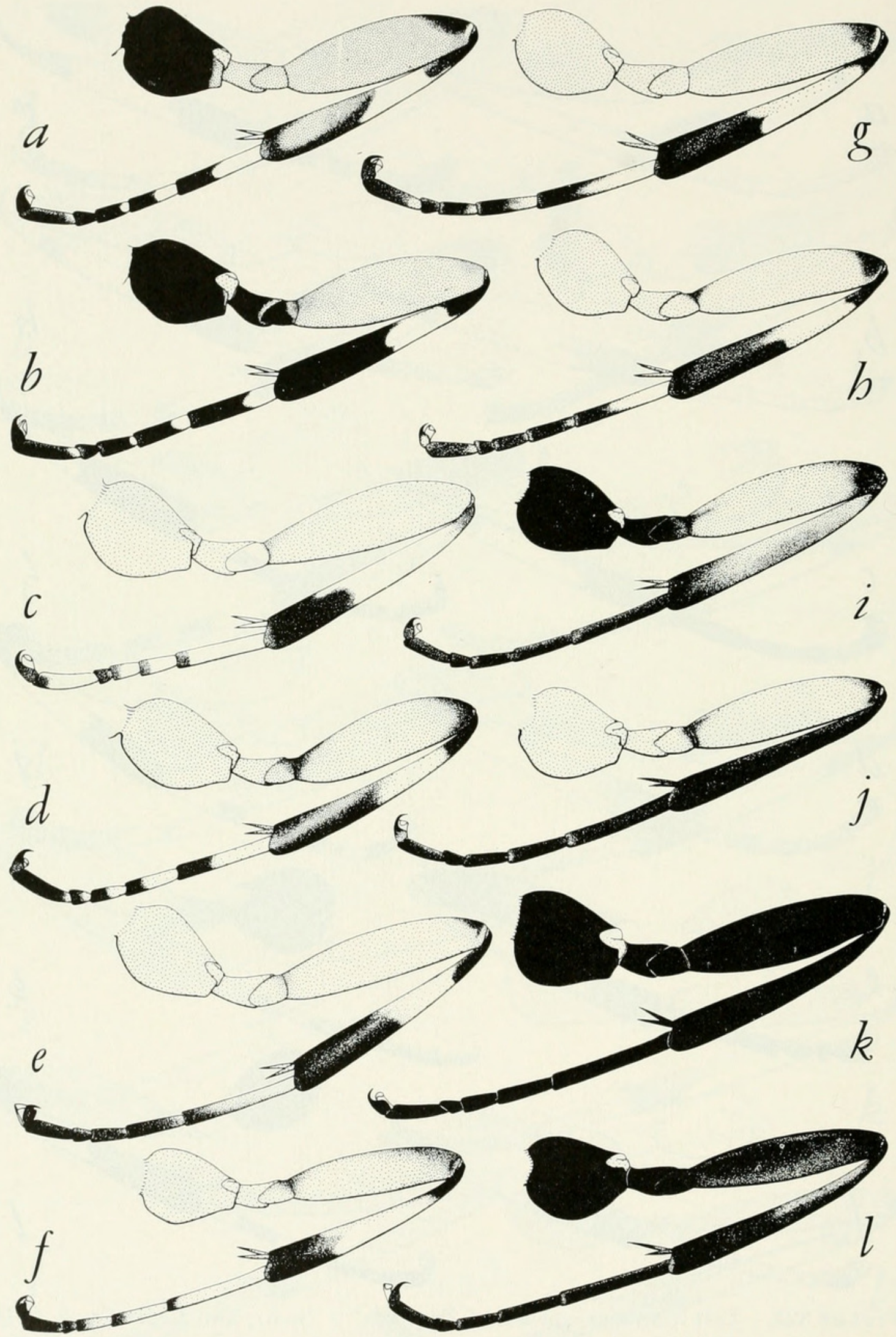

Figure 326.- - Left hind legs, species of Itoplectis, $\uparrow$ (a-d); Ephialtes, $\uparrow(\mathrm{e}-\mathrm{h})$; and Coccygomimus, $q$ (i-1):
a, I. behrensii
e, E. picticornis
i, C. silvicola
b, I. vescas
f, E. annulicornis
j, C. pedalis
c, I. fustiger
g, E. pacificus
k, C. maurus
d, I. curticauda brevacus
h, E. ontario
1, C. ellopiae 


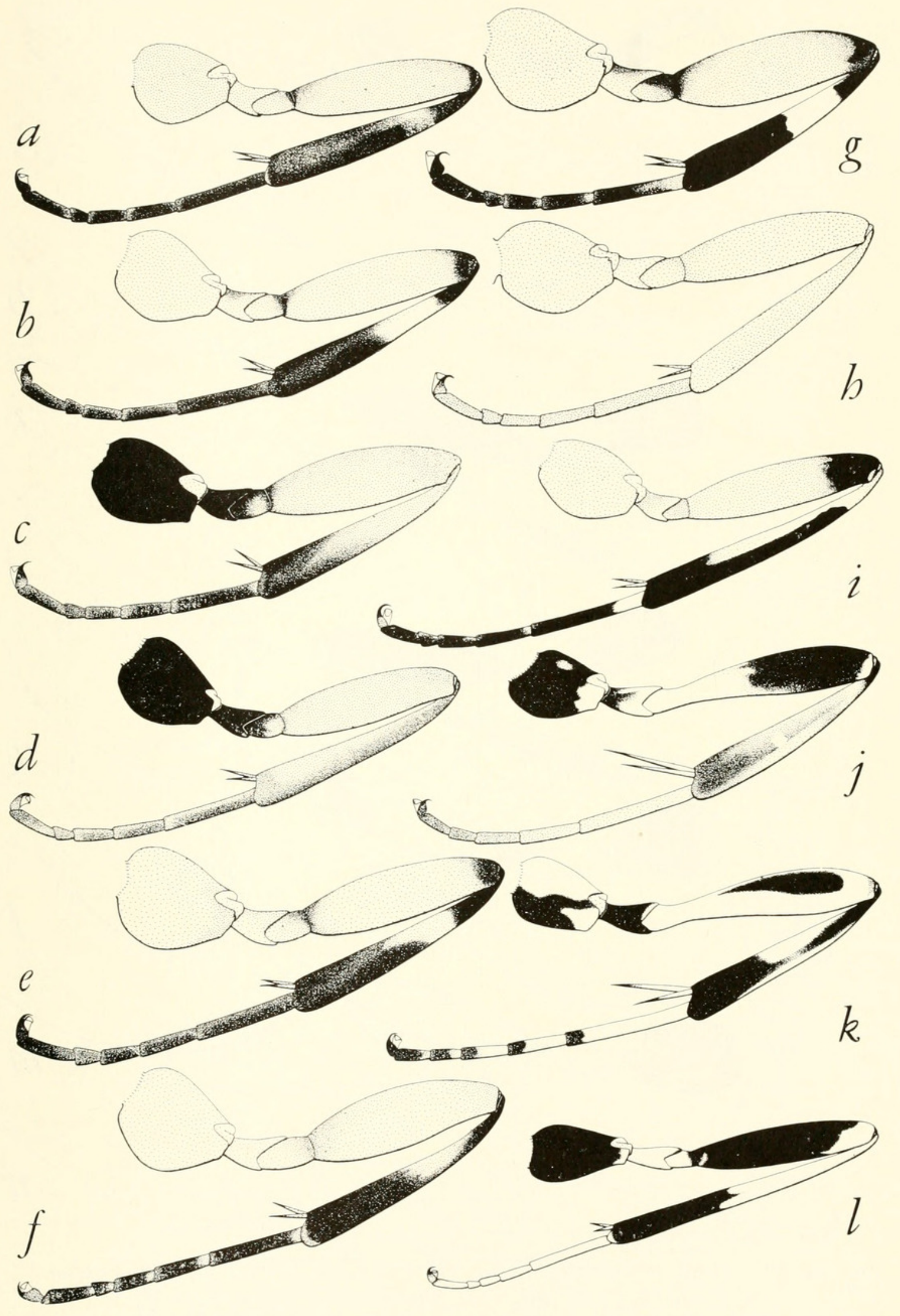

FigurE 327.- - Left hind legs, species of Coccygomimus, $q(\mathrm{a}-\mathrm{h}) ;$ Delomerista, $q$

(i); Brachycyrtus, + ( $\mathrm{j}-\mathrm{k})$; and Arotes, $q$ (l):
a, C. aquilonius exareolatus e, C. tenuicornis
i, D. novita
b, C. aquilonius aquilonius f, C. stricklandi
$\mathrm{j}$, B. ornatus
c, C. sodalis sodalis
g, C. aequalis
$\mathrm{k}$, B. pretiosus
d, C. sodalis longigenatis
h, C. punicipes
1, A. amoenus 


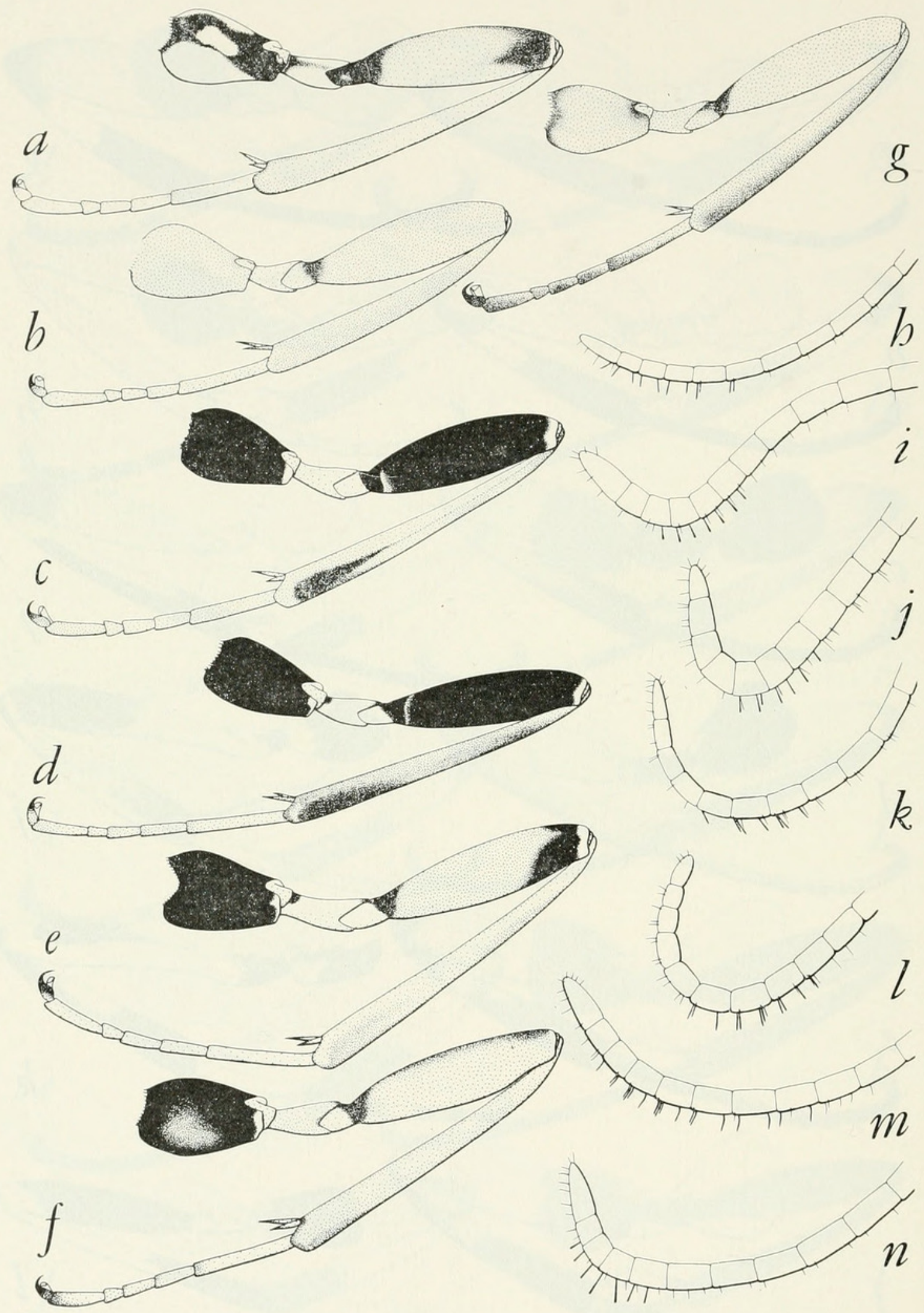

Figure 328.- - Left hind legs, species of Arotes, $\uparrow(\mathrm{a}-\mathrm{b})$; and Spilopteron, $q$ $(\mathrm{c}-\mathrm{g})$; and tips of antennae, species of Xorides, $q(\mathrm{~h}-\mathrm{l})$ :
a, A. decorus
f, S. vicinum vicinum
$\mathrm{k}, X$. rileyi
b, A. melleus
g, S. occiputale
1, X. medius
c, S. franclemonti
$\mathrm{h}, X$. frigidus
$\mathrm{m}, X$. insularis
d, S. formosum formosum
i, $X$. pictus
m, X. insularis
n. $X$. albopictus
e, S. formosum australe j, X. peniculus 


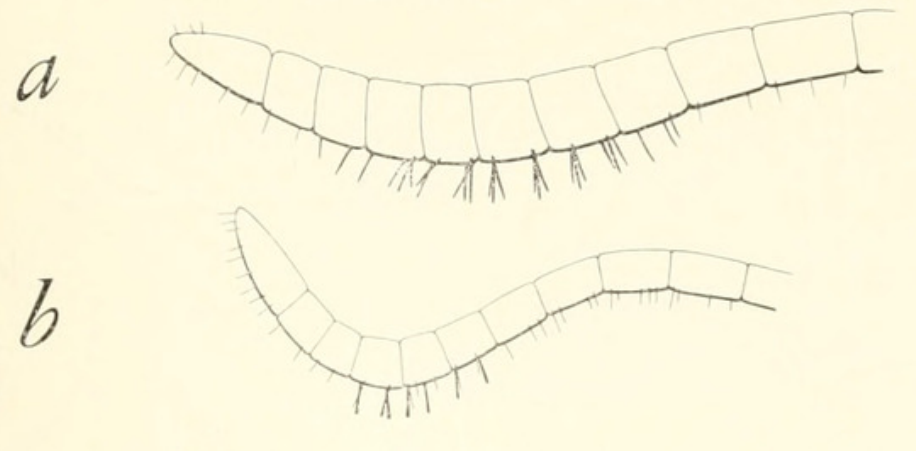

C
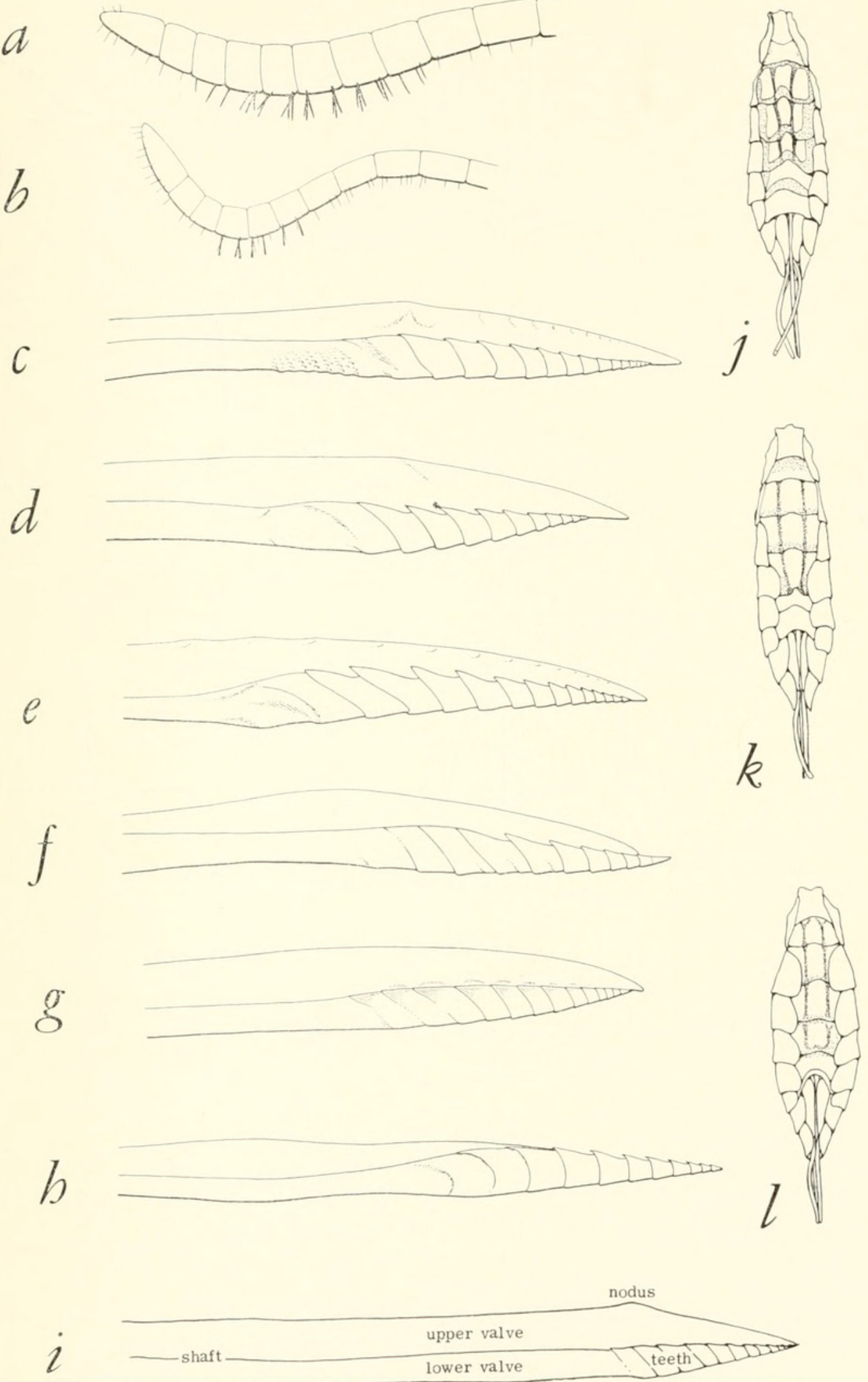

Figure 329.-Tips of antennae, species of Xorides, $q(\mathrm{a}-\mathrm{b})$; ovipositor tips, various species $(\mathrm{c}-\mathrm{h})$; diagram of ovipositor to show terminology (i); and underside of abdomen species of Coccygomimus, to show epipleura (j-1).
a, X. harringtoni
b, X. stigmapterus
c, Exeristes comstockii
e, Apistephialtes tenuiven- tris
i, Ovipositor diagram
d, Calliephialtes grapho-
$\mathrm{j}$, C. aquilonius
f, Apistephialtes variatipes
$\mathrm{k}$, C. tenuicornis
lithae
g, Apistephialtes arcticus
1, C. aequalis
$526527-60-41$ 

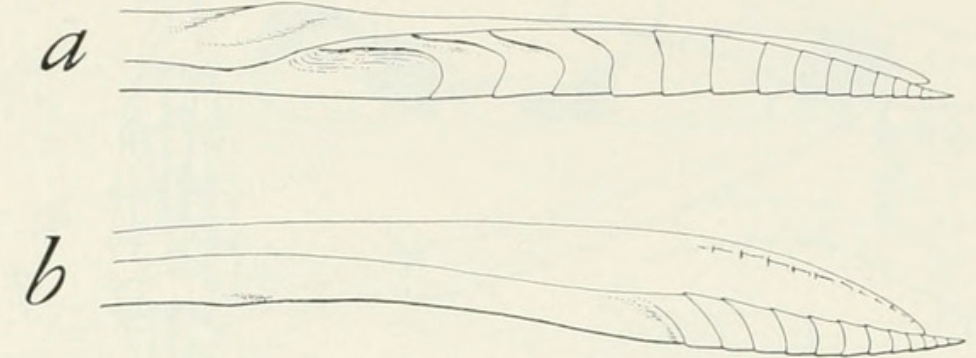

C
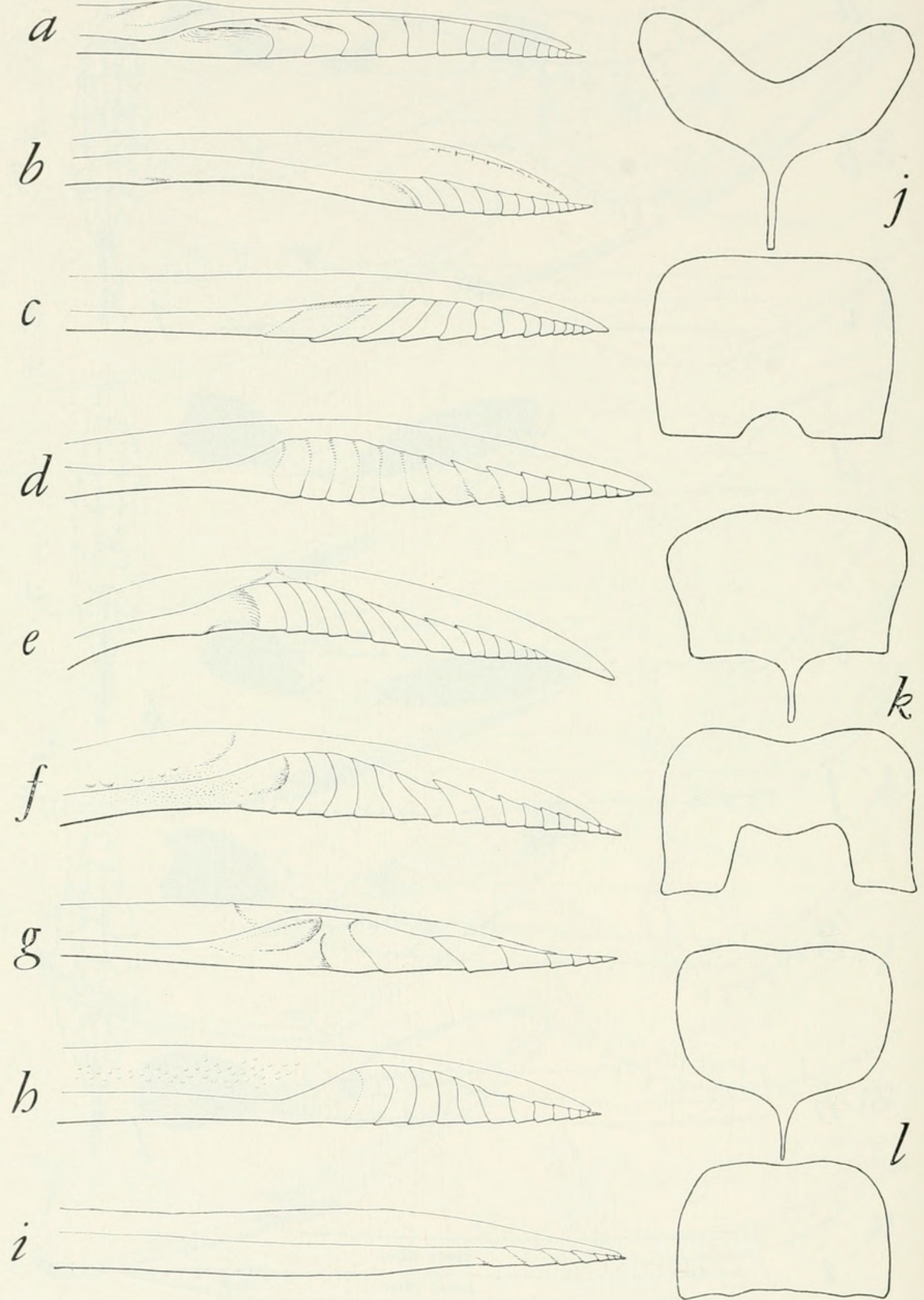

Figure 330.-Ovipositor tips, various species (a-i); and sixth and seventh sternites, species of Apistephialtes, or (j-1).

a, Pimpla spatulata

b, Anastelgis terminalis

c, Dolichomitus taeniatus

d, Dolichomitus tuberculatus. e, Dolichomitus populneus j, Apistephialtes tenuiven$\mathrm{f}$, Dolichomitus messor tris

g, Dolichomitus imperator k, Apistephialtes variatipes h, Dolichomitus sericeus 1, Apistephialtes nucicola 

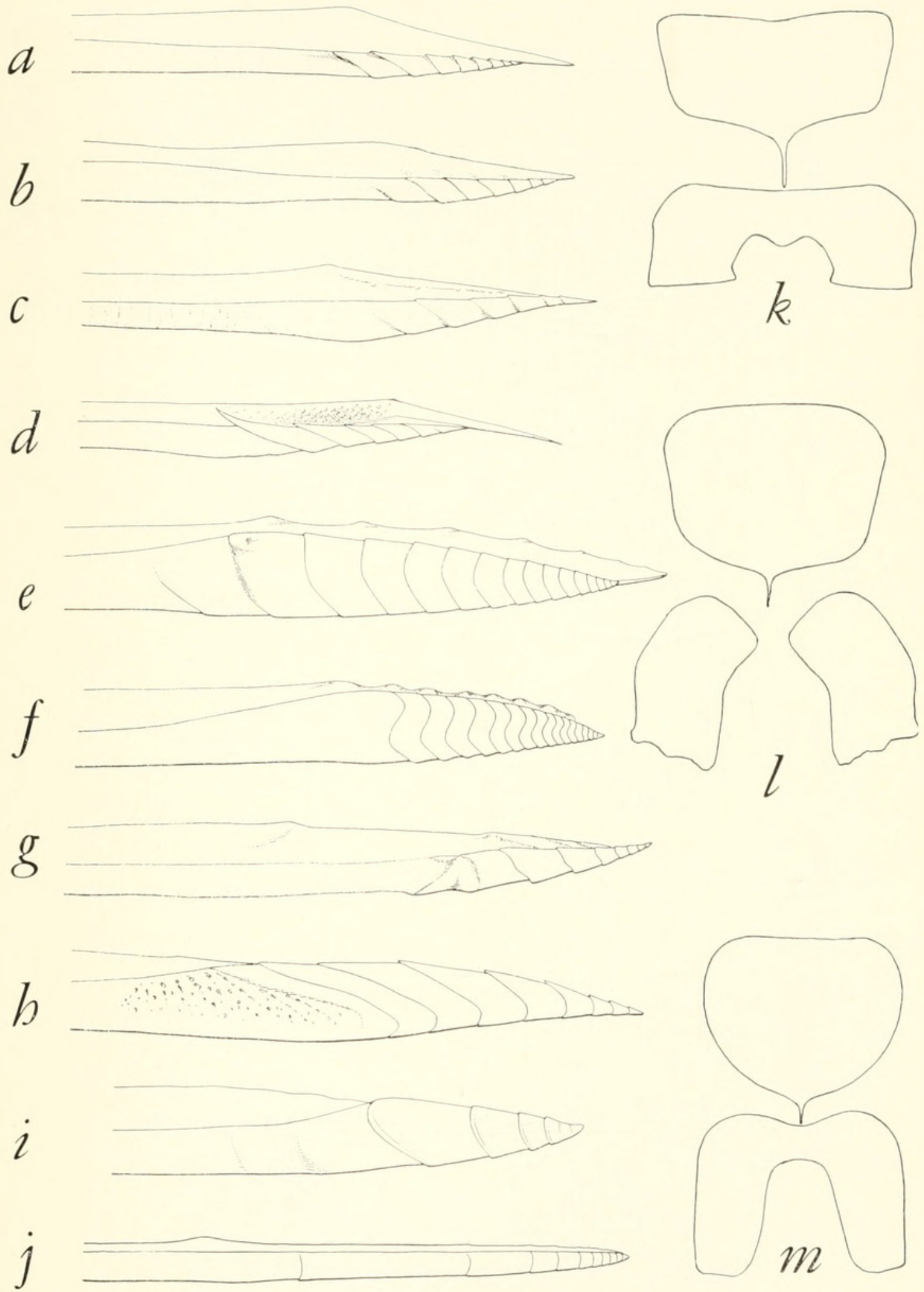

Figure 331.-Ovipositor tips, various species $(a-j)$; and sixth and seventh sternites, species of Apistephialtes, or $(\mathrm{k}-\mathrm{m})$.
a, Acropimpla alboricta
f, Perithous divinator
k, Apistephialtes petulcus
b, Iseropus stercorator
g, Odontocolon vicinum
1, A pistephialtes dentatus
c, Tromatobia ovivora
$\mathrm{h}$, Xorides albopictus
$\mathrm{m}$, A pistephialtes cora
d, Zaglyptus varipes
i, Coleocentrus rufus
cinus.
e, Perithous mediator
$\mathrm{j}$, Arotes amoenus 


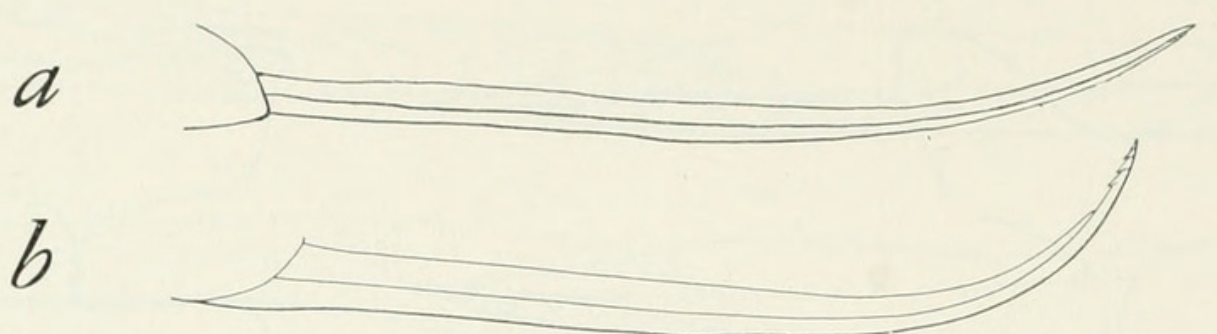

C

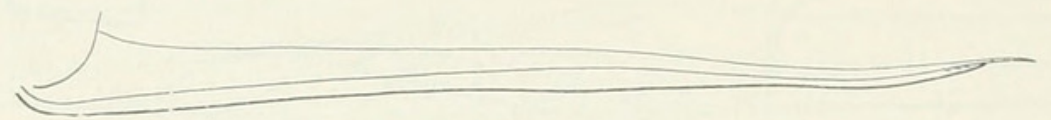

d

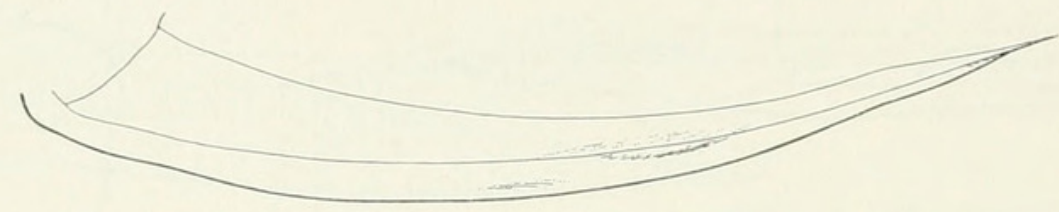

$e$

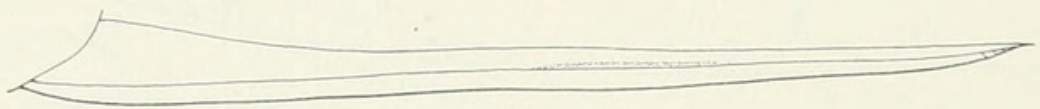

f

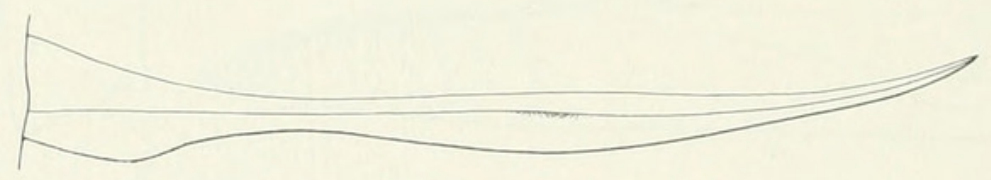

$\zeta$

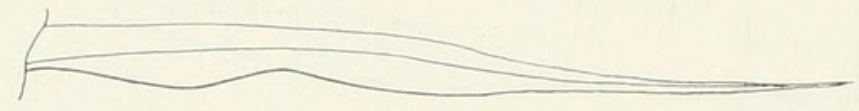

b

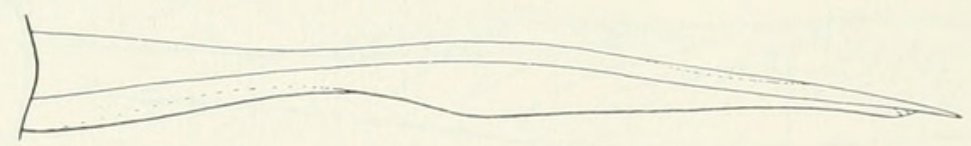

$i$

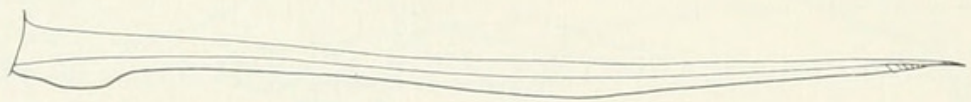

$j$

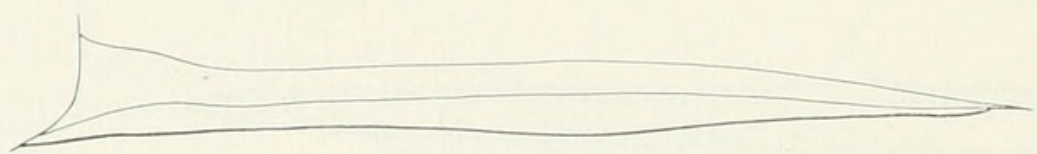

$k$

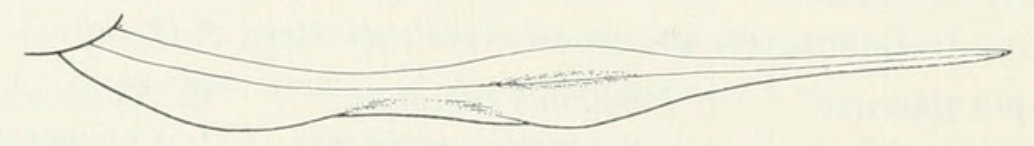

FIGURE 332.-Ovipositors, side view.
a, Clistopyga canadensis
e, Zabrachypus primus
h, Oxyrrhexis carbonator
b, Clistopyga recurva
c, Laufeia slossonae
f, Acrodactyla quadri-
i, Polysphincta tuberosa
d, Schizopyga frigida sculpta
j, Zatypota bohemani
g, Eruga lineata
$\mathrm{k}$, Zatypota nigriceps 

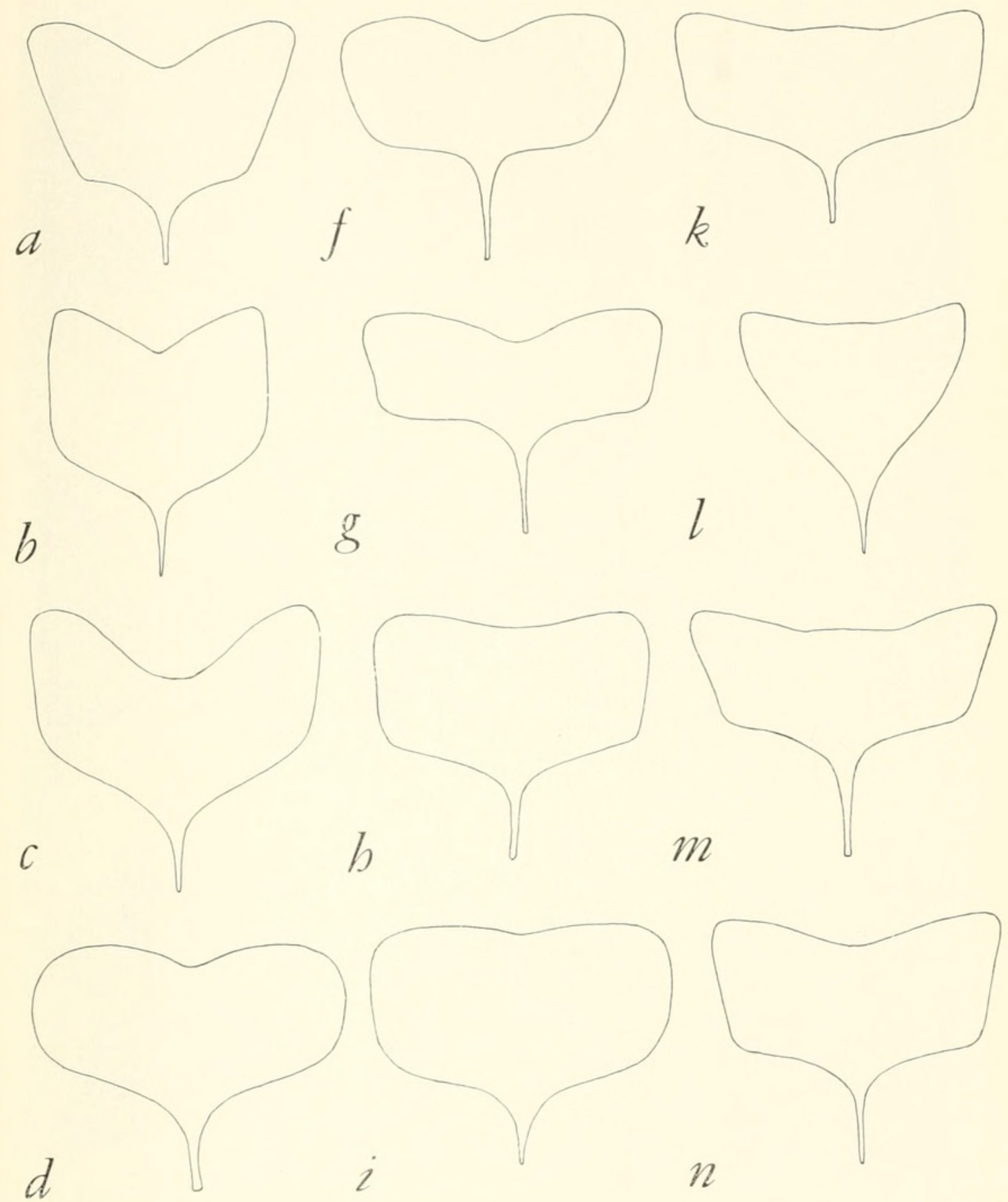

\section{$n$}
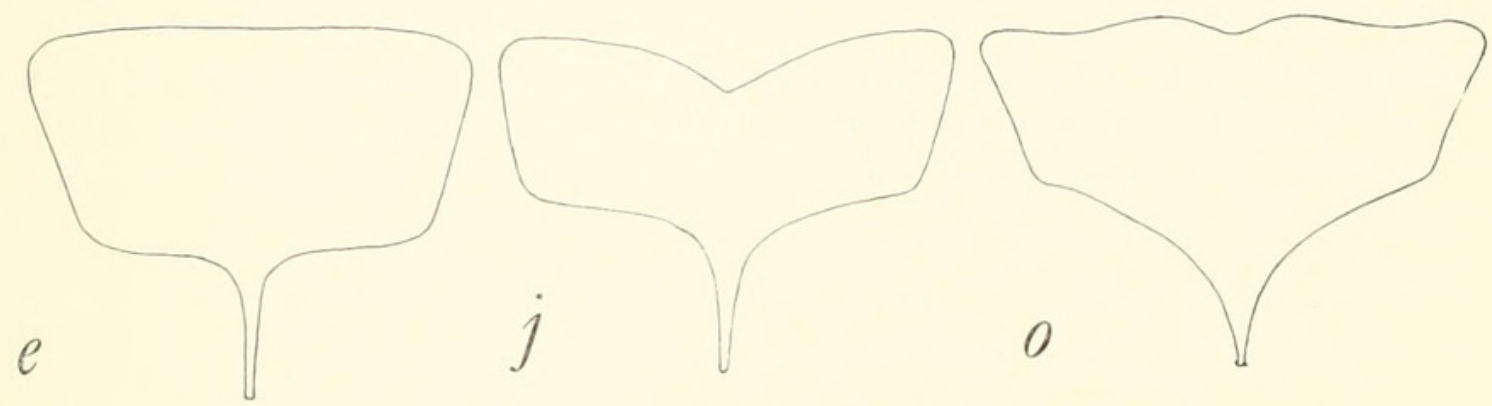

Figure 333.- Male subgenital plates, species of Dolichomitus.
a, dolichosoma
f, populneus
$\mathrm{k}$, vitticrus
b, taeniatus
g, messor
1, pygmaeus
c, cuspidatus
$\mathrm{h}$, irritator
$\mathrm{m}$, pterelas
d, terebrans
i, aciculatus
$\mathrm{n}$, imperator
e, tuberculatus
j, californicus
$\mathrm{o}$, sericeus 

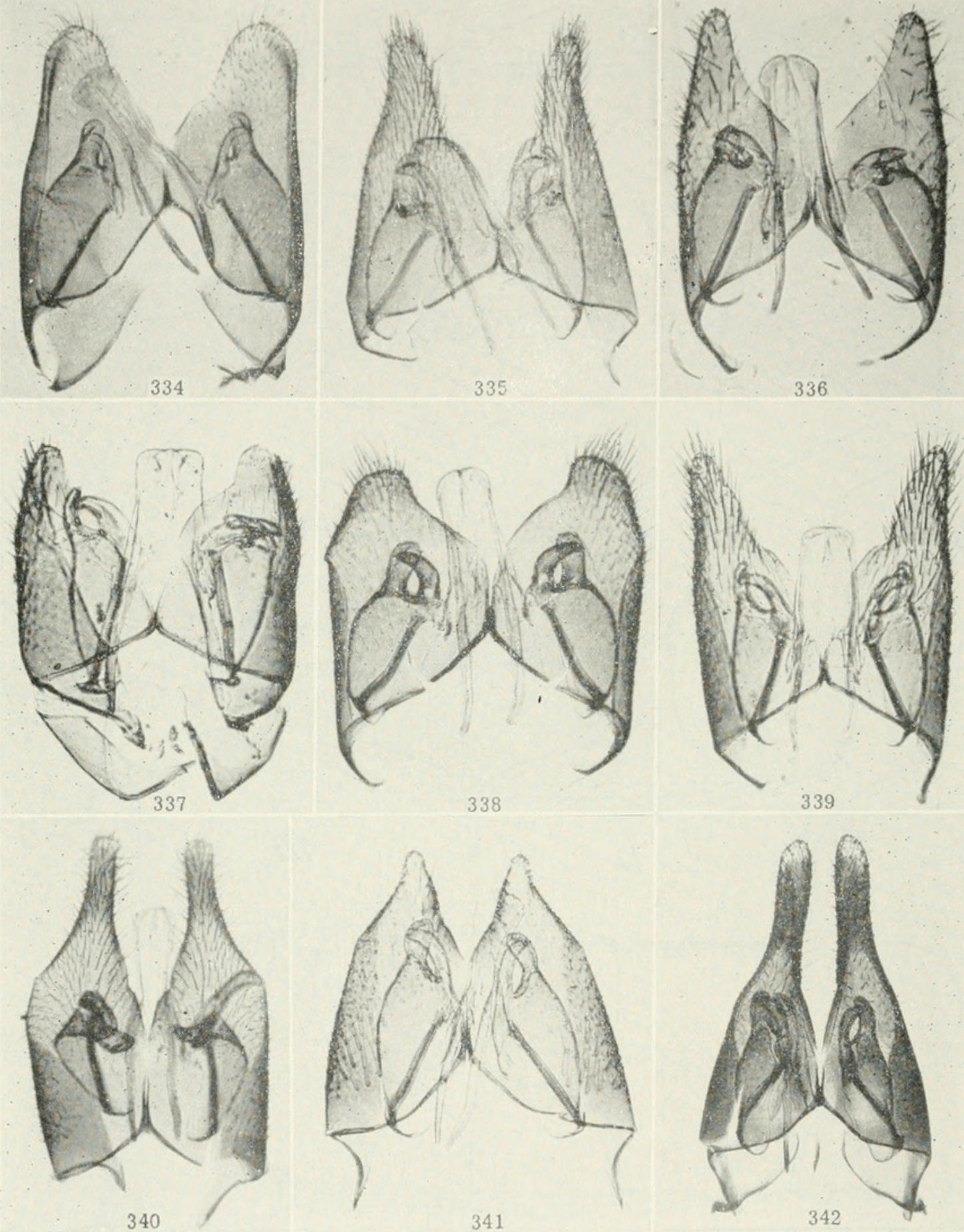

Figures 334-342.-Male genitalia, species of Apistephialies and Pimpla: 334, A. tenuiventris; 335, A. variatipes; 336, A. nucicola; 337, A. petulcus; 338, A. dentatus; 339, A. coracinus; 340, P. decumbens; 341, P. macra; 342, P. brevis. 

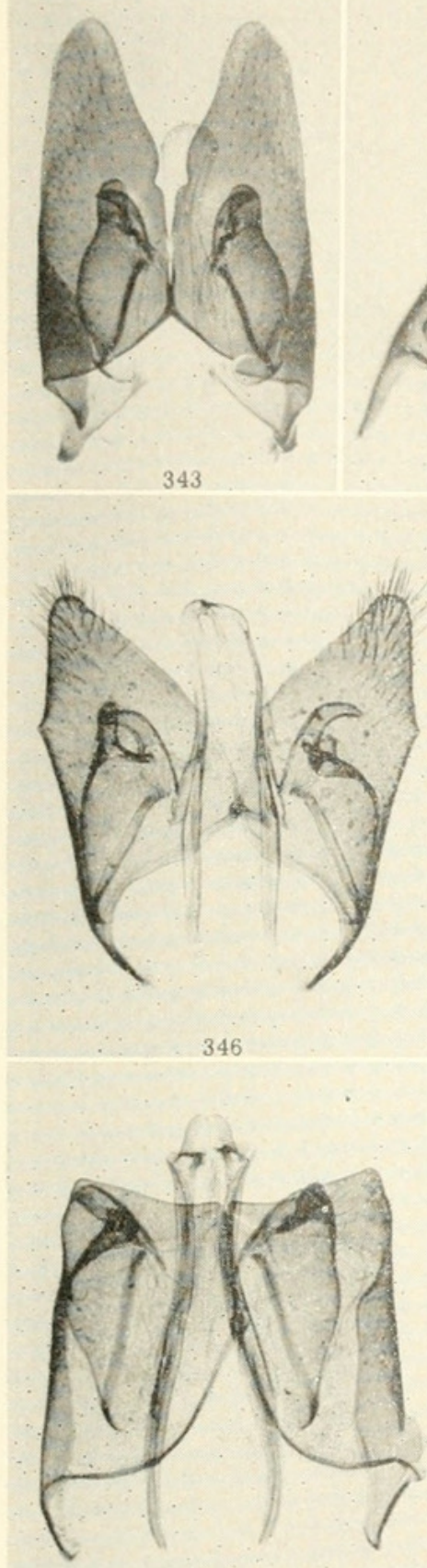

349
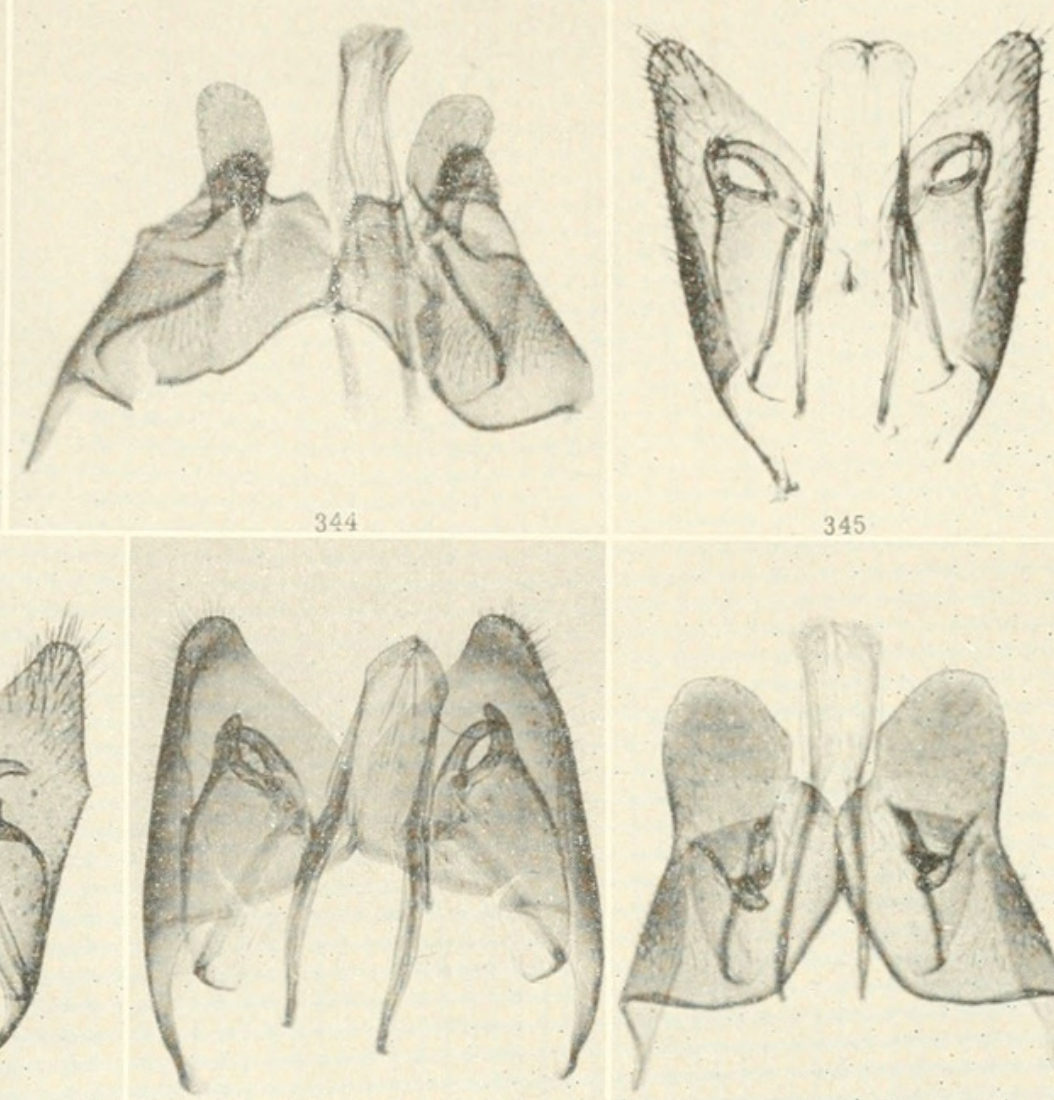

347

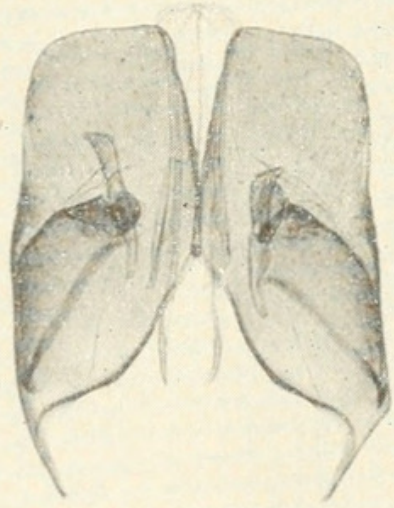

350

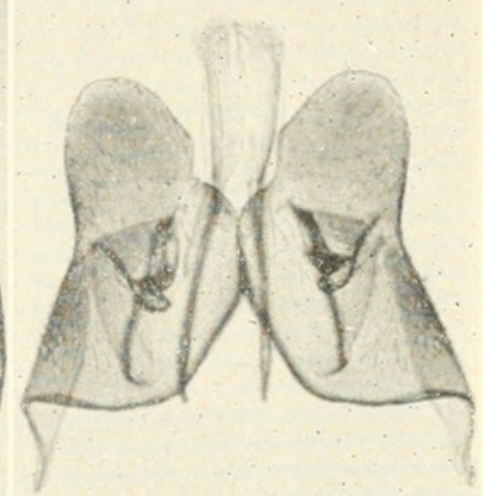

348

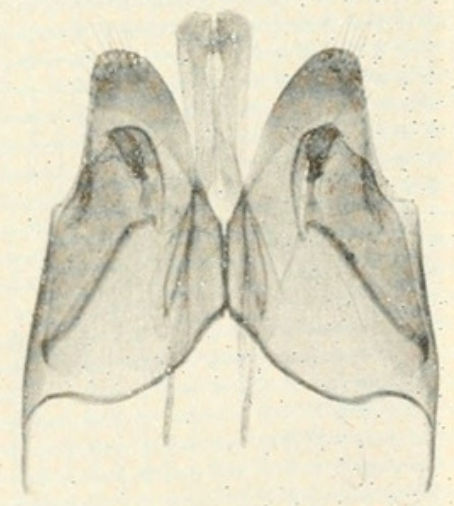

351

Figures 343-351.-Male genitalia, species of Pimpla and Dolichomitus: 343, P. spatulata; 344, D. tuberculatus; 345, D. dotichosoma; 346, D. taeniatus; 347 , D. cuspidatus; 348, D. terebrans; 349, D. populneus; 350, D. messor; 351, D. irritator. 

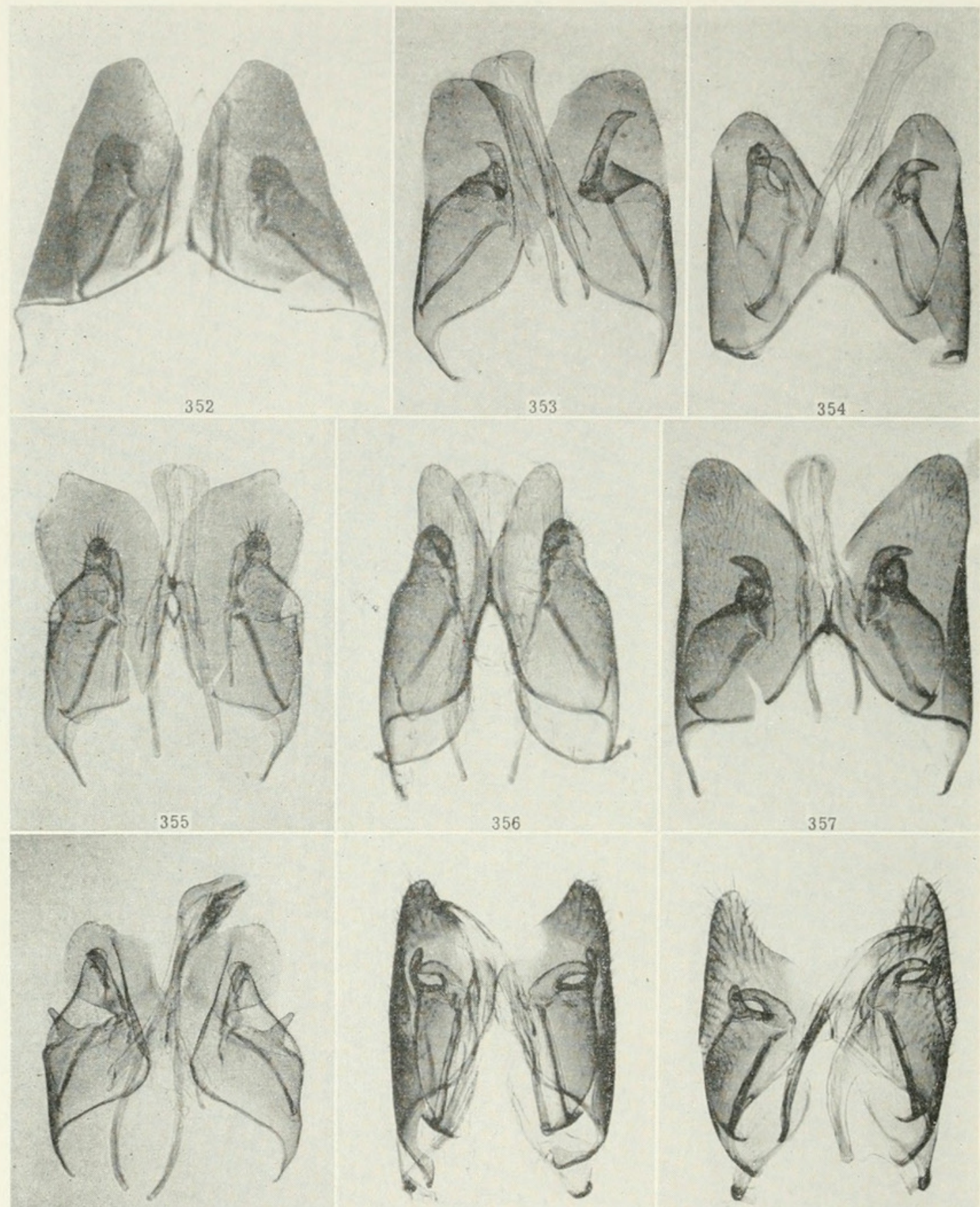

358

359

360

Figures 352-360.-Male genitalia, species of Dolichomitus and Acropimpla: 352, D. aciculatus; 353, D. californicus; 354, D. vitticrus; 355, D. pygmaeus; 356, D. pterelas; $357, D$. imperator; $358, D$. sericeus; $359, A$. pronexus; $360, A$. alboricta. 


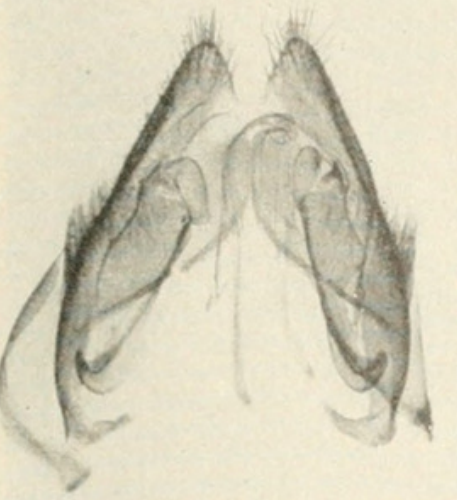

361

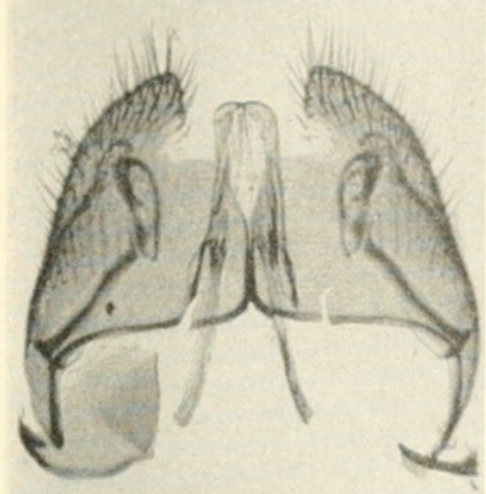

364

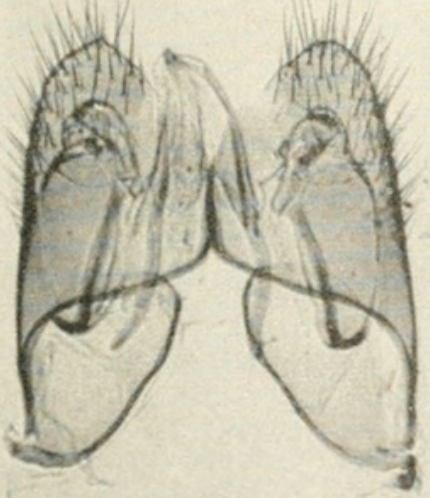

367

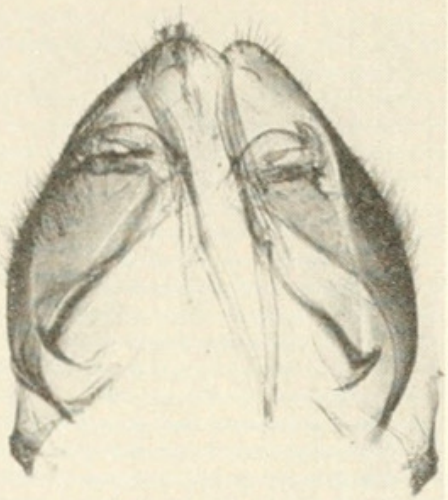

362

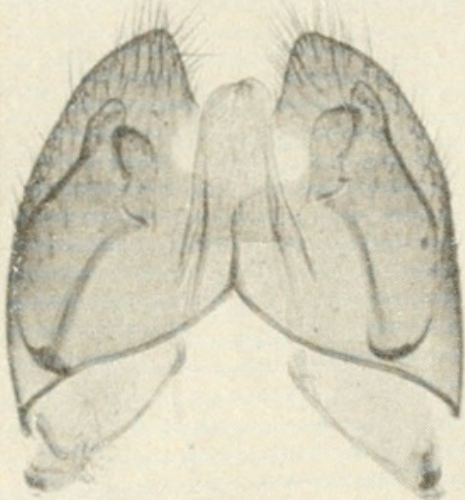

365

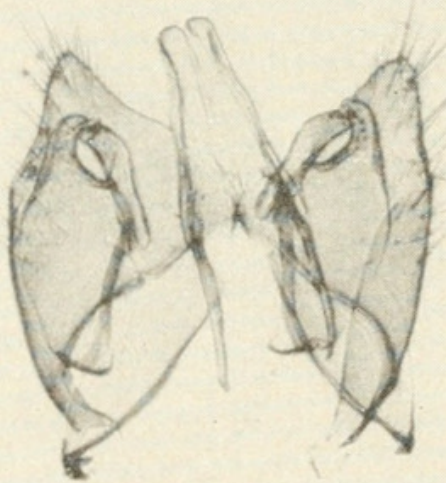

368

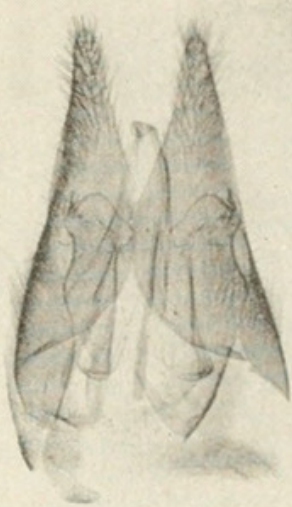

363

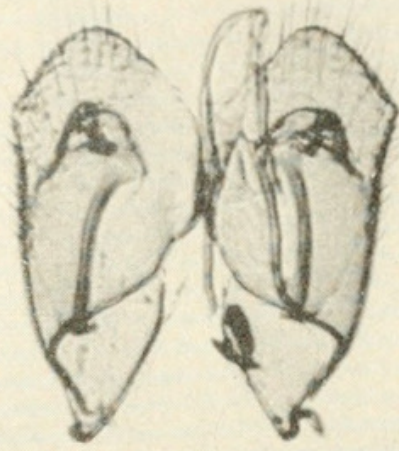

366

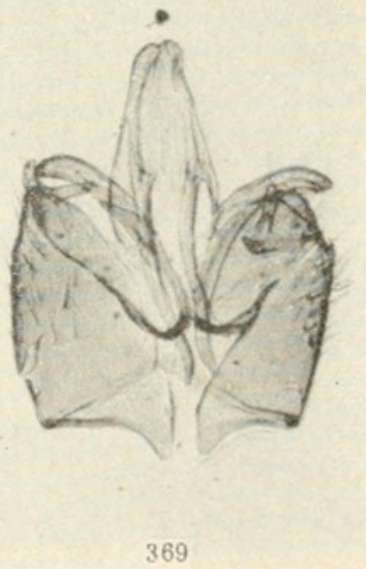

Figures 361-369.-Male genitalia, species of Iseropus, Tromatobia, and $Z$ aglyptus: 361, I. stercorator; 362 , I. californiensis; 363 , I. coelebs; 364 , T. variabilis; $365, T$. ovivora; $366, T$. zonata; $367, T$. notator; $368, Z$. varipes; $369, Z$. pictilis. 


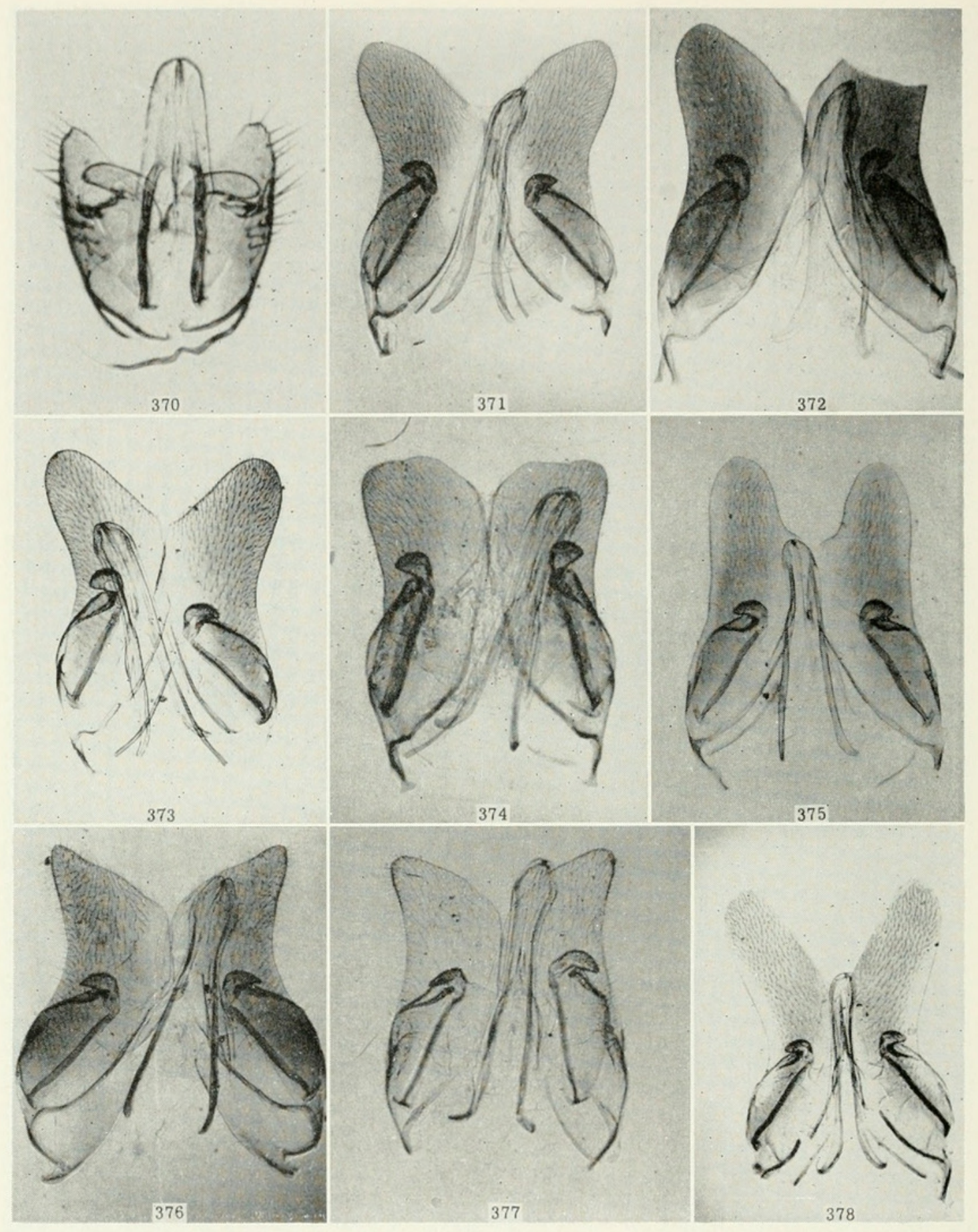

Figures 370-378.- Male genitalia, species of Alophosternum and Coleocentrus: 370 , A. foliicola; 371, C. occidentalis; 372, C. quebecensis; 373, C. pettiti; 374, C. harringtoni; 375 , C. rufocoxatus; 376, C. manni; 377 , C. rufus; 378 , C. flavipes. 


\section{Index}

(Page numbers of principal entries are in italics. For index of hosts, see page 666. Nоте: Second and following generic names appearing after species entry indicates previous taxonomic position of the form.)

abaddon, Xorides (Cyanoxorides), Xylonomus, 494

abdominale, Odontocolon, Odontomerus, 450 and 452 (key), 462

abdominale abdominale, Odontocolon, 463 (key), 464

abdominale fergusoni, Odontocolon, 463 (key), 464

Acaenitinae, 3, 4 (key), 544; and 604, 605,606 (figs.)

Acaenitus decorus, 565

melleus, 567

aciculatus, Dolichomitus, Ephialtes, 114 and 115 (key), 143, 629 and 632 (figs.)

aciculatus, Odontocolon, 480

aciculatus, Xorides (Gonioprymnus), Gymnacanthus, 495

Acoenites canadensis, 558

rufipes, 560

Acoenitus rupinsulensis, 578

stigmapterus, 525, 526

Acrodactyla, 219 (key), 230, 590 (fig.)

degener, 231 (key), 239, 234, 590 and 619 (figs.)

erratica, 238

jubata, 231 (key), 232, 619 (fig.)

lubumbashica, 238

ocellata, 231 (key), 232, 619 (fig.)

orientalis, 235

paulisiana, 238

quadrisculpta, 231 (key), 235, 236, 619 and 628 (figs.)

rutshurica, 238

viatrix, 238

Acropimpla, 6, 7, 9 (key), 16, 159, 217, 585 (fig.)

alboricta, 15, 161 (key), 162, 163; and 585, 617, 627, 632 (figs.)

alboscutellaris, 159,160

bicarinata, 160

didyma, 160

flavoscutis, 160
Acropimpla-Continued

latifoveata, 160

leucostoma, 160

lucifugus, 160

nigrescens, 160

nigroseutis, 160

pictipes, 160

pronexus, 161 (key); and 617, 626, 632 (figs.)

uchidai, 160

yezoensis, 160

Acrotaphus, 219 (key), 256, 592 (fig.)

fasciata, 256

fuscipennis, 256

latifasciatus, 256

tibialis, 256

wiltii, 256, 25\%, 592 and 620 (figs.) acuta, Polysphincta, 197

aequalis, Coccygomimus, Pimpla, 313 and 314 (key), 341, 343, 623 and 625 (figs.)

Aequalis group, Coccygomimus, 337

aethiops, Coccygomimus, 312

aethiops, Odontocolon, Odontomerus, 450 and 453 (key), 460, 461

Afrephialtes, 7

agnoscendus, Dolichomitus, Ephialtes, 129

Ahyborhyssa, 494

elizabethae, 494

alaskensis, Odontocolon, Odontomerus, 450 and 453 (key), 460

alaskensis, Rhyssa, 397 (key), 401, 402, 613 (fig.)

albicinctus, Arotes, 561

albicinctus, Perithous, Ephialtes, 209, 588 (fig.)

albipes, Poemenia, Ephialtes, 377 (key), 379,880

albipes, Polysphincta, 246 (key), 255

albipes, Scambus (Erythroscambus), Pimpla, 77 
albitibia, Scambus (Erythroseambus), Epiurus, 77

alboannulata, Coceygomimus, Pimpla, 328

albomaculata, Rhyssa, 400, 404

albopictus, Xorides (Xorides), Xylonomus, 492 (key), 517, 518; and 609, 611, 612, 624, 627 (figs.)

albopictus species group, Xorides, 492 (key), 515

alborhombarta Zatypota, Clistopyga, 265 (key), 278, 279, 621 (fig.)

alboricta, Acropimpla, Pimpla, 161 (key), 162, 163; and 585, 617, 627,632 (figs.)

alboscutellaris, Acropimpla, Hemipimpla, Selenaspis, 159, 160

albotibiale, Odontocolon, Odontomerus, 451 and 454 (key), 480, 482

Alophosternum, 5, 6, 7, 8 (key), 16, 206, 587 (fig.)

foliicola, 207, 208, 587 and 634 (figs.)

Alophosternum generic group, Pimplini, 7

alpensis, Podoschistus, Xorides, 387

alternans, Itoplectis, 284

alternans spectabilis, Itoplectis, 281

alutaria, Clistopyga, 196 (key), 200, 201

americana, Poemenia, Euxorides, 377 (key), 382

americana americana, Poemenia, 382 (key), 384

americana nebulosa, Poemenia, 382 (key), 383, 384

americana, Theronia atalantae, 354

americanus, Euxorides, 376, 384

amoena, Rhyssa, 401

amoena species group, Rhyssa, 397 (key), 400

amoenus, Arotes, 561 (key), 563; and 605, 615, 623, 627 (figs.)

Amphixylonomus, 502

konduensis, 502

Anastelgis, 7, 10 (key), 109, 584 (fig.)

brasiliensis, 110

terminalis, 109, 110, 584 and 626

(figs.)

angens, Tromatobia, 181

anguina, Grotea, 588 (key), 540, 603 (fig.)

animosa, Pimpla, 190 annulata, Scambus (Ateleophadnus).

Pseudopoemenia, 27

annulicornis, Ephialtes, Pimpla, 303 (key), 305, 622 (fig.)

annulicornis, Epirhyssa, 494, 495

annulipes, Clistopyga, 204

annulipes, Coccygomimus, Pimpla, 313 and 314 (key), 346,348

Anodontomerus, 439

tibialis, 439

anomala, Sinarachna, Polysphincta, 259 (key), 261, 620 (fig.)

Anomalon humeralis, 498

mellipes, 467, 468

recurva, 204

antennalis, Xorides (Cyanoxorides), 494

antennalis, Xorides (Periceros), Neoxylonomus, 501

Apechthis, 302

ornatulus, 303

pacificus, 307

Apechtis, 302

flavonotata, 302

rugulosa, 179

apicalis, Labena, Microtritus, 531, 533

apicalis, Theronia, Epimecoideus, 351

apicatus, Arotes, 576

Apistephialtes, 7, 10 (key), 87, 583 (fig.)

arcticus, 87, 89 (key), 94, 625 (fig.)

ascaniae, 87

atriceps, 88

caudata, 87,88

coracinus, 88 and 89 (key), 99, 627

and 630 (figs.)

crassiseta, 87,88

cydiae, 87,88

dentatus, 88 (key), 97, 99, 627 and 630 (figs.)

laspeyresiae, 88

masoni, 89 (key), 93, 94

nucicola, 88 and 89 (key), 95, 96; and $583,626,630$ (figs.)

petulcus, 88 and 89 (key), 96, 97, 627 and 630 (figs.)

punctulata, 87,88

tenuiventris, 87, 88 (key), 89, 91; and $625,626,630$ (figs.)

variatipes, 88 and 89 (key), 91; and $625,626,630$ (figs.)

Apistes, 87

perversus, 87 
Aplomerus, 438 (key), 489, 601 (fig.)

arugosus, 441 (key), 446

buprestivorus, 440 and 441 (key), 446

decorus, 441

foutsi, 441

lineatulus, 440 and 441 (key), 442 nasonii, 515

robustus, 440 and 441 (key), 442, 443

tibialis, 440 (key), 444, 446, 601 (fig.)

aplopappi, Scambus (Scambus), Pimpla, 38 and 39 (key), 62, 63, 608 and 616 (figs.)

appendiculatus, Odontocolon, Odontomerus, 456

approximator, Rhysella, Ichneumon, 409,410

approximator, Rhyssa, 373

approximator var. ruficoxis, Rhyssa, 373 aquilonius, Coccygomimus, Pimpla, 313 (key), 32s, 325, 625 (fig.)

aquilonius aquilonius, Coceygomimus 324 (key) 325, 326, 623 (fig.)

aquilonius exareolatus, Coccygomimus, 324 (key), 326, 623 (fig.)

aquilonius flavicoxis, Coccygomimus, 324

arctica, Coccygomimus, Pimpla, 315

arcticus, Apistephialtes, Ephialtes, 87, 89 (key), 94, 625 (fig.)

arisanus, Pimpla, Ephialtes, 102

arizonensis, Scambus (Lissoscambus), 25,607 (fig.)

arizonica, Zatypota, 264 (key), 270, 271, 621 (fig.)

arizonicus, Zaglyptus, 189 (key), 192, 193, 618 (fig.)

Arotes, 546 (key), 561, 605 (fig.)

albicinctus, 561

amoenus, 561 (key), 563; and 605, $615,623,627$ (figs.)

apicatus, 576

decorus, 561 (key), 565, 567, 624 (fig.)

facialis, 561

formosum, 572

maurus, 561 (key), 563, 564

melleus, 561 (key), 56\%, 624 (fig.)

occiputale, 576

superbus, 573

venustus, 573

arugosus, Aplomerus, 441 (key), 446 arundinis, Exeristes, Ephialtes, 10, 11 ascaniae, Apistephialtes, Ephialtes, 87 ashmeadii, Meniscus, 341

atalantae, Theronia, Ichneumon, 292 351,352 (key), 353,595 and 610 (figs.)

atalantae var. americana, Theronia, 354

atalantae atalantae, Theronia, 353 (key), 354

atalantae fulvescens, Theronia, 353 (key), 354, 357

atalantae gestator, Theronia, 353 (key), 354

Ateleophadnus (subg. of Scambus), 16, 17 and 18 (key), 25, 2y

Ateleophadnus annulata, 27

bicarinata, 27, 28,

cincticarpus, 27

deceptor, 28 (key), 35, 606 and 616 (figs.)

granulosus, 28 (key), 31, 32; and $606,607,616$ (figs.)

nigricans, 27

pterophori, 27 and 28 (key), 29, 35, 607 and 616 (figs.)

similis, 27

ater, Xorides (Xorides), Rhadina, Xylonomus, 502, 510

atra, Schizopyga 225

Atractogaster, 350, 351

atrata, Clistopyga, 197 (key), 198

atrata, Eruga, 238 (key), 239

atrata, Megarhyssa, Ichneumon, 416, 417 (key), 424

atrata atrata, Megarhyssa, 426 (key), 427,614 (fig.)

atrata lineata, Megarhyssa, 426 (key), 427

atriceps, Apistephialtes, Ephialtes, 88 atripes, Odontocolon, Odontomerus, 450 and 452 (key), 478, 479

atrocoxalis, Pimpla, 293

atrocoxalis, Scambus (Scambus), Epiurus, 39 (key), 52, 53, 606 (fig.)

atrocoxalis species group, Scambus (Scambus), 39 (key), 53

atrox, Xorides (Xorides), 492 (key), 520,521

australe, Spilopteron formosum, 571 (key), 572, 573, 624 (fig.)

australis, Xylonomus, 498

Austropimpla, 174

hübrichi, 174 
balteata, Labena grallator, 532 (key), 536

Barypus degener, 230

Bassus cylindricus, 325

bazani, Ephialtes, Parapechthis, 302

behrensii, Itoplectis, Pimpla, 282 (key), 296, 297, 622 (fig.)

benefactor, Calliephialtes, 92

bicarinata, Acropimpla, Pimpla, 160

bicarinata, Ateleophadnus, 27, 28

bicarinata, Polysphineta, 243

bicincta, Theronia, 352 (key), 360,361 , 610 (fig.)

bicincta bicincta, Theronia, 361 (key), 362

bicincta floridana, Theronia, 361 (key), 362

bicolor, Odontocolon, Odontomerus, 449 and 452 (key), 455

bicoloripes, Epiurus, 15, 55

bifasciatus, Sphalerus, 561

bilineata, Coccygomimus, Habropimpla, 311

blanditor, Xylonomus, 495

boharti, Xorides (Xorides), 493 (key), 507,508

bohemani, Zatypota, Polysphincta, 264 (key), 265, 267, 620 and 628 (figs.)

boops, Polysphincta, 246

borealis, Delomerista, 365 (key), 370

borealis, Neoxorides, Xorides, 390 (key), 392, 393, 598 (fig.)

Brachycentropsis, 8

Brachycentropsis generic group, Pimplini, 8

Brachycyrtini, 437 (key), 541

Brachycyrtomorpha, 542

crossi, 542

Brachycyrtus 542, 603 (fig.)

chrysopea, 544

crossi, 542

eublemmae, 542

luteoniger, 542

luteoniger fianarensis, 542

nawaii, 542

ornatus, 542, 543 (key), 544, 603 (fig.)

pretiosus, 543 (key), 623 (fig.)

primus, 542

taitensis, 542

brasiliensis, Anastelgis, Calliephialtes, 110 braucheri, Zatypota, Polysphincta, 273

brevacus, Itoplectis curticauda, 300 (key), 301, 622 (fig.)

brevicaudus, Odontocolon, Odontomerus, 450 and 452 (key), 474

brevicornis, Scambus (Scambus) Epiurus, Pimpla, 36, 38, and 39 (key), 55,607 and 616 (figs.)

brevis, Pimpla, Ephialtes, 101, 102 (key), 105, 630 (fig.)

brookei, Xorides (Cyanoxorides), 494

bruneti, Polysphincta tuberosa, 251 (key), 253, 620 (fig.)

brunneifrons, Pimpla (Epiurus), 168

brunneifrons septentrionalis, Iseropus, 168

buccatus, Dolichomitus, 115 (key), 139, 141

buolianae, Scambus (Scambus), 68

buprestivorus, Aplomerus, 440 and 441 (key), 446

burgessii, Polysphineta, 246 (key), 247, 620 (fig.)

cacoeciae, Ephialtes, 283

Caenostoma, 494

exquisitus, 494

filicorne, 494

caerulescens, Xorides (Epixorides), $\mathrm{Xy}$ lonomus, 494

caeruleus, Xorides (Cyanoxorides), 494

calidus, Xorides (Xorides), Xylonomus, 492 (key), 516, 517

californica, Grotea, 538 (key), 540

californicus, Dolichomitus, 113 and 116 (key), 146, 629 and 632 (figs.)

californicus, Xorides (Xorides), Xylonomus, 493 (key), 524

californiensis, Iseropus, 166 and 167 (key), 170, 172, 617 and 633 (figs.)

californiensis, Zatypota, Polysphincta, 273

Calliclisis, 376

hecticus, 376

Calliephialtes, 7, 9 (key), 80, 582 (fig.)

benefactor, 92

brasiliensis, 110

ferrugineus, 81 (key), 86, 617 (fig.) grapholithae, 80, 81 (key), 85, 86; and $582,617,625$ (figs.)

notandus, 81 (key), 83, 617 (fig.)

nucicola, 95 
Calliephialtes - Continued thurberiae, 81 (key), 88, 617 (fig.) xanthothorax, 80

cameronii, Coccygomimus, Pimpla, 328 Camptotypus, 8

Camptotypus generic group, Pimplini, 8 canadense, Odontocolon, Odontomerus, 451 and 453 (key), 466, 469

canadensis, Acoenites, 558

canadensis, Clistopyga, 197 (key), 198, 628 (fig.)

canadensis, Coleocentrus, 553

canadensis, Rhyssa, 409

canadensis, Scambus (Scambus), 38 and 39 (key), 58; and 606, 608, 616 (figs.)

canadensis, Xorides, 518

canadensis, Xylonomus, 523

canadensis navajoe, Polistes, 532

carbonator, Oxyrrhexis, Cryptus, 242, 591 and 628 (figs.)

carbonator carbonator, Oxyrrhexis, 243 (key)

carbonator texana, Oxyrrhexis, 243 (key), 619 (fig.)

caryae, Neoxorides, Xorides, 390 (key), 393,894

Caryoecus, 531

fuscipennis, 531

catomus, Xylonomus, 524

caudata, Apistephialtes, Pimpla, 87, 88 caudata, Polysphincta, 260

centromaculatus, Xorides (Xorides), 503,515

cephalotes, Dolichomitus, Ephialtes, 111, 115 (key), 127, 128

ceylonica, Sinarachna, Polysphincta, 259

chadwickii, Labena, Neonotus, 531

chalybeator, Xorides (Epixorides), 494, 495

Charitopimpla flavoscutis, 160

leucostoma, 160

nigrescens, 160

nigroscutis, 160

uchidai, 160

chiricensis, Xorides (Exomus) humeralis, 497 (key), 500, 501

chrysopae, Brachyeyrtus, 544

chui, Ephialtes, 110

cilipes, Odontocolon, 449 and 452 (key), 454,455 cilipes species group, Odontocolon, 449 and 452 (key), 454

cincticarpus, Scambus (Ateleophadnus), 27

cincticornis, Xorides (Xorides), Xylonomus, 493 (key), 528

cincticornis cincticornis, Xorides (Xorides), 528 (key), 529

cincticornis rufus, Xorides (Xorides), 528 (key), 529, 580

cingulata, Polysphineta, 176

cingulata, Zatypota, 264 (key), 270, 621 (fig.)

circulator, Schizopyga, 227

clavata, Epirhyssa, 410

clavator, Thalessa, Ichneumon, 415

clavicornis, Itoplectis, 298, 299, 300

Clistopyga, 6, 7, 8 (key), 195, 218, 219, 587 (fig.)

alborhombarta, 279

alutaria, 196 (key), 200, 201

annulipes, 204

atrata, 197 (key), 198

canadensis, 197 (key), 198, 628 (fig.)

incitator, 195, 196, 587 (fig.)

lateralis, 186

latifrontalis, 195

lopez-richinii, 195

maculifrons, 197 (key), 199, 201

manni, 196 (key), 202, 204

nigrifrons, 196 (key), 201,

nigrocephala, 273

pulchripicta, 204

recurva, 196 (key), 204, 628 (fig.)

sauberi, 199

zonata, 185

clivulus, Ischnoceros, 438,439

Closterocerus, 111

sericeus, 111, 158

Cnemopimpla, 7

Coccygomimus, 101, 281 (key), 311,

595 (fig.)

aequalis, 313 and 314 (key), 341,

343,623 and 625 (figs.)

aethiops, 312

alboannulata, 328

annulipes, 313 and 314 (key), 346, 348

aquilonius, 313 (key), 323, 625 (fig.) aquilonius aquilonius, 324 (key),

325, 326, 623 (fig.)

aquilonius exareolatus, 324 (key)

326,623 (fig.) 


\section{Coceygomimus - Continued}

aquilonius flavicoxis, 324

arctica, 315

bilineata, 311

cameronii, 328

contemplator, 338

cyanipennis, 328

dimidiatus, 313 (key), 348, 350

disparis, 323

ellopiae, 313 (key), 322, 622 (fig.)

erebus, 315

flavipalpis, 315

flavipennis, 311

flavipes, 311

fuscipes, 338

hesperus, 314 and 315 (key), 338, 339

illecebrator, 323

indra, 315

inflata, 347

instigator, 315

intermedius, 328

kriegeri, 311

laöthoë, 315

luctuosa, 315

madecassus, 311

marginellus, 313 (key), 336, 337

maurus, 313 (key), 321, 322, 622

(fig.)

melanacrias, 338

nigricolor, 315

nipponica, 338

nudus, 313 and 314 (key), 343, 345

paulistana, 311

pedalis, 313 (key), 316, 317, 580 and 622 (figs.)

pluto, 323

punicipes, 314 and 315 (key), 348, 349, 623 (fig.)

rufipes, 338

sanguinipes, 314 (key), 334

sanguinipes erythropus, 335 (key), 336

sanguinipes sanguinipes, 835 (key), 336

sedula, 315

silvicola, 313 (key), 315, 317, 622 (fig.)

sodalis, 313 (key), 328

sodalis longigenalis, 328 (key), 329, 330, 623 (fig.)

sodalis sodalis, 328 (key), 329, 623

(fig.)
Coceygomimus - Continued

sordidella, 338

spuria, 338

stricklandi, 314 and 315 (key), 339, 340, 623 (fig.)

tenuicornis, 313 (key), 390, 332, 623 and 625 (figs.)

thoracica, 315, 323

turionellae, 312 , 323

varians, 314 (key), 332, 333

viridescens, 315

waterloti, 311

coelebs, Iseropus, Pimpla, 166 (key), 171, 172, 617 and 633 (figs.)

Coleocentrus, 545 (key), 546, 604 (fig.) canadensis, 553

excitator, 546, 604 (fig.)

flavipes, 546 and 547 (key) ,558,634 (fig.)

harringtoni, 546 and 547 (key), 552, 553,634 (fig.)

manni, 546 and 547 (key), 555, 634

(fig.)

manni coloradensis, 555 (key), 556

manni manni, 555 (key)

minor, 559

niger, 559

occidentalis, 546 and 547 (key), 548, 634 (fig.)

occidentalis occidentalis, 548 (key), 549

occidentalis pulchripennis, 548 (key), 549

pettiti, 546 and 547 (key), 551, 552, 634 (fig.)

quebecensis, 547 (key), 549, 550, 634 (fig.)

rufocoxatus, 546 and 547 (key), $554,555,634$ (fig.)

rufus, 546 and 547 (key), 556, 558, 627 and 634 (figs.)

similis, 556

collaris, Neoxorides, Xorides, 390, 392

coloradensis, Coleocentrus manni, 555 (key), 556

Colpomeria, 230

laevigata, 230

litoralis, 28

mellithorax, 235

quadrisculpta, 230

componotus, Ephialtes, Pimpla, 303 (key), 308

compunctor, Ephialtes, Ichneumon, 302 
comstockii, Exeristes, Ephialtes, 11, 16, cyanipennis, Coccygomimus, Pimpla, 616 and 625 (figs.)

confusa, Labena, 533

confusa minor, Labena, 533

conquisitor, Itoplectis, Cryptus, 282 (key), 287, 288, 621 (fig.)

conquisitor var. rufuscula, Pimpla, 341 contemplator, Coccygomimus, Ichneumon, 338

contemplator species group, Coccygomimus, 312

coracinus, Apistephialtes, 88 and 89 (key), 99, 627 and 630 (figs.)

corcyrensis, Xorides (Gonophonus), Xylonomus, 494

coxata, Scambus (Erythroscambus), Pimpla, 77

crassicauda, Scambus (Lissoscambus), Pimpla, 25

crassipes, Zatypota, 265 (key), 278, 621 (fig.)

crassiseta, Apistephialtes, Ephialtes, 87, 88

crassus, Dolichomitus, Ephialtes, 121

cressoni, Ephialtes, 187

crevieri, Rhyssa, Epirhyssa, 397 (key), 403, 404, 613 (fig.)

crosbyi, Zatypota, Polysphincta, 273

crossi, Brachycyrtus, Brachycyrtomorpha, 542

crudelis, Xorides (Cyanoxorides), Xylonomus, 494

Cryptocentrum, 396

lineolatum, 396, 404

Cryptus carbonator, 242

conquisitor, 287

degener, 233

grallator, 531,533

pleurivinctus, 287

curticauds, Itoplectis, Pimpla, 282 (key), 800

curticauda brevacus, Itoplectis, 300 (key), 301, 622 (fig.)

curticauda curticauda, Itoplectis, 300 (key), $\$ 01$

curticornis, Dolichomitus, Ephialtes, 129

curtum, Odontocolon, 450 and 453 (key), 469, 470

curvipes, Rhyssa, 409

cushmani, Mesoclistus, 560

cuspidatus, Dolichomitus, 5, 6, 8, 113 and 114 (key), 120, 121, 629 and 631 (figs.)

328

Cyanoxorides (subg. of Xorides), 491

(key), 494

Cyanoxorides abaddon, 494

antennalis, 494

brookei, 494

caeruleus, 494

crudelis, 494

erythrothorax, 495

formosanus, 494

maculipennis, 494

propodeum, 494

ruficeps, 494

rufipleuralis, 494

rufomaculata, 495

smithi, 494

spectabilis, 494

vitalisi, 495

cydiae, Apistephialtes, Ephialtes, 87, 88

cylindricus, Bassus, 325

Cylloceria lemoinei, 190

deceptor, Scambus (Ateleophadnus), 28

(key), 35, 606 and 616 (figs.)

decorus, Aplomerus, 441

decorus, Arotes, Acaenitus, 561 (key), $565,567,624$ (fig.)

decorus, Scambus (Scambus), 37 and 40 (key), 75, 77, 608 (fig.)

decumbens, Pimpla, 102 (key), 103, 630 (fig.)

defensator, Pimpla, 179

degener, Acrodactyla, Cryptus, Barypus, 230, 231 (key), 299, 234, 590 and 619 (figs.)

degener species group, Acrodactyla, 291 (key)

Delaulax, 7

Delomerista, 351 (key), 362, 596 (fig.)

borealis, 365 (key), 370

diprionis, 367

gelida, 365 (key), \$66, 609 and 612 (figs.)

japonica, 365 (key), 367, 609 (fig.) laevis, 368

lepteces, 365 (key), 368, 609 (fig.) novita, 365 (key), 372, 609 and 623 (figs.)

pfankuchi, 365 (key), s71, 609 (fig.) texana, 364 and 365 (key), 609 and 612 (figs.)

dentatus Apistephialtes, 88 (key), 97, 99, 627 and 630 (figs.)

$526527-60-42$ 
dentipes, Odontocolon, Odontomerus, Ichneumon, 448

depressum, Odontocolon, 449 and 453 (key), 459, 460

detritus, Scambus (Endromopoda), Pimpla, 18, 19 (key), 21, 22; and 581, $606,607,616$ (figs.)

Deuteroxorides, 5

diabolus, Exochilum, 526

dichrous, Odontocolon, Odontomerus, 450 and 453 (key), 474, 475

Diclosterocerus, 111

dictynae, Polysphincta, 261

didyma, Acropimpla, Pimpla, 160

dietrichi, Epirhyssa, 414, 599 (fig.)

Dihyboplax, 311

flavipennis, 311

dimidiatus, Coccygomimus, 313 (key), 348,350

dioryctriae, Scambus (Scambus), 38 and 40 (key), 61, 62, 608 (fig.)

diprionis, Delomerista, 367

discolor, Zatypota, Polysphincta, 263

disparis, Coccygomimus, Pimpla, 323

divinator, Perithous, Ichneumon, 209 (key), 215, 618 and 627 (figs.)

Dolichomitus, 7, 10 (key), 111, 584 (fig.) aciculatus, 114 and 115 (key), 143 , 629 and 632 (figs.)

agnoscendus, 129

buccatus, 115 (key), 139, 141

californicus, 113 and 116 (key), 146,629 and 632 (figs.)

cephalotes, 111, 115 (key), 127, 128 crassus, 121

curticornis, 129

cuspidatus, 5, 6, 8, 113 and 114 (key), 120, 121, 629 and 631 (figs.)

dolichosoma, 113 and 114 (key), $116,118,629$ and 631 (figs.)

dux, 129

elongatus, 127, 128

feralis, 129

flexilis, 115 (key), 142, 143

foxleei, 116 (key), 145, 146

imperator, 114 (key), 154, 155; and $626,629,632$ (figs.)

iridipennis, 129

irritator, 113 and 114 (key), 13\%, 139 ; and 584, 629, 631 (figs.)

longicauda, 111

macropunctatus, 129
Dolichomitus-Continued

melanomerus, 129

mesocentrus, 129

messor, 113 and 115 (key), 191; and 626, 629, 631 (figs.)

messor messor, 132 (key), 136

messor perlongus, 132 (key), 134

messor sparsus, 132 (key), 133, 134

nakamurai, 129

nigricans, 129

populneus, 113 and 115 (key), 129;

and $626,629,631$ (figs.)

pterelas, 114 (key), 152, 153, 629 and 632 (figs.)

pygmaeus, 113 and 115 (key), 149, 150, 629 and 632 (figs.)

rufescens, 116

sericeus, 111, 113 and 114 (key), 158; and 626, 629, 632 (figs.)

taeniatus, 113 and 114 (key), 118; and $626,629,631$ (figs.)

terebrans, 113 and 115 (key), 121, 629 and 631 (figs.)

terebrans nubilipennis, 121, 122 (key)

terebrans terebrans, 122 (key), 124 tinctipennis, 129

tschitscherini, 129

tuberculatus, 113 and 115 (key), 124; and $626,629,631$ (figs.)

tuberculatus jezoensis, 125 (key), 127

tuberculatus tuberculatus, 125 (key)

vitticrus, 114 and 116 (key), 148, 150, 629 and 632 (figs.)

dolichosoma, Dolichomitus, Ephialtes, 113 and 114 (key), 116, 118, 629 and 631 (figs.)

dreisbachi, Odontocolon, 450 and 453 (key), 479, 480

drewseni, Polysphincta, 246

dubiosa, Rhyssa, 409

duplicatus, Xylonomus (Moerophora), 518

duplicauda, Pimpla, Ephialtes, 101

dux, Dolichomitus, Ephilates, 129

Dyseidopus, 531

sericeus, 531

eastoni, Xorides (Xorides), Xylonomus (Moerophora), 493 (key), 512, 513 
eboripes, Polysphincta, 246 (key), 254, 255, 620 (fig.)

Echthromorpha, 280

elegans, Scambus (Scambus), Troctocerus, 36

elegans vulpinus, Tricyphus, 532

elizabethae, Xorides (Epixorides), Xylonomus, 494, 495

ellopiae, Coccygomimus, Pimpla, 313 (key), 322, 622 (fig.)

elongata, Polysphincta, 251

elongatus, Dolichomitus, Ephialtes, 127, 128

Endromopoda (subg. of Scambus), 16, 17 (key), 18, 581 (fig.)

Endromopoda detritus, 18, 19 (key), 21, 22 ; and 581, 606, 607, 616 (figs.) melanopyga, 18

productus, 19 (key), 23, 25, 607 and 616 (figs.)

rubescens, 18 (key), 19, 607 and 616 (figs.)

Ephialtes, 281 (key), 302, 311, 594 (fig.)

aciculatus, 143

agnoscendus, 129

albicinctus, 209

albipes. 380

annulicornis, 303 (key), 305, 622 (fig.)

arcticus, 94

arisanus, 102

arundinis, 11

ascaniae, 87

atriceps, 88

bazani, 302

brevis, 105

cacoeciae, 283

cephalotes, 127

chui, 110

componotus, 303 (key), $\$ 08$

compunctor, 302

comstockii, 11

crassiseta, 87,88

crassus, 121

cressoni, 187

curticornis, 129

cydiae, 87,88

dolichosoma, 116

duplicauda, 101

dux, 129

elongatus, 127, 128

esuchus, 283

$526527-60-43$
Ephialtes-Continued

feralis, 129

flavonotata, 302

gigas, 134, 135

gnathaulax, 110

hecticus, 376

hokkaidonis, 102

imperator, 154

iridipennis, 129

laspeyresiae, 88

latus, 283

leavitti, 283

longigenalis, 330

longiseta, 11

macra, 104

macropunctatus, 129

melanomerus, 129

mesocentrus, 129

messor, 136

montana, 283

nakamurai, 129

nigricans, 129

nigriceps, 77

occidentalis, 154

ontario, 303 (key), 308, 309, 622 (fig.)

pacificus, 89, 283, 303 (key), 807, 308, 622 (fig.)

picticornis, 303 (key), 305, 622

(fig.)

perlongus, 134

polytauma, 101

populneus, 129

pusio, 89

pygmaeus, 149

rufatus, 302

rufescens, 116

taiwana, 302

temnopleuris, 287

tenchozanus, 102

tenuiventris, 89

thoracicus, 377

tinctipennis, 129

tschitscherini, 129

tuberculatus jezoensis, 127

vancouverensis, 377

variatipes, 91

Ephialtinae, 3, 4 (key), 580-600 (figs.)

Ephialtini, 5 (key), 101, 280; and 580, 594, 595 (figs.)

ephialtoides, Scambus (Scambus), 37 and 38 (key), 42, 46, 607 (fig.) 
ephialtoides species group, Scambus (Scambus), 36, 37 and 38 (key), 40

epicnapterus, Iseropus, 166

Epimecis fasciata, 256

fuscipennis, 256

latifasciatus, 256

thoracicus, 246

tibialis, 256

wiltii, 256, 257

Epimecoideus, 351 apicalis, 351

Epirhyssa, 395 (key), 413, 599 (fig.) annulicornis, 494, 495

clavata, 410

crevieri, 403

dietrichi, 414, 599 (fig.)

speciosa, 413

Epiurus albitibia, 77

atrocoxalis, 53

bicoloripes, 15,55

brevicornis, 36

brunneifrons, 168

flavipes, 77

hakonensis, 166

innominatus, 15,65

kimishimae, 166

mencianae, 166

nankingensis, 166

nigrifrons, 74

quersifoliae, 166

satanus, 166

taiwanensis, 160

Epixorides (subg. of Xorides), 491 (key), 494

Epixorides caerulescens, 494

chalybeator, 494,495

elizabethae, 494, 495

erythrothorax, 495

fracticornis, 495

fulgidipennis, 495

rufomaculata, 495

vitalisi, 495

erebus, Coccygomimus, Pimpla, 315

Eremochila, 6, 7

ruficollis, 6

errans, Odontomerus, 467

erratica, Eruga, Acrodactyla, 238

Eruga, 220 (key), 238, 590 (fig.)

atrata, 238 (key), 239

erratica, 238

lineata, 238 (key), 239; and 590, 619,628 (figs.)
Eruga-Continued

lubumbashica, 238

paulisiana, 238

rufa, 238 (key), 239, 240, 619 (fig.)

rutshurica, 238

viatrix, 238

erythrocephalus, Spiloxorides, 494

erythropus, Coccygomimus sanguinipes, Pimpla, 335 (key), 336

Erythroscambus (subg. of Scambus), 16, 17 (key), 76

Erythroscambus albipes, 77

albitibia, 77

coxata, 77

flavipes, 77

hirticauda, 77, 608 and 617 (figs.)

nigriceps, 77

Erythrotheronia, 351

flavolineata, 351

erythrothorax, Xorides (Epixorides),

Cyanoxorides, 495

esuchus, Itoplectis, Ephialtes, 283

eublemmae, Brachycyrtus, Hemigaster, 542

Eurhyssa, 415

superbus, 415

euurae, Scambus (Scambus) vesicarius, Pimpla, 15, 49 (key), 50; and 606, 607, 616 (figs.)

Euxorides, 376

americanus, 376,384

vancouveriensis, 377

evetriae, Itoplectis, 282 (key), 294, 295, 621 (fig.)

evetrivorus, Scambus, 63

exareolatus, Coccygomimus aquilonius, Itoplectis, 324 (key), 326, 623 (fig.)

excitator, Coleocentrus, Ichneumon, 546, 604 (fig.)

excomptus, Xorides (Exomus) humeralis, 497 (key), 500

Exeristes, 7, 10 (key), 16, 101, 581 (fig.) arundinis, 10, 11

comstockii, 11, 16, 616 and 625 (figs.)

hyalinipennis, 122

longiseta, 11, 12

nubilipennis, 122

pulchella, 160

roborator, 10, 581 (fig.)

Exeristesoides, 281

alternans spectabilis 281 
Exeristoidea, 111

watsoni, 111, 127

exilis, Zatypota, 264 (key), 269, 270, 621 (fig.)

eximia, Zatypota, Polysphincta, Polysphinctopsis, 262, 263

Exochilum diabolus, 526

Exomus (subg. of Xorides), 491 and 492 (key), 496

Exomus humeralis, 492 (key), 496; and 609, 610, 611 (figs.)

humeralis chiricensis, 497 (key), 500,501

humeralis excomptus, 497 (key), 500

humeralis humeralis, 497 (key), 498

humeralis mexicanus, 497 (key), 498

humeralis piceatus, 497 (key), 498

humeralis sierrae, 497 (key), 500

exquisitus, Xorides (Gonophonus), Moansa, 494

facialis, Arotes, Retanisia, 561

fasciata, Acrotaphus, Epimecis, 256

fasciipennis, Xorides (Gonophonus), Xylonomus, 494

favosa, Zutypota, 264 (key), 267, 269, 620 (fig.)

feralis, Dolichomitus, Ephialtes, 129

feralis, Pimpla, 349

fergusoni, Odontocolon abdominale, 463 (key), 464

ferrugineus, Calliephialtes, 81 (key), 86 , 617 (fig.)

fianarensis, Brachycyrtus luteoniger, 542

filicorne, Caenostoma, 494

filiformis, Xorides (Xorides), Sichelia, Xylonomus, 502

flavicans, Theronia, Pimpla, 351

flavicoxis, Coccygomimus aquilonius, 324

flavipalpis, Coccygomimus, Pimpla, 311, 315

flavipennis, Coccygomimus, Dihyboplax, 311

flavipes, Coccygomimus, Lissotheronia, 311

flavipes, Coleocentrus, Acoenites, 546 and 547 (key), 558, 634 (fig.)

flavipes, Scambus (Erythroscambus), Epiurus, 77 flavitarsis navajo, Mischocyttarus, 532

flavolineata, Theronia, Erythrotheronia, 351

flavonotata, Ephialtes, Apechtis, 302

Flavopimpla, 7

flavoscutis, Acropimpla, Charitopimpla, 160

flexilis, Dolichomitus, 115 (key), 142, 143

floridana, Megarhyssa greenei, 421 (key), 423, 424, 615 (fig.)

floridana, Theronia bicincta, 361 (key). 362

floridanus, Xorides (Xorides) stigmapterus, 526 (key), 527, 528

foliicola, Alophosternum, 207, 208, 587 and 634 (figs.)

formicoides, Odontocolon, 449 and 452 (key), 457, 458

formosanus, Xorides (Cyanoxorides), 494

formosum, Spilopteron, Arotes, 569 (key), 571, 615 (fig.)

formosum australe, Spilopteron, 571 (key), 572, 578, 624 (fig.)

formosum formosum, Spilopteron, 571 (key), 572, 624 (fig.)

forsiusi, Polysphincta, 176

foutsi, Aplomerus, 441

foxleei, Dolichomitus, 116 (key), 145, 146.

fracticornis, Xorides (Epixorides), Xylonomus, 495

franclemonti, Spilopteron, 569 (key), 570 ; and 605, 615, 624 (figs.)

frigida, Schizopyga, 224 (key), 225, 619 and 628 (figs.)

frigidus, Xorides (Xorides), Xylonomus, 493 (key), 503, 504; and 609, 610, 611, 624 (figs.)

frigidus species group, Xorides, 493 (key), 503

fulgidipennis, Xorides (Epixorides), Xylonomus, 495

fuligator, Xorides (Xorides), 502

fulvescens, Theronia atalantae, Pimpla, 353 (key), 354, 357

fulvescens var. mellipennis, Theronia, 354

furannus, Rhysella, Rhyssa, 409

fuscipennis, Acrotaphus, Epimecis, 256

fuscipennis, Caryoecus, Mesochorus, 531, 533 
fuscipennis, Pimpla, 338

fuscipes, Coccygomimus, Pimpla, 338

fustiger, Itoplectis, 282 (key), 298, 299, 622 (fig.)

gelida, Delomerista, 365 (key), 366 , 609 and 612 (figs.)

geniculatus, Odontocolon, Odontomerus, 459

georgicus, Ichneumon, 434

gestator, Theronia atalantae, Ichneumon, 353 (key), 354

gigas, Ephialtes, 134, 135

Glypta maculipennis, 494

Glypta? parva, 266

gnathaulax, Ephialtes, 110

Gonioprymnus (subg. of Xorides), 491 (key), 495

Gonioprymnus maculiceps, 495

Gonophonus (subg. of Xorides), 491 (key), 494

Gonophonus corcyrensis, 494

exquisitus, 494

fasciipennis, 494

mokrzeckii, 494

propinquus, 494

scaber, 494

gossypii, Pimpla, 71

gracilicornis, Xorides (Xorides), Xylonomus, Xylonomimus, 490, 502 gracilis, Polysphincta, 275

grallator, Labena, Cryptus, 531 (key), 602 (fig.)

grallator balteata, Labena, 532 (key), 536

grallator grallator, Labena, 532 (key), 583, 534

grallator lutea, Labena, 532 (key), 536

grallator xutha, Labena, 532 (key), 534, 535

graminellae, Iseropus, Ichneumon, 165 granulosa, Polysphincta, 275

granulosus, Scambus (Ateleophadnus), 28 (key), 31, 32; and 606, 607, 616 (figs.)

grapholithae, Calliephialtes, Pimpla, 80, 81 (key), 85,86 ; and 582,617 , 625 (figs.)

Grapholithae group, Calliephialtes, 80 (key), 84

greenei, Megarhyssa, 416, 417 (key), 421

greenei floridana, Megarhyssa, 421 (key), 423, 424, 615 (fig.) greenei greenei, Megarhyssa, 421 (key), 422, 423, 614 and 615 (figs.)

Grotea, 538, 603 (fig.)

anguina, 538.(key), 540, 603 (fig.)

californica, 538 (key), 540

Gymnacanthus, 495

aciculatus, 495

Habropimpla, 311

bilineata, 311

Habryllia, 542

hadrodactylus, Symphylus, 230, 233, 234

hakonensis, Iseropus, Epiurus, 165, 166

Haplomerus, 439

harringtoni, Coleocentrus, 546 and 547 (key), 552, 553, 634 (fig.)

harringtoni, Xorides (Xorides), 492

(key), 523, 524, 611 and 625

(figs.)

hawaiiensis, Pimpla, 349

hectica, Poemenia, Ephialtes, Calliclisis, Phthinodes, 376, 597 (fig.)

Hemigaster eublemmae, 542

Hemipimpla alboscutellaris, 159, 160

hesperus, Coccygomimus, 314 and 315 (key), 338, 339

Hierax, 414

hilaris, Theronia, Ichneumon, 352 (key), 35\%, 610 (fig.)

himalayensis, Iseropus, Pimpla, 166

hirticauda, Scambus (Erythroscambus), Pimpla, 7\%, 608 and 617 (figs.)

hispae, Scambus (Scambus), Ichneumon, 15, 37 and 40 (key), 71 , 73 ; and 606, 608, 617 (figs.)

hispae species group, Scambus (Scambus), 39 (key), 54

histrio, Megarhyssa, Thalessa, 415, 430

hoferi, Rhyssa, 396 (key), 899, 613 and 615 (figs.)

Hoferi group, Rhyssa, 396 (key), 397

hokkaidonis, Pimpla, Ephialtes, 102

Holcopimpla, 7

holsaticus, Xorides (Xorides), 503

howdenorum, Rhyssa, 396 (key), 398, 399, 613 (fig.)

hübrichi, Tromatobia, Austropimpla, 174

humeralis, Anomalon, 498

humeralis, Xorides (Exomus), Anomalon, 492 (key), 496; and 609, 610, 611 (figs.) 
humeralis chiricensis, Xorides (Exomus), 497 (key), 500, 501

humeralis excomptus, Xorides (Exomus), 497 (key), 500

humeralis humeralis, Xorides (Exomus), 497 (key), 498

humeralis mexicanus, Xorides (Exomus), 497 (key), 498

humeralis piceatus, Xorides (Exomus), 497 (key), 498

humeralis sierrae, Xorides (Exomus), 497 (key), 500

humida, Rhysella, Pimpla, 409 (key), 411, 412, 614 (fig.)

hungaricus, Odontocolon, Odontomerus, 459

hyalinipennis, Exeristes, 122

Hymenoepimecis, 256

Hymenomacropyga, 195

latifrontalis, 195

Ichneumon approximator, 409

atalantae, 354

atratus, 427

clavator, 415

compunctor, 302

contemplator, 338

dentipes, 448

divinator, 215

excitator, 546

georgicus, 434

gestator, 354

graminellae, 165

hilaris, 357

hispae, 71

illecebrator, 323

incitator, 195, 196

indicatorius, 490, 501

inquisitor, 166, 171

instigator, 315

irrigator, 501

irritator, 137

lunator, 430

maculator, 281

manifestator, 100

percontatorius, 262, 275

persuasorius, 396, 406

(Pimpla) pterelas, 152

quadrisculpta, 235

roborator, 11

rusticus, 438

stercorator, 165,168
Ichneumon-Continued

superbus, 415

tenebrator, 427

tuberculatus, 125

turionellae, 323

watsoni, 111, 127

Ichneumonoglypta, 195

lopez-richinii, 195

icterosticta, Megarhyssa lunator, 435

icterosticta, Megarhyssa macrurus, 429 and 430 (key), 485, 614 and 615 (figs.)

Ictoplectis (!) orgyiae, 168

illecebrator, Coccygomimus, Ichneumon, 323

imparis, Scambus (Scambus), 18, 36, 37, and 38 (key), 51, 52, 606 and 607 (figs.)

imparis species group, Scambus (Scambus), 38 (key), 51

imperator, Dolichomitus, Ephialtes, 114 (key), 154, 155; and 626, 629, 632 (figs.)

Imperator group, Dolichomitus, 113 and 114 (key), 152

incitator, Clistopyga, Ichneumon, 195, 196, 587 (fig.)

incompletus, Zaglyptus varipes, Pimpla, 189 (key), 190, 618 (fig.)

indicatorius, Xorides, Ichneumon, 490, 501

indicatorius species group, Xorides, 502

indigatrix, Pimpla, 71

indra, Coccygomimus, Pimpla, 315

inexpectata, Zatypota, 263

inflata, Coccygomimus, Pimpla, 346, 347

innominatus, Epiurus, 15, 65

inquisitor, Iseropus, Ichneumon, 165, 166,171

inquisitoriella, Pimpla, 172

instigator, Coccygomimus, Ichneumon, 315

instigator species group, Coccygomimus, 315

instigator var. intermedia, Pimpla, 328

insularis, Xorides (Xorides), Poemeria!, 493 (key), 51s, 514; and 609, 611, 612, 624 (figs.)

insularis species group, Xorides, 493 (key), 509

intermedius, Coccygomimus, Pimpla, 328 


\section{investigator, Xorides} Xylonomus, 496

investigatrix, Pimpla, 162

iridipennis, Dolichomitus, Ephialtes, 129

irrigator, Xorides (Xorides), Ichneumon, Xylonomus, 501,

irritator, Dolichomitus, Ichneumon, 113 and 114 (key), 137, 139; and 584, 629, 631 (figs.)

Irritator group, Dolichomitus, 113, 114, and 115 (key), 128

Ischnoceros, 438 (key), 600 (fig.)

clivulus, 488, 439

rusticus, 438

Iseropus, 7,9 (key), 16, 101, 165, 217, 585 (fig.)

brunneifrons septentrionalis, 168 californiensis, 166 and 167 (key), $170,172,617$ and 633 (figs.)

coelebs, 166 (key), 171, 172, 617 and 633 (figs.)

epicnapterus, 166

graminellae, 165

hakonensis, 165,166

himalayensis, 166

inquisitor, 165,166

orientalis, 166

satanus, 166

stercorator, 166 and 167 (key); and $585,627,633$ (figs.)

stercorator orgyiae, 167 (key), 168 stercorator stercorator, 167 (key), 168

Itoplectis, 281 (key), 594 (fig.)

alternans, 284

behrensii, 282 (key), 296, 297, 622 (fig.)

clavicornis, 298, 299, 300

conquisitor, 282 (key), 287, 288, 621 (fig.)

curticauda, 282 (key), 300

curticauda brevacus, 300 (key), 301, 622 (fig.)

curticauda curticauda, 300 (key), 301

esuchus, 283

evetriae, 282 (key), 294, 295, 621 (fig.)

exareolatus, 324

fustiger, 282 (key), 298, 299, 622 (fig.)

kolthoffi, 283

\section{Itoplectis-Continued}

latus, 283

leavitti, 283

maculator, 281

melanocephala, 300

montana, 283

obesus, 283

pacificus, 283

plesia, 295

quadricingulata, 282 (key), 283, 580 and 621 (figs.)

temnopleuris, 287

vesca, 282 (key), 297, 622 (fig.)

viduata, 282 (key), 293, 294, 621 (fig.)

jakolevi, Xorides (Moerophora), Xylonomus, Macrosterotrichus, 496 japonica, Delomerista, 365 (key), 367, 609 (fig.)

japonica, Theronia, 354

japonica, Zatypota, Polysphincta, 263

Japonica group, Delomerista, 364 and 365 (key)

japonicus, Perithous mediator, 210 (key), 214

jezoensis, Dolichomitus tuberculatus, 125 (key), 127

jezoensis, Odontocolon, Odontomerus, 454

jezoensis, Xorides (Moerophora), Xylonomus, 496

jozana, Rhyssa, 401

jubata, Acrodactyla, 231 (key), 232, 619 (fig.)

kimishimae, Epiurus, 166

kincaidii, Zaglyptus, 235

koebelei, Polysphincta, Zaglyptus, 246 (key), 253, 620 (fig.)

kolthoffi, Itoplectis, Pimpla, 283

konduensis, Xorides (Xorides), Xylonomus (Amphixylonomus), 502

kriegeri, Coccygomimus, Liotheronia, 311

Labena, 531, 602 (fig.)

apicalis, 533

chadwickii, 531

confusa, 533

confusa minor, 533

grallator, 531 (key), 602 (fig.)

grallator balteata, 532 (key), 536 
Labena-Continued

grallator grallator, 532 (key), 5s3, 534

grallator lutea, 532 (key), 586

grallator ochreata, 532 (key), 585, 536

grallator xutha, 532 (key), 534, 585

tinctipennis, 531 (key), 536, 587

Labenini, 437 (key), 530

Labiini, 437 (key), 537

Labium, 538

laevifrons, Pimpla, 365

laevigata, Colpomeria, 230

laevigata, Rhyssa, 427

laevigata, Theronia, 351, 358

laevis, Delomerista, 368

landerensis, Pimpla, 179

laöthoë, Coccygomimus, Pimpla, 315

laspeyresiae, Apistephialtes, Ephialtes, 88

lateralis, Clistopyga, 186

latifasciatus, Acrotaphus, Epimecis, 256 latifoveata, Acropimpla, Pimpla, 160 latifrontalis, Clistopyga, Hymenomacropyga, 195

latus, Itoplectis, Ephialtes, 283

Laufeia, 6, 219 (key), 220, 588 (fig.) mira, 220, 588 (fig.)

navajo, 221 (key), 222, 223, 619 (fig.)

pictifrons, 220, 222

slossonae, 221 (key), 222, 618 and 628 (figs.)

stigmata, 220

lavallensis, Xylonomus, 498

Lavaudenia, 495

mirabilis, 495

leavitti, Itoplectis, Ephialtes, 283

lemoinei, Cylloceria, 190

lepteces, Delomerista, 365 (key), 368, 609 (fig.)

lepturae, Xylonomus (Xylonomus), 508

leucostoma, Acropimpla, Charitopimpla, 160

limata, Polysphincta, 246 (key), 249, 620 (fig.)

lineata, Eruga, 238 (key), 239; and 590, 619, 628 (figs.)

lineata, Megarhyssa atrata, 426, (key), 427

lineatulus, Aplomerus, Anomalon, 440 and 441 (key), 442

lineatus, Xylonomus, 496 lineiger, Tromatobia, 178

lineolata, Rhyssa, Cryptocentrum, 397 (key), 404, 613 (fig.)

lineolatum, Cryptocentrum, 396, 404

Liogaster, 10

longulus, 10

Liotheronia, 311

kriegeri, 311

Liotryphon, 10

Lissonotopsis, 376

rufa, 376

Lissopimpla, 280

Lissoscambus (subg. of Scambus), 16, 17 (key), 25, 27

Lissoscambus arizonensis, 25, 607 (fig.) crassicauda, 25

Lissotheronia, 311 flavipes, 311

lithocolletidis, Scambus (Scambus), 15

litoralis, Colpomeria, 28

longicauda, Dolichomitus, 111

longicorpus, Scambus (Scambus), 37 and 38 (key), 43

longicorpus longicorpus, Scambus (Scambus), 43 (key), 44, 45, 606 and 607 (figs.)

longicorpus occidentalis, Scambus(Scambus), 43 (key), 45,46

longigenalis, Coccygomimus sodalis, Ephialtes, 328 (key), 329, 330, 623 (fig.)

longiseta, Ephialtes, Exeristes, 11, 12

longiventris, Macrocoleus, Macrus, 546

longulus, Liogaster, 10

lopez-richinii, Clistopyga, Ichneumonoglypta, 195

lubumbashica, Eruga, Acrodactyla, 238

lucida, Theronia, Poecilopimpla, 351

lucifugus, Acropimpla, Selenaspis, 160

luctuosa, Coccygomimus, Pimpla, 315

lunator, Megarhyssa macrurus, Ichneumon, 429 and 430 (key), 431, 614 and 615 (figs.)

lunator icterosticta, Megarhyssa, 435

lunator phaeoptila, Megarhyssa, 434

lutea, Labena grallator, 532 (key), 586

luteipes, Zatypota, 275 (key), 276, 277, 621 (fig.)

luteoniger, Brachycyrtus, 542

luteoniger fianarensis, Brachycyrtus, 542

Lycorinopsis, 262

rhombifer, 262, 263 
macra, Pimpla, Ephialtes, 102 (key), 104,625 and 630 (figs.)

Macrocoleus, 546

longiventris, 546

Macrogrotea, 538

macropunctatus, Dolichomitus, Ephialtes, 129

Macrosterotrichus, 495

jakolevi, 495

macrurus, Megarhyssa, Ichneumon, 416, 417 (key), 429

macrurus icterosticta, Megarhyssa, 429 and 430 (key), 435, 614 and 615 (figs.)

macrurus lunator, Megarhyssa, 429 and 480 (key), 431, 614 and 615 (figs.)

macrurus macrurus, Megarhyssa, 429 and 430 (key), 434, 435, 615 (fig.)

Macrus longiventris, 546

maculata, Piogaster, 241, 242, 619 (fig.) maculator, Itoplectis, Ichneumon, 281 maculiceps, Xorides (Gonioprymnus), 495

maculifrons, Clistopyga, 197 (key), 199, 201

maculipennis, Xorides (Cyanoxorides), Glypta, 494

madecassus, Coccygomimus, 311

mahasenae, Taiwatheronia, 302

mandibularis, Delomerista, Pimpla, 362, 363,371

manifestator, Pimpla, Ichneumon, 100, 101

manni, Clistopyga, 196 (key), 202, 204

manni, Coleocentrus, 546 and 547 (key), 555,634 (fig.)

manni coloradensis, Coleocentrus, 555 (key), 556

manni manni, Coleocentrus, 555 (key) marginatus, Meniscus, 325

marginellus, Coccygomimus, Pimpla, 313 (key), 336, 337

matsuyamensis, Neoxorides, Xorides, 390

maudae, Xorides (Xorides), Xylonomus, 492 (key), 521

maudae species group, Xorides, 492 (key), 520

maurus, Arotes, 561 (key), 563, 564

maurus, Coccygomimus, Pimpla, 313 (key), 321, 322, 622 (fig.) mediator, Perithous, Pimpla, 209 (key), 210, 627 (fig.)

mediator japonicus, Perithous, 210 (key), 214

mediator mediator, Perithous, 210 (key), 214

mediator neomexicanus, Perithous, 210 (key), 212, 213, 618 (fig.)

mediator pleuralis, Perithous, 210 (key), 211, 212, 618 (fig.)

megaera, Phytodiaetoides, 311,315

Megalorhyssa, 415

Megarhyssa, 395 (key), 415, 600 (fig.)

atrata, 416, 417 (key), 424

atrata atrata, 426 (key), 427, 614 (fig.)

atrata lineata, 426 (key), 427

greenei, 416, 417 (key), 421

greenei floridana, 421 (key), 423, 424, 615 (fig.)

greenei greenei, 421 (key), 422, 423, 614 and 615 (figs.)

histrio, 415

lunator icterosticta, 435

lunator phaeoptila, 434

macrurus, 416, 417 (key), 429

macrurus icterosticta, 429 and 430

(key), 485, 614 and 615 (figs.)

macrurus lunator, 429 and 430

(key), 431, 614 and 615 (figs.)

macrurus macrurus, 429 and 430

(key), 434, 435, 615 (fig.)

nortoni, 417 (key), 600 (fig.)

nortoni nortoni, 418 (key), 420, 614

(fig.)

nortoni quebecensis, 418 (key), 420 superba, 415, 418

melanacrias, Coccygomimus, Pimpla, 338

melanderi, Spilopteron vicinum, 573

(key), 575, 576

melanocephala, Itoplectis, 300

melanocephala, Pimpla, 357

melanomerus, Dolichomitus, Ephialtes, 129

melanopyga, Scambus (Endromopoda), 18

melleus, Arotes, Acaenitus, 561 (key), 567, 624 (fig.)

mellipennis, Theronia fulvescens, 354

mellipes, Odontocolon, Anomalon, 451 and 453 (key), 467, 469 
mellipes species group, Odontocolon, 449 and 452 (key), 458

mellithorax, Colpomeria, 235

mencianae, Epiurus, 166

Meniscus ashmeadii, 341

marginatus, 325

mesocentrus, Dolichomitus, Ephialtes, 129

Mesochorus fuscipennis, 531, 533

Mesoclistus, 545 (key), 560, 604 (fig.)

cushmani, 560

rufipes, 560, 604 (fig.)

Mesoephialtes, 7

messor, Dolichomitus, Ephialtes, 113 and 115 (key), 131; and 626, 629, 631 (figs.)

messor messor, Dolichomitus, 132 (key), 136

messor perlongus, Dolichomitus, 132 (key), 194

messor sparsus, Dolichomitus, 132 (key), 183, 134

mexicanus, Xorides (Exomus) humeralis, 497, (key), 498

Microtritus, 531

apicalis, 531

minor, Coleocentrus, 559

minor, Labena confusa, 533

minuta, Pimpla, 71

minuta, Polysphincta, 261

mira, Laufeia, 220, 588 (fig.)

mirabilis, Xorides (Gonioprymnus), Lavaudenia, 495

Mischocyttarus flavitarsis navajo, 532

Moansa (subg. of Xorides), 491 (key), 495

Moansa exquisitus, 494

ornatus, 503, 515

praestans, 495

spectabilis, 494

Moerophora (subg. of Xorides), 491 (key), 495

Moerophora duplicatus, 518

eastoni, 513

investigator, 496

jakolevi, 496

jezoensis, 496

neoclyti, 522

piceatus, 497

rufipes, 495

yukonensis, 503

mokrzeckii, Gonophonus, 494

montana, Itoplectis, Ephialtes, 283 moravicus, Pseudacoenites, 351

nakamurai, Dolichomitus, Ephialtes, 129

nankingensis, Epiurus, 166

naranyae, Itoplectis, Nesopimpla, 281, 300

nasonii, Aplomerus, 515

navajo, Laufeia, 221 (key), 222, 22S, 619 (fig.)

navajo, Mischocyttarus flavitarsis, 532

navajoe, Polistes canadensis, 532

nawaii, Brachycyrtus, Proterocryptus, 542

nebulosa, Poemenia americana, 382 (key), 383, 384

neoclyti, Xorides (Xorides), Moerophora, 492 (key), 521, 522; and $609,611,612$ (figs.)

Neogabunia, 311

paulistana, 311

neomexicanus, Perithous mediator, Pimpla, 210 (key), 212, 213, 618 (fig.)

Neonotus, 531

chadwickii, 531

Neotheronia, 351

tolteca, 351

winnemanae, 359

Neoxorides, 376 (key), 390, 598 (fig.)

borealis, 390 (key), 392, 393, 598 (fig.)

caryae, 390 (key), 393, 394

collaris, 390,392

matsuyamensis, 390

nitens, 390

pilulus, 390 (key), 391

Neoxylonomus, 501, 502

antennalis, 490,501

strandi, 502, 505

nepe, Pimpla, 315

Nesopimpla, 281

naranyae, 281

niger, Coleocentrus, 559

nigrescens, Acropimpla, Charitopimpla, 160

nigricans, Dolichomitus, Ephialtes, 129

nigricans, Scambus (Ateleophadnus), 27

nigriceps, Scambus (Erythroscambus), Ephialtes, 77

nigriceps, Zatypota, Polysphincta, 264 (key), 273, 621 and 628 (figs.)

nigricolor, Coccygomimus, Pimpla, 315 
nigricornis, Sinarachna, Polysphincta, 259

nigrifrons, Clistopyga, 196 (key), 201

nigrifrons, Scambus (Scambus), Pimpla (Epiurus) 15, 37, and 40 (key), $73,74,608$ (fig.)

nigrita, Polysphincta, 273

nigrocephala, Clistopyga, 273

nigroscutis, Acropimpla, Charitopimpla, 160

nikkoensis, Odontocolon, Odontomerus, 459

nikkoensis, Zabrachypus, Polysphincta, 225

nipponica, Coccygomimus, Pimpla, 338 nitens, Neoxorides, Xorides, 390

nitida, Rhysella, Rhyssa, 409 (key), 411, 599 and 614 (figs.)

nordenskiöldii, Pimpla, 329

nortoni, Megarhyssa, 417 (key), 600 (fig.)

nortoni nortoni, Megarhyssa, 418 (key), 420,614 (fig.)

nortoni quebecensis, Megarhyssa, 418 (key), 420

notandus, Calliephialtes, Pimpla, 81 (key), 83, 617 (fig.)

notandus species group, Calliephialtes, 80 (key), 81

notata, Poemenia, 376, 386

notator, Tromatobia, Pimpla, 175 (key), 185, 186, 618 and 633 (figs.)

notator species group, Tromatobia, 175 (key), 186

novita, Delomerista, Pimpla, 365 (key), 372, 609 and 623 (figs.)

novita species group, Delomerista, 364 and 365 (key)

nubilipennis, Dolichomitus terebrans, Exeristes, 121, 122 (key)

nucicola, Apistephialtes, Calliephialtes, 88 and 89 (key), 95, 96; and 583, 626, 630 (figs.)

nucum, Scambus (Scambus), Pimpla, 15, 37 and 39 (key), 70, 608 (fig.)

nudus, Coccygomimus, Pimpla, 313 and 314 (key), 343, 345

nuperus, Priocnessus, 532

obesus, Itoplectis, 283

obliterata, Rhysella, Rhyssa, 409 occidentalis, Coleocentrus, 546 and 547 (key) 548, 634 (fig.)

occidentalis, Ephialtes, 154

occidentalis, Scambus (Scambus) longicorpus, 43 (key), 45, 46

occidentalis, Xorides, 392

occidentalis occidentalis, Coleocentrus, 548 (key), 549

occidentalis pulchripennis, Coleocentrus, 548 (key), 549

occiputale, Spilopteron, Arotes, 569 (key), 576, 624 (fig.)

ocellata, Acrodactyla, 231 (key), 232, 619 (fig.)

ochropus, Odontocolon, 451 and 454 (key), 482, 601 (fig.)

oculatoria, Tromatobia, 175

oculatoria species group, Tromatobia, 175 (key), 178

Odontocolon, 438 (key), 448, 601 (fig.) abdominale, 450 and 452 (key), 462 abdominale abdominale, 463 (key), 464

abdominale fergusoni, 463 (key), 464

aciculatus, 480

aethiops, 450 and 453 (key), 460, 461

alaskensis, 450 and 453 (key), 460

albotibiale, 451 and 454 (key), 480, 482

appendiculatus, 456

atripes, 450 and 452 (key), 478, 479

bicolor, 449 and 452 (key), 455

brevicaudus, 450 and 452 (key), 474

canadense, 451 and 453 (key), 466, 469

cilipes, 449 and 452 (key), 454, 455

curtum, 450 and 453 (key), 469, 470

dentipes, 448

depressum, 449 and 453 (key), 459,460

dichrous, 450 and 453 (key), 474, 475

dreisbachi, 450 and 453 (key), 479, 480

formicoides, 449 and 452 (key), 457,458

geniculatus, 459

hungaricus, 459

jezoensis, 454 
Odontocolon-Continued

mellipes, 451 and 453 (key), 467, 469

nikkoensis, 459

ochropus, 451 and 454 (key), 482, 601 (fig.)

parvum, 450 and 454 (key), 472, 474

pinetorum, 459

polymorphum, 449 and 452 (key), 457

pullum, 449 and 452 (key), 456

punctatum, 451 and 453 (key), 464,465

punctulatus, 459,461

quercinus, 454

rufiventris, 459

rufum, 459,488

sierrae, 451 and 454 (key), 471, 474

spinipes, 459

stejnegeri, 459

strangaliae, 451 and 452 (key), 485,487

thomsoni, 454

vicinum, 450 and 453 (key), 487

Odontomerus, 448

abdominale, 462

aethiops, 461

alaskensis, 460

albotibiale, 480

appendiculatus, 456

atripes, 478

bicolor, 455

brevicaudus, 474

canadensis, 466

dentipes, 448

dichrous, 475

errans, 467

geniculatus, 459

hungaricus, 459

jezoensis, 454

nikkoensis, 459

pinetorum, 459

punctatum, 465

punctulatus, 459

quercinus, 454

rufiventris, 459

rufus, 459

spinipes, 459

stejnegeri, 459

strangaliae, 485

striatus, 480

thomsoni, 454
Odontomerus-Continued

tibialis, 466

vicinum, 487

Odontopimpla, 8

ontario, Ephialtes, Pimpla, 303 (key), 308, 309, 622 (fig.)

Opodactyla, 311

waterloti, 311

orgyiae, Iseropus stercorator, Ietoplectis (!), 167 (key), 168

orientalis, Acrodactyla, Polemophthorus, 235

orientalis, Iseropus, 166

Orientotheronia, 351

rufescens, 351

ornatulus, Apechthis, 303

ornatus, Brachycyrtus, 542, 543 (key), 544, 603 (fig.)

ornatus, Xorides (Xorides), Moansa, 503, 515

Orthognathella, 538

ovivora, Tromatobia, Pimpla, 175 (key), $178,179,627$ and 633 (figs.)

ovivora ovivora, Tromatobia, 179, (key) 180, 618 (fig.)

ovivora rufopectus, Tromatobia, 179 (key), 18s, 185, 618 (fig.)

Oxypimpla, 311

turionellae, 311

Oxyrrhexis, 220 (key), 242, 591 (fig.) carbonator, 242, 591 and 628 (figs.) carbonator carbonator, 243 (key) carbonator texana, 243 (key), 619 (fig.)

tuberculata, 242

pacifica, Poemenia, 377 (key), 384, 385

pacificus, Ephialtes, Apechthis, 89, 303 (key), 307, 308, 622 (fig.)

pacificus, Itoplectis, Ephialtes, 283

pallipes, Sinarachna, Polysphincta, 233, 259, 260, 593 (fig.)

pallipes pallipes, Sinarachna, 259 (key), 260

pallipes strigis, Sinarachna, 259 (key), 260, 620 (fig.)

Parapechthis, 302

bazani, 302

Pararhyssa, 396

persuasorius, 396

parva, Zatypota, Glypta?, 264 (key), 266, 267, 620 (fig.) 
parvum, Odontocolon, 450 and 454 (key), 472, 474

patellata, Zatypota, 264 (key), 267, 268, 620 (fig.)

paulisiana, Eruga, Acrodactyla, 238

paulistana, Coccygomimus Neogabunia, 311

pedalis, Coccygomimus, Pimpla, Pimplidea, 311, 313 (key), 316, 317, 580 and 622 (figs.)

peniculus, Xorides (Xorides), 494 (key), 506, 507, 609 and 624 (figs.)

pennator, Trogus, 532

percontatoria, Zatypota, Ichneumon, 262, 265 (key), 275, 276, 593 and 621 (figs.)

Periceros (subg. of Xorides), 491 (key), 501

antennalis, 501

Perissocerus, 501

plumicornis, 501

Perithous, 6, 8 (key), 209, 588 (fig.)

albicinctus, 209, 588 (fig.)

divinator, 209 (key), 215, 618 and 627 (figs.)

mediator, 209 (key), 210, 627 (fig.) mediator japonicus, 210 (key), 214 mediator mediator, 210 (key), 214 mediator neomexicanus, 210 (key), 212, 213, 618 (fig.)

mediator pleuralis, 210 (key), 211, 212, 618 (fig.)

Perithous generic group, Pimplini, 8

perlongus, Dolichomitus messor, Ephialtes 132 (key), 134

persuasoria, Rhyssa, Ichneumon, Pararhyssa, 397 (key), 406, 407, 598 and 613 (figs.)

persuasoria species group, Rhyssa, 387 (key), 400, 406

perversus, Apistes, 87

pettiti, Coleocentrus, 456 and 547 (key), $551,552,634$ (fig.)

petulcus, Apistephialtes, Pimpla, 88 and 89 (key), 96, 97, 627 and 630 (figs.)

pfankuchi, Delomerista, Pimpla, 365 (key), 371, 609 (fig.)

phaeoptila, Megarhyssa lunator, 434

Phthinodes, 376

Phytodiaetoides, 311

flavipalpis, 311

megaera, 311, 315 piceatus, Xorides (Exomus) humeralis, Xylonomus (Moerophora), 497 (key), 498

picticollis, Zatypota, Polysphincta, 264 picticornis, Ephialtes, Pimpla, 303 (key), 305, 622 (fig.)

pictifrons, Laufeia, Pimpla, 220, 222

pictilis, Zaglyptus, 189 (key), 193, 194, 618 and 633 (figs.)

pictipes, Acropimpla, Pimpla, 160

pictipes, Pimpla, 287

pictus, Xorides (Xorides), 493 (key), 504, 505; and 609, 610, 612, 624 (figs.)

pilicornis, Sterotrichus, Xylonomus, 502

pilulus, Neoxorides, 890 (key), 391

Pimpla, 7, 9, 10 (key), 100, 311, 583 (fig.)

aequalis, 341

albipes, 77

alboannulata, 328

alboricta, 162

animosa, 190

annulicornis, 305

annulipes, 346

aplopappi, 63

aquilonia, 325

arctica, 315

arisanus, 102

atrocoxalis, 293

behrensii, 296

bicarinata, 160

brevicornis, 36,55

brevis, 101, 102 (key), 105, 630 (fig.)

brunneifrons, 168

cameronii, 328

caudata, 87,88

coelebs, 172

componotus, 308

conquisitor var. rufuscula, 341

coxata, 77

crassicauda, 25

cyanipennis, 328

decumbens, 102 (key), 103, 630 (fig.)

defensator, 179

detrita, 21

didyma, 160

disparis, 323

duplicauda, 101

ellopiae, 322

erebus, 315 
Pimpla-Continued erythropus, 336 euurae, 50

feralis, 349

flavicans, 351

flavipalpis, 315

fuscipennis, 338

fuscipes, 338

gossypii, 71

grapholithae, 85

hawaiiensis, 349

himalayensis, 166

hirticauda, 76, 77

hokkaidonis, 102

humida, 412

indigatrix, 71

indra, 315

inflata, 346

inquisitoriella, 172

instigator var. intermedia, 328

investigatrix, 162

kolthoffi, 283

laevifrons, 365

landerensis, 179

laöthoë, 315

latifoveata, 160

luctuosa, 315

macra, 102 (key), 104, 625 and 630

(figs.)

mandibularis, 362,363

manifestator, 100, 101

marginella, 337

maura, 321

mediator, 214

melanacrias, 338

melanocephala, 357

minuta, 71

neomexicanus, 213

nepe, 315

nigricolor, 315

nigrifrons, 74

nipponica, 338

nordenskiöldii, 329

notandus, 81

notator, 186

novita, 372

nucum, 70

nuda, 345

ontario, 309

ovivora, 179

pedalis, 311,316

petulcus, 97

pfankuchi, 371
Pimpla-Continued

picticornis, 303

pictifrons, 220

pictipes, 160, 287

pluto, 323

poesia, 315

polytauma, 101

pomorum, 36

pterelas, 28, 152

pterophori, 28

punctulata, 87,88

punicipes, 349

4-cingulatus, 283

roborator, 10

rubata, 302

rufipes, 338

rufopectus, 183

rufovariata, 176

sagax, 36

sanguinipes, 335

scriptifrons, 179

sedula, 315

silvicola, 315

simonis, 193

sodalis, 328

sordidella, 338

spatulata, 101, 102 (key), 106, 107, 626 and 631 (figs.)

spectabilis, 281

spuria, 338

stultor, 92

tenchozanus, 102

tenuicornis, 330

terebrans, 124

texana, 365

thoracica, 315

transgressa, 65

turionellae, 311

variabilis, 174, 176

vesicaria, 49

vidua, 179

viduata, 293

viridescens, 315

walshii, 287

waterloti, 311

xanthothorax, 80, 85

yakutatensis, 324

yezoensis, 160

Pimpla generic group, Pimplini, 7

Pimpla generic subgroup, Pimplini, 7

Pimplaetus, 7

Pimplidea, 311

pedalis, 311 
Pimplinae, 3, 4, 5

Pimplini, 6 (key), 581-588 (figs.)

pimploides, Polysphincta, 190

pinetorum, Odontocolon, Odontomerus, 459

Piogaster, 219 (key), 241, 591 (fig.)

maculata, 241, 242, 619 (fig.)

rugosa, 241, 591 (fig.)

planus, Xorides (Xorides), 493 (key), 510,511

Platysoma, 439

tibialis, 439, 444

plesia, Itoplectis, 295

plesius, Xylonomus (Xylonomus), 503

pleuralis, Perithous mediator, 210 (key), 211, 212, 618 (fig.)

pleurivinctus, Cryptus, 287

plumicornis, Xorides (Periceros), Perissocerus, 501

pluto, Coccygomimus, Pimpla, 323

podagrica, Schizopyga, 224, 589 (fig.)

Podoschistus, 376 (key), 387, 597 (fig.)

alpensis, 387

scutellaris, 387

vittifrons, 388,597 (fig.)

vittifrons schlingeri, 388 (key)

vittifrons vittifrons, 388 (key), 389

Poecilocryptini, 437 (key), 541

Poecilocryptus, 541

Poecilopimpla, 351

lucida, 351

Poemenia, 5, 376 (key), 597 (fig.)

albipes, 377 (key), 379, 880

americana, 377 (key), 382

americana americana, 382 (key), 384

americana nebulosa, 382 (key), 383 , 384

(Poemeria!) insularis, 513

notata, 376,386

pacifica, 377 (key), 384, 385

thoracica, 877 (key), 379

Poemeniini, 375, 597 and 598 (figs.)

poesia, Pimpla, 315

Polemophthorus, 230

orientalis, 235

Polistes canadensis navajoe, 532

rubiginosus, 532

politus, Symphylus, 234

polymorphum, Odontocolon, 449 and 452 (key), 457

polymorphum species group, Odontocolon, 449 and 452 (key), 456
Polysphincta, 220 (key), 245, 592 (fig.)

acuta, 197

albipes, 246 (key), 255

anomala, 261

bicarinata, 243

bohemani, 265

boops, 246

braucheri, 273

burgessii, 246 (key), 247, 620 (fig.)

californiensis, 273

caudata, 260

ceylonica, 259

cingulata, 176

crosbyi, 273

dictynae, 261

discolor, 263

drewseni, 246

eboripes, 246 (key), 254, 255, 620

(fig.)

elongata, 251

eximia, 262, 263

forsiusi, 176

gracilis, 275

granulosa, 275

japonica, 263

koebelei, 246 (key), 25s, 620 (fig.)

limata, 246 (key), 249, 620 (fig.)

minuta, 261

nigriceps, 273

nigricornis, 259

nigrita, 273

nikkoensis, 225

pallipes, 233, 259, 260

picticollis, 264

pimploides, 190

pontiaci, 225

pulchrator, 264

rubricapensis, 190

rufigaster, 190

rufipes, 246

rufopectus, 247

scutellaris, 275

slossonae, 221

spinosa, 190

stigmata, 220

strigis, 260

takewakii, 236

taschenbergi, 246

tenuiabdominalis, 225

theridii, 275

thoracicus, 246

tuberculata, 242 
Polysphincta-Continued

tuberosa, 245, 246 (key), 251, 592 and 628 (figs.)

tuberosa bruneti, 251 (key), 253, 620 (fig.)

tuberosa tuberosa, 251 (key)

varipes, 188,189

venatrix, 247

vicina, 243

Polysphinctini, 6 (key), 216, and 588593 (figs.)

Polysphinctopsis, 262

polytauma, Pimpla, Ephialtes, 101

pomorum, Scambus (Scambus), Tromera, Pimpla, 36

ponderosae, Rhyssa, 397 (key), 401, 402, 613 (fig.)

pontiaci, Polysphincta, 225

populneus, Dolichomitus, Ephialtes, 113 and 115 (key), 129; and 626, 629, 631 (figs.)

praestans, Xorides (Moansa), 495

pretiosus, Brachycyrtus, 543 (key), 623 (fig.)

prima, Zatypota, 263

primus, Brachycyrtus, Xanthocharops, 542

primus, Zabrachypus, 228, 229; and 589, 619,628 , (figs.)

Priocnessus nuperus, 532

productus, Scambus (Endromopoda), 19 (key), 23, 25, 607 and 616 (figs.)

pronexus, Acropimpla, 161 (key); and $617,626,632$ (ifgs.)

propinquus, Xorides (Gonophonus), Xylonomus, 494

propodeum, Xorides (Cyanoxorides), Spiloxorides, 494

protentus, Scambus (Scambus), 18, 36, 37 and 38 (key), 40, 42, 607 (fig.)

Proterocryptus, 542 nawaii, 542

Psammochares, 101

Pseudacoenites, 351 moravicus, 351

Pseudopoemenia, 27 annulata, 27

Pseudorhyssa, 5351 (key), 379, 596 (fig.)

ruficoxis, $373,374,596$ (fig.)

sternata, 373 pterelas, Dolichomitus, Ichneumon (Pimpla), 28, 114 (key), 152, 153, 629 and 632 (figs.)

pterophori, Scambus (Ateleophadnus), Pimpla 27 and 28 (key), 29, 35, 607 and 616 (figs.)

pulchella, Exeristes, 160

pulcher, Xylonomus, 515

pulchra, Schizopyga, 224 (key), 226, 227, 619 (fig.)

pulchrator, Zatypota, Polysphincta, 264

pulchripennis, Coleocentrus occidentalis, 548 (key), 549

pulchripicta, Clistopyga, 204

pullum, Odontocolon, 449 and 452 (key), 456

punctatum, Odontocolon, Odontomerus, 451 and 453 (key), 464, 465

punctulata, Apistephialtes, Pimpla, 87, 88

punctulatus, Odontocolon, Odontomerus, 459,461

puniceipes, Pimpla, 349

punicipes, Coccygomimus, Pimpla, 314 and 315 (key), 348, 349, 623 (fig.)

pusio, Ephialtes, 89

pygmaeus, Dolichomitus, Ephialtes, 113 and 115 (key), 149, 150, 629 and 632 (figs.)

Pyramirhyssa (subg. of Xorides), 491 (key), 580

quadricingulata, Itoplectis, Pimpla, 282 (key), 283, 580 and 621 (figs.)

quadrisculpta, Acrodactyla, Ichneumon, 230, 231 (key), 235, 236, 619 and 628 (figs.)

quadrisculpta species group, Acrodactyla, 231 (key), 235

quebecensis, Coleocentrus, 547 (key), $549,550,634$ (fig.)

quebecensis, Megarhyssa nortoni, Thalessa, 418 (key), 420

quercinus, Odontocolon, Odontomerus, 454

quersifoliae, Epiurus, 166

recurva, Clistopyga, Anomalon, 196 (key), 204, 628 (fig.)

Retanisia, 561

facialis, 561 
Rhadina, 502 ater, 502

Rhadinopimpla, 502

rhombifer, Zatypota, Lycorinopsis, 262, 263

Rhyssa, 395 (key), 396, 598 (fig.)

alaskensis, 397 (key), 401, 402, 613 (fig.)

albomaculata, 400, 404

amoena, 401

approximator, 373

approximator var. ruficoxis, 373

canadensis, 409

crevieri, 397 (key), 403, 404, 613 (fig.)

curvipes, 409

dubiosa, 409

furannus, 409

hoferi, 396 (key), 399, 613 and 615 (figs.)

howdenorum, 396 (key), 398, 399, 613 (fig.)

jozana, 401

laevigata, 427

lineolata, 397 (key), 404, 613 (fig.)

nitida, 409

obliterata, 409

persuasoria, 397 (key), 406, 407, 598 and 613 (figs.)

ponderosae, 397 (key), 401, 402, 613 (fig.)

skinneri, 401

Rhyssella, 395 (key), 409, 599 (fig.)

approximator, 409, 410

furannus, 409

humida, 409 (key), 411, 412, 614 (fig.)

nitida, 409 (key), 411, 599 and 614 (figs.)

obliterata, 409

Rhyssini, 5 (key), 395; and 598, 599, 600 (figs.)

Rhyssonota, 413

tristis, 413

rileyi, Xorides (Xorides), Xylonomus, 493 (key), 508, 510; and 609, 610, 612, 624 (figs.)

rileyi species group, Xorides, 493 (key), 504

roborator, Exeristes, Ichneumon, Pimpla, 10, 581 (fig.)

robustus, Aplomerus, 440 and 441 (key), 442,443 rubata, Apechthis Pimpla, 302

rubescens, Scambus (Endromopoda), 18 (key), 19, 607 and 616 (figs.)

rubiginosus, Polistes, 532

rubricapensis, Polysphincta, 190

rudis, Xorides (Xorides), 493 (key), 510

rufa, Eruga, 238 (key), 239, 240, 619 (fig.)

rufa, Lissonotopsis, 376

rufatus, Ephialtes, 302

rufescens, Dolichomitus, Ephialtes, 116

rufescens, Theronia, Orientotheronia, 351

ruficeps, Xorides (Cyanoxorides), Spiloxorides, 494

ruficollis, Eremochila, 6

ruficoxis, Pseudorhyssa, Rhyssa, 373, 374, 596 (fig.)

ruficoxis, Rhyssa approximator, 373

ruficoxis, Xylonomus (Xylonomus), 508

rufigaster, Polysphincta, 190

rufipes, Coccygomimus, Pimpla, 338

rufipes, Mesoclistus, Acoenites, 560, 604 (fig.)

rufipes, Polysphincta, 246

rufipes, Xorides (Moerophora), Xylonomus, 495, 496

rufipleuralis, Xorides (Cyanoxorides), Spiloxorides, 494

rufiventris, Odontocolon, Odontomerus, 459

rufocoxatus, Coleocentrus, 546 and 547 (key), 554, 555, 634 (fig.)

rufomaculata, Xorides (Epixorides), Cyanoxorides, 495

rufopectus, Polysphincta, 247

rufopectus, Tromatobia, 362

rufopectus, Tromatobia ovivora, Pimpla, 179 (key), 18s, 185, 618 (fig.)

rufovariata, Pimpla, 176

rufum, Odontocolon, Odontomerus, 459, 488

rufus, Coleocentrus, 546 and 547 (key), $556,558,627$ and 634 (figs.)

rufus, Xorides (Xorides) cincticornis, 528 (key), 529, 530

rufuscula, Pimpla conquisitor, 341

rugosa, Piogaster, 241, 591 (fig.)

rugulosa, Apechtis, 179

rupinsulensis, Yezoceryx, Acoenitus, $578,579,606$ (fig.)

rusticus, Ischnoceros, Ichneumon, 438

rutshurica, Eruga, Acrodactyla, 238 
sagax, Scambus (Scambus), Pimpla, 36 sanguinipes, Coceygomimus, Pimpla, 314 (key), 394

sanguinipes erythropus, Coccygomimus, 335 (key), 936

sanguinipes sanguinipes, Coccygomimus, 395 (key), 336

satanus, Iseropus, Epiurus, 166

sauberi, Clistopyga, 199

scaber, Xorides (Gonophonus), Xylonomus, 494

Scambus, 7, 9 (key), 14, 101, 581 and 582 (figs.)

(Erythroscambus) albipes, 77

(Erythroscambus) albitibia, 77

(Ateleophadnus) annulata, 27

(Scambus) aplopappi, 38 and 39 (key), 62, 63, 608 and 616 (figs.)

(Lissoscambus) arizonensis, 25, 607 (fig.)

(Scambus) atrocoxalis, 39 (key), 52, 5s, 606 (fig.)

(Scambus) brevicornis, 36, 38 and 39 (key), 55, 607 and 616 (figs.)

(Scambus) buolianae, 68

(Scambus) canadensis, 38 and 39 (key), 58; and 606, 608, 616 (figs.)

(Ateleophadnus) cincticarpus, 27 (Erythroscambus) coxata, 77

(Lissoscambus) crassicauda, 25

(Ateleophadnus) deceptor, 28 (key), 35, 606 and 616 (figs.)

(Scambus) decorus, 37 and 40 (key), 75, 77, 608 (fig.)

(Endromopoda) detritus, 18, 19 (key), 81,22 ; and 581, 606, 607, 616 (figs.)

(Scambus) dioryctriae, 38 and 40 (key), 61, 62, 608 (fig.)

(Scambus) elegans, 36

(Scambus) ephialtoides, 37 and 38 (key), 42, 46, 607 (fig.)

evetrivorus, 63

(Erythroscambus) flavipes, 77

(Ateleophadnus) granulosus, 28 (key), 31, 32; and $606,607,616$ (figs.)

(Erythroscambus) hirticauda, $\gamma \gamma$, 608 and 617 (figs.)

(Scambus) hispae, 15, 37 and 40 (key), 71,73 ; and $606,608,617$ (figs.)
Scambus-Continued

(Scambus) imparis, 18, 36, 37 and 38 (key), 51, 52, 606 and 607 (figs.)

lithocolletidis, 15

(Scambus) longicorpus, 37 and 38 (key), 48

(Scambus) longicorpus longicorpus, 43 (key), 44, 45, 606 and 607 (figs.)

(Scambus) longicorpus occidentalis, 43 (key), 45, 46

(Endromopoda) melanopyga, 18

(Ateleophadnus) nigricans, 27

(Erythroscambus) nigriceps, 77

(Scambus) nigrifrons, 15, 37 and 40 (key), 73, 74, 608 (fig.)

(Scambus) nucum, 15, 37 and 39 (key), 70, 608 (fig.)

(Scambus) pomorum, 36

(Endromopoda) productus, 19 (key), 23, 25, 607 and 616 (figs.)

(Scambus) protentus, 18, 36, 37 and 38 (key), 40, 42, 607 (fig.)

(Ateleophadnus) pterophori, 27 and 28 (key), 29, 35, 607 and 616 (figs.)

(Endromopoda) rubescens, 18 (key), 19, 607 and 616 (figs.)

(Scambus) sagax, 36

(Ateleophadnus) similis, 27

(Scambus) subtilis, 39 (key), , f7, 49

(Scambus) tecumseh, 37 and 40 (key), 67; and 606, 608, 617 (figs.)

(Scambus) tenebrosus, 38 and 39 (key), 60, 62, 608 (fig.)

(Scambus) transgressus, 15, 37 and 40 (key), 65, 67, 608 (fig.)

(Scambus) versicarius, 37 and 39 (key), 48

(Scambus) vesicarius euurae, 15, 49 (key), 50; and 606, 607, 616 (figs.)

(Scambus) vesicarius vesicarius, 15 , 48 (key), 49, 616 (fig.)

Scambus (Scambus), 16, 17 and 18 (key), 86, 582 (fig.)

aplopappi, 38 and 39 (key), 62, 63, 608 and 616 (figs.)

atrocoxalis, 39 (key), 52, 53, 606 (fig.) 
Scambus (Scambus)-Continued

brevicornis, 36, 38 and 39 (key), 55,607 and 616 (figs.)

buolianae, 68

canadensis, 38 and 39 (key), 58; and $606,608,616$ (figs.)

decorus, 37 and 40 (key), 75,77 , 608 (fig.)

dioryctriae, 38 and 40 (key), 61, 62,608 (fig.)

elegans, 36

ephialtoides, 37 and 38 (key), 42, 46,607 (fig.)

hispae, 15, 37 and 40 (key), 71, 73; and $606,608,617$ (figs.)

imparis, 18, 36, 37 and 38 (key), 51 , 52,606 and 607 (figs.)

longicorpus, 37 and 38 (key), 48

longicorpus longicorpus, 43 (key), 44, 45, 606 and 609 (figs.)

longicorpus occidentalis, 43 (key), 45,46

nigrifrons, 15,37 and 40 (key), 73, 74, 608 (fig.)

nucum, 15, 37 and 39 (key), 70 , 608 (fig.)

pomorum, 36

protentus, 18, 36, 37 and 38 (key), 40, 42, 607 (fig.)

subtilis, 39 (key), 4\%, 49

tecumseh, 37 and 40 (key), 67; and 606, 608, 617 (figs.)

tenebrosus, 38 and 39 (key), 60, 62, 608 (fig.)

transgressus, 15,37 and 40 (key), $65,67,608$ (fig.)

vesicarius, 37 and 39 (key), 48

vesicarius euurae, 15, 49 (key), 50; and $606,607,616$ (figs.)

vesicarius vesicarius, 15,48 (key), 49, 616 (fig.)

Schisopyga, 219 (key), 224, 589 (fig.)

atra, 225

circulator, 227

frigida, 224 (key), 225, 619 and 628 (figs.)

podagrica, 224, 589 (fig.)

pulchra, 224 (key), 226, 227, 619 (fig.)

schlingeri, Podoschistus vittifrons, 388 (key)

scriptifrons, Pimpla, 179

scutellaris, Podoschistus, Xorides, 387 scutellaris, Polysphincta, 275

scutellaris, Yezoceryx, 578

sedula, Coccygomimus, Pimpla, 315

Selenaspis, 159

alboscutellaris, 159, 160

lucifugus, 160

semirufus, Xorides (Xorides), 494 (key), 506,507

septemtrionalis, Theronia, Neotheronia, 352 (key), 359, 361, 610 (fig.)

septentrionalis, Iseropus brunneifrons, 168

sericeus, Dolichomitus, Closteroceros, 111, 113 and 114 (key), 158; and $626,629,632$ (figs.)

sericeus species group, Dolichomitus, 113 (key), 157

sericeus, Labena, Dyseidopus, 531

Sericopimpla, 7, 217

Sichelia, 502

filiformis, 502

sierrae, Odontocolon, 451, and 454 (key) $4 \pi 1,474$

sierrae, Xorides (Exomus) humeralis, 497 (key), 500

silvicola, Coccygomimus, Pimpla, 313 (key), 315, 317, 622 (fig.)

similis, Coleocentrus, 556

similis, Scambus (Ateleophadnus), 27

simonis, Zaglyptus, Pimpla, 193

Sinarachna, 219 (key), 258, 593 (fig.)

anomala, 259 (key), 261,620 (fig.)

ceylonica, 259

nigricornis, 259

pallipes, 259 (key), 593 (fig.)

pallipes pallipes, 259 (key), 260

pallipes strigis, 259 (key), 260, 620 (fig.)

skinneri, Rhyssa, 401

slossonae, Laufeia, Polysphincta, 221

(key), 222, 618 and 628 (figs.)

smithi, Xorides (Cyanoxorides), 494

sodalis, Coccygomimus, Pimpla, 313 (key), 328

sodalis longigenalis, Coccygomimus, 328 (key), 329, 830, 623 (fig.)

sodalis sodalis, Coccygomimus, 328 (key), 329, 623 (fig.)

sodalis species group, Coccygomimus, 312,327

sordidella, Coccygomimus, Pimpla, 338 sparsus, Dolichomitus messor, 132 (key), 133, 134 
spatulata, Pimpla, 101, 102 (key), 106, 107, 626 and 631 (figs.)

speciosa, Epirhyssa, 413

spectabilis, Exeristesoides, Pimpla, 281 spectabilis, Xorides (Cyanoxorides), Moansa, 494

Sphalerus, 561

bifasciatus, 561

Spilopteron, 546 (key), 568, 605 (fig.)

formosum, 569 (key), 571, 615 (fig.)

formosum australe, 571 (key), 572, 573,624 (fig.)

formosum formosum, 571 (key), 572, 624 (fig.)

franclemonti, 569 (key), 570; and $605,615,624$ (figs.)

occiputale, 569 (key), 576, 624 (fig.)

vicinum, 569 (key), 573

vicinum melanderi, 573 (key), 575, 576

vicinum vicinum, 573 (key), 574 624 (fig.)

Spiloxorides, 494

erythrocephalus, 494

propodeum, 494

ruficeps, 494

rufipleuralis, 494

spinipes, Odontocolon, Odontomerus, 459

spinosa, Polysphincta, 190

spuria, Coccygomimus, Pimpla, 338

stejnegeri, Odontocolon, Odontomerus, 459

stercorator, Iseropus, Ichneumon, 166 and 167 (key), 168; and 585, 627, 633 (figs.)

stercorator orgyiae, Iseropus, 167 (key), 168

stercorator stercorator, Iseropus, 167 (key), 168

sternata, Pseudorhyssa, 373

Sterotrichus, 502

pilicornis, 502

stigmapterus, Xorides (Xorides), Aco enitus, 492 (key), 525; and 609, $611,612,625$ (figs.)

stigmapterus floridanus, Xorides (Xorides), 526 (key), 527, 528

stigmapterus species group, Xorides, 492 (key), 522

stigmapterus stigmapterus, Xorides (Xorides), 526 (key), 527

$526527-60-44$ stigmata, Laufeia, Polysphincta, 220

strandi, Xorides (Xorides), Neoxylonomus, 502, 505

strangaliae, Odontocolon, Odontomerus, 451 and 452 (key), 485, 487

striatus, Odontomerus, 480

stricklandi, Coccygomimus, 314 and 315 (key), 339, $\$ 40,623$ (fig.)

strigis, Sinarachna pallipes, Polysphincta, Zatypota, 259 (key), 260, 620 (fig.)

Strongylopsis, 280, 312

stultor, Pimpla, 92

subtilis, Scambus (Scambus), 39 (key), 47,49

superba, Megarhyssa, Eurhyssa, Ichneumon, 415, 418

superbus, Arotes, 573

Symphylus, 230

hadrodactylus, 230, 233, 234

politus, 234

taeniatus, Dolichomitus, 113 and 114

(key), 118; and 626, 629, 631

(figs.)

taeniatus species group, Dolichomitus, 113 and 114 (key), 116

taitensis, Brachycyrtus, Vakau, 542

taiwana, Ephialtes, 302

taiwanensis, Epiurus, 160

Taiwatheronia, 302

mahasenae, 302

takewakii, Polysphincta, 236

tartarus, Xylonomus, 526

taschenbergi, Polysphincta, 246

tecumseh, Scambus (Scambus), 37 and 40 (key), 67; and 606, 608, 616 (figs.)

temnopleuris, Itoplectis, Ephialtes, 287

tenchozanus, Pimpla, Ephialtes, 102

tenebrator, Ichneumon, 427

tenebrosus, Scambus (Scambus), 38 and 39 (key), 60, 62, 608 (fig.)

tenuiabdominalis, Zabrachypus, Polysphincta, 225

tenuicornis, Coccygomimus, Pimpla, 313 (key), 330, 332, 623 and 625 (figs.)

tenuipes, Therion, 526

tenuiventris, Apistephialtes, Ephialtes, 87,88 (key), 89,91 ; and 625,626 , 630 (figs.) 
terebrans, Dolichomitus, Pimpla, 113 and 115 (key), 121, 124, 629 and 631 (figs.)

terebrans nubilipennis, Dolichomitus, 121, 122 (key)

terebrans terebrans, Dolichomitus, 122 (key), 124

terminalis, Anastelgis, 109, 110, 584 and 626 (figs.)

texana, Delomerista, Pimpla, 364 and $\$ 65$ (key), 609 and 612 (figs.)

texana, Oxyrrhexis carbonator, Polysphincta, 243 (key) 619 (fig.)

Thalessa, 415

clavator, 415

histrio, 415, 430

theridii, Polysphincta, 275

Therion tenuipes, 526

Theronia, 851 (key), 595 (fig.)

apicalis, 351

atalantae, 292, 351, 352 (key), 353, 595 and 610 (figs.)

atalantae, var. americana, 354

atalantae atalantae, 353 (key), 354

atalantae fulvescens, 353 (key), $₫ 54$, 357

atalantae gestator, 353 (key), 354

bicincta, 352 (key), 360, 361, 610 (fig.)

bicincta bicincta, 361 (key), \$62

bicincta floridana, 361 (key), 362

flavicans, 351

flavolineata, 351

fulvescens var. mellipennis, 354

hilaris, 352 (key), 35\%, 610 (fig.)

japonica, 354

laevigata, 351,358

lucida, 351

rufescens, 351

septemtrionalis, 352 (key), 359,361 , 610 (fig.)

tolteca, 351

Theroniini, 5 (key), 101, 350, 595 and 596 (figs.)

thomsoni, Odontocolon, Odontomerus, 454

thoracica, Coccygomimus, Pimpla, 315, 323

thoracica, Poemenia, Ephialtes, 377 (key), 379

thoracica, Polysphincta, Epimecis, 246

thurberiae, Calliephialtes, 81 (key), 8s, 617 (fig.) tibialis, Acrotaphus, Epimecis, 256

tibialis, Aplomerus, Platysoma, Anodontomerus, 440 (key), 444, 446, 601 (fig.)

tibialis, Odontomerus, 446

tinctipennis, Dolichomitus, Ephialtes, 129

tinctipennis, Labena, 531 (key), 536, 587

tolteca, Theronia, Neotheronia, 351

transgressus, Scambus (Scambus), Pimpla, 15, 37 and 40 (key), 65, 67, 608 (fig.)

Tricyphus elegans vulpinus, 532

tristis, Epirhyssa, Rhyssonota, 413

Troctocerus, 36

elegans, 36

Trogus pennator, 532

Tromatobia, 6, 7, 9 (key), 16, 101, 174, $217,219,586$ (fig.)

angens, 181

hübrichi, 174

lineiger, 178

notator, 175 (key), 185, 186, 618 and 633 (figs.)

oculatoria, 175

ovivora, 175 (key), 178, 627 and 633 (figs.)

ovivora ovivora, 179 (key), 180, 618 (fig.)

ovivora rufopectus, 179 (key), 18s, 185, 618 (fig.)

rufopectus, 362

variabilis, 174, 175 (key), 176; and $586,618,633$ (figs.)

zonata, 175 (key), 185, 618 and 633 (figs.)

Tromatobia generic subgroup, Pimplini, 7

Tromera, 36

pomorum, 36

tschitscherini, Dolichomitus, Ephialtes, 129

tuberculata, Oxyrrhexis, Polysphincta, 242

tuberculatus, Dolichomitus, Ichneumon, 113 and 115 (key), 124; and 626, 629, 631 (figs.)

tuberculatus species group, Dolichomitus, 113 and 115 (key), 121

tuberculatus jezoensis, Dolichomitus, Ephialtes, 125 (key), 127

tuberculatus tuberculatus, Dolichomitus, 125 (key) 
tuberosa, Polysphincta, 245, 246 (key), 251, 592 and 628 (figs.)

tuberosa bruneti, Polysphincta, 251 (key), 253, 620 (fig.)

tuberosa tuberosa, Polysphincta, 251 (key)

turionellae, Coccygomimus, Ichneumon, Pimpla, Oxypimpla, 311, 312, 323 turionellae species group, Coccygomimus, 323

uchidai, Acropimpla, Charitopimpla, 160

Vakau, 542

taitensis, 542

vancouverensis, Ephialtes, 377

vancouveriensis, Euxorides, 377

variabilis, Tromatobia, Pimpla, 174, 175 (key), 176; and 586, 618, 633 (figs.)

variabilis species group, Tromatobia, 175 (key), 176

varians, Coccygomimus, 314 (key), 332, SBS

variatipes, Apistephialtes, Ephialtes, 88 and 89 (key), 91; and 625, 626, 630 (figs.)

varipes, Zaglyptus, Polysphincta, 188 (key), 189; and 586, 627, 633 (figs.)

varipes incompletus, Zaglyptus, 189 (key), 190, 618 (fig.)

varipes varipes, Zaglyptus, 189 (key)

venatrix, Polysphincta, 247

venustus, Arotes, 573

vesca, Itoplectis, 282 (key), 297, 622 (fig.)

vesicarius, Scambus (Scambus), Pimpla, 37 and 39 (key), 48

vesicarius euurae, Scambus (Scambus), 15, 49 (key), 50; and 606, 607, 616 (figs.)

vesicarius vesicarius, Scambus (Scambus), 15, 48 (key), 49, 616 (fig.)

vesicarius species group, Scambus (Scambus), 38 (key), 46

viatrix, Eruga, Acrodactyla, 238

vicina, Polysphincta, 243

vicinum, Odontocolon, Odontomerus, 450 and 453 (key), 487

vicinum, Spilopteron, 569 (key), 578 vicinum melanderi, Spilopteron, 573 (key), 575, 576

vicinum vicinum, Spilopteron, 573 (key), 574, 624 (fig.)

vidua, Pimpla, 179

viduata, Itoplectis, Pimpla, 282 (key), 293, 294, 621 (fig.)

viridescens, Coccygomimus, Pimpla, 315

vitalisi, Xorides (Epixorides) Cyanoxorides, 495

vitiosus, Xorides (Xorides), Xylonomus, 503,515

vitticrus, Dolichomitus, 114 and 116 (key), 148, 150, 629 and 632 (figs.)

vittifrons, Podoschistus, Xorides, 388, 597 (fig.)

vittifrons schlingeri, Podoschistus, 388 (key)

vittifrons vittifrons, Podoschistus, 388 (key), 389

vulpinus, Tricyphus elegans, 532

walleyi, Zatypota, 264 (key), 272, 273

walshii, Pimpla, 287

waterloti, Coccygomimus, Pimpla, Opodactyla, 311

watsoni, Exeristoidea, Ichneumon, 111, 127

wiltii, Acrotaphus, Epimecis, 256, 257, 592 and 620 (figs.)

winnemanae, Neotheronia, 359

Xanthephialtes, 7

Xanthocharops primus, 542

Xanthophenax, 7

Xanthopimpla, 5, 280

xanthothorax, Pimpla, Calliephialtes, 80,85

Xorides, 438 (key), 489, 602 (fig.)

(Cyanoxorides) abaddon, 494

(Gonioprymnus) aciculatus, 495

(Xorides) albopictus, 492 (key), 517,518 ; and 609, 611, 612, 624, 627 (figs.)

alpensis, 387

(Cyanoxorides) antennalis, 494

(Periceros) antennalis, 501

(Xorides) ater, 502, 510

(Xorides) atrox, 492 (key), 520, 521

(Xorides) boharti, 493 (key), 507, 508

borealis, 392 
Xorides-Continued

(Cyanoxorides) brookei, 494

(Epixorides) caerulescens, 494

(Cyanoxorides) caeruleus, 494

(Xorides) calidus, 492 (key), 516, 517

(Xorides) californicus, 493 (key), 524

canadensis, 518

caryae, 394

(Xorides) centromaculatus, 503, 515

(Epixorides) chalybeator, 494

(Xorides) cincticornis, 493 (key), 528

(Xorides) cincticornis cincticornis, 528 (key), 529

(Xorides) cincticornis rufus, 528 (key), 529, 530

collaris, 390

(Gonophonus) corcyrensis, 494

(Cyanoxorides) crudelis, 494

(Xorides) eastoni, 493 (key), 512, 513

(Epixorides) elizabethae, 494, 495

(Epixorides) erythrothorax, 495

(Gonophonus) exquisitus, 494

(Gonophonus) fasciipennis, 494

(Xorides) filiformis, 502

(Cyanoxorides) formosanus, 494

(Epixorides) fracticornis, 495

(Xorides) frigidus, 493 (key), 503, 504; and 609, 610, 611, 624 (figs.)

(Epixorides) fulgidipennis, 495

(Xorides) fuligator, 502

(Xorides) gracilicornis, 502

(Xorides) harringtoni, 492 (key), 523, 524, 611 and 625 (figs.)

(Xorides) holsaticus, 503

(Exomus) humeralis, 492 (key), 496 ; and 609, 610, 611 (figs.)

(Exomus) humeralis chiricensis, 497 (key), 500, 501

(Exomus) humeralis excomptus, 497 (key), 500

(Exomus) humeralis humeralis, 497 (key), 498

(Exomus) humeralis mexicanus, 497 (key), 498

(Exomus) humeralis piceatus, 497 (key), 498

(Exomus) humeralis sierrae, 497 (key), 500
Xorides-Continued

indicatorius, 501

(Xorides) insularis, 493 (key), 513, 514 ; and 609, 611, 612, 624 (figs.)

(Moerophora) investigator, 496

(Xorides) irrigator, 501

(Moerophora) jakolevi, 496

(Moerophora) jezoensis, 496

(Xorides) kinduensis, 502

(Gonioprymnus) maculiceps, 495

(Cyanoxorides), maculipennis, 494 matsuyamensis, 390

(Xorides) maudae, 492 (key), 521

(Xorides) medius, 493 (key), 511,

512 ; and 609, 611, 612, 624 (figs.)

(Gonioprymnus) mirabilis, 495

(Xorides) neoclyti, 492 (key), 521, 522; and 609, 611, 612 (figs.)

nitens, 390

occidentalis, 392

(Xorides) ornatus, 503, 515

(Xorides) peniculus, 494 (key), 506, 507, 609 and 624 (figs.)

(Xorides) pictus, 493 (key), 504, 505 ; and 609, 610, 612, 624 (figs.)

(Xorides) planus, 493 (key), 510, 511

(Periceros) plumicornis, 501

(Moansa) praestans, 495

(Gonophonus) propinquus, 494

(Cyanoxorides), propodeum, 494

(Xorides) rileyi, 493 (key), 508, 510 ; and 609, 610, 612, 624 (figs.)

(Xorides) rudis, 493 (key), 510

(Cyanoxorides) ruficeps, 494

(Moerophora) rufipes, 495, 496

(Cyanoxorides) rufipleuralis, 494

(Epixorides) rufomaculata, 495

(Gonophonus) scaber, 494

scutellaris, 387

(Xorides) semirufus, 494 (key), 506, 507

(Cyanoxorides) smithi, 494

(Cyanoxorides) spectabilis, 494

(Xorides) stigmapterus, 492 (key), 525 ; and 609, 611, 612, 625 (figs.)

(Xorides) stigmapterus floridanus, 526 (key), 527, 528

(Xorides) stigmapterus stigmapterus, 526 (key), 527

(Xorides) strandi, 502 


\section{Xorides-Continued}

(Epixorides) vitalisi, 495

(Xorides) vitiosus, 503, 515 vittifrons, 387,389

Xorides (Cyanoxorides), 491 (key), 494 (Epixorides), 491 (key), 494

(Exomus), 491 and 492 (key), 496 (Gonioprymnus), 491 (key), 495

(Gonophonus), 491 (key), 494

(Moansa), 491 (key), 495

(Moerophora), 491 (key), 495

(Periceros), 491 (key), 501

(Pyramirhyssa), 491 (key), 530

(Xorides), 491 and 492 (key), 501

Xorides (Xorides) albopictus, 492 (key), 517,518 ; and $609,611,612,624$, 627 (figs.)

ater, 502,510

atrox, 492 (key), 520, 521

boharti, 493 (key), 507, 508

calidus, 492 (key), 516, 517

californicus, 493 (key), 524

centromaculatus, 503, 515

cincticornis, 493 (key), 528

cincticornis cincticornis, 528 (key), 529

cincticornis rufus, 528 (key), 529, 580

eastoni, 493 (key), 512, 513

filiformis, 502

frigidus, 493 (key), 503, 504; and $609,610,611,624$ (figs.)

fuligator, 502

gracilicornis, 502

harringtoni, 492 (key), 523, 524, 611 and 625 (figs.)

holsaticus, 503

insularis, 493 (key), 513, 514; and 609, 611, 612, 624 (figs.)

irrigator, 501

konduensis, 502

maudae, 492 (key), 521

medius, 493 (key), 511, 512; and 609, 611, 612, 624 (figs.)

neoclyti, 492 (key), 521, 522; and $609,611,612$ (figs.)

ornatus, 503,515

peniculus, 494 (key), 506, 507, 609 and 624 (figs.)

pictus, 493 (key), 504, 505; and 609, $610,612,624$ (figs.)

planus, 493 (key), 510, 511
Xorides-Continued

rileyi, 493 (key), 508, 510; and 609, 610, 612, 624 (figs.)

rudis, 493 (key), 510

semirufus, 494 (key), 506, 507

stigmapterus, 492 (key), 525; and 609, 611, 612, 625 (figs.)

stigmapterus floridanus, 526 (key), 527,528

stigmapterus stigmapterus, 528

(key), 527

strandi, 502

vitiosus, 503,515

Xoridinae, 3, 4 (key), 486

Xoridini, 487 (key); and 600, 601, 602 (figs.)

xutha, Labena grallator, 532 (key), 534, 535

Xylonomimus, 502

gracilicornis, 490, 502

Xylonomus, 501

abaddon, 494

albopictus, 518

ater, 502

australis, 498

blanditor, 495

caerulescens, 494

californicus, 524

canadensis, 523

catomus, 524

cincticornis, 528

corcyrensis, 494

crudelis, 494

(Moerophora) duplicatus, 518

eastoni, 513

elizabethae, 495

fasciipennis, 494

filiformis, 502

fracticornis, 495

frigidus, 503

fulgidipennis, 495

gracilicornis, 502

investigator, 496

irrigator, 501

jakolevi, 496

jezoensis, 496

(Amphixylonomus) konduensis, 502

lavallensis, 498

(Xylonomus) lepturae, 508

lineatus, 496

(Moerophora) piceatus, 497

pilicornis, 502

(Xylonomus) plesius, 503 
Xylonomus-Continued

propinquus, 494

pulcher, 515

rileyi, 508

(Xylonomus) ruficoxis, 508

rufipes, 496

scaber, 494

tartarus, 526

vitiosus, 503, 515

(Moerophora) yukonensis, 503

yakutatensis, Pimpla, 324

Yezoceryx, 545 (key), 578, 606 (fig.)

rupinsulensis, $578,579,606$ (fig.)

scutellaris, 578

yezoensis, Acropimpla, Pimpla, 160

yukonensis, Xylonomus (Moerophora), 503

Zabrachypus, 220 (key), 228, 589 (fig.) nikkoensis, 228

primus, 228, 229; and 589, 619, 628 (figs.)

tenuiabdominalis, 225

Zaglyptus, 6, 7, 9 (key), 188, 218, 219, 586 (fig.)

arizonicus, 189 (key), 192, 193, 618 (fig.)

kincaidii, 235

koebelei, 253

pictilis, 189 (key), 193, 194, 618 and 633 (figs.)

simonis, 193

varipes, 188 (key), 189; and 586, 627, 633 (figs.)

varipes incompletus, 189 (key), 190, 618 (fig.)

varipes varipes, 189 (key)
Zatypota, 220 (key), 262, 593 (fig.)

alborhombarta, 265 (key), 278, 279 , 621 (fig.)

arizonica, 264 (key), 270, 271, 621 (fig.)

bohemani, 264 (key), 265, 267, 620 and 628 (figs.)

braucheri, 273

californiensis, 273

cingulata, 264 (key), 270, 621 (fig.)

crassipes, 265 (key), 278, 621 (fig.)

crosbyi, 273

discolor, 263

exilis, 264 (key), 269, 270, 621 (fig.)

eximia, 263

favosa, 264 (key), 267, 269, 620

(fig.)

inexpectata, 263

japonica, 263

luteipes, 275 (key), 276, 277, 621 (fig.)

nigriceps, 264 (key), 273, 621 and 628 (figs.)

parva, 264 (key), 266, 267, 620 (fig.)

patellata, 264 (key), 267, 268, 620

(fig.)

percontatoria, 262, 265 (key), 275, 276, 593 and 621 (figs.)

picticollis, 264

prima, 263

pulchrator, 264

strigis, 260

walleyi, 264 (key), 272, 273

zonata, Tromatobia, Clistopyga, 175 (key), 185, 618 and 633 (figs.)

Zonopimpla, 8

\section{HOSTS}

abbotii, Oiketicus, 292

abdominalis, Xiphydria, 413

Abies, 13, 40, 161, 162, 458, 466, 560

amabilis, 13, 515

balsamea, 271, 404, 406, 409

concolor, 13, 43, 145, 148, 309, 337,

$375,380,391,409,420,515$

grandis, 13, 420, 466

lasiocarpa, 124, 393, 403, 406, 420, 499

magnifica, $157,420,447$ abietis, Neodiprion, 368

Acanthocinus, 146

Acer, 140, 389, 434, 469, 527

negundo, 434, 499, 518

rubrum, 411, 424, 427, 434

aceriella, Cameraria, 208

acerifoliella, Paraclemensia, 76, 208

Acleris, 70, 291

hastiana, 291

minuta, 291

variana, $67,286,298$ 
acorns, 96

Acrobasis, 292

betulella, 73, 165, 291

caryivorella, 292

comptoniella, 73

hebescella, 86

juglandis, 86, 292

kearfottella, 292

rubrifasciella, $73,86,373$

aculeate $\mathrm{Hymenoptera,} 209$

Adelges, 271

aereus, Phymatodes, 509

agassizi, Xylocrius, 134

Agelenopsis, 203

agrifolia, Quercus, 387

Alabama argillacea, 292, 335, 344

alacris, Thrincopyge, 534

Alaus oculatus, 525

alba, Quercus, 424, 434, 534

albicapitana, Petrova, 13

albicornis, Uroceros, 404

albolineana, Taniva, 286

"Aletia," 344

Alnus, 275, 458

amabilis, Abies, 13, 515

amatella, Dioryctria, 13

ambigualis, Lascoria, 292

Ambrosia, 83, 86

americana, Apatela, 321

americana, Ceanothus, 320

americana, Prunus, 117

americana, Ulmus, 389, 499, 519

americanum, Malacosoma, 174, 292, 321, 356

Amorbia humerosana, 76

“amorphella", Walshia, 83

Anacampsis, 165

Anarsia lineatella, 339

Ancylis comptana, 286, 294

Andricus, 96

Aneflomorpha, 537

angulatus, Araneus, 183

angustus, Calopus, 197

Anisota rubicunda, 73, 292

annosus, Xylotrechus, 140

anobiid larva, 458

Anomis erosa, 292

Anoplodera nigrella, 575

nitens, 509

proxima, 140, 527

vittata, 568

anthomyid larva, 43

Anthonomis grandis thurberiae, 84
Anthophila pariana, 57, 67, 73, 286

anthracina, Peghylemyia, 45

antiqua, Orgyia, 292, 308

antiquua badia, Orgyia, 321

Apatela, 321

americana, 321

apple, 76, 84, 170, 277

Araneus angulatus, 183 diadema, 183

Archips, 292

argyrospilus, 165, 286, 292, 321

cerasivoranus, 292

fervidanus, 292

rosanus, $67,73,286$

arctiid cocoon, 321

areolatus, Sirex, 401, 409

argentata, Argiope, 183

argillacea, Alabama, 292, 335, 344

Argiope argentata, 183

aurantia, 184, 362

avara, 183

trifasciata, 184

argutanus, Episimus, 74, 165

argyrospilus, Archips, 165, 286, 292, 321

Argyrotaenia, 286

pinatubana, 165, 292

quercifoliana, 292

arizonica, Quercus, 522

Arthrochlamys bebbianae, 73

Asemum nitidum, 157

Astylopsis macula, 518

attenuata, Pinus, 384

Attus, 189

aurantia, Argiope, 184, 362

auranticella, Dioryctria, 13

Autographa californica, 294

avocado, 84

avara, Argiope, 183

baccharisella, Gnorimoschema, 83, 96

bagworm, 86

balsamea, Abies, 271, 404, 406, 409

Baptisia, 86

Barbara, 296

colfaxiana siskiyouana, 13, 43, 296

colfaxiana taxifoliella, 13, 296

mappana, 296

beach pea, 57

bebbianae, Arthrochlamys, 73

bee stem, 213

Bellamira scalaris, 573

berlandieri, Lycium, 536, 537 
Betula lenta, 564

lutea, 523

nigra, 489, 573

betulella, Acrobasis, 73, 165, 291

bicolor, Lexis, 74

bicolor, Strangalina, 578

bidentata, Tomoxia, 566

black oak, 509

bolliana, Gretchena, 348

borealis, Steatoda, 245

bruchid, 83

brunnea, Parandra, 469

bud moth, 286

budworm, 199

buoliana, Rhyacionia, 13, 70, 74, 286, 292,296

buprestid, 389, 444, 489

buprestid gallery, 393, 447

Buprestidae, 399

Buprestis confluens, 134

viridisuturalis, 525

"Cacoecia," 305

calcarata, Saperda, 136

californica, Autographa, 294

californica, Phryganidia, 297

californica, Pontania, 51

californica, Salix, 51

californicum, Malacosoma, 171, 356

californicus, Nymphalis, 356

californiensis, Cyrtophora, 183

Calopus angustus, 197

cambiicola, Dioryctria, 296

Cameraria aceriella, 208

canadensis, Cercis, 109

canadensis, Picea, 45, 63, 109, 159

canadensis, Tsuga, 406, 421, 568

Canarsia ulmiarrosorella, 93

canosaria, Nepytia, 310

capitata, Malachra, 349

caprea, Neoclytus, 522

carmelita, Thalpochares, 373

Carmenta texana, 86

carnifex, Cheiracanthium, 224

caroliniana, Carpinus, 413

carota, Daucus, 292, 320

Carpinus, 291, 413

caroliniana, 413

Carpocapsa pomonella, 88, 93, 96, 286, $334,337,344,348$

Carya, 13, 86, 140, 394, 424, 429, 434, $499,509,519,527,535,566$

glabra, 394 caryae, Halisidota, 320, 359

caryana, Laspeyresia, 13, 86

caryivorella, Acrobasis, 292

Cassia, 499

Castanea dentata, 117, 140, 389, 391, $394,509,518$

castella, Euceratia, 286

catenaria, Cingilia, 292

ceanothiella, Stagmatophora, 86

Ceanothus, 292

americana, 320

cuneatus, 254

cedar, 420,515

Celtis, 434 occidentalis, 507

Cephus cinctus, 23

pygmaeus, 23

cerambycid, 515,566

cerasivoranus, Archips, 292

Ceratina, 539

dupla, 540

Cercidium, 119

Cercis canadensis, 109

Cercocarpus parvifolius, 117, 447

Chamaecyparis lawsoniana, 515

chaparral, 536

Cheiracanthium, 189

carnifex, 224

Chion, 534

Choristoneura conflictana, 60, 70, 292, 305

fumiferana, $13,60,67,70,73,76$, $161,162,165,286,292,296,307$, 310,356

pinus, 73, 286, 292, 296

rosaceana, $165,170,292,294,305$, 307

Chrysobothris, 420

edwardsii, 119

impressa, 534

Chrysopa lateralis, 543

chrysopid, 544

Chrysopora stipella var. naeviferella, 76

Cicuta maculata, 320

cicutaella, Epermenia, 292

cinctus, Cephus, 23

Cingilia catenaria, 292

cingulatus, Oncideres, 292

cinnamopterum, Tetropium, 109, 159, 375

Cirsium lanceolatum, 292

clarus, Epargyreus, 321

Clubiona, 189 
Cnephasia longana, 286

codlin moth, 88

Coleophora laricella, 298

pruniella, 74, 76, 292

salmani, $76,327,344$

Coleoptera, 375, 449

colfaxiana siskiyouana, Barbara, 13, 43, 296

colfaxiana taxifoliella, Barbara, 13, 296

Colias eurytheme, 294

columba, Tremex, 424, 427, 429, 434

commutata, Euphorbia, 292

comptana, Ancylis, 286, 294

comptoniella, Acrobasis, 73

comstockiana, Petrova, 13

concolor, Abies, 13, 43, 145, 148, 309, $337,375,380,391,409,420,515$ concolor, Pemphredon, 213

concolor, Saperda, 136

cones, 13, 40, 43, 45, 62, 63, 377, 384

conflictana, Choristoneura, 60, 70, 292, 305

confluens, Buprestis, 134

conicola, Paratimia, 384

connectum, Exartema, 74

Conotrachelus nenuphar, 86

consputa, Melanophila, 91

contorta, Pinus, 13, 52, 124, 286, 387, $445,462,549$

contorta murrayana, Pinus, 403, 420

Corcina quercana, 286

Cornus, 70, 165

Corylus, 96, 356

Coryphista meadi, 344

costata, Oeme, 148

cryptopoda, Razoumotskya, 13

Ctenucha virginica, 170, 321

cunea, Hyphantria, 292

cuneatus, Ceanothus, 254

cupressana, Laspeyresia, 13

Cupressus macrocarpa, 515

cynipid galls, 84, 96, 387

Cyrtophora californiensis, 183

Daucus carota, 292, 320

decurrens, Libocedrus, 99, 393, 515

Dendroctonus, 445, 462

dentata, Castanea, 117, 140, 389, 391, 394, 509, 518

Depressaria, 286

desertana, Epiblema, 83

desmodioides, Pontania, 51

Diacrisia virginica, 337 diadema, Araneus, 183

diademata, Epeira, 260

Diaphania hyalinata, 292

Dicerca divaricata, 489, 524

obscura, 499

Dichomeris marginella, 292

Dictyna volupis, 262

Dioryctria amatella, 13

auranticella, 13

cambiicola, 296

reniculella, 45, 63, 286, 292

zimmermani, 13

Diospyros virginiana, 499

Diprion frutetorum, 368

hercyniae, 321,368

nipponicus, 368

similis, 368

Diprionidae, 363

Diptera, 286

discoidea, Saperda, 140, 394, 519

Disholcaspis, 84

eldoradensis, 96

truckeensis, 387

dispar, Porthetria, 356

disstria, Malacosoma, 74, 165, 170, 174, $199,286,292,294$

distichum, Taxodium, 535

divaricata, Dicerca, 489, 524

dodecella, Exotelia, 70

drummondi, Melanophila, 145, 393, 515

Dryobius sexfasciatus, 527

dubius, Pissodes, 123

dupla, Ceratina, 540

dyspteraria, Meskea, 86

edulis, Pinus, 13, 148, 399, 409, 515

edwardsii, Chrysobothris, 119

Elaphidion incertum, 140

parallelum, 140

villosum, 140

eldoradensis, Disholcaspis, 96

eloisella, Mompha, 31, 35

Endothenia hebesana, 70

engelmanni, Picea, 99, 124, 391, 515

engelmanni, Pissodes, 123

Ennomus subsignarius, 292

Enoclerus sphegeus, 98, 99

Epargyreus clarus, 321

Epeira, 184

diademata, 260

quadrata, 260

scolopetaria, 254

strix, 254, 261 
Epeira-Continued

trivittata, 257

Epermenia cicutaella, 292

ephemeraeformis, Thyridopteryx, 86, 292

Epiblema desertana, 83

otiosana, 31

strenuana, 31,83

Episimus argutanus, 74, 165

ericaceous shrubs, 227

erosa, Anomis, 292

Eublemma ninima, 373

Euceratia castella, 286

Euphorbia commutata, 292

europea, Larix, 144

eurytheme, Colias, 294

Euura, 51

Exartema connectum, 74 olivaceanum, 373

excelsa, Picea, 381

Exotelia dodecella, 70

Exyra semicrocea, 292

faginella, Psilocorsis, 327

Fagus, 86, 140, 424, 429, 434, 484, 519

fasciatus, Pissodes, 123

fervidanus, Archips, 292

fiscellaria, Lambdina, 310, 327

fiscellaria lugubrosa, Lambdina, 286

fiscellaria somniaria, Lambdina, 320, 323,356

flavibasana, Sparganothis, 292

forficaria, Prochoerodes, 337

Fouquiera, 119

fragile, Malacosoma, 171, 292, 294, 321, 337,356

Fraxinus, 140, 165, 499, 564

oregona, 296

frustrana, Rhyacionia, 13, 292

frustrana bushnelli, Rhyacionia, 65, 292, 339

frutetorum, Diprion, 368

fumiferana, Choristoneura, 13, 60, 67, $70,73,76,161,162,165,286,292$, $296,307,310,356$

fumiferanae, Glypta, 60, 161

gabrieli, Tetropium, 144

gallae-asteriella, Gnorimoschema, 83

gallaesolidaginis, Gnorimoschema, 83

galls, $47,50,51,67,80,83,86,96$

garryana, Quercus, 79

"Gelechia," 83
Gelechia tragicella, 363

Geometridae, 305

gibbicollis, Ptosima, 109

glabra, Carya, 394

glauca, Picea, 63

glauca albertinana, Picea, 13

Glypta fumiferanae, 60, 161

Gnorimoschema baccharisella, 83, 96

gallae-asteriella, 83

gallaesolidaginis, 83

gossypiella, Pectinophora, 87

Gossypium thurberi, 84

Gracillaria, 76, 79, 286

rhoifoliella, 165

grandella, Hypsipyla, 87

grandis, Abies, 13, 420, 466

grandis thurberiae, Anthonomis, 84

Graphisurus, 140

Grapholitha molesta, 86, 93, 292, 344, 348

packardi, 67

Gretchena bolliana, 348

haimbachi, Zelleria, 52

Halisidota, 170, 359

caryae, 320,359

hastata, Rheumaptera, 292

hastiana, Acleris, 291

hawthorn, 76

hebesana, Endothenia, 70

hebescella, Acrobasis, 86

Hedia variegana, 74

Helianthus, 321

Hemerocampa, 292

leucostigma, 75, 170, 174, 292, 309, 321

pseudotsugata, 294

vetusta, 170,337

Hemileuca, 292, 337

oliviae, 294

henrici, Simyra, 170, 292

Heracleum lanatum, 320

hercyniae, Diprion, 321,368

Heterarthrus nemoratus, 74, 208

heterophylla, Tsuga, 13, 515

hickory, 117

humerosana, Amorbia, 76

hyalinata, Diaphania, 292

Hyaloscotes sheppardi, 292

Hylobius pinicolus, 126

Hylotrupes ligneus, 515

Hyphantria cunea, 292

Hypsipyla grandella, 87 
ichneumonid, 356

ichneumonid larva, 269

Ilex, 499

impressa, Chrysobothris, 534

incertum, Elaphidion, 140

inermis, Megachile, 106

inornatus, Pemphredon, 213

Iris, 31

jeffreyi, Pinus, 13, 420

juglandis, Acrobasis, 86, 292

Juglans, 96

juniper, 544

Juniperus, 399, 518

scopulorum, 393, 522

kearfottella, Acrobasis, 292

laboriosa, Tetragnatha, 237

Lambdina fiscellaria, 310,327

fiscellaria lugubrosa, 286

fiscellaria somniaria, 320, 323, 356

lambertiana, Pinus, 98

lamed, Pachyta, 140

lanatum, Heracleum, 320

lanceolatum, Cirsium, 292

laricella, Coleophora, 298

Larix, 124, 375, 393

europea, 144

Lascoria ambigualis, 292

Lasiocampidae, 166

lasiocarpa, Abies, 124, 393, 403, 406, 420,499

lasiolepis, Salix, 51

Laspeyresia, 13, 41, 57

caryana, 13,86

cupressana, 13

molesta, 74

nigricana, 57,348

toreuta, 13, 384, 393

youngana, 13,45

lateralis, Chrysopa, 543

laurel, 471

lawsoniana, Chamaecyparis, 515

legumes, 58

lenta, Betula, 564

lepidopterous pupae, 302, 321, 346

Leptura, 140, 486, 564

obliterata, 466

Leucania linita, 321

leucostigma, Hemerocampa, 75, 170, $174,292,309,321$ levisella, Trichotaphe, 70

Lexis bicolor, 74

Libocedrus decurrens, 99, 393, 515

ligneus, Hylotrupes, 515

ligneus, Semanotus, 145

limata, Pantographa, 165

limbata, Nematocampa, 292

limitata, Pandemis, 165

lineatella, Anarsia, 339

lineatus, Stenocorus, 140

linita, Leucania, 321

Linyphia phrygiana, 233

Liquidamber, 573

Liriodendron, 564

live oak, 321

lobata, Quercus, 96

longana, Cnephasia, 286

Lonicera, 292

looper, 308

Lotus, 83

lunatum, Theridium, 260

lutea, Betula, 523

luteicornis, Strangalina, 486

Lycium berlandieri, 536, 537

Lymantriidae, 166

Lymnaecia phragmitella, 70

Macremphytus, 213

macrocarpa, Cupressus, 515

Macrocentrus, 300

macula, Astylopsis, 518

maculata, Cicuta, 320

maculata, Xiphydria, 411

maculosus, Monochamus, 120

magnifica, Abies, 157, 420, 447

Malachra capitata, 349

Malacosoma, 286, 292, 294, 320, 337, 356

americanum, 174, 292, 321, 356

californicum, 171,356

disstria, 74, 165, 170, 174, 199, 286, 292, 294

fragile, $171,292,294,321,337,356$

pluviale, 70, 79, 171

Malus, 174,275

mappana, Barbara, 296

marcellus, Papilio, 292

marginella, Dichomeris, 292

mariana, Picea, 63, 375

meadi, Coryphista, 344

Megachile inermis, 106

nivalis, 106

Megacyllene pictus, 140

Melandrya striata, 140, 564 
Melanophila, 375, 515

consputa, 91

drummondi, $145,393,515$

Melanopus spretus, 83

menapia, Neophasia, 356

menziesii, Pseudotsuga, 393

Meskea dyspteraria, 86

Meta reticulata, 237

Metallus rohweri, 74

rubi, 174

milleri, Recurvaria, 65, 298

Mineola, 344

minima, Eublemma, 373

minuta, Acleris, 291

moesta, Saperda, 134, 136

molesta, Grapholitha, 86, 93, 292, 344, 348

molesta, Laspeyresia, 74

Mompha eloisella, 31, 35

Monochamus, 375

maculosus, 120

scutellatus, 126

Mononychus vulpeculus, $31,363,373$

montana, Pinus, 145

monticola, Pinus, 515

mud wasp, 174

murrayana, Pinus, 13, 157, 197

negundo, Acer, 434, 499, 518

Nematocampa limbata, 292

Nematus, 51

nemoratus, Heterarthrus, 74, 208

nenuphar, Conotrachelus, 86

Neoclytus, 499

caprea, 522

Neodiprion, 286, 346, 368

abietis, 368

tsugae, 286,368

Neophasia menapia, 356

Nepytia canosaria, 310

phantasmaria, 286, 356

Neuroptera, 300

ni, Trichoplusia, 292

nicolas, Semanotus, 148

nigra, Betula, 489, 573

nigrella, Anoplodera, 575

nigrella, Stomopteryx, 65

nigricana, Laspeyresia, 57, 348

nigriventris, Thanasimus, 99

nipponicus, Diprion, 368

nitens, Anoplodera, 509

nitidum, Asemum, 157

nivalis, Megachile, 106
Noctuidae, 305,321

noctuids, 165

Notodontidae, 166

nubilalis, Pyrausta, 216, 292, 346

nuts, $13,80,86,96$

Nymphalis californicus, 356

oak apple, 96

oak gall, 387

oat stem, 23

obliterata, Leptura, 466

oblongifolia, Quercus, 84

Obrium rufulum, 140

obscura, Dicerca, 499

obtusa, Tetragnatha, 237

occidentalis, Celtis, 507

occidentalis, Platanus, 213

ocellana, Spilonota, 57, 70, 71, 74, 76, $165,286,292$

oculatus, Alaus, 525

Oeme costata, 148

Oiketicus abbotii, 292

Olene, 174

plagiata, 321

olivaceanum, Exartema, 373

oliviae, Hemileuca, 294

Oncideres cingulatus, 292

oregona, Fraxinus, 296

Oreta rosea, 356

“Orgyia," 75, 321

Orgyia antiqua, 292, 308

antiquua badia, 321

otiosana, Epiblema, 31

Pachyta lamed, 140

packardi, Grapholitha, 67

pallipes, Phobocampe, 292

Pandemis limitata, 165

Pantographa limata, 165

Papilio marcellus, 292

Paraclemensia acerifoliella, 76, 208

parallelum, Elaphidion, 140

Parandra brunnea, 469

Paranthrene robiniae perlucida, 525

Paratimia conicola, 384

pariana, Anthophila, 57, 67, 73, 286

parryana, Picea, 515

parvifolius, Cercocarpus, 117, 447

Pastinaca sativa, 320

pecan, 117

Pectinophora gossypiella, 87

Peghylemyia anthracina, 45 
Pemphredon, 213

concolor, 213

inornatus, 213

unicolor, 216

periscelidactylus, Pterophorus, 292

petiolaris, Salix, 51

Petrova, 13

albicapitana, 13

comstockiana, 13

pettitana, Sparganothis, 292

Phalonia rutilana, 70, 76

phantasmaria, Nepytia, 286, 356

Phobocampe, 300

pallipes, 292

phragmitella, Lymnaecia, 70

Phryganidia californica, 297

phrygiana, Linyphia, 233

Phycis rubrifasciella, 373

Phylloxera, 86

Phymatodes aereus, 509

testaceus, 509

varius, 499

Picea, 13, 40, 162, 199, 393, 406, 458, 560

canadensis, 45, 63, 109, 159

engelmanni, 99, 124, 391, 515

excelsa, 381

glauca, 63

glauca albertinana, 13

mariana, 63, 375

parryana, 515

pungens, 62,63

sitchensis, 13, 403, 406, 420, 515

pictipes, Synanthedon, 348

pictus, Megacyllene, 140

Pieris rapae, 292

pinatubana, Argyrotaenia, 165, 292

pine tussock, 170

pinicolus, Hylobius, 126

Pinus, 13, 127, 398

attenuata, 384

contorta, $13,52,124,286,387,445$, 462,549

contorta murrayana, 403, 420

edulis, 13, 148, 399, 409, 515

jeffreyi, 13,420

lambertiana, 98

montana, 145

monticola, 515

murrayana, 13, 157, 197

ponderosa, 13, 105, 109, 145, 157, $375,379,393,401,409,420$,

515,525

radiata, 91,444
Pinus-Continued

rigida, 535

scopulorum, 13, 145, 157, 393, 409, 529

strobus, 13, 535

sylvestris, 13

tuberculata, 384

virginiana, 13, 124, 271, 398, 544

pinus, Choristoneura, 73, 286, 292

Pisaurina, 224

Pissodes, 13, 124

dubius, 123

engelmanni, 123

fasciatus, 123

rotundatus, 123

strobi, 13, 124

plagiata, Olene, 321

Platanus occidentalis, 213

Platyptilia, 286

Plectrura spinicauda, 151

plicata, Thuja, 515

pluviale, Malacosoma, 70, 79, 171

Polychrosis viteana, $57,292,344$

pomonella, Carpocapsa, 88, 93, 96, 286, $334,337,344,348$

ponderosa, Pinus, 13, 105, 109, 145, 157, $375,379,393,401,409,420,515$, 525

Pontania, 50, 51, 96

californica, 51

desmodioides, 51

populnea, Saperda, 137

Populus, 106, 458

tremuloides, 134, 136, 141

trichocarpa, 134, 525

Porthetria dispar, 356

Prochoerodes forficaria, 337

Prosopis, 119

proteus, Urbanus, 292

proxima, Anoplodera, 140, 527

pruniella, Coleophora, 74, 76, 292

Prunus americana, 117

Pseudotsuga, 99, 444

menziesii, 393

taxifolia, 13, 109, 124, 145, 286, 296, $392,393,409,420,515,521,549$

pseudotsugata, Hemerocampa, 294

Psilocorsis, 74

faginella, 327

Pteronea, 286

Pterophoridae, 286

Pterophorus periscelidactylus, 292

Ptosima gibbicollis, 109 
punctata, Synchroa, 140

puncticollis, Saperda, 534

pungens, Picea, 62, 63

pygmaeus, Cephus, 23

Pyrausta nubilalis, 216, 292, 346

pyraustid, 321

pyri, Thamnosphecia, 348

quadrata, Epeira, 260

quercana, Corcina, 286

quercifoliana, Argyotaenia, 292

Quercus, 83, 96, 117, 140, 305, 389, 499, $509,524,535,578$

agrifolia, 387

alba, 424, 434, 534

arizonica, 522

garryana, 79

lobata, 96

oblongifolia, 84

undulata, 96

wializenii, 387

radiata, Pinus, 91, 444

Ramosia tipuliformis, 140

rapae, Pieris, 292

Razoumotskya cryptopoda, 13

Recurvaria, 65, 70

milleri, 65, 298

red haw, 84

reniculella, Dioryctria, 45, 63, 286, 292 reticulata, Meta, 237

reversalis, Tholeria, 337

Rheumaptera hastata, 292

Rhogas terminatus, 292

rhoifoliella, Gracillaria, 165

Rhus, 216

Rhyacionia, 13

buoliana, 13, 70, 74, 286, 292, 296

frustrana, 13, 292

frustrana bushnelli, $65,292,339$

rigidana, 13

Ribes, 134

rigida, Pinus, 535

rigidana, Rhyacionia, 13

robiniae perlucida, Paranthrene, 525

rohweri, Metallus, 74

Rosa, 216, 286, 535

rosaceana, Choristoneura, $57,165,170$, 292, 294, 305, 307

rosanus, Archips, 67, 73, 286

rosea, Oreta, 356

rotundatus, Pissodes, 123

rubi, Metallus, 174 rubicunda, Anisota, 73, 292

rubigalis, Udea, 339

rubrifasciella, Acrobasis, 73, 86, 373

rubrifasciella, Phycis, 373

rubrum, Acer, 411, 424, 427, 434

Rubus, 286

rufopectus, Tromatobia, 362

rufulum, Obrium, 140

rutilana, Phalonia, 70, 76

Rygchium, 109

Salebriaria tenebrosella, 348

Salix, 47, 50, 67, 86, 96, 119

californica, 51

lasiolepis, 51

petiolaris, 51

salmani, Coleophora, 76, 327, 344

salticid spider, 203

Sambucus, 213

Saperda calcarata, 136

concolor, 136

discoidea, 140, 394, 519

moesta, 134, 136

populnea, 137

puncticollis, 534

tridentata, 519

tulari, 134

Sassafras, 213

sativa, Pastinaca, 320

scalaris, Bellamira, 573

Sciaphila, 305

scolopetaria, Epeira, 254

Scolytus, 124, 515

scopulorum, Juniperus, 393, 522

scopulorum, Pinus, 13, 145, 157, 393, 409, 529

scutellatus, Monochamus, 126

seeds, 31

Semanotus ligneus, 145

nicolas, 148

semicrocea, Exyra, 292

Semiothisa, 332

sempervirens, Sequoia, 515

senoculata, Sergestria, 196

Sequoia sempivirens, 515

Sergestria senoculata, 196

sexfasciatus, Dryobius, 527

sheppardi, Hyaloscotes, 292

similis, Diprion, 368

Simyra henrici, 170, 292

sinensis, Vigna, 292

Sirex areolatus, 401, 409

siricid, 375, 420, 421 
Siricidae, 416 sitchensis, Picea, 13, 403, 406, 420, 515 slug larva, 174

Solidago, 320

Sparganothis, 292

flavibasana, 292

pettitana, 292

sulphureana, 70

sphegeus, Enoclerus, 98, 99

spice bush, 258

spider, 217,241

spider eggs, 175, 183, 186, 188, 189, 196, $199,218,362$

spider nest, 202

Spilonota ocellana, 57, 70, 71, 74, 76, 165, 286, 292

spinicauda, Plectrura, 151

spretus, Melanopus, 83

Stagmatophora ceanothiella, 86

Steatoda borealis, 245

Stenocorus lineatus, 140

Stenogaster, 352

stipella var. naeviferella, Chrysopora, 76

Stomopteryx nigrella, 65

Strangalina bicolor, 578

luteicornis, 486

strenuana, Epiblema, 31, 83

striata, Melandrya, 140, 564

strix, Epiera, 254, 261

strobi, Pissodes, 13, 124

strobus, Pinus, 13, 535

subsignarius, Ennomus, 292

sulphureana, Sparganothis, 70

sumac, 216, 540

sylvestris, Pinus, 13

Synanthedon pictipes, 348

Synchroa punctata, 140

Taniva albolineana, 286

taxifolia, Pseudotsuga, 13, 109, 124, 145, $286,296,392,393,409,420,515$, 521,549

Taxodium distichum, 535

tenebrosella, Salebriaria, 348

tent caterpillar, 294

terminatus, Rhogas, 292

testaceus, Phymatodes, 509

Tetragnatha laboriosa, 237 obtusa, 237

Tetropium cinnamopterum, 109, 159, 375

gabrieli, 144

texana, Carmenta, 86
Thalpochares carmelita, 373

Thamnosphecia pyri, 348

Thanasimus nigriventris, 99

theridiid spider, 269

Theridium lunatum, 260

Tholeria reversalis, 337

Thrincopyge alacris, 534

Thuja plicata, 515

thurberi, Gossypium, 84

Thyridopteryx ephemeraeformis, 86, 292

Tilia, 413, 527

tipuliformis, Ramosia, 140

Tischeria, 74

Tolype velleda, 345

Tomoxia bidentata, 566

toreuta, Laspeyresia, 13, 384, 393

tortricid, 13, 165, 305

tragicella, Gelechia, 363

tranquilla, Zotheca, 165

Tremex columba, 424, 427, 429, 434

tremuloides, Populus, 134, 136, 141

trichocarpa, Populus, 134, 525

Trichoplusia ni, 292

Trichotaphe levisella, 70

tridentata, Saperda, 519

trifasciata, Argiope, 184

trivittata, Epeira, 257

Tromatobia rufopectus, 362

truckeensis, Disholcaspis, 387

Tsuga, 286

canadensis, 406, 421, 568

heterophylla, 13, 515

tsugae, Neodiprion, 286, 368

tuberculata, Pinus, 384

tulari, Saperda, 134

tussock moth, $75,174,294,356$

Udea rubigalis, 339

ulmiarrosorella, Canarsia, 93

Ulmus, 434, 499, 519

americana, 389, 499, 519

undulata, Quercus, 96

unicolor, Pemphredon, 216

Urbanus proteus, 292

Urocerus albicornis, 404

Vaccinium, 76

vacillans, 535

vacillans, Vaccinium, 535

variana, Acleris, 67, 286, 298

variegana, Hedia, 74

varius, Phymatodes, 499

velleda, Tolype, 345 
vetusta, Hemerocampa, 170, 337

Viburnum, 540

Vigna sinensis, 292

villosum, Elaphidion, 140

virginiana, Diospyros, 499

virginiana, Pinus, 13, 124, 271, 398, 544

virginica, Ctenucha, 170, 321

virginica, Diacrisia, 337

viridisuturalis, Buprestis, 525

viteana, Polychrosis, 57, 292, 344

Vitis, 487

vittata, Anoplodera, 568

volupis, Dictyna, 262

vulpeculus, Mononychus, 31, 363, 373

Walshia "amorphella", 83

wheat stem, 23

wheat stubble, 201

white birch, 413 white thorn, 170

wializenii, Quercus, 387

Xiphydria, 91, 157, 413 abdominalis, 413 maculata, 411

Xiphydriidae, 409

Xylocrius agassizi, 134

Xylotrechus, 321

annosus, 140

youngana, Laspeyresia, 13, 45

Yucca, 83

Zelleria hiambachi, 52

zimmermani, Dioryctria, 13

Zophodia, 337

Zotheca tranquilla, 165 


\section{$2 \mathrm{BHL}$ Biodiversity Heritage Library}

Townes, Henry and Townes, Marjorie. 1960. "Ichneumon-flies of America North of Mexico pt. 2: Subfamilies Ephialtinae, Xoridinae, and Acaenitinae." Bulletin 1-676. https://doi.org/10.5479/si.03629236.216.1-2.

View This Item Online: https://www.biodiversitylibrary.org/item/32635

DOI: https://doi.org/10.5479/si.03629236.216.1-2

Permalink: https://www.biodiversitylibrary.org/partpdf/172276

\section{Holding Institution}

Smithsonian Libraries

\section{Sponsored by}

Smithsonian

\section{Copyright \& Reuse}

Copyright Status: NOT_IN_COPYRIGHT

This document was created from content at the Biodiversity Heritage Library, the world's largest open access digital library for biodiversity literature and archives. Visit BHL at https://www.biodiversitylibrary.org. 